TESIS DOCTORAL

COMPORTAMIENTO SÍSMICO DE ESTRUCTURAS CON FORJADOS RETICULARES Y DISIPADORES DE ENERGÍA BAJO ACCIÓN SIMULTÁNEA DE DOS COMPONENTES HORIZONTALES

DEL TERREMOTO

TESIS DOCTORAL PARA LA OBTENCIÓN DEL TÍTULO DE DOCTOR
JULIO 2020

DAVID GALÉ LAMUELA

DIRECTOR DE LA TESIS DOCTORAL:

AMADEO BENAVENT CLIMENT
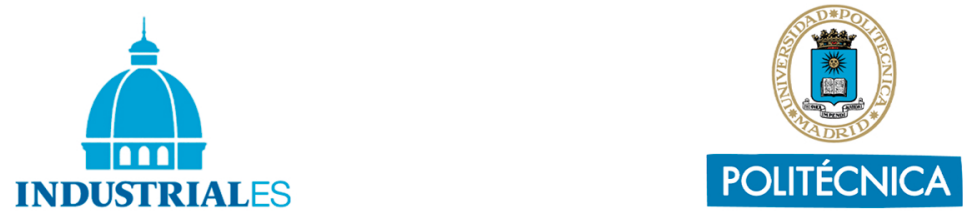
David Galé Lamuela

Madrid, 2020 

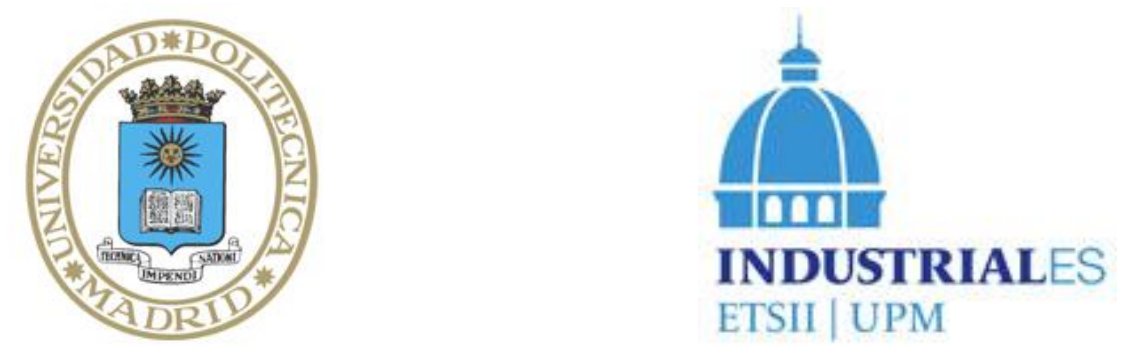

Departamento de Ingeniería Mecánica

Escuela Técnica Superior de Ingenieros Industriales

Universidad Politécnica de Madrid

\title{
Comportamiento sísmico de estructuras con forjados reticulares y disipadores de energía bajo acción simultánea de dos componentes horizontales del terremoto
}

\author{
Tesis Doctoral
}

\author{
David Galé Lamuela \\ Ingeniero de Caminos, Canales y Puertos
}

Director de la Tesis:

Amadeo Benavent Climent

Doctor en Ingeniería

Madrid, 2020 


\section{POLITÉCNICA}

\section{Tesis Doctoral}

Comportamiento sísmico de estructuras con forjados reticulares y disipadores de energía bajo acción simultánea de dos componentes horizontales del terremoto

Tribunal nombrado por el Mgfco. Y Excmo. Sr Director de la Universidad Politécnica de Madrid, el día ..... de ... de 2020

Presidente

Vocal

Vocal

Vocal

Secretario

Suplente

Suplente

Realizado el acto de defensa y lectura de la tesis el día ..... de de 2020 en la E.T.S. de Ingenieros Industriales de la U.P.M.

Calificación:

EL PRESIDENTE LOS VOCALES 
A mis padres y hermana

"Las estructuras no colapsan por el terremoto si no por el efecto de la gravedad" Profesor Hiroshi Akiyama a través del

Profesor Amadeo Benavent 


\section{Agradecimientos}

Quiero expresar mi más sincero agradecimiento a Amadeo Benavent, mi director de Tesis y a todas luces mi maestro, por haberme formado en el campo de la ingeniería sísmica y haberme dado las herramientas suficientes para seguir mi camino como docente e investigador al más alto nivel. Además, por haberme dado la oportunidad de incorporarme a su equipo de trabajo a partir de un contrato de investigación de cuatro años como personal investigador en formación financiado por el Ministerio de Economía y Competitividad del Gobierno de España, así como por su incansable dedicación, apoyo y comprensión durante estos años. Quiero agradecer igualmente a Jesús Donaire por su ayuda, esfuerzo y paciencia con muchas horas de discusiones telefónicas, por haberme acompañado gran parte de mi proceso de aprendizaje con multitud de consejos y opiniones, y por la cantidad de trabajo que hemos compartido. Jesús no llegó a ser codirector de mi Tesis por problemas administrativos, pero en lo que a mí respecta ha realizado ese papel sobradamente. A ambos mi más sincero agradecimiento por su labor docente y por haberme hecho sentir parte del equipo de investigación desde el primer día.

Deseo extender mi agradecimiento a mis compañeros de laboratorio: Marino Risueño, Santiago Félix Mota, Guillermo González, David Escolano, Julio Arcos y Hermes Ponce, con quienes se ha forjado una relación de amistad que espero se prolongue en el tiempo, aunque yo abandone el laboratorio. A todos los compañeros del Laboratorio de Estructuras de la Universidad de Granada, con quienes compartí maratonianas jornadas de ensayos que llegaron a ser de casi $24 \mathrm{~h}$ seguidas para entrenar la mesa sísmica y realizar los ensayos. A mis supervisores de las estancias internacionales en China (Profesora Ying Zhou) y EE.UU. (Profesor Santiago Pujol), así como a los amigos que hice en ambos países, los cuales me mostraron la forma de trabajar en otros entornos, y contribuyeron a formarme como una persona abierta, solidaria e internacional. A los compañeros del Laboratorio de Materiales de Construcción de la Escuela de Caminos, con quienes me inicié en la investigación, compartí multitud de experiencias y sigo manteniendo relación, espero que por mucho tiempo. A mis amigos de siempre, que no hace falta que nombre porque siempre están ahí.

Por último y en especial, quiero agradecer a mis padres y hermana su inextinguible apoyo en todos los sentidos y para los que no faltarán ocasiones para expresar lo mucho que significan para mí y lo mucho que he aprendido de ellos. Finalmente, al resto de mi familia, abuelos, tíos, primos y futuro cuñado que no saben muy bien que he hecho durante estos cuatro años a parte de tener relación con los terremotos, pero que saben el enorme esfuerzo y dedicación que le he dedicado.

Para concluir, me gustaría puntualizar que he realizado la Tesis siendo beneficiario durante cuatro años de una ayuda para contratos predoctorales para la formación de doctores contemplada en el Subprograma Estatal de Formación del Programa Estatal de Promoción del Talento y su Empleabilidad, en el marco del Plan Estatal de Investigación Científica y Técnica y de Innovación 2013-2016, del Ministerio de Economía y Competitividad del Gobierno de España (BES-2015073120). La investigación desarrollada ha sido financiada con los siguientes proyectos públicos competitivos:

- BIA2014-60093-R. Proyectos del Plan Nacional del Ministerio de Economía y Competitividad "Comportamiento sísmico de estructuras con forjados reticulares y disipadores de energía bajo la acción simultánea de dos componentes horizontales del terremoto". IP: Amadeo Benavent-Climent. 
- BIA2017-88814 R. Proyectos del Plan Nacional I+D+i del Ministerio de Ciencia, Innovación y Universidades, "Estudio numérico y experimental de la respuesta sísmica de estructuras con disipadores de energía híbridos que combinan componentes viscosas y elastoplásticas". IP: Amadeo Benavent-Climent.

Las estancias en Tongi University en Shanghái (China) y Purdue University en West Lafayette (Indiana, EE.UU.) fueron financiadas por el programa ERASMUS+ y el Ministerio de Economía y Competitividad del Gobierno de España, respectivamente. 


\section{Resumen}

Esta Tesis investiga el comportamiento sísmico de las estructuras de hormigón armado formadas por forjados reticulares sobre pilares aislados, sin y con disipadores histeréticos de energía, bajo la acción simultánea de las dos componentes horizontales del movimiento del suelo provocado por el terremoto. La metodología aplicada tiene dos enfoques: uno experimental (ensayos dinámicos con mesa sísmica) y otro numérico (cálculos dinámicos directos con modelos de elementos finitos en 3D). El comportamiento se aborda desde las fases iniciales elásticas, hasta el colapso de la estructura. La caracterización del efecto de carga del sismo y la evaluación de la respuesta de la estructura se realiza empleando diferentes parámetros, con especial énfasis en los basados en consideraciones energéticas.

Dentro del enfoque experimental, se proyectó en primer lugar un prototipo de estructura con forjador reticulares, siguiendo la normativa española. La estructura se supuso ubicada en Granada (España). De este prototipo se separó una parte y se construyó a escala en el Laboratorio de Estructuras de la Universidad de Granada (espécimen de ensayo). El espécimen se ensayó con una mesa sísmica biaxial bajo la acción de las componentes horizontales $\mathrm{X}$ e $\mathrm{Y}$ de un terremoto de campo lejano. Estas componentes se aplicaron de forma sucesiva, escaladas en amplitud por un factor que se fue incrementando hasta el colapso de la estructura. El análisis de los resultados permitió describir la evolución de la respuesta en términos de deriva, rotación de arranque de columnas, fuerzas, deformaciones locales y energía que contribuye al daño. Los elementos críticos donde se concentró el daño fueron los arranques de las columnas y la conexión exterior forjado-pilar. La energía introducida en la estructura hasta el colapso bajo la acción simultánea de las dos componentes del terremoto resultó ser muy cercana al valor obtenido en una investigación previa donde se ensayó un espécimen similar ante una única componente del sismo. Los resultados han permitido proponer un valor del factor de comportamiento $(q=2)$ para diseñar este tipo de estructuras mediante los métodos basados en fuerzas.

El enfoque numérico tuvo dos partes. En la primera, se desarrolló un modelo de elementos finitos que representaba el espécimen ensayado con la mesa sísmica. El modelo numérico se calibró con los resultados experimentales hasta conseguir un ajuste satisfactorio en términos de historias de desplazamiento y de energía. Con este modelo numérico, se realizó un extenso estudio paramétrico consistente en cálculos dinámicos directos con un amplio conjunto de terremotos históricos, para cuantificar la capacidad límite última de este tipo de estructuras en términos de energía. Como resultado, se han obtenido capacidades últimas de disipación de energía para este tipo de estructuras bajo cargas sísmicas biaxiales y uniaxiales. En la segunda parte, al modelo numérico se le añadieron disipadores de energía dependientes del desplazamiento (histeréticos). Con el nuevo modelo, se llevó a cabo un segundo estudio paramétrico para evaluar la respuesta y cuantificar la capacidad límite última de disipación de energía de las estructuras con forjados reticulares y disipadores histeréticos. Se concluye que la capacidad sísmica última en términos de energía de la estructura se mantiene muy estable independientemente del terremoto considerado. Esto se observa tanto en las estructuras sin disipadores como en las estructuras con disipadores de energía. Se cuantifica también la notable mejora en el comportamiento sísmico debida a la introducción de los disipadores histeréticos. 


\section{Abstract}

This Thesis investigates the seismic behavior of reinforced concrete structures consisting of waffle-flat plates supported on isolated columns, without and with hysteretic dampers, subjected to the simultaneous action of two components of the ground motion caused by an earthquake. The methodology applied involves two approaches: the experimental approach (dynamic shaking table tests), and the numerical approach (nonlinear response history analyses with a refined 3D finite element model). The study addresses the response of the structure from the initial elastic stages until collapse. Different parameters are used to characterize the seismic action and to evaluate the response and particular attention is given to the energy.

Within the experimental approach, a prototype structure with waffle-flat plates and square columns was first designed following the Spanish structural codes. The structure was assumed to be located in Granada. A portion of this prototype was selected, scaled and built in the Laboratory of Structures of the University of Granada (test specimen). The specimen was tested with a biaxial shaking table using the horizontal components of a far field ground motion. These two components were applied simultaneously, scaled in amplitude to increasing values, until collapse. The analyses of the results allowed to describe in detail the evolution of the response in terms of drifts, rotations in column, forces, local deformations and energy that contributes to damage. Damage concentrated at column bases and at the exterior plate-column connection. The energy input in the structure until collapse under the biaxial seismic action was found very close to that obtained in past tests conducted with a similar specimen subjected to unidirectional seismic loadings. Further, based on the results of the tests, it is proposed to adopt the value $q=2$ as spectrum reduction factor in force-based seismic design methods.

The numerical approach had two parts. The first part consisted on developing a refined 3D finite element model that represented the specimen tested with the shaking table. The model was calibrated with the experimental results to obtain a satisfactory fit between tests results and numerical prediction in terms of displacements and energies. This model was used to conduct a parametric study consisting on nonlinear response history analyses with a large set of ground motions. As a result, the ultimate energy dissipation capacity of this type of structures was evaluated, under uniaxial and under biaxial seismic loadings. In the second part of the numerical study, the model was equipped with displacement-dependent (hysteretic) dampers. A second parametric study was conducted with the new model to evaluate the response and the ultimate energy dissipation capacity of the mixed system. As a global result of the numerical approach, it is concluded that the ultimate energy dissipation capacity of the structure (without or with hysteretic dampers) is a relatively stable amount, scarcely influenced by the characteristics of the ground motion considered. It is also evaluated quantitatively how the response of the structure improves due to the addition of the hysteretic dampers. 


\section{Content}

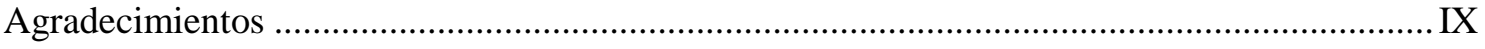

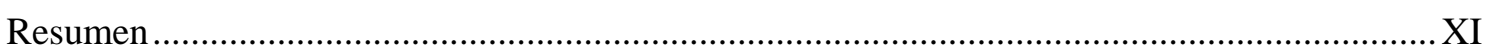

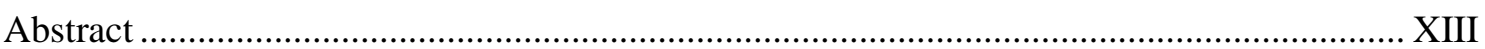

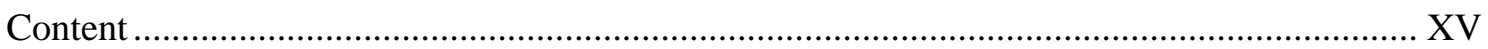

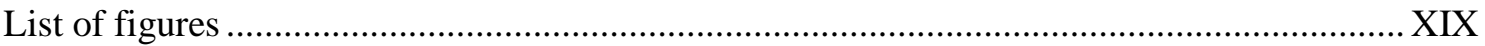

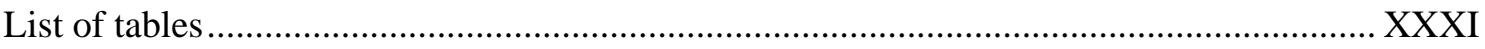

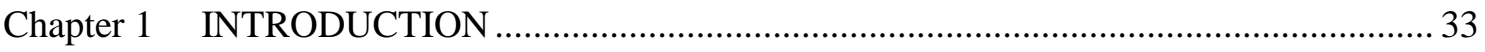

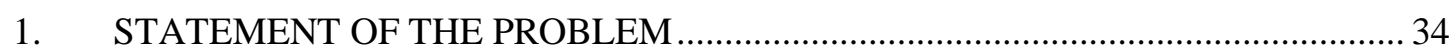

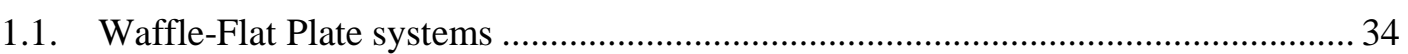

1.2. Waffle-Flat Plate systems with passive energy dissipation systems ......................... 36

1.3. The energy approach to seismic design .................................................................... 39

1.4. Energy-Based Design Framework …………........................................................... 41

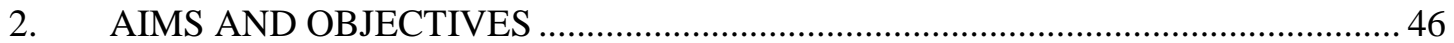

3. PUBLISHED WORKS DERIVATED FROM THIS THESIS ........................................ 48

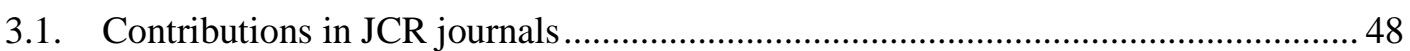

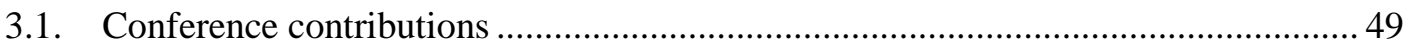

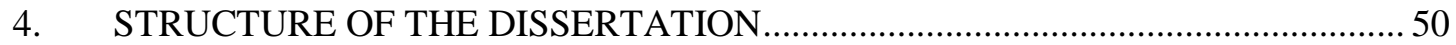

Chapter 2 EXPERIMENTAL INVESTIGATION: BIDIRECTIONAL SHAKE TABLE TESTS

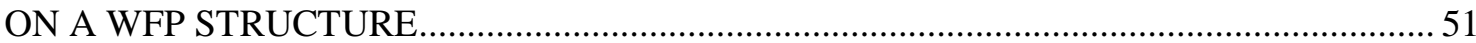

1. PROTOTYPE STRUCTURE AND TEST SPECIMEN ……..................................52

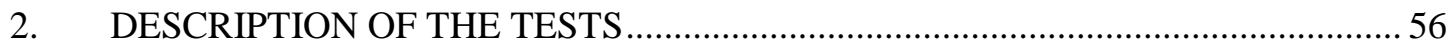

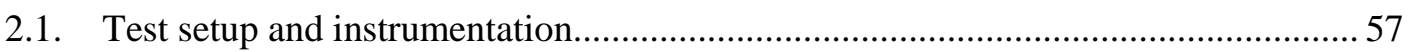

2.2. Procedures for computing displacements and accelerations .................................... 59

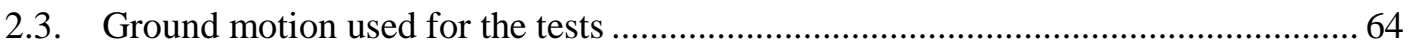

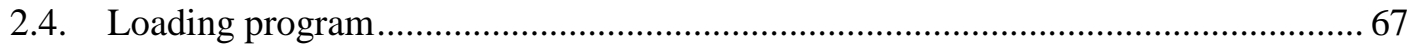

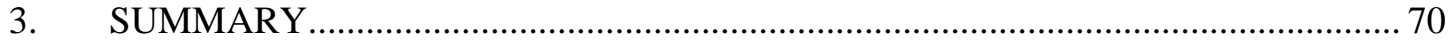

Chapter 3 EXPERIMENTAL INVESTIGATION: CHARACTERIZATION OF TEST

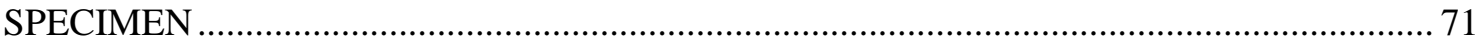

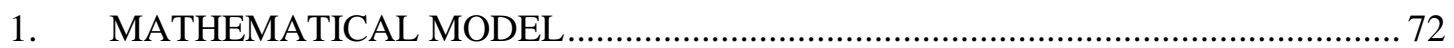

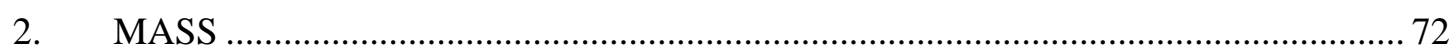

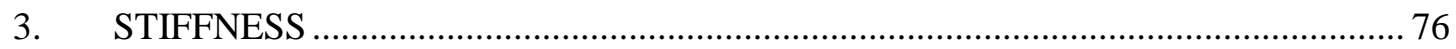

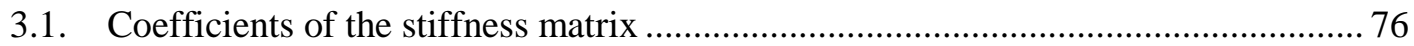

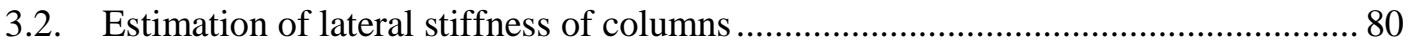

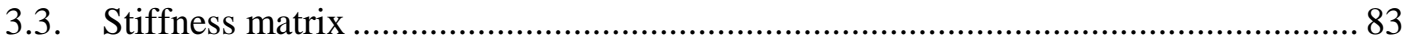




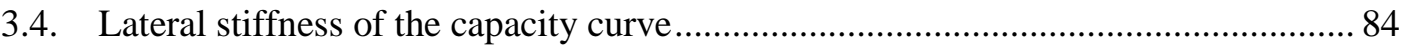

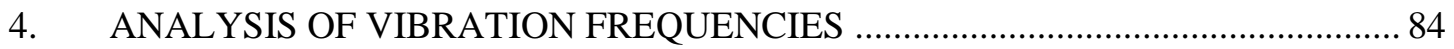

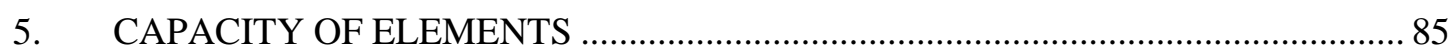

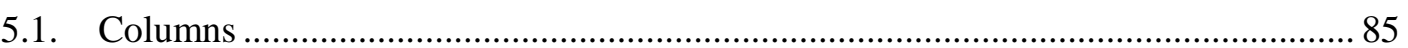

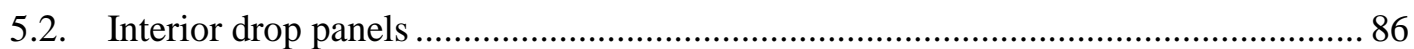

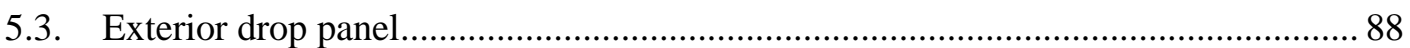

6. GLOBAL COLLAPSE MECHANIMS OF THE SPECIMEN ……............................ 91

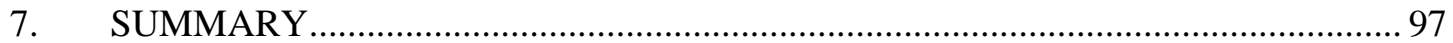

Chapter 4 EXPERIMENTAL INVESTIGATION: RESULTS OF BIDIRECTIONAL

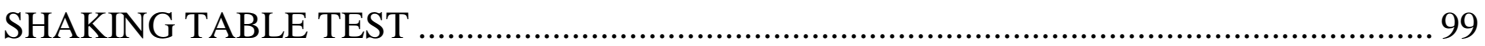

1. SHAKE TABLE TRAINING AND SEISMIC SIMULATIONS …........................... 100

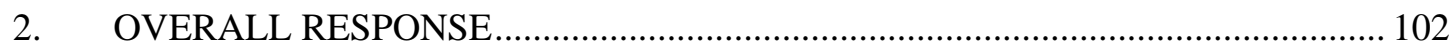

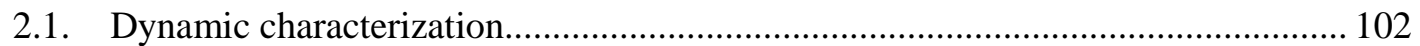

2.2. Quantitative response in terms of displacements and rotations ............................ 103

2.3. Quantitative response in terms of forces ............................................................... 110

2.4. Quantitative response in terms of strains ............................................................ 117

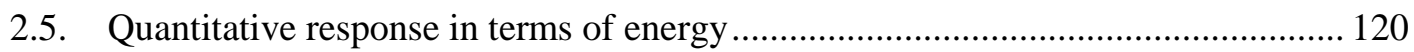

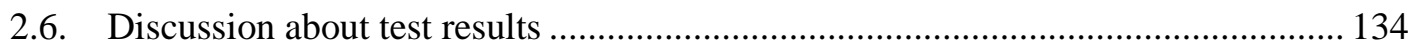

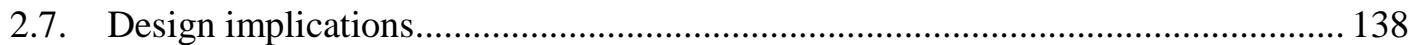

2.7.1. Behavior factor for applying the reduced-spectrum force-based approach......... 138

2.7.2. Reinforcement passing through the exterior plate-column connection ............... 139

2.7.3. Consideration of torsional effects ...................................................................... 139

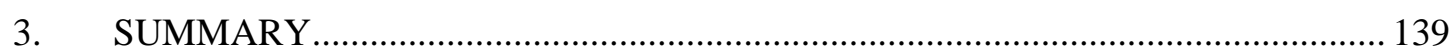

Chapter 5 NUMERICAL INVESTIGATION: RESPONSE OF WFP STRUCTURES UNDER

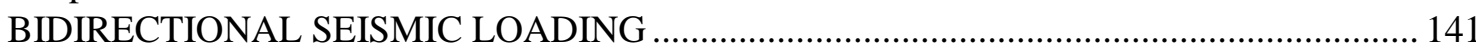

1. DESCRIPTION OF BENCHMARK NUMERICAL MODEL …............................. 142

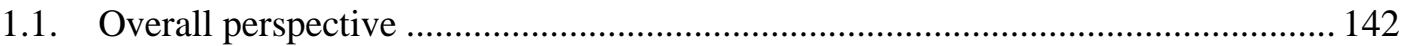

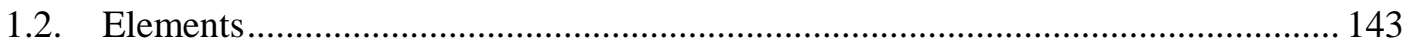

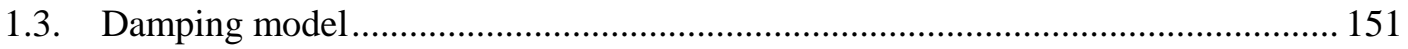

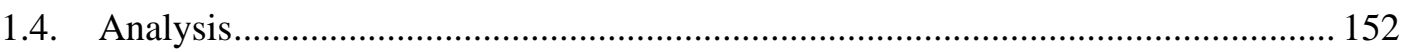

2. RESPONSE predicted with numerical model.......................................................... 153

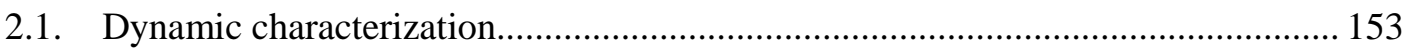

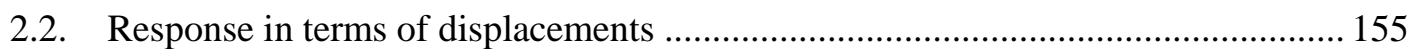

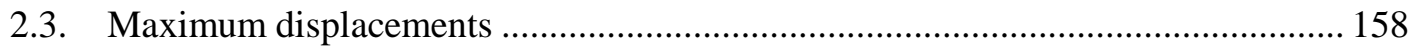

2.4. History of base shears exerted by inertial forces.................................................. 158

2.5. Maximum base shears exerted by inertial forces .................................................... 160

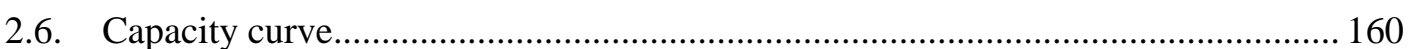

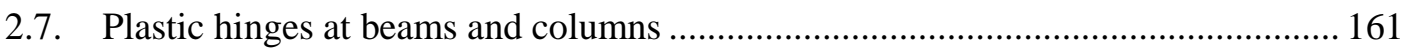




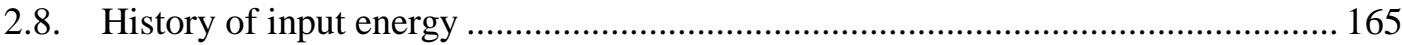

3. SEISMIC CAPACITY OF WFP STRUCTURES IN TERMS OF ENERGY ........... 166

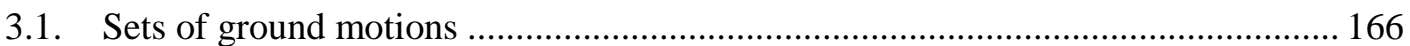

3.2. Non-linear analyses in successive numerical simulations...................................... 169

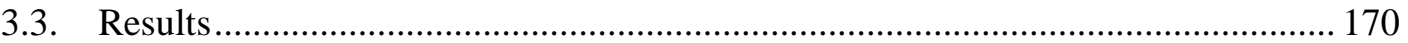

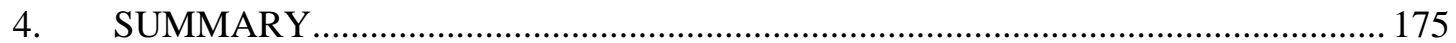

Chapter 6 NUMERICAL INVESTIGATION: RESPONSE OF WFP STRUCTURES WITH ENERGY DISSIPATION DEVICES UNDER BIDIRECTIONAL SEISMIC LOADING ..... 177

1. DESCRIPTION OF THE SLIT-PLATE HYSTERETIC DAMPER .......................... 178

2. STATIC CYCLIC TEST OF SLIT-PLATE DAMPERS …...................................... 179

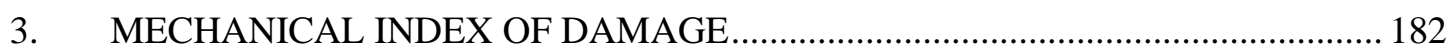

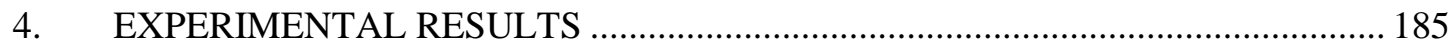

5. NUMERICAL model for SLIT-PLATE DAMPERS …............................................. 187

6. DESIGN AND IMPLEMENTATION OF SLIT-PLATE DAMPERS IN SPECIMEN BS1 188

7. SEISMIC RESPONSE OF SPECIMEN BS1 WITH DAMPERS............................... 191

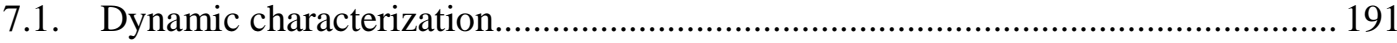

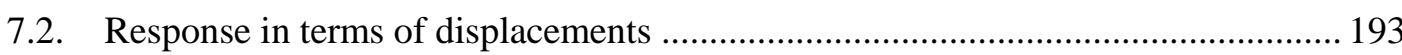

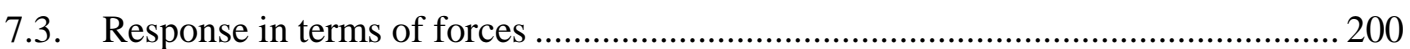

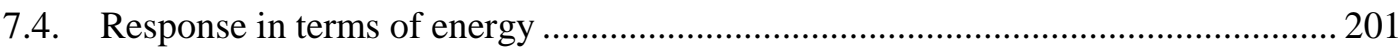

8. COMPARISON of the repsonse of SPECIMEN bs1 without and with dampers ....... 204

9. SEISMIC CAPACITY OF WFP STRUCTURES with hysteretic dampers IN TERMS

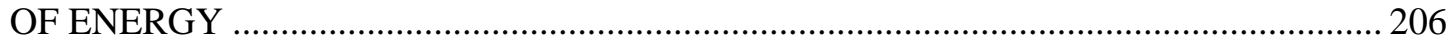

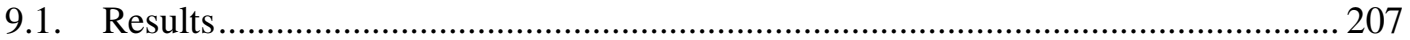

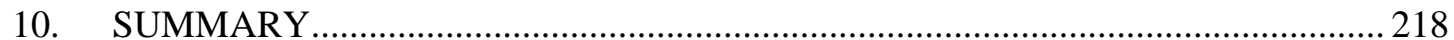

Chapter 7 SUMMARY, CONCLUSIONS AND FUTURE RESEARCH DIRECTIONS ... 221

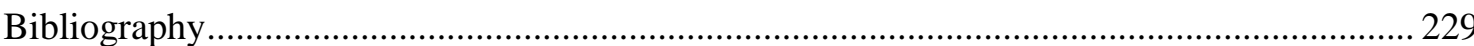

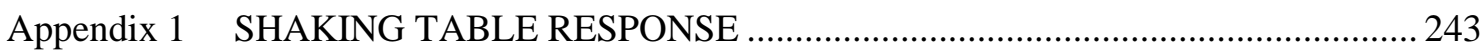

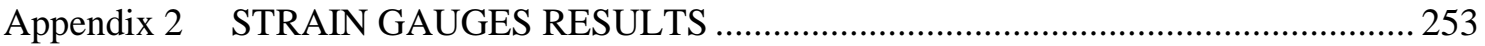

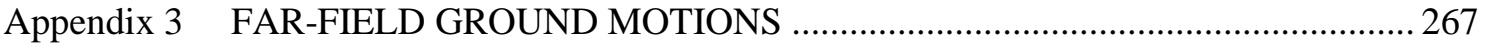




\section{List of figures}

Figure 1. 1. Waffle-Flat Plate building: square domes in construction, b) structure and c) building model (Vargas, Pujades, Barbat, \& Hurtado, 2013) .................................................................. 35

Figure 1. 2. Hysteretic behavior of a flexible-stiff mixed structure: a) monotonic loading and b) cyclic loading 37

Figure 1. 3. Types of dampers and installations: a) metallic (González-Sanz, Escolano-Margarit, \& Benavent-Climent, 2020), b) friction (Nielsen, Mualla, \& Iwai, 2004), c) viscoelastic solid (Zhou, Gong, \& Lu, 2013) d) viscoelastic fluid dampers (Taylor Devices inc.) and e)

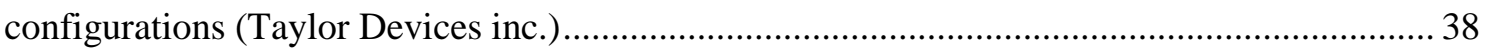
Figure 1. 4. Test campaigns conducted by Benavent-Climent: a) specimen without dampers (2016) and b) specimen with dampers (2018)

Figure 1. 5. Energy balance of an elastic-perfectly plastic SDOF system: a) amount of energies and b) energy balance.

Figure 2. 1. Prototype structure: a) plan; b) elevation................................................................ 52

Figure 2. 2. Geometry and reinforcement of columns and footings for specimens BS1.............54

Figure 2. 3. Geometry and reinforcing details of the waffle-flat-plate for specimens BS1 ........55

Figure 2. 4. General view of test specimen on shaking table (view from actuator X)...............56

Figure 2. 5. General view of test specimen a) elevation and b) plan ...................................... 57

Figure 2. 6. Test setup and instrumentation: a) Critical column sections (elevation), b) Critical slab sections (plan), c) Sensors at level 1 (plan) and d) Sensors at level 2 (plan)....................... 58

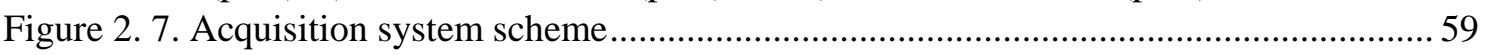

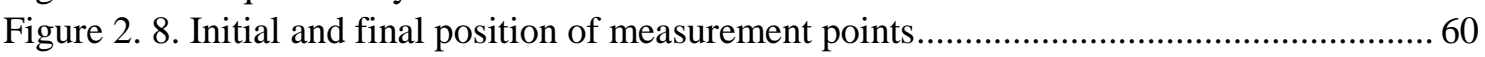

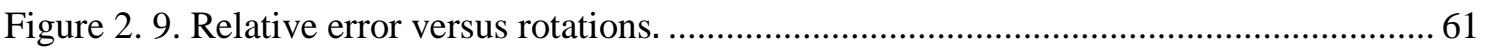

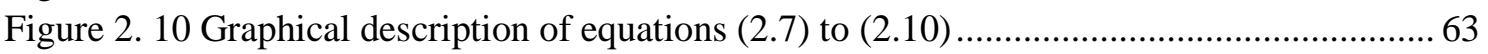

Figure 2. 11. Unscaled Calitri Earthquake histories of: a) Acceleration (NS), b) Acceleration

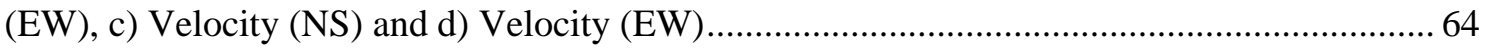

Figure 2. 12. Spectrums 2\% and 5\% damped of the unscaled Calitri Earthquake (NS): a) Acceleration, b) Velocity, c) Displacement and d) Input Energy .............................................. 65

Figure 2. 13. Spectrums $2 \%$ and 5\% damped of the unscaled Calitri Earthquake (EW): a)

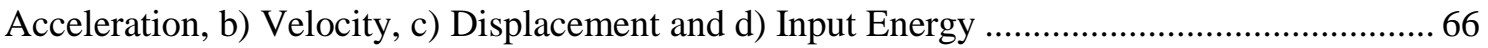
Figure 2. 14. Newmark's logarithmic spectra $2 \%$ and $5 \%$ damped of the unscaled Calitri

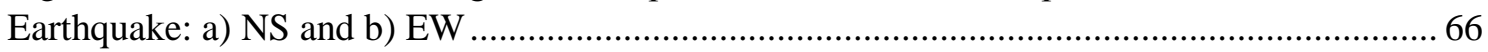
Figure 2. 15. Scaled Calitri Earthquake histories of: a) Acceleration (NS), b) Acceleration (EW),

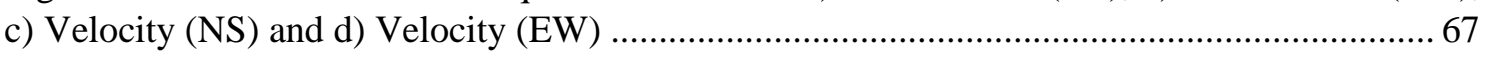
Figure 2. 16. Target spectra input motion (NS): a) Acceleration, b) Velocity, c) Displacement and

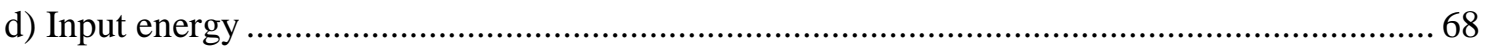
Figure 2. 17. Target spectra input motion (EW): a) Acceleration, b) Velocity, c) Displacement and d) Input energy ....

Figure 2. 18. Newmark's logarithmic spectra $2 \%$ and 5\% damped of input base motions (Calitri scaled in time and unscaled in amplitude): a) NS and b) EW 69

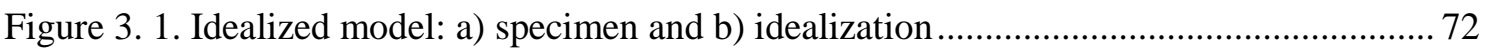

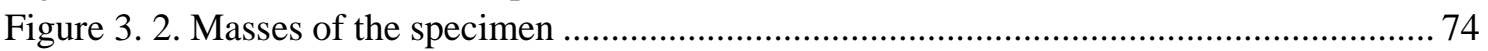

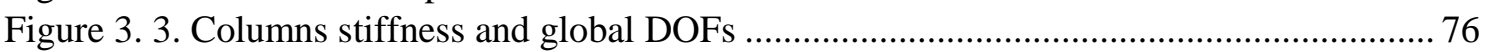




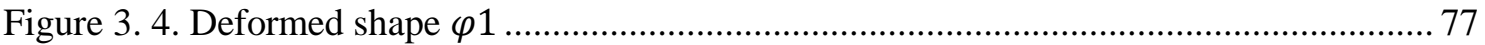

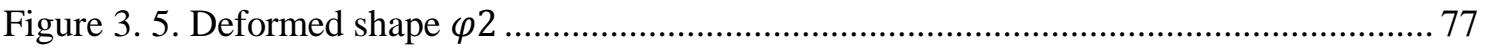

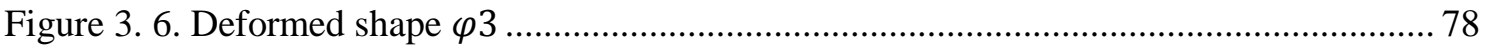

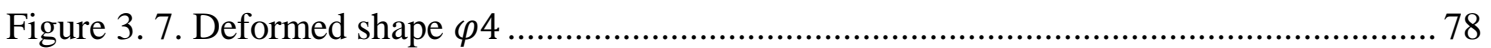

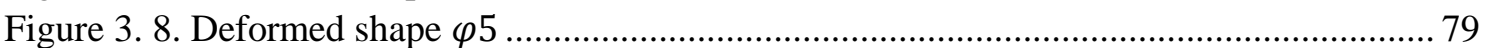

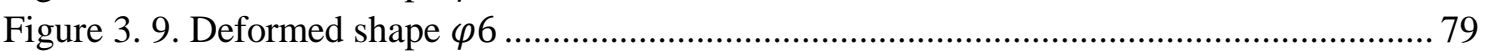

Figure 3. 10. Substructures for stories: a) first floor and b) intermediate floor........................... 80

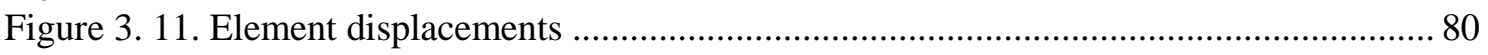

Figure 3. 12. System displacements and deformed shapes for the first floor substructure

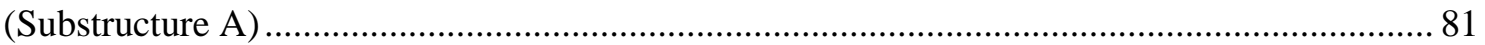

Figure 3. 13. System displacements and deformed shapes for the intermediate floor substructure

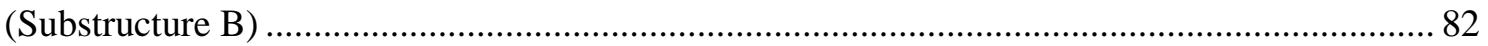

Figure 3.14 Assumptions to calculate the flexural capacity of the interior drop panels ............ 87

Figure 3. 15. Assumptions to calculate the flexural capacity of the exterior drop panel ............ 89

Figure 3. 16. Two path model for the exterior plate-column connection .................................... 91

Figure 3. 17. Likely collapse mechanisms for direction X...................................................... 92

Figure 3. 18. Base shear force for each collapse mechanism for Direction X ............................ 95

Figure 3. 19. Likely collapse mechanisms for direction Y .......................................................... 96

Figure 3. 20. Base shear force for each collapse mechanism for Direction Y ............................ 97

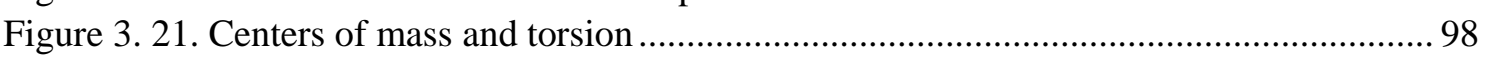

Figure 3. 22. Estimation of capacity curve: a) direction X (NS) and b) direction Y (EW) ......... 98

Figure 4. 1. Histories of acceleration inputs reproduced in the test: a) Component NS in Direction $\mathrm{X}, \mathrm{b})$ Component EW in Direction Y and c) Bidirectional response ...................................... 101

Figure 4. 2. Histories of earthquake-tail displacement response for obtaining periods and the

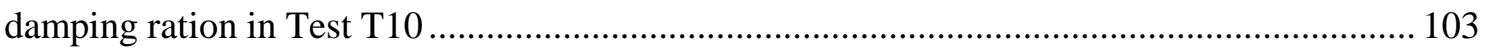

Figure 4. 3. Histories of displacement response of the two-mass lumped model: ..................... 104

Figure 4. 4. Chord rotations of sections S10/S11, S20/S21 and S30/S31 at base and at top columns of first story for simulation T10, C35, C50 and C100 (quasi-linear behavior) .......................... 106 Figure 4. 5. Chord rotations of sections S10/S11, S20/S21 and S30/S31 at base and at top columns of first story for simulation C200i, C200 and C300 (nonlinear behavior) ............................... 107

Figure 4. 6. Chord rotations of sections S12, S22 and S32 at base columns of second story for simulation T10, C35, C50 and C100 (quasi-linear behavior) ............................................... 108

Figure 4. 7. Chord rotations of sections S12, S22 and S32 at base columns of second story for

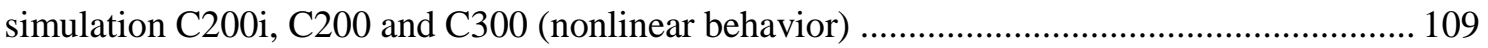

Figure 4. 8. Histories of inertial force response of the two-mass lumped model:...................... 111

Figure 4. 9. Histories of base shears exerted by inertial forces .............................................. 112

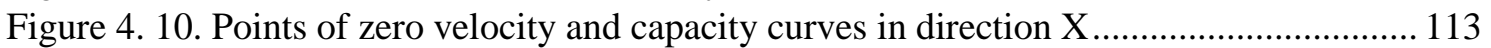

Figure 4. 11. Points of zero velocity and capacity curves in direction Y ................................ 114

Figure 4. 12. Base shear Force versus Top displacements in direction X: a) Test T10 b) Test C35,

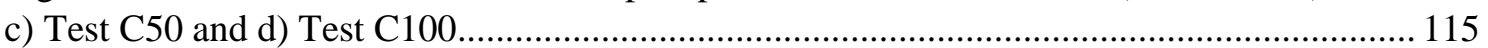

Figure 4. 13. Base shear Force versus Top displacements in direction Y: a) Test T10 b) Test C35,

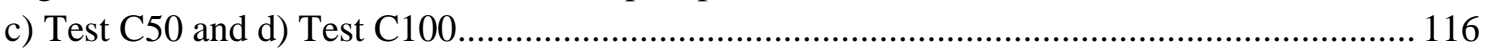

Figure 4. 14. Base shear Force versus Top displacements in direction X: a) Test C200i, b) Test

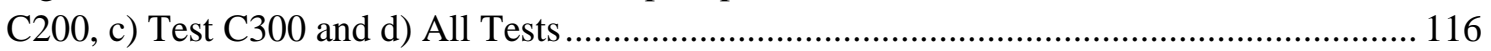

Figure 4. 15. Base shear Force versus Top displacements in direction Y: a) Test C200i, b) Test

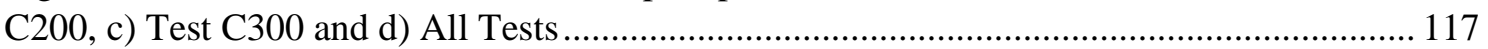

Figure 4. 16. Accumulated damage up to the end of test C100: a) elevation (actuator X point of view) and b) plan. 119 
Figure 4. 17. Accumulated damage up to the end of test C200i: a) elevation (actuator X point of view) and b) plan 119

Figure 4. 18. Accumulated damage up to the end of test C200: a) elevation (actuator X point of view) and b) plan 119

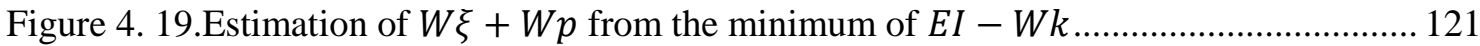

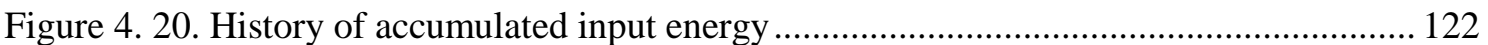

Figure 4. 21. History of energy dissipated by inherent viscous damping ............................... 123

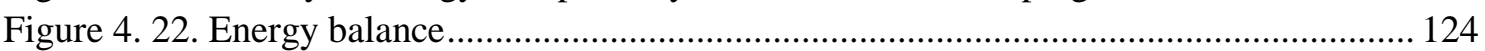

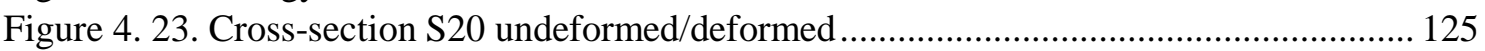

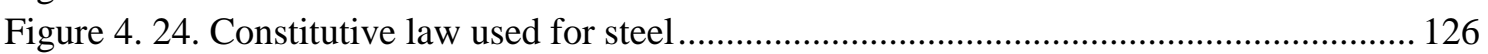

Figure 4. 25. Constitutive laws for concretes: a) C01, b) C02, c)C07 and d) M....................... 127

Figure 4. 26.Energy calibration of concrete models: a) Stress-strain curves and b) Energy

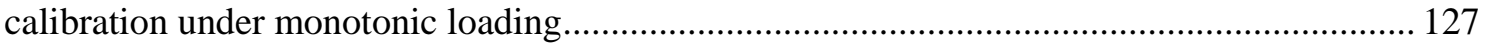

Figure 4. 27. Histories of dissipated energy by all columns depending on concrete model ..... 129

Figure 4. 28. Energy stored/dissipated by columns at: a) base second story, b) top first story and

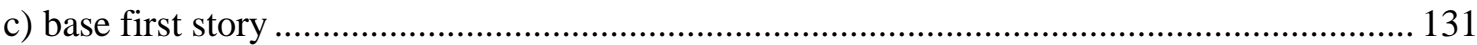

Figure 4. 29. Energy stored/dissipated by steel and concrete in columns at: a) base second story,

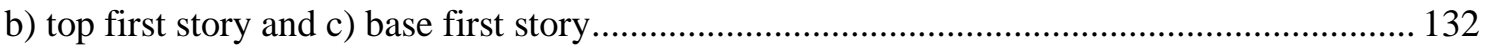

Figure 4. 30. Energy stored/dissipated by columns, WFP and damping..................................... 134

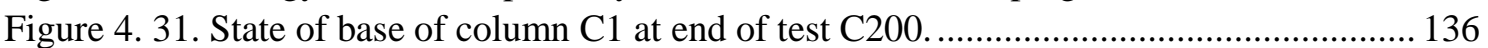

Figure 4. 32. Exterior plate-column connetcion at end of test C200.................................... 136

Figure 4. 33. Cracks and concrete spalling at exterior plate-column connetcion at end of test $\mathrm{C} 300$ :

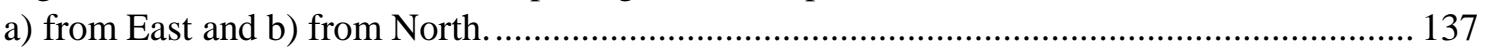

Figure 4. 34. Cracks and concrete spalling at head of column $\mathrm{C} 2$ at end of test $\mathrm{C} 300 \ldots \ldots \ldots \ldots . . .137$

Figure 4. 35. State of columns bases at end of test C300: a) Column C1 and b) C3 ................ 138

Figure 4. 36. State of columns at end of test C300: Columns a) C1, b) C2 and c) C3 .............. 138

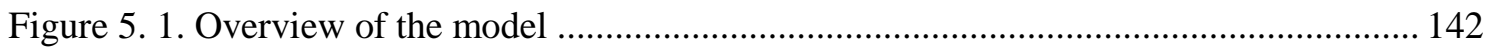

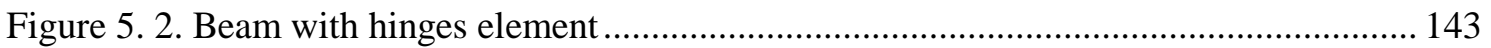

Figure 5. 3. Hysteretic curves of fiber materials: a) Concrete and b) Steel ................................ 144

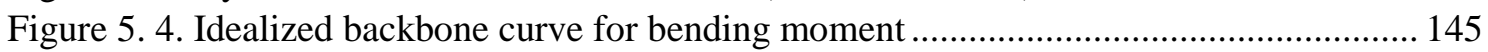

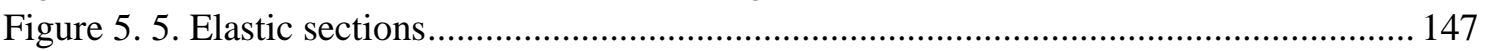

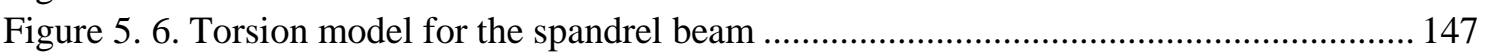

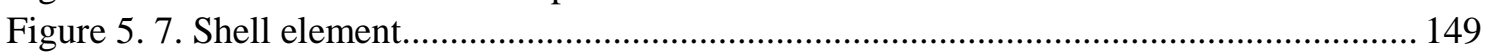

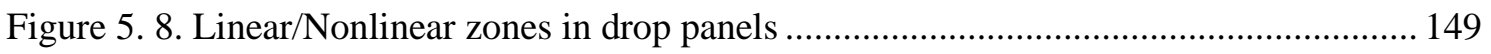

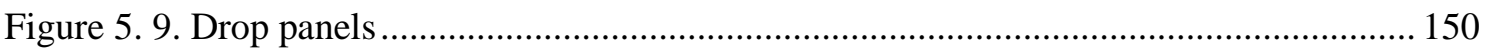

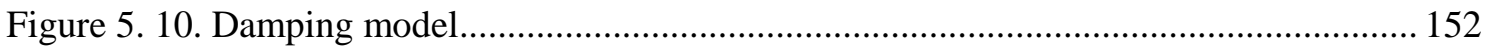

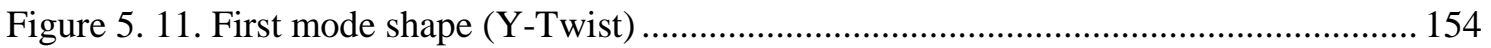

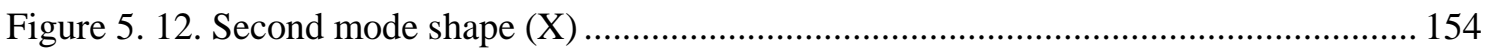

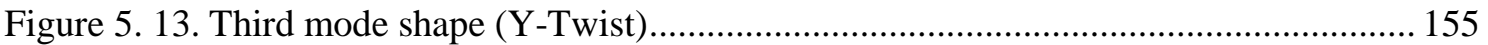

Figure 5. 14. History of slab-level (first level) displacements in directions $\mathrm{X}$ and $\mathrm{Y}$ with zooms at

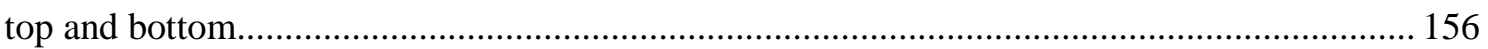

Figure 5. 15. History of top-level (second level) displacements in directions $\mathrm{X}$ and Y with zooms

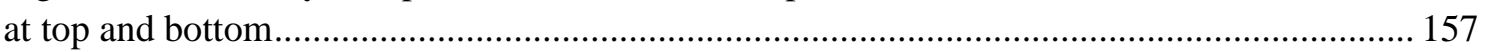

Figure 5. 16. Maximum of displacements: a) Slab-level and b) Top level .............................. 158

Figure 5. 17. History of base shears exerted by inertial forces in direction $\mathrm{X}$ and $\mathrm{Y}$ with zooms at

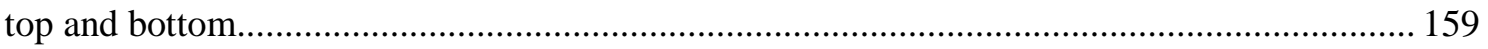

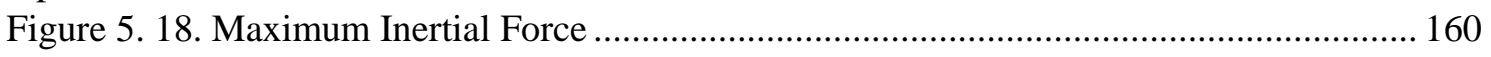

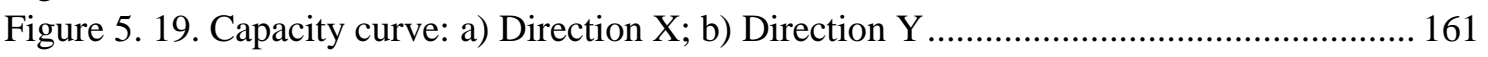

Figure 5. 20. Hysteretic behavior or the spandrel beam: a) West side and b) East side............. 161 
Figure 5. 21Bidirectional behavior of plastic hinges at columns base of first level.................. 162

Figure 5. 22 Bidirectional behavior of plastic hinges at columns head of first level ................ 163

Figure 5. 23 Bidirectional behavior of plastic hinges at columns base of second level ............ 164

Figure 5. 24. Input Energy response: a) Total, b) direction X and c) direction Y..................... 165

Figure 5. 25. Energy capacity of the structure with dampers: a) elastic input energy b) input

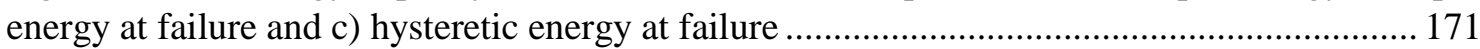

Figure 5. 26. Mean and error bars for $\theta V E=\operatorname{atan}(V E Y / V E X)$ in the different sets of records

Figure 6. 1. General view of a damper installed in a building ............................................. 178

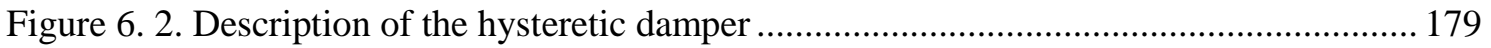

Figure 6. 3. Test Dissipative Component (TDC) of the hysteretic damper................................. 180

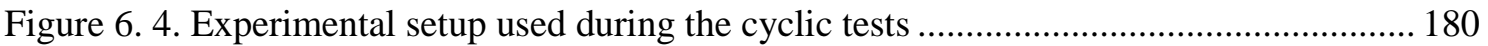

Figure 6. 5. Relative displacement between external and internal flanges .............................. 181

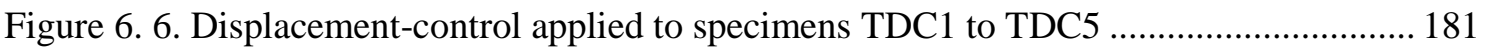

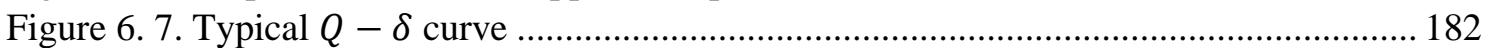

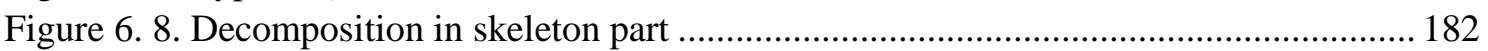

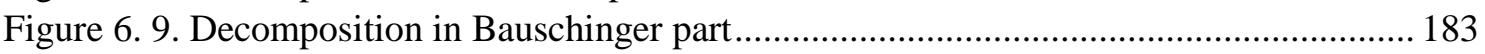

Figure 6. 10. TDC1: a) $Q-\delta$ curve and b) ID and the path followed in plane $s \eta-\eta \ldots \ldots \ldots \ldots .185$

Figure 6. 11. TDC2: a) $Q-\delta$ curve and b) ID and the path followed in plane $s \eta-\eta \ldots \ldots \ldots \ldots . .186$

Figure 6. 12. TDC3: a) $Q-\delta$ curve and b) ID and the path followed in plane $s \eta-\eta \ldots \ldots \ldots . . .186$

Figure 6. 13. TDC4: a) $Q-\delta$ curve and b) ID and the path followed in plane $s \eta-\eta \ldots \ldots \ldots \ldots 186$

Figure 6. 14. TDC5: a) $Q-\delta$ curve and b) ID and the path followed in plane $s \eta-\eta \ldots \ldots \ldots . . .187$

Figure 6. 15. Decomposition of the cyclic curve of specimen TDC5 into: a) Skeleton part and b)

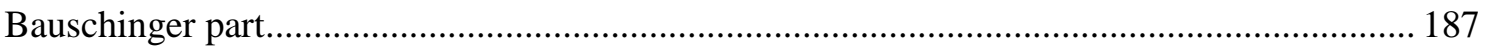

Figure 6. 16. Superposition of the $Q-\delta$ curve for the specimen TDC5 (Test and calibrated

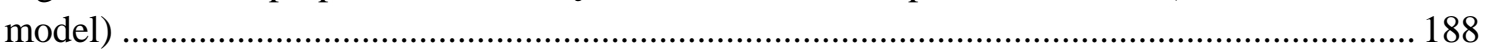

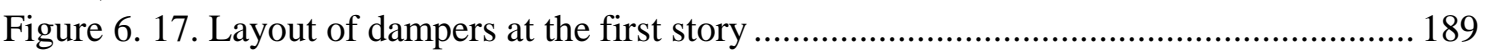

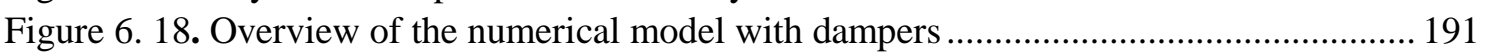

Figure 6. 19. Damping model and damping values at the beginning and at the end of simulations

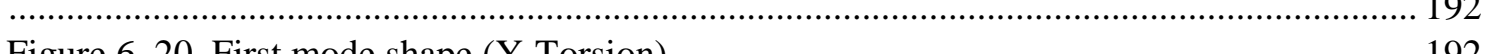

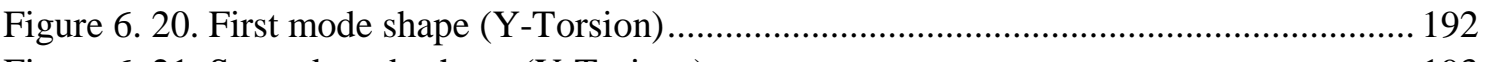

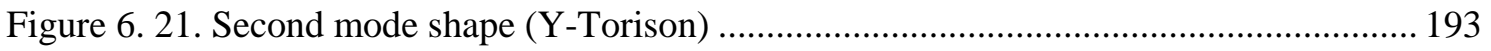

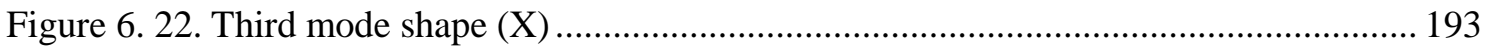

Figure 6. 23. Histories of displacement of the centers of mass for the specimen with dampers following the two-mass model schema: DOF 1, b) DOF 2, c) DOF 3, d) DOF 4, e) DOF 5 and f)

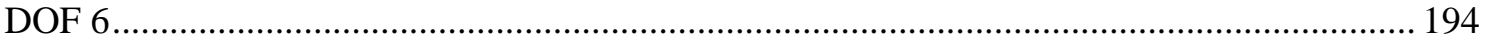

Figure 6. 24. Chord rotations of sections S10/S11, S20/S21 and S30/S31 at base and at top columns of first story for simulation T10, C35, C50 and C100 with dampers ......................... 196 Figure 6. 25. Chord rotations of sections S10/S11, S20/S21 and S30/S31 at base and at top columns of first story for simulation C200i, C200 and C300 with dampers........................... 197 Figure 6. 26. Chord rotations of sections S10/S11, S20/S21 and S30/S31 at base and at top columns of first story for simulation T10, C35, C50 and C100 with dampers ......................... 198 Figure 6. 27. Chord rotations of sections S12, S22 and S32 for simulation C200i, C200 and C300

Figure 6. 28. History of restoring forces developed in the first level: a) $X$ and b) Y............... 200

Figure 6. 29. History of restoring forces developed in the second level: a) X and b) Y ...........200

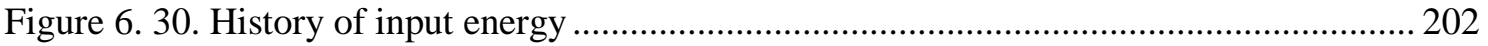

Figure 6. 31. History of energy dissipated by the structure ................................................... 203 
Figure 6. 32. Damper force-displacement curves up to simulation C300: a) Damper $\mathrm{N}^{\mathrm{o}} 1$, b)

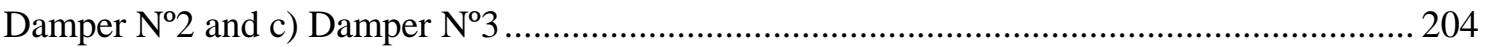
Figure 6. 33.Damping models for the specimens with and without dampers .......................... 205 Figure 6. 34. Energy capacity of the structure with dampers: a) input energy for SPL FO, b) input energy for SPL OP, c) hysteretic energy for SPL OP, d) input energy for SPL NC and e) hysteretic

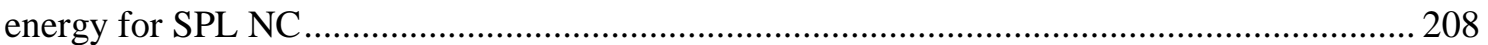
Figure 6. 35. Energy capacity of the structure without dampers: a) input energy for SPL OP, b) input energy for SPL NC and c) hysteretic energy for SPL NC .............................................2. 209

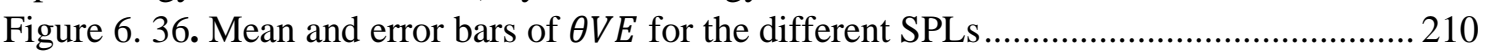
Figure 6. 37. Mean and error bars for $\mu$ along $\mathrm{X}$ and $\mathrm{Y}$ directions: a) main structure and $\mathrm{b}$ ) hysteretic dampers.

Figure 6. 38. Ratio of the dissipated energy in the hysteretic dampers respect to the total one at the first story, overall $(s W p, 1 / W p, 1)$ and by components $(s W p X, 1 / W p X, 1$ and $s W p Y, 1 /$ $W p Y, 1)$.

Figure 6. 39. Dimensionless representation of the damage: a) for WFP system at the first story and b) at second story; for hysteretic dampers, c) damage level and d) damage index ............216 Figure 6. 40. Equivalent number of cycles obtained in the analyses at the first story: a) for WFP system and b) for hysteretic dampers 218

Figure A1. 1. History of accelerations superposed (Target and Test) for simulation C35: a) Component NS (direction X) and b) Component EW (direction Y) ........................................ 244 Figure A1. 2. Spectrums superposed (Target and Test) for Component NS (direction X) simulation C35: a) Acceleration, b) Velocity, c) Displacement and d) Energy ......................... 244 Figure A1. 3. Spectrums superposed (Target and Test) for Component EW (direction Y) simulation C35: a) Acceleration, b) Velocity, c) Displacement and d) Energy ......................... 245 Figure A1. 4. History of accelerations superposed (Target and Test) for simulation C50: a) Component NS (direction X) and b) Component EW (direction Y) ........................................ 245 Figure A1. 5. Spectrums superposed (Target and Test) for Component NS (direction X) simulation C50: a) Acceleration, b) Velocity, c) Displacement and d) Energy .........................2. 246 Figure A1. 6. Spectrums superposed (Target and Test) for Component EW (direction Y) simulation C50: a) Acceleration, b) Velocity, c) Displacement and d) Energy ......................... 246 Figure A1. 7. History of accelerations superposed (Target and Test) for simulation C100: a) Component NS (direction X) and b) Component EW (direction Y) ......................................24 Figure A1. 8. Spectrums superposed (Target and Test) for Component NS (direction X) simulation C100: a) Acceleration, b) Velocity, c) Displacement and d) Energy ....................... 247 Figure A1. 9. Spectrums superposed (Target and Test) for Component EW (direction Y) simulation C100: a) Acceleration, b) Velocity, c) Displacement and d) Energy ....................... 248 Figure A1. 10. History of accelerations superposed (Target and Test) for simulation C200: a) Component NS (direction X) and b) Component EW (direction Y) ........................................ 248 Figure A1. 11. Spectrums superposed (Target and Test) for Component NS (direction X) simulation C200: a) Acceleration, b) Velocity, c) Displacement and d) Energy ........................ 249 Figure A1. 12. Spectrums superposed (Target and Test) for Component EW (direction Y) simulation C200: a) Acceleration, b) Velocity, c) Displacement and d) Energy ....................... 249 Figure A1. 13. History of accelerations superposed (Target and Test) for simulation C300: a) Component NS (direction X) and b) Component EW (direction Y) ......................................2.250 Figure A1. 14. Spectrums superposed (Target and Test) for Component NS (direction X) simulation C300: a) Acceleration, b) Velocity, c) Displacement and d) Energy .......................250 Figure A1. 15. Spectrums superposed (Target and Test) for Component EW (direction Y) simulation C300: a) Acceleration, b) Velocity, c) Displacement and d) Energy ..... 251 
Figure A2. 1. Gauges locations at base column sections in first story …................................ 254

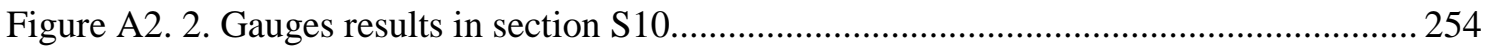

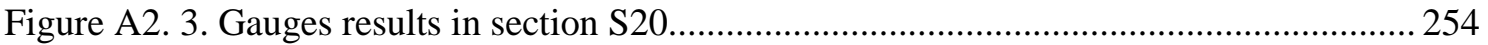

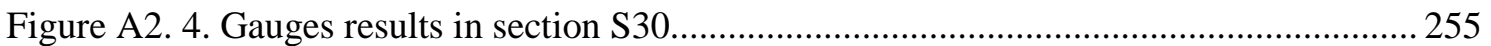

Figure A2. 5. Gauges locations at head column sections in first story ....................................2 255

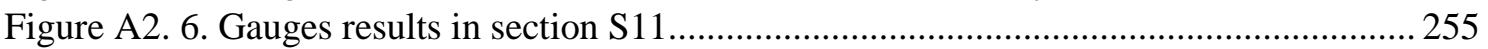

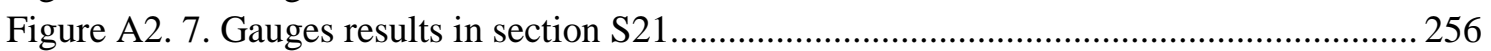

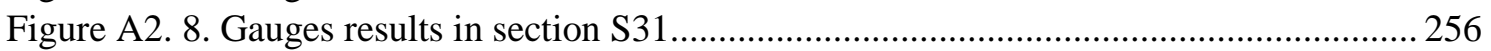

Figure A2. 9. Gauges locations at base column sections in second story ...............................256

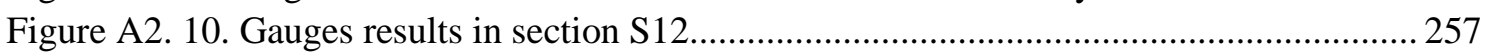

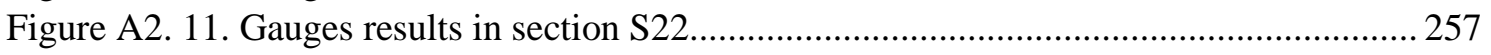

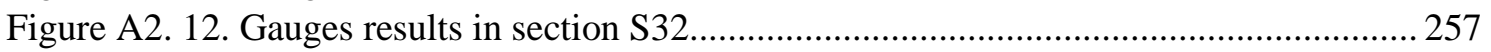

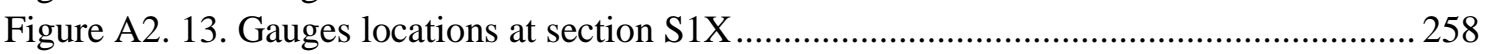

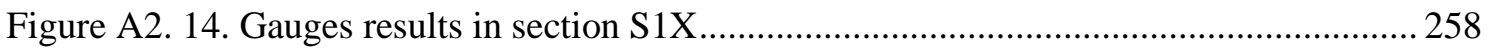

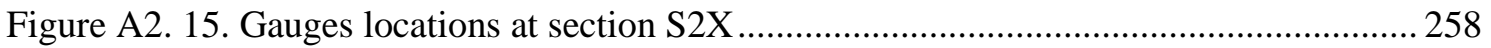

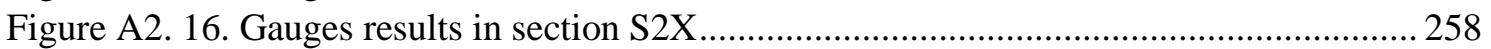

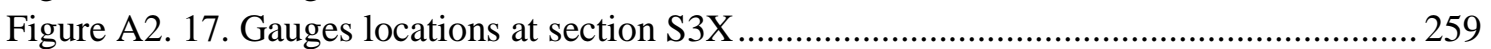

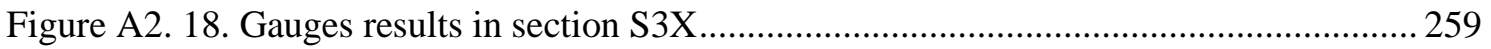

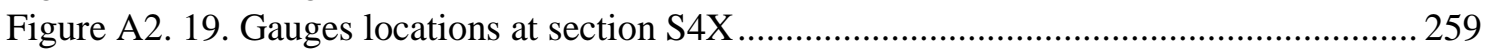

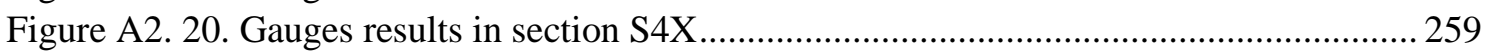

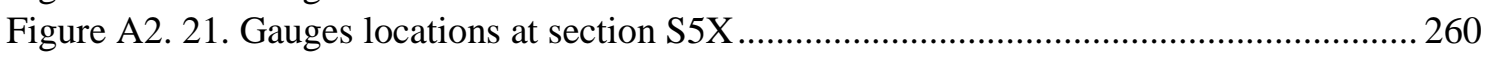

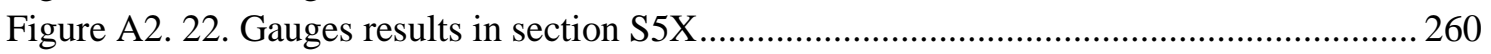

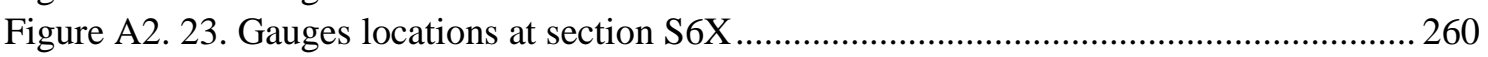

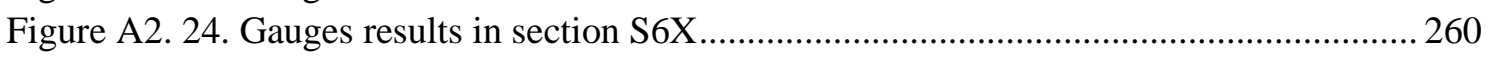

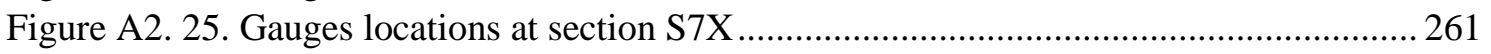

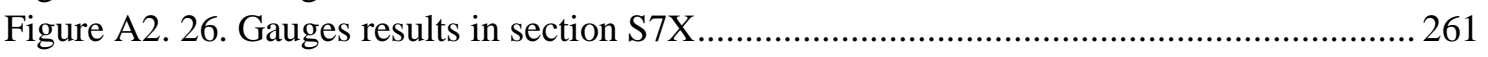

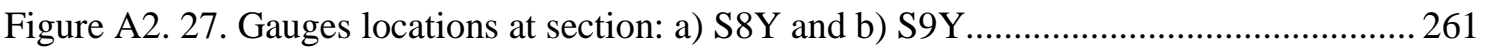

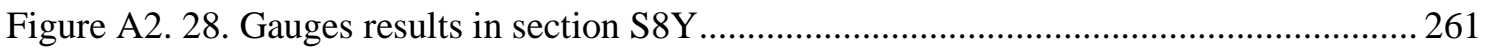

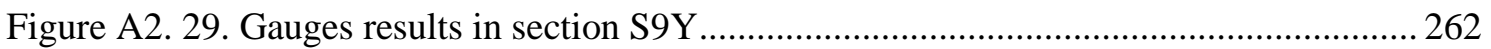

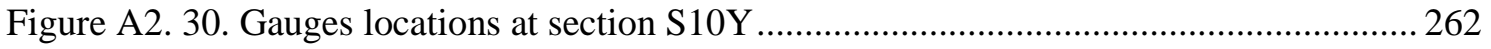

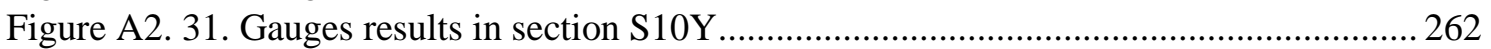

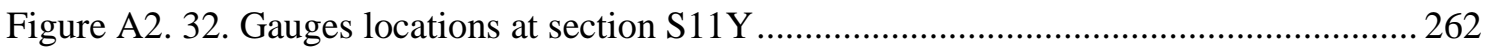

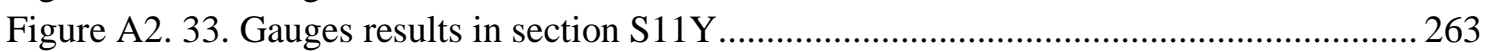

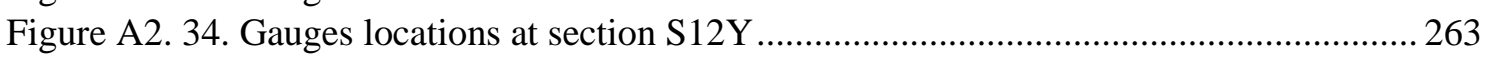

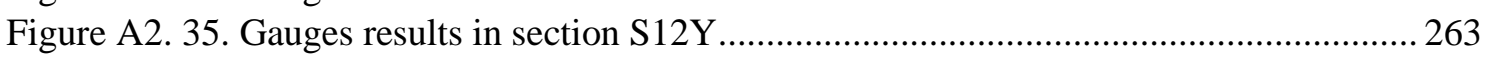

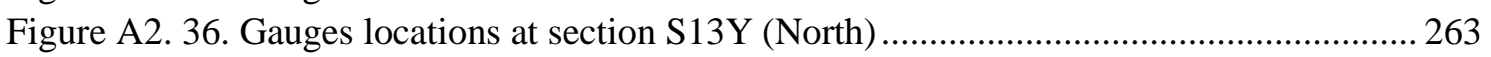

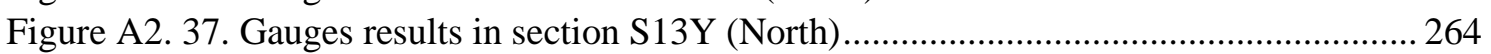

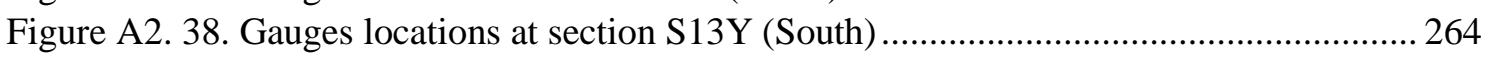

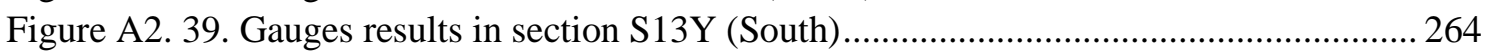

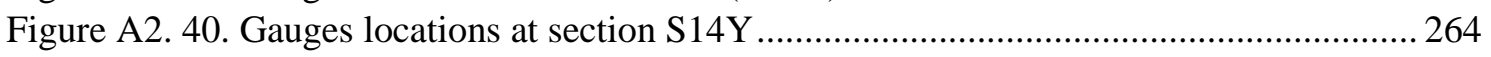

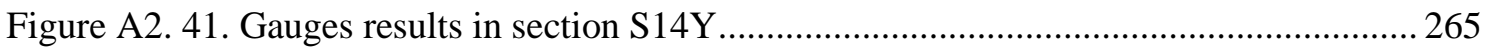

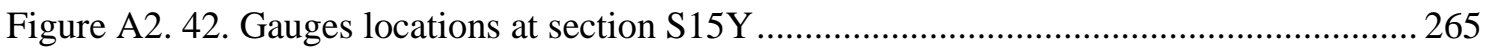

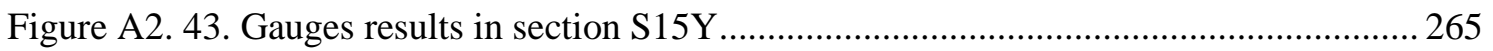

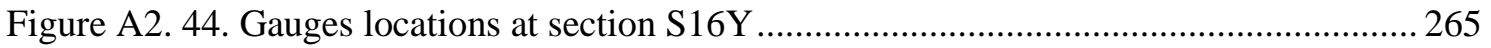

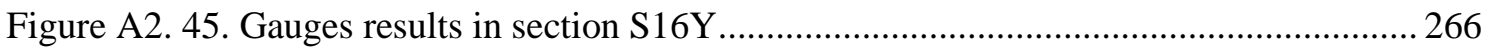

Figure A3. 1. Acceleration and velocity signals for Manjil-1636: a) Acceleration (NS), b) Acceleration (EW), c) Velocity (NS) and d) Velocity (EW) .................................................. 268 Figure A3. 2. Spectra of Manjil-1636 (NS): a) Acceleration, b) Velocity, c) Displacement and d) Input energy 
Figure A3. 3. Spectra of Manjil-1636 (EW): a) Acceleration, b) Velocity, c) Displacement and d) Input energy

Figure A3. 4. Acceleration and velocity signals for Capemend-826: a) Acceleration (NS), b) Acceleration (EW), c) Velocity (NS) and d) Velocity (EW) .................................................. 269 Figure A3. 5. Spectra of Capemend-826 (NS): a) Acceleration, b) Velocity, c) Displacement and

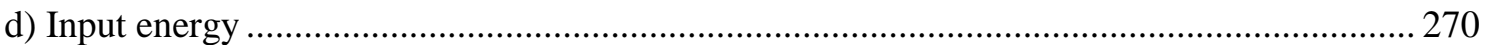
Figure A3. 6. Spectra of Capemend-826 (EW): a) Acceleration, b) Velocity, c) Displacement and

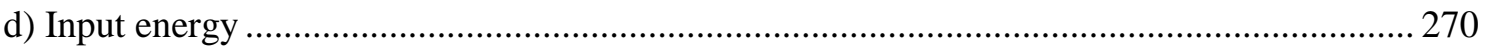
Figure A3. 7. Acceleration and velocity signals for Sfern-68: a) Acceleration (NS), b) Acceleration (EW), c) Velocity (NS) and d) Velocity (EW) ................................................. 271 Figure A3. 8. Spectra of Sfern-68 (NS): a) Acceleration, b) Velocity, c) Displacement and d) Input energy

Figure A3. 9. Spectra of Sfern-68 (EW): a) Acceleration, b) Velocity, c) Displacement and d) Input energy 272

Figure A3. 10. Acceleration and velocity signals for Smadre-1643: a) Acceleration (NS), b) Acceleration (EW), c) Velocity (NS) and d) Velocity (EW) 272 Figure A3. 11. Spectra of Smadre-1643 (NS): a) Acceleration, b) Velocity, c) Displacement and d) Input energy 273 Figure A3. 12. Spectra of Smadre-1643(EW): a) Acceleration, b) Velocity, c) Displacement and d) Input energy 273

Figure A3. 13. Acceleration and velocity signals for Chichi-1435: a) Acceleration (NS), b) Acceleration (EW), c) Velocity (NS) and d) Velocity (EW)

Figure A3. 14. Spectra of Chichi-1435 (NS): a) Acceleration, b) Velocity, c) Displacement and d) Input energy ...... 274 Figure A3. 15. Spectra of Chichi-1435 (EW): a) Acceleration, b) Velocity, c) Displacement and d) Input energy ... 275 Figure A3. 16. Acceleration and velocity signals for Impvall-186: a) Acceleration (NS), b)

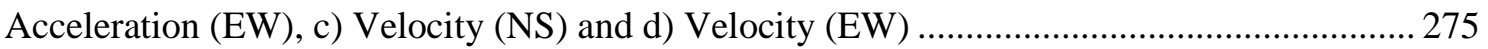
Figure A3. 17. Spectra of Impvall-186 (NS): a) Acceleration, b) Velocity, c) Displacement and

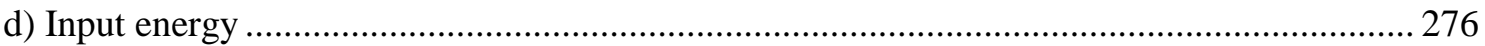
Figure A3. 18. Spectra of Impvall-186 (EW): a) Acceleration, b) Velocity, c) Displacement and

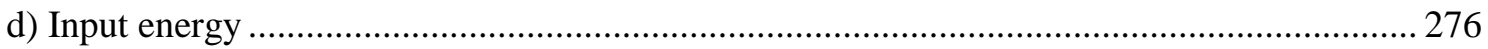
Figure A3. 19. Acceleration and velocity signals for Landers-833: a) Acceleration (NS), b) Acceleration (EW), c) Velocity (NS) and d) Velocity (EW) 277 Figure A3. 20. Spectra of Landers-833 (NS): a) Acceleration, b) Velocity, c) Displacement and

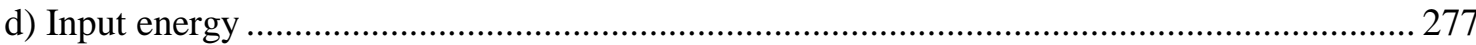
Figure A3. 21. Spectra of Landers-833 (EW): a) Acceleration, b) Velocity, c) Displacement and

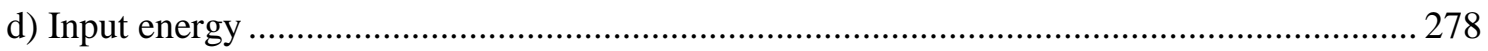
Figure A3. 22. Acceleration and velocity signals for Chichi-1490: a) Acceleration (NS), b) Acceleration (EW), c) Velocity (NS) and d) Velocity (EW) ..............................................2 278 Figure A3. 23. Spectra of Chichi-1490 (NS): a) Acceleration, b) Velocity, c) Displacement and

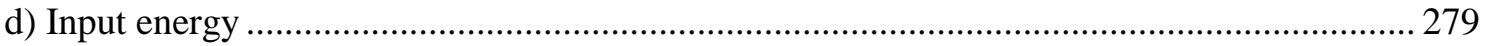
Figure A3. 24. Spectra of Chichi-1490 (EW): a) Acceleration, b) Velocity, c) Displacement and

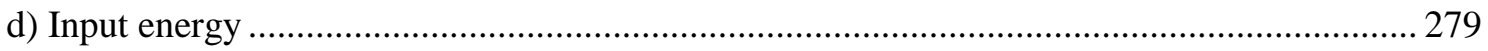
Figure A3. 25. Acceleration and velocity signals for Northr-971: a) Acceleration (NS), b) Acceleration (EW), c) Velocity (NS) and d) Velocity (EW) ..................................................2 280 Figure A3. 26. Spectra of Northr-971 (NS): a) Acceleration, b) Velocity, c) Displacement and d)

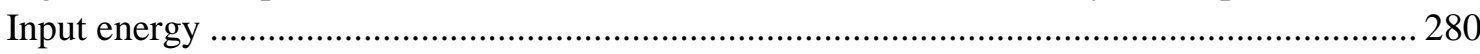
Figure A3. 27. Spectra of Northr-971 (EW): a) Acceleration, b) Velocity, c) Displacement and d) Input energy 
Figure A3. 28. Acceleration and velocity signals for Hector-1762: a) Acceleration (NS), b) Acceleration (EW), c) Velocity (NS) and d) Velocity (EW) ................................................ 281

Figure A3. 29. Spectra of Hector-1762 (NS): a) Acceleration, b) Velocity, c) Displacement and

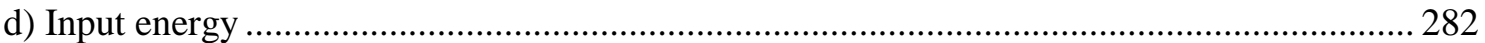

Figure A3. 30. Spectra of Hector-1762 (EW): a) Acceleration, b) Velocity, c) Displacement and

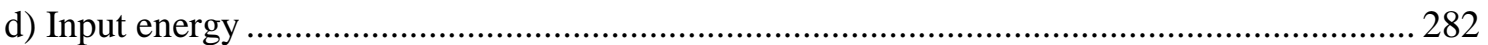

Figure A3. 31. Acceleration and velocity signals for Duzce-1619: a) Acceleration (NS), b) Acceleration (EW), c) Velocity (NS) and d) Velocity (EW) ................................................... 283

Figure A3. 32. Spectra of Duzce-1619 (NS): a) Acceleration, b) Velocity, c) Displacement and d) Input energy 283

Figure A3. 33. Spectra of Duzce-1619 (EW): a) Acceleration, b) Velocity, c) Displacement and

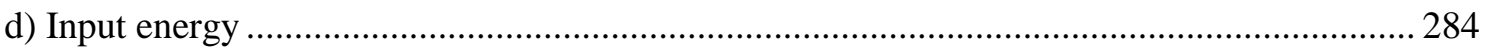
Figure A3. 34. Acceleration and velocity signals for Morgan-460: a) Acceleration (NS), b) Acceleration (EW), c) Velocity (NS) and d) Velocity (EW) ............................................... 284 Figure A3. 35. Spectra of Morgan-460 (NS): a) Acceleration, b) Velocity, c) Displacement and

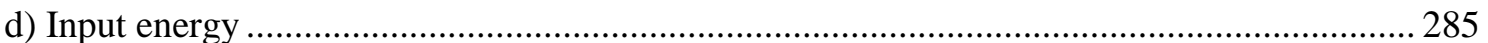
Figure A3. 36. Spectra of Morgan-460 (EW): a) Acceleration, b) Velocity, c) Displacement and

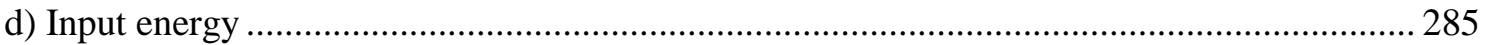
Figure A3. 37. Acceleration and velocity signals for Impvall-175: a) Acceleration (NS), b) Acceleration (EW), c) Velocity (NS) and d) Velocity (EW) ................................................... 286 Figure A3. 38. Spectra of Impvall-175 (NS): a) Acceleration, b) Velocity, c) Displacement and

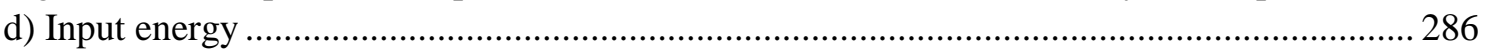
Figure A3. 39. Spectra of Impvall-175 (EW): a) Acceleration, b) Velocity, c) Displacement and

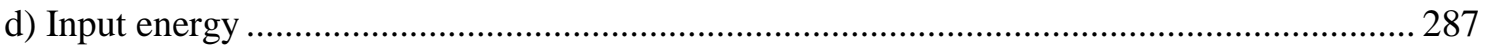
Figure A3. 40. Acceleration and velocity signals for Lomap-799: a) Acceleration (NS), b) Acceleration (EW), c) Velocity (NS) and d) Velocity (EW) ...............................................28 Figure A3. 41. Spectra of Lomap-799 (NS): a) Acceleration, b) Velocity, c) Displacement and d)

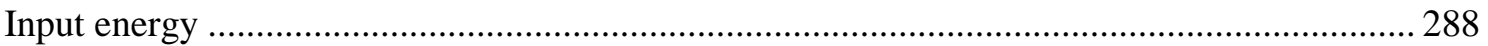
Figure A3. 42. Spectra of Lomap-799 (EW): a) Acceleration, b) Velocity, c) Displacement and

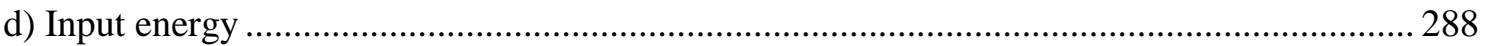
Figure A3. 43. Acceleration and velocity signals for Chichi-1534: a) Acceleration (NS), b) Acceleration (EW), c) Velocity (NS) and d) Velocity (EW) ...............................................2. 289 Figure A3. 44. Spectra of Chichi-1534 (NS): a) Acceleration, b) Velocity, c) Displacement and

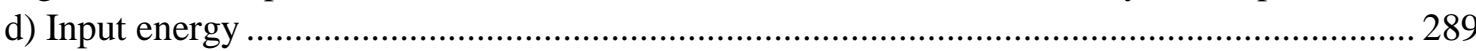
Figure A3. 45. Spectra of Chichi-1534 (EW): a) Acceleration, b) Velocity, c) Displacement and

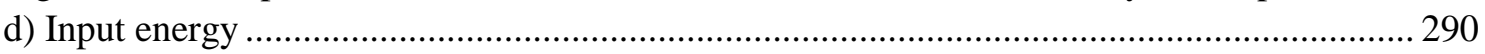
Figure A3. 46. Acceleration and velocity signals for Kobe-1115: a) Acceleration (NS), b) Acceleration (EW), c) Velocity (NS) and d) Velocity (EW) ................................................2. 290 Figure A3. 47. Spectra of Kobe-1115 (NS): a) Acceleration, b) Velocity, c) Displacement and d) Input energy

Figure A3. 48. Spectra of Kobe-1115 (EW): a) Acceleration, b) Velocity, c) Displacement and d)

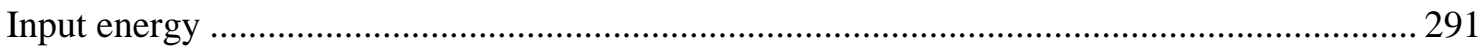

Figure A3. 49. Acceleration and velocity signals for Northr-986: a) Acceleration (NS), b) Acceleration (EW), c) Velocity (NS) and d) Velocity (EW) .................................................. 292 Figure A3. 50. Spectra of Northr-986 (NS): a) Acceleration, b) Velocity, c) Displacement and d) Input energy 292 Figure A3. 51. Spectra of Northr-986 (EW): a) Acceleration, b) Velocity, c) Displacement and d)

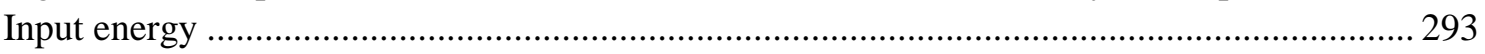
Figure A3. 52. Acceleration and velocity signals for Landers-850: a) Acceleration (NS), b) Acceleration (EW), c) Velocity (NS) and d) Velocity (EW) ................................................. 293 
Figure A3. 53. Spectra of Landers-850 (NS): a) Acceleration, b) Velocity, c) Displacement and d) Input energy 294

Figure A3. 54. Spectra of Landers-850 (EW): a) Acceleration, b) Velocity, c) Displacement and d) Input energy ..... 294 Figure A3. 55. Acceleration and velocity signals for Hector-1766: a) Acceleration (NS), b) Acceleration (EW), c) Velocity (NS) and d) Velocity (EW) 295 Figure A3. 56. Spectra of Hector-1766 (NS): a) Acceleration, b) Velocity, c) Displacement and d) Input energy .... 295

Figure A3. 57. Spectra of Hector-1766 (EW): a) Acceleration, b) Velocity, c) Displacement and d) Input energy .... 296

Figure A3. 58. Acceleration and velocity signals for Coalinga-362: a) Acceleration (NS), b) Acceleration (EW), c) Velocity (NS) and d) Velocity (EW) 296 Figure A3. 59. Spectra of Coalinga-362 (NS): a) Acceleration, b) Velocity, c) Displacement and d) Input energy ..... 297 Figure A3. 60. Spectra of Coalinga-362 (EW): a) Acceleration, b) Velocity, c) Displacement and

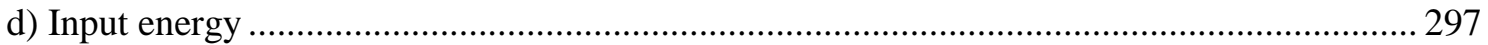
Figure A3. 61. Acceleration and velocity signals for Whittier-673: a) Acceleration (NS), b)

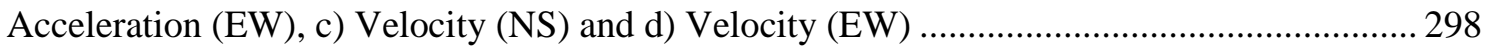
Figure A3. 62. Spectra of Whittier-673 (NS): a) Acceleration, b) Velocity, c) Displacement and d) Input energy . 298 Figure A3. 63. Spectra of Whittier-673 (EW): a) Acceleration, b) Velocity, c) Displacement and d) Input energy 299

Figure A3. 64. Acceleration and velocity signals for Superst-729: a) Acceleration (NS), b) Acceleration (EW), c) Velocity (NS) and d) Velocity (EW)

Figure A3. 65. Spectra of Superst-729 (NS): a) Acceleration, b) Velocity, c) Displacement and d) Input energy 300 Figure A3. 66. Spectra of Superst-729 (EW): a) Acceleration, b) Velocity, c) Displacement and

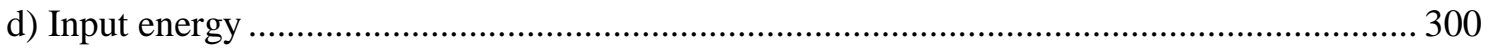
Figure A3. 67. Acceleration and velocity signals for Italy-289: a) Acceleration (NS), b)

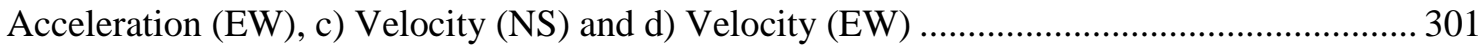
Figure A3. 68. Spectra of Italy-289 (NS): a) Acceleration, b) Velocity, c) Displacement and d) Input energy 301 Figure A3. 69. Spectra of Italy-289 (EW): a) Acceleration, b) Velocity, c) Displacement and d)

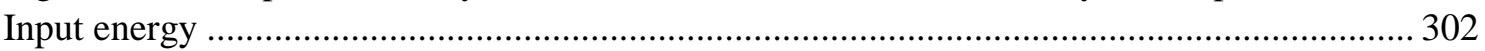
Figure A3. 70. Acceleration and velocity signals for Kocaeli-1162: a) Acceleration (NS), b) Acceleration (EW), c) Velocity (NS) and d) Velocity (EW) 302 Figure A3. 71. Spectra of Kocaeli-1162 (NS): a) Acceleration, b) Velocity, c) Displacement and d) Input energy . 303 Figure A3. 72. Spectra of Kocaeli-1162 (EW): a) Acceleration, b) Velocity, c) Displacement and d) Input energy . 303 Figure A3. 73. Acceleration and velocity signals for Hector-1829: a) Acceleration (NS), b)

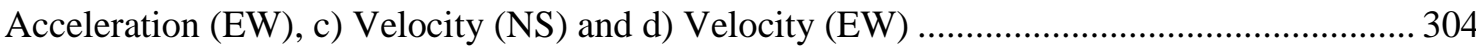
Figure A3. 74. Spectra of Hector-1829 (NS): a) Acceleration, b) Velocity, c) Displacement and

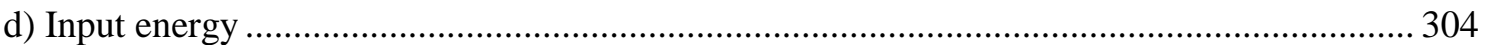
Figure A3. 75. Spectra of Hector-1829 (EW): a) Acceleration, b) Velocity, c) Displacement and

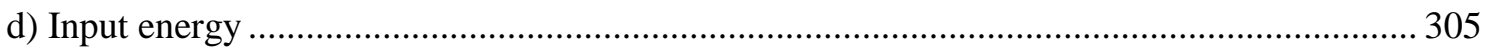
Figure A3. 76. Acceleration and velocity signals for Coalinga-352: a) Acceleration (NS), b) Acceleration (EW), c) Velocity (NS) and d) Velocity (EW) 305 Figure A3. 77. Spectra of Coalinga-352 (NS): a) Acceleration, b) Velocity, c) Displacement and d) Input energy ...... 306 
Figure A3. 78. Spectra of Coalinga-352 (EW): a) Acceleration, b) Velocity, c) Displacement and

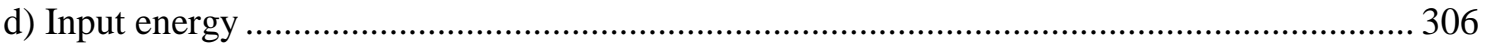
Figure A3. 79. Acceleration and velocity signals for Landers-888: a) Acceleration (NS), b) Acceleration (EW), c) Velocity (NS) and d) Velocity (EW) ................................................. 307 Figure A3. 80. Spectra of Landers-888 (NS): a) Acceleration, b) Velocity, c) Displacement and

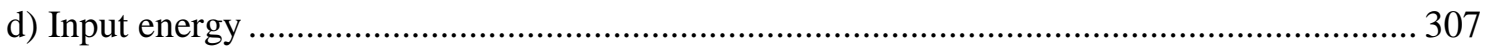
Figure A3. 81. Spectra of Landers-888 (EW): a) Acceleration, b) Velocity, c) Displacement and

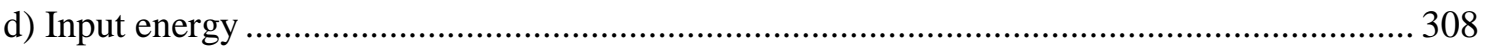
Figure A3. 82. Acceleration and velocity signals for Friuli-125: a) Acceleration (NS), b) Acceleration (EW), c) Velocity (NS) and d) Velocity (EW) ................................................ 308 Figure A3. 83. Spectra of Friuli-125 (NS): a) Acceleration, b) Velocity, c) Displacement and d)

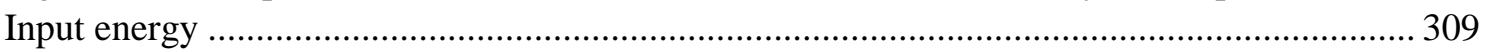
Figure A3. 84. Spectra of Friuli-125 (EW): a) Acceleration, b) Velocity, c) Displacement and d)

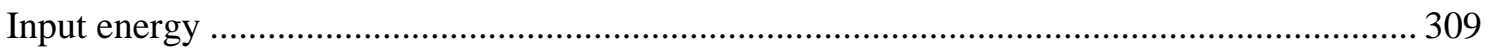
Figure A3. 85. Acceleration and velocity signals for Hector-1794: a) Acceleration (NS), b) Acceleration (EW), c) Velocity (NS) and d) Velocity (EW) .............................................. 310 Figure A3. 86. Spectra of Hector-1794 (NS): a) Acceleration, b) Velocity, c) Displacement and

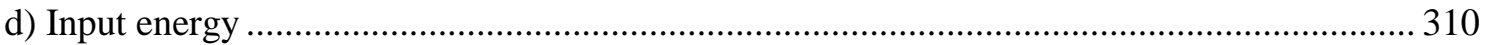
Figure A3. 87. Spectra of Hector-1794 (EW): a) Acceleration, b) Velocity, c) Displacement and

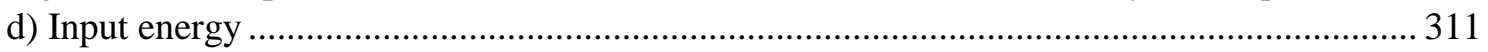
Figure A3. 88. Acceleration and velocity signals for Chichi-1349: a) Acceleration (NS), b) Acceleration (EW), c) Velocity (NS) and d) Velocity (EW) ................................................. 311 Figure A3. 89. Spectra of Chichi-1349 (NS): a) Acceleration, b) Velocity, c) Displacement and

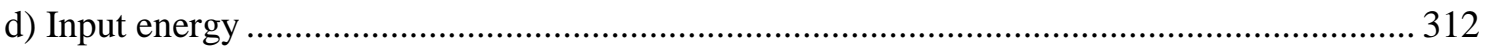
Figure A3. 90. Spectra of Chichi-1349 (EW): a) Acceleration, b) Velocity, c) Displacement and d) Input energy .... 312 Figure A3. 91. Acceleration and velocity signals for Chalfant-549: a) Acceleration (NS), b) Acceleration (EW), c) Velocity (NS) and d) Velocity (EW)

Figure A3. 92. Spectra of Chalfant-549 (NS): a) Acceleration, b) Velocity, c) Displacement and

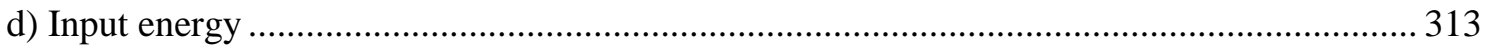
Figure A3. 93. Spectra of Chalfant-549 (EW): a) Acceleration, b) Velocity, c) Displacement and

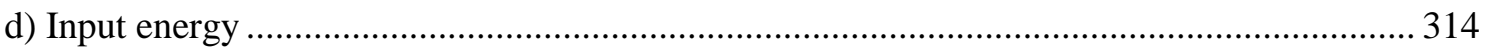
Figure A3. 94. Acceleration and velocity signals for Landers-854: a) Acceleration (NS), b) Acceleration (EW), c) Velocity (NS) and d) Velocity (EW) .................................................. 314 Figure A3. 95. Spectra of Landers-854 (NS): a) Acceleration, b) Velocity, c) Displacement and

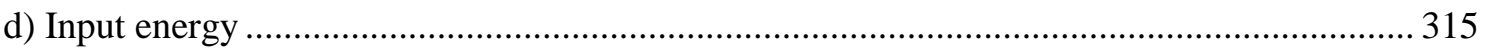
Figure A3. 96. Spectra of Landers-854 (EW): a) Acceleration, b) Velocity, c) Displacement and

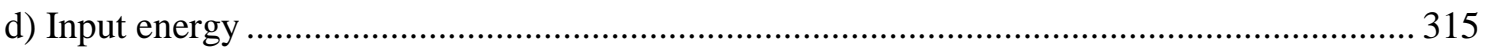
Figure A3. 97. Acceleration and velocity signals for Northr-1079: a) Acceleration (NS), b)

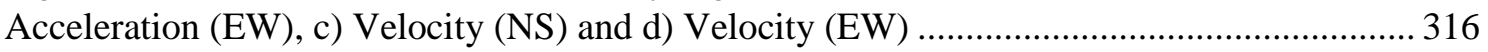
Figure A3. 98. Spectra of Northr-1079 (NS): a) Acceleration, b) Velocity, c) Displacement and

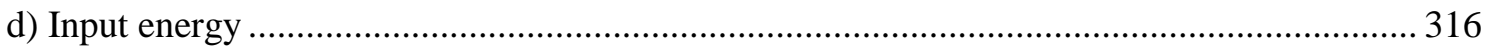
Figure A3. 99. Spectra of Northr-1079 (EW): a) Acceleration, b) Velocity, c) Displacement and

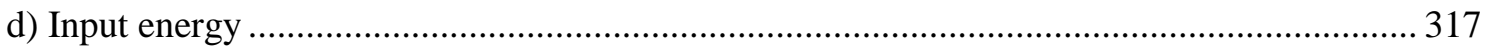
Figure A3. 100. Acceleration and velocity signals for Chichi-1328: a) Acceleration (NS), b) Acceleration (EW), c) Velocity (NS) and d) Velocity (EW) ............................................... 317 Figure A3. 101. Spectra of Chichi-1328 (NS): a) Acceleration, b) Velocity, c) Displacement and

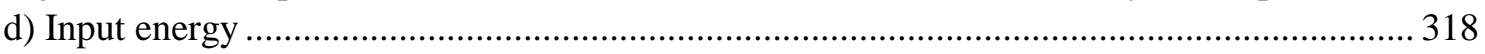
Figure A3. 102. Spectra of Chichi-1328 (EW): a) Acceleration, b) Velocity, c) Displacement and

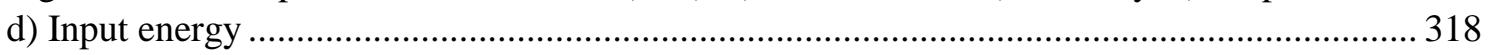


Figure A3. 103. Acceleration and velocity signals for Lomap-765: a) Acceleration (NS), b) Acceleration (EW), c) Velocity (NS) and d) Velocity (EW)

Figure A3. 104. Spectra of Lomap-765 (NS): a) Acceleration, b) Velocity, c) Displacement and d) Input energy

Figure A3. 105. Spectra of Lomap-765 (EW): a) Acceleration, b) Velocity, c) Displacement and d) Input energy 320 


\section{List of tables}

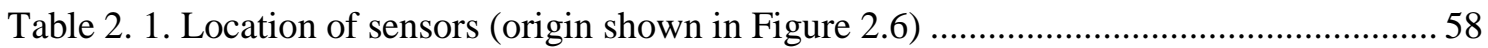

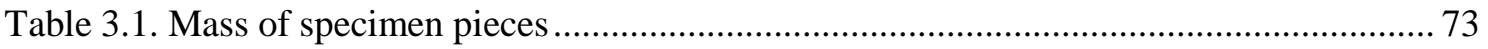

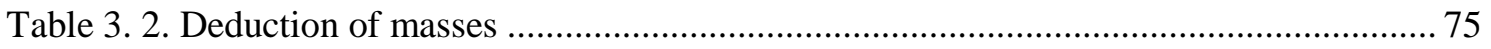

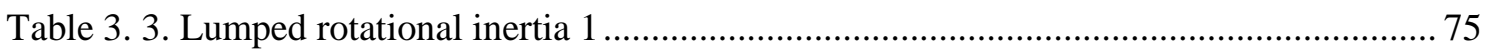

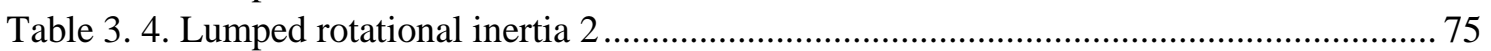

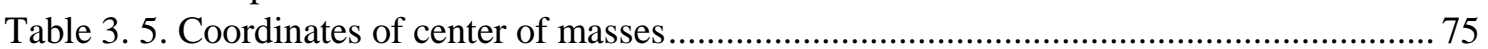

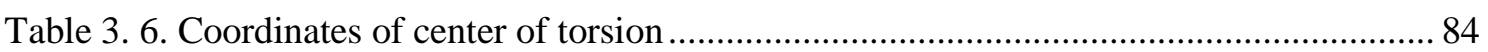

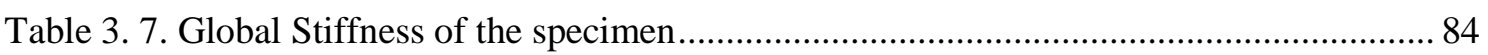

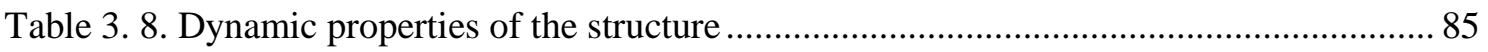

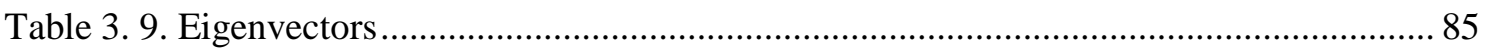

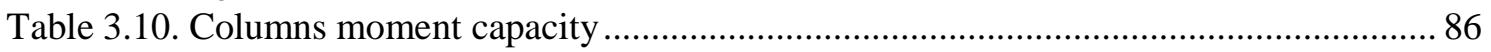

Table 4. 1. Main return period and probability of occurrence of simulations ............................ 101

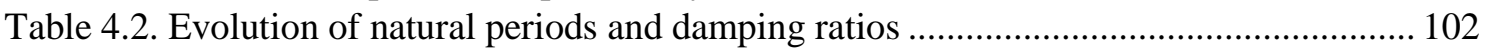

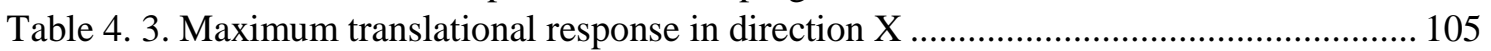

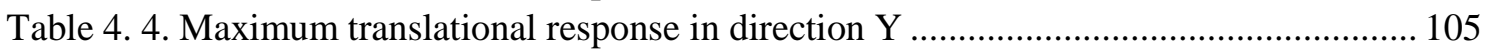

Table 4. 5. Maximum rotational response about the centers of mass...................................... 105

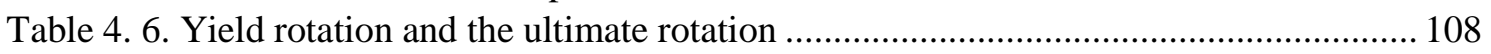

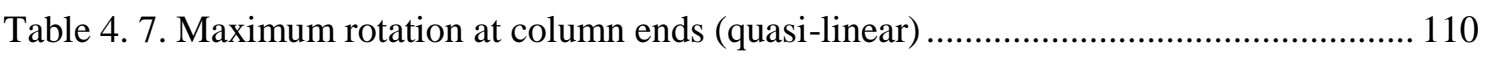

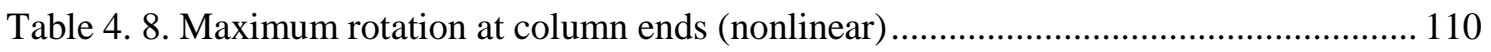

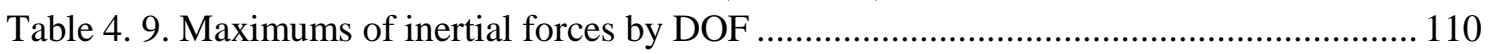

Table 4. 10. Maximum values of base shears exerted by inertial forces (Figure 4.9) ............... 112

Table 4. 11. Deformation of longitudinal reinforcement by sections....................................... 118

Table 4. 12. Input energies in training and successive seismic simulations.............................. 122

Table 4. 13. Energy dissipated by inherent viscous damping ................................................ 123

Table 4. 14. Energies in terms of equivalent velocities and relations with $E I \ldots \ldots \ldots \ldots \ldots \ldots \ldots \ldots \ldots . . . . . . . . .123$

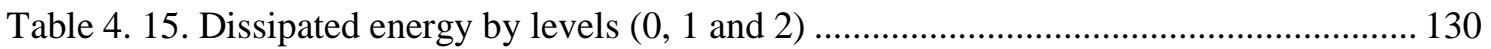

Table 4. 16. Dissipated energy by sections at level 0.............................................................. 130

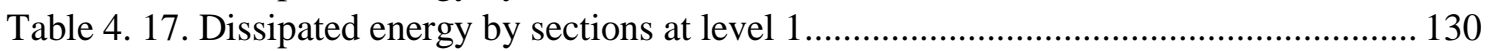

Table 4. 18. Energy stored/dissipated by steel and concrete in columns ................................ 133

Table 4. 19. Energy stored/dissipated by columns, WFP and damping ................................... 134

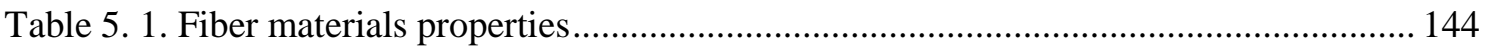

Table 5. 2. Yield and ultimate curvatures of columns from Fardis's equations ......................... 145

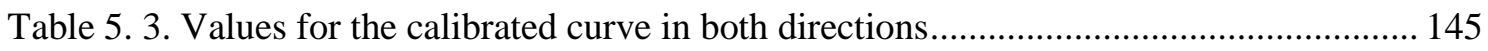

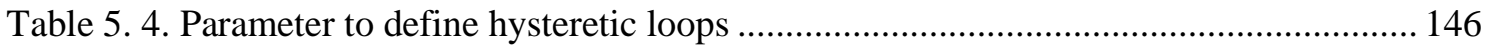

Table 5. 5. Thickness of layers in mm (form bottom to top) for internal panels ...................... 150

Table 5. 6. Thickness of layers in mm (form bottom to top) for external panel ........................ 151

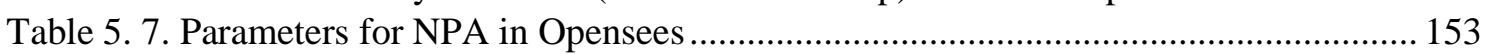

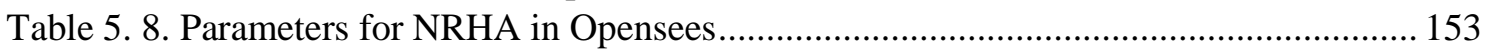

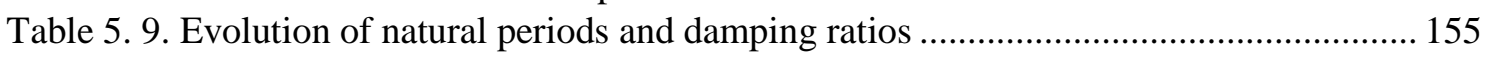

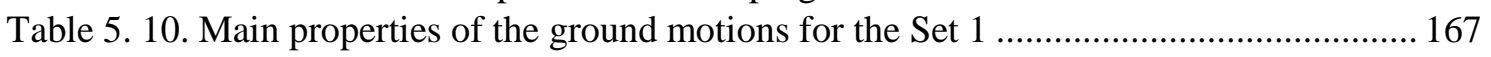

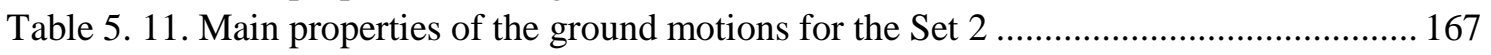




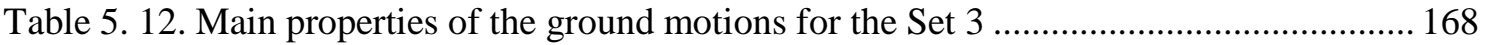

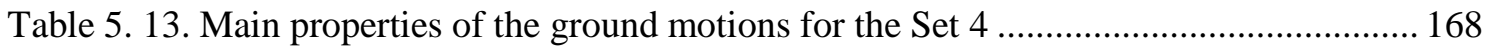

Table 5. 14. Main properties of the ground motions for the Set 5 ......................................... 169

Table 5. 15. Analysis of the input energy and the energy that contributes to damage obtained from

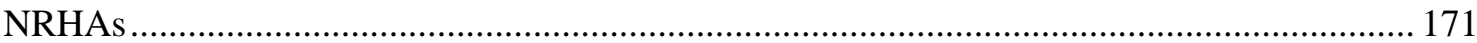

Table 5. 16. Uni and bidirectional input energy absorbed by the specimen for elastic deformations

Table 5. 17. Uni and bidirectional input energy absorbed by the specimen at failure .............. 174

Table 5. 18. Uni and bidirectional energy dissipated by the specimen at failure ...................... 175

Table 6. 1. Calibrated nonlinear spring to simulate the slit-plate damper tested ...................... 188

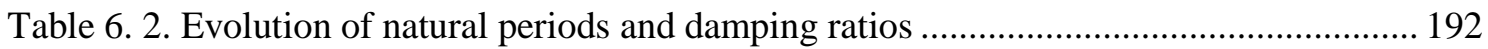

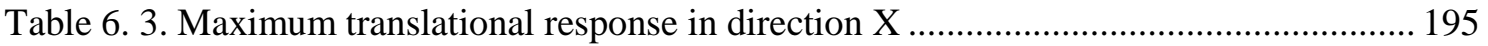

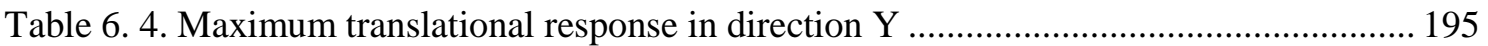

Table 6. 5. Maximum rotational response about the centers of mass......................................... 195

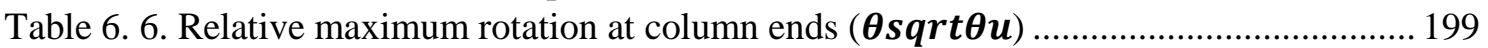

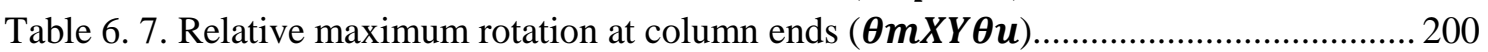

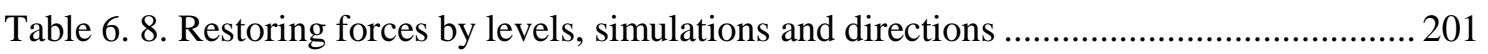

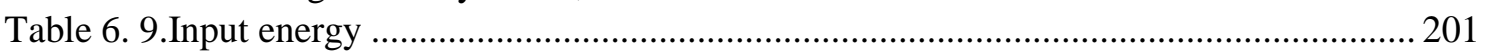

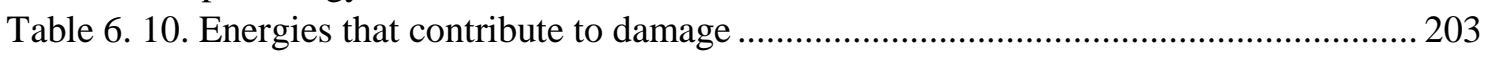

Table 6. 11. Energies in terms of equivalent velocities and relations with $E I$.........................203

Table 6. 12.Mechanical index of damage IDi of the slit-plate dampers (Figure 6.18) ............. 204

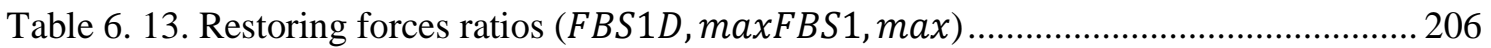

Table 6. 14. Analysis of the input energy obtained from NRHAs. ......................................... 210

Table 6. 15. Analysis of the energy that contributes to damage obtained from NRHAs.......... 211

Table 6. 16. Seismic capacity comparison in terms of input energy: unidirectional vs bidirectional loadings

Table 6. 17. Seismic capacity comparison in terms of dissipated energy: unidirectional vs

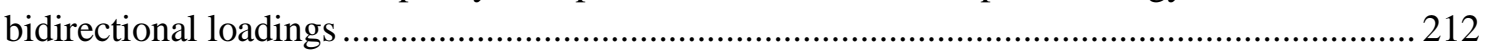




\section{Chapter 1}

\section{INTRODUCTION}

Numerical analysis is a tool for the estimation of structural response in the process of designing earthquake resistant structures and/or retrofitting vulnerable existing structures. The analysis is a process where the complexity of the reality is boiling down in measurable parameters such as displacements, velocities, accelerations, forces and energies. In general, especially in earthquake engineering, this is tricky, because the process encompasses the solution of dynamic systems with nonlinearities (material, geometric and contact) and random ground motions. But, it is also true that, nowadays we count on a huge development in computer power and the work of engineers consists mainly on introducing correct information in software and, once the analysis is complete, checking results. However, Clough (1980) warned that depending on the validity of the assumptions made in reducing the physical problem to a numerical algorithm, the computer output may provide a detailed picture of the true physical behavior or it may not even remotely resemble it. So that, not only must the engineer know how to use a software but also he/she must have a deep understanding of structures (Fajfar, 2018).

In research, we must go farther, numerical simulations and experimental tests in laboratory must go hand in hand. They are the most powerful tools for performance-based earthquake engineering research and we must explode them as much as possible. The paradigm of the Performance Based Design (SEAOC, 1995) establishes seismic performance levels that the structure must satisfy 
under different seismic hazard levels. The development of seismic codes within the framework of Performance Based Seismic Design requires information on the inelastic response characteristics and on the behavior of typical structures designed under current codes. This information comes from both experiments (preferably shaking table tests) and nonlinear response history analyses (NRHAs) of numerical models calibrated with test results. Shaking table tests can reproduce in a very realistic way the seismic demands on structures, and can capture accurately complex phenomena such cumulative damage and rate-of-loading effects. However, it is worth bearing in mind that shaking table tests are very expensive and time consuming. This makes this experimental approach unfeasible for conducting parametric studies, which require obtaining and summarizing the responses of a large number of structures subjected to a different types of ground motions. On the other hand, the capabilities of modern computers and specialized software allow to conduct a large number of nonlinear dynamic analyses of complex models with a reasonable limited amount of time. However, to consider these results reliable and valid, it is important to use numerical models properly calibrated with test results. The best calibration is attained using the results of shaking table tests. In this context the investigation presented in this dissertation aims at investigating the response of reinforced concrete (RC) waffle-flat plate (WFP) systems subjected to bidirectional seismic loadings and the enhancement in the dynamic response when passive energy dissipation devices (EDDs) are added to WFP systems.

\section{STATEMENT OF THE PROBLEM}

\subsection{Waffle-Flat Plate systems}

Reinforced concrete (RC) waffle-flat plate (WFP) supported on isolated columns belongs to the family of Beamless Slab (BS) or Flat Plates (FP) systems (Figure 1.1). It consists of orthogonal ribs with drop panels or solid zones around columns to increase the moment and shear capacity of the slab (Taranath, 2004). The WFP and FP structures are an effective system to support gravitational loads and have some additional benefits in comparison with frame systems: (i) they allow cheaper formworks; (ii) freedom for irregular layouts of the column grid in plan, what allows flexibility in design; and (iii) large spans between columns $(10-12 \mathrm{~m})$ with thin plates $(40-45 \mathrm{~cm})$, minimizing the number of supporting points. In contrast, its seismic behavior presents serious deficiencies, owing to: (i) low lateral stiffness which implies high lateral displacements that can cause impact between buildings plus problems of stability due to P- $\Delta$ effects (Meli, R. \& Avila, 1989; Meli, Roberto \& Rodriguez, 1988); (ii) low ductility and low capacity to dissipate energy (Sordo, Teran, Guerrero, Juarez, \& Iglesias, 1989); and (iii) brittle punching failure owing to shear-strength degradation under lateral displacements (Hueste \& Wight, 1999). As a consequence, worldwide standards have implemented restrictions, rules and recommendations for the use of FP and WFP structures. Spanish standard NCSE-02 (Ministerio de Fomento, 2003) establishes a low ductility class for FP and WFP buildings, and limits the ductility factor, $\mu$, to $\mu=2$. Eurocode 8 (CEN, 2004) also proposes a low ductility class (DCL) for FP buildings with a behavior factor, $q$, of 1.5 and limits their use only in low seismicity areas. ACI 318M-14 (ACI, 2014) indicates that two-way slabs without beam structures can be used only in areas with a moderate (level C) seismic category design (SCD). In addition, most codes lack dimensioning and detailing rules for WFP systems. Despite these limitations, there are experiences for which this kind of structures exhibited good performance under heavy seismic actions (Fardis, 2009): Kalamata (Greece, 1986), Aegio (Greece, 1995) and Athens (Greece, 1999). Therefore, new research and studies are needed to improve our knowledge on the seismic behavior of this type of structures. 


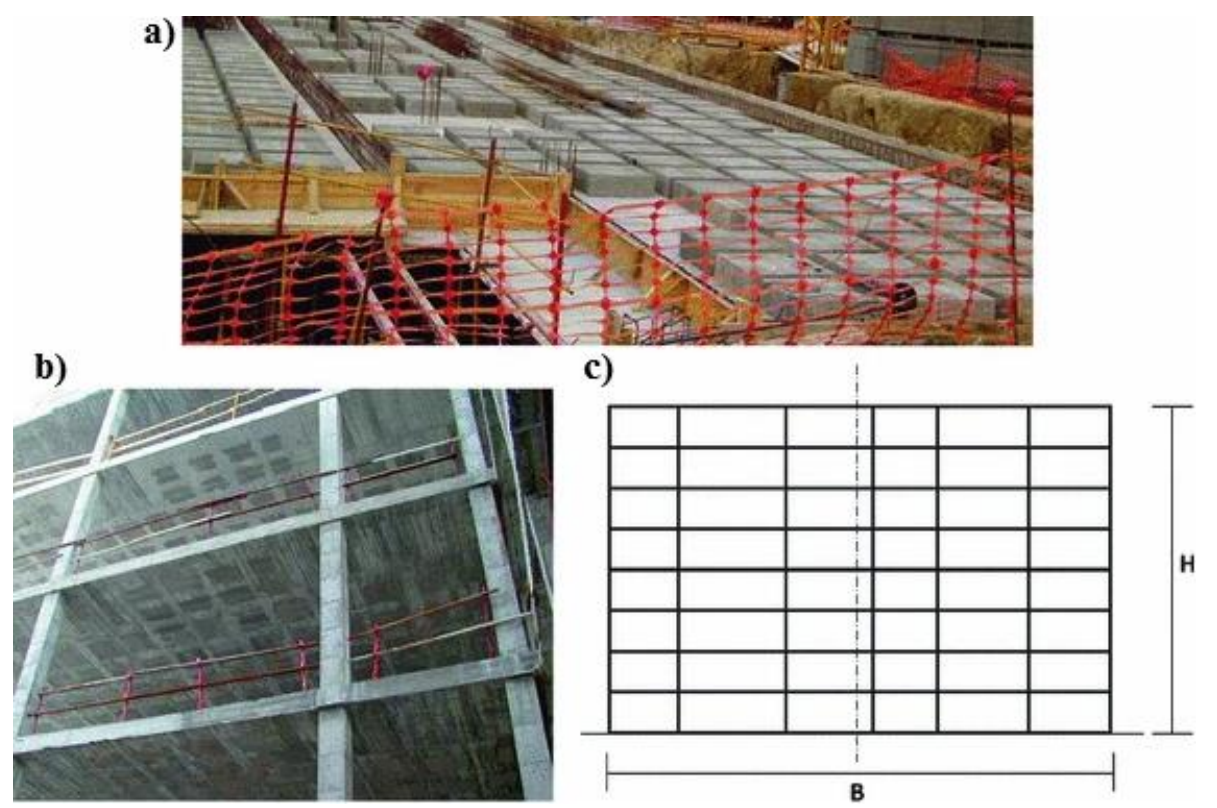

Figure 1. 1. Waffle-Flat Plate building: square domes in construction, b) structure and c) building model (Vargas, Pujades, Barbat, \& Hurtado, 2013)

Past experimental and numerical research has focused on FP system at local or global levels. From the point of view of the experimental work, it has been investigated the seismic response of existing non-ductile FP buildings (Chow \& Selna, 1995; Durrani, Du, \& Luo, 1995; Robertson, Ian \& Johnson, 2006). Mosalam and Naito (2002) addressed column-grid systems designed only for gravity loads. Kang and Wallace (2004) subjected a two-story one-bay FP structure to unidirectional shake table test and found substantially less drift capacity than that obtained with test of isolated connections. Rizwan et al. (2020) investigated the damage suffered in code compliant FP systems and in those with construction/design defects, analyzing the structures under unidirectional loadings. At the local level, Robertson et al. (2002) investigated the effect of the shear reinforcement on the cyclic response. On the numerical side, Hwang and Moehle (2000) developed models for laterally loaded FP systems, and Dovich and Wight (2005) proposed an effective slab width to analyze regular FP systems as equivalent frames. Bayhan (2013) developed a success numerical blind prediction of the nonlinear seismic response of two fullscale, three dimensional, one-story RC frame system subjected to bidirectional seismic loadings on shaking table test.

The analysis of a structures under biaxial cyclic loadings cannot be treated merely as an extension of the analysis under uniaxial loadings because there are more effects to account for. Manglio and Ramasco (2007) compared the response of a RC multistory frame building under unidirectional and bidirectional seismic loadings and reported that even though the base shears and the top displacements were similar, there were significant differences for plastic deformations in columns. Unlike uniaxial loading, Sabastini et al. (2018) proposed a method to obtain the critical incidence angle in bidirectional seismic loading that produces the maximum response of the structure. De Stefano and Faella (1996) reported that a lumped mass system subjected to bidirectional seismic loading shows a clear tendency to concentrate damage in the stiff direction (lower period), respect to the response obtained under unidirectional loading. In addition, the authors proposed a theoretically overstrength (between 20 and 40\%) required to design structures considering only one-component of the earthquake. Dutta and Kunnath (2013) observed, through numerical analysis, a considerable increase of the displacement response and lengthening of periods in structural systems under bidirectional loadings respect to what was obtained under unidirectional. 
The influence of the spatial effects derived from torsion is also a critical issue in structures subjected to bidirectional loadings (De Stefano \& Faella, 1996; Kuang, Jiang, \& Jiang, 2018; Magliulo \& Ramasco, 2007; Marušić \& Fajfar, 2005; Zeris \& Mahin, 1991). Buildings can be classified as torsional stiff or torsional flexible, depending on the ratio that relates the first translational period, $T_{1, t}$, with the first torsional period, $T_{1, \vartheta}$ as $\Omega=T_{1, t} / T_{1, \vartheta}$. Values of $\Omega>1$ correspond to torsional stiff buildings and $\Omega<1$ correspond to torsional flexible buildings. Moreover, it is possible the combination of torsional stiff and torsional flexible behavior in the same buildings because of different values of $\Omega$ for the orthogonal main directions. Goel (1997) investigated symmetric and asymmetric structures and observed that both have similar demand for input and hysteretic energy. However, the distribution of hysteretic energy can be significantly different, with higher demand in flexible frames (those closer to the mass center) than that in stiff frames (those farther to the mass center). Marussić and Fajfar (2005) found that stiffness degradation in one direction may substantially influence the behavior in the orthogonal direction, which in turn relies on the characteristics of the ground motions. As long as the intensity of ground motion increases, the center of stiffness changes and tends to be closer to the center of mass. Therefore, torsional effects decrease with increasing plastic deformations, unless the plastic deformations are small.

After a deep revision of the literature about WFP systems, it is concluded that research on this type of structure is quite scarce, particularly experimental investigations. The development and improvement of seismic codes calls for experimental information to check the adequacy of current provisions and to evaluate the inelastic response of structural systems. The latter results particularly important for the Seismic Performance Level (SPL) of Near Collapse (NC), which does not require an explicit check in most seismic codes. In case of FP or WFP systems are still more important because experimental data is very limited. Namely, the references of shaking table test conducted on WFP systems are very few. Rodriguez and Meli (1995) tested a two-story WFP structure designed according to past Mexican seismic codes and demonstrated the relatively low energy-dissipation and displacement-ductility capacities. Benavent-Climent et al. (2016) tested a WFP structure designed following modern codes, evaluated its seismic performance and damage, and proposed force reduction factors for designing this type of structure using force-based methods (Figure 1.4a). In all these tests, the specimens were subjected to only one component of the ground motion. The research conducted for this Thesis attempts to go one step beyond evaluating experimentally the seismic performance and damage evolution of a portion of a WFP structure (specimen) subjected to a series of bidirectional seismic loading on shaking table test until failure. The research is completed with extensive non-lineal time history analyses conducted on numerical models calibrated with the results of shake table tests.

\subsection{Waffle-Flat Plate systems with passive energy dissipation systems}

The use of energy dissipation devices (EDDs) as primary seismic elements has proven effective to control the response of a structure under seismic actions (Christopoulos \& Filiatrault, 2006; Kasai, Kazuhiko et al., 2009; Oviedo, A., Midorikawa, \& Asari, 2010; Symans et al., 2008). One example can be found in tall structures with a combination of different types of EDDs (hysteretic and viscous dampers) during the Tohoku earthquake (Japan, 2011) (Kasai, K., Pu, \& Wada, 2012). Different methods for the design of dampers have been developed, to ensure a reasonably uniform story drift distribution (Connor, 2003; Kasai, Kazuhiko et al., 2009) or a reasonably uniform distribution of the hysteretic energy dissipation demand, i.e. plastic deformations (Akiyama, 1985; Benavent-Climent, 2011; Donaire-Ávila \& Benavent-Climent, 2020). A design method based on the energy-balance approach proposed by Akiyama (1985) was recently adopted by the Japanese Building Code (BSL, 2009) for the design of structures equipped with hysteretic 
dampers. A similar energy-based approach will be implemented in the next generation of Eurocode 8 for designing building structures equipped with displacement-dependent dampers.

One effective way to improve the seismic behavior of WFP systems is to add EDDs. Combining the inherent flexibility of the WFP system with the high lateral stiffness and high energy dissipation capacity provided by EDDs leads to mixed systems with important advantages in terms of seismic response. This type of systems are called in the literature "flexible-stiff mixed structures" (Akiyama, 1985). The flexible part (the main system, in this case the WFP system) must be able to support the gravitational loads while it moves laterally due to that seismic action. The stiff part must be able to absorb by plastic deformations most of the energy introduced by earthquake. The flexible part must have low stiffness and large lateral deformation capacity within the elastic range. The stiff part must have relatively low strength, large lateral stiffness and large energy dissipation capacity. This combination is very efficient in controlling the maximum lateral displacement of the building and in reducing permanent plastic deformations in the parent structure once the ground motion stops (Akiyama, 2002), since the inelastic deformations are concentrated in the seismic dampers.

In a schematic way, Figure 1.2 shows how a "flexible-stiff mixed structure" works. In the figure, the bold lines represent the idealized curve of the $i_{t h}$ story shear force versus drift, $Q_{i}-\delta_{i}$, of a structure with hysteretic dampers subjected to monotonic (Figure 1.2a) and cyclic (Figure 1.2b) loading. This curve is the sum of the idealized curve of the main system, ${ }_{f} Q_{i}-{ }_{f} \delta_{i}$, which is defined by the elastic stiffness ${ }_{f} k_{i}$, the yield strength ${ }_{f} Q_{y, i}$ and the yield displacement ${ }_{f} \delta_{y, i}$, plus the curve that represents the energy dissipation system, ${ }_{s} Q_{i}-{ }_{s} \delta_{i}$, which is defined by the initial stiffness ${ }_{s} k_{i}$, the yield strength, ${ }_{s} Q_{y, i}$, and the yield displacement ${ }_{s} \delta_{y, i}$. Accordingly, hereafter, the "energy dissipation system" will be designated with the subindex " $s$ " (stiff part) and the "main structure" with the subindex " $f$ " (flexible).

a)

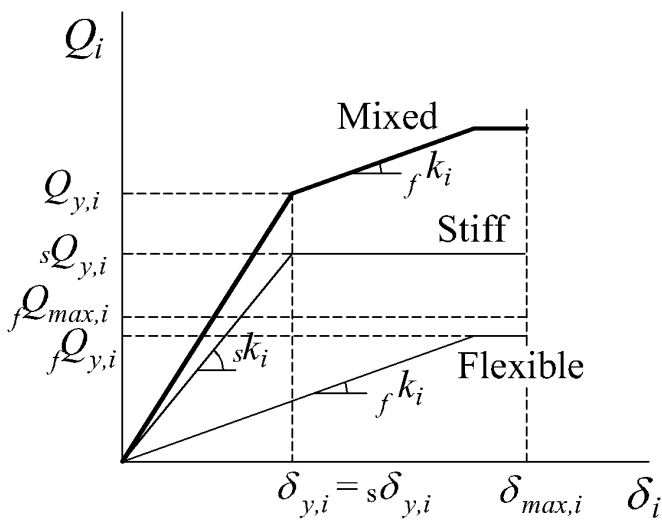

b)

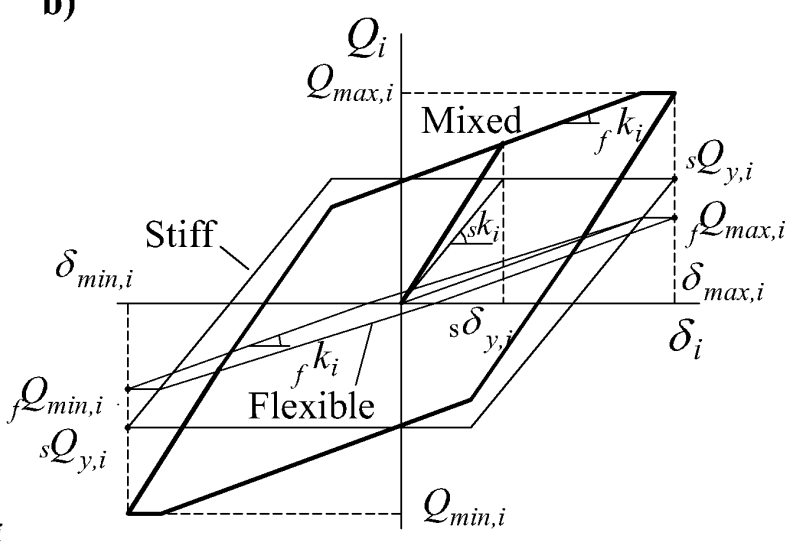

Figure 1. 2. Hysteretic behavior of a flexible-stiff mixed structure: a) monotonic loading and b) cyclic loading

The energy dissipation systems that form the stiff part of the "flexible-stiff mixed structure" are mechanical devices that are incorporated into the frame of the main system and dissipate energy throughout the height of the structure. The mechanism by which energy is dissipated is either yielding of mild steel, sliding friction, motion of a piston or a plate within a viscous fluid, orificing of fluid, or viscoelastic action in polymeric materials. Some energy dissipation systems such as metallic-yielding, friction and viscoelastic, in addition to increasing the energy dissipation capacity of the structure, they also increase strength and stiffness. Energy dissipation systems 
utilizing fluid viscous dampers do not generally increase the strength or stiffness unless the excitation frequency is high (Constantinou, Soong, \& Dargush, 1998). These devices can be classified as displacement-dependent such as metallic (Figure 1.3a) and friction dampers (Figure $1.3 b$ ), and velocity-dependent such as viscous dampers (V), viscoelastic (VE) solid dampers (Figure 1.3c) and viscoelastic fluid dampers (Figure 1.3d). Displacement-dependent systems allow to concentrate damage in certain elements fabricated under severe quality controls to guarantee a ductile behavior and a large energy dissipation capacity. On the other hand, velocitydependent systems modify the damping ratio of the structure, from $4-5 \%$ to more than $30 \%$. Overall, these devices do not change the main system stiffness and, thus, the fundamental period remains unaltered. Both displacement-dependent and velocity-dependent systems must be installed in accessible places for inspection and possible replacement after a seismic event. There are different configurations to install dampers in a structure. The concept is simple, for the sake of efficiency the dampers should connect points of largest relative displacements. Some common configurations are shown in Figure 1.3e: diagonal (at first floor), Chevron (at second and third floor), toggle (at fourth floor) and open Space (at fifth floor).

a)

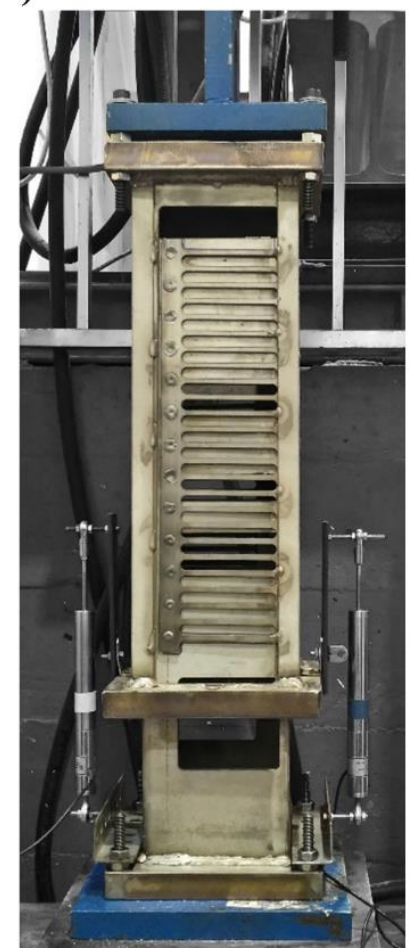

b)

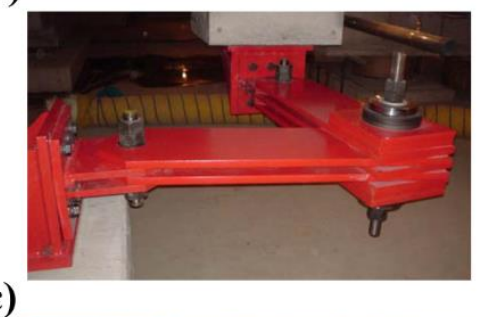

c)

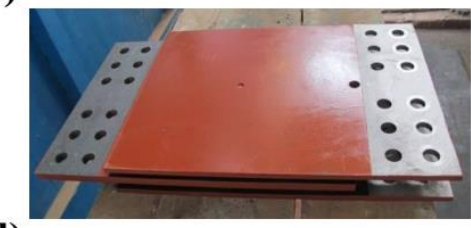

d)

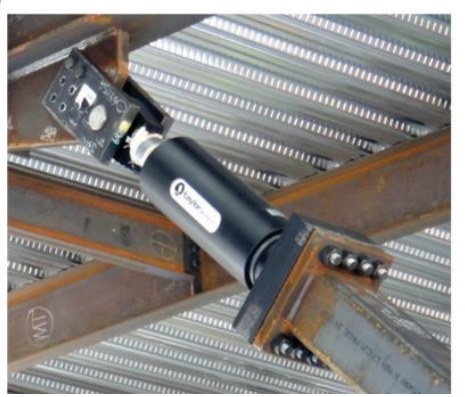

e)

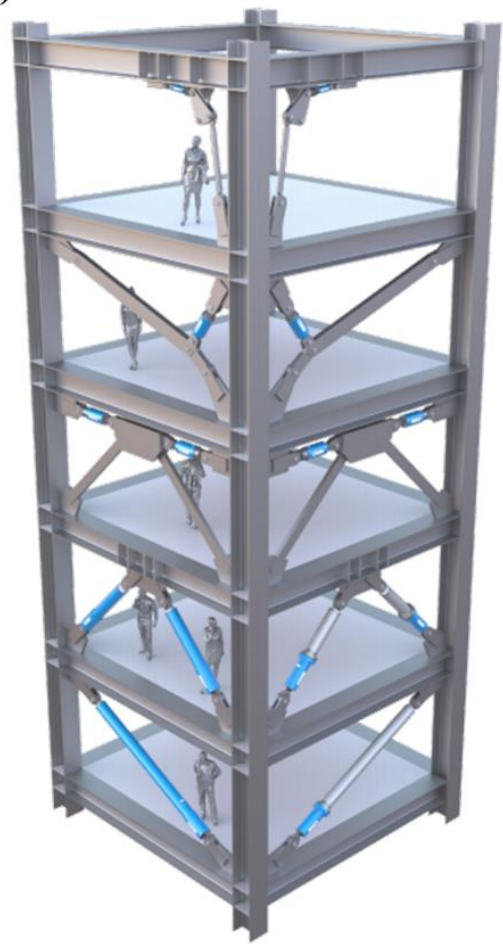

Figure 1. 3. Types of dampers and installations: a) metallic (González-Sanz, EscolanoMargarit, \& Benavent-Climent, 2020), b) friction (Nielsen, Mualla, \& Iwai, 2004), c) viscoelastic solid (Zhou, Gong, \& Lu, 2013) d) viscoelastic fluid dampers (Taylor Devices inc.) and e) configurations (Taylor Devices inc.)

Oviedo (2012) investigated the influence of the story stiffness of RC frames with hysteretic dampers and concluded that the lateral stiffness and strength of the main system influence significantly the seismic response. In detail, the author concluded that the ratio ${ }_{s} \delta_{y, i} /{ }_{f} \delta_{y, i} \leq$ 0.5 , and the ratio ${ }_{s} Q_{y, i} /{ }_{f} Q_{y, i} \leq 1.0$ are crucial in reducing the story drift demand when dampers are installed into a flexible RC frame. The benefits of the energy dissipation systems in buildings were demonstrated experimentally by Aiken (1993), who carried out tests comparing the response of structures without dampers and using different types of dampers. In recent times, BenaventCliment conducted two test campaigns summarized in (Benavent-Climent et al., 2016; BenaventCliment, Donaire-Avila, \& Oliver-Sáiz, 2018), to investigate the seismic response of a WFP 
specimen subjected to series of unidirectional ground motions until failure. Two specimens with similar geometry and details were casted and tested under the same ground records. One was designed as a conventional construction under current building codes in the Mediterranean area (see Figure 1.4a), and the other was designed to carry only gravity loads, yet with hysteretic dampers (see Figure 1.4b). As a result, while the former reached the failure, the latter (introducing the same input for which the former failed) remained basically undamaged, reaching an Interstory Drift Index (IDI) of $1.25 \%$, consuming only a $30 \%$ of chord rotation capacity of columns and a $19 \%$ of its capacity in terms of the energy that contribute to damage. Moreover, the authors recommended that, in the design of structures with EDDs, the ratio $\delta_{y, d} / \delta_{y, R C}$ should be $\leq 0.4$, this value is similar to that suggested by Oviedo (2012). Further, Donaire-Ávila (2014) investigated the behavior of WFP structures with hysteretic dampers subjected to different seismic hazard levels (SHLs), finding that the hysteretic dampers can effectively control the response of WFP systems subjected to near- and far-field earthquakes with low and high SHLs.

a)

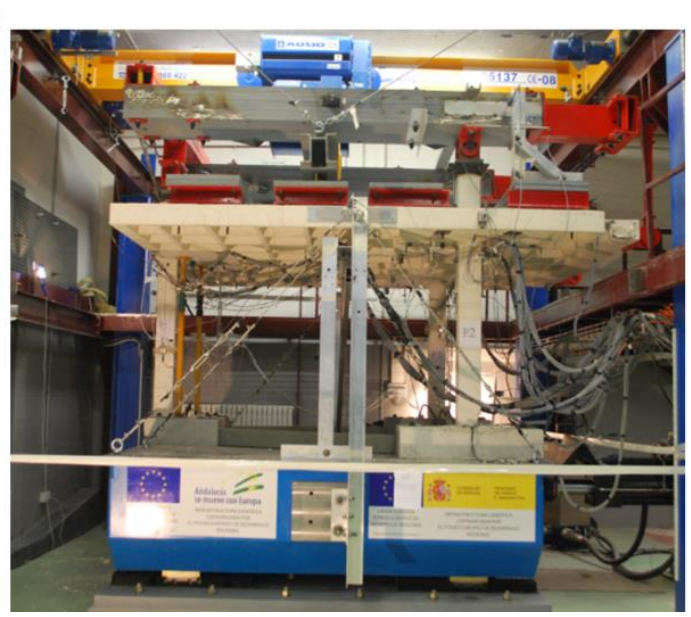

b)

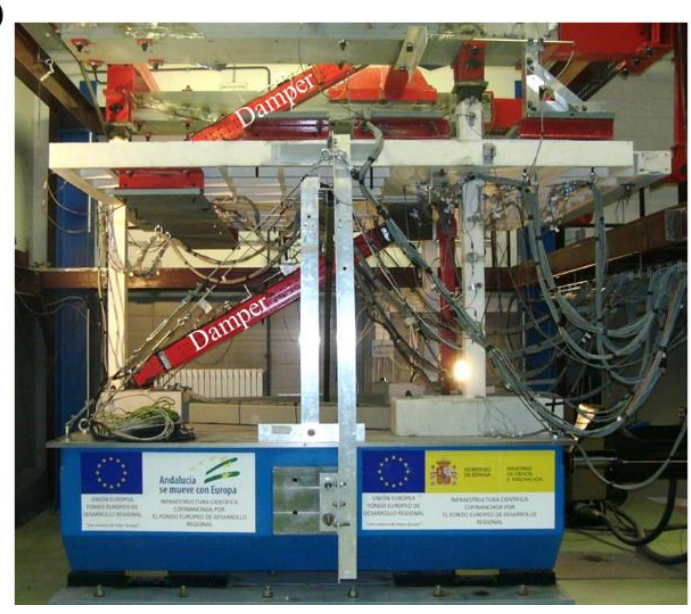

Figure 1. 4. Test campaigns conducted by Benavent-Climent: a) specimen without dampers (2016) and b) specimen with dampers (2018)

In the past decades, there has been an exponential increase in the use of EDDs for controlling the response of structures subjected to ground motions. Among the different types of EDDs available, hysteretic dampers are usually the cheapest and do not require maintenance. This feature makes them very attractive to the industry, because one of the handicaps to incorporate these special devices is the cost. Further, implementing this new technology requires highly qualified and trained manpower for design and installation. This research attempts to go one step further in the direction of assessing the behavior of a WFP structures with hysteretic EDDs and subjected to bidirectional seismic loading. In this case, due to the lack of a specimen tested in a shaking table, a numerical approach is applied using a model calibrated with the results of the shake table tests.

\subsection{The energy approach to seismic design}

Nowadays, the seismic design of structures is based on the so-called force-based approach, which characterizes the loading effect of earthquakes on structures in term of forces. This approach uses ductility factors and the assumption of the "equal displacement" rule to design structures that can be damaged during earthquakes. The origin of this approach can be found in the studies carried out for Single Degree of Freedom (SDOF) systems by Veletsos and Newmark (1960). The equal displacement rule assumes that the peak displacement of a SDOF elastoplastic system is the same than the peak displacement reached by a SDOF elastic system under the same ground motion. Based on this assumption, the design lateral strength of the structure is reduced by the ductility 
factor $\mu$, counterpart of factor $q$ in EN 1998 (CEN, 2004). However, many difficulties come up when this approach is generalized to multi-story structures. Among them, the incapacity of the method to predict the cumulative damage among stories. The force-based method attempts to solve this issue prescribing rules aimed at preventing the damage concentration in one of few stories, such as a minimum ratio of $\sum M_{R c} / \sum M_{R b}$ where $M_{R c}$ and $M_{R b}$ is the moment capacity of columns and beams framing to a joint or avoiding abrupt variations in lateral stiffness and mass distribution.

Contrary to the presumption that an earthquake exerts specified forces on a structure, in reality it imparts seismic energy. That is, it produces displacements relative to the ground and the forces are a product of this displacements, not the other way around (Fardis, 2018). Characterizing the loading effect of earthquakes in terms of energy instead of forces provides a more rational base for seismic design and constitutes the basis of the so-called energy-based design method. The energy-based approach was first proposed by Housner (1956) and later developed by Akiyama (1985), Bertero (1988) and others up to the present. The Vision 2000 report on future seismic design codes (SEAOC, 1995) identified this method as one of the promising approaches to be developed within a conceptual framework for Performance-Based Seismic Design. Its advantages are well summarized in (Fardis, 2018):

1. Energy balance (or conservation), the base of the energy approach, is a law of nature, as solid, familiar to engineers and easy to apply as the foundation of the force-based approach, i.e., equilibrium.

2. Giving an earthquake, the input energy depends almost exclusively on the structure's fundamental period and the total mass, and is roughly independent of the viscous damping ratio, the post-yield hardening ratio, the degree of inelastic action (measured by the ductility factor) and the numbers of DOFs.

3. Energy is a scalar measure and can synthesize in a single value the complex 3D loading effects caused by earthquakes on structures, while others approaches use vectors and they are more difficult to handle. Further, their components in the two orthogonal directions are normally considered separately in design, despite the fact that the most critical response to concurrent shaking in both horizontal directions and the associate damage occurs in an intermediate direction.

4. Energy embodies the damage-related-information very efficiently, thanks, between others, to the definition of the number of equivalent cycles.

5. Energy identifies numerical problems. Numerical instabilities or lack of convergence during a nonlinear response-history analysis clearly show up in the evolution of the components of energy.

The evaluation of the SPLs under different scenarios of seismic hazard requires quantification of the damage not only in terms of maximum deformations but also in terms of dissipated energy (cumulative damage). The most rational way to evaluate safety is by comparing the energy dissipation demand with the energy dissipation capacity of the structure. Fardis (2018) also highlighted that there is still a long way to go until this method is used for professionals. Although big efforts have been done to characterize the energy demand, i.e, the input energy, there is still a large gap of knowledge that concerns the energy capacity of structural elements and systems, which is more challenging than the energy demand and has barely addressed so far.

The majority of studies in the literature related to the seismic capacity of RC structures under bidirectional seismic loadings are related to their structural elements, mainly columns. There are models that consider the interaction of both biaxial bending moment and the axial force (Bajaj \& Mendis, 2005; Bousias, Panagiotakos, \& Fardis, 2002) and other studies that address the stiffness 
degradation (Rodrigues, Varum, Arêde, \& Costa, 2012; Rodrigues, Furtado, \& Arêde, 2015). Furthermore, the capacity of columns subjected to bidirectional loadings has been also studied. De Stefano and Faella (1996) proposed a yield condition in 2 DOF models under bidirectional loadings represented by an elliptical domain for both strength and displacement, respectively. Bousias (2002) carried out experimental tests on columns under biaxial loading and proposed an ultimate elliptical domain for the chord rotation from the one obtained under uniaxial loadings along the two main axes. Fardis (2009) proposed a similar expression for yielding. The capacity of columns in terms of dissipated energy has been also studied. De Stefano and Faella (1996) and Rodrigues (2012) found that columns subjected to bidirectional loadings with constant axial load lead to higher levels of dissipated energy than the observed in columns under uniaxial load. Nevertheless, this is not so evident when varying the axial loads (Rodrigues et al., 2015), just as in extreme or corner columns. The evolution of damage for columns under bidirectional loadings is an important issue studied by Rodrigues (2013), who proposed new approaches to evaluate the damage in RC columns. It is important to note that the hysteretic behavior is also affected by biaxial loadings. Zeris and Mahin (1991) found that the biaxial response affects both, the hysteretic and softening properties of columns, being different that the obtained for uniaxial loading.

This Thesis attempts to shed some light to this problem, providing experimental and numerical evidences on the seismic capacity, in terms of energy, of WFP structures with and without hysteretic dampers subjected to biaxial seismic actions. First, a subassembly of a WFP structure with an irregular layout of columns was subjected to a shaking table test using the two horizontal components of a far-field earthquake. The loading was applied in successive seismic simulations, by scaling both components to increasing values of acceleration until the collapse of the structure. Next, a numerical model of the specimen was developed and validated with the experimental test. After that, a second numerical model was developed upgrading the latter with hysteretic dampers. Eventually, both models were subjected to several unidirectional and bidirectional ordinary records until failure. The input energy and the energy dissipation of the specimen was obtained and discussed.

\subsection{Energy-Based Design Framework}

The equation of motion (1.1) expresses the equilibrium of all forces involved in the dynamic Multi-Degree of Freedom (MDOF) system that represents the structure subjected to the three translational components of the ground motion.

$$
\mathbf{M} \ddot{\mathbf{u}}(t)+\mathbf{C} \dot{\mathbf{u}}(t)+\mathbf{F}_{\mathbf{S}}(\mathbf{u}(t), \dot{\mathbf{u}}(t))=-\sum_{i=1}^{N_{g}} \mathbf{M J}_{\mathbf{i}} \ddot{u}_{g, i}(t)+\mathbf{p}(t)
$$

Where $\mathbf{u}, \dot{\mathbf{u}}$ and $\ddot{\mathbf{u}}$ are the vectors of displacement, velocity and acceleration along the time $t$ at each Degrees Of Freedom (DOF) of the system. The term $\mathbf{F}_{\mathbf{I}}=\mathbf{M} \ddot{\mathbf{u}}(t)$ represents the inertial forces ( $\mathbf{M}$ is the mass matrix), the term $\mathbf{F}_{\xi}=\mathbf{C} \dot{\mathbf{u}}(t)$ represents the damping forces due to inherent viscous damping ( $\mathbf{C}$ is the damping matrix) and the term $\mathbf{F}_{\mathbf{S}}(\mathbf{u}(t), \dot{\mathbf{u}}(t))$ represents the nonlinear relation between resisting forces and deformations, which includes both material and geometry nonlinearities (Chopra \& McKenna, 2016). For systems without velocity-dependent energy dissipation systems, $\mathbf{F}_{\mathbf{s}}=\mathbf{K}(\mathbf{u}(t)) \mathbf{u}(t)$, where $\mathbf{K}$ is the stiffness matrix that changes with the displacements $\mathbf{u}(t)$ in the general non-linear case. The right side represents the dynamic excitation: $\ddot{u}_{g, i}$ represents the ground acceleration of each earthquake component, $i$, of the total $N_{g}$ components of the ground motion; $\mathbf{J}_{\mathbf{i}}$ is the corresponding influence vector; and $\mathbf{p}$ 
represents the external loads such as the gravity loads, dynamic loads due to machines, wind, etc. However, if only gravity loads are accounted for as external loads, the displacement caused by gravity $\left(\mathbf{K u}_{\mathbf{s t}}=\mathbf{p}\right)$ in elastic range is uncoupled from the total displacement, taking as reference the static-equilibrium position (Clough \& Penzien, 1992), in this case, the equation of motion (1.1) yields:

$$
\mathbf{M} \ddot{\mathbf{u}}(t)+\mathbf{C} \dot{\mathbf{u}}(t)+\mathbf{F}_{\mathbf{S}}(\overline{\mathbf{u}}(t), \dot{\mathbf{u}}(t))=-\sum_{i=1}^{N_{g}} \mathbf{M J}_{\mathbf{i}} \ddot{u}_{g, i}(t)
$$

Where the line over the displacement vector $(\overline{\mathbf{u}}(t))$ means the additional dynamic displacement to add to the displacement caused by static forces $\left(\mathbf{u}_{\mathbf{s t}}\right)$.

Pre-multiplying (1.2) by $d \mathbf{u}^{\mathrm{T}}$ or what is the same $\dot{\mathbf{u}}^{\mathrm{T}} d t$ and integrating over the duration of the earthquake, $t=t_{d}$, the energy balance equation (1.3) is obtained as follows:

$$
\begin{gathered}
\int_{\mathbf{0}}^{t_{d}} \dot{\mathbf{u}}^{\mathrm{T}} \mathbf{M} \ddot{\mathbf{u}} d t+\int_{\mathbf{0}}^{t_{d}} \dot{\mathbf{u}}^{\mathrm{T}} \mathbf{C} \dot{\mathbf{u}} d t+\int_{\mathbf{0}}^{t_{d}} \dot{\mathbf{u}}^{\mathrm{T}} \mathbf{F}_{\mathbf{S}} d t=-\int_{0}^{t_{d}} \dot{\mathbf{u}}^{\mathrm{T}} \sum_{i=1}^{N_{g}} \mathbf{M J}_{\mathbf{i}} \ddot{u}_{g, i} d t \\
E_{I}=-\int_{0}^{t_{d}} \dot{\mathbf{u}}^{\mathrm{T}} \sum_{i=1}^{N} \mathbf{M J}_{\mathbf{i}} \ddot{u}_{g, i} d t \\
W_{k}=\int_{\mathbf{0}}^{t_{d}} \dot{\mathbf{u}}^{\mathrm{T}} \mathbf{M} \ddot{\mathbf{u}} d t=\frac{1}{2} \dot{\mathbf{u}}^{\mathrm{T}} \mathbf{M} \dot{\mathbf{u}} \\
W_{\xi}=\int_{\mathbf{0}}^{t_{d}} \dot{\mathbf{u}}^{\mathrm{T}} \mathbf{C} \dot{\mathbf{u}} d t \\
W_{e s}+W_{p}=\int_{\mathbf{0}}^{t_{d}} \dot{\mathbf{u}}^{\mathrm{T}} \mathbf{F}_{\mathbf{S}} d t
\end{gathered}
$$

The right-hand side of (1.3) expresses the total amount of energy exerted by the earthquake, $E_{I}$ (1.3a), herein input energy. The input energy is a very stable quantity that is governed solely by the total mass and the fundamental natural period in structural system for which flexural deformations are predominant (Akiyama, 1985). The first term of the left-hand side, which can be boiled down to $W_{k}=1 / 2 \dot{\mathbf{u}}^{\mathrm{T}}$ Mù by partial integral, expresses the kinetic energy, $W_{k}(1.3 \mathrm{~b})$, at the instant when the earthquake motion vanished. The second term represents the energy consumed by damping mechanism $W_{\xi}(1.3 \mathrm{c})$. The third term expresses the strain energy stored/dissipated in the resisting system (1.3d), which consists of cumulative plastic strain energy (dissipated), $W_{p}$, and elastic strain energy (stored), $W_{e s}$, at the instant when the earthquake motion fades away. The sum of kinetic and elastic strain energies prompts the elastic vibrational elastic energy, $W_{e}\left(=W_{e s}+W_{k}\right)$. With these definitions, (1.3) becomes as follows:

$$
W_{e}+W_{\xi}+W_{p}=E_{I}
$$

The above equation is the fundamental equation of the Energy-Based Design. Equation (1.3) and (1.4) are strictly the energy balance equations. While, with (1.1), it is possible to know directly the history response, this is not possible with (1.3) and (1.4), but the latter play an important role to understand globally the system performance. Whereas (1.1) expresses the force balance at each 
DOF and instant, (1.3) and (1.4) represent the information along the time in a holistic way. Figure 1.5 shows the energy balance of an elastic-perfectly plastic single degree-of-freedom (SDOF) system $\left(\mathbf{M}=1 \mathrm{~T}, \mathbf{C}=2.6 \mathrm{Ns} / \mathrm{mm}\right.$ and $\mathbf{F}_{\mathbf{s}}=\mathbf{K u}$ where $\left.\mathbf{K}=500 \mathrm{~N} / \mathrm{mm}\right)$ subjected unidirectionally to the NS component of the Calitri Earthquake as an example.
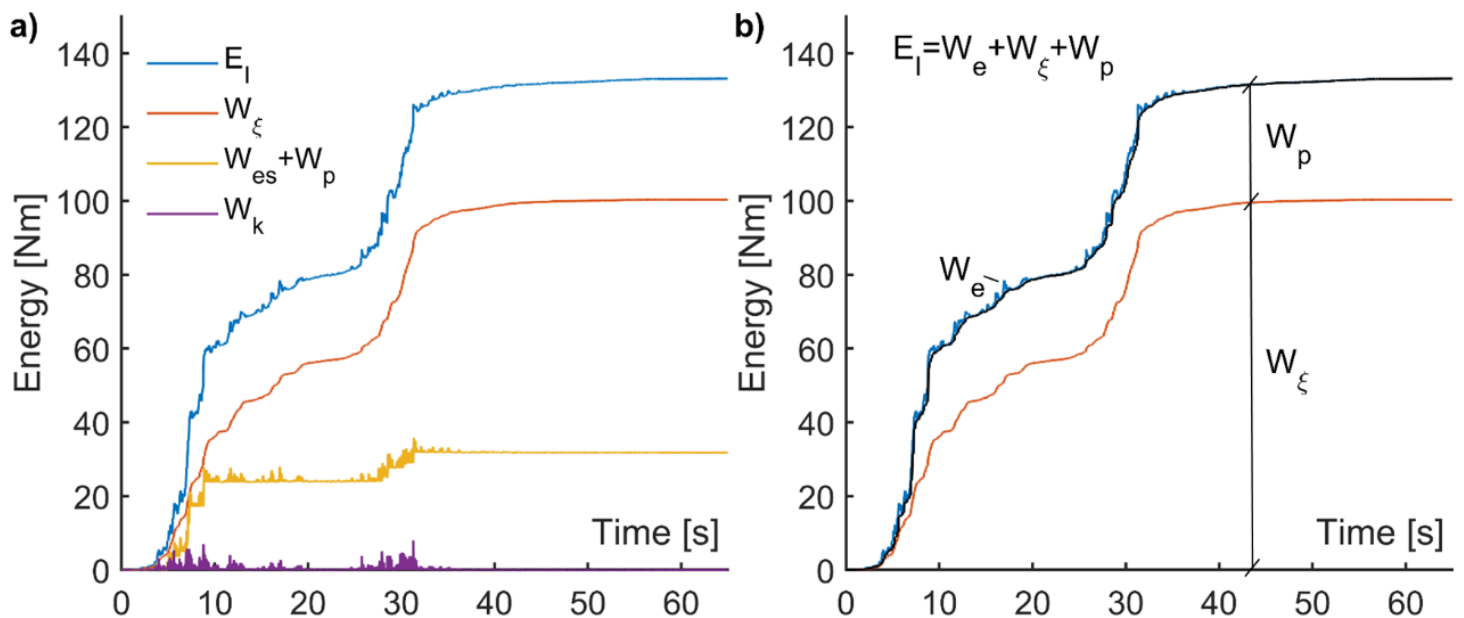

Figure 1. 5. Energy balance of an elastic-perfectly plastic SDOF system: a) amount of energies and b) energy balance

The difference between $E_{I}$ and $W_{\xi}$ is what Housner (1956) defined as the energy that contributes to damage, i.e., $E_{D}=E_{I}-W_{\xi}$. Further, both $E_{I}$ and $E_{D}$ can also be expressed as equivalent velocities, $V_{E}$ and $V_{D}$, defined in (1.5) and (1.6) respectively, where $M_{T}$ is the total mass of the structure.

$$
\begin{gathered}
V_{E}=\sqrt{\frac{2 E_{I}}{M_{T}}} \\
V_{D}=\sqrt{\frac{2 E_{D}}{M_{T}}}
\end{gathered}
$$

In addition, several empirical expressions have been proposed in the literature to estimate $V_{D}$ from $V_{E}$ (Benavent-Climent, A., López-Almansa, \& Bravo-González, 2010; Decanini \& Mollaioli, 2001; Fajfar \& Vidic, 1994; Kuwamura \& Galambos, 1989; Lawson \& Krawinkler, 1995; LópezAlmansa, Yazgan, \& Benavent-Climent, 2013). In this study, (1.7) is used, which was proposed by Akiyama (1985):

$$
\frac{V_{D}}{V_{E}}=\frac{1}{1+3 \xi+1.2 \sqrt{\xi}}
$$

Where $\xi$ is the inherent fraction of damping of the structure (the damping ratio).

Therefore, the fundamental equation in the Energy-Based Design of Earthquake-Resistant Buildings can be written as follows:

$$
W_{e}+W_{p}=\frac{1}{2} M_{T} V_{D}^{2}
$$


Where the elastic vibrational energy, $W_{e}$, can be approximated from the maximum shear force sustained by the main structure on the first story (Akiyama, 1985) as follows:

$$
W_{e}=\frac{M_{T} g^{2} T^{2}}{4 \pi^{2}} \frac{\alpha_{1}^{2}}{2}
$$

Where $g$ is the acceleration of the gravity, $T$ is the fundamental period of the MDOF system and $\alpha_{1}$ is the yield shear force coefficient of the first story. The yield shear force coefficient $\alpha_{i}$ of the $i_{t h}$ story is referred to as the ratio of story yield-shear force to the weight of the above mass as follows:

$$
\alpha_{i}=\frac{Q_{y, i}}{\sum_{j=i}^{N_{s}} m_{j} g}
$$

Where $m_{i}$ and $Q_{y, i}$ are the mass and the yield-shear force of the $i_{t h}$ story and $N_{s}$ the total number of stroies. Therefore, in (1.9) $\alpha_{1}$ is equal to $Q_{y, 1} / M_{T} g$, being $Q_{y, 1}$ the yield-shear force of the first story (i.e. base yield-shear force).

The approximation (1.9) underestimates $W_{e}$, and due to this energy represents part of structural endurance, the equation remains on the conservative side.

The energy absorbed by inelastic deformations, $W_{p}$, can be calculated from the following equation:

$$
W_{p}=\frac{M_{T} g^{2} T^{2}}{4 \pi^{2}} c_{i} \eta_{i} \alpha_{i}^{2} \gamma_{i}
$$

Where $c_{i}$ is a coefficient that relates the total mass $\left(M_{T}\right)$, the sum of above masses, the stiffness of the story $i_{t h}, k_{i}$, and the equivalent stiffness, $k_{e q}=\frac{4 \pi^{2} M_{T}}{T^{2}}$, as follows:

$$
c_{i}=\frac{\left(\frac{\sum_{j=i}^{N_{s}} m_{j}}{M_{T}}\right)^{2}}{\frac{k_{i}}{\frac{4 \pi^{2} M_{T}}{T^{2}}}}
$$

The coefficient $\eta_{i}$ is a non-dimensional coefficient that represents the energy absorbed by inelastic deformations in the $i_{t h}$ story, and is defined as follows:

$$
\eta_{i}=\frac{W_{p, i}}{Q_{y, i} \delta_{y, i}}
$$

Where $W_{p, i}$ is the energy dissipated by inelastic deformations, $Q_{y, i}$ is the yield-shear force and $\delta_{y, i}$ is the yield displacement, all of them for the $i_{t h}$ story.

In design, the objective is to attain an even distribution of damage among the stories because this allows to maximize the energy dissipated by inelastic deformations. This is possible achieving the same $\eta_{i}$ in all stories. For that purpose, there are different expressions for obtaining the optimum yield-shear force distribution $\bar{\alpha}_{i}$ in the literature (Benavent-Climent, A, 2011; BSL, 
2009; Connor, 2003; Donaire-Ávila \& Benavent-Climent, 2020). In this study, $\bar{\alpha}_{i}$ is approximated for design purposes with the expression proposed by the Building Standard Law of Japan (2009):

$$
\bar{\alpha}_{i}=1+\left(\frac{1}{\sqrt{\frac{\sum_{j=i}^{N_{s}} m_{j}}{M_{T}}}}-\frac{\sum_{j=i}^{N_{s}} m_{j}}{M_{T}}\right) \frac{2 T_{1}}{1+3 T_{1}}
$$

For an ideal structure with the optimum yield shear force coefficient distribution, $\alpha_{i}$ is $\alpha_{i}=\bar{\alpha}_{i} \alpha_{1}$. However, in real structures, the variability on the mechanical properties of the materials or the rationalization of the geometry of the members to easy the construction process, cause deviations of the actual lateral strength with respect to the ideal value. These deviations must be taken into account in design because they are a source of damage concentration. The damage distribution of each story in shear-type multi-story frame structures is governed by the damage concentration factor $\gamma_{i}$ in (1.11), which is defined by the following relation:

$$
\gamma_{i}=\frac{\sum_{j=1}^{N_{s}} s_{j} p_{j}^{-n}}{s_{i} p_{i}^{-n}}
$$

Where $s_{j}$ and $p_{j}$ are defined below.

$$
\begin{gathered}
s_{j}=\sum_{j=i}^{N_{S}}\left(\frac{m_{j}}{M_{T}}\right)^{2} \bar{\alpha}_{i}^{2}\left(\frac{k_{1}}{k_{i}}\right) \\
p_{j}=\frac{\alpha_{j}}{\bar{\alpha}_{j} \alpha_{1}}
\end{gathered}
$$

The coefficient $p_{j}$ measures the deviation of the actual lateral strength of the $i_{t h}$ story, $\alpha_{j}$, with respect to the optimum one $\left(\bar{\alpha}_{j} \alpha_{1}\right)$. The exponent $n$ in (1.15) is influenced by several parameters involved in the analysis and is not a constant value, but seems to vary within a range of $6 \leq n \leq$ 12 (Akiyama, 1985). The higher $n$-value, the greater damage concentration. Akiyama (1985) showed that the $n$-value for structures with beam-sway collapse mechanism is about 6 and for structures with column-sway collapse mechanism is approximately 12 . On the basis that the overestimation of the damage concentration leads to a safe-side evaluation of seismic resistibility, it is suitable to adopt an $n$-value equal to 12 for design proposes.

In regards to the equivalent velocity of the energy that contribute to damage, $V_{D}$ in (1.8), Akiyama (1985) concluded by means of numerous response analyses that, in general MDOF damped inelastic systems, the total input energy supplied by the earthquake $E_{I}$, and consequently $V_{E}$, coincides approximately with that of an equivalent elastic SDOF system with mass $M_{T}$ equal to the total mass of the MDOF system, and period $T$ equal to that of its first vibration mode. This conclusion was validated experimentally in (Uang \& Bertero, 1988) and other studies. Therefore, $V_{D}$ can be approximated taking the value of the fundamental period in the design spectrum $V_{E}-$ $T$ and then, applying (1.7) using the inherent damping ratio $\xi$ of the structure. In the energy-based seismic design approach, the energy input spectrum in the form of equivalent velocity $V_{E}-T$ characterizes the loading effect of the earthquake. 
Actually, the characterization of the design earthquake in terms of energy input spectra $V_{D}-T$ is not as common for professionals as in the form of absolute acceleration spectra $S_{a}-T$. Though, recent versions of some building codes, such as the Building Standard Law of Japan (2009) or the next generation of EN 1998, include the $V_{D}-T$ spectra. Energy input spectra in terms of $V_{D}-T$ can be obtained from the $S_{a}-T$ spectra on the basis of the following considerations: (i) over the range of damping ratios exhibited by actual structures (around 5-10\%) the spectral absolute acceleration $S_{a}$ of damped elastic SDOF system is related to the pseudo-velocity spectral response, $S_{p v}$, by the expression $S_{a}=\omega S_{p v}$, where $\omega$ is the circular frequency; (ii) the spectral relative velocity, $S_{v}$, differs very little from $S_{p v}$ except in the case of very long periods (Hudson, 1956; 1962); (iii) Akiyama (1985) showed that $S_{v}$ provides a good approximation of $V_{D}$, and validated Housner's (1956) assumption that $V_{D}$ can be taken as equal to $S_{v}$ for the propose of earthquake-resistant design (Benavent-Climent, 2011).

Substituting (1.9) and (1.11) into (1.8) and solving for $\alpha_{1}$ the following equation is obtained:

$$
\alpha_{1}=\frac{2 \pi V_{D}}{T g} \frac{1}{\sqrt{1+2 c_{i} \bar{\alpha}_{i}^{2} \eta_{i} \gamma_{i}}}
$$

Where $2 \pi V_{D} / T g$ is the required minimum yield-shear force coefficient for the system to remain elastic under the ground motion characterized by $V_{D}, \alpha_{e}=2 \pi V_{D} / \mathrm{Tg}$. A strength reduction factor $D_{s}$ for the yield-shear force coefficient can be defined by $D_{s}=1 / \sqrt{1+2 c_{i} \bar{\alpha}_{i}{ }^{2} \eta_{i} \gamma_{i}}$, which depends essentially on $\eta_{i}$. However, $\eta_{i}$ is currently not an engineering demand parameter, instead codes tend to use parameters such as Inter-story Drift Index $\left(I D I_{i}=\left(\delta_{i}-\delta_{i-1}\right) / h_{i}\right.$, where $\delta_{i}$ and $h_{i}$ are the displacement and the height of the story $i$ ) that depends on the displacements of the structure. In this line, the relation between $\eta_{i}$ and $\mu_{i}\left(=\left(\delta_{\max , i}-\delta_{y, i}\right) / \delta_{y, i}\right.$, where $\delta_{\max , i}$ and $\delta_{y, i}$ are the maximum displacement and the yield displacement of the story $i$ ) becomes a key parameter in seismic design methodologies based on the energy concept, and it has been addressed in different ways in the past (Cosenza \& Manfredi, 1997; Manfredi, 2001; Uang \& Bertero, 1988). This relation $\eta_{i} / \mu_{i}$ coincides with the equivalent number of cycles proposed by Cosenza and Manfredi (2003) and defined as $n_{e q}=W_{p, i} /\left[Q_{y, i}\left(\delta_{\max }-\delta_{y, i}\right)\right]$. Since $\eta_{i}$ was assumed constant in all stories, $\eta_{i}=\eta$, because the optimum yield-shear force distribution $\bar{\alpha}_{i}$ was imposed, the maximum plastic deformation ratio $\mu_{i}$ has the same value $\mu_{i}=\mu\left(=\eta / n_{e q}\right)$ in all stories. Consequently, $\eta_{i}$ can be related with the design $I D I_{i}$ as follows:

$$
\eta_{i}=n_{e q}\left(\frac{I D I_{i} h_{i}-\delta_{y, i}}{\delta_{y, i}}\right)
$$

This dissertation treats to shed some light on the parameters $V_{E}, V_{D}$ and $n_{e q}$ for WFP structures whether or not equipped with hysteretic dampers.

\section{AIMS AND OBJECTIVES}

This dissertation continues the work conducted in the research group led by Professor BenaventCliment on the seismic performance of FP structures and passive control systems. In this case, the research is focused on WFP structures with and without metallic dampers. Previous investigations of the group focused on the seismic response of RC Frames (Benavent-Climent, A., Morillas, \& Escolano-Margarit, 2014; Benavent-Climent, Amadeo, Morillas, \& EscolanoMargarit, 2014; Benavent-Climent, Amadeo, Escolano-Margarit, \& Morillas, 2014) and WFP 
systems (Benavent-Climent et al., 2016; Benavent-Climent et al., 2018) under unidirectional seismic loading, as well as, the performance of structural sub-elements under pseudo-statics loadings such as slab-columns connections (Benavent-Climent, A, Cahís, \& Catalán, 2008; Benavent-Climent, A, Cahis, \& Catalan, 2009). One of the main goals of this Thesis is to investigate the response of a WFP system subjected to bidirectional seismic loading. This is a substantial step because the level of complexity grows exponentially when passing from 2D to $3 \mathrm{D}$, and moving from a single component of the ground motion to two components. Torsion effects and interaction between forces come into play, as well as, the sheer complexity of the response of the structures when they enter in the nonlinear range. On the other hand, the group has also majored in designing and health monitoring metallic dampers (Benavent-Climent, Amadeo, 2010; Benavent-Climent, Amadeo, 2011; Benavent-Climent, Amadeo, Morillas, \& Vico, 2011; Benavent-Climent, Amadeo, Gallego, Romo-Melo, \& Morillas, 2014; Gallego, Benavent-Climent, \& Romo-Melo, 2015; Romo, Benavent-Climent, Morillas, Escolano, \& Gallego, 2015). In this regard, this Thesis contributes also in this field by firstly evaluating the energy dissipation capacity and characterizing the damage of a metallic damper and then using it to improve the seismic response of the WFP systems. Eventually, the seismic energy capacity of WFP systems without and with metallic dampers is evaluated and discussed.

In summary, the primary objectives of the present study are to:

1. Design a tests specimen that represents a portion of a WFP structure, and test it in a bidirectional shaking table facility.

2. Assess experimentally through shake tables tests the seismic response of a WFP system subjected simultaneously to two horizontal components of a far field ground motion (Calitri Earthquake) in terms of displacements, forces, deformations and energies.

3. Develop a 3D FEM model that represents the WFP structure, and calibrate it with the experimental results.

4. Investigate the overall performance of WFP systems subjected to bidirectional seismic actions through an extensive parametric study that uses a large number of far field ground motions.

5. Study experimentally the hysteretic behavior and ultimate energy dissipation capacity of a metallic damper suitable for installation in WFP systems, through pseudo-static tests.

6. Develop a numerical model of the tested metallic damper and characterization of damage.

7. Implementation of metallic dampers in WFP systems to control and improve their response under bidirectional seismic actions.

8. Evaluate the response of WPF structures without and with hysteretic dampers and compare their seismic behavior under bidirectional seismic actions.

9. Investigate the overall seismic response of WFP structures with hysteretic dampers under two components of the seismic action, through an extensive parametric study using a large number of far field ground motions. 


\section{PUBLISHED WORKS DERIVATED FROM THIS THESIS}

\subsection{Contributions in JCR journals}

This dissertation has contributed to the following research papers:

Authors: C. Abarkane, D. Galé-Lamuela, A. Benavent-Climent, E. Suárez, A. Gallego.

Title: Ultrasonic pulse-echo signal analysis for damage evaluation of metallic slit-plate hysteretic dampers

Journal: Metals

ISSN: 2075-4701

Impact Factor (2017): 1.704

JCR rank: 23/75 (Q2) in Metallurgy \& Metallurgical Engineering

Volume: 7 (12)

Date: 26 November 2017

Editorial: MDPI

DOI: https://doi.org/10.3390/met7120526

Authors: C. Abarkane, D. Galé-Lamuela, A. Benavent-Climent, F.Rescalvo, A. Gallego.

Title: Diagnosis of hysteretic dampers used for seismic protection of structures by means ultrasonic measurements

Journal: Measurement

ISSN: 0263-2241

Impact Factor (2018): 2.791

JCR rank: 17/61 (Q2) in Instruments \& Instrumentation

Volume: 137

Pages: $344-354$

Date: April 2019

Editorial: Elsevier

DOI: https://doi.org/10.1016/j.measurement.2019.01.056

Authors: A. Benavent-Climent, D. Galé-Lamuela, Jesús Donaire-Avila.

Title: Energy capacity and seismic performance of RC waffle-flat plate structures under two components of far-field ground motions: shake table tests.

Journal: Earthquake Engineering \& Structural Dynamics

ISSN: 0098-8847

Impact Factor (2018): 3.419

JCR rank: 18/132 (Q1) in Civil Engineering

Volume: 48(8)

Date: 17 April 2019

Editorial: Wiley

DOI: https://doi.org/10.1002/eqe.3161

Authors: C. Abarkane, F.Rescalvo, J. Donaire-Ávila, D. Galé-Lamuela, A. Benavent-Climent, A. Gallego.

Title: Temporal Acoustic Emission Index for Damage Monitoring of RC Structures Subjected to bidirectional Seismic Loadings

Journal: Materials

ISSN: 1996-1944

Impact Factor (2018): 2.972

JCR rank: 102/293 (Q2) in Materials Science, Multidisciplinary

Volume: 12(17)

Date: 30 August 2019

Editorial: MDPI

DOI: https://doi.org/10.3390/ma12172804 
Authors: C. Abarkane, G. Ríos-García, D. Galé-Lamuela, F.Rescalvo, A. Gallego, A. Benavent-Climent.

Title: Metallic Slit-Plate Dampers: Damage Evaluation with Metal Magnetic Memory Technique and application to Structures with Rocking Columns

Journal: Metals

ISSN: 2075-4701

Impact Factor (2018): 2.259

JCR rank: 18/76 (Q1) in Metallurgy \& Metallurgical Engineering

Volume: 9(9)

Date: 30 August 2019

Editorial: MDPI

DOI: https://doi.org/10.3390/met9090953

Authors: J. Donaire-Ávila, D. Galé-Lamuela

Title: Energy capacity of waffle-flat-plate structures with hysteretic dampers subjected to bidirectional seismic loadings

Journal: Applied Science

ISSN: 2076-3417

Impact Factor (2018): 2.217

JCR rank: 67/148 (Q2) Physics Applied Science

Volume: $10(9)$

Date: 30 April 2020

Editorial: MDPI

DOI: https://doi.org/10.3390/app10093133

\subsection{Conference contributions}

During the time of the $\mathrm{PhD}$ program, the author has published and presented works related with the dissertation in the following conferences:

C. Abarkane, D. Gale-Lamuela, E. Suarez, A. Gallego, A. Benavent-Climent, V. Svoboda, E. Svobodova. Ultrasonic testing and magnetic memory method for inspection of damage in hysteretic dampers subjected to cyclic loading. Application of Contemporary Non-Destructive Testing in Enginering 14th. September 4-6 2017, Bernardin (Slovenia)

D. Galé-Lamuela, A. Benavent-Climent, G. Gonzalez-Sanz. Numerical simulation of shaking table test on a reinforced concrete waffle-flat plate structure using OpenSees. 1st Conference on Structural Dynamics (DinEst 2018), June 20-21 2018. Madrid (Spain) https://doi.org/10.7712/120119.7078.19108

C. Abarkane, J. Donaire-Ávila, F. Rescalvo, D. Galé-Lamuela, A. Benavent-Climent, A. Gallego. 16 - Acoustic emission energy for condition monitoring of RC waffle slab structure subjected to bidirectional ground seismic motions. 33rd European Conference on Acoustic Emission Testing September 12-14 2018. Senlis (France)

D. Galé-Lamuela, J. Donaire-Ávila, A. Benavent-Climent. Numerical simulation of shaking table test on a RC waffle-flat plate structure. $16^{\text {th }}$ European Conference on Earthquake Engineering. June 18-21 2018. Thessaloniki (Greece)

D. Galé-Lamuela, J. Donaire-Avila, and D. Escolano-Margarit, G. González-Sanz, A. Benavent-Climent. Energy dissipation capacity of RC columns subjected to unidirectional and bidirectional seismic loading. 7th ECCOMAS Thematic Conference on Computational Methods in Structural Dynamics and Earthquake Engineering (COMPDYN 2019). 24-26 June 2019 Crete (Greece) 


\section{STRUCTURE OF THE DISSERTATION}

This dissertation is divided into seven chapters. Chapter 1 exposes the statement of the problem with an overview of previous studies conducted on FP structures and hysteretic dampers, focusing on WFP systems with and without hysteretic dampers. This chapter also summarizes the energybased design framework and the main objectives of the dissertation. Chapter 2 describes the steps followed to develop a scaled specimen from a real prototype that represents a WFP structure. The specimen must have dimensions and weight compatible with the shaking table that was used for the tests (the shake table of the Laboratory of Structures of the University of Granada), which is a $3 \times 3 \mathrm{~m}$ capable of shaking about 10-ton payload. Chapter 3 estimates the dynamic behavior and the capacity curve of the specimen. Chapter 4 presents and discusses the results of the shake table tests conducted on the test specimen under bidirectional loading in terms of displacements, deformations, forces and energies. Chapter 5 develops a 3D nonlinear numerical model capable of reproducing the results of the shake table tests and summarizes the results of an overall parametric study on the seismic performance of the WFP specimen subjected to a large number of far field ground motions. Chapter 6 presents static tests conducted on a hysteretic damper, and characterizes its cyclic behavior and level of damage. This type of damper is implemented in the WFP model and several nonlinear response history analyses are conducted with the same far field ground motions used in Chapter 5, to investigate the seismic response of WFP systems equipped with hysteretic dampers subjected simultaneously to two components of the seismic action. Finally, a summary and conclusions, along with future research direction for WFP structures with and without dampers are presented in Chapter 7. 


\section{Chapter 2}

\section{EXPERIMENTAL INVESTIGATION: BIDIRECTIONAL SHAKE TABLE TESTS ON A WFP STRUCTURE}

Empirical evidences using real ground motions in dynamic test provides a basis for judging the behavior of structures under earthquakes. The most realistic method for verifying the seismic behavior of structures is the dynamic testing of full-scale structures in an earthquake simulator, also called shaking table. However, shaking tables including bidirectional dynamic loading with capacity for testing three dimensional full-scale structures are scarce. There are very few labs in the world with this kind of facilities (e.g., UC Berkeley Shaking Table in California, USA; Buffalo's Shaking Table in New York, USA; NCREE in Taiwan; EUCENTRE Trees Lab in Italy; NIED E-Defense Laboratory in Miki, Japan; Structural Laboratory of the University of Canterbury in New Zealand). When the earthquake simulator is much smaller, some scale reductions and/or simplifications are required in order to define a test structure that represents a real building. This Chapter presents the design of the experimental investigation conducted on a portion of a WFP structure that was subjected to bidirectional dynamic seismic loadings with the shake table of the Laboratory of Structures of the University of Granada. 


\section{PROTOTYPE STRUCTURE AND TEST SPECIMEN}

The prototype structure is a building that consists of three-story RC WFP system supported on isolated columns. Every story has a height of $3.1 \mathrm{~m}$ and a span between columns of $6 \mathrm{~m}$. The pattern of columns forms a quincunx grid in order to avoid double symmetry. The prototype structure is shown in Figure 2.1.

a)

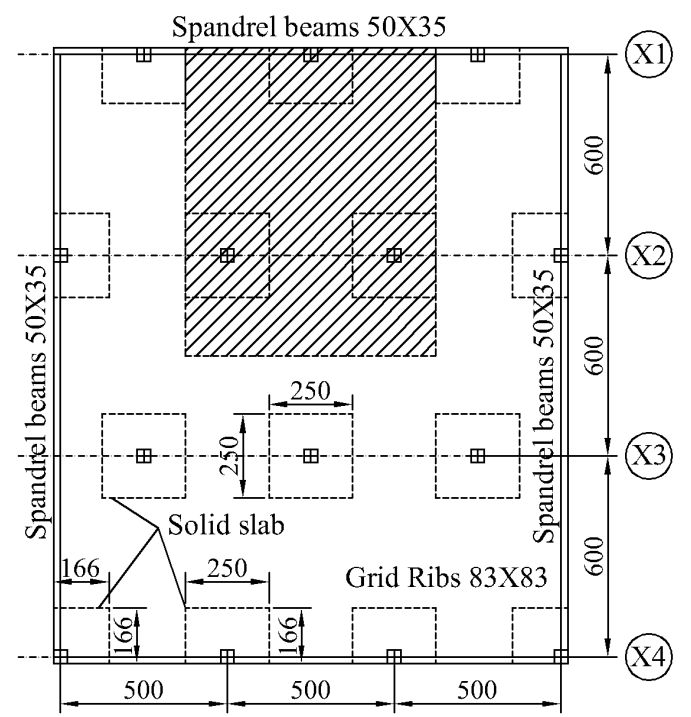

b)

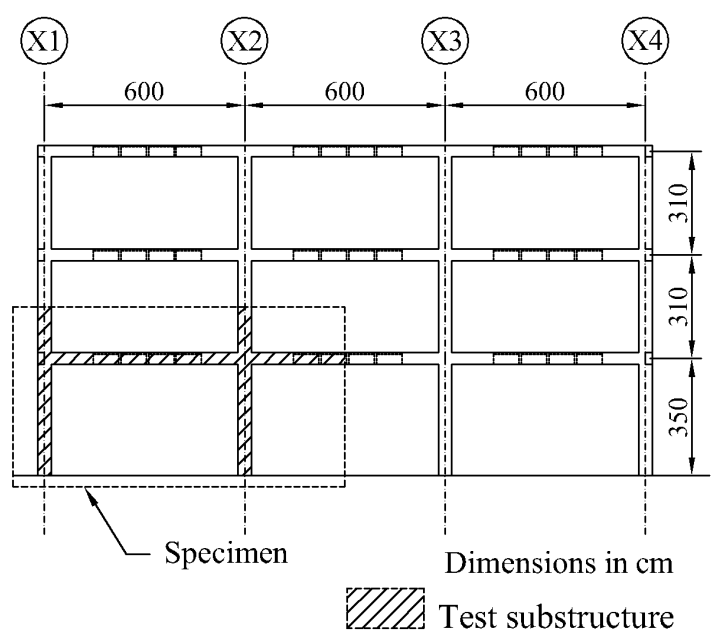

Figure 2. 1. Prototype structure: a) plan; b) elevation

The structure was designed applying the limit stated method prescribed by the Spanish Concrete Code EHE-08 (Ministerio de Fomento 2008) to sustain gravity loads and the Spanish Seismic Code NCSE-02 (Ministerio de Fomento 2003) to support lateral seismic loads. On one hand, the dead loads considered were $3.13 \mathrm{kN} / \mathrm{m}^{2}$ for floors and $3.46 \mathrm{kN} / \mathrm{m}^{2}$ for the roof, and in addition, the corresponding live loads were $2 \mathrm{kN} / \mathrm{m}^{2}$ and $1 \mathrm{kN} / \mathrm{m}^{2}$, respectively. In regard to the seismic design, the location of the structure was Granada (Spain), which has a soil type $\mathrm{C}\left(180<v_{s, 30}<\right.$ 360 , where $v_{s, 30}$ is the average shear wave velocity in $\mathrm{m} / \mathrm{s}$ ). Furthermore, the structure was assumed as ordinary building (importance factor $\gamma_{1}=1.0$ ). The maximum value of the behavior factor $\mu$ allowed by NCSE-02 for flat plate systems is 2 , which was adopted to reduce the elastic response spectra.

The mechanical properties assumed for materials were $500 \mathrm{MPa}$ for yield strength of steel and $25 \mathrm{MPa}$ for the concrete compressive strength. The structure was made up of RC plates having $0.35 \mathrm{~m}$ depth with a regular pattern of voids and a drop panel around each column. The WFP ribs were placed each $0.83 \mathrm{~m}$, forming an orthogonal grid. Around the perimeter, the flat plate was bordered by spandrel beams (also called transverse beam) with the same depth. It was ensured that in all elements the flexure failure would precede the shear failure.

From the prototype, a substructure, which will be the test specimen, was extracted by cutting through points and lines of nominal zero bending moment under lateral loads (hereafter partial structure). This partial structure had the height of one-story and a half and the width of one-bay and a half, which is shown in Figure 2.1 with hatched area. Afterwards, a test specimens, called BS1 hereafter, was cast applying to the partial structure the scaling factors of $2 / 5$ for length $\left(\lambda_{L}\right)$, 1.0 for accelerations $\left(\lambda_{a}\right)$ and 1.0 for stresses $\left(\lambda_{\sigma}\right)$. The rest of the physical quantities were scaled to satisfy similitude requirements. 
It is worth noting that, there are some drawbacks in the manner of obtaining the partial structure. The main one is the loss of continuity in the slab, which may alter the state of stress and deformation over the supporting columns. It should be noted, however, that the propose of the experiments was to investigate the behavior of the test specimen under earthquake-type bidirectional dynamic loadings, not to reproduce the particular response that the partial structure would experience inside the overall 3-story prototype, which is influenced by dynamic interactions of the rest of the structure. Therefore, the result of the test specimen cannot be extrapolated directly to the response of the 3-story prototype. In any case, if the partial structure results are extrapolated to the prototype, they would only be a rough approximation.

The geometry and reinforcing details of the test specimen are shown in Figure 2.2 and 2.3. Steel and concrete used in the specimen were tested. The maximum compression strength obtained from testing conducted on standard size cylindrical specimen were $43 \mathrm{MPa}$ on the $28^{\text {th }}$ day and $44 M P a$ on the day of the dynamic test. These strengths are higher than those assumed to design the prototype. Due to the reduction scale used, there was not enough space between rebars to use a usual concrete vibrator. As solution, a self-compacted concrete was used instead of the concrete assumed for the design of the prototype. The solution was successful in making the concrete more fluid, and so, improving the casting. This change probably ended up increasing the concrete strength. This overstrength was not considered in the design of the prototype, although it was taken into account in the post process of data. The yield stress of the steel used was 525 and $543 \mathrm{MPa}$ for the longitudinal rebars of diameters $8(\varnothing 8)$ and $6 \mathrm{~mm}(\emptyset 6)$, respectively. The yield stress of the steel used for the stirrups was $656 \mathrm{MPa}$. This steel wire (Ø4) was not treated (annealed) to match its main property (yield stress) as much as possible to the prototype.

Focusing on colums, three cros-sections were investigated; they are called $C i j$ where $i$ is the column number and $j$ is the cross-section number: 0,1 and 2 , which were located at connection points between footing-column, column-slab (first story) and slab-column (second story), restectively (Figure 2.2). Column 1 was the exterior one at north side, column 2 at west side in the interior and column 3 at east side in the interior of the specimen (Figure 2.3). The ratio between longitudinal reinforcement and gross section area $\left(A_{s} / A_{g}\right)$ was 0.031 and 0.024 for interior and exterior columns, respectively, in the first story; and 0.018 for columns in the second story. The shear reinforcement had a volumetric ratio $\rho_{s t}=V_{s t} / V_{c c}$ equal to 0.03 in the interior columns of the first story and 0.02 for the rest. Here, $V_{s t}=n A_{s t} l_{s}$ denotes the volume of the shear reinforcement ( $n, A_{s t}, l_{s}$ are the number, cross-section area and length of the stirrups) and $V_{c c}$ is the volume of concrete confined by the shear reinforcement. The waffle-flat plate had a top and bottom base reinforcement that consisted of a mesh of $\emptyset 6$ bars separated $332 \mathrm{~mm}$. Additionaly, longitudinal bars of $\emptyset 6$ and $\emptyset 8 \mathrm{~mm}$ were located in the drop panels around each column, as Figure 2.3 shows. 


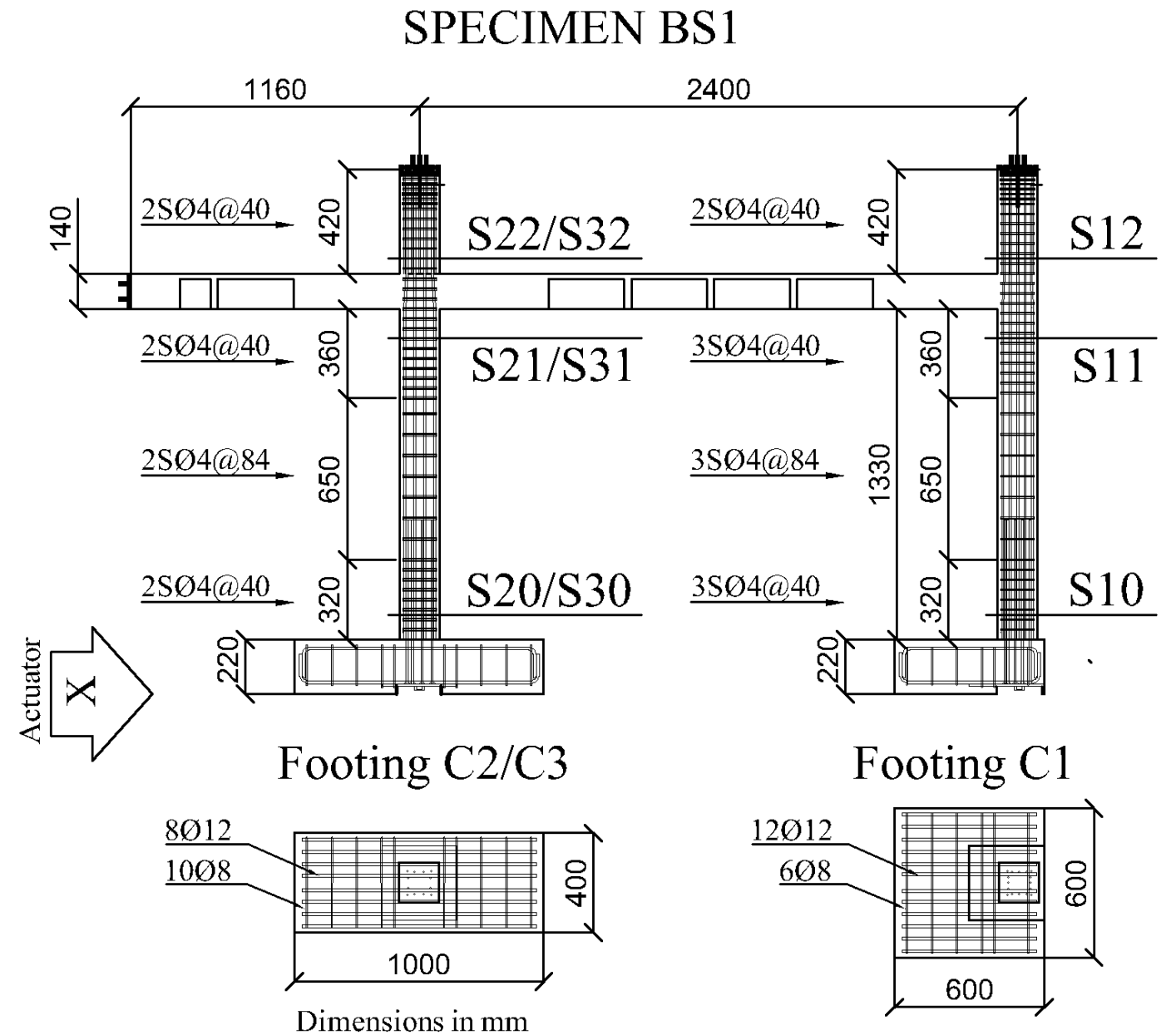

\section{Column Sections}

$\mathrm{S} 12$

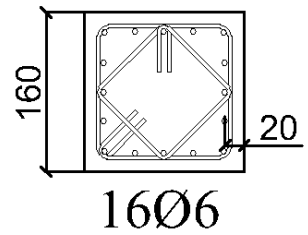

$\mathrm{S} 22 / \mathrm{S} 32$

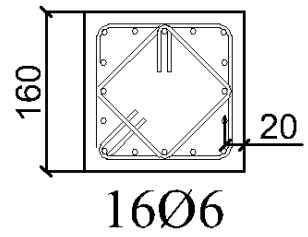

S11

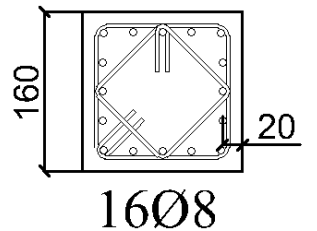

Stirrups $\varnothing 4$

$\mathrm{S} 21 / \mathrm{S} 31$

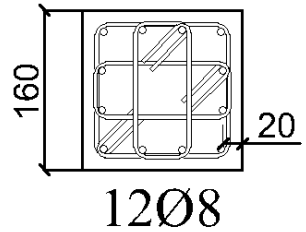

$\mathrm{S} 10$

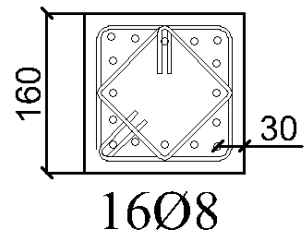

S20/S30

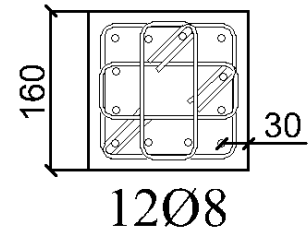

Figure 2. 2. Geometry and reinforcement of columns and footings for specimens BS1 

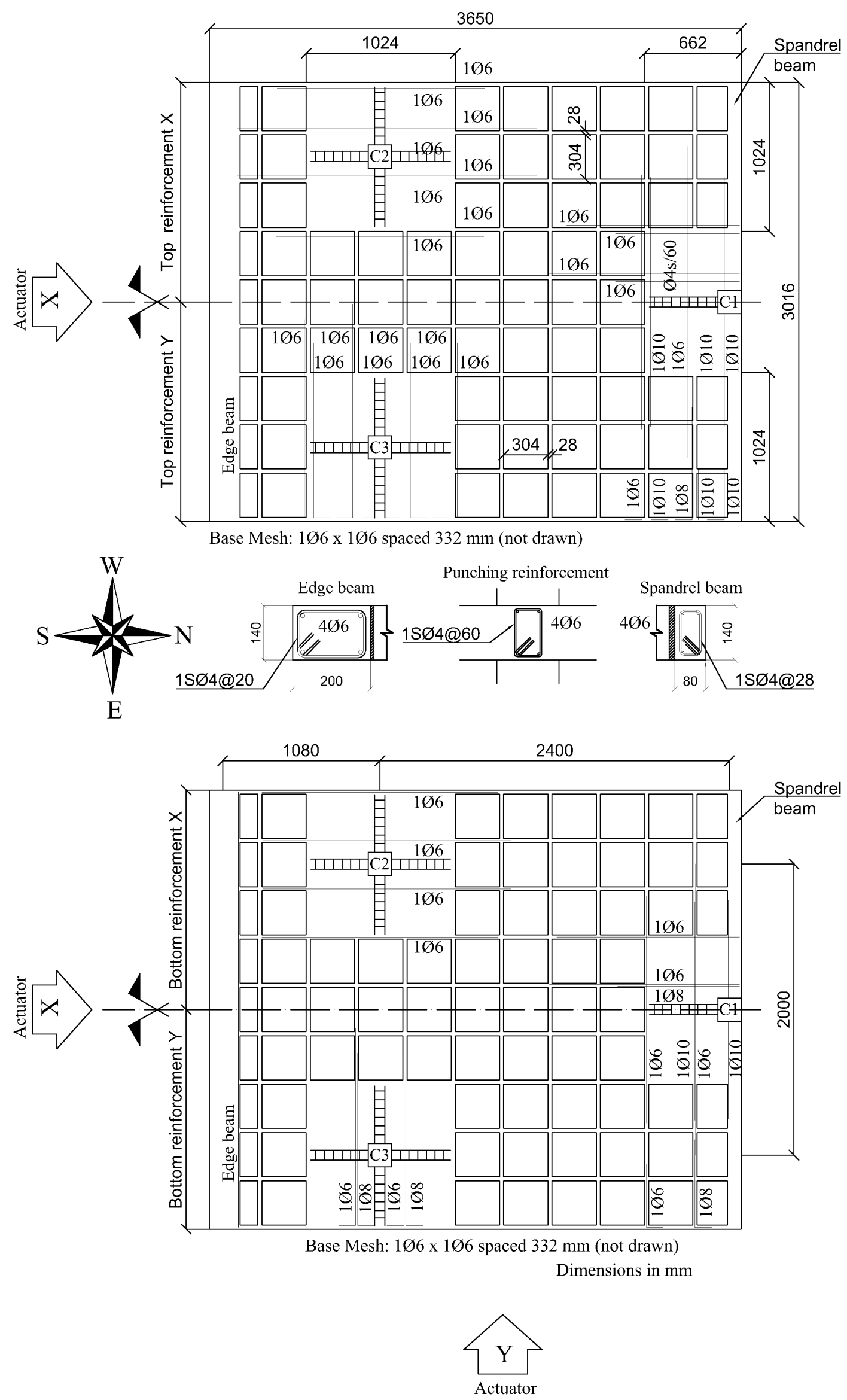

Figure 2. 3. Geometry and reinforcing details of the waffle-flat-plate for specimens BS1 


\section{DESCRIPTION OF THE TESTS}

The specimen was tested using the Earthquake Simulator of the University of Granada, a bidirectional shaking table facility of $3 \times 3 \mathrm{~m}^{2}$ designed by MTS. The facility, located in the Laboratory of Structural Dynamics of the University of Granada, had initially just one horizontal actuator and was updated with a second horizontal actuator in 2015. The new actuator was perpendicular to the older one. Tests were performed with the updated shaking table. A general view of the specimen installed on the shaking table is shown in Figure 2.4.

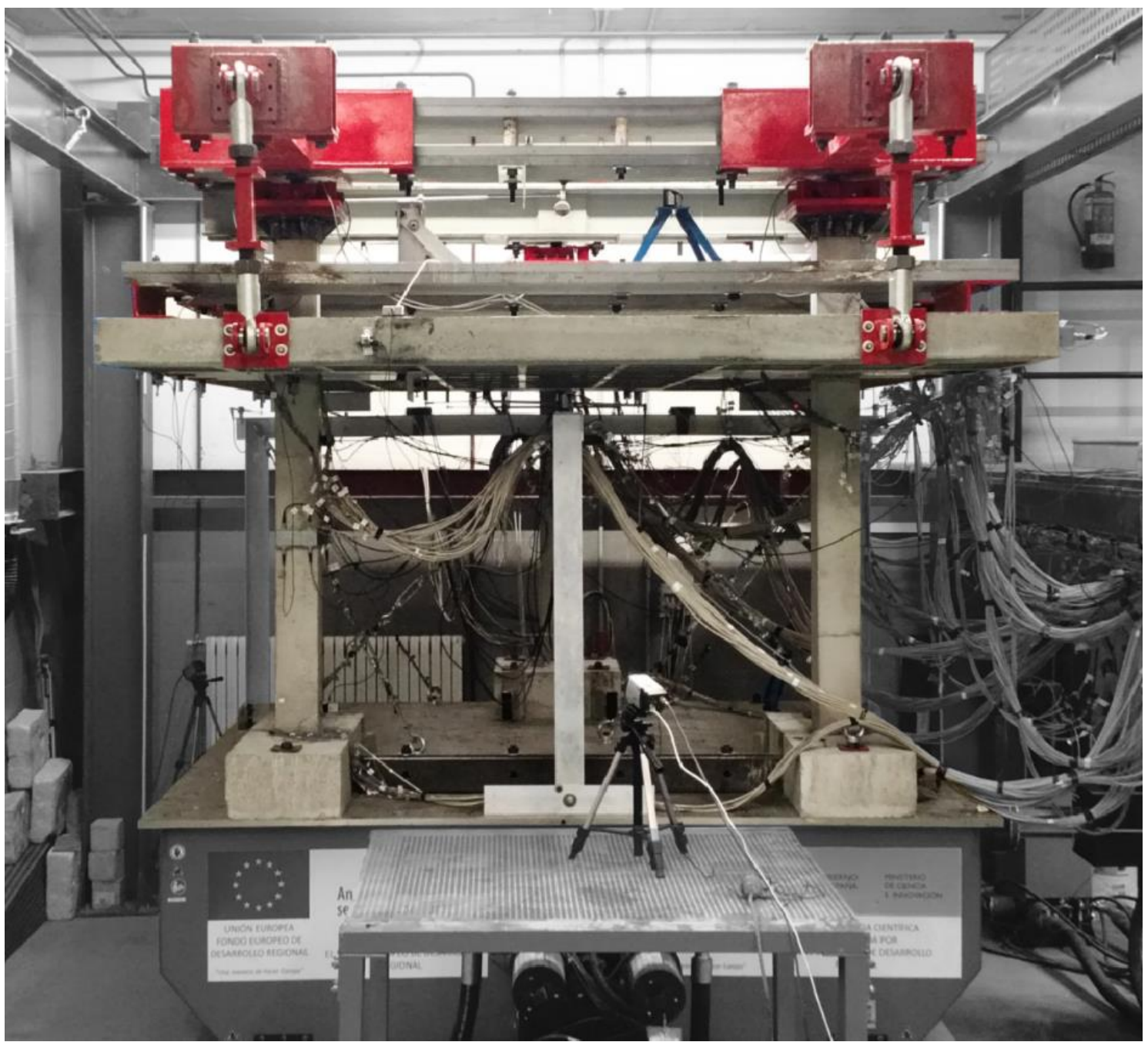

Figure 2. 4. General view of test specimen on shaking table (view from actuator X).

Figure 2.5 shows the main dimensions of the specimen tested on the earthquake simulator. In general, the specimen occupies a volume of $4 \times 3 \times 2.6 \mathrm{~m}^{3}$ and a weight of $12.23 \mathrm{~T}$. Steel blocks that were put at the top of the columns of the second story to simulate the scaled weight of the building above and to satisfy similitude requirements. A more detailed description of the test specimen is given Chapter 3 The earthquake simulator with 2-DOFs testing capability has a maximum payload of $10 \mathrm{~T}$ and a maximum overturning moment of $30 \mathrm{Tm}$. Therefore, the maximum weight capacity of the shaking table was slightly overcome with the test specimen. Under no circumstances was the overturning limit allowed to exceed during tests. 
a)
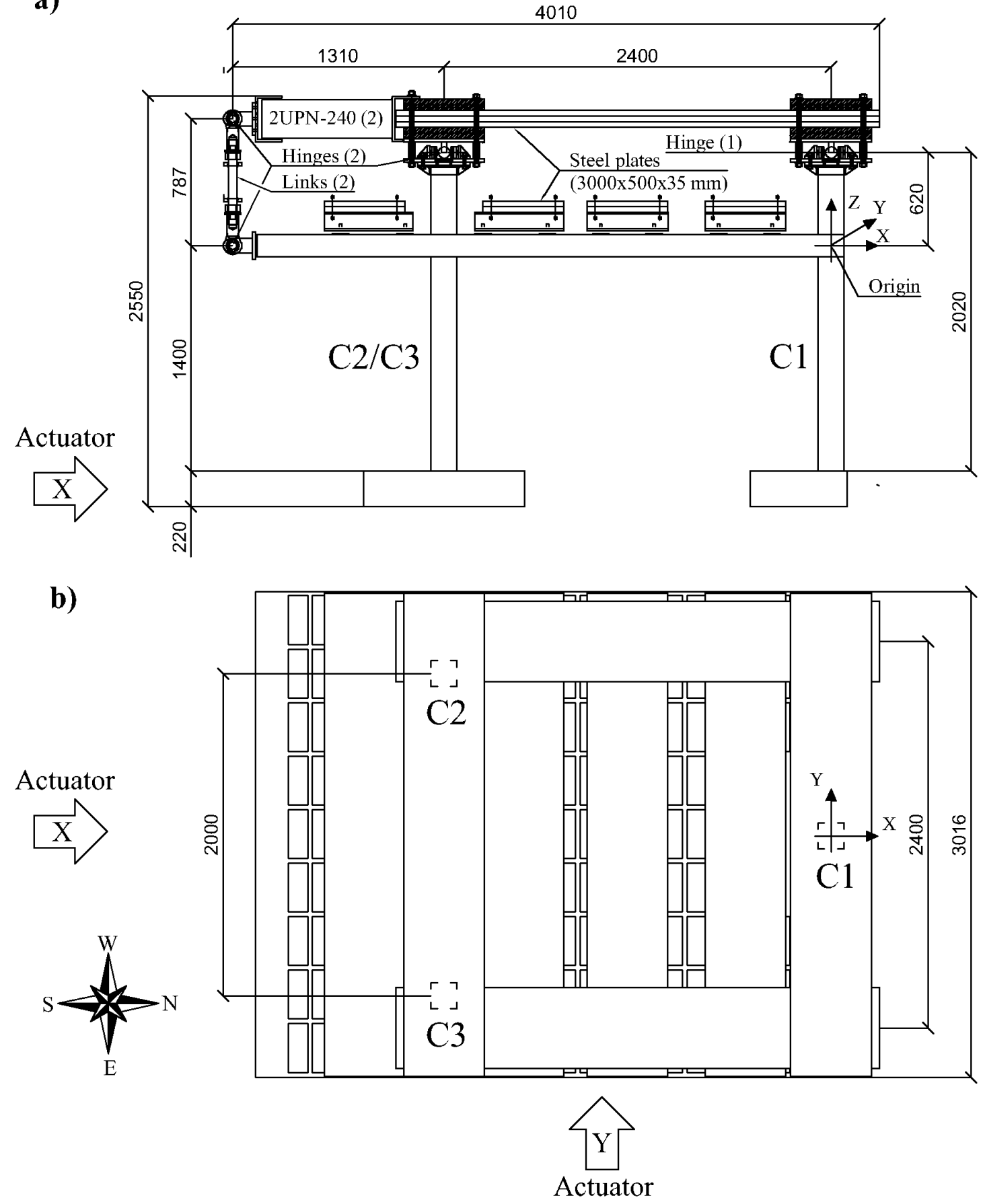

Figure 2. 5. General view of test specimen a) elevation and b) plan

\subsection{Test setup and instrumentation}

The test specimen was instrumented to obtain results not only for the purpose of this research but also for future investigations on the field. The test setup had displacement transducers (LVDT and Laser), accelerometers (Seismic and Piezoelectric), strain gauges and load cells at hinges located at top of the columns of the second story (Figure 2.6). Eight LVDT measured the relative displacement between floors in four points in plan, two points in direction $\mathrm{X}$ and other two points in direction $\mathrm{Y}$ for each level. Furthermore, six Lasers measured also the relative displacement between floors in three points in plan, two points in direction $\mathrm{X}$ and only one point in direction $\mathrm{Y}$ 
for each level. The latter worked as support displacement sensors in case of malfunction of the former ones. Eight unidirectional accelerometers measured absolute acceleration in four points per floor, two in direction $\mathrm{X}$ and two in direction $\mathrm{Y}$. In addition, 472 strain gauges were fixed to the longitudinal reinforcement in critical sections (S) as Figure 2.6 a) and b) show. Twelve load cells were located at hinges, four per hinge, to measure shear force at the top of the specimen in all directions. A global origin was stablished at column $\mathrm{C} 1$ at the slab height, axes $\mathrm{X}$ and $\mathrm{Y}$ were coincident with actuators $\mathrm{X}$ and $\mathrm{Y}$, and axis $\mathrm{Z}$ was the vertical axis. Further, the four points of the compass were also included, in such a way that the North $(\mathrm{N})$ indicated the direction $X$. The location of the measuring point of each sensor is defined in Table 2.1.

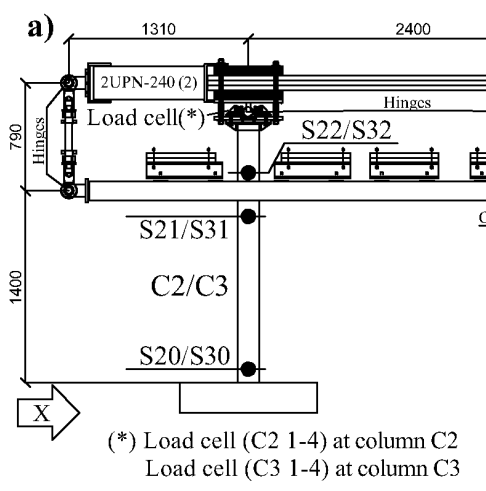

c)

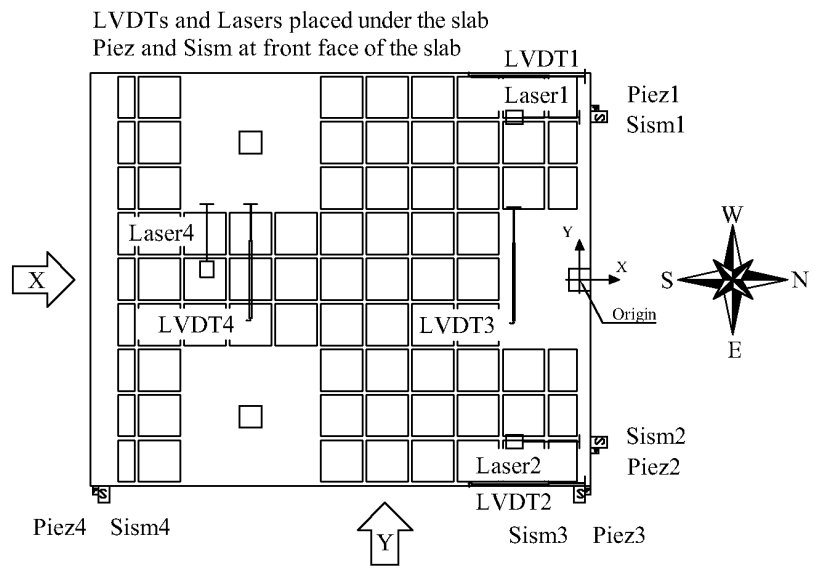

b)

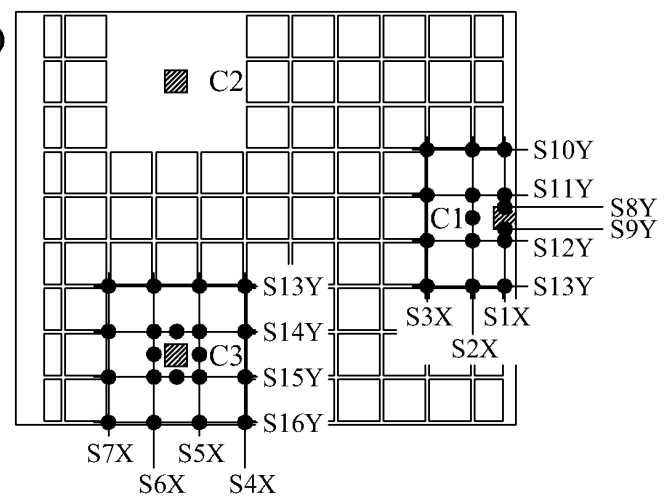

d)

LVDTs and Lasers placed between the slab and top masses Piez and Sism at front face of top masses

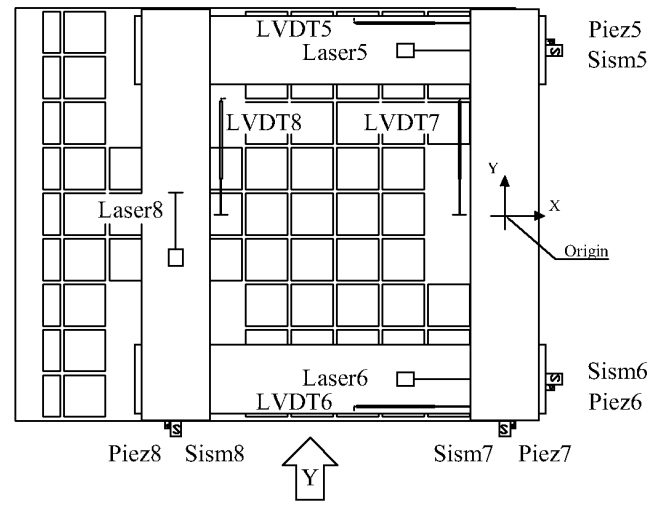

Figure 2. 6. Test setup and instrumentation: a) Critical column sections (elevation), b) Critical slab sections (plan), c) Sensors at level 1 (plan) and d) Sensors at level 2 (plan)

Table 2. 1. Location of sensors (origin shown in Figure 2.6)

\begin{tabular}{cccccccccc}
\hline Sensors & Coordinates & $\mathbf{1}$ & $\mathbf{2}$ & $\mathbf{3}$ & $\mathbf{4}$ & $\mathbf{5}$ & $\mathbf{6}$ & $\mathbf{7}$ & $\mathbf{8}$ \\
\hline \multirow{2}{*}{ LVDT } & $\mathbf{X}[\mathbf{m m}]$ & 40 & 40 & -480 & -2400 & -250 & -250 & -330 & -2070 \\
& $\mathbf{Y}[\mathbf{m m}]$ & 1484 & -1484 & 530 & 550 & 1400 & -1400 & 0 & 0 \\
\multirow{4}{*}{ Laser } & $\mathbf{X}[\mathbf{m m}]$ & 0 & 0 & --- & -2720 & -250 & -250 & --- & -2400 \\
& $\mathbf{Y}[\mathbf{m m}]$ & 1184 & -1184 & -- & 550 & 1200 & -1200 & -- & 160 \\
\multirow{2}{*}{ Piez/Sism } & $\mathbf{X}[\mathbf{m m}]$ & 80 & 80 & 0 & -3470 & 300 & 300 & 0 & -2400 \\
& $\mathbf{Y}[\mathbf{m m}]$ & 1190 & -1190 & -1508 & -1508 & 1200 & -1200 & -1500 & -1500 \\
\hline \hline
\end{tabular}

Sensors were connected to the acquisition data system fabricated and tuned by HBM. The acquisition system had the connection scheme shown in Figure 2.7. Mainly, two blocks formed the system. The block 1, the oldest, was formed of the modules MGCPlus_1, MGCPlus_2 and MGCPlus_3, while the block 2, newly updated with the new actuator, was formed of modules 
CX27, MX1615_Real9, MX1604_4, MX840B_1 and MX840B_2, where CX27 was a cluster of the modules MX1615_Real1-8. There were sync cables to stablish an absolute zero between all modules and to ensure the synchronization of the whole system. Finally, blocks were connected to PC through a switch connected by Ethernet cables. Apparently, this scheme should work perfectly synchronous, however, there was a delay between blocks 1 and 2 of around $0.17 s$ and, therefore, the data acquired had to be corrected a posteriori.

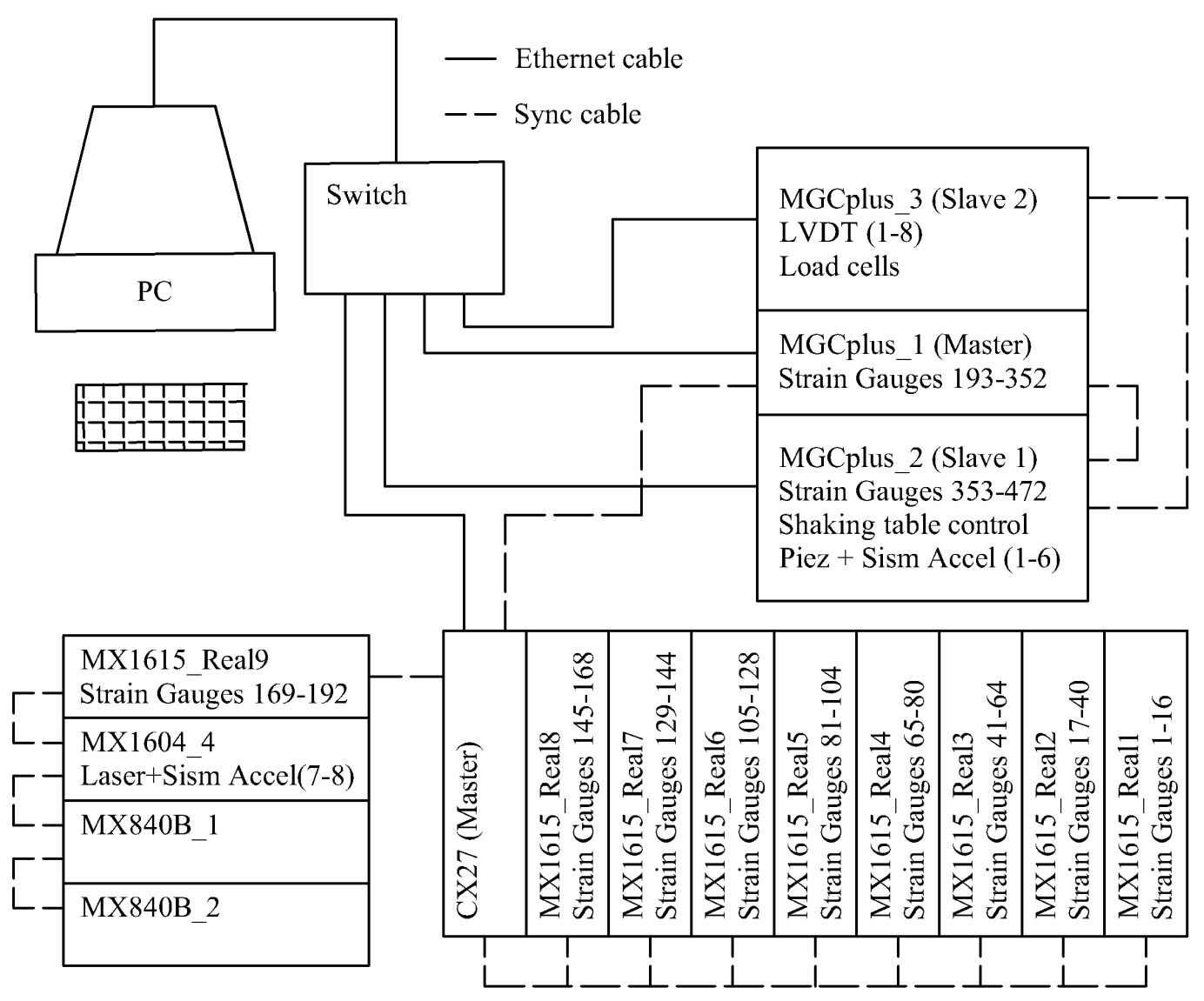

Figure 2. 7. Acquisition system scheme

\subsection{Procedures for computing displacements and accelerations}

For convenience, the tested structure was idealized as a two mass-lumped system with 3 DOF per mass. The masses were lumped at two levels: (i) at the center of mass of the RC slab, and (ii) at the center of mass of the steel blocks put at the top of the columns of the second story. The DOFs assigned to each mass are two orthogonal horizontal translations along axes $\mathrm{X}$ and $\mathrm{Y}$ of the center of mass with respect to global reference system located at the foundation, and a rotation about a vertical axis passing through the center of mass. A more detailed description of the two masslumped system is provided in Chapter 3. The acquisition system provides relative displacements between levels measured by the Laser and LVDTs (i.e. Inter-story Drifts) and absolute accelerations at the points were the sensors are located (Figure $2.6 \mathrm{c}$ and $\mathrm{d}$ and Table 2.1). The following procedure is applied to obtain the displacements and absolute accelerations at the DOFs described above from the information provided by sensors (LVDTs, Lasers, Piezoelectric accelerometers and Seismic accelerometers). The procedure first transfers the information of each story to the center of mass of the top level of the story. Afterwards, that information is transferred 
to a global reference system located on the shake table (i.e. on the top of footing), that is referred to as level 0 herein.

The RC slab (level 1) and the steel blocks put at the top of the columns of the second story (level 2 ) are assumed rigid bodies. Let's consider three points located on level $j$ around the center of mass $C_{j}$, identified as points 1,2 and 3 in Figure 2.8. Consider that level $j$ experiences a rigid body movement (within an horizontal plane), consisting of two translations $d_{x}$ and $d_{y}$ of the center of mass along the horizontal $\mathrm{X}$ and $\mathrm{Y}$ axes (measured from the original position of $\mathrm{C}_{\mathrm{j}}$ ), which gives the triangle 1'2'3' (Figure 2.8), and a counterclockwise rotation $\theta$ about a vertical axis passing through the new position of $\mathrm{C}_{\mathrm{j}}$, which gives the final triangle 1' 2 "' 3 "' (Figure 2.8).

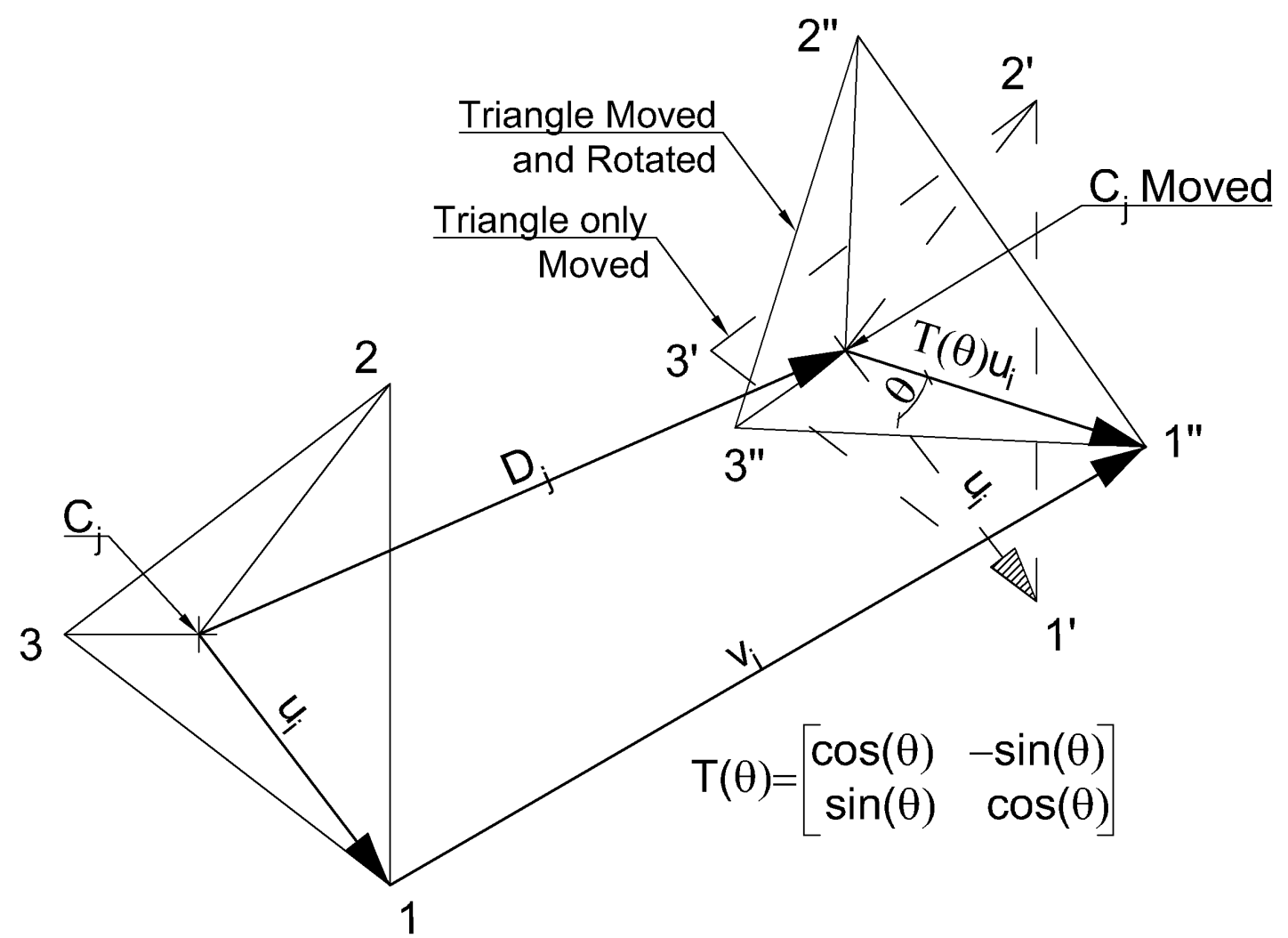

Figure 2. 8. Initial and final position of measurement points

Let's focus in one of the three points (denoted as point $i$ hereafter) which $\mathrm{X}$ and $\mathrm{Y}$ coordinates before the rigid body movement and measured from the original position of $\mathrm{C}_{\mathrm{j}}$ are $\mathbf{u}_{i}=$ $\left[\begin{array}{ll}u_{x i} & u_{y i}\end{array}\right]^{T}$. The new $\mathrm{X}$ and $\mathrm{Y}$ coordinates of this point $i$ (measured from the original position of $\left.\mathrm{C}_{\mathbf{j}}\right)$ after the rigid body movement of level $j$ can be expressed as $\left(\mathbf{u}_{\mathbf{i}}+\mathbf{v}_{\mathbf{i}}\right)$ where $\mathbf{v}_{\mathbf{i}}=$ $\left[\begin{array}{ll}v_{x i} & v_{y i}\end{array}\right]^{T}$ represents the increment of displacement along the $\mathrm{X}$ and $\mathrm{Y}$ axes of point $i$ with respect to the original position. From basic geometric considerations, the translations of the center of mass $\mathbf{C}_{\mathbf{j}}$ with respect to its original position, i.e. vector $\mathbf{D}_{\mathbf{j}}=\left[\begin{array}{ll}d_{x} & d_{y}\end{array}\right]^{T}$, and the rotation angle $\theta$ can be related with $\left(\mathbf{u}_{\mathbf{i}}+\mathbf{v}_{\mathbf{i}}\right)$ by Equation (2.1).

$$
\left[\begin{array}{l}
d_{x} \\
d_{y}
\end{array}\right]+\left[\begin{array}{cc}
\cos (\theta) & -\sin (\theta) \\
\sin (\theta) & \cos (\theta)
\end{array}\right]\left[\begin{array}{l}
u_{x i} \\
u_{y i}
\end{array}\right]=\left[\begin{array}{l}
u_{x i} \\
u_{y i}
\end{array}\right]+\left[\begin{array}{l}
v_{x i} \\
v_{y i}
\end{array}\right]
$$

The relative displacements $\mathbf{v}_{\mathbf{i}}=\left[\begin{array}{ll}v_{x i} & v_{y i}\end{array}\right]^{T}$ are measured by the Lasers and LVDTs (i.e. Interstory Drifts), and the instrumentation provided these displacements at three points at least. Since 
there are three unknowns $\left(d_{x}, d_{y}\right.$ and $\left.\theta\right)$ and Equation (2.1) can be written for each point, several alternatives are possible to determine $d_{x}, d_{y}$ and $\theta$ from the information provided by the instrumentation. Two alternatives are given by Equations (2.2) and (2.3). For solving Equation (2.2) the relative displacements $\mathbf{v}_{\mathbf{i}}$ of two points along direction $\mathrm{X}$ and one point along direction $\mathrm{Y}$ is needed. To solve Equation (2.3), we need information from two points in direction $\mathrm{Y}$ and only one point in direction $\mathrm{X}$.

$$
\begin{aligned}
& d_{x}+u_{x 1} \cos (\theta)-u_{y 1} \sin (\theta)=u_{x 1}+v_{x 1} \\
& d_{x}+u_{x 2} \cos (\theta)-u_{y 2} \sin (\theta)=u_{x 2}+v_{x 2} \\
& d_{y}+u_{x 3} \sin (\theta)+u_{y 3} \cos (\theta)=u_{y 3}+v_{y 3} \\
& d_{x}+u_{x 1} \cos (\theta)-u_{y 1} \sin (\theta)=u_{x 1}+v_{x 1} \\
& d_{y}+u_{x 2} \sin (\theta)+u_{y 2} \cos (\theta)=u_{y 2}+v_{y 2} \\
& d_{y}+u_{x 3} \sin (\theta)+u_{y 3} \cos (\theta)=u_{y 3}+v_{y 3}
\end{aligned}
$$

The above systems are nonlinear and they must be solved with an iterative algorithm such as Newton, Broyden or others. Another possibility to solve the system is to simplify it considering infinitesimal displacement theory where $\sin (\theta)=\theta$ and $\cos (\theta)=1$. Applying this simplification and then reorganizing, yields (2.4) and (2.5) from (2.2) and (2.3), respectively.

$$
\begin{aligned}
& {\left[\begin{array}{l}
v_{x 1} \\
v_{x 2} \\
v_{y 3}
\end{array}\right]=\left[\begin{array}{ccc}
1 & 0 & -u_{y 1} \\
1 & 0 & -u_{y 2} \\
0 & 1 & u_{x 3}
\end{array}\right]\left[\begin{array}{c}
d_{x} \\
d_{y} \\
\theta
\end{array}\right]} \\
& {\left[\begin{array}{l}
v_{x 1} \\
v_{y 2} \\
v_{y 3}
\end{array}\right]=\left[\begin{array}{ccc}
1 & 0 & -u_{y 1} \\
0 & 1 & u_{x 2} \\
0 & 1 & u_{x 3}
\end{array}\right]\left[\begin{array}{c}
d_{x} \\
d_{y} \\
\theta
\end{array}\right]}
\end{aligned}
$$

These systems are linear and they are able to approximate the solution accurately for small rotations. In addition, Figure 2.9 shows the relative error versus rotation $\theta$, which was obtained doing a parametric study using both systems, linear [(2.4) or (2.5)] and nonlinear [(2.2) or (2.3)].

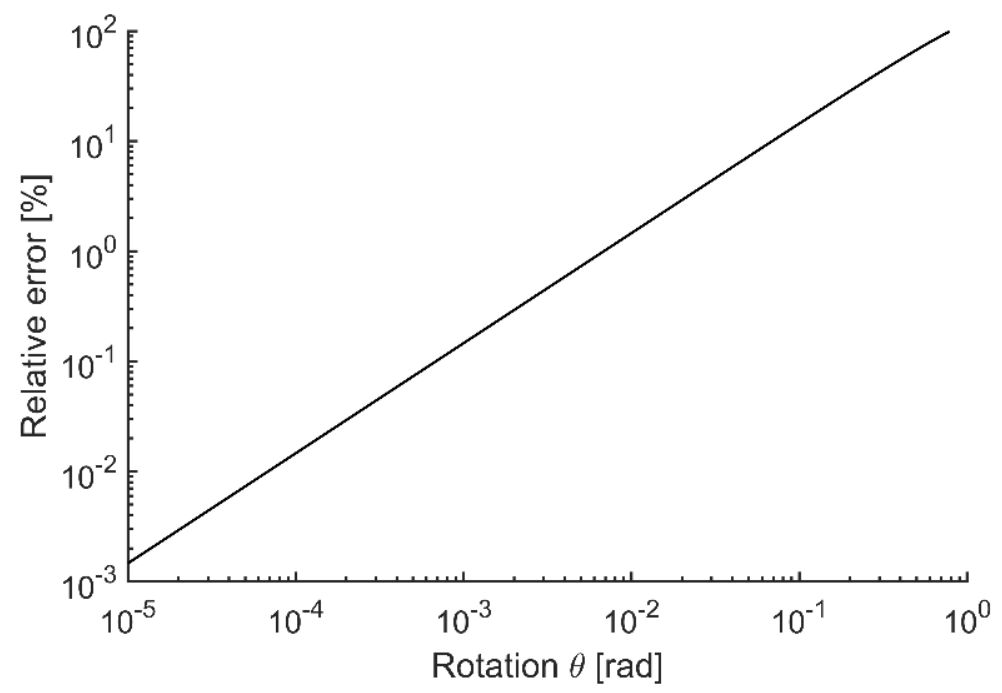

Figure 2. 9. Relative error versus rotations. 
This relationship is linear applying logarithmic scales for axes in the range of the data analyzed. The least squares approach was used to predict the relative error as function of the rotation $\theta$, giving:

$$
\log (\text { rel.error })=0.97 \log (\theta)+0.12
$$

Once the relative movements between levels of the centers of mass of each level $\left(d_{x}, d_{y}\right.$ and $\left.\theta\right)$ are determined from the Inter-story Drifts measured by the Lasers and LVDTs, the movements and rotations with respect to the base of the shaking table of any center of mass $C_{j}$ and any point in its horizontal rigid body plane $\mathrm{P}_{\mathrm{j}}, \Delta \mathbf{C}_{\mathrm{j}}$ and $\Delta \mathbf{P}_{\mathrm{j}}$ respectively, are readily obtained with Equations 2.7 to 2.10 . Figure 2.10 explains these equations graphically, corresponding equation 2.7 to Figure 2.10a, 2.8 to Figure 2.10b, 2.9 to Figure 2.10c and 2.10 to Figure 2.10d.

In Figure 2.10, point $\mathrm{O}$ is the origin of the global $\mathrm{X}-\mathrm{Y}$ reference system located on the shake table, $\mathrm{C}_{1}$ and $\mathrm{C}_{2}$ are the centers of mass of levels 1 and 2 respectively, and $\mathrm{P} 1$ and $\mathrm{P} 2$ represent two random points located at level 1 and 2, respectively. Vectors are denoted either by the names of two points with a bar on the top, e.g. $\overline{\mathrm{C}}_{1} \mathrm{C}_{2}$ is the projection on the horizontal plane of the vector connecting point $\mathrm{C}_{1}$ and $\mathrm{C}_{2}$; or by its components, e.g. $\mathbf{D}_{1}=\left[d_{x 1}, d_{y 1}\right]$ and $\mathbf{D}_{2}=\left[d_{x 2}, d_{y 2}\right]$ are the relative translational movements between level 1 and the shake table and between level 2 and level 1 , respectively. In addition, $\theta_{\mathrm{j}}$ represent the relative rotations between levels about a vertical axis passing through each center of mass, i.e. $\theta_{1}$ is the rotation of the first level with respect to the shake table, and $\theta_{2}$ the rotation of level 2 with respect to level 1 . Furthermore, $\mathbf{T}\left(\theta_{j}\right)$ is the transformation matrix:

$$
\mathbf{T}\left(\theta_{j}\right)=\left[\begin{array}{cc}
\cos \theta_{j} & -\sin \theta_{j} \\
\sin \theta_{j} & \cos \theta_{j}
\end{array}\right]
$$

Therefore, for example the displaced position of point $\mathrm{P}_{2}$ measured from the origin $\mathrm{O}$ can be readily determined from the relative translational $\mathbf{D}_{1}$ and $\mathbf{D}_{2}$ and rotational $\theta_{1}$ and $\theta_{2}$ movements between levels, by $\left[\overline{\mathrm{OC}_{1}}+\mathbf{D}_{1}+\mathbf{T}\left(\theta_{1}\right)\left(\overline{\mathrm{C}_{1} \mathrm{C}_{2}}+\mathbf{D}_{2}+\mathbf{T}\left(\theta_{2}\right) \overline{\mathrm{C}_{2} \mathrm{P}_{2}}\right)\right]$. The relative displacement of point $\mathrm{P}_{2}$ with respect to its initial position along the global $\mathrm{X}$ and $\mathrm{Y}$ axes, $\Delta \mathbf{P}_{2}$, is simply $\left[\overline{\mathrm{OC}_{1}}+\mathbf{D}_{1}+\mathbf{T}\left(\theta_{1}\right)\left(\overline{\mathrm{C}_{1} \mathrm{C}_{2}}+\mathbf{D}_{2}+\mathbf{T}\left(\theta_{2}\right) \overline{\mathrm{C}_{2} \mathrm{P}_{2}}\right)\right]-\overline{\mathrm{OP}_{2}}$. The rotation of point $\mathrm{P}_{2}$ with respect to the shake table is the rotation of the first level plus the rotation of the second level $\left(\theta_{1}+\theta_{2}\right)$.

$$
\begin{aligned}
& \Delta \mathbf{C}_{1}=\left[\begin{array}{c}
\overline{O C_{1}}+\mathbf{D}_{1}-\overline{O \mathrm{C}_{1}} \\
\theta_{1}
\end{array}\right] \\
& \Delta \mathbf{C}_{2}=\left[\begin{array}{c}
\overline{O C_{1}}+\mathbf{D}_{1}+\mathbf{T}\left(\theta_{1}\right)\left(\overline{\mathrm{C}_{1} \mathrm{C}_{2}}+\mathbf{D}_{2}\right)-\overline{O \mathrm{C}_{2}} \\
\theta_{1}+\theta_{2}
\end{array}\right] \\
& \Delta \mathbf{P}_{1}=\left[\begin{array}{c}
\overline{O C_{1}}+\mathbf{D}_{1}+\mathbf{T}\left(\theta_{1}\right) \overline{\mathrm{C}_{1} \mathrm{P}_{1}}-\overline{O \mathrm{P}_{1}} \\
\theta_{1}
\end{array}\right] \\
& \Delta \mathbf{P}_{2}=\left[\begin{array}{c}
\overline{\mathrm{OC}_{1}}+\mathbf{D}_{1}+\mathbf{T}\left(\theta_{1}\right)\left(\overline{\mathrm{C}_{1} \mathrm{C}_{2}}+\mathbf{D}_{2}+\mathbf{T}\left(\theta_{2}\right) \overline{\mathrm{C}_{2} \mathrm{P}_{2}}\right)-\overline{O \mathrm{P}_{2}} \\
\theta_{1}+\theta_{2}
\end{array}\right]
\end{aligned}
$$


a) Relative displacement of $C_{1}\left(\Delta C_{1}\right)$

b) Relative displacement of $C_{2}\left(\Delta C_{2}\right)$
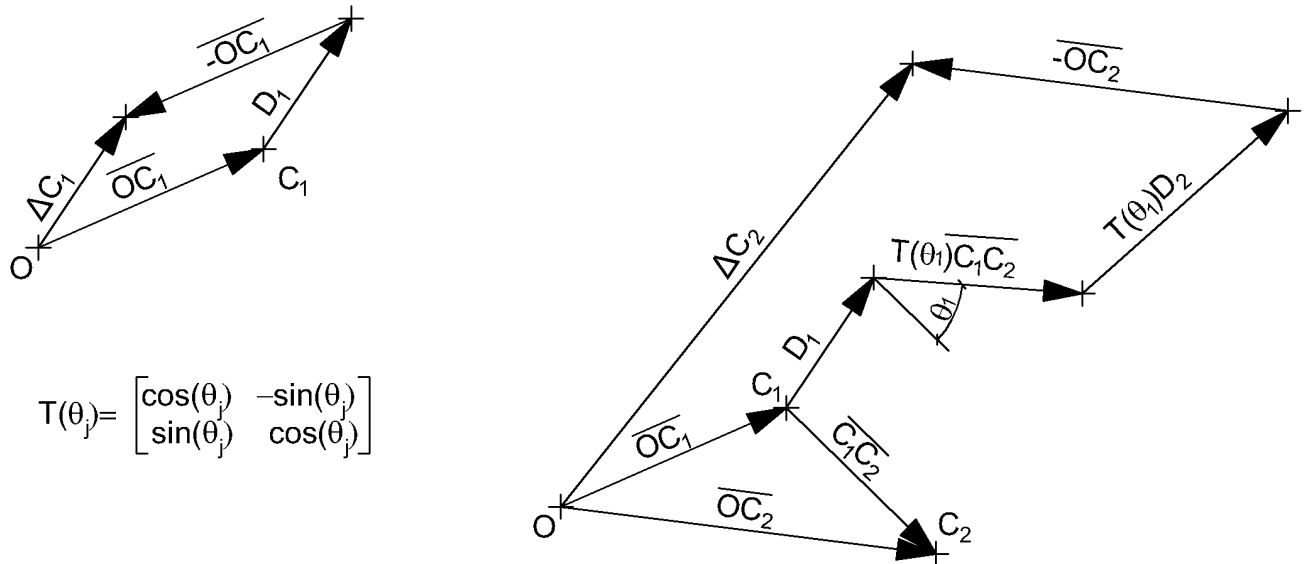

c) Relative displacement of $P_{1}\left(\Delta P_{1}\right)$

d) Relative displacement of $P_{2}\left(\Delta P_{2}\right)$

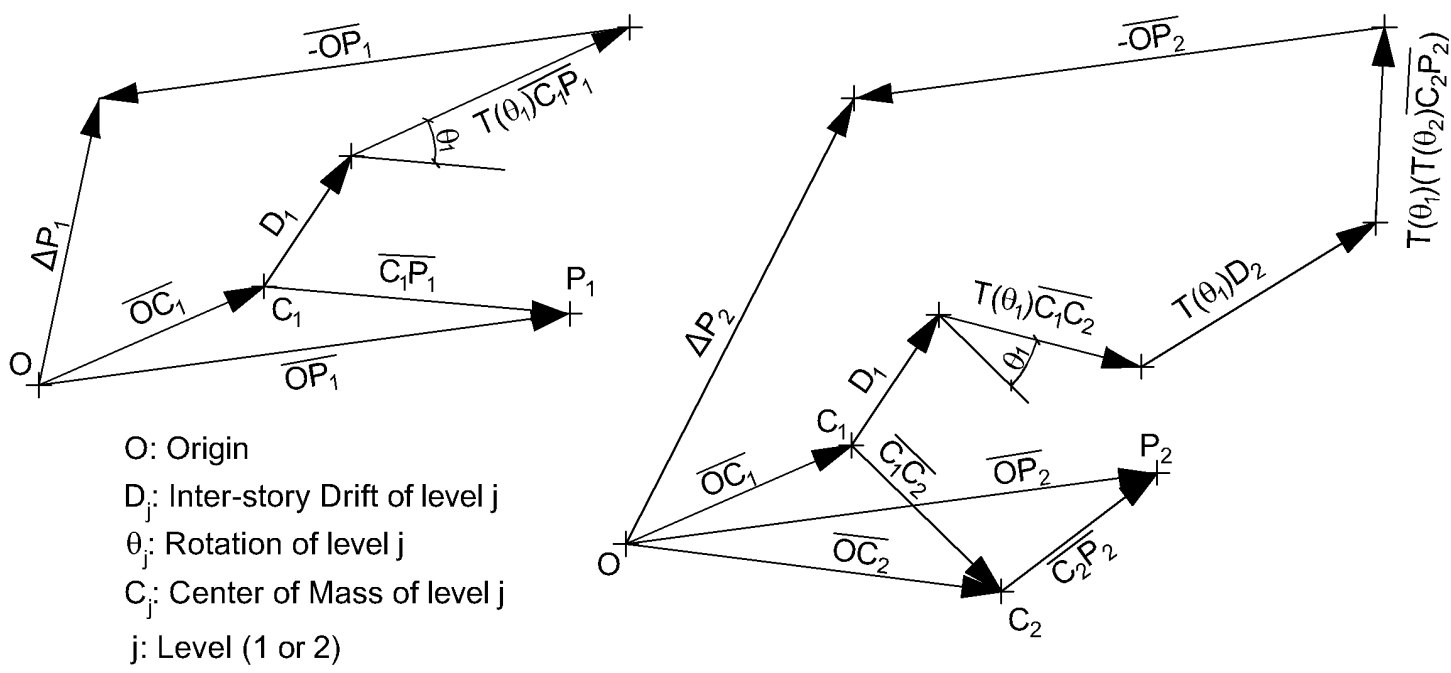

Figure 2. 10 Graphical description of equations (2.7) to (2.10)

On the other hand, the absolute (i.e. with respect to a Newtonian or inertial reference system) translational accelerations along the global $\mathrm{X}$ and $\mathrm{Y}$ axes, $\ddot{v}_{x i}^{t}$ and $\ddot{v}_{y i}^{t}$, and the rotational $\ddot{\theta}_{i}^{t}$ accelerations, of a point $\mathrm{P}_{\mathrm{i}}$ located in level $i$ at distances $u_{x i}$ and $u_{y i}$ (measured along the global $\mathrm{X}$ and $\mathrm{Y}$ axes) from its center of mass, can be related with the absolute translational, $\ddot{d}_{x}^{t}$ and $\ddot{d}_{y}^{t}$, and rotational, $\ddot{\theta}^{t}$, accelerations of the center of mass by:

$$
\left[\begin{array}{c}
\ddot{v}_{x i}^{t} \\
\ddot{v}_{y i}^{t} \\
\ddot{\theta}_{i}^{t}
\end{array}\right]=\left[\begin{array}{ccc}
1 & 0 & -u_{y i} \\
0 & 1 & u_{x i} \\
0 & 0 & 1
\end{array}\right]\left[\begin{array}{c}
\ddot{d}_{x}^{t} \\
\ddot{d}_{y}^{t} \\
\ddot{\theta}^{t}
\end{array}\right]
$$

The absolute translational accelerations $\mathbf{v}_{i}^{t}=\left[\begin{array}{ll}\ddot{v}_{x i}^{t} & \ddot{v}_{y i}^{t}\end{array}\right]^{T}$ are directly measured by the accelerometers located at point $i$ of a given level. Translational absolute accelerations along $\mathrm{X}$ and $\mathrm{Y}$ were measured at least at three points of each level. Since there are three unknowns $\left(\ddot{d}_{x}^{t}\right.$, $\ddot{d}_{y}^{t}$ and $\ddot{\theta}^{t}$ ) for each level and Equation (2.11) can be written for each point, several alternatives are possible to determine $\ddot{d}_{x}^{t}, \ddot{d}_{y}^{t}$ and $\ddot{\theta}^{t}$ from the information provided by the accelerometers. 
Two alternatives are given by Equations (2.12) and (2.13). For solving equations (2.12) the relative absolute accelerations $\mathbf{v}_{\boldsymbol{i}}^{\boldsymbol{t}}$ of two points along direction $\mathrm{X}$ and one point along direction $\mathrm{Y}$ is needed. To solve Equations (2.13), we need information from two points in direction $\mathrm{Y}$ and only one point in direction $\mathrm{X}$.

$$
\begin{aligned}
& {\left[\begin{array}{c}
\ddot{v}_{x 1}^{t} \\
\ddot{v}_{x 2}^{t} \\
\ddot{v}_{y 3}^{t}
\end{array}\right]=\left[\begin{array}{ccc}
1 & 0 & -u_{y 1} \\
1 & 0 & -u_{y 2} \\
0 & 1 & u_{x 3}
\end{array}\right]\left[\begin{array}{l}
\ddot{d}_{x}^{t} \\
\ddot{d}_{y}^{t} \\
\ddot{\theta}^{t}
\end{array}\right]} \\
& {\left[\begin{array}{c}
\ddot{v}_{x 1}^{t} \\
\ddot{v}_{y 2}^{t} \\
\ddot{v}_{y 3}^{t}
\end{array}\right]=\left[\begin{array}{ccc}
1 & 0 & -u_{y 1} \\
0 & 1 & u_{x 2} \\
0 & 1 & u_{x 3}
\end{array}\right]\left[\begin{array}{l}
\ddot{d}_{x}^{t} \\
\ddot{d}_{y}^{t} \\
\ddot{\theta}^{t}
\end{array}\right]}
\end{aligned}
$$

These equations give the absolute accelerations at the centers of mass in each level.

\subsection{Ground motion used for the tests}

Ground motion designated as Calitri, recorded at Calitri station in the Campano Lucano Earthquake (1980) was adopted for testing. The Campano Lucano event happened on November $23^{\text {rd }} 1980$ and the hypocenter was located at the east of Campania region $\left(40^{\circ} 46^{\prime} \mathrm{N}\right.$ and $\left.15^{\circ} 18^{\prime} \mathrm{E}\right)$, at $16 \mathrm{~km}$ depth. It was a moderate large earthquake $\left(M_{S}=6.9\right)$ causing severe damage and casualties (2.735 dead, 8.848 injured and about 200.000 homeless) (Del Pezzo, Iannaccone et al. 1983). Figure 2.11 shows the history of the original (unscaled) accelerations and velocities recorded at Calitri, located at $26 \mathrm{~km}$ direction NE from the epicenter.

a)
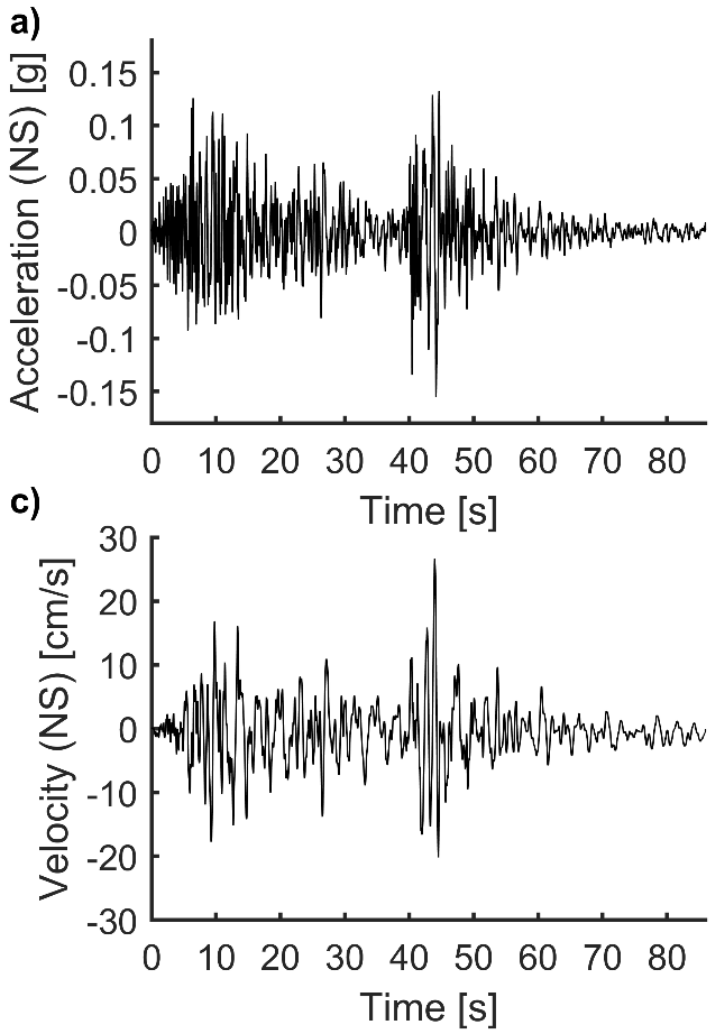

b)
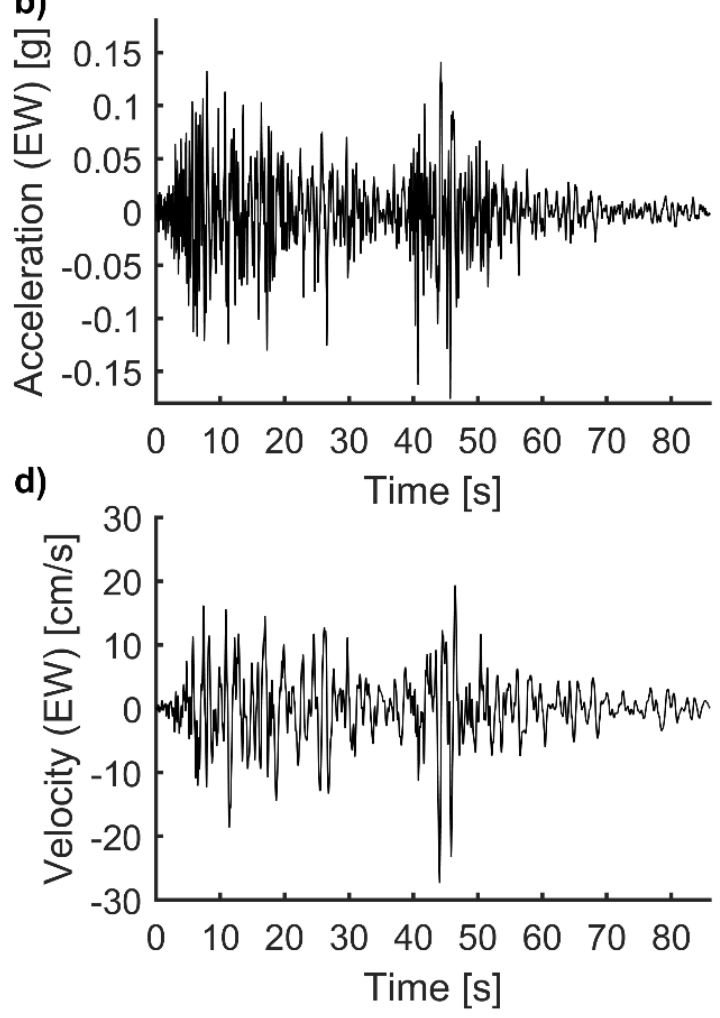

Figure 2. 11. Unscaled Calitri Earthquake histories of: a) Acceleration (NS), b) Acceleration (EW), c) Velocity (NS) and d) Velocity (EW) 
This earthquake was classified as a far-field ground motion with no visible pulses in its velocity time history. The Peak Ground Accelerations (PGAs) measured were $0.16 \mathrm{~g}$ (NS) and $0.18 \mathrm{~g}$ $(\mathrm{EW})$, the Peak Ground Velocities (PGVs) were $27 \mathrm{~cm} / \mathrm{s}$ in both directions and the earthquake duration was $86 \mathrm{~s}$.

Figures 2.12 and 2.13 show the acceleration, velocity, displacement and energy spectra $2 \%$ and $5 \%$ damped of the original ground motions for its components $\mathrm{X}$ and $\mathrm{Y}$. Spectra are actually the fingerprints of an earthquake. They were calculated running a linear response history analysis (LRHA) to a Single Degree of Freedom (SDOF) system where mass remained constant and stiffness went changing to compute periods from 0.04 to $5 \mathrm{~s}$. Newmark-Beta algorithm with $\gamma=$ $1 / 2$ and $\beta=1 / 4$ was used to solve the equation of motion in each step. Once results in terms of displacements, velocity and acceleration were obtained for each step, the maximum absolute value of each one was taken for each period. The energy value was post-processed for each period and for each direction using $E_{I}=\int_{0}^{t_{d}} \dot{u} m \ddot{u}_{g} d t$, where $m$ is the mass, $\ddot{u}_{g}$ is the ground motion accelerations and $\dot{u}$ is the velocity of the SDOF, all integrated along the earthquake time $t_{d}$.
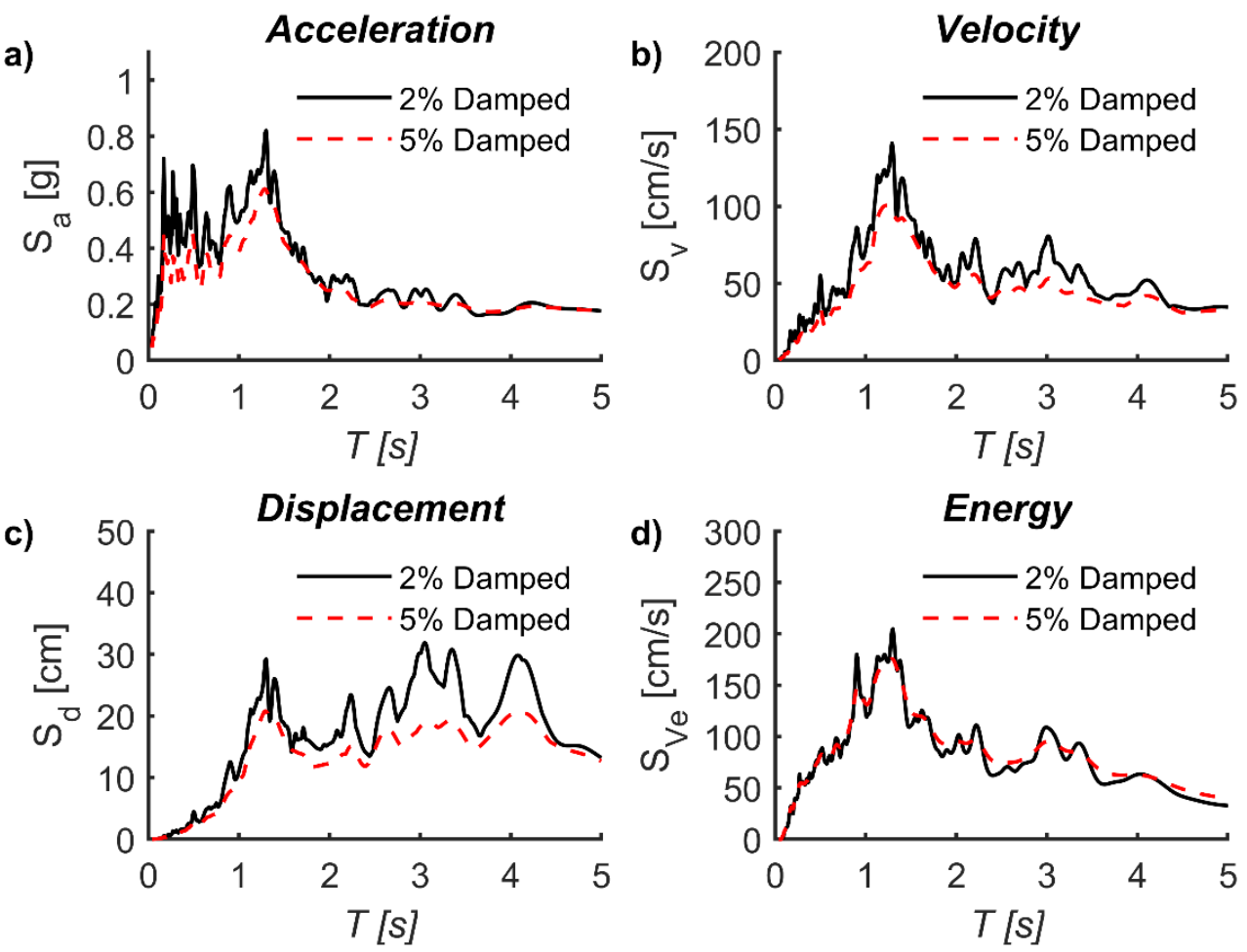

Figure 2. 12. Spectrums 2\% and 5\% damped of the unscaled Calitri Earthquake (NS): a) Acceleration, b) Velocity, c) Displacement and d) Input Energy 

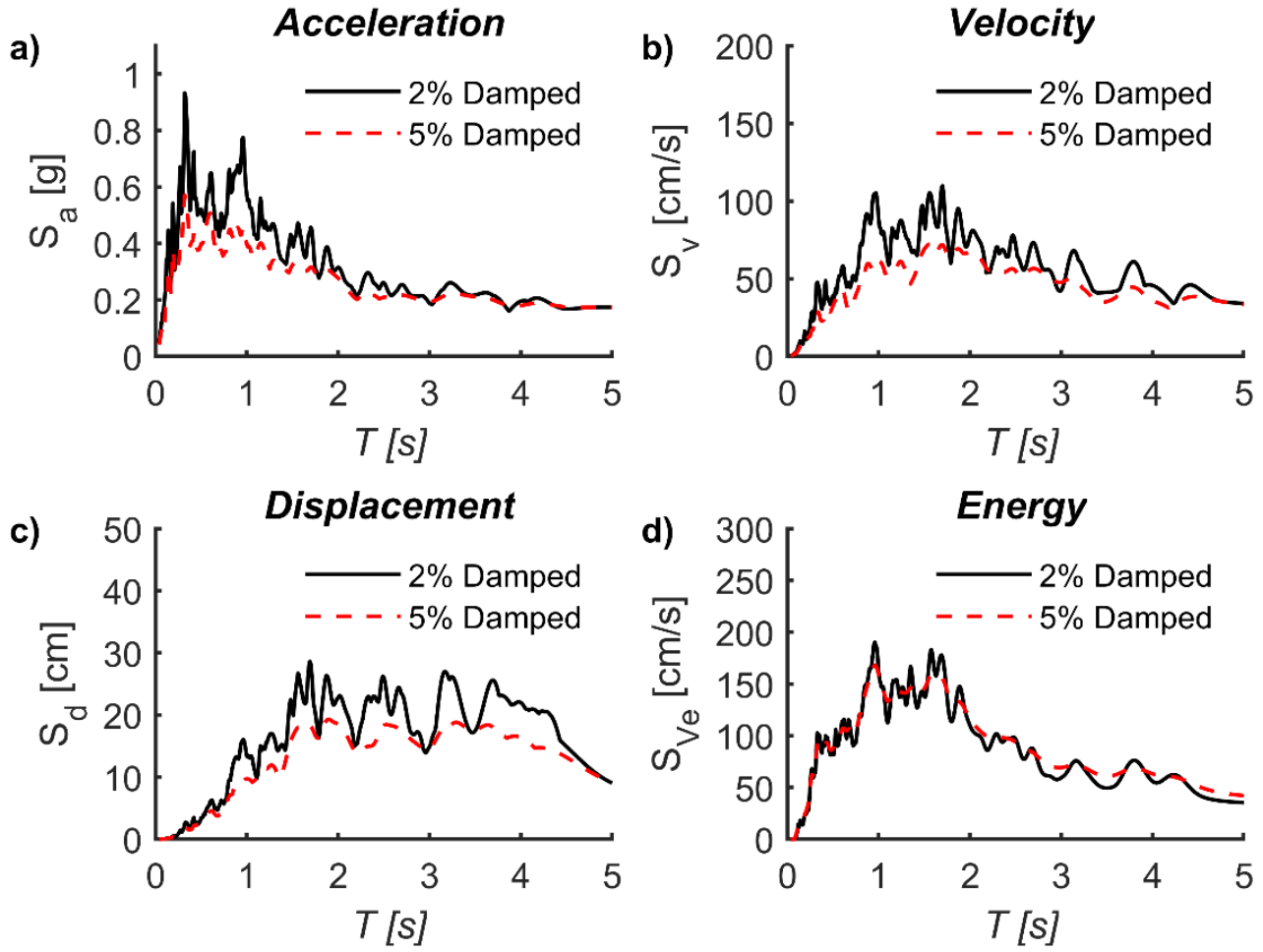

Figure 2. 13. Spectrums 2\% and 5\% damped of the unscaled Calitri Earthquake (EW): a) Acceleration, b) Velocity, c) Displacement and d) Input Energy

Figure 2.14 represents an approximation of the acceleration $\left(S_{a}\right)$, velocity $\left(S_{v}\right)$ and displacement $\left(S_{d}\right)$ spectra using the pseudo-acceleration $\left(P S_{a}\right)$, pseudo-velocity $\left(P S_{v}\right)$ and pseudo-displacement $\left(P S_{d}\right)$ in only one tripartite logarithmic plot, following the work of Newmark (1982). In the figure, plots use four logarithmic scales to show the three response quantities with the period also plotted logarithmically. This is possible because all of them have a relationship between each other through the angular frequency $(\omega[\mathrm{rad} / \mathrm{s}])$ or the frequency $(f[\mathrm{~Hz}])$ as follows.

$$
\begin{gathered}
P S_{a}=w P S_{v}=2 \pi f P S_{v} \\
P S_{d}=P S_{v} / w=P S_{v} /(2 \pi f)
\end{gathered}
$$
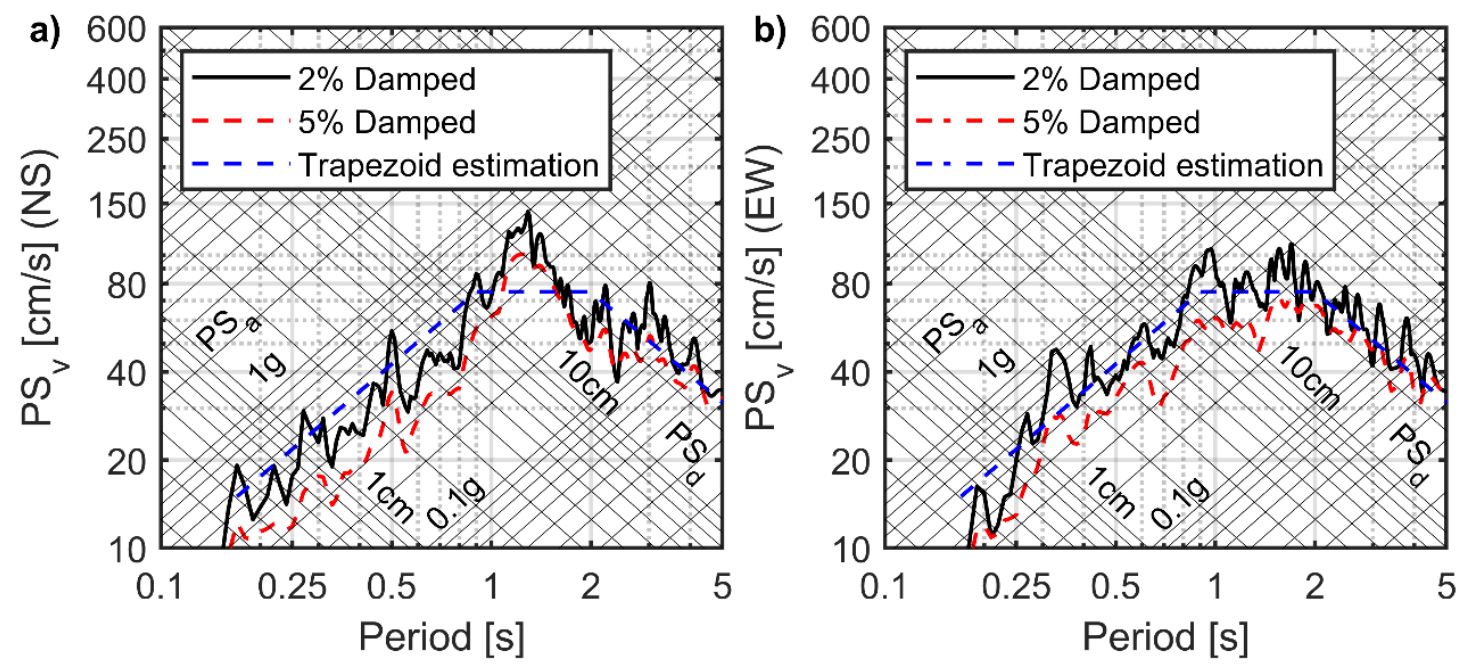

Figure 2. 14. Newmark's logarithmic spectra $2 \%$ and $5 \%$ damped of the unscaled Calitri Earthquake: a) NS and b) EW 
Actually, the response spectra for earthquake motions are quite irregular, as noted in Figures 2.12 and 2.13. However, they have a general shape of a trapezoid when plotted on logarithmic tripartite graph paper. In Figure 2.14, it is drawn an estimation of the trapezoid in dotted blue line. This trapezoid divide the plot in three zones: the constant acceleration zone, the constant velocity zone and the constant displacement zone. Despite the constant velocity zone is not as easy to see as the other ones, it was estimated that the constant acceleration zone spread from 0 to $0.9 \mathrm{~s}$, the constant velocity zone from 0.9 to $2 \mathrm{~s}$ and the constant displacement zone from 2 to $5 \mathrm{~s}$.

\subsection{Loading program}

The test specimen was subjected to the two horizontal components of Calitri Earthquake scaled in time by a factor $\lambda_{t}=\sqrt{\lambda_{L} / \lambda_{a}}=\sqrt{2 / 5}$ to fulfill similitude requirements, and in amplitude to several levels, as explained later. The time scaling means a time contraction of the signal and, thus, a contraction of the duration determined by the dimensional factors $\left(\lambda_{a}=1, \lambda_{v}=\lambda_{a} \lambda_{t}=\right.$ $\sqrt{2 / 5}$ and $\left.\lambda_{L}=2 / 5\right)$. As a consequence, while acceleration amplitudes remain unaltered, displacements and velocities amplitudes were reduced for their corresponding factors $\lambda_{v}$ and $\lambda_{L}$.

Bidirectional shaking table tests need an input base motions for each horizontal direction. The North-South (NS) direction wave and the East-West (EW) direction wave were input to the Xdirection and $\mathrm{Y}$-direction of the specimen, respectively. Figure 2.15 shows the target acceleration and velocity shaking table inputs of the time scaled Calitri ground motion at $100 \%$ of span in directions $\mathrm{X}$ and $\mathrm{Y}$.
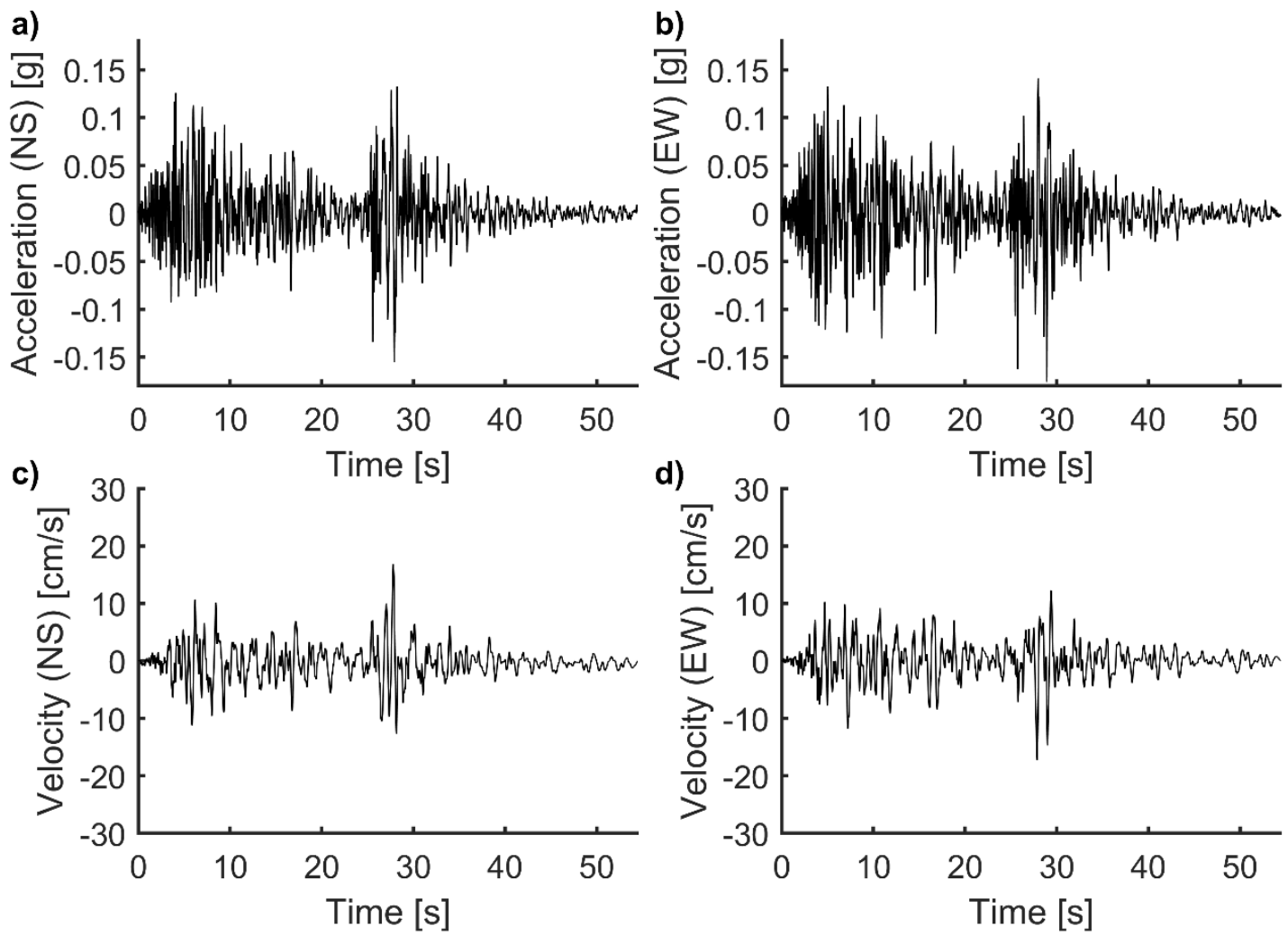

Figure 2. 15. Scaled Calitri Earthquake histories of: a) Acceleration (NS), b) Acceleration (EW), c) Velocity (NS) and d) Velocity (EW)

The intensity of input motions was gradually increased to observe the damage progression in the specimen. A study referred in Ministerio de Fomento (Martínez Solares, Cabañas et al. 2013) was 
used to define tentatively scaling factors in amplitude. The study stablishes several Seismic Hazard Levels (SHLs) in terms of a reference maximum ground acceleration in rock: $a_{g}=0.10 \mathrm{~g}$ for $P_{R}=95$ years, $a_{g}=0.24 \mathrm{~g}$ for $P_{R}=475$ years and $a_{g}=0.44 \mathrm{~g}$ for $P_{R}=2475$ years years. Here $P_{R}$ is the return period. Since the prototype building was designed assuming soil type $\mathrm{C}$, these values must be corrected multiplying by an appropriate site amplification factor $F$. Different empirical expressions have been proposed in the literature to estimate $F$. The expressions developed by Borcherdt (2002) and by Choi and Stewart (2005) were used for this purpose. These expressions give the following ranges of amplified acceleration for soil type $\mathrm{C}$ : $0.14 g<a_{g} F<0.17 g$ for $P_{R}=95$ years, $0.32 g<a_{g} F<0.39 g$ for $P_{R}=475$ years and $0.58 g<a_{g} F<0.63 g$ for $P_{R}=2475$ years.

In bidirectional ground motions, the peak ground acceleration (PGA) does not necessarily occur in the NS or EW direction, in this regard, it was calculated as follows. Denoting by $G A_{N S}(t)$ and $G A_{E W}(t)$ as the horizontal ground acceleration at instant $t$ in directions NS and EW, the bidirectional peak ground acceleration was taken as $P G A_{b}=\max \left(\sqrt{G A_{N S}(t)^{2}+G A_{E W}(t)^{2}}\right)$. Therefore, applying above range of $a_{g} F$, it would be expectable to find amplitude scaling factors of $0.8\left(\mathrm{P}_{\mathrm{R}}=95\right.$ years $), 1.8\left(\mathrm{P}_{\mathrm{R}}=475\right.$ years $)$ and $3.0\left(\mathrm{P}_{\mathrm{R}}=2475\right.$ years $)$ for Calitri earthquake. In consequence, the adopted amplitude scaling factors for Calitri were 35, 50, 100, 200 and 300\%. 35 and $50 \%$ are associated with "very frequent" earthquakes for the building site, $100 \%$ is related with a "frequent" earthquake, 200\% represents the "design earthquake" and 300\% represents a "very rare" earthquake at the building site. Figures 2.16 and 2.17 present the target spectra for accelerations, velocities, displacements and input energies, for each horizontal directions and for the five levels of intensity established for the test. According to these figures, Calitri is particularly intense in the short-period range in both directions corresponding to the fundamental period of the specimen in elastic range $\left(T_{1}=0.38 \mathrm{~s}\right.$, see Table 4.2).
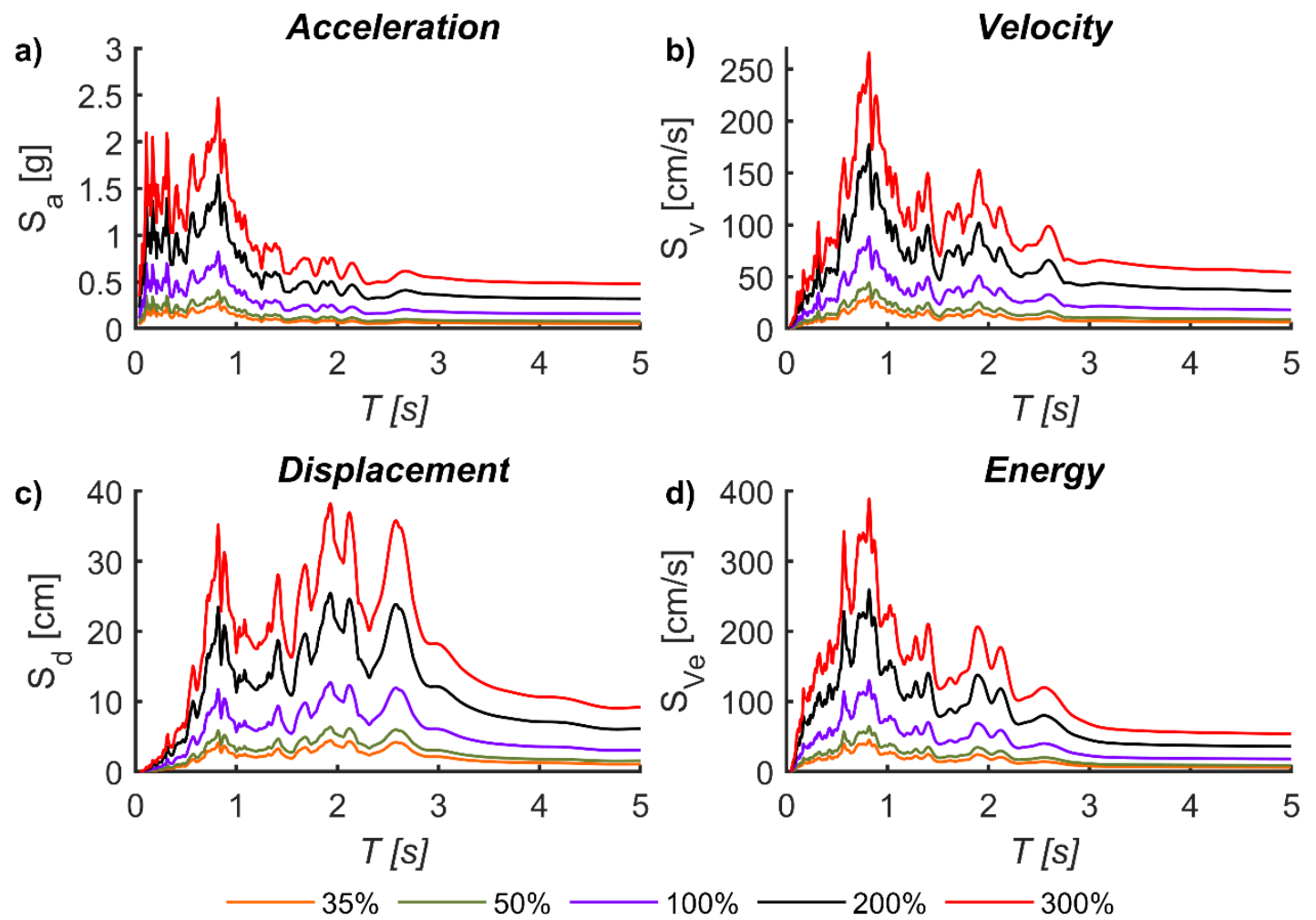

Figure 2. 16. Target spectra input motion (NS): a) Acceleration, b) Velocity, c) Displacement and d) Input energy 

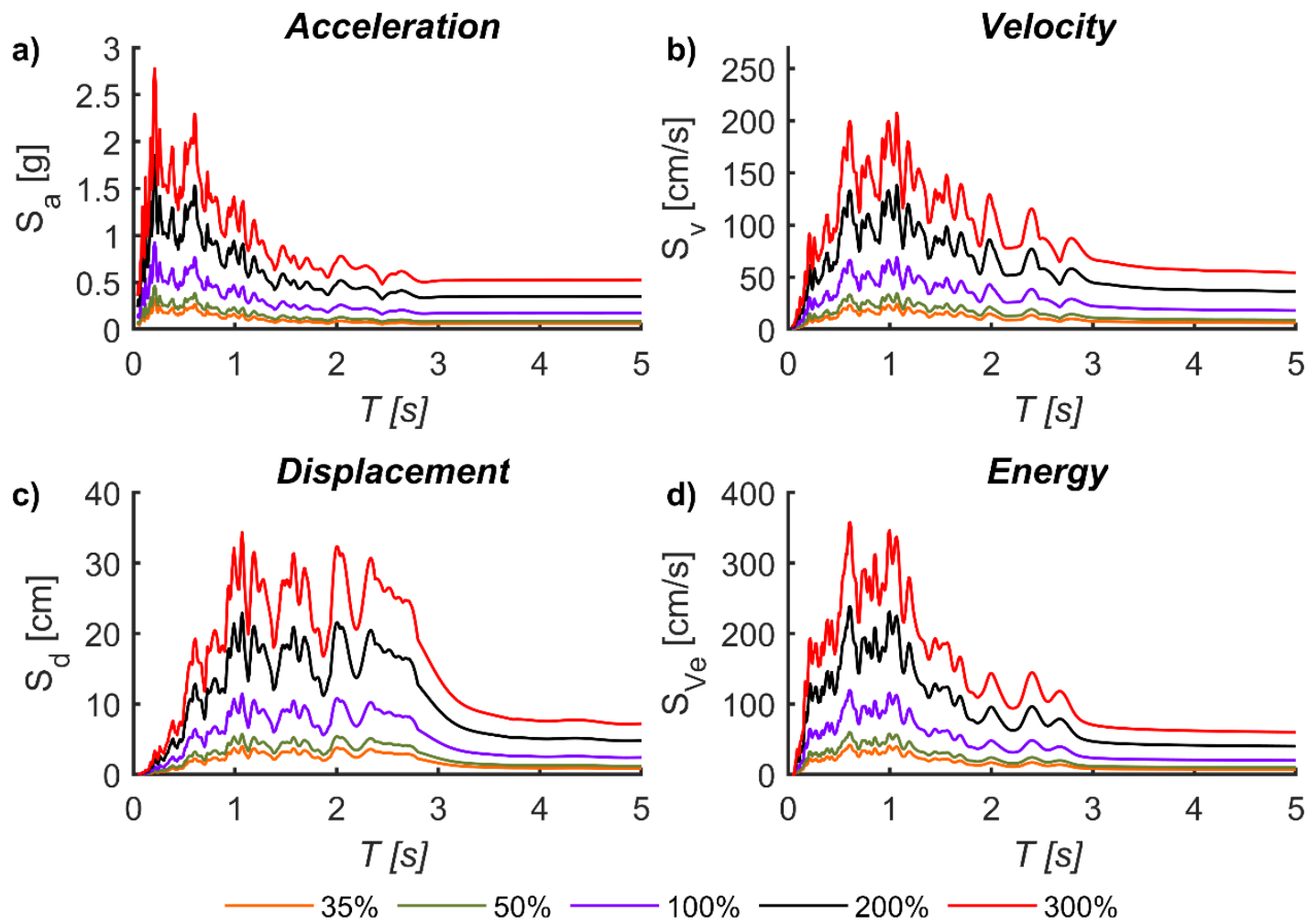

Figure 2. 17. Target spectra input motion (EW): a) Acceleration, b) Velocity, c) Displacement and d) Input energy

Figure 2.18 shows once again the tripartite logarithmic plot ideated by Newmark (1982) for spectra approximation, but in this case for the input base motions used in the test with a scaling factor of $100 \%$ in both directions. In the plot, it is drawn an estimation of the new trapezoid in dotted blue line. The trapezoid divides the plot in three zones: the constant acceleration zone (period until $0.6 s$ ), the constant velocity zone (period between $0.6 s$ and $1.3 s$ ) and the constant displacement zone (period above $1.3 \mathrm{~s}$ ). Considering that fundamental period changes as long as the specimen enters more and more in the nonlinear range during test, from 0.38 to $0.75 \mathrm{~s}$ (Table 4.2), Figure 2.18 suggests that the specimen starts the test in the constant acceleration zone and finishes the test in the constant velocity zone of the tripartite logarithmic plot.
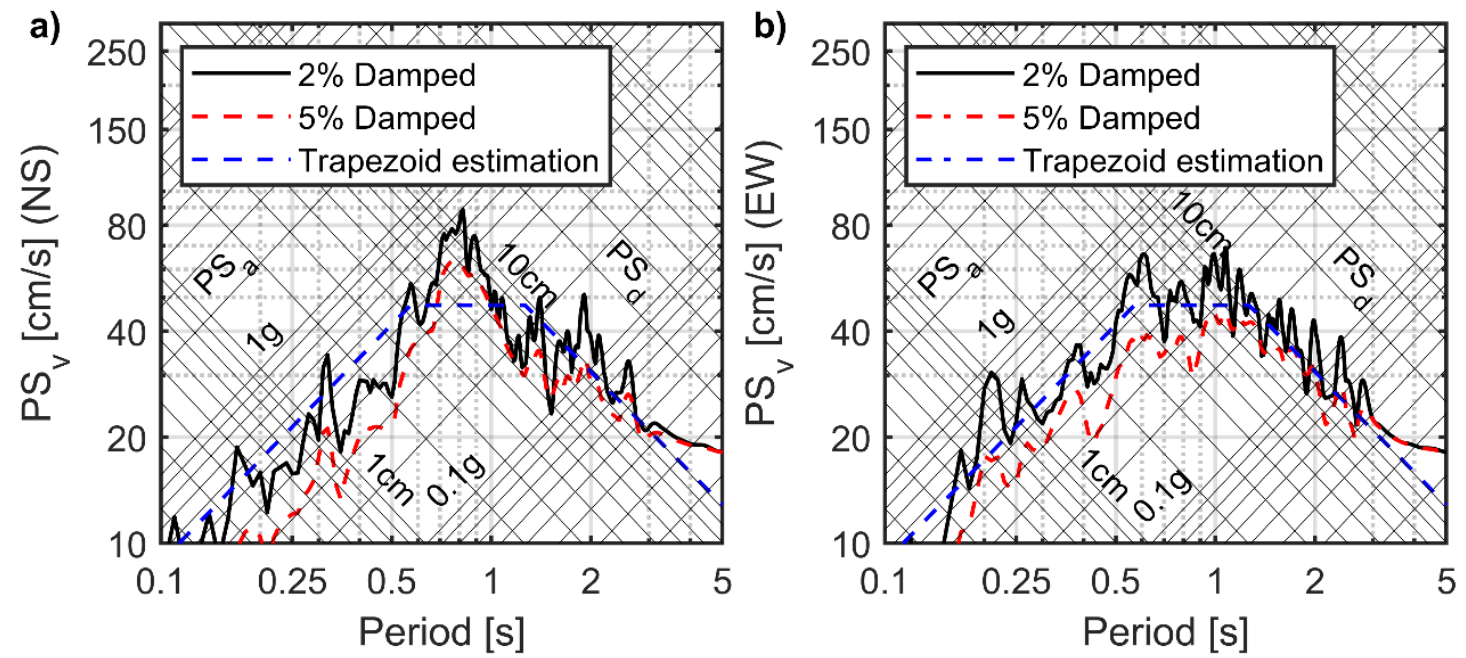

Figure 2. 18. Newmark's logarithmic spectra $2 \%$ and $5 \%$ damped of input base motions (Calitri scaled in time and unscaled in amplitude): a) NS and b) EW 


\section{SUMMARY}

This Chapter described the design of the shake table tests. Firstly, a prototype structure that consisted of three-story RC WFP system supported on isolated columns was designed following the Spanish codes (Ministerio de Fomento 2003, 2008). Afterwards, a specimen was obtained as a partial structure extracted from the prototype cutting at points where the moment are approximately zero under lateral loads. Then, the dimensions of this partial structure were escalated to 2/5, to make them compatible with the size of the shaking table of the University of Granada.

The specimens, named BS1, was built in laboratory, instrumented and set in a $3 \times 3 \mathrm{~m}^{2}$ bidirectional shake table. The instrumentation consisted of displacement traducers (LVDTs and Laser), accelerometers (Seismic and Piezo-electrics) at each of the two levels of the structure, and almost 500 strain gauges placed at critical sections of the RC elements. Load cells were also located at the top end of the columns of the second story. Due to the fact that displacement traducers only measured the Inter-story Drift at specific points, a procedure was designed to obtain the displacements of the centers of mass of each level relative to the base of shaking table in directions $\mathrm{X}$ and $\mathrm{Y}$, and rotations. A similar procedure was designed to calculate the absolute accelerations at the center of mass of each level.

Finally, a European earthquake was selected to test the specimen. The base-motion acceleration recorded at Calitri during the Campano Lucano Earthquake (1980), which is an earthquake classified as far-field ground motion, was adopted as the input base motion of the shaking table. The original earthquake was escalated in time by a factor of 0.632 to fulfill similitude requirements, and in amplitude to 35, 50, 100, 200 and 300\% of its original acceleration values. Both original and scaled earthquake were characterized with their PGAs, PGVs and spectra in terms of displacement, velocity, acceleration and input energy. A useful tripartite logarithmic plot of displacement, velocity and acceleration spectra (Newmark, Hall 1982) was used to divide the earthquake behavior in three zones: the constant acceleration zone, the constant velocity zone and the constant displacement zone. According to the evolution of the value of fundamental period measured along the test (as discussed later and shown in Table 4.2), the initial elastic period of the specimen was in the constant acceleration zone, and enlarged reaching the constant velocity region. 


\section{Chapter 3}

\section{EXPERIMENTAL INVESTIGATION: CHARACTERIZATION OF TEST SPECIMEN}

Before performing a dynamic shaking table tests it is important to estimate the mechanical properties (stiffness, strength) and dynamic characteristics of the specimen to be tested. This information is crucial, for example, to scale the amplitude of the acceleration to be applied to the shake table. The Chapter aims to estimate the response of the specimen before performing the dynamic test using a relatively simple model. It consists of a two-mass lumped model with 3 degrees of freedom (DOF) per lumped mass. Within the elastic range, the model is characterized by the mass matrix and the stiffness matrix. With these matrices, the linear response of the structure can be predicted. In order to make an approximation to the nonlinear behavior, a rough estimation of the strength is required, and this can be done studying the possible global collapse mechanisms of the specimen. The mechanism that generates the collapse of the structure comes from the weakest configuration of plastic hinges. With this information it is possible to anticipate the range of frequencies that the specimen is going to show along the test, which is fundamental to estimate the amount of energy that the ground motion will input to the specimen during the test, and the maximum base shear force and overturning moment that can be expected. This estimation is also crucial for the safety of the earthquake simulator. 


\section{MATHEMATICAL MODEL}

For convenience the specimen was idealized with a two-mass lumped model, each mass having 3 DOFs: two orthogonal horizontal translations in direction $\mathrm{X}$ and $\mathrm{Y}$ of the centers of mass, following the actuators directions as Figure 2.5 shows, and one rotation about a vertical axis passing through the centers of masses. The two centers of mass are not on the same vertical axis. The DOFs are numbered as 1 (translation $\mathrm{X}$ at first level), 2 (translation $\mathrm{Y}$ at first level), 3 (rotation about $\mathrm{Z}$ at first level), 4 (translation $\mathrm{X}$ at second level), 5 (translation $\mathrm{Y}$ at second level) and 6 (rotation about $\mathrm{Z}$ at second level). Figure 3.1 shows specimen and the model.

a)

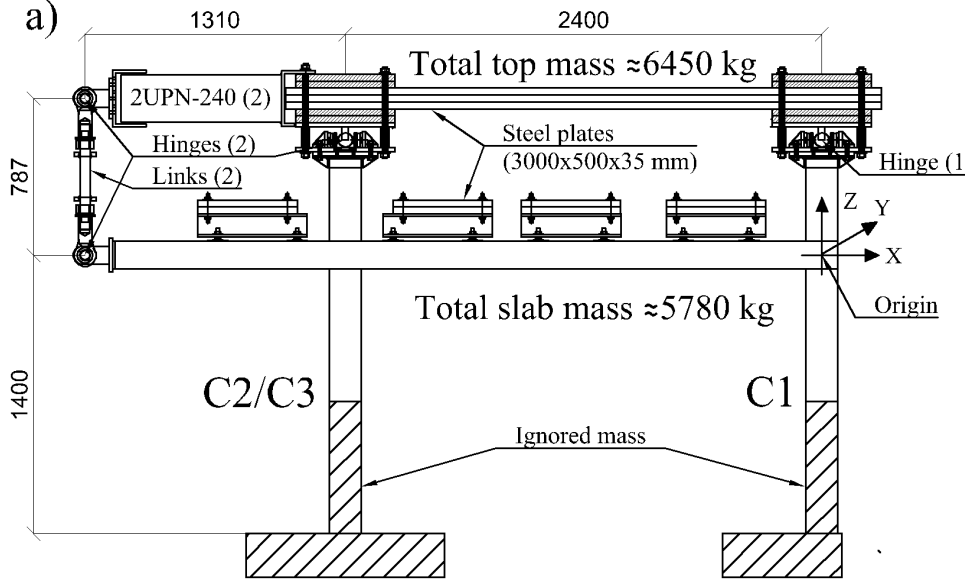

b)

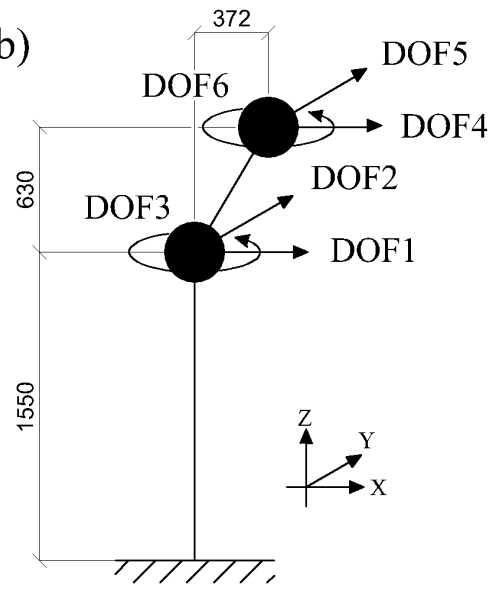

Figure 3. 1. Idealized model: a) specimen and b) idealization

The equations of motion (1.2) are specialized in (3.1) for the shaking table with only 2 DOFs (the two horizontal directions of the actuators) and for the test specimen (without velocity-dependent dampers), defined previously as a Multi-Degree of Freedom (MDOF) system with 6 DOFs in total. Within the elastic range, the equations of motion are:

$$
\mathbf{M} \ddot{\mathbf{u}}(t)+\mathbf{C u}(t)+\mathbf{F}_{\mathbf{S}}(\overline{\mathbf{u}}(t))=-\mathbf{M J}_{\mathbf{X}} \ddot{u}_{g X}(t)-\mathbf{M J}_{\mathbf{Y}} \ddot{u}_{g Y}(t)
$$

Where $\overline{\mathbf{u}}$, $\dot{\mathbf{u}}$ and $\ddot{\mathbf{u}}$ are the relative vectors of displacement (due only to dynamic loadings), velocity and acceleration. The matrices $\mathbf{M}$ and $\mathbf{C}$ are the mass matrix and the damping matrix; $\mathbf{F}_{\mathbf{s}}(\overline{\mathbf{u}}(t)$ represents the nonlinear relation between resisting forces and deformations; in linear systems $\mathbf{F}_{\mathbf{s}}=\mathbf{K}(\overline{\mathbf{u}}(t))$ and the stiffness matrix $\mathbf{K}$ does not change with time. The right side represents the dynamic excitation: where $\ddot{u}_{g X}$ and $\ddot{u}_{g Y}$ are the $\mathrm{X}$ and $\mathrm{Y}$ components of ground acceleration generated by the actuators and $\mathbf{J}_{\mathbf{X}}$ and $\mathbf{J}_{\mathbf{Y}}$ are the corresponding influence vectors,

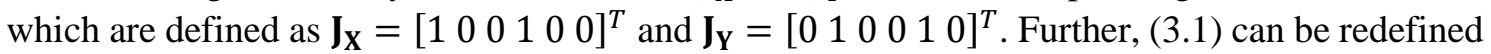
to work with the information recorded by accelerometers (absolute acceleration, $\ddot{\mathbf{u}}(t)^{\boldsymbol{t}}$ ) and displacement and velocity transducers (relative values, $\overline{\mathbf{u}}(t), \dot{\mathbf{u}}(t)$ ), as follows:

$$
\mathbf{M} \ddot{\mathbf{u}}(t)^{t}+\mathbf{C u}(t)+\mathbf{F}_{\mathbf{s}}(\overline{\mathbf{u}}(t))=\mathbf{0}
$$

\section{MASS}

In order to hold the stress state in the specimen due to gravity loads and to satisfy prototypespecimen similitude requirements, additional eight steel blocks were attached on the top of the slab plate (first level) and fourteen steel blocks on the top half columns of the second story (second 
level). Each steel block weighed $412 \mathrm{~kg}$. The additional masses on the slab included the dead and live load on the first floor. The additional mass on top of the columns included the dead and live load of the missing upper floors. The total mass of the test specimen was $12996 \mathrm{~kg}$, which included the additional masses due to steel plates, hinges and hardware $(9820 \mathrm{~kg})$ and the selfweight of the specimen $(3135 \mathrm{~kg})$.

The simplest procedure for defining the mass properties of any structure for a model is to assume that the entire mass is concentrated at the points at which the translational and rotational displacements are defined (Clough \& Penzien, 1992). With this idea in mind, the specimen was idealized with a two-mass lumped model. Every mass point can be accelerated following the DOFs show in Figure $3.1 \mathrm{~b}$ ). Although, the total mass of specimens was $12996 \mathrm{~kg}$, the model only accounted with $12300 \mathrm{~kg}$ because foundations and half height of the columns were excluded (Tables 3.1 and 3.2). The lumped mass at first level was $5784 \mathrm{~kg}$, where the mass of the RC elements and the steel plates fixed on the slab were included. The lumped mass at second level was $6446 \mathrm{~kg}$, where the masses of the hardware, top steel plates and hinges were included (Table 3.1). In addition, it was necessary to define a rotational inertia of each lumped mass because masses were not concentrate in a point but they were spread around each lumped-mass point, and therefore, its rotational inertia is important. The calculated lumped rotational inertia for the first level was $9650 \mathrm{Kgm}^{2}$ and for the second level, $13003 \mathrm{Kgm}^{2}$ as Tables 3.3 and 3.4 show. Figure 3.2 shows every piece that appears in Tables 3.1 to 3.4.

Table 3.1. Mass of specimen pieces

\begin{tabular}{cccccc}
\hline Piece & $\begin{array}{c}\text { Amount } \\
{[\text { Units }]}\end{array}$ & $\begin{array}{c}\text { Unitary } \\
\text { weight } \\
{[\mathbf{k g}]}\end{array}$ & $\begin{array}{c}\text { Weight } \\
{[\mathbf{k g}]}\end{array}$ & $\begin{array}{c}\text { Accumulated } \\
\text { Weight } \\
{[\mathbf{k g}]}\end{array}$ & $\begin{array}{c}\text { Lumped } \\
\text { mass } \\
{[\mathbf{k g}]}\end{array}$ \\
\hline P2/2 & 2 & 4.65 & 9.30 & 9.30 & \\
P3 & 2 & 9.20 & 18.40 & 27.70 & \\
P4 & 2 & 32.50 & 65.00 & 92.70 & \\
P5 & 2 & 120.00 & 240.00 & 332.70 & \\
H11 & 8 & 4.30 & 34.40 & 367.10 & 6446 \\
H12 & 1 & 15.90 & 15.90 & 383.00 & (Level 2) \\
H13 & 1 & 37.60 & 37.60 & 420.60 & \\
H21 & 16 & 4.30 & 68.80 & 489.40 & \\
H22 & 2 & 27.30 & 54.60 & 544.00 & \\
H23 & 2 & 15.90 & 31.80 & 575.80 & \\
Top Mass & 1 & 5870.00 & 5870.00 & 6445.80 & \\
\hline Specimen & 1 & 3135.00 & 3135.00 & 9580.80 & \\
P1 & 2 & 8.50 & 17.00 & 9597.80 & \\
P2/2 & 2 & 4.65 & 9.30 & 9607.10 & 5784 \\
Plate support & 8 & 16.10 & 128.80 & 9735.90 & $($ Level 1) \\
steel plates & 4 & 815.00 & 3260.00 & 12995.90 & \\
1/2 Columns & -1 & 1.00 & -765.97 & 12229.93 & \\
+Footing & & & & & \\
\hline \hline
\end{tabular}


Top Mass: $5870 \mathrm{~kg}$

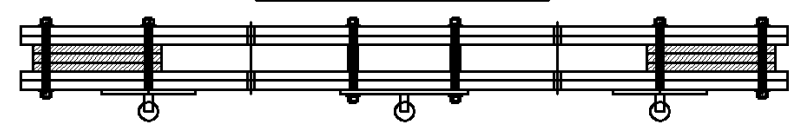

$\underline{\text { HINGE } 1}$

HINGES 2-3
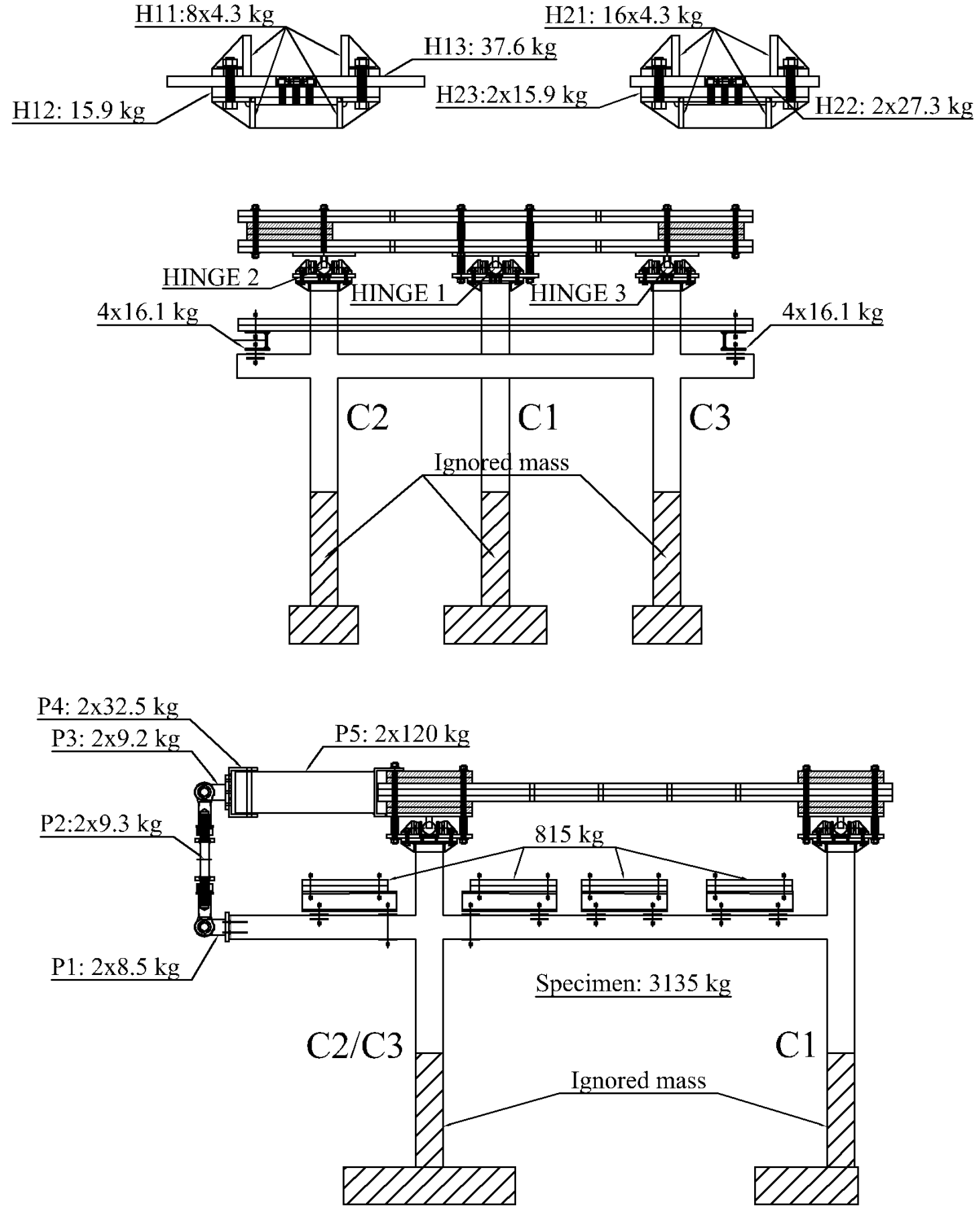

Figure 3. 2. Masses of the specimen 
Table 3. 2. Deduction of masses

\begin{tabular}{ccccccc}
\hline Piece & $\begin{array}{c}\text { Amount } \\
{[\text { Units }]}\end{array}$ & $\begin{array}{c}\text { Height } \\
{[\mathbf{m}]}\end{array}$ & $\begin{array}{c}\text { Section } \\
{\left[\mathbf{m}^{2}\right]}\end{array}$ & $\begin{array}{c}\text { Specific } \\
\text { weight } \\
{\left[\mathbf{k g} / \mathbf{m}^{3}\right]}\end{array}$ & $\begin{array}{c}\text { Weight } \\
{[\mathbf{k g}]}\end{array}$ & $\begin{array}{c}\text { Accumulated } \\
\text { weight } \\
{[\mathbf{k g}]}\end{array}$ \\
\hline 1/2 Column & 3 & 0.67 & 0.03 & 2500.00 & 127.97 & -127.97 \\
Footing 1 & 1 & 0.22 & 0.36 & 2500.00 & 198.00 & -325.97 \\
Footing 2-3 & 2 & 0.22 & 0.40 & 2500.00 & 440.00 & -765.97 \\
\hline \hline
\end{tabular}

Table 3. 3. Lumped rotational inertia 1

\begin{tabular}{cccccccc}
\hline Piece & $\begin{array}{c}\text { Mass } \\
{[\mathbf{k g}]}\end{array}$ & $\begin{array}{c}\text { Length } \\
{[\mathbf{m}]}\end{array}$ & $\begin{array}{c}\text { Width } \\
{[\mathbf{m}]}\end{array}$ & $\begin{array}{c}\text { Rot. Inertia } \\
{\left[\mathbf{k g m}^{2}\right]}\end{array}$ & $\begin{array}{c}\text { Distance } \\
{[\mathbf{m}]}\end{array}$ & $\begin{array}{c}\text { Unitary } \\
\text { Rot. Inertia } \\
{\left[\mathbf{k g m}^{2}\right]}\end{array}$ & $\begin{array}{c}\text { Rot. } \\
\text { Inertia } \\
{\left[\mathbf{k g m}^{2}\right]}\end{array}$ \\
\hline Plate 1 & 847.2 & 3.00 & 0.50 & 653.1 & 0.53 & 1789.7 & \\
Plate 2 & 847.2 & 3.00 & 0.50 & 653.1 & 1.26 & 808.2 & \\
Plate 3 & 847.2 & 3.00 & 0.50 & 653.1 & 1.91 & 693.4 & 9650 \\
Plate 4 & 847.2 & 3.00 & 0.50 & 653.1 & 2.89 & 1876.5 & \\
Slab & 2395.3 & 3.02 & 3.65 & 4475.0 & 1.74 & 4481.0 & \\
\hline \hline
\end{tabular}

Table 3. 4. Lumped rotational inertia 2

\begin{tabular}{ccccccc}
\hline Piece & $\begin{array}{c}\text { Mass 1 } \\
{[\mathbf{k g}]}\end{array}$ & $\begin{array}{c}\text { Mass 2 } \\
{[\mathbf{k g}]}\end{array}$ & $\begin{array}{c}\mathbf{a}_{\mathbf{1}} \\
{[\mathbf{m}]}\end{array}$ & $\begin{array}{c}\mathbf{a}_{2} \\
{[\mathbf{m}]}\end{array}$ & $\begin{array}{c}\text { Distance } \\
{[\mathbf{m}]}\end{array}$ & $\begin{array}{c}\text { Lumped Rot. Inertia } \\
{\left[\mathbf{k g m}^{2}\right]}\end{array}$ \\
\hline Top mass & 11294 & 4848 & 2.9 & 1.9 & 1.2 & 13003 \\
\hline \hline
\end{tabular}

The coordinates of the centers of mass for each floor measured from the origin (Figure 2.5) are listed in Table 3.5 .

Table 3. 5. Coordinates of center of masses

\begin{tabular}{ccccc}
\hline & $\begin{array}{c}\text { Mass } \\
{[\mathbf{k g}]}\end{array}$ & $\begin{array}{c}\mathbf{X} \\
{[\mathbf{m m}]}\end{array}$ & $\begin{array}{c}\mathbf{Y} \\
{[\mathbf{m m}]}\end{array}$ & $\begin{array}{c}\mathbf{Z} \\
{[\mathbf{m m}]}\end{array}$ \\
\hline Center of mass 1 & 5780 & -1690 & 0 & 150 \\
Center of mass 2 & 6450 & -1320 & 0 & 780 \\
\hline \hline
\end{tabular}

Through the information of masses defined previously, the mass matrix gives:

$$
\mathbf{M}=\left[\begin{array}{cccccc}
5784 & 0 & 0 & 0 & 0 & 0 \\
0 & 5784 & 0 & 0 & 0 & 0 \\
0 & 0 & 9650 & 0 & 0 & 0 \\
0 & 0 & 0 & 6446 & 0 & 0 \\
0 & 0 & 0 & 0 & 6446 & 0 \\
0 & 0 & 0 & 0 & 0 & 13003
\end{array}\right]\left[{\left.\mathrm{kg}, \mathrm{kgm}^{2}\right]}^{2}\right.
$$




\section{STIFFNESS}

The initial stiffness of the specimen in the elastic range is represented by the stiffness matrix $\boldsymbol{K}$ (3.4). This matrix is made of the stiffness coefficients $\boldsymbol{k}_{\boldsymbol{i} \boldsymbol{j}}$, which represent the forces developed in a structure when a unit displacement corresponding to one DOF or coordinate is introduced and no other nodal displacements are permitted. Numerically, they would be equal to the applied forces required to maintain a specified displacement condition (Clough \& Penzien, 1992).

$$
\mathbf{K}=\left[\begin{array}{llllll}
k_{11} & k_{12} & k_{13} & k_{14} & k_{15} & k_{16} \\
k_{21} & k_{22} & k_{23} & k_{24} & k_{25} & k_{26} \\
k_{31} & k_{32} & k_{33} & k_{34} & k_{35} & k_{36} \\
k_{41} & k_{42} & k_{43} & k_{44} & k_{45} & k_{46} \\
k_{51} & k_{52} & k_{53} & k_{54} & k_{55} & k_{56} \\
k_{61} & k_{62} & k_{63} & k_{64} & k_{65} & k_{66}
\end{array}\right]
$$

\subsection{Coefficients of the stiffness matrix}

Figures 3.4 to 3.9 show the procedure to obtain those coefficients $\boldsymbol{k}_{\boldsymbol{i} j}$ of the stiffness matrix, defined from (3.5) to (3.10), applying a unit displacement corresponding to each coordinate and evaluating the forces acting in each coordinate required for equilibrium. Columns stiffness in direction $\mathrm{X}$ and $\mathrm{Y}, k_{x, a b}$ and $k_{y, a b}$, were taken into account, but the rotational stiffness of the columns around their axes were neglected. Each column is identified by two subindices , $a$ and $b$. The slab and the steel plates attached to the slab (first level) are assumed to behave as a rigid diaphragm. The same assumption is made for the steel plates on the top of the columns of the second story (second level), (Figure 3.3).

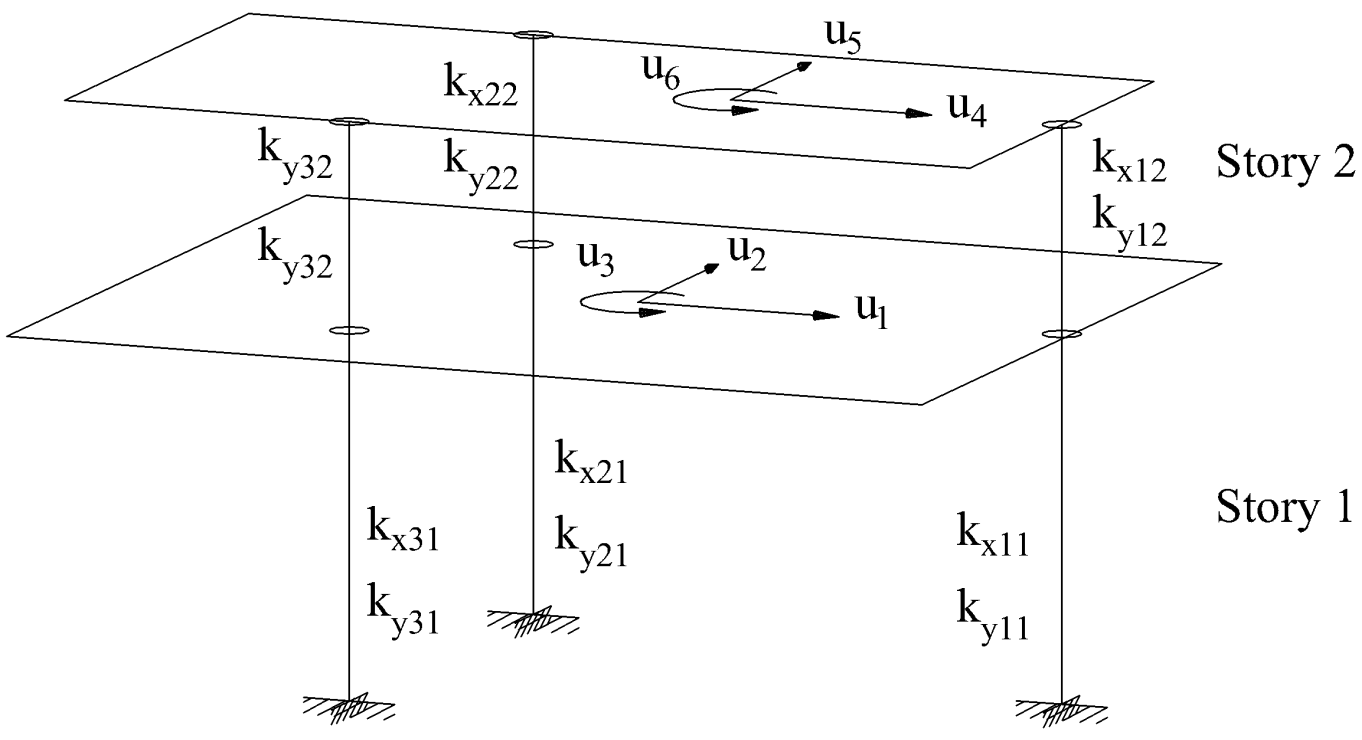

Figure 3. 3. Columns stiffness and global DOFs 
Story 1

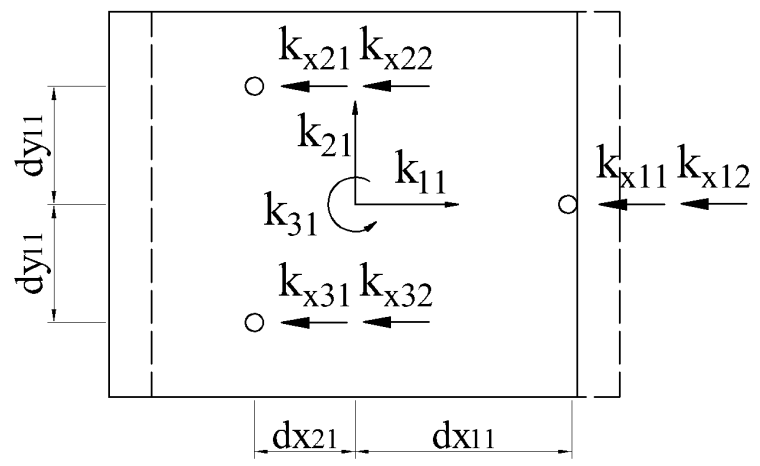

Story 2

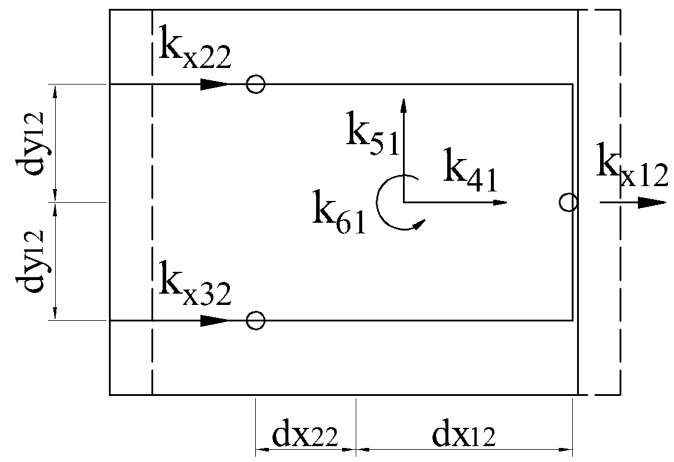

Deformed shape $\varphi_{1}$ where $\mathrm{u}_{1}=1, \mathrm{u}_{2}=0, \mathrm{u}_{3}=0, \mathrm{u}_{4}=0, \mathrm{u}_{5}=0, \mathrm{u}_{6}=0$

Figure 3. 4. Deformed shape $\varphi_{1}$

$$
\begin{aligned}
& \mathrm{k}_{11}=\mathrm{k}_{x 11}+\mathrm{k}_{x 12}+\mathrm{k}_{x 21}+\mathrm{k}_{x 22}+\mathrm{k}_{x 31}+\mathrm{k}_{x 32} \\
& \mathrm{k}_{21}=0 \\
& \mathrm{k}_{31}=\left(\mathrm{k}_{x 31}+\mathrm{k}_{x 32}-\mathrm{k}_{x 21}-\mathrm{k}_{x 22}\right) \mathrm{d}_{y 11} \\
& \mathrm{k}_{41}=-\left(\mathrm{k}_{x 12}+\mathrm{k}_{x 22}+\mathrm{k}_{x 32}\right) \\
& \mathrm{k}_{51}=0 \\
& \mathrm{k}_{61}=\left(\mathrm{k}_{x 22}-\mathrm{k}_{x 32}\right) \mathrm{d}_{y 12}
\end{aligned}
$$

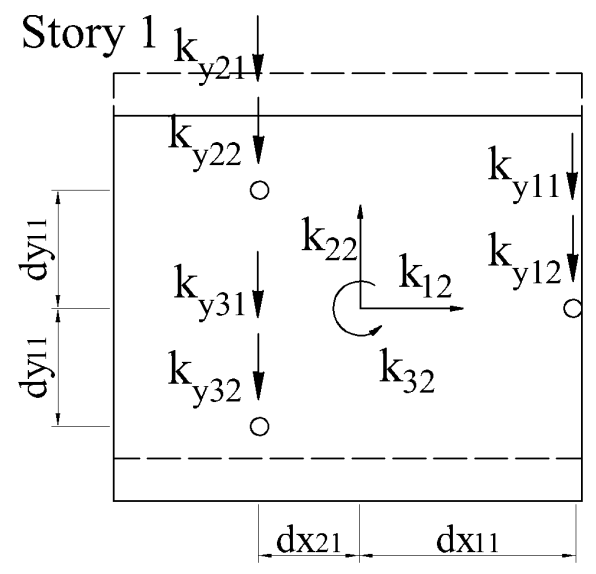

Story 2

Deformed shape $\varphi_{2}$ where $\mathrm{u}_{1}=0, \mathrm{u}_{2}=1, \mathrm{u}_{3}=0, \mathrm{u}_{4}=0, \mathrm{u}_{5}=0, \mathrm{u}_{6}=0$

Figure 3. 5. Deformed shape $\varphi_{2}$

$$
\begin{aligned}
& \mathrm{k}_{12}=0 \\
& \mathrm{k}_{22}=\mathrm{k}_{y 11}+\mathrm{k}_{y 12}+\mathrm{k}_{y 21}+\mathrm{k}_{y 22}+\mathrm{k}_{y 31}+\mathrm{k}_{y 32} \\
& \mathrm{k}_{32}=\left(\mathrm{k}_{y 11}+\mathrm{k}_{y 12}\right) \mathrm{d}_{x 11}-\left(\mathrm{k}_{y 31}+\mathrm{k}_{y 32}+\mathrm{k}_{y 21}+\mathrm{k}_{y 22}\right) \mathrm{d}_{x 21} \\
& \mathrm{k}_{42}=0 \\
& \mathrm{k}_{52}=-\left(\mathrm{k}_{y 12}+\mathrm{k}_{y 22}+\mathrm{k}_{y 32}\right) \\
& \mathrm{k}_{62}=\left(\mathrm{k}_{y 32}+\mathrm{k}_{y 22}\right) \mathrm{d}_{x 22}-\mathrm{k}_{y 12} \mathrm{~d}_{x 12}
\end{aligned}
$$



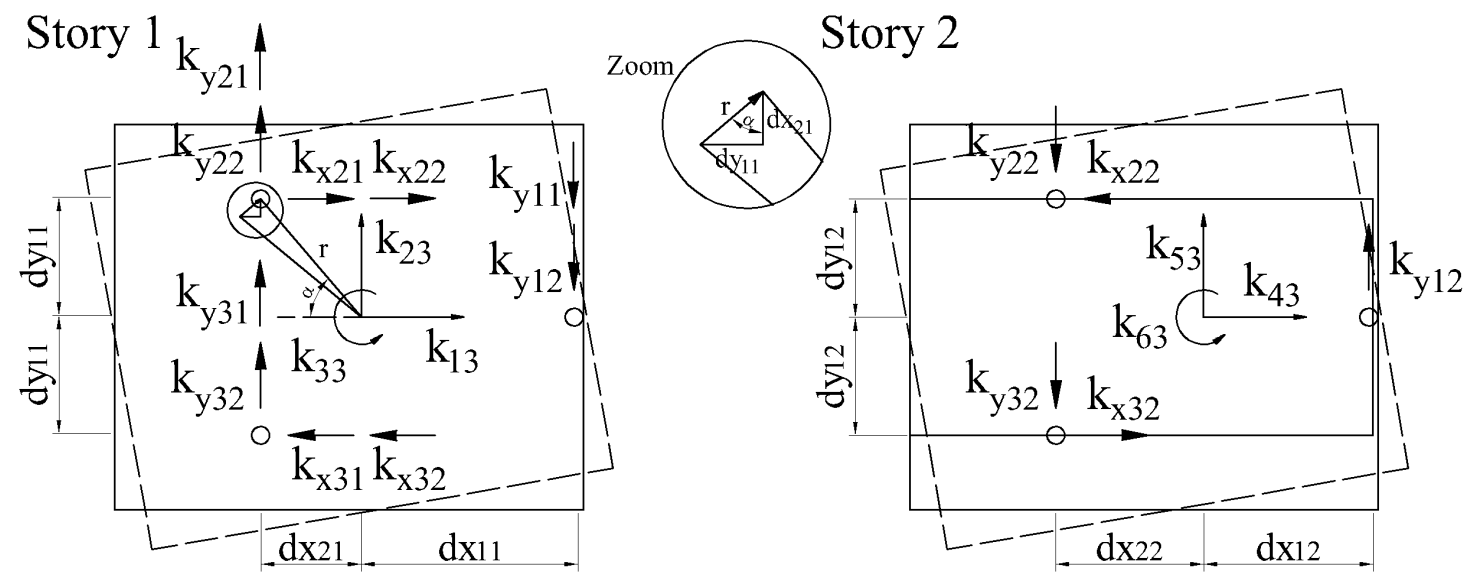

Deformed shape $\varphi_{3}$ where $\mathrm{u}_{1}=0, \mathrm{u}_{2}=0, \mathrm{u}_{3}=1, \mathrm{u}_{4}=0, \mathrm{u}_{5}=0, \mathrm{u}_{6}=0$

Figure 3. 6. Deformed shape $\varphi_{3}$

$$
\begin{aligned}
& \mathrm{k}_{13}=\left(\mathrm{k}_{x 31}+\mathrm{k}_{x 32}-\mathrm{k}_{x 21}-\mathrm{k}_{x 22}\right) \mathrm{d}_{y 11} \\
& \mathrm{k}_{23}=\left(\mathrm{k}_{y 11}+\mathrm{k}_{y 12}\right) \mathrm{d}_{x 11}-\left(\mathrm{k}_{y 21}+\mathrm{k}_{y 22}+\mathrm{k}_{y 31}+\mathrm{k}_{y 32}\right) \mathrm{d}_{x 21} \\
& \mathrm{k}_{33}=\left(\mathrm{k}_{y 11}+\mathrm{k}_{y 12}\right) \mathrm{d}_{x 11}{ }^{2}+\left(\mathrm{k}_{y 21}+\mathrm{k}_{y 22}+\mathrm{k}_{y 31}+\mathrm{k}_{y 32}\right) \mathrm{d}_{x 21}{ }^{2}+ \\
& \left(\mathrm{k}_{x 21}+\mathrm{k}_{x 22}+\mathrm{k}_{x 31}+\mathrm{k}_{x 32}\right) \mathrm{d}_{y 11} \\
& \mathrm{k}_{43}=\left(\mathrm{k}_{x 22}-\mathrm{k}_{x 32}\right) \mathrm{d}_{y 12} \\
& \mathrm{k}_{53}=-\mathrm{k}_{y 12} \mathrm{~d}_{x 11}+\left(\mathrm{k}_{y 22}+\mathrm{k}_{y 32}\right) \mathrm{d}_{x 21} \\
& \mathrm{k}_{63}=-\left(\mathrm{k}_{y 12} \mathrm{~d}_{x 11} \mathrm{~d}_{x 12}+\left(\mathrm{k}_{x 22}+\mathrm{k}_{x 32}\right) \mathrm{d}_{y 11} \mathrm{~d}_{y 12}+\left(\mathrm{k}_{y 22}+\mathrm{k}_{y 32}\right) \mathrm{d}_{x 21} \mathrm{~d}_{x 22}\right)
\end{aligned}
$$

\section{Story 1}

Story 2
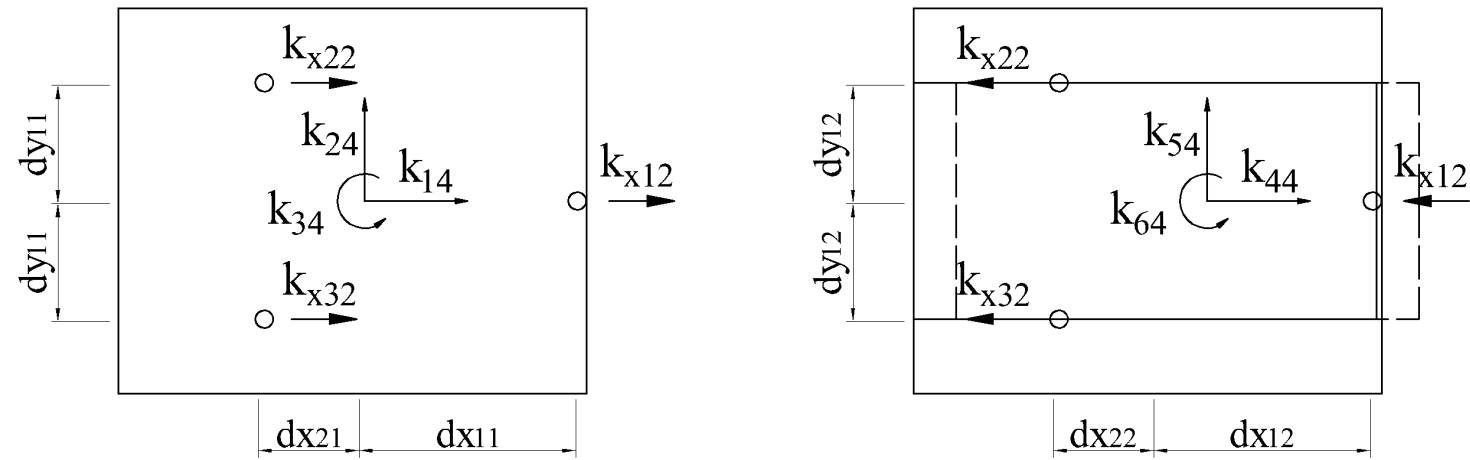

Deformed shape $\varphi_{4}$ where $\mathrm{u}_{1}=0, \mathrm{u}_{2}=0, \mathrm{u}_{3}=0, \mathrm{u}_{4}=1, \mathrm{u}_{5}=0, \mathrm{u}_{6}=0$

Figure 3. 7. Deformed shape $\varphi_{4}$

$$
\begin{aligned}
& \mathrm{k}_{14}=-\left(\mathrm{k}_{x 12}+\mathrm{k}_{x 22}+\mathrm{k}_{x 32}\right) \\
& \mathrm{k}_{24}=0 \\
& \mathrm{k}_{34}=\left(\mathrm{k}_{x 22}-\mathrm{k}_{x 32}\right) \mathrm{d}_{y 12} \\
& \mathrm{k}_{44}=\mathrm{k}_{x 12}+\mathrm{k}_{x 22}+\mathrm{k}_{x 32} \\
& \mathrm{k}_{54}=0 \\
& \mathrm{k}_{64}=\left(\mathrm{k}_{x 32}-\mathrm{k}_{x 22}\right) \mathrm{d}_{y 12}
\end{aligned}
$$




\section{Story 1}

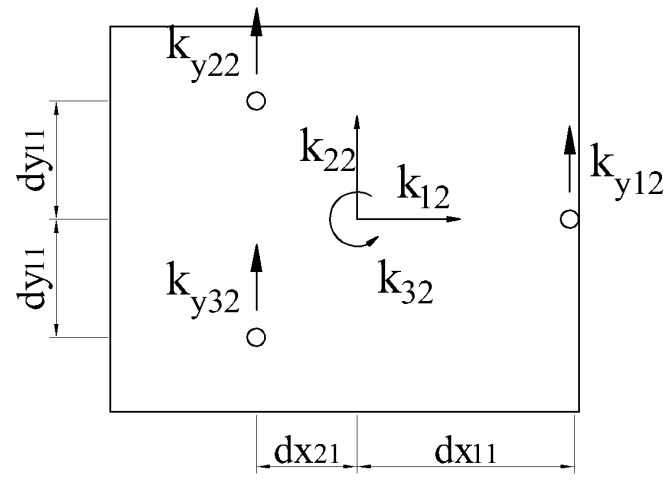

Story 2

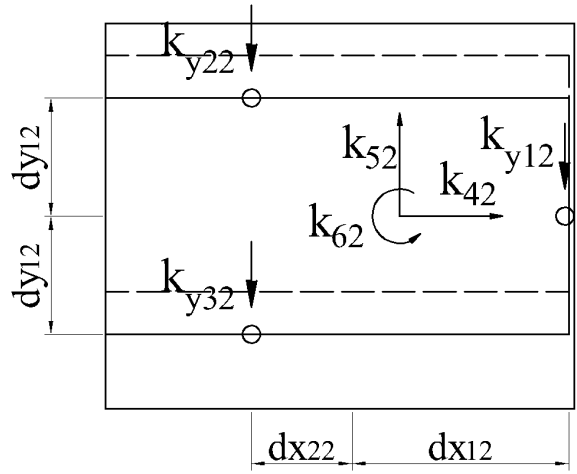

Deformed shape $\varphi_{5}$ where $\mathrm{u}_{1}=0, \mathrm{u}_{2}=0, \mathrm{u}_{3}=0, \mathrm{u}_{4}=0, \mathrm{u}_{5}=1, \mathrm{u}_{6}=0$

Figure 3. 8. Deformed shape $\varphi_{5}$

$$
\begin{aligned}
& \mathrm{k}_{15}=0 \\
& \mathrm{k}_{25}=-\left(\mathrm{k}_{y 12}+\mathrm{k}_{y 22}+\mathrm{k}_{y 32}\right) \\
& \mathrm{k}_{35}=\left(\mathrm{k}_{y 22}+\mathrm{k}_{y 32}\right) \mathrm{d}_{x 21}-\mathrm{k}_{y 12} \mathrm{~d}_{x 11} \\
& \mathrm{k}_{45}=0 \\
& \mathrm{k}_{55}=\mathrm{k}_{y 12}+\mathrm{k}_{y 22}+\mathrm{k}_{y 32} \\
& \mathrm{k}_{65}=\mathrm{k}_{y 12} \mathrm{~d}_{x 12}-\left(\mathrm{k}_{y 22}+\mathrm{k}_{y 32}\right) \mathrm{d}_{x 22}
\end{aligned}
$$

Story 1

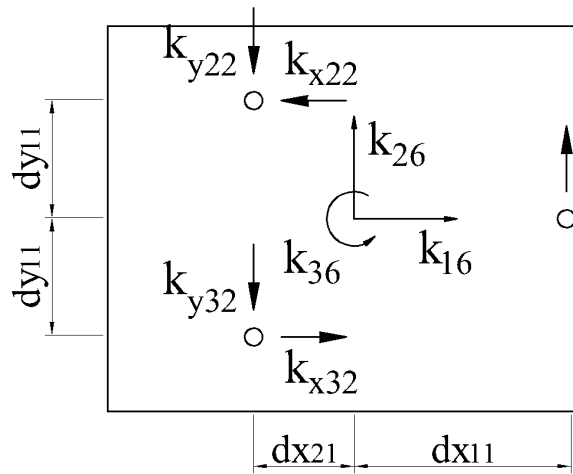

Story 2

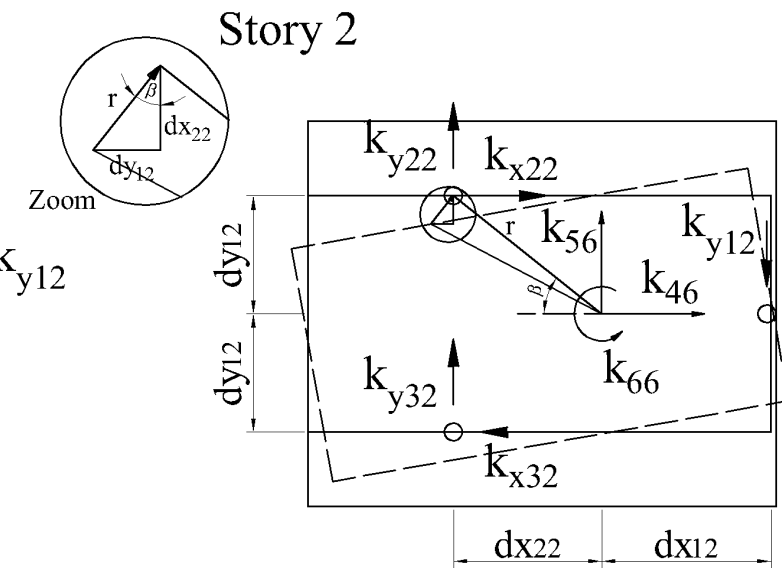

Deformed shape $\varphi_{6}$ where $\mathrm{u}_{1}=0, \mathrm{u}_{2}=0, \mathrm{u}_{3}=0, \mathrm{u}_{4}=0, \mathrm{u}_{5}=0, \mathrm{u}_{6}=1$

Figure 3. 9. Deformed shape $\varphi_{6}$

$$
\begin{aligned}
& \mathrm{k}_{16}=\left(\mathrm{k}_{x 22}-\mathrm{k}_{x 32}\right) \mathrm{d}_{y 12} \\
& \mathrm{k}_{26}=-\mathrm{k}_{y 12} \mathrm{~d}_{x 12}+\left(\mathrm{k}_{y 22}+\mathrm{k}_{y 32}\right) \mathrm{d}_{x 22} \\
& \mathrm{k}_{36}=-\left(\mathrm{k}_{y 12} \mathrm{~d}_{x 11} \mathrm{~d}_{x 12}+\left(\mathrm{k}_{y 22}+\mathrm{k}_{y 32}\right) \mathrm{d}_{x 21} \mathrm{~d}_{x 22}+\left(\mathrm{k}_{x 22}+\mathrm{k}_{x 32}\right) \mathrm{d}_{y 11} \mathrm{~d}_{y 12}\right) \\
& \mathrm{k}_{46}=-\left(\mathrm{k}_{x 22}-\mathrm{k}_{x 32}\right) \mathrm{d}_{y 12} \\
& \mathrm{k}_{56}=\mathrm{k}_{y 12} \mathrm{~d}_{x 12}-\left(\mathrm{k}_{y 22}+\mathrm{k}_{y 32}\right) \mathrm{d}_{x 22} \\
& \mathrm{k}_{66}=\mathrm{k}_{y 12} \mathrm{~d}_{x 12}{ }^{2}+\left(\mathrm{k}_{x 22}+\mathrm{k}_{x 32}\right) \mathrm{d}_{y 12}{ }^{2}+\left(\mathrm{k}_{y 22}+\mathrm{k}_{y 32}\right) \mathrm{d}_{x 22}{ }^{2}
\end{aligned}
$$




\subsection{Estimation of lateral stiffness of columns}

The lateral stiffness of each column of the story $j$, assuming that they are perfectly clamped at both ends, and accounting only for bending deformations, is given by $K_{j}=12 E I / L_{j}{ }^{3}$. The parameter $E I$ is assumed constant because columns have the same gross section and material. In the test specimen columns are not perfectly clamped at both ends; to include the influence of the out-of-plane deformation of the slab, a new factor $\alpha_{d i j}$ must be added to the formula such as $K_{d i j}=\alpha_{d i j} 12 E I / L_{j}{ }^{3}$, where $d$ is the direction (X or Y), $i$ identifies the column and $j$ is the story. This factor ranges from 0 to 1 . It can be obtained isolating every story and then computing the lateral stiffness of the substructure. Depending on the position of the story (first or second story), there are two alternatives (Figure 3.10).

a)

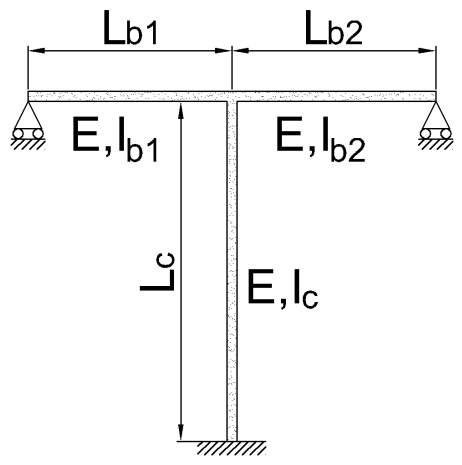

b)

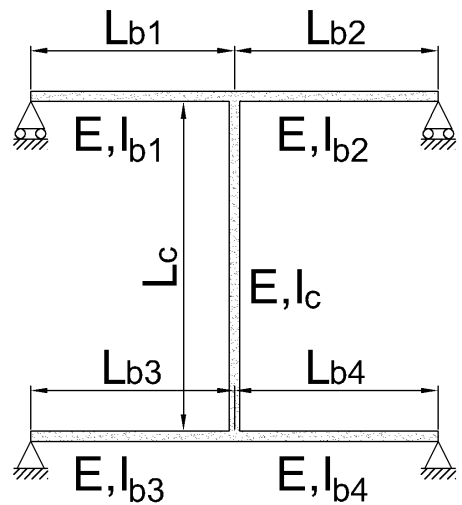

Figure 3. 10. Substructures for stories: a) first floor and b) intermediate floor

To obtain the lateral stiffness of each substructure, firstly, the stiffness matrix is obtained applying the Indirect Stiffness Method (Rubinstein, 1966) and, next a static condensation is made to 1 DOF (the lateral displacement).

The Indirect Stiffness Method allows to easily obtain the stiffness matrix of the substructure using a minimum number of local coordinates for the elements $\delta_{i}$ (indicated in Figure 3.11). For the sake of simplicity, beams and columns were considered infinitely stiff in the axial direction. The global coordinates $u_{i}$ (DOFs) of the substructures shown in Figure 3.10a) and 3.10b) are shown in Figures 3.12 and 3.13. The stiffness matrix is obtained with Eq. (3.11), where $N$ is the number of elements (beams or columns), $\beta_{i}$ is the connectivity matrix of the element $i$ and $k_{i}$ the stiffness matrix of the element in the local coordinate system. In both substructures of Figure 3.10, there are beams $(b i)$ and one column $(c)$ which stiffness matrices in the local coordinates $\delta_{i}$, are given by (3.12) and (3.13) respectively.

Beams

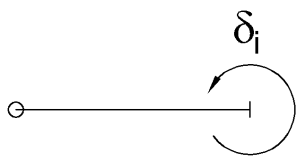

Column

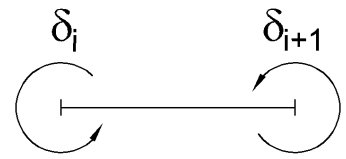

o- Hinged end

$\vdash$ Fixed end

Figure 3. 11. Element displacements 


$$
\begin{gathered}
K=\sum_{i=1}^{N} \beta_{i}^{T} k_{i} \beta_{i} \\
\mathbf{k}_{\boldsymbol{c}}=\frac{3 E I_{c}}{L_{c}}\left[\begin{array}{ll}
4 & 2 \\
2 & 4
\end{array}\right] \\
\mathrm{k}_{b i}=\frac{3 E I_{b i}}{L_{b i}}
\end{gathered}
$$

Figures 3.12 and 3.13 show the deformed shape due to a unit displacement following one global DOF $u_{i}$ when the rest of them remain immobilized. The connectivity matrix $(\beta)$ relates element displacements $\left(\delta_{i}\right)$ with system displacements $\left(u_{i}\right)$ of each substructure and they are shown in (3.14) and (3.16), respectively. The assembled stiffness matrices are shown in (3.15) and (3.17).

a)

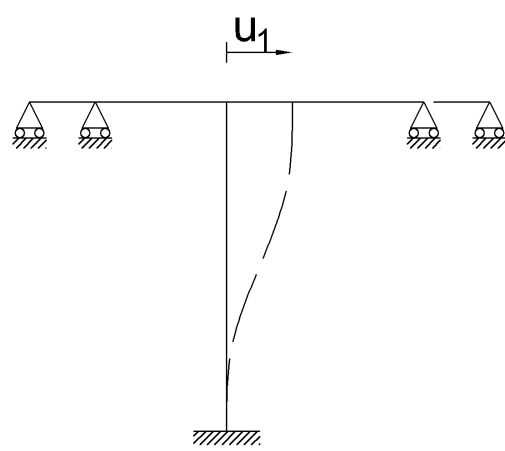

$$
\mathrm{u}_{1}=1, \mathrm{u}_{2}=0
$$

b)

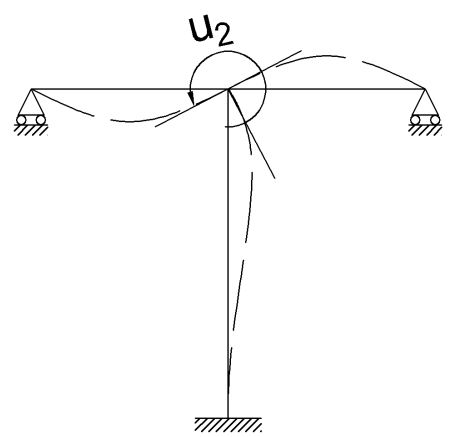

$\mathrm{u}_{1}=0, \mathrm{u}_{2}=1$

Figure 3. 12. System displacements and deformed shapes for the first floor substructure (Substructure A)

$$
\begin{gathered}
\boldsymbol{\beta}=\left[\begin{array}{rr}
0 & 1 \\
0 & 1 \\
1 / L_{c} & 1 \\
1 / L_{c} & 0
\end{array}\right] \\
\mathbf{K}=\left[\begin{array}{cc}
\frac{12 E I_{c}}{L_{c}^{3}} & \frac{6 E I_{c}}{L_{c}^{2}} \\
\frac{6 E I_{c}}{L_{c}{ }^{2}} & \frac{4 E I_{c}}{L_{c}}+\frac{3 E I_{b 1}}{L_{b 1}}+\frac{3 E I_{b 2}}{L_{b 2}}
\end{array}\right]
\end{gathered}
$$


a)

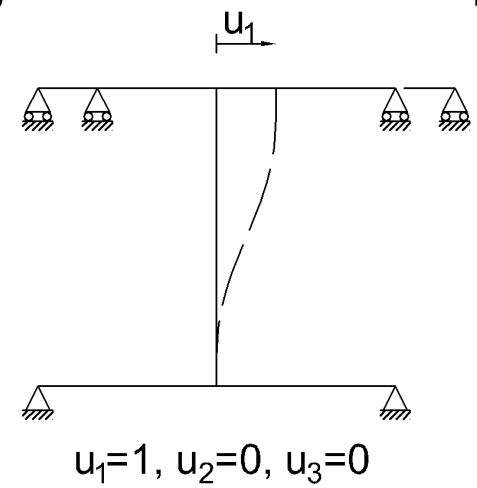

b)

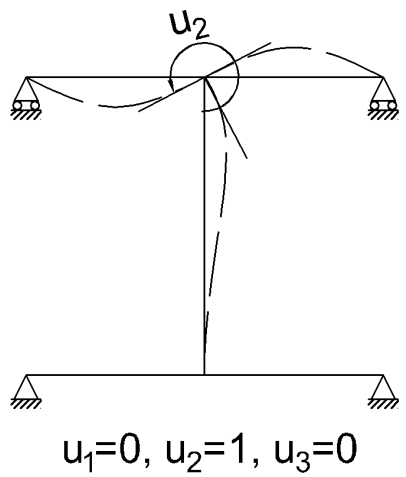

c)

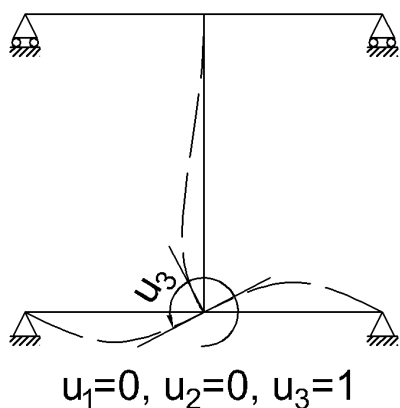

Figure 3. 13. System displacements and deformed shapes for the intermediate floor substructure (Substructure B)

$$
\begin{gathered}
\boldsymbol{\beta}=\left[\begin{array}{ccc}
0 & 1 & 0 \\
0 & 1 & 0 \\
1 / L_{c} & 1 & 0 \\
1 / L_{c} & 0 & 1 \\
0 & 0 & 1 \\
0 & 0 & 1
\end{array}\right] \\
\mathbf{K}=\left[\begin{array}{ccc}
\frac{12 E I_{c}}{L_{c}{ }^{2}} & \frac{6 E I_{c}}{L_{c}{ }^{2}} & \frac{6 E I_{c}}{L_{c}{ }^{2}} \\
\frac{6 E I_{c}}{L_{c}{ }^{2}} & \frac{4 E I_{c}}{L_{c}}+\frac{3 E I_{b 1}}{L_{b 1}}+\frac{3 E I b_{2}}{L_{b 2}} & \frac{2 E I_{c}}{L_{c}} \\
\frac{6 E I_{c}}{L_{c}{ }^{2}} & \frac{2 E I_{c}}{L_{c}} & \frac{4 E I_{c}}{L_{c}}+\frac{3 E I_{b 3}}{L_{b 3}}+\frac{3 E I_{b 4}}{L_{b 4}}
\end{array}\right]
\end{gathered}
$$

Next, a static condensation is made to reduce the number of DOFs to only one: the lateral displacement $\left(u_{1}\right)$. This is achieved by treating the rotations $\left(u_{2}\right.$ and/or $\left.u_{3}\right)$ as dependent variables and expressing them in terms of the lateral displacement $u_{1}$. The relationship between the dependent and independent displacements is then substituted into the original stiffness relations to obtain a condensed system of stiffness equations, which contains only the independent displacement $u_{1}$ as unknown (Kassimali, 2012). The parameters $\alpha_{d i j}$ for both substructures turn out to be the condensed stiffness matrices divided by the bending column stiffness $\left(k_{c}=12 E I / L_{c}{ }^{3}\right)$, whose equations for substructures shown in Figures 3.10a) and 3.10b) are given by (3.18) and (3.19), respectively. These equations contain the parameter $\bar{k}$ which is defined in (3.20).

$$
\begin{gathered}
\alpha_{d i 1}=\frac{1+3 \bar{k}}{4+3 \bar{k}} \\
\alpha_{d i 2}=\frac{\bar{k}}{\bar{k}+4} \\
\bar{k}=\frac{L_{c}}{E I_{c}}\left(\sum_{i=1}^{N_{b}} \frac{E I_{i}}{L_{i}}\right)
\end{gathered}
$$


Where $L_{c}$ is the column length, $L_{i}$ is the length of each beam, $E=30 G P a$ is the Young modulus of concrete, which cancels because it is the same for beams and the column. Finally, $I_{c}$ is column inertia, $I_{i}$ is the inertia of each beam and $N_{b}$ is the number of beams in the substructure.

\subsection{Stiffness matrix}

The stiffness matrix of the test specimen is computed applying the procedure explained in previous section and the following considerations. The length $L_{c}$ was taken as the length of the column plus the tensile strain penetration zone, assumed equal to $L_{t s p 1}=0.022 d_{b} f_{y l}$ (Paulay \& Priestley, 1992) for columns connected to footings $\left(L_{t s p 1}=92 \mathrm{~mm}\right)$, plus one half of the thickness of the slab $\left(L_{t s p 2}=70 \mathrm{~mm}\right)$. With these assumptions for the column of the first story $L_{c 1}=1330+92+70=1492 \mathrm{~mm}$ and for those of the second story $L_{c 2}=2(420+70)=$ $980 \mathrm{~mm}$. The number two multiplies the latter in order to take into account a virtual column with both ends fixed. The moment of inertia of columns comes from its gross sections $(160 \times 160 \mathrm{~mm})$. In the case of the waffle-flat-plate, an equivalent uniform thickness $\left(h_{e}\right)$ was obtained by (3.21). This thickness corresponds to a plate that has the same bending stiffness than the waffle flat plate (Abdul-Wahab \& Khalil, 2000).

$$
h_{e}=\left(\frac{12 I_{\text {rib }}}{S_{\text {ribs }}}\right)^{\frac{1}{3}}=82 \mathrm{~mm}
$$

Where $S_{\text {ribs }}=332 \mathrm{~mm}$ is the center to center distance between ribs and $I_{\text {rib }}=1.52 \times 10^{7} \mathrm{~mm}^{4}$ is the moment of inertia of a T-shape section composed of one rib and the top rectangular concrete section of width $S_{\text {ribs }}$. The moment of inertia of equivalent beams in the slab level $\left(I_{i}\right)$ come from a section of $82 \mathrm{~mm}$ (he) $x 1024 \mathrm{~mm}$ (the drop panel length). All these assumptions prompt to the stiffness matrix of the specimen in the elastic-no-cracked range given by (3.22).

$$
\mathbf{K}=\left[\begin{array}{cccccc}
34.5 & 0 & 0 & -22.6 & 0 & 0 \\
0 & 30.4 & -7.8 \times 10^{3} & 0 & -19.3 & 8.4 \times 10^{3} \\
0 & -7.8 \times 10^{3} & 9.1 \times 10^{7} & 0 & 4.6 \times 10^{3} & -4.3 \times 10^{7} \\
-22.6 & 0 & 0 & 19.3 & 0 & 0 \\
0 & -19.3 & 4.6 \times 10^{3} & 0 & 19.3 & -8.4 \times 10^{3} \\
0 & 8.4 \times 10^{3} & -4.3 \times 10^{7} & 0 & -8.4 \times 10^{3} & 3.5 \times 10^{7}
\end{array}\right]
$$

Owing to the distribution of zero coefficients in the stiffness matrix, it is evident that the movement in direction $\mathrm{X}$ is uncoupled with the movement in direction $\mathrm{Y}$ and twist in elastic range. This is because the structure has symmetry along the $\mathrm{X}$ axis. Therefore, within the elastic range, it is possible to study the specimen movement separately, using the submatrices $\mathbf{K}_{\boldsymbol{x}}$ given by (3.23) and $\mathbf{K}_{\boldsymbol{y} \boldsymbol{\vartheta}}$ given by (3.24) taken them out from $\mathbf{K}$ (3.22) as follows:

$$
\begin{gathered}
\mathbf{K}_{x}=\left[\begin{array}{ll}
k_{11} & k_{14} \\
k_{41} & k_{44}
\end{array}\right] \\
\mathbf{K}_{y \vartheta}=\left[\begin{array}{llll}
k_{22} & k_{23} & k_{25} & k_{26} \\
k_{32} & k_{33} & k_{35} & k_{36} \\
k_{52} & k_{53} & k_{55} & k_{56} \\
k_{62} & k_{63} & k_{65} & k_{66}
\end{array}\right]
\end{gathered}
$$


Furthermore, in a structure with double symmetry, the center of torsion and the center of mass are at the same point, whose position is defined by the crossing of symmetry axes. However, in case of asymmetric structures (this case), the center of torsion and the center of mass are not in the same point and its eccentricity generates twisting in the structure. Table 3.6 shows the coordinates of the center of torsion in plan from the origin of coordinates showed in Figure 2.5.

\begin{tabular}{|c|c|c|}
\hline & $\begin{array}{c}\mathrm{X} \\
{[\mathrm{mm}]}\end{array}$ & $\begin{array}{c}\mathrm{Y} \\
{[\mathrm{mm}]}\end{array}$ \\
\hline Center of torsion 1 & -1613 & 0 \\
\hline Center of torsion 2 & -1630 & 0 \\
\hline
\end{tabular}

\subsection{Lateral stiffness of the capacity curve}

The initial elastic lateral stiffness of the capacity curve of the specimen is obtained in this section using the stiffness matrix developed previously (3.22). The capacity curve refers to the relationship between the roof displacement and the base shear force developed by the structural system when a monotonic loading is applied. The Static Condensation Method is applied to the stiffness matrix considering as dependent variables all DOFs with the exception of the roof displacement. The condensed stiffness resultant for direction $\mathrm{X}$ with symmetric distribution of mass and stiffness, and direction $\mathrm{Y}$ with asymmetric distribution of mass and stiffness are shown in Table 3.7. Euro Code 8 (CEN, 2004) prescribes a reduction of the inertia of the gross section of $50 \%$ for sections to take into account concrete cracking. This reduction has been applied in the lateral stiffness shown in the third columns of Table 3.7. In the test specimen, this loss of stiffness is imputable to the concrete cracking due to the gravity loads and also the (low amplitude) movements applied to the specimens before the tests for training the shaking table.

Table 3. 7. Global Stiffness of the specimen

\begin{tabular}{ccc}
\hline Stiffness & $\begin{array}{c}\text { No-Cracked sections } \\
{[\mathbf{k N} / \mathbf{m m}]}\end{array}$ & $\begin{array}{c}\text { Cracked sections } \\
{[\mathbf{k N} / \mathbf{m m}]}\end{array}$ \\
\hline $\mathbf{K}_{\mathbf{x}}$ & 7.78 & 3.89 \\
$\mathbf{K}_{\mathbf{y}}$ & 6.30 & 3.15 \\
\hline \hline
\end{tabular}

\section{ANALYSIS OF VIBRATION FREQUENCIES}

The eigenvalue or characteristic value problem is defined as follows:

$$
\left(\mathbf{K}-\omega^{2} \mathbf{M}\right) \boldsymbol{\phi}=\mathbf{0}
$$

Where $\omega^{2}$ are the eigenvalues or characteristic values indicating the square of the free-vibration frequencies in $\mathrm{rad} / \mathrm{s}$, while the corresponding displacement vectors $\boldsymbol{\phi}$ express the corresponding shapes of the vibrating system, which are known as the eigenvectors or mode shapes (Clough \& Penzien, 1992). With the stiffness matrix $\mathbf{K}$ and the mass matrix $\mathbf{M}$ presented in sections above, the free-vibration frequencies and eigenvectors were computed through eigenvalue analysis. Table 3.8 shows the free-vibration frequencies for no-cracked and cracked sections in terms of $\mathrm{rad} / \mathrm{s}$ and $\mathrm{Hz}$, the latter applying the switch $f=w / 2 \pi$, and also the periods as $T=1 / f$. Table 3.9 shows the eigenvectors resulted from the eigenvalue analysis. 
Table 3. 8. Dynamic properties of the structure

\begin{tabular}{|c|c|c|c|c|c|c|c|c|c|}
\hline \multirow[b]{2}{*}{ Modes } & \multirow[b]{2}{*}{ Shapes } & \multicolumn{3}{|c|}{ No-Cracked Sections } & \multicolumn{3}{|c|}{ Cracked Sections } & \multirow{2}{*}{$\begin{array}{c}\text { Mass } \\
\text { Mobilized } \\
{[\mathrm{T}]} \\
\end{array}$} & \multirow[b]{2}{*}{$\begin{array}{c}\text { Particip. } \\
\text { Factor }\end{array}$} \\
\hline & & $\begin{array}{c}\mathrm{w} \\
{[\mathrm{rad} / \mathrm{s}]}\end{array}$ & $\begin{array}{c}\mathbf{f} \\
{[\mathrm{Hz}]}\end{array}$ & $\begin{array}{c}\mathbf{T} \\
{[\mathbf{s}]}\end{array}$ & $\begin{array}{c}\mathbf{w} \\
{[\mathrm{rad} / \mathrm{s}]}\end{array}$ & $\begin{array}{c}\mathbf{f} \\
{[\mathrm{Hz}]}\end{array}$ & $\begin{array}{c}\mathbf{T} \\
{[\mathrm{s}]}\end{array}$ & & \\
\hline 1 & Y-Tors & 24.24 & 3.86 & 0.26 & 17.14 & 2.73 & 0.37 & 7.05 & -0.70 \\
\hline 2 & $\mathbf{X}$ & 28.88 & 4.60 & 0.22 & 20.42 & 3.25 & 0.31 & 12.02 & 1.11 \\
\hline 3 & Y-Tors & 32.36 & 5.15 & 0.19 & 22.88 & 3.64 & 0.27 & 4.94 & -0.41 \\
\hline 4 & Y-Tors & 83.24 & 13.25 & 0.08 & 58.86 & 9.37 & 0.11 & 0.20 & -0.14 \\
\hline 5 & $\mathbf{X}$ & 92.97 & 14.79 & 0.07 & 65.74 & 10.46 & 0.10 & 0.21 & 0.16 \\
\hline 6 & Y-Tors & 108.50 & 17.27 & 0.06 & 76.72 & 12.21 & 0.08 & 0.04 & 0.02 \\
\hline
\end{tabular}

Table 3. 9. Eigenvectors

\begin{tabular}{ccccccc}
\hline DOF & Mode 1 & Mode 2 & Mode 3 & Mode 4 & Mode 5 & Mode 6 \\
\hline 1 & 0.0000 & 0.7624 & 0.0000 & 0.0000 & 1.0000 & 0.0000 \\
2 & -0.6148 & 0.0000 & -0.9922 & -1.0000 & 0.0000 & 1.0000 \\
3 & -0.0003 & 0.0000 & 0.0005 & -0.0004 & 0.0000 & -0.0022 \\
4 & 0.0000 & 1.0000 & 0.0000 & 0.0000 & -0.6832 & 0.0000 \\
5 & -1.0000 & 0.0000 & -1.0000 & 0.6741 & 0.0000 & -0.6578 \\
6 & -0.0006 & 0.0000 & 0.0011 & 0.0000 & 0.0000 & 0.0009 \\
\hline \hline
\end{tabular}

According to the results obtained, there are three dominant modes: 1, 2 and 3. These modes are able to mobilize virtually the $100 \%$ of the specimen mass. Exceptional attention should be payed to modes 1 and 3 because they have a strong torsional component and share out the mass mobilized. Further, the range of frequencies found in the main modes is $3.9-5.1 \mathrm{~Hz}$ in elastic range and $2.7-3.6 \mathrm{~Hz}$ when the sections are cracked. This shift of frequencies due to cracking locates them in the constant acceleration range, close to the constant velocity range, in the tripartite spectrum of Calitri (Figure 2.18).

\section{CAPACITY OF ELEMENTS}

To assess the inelastic response of the structure it is necessary to estimate the flexural strength capacity of the members. This section evaluates the moment capacity of the columns and drop panels that form the specimen.

\subsection{Columns}

Columns moment capacity at yielding $\left(M_{y}\right)$ were estimated according to the formula (3.26) proposed by Fardis (2009).

$$
\begin{aligned}
M_{y}=b d^{3} \varphi_{y}( & E_{c} \frac{\xi_{y}^{2}}{2}\left(\frac{1+\delta_{1}}{2}-\frac{\xi_{y}}{3}\right) \\
& \left.+\frac{E_{s}\left(1-\delta_{1}\right)}{2}\left(\left(1-\xi_{y}\right) \rho_{1}+\left(\xi_{y}-\delta_{1}\right) \rho_{2}+\frac{\rho_{\mathrm{v}}}{6}\left(1-\delta_{1}\right)\right)\right)
\end{aligned}
$$

Where $\varphi_{y}$ is the yielding curvature; $\xi_{y}$ is the neutral axis depth at yielding (normalized to the section effective depth, $d$ ); $b$ is the width of the section; $E_{c}$ is the modulus of the concrete; $\delta_{1}=$ $d_{1} / d$ where $d_{1}$ is the distance from the extreme compression fibers to the center of the compression reinforcement; and $\rho_{1}, \rho_{2}$ and $\rho_{\mathrm{v}}$ are the geometric reinforcement ratios of the tension, compression and web reinforcement, respectively. $\xi_{y}$ is defined as $\xi_{y}=$ 
$\left(\alpha^{2} A^{2} 22 \alpha B\right)^{0.5}-\alpha A$ where $\alpha=E_{S} / E_{c}, E_{S}$ is the moduli of steel, and $A$ and $B$ are variables that depend on $\rho_{1}, \rho_{2}, \rho_{\mathrm{v}}, f_{\mathrm{y}}$ and the axil force $N$ in the column. $f_{\mathrm{y}}$ is the yield strength of steel and the axil forces used were $44.8 \mathrm{kN}$ for column $\mathrm{C} 1$ and $38.2 \mathrm{kN}$ for columns $\mathrm{C} 2$ and $\mathrm{C} 3$ at first story and $30.4 \mathrm{kN}$ for column $\mathrm{C} 1$ and $16.1 \mathrm{kN}$ for columns $\mathrm{C} 2$ and $\mathrm{C} 3$ at second story.

The equation (3.26) was born to predict the moment capacity of beams under uniaxial loading. Rodrigues el al. (2013) made a deep analysis on the differences between uniaxial and biaxial loading in columns. The authors concluded that biaxial interaction induces: i) no changes in the initial column stiffness; ii) a reduction of the maximum strength of the columns; iii) a significant reduction in the ultimate ductility; iv) a pronounced strength degradation; v) a higher energy dissipation; and vi) a strong equivalent viscous damping dependence due to the biaxial load paths.

In regards to point ii) the authors found reduction factors of strength between $10 \%$ and $30 \%$ in comparison with unidirectional loading. As a consequence, a reduction factor of $20 \%$ was adopted for the bending capacity in this study. Table 3.10 shows the moment capacity under unidirectional and bidirectional loading of the column sections defined in Figure 2.2. To obtain the moment capacity under biaxial loading the moment obtained with (3.26) was multiplied by 0.8 (interaction factor).

Table 3.10. Columns moment capacity

\begin{tabular}{|c|c|c|c|c|c|c|}
\hline Section & S10 & $\mathbf{S 2 0 / S 3 0}$ & S11 & S21/S31 & S12 & S22/S32 \\
\hline $\begin{array}{c}\mathrm{M}_{\mathrm{y}}[\mathrm{kNm}] \\
\text { (Unidirectional) }\end{array}$ & 22.0 & 17.5 & 26.0 & 18.7 & 23.6 & 18.7 \\
\hline $\begin{array}{c}\mathrm{M}_{\mathbf{y}}[\mathrm{kNm}] \\
\text { (Bidirectional) }\end{array}$ & 17.6 & 14.0 & 20.8 & 15.0 & 18.9 & 15.0 \\
\hline
\end{tabular}

\subsection{Interior drop panels}

The specimen has two interior drop panels which flexural capacity needs to be evaluated. The nominal design capacity of the interior plate-column connection was evaluated following ACI 318-05 (2005) and Benavent-Climent et al. (2008). These authors conducted static cyclic tests on waffle-flat-plate subassemblages and the results supported the effective slab width $b_{\text {eff }}$ and the fraction of total unbalanced moment transferred by flexion for square columns $\gamma_{f}$, recommended by ACI 318-05 for flat slabs. ACI 318-05 recommends $b_{e f f}=c+3 h$ (where $c$ is the dimension of the column perpendicular to the direction of loading and $h$ is the thickness of the plate, Figure 3.14), and $\gamma_{f}=0.6$. In addition, Benavent-Climent et al. (2008) concluded the controversy over the reduction of the parameter $\gamma_{v}$ defined as $1-\gamma_{f}$ recommending that, in concordance with their results, it is better to avoid the variation allowed in Section 13.5.3.3 of the ACI 318-05 (2005).

Following these recommendations, the total moment resistance of the plate-column connection $\left(M_{u}\right)$ was computed with ACI 318-05 code using strength reduction factors $\phi=1$ and the measured strength of the materials defined in Chapter 2. The code stablishes $M_{u}$ as the minimum of $\left(M_{u}\right)_{\text {flex }}$ and $\left(M_{u}\right)_{\text {punch }}$, where these parameters are the capacity of the connection controlled by flexion failure and punching failure modes, respectively. The flexural capacity of the plate section can be estimated by:

$$
M_{y}=A_{s} f_{s} d\left(1-\left(\frac{A_{s} f_{s}}{1.7 b_{e f f} f_{c}^{\prime} d}\right)\right)
$$


Where $A_{s}$ is the area of the longitudinal bars in tension within $b_{\text {eff }}$ (Figure 3.14), $f_{s}$ is the strength of longitudinal bars, $f_{c}{ }^{\prime}$ is the strength of concrete and $d$ is the distance from extreme compression fiber to the centroid of longitudinal tension reinforcement, given $\left(M_{y}{ }^{+}\right)_{x}=$ $11.4 \mathrm{kNm},\left(M_{y}{ }^{-}\right)_{x}=15.1 \mathrm{kNm},\left(M_{y}{ }^{+}\right)_{y}=15.1 \mathrm{kNm}$ and $\left(M_{y}{ }^{-}\right)_{y}=15.1 \mathrm{kNm}$ for positive and negative flexure and for directions $\mathrm{X}$ and $\mathrm{Y}$. Therefore, the latter yields:

$$
\begin{aligned}
& \left(\left|M_{y}{ }^{+}\right| / \gamma_{f}\right)_{x}=19.0 \mathrm{kNm} \text { and }\left(\left|M_{y}{ }^{-}\right| / \gamma_{f}\right)_{x}=25.2 \mathrm{kNm} \\
& \left(\left|M_{y}{ }^{+}\right| / \gamma_{f}\right)_{y}=25.2 \mathrm{kNm} \text { and }\left(\left|M_{y}{ }^{-}\right| / \gamma_{f}\right)_{y}=25.2 \mathrm{kNm} \\
& \left(M_{u}\right)_{\text {flex }}^{x}=\left(\left|M_{y}{ }^{+}\right| / \gamma_{f}\right)_{x}+\left(\left|M_{y}{ }^{-}\right| / \gamma_{f}\right)_{x}=44.2 \mathrm{kNm} \\
& \left(M_{u}\right)_{\text {flex }}^{y}=\left(\left|M_{y}{ }^{+}\right| / \gamma_{f}\right)_{y}+\left(\left|M_{y}{ }^{-}\right| / \gamma_{f}\right)_{y}=50.4 \mathrm{kNm}
\end{aligned}
$$

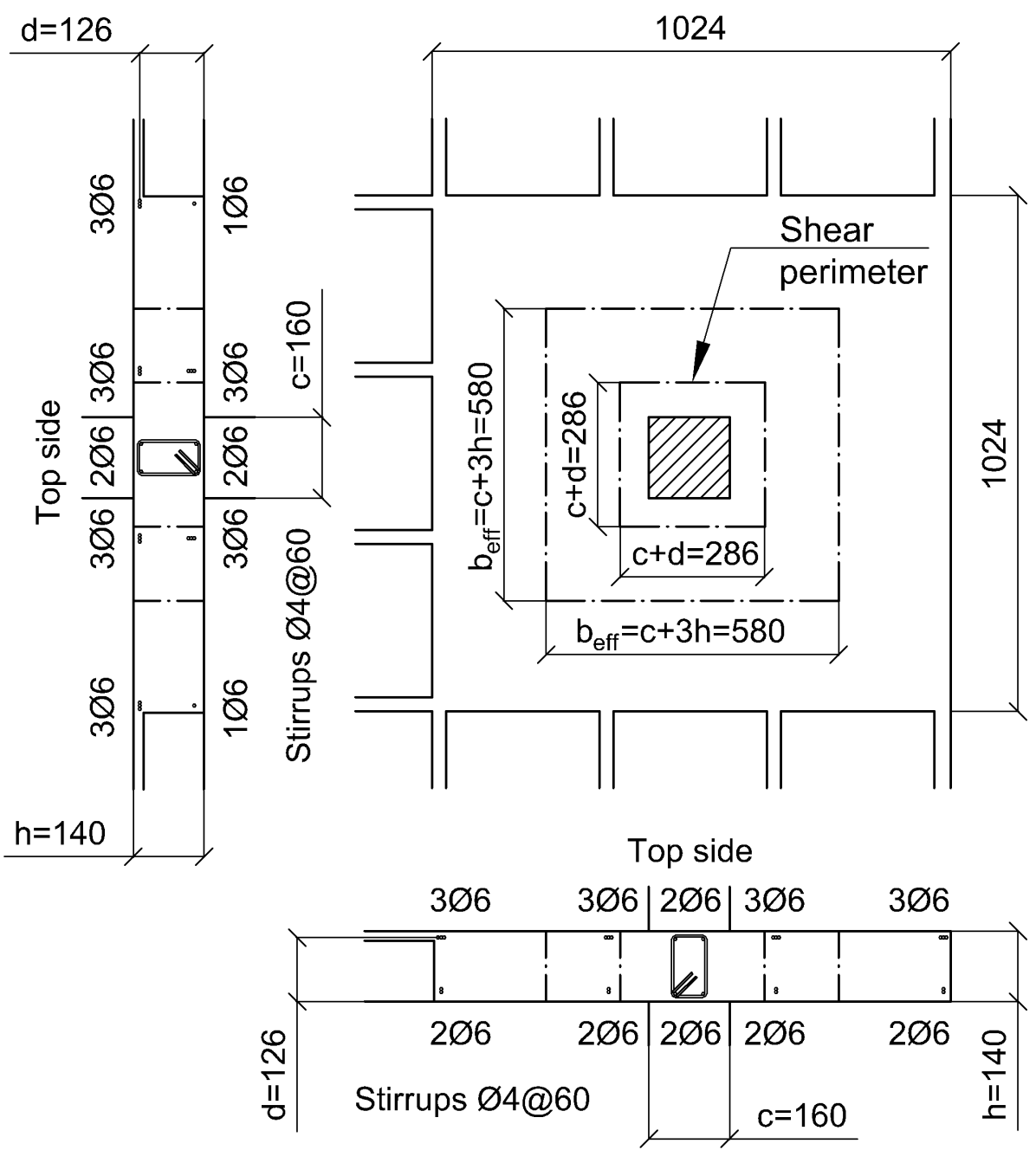

Dimensions in $\mathrm{mm}$

Figure 3. 14 Assumptions to calculate the flexural capacity of the interior drop panels

On the other hand, the nominal punching shear capacity was computed by adding the contribution of the concrete $\left(\sqrt{f_{c}{ }^{\prime}} / 6\right)$ and the reinforcement $\left(0.14 \sqrt{f_{c}{ }^{\prime}}\right)$ under punching, which gives $0.31 \sqrt{f_{c}{ }^{\prime}} M P a$ in total. Using ACI $318-05$ code, the punching shear stress $v_{u}$ is estimated by: 


$$
v_{u}=\frac{V_{u}}{A_{c}}+\frac{\gamma_{v} M_{u} c^{\prime}}{J_{c}}
$$

Where $V_{u}$ is the shear force at the centroid axis of the shear perimeter $\left(V_{u}=22.1 \mathrm{kN}\right) ; A_{c}$ is the area of concrete of assumed critical section located at $d / 2$ outside the column face $\left(A_{c}=\right.$ $4(c+d) d=1.44 \times 10^{5} \mathrm{~mm}^{2}, c$ is the dimension of the column in the direction of loading $) ; c^{\prime}$ is the distance from the centroid axis of the shear perimeter to the critical shear perimeter $\left(c^{\prime}=\right.$ $c / 2+d / 2=143 \mathrm{~mm}) ; J_{c}$ is the polar moment of inertia of the shear perimeter that comes from the following:

$$
J_{c}=\frac{d(c+d)^{3}}{6}+\frac{d^{3}(c+d)}{6}+\frac{d(c+d)^{3}}{2}=2.06 \times 10^{9} \mathrm{~mm}^{4}
$$

Solving $M_{u}$ from (3.29) and giving the value of $0.31 \sqrt{f_{c}{ }^{\prime}}$ for $v_{u}$ and 0.4 for $\gamma_{v}$ because $\gamma_{v}=1-$ $\gamma_{f}$, yields:

$$
\left(M_{u}\right)_{\text {punch }}^{x}=\left(M_{u}\right)_{\text {punch }}^{y}=\frac{J_{c}}{\gamma_{v} c^{\prime}}\left(0.31 \sqrt{f_{c}^{\prime}}-\frac{V_{u}}{A_{c}}\right)=69.2 \mathrm{kNm}
$$

Consequently, the above calculations turn out:

$$
\begin{aligned}
& M_{u}=\min \left(\left(M_{u}\right)_{\text {flex }}^{x},\left(M_{u}\right)_{\text {punch }}^{x}\right)=44.2 \mathrm{kNm} \\
& M_{u}=\min \left(\left(M_{u}\right)_{\text {flex }}^{y},\left(M_{u}\right)_{\text {punch }}^{y}\right)=50.4 \mathrm{kNm}
\end{aligned}
$$

Since the flexural capacity is lower than the punching capacity, the former controls the mode of failure, and punching failure is not expected during the tests. Further, based on the nominal capacities estimated in this section, a sideways mechanism with hinges at columns ends is expected in the interior plate-column connections since the sum of nominal strength of columns $(15+15=30 \mathrm{kNm})$ is lower than the maximum unbalanced moments $M_{u}$ for both directions $(43.4 \mathrm{kNm}$ and $50.2 \mathrm{kNm})$. Therefore, a weak-column \& strong-plate mechanism is expected during the test for the interior connections.

\subsection{Exterior drop panel}

The moment capacity of the exterior drop panel is evaluated here. The nominal design capacity of the exterior plate-column connection was computed with ACI 318-05 code (2005) using strength reduction factors $\phi=1$ and the measured strength of the materials defined in Chapter 2 . According to this code, the total unbalanced moment resistance of the plate-column connection, taken about the axis perpendicular to the direction of lateral loading at the centroid of the shear perimeter located $d / 2$ outside the column face, is $M_{u}$. The fraction of the total unbalanced moment transferred by flexure in this case is obtained by:

$$
\gamma_{f}=\frac{1}{1+\frac{2}{3} \sqrt{\frac{b_{1}}{b_{2}}}}=0.63
$$

Where $b_{1}=c+d / 2$ is the dimension of the critical section, measured in the direction of the span, and $b_{2}=c+d$ is the dimension of the critical section, measured in the perpendicular direction (Figure 3.15). 


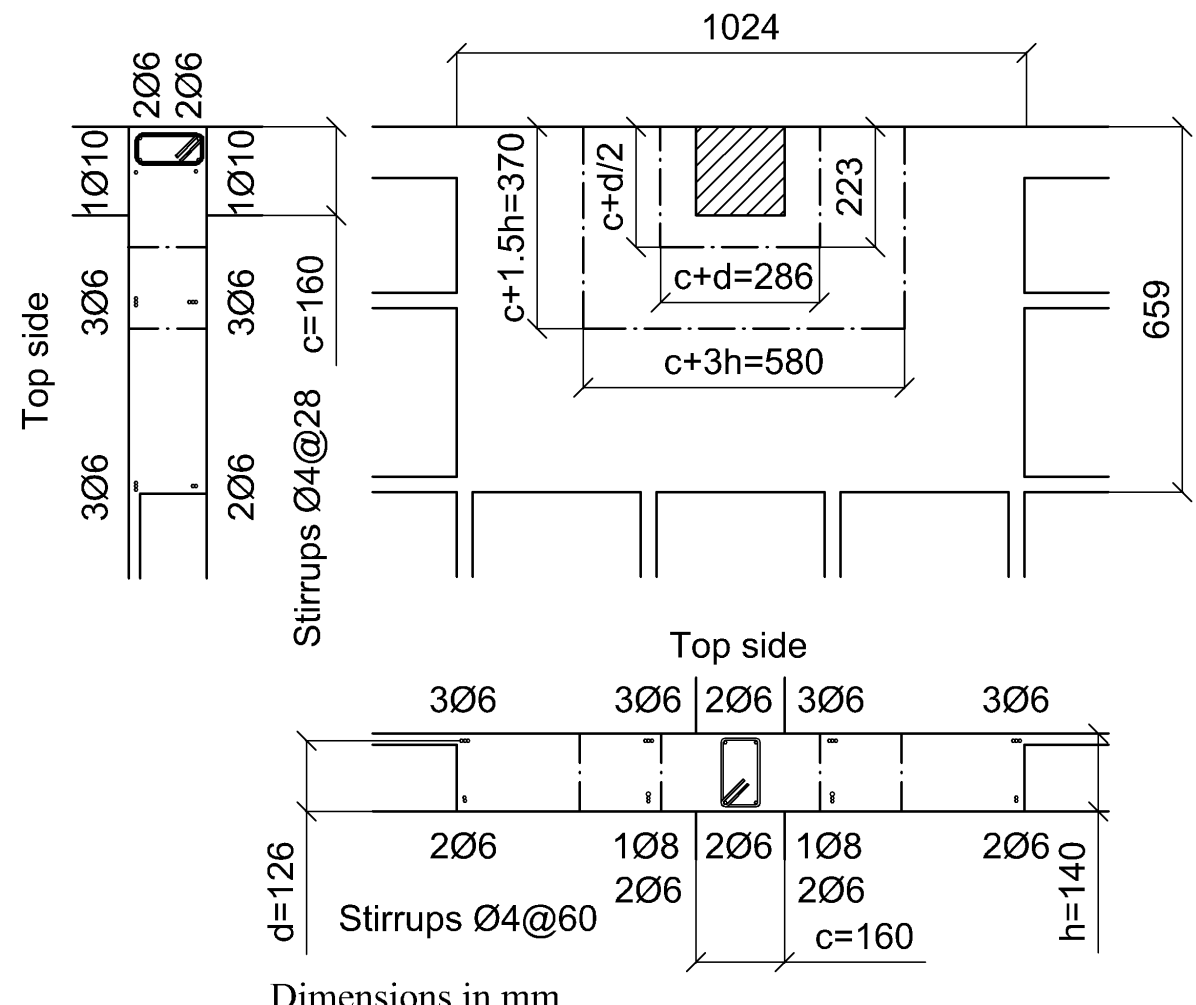

Figure 3. 15. Assumptions to calculate the flexural capacity of the exterior drop panel

In the X direction (see Figure 2.5), ACI 318-05 code considers that the fraction of unbalanced moment $\left(\gamma_{f} M_{u}\right)$ is transferred within a slab strip of width $(c+3 h)$. The flexure capacity $\left(M_{y}\right)$ of the slab in direction $\mathrm{X}$, is obtained with (3.27), giving $\left(M_{y}{ }^{+}\right)_{x}=18 \mathrm{kNm},\left(M_{y}{ }^{-}\right)_{x}=$ $15.1 \mathrm{kNm}$, for positive and negative flexure. Therefore, the latter yields:

$$
\begin{aligned}
& \left(\left|M_{y}{ }^{+}\right| / \gamma_{f}\right)_{x}=28.6 \mathrm{kNm} \\
& \left(\left|M_{y}{ }^{-}\right| / \gamma_{f}\right)_{x}=24.0 \mathrm{kNm} \\
& \left(M_{u}\right)_{\text {flex }}^{x}=\min \left(\left|M_{y}{ }^{+}\right| / \gamma_{f}\right)_{x^{\prime}}\left(\left|M_{y}{ }^{-}\right| / \gamma_{f}\right)_{x}=24.0 \mathrm{kNm}
\end{aligned}
$$

On the other hand, the nominal punching shear capacity was computed by adding the contribution of the concrete $\left(\sqrt{f_{c}} / 6\right)$ and the reinforcement $\left(0.30 \sqrt{f_{c}^{\prime}}\right)$ under punching, which gives $0.47 \sqrt{f_{c}{ }^{\prime}} \mathrm{MPa}$ in total. Using ACI 318-05 code, the punching shear stress $v_{u}$ is estimated by (3.29). In this formula, the shear force at the centroid axis of the shear perimeter had a value of $V_{u}=14.4 \mathrm{kN}$. In addition, the critical section area is defined as a rectangle of sides $(c+d / 2)$ and $(c+d)$, the area is $2(c+d / 2)+(c+d)=9.22 \times 10^{4} \mathrm{~mm}^{2} ; c^{\prime}$ is the distance from the centroid axis of the shear perimeter located at column face to the critical shear perimeter $\left(c^{\prime}=\right.$ $d / 2=63 \mathrm{~mm}$ ); the polar moment of inertia of the shear perimeter $\left(J_{c}\right)$ comes from the following:

$$
J_{c}=\frac{1}{6} d\left(c+\frac{d}{2}\right)\left(d^{2}+\left(c+\frac{d}{2}\right)^{2}\right)+(c+d) d\left(\frac{d}{2}\right)^{2}=4.5 \times 10^{8} \mathrm{~mm}^{4}
$$

Solving $M_{u}$ from equation (3.29) and giving the value $0.47 \sqrt{f_{c}{ }^{\prime}}$ for $v_{u}$ and 0.37 for $\gamma_{v}$ because $\gamma_{v}=1-\gamma_{f}$, yields: 


$$
\left(M_{u}\right)_{\text {punch }}^{x}=\frac{J_{c}^{x}}{\gamma_{v} c^{x}}\left(0.47 \sqrt{f_{c}^{\prime}}-\frac{V_{u}}{A_{c}}\right)=57.3 \mathrm{kNm}
$$

Consequently, the moment capacity gives:

$$
M_{u}=\min \left(\left(M_{u}\right)_{\text {flex }}^{x},\left(M_{u}\right)_{\text {punch }}^{x}\right)=52.6 \mathrm{kNm}
$$

ACI's method considers that the failure due to shear and moment can be considered separately. This assumption is sustained by experimental evidence (Wight et al., 1988). However, it is also true that the method is very dependent on the fraction of the total unbalanced moment $\left(\gamma_{f}\right)$, which controls the contribution of shear and flexure to endure the unbalanced moment. BenaventCliment et al. (2009) analyzed the influence of this factor as well the ACI's capacity moment prediction for an exterior waffle-flat-plate-column connection, concluding that the code does not adequately predict the moment transfer capacity of the connection in regards to their results. In addition, they proposed a new method that holds that the moment is transferred from the plate to the column over two load paths. The first path rely both on the plate longitudinal reinforcement anchored directly in the column width $c$, and on the plate's longitudinal reinforcement passing outside the column and located within a distance $b_{L}$ that is able to transfer the load through the formation of a strut-and-tie mechanism. In the second path, the moment is transferred from the plate longitudinal reinforcement outside the $b_{L}$ to the column through torsion in the transverse beam (Benavent-Climent, Donaire-Avila, \& Oliver-Saiz, 2016; Benavent-Climent et al., 2009).

To calculate $b_{L}$, the equilibrium of moments at point $\mathrm{O}$ is performed due to the strut-and-tie mechanism (Figure 3.16), which yields:

$$
0.9 d_{1} A_{s T} f_{s}=\int_{0}^{b_{L}} A_{s i}(x) f_{s} x d x
$$

Where $A_{S T}$ is the area of the longitudinal reinforcement of the transverse beam that forms the tension chord (tie) of the idealized truss model; $0.9 d_{I}$ is the lever arm where $d_{1}$ is the distance shows in Figure 3.16; $f_{s}$ is the yield stress of the reinforcing steel; $A_{s i}(x)$ is a function of the amount of the plate longitudinal reinforcement connected with the longitudinal reinforcement of the transverse beam against $\mathrm{x}$ (Figure 3.16), the latter is a variable that measures the distance between the column face and the position of the plate longitudinal reinforcement. In this case, $A_{s i}(x)=0$ for $0<x<77 \mathrm{~mm}$ and $A_{s i}(x)=4.72 \mathrm{~mm}^{2} / \mathrm{mm}$ for $77 \leq x \leq 95 \mathrm{~mm}$, transforming the area of three bars of diameter $6 \mathrm{~mm}$ in a rectangle of $18 x 4.72 \mathrm{~mm}$. Solving $b_{L}$ in (3.38) gives $b_{L}=86.26 \mathrm{~mm}$.

Once $b_{L}$ is known, the moment transferred by the first path $\left(M_{f I}\right)$ is defined as the flexural capacity of the longitudinal reinforcement within $b_{\text {eff }}=c+2 b_{L}$, using (3.27). This equation gives $M_{f I}=9.6 \mathrm{kNm}$. The moment transferred by the second path $\left(M_{f O}\right)$ is defined as the sum of the flexure capacity of the longitudinal reinforcement at each side of $c+2 b_{L}$, as long as the torsional capacity of the transverse beam has enough strength. Otherwise, the sum of the torsional capacity of each side of the transverse beam gives $M_{f O}$. The flexural capacity of the longitudinal reinforcement in the outer parts of the plate is calculated by (3.27), giving $M_{f O}^{l}=8.45 \mathrm{kNm}$ taking as $b_{\text {eff }}=\left(b_{0}-c+2 b_{L}\right) / 2$, where $b_{0}$ is the plate width $(1024 \mathrm{~mm})$. The torsion capacity was calculated applying EHE-08 (Ministerio de Fomento, 2008), giving $M_{f O}^{T}=1.75 \mathrm{kNm}$. Therefore, the maximum moment that the plate can transfer along the second load path is defined 
by $M_{f O}=2\left(\min \left(M_{f O}^{l}, M_{f O}^{T}\right)\right)=3.5 \mathrm{kNm}$. Finally, the flexure capacity of the exterior platecolumn connection in direction $\mathrm{X}$ is $M_{u}=M_{f I}+M_{f O}=13.1 \mathrm{kNm}$, which is a value quite close to the ACI's result considering $\gamma_{f}=1$. Finally, taking into account that the sum of the capacity moments in columns $(18.9+18.9=37.8)$ is larger than the capacity of the plate $M_{u}$, a weakplate \& strong-column mechanism is expected in the exterior plate-column connection, with a torsion failure in the transverse beam caused by the loading in direction $\mathrm{X}$. The loading in the $\mathrm{Y}$ direction is not expected to cause damage in the exterior connection because the connection is basically free to rotate in a vertical plane containing the $\mathrm{Y}$ axis.

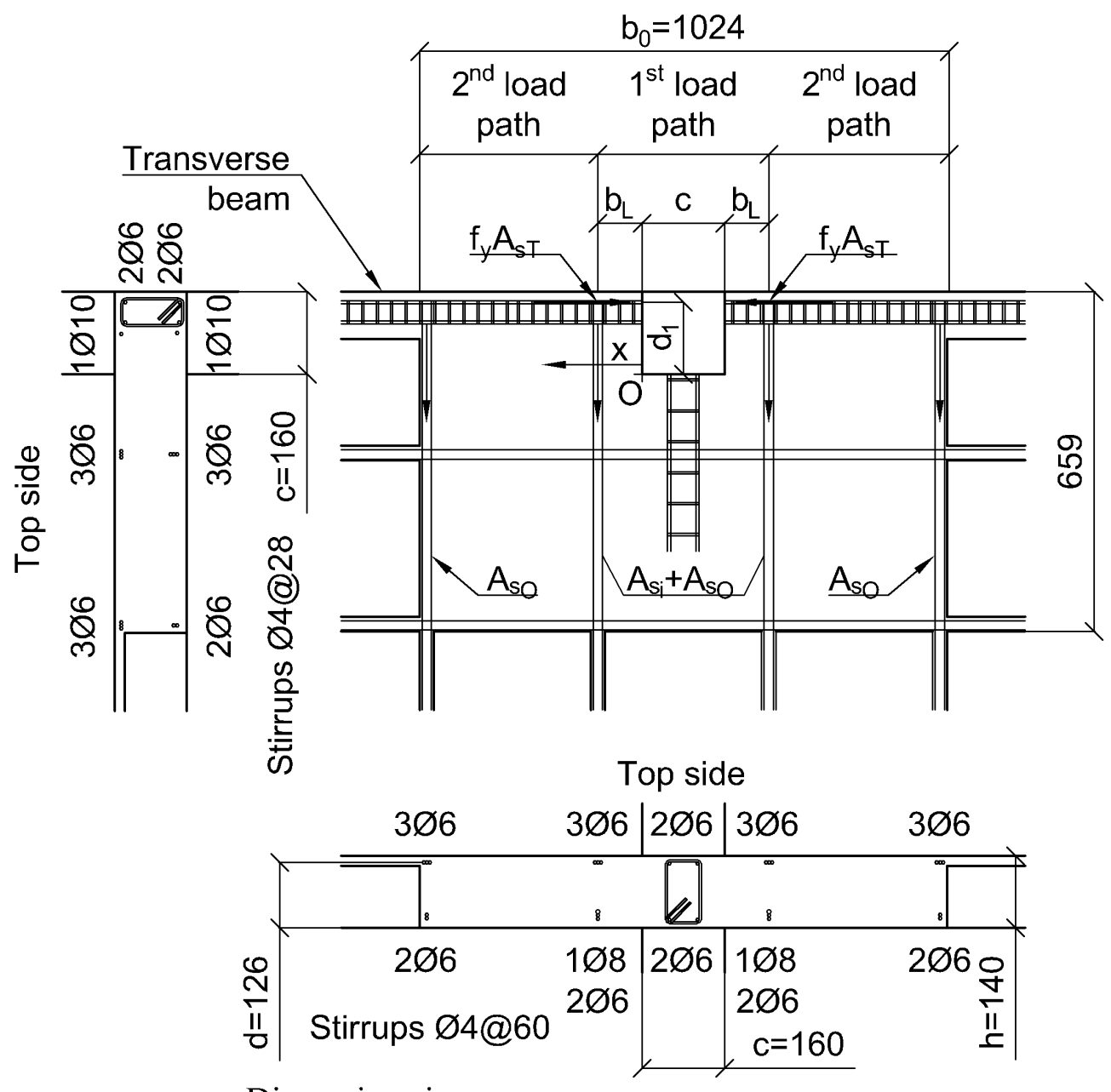

Dimensions in $\mathrm{mm}$

Figure 3. 16. Two path model for the exterior plate-column connection

\section{GLOBAL COLLAPSE MECHANIMS OF THE SPECIMEN}

An important seismic performance objective in conventional buildings is to prevent global collapse during a very strong and rare earthquake. This performance objective is pursued via systematic and across-the-board application of capacity design, which imposes a hierarchy of strengths that permits full control of the inelastic response mechanism. Current seismic design codes use the concept "capacity design" as the main instrument. This philosophy works with and on the strengths of individual elements to ensure that all-along the load path of inertia forces, from the masses to the foundation, the strength of the structural system is governed by the ductile elements (Fardis, 2009). 
Ductility is a key-concept in the response of yielding structures subject to very strong earthquake ground motions. Ductility is qualitatively defined as the ability of a cross-section, a structural member, or a structure as a whole to exhibit significant inelastic deformations under cyclic/seismic external loads without losing a significant part of its original stiffness and strength after each loading cycle (Avramidis, Athanatopoulou, Morfidis, Sextos, \& Giaralis, 2015). A structural system as a whole must resist the lateral loadings forming a sequence of plastic hinges, which dissipate the input energy via hysteretic behavior.

This section investigates the collapse mechanism of the tests specimen analyzing the possible plastic mechanisms that can develop along the direction $\mathrm{X}$ and $\mathrm{Y}$. The goal is to predict the maximum shear base force that the specimen develops under an inverted triangle pattern of lateral loading. The mechanisms are computed through the method of virtual work, where the fundamental relation is that the external work must be balanced with the internal work $\left(W_{\text {ext }}=\right.$ $\left.W_{\text {int }}\right)$.

\section{$\underline{\text { Plastic mechanisms in direction } X}$}

Figure 3.17 shows the four possible mechanisms for direction X.
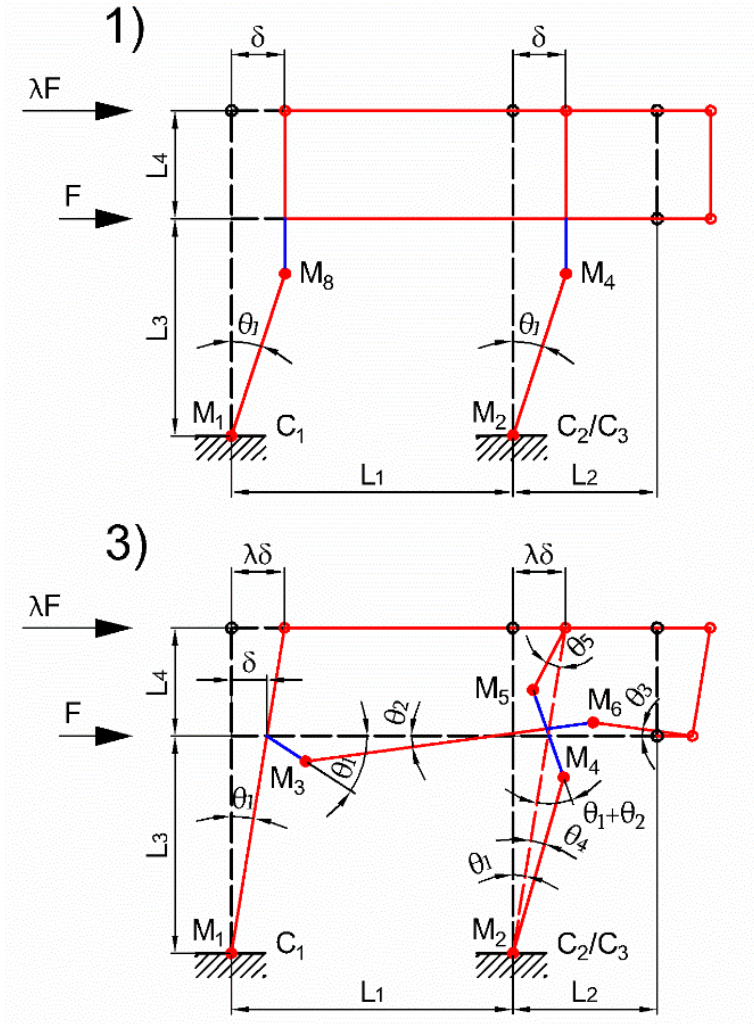
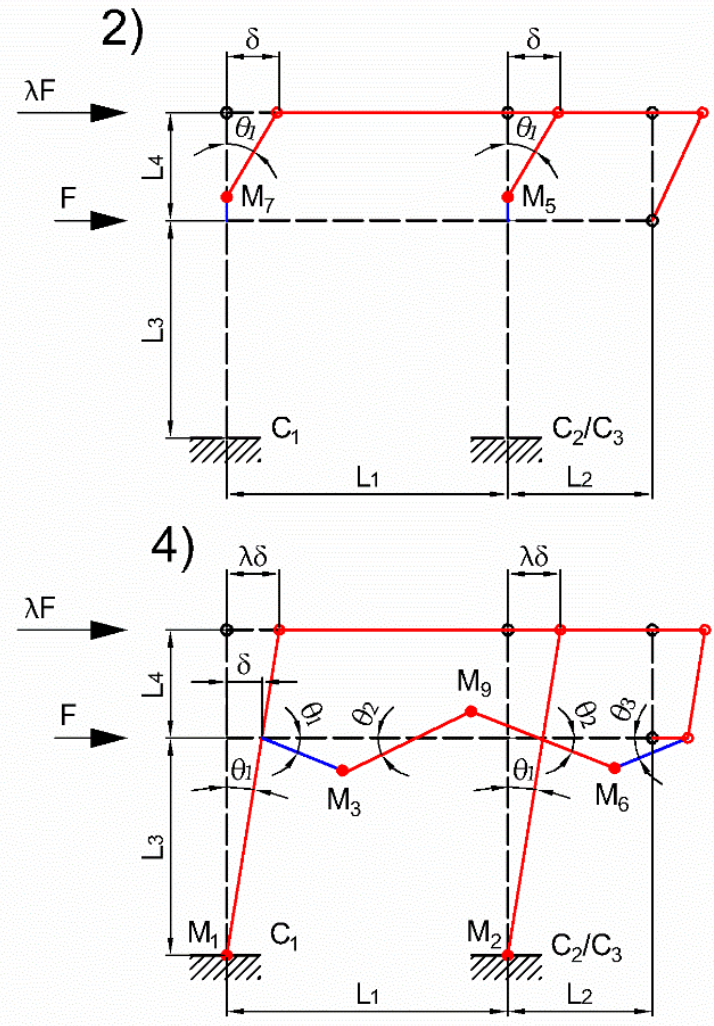

$$
\text { \% Frictionless hinges }- \text { - Undeformed shapes }-r
$$

- Plastic hinges - Deformed shapes

Figure 3. 17. Likely collapse mechanisms for direction $\mathrm{X}$

In the above figure, $L_{1}$ is $2394 \mathrm{~mm}, L_{2}$ is $976 \mathrm{~mm} L_{3}$ is $1400 \mathrm{~mm}, L_{4}$ is $620 \mathrm{~mm}, \lambda$ is the force amplification factor defined as $1+L_{4} / L_{3}$ and $r$ is the distance between the plastic hinge and the nearest connection. Moments $\left(M_{i}\right)$ refer to the values obtained in the previous section where $M_{1}$ is $17.6 \mathrm{MPa}, M_{2}$ is $14.0 \mathrm{MPa}, M_{3}$ is $13.1 \mathrm{MPa}, M_{4}$ is $15.0 \mathrm{MPa}, M_{5}$ is $15.0 \mathrm{MPa}$, 
$M_{6}$ is $25.2 \mathrm{MPa}, M_{7}$ is $18.9 \mathrm{MPa}, M_{8}$ is $20.8 \mathrm{MPa}$ and $M_{9}$ is $19.0 \mathrm{MPa}$. The moments are those that take into account the biaxial interaction for columns applying an interaction factor of 0.8. The rest of parameters are obtained for each mechanism.

Mechanism 1) corresponds to a "story-sway mechanism" that involves plastic hinges formation at the base and at the head of columns of the first story. The relationship between variables within this structural system are shown in (3.39).

$$
\theta_{1}=\frac{\delta}{L_{3}-r}
$$

Applying the method of virtual work, the external and internal works turn out:

$$
\begin{aligned}
& W_{\text {ext }}=F \delta(1+\lambda) \\
& W_{\text {int }}=M_{1} \theta_{1}+M_{2} \theta_{1}+M_{4} \theta_{1}+M_{8} \theta_{1}
\end{aligned}
$$

Then, equaling both works, the base shear force yields:

$$
F_{1}^{x}=F_{1}^{y}=\frac{1}{\left(L_{3}-r\right)(1+\lambda)}\left(M_{1}+M_{2}+M_{4}+M_{8}\right)
$$

Mechanism 2) corresponds to a "story-sway mechanism" that involves plastic hinges formation at the base of columns of the upper story. The relationship between variables within this structural system are shown in (3.42).

$$
\theta_{1}=\frac{\delta}{L_{4}-r}
$$

Applying the method of virtual work, the external and internal works turn out:

$$
\begin{aligned}
& W_{\text {ext }}=F \delta \lambda \\
& W_{\text {int }}=2 M_{5} \theta_{1}+M_{7} \theta_{1}
\end{aligned}
$$

Then, equaling both works, the base shear force yields:

$$
F_{2}^{x}=F_{2}^{y}=\frac{1}{\lambda\left(L_{4}-r\right)}\left(2 M_{5}+M_{7}\right)
$$

Mechanism 3) corresponds to a mix of "beam-sway mechanism" and "column-sway mechanism" because it involves plastic hinges formation in the external plate at column $C_{1}$ and plastic hinges at the base and at the head of columns $C_{2}$ and $C_{3}$. The relationships between variables within this structural system are shown in (3.45a-e).

$$
\begin{aligned}
\theta_{1} & =\frac{\delta}{L_{3}} \\
\theta_{2} & =\frac{r}{L_{1}-r} \theta_{1} \\
\theta_{3} & =\frac{r}{L_{2}-r} \theta_{2} \\
\theta_{4} & =\frac{r}{L_{3}-r}\left(\theta_{1}+\theta_{2}\right)
\end{aligned}
$$




$$
\theta_{5}=\frac{r}{L_{4}-r}\left(\theta_{1}+\theta_{2}\right)
$$

Applying the method of virtual work, the external and internal works turn out:

$$
\begin{aligned}
& W_{\text {ext }}=F \delta\left(1+\lambda^{2}\right) \\
& W_{\text {int }}=M_{1} \theta_{1}+2 M_{2}\left(\theta_{1}+\theta_{4}\right)+M_{3}\left(\theta_{1}+\theta_{2}\right)+2 M_{4}\left(\theta_{1}+\theta_{2}+\theta_{4}\right)+2 M_{5}\left(\theta_{1}+\right. \\
& \left.\theta_{2}+\theta_{5}\right)+2 M_{6}\left(\theta_{2}+\theta_{3}\right)
\end{aligned}
$$

Then, equaling both works, the base shear force yields:

$$
\begin{aligned}
& F_{3}^{x}=\frac{1}{L_{3}\left(1+\lambda^{2}\right)}\left(M_{1}+2 M_{2}\left(1+\frac{r}{L_{3}-r}\left(1+\frac{r}{L_{1}-r}\right)\right)+M_{3}\left(1+\frac{r}{L_{1}-r}\right)+2 M_{4}\left(1+\frac{r}{L_{1}-r}+\right.\right. \\
& \left.\left.\frac{r}{L_{3}-r}\left(1+\frac{r}{L_{1}-r}\right)\right)+2 M_{5}\left(1+\frac{r}{L_{1}-r}+\frac{r}{L_{4}-r}\left(1+\frac{r}{L_{1}-r}\right)\right)+2 M_{6}\left(\frac{r}{L_{1}-r}\left(1+\frac{r}{L_{2}-r}\right)\right)\right)
\end{aligned}
$$

Mechanism 4) corresponds to the "desirable" plastic mechanism commonly referred as the "beam-sway mechanism". It involves plastic hinges at plates, remaining columns without damage. It should be the target via capacity design rules and requirements in code-compliant seismic design. The relationships between variables within this structural system are shown in (3.48a-c).

$$
\begin{aligned}
& \theta_{1}=\frac{\delta}{L_{3}} \\
& \theta_{2}=\frac{2 r}{L_{1}-2 r} \theta_{1} \\
& \theta_{3}=\frac{r}{L_{2}-r} \theta_{1}
\end{aligned}
$$

Applying the method of virtual work, the external and internal works turn out:

$$
\begin{aligned}
& W_{\text {ext }}=F \delta\left(1+\lambda^{2}\right) \\
& W_{\text {int }}=M_{1} \theta_{1}+2 M_{2} \theta_{2}+M_{3}\left(\theta_{1}+\theta_{2}\right)+2 M_{6}\left(\theta_{1}+\theta_{3}\right)+2 M_{9}\left(\theta_{1}+\theta_{2}\right)
\end{aligned}
$$

Then, equaling both works, the base shear force yields:

$$
F_{4}^{x}=\frac{1}{L_{3}\left(1+\lambda^{2}\right)}\left(M_{1}+2 M_{2}+M_{3}\left(1+\frac{2 r}{L_{1}-2 r}\right)+2 M_{9}\left(1+\frac{2 r}{L_{1}-2 r}\right)+2 M_{6}\left(1+\frac{r}{L_{2}-r}\right)\right)
$$

Figure 3.18a shows the Base Shear Force predicted by the collapse mechanisms for direction X considering a distance $r=80 \mathrm{~mm}$, while Figure $3.18 \mathrm{~b}$ ) shows the base shear forces predicted considering a distance $r$ variable between 0 and $350 \mathrm{~mm}$. It is worth recalling that the parameter $r$ is the distance between the plastic hinge and the nearest connection, considering the same distance for all plastic hinges (Figure 3.17 in blue). Figure $3.18 \mathrm{~b}$ shows that the collapse mechanism depends strongly on the location of the plastic hinges (distance $r$ ). Part 1 of Eurocode 8 (CEN, 2004) calls the zones where plastic hinges appear as "critical regions". They are located at a certain distance from the section of maximum positive (hogging) moment under the combination of the design seismic action and the concurrent gravity loads (Fardis, 2009). 
According to Eurocode 8 (CEN, 2004), the length of the "critical regions" is equal to 1 or 1.5 the depth of the beam $(140-210 \mathrm{~mm})$ or the width of the column $(160-240 \mathrm{~mm})$ depending on the Ductility Class (DC) of the building.
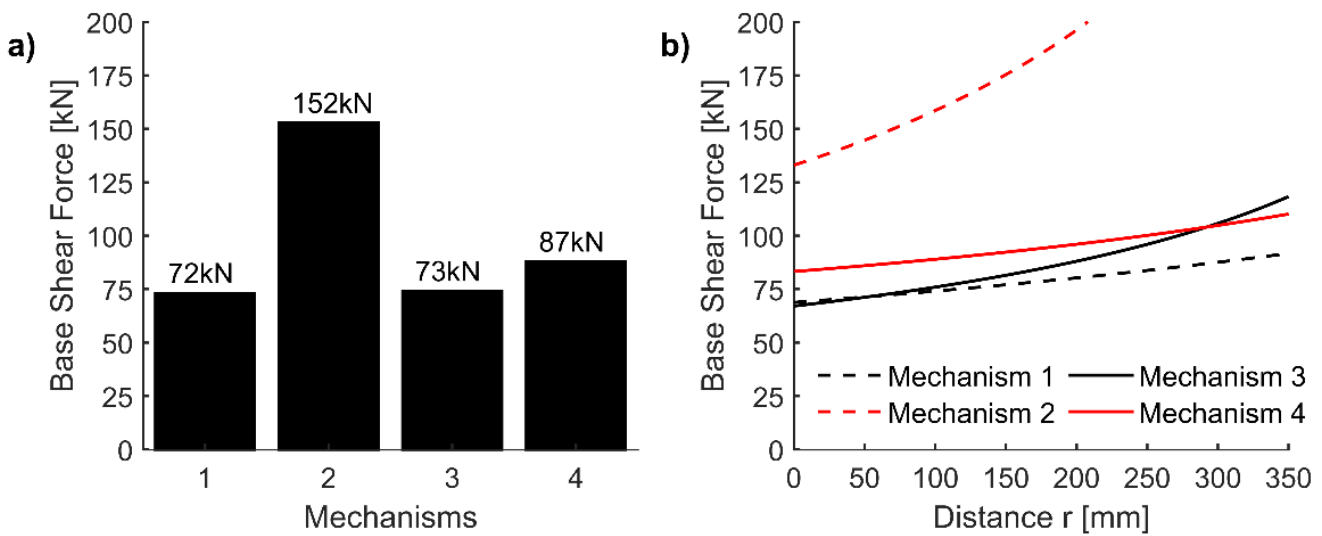

Figure 3. 18. Base shear force for each collapse mechanism for Direction X

Figure 3.18a is a bar diagram where it is clear that the mechanisms 1,3 and 4 are the likely collapse mechanisms, rejecting the mechanism 2 utterly because of the large difference in terms of base shear force with the rest. Among the three, mechanisms 1 or 3 provide the minimum base shear force depending on the distance $r$, as shown in i Figure 3.18b. Therefore, they are the most likely to form. However, the differences between them and mechanism 4 are not big enough to reject it because the method used is just a rough approximation, and the exact position of the plastic hinges cannot be determined.

Assuming a distance $r$ equal to a half of column width the mechanism of collapse would be the number 1 that corresponds to a "first soft story". Yet, it is also true that the difference with mechanism number 3, which represents a mix of "beam-sway mechanism" and "column-sway mechanism", is very small. Thus, any of two might form. For any of the two cases, the base shear force developed is around $70-75 \mathrm{kN}$. It is worth noting also that, during the dynamic loadings the position of plastic hinges (i.e. the value of $r$ ) can experience small variations.

\section{Plastic mechanisms in direction $Y$}

The three possible collapse mechanisms in direction Y are shown in Figure 3.19. Mechanisms 1 and 2 are local, which means that develop hinges in one story, while mechanism 3 is a global mechanism that involves hinges in both stories. It is worth noting that direction $\mathrm{Y}$ is the asymmetric direction of the specimen and therefore, there are interactions between the resistant mechanisms presented in the specimen. Column $C_{1}$, on one hand, and the frame formed by columns $C_{2}, C_{3}$ and the slab, on the other hand, represent the resistant mechanisms in direction Y. Due to that scenario, a two dimensional model cannot reproduce with enough accuracy the real collapse mechanism but it could be a rough approach.

In Figure 3.19, $L_{5}$ is $1000 \mathrm{~mm}$ and the rest of parameters were already defined in Figure 3.17. The relationship between parameters are obtained for each mechanism.

Mechanism 1) and 2) are the same in both direction and its relationships were already defined previously. Mechanism 3) develops a "column-sway mechanism" for column $C_{1}$ and a "beamsway mechanism" for columns $C_{2}$ and $C_{3}$. The relationships between variables within this structural system are shown in (3.51a-d). 


$$
\begin{aligned}
\theta_{1} & =\frac{\delta}{L_{3}} \\
\theta_{2} & =\frac{r}{L_{5}-r} \theta_{1} \\
\theta_{3} & =\frac{r}{L_{4}-r}\left(\theta_{1}+\theta_{2}\right) \\
\theta_{4} & =\frac{r}{L_{3}-r}\left(\theta_{1}+\theta_{2}\right)
\end{aligned}
$$
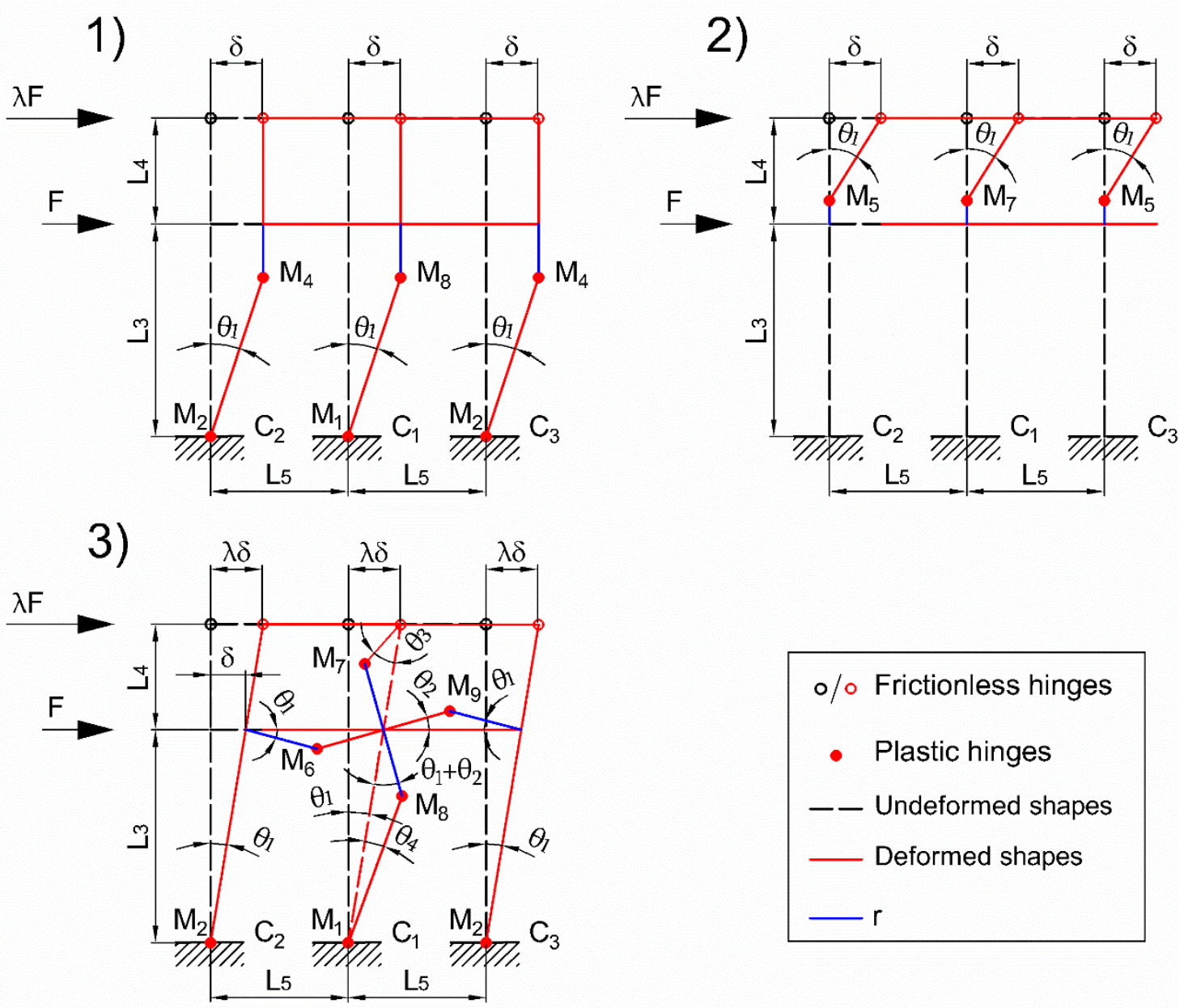

Figure 3. 19. Likely collapse mechanisms for direction Y

Applying the method of virtual work, the external and internal works give:

$$
\begin{aligned}
& W_{\text {ext }}=F \delta\left(1+\lambda^{2}\right) \\
& W_{\text {int }}=M_{1}\left(\theta_{1}+\theta_{4}\right)+2 M_{2} \theta_{1}+M_{6}\left(\theta_{1}+\theta_{2}\right)+M_{7}\left(\theta_{1}+\theta_{2}+\theta_{3}\right)+M_{8}\left(\theta_{1}+\right. \\
& \left.\theta_{2}+\theta_{4}\right)+M_{9}\left(\theta_{1}+\theta_{2}\right)
\end{aligned}
$$

Then, equaling both works, the base shear force yields: 


$$
\begin{aligned}
& F_{3}^{y}=\frac{1}{\left(1+\lambda^{2}\right)}\left(M_{1}\left(\frac{1}{L_{3}}+\frac{r}{L_{3}-r}\left(\frac{1}{L_{3}}+\frac{r}{L_{5}-r}\left(\frac{1}{L_{3}}\right)\right)\right)+2 M_{2}\left(\frac{1}{L_{3}}\right)+M_{6}\left(\frac{1}{L_{3}}+\frac{r}{L_{5}-r}\left(\frac{1}{L_{3}}\right)\right)+\right. \\
& M_{7}\left(\frac{1}{L_{3}}+\frac{r}{L_{5}-r}\left(\frac{1}{L_{3}}\right)+\frac{r}{L_{4}-r}\left(\frac{1}{L_{3}}+\frac{r}{L_{5}-r}\left(\frac{1}{L_{3}}\right)\right)\right)+M_{8}\left(\frac{1}{L_{3}}+\frac{r}{L_{5}-r}\left(\frac{1}{L_{3}}\right)+\frac{r}{L_{3}-r}\left(\frac{1}{L_{3}}+\right.\right. \\
& \left.\left.\left.\frac{r}{L_{5}-r}\left(\frac{1}{L_{3}}\right)\right)\right)+M_{9}\left(\frac{1}{L_{3}}+\frac{r}{L_{5}-r}\left(\frac{1}{L_{3}}\right)\right)\right)
\end{aligned}
$$

Figure 3.20a shows the Base Shear Force predicted by the collapse mechanisms for direction $\mathrm{Y}$ considering a distance $r=80 \mathrm{~mm}$ (at the column face), while Figure 3.18b shows the Base Shear Forces predicted considering a distance $r$ variable between 0 and $350 \mathrm{~mm}$. This distance is shown in Figure 3.19 in blue.
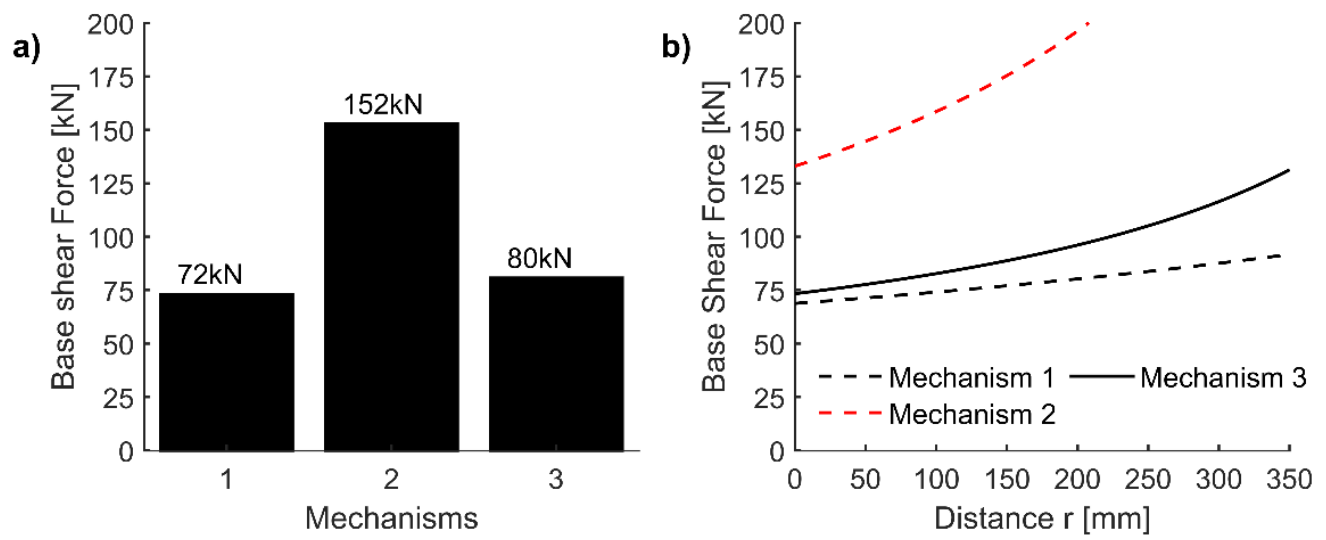

Figure 3. 20. Base shear force for each collapse mechanism for Direction Y

In the bar diagram of Figure 3.20a, it is seen again that the mechanism 2, which represents the collapse of the upper story is out of range in regards to the other mechanisms, therefore this mechanism is rejected again. Mechanisms 1 and 3, which represent a "first soft story" and a mix of a "desired" collapse mechanism for the interior connection and "undesired" collapse mechanism for the exterior connections, give results in the same range. In this case, the "first soft story" mechanism is always the minimum in the Figure $3.20 \mathrm{~b}$. Therefore, this might be the most likely collapse mechanism. Nevertheless, it is not possible to reject the mechanism 3 because the high uncertainties of the method used due to the asymmetry in this direction. For these reasons, the most probable maximum base shear force is around $75-80 \mathrm{kN}$.

\section{SUMMARY}

This Chapter made a preliminary characterization of the dynamic properties and lateral strength of the test specimen. This information is crucial to conduct the shaking table test; it is needed to determine the most appropriate scaling factor for the accelerograms that will be applied to the shake table, and to avoid damaging the equipment. The dynamic properties of the specimen while it remains in the elastic range (i.e. for low levels of acceleration applied to the shake table) was estimated using a two-mass lumped model with 3 DOF per lumped mass, considering a stiffness loss of $50 \%$ due to concrete cracking. In this regards, the mass matrix is given by (3.3) and the stiffness matrix with a 50\% reduction of the inertia of the elements by (3.22). Further, the position of the centers of mass and torsion are depicted in Figure 3.21. 
Performing a eigenvalue analysis using these matrices, the main periods obtained were $0.37,0.31$ and $0.27 \mathrm{~s}$, which correspond to modes 1,2 and 3 . These periods are able to mobilize more than $95 \%$ of the total mass. Further, this range of periods is found within the constant acceleration zone, close to the constant velocity zone in the logarithmic tripartite graph paper (Figures 2.18) developed by Newmark (1982). This information is valuable in the tuning of the shaking table.

\section{Story 1}

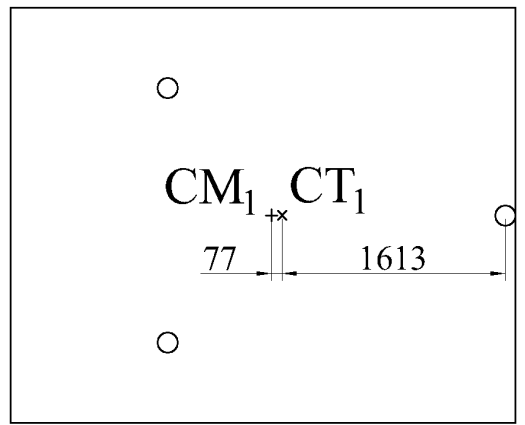

\section{Story 2}

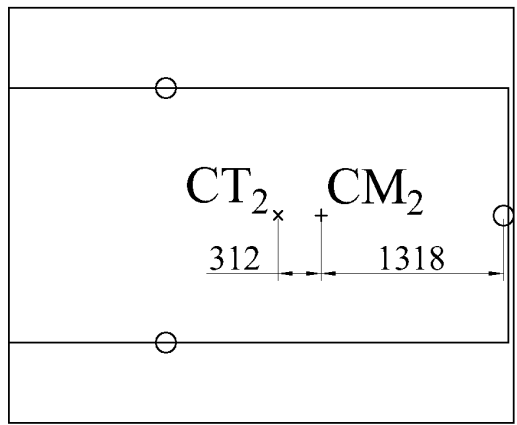

Figure 3. 21. Centers of mass and torsion

Furthermore, the maximum capacity of the specimen in term of base shear force in directions $\mathrm{X}$ and $\mathrm{Y}$ was estimated studding the failure mode (flexure, punching shear) and determining the capacity at the critical sections, and the possible plastic mechanisms. It was found that the base shear force in directions $\mathrm{X}$ and $\mathrm{Y}$ were around $70-75 \mathrm{kN}$ and $75-80 \mathrm{kN}$, respectively. Therefore, considering a mean lever arm equal to $\frac{\left(m_{1} d_{1}+m_{2} d_{2}\right)}{\left(m_{1}+m_{2}\right)}=1882 \mathrm{~mm}$, the maximum overturning moment would be around $15 \mathrm{Tm}$, quite far from $30 \mathrm{Tm}$ that is the maximum capacity of the shaking table, ensuring the safety of the facility. Finally, the overall nonlinear behavior of the test specimen in terms of capacity curves, was approximated with elastic perfectly plastic models as shown in Figure 3.22.
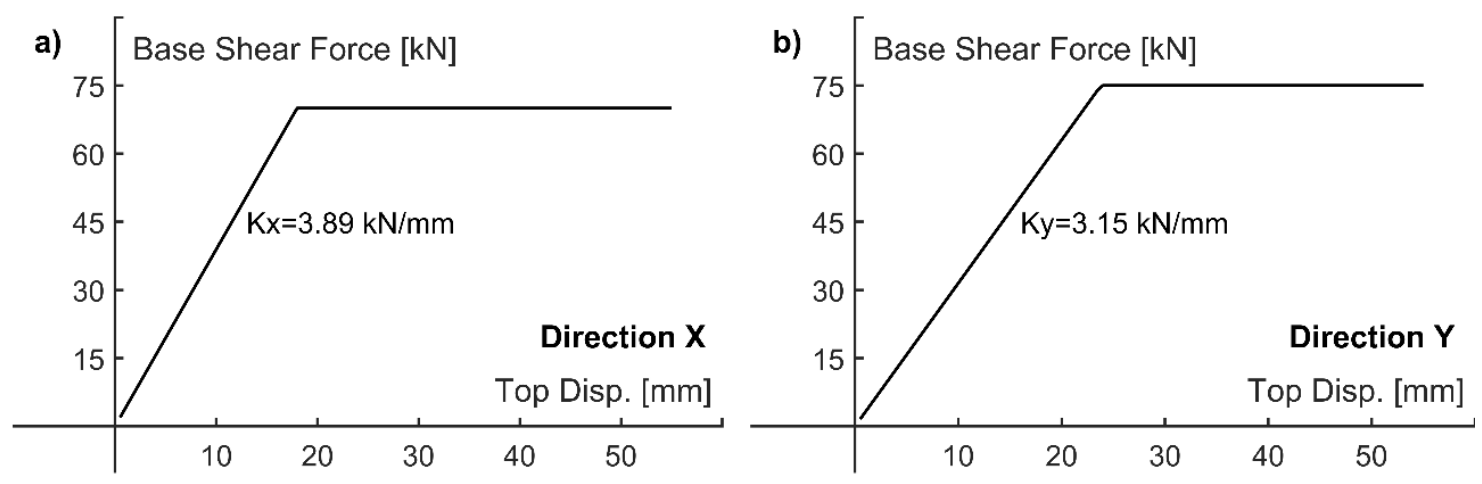

Figure 3. 22. Estimation of capacity curve: a) direction X (NS) and b) direction Y (EW) 


\section{Chapter 4}

\section{EXPERIMENTAL INVESTIGATION: RESULTS OF BIDIRECTIONAL SHAKING TABLE TEST}

The evaluation the seismic performance and the energy dissipation capacity of structural elements and structures in the nonlinear range, and particularly at stages close to collapse, calls for experimental data. The optimal source for such information is through dynamic shake table tests because they can reproduce complex effects such as cumulative damage and rate-of-loading effects. Both are difficult to capture with numerical simulations and play an important role in the response of the structure. This Chapter presents the results of the bidirectional shake table test described in previous Chapters, in terms of displacement capacity, strength and energy dissipation capacity of WFP systems designed following current seismic codes under a far-field ground motion. The damage imparted upon the test structure, in terms of deformation and cumulated energy for different levels of seismic hazard until collapse, is quantified and discussed. 


\section{SHAKE TABLE TRAINING AND SEISMIC SIMULATIONS}

The specimen BS1 was subjected to a bidirectional shaking table test until failure, using the two horizontal components of Calitri ground motion, which was scaled in time by a factor of $\lambda_{t}=$ 0.63 (Chapter 2). Component NS was aligned with direction $\mathrm{X}$ and component EW with direction $\mathrm{Y}$ (Figure 2.5). The loading program consisted on applying simultaneously the two components of the ground motion recorded at Calitri earthquake in successive seismic simulations. In each simulation, both components of acceleration were applied to the shake table scaled in amplitude to $35 \%, 50 \%, 100 \%, 200 \%$ and $300 \%$ of the original values. When conducting dynamic shake table tests, the control system of the shake table must be trained so that the internal algorithms can adjust properly in real time the signal sent to the table and adjust the actual acceleration measured on the table to the target accelerogram. This training is conducted by applying white noise signals to the shake table. The amplitude of this signal is set low enough so that the specimen remains basically within the elastic range (although some cracking in the concrete cannot be avoided). During this training process, a white noise signal referred to as T10 herein imposed an unexpected short-pulse of acceleration which amplitude was larger than expected. For this reason, this white-noise signal T10 has been also included in the analyses of the test results, although it has not been considered as a "seismic simulation". Also, the first attempt to apply the accelerograms scaled to $200 \%$ was interrupted due to a problem with the control system of the shake table and repeated. The first (incomplete) attempt is referred to as test C200i and included in the analyses. The subsequent complete and successful seismic simulation with the same scaling factor is called C200 hereafter. Therefore, hereafter T10 identifies the white noise signal used to train the shake table; and C35, C50, C100, C200i, C200 and C300 identify ground motion simulations (seismic simulations herein).

The earthquake simulator replicated the series of ground motions using acceleration control. This control system is extremely difficult because of inherent nonlinearities in servo hydraulic systems (i.e. valve dynamics, oil flow, etc.), control-structure interaction, dynamics of the base support, etc (Nakata, 2010). In order to check the shaking table performance, Appendix 1 shows the results superposed of the target and the reproduced signal by the shaking table in terms of history of accelerations and acceleration, velocity, displacement and input energy spectra for both components. Among them, velocity and energy spectra (that are closely related) are the most important because are directly related to the damage potential of the earthquake. All sequences were showed in the appendix with the exception of T10 and C200i; the former because is not a seismic simulation and the later because it was and incomplete ground motion.

In view of the results showed in the Appendix 1, the shaking table reproduced very well the target signal in term of acceleration, velocity, displacement and input energy, with some deviation for periods below $0.18 \mathrm{~s}$. This means that the earthquake simulator did not replicate properly the part of the target signal with higher frequencies. The main natural periods of the specimen (Table 4.2) are higher than $0.18 \mathrm{~s}$, and therefore the test specimen was subjected to a ground motion very close to that recorded in Calitri during the Campano-Luchano earthquake. It must be noted however that, since the analysis of the test results is conducted using the actual acceleration measured in the shake table during the tests (not the target acceleration), approaching more or less the target accelerogram is a matter of secondary importance, as far as the applied signal does not deviates too much from what can be expected during a "realistic" ground motion.

Figure 4.1 shows the accelerations measured in the shake table for all seismic simulations. The figure shows components $G A_{N S}(t)$ in direction $\mathrm{X}, G A_{E W}$ in direction $\mathrm{Y}$ and the Bidirectional Ground Acceleration defined as $G A(t, \theta)=G A_{N S}(t) \sin \theta+G A_{E W}(t) \cos \theta$, where $\theta$ is the angle defined as $\operatorname{atan}\left(G A_{N S}(t) / G A_{E W}(t)\right)$ (Hong, Pozos-Estrada, \& Gomez, 2009). 


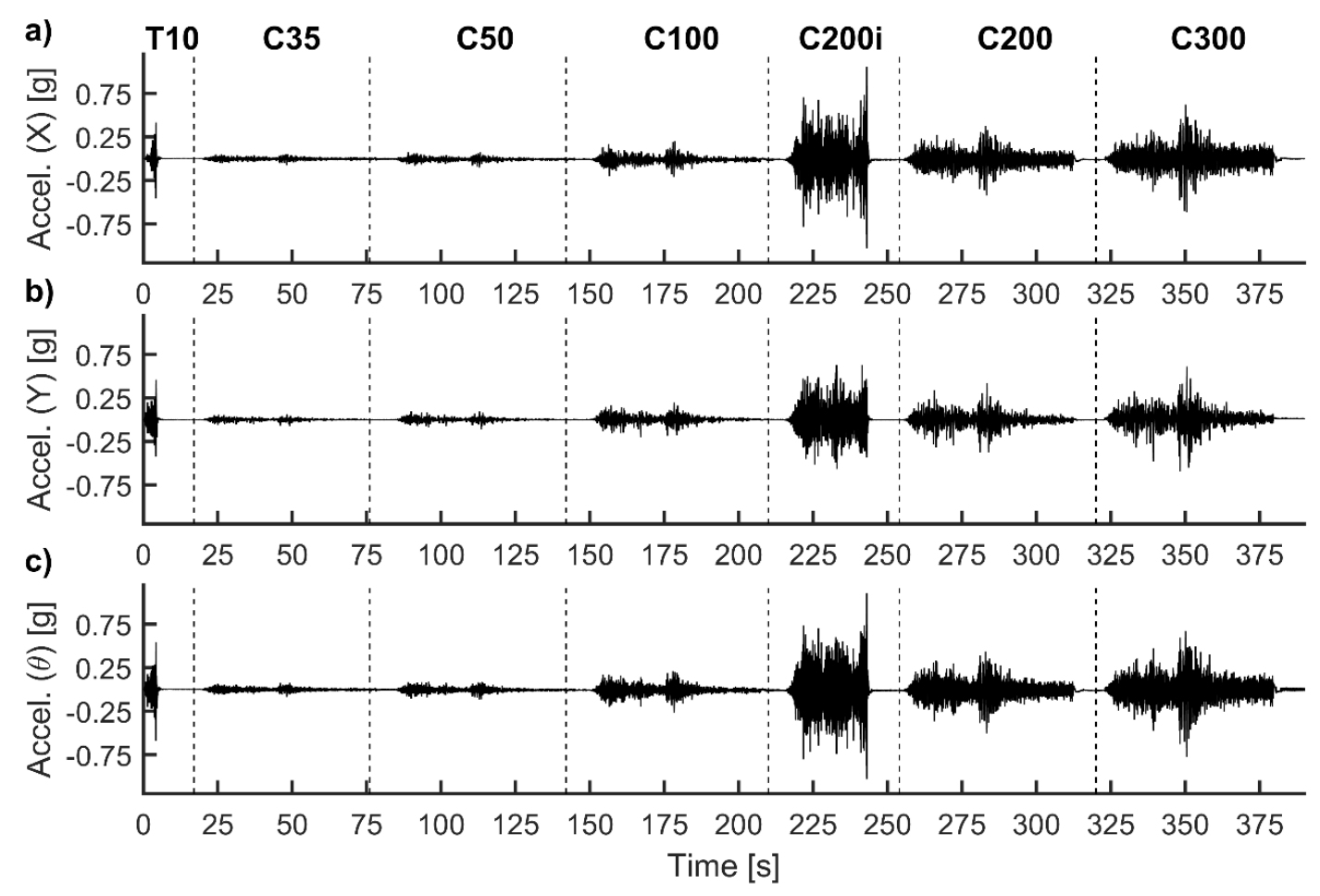

Figure 4. 1. Histories of acceleration inputs reproduced in the test: a) Component NS in

Direction $\mathrm{X}, \mathrm{b}$ ) Component $\mathrm{EW}$ in Direction $\mathrm{Y}$ and c) Bidirectional response

The horizontal acceleration at instant $t$ in a direction forming a counterclockwise angle $\theta$ with EW-axis is $G A(t, \theta)=G A_{N S}(t) \sin \theta+G A_{E W}(t) \cos \theta$. $G A(t, \theta)$ was calculated for different $t$ and $\theta$, and the maximum was taken as PGA. The PGAs obtained were $0.59,0.09,0.12,0.27,1.10,0.51,0.77 \mathrm{~g}$ (here $g$ is the acceleration of gravity) for T10, C35, C50, C100, C200i, C200 and C300 respectively. It is worth noting that although T10 and C200i developed very large accelerations the amount of energy input in the specimen was relatively small and the damage imparted to the test specimen was negligible in case of T10 and small in case of C200i, as discussed later in Section 2.5. This emphasizes the well-known fact (DonaireÁvila, Mollaioli, Lucchini, \& Benavent-Climent, 2015) that the PGA is not an appropriate indicator of damage potential of the earthquake. Instead, the response acceleration, the response velocity, or most preferably the amount of input energy are much better intensity measures of the ground motion, since they correlate much better with the response quantities (i.e. displacements, cumulative plastic strain energy, damage). Moreover, as noted above, T10 is not a ground motion; it is a white noise signal with a spurious acceleration pulse, and therefore signal T10 is not treated as a ground motion in the following discussion, although it is included in the analysis of the structural response. These PGAs reported above are directly obtained using the accelerations recorded in the shaking table, that included spurious peaks. If these spurious peaks are removed, the PGAs obtained for the simulations that represent realistic complete ground motions C35, C50, $\mathrm{C} 100, \mathrm{C} 200$ and $\mathrm{C} 300$, are $0.07 \mathrm{~g}, 0.10 \mathrm{~g}, 0.19 \mathrm{~g}, 0.39 \mathrm{~g}$ and $0.59 \mathrm{~g}$, respectively. Applying the ranges of $a_{g} F$ explained in Chapter 2, the ground motions simulated can be grouped as function of the Mean Return Period and the Probability of Occurrence (Table 4.1).

Table 4. 1. Main return period and probability of occurrence of simulations

\begin{tabular}{cccc}
\hline Test & $\boldsymbol{a}_{\boldsymbol{g}} \boldsymbol{F}$ values & $\begin{array}{c}\text { Mean Return } \\
\text { Period }\end{array}$ & Probability of Occurrence \\
\hline $\mathrm{C} 35, \mathrm{C} 50$ & $a_{g} F<0.14 g$ & $<95$ years & Very frequent \\
$\mathrm{C} 100$ & $0.14 g<a_{g} F<0.17 g$ & 95 years & Frequent \\
$\mathrm{C} 200$ & $0.32 g<a_{g} F<0.39 g$ & 475 years & Design \\
$\mathrm{C} 300$ & $0.58 g<a_{g} F$ & $\geq 2475$ years & Very rare \\
\hline \hline
\end{tabular}




\section{OVERALL RESPONSE}

For convenience in the forthcoming discussions, the test specimen is idealized as a two-mass lumped model. The data from sensors was transferred to the mass centers of each level (Table 3.5) through the procedure described in Chapter 2 considering a system with 3 DOFs per lumped mass as Figure 3.1b shows.

\subsection{Dynamic characterization}

The dynamic characterization consisted on obtaining natural periods and the damping ratios of the structure. Table 4.2 lists natural periods, frequencies and the damping ratio of the first three main modes of the structure.

Table 4.2. Evolution of natural periods and damping ratios

\begin{tabular}{lccccccc}
\hline Test & $\begin{array}{c}\mathbf{T}_{\mathbf{1}} \\
{[\mathbf{s}]}\end{array}$ & $\begin{array}{c}\mathbf{f}_{\mathbf{1}} \\
{[\mathbf{H z}]}\end{array}$ & $\begin{array}{c}\mathbf{T}_{\mathbf{2}} \\
{[\mathbf{s}]}\end{array}$ & $\begin{array}{c}\mathbf{f}_{\mathbf{2}} \\
{[\mathbf{H z}]}\end{array}$ & $\begin{array}{c}\mathbf{T}_{\mathbf{3}} \\
{[\mathbf{s}]}\end{array}$ & $\begin{array}{c}\mathbf{f}_{\mathbf{3}} \\
{[\mathbf{H z}]}\end{array}$ & $\begin{array}{c}\boldsymbol{\xi}_{\mathbf{1}} \\
{[\mathbf{\%}]}\end{array}$ \\
\hline Prior & 0.38 & 2.63 & 0.27 & 3.7 & 0.23 & 4.34 & 2.4 \\
T10 & 0.43 & 2.33 & 0.32 & 2.33 & 0.23 & 4.33 & 4.6 \\
C35 & 0.38 & 2.63 & 0.27 & 3.7 & 0.23 & 4.34 & 2.4 \\
C50 & 0.38 & 2.63 & 0.27 & 3.7 & 0.23 & 4.34 & 2.4 \\
C100 & 0.43 & 2.32 & 0.33 & 3.03 & 0.25 & 4.00 & 4.1 \\
C200i & 0.50 & 2.00 & 0.39 & 2.56 & 0.25 & 4.00 & 4.5 \\
C200 & 0.60 & 1.66 & 0.39 & 2.56 & 0.30 & 3.33 & 5.7 \\
C300 & 0.75 & 1.33 & 0.42 & 2.38 & 0.30 & 3.33 & 9.2 \\
\hline \hline
\end{tabular}

They were obtained from a range of data at the end of the displacement response for each test (earthquake-tail hereafter). This zone was used because acceleration feedback is almost zero at the end of each simulation, i.e. the shaking table was virtually motionless, and therefore, the structure was moving in free vibration. Apparently, this situation is the optima (free vibration) to obtain the natural periods and damping ratios without interferences from the ground motion, but it has the inconvenient that the signal amplitude in this zone sometimes is very low. In contrast, very low displacements guarantee that the structure is responding within the elastic range and the period obtained is associated with the initial elastic stiffness. Test T10 and C200i (underlined in Table 4.2), provided two free vibration zones with relatively large displacements that overcome the inconvenient mentioned above. However, since the displacements are relatively large the specimen is not moving within the elastic range, and therefore the periods obtained are associated with a secant stiffness (not with the initial elastic stiffness). This would explain the larger period obtained for test $\mathrm{T} 10$ in comparison with $\mathrm{C} 35$ and C50. For the same reason, the damping fraction can be affected by minor plastic deformations and this would explain the larger $\xi_{1}$ obtained for $\mathrm{T} 10$ in comparison with $\mathrm{C} 35$ and C50.

Natural periods were obtained in terms of frequencies $(f=1 / T)$ applying the Fast Fourier Transform (FFT) to the earthquake-tail displacement response for each test. In the case of the damping ratio, the true damping characteristic of typical structural systems are very complex and difficult to define. However, it is common practice to express the damping of a real system in terms of equivalent viscous-damping ratios $\xi$, which show similar decay rates under freevibration conditions (Clough \& Penzien, 1992). To evaluate the damping ratio, it is common to use equation (4.1):

$$
\ln \left(\frac{v_{n}}{v_{n+m}}\right)=\frac{2 m \pi \xi}{\sqrt{1-\xi^{2}}}
$$


Where $v_{n}$ is a positive peak displacement and $v_{n+m}$ is a positive peak displacement $m$ cycles later. To calculate the damping ratio in this study, two functions $\mathrm{f}_{a}(t)=\rho e^{-\xi_{a} \omega t}$ and $\mathrm{f}_{b}(t)=-\rho e^{-\xi_{b} \omega t}$ were adjusted to the earthquake-tail peaks displacement response for each test using Matlab algorithms. Firstly, the Matlab algorithm envelope captured the peaks and then, the algorithm fit created an exponential function with the form $f(t)=a e^{b x}$. Finally, the damping ration was the average of $\xi_{a}$ and $\xi_{b}$. Figure 4.2 shows the fitting curves adjusted to the earthquake-tail of test T10 as an example. It is worth noting that the estimation of damping ratios by this method is always a rough approximation, because it is strongly dependent of the range of data considered.

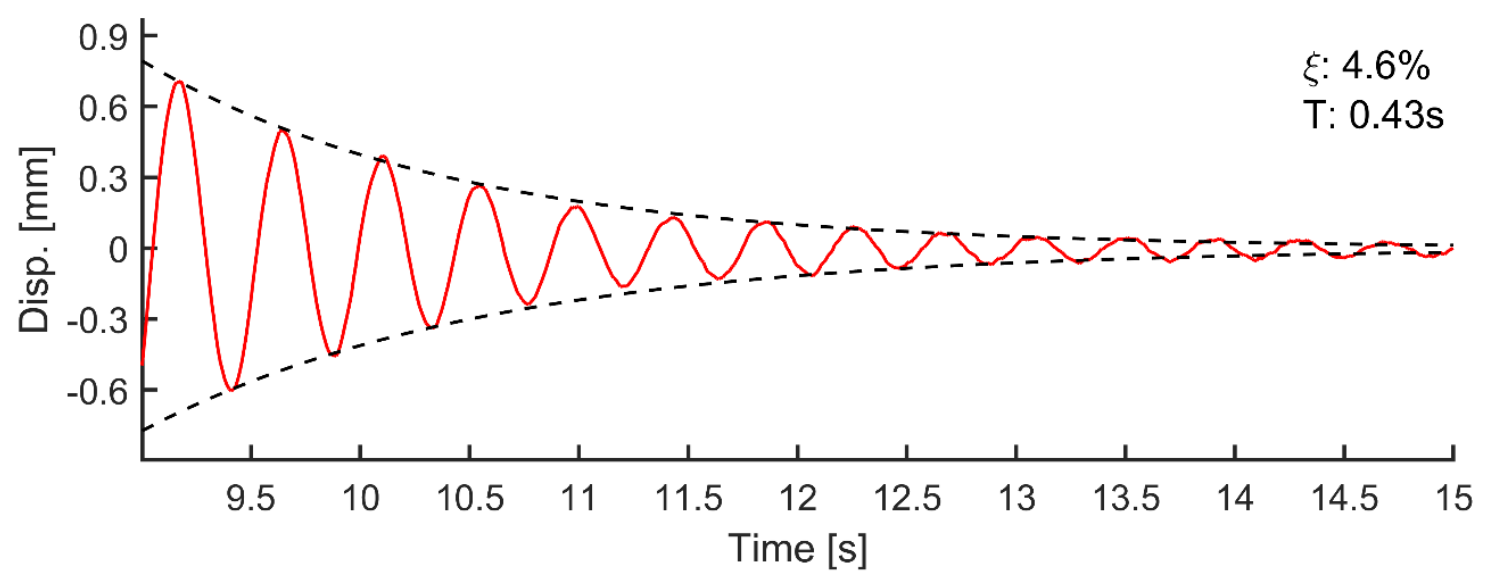

Figure 4. 2. Histories of earthquake-tail displacement response for obtaining periods and the damping ration in Test $\mathrm{T} 10$

\subsection{Quantitative response in terms of displacements and rotations}

\subsubsection{History of displacements}

Figure 4.3 shows the histories of displacement relative to the shaking table of the points located at the centers of mass defined in the two-mass model (Chapter 3). DOFs 1 to 3 corresponds to displacements $\mathrm{X}, \mathrm{Y}$ and rotation about $\mathrm{Z}$ at the first level, and DOFs 4 to 6 corresponds to the displacements $\mathrm{X}, \mathrm{Y}$ and rotation about $\mathrm{Z}$ at the second level. To obtain this data, the linear procedure explained in Chapter 2 was applied to the displacements recorded by the displacement transducers.

Plots show that the structure endured the shaking until test C300. In this test C300, a large peak displacement occurred at $350.9 \mathrm{~s}$ and after that, a large permanent displacement remained in all DOFs. This point is considered as the point of failure and hereafter is identified as C300*. 


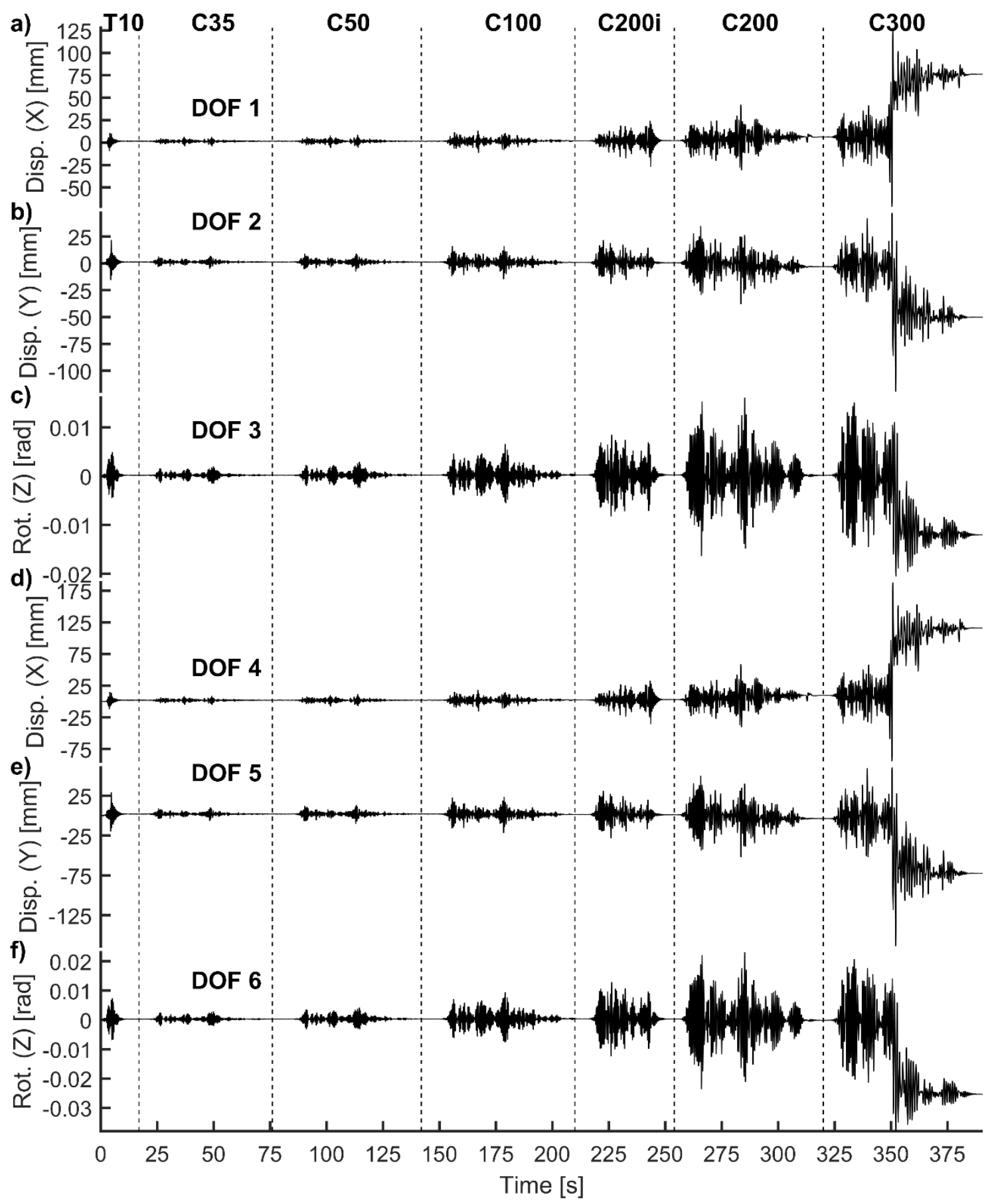

Figure 4. 3. Histories of displacement response of the two-mass lumped model:

DOF 1, b) DOF 2, c) DOF 3, d) DOF 4, e) DOF 5 and f) DOF 6

\subsubsection{Maximum inter-story drift index}

The maximum response in terms of Inter-story Drift Index (IDI) and residual or permanent Interstory Drift Index $\left(I D I_{r}\right)$ in direction $\mathrm{X}$ and $\mathrm{Y}$ are showed in Tables 4.3 and 4.4. These values were computed normalizing the Inter-story Drift by the story height, $1400 \mathrm{~mm}$ (story 1) and $620 \mathrm{~mm}$ (story 2), and by the total height, $2020 \mathrm{~mm}$, for the case of Top (Figure 2.5). In these Tables, the response for each seismic simulation is related with a SPL applying two different criteria. The first criterion is based on the drift limits proposed by the Structural Engineers Association of California (SEAOC, 1995), that is, $I D I<0.5 \%$ and $I D I_{r}$ negligible for "Operational" (O), 
$I D I<1.5 \%$ and $I D I_{r}<0.5 \%$ for "Life Safety" (LS), IDI $<2.5 \%$ and $I D I_{r}<2.5 \%$ for "Near Collapse" (NC) and IDI $>2.5 \%$ and $I D I_{r}>2.5 \%$ for "Collapse" (C). The SEAOC admits a tolerance of these limits that depends on the lateral stiffness of the structure and can be taken as $\pm 0.1 \%$ for WFP systems. The second criterion is based on the results of this study (proposed), after an evaluation of the damage observed and measured in the specimen in terms of deformations and energy dissipated. In addition, Table 4.5 summarizes the maximum rotational response about the center of mass per story and at the top. Note that $\mathrm{C} 300^{*}$ in tables refers to the instant where the specimen reached the point of collapse.

Table 4. 3. Maximum translational response in direction $\mathrm{X}$

\begin{tabular}{|c|c|c|c|c|c|c|c|c|c|c|}
\hline \multirow[b]{2}{*}{ Test } & \multicolumn{3}{|c|}{ Story 1} & \multicolumn{3}{|c|}{ Story 2} & \multicolumn{2}{|c|}{ Top } & \multicolumn{2}{|c|}{ SPL } \\
\hline & $\begin{array}{c}\ddot{\boldsymbol{u}}_{\max }^{t} \\
{[\boldsymbol{g}]}\end{array}$ & $\begin{array}{l}\text { IDI } \\
{[\%]}\end{array}$ & $\begin{array}{c}I D I_{r} \\
{[\%]}\end{array}$ & $\begin{array}{c}\ddot{\boldsymbol{u}}_{\text {max }}^{t} \\
{[\boldsymbol{g}]}\end{array}$ & $\begin{array}{l}I D I \\
{[\%]}\end{array}$ & $\begin{array}{c}I D I_{r} \\
{[\%]}\end{array}$ & $\begin{array}{l}\text { IDI } \\
{[\%]}\end{array}$ & $\begin{array}{c}I D I_{r} \\
{[\%]}\end{array}$ & SEAOC & Proposed \\
\hline C35 & 0.14 & 0.48 & 0.11 & 0.18 & 0.38 & 0.08 & 0.45 & 0.10 & $\mathrm{O}$ & $\mathrm{O}$ \\
\hline C50 & 0.19 & 0.62 & 0.11 & 0.23 & 0.49 & 0.07 & 0.58 & 0.10 & $\mathrm{O}$ & $\mathrm{O}$ \\
\hline C100 & 0.36 & 0.95 & 0.14 & 0.38 & 0.77 & 0.07 & 0.89 & 0.12 & LS & $\mathrm{O}$ \\
\hline C200i & 0.50 & 1.98 & 0.16 & 0.85 & 1.60 & 0.13 & 1.79 & 0.15 & $\mathrm{NC}$ & LS \\
\hline $\mathrm{C200}$ & 0.47 & 3.03 & 0.45 & 0.60 & 2.68 & 0.52 & 2.91 & 0.47 & $\mathrm{C}$ & LS-NC \\
\hline C300* & 0.54 & 5.91 & 5.91 & 0.50 & 5.76 & 5.76 & 5.86 & 5.86 & C & $\mathrm{C}$ \\
\hline C300 & 0.54 & 9.15 & 5.44 & 0.49 & 10.21 & 6.47 & 9.32 & 5.75 & C & C \\
\hline
\end{tabular}

Table 4. 4. Maximum translational response in direction $\mathrm{Y}$

\begin{tabular}{|c|c|c|c|c|c|c|c|c|c|c|}
\hline \multirow[b]{2}{*}{ Test } & \multicolumn{3}{|c|}{ Story 1} & \multicolumn{3}{|c|}{ Story 2} & \multicolumn{2}{|c|}{ Top } & \multicolumn{2}{|c|}{ SPL } \\
\hline & $\begin{array}{c}\ddot{u}_{\text {max }}^{t} \\
{[g]}\end{array}$ & $\begin{array}{l}\text { IDI } \\
{[\%]}\end{array}$ & $\begin{array}{c}I D I_{r} \\
{[\%]}\end{array}$ & $\begin{array}{c}\ddot{u}_{\max }^{t} \\
{[g]}\end{array}$ & $\begin{array}{l}\text { IDI } \\
{[\%]}\end{array}$ & $\begin{array}{c}I D I_{r} \\
{[\%]}\end{array}$ & $\begin{array}{l}\text { IDI } \\
{[\%]}\end{array}$ & $\begin{array}{c}I D I_{r} \\
{[\%]}\end{array}$ & SEAOC & Proposed \\
\hline C35 & 0.14 & 0.49 & 0.09 & 0.17 & 0.43 & 0.11 & 0.49 & 0.10 & $\mathrm{O}$ & $\mathrm{O}$ \\
\hline C50 & 0.20 & 0.65 & 0.09 & 0.25 & 0.55 & 0.11 & 0.65 & 0.10 & $\mathrm{O}$ & $\mathrm{O}$ \\
\hline C100 & 0.34 & 1.16 & 0.06 & 0.47 & 0.96 & 0.08 & 1.17 & 0.07 & LS & $\mathrm{O}$ \\
\hline C200i & 0.42 & 1.54 & 0.04 & 0.69 & 1.31 & 0.07 & 1.54 & 0.05 & $\mathrm{NC}$ & LS \\
\hline C200 & 0.51 & 2.71 & 0.22 & 0.62 & 1.98 & 0.12 & 2.57 & 0.18 & C & LS-NC \\
\hline C300* & 0.65 & 3.37 & 2.75 & 1.36 & 2.27 & 1.38 & 2.99 & 2.13 & C & C \\
\hline C300 & 0.65 & 8.78 & 3.58 & 1.36 & 6.18 & 2.79 & 8.26 & 3.58 & $\mathrm{C}$ & $\mathrm{C}$ \\
\hline
\end{tabular}

Table 4. 5. Maximum rotational response about the centers of mass

\begin{tabular}{|c|c|c|c|c|c|c|c|c|}
\hline \multirow[b]{2}{*}{ Test } & \multicolumn{3}{|c|}{ Story 1} & \multicolumn{3}{|c|}{ Story 2} & \multicolumn{2}{|c|}{ Top } \\
\hline & $\ddot{u}_{\text {max }}^{t}\left[\frac{r a d}{s^{2}}\right]$ & $\begin{array}{c}u \\
{\left[10^{-3}\right.} \\
\text { rad }]\end{array}$ & $\begin{array}{c}u_{r} \\
{\left[10^{-3}\right.} \\
\text { rad }]\end{array}$ & $\ddot{u}_{\max }^{t}\left[\frac{\mathrm{rad}}{s^{2}}\right]$ & $\begin{array}{c}u \\
{\left[10^{-3}\right.} \\
\text { rad }]\end{array}$ & $\begin{array}{c}u_{r} \\
{\left[10^{-3}\right.} \\
\text { rad }]\end{array}$ & $\begin{array}{c}u \\
{\left[10^{-3}\right.} \\
\text { rad }]\end{array}$ & $\begin{array}{c}\boldsymbol{u}_{r} \\
{\left[\mathbf{1 0}^{-3}\right.} \\
\text { rad }]\end{array}$ \\
\hline C35 & 0.53 & 2.03 & 0.19 & 0.56 & 1.00 & 0.08 & 2.91 & 0.27 \\
\hline C50 & 0.72 & 2.95 & 0.22 & 0.84 & 1.36 & 0.11 & 4.18 & 0.32 \\
\hline C100 & 1.44 & 6.57 & 0.22 & 1.69 & 2.98 & 0.14 & 9.44 & 0.36 \\
\hline $\mathrm{C} 200 \mathrm{i}$ & 1.79 & 8.47 & 0.30 & 2.14 & 4.50 & 0.06 & 12.95 & 0.30 \\
\hline $\mathrm{C} 200$ & 2.37 & 16.42 & 0.18 & 2.79 & 7.31 & 0.28 & 23.63 & 0.10 \\
\hline C300* & 1.44 & 15.10 & 9.8 & 5.55 & 7.20 & 0.80 & 21.50 & 9.00 \\
\hline $\mathbf{C 3 0 0}$ & 1.79 & 20.52 & 12.04 & 5.55 & 18.58 & 13.33 & 37.93 & 25.37 \\
\hline
\end{tabular}

In view of the maximums rotations per story (about $0.02 \mathrm{rad}$ ), the relative error discussed in Chapter 2 (Section 2.2) associated with assuming $\sin (\theta)=\theta$ and $\cos (\theta)=1$ for calculating the movements of the centers of mass from the information provided by the displacement transducers was very small (about 3\%) according to Equation (2.6). 


\subsubsection{Chord rotations}

The chord rotations were determined as the quotient between the relative displacements between the top and bottom ends of the columns (obtained with the linear procedure described in Chapter 2 ) and the column height. The chord rotation demands in direction $X$ and $Y, \theta_{X}$ and $\theta_{Y}$, are shown in Figures 4.4 to 4.7 for each plastic hinge located at columns ends.
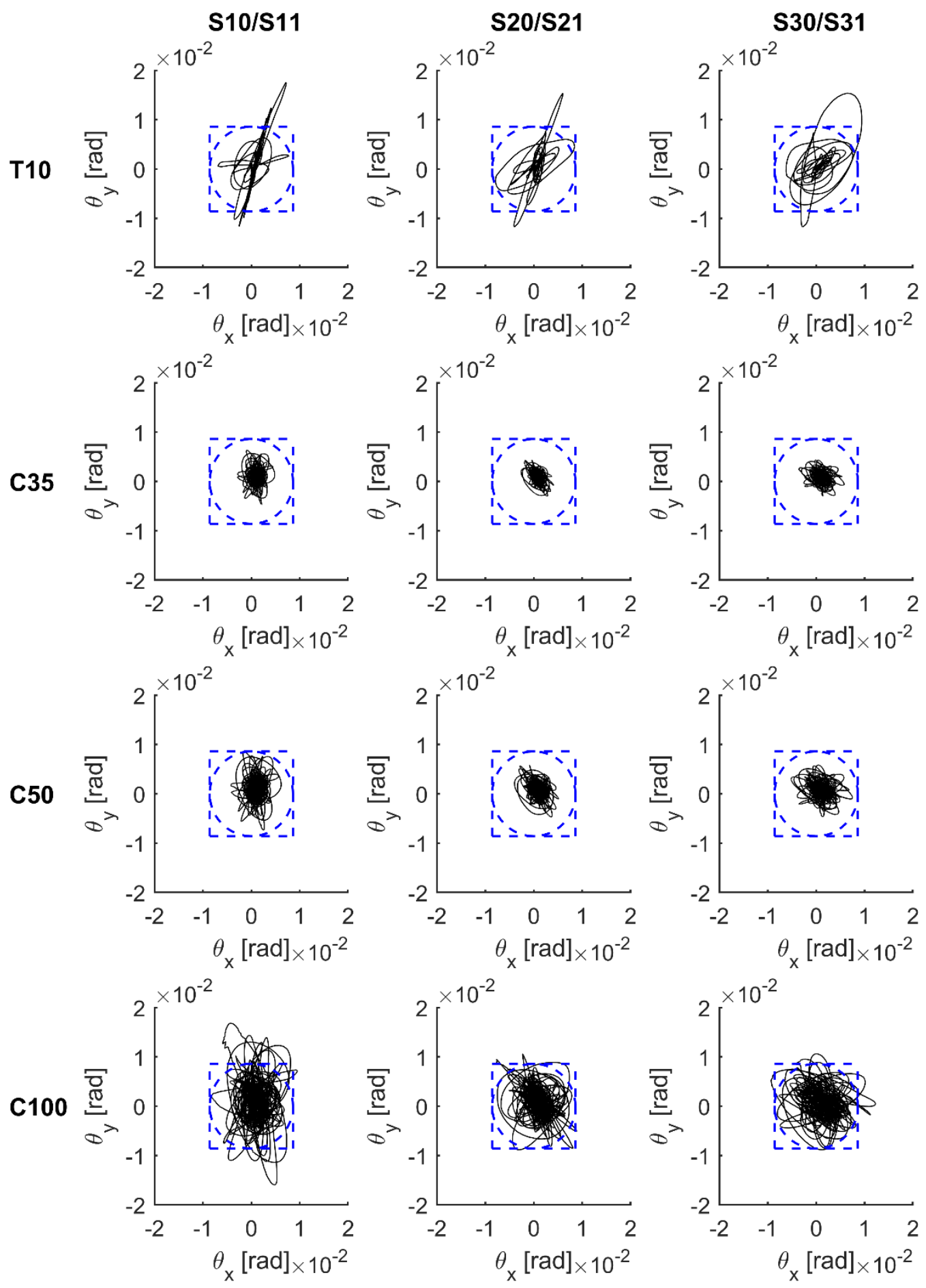

Chord rotation - - - - Yield rotation capacity

Figure 4. 4. Chord rotations of sections S10/S11, S20/S2 1 and S30/S 31 at base and at top columns of first story for simulation T10, C35, C50 and C100 (quasi-linear behavior) 
The name of the column section is shown in Figure 2.2. In Figures 4.4, 4.6 and Tables 4.7 and 4.8 the training signal $\mathrm{T} 10$ has been included although it does not represent a ground motion, in order to show the level of deformations that it imposed to the specimen.
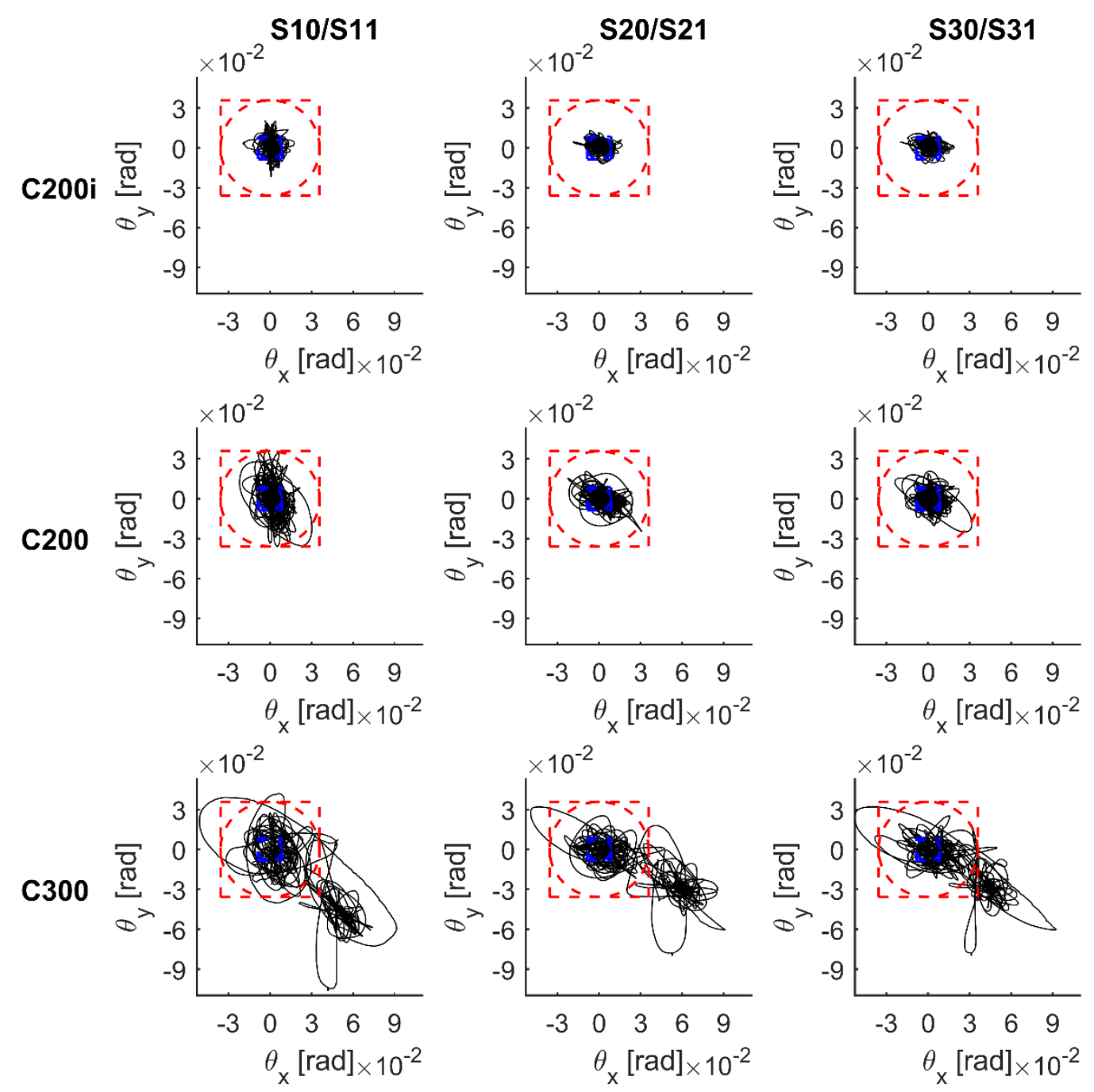

- Chord rotation -- - - Yield rotation capacity

-- - - - Ultimate rotation capacity

Figure 4. 5. Chord rotations of sections S10/S11, S20/S21 and S30/S31 at base and at top columns of first story for simulation C200i, C200 and C300 (nonlinear behavior)

Figures 4.4 to 4.7 are organized showing the different tests (T10 to C300) in rows and the different column sections (S10 to S32) in columns. Moreover, the tests where the specimen behavior was quasi-linear (Figures 4.4 and 4.6) were separated from the tests where the specimen behavior was clearly nonlinear (Figures 4.5 and 4.7). This division makes sense in order to show the trajectories in a visible scale.

In the figures, it is also shown with dot lines the yield rotation $\theta_{y}$ and the ultimate rotation $\theta_{u}$ (Table 4.6), considering two possible interaction curves in $\mathrm{X}$ and $\mathrm{Y}$ directions (circular and square). These chord rotation capacities $\theta_{y}$ and $\theta_{u}$ were predicted using the equations recommended by CEN (2005), based on the work by Fardis (2009). 
Table 4. 6. Yield rotation and the ultimate rotation

\begin{tabular}{ccccccc}
\hline & S12 & S22 & S32 & S10/S11 & S20/S21 & S30/S31 \\
\hline$\theta_{y}$ & 0.00785 & 0.00779 & 0.00779 & 0.00865 & 0.00860 & 0.00860 \\
$\theta_{u}$ & 0.03451 & 0.03483 & 0.03483 & 0.03583 & 0.03776 & 0.03776 \\
\hline \hline
\end{tabular}
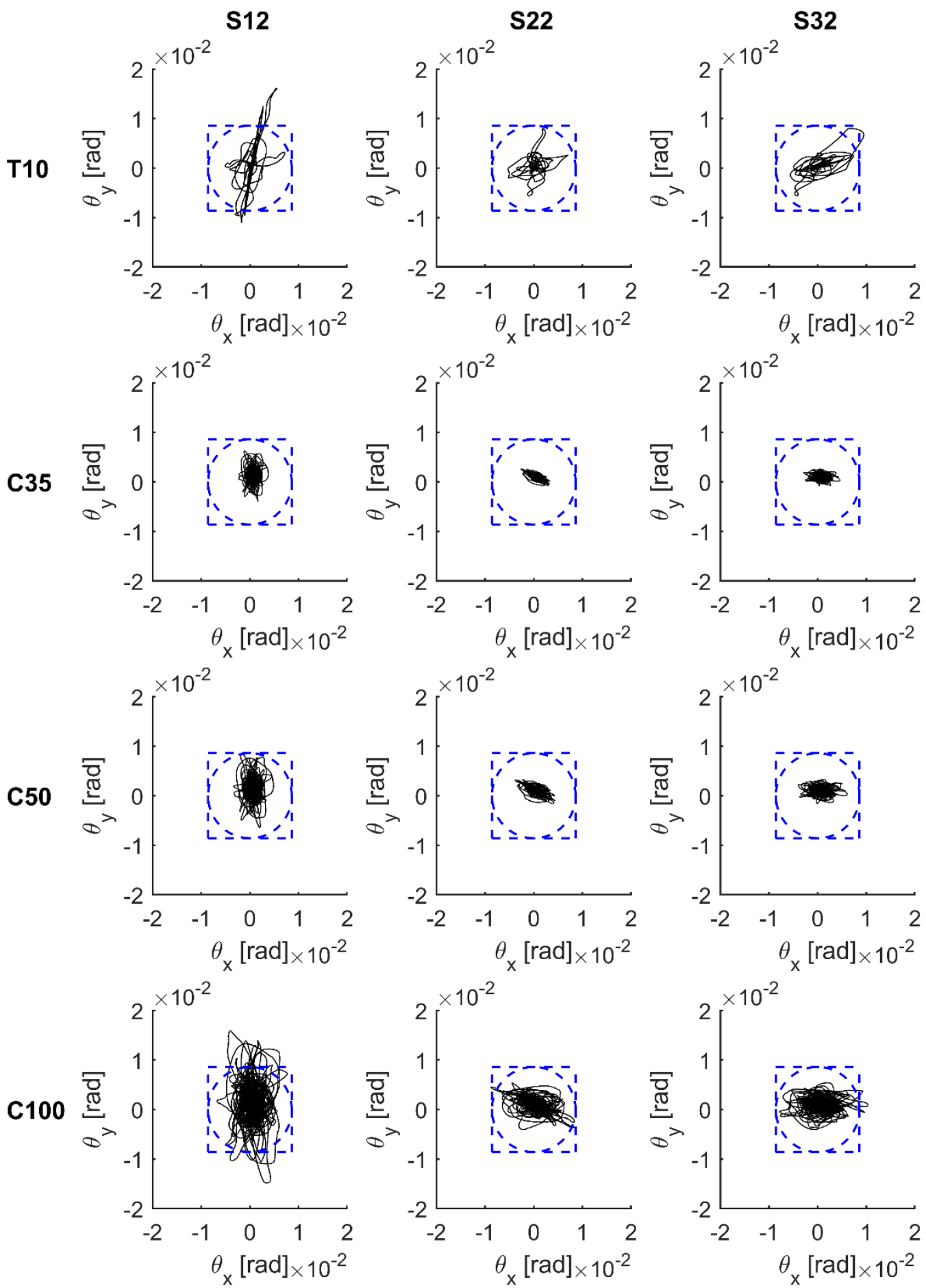

Chord rotation - - - - Yield rotation capacity

Figure 4. 6. Chord rotations of sections S12, S22 and S32 at base columns of second story for simulation $\mathrm{T} 10, \mathrm{C} 35, \mathrm{C} 50$ and $\mathrm{C} 100$ (quasi-linear behavior) 

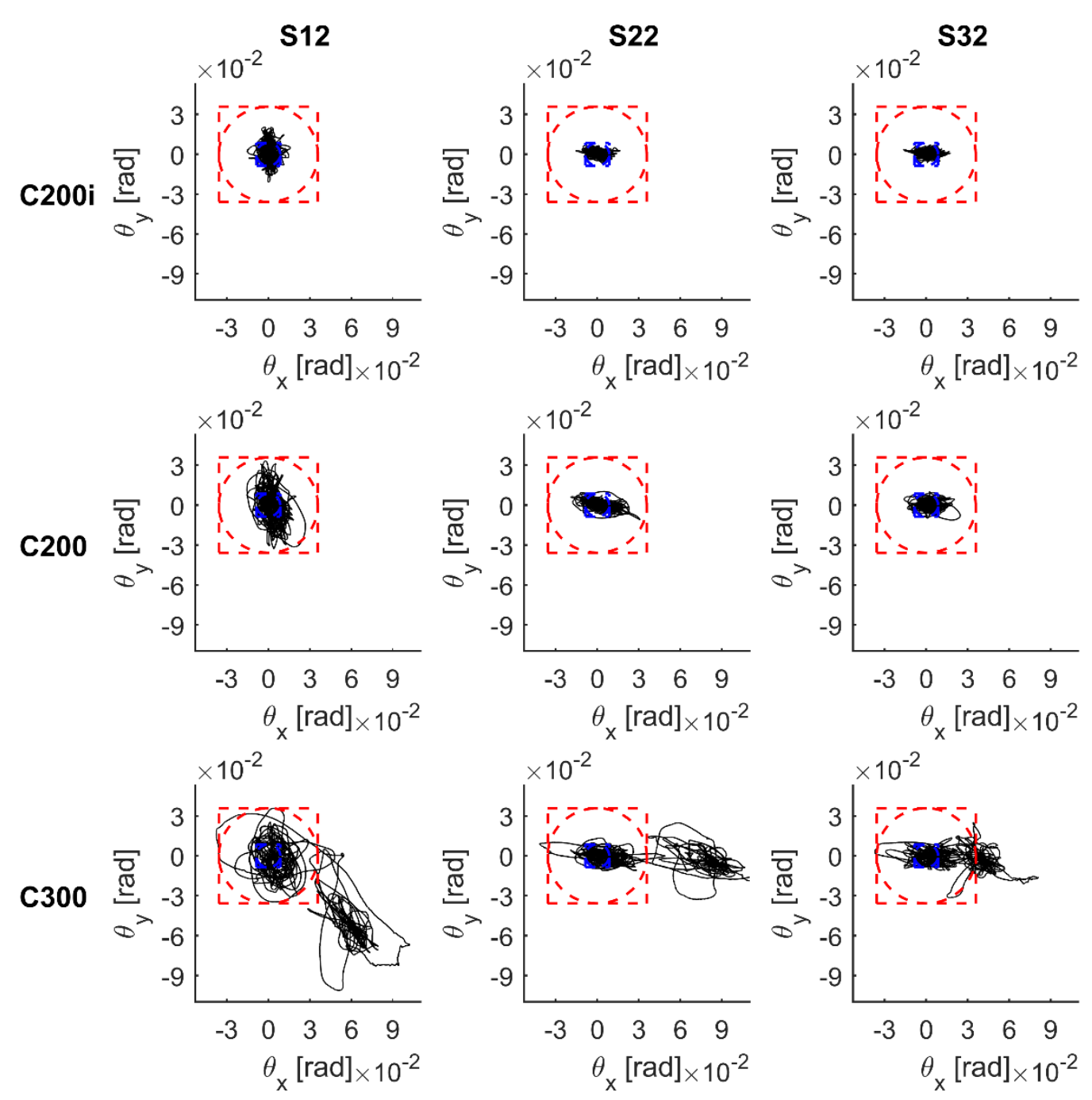

Chord rotation -- - - Yield rotation capacity

- Ultimate rotation capacity

Figure 4. 7. Chord rotations of sections S12, S22 and S32 at base columns of second story for simulation C200i, C200 and C300 (nonlinear behavior)

The maximum rotations in each test was calculated in two different ways: $\theta_{\text {sqrt }}=$ $\max \left\{\sqrt{\theta_{X}^{2}+\theta_{Y}^{2}}\right\}$ (circular) and $\theta_{m X Y}=\max \left\{\theta_{X}, \theta_{Y}\right\}$ (square). Tables 4.7 and 4.8 summarize the plastic hinges performance expressed as the ratio of these values and the ultimate rotation capacity of each section $\theta_{u}$. During test T10, C35, C50 and C100, all columns remained basically elastic with maximum rotations near or slightly above the yield capacity $\theta_{y}$. During test C200 almost all plastic hinges reached the circular ultimate capacity, while only some of them reached the rectangular ultimate capacity. During the initial seconds until the instant of failure in test C300, columns reached chord rotations close to or slightly above $\theta_{u}$. Immediately afterwards, they experienced a single cycle of very large rotation that approached $0.06 \mathrm{rad}$. At the completion of this cycle, it was considered that the test specimen reached its ultimate state. This cycle of large amplitude took place in a direction $\mathrm{E}$ and SE in almost all hinges, as can be observed in the last row of Figures 4.5 and 4.7. 
Table 4. 7. Maximum rotation at column ends (quasi-linear)

\begin{tabular}{|c|c|c|c|c|c|c|c|c|}
\hline \multirow{3}{*}{$\begin{array}{l}\text { Section } \\
\text { Columns }\end{array}$} & \multicolumn{2}{|c|}{ T10 } & \multicolumn{2}{|c|}{ C35 } & \multicolumn{2}{|c|}{ C50 } & \multicolumn{2}{|c|}{ C100 } \\
\hline & $\theta_{\text {sqrt }}$ & $\boldsymbol{\theta}_{m X Y}$ & $\theta_{\text {sqrt }}$ & $\boldsymbol{\theta}_{m X Y}$ & $\boldsymbol{\theta}_{\text {sqrt }}$ & $\boldsymbol{\theta}_{m X Y}$ & $\boldsymbol{\theta}_{\text {sqrt }}$ & $\boldsymbol{\theta}_{m X Y}$ \\
\hline & $\overline{\boldsymbol{\theta}_{u}}$ & $\overline{\theta_{u}}$ & $\overline{\boldsymbol{\theta}_{u}}$ & $\overline{\boldsymbol{\theta}_{u}}$ & $\overline{\theta_{u}}$ & $\overline{\theta_{u}}$ & $\overline{\boldsymbol{\theta}_{u}}$ & $\overline{\theta_{u}}$ \\
\hline S12 & 0.50 & 0.47 & 0.18 & 0.18 & 0.25 & 0.24 & 0.47 & 0.46 \\
\hline S22 & 0.24 & 0.23 & 0.11 & 0.10 & 0.14 & 0.12 & 0.28 & 0.25 \\
\hline S32 & 0.34 & 0.27 & 0.13 & 0.13 & 0.17 & 0.17 & 0.30 & 0.30 \\
\hline S10/S11 & 0.53 & 0.49 & 0.18 & 0.18 & 0.24 & 0.24 & 0.48 & 0.47 \\
\hline S20/S21 & 0.44 & 0.41 & 0.12 & 0.11 & 0.17 & 0.15 & 0.32 & 0.28 \\
\hline S30/S31 & 0.45 & 0.41 & 0.15 & 0.15 & 0.20 & 0.20 & 0.32 & 0.32 \\
\hline
\end{tabular}

Table 4. 8. Maximum rotation at column ends (nonlinear)

\begin{tabular}{|c|c|c|c|c|c|c|}
\hline \multirow{3}{*}{$\begin{array}{l}\text { Section } \\
\text { Columns }\end{array}$} & \multicolumn{2}{|c|}{ C200i } & \multicolumn{2}{|c|}{$\mathrm{C200}$} & \multicolumn{2}{|c|}{$\mathbf{C 3 0 0}$} \\
\hline & $\boldsymbol{\theta}_{\text {sqrt }}$ & $\underline{\boldsymbol{\theta}_{m X Y}}$ & $\boldsymbol{\theta}_{\text {sqrt }}$ & $\underline{\boldsymbol{\theta}_{m X Y}}$ & $\boldsymbol{\theta}_{\text {sqrt }}$ & $\boldsymbol{\theta}_{m X Y}$ \\
\hline & $\overline{\theta_{u}}$ & $\overline{\theta_{u}}$ & $\overline{\theta_{u}}$ & $\overline{\theta_{u}}$ & $\overline{\boldsymbol{\theta}_{u}}$ & $\boldsymbol{\theta}_{\boldsymbol{u}}$ \\
\hline S12 & 0.60 & 0.60 & 1.08 & 0.97 & 3.62 & 2.95 \\
\hline S22 & 0.48 & 0.48 & 0.94 & 0.88 & 3.56 & 3.53 \\
\hline S32 & 0.51 & 0.50 & 0.74 & 0.71 & 2.38 & 2.33 \\
\hline S10/S11 & 0.60 & 0.60 & 1.20 & 1.04 & 3.18 & 2.92 \\
\hline S20/S21 & 0.52 & 0.50 & 1.05 & 0.82 & 2.90 & 2.42 \\
\hline S30/S31 & 0.53 & 0.52 & 1.01 & 0.83 & 2.93 & 2.45 \\
\hline
\end{tabular}

\subsection{Quantitative response in terms of forces}

\subsubsection{History of inertial forces}

The inertial forces during the test were measured using the mass matrix of the two-mass model defined in (3.3) and the data acquired by accelerometers. The latter were transferred to the centers of masses through the linear procedure defined in Chapter 2. With this information and the equation of motion redefined in terms of absolute accelerations (3.2), the vector of inertial forces $\left(\mathbf{F}_{\mathrm{I}}\right)$ is related with the damping and restoring forces as follows:

$$
\mathbf{F}_{\mathbf{I}}=\mathbf{M} \ddot{\boldsymbol{u}}(t)^{t}=-\left(\mathbf{C} \dot{\mathbf{u}}(t)+\mathbf{F}_{\mathbf{S}}(\overline{\mathbf{u}}(t))\right)
$$

Figure 4.8 shows the history of inertial forces for each DOF and Table 4.9 lists the maximum absolute of each DOF for each test. It is worth noting that the maximums listed in this table do not correspond in general to the same instants. In Figure 4.8 and 4.9 the training signal T10 has been included although it does not represent a ground motion, in order to show the level of inertial forces that it imposed to the specimen.

Table 4. 9. Maximums of inertial forces by DOF

\begin{tabular}{ccccccc}
\hline Test & $\begin{array}{c}\text { DOF 1 } \\
{[\mathbf{k N ]}}\end{array}$ & $\begin{array}{c}\text { DOF 2 } \\
{[\mathbf{k N}]}\end{array}$ & $\begin{array}{c}\text { DOF 3 } \\
{[\mathbf{k N m}]}\end{array}$ & $\begin{array}{c}\text { DOF 4 } \\
{[\mathbf{k N}]}\end{array}$ & $\begin{array}{c}\text { DOF 5 } \\
{[\mathbf{k N}]}\end{array}$ & $\begin{array}{c}\text { DOF 6 } \\
{[\mathbf{k N m}]}\end{array}$ \\
\hline $\mathbf{T 1 0}$ & 23.11 & 24.24 & 21.02 & 34.34 & 40.94 & 24.84 \\
$\mathbf{C 3 5}$ & 7.67 & 8.05 & 5.11 & 11.05 & 10.76 & 7.34 \\
$\mathbf{C 5 0}$ & 10.37 & 11.22 & 6.94 & 14.55 & 15.75 & 10.89 \\
$\mathbf{C 1 0 0}$ & 20.15 & 19.22 & 13.54 & 24.26 & 29.33 & 22.03 \\
$\mathbf{C 2 0 0 i}$ & 27.52 & 23.29 & 17.11 & 53.78 & 42.70 & 27.67 \\
$\mathbf{C 2 0 0}$ & 26.29 & 28.81 & 22.92 & 37.26 & 38.81 & 36.32 \\
$\mathbf{C 3 0 0 *}$ & 30.12 & 35.99 & 16.51 & 31.29 & 85.91 & 72.11 \\
$\mathbf{C 3 0 0}$ & 11.06 & 19.18 & 7.61 & 21.70 & 63.60 & 31.62 \\
\hline \hline
\end{tabular}

Note: $\mathrm{C} 300^{*}$ refers to the instant where the specimen reached the point of collapse 


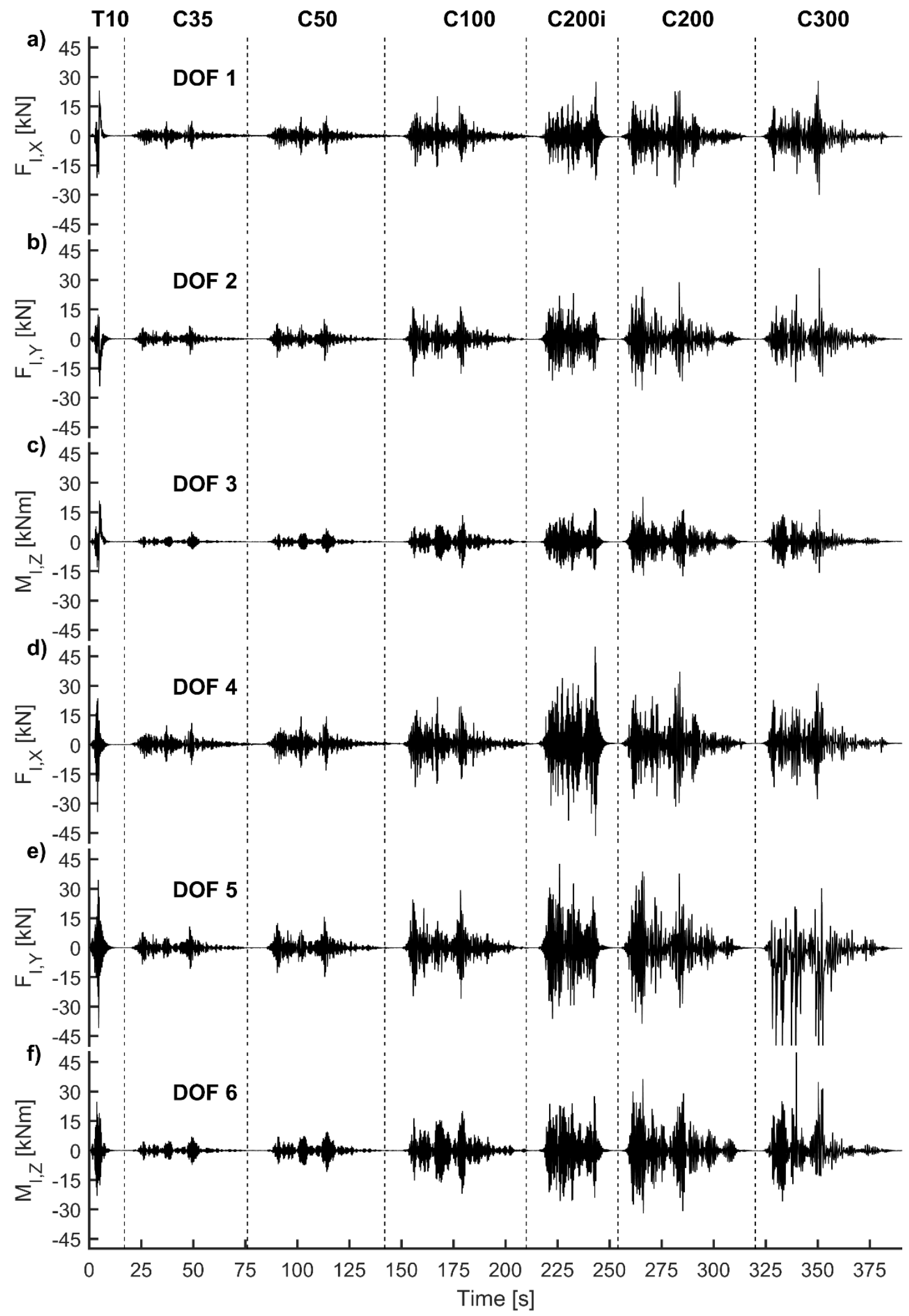

Figure 4. 8. Histories of inertial force response of the two-mass lumped model:

a) DOF 1, b) DOF 2, c) DOF 3, d) DOF 4, e) DOF 5 and f) DOF 6 


\subsubsection{History of base shears exerted by inertial forces}

The base shear forces exerted by the inertial forces $\mathbf{F}_{\mathbf{I}}$ in direction $\mathrm{X}$ and $\mathrm{Y}\left(F_{I B, X}\right.$ and $\left.F_{I B, Y}\right)$ were calculated through the inertial forces $\left(\mathbf{F}_{\mathbf{I}}\right)$ simply applying $F_{I B, X}=\mathbf{F}_{\mathbf{I}}^{\mathrm{T}} \mathbf{J}_{\mathbf{X}}$ and $F_{I B, Y}=\mathbf{F}_{\mathbf{I}}^{\mathrm{T}} \mathbf{J}_{\mathbf{y}}$, where $\mathbf{J}_{\mathbf{X}}=\left[\begin{array}{llllll}1 & 0 & 0 & 1 & 0 & 0\end{array}\right]^{T}$ and $\mathbf{J}_{\mathbf{y}}=\left[\begin{array}{llllll}0 & 1 & 0 & 0 & 1 & 0\end{array}\right]^{T}$ are the influence vectors. It is worth noting that, in general, these forces $F_{I B, X}$ and $F_{I B, Y}$ differ from the base shears endured by the structure because the damping forces are involved. $F_{I B, X}$ and $F_{I B, Y}$ are equal to the base shears endured by the structure only at the instants when velocity is zero and thus the viscous damping forces cancel. Separating damping forces $\mathbf{F}_{\boldsymbol{\xi}}=\mathbf{C} \dot{\mathbf{u}}$ from restoring forces $\left(\mathbf{F}_{\mathbf{S}}\right)$ is difficult because the damping forces are not directly measured; the indirect calculation of $\mathbf{F}_{\xi}=\mathbf{C} \dot{\mathbf{u}}$ from the velocities and the damping matrix $\mathbf{C}$ provides only a very rough estimation because the actual $\mathbf{C}$ of the structure is unknown. Figure 4.9 shows the history of base shear forces exerted by the inertial forces in directions $\mathrm{X}$ and $\mathrm{Y}$.

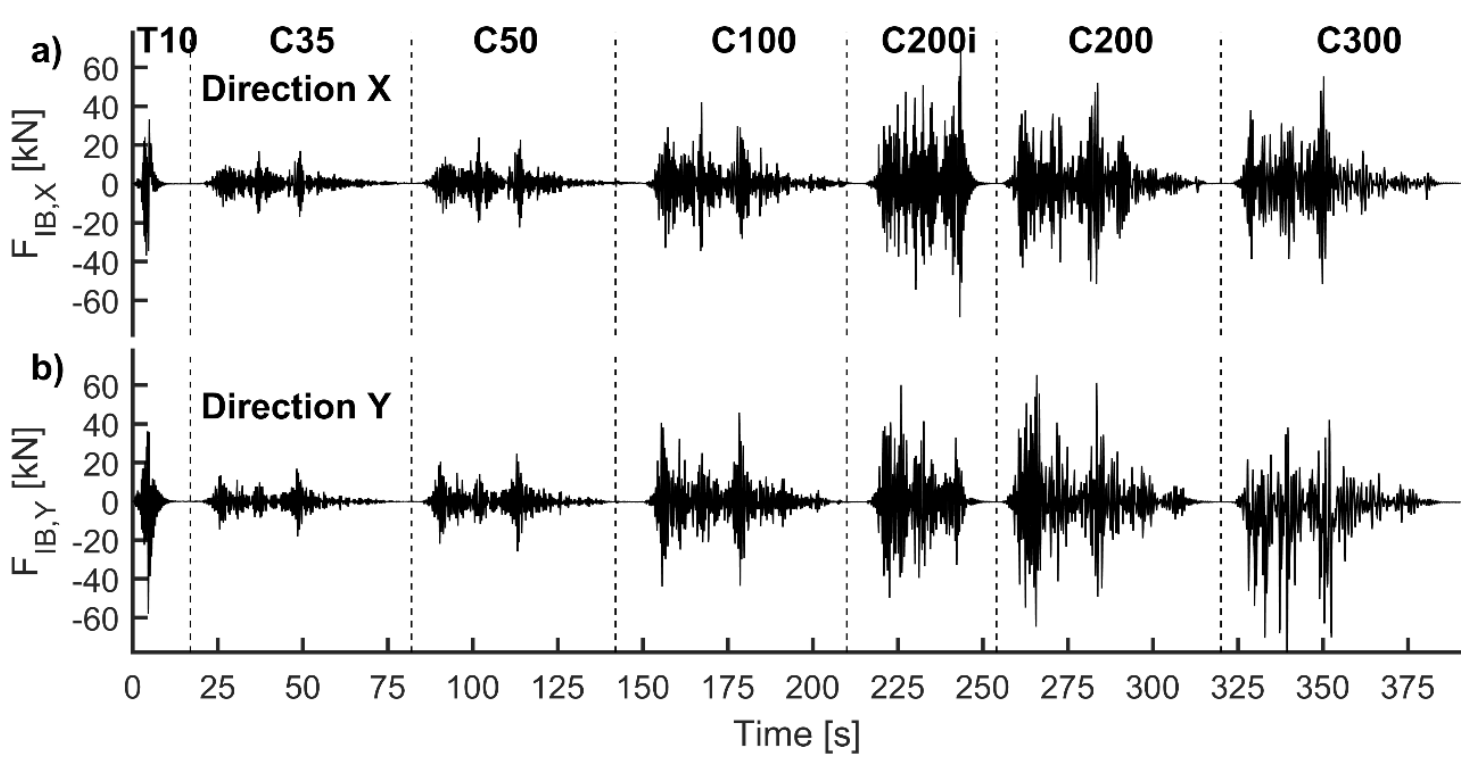

Figure 4. 9. Histories of base shears exerted by inertial forces

: a) Direction $X$ and b) Direction $Y$

Table 4. 10. Maximum values of base shears exerted by inertial forces (Figure 4.9)

\begin{tabular}{ccccc}
\hline \multirow{3}{*}{ Simulation } & \multicolumn{3}{c}{ Floor 1 } & \multicolumn{2}{c}{ Floor 2 } \\
\cline { 2 - 5 } & $\begin{array}{c}\text { Dir X } \\
{[\mathbf{k N}]}\end{array}$ & $\begin{array}{c}\text { Dir Y } \\
{[\mathbf{k N}]}\end{array}$ & $\begin{array}{c}\text { Dir X } \\
{[\mathbf{k N}]}\end{array}$ & $\begin{array}{c}\text { Dir Y } \\
{[\mathbf{k N}]}\end{array}$ \\
\hline T10 & 36.89 & 58.08 & 34.34 & 40.94 \\
C35 & 17.13 & 18.11 & 11.05 & 10.76 \\
C50 & 23.83 & 25.98 & 14.55 & 15.75 \\
C100 & 42.09 & 45.90 & 24.26 & 29.33 \\
C200i & 68.79 & 60.13 & 53.78 & 42.70 \\
C200 & 52.08 & 65.35 & 37.26 & 38.81 \\
C300* & 55.43 & 103.19 & 31.29 & 85.91 \\
C300 & 26.62 & 70.20 & 21.70 & 63.60 \\
\hline \hline
\end{tabular}

Note: $\mathrm{C} 300 *$ refers to the instant where the specimen reached the point of collapse

The maximum shear forces exerted by the inertial forces $\mathbf{F}_{\mathbf{I}}$ in each direction $\mathrm{X}$ and $\mathrm{Y}$ and in each story are shown in Table 4.10. For the reasons explained above, they can be viewed as an upper bound of the maximum restoring forces exerted by the structure. The maximum shear forces of the first story come from the history of base shear forces (Figure 4.9) and the maximums of 
restoring forces of the second story are directly the maximum of the force response of DOF 4 and 5 (Figure 4.8). In Figure 4.9 and Table 4.10 the training signal T10 has been included although it does not represent a ground motion, in order to show the level of shear forces that it imposed to the specimen.

\subsubsection{Capacity curve}

As noted in previous subsection, there are some instants where the velocity cancels, and thus, the restoring forces exerted by the structure are equal to the inertial forces developed on the system. These instants of zero velocity correspond to maximums or minimums in the history of displacement. Figure 4.10 and 4.11 show these instants with black circles up to the point of collapse in a graph force-displacement. The capacity curve can be obtained, independently for each domain of loading, by connecting the black circles points whose displacements are larger than those attained in previous cycles. This capacity curve can be further appropriated with two segments (bilinear approximation) taking the envelope drawn with red dash lines. The end points of these bilinear curves, referred to as "ultimate displacements" hereafter, are taken as the minimum of either the maximum displacements reached by the specimen during the test or the displacement when the strength drops $20 \%$ in regards to the maximum value attained in the capacity curve. This bilinear approximation serves to define yield base shear forces $Q_{B y}$ and yield top displacements $\delta_{T y}$, in the negative and positive domains and in directions $\mathrm{X}$ and $\mathrm{Y}$, respectively. The values obtained are $Q_{B X y}^{+}=57 \mathrm{kN}, \delta_{T X y}^{+}=23 \mathrm{~mm}, Q_{B X y}^{-}=58 \mathrm{kN}, \delta_{T X y}^{-}=$ $23 \mathrm{~mm}, Q_{B Y y}^{+}=59 \mathrm{kN}, \delta_{T Y y}^{+}=31 \mathrm{~mm}, Q_{B Y y}^{-}=66 \mathrm{kN}$ and $\delta_{T Y y}^{-}=35 \mathrm{~mm}$.

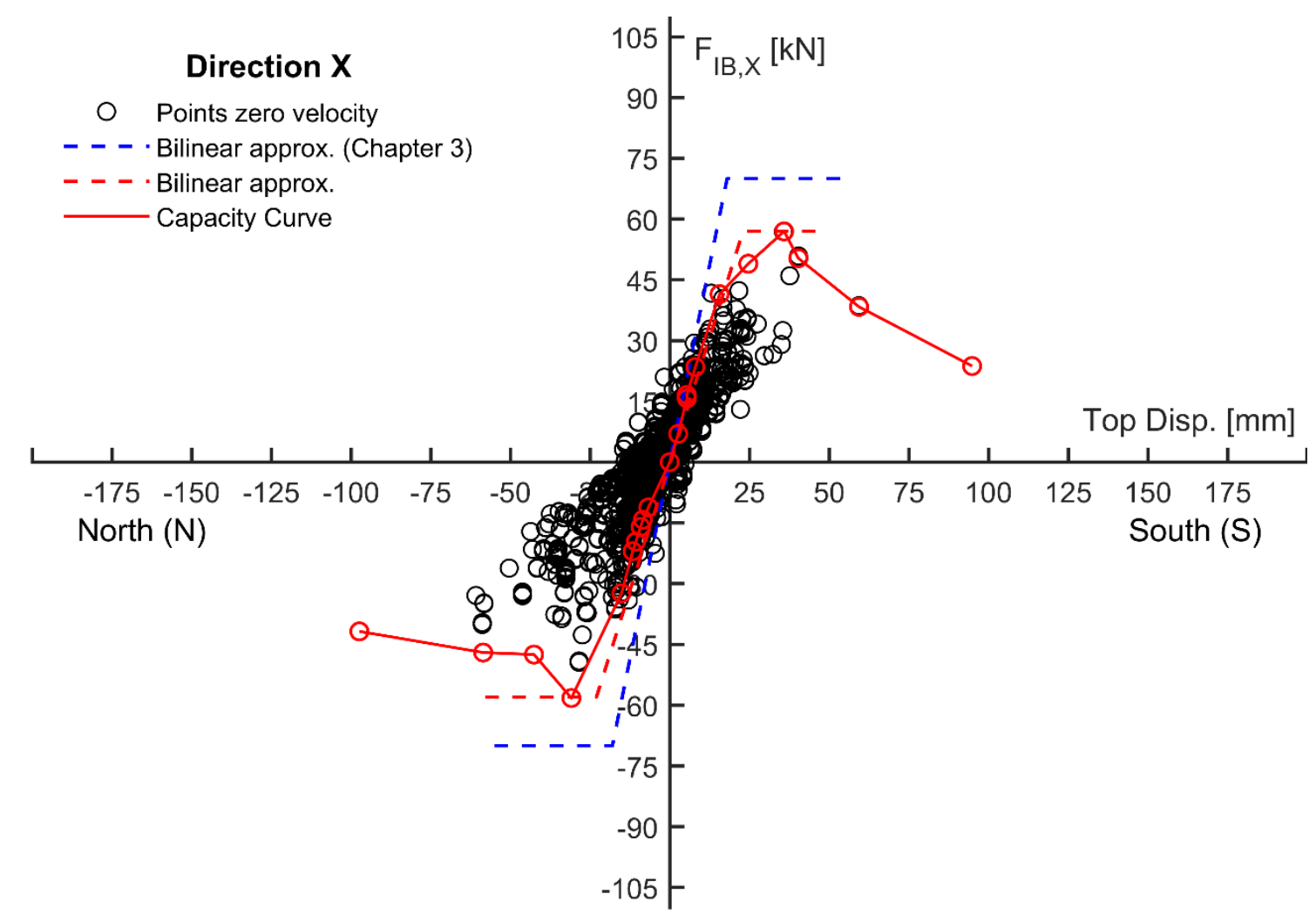

Figure 4. 10. Points of zero velocity and capacity curves in direction $\mathrm{X}$ 
The base shear force coefficients in X direction are $\alpha_{B X}^{+}=\frac{Q_{B X y}^{+}}{g m_{T}}=0.47$ and $\alpha_{B X}^{-}=\frac{Q_{B X y}^{-}}{g m_{T}}=0.48$ and in $\mathrm{Y}$ direction are $\alpha_{B Y}^{+}=\frac{Q_{B Y y}^{+}}{g M}=0.49$ and $\alpha_{B Y}^{-}=\frac{Q_{B Y y}^{-}}{g M}=0.55$. On the other hand, the maximum displacements in the positive and negative domains and each direction $\mathrm{X}$ and $\mathrm{Y}$ are $\delta_{T X u}^{-}=58 \mathrm{~mm}, \delta_{T X u}^{+}=48 \mathrm{~mm}, \delta_{T Y u}^{-}=59 \mathrm{~mm}$ and $\delta_{T Y u}^{+}=46 \mathrm{~mm}$. These values corresponds to ductility values of $\mu_{X}^{-}=\frac{\delta_{T X u}^{-}}{\delta_{T X y}^{-}}=\frac{58}{23}=2.5, \mu_{X}^{+}=\frac{\delta_{T X u}^{+}}{\delta_{T X y}^{+}}=\frac{48}{23}=2.1, \mu_{Y}^{-}=\frac{\delta_{T Y u}^{-}}{\delta_{T Y y}^{-}}=$ $\frac{59}{35}=1.7$ and $\mu_{Y}^{+}=\frac{\delta_{T Y u}^{+}}{\delta_{T Y y}^{+}}=\frac{46}{31}=1.5$. The ductility values in $X$ directions are very similar to those obtained by the research group in previous investigations for a similar test specimen under unidirectional loading $\left(\mu_{X}=2.2\right)$ (Benavent-Climent, Donaire-Avila, \& Oliver-Saiz, 2016).

Furthermore, in Figures 4.10 and 4.11 it is also plot the capacity curve estimated in Chapter 3. This estimation is stiffer and more resistant than the actual structure according with the test results. Even considering cracking sections, the prediction in direction $\mathrm{X}$ and $\mathrm{Y}$ is a $55 \%$ and $60 \%$ stiffer, and in regards to the maximum strength, the prediction in direction $\mathrm{X}$ and $\mathrm{Y}$ is $22 \%$ and $20 \%$ more resistant, even considering an interaction factor in columns of 0.8 .

Direction $\mathbf{Y}$

O Points zero velocity

- - - Bilinear approx. (Chapter 3)

- - - Bilinear approx.

Capacity Curve

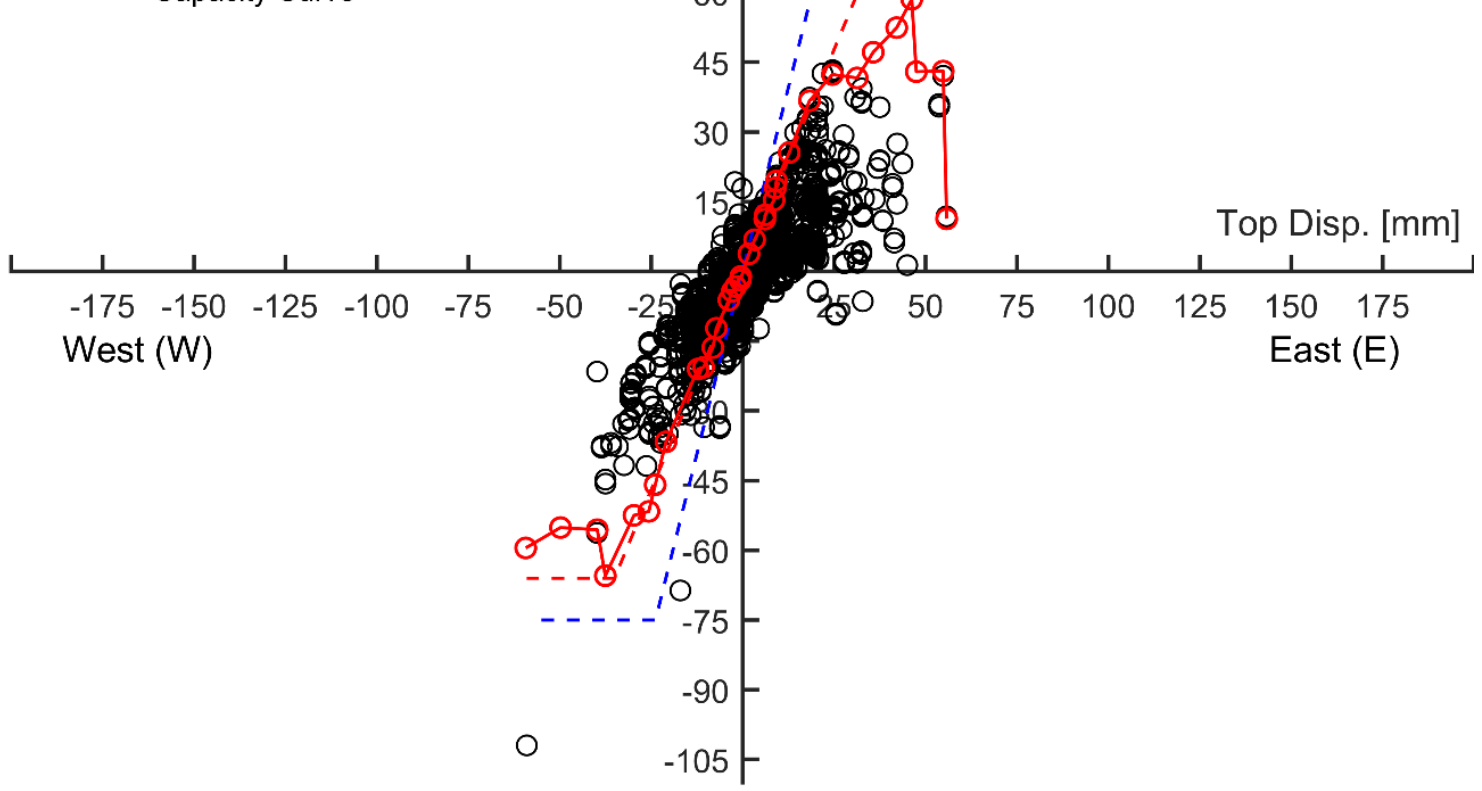

Figure 4. 11. Points of zero velocity and capacity curves in direction Y 


\subsubsection{Base shears exerted by inertial forces versus top displacements}

The Top Displacements (DOF 4 and 5 from section 3.2.1) are met with the base shears exerted by the inertial forces $\left(F_{I B}\right)$ calculated in section 2.3.2 to obtain the force-displacement curves of the structure for each test (Figures 4.12 to 4.15). Moreover, these figures also contain the bilinear approximation of the capacity curve as a reference. While the specimen remains completely elastic (seismic simulations C35 to C50 in Figures 4.12 and 4.14), the force-displacement curves exhibited a form of tilted ellipse with average slope close to the stiffness of the bilinear approximation of the capacity curve. This shape points a linear visco-type damping of the structure in both directions and justifies the use of linear viscous damping models in computational simulations. From here on, the specimen started to yield and dissipate energy not only by damping, but also by plastic deformations. As long as the structure enters in the plastic domain, its stiffness and strength start to drop. This is visible in seismic simulations C200i, C200 and at the beginning of the $\mathrm{C} 300$ in Figures 4.13 and 4.15. As the level of strength and stiffness degradation increases, the structure approaches a mechanism, showing loops far from the origin that eventually lead to the collapse of the structure in Test C300. In Figures 4.12 to 4.15 the training signal T10 has been included although it does not represent a ground motion, in order to show the response of the specimen under this short-pulse acceleration.

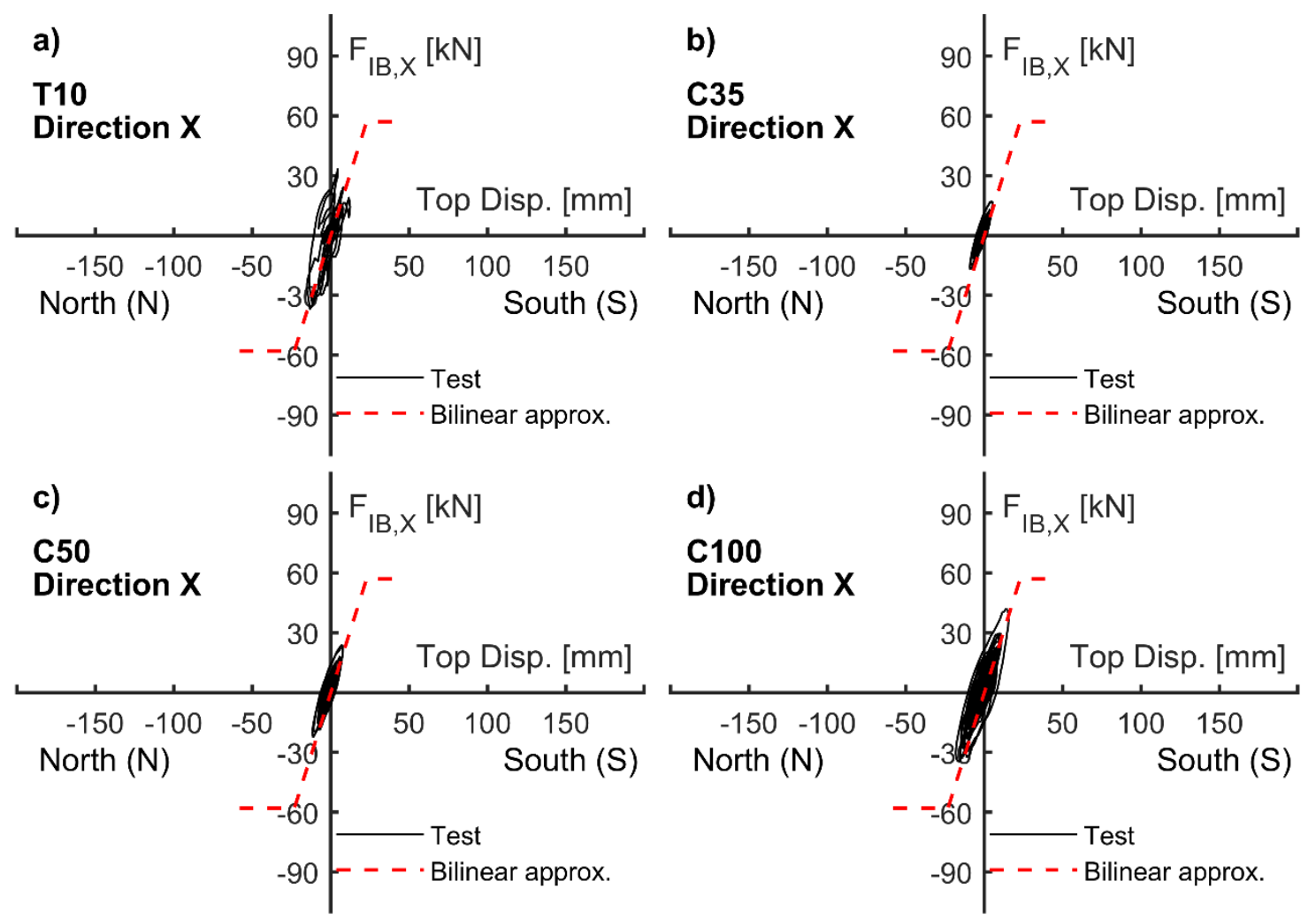

Figure 4. 12. Base shear Force versus Top displacements in direction X: a) Test T10 b) Test C35, c) Test C50 and d) Test C100 


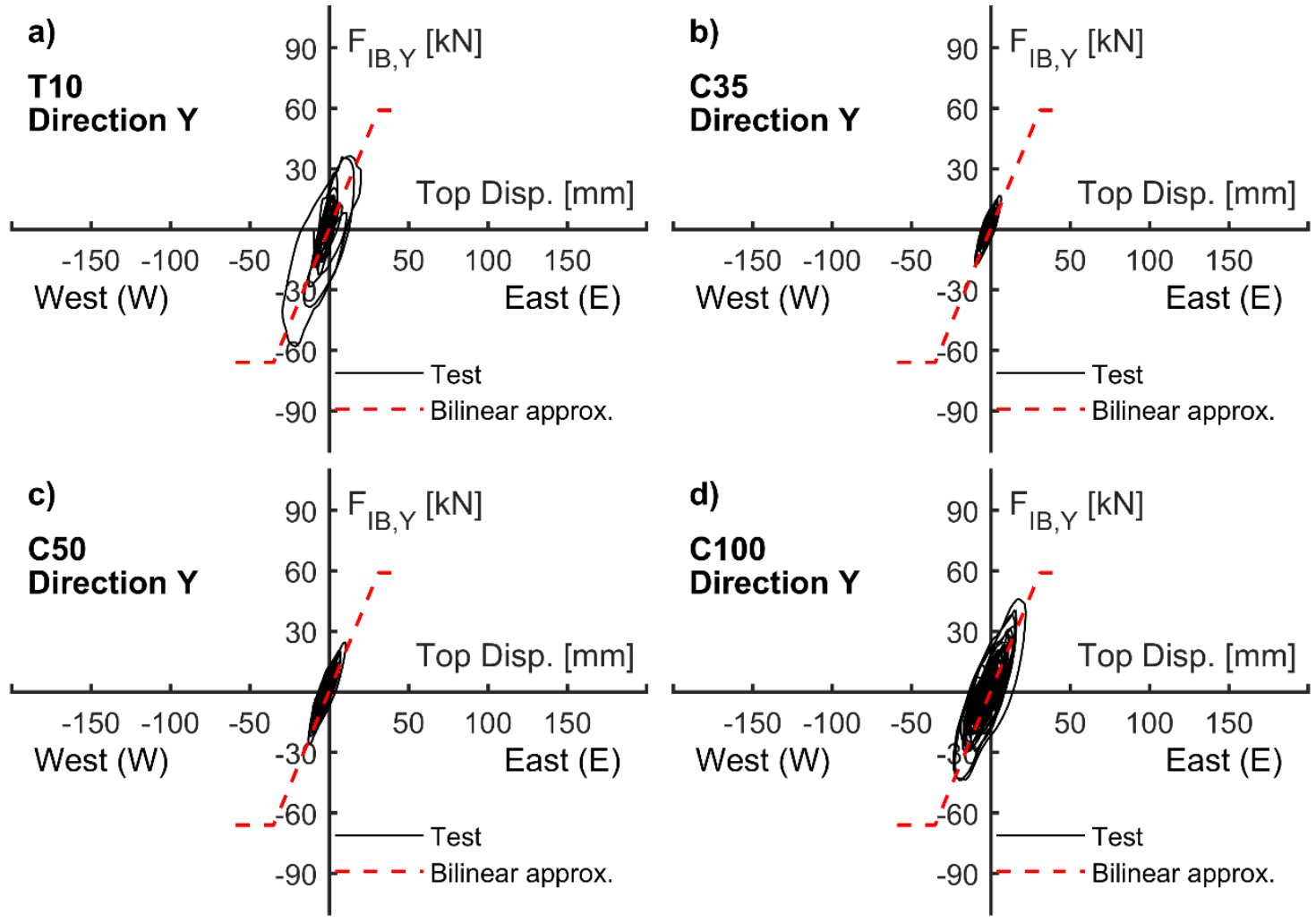

Figure 4. 13. Base shear Force versus Top displacements in direction Y: a) Test T10 b) Test C35, c) Test C50 and d) Test C100

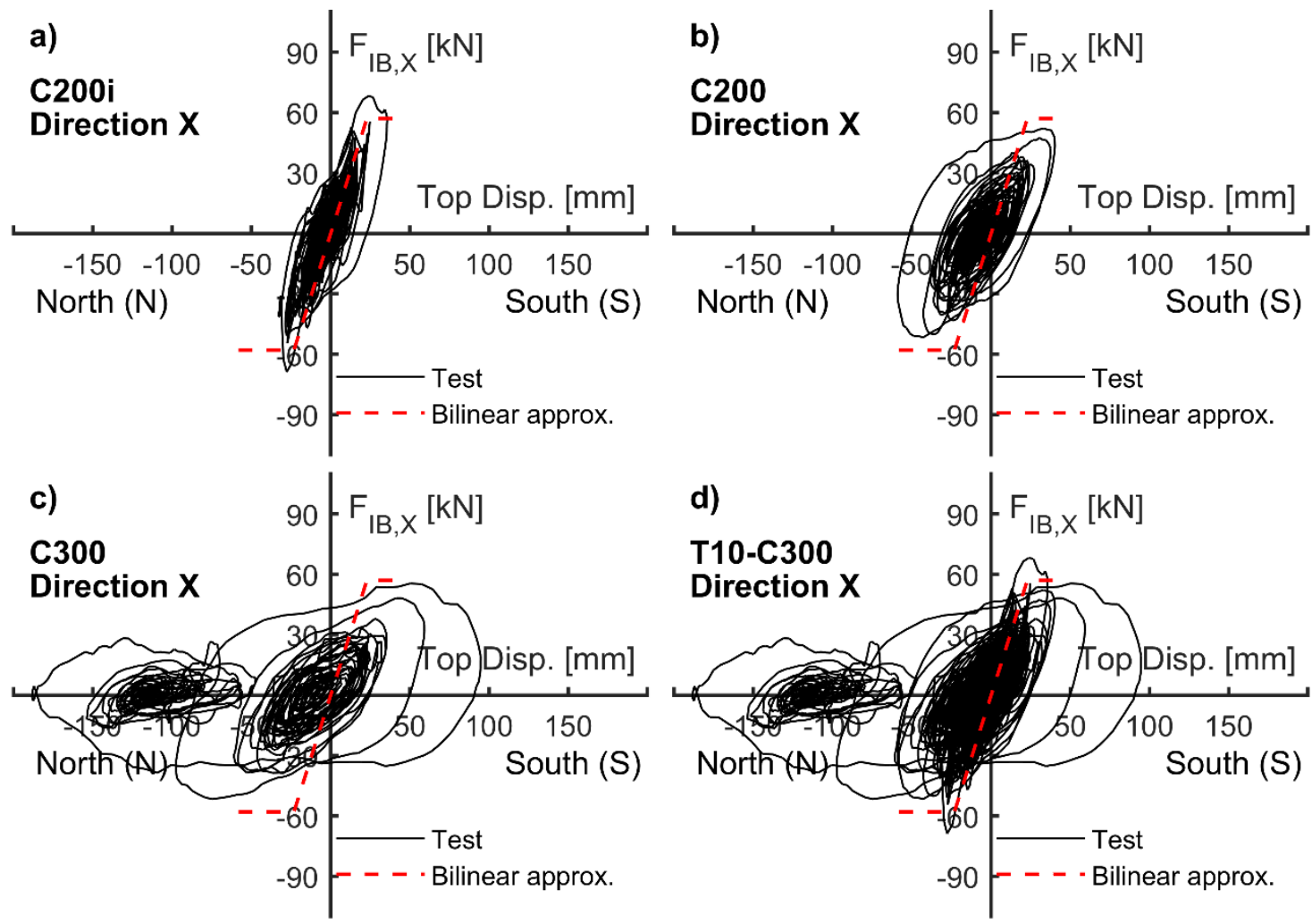

Figure 4. 14. Base shear Force versus Top displacements in direction X: a) Test C200i, b) Test C200, c) Test C300 and d) All Tests 


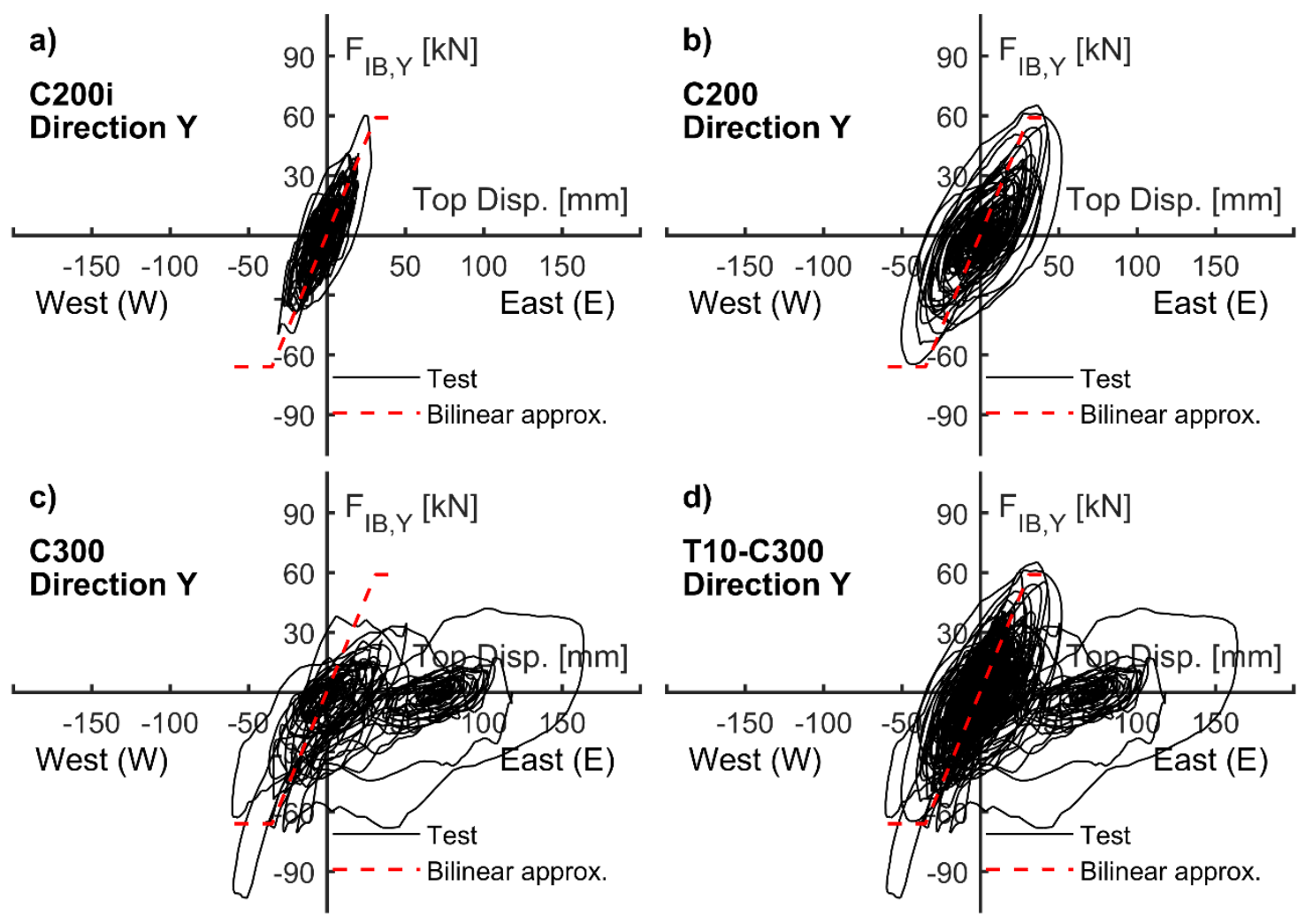

Figure 4. 15. Base shear Force versus Top displacements in direction Y: a) Test C200i, b) Test C200, c) Test C300 and d) All Tests

\subsection{Quantitative response in terms of strains}

During the test, the specimen deformed in the critical sections (S) shown in Figure 2.6, subfigures a) and b). In order to measure the deformation of these sections, 472 strain gauges were fixed to the longitudinal reinforcement contained in these sections. A strain gauge is an electrical sensor, which responds to elongation/contraction with a linear change in electrical resistance. When the sensor is installed in a structure under ideal conditions (smooth surfaces of metallic materials, suitable temperature, humidity and so on), the device can measure the strain with high accuracy provided that the measurement is in the range of the sensor. However, test conditions were far from the optimal because strain gauges were installed on rebars, and this, in turn, were inside concrete, where humidity, temperature, interaction between the gauge and concrete around and the movement of cables during the test played an important role. Therefore, the quality of the measurement can be not as good as intended. Because of that, the results from strain gauges were considered as a rough approximation in this study.

Table 4.11 lists the maximum strains $\varepsilon_{\max }$ registered by strain gauges fixed to the longitudinal bars located at the regions of potential plastic hinges. Appendix 2 shows the position of each strain gauge in each section defined in Figure 2.6b, and the history of the strains registered. Test C300 was not included because the values measured by most of gauges were out of range. The regions of potential plastic hinges in columns were labeled as S10, S20, S30, S11, S21, S31, S12, S22 and S32 (Figure 2.6a). Regions at the connection of the spandrel beam with column $C_{1}$ were labeled as S8Y and S9Y (Figure 2.6b). In the exterior drop panel, the critical sections were labeled as S1X, S2X, S3X, S10Y, S11Y, S12Y and S13Y North (Figure 2.6b), and in the interior drop panel at column $C_{2}$, they were labeled as S4X, S5X, S6X, S7X, S13Y South, S14Y, S15Y and 
S16Y (Figure 2.6b). In critical sections at drop panels, the strains were measured at several points, which are indicated with solid circles in Figure 2.6b.

Table 4. 11. Deformation of longitudinal reinforcement by sections

\begin{tabular}{|c|c|c|c|c|c|c|c|}
\hline & Section & $\begin{array}{c}\mathbf{T 1 0} \\
\varepsilon_{\max } \\
{[\mu \mathrm{m} / \mathbf{m}]}\end{array}$ & $\begin{array}{c}\text { C35 } \\
\varepsilon_{\max } \\
{[\mu \mathrm{m} / \mathrm{m}]}\end{array}$ & $\begin{array}{c}\text { C50 } \\
\varepsilon_{\max } \\
{[\mu \mathrm{m} / \mathbf{m}]}\end{array}$ & $\begin{array}{c}\text { C100 } \\
\varepsilon_{\max } \\
{[\mu \mathrm{m} / \mathbf{m}]}\end{array}$ & $\begin{array}{c}\text { C200i } \\
\varepsilon_{\max } \\
{[\mu \mathrm{m} / \mathrm{m}]}\end{array}$ & $\begin{array}{c}\text { C200 } \\
\varepsilon_{\max } \\
{[\mu \mathrm{m} / \mathrm{m}]}\end{array}$ \\
\hline \multirow{3}{*}{$\begin{array}{c}\text { Column } \\
\text { bases }\end{array}$} & S10 & 6670 & 3814 & 3892 & 9542 & 7680 & 16109 \\
\hline & S20 & 10030 & 3923 & 4553 & 7989 & 14029 & 16474 \\
\hline & $\mathrm{S} 30$ & 14074 & 10458 & 10774 & 12164 & 18287 & 18896 \\
\hline \multirow{11}{*}{$\begin{array}{c}\text { Exterior } \\
\text { connection } \\
\text { of plate and } \\
\text { column C1 }\end{array}$} & S11 & 1221 & 513 & 734 & 1370 & 1766 & 2422 \\
\hline & S12 & 756 & 265 & 390 & 820 & 1249 & 1482 \\
\hline & S1X & 1388 & 632 & 836 & 1427 & 2168 & 1954 \\
\hline & $\mathrm{S} 2 \mathrm{X}$ & 1487 & 801 & 950 & 1412 & 2323 & 3239 \\
\hline & S3X & 1160 & 758 & 996 & 1680 & 1769 & 2010 \\
\hline & S8X & 1563 & 1091 & 1464 & 2687 & 4857 & 18108 \\
\hline & S9X & 3160 & 1412 & 1695 & 2419 & 3298 & 22818 \\
\hline & S10Y & 768 & 405 & 602 & 1193 & 1353 & 1704 \\
\hline & S11Y & 1225 & 851 & 1108 & 1805 & 2203 & 5983 \\
\hline & S12Y & 1998 & 853 & 1052 & 1519 & 2188 & 12796 \\
\hline & S13Y (N) & 740 & 271 & 363 & 728 & 988 & 1249 \\
\hline \multirow{10}{*}{$\begin{array}{c}\text { Interior } \\
\text { connection } \\
\text { of plate and } \\
\text { column C3 }\end{array}$} & S31 & 3850 & 1226 & 1535 & 2486 & 3508 & 12729 \\
\hline & S32 & 1795 & 797 & 1023 & 1546 & 2726 & 2461 \\
\hline & S4X & 1641 & 686 & 833 & 1426 & 1947 & 2238 \\
\hline & S5X & 2143 & 914 & 1042 & 1543 & 2007 & 2314 \\
\hline & S6X & 600 & 368 & 416 & 561 & 1068 & 2441 \\
\hline & S7X & 797 & 468 & 598 & 1009 & 1339 & 1500 \\
\hline & S13Y (S) & 1589 & 806 & 913 & 1255 & 1635 & 2064 \\
\hline & S14Y & 2752 & 868 & 1088 & 1898 & 2371 & 3958 \\
\hline & S15Y & 317 & 188 & 216 & 311 & 503 & 2059 \\
\hline & S16Y & 127 & 33 & 35 & 92 & 256 & 407 \\
\hline \multirow{2}{*}{ Column C2 } & $\mathrm{S} 21$ & 4026 & 1884 & 2196 & 3304 & 4567 & 16354 \\
\hline & S22 & 5279 & 3950 & 4295 & 5303 & 5527 & 9929 \\
\hline
\end{tabular}

Notes: Sections with strains above $\varepsilon_{y}=2586 \mu \mathrm{m} / \mathrm{m}$ in red

Furthermore, the information of the Table 4.11 was also shown graphically in Figures 4.16 to 4.18 by means of a color code; the goal is to show the plastic hinge formation along the tests. These figures represent the state of damage of each critical section at three instants: (i) at the end of test C100, (ii) at the end of test C200i and (iii) at the end of C200. Sections with green solid circle mean $\varepsilon_{\max }<\varepsilon_{y}$, with yellow solid circle $\varepsilon_{y}<\varepsilon_{\max }<2 \varepsilon_{y}$ and with red solid circle $\varepsilon_{\max }>2 \varepsilon_{y}$. The yield strain of the steel $\varepsilon_{y}$ was $2586 \mu \mathrm{m} / \mathrm{m}$. 
a)

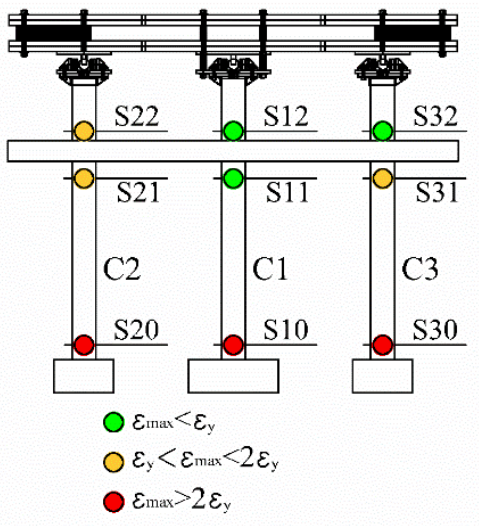

b)

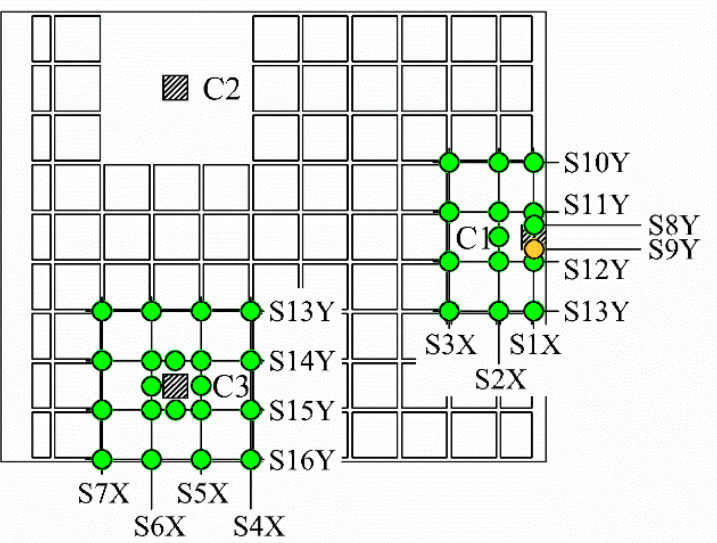

Figure 4. 16. Accumulated damage up to the end of test C100: a) elevation (actuator X point of view) and b) plan

a)

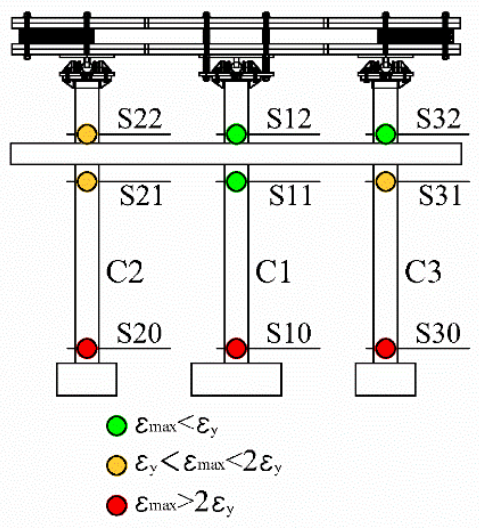

b)

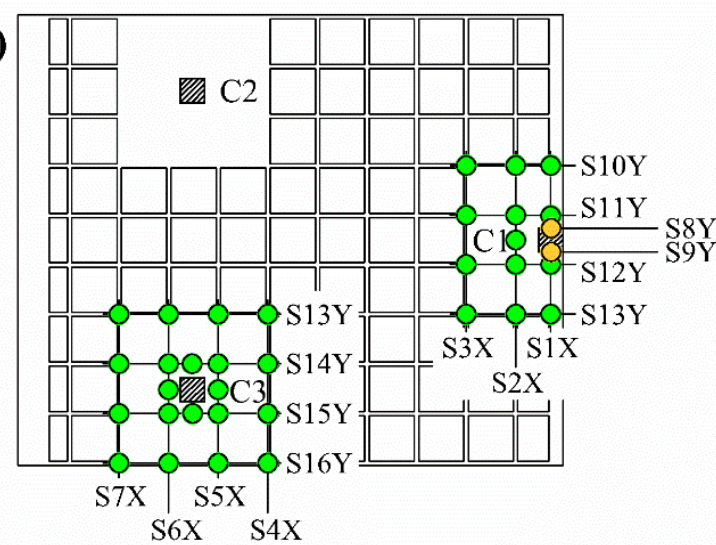

Figure 4. 17. Accumulated damage up to the end of test C200i: a) elevation (actuator X point of view) and b) plan

a)

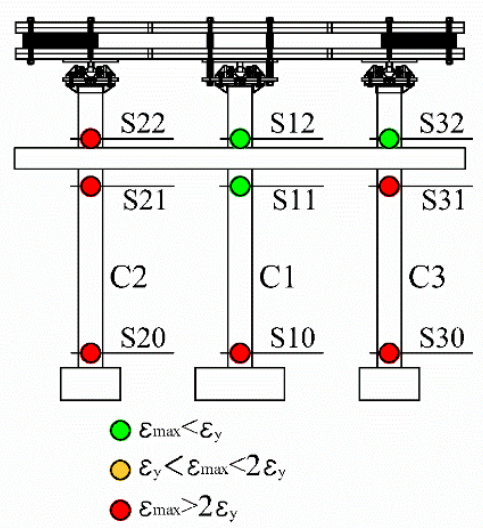

b)

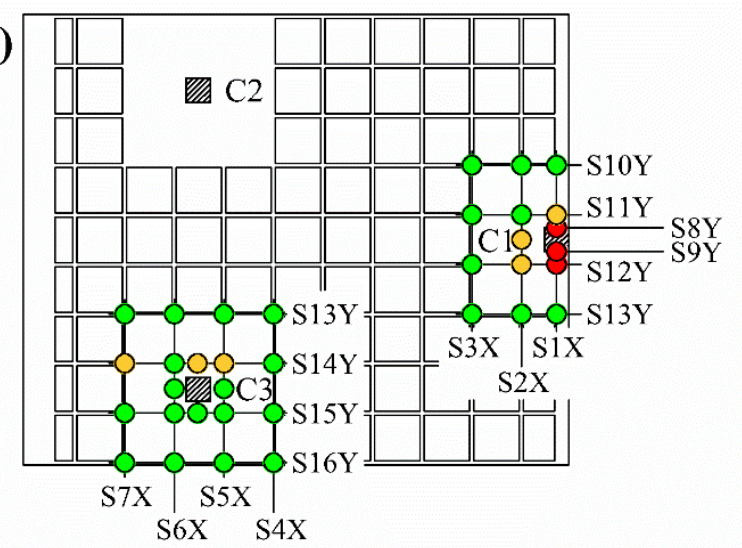

Figure 4. 18. Accumulated damage up to the end of test C200: a) elevation (actuator X point of view) and b) plan

The overall response of the tested structure was characterized by the early formation of plastic hinges at column bases. The training signal T10 and the seismic simulation C100 contributed initially to the formation of these plastic hinges. Moreover, in these tests, sections at columns head of $C_{2}$ and $C_{3}$ in first story, at base column of $C_{2}$ in the second story and in one side of the 
connection of $C_{1}$ with the spandrel beam reached values of $\varepsilon_{\max }$ above $\varepsilon_{y}$, what means the beginning of the formation of the plastic hinge. In test C200i, the damage in the specimen continues going forward in the cited sections and a new possible plastic hinges appeared at the other side of the connection of column $C_{1}$ with the spandrel beam. Test C200 subjected the structure to a large displacement cycle taking place approximately in the NE direction of the floor plan. Due to this displacement, large strains were registered in sections S8Y, S9Y and at the top side of section S1X, which are located around the external connection, and at base and head of columns $C_{2}$ and $C_{3}$. These measurements indicate that the external connection approached failure and the complete formation of plastic hinges at columns $C_{2}$ and $C_{3}$. At this point, the tested structure was heavily damaged but kept the capacity to sustain the vertical loads. The structure collapse during seismic simulation $\mathrm{C} 300$ but the data acquired by strain gauges was untrustworthy because of the high grade of damage. In Table 4.11 the training signal T10 has been included although it does not represent a ground motion, in order to show the level of strains that it imposed to the specimen.

\subsection{Quantitative response in terms of energy}

\subsubsection{Energy dissipation at global level}

The energy dissipation at global level is defined through the history of total absorbed energy $\left(W_{\xi}+W_{p}\right)$ accumulated during successive tests. This energy can be defined reorganizing the energy balance equation (1.4) as follows:

$$
W_{\xi}+W_{p}=E_{I}-\left(W_{k}+W_{e s}\right)
$$

Where $W_{\xi}$ is the damping energy, $W_{p}$ is the plastic strain energy, $E_{I}$ is the input energy, $W_{k}$ is the kinetic energy and $W_{e s}$ elastic strain energy. $E_{I}$ and $W_{k}$ can be obtained easily by equations (4.3) and (4.4) idealizing the structure with a two-mass lumped model (Chapter 3).

$$
\begin{gathered}
E_{I}=E_{I, X}+E_{I, Y}=\int_{0}^{t}-\dot{\mathbf{u}}^{\mathbf{T}} \mathbf{M} \mathbf{J}_{\mathbf{X}} \ddot{u}_{g, X} d t+\int_{0}^{t}-\dot{\mathbf{u}}^{\mathbf{T}} \mathbf{M} \mathbf{J}_{\mathbf{Y}} \ddot{u}_{g, Y} d t \\
W_{k}=\frac{1}{2} \sum_{i=1}^{6} \int_{0}^{t} m_{i} \dot{u}_{i}^{2} d t
\end{gathered}
$$

Where, $\mathbf{M}$ is the diagonal mass matrix presented in (3.3), whose component are named $m_{i}, \mathbf{J}_{\mathbf{X}}=$ $\left[\begin{array}{llllll}1 & 0 & 0 & 1 & 0 & 0\end{array}\right]^{T}$ and $\mathbf{J}_{\mathbf{Y}}=\left[\begin{array}{llllll}0 & 1 & 0 & 0 & 1 & 0\end{array}\right]^{T}$ are the corresponding influence vectors, $\ddot{u}_{g, X}$ and $\ddot{u}_{g, Y}$ are the ground motion accelerations records of Calitri earthquake and $\dot{\mathbf{u}}$ is the relative velocity vector whose components are named $\dot{u}_{i}$. These energies are calculated by integration up to a given instant $t$.

$W_{e S}$ is the recoverable elastic strain energy that causes the oscillation part of the history of $E_{I}-$ $W_{k}=W_{\xi}+W_{e s}+W_{p}$. That is, if $W_{e s}$ is removed from the history of $E_{I}-W_{k}$, the resulting history, i.e. the history of $W_{\xi}+W_{p}$, must necessarily be a monotonically increasing curve. Thus, $W_{\xi}+W_{p}$ can be calculated from the history of $E_{I}-W_{k}$ by taking the lower bound enveloped. $W_{e s}$ can be easily calculated as the difference between the history of $E_{I}-W_{k}$ and the low bound envelope of this history. To show the procedure, the curves of $E_{I}, E_{I}-W_{k}$ and $W_{\xi}+W_{p}$ are 
shown in detail in Figure 4.19, which is a zoom of the history of energies from test C200i in Figure 4.20a.

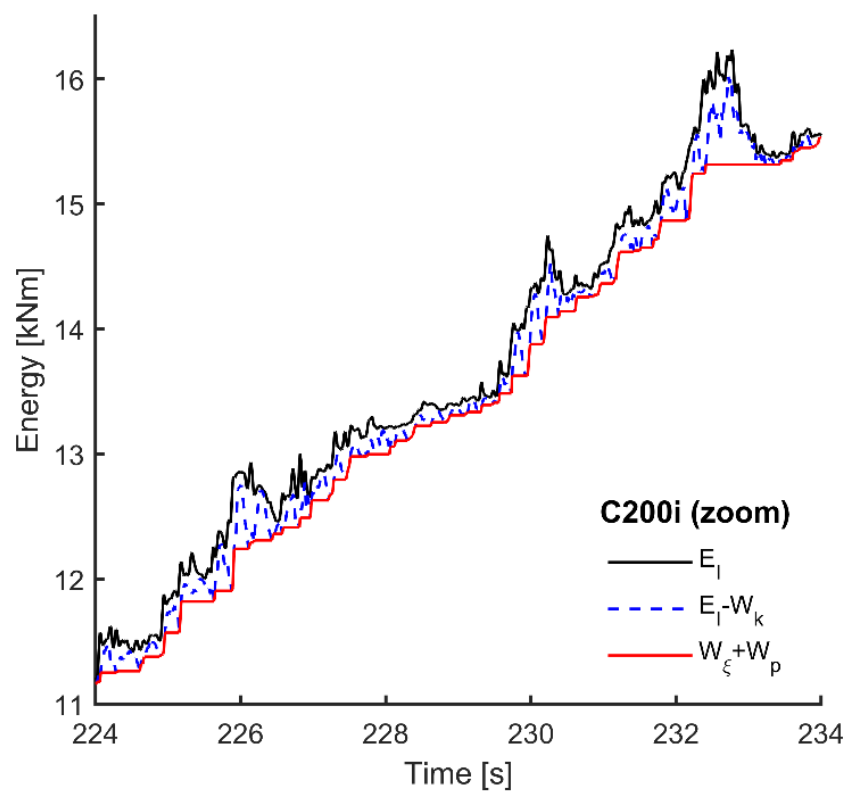

Figure 4. 19.Estimation of $W_{\xi}+W_{p}$ from the minimum of $E_{I}-W_{k}$

The history of the total absorbed energy $\left(W_{\xi}+W_{p}\right)$ accumulated during all tests was calculated and drawn in Figure 4.20 together with $E_{I}$ and its components $E_{I, X}$ and $E_{I, Y}$. Although signal T10 does not represent a ground motion it has included in the following Figures and Tables to show the amount of energy involved.

Several features deserve attention in this figure:

1. The curves of $W_{\xi}+W_{p}$ and $E_{I}$ are almost coincident since the elastic vibration energy $W_{e}\left(=W_{e s}+W_{k}\right)$ becomes negligible in comparison with $E_{I}$ when the structure starts to undergo plastic deformations.

2. The components $\mathrm{X}$ and $\mathrm{Y}$ of the accumulated input energy $\left(E_{I, X}\right.$ and $\left.E_{I, Y}\right)$ differ while the structure remains basically elastic (i.e. approximately up to instant $240 \mathrm{~s}$ in Figure $4.20)$, but become very similar once the structure starts to undergo plastic deformations. In other words, plastic deformations enhance energy transfer from the $\mathrm{Y}$ to the $\mathrm{X}$ direction so that the input energies in both directions tend to approach. This behavior has been reported in previous numerical studies (Marušić \& Fajfar, 2005).

3. The amount of energy introduced during the training signal T10 and the seismic simulations C35, C50 and C100 for which the response was basically elastic is about $19 \%$ of the input energy reached by the "design earthquake" C200 (see Table 4.12).

4. An input energy of a significant amount of energy $(44.15 \mathrm{kNm})$ was necessary to lead the specimen from the state at the end of the "design earthquake" (seismic simulation $\mathrm{C} 200)$ to the brim of collapse (C300*). This value was approximately equal to the total energy input up to the SPL of LS (end of C200), which was $48.57 \mathrm{kNm}$ (see Table 4.12). That is, after several very frequent or frequent earthquakes (C35, C50, and C100) and one design earthquake (C200), the structure consumed about one half of its ultimate energy dissipation capacity. 


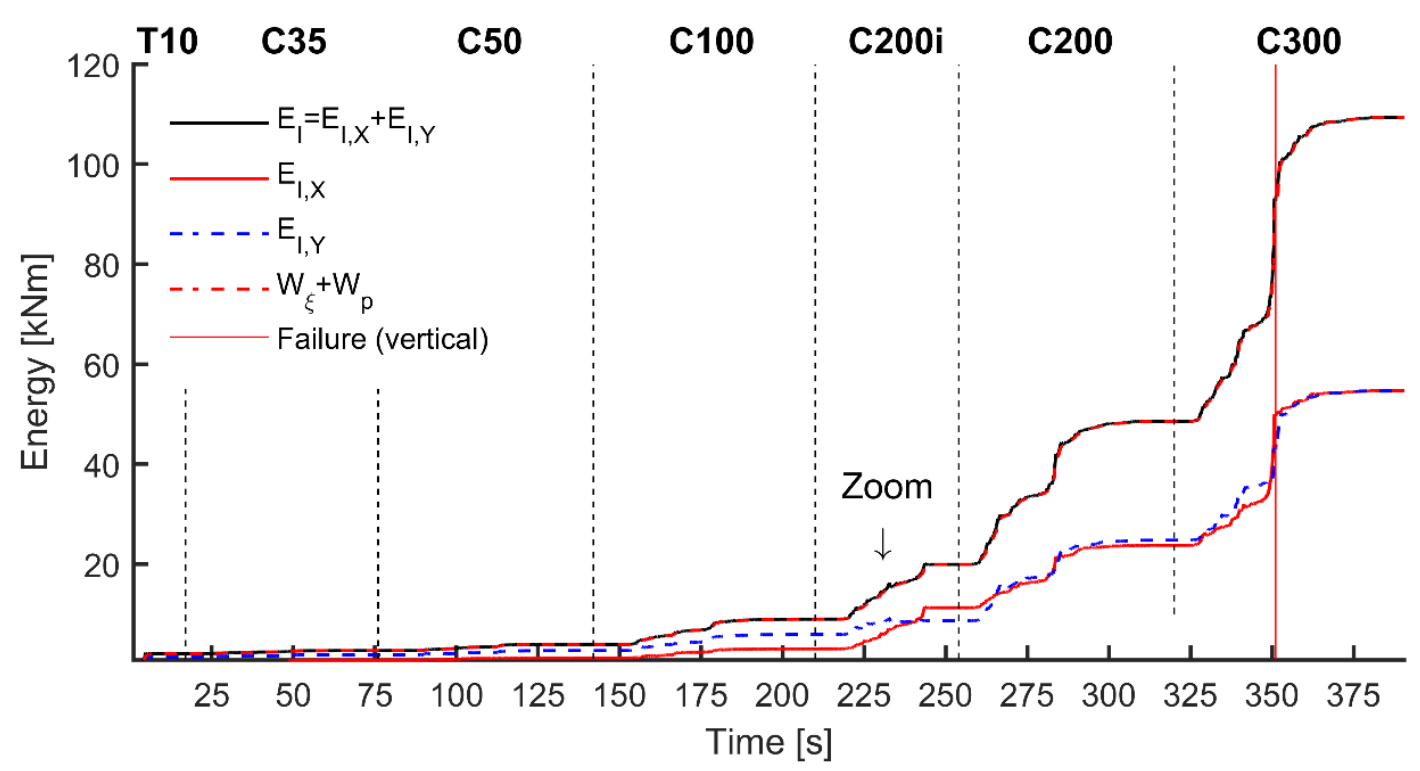

Figure 4. 20. History of accumulated input energy

Table 4. 12. Input energies in training and successive seismic simulations

\begin{tabular}{|c|c|c|c|c|c|c|c|c|}
\hline Test & $\begin{array}{r}\Delta E_{I, X} \\
{[\mathrm{kNm}]}\end{array}$ & $\begin{array}{c}E_{I, X} \\
{[\mathrm{kNm}]}\end{array}$ & $\begin{array}{r}\Delta E_{I, Y} \\
{[\mathrm{kNm}]}\end{array}$ & $\begin{array}{c}E_{I, Y} \\
{[\mathrm{kNm}]}\end{array}$ & $\begin{array}{c}\Delta E_{I} \\
{[\mathrm{kNm}]}\end{array}$ & $\begin{array}{c}E_{I} \\
{[\mathrm{kNm}]}\end{array}$ & $\frac{E_{I, X}}{E_{I}}$ & $\frac{E_{I, Y}}{E_{I}}$ \\
\hline T10 & 0.62 & 0.62 & 1.47 & 1.47 & 2.09 & 2.09 & 0.30 & 0.70 \\
\hline C35 & 0.21 & 0.83 & 0.41 & 1.88 & 0.62 & 2.71 & 0.31 & 0.69 \\
\hline C50 & 0.43 & 1.26 & 0.82 & 2.70 & 1.25 & 3.96 & 0.32 & 0.68 \\
\hline C100 & 1.82 & 3.08 & 3.22 & 5.92 & 5.04 & 9.00 & 0.34 & 0.66 \\
\hline C200i & 8.21 & 11.29 & 2.74 & 8.66 & 10.95 & 19.95 & 0.57 & 0.43 \\
\hline $\mathrm{C200}$ & 12.50 & 23.79 & 16.12 & 24.78 & 28.61 & 48.57 & 0.49 & 0.51 \\
\hline $\mathrm{C300}^{*}$ & 25.97 & 49.76 & 18.17 & 42.95 & 44.15 & 92.71 & 0.54 & 0.46 \\
\hline C300 & 4.93 & 54.70 & 11.66 & 54.61 & 16.60 & 109.31 & 0.50 & 0.50 \\
\hline Mean & --- & --- & --- & --- & --- & --- & 0.40 & 0.60 \\
\hline
\end{tabular}

Note: $\mathrm{C} 300 *$ refers to the instant where the specimen reached the point of collapse

The total absorbed energy $W_{\xi}+W_{p}$ includes the energy dissipated by inherent viscous damping $W_{\xi}$. When the structure goes deeply into the nonlinear domain, it is not possible to calculate $W_{\xi}$ with accuracy because it is tricky to distinguish it from the energy loss referred to the nonlinearity of members. An attempt was nonetheless made to obtain a rough estimation of $W_{\xi}$, using the two-mass lumped model presented in Chapter 3, as follows. It was assumed that the inherent viscous damping can be represented by the damping matrix $\mathbf{C}$ proportional to the mass matrix $\mathbf{M}$, i.e., $\mathbf{C}=a_{o} \mathbf{M}$. The parameter $a_{o}$ is determined so that the damping ratio for the chosen natural mode of frequency $\omega$ is equal to the target damping ratio $\xi$, and thus it is given by $a_{o}=2 \xi w$. The values of $\xi$ and $\omega$ used were those obtained after the calibration of the numerical model defined in Chapter 5, i.e., $\xi=3 \%$ and $\omega=20.17 \mathrm{rad} / \mathrm{s}$. Further, provided that the displacements in $\mathrm{X}$ direction are decoupled from the displacements in $\mathrm{Y}$ direction and twist in elastic range (Chapter 3), an approximation of the distribution of $W_{\xi}$ by components is possible. $W_{\xi, X}$ is estimated from the DOFs 1 and 4 and $W_{\xi, X}$ from the DOFs 2, 3, 5 and 6 . Therefore, the energy dissipated due to inherent damping by components up to a given instant $t$ is shown in Figure 4.21 and Table 4.13, and is calculated as follows:

$$
W_{\xi}=W_{\xi, X}+W_{\xi, Y}=\sum_{i=1,4} 2 \xi \omega \int_{0}^{t} m_{i} \dot{u}_{i}^{2} d t+\sum_{i=2,3,5,6} 2 \xi \omega \int_{0}^{t} m_{i} \dot{u}_{i}^{2} d t
$$




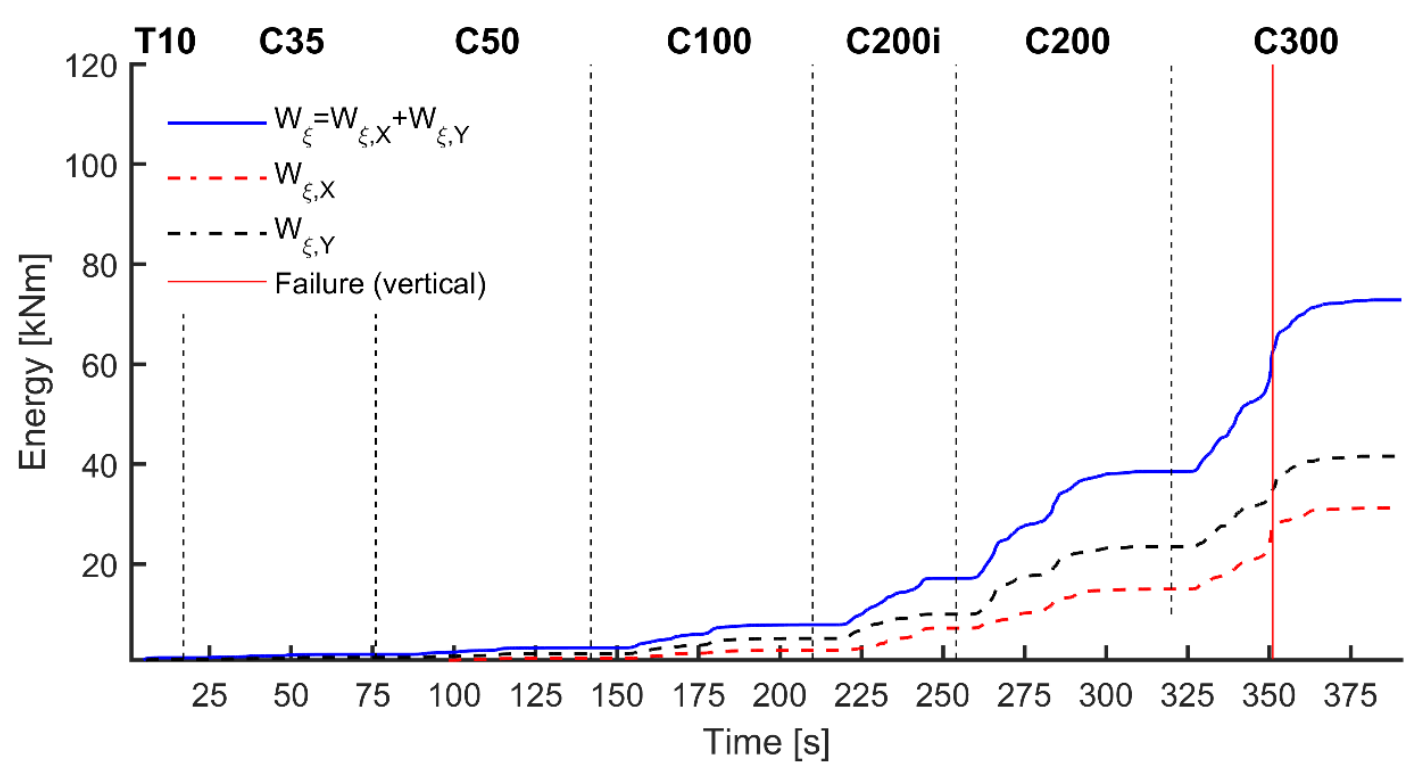

Figure 4. 21. History of energy dissipated by inherent viscous damping

Table 4. 13. Energy dissipated by inherent viscous damping

\begin{tabular}{|c|c|c|c|c|c|c|c|c|}
\hline Test & $\begin{array}{l}\Delta W_{\xi, X} \\
{[\mathrm{kNm}]}\end{array}$ & $\begin{array}{c}W_{\xi, X} \\
{[\mathrm{kNm}]}\end{array}$ & $\begin{array}{l}\Delta W_{\xi, Y} \\
{[\mathrm{kNm}]}\end{array}$ & $\begin{array}{c}W_{\xi, Y} \\
{[\mathrm{kNm}]}\end{array}$ & $\begin{array}{c}\Delta W_{\xi} \\
{[\mathrm{kNm}]}\end{array}$ & $\begin{array}{c}W_{\xi} \\
{[\mathrm{kNm}]}\end{array}$ & $\frac{\boldsymbol{W}_{\xi, \boldsymbol{X}}}{\boldsymbol{W}_{\xi}}$ & $\frac{W_{\xi, Y}}{W_{\xi}}$ \\
\hline T10 & $\begin{array}{l}0.34 \\
\end{array}$ & 0.34 & 0.94 & $\begin{array}{l}0.94 \\
\end{array}$ & 1.28 & 1.28 & 0.27 & 0.73 \\
\hline C35 & 0.27 & 0.61 & 0.35 & 1.29 & 0.62 & 1.90 & 0.32 & 0.68 \\
\hline C50 & 0.50 & 1.11 & 0.75 & 2.04 & 1.25 & 3.15 & 0.35 & 0.65 \\
\hline C100 & 1.56 & 2.67 & 3.03 & 5.07 & 4.59 & 7.74 & 0.34 & 0.66 \\
\hline C200i & 4.46 & 7.13 & 4.83 & 9.90 & 9.29 & 17.03 & 0.42 & 0.58 \\
\hline $\mathrm{C200}$ & 7.80 & 14.93 & 13.54 & 23.44 & 21.34 & 38.37 & 0.39 & 0.61 \\
\hline C300* & 12.66 & 27.59 & 11.37 & 34.81 & 24.03 & 62.40 & 0.44 & 0.56 \\
\hline C300 & 3.58 & 31.17 & 6.71 & 41.52 & 10.29 & 72.69 & 0.43 & 0.57 \\
\hline Mean & --- & --- & --- & --- & --- & --- & 0.36 & 0.64 \\
\hline
\end{tabular}

Note: $\mathrm{C} 300 *$ refers to the instant where the specimen reached the point of collapse

Figure 4.22 depicts in the same graph the previously shown histories of $W_{\xi}$ and $E_{I}$, and what Housner (1956) defined as the energy that contributes to damage, i.e., $E_{D}=E_{I}-W_{\xi}$. Moreover, since $W_{e}=W_{e s}-W_{k}$ is very small in comparison with $E_{D}$ once the structure starts to undergo plastic deformations, $W_{p}$ can be taken as approximately equal to $E_{D}$, and $W_{\xi}+W_{p}$ as approximately equal to $E_{I}$.

Table 4. 14. Energies in terms of equivalent velocities and relations with $E_{I}$

\begin{tabular}{cccccccccc}
\hline Test & $\begin{array}{c}\Delta \boldsymbol{V}_{\boldsymbol{E}} \\
{[\mathbf{c m} / \mathbf{s}]}\end{array}$ & $\begin{array}{c}\boldsymbol{V}_{\boldsymbol{E}} \\
{[\mathbf{c m} / \mathbf{s}]}\end{array}$ & $\begin{array}{c}\Delta \boldsymbol{E}_{\boldsymbol{D}} \\
{[\mathbf{k N m}]}\end{array}$ & $\begin{array}{c}\boldsymbol{E}_{\boldsymbol{D}} \\
{[\mathbf{k N m}]}\end{array}$ & $\begin{array}{c}\Delta \boldsymbol{V}_{\boldsymbol{D}} \\
{[\mathbf{c m} / \mathbf{s}]}\end{array}$ & $\begin{array}{c}\boldsymbol{V}_{\boldsymbol{D}} \\
{[\mathbf{c m} / \mathbf{s}]}\end{array}$ & $\begin{array}{c}\boldsymbol{W}_{\boldsymbol{\xi}} \\
\boldsymbol{E}_{\boldsymbol{I}}\end{array}$ & $\begin{array}{c}\boldsymbol{E}_{\boldsymbol{D}} \\
\boldsymbol{E}_{\boldsymbol{I}}\end{array}$ & $\frac{\boldsymbol{V}_{\boldsymbol{D}}}{\boldsymbol{V}_{\boldsymbol{E}}}$ \\
\hline $\mathbf{T 1 0}$ & 58.46 & 58.46 & 0.81 & 0.81 & 36.40 & 36.40 & 0.61 & 0.39 & 0.62 \\
$\mathbf{C 3 5}$ & 31.84 & 66.57 & 0.00 & 0.81 & 0.00 & 36.40 & 0.70 & 0.30 & 0.55 \\
$\mathbf{C 5 0}$ & 45.21 & 80.47 & 0.00 & 0.81 & 0.00 & 36.40 & 0.80 & 0.20 & 0.45 \\
$\mathbf{C 1 0 0}$ & 90.79 & 121.32 & 0.45 & 1.26 & 27.13 & 45.39 & 0.86 & 0.14 & 0.37 \\
$\mathbf{C 2 0 0 i}$ & 133.82 & 180.62 & 1.66 & 2.92 & 52.10 & 69.10 & 0.85 & 0.15 & 0.38 \\
$\mathbf{C 2 0 0}$ & 216.30 & 281.80 & 7.27 & 10.19 & 109.04 & 129.09 & 0.79 & 0.21 & 0.46 \\
$\mathbf{C 3 0 0 *}$ & 268.70 & 389.37 & 20.12 & 30.31 & 181.39 & 222.64 & 0.67 & 0.33 & 0.57 \\
$\mathbf{C 3 0 0}$ & 164.76 & 422.80 & 6.31 & 36.62 & 101.58 & 244.72 & 0.66 & 0.34 & 0.58 \\
\hline \hline
\end{tabular}

Note: $\mathrm{C} 300^{*}$ refers to the instant where the specimen reached the point of collapse 


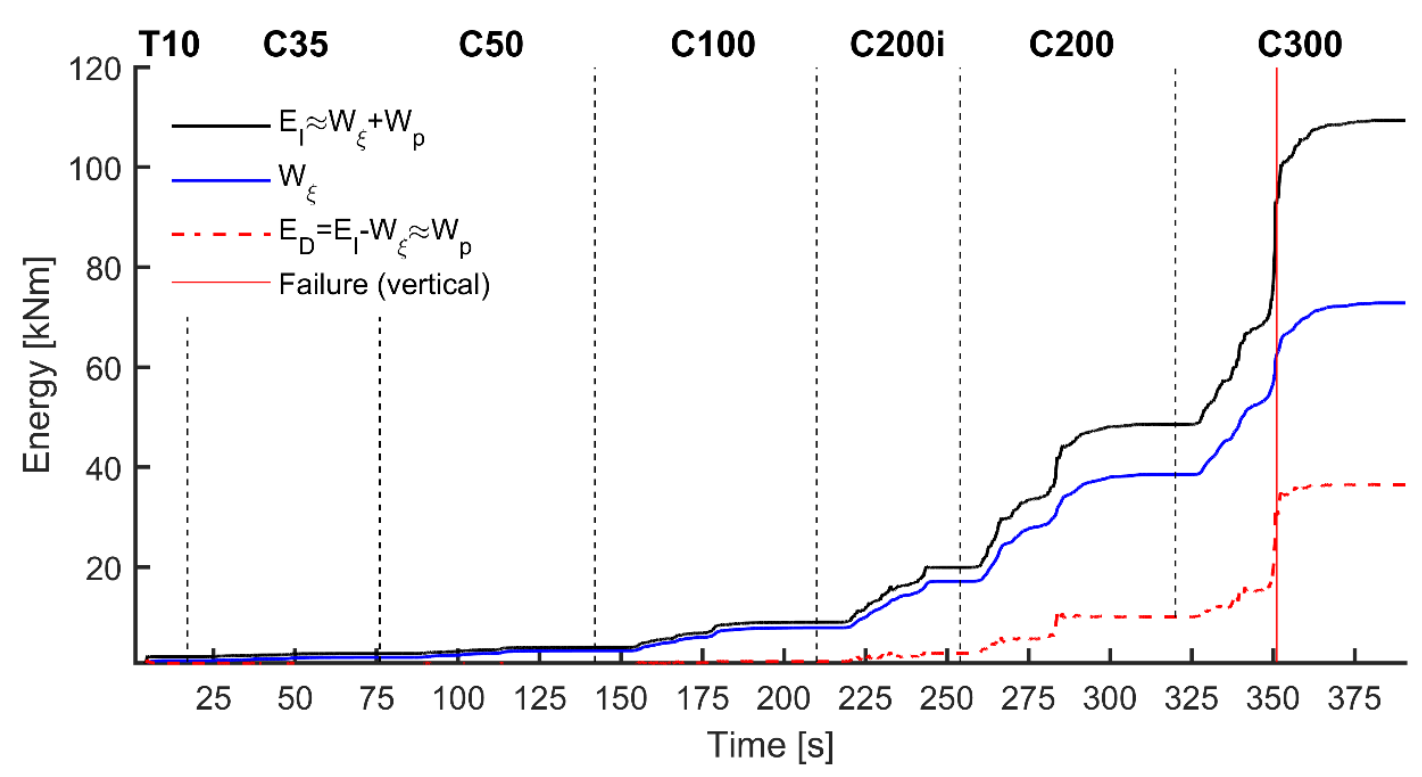

Figure 4. 22. Energy balance

Some features deserve mention in Figure 4.22:

1. The energies grow exponentially while the acceleration amplitudes increase linearly.

2. The specimen got deeply into nonlinear range in Test C200i. This is visible in Figure 4.22 because $E_{D}$ started to grow at the beginning of Test C200i. The structure dissipated energy by plastic deformations in tests T10 and C100 as well, but the amount of energy dissipated by hysteresis was very small ( $3 \%$ of the total $\left.E_{D}\right)$. Particularly, although the PGA reached during the training T10 was very high $(0.59 \mathrm{~g})$ the damage imparted to the structure quantified in terms of $E_{D}$ was negligible. A similar observation can be made with the incomplete seismic simulation C200i, which PGA was 1.1g (two times that of C200), but input an amount of energy contributable to damage of about only one fourth of the energy input by seismic simulation C200. This corroborates the well-know fact that the PGA is a bad indicator of the damage potential of the earthquake; i.e. PGA and $E_{D}$ are not correlated.

3. Along the seismic simulations $\mathrm{C} 200 \mathrm{i}$ to $\mathrm{C} 300$, the ratio $E_{D} / E_{I}$ increased from 0.14 to 0.33 or, in the other way around, the ratio $W_{\xi} / E_{I}$ decreased from 0.86 to 0.67 (see Table 4.14). This means that the amount of energy dissipated by inherent damping in relation to the total input energy tends to diminish as the level of plastic deformations on the structure increases, as noted in past studies (Akiyama, 1985).

4. Energies $E_{I}$ and $E_{D}$ can be normalized with respect to the total mass of the structure $M$ and expressed by equivalent velocities $V_{E}$ (1.5) and $V_{D}$ (1.6). Akiyama (1985) proposed an approximate prediction of the ratio $V_{D} / V_{E}$, ie. $\sqrt{E_{D} / E_{I}}$, that depends exclusively on the inherent damping ratio $\xi$ in elastic range (1.7). This expression gives $V_{D} / V_{E}=0.79$ using $\xi=0.024$ (Table 4.2). This result is conservative for design purposes.

5. The accumulated input energy $E_{I}$ in terms of equivalent velocity $V_{E}$ necessary to carry the structure to the brim of collapse $\left(\mathrm{C} 300^{*}\right)$ was $390 \mathrm{~cm} / \mathrm{s}$ (see Table 4.14). It is worth noting that a very similar value was obtained in a past study (Benavent-Climent et al., 2016) using a very similar specimen subjected to unidirectional loading up to collapse, giving a value equal to $395 \mathrm{~cm} / \mathrm{s}$. In this study, the sequence of escalated earthquake was also similar $(100 \%, 200 \%, 300 \%$ and $350 \%)$. 
6. The capacity of the structure to dissipate energy by plastic deformations $W_{p}$ up to the brim of collapse $\left(\mathrm{C} 300^{*}\right)$ can be approximated by $E_{D}$ and expressed in terms of $V_{D}$, giving a value of $223 \mathrm{~cm} / \mathrm{s}$ (see Table 4.14).

\subsubsection{Energy dissipation at local level}

The elastic strain energy stored, $W_{e s, k}$, and the plastic strain energy dissipated, $W_{p, k}$ in a plastic hinge $k$ located at the ends of a column from instant $t=0$ to $t=t_{t}$ is the sum of energy stored/dissipated by concrete, $W_{C, k}$, and by steel rebars, $W_{S, k}$ (Park \& Eom, 2006). The plastic strain energy $W_{p, k}$ is a fundamental parameter to characterize member's earthquake resistance. Plastic hinge is defined here as a portion of a column enclosed by two parallel planes perpendicular to the longitudinal axis of the column and spaced a distance $l_{p}$. In this investigation, $W_{C, k}$ and $W_{S, k}$ were estimated assuming the Navier-Bernoulli plane section hypothesis (the assumption that plane cross-sections remain planar and normal to the rod axis). There is experimental evidence that this hypothesis can be applied as a rough approximation to slender concrete members during practically all ranges of flexural behaviour: till and beyond concrete cracking, towards yielding of the reinforcement and even further, almost up to the ultimate deformation of the member (Fardis, 2009).

The cross-section of the plastic hinge, of depth $h$ and width $b$, was divided in $N x N$ fiber of depth $h / N$ and width $b / N$. Each fiber represents a point in the cross-section whose deformation was estimated using the strains captured by the strain gauges. With this information, a plane defined by the equation $(x=\mathrm{ay}+\mathrm{bz}+\mathrm{c})$ was obtained at each time step using the least squares method. The method minimizes the sum of the square difference between the actual strain $\varepsilon_{S i}$ measured by the strain gauge $i$ located in a rebar at coordinates $\left(y_{i}, z_{i}\right)$ of the cross-section, and the estimated value $x_{i}$ on the plane. That means that the function to minimize is defined as $E=$ $\sum_{i=1}^{n}\left(\varepsilon_{S i}-\left(\mathrm{a} y_{i}+\mathrm{b} z_{i}+\mathrm{c}\right)\right)^{2}$, where $n$ is the number of strain gauges in the cross-section. Coefficients a, $b$ and $c$ were obtained imposing $d E / d a=0, d E / d b=0$ and $d E / d c=0$ and solving the resultant system of equations. It is worth noting that when the plane approximation is applied, the strain used for computing the energy dissipated by the steel at points where data provided by gauges are available, are not the actual strains measured by gauges, but the strains estimated with the plane approximation. In advanced levels of damage, the degradation of anchorage conditions of the longitudinal reinforcement under cyclic loading is not necessarily the same in all rebars of the section. This can cause significant differences in rebars strains due to different bond degradation that the use of the plain approximation can either smooth or even almost ignore. Figure 4.23 depicts undeformed/deformed S20 (Figure 2.2) divided in $N x N$ fibers for a given instant. It shows how strains are assigned to each fiber applying the plane approach.

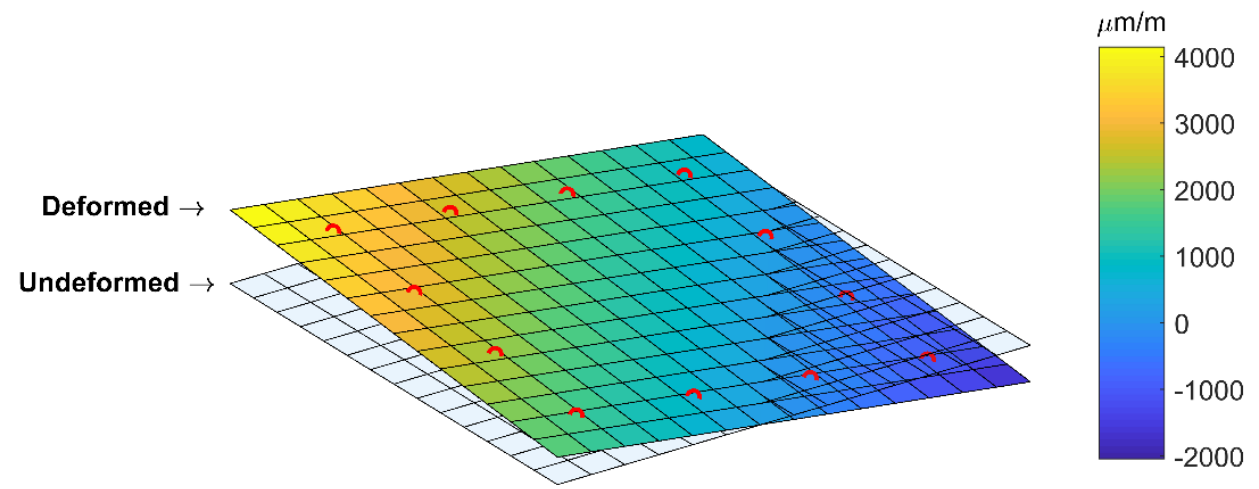

Figure 4. 23. Cross-section S20 undeformed/deformed 
Once the strains of the $N x N$ fibers were determined, the corresponding stresses were estimated as follows. The stress on the steel fibers $\sigma_{S i}(t)$ were estimated using an energy conservative steel constitutive model, the Menegotto-Pinto model (Filippou, Bertero, \& Popov, 1983). The model incorporates strain-hardening and Bauschinger effects. Figure 4.24 shows the stress-strain curve obtained for this constitutive model for a loading history consisting of cycles of incremental amplitude.

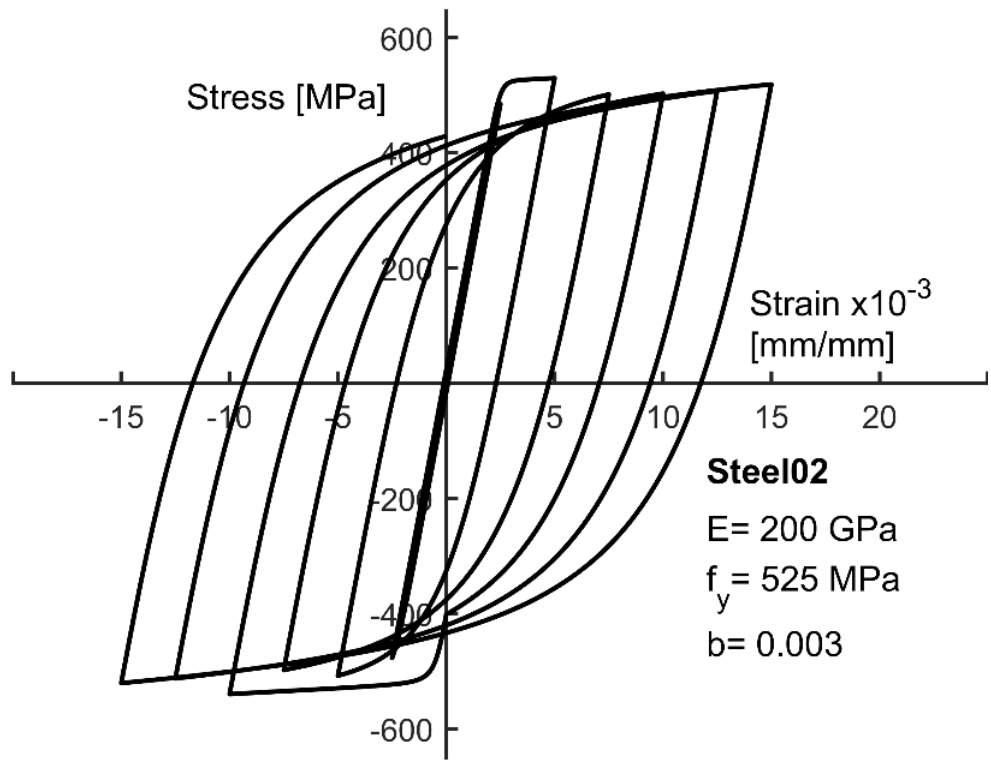

Figure 4. 24. Constitutive law used for steel

The stress on concrete fibers $\sigma_{C i}(t)$ were estimated using four different constitutive models proposed in the literature and referred hereafter to C01, C02, C07 and M (simplified). Figure 4.25 shows the stress-strain relationship for each concrete model. Model C01 and C02 were developed by Mohd (1995). The difference between these models is the shape of the unloading and reloading branches. In model $\mathrm{C} 01$, the unloading and reloading branches follow the same path, hence no energy is dissipated when reloading, whereas $\mathrm{C} 02$ dissipates energy in the unloading-reloading cycles. The same occurs with the model M, developed by Maekawa (2014), but in this case the unloading-reloading cycles have a smoother shape. The simplification made in the Maekawa model consisted on neglecting the resistance of the concrete in tension and the re-contact effects. Model C07 is the well-know Mander model (Chang \& Mander, 1994) and differs from the other three models in the shape of strain-stress curve when the concrete is reloaded after having experienced some permanent deformations in previous cycles.

The common mechanical properties adopted for concrete in all models are: Young's modulus $E_{c}=30 \mathrm{GPa}$, compressive strength $f_{c}=44 \mathrm{MPa}$, strain at maximum compressive stress $0.28 \%$. The four models were calibrated so that the area enclosed by stress-strain curve under monotonic loading were the same (Figure 4.26). This was attained modifying slightly the strain-stress point at failure, what resulted in all cases very close to $1.5 \%$ and almost $0.0 \mathrm{MPa}$, respectively. 

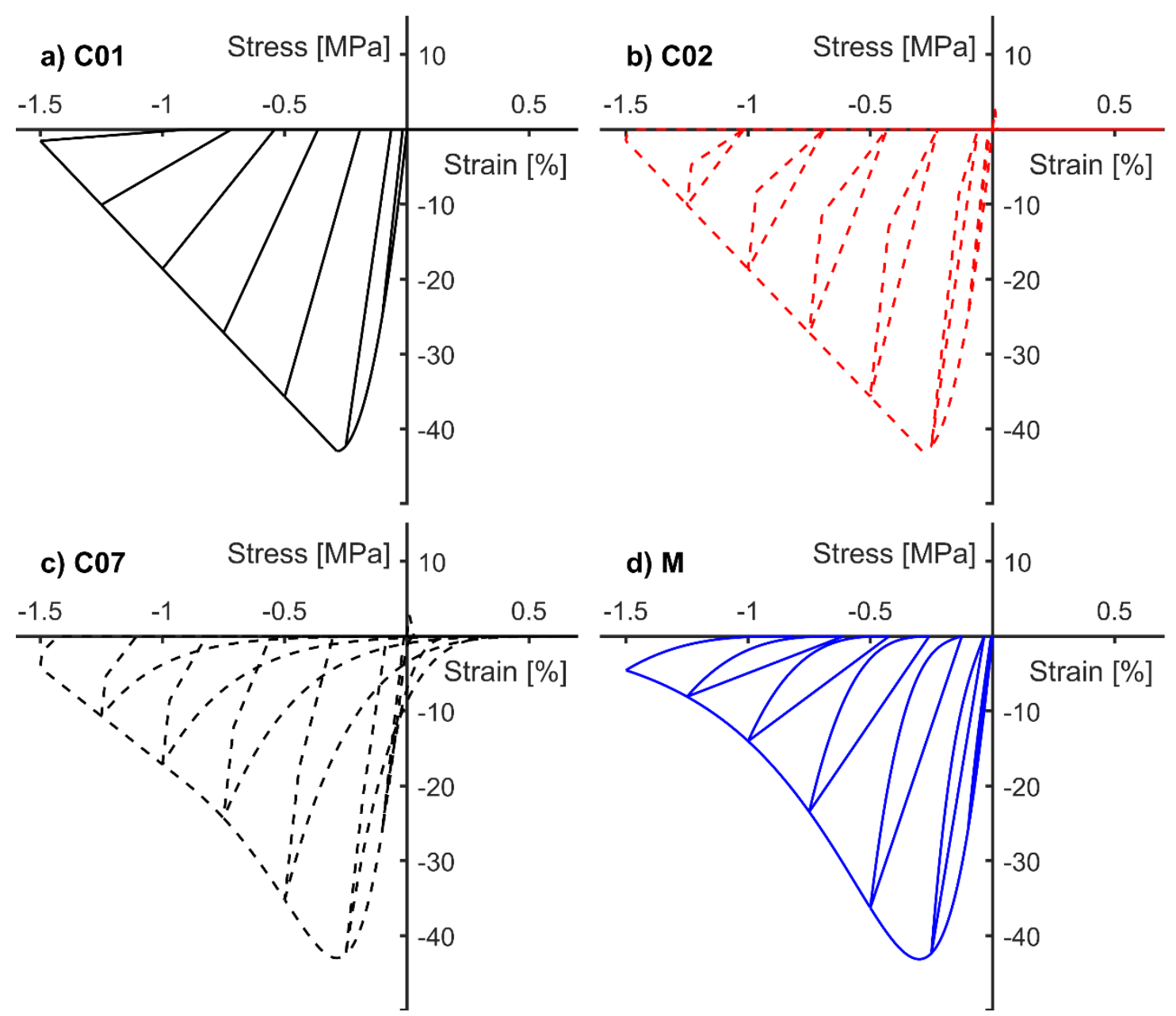

Figure 4. 25. Constitutive laws for concretes: a) $\mathrm{C} 01$, b) $\mathrm{C} 02$, c) $\mathrm{C} 07$ and d) $\mathrm{M}$
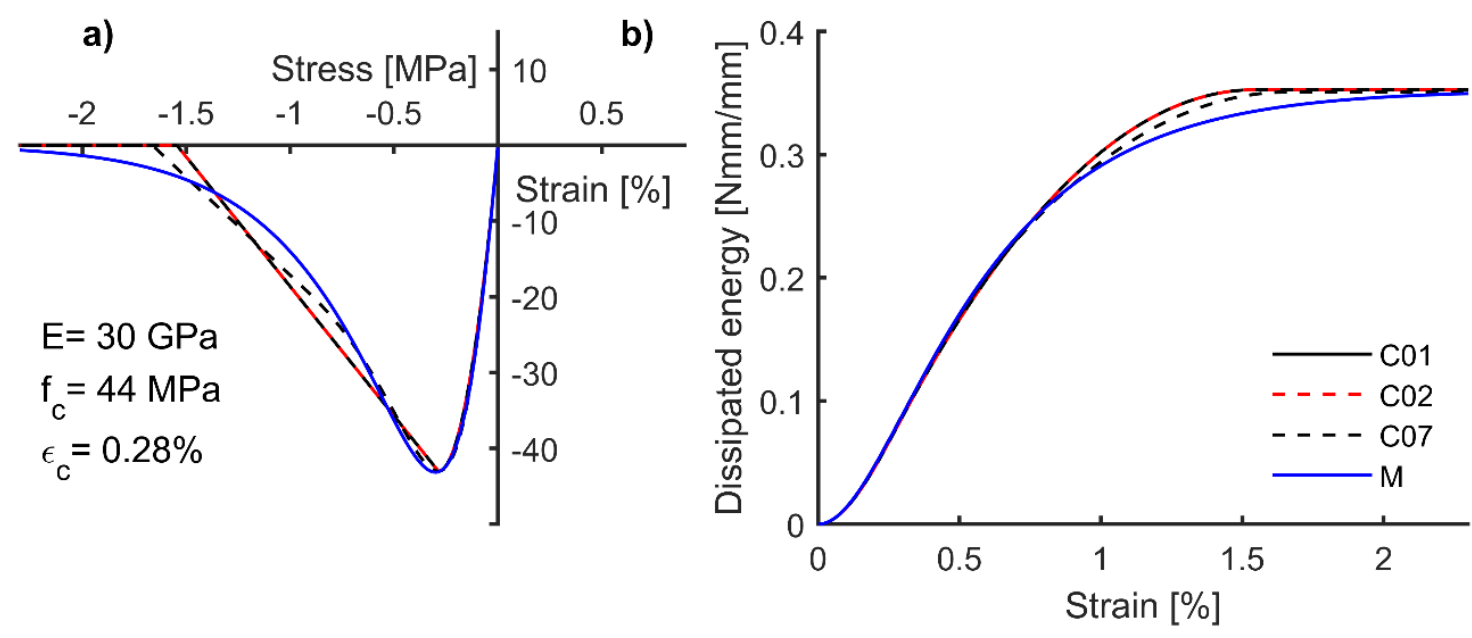

Figure 4. 26.Energy calibration of concrete models: a) Stress-strain curves and b) Energy calibration under monotonic loading

Once the stress in each steel fiber $\sigma_{S r}(t)$ and at each instant $t$ of a given plastic hinge $k$ is obtained, the approximation of the energy dissipated by the steel reinforcement up to this instant, $W_{S, k}(t)$ is calculated as follows: 


$$
W_{S, k}(t)=\sum_{S r=1}^{S R} \int_{0}^{t} l_{p} A_{S r} \sigma_{S r} \dot{\varepsilon}_{S r} d t
$$

Where $A_{S r}$ is the area of the steel fiber $r, S R$ is the number of steel fibers, i.e., number of longitudinal rebars, in the plastic hinge, $\dot{\varepsilon}_{S r}$ is the strain rate velocity of steel, i.e., $\dot{\varepsilon}_{S r}=d \varepsilon_{S r} / d t$ and $l_{p}$ is the plastic hinge length. Similarity, once the stress in each concrete fiber $\sigma_{C r}(t)$ is determined, the energy dissipated by concrete $W_{C, k}(t)$ until a given instant $t$ is obtained as follows:

$$
W_{C, k}(t)=\sum_{C r=1}^{C R} \int_{0}^{t} l_{p} \frac{b}{N} \frac{h}{N} \sigma_{C r} \dot{\varepsilon}_{C r} d t
$$

Where $\frac{b}{N} \frac{h}{N}$ represents the area of the concrete fiber $\left(A_{C r}\right), C R$ is the number of concrete fibers in the plastic hinge and $\dot{\varepsilon}_{C r}$ is the strain rate velocity of concrete, i.e., $\dot{\varepsilon}_{C r}=d \varepsilon_{C r} / d t$. The plastic hinge length adopted was $l_{p}=h$, the value commonly selected in experiments should be in the range of $h / 2$ to $h$ (Fardis, 2009).

The history of the total amount of energy stored $W_{e s, k}(t)$ and dissipated $W_{p, k}(t)$ by a plastic hinge $k$ gives:

$$
W_{e s, k}(t)+W_{p, k}(t)=W_{S, k}(t)+W_{C, k}(t)
$$

The recoverable elastic strain energy stored $W_{e s, k}(t)$ in the plastic hinge for steel and concrete can be easily removed by taking the minimum envelope of the histories $W_{S, k}(t)$ and $W_{C, k}(t)$, this procedure was explained previously in Section 2.5.1. It is worth noting that the use of fiber section discretization ignores the contribution of shear in the response, however the energy dissipated by shear is believed very small with regard to the energy dissipated by flexure in this kind of structures.

The histories of dissipated energy by all columns, depending on the type of concrete model used $(\mathrm{C} 01, \mathrm{C} 02, \mathrm{C} 03$ and $\mathrm{M})$, are shown in Figure 4.27 together with the total dissipated energy by the system defined as $W_{p}=E_{I}-\left(W_{\xi}+W_{k}+W_{e s}\right)$. Although signal T10 does not represent a ground motion, it has been included in following Figures and Tables to show the amount of energy involved.

As can be seen in Figure 4.27, model C01 is the one that fits better with the approximation of the total energy dissipated by the complete structural system, especially, until the instant $t=218 \mathrm{~s}$. Up to that instant, only columns dissipated energy, as can be observed in Figure 4.16, therefore it makes sense to compare $W_{p, \text { col }}(\mathrm{C} 01)$ with $W_{p}$. After approximately instant $\mathrm{t}=218 \mathrm{~s}$, the waffleflat plate started to dissipate also plastic strain energy, and therefore $W_{p, c o l}(\mathrm{C} 01)$ is necessarily smaller that $W_{p}$.

On the other hand, the model C07 estimates a much higher amount of energy that the rest of the models, and far above the estimation of the total dissipated energy $W_{p}$ up to instant $t=218 \mathrm{~s}$. This does not make any sense. The reason can be easily found in the shape of the hysteresis loops of each model, shown in Figure 4.25. The area enclosed by the reloading branch up to the stress reached in previous cycle of loading, when previously the unloading reached positive strains is 
notably higher in model $\mathrm{C} 07$ than in model $\mathrm{C} 01$. The prediction with constitutive models $\mathrm{C} 02$ and $\mathrm{M}$ are close to $\mathrm{C} 01$, and can be judged as reasonable approaches taking into account that the estimation of $W_{p}$ is rough. Therefore, for the columns tested in this study, the use of the constitutive model $\mathrm{C} 07$ is not appropriate because it leads to absurd results, even for a value of $l_{p}$ equal to $h / 2$.

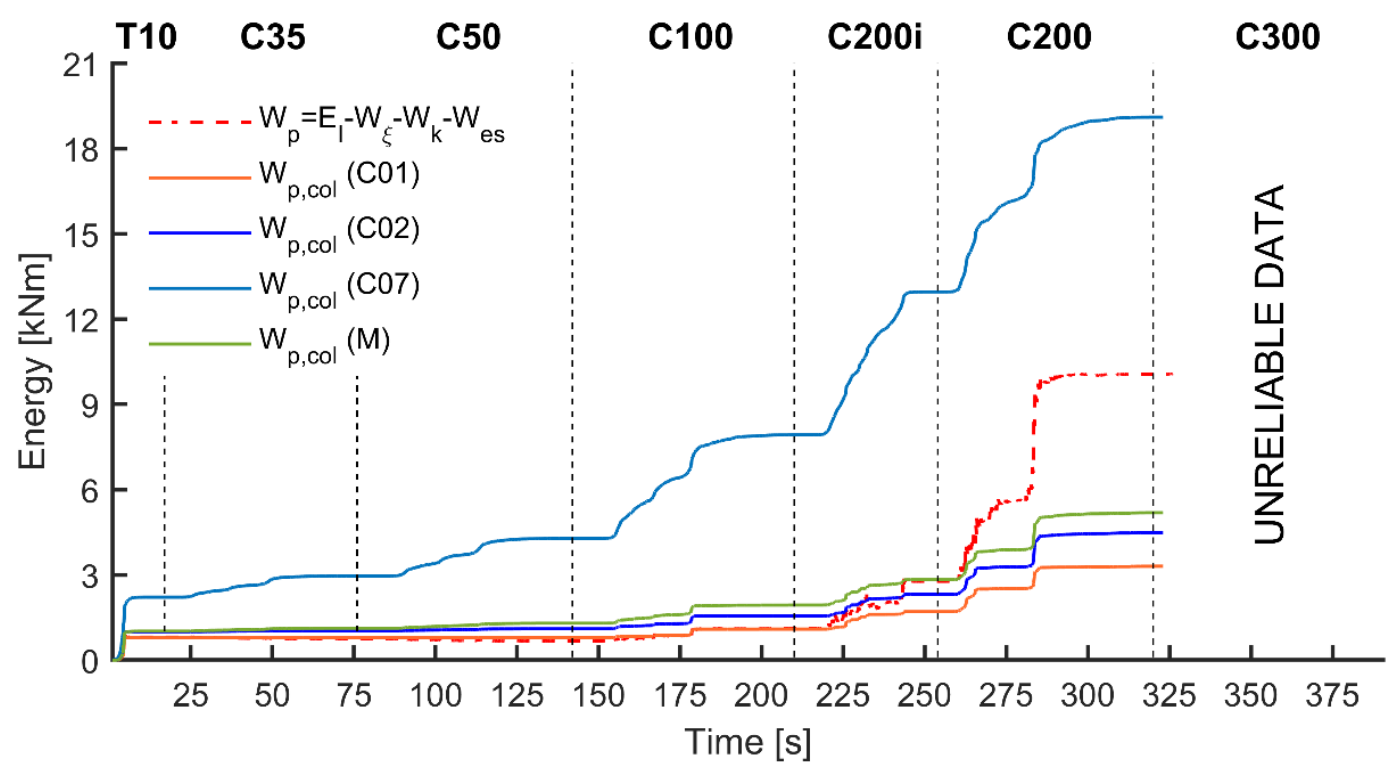

Figure 4. 27. Histories of dissipated energy by all columns depending on concrete model

The energy stored/dissipated by plastic hinges at columns ends obtained applying the concrete model C01 was grouped by levels ( 0,1 and 2 ) and sections (see Figure 2.6a) in Figure 4.28. Figure 4.28a corresponds to the energy stored/dissipated by columns at base of second story, Figure $4.28 \mathrm{~b}$ at top of first story and Figure $4.28 \mathrm{c}$ at base of first story.

Several features may be underlined from Figure 4.28:

1. In all curves the energy increases almost monotonically. This means that the recoverable elastic strain energy $W_{e s, k}(t)$ that cause the oscillating part of the curves is negligible in comparison with the energy dissipated by plastic deformations.

2. Most of the energy (about 70\%) was dissipated at base of columns of first story. The energy dissipated at top of columns of first story was about $30 \%$ and the energy dissipated by the base of columns at second story was negligible (see Table 4.15).

3. At the end of test $\mathrm{C} 200$, the energy absorbed/dissipated by the columns represents $6.8 \%$ of the total input energy in C200, and $32.4 \%$ of $E_{D}$ (see Tables $4.12,4.14$ and 4.15).

4. Focusing on the critical sections (base of columns of first story) the amount of energy dissipated by each column is quite different, most probably due to torsion effects. In detail, the interior column $\mathrm{C} 3$ dissipated about twice more energy than the other two columns. This proportion continues unaltered in the elastic tests C35 and C50, and after that, as the level of deformation increases, the amount of energy dissipated by the three columns tends to approach, becoming almost the same about $1.0 \mathrm{kNm}$ at the end of test $\mathrm{C} 200\left(W_{p, C 1}=1.09+0.03, W_{p, C 1}=0.30+0.71\right.$ and $W_{p, C 3}=0.22+0.88$ in Tables 4.16 and 4.17). Note that the three columns have the same dimension and similar reinforcement. This suggests that the energy tends to be dissipated by the members less damaged, that is with less stiffness degradation. This is compatible with the fact that forces tend to concentrate in the stiffest elements of the system. Therefore, for high levels 
of plastic deformations the torsion effects are not relevant and scarcely jeopardize the distribution of dissipated energy. The results of this test indicate that in the proximity of the collapse, all plastic hinges located at the base of the first story were able to exhaust their ultimate energy dissipation capacity.

5. Columns at the second story barely suffered damage.

Table 4. 15. Dissipated energy by levels $(0,1$ and 2$)$

\begin{tabular}{|c|c|c|c|c|c|c|c|}
\hline Test & $\begin{array}{c}W_{p, L 0} \\
{[\mathrm{kNm}]}\end{array}$ & $\frac{W_{p, L 0}}{W_{p, c o l}}$ & $\begin{array}{c}W_{p, L 1} \\
{[\mathrm{kNm}]}\end{array}$ & $\frac{W_{p, L 1}}{W_{p, c o l}}$ & $\begin{array}{c}W_{p, L 2} \\
{[\mathrm{kNm}]}\end{array}$ & $\frac{W_{p, L 2}}{W_{p, c o l}}$ & $\begin{array}{l}W_{p, c o l} \\
{[\mathrm{kNm}]}\end{array}$ \\
\hline T10 & 0.66 & $82.7 \%$ & 0.12 & $15.5 \%$ & 0.01 & $1.8 \%$ & 0.80 \\
\hline C35 & 0.66 & $82.7 \%$ & 0.12 & $15.5 \%$ & 0.01 & $1.8 \%$ & 0.80 \\
\hline C50 & 0.67 & $82.7 \%$ & 0.12 & $15.5 \%$ & 0.01 & $1.8 \%$ & 0.81 \\
\hline C100 & 0.96 & $86.9 \%$ & 0.13 & $11.6 \%$ & 0.02 & $1.5 \%$ & 1.11 \\
\hline C200i & 1.56 & $90.9 \%$ & 0.15 & $8.7 \%$ & 0.01 & $0.5 \%$ & 1.72 \\
\hline $\mathrm{C200}$ & 2.27 & $68.7 \%$ & 0.96 & $29.2 \%$ & 0.07 & $2.1 \%$ & 3.30 \\
\hline
\end{tabular}

Table 4. 16. Dissipated energy by sections at level 0

\begin{tabular}{|c|c|c|c|c|c|c|c|}
\hline Test & $\begin{array}{l}W_{p, S 10} \\
{[\mathrm{kNm}]}\end{array}$ & $\frac{W_{p, S 10}}{W_{p, L 0}}$ & $\begin{array}{l}W_{p, S 20} \\
{[\mathrm{kNm}]}\end{array}$ & $\frac{W_{p, S 20}}{W_{p, L 0}}$ & $\begin{array}{l}W_{p, S 30} \\
{[\mathrm{kNm}]}\end{array}$ & $\frac{W_{p, S 30}}{W_{p, L 0}}$ & $\begin{array}{c}W_{p, S 0} \\
{[\mathbf{k N m}]}\end{array}$ \\
\hline T10 & 0.16 & $23.9 \%$ & 0.16 & $23.3 \%$ & 0.35 & $52.8 \%$ & 0.66 \\
\hline C35 & 0.16 & $23.9 \%$ & 0.16 & $23.3 \%$ & 0.35 & $52.8 \%$ & 0.66 \\
\hline C50 & 0.16 & $23.9 \%$ & 0.16 & $23.3 \%$ & 0.35 & $52.8 \%$ & 0.67 \\
\hline C100 & 0.36 & $37.5 \%$ & 0.18 & $19.1 \%$ & 0.42 & $43.4 \%$ & 0.96 \\
\hline C200i & 0.57 & $36.2 \%$ & 0.25 & $15.7 \%$ & 0.75 & $48.1 \%$ & 1.56 \\
\hline $\mathrm{C200}$ & 1.09 & $47.9 \%$ & 0.30 & $13.4 \%$ & 0.88 & $38.7 \%$ & 2.27 \\
\hline
\end{tabular}

Table 4. 17. Dissipated energy by sections at level 1

\begin{tabular}{|c|c|c|c|c|c|c|c|}
\hline Test & $\begin{array}{l}W_{p, S 11} \\
{[\mathrm{kNm}]}\end{array}$ & $\frac{W_{p, S 11}}{W_{p, L 1}}$ & $\begin{array}{l}W_{p, S 21} \\
{[\mathrm{kNm}]}\end{array}$ & $\frac{W_{p, S 21}}{W_{p, L 1}}$ & $\begin{array}{l}W_{p, S 31} \\
{[\mathrm{kNm}]}\end{array}$ & $\frac{W_{p, S 31}}{W_{p, L 1}}$ & $\begin{array}{c}W_{p, S 1} \\
{[\mathrm{kNm}]}\end{array}$ \\
\hline T10 & 0.00 & $4.0 \%$ & 0.08 & $64.9 \%$ & 0.04 & $31.1 \%$ & 0.12 \\
\hline C35 & 0.00 & $4.0 \%$ & 0.08 & $64.9 \%$ & 0.04 & $31.1 \%$ & 0.12 \\
\hline C50 & 0.00 & $4.0 \%$ & 0.08 & $64.9 \%$ & 0.04 & $31.1 \%$ & 0.12 \\
\hline C100 & 0.01 & $5.2 \%$ & 0.08 & $64.6 \%$ & 0.04 & $30.2 \%$ & 0.13 \\
\hline C200i & 0.01 & $7.7 \%$ & 0.09 & $61.4 \%$ & 0.05 & $30.8 \%$ & 0.15 \\
\hline $\mathrm{C200}$ & 0.03 & $2.6 \%$ & 0.71 & $74.1 \%$ & 0.22 & $23.2 \%$ & 0.96 \\
\hline
\end{tabular}

Figure 4.29 shows the distribution of the stored/dissipated energy between steel and concrete at the three levels, using the concrete model C01. Focusing on columns in the first story, since columns in second story were barely damaged, the contribution of concrete was $21 \%$ and $51 \%$ at base and top of columns, respectively, for low states of deformation (test T10). However, with higher deformations, the contribution of concrete decreases up to $10 \%$ and $16 \%$ respectively in test $\mathrm{C} 200$. In other words, the higher damage the less concrete contribution to the energy dissipation. Provided that columns at the base of first story exhausted their energy dissipation capacity with $0.22 \mathrm{kNm}$, columns at top of first story are at $73 \%$ and columns at base of the second story at $4 \%$ of their ultimate energy dissipation capacity. Numerical values are found in Table 4.18. 


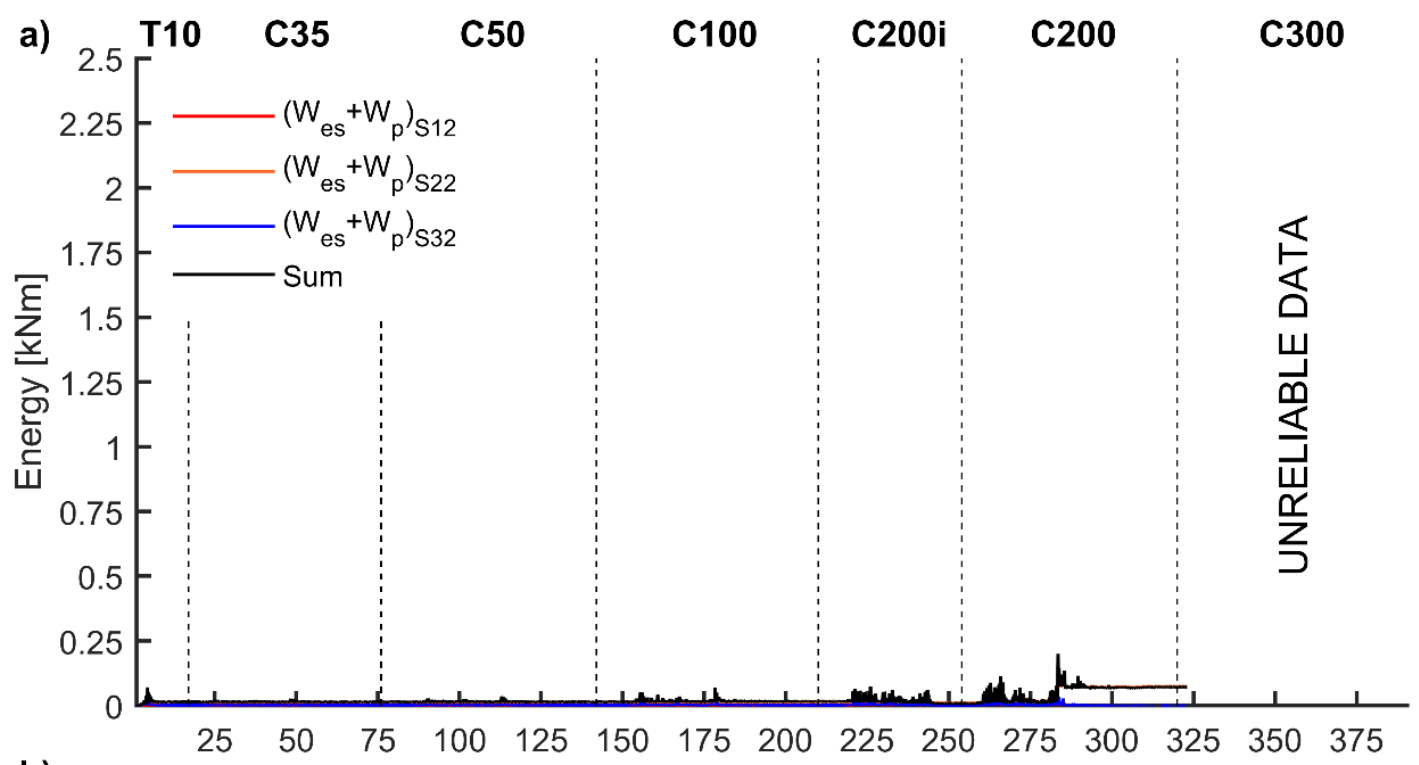

b)
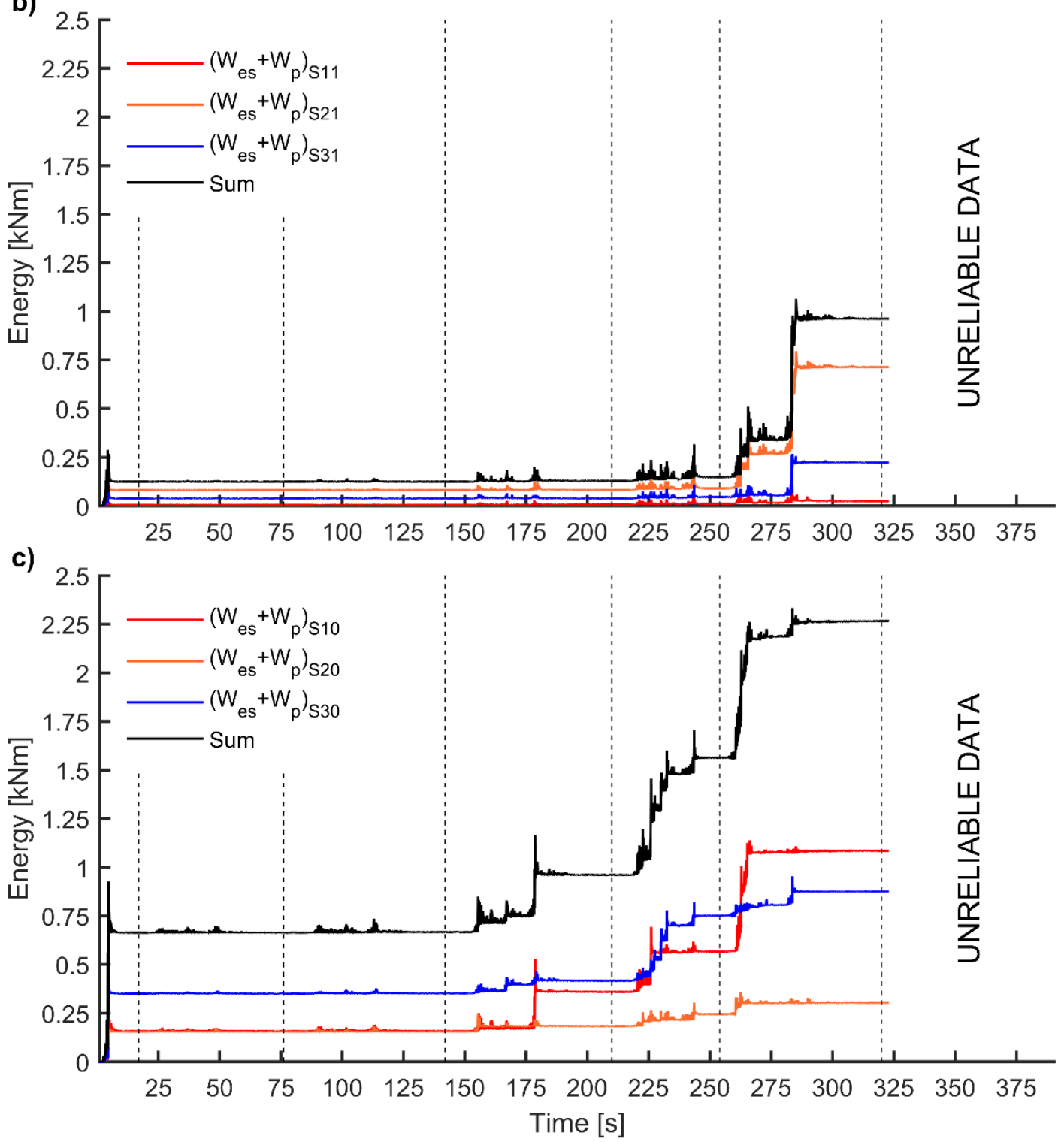

Figure 4. 28. Energy stored/dissipated by columns at: a) base second story, b) top first story and c) base first story 


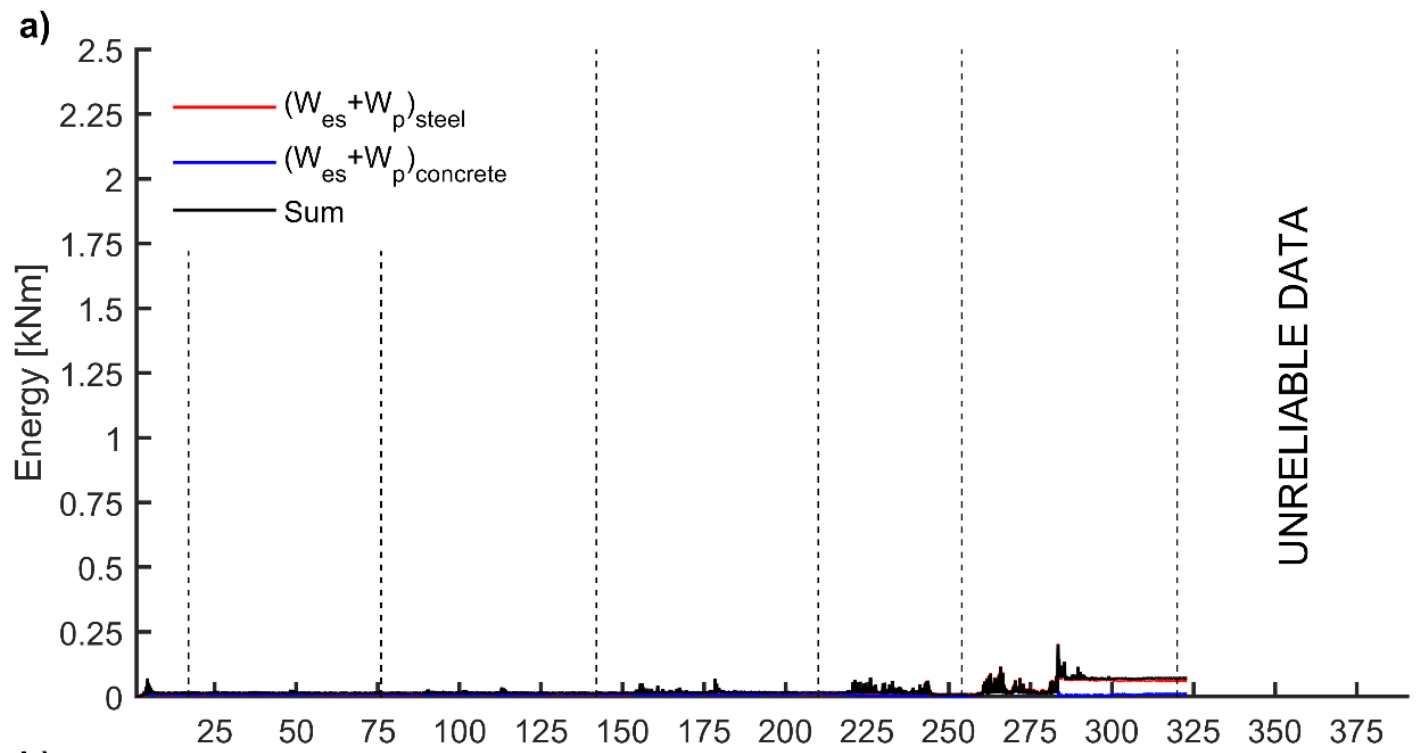

b)
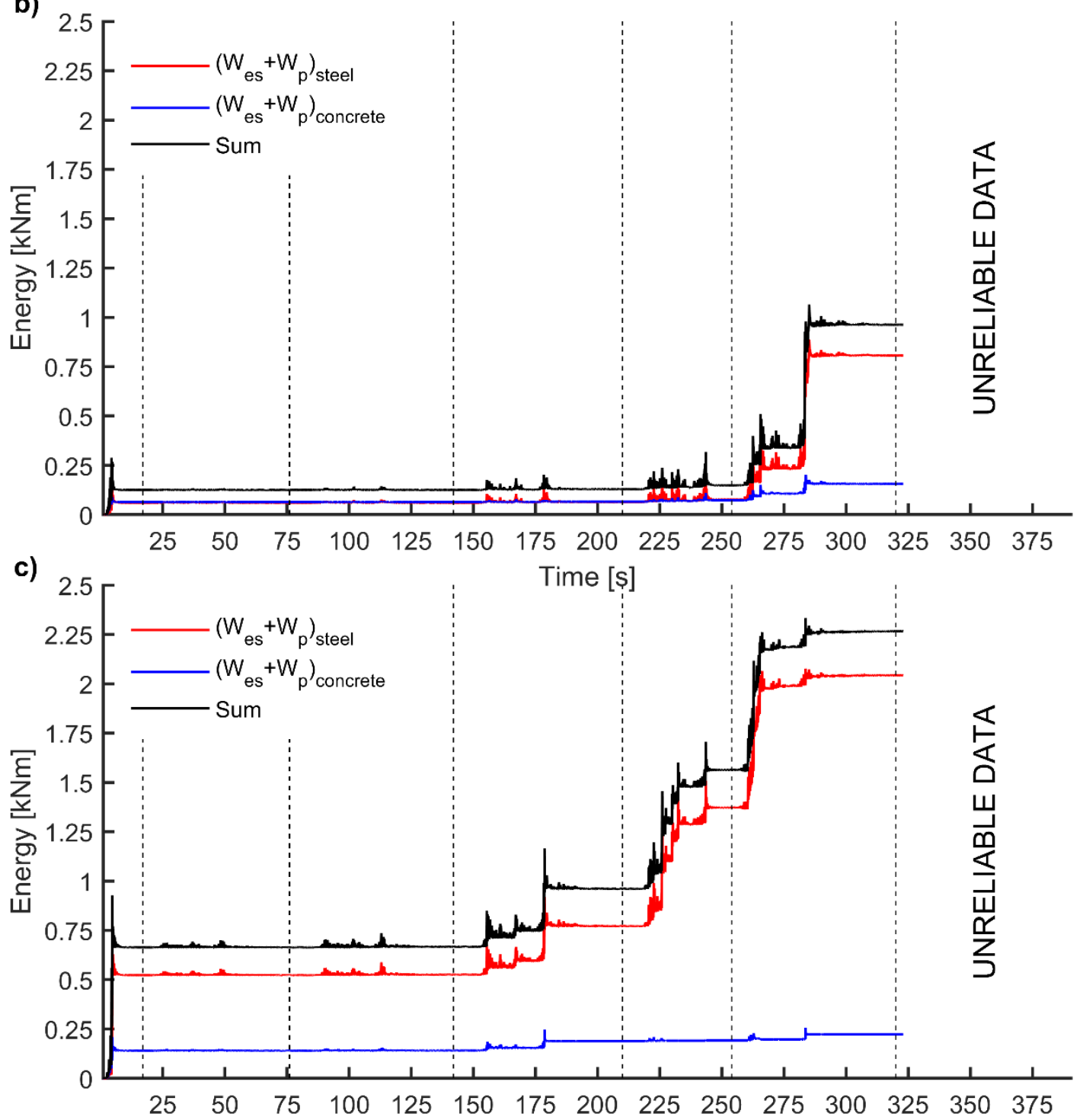

Figure 4. 29. Energy stored/dissipated by steel and concrete in columns at: a) base second story, b) top first story and c) base first story 
Table 4. 18. Energy stored/dissipated by steel and concrete in columns

\begin{tabular}{|c|c|c|c|c|c|c|c|c|c|c|}
\hline \multirow[b]{2}{*}{ Test } & \multicolumn{2}{|c|}{ Steel } & \multicolumn{2}{|c|}{ Concrete } & \multirow[b]{2}{*}{$\begin{array}{c}W_{p, L 0} \\
{[\mathrm{kNm}]}\end{array}$} & \multicolumn{2}{|c|}{ Steel } & \multicolumn{2}{|c|}{ Concrete } & \multirow[b]{2}{*}{$\begin{array}{c}W_{p, L 1} \\
{[\mathrm{kNm}]}\end{array}$} \\
\hline & $\begin{array}{l}W_{p, L 0, s} \\
{[\mathrm{kNm}]} \\
\end{array}$ & $\frac{W_{p, L 0, s}}{W_{p, L 0}}$ & $\begin{array}{l}W_{p, L 0, c} \\
{[\mathrm{kNm}]} \\
\end{array}$ & $\frac{W_{p, L 0, c}}{W_{p, L 0}}$ & & $\begin{array}{l}W_{p, L 1, s} \\
{[\mathrm{kNm}]}\end{array}$ & $\frac{W_{p, L 1, s}}{W_{p, L 1}}$ & $\begin{array}{l}W_{p, L 1, c} \\
{[\mathrm{kNm}]}\end{array}$ & $\frac{W_{p, L 1, c}}{W_{p, L 1}}$ & \\
\hline T10 & 0.52 & $78.8 \%$ & 0.14 & $21.2 \%$ & 0.66 & 0.06 & $48.5 \%$ & 0.06 & $51.5 \%$ & 0.12 \\
\hline C35 & 0.52 & $78.8 \%$ & 0.14 & $21.2 \%$ & 0.66 & 0.06 & $48.5 \%$ & 0.06 & $51.5 \%$ & 0.12 \\
\hline C50 & 0.53 & $78.8 \%$ & 0.14 & $21.2 \%$ & 0.67 & 0.06 & $48.5 \%$ & 0.06 & $51.5 \%$ & 0.12 \\
\hline C100 & 0.77 & $80.3 \%$ & 0.19 & $19.7 \%$ & 0.96 & 0.06 & $48.7 \%$ & 0.07 & $51.3 \%$ & 0.13 \\
\hline C200i & 1.37 & $87.8 \%$ & 0.19 & $12.2 \%$ & 1.56 & 0.08 & $50.9 \%$ & 0.07 & $49.1 \%$ & 0.15 \\
\hline C200 & 2.04 & $90.2 \%$ & 0.22 & $9.8 \%$ & 2.27 & 0.81 & $83.8 \%$ & 0.16 & $16.2 \%$ & 0.96 \\
\hline
\end{tabular}

The energy stored and dissipated by plastic hinges located at column ends can be estimated from the strains measured by the gauges because energy is mostly dissipated by flexure. However, it is only a rough estimation because:

1. The plastic hinge region is defined by a plastic length $l_{p}$ whose range varies between $h$ and $h / 2$, what can result in halving or doubling the energy calculated.

2. Although the ends of columns were instrumented by strain gauges, not all rebars contained in a section of interest had a gauge working. Therefore, the strain of some rebars were estimated through the information captured in the others. Further, even having the strains information of these gauges, its value was obtained by means of a plane of interpolation assuming the Navier-Bernoulli hypothesis.

Despite this lack of accuracy, some values were obtained to understand the energy performance of columns in a dynamic test. In contrast, the energy stored and dissipated by the WFP (the slab) cannot be evaluated with the data provided by the instrumentation for several reasons:

1. The number of strain gauges was limited and did not cover the whole plate.

2. The geometry of the regions of potential plastic deformations cannot be clearly defined, that is, the concept of "plastic hinge" of length $l_{p}$ developed for linear members, such as frames, is not directly applicable to bidirectional plate elements.

3. The plate dissipated most of the energy in the transverse beams of the exterior connection under torsional deformation, whose behavior is out of the field of normal strains and it is still more challenging to estimate it.

Nevertheless, a rough estimation of the energy dissipated by the WFP can be made indirectly as a difference between the energy dissipated by the whole structure $W_{p}=E_{I}-W_{k}-W_{\xi}-W_{e s}$, and the energy dissipated by the columns $W_{p, c o l}$. The dissipated energy by the plate calculated in this way is shown in Figure 4.30. As can be seen in this figure and in Table 4.19, the energy dissipated by the WFP is negligible in comparison with the energy dissipated by columns (the ratio $W_{p, W F P} / W_{p, \text { col }}$ is about 0.02 ), while the specimen remains elastic or quasi-elastic (tests T10, $\mathrm{C} 35, \mathrm{C} 50$ and $\mathrm{C} 100$ ). Once the structure enters the nonlinear range, the energy dissipated by the WFP starts to grow becoming larger than the energy dissipated by the columns at the end of test C200; more precisely the ratio $W_{p, W F P} / W_{p, \text { col }}$ gives 0.63 for Test C200i and then 2.04 for test C200. Moreover, it is worth noting that as long as the damage on the structure increases, the contribution of dissipated energy by plastic deformations with respect to the total dissipated energy increases. This means that when the structure enters the plastic domain the damping contribution to dissipate energy decreases. More preciselly, this can be observed with the ratios $W_{\xi} /\left(W_{p}+W_{\xi}\right)$ and $W_{p} /\left(W_{p}+W_{\xi}\right)$, which give 0.86 and 0.14 for test $\mathrm{C} 200 \mathrm{i}$ and 0.79 and 0.21 for test C200. 


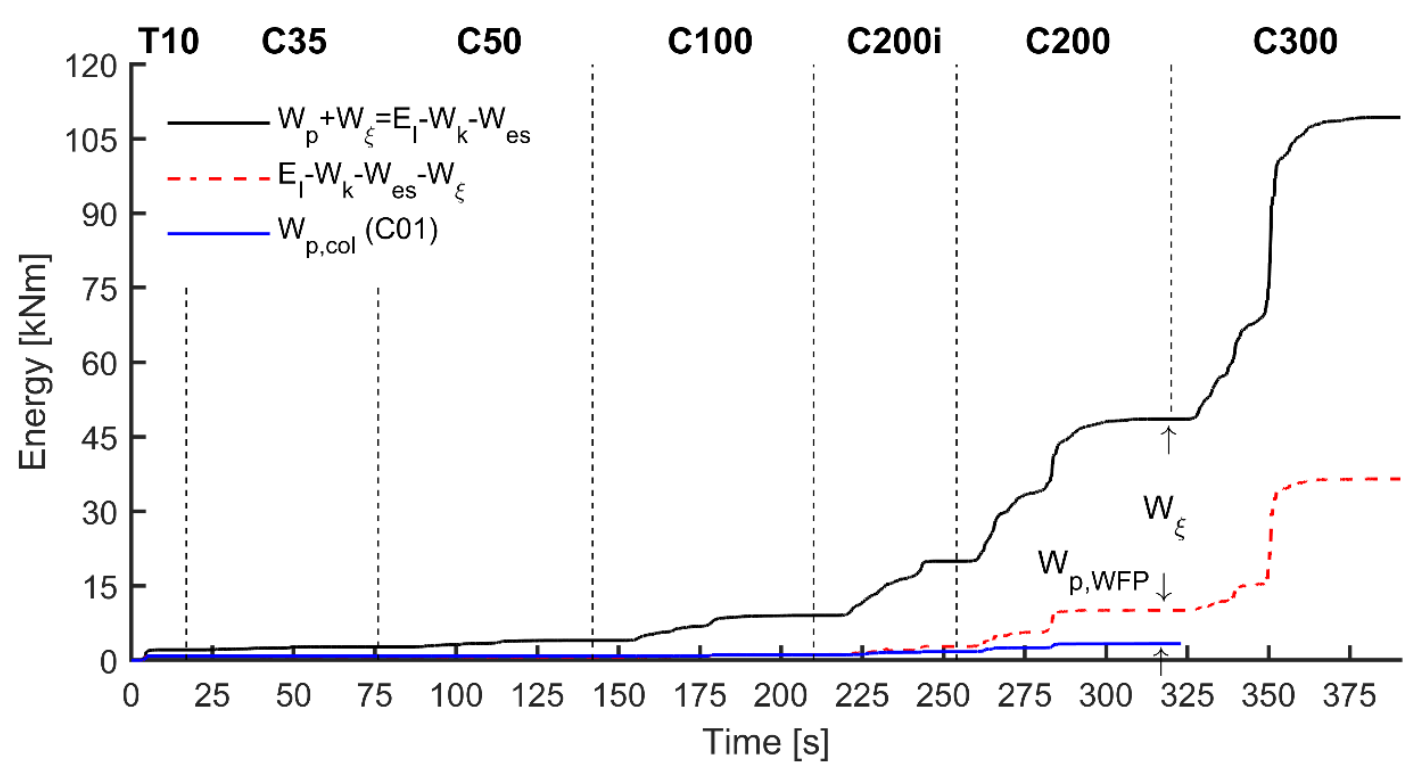

Figure 4. 30. Energy stored/dissipated by columns, WFP and damping.

Table 4. 19. Energy stored/dissipated by columns, WFP and damping

\begin{tabular}{|c|c|c|c|c|c|c|c|}
\hline Test & $\begin{array}{c}W_{\xi} \\
{[\mathrm{kNm}]}\end{array}$ & $\frac{W_{\xi}}{W_{p}+W_{\xi}}$ & $\begin{array}{l}W_{p, c o l} \\
{[\mathrm{kNm}]}\end{array}$ & $\frac{W_{p, c o l}}{W_{p}+W_{\xi}}$ & $\begin{array}{c}W_{p, W F P} \\
{[\mathrm{kNm}]}\end{array}$ & $\frac{W_{p, W F P}}{W_{p}+W_{\xi}}$ & $\begin{array}{c}W_{p}+W_{\xi} \\
{[\mathrm{kNm}]} \\
\end{array}$ \\
\hline T10 & 1.28 & $61.5 \%$ & 0.8 & $38.3 \%$ & 0.02 & $1.0 \%$ & 2.09 \\
\hline C35 & 1.97 & $72.5 \%$ & 0.8 & $29.5 \%$ & 0.02 & $0.7 \%$ & 2.71 \\
\hline C50 & 3.30 & $83.2 \%$ & 0.81 & $20.4 \%$ & 0.02 & $0.5 \%$ & 3.96 \\
\hline C100 & 7.89 & $87.7 \%$ & 1.11 & $12.3 \%$ & 0.02 & $0.3 \%$ & 9.00 \\
\hline C200i & 17.18 & $86.1 \%$ & 1.72 & $8.6 \%$ & 1.07 & $5.4 \%$ & 19.95 \\
\hline $\mathrm{C200}$ & 38.51 & $79.3 \%$ & 3.3 & $6.8 \%$ & 6.76 & $13.9 \%$ & 48.56 \\
\hline
\end{tabular}

\subsection{Discussion about test results}

\subsubsection{Response under training $\mathrm{T} 10$ and seismic simulations $\mathrm{C35}, \mathrm{C} 50$ and $\mathbf{C 1 0 0}$}

Before starting the seismic simulations, during the training of the shake table with white noise signals (T10), the specimen was subjected to a short-pulse of acceleration that caused negligible damage in the structure although the PGA was large. More precisely, the amount of energy that contributes to damage $E_{D}$ inputted by T10 was only $2.7 \%$ of the total amount of $E_{D}$ dissipated by the specimen when it was on the brim of failure. Only hairlines flexural cracks were observed on the top of the plate, at column bases and in the transverse beams at the connection with the exterior column $\mathrm{C} 1$. Permanent Inter-story Drift Indexes $\left(I D I_{r}\right)$ were negligible (about $\left.0.1 \%\right)$ and the maximum transient Inter-story Drift Indexes IDI ranged between $0.72 \%$ and $1.57 \%$ with an average value of $1.1 \%$.

Under the seismic simulations C35 and C50 that represent "very frequent" earthquakes for the building site, the test specimen exhibited an elastic response as Figures $4.12 \mathrm{~b}$ and $4.13 \mathrm{c}$ show. Permanent Inter-story Drift Indexes $\left(I D I_{r}\right)$ were about $0.1 \%$ and the maximum transient Interstory Drift Indexes $I D I$ were between $0.45 \%$ and $0.65 \%$, with an average value of $0.58 \%$. According to SEAOC (1995), these values of $I D I$ and $I D I_{r}$ are on the upper bound of the SPL "Operational" $(0.5 \pm 0.1 \%)$. The specimen did not experience plastic deformations $\left(\Delta E_{D}=\right.$ $0.0 \mathrm{kNm}$ in Table 4.14). 
With the seismic simulation $\mathrm{C} 100$, associated with a "frequent" earthquake, the response was nearly elastic and the original strength and stiffness were substantially retained as shown in Figures $4.12 \mathrm{~d}$ and $4.13 \mathrm{~d}$. New hairline flexural cracks appeared on the top of the plate, at column bases and in the transverse beams. Permanent Inter-story Drift Indexes $\left(I D I_{r}\right)$ were still negligible (less than $0.14 \%$ ). The maximum transient Inter-story Drift Indexes IDI ranged between $0.77 \%$ and $1.17 \%$ with an average value of $1 \%$. According to SEAOC (1995), these values of IDI and $I D I_{r}$ are in the SPL "Life Safety" (IDI $<1.5 \pm 0.1 \%$ and $\left.I D I_{r}<0.5 \% \pm 0.1 \%\right)$. Further, this was confirmed in terms of $E_{D}$; during this ground motion $\Delta E_{D}=0.44 \mathrm{kNm}$ represented $1.5 \%$ of the energy dissipated through plastic deformations when the specimen was at the at brim of collapse (Table 4.14).

The typically large lateral flexibility of this type of systems allowed the structure to attain these $I D I_{S}$ with light damage, which was quantified in terms of $E_{D}$. This suggests that the limit set by SEAOC (1995) for the "Operational" SPL (IDI and $I D I_{r}<0.5 \% \pm 1 \%$ ) is too conservative for waffle-flat plate systems and could be increased to $1.0 \% \pm 0.1 \%$.

\subsubsection{Response under seismic simulations C200i and C200}

Under test C200i, an initial run was interrupted due to a problem with the control system. The seismic simulations with the original ground motion scaled to $200 \%$ was then successfully repeated, C200. The base shear-top displacement curves shown in Figures 4.14a, 4.14b, 4.15a and $4.15 \mathrm{~b}$ clearly evidence a significant plastic response at the end of test C200. Test C200 represents the "design earthquake". The permanent Inter-story Drift Index $I D I_{r}$ was relatively small (between $0.13 \%$ and $0.52 \%$ ) and the maximum transient Inter-story Drift Index IDI was between $1.31 \%$ and $3.03 \%$, with an average value of $2.58 \%$. Based on these data, according to SEAOC (1995) the state of the structure is in the SPL "Near Collapse" (IDI $<2.5 \% \pm 0.1 \%$ and $\left.I D I_{r}<2.5 \% \pm 0.1 \%\right)$. A visual inspection of the specimen after these tests revealed concrete crushing at the base of the columns (see Figure 4.31), and large torsional cracks with concrete spalling in the transverse beams close to the exterior column (see Figure 4.32). The interior platecolumn connections developed a weak column mechanism in both the $\mathrm{X}$ and $\mathrm{Y}$ directions. The maximum strains in the longitudinal reinforcement of the interior columns were about $1.6 \varepsilon_{y}$ in test $\mathrm{C} 200 \mathrm{i}$ and then, in test $\mathrm{C} 200$, were about $5.6 \varepsilon_{y}$, while the maximum strains measured in the interior plate were bellow $\varepsilon_{y}$ in test $\mathrm{C} 200 \mathrm{i}$ and slightly above $\varepsilon_{y}$ (about $1.5 \varepsilon_{y}$ ) in a little zone of the section S14Y in test C200 (see Figures 4.17 and 4.18). The exterior plate-column connection developed a strong column-weak plate mechanism in the $\mathrm{X}$ and $\mathrm{Y}$ direction. The damage on the transverse beam due to torsion was severe. Despite these damages, the structure kept substantial capacity to support vertical loads and the lateral system was still functional. This also suggests that the limit set by SEAOC for the "Life Safety" SPL could be increased to $2.5 \pm 0.1 \%$ for waffle-flat plate systems. 


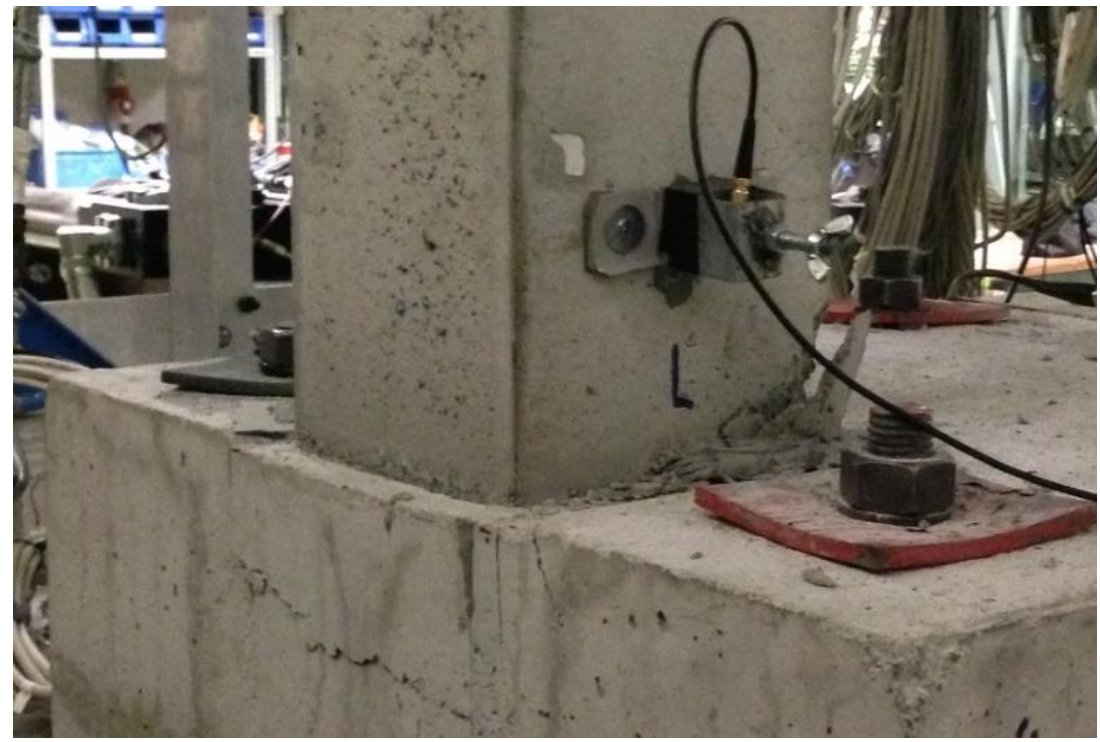

Figure 4. 31. State of base of column C1 at end of test C200.

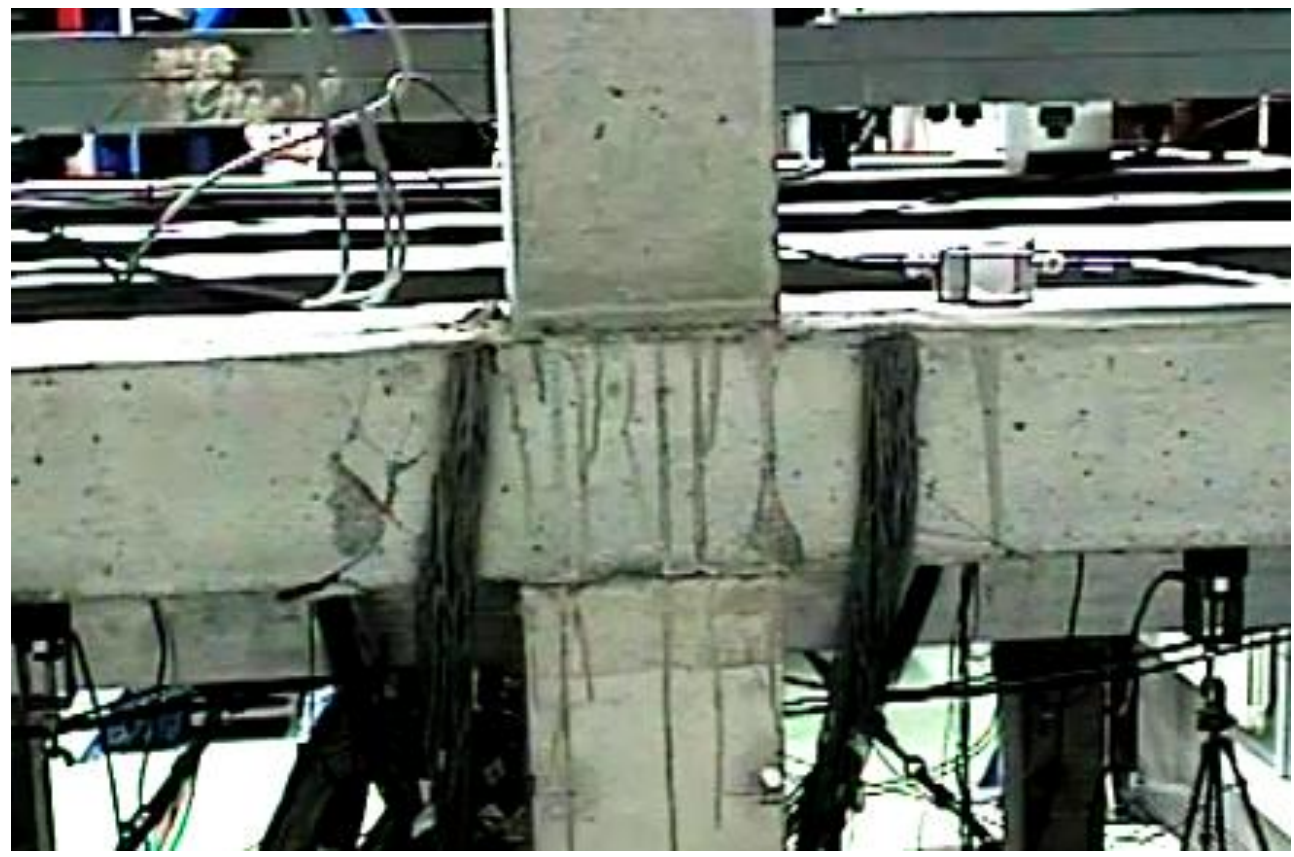

Figure 4. 32. Exterior plate-column connetcion at end of test C200.

\subsubsection{Response under tests $\mathrm{C} 300$}

Test C300 represents a "very rare" earthquake at the building site. During this test, the structure experienced a large cycle of displacement reaching a maximum Inter-story Drift Index IDI of above $6 \%$ at instant 351.11s (27.6 seconds after the beginning of test C300). This instant was considered the point of failure of the structure. The failure was triggered by the complete degradation of the transverse beam in the exterior connection in which shear stresses, induced by combined torsion, bending and gravity forces, played a decisive role. Damage concentrated in the transverse beams, visible by the pairs of crisscrossing inclined cracks (torsional cracks with concrete spalling) in Figure 4.33, left the plate hanging from the column with all the shear forces solely transferred by the dowel action of the longitudinal reinforcement crossing the plate-column interface. This failure together with the very poor state of all column bases and the head of columns C2 and C3, where extensive concrete spalling occurred (see Figure 4.34 and 4.35), left 
the test structure in critical conditions (Figure 4.36). Although certainly, the structure continued supporting gravity loads. Moreover, the lateral strength of the specimen dropped as much as $50 \%$ as seen in Figures $4.14 \mathrm{c}$ and $4.15 \mathrm{c}$. The maximum IDI ranged between $2.27 \%$ and $5.91 \%$ with an average value of $4.3 \%$. Similarly, the maximum $I D I_{r}$ ranged between $2.13 \%$ and $5.91 \%$ with an average value of $4.2 \%$. These values are higher than those proposed by SEAOC (1995) for NC (>2.5\%), suggesting that they could be increased to $4 \% \pm 0.1 \%$ for waffle-flat plate systems.

a)

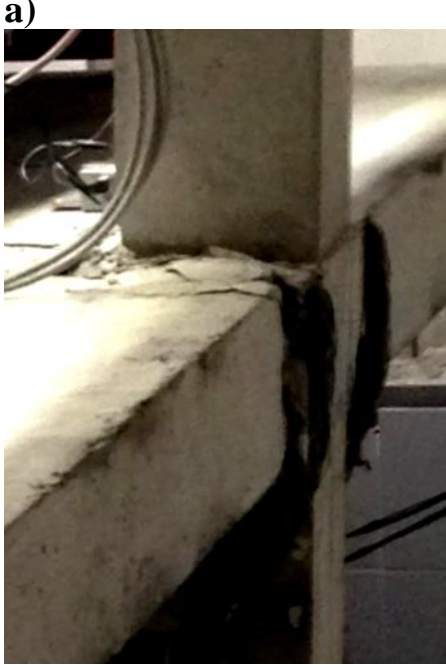

b)

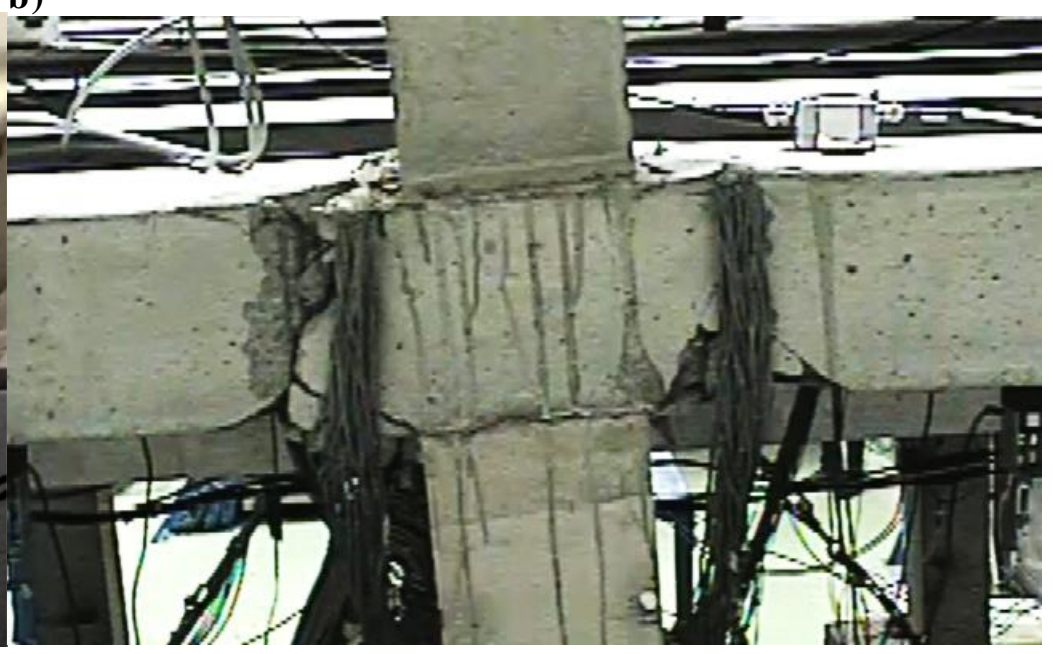

Figure 4. 33. Cracks and concrete spalling at exterior plate-column connetcion at end of test C300: a) from East and b) from North.

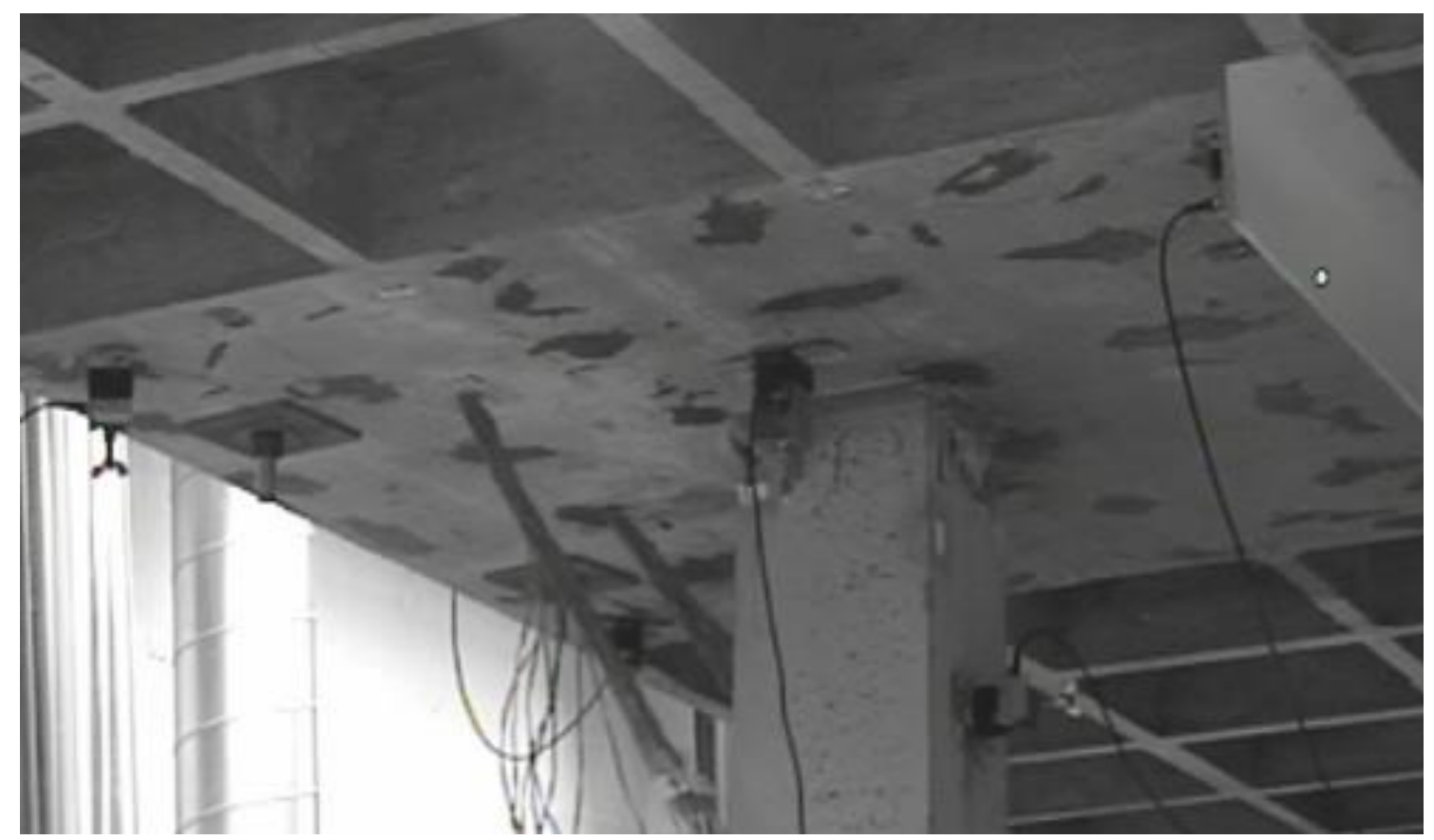

Figure 4. 34. Cracks and concrete spalling at head of column C2 at end of test C300 
a)

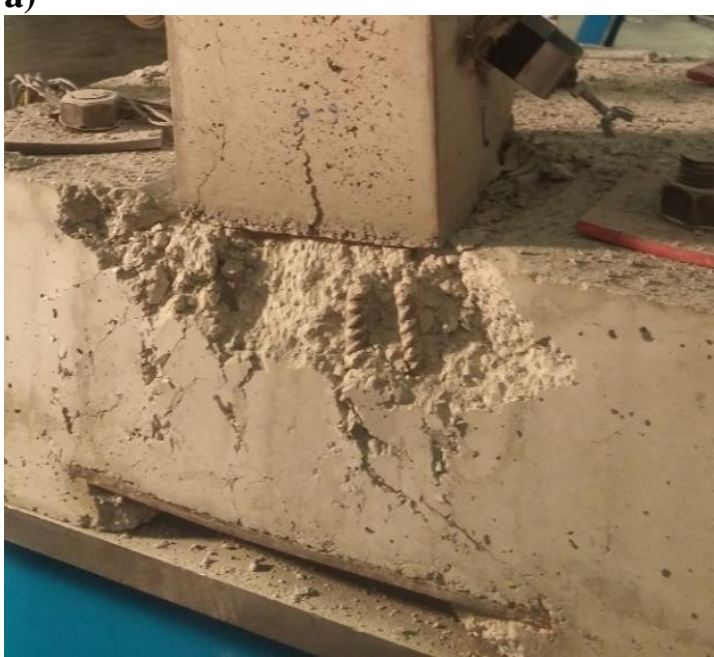

b)

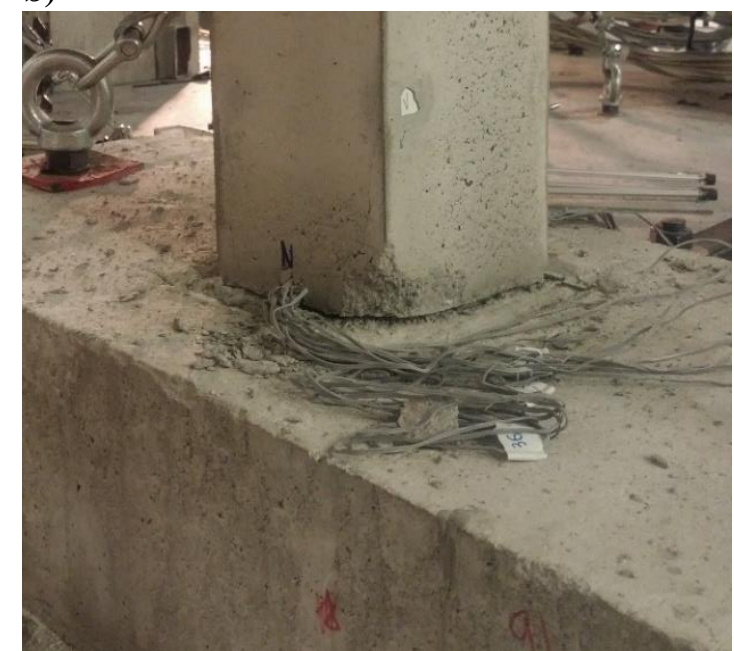

Figure 4. 35. State of columns bases at end of test C300: a) Column C1 and b) C3

a)

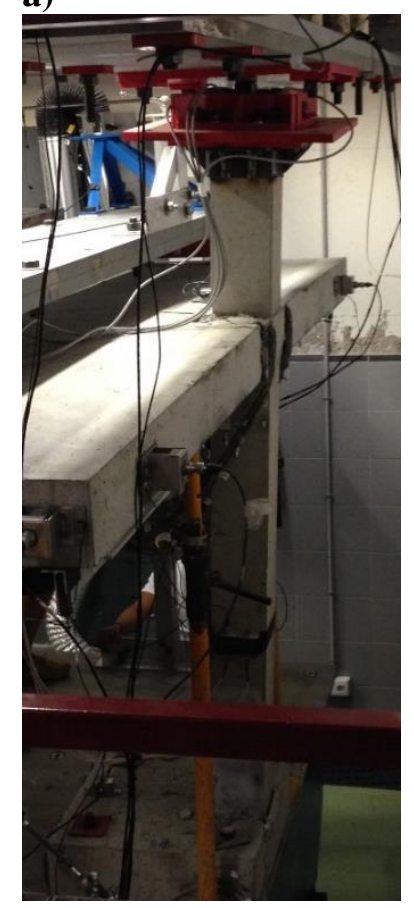

b)

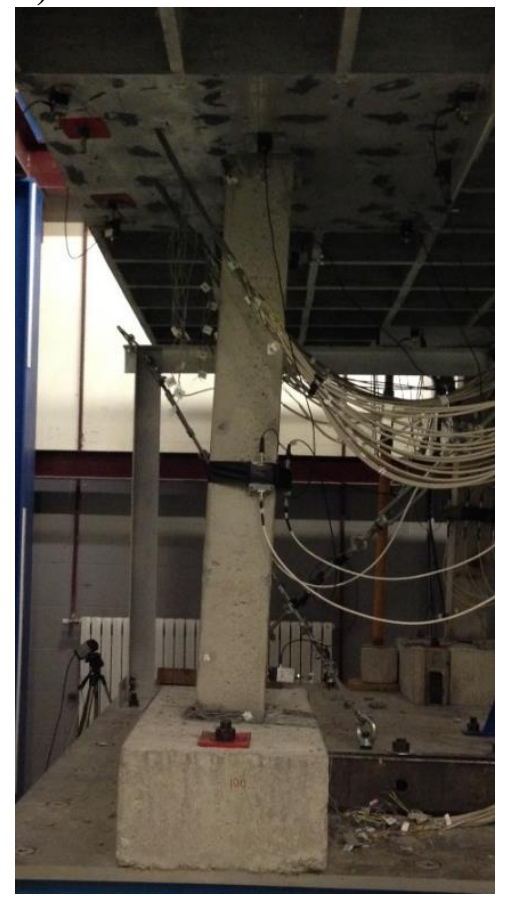

c)

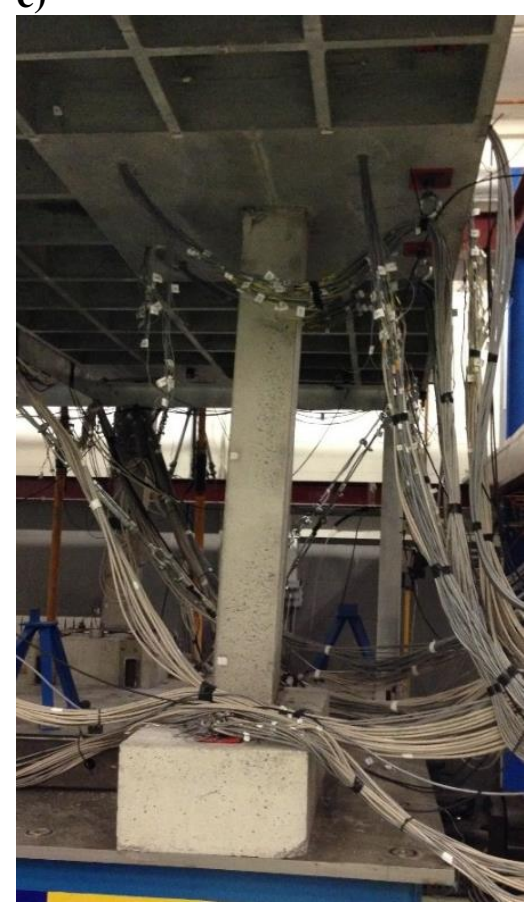

Figure 4. 36. State of columns at end of test C300: Columns a) C1, b) C2 and c) C3

\subsection{Design implications}

\subsubsection{Behavior factor for applying the reduced-spectrum force-based approach}

The design of structures applying the reduced-spectrum force-based approach requires the assignment of a behavior factor to the structure named $q$ in EN-1998-1 (CEN 2004). The next generation of EN 1998 defines $q$ as the product of three components, $q=q_{R} q_{S} q_{D}$. Where, $q_{R}$ accounts for the overstrength due to a redistribution of seismic action in redundant structures, $q_{S}$ accounts for overstrength due to all other sources, and $q_{D}$ accounts for the plastic deformation capacity. Actually, $q$ is a force reduction factor $(F R F)$ which is defined as $F R F=\alpha_{e u} / \alpha_{s}$, where $\alpha_{e u}$ is the elastic base shear force coefficient and $\alpha_{s}$ is base shear force coefficient used in design. 
Pre-multiplying up and down this equation by the base shear force coefficient at yielding $\alpha_{y}$ and reorganizing yields:

$$
F R F=\frac{\alpha_{e u}}{\alpha_{y}} \frac{\alpha_{y}}{\alpha_{s}}
$$

Where $\alpha_{y} / \alpha_{s}$ is the overstrength factor, i.e., $q_{R} q_{S}$ and $\alpha_{e u} / \alpha_{y}$ is the ductility factor, i.e. $q_{D}$. $q_{R} q_{S}$ can be readily obtained from test results. $q_{D}$ can be obtained assuming an elastic perfectly plastic behavior for the structure and applying the "equal displacement" rule (the "key" rule of the force-based approach). Applying the equal displacement rule it follows that $\alpha_{e u} / \alpha_{y}$ is equal to the ductility factor, $\mu=\delta_{\max } / \delta_{y}$, that can be estimated from the test results. Therefore, dividing the base shear force coefficients obtained from the tests, $\alpha_{B X}^{+}=0.47, \alpha_{B X}^{-}=0.48$, $\alpha_{B Y}^{+}=0.49$ and $\alpha_{B Y}^{-}=0.55$, by the base shear force coefficient used in the design $\left(\alpha_{s}=0.33\right)$ gives $1.42,1.45,1.48$ and 1.64 , respectively. The minimum of these values can be taken as a safe side estimation of overstrength $\left(q_{R} q_{S}=1.42\right)$. On the other hand, the ductility values obtained from tests are $\mu_{X}^{-}=2.5, \mu_{X}^{+}=2.1, \mu_{Y}^{-}=1.7$ and $\mu_{Y}^{+}=1.5$. The minimum of these values can be taken as a safe side estimation of plastic deformation capacity $\left(q_{D}=1.5\right)$. Accordingly, and bearing in mind the bidirectional seismic action, the results of the tests suggest that for WFP structures the product $q_{R} q_{S}$ should not be taken larger than 1.4 and the behavior factor $q_{D}$ not larger than 1.5. This would give a behavior factor $q\left(=q_{R} q_{S} q_{D}\right)$ of $q=2.1$. Due to the limited volume of experimental data, these suggestions are tentative and should be supported by additional tests. The value $q=2.1$ is smaller than the proposed by Benavent-Climent (2016), $(q=3.0)$ based on unidirectional shake table tests conducted on a similar specimen. It is worth noting that the current EN-1998 (CEN 2004) does not provide specific behavior factors for FP structures.

\subsubsection{Reinforcement passing through the exterior plate-column connection}

The bidirectional seismic action exacerbates the concentration of damage in the exterior platecolumn connection. The occurrence of severe torsional cracking in the torsional beams and the concrete spalling causes a loss of moment transfer on the exterior connection. After this loss, the only remaining resistance is the longitudinal reinforcement passing through the damaged region. A minimum amount of bottom longitudinal steel passing through the exterior connection and anchored outside the critical perimeter should be provided to reduce the risk of progressive collapse.

\subsubsection{Consideration of torsional effects}

Torsional effects are not relevant for high levels of plastic deformations and could be neglected for checking the structure for SPL of LS and NC.

\section{SUMMARY}

A two-fifth scale portion of a RC waffle-flat plate structure designed according to the current Spanish Seismic code was tested under bidirectional horizontal seismic loadings on a shake table until collapse. During the training of the shake table with white noise signals, the specimen was subjected to a short-pulse of acceleration (T10). Next, the specimen was subjected to several seismic simulations that represented very frequent (C35 and C50), frequent (C100), design (C200) 
and very rare (C300) earthquakes at the assumed building site. Due to a problem in the control system of the shake table, the seismic simulation C200 was preceded by a failed attempt, C200i, that was interrupted when about one third of the intended duration of the signal elapsed. The results of the tests can be summarized as follows:

1. The structure behaved as expected, i.e., within the elastic range, for the ground motion simulations associated with very frequent or frequent ground motions at the site.

2. Under the design earthquake (C200) the lateral strength dropped by about $20 \%$ and the maximum IDI was on the limit of the SPL of LS and NC, according to SEAOC (1995). The specimen developed a plastic mechanism consisting on weak column-strong plate in the interior connections, in both directions, and a strong column-weak plate, in both directions, in the exterior connection. The damage concentrated in the spandrel (transverse) beam of the exterior connection.

3. The structure collapsed at the beginning of the seismic simulation C300, associated with a very rare earthquake. Column bases, head of columns C2 and C3 and the exterior platecolumn connection concentrated the damage. The torsional failure of the spandrel beam triggered the loss of the moment transfer capacity of the exterior plate-column connection. This failure compromised the stability of the test structure but collapse was prevented by bottom slab reinforcement passing through the column core (dowel action).

4. The total (accumulated) energy input by the two horizontal components of the ground motion $E_{I}$ when the specimen reached the collapse state $(3.90 \mathrm{~m} / \mathrm{s}$ in terms of equivalent velocity) is very similar to the value obtained on a similar specimen subjected to a single component of the ground motion $(3.95 \mathrm{~m} / \mathrm{s}$ ) (Benavent-Climent et al., 2016). This means that the ultimate energy dissipation capacity of the tested structure under unidirectional and under bidirectional seismic loadings was basically the same.

5. The energy that contributes to damage defined as $E_{D}=E_{I}-W_{\xi}$, assuming a damping ratio of $3 \%$, represented $33 \%$ of the energy input $E_{I}$ at the failure. The amount of energy dissipated by damping represented $79 \%$, the energy dissipated through plastic deformations at column ends represented $7 \%$ and remainder of energy was dissipated mainly by the exterior plate-column connection.

6. For high levels of plastic deformations, the torsional effects scarcely jeopardize the distribution of dissipated energy among the columns. All columns dissipated approximately the same amount of energy when they approached to their ultimate capacity.

7. The collapse was characterized by the occurrence of a single cycle of very large amplitude in direction NE, forming an angle of about 30 degrees with the X-direction. This coincided with a sudden increase of the input energy.

8. Owing to the large lateral flexibility of WFP systems and according to the results of the tests, the permissible transient drift limits for "Operational", "Life Safety" and "Collapse" SPL for this type of structures should be taken as $1.0 \%, 2.5 \%$ and $4 \%$, respectively, with a tolerance of $\pm 0.1 \%$, assuming the test results. These values are from 1.6 times to twice larger than those adopted by SEAOC for conventional frame structures. 


\section{Chapter 5}

\section{NUMERICAL INVESTIGATION: RESPONSE OF WFP STRUCTURES UNDER BIDIRECTIONAL SEISMIC LOADING}

Shaking table tests are certainly the best approach to reproduce the seismic demand on structures because they can capture accurately complex phenomena such as cumulative damage and rate-ofloading effects. However, this type of test are very costly and time demanding. For these reasons, conducting a large number of shaking table tests with different ground motions is unfeasible. To solve this issue, refined numerical models calibrated with experimental test results can be used instead. This Chapter investigates the seismic response (capacity) in terms of energy of WFP structures subjected simultaneously to two horizontal components of the seismic action. To that end, a detailed Finite Element (FE) nonlinear model (benchmark model hereafter) that represents the specimen BS1 is developed and calibrated with the results of the shaking table tests. The parameters that were adjusted in the calibration of the model are: (i) the bending moment $M_{y}$ and curvature $\varphi_{y}$ at yielding and at failure $\varphi_{u}$ of the plastic hinges located at columns ends, and the parameters that control their hysteretic rules under cyclic loading; (ii) the reduction of inertia of the sections due to concrete cracking; (iii) the interaction factor to take into account bidirectional 
loading at columns; and (iv) the damping ratio of each mode. The values of these parameters were determined so that the frequencies and the histories of displacement and input energy predicted with the numerical model fit as much as possible with the results obtained experimentally with the shake table tests. The values adopted for the rest of parameters that define the model are based on formulae proposed in the literature or on the properties obtained testing the materials. Then, different sets of two-directional ground motions are selected and applied to the benchmark model. The selected ground motions have different ratios of input energy between the two horizontal components. Afterwards, the ground motions are applied to the numerical model in successive seismic simulations with increasing scaling amplitudes until collapse. Eventually, the ultimate input energy and the ultimate energy dissipated by plastic deformations in the structure are obtained for each ground motion.

\section{DESCRIPTION OF BENCHMARK NUMERICAL MODEL}

A 3-D numerical model to predict the nonlinear dynamic response of the specimen BS1 was built in Opensees (Mazzoni, McKenna, Scott, \& Fenves, 2006; Mckenna, Francis Thomas, 1999; McKenna, Frank, Scott, \& Fenves, 2009), an open source Finite Element Analysis (FEA) software framework developed in Berkeley (University of California, USA). The model was created to understand the behavior and performance of WFP structural system during earthquakes. The software allows users to choose between a wide range of elements and materials. There are different types of elements with distributed and concentrated plasticity, which are themselves fed by uniaxial materials. If none of them meets expectations, the user can create a new one. Moreover, the software uses object-oriented methodologies to maximize modularity, what makes it possible to simulate almost anything. However, the software unfortunately is not user-friendly, basically due to the lack of a Graphical User Interface (GUI), especially for stages of preprocessing and post-processing.

\subsection{Overall perspective}

Figure 5.1 shows an overview of the model, which was made up of 1802 nodes and 1810 elements following the geometry and structural details defined in Figures 2.2, 2.3 and 2.5.

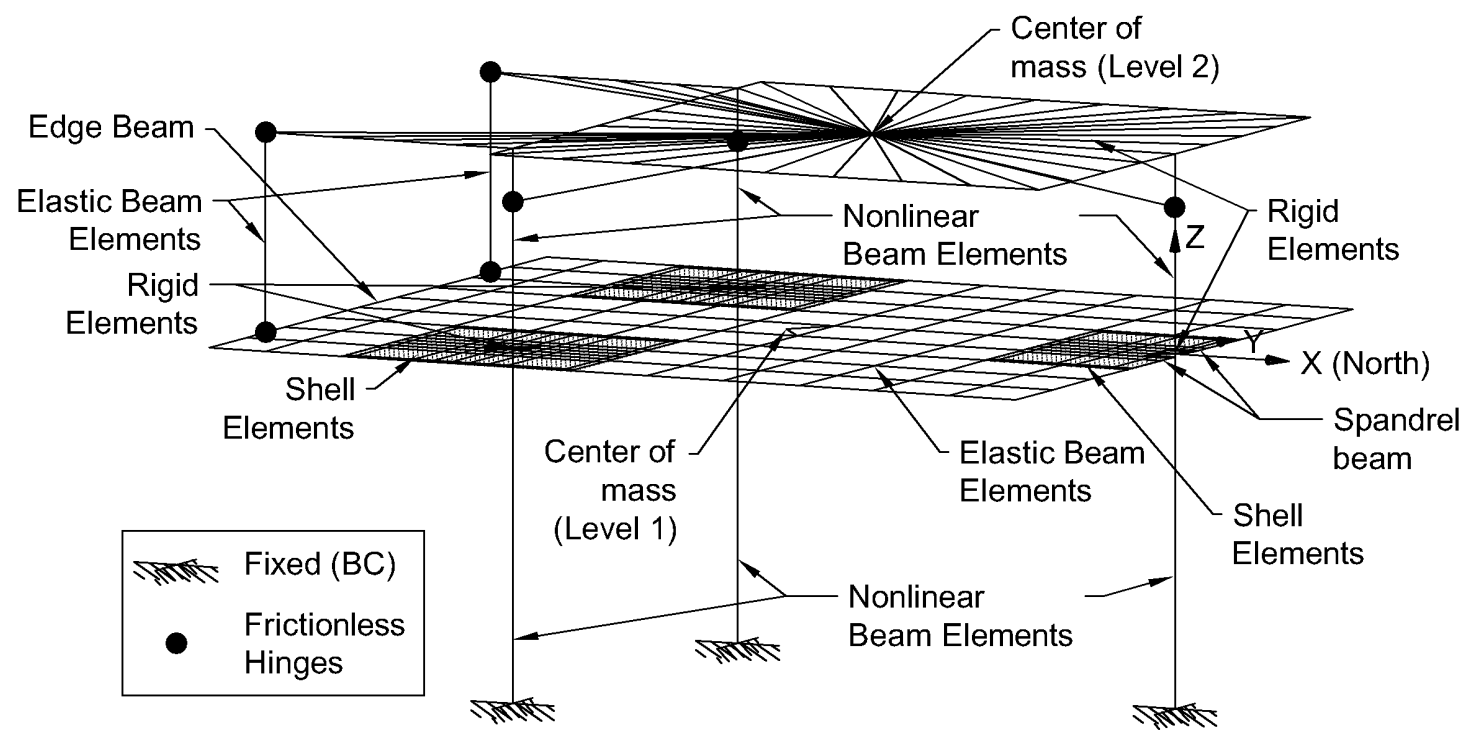

Figure 5. 1. Overview of the model 
In the model, nonlinear beam elements were used to simulate columns and the spandrel beam of the exterior column-plate connection, elastic beam element for the rest of the slab joists including the edge beam, rigid elements for slab-column joints and hardware, and linear and nonlinear shell elements for drop panels. In addition, frictionless hinges were used to idealize the connection between column tops and top hardware as well as ends of links connecting the slab to the top hardware. Furthermore, as boundary conditions, columns were assumed fixed on the foundation blocks.

\subsection{Elements}

This section aims to describe the elements used in each part of the model. All of them were chosen as linear or nonlinear elements depending on its performance during the dynamic tests in order to reduce the computational burden. Opensees introduces nonlinear behavior of unidirectional elements, such as beams and columns, through distributed plasticity using fiber sections and through concentrate plasticity using lumped plastic hinges. For bidimensional elements such as shells, the nonlinear behavior is taken into account through multilayered shell sections.

\subsubsection{Columns}

Columns proved to be the critical elements in the model, since they exhibited the largest nonlinear behavior during tests and governed the overall response of the structure. They were modeled using nonlinear frame elements defined as the newest Beam with Hinges element. The Opensees command used to define them was element forceBeamColumn adding the keyword HingeRadau to include the integration method. This element has a formulation based on the Modification of Two-Point Gauss-Radau Integration (Scott \& Fenves, 2006) with 6 integration points located at $-1,-0.36,-0.22,0.22,0.35,1$ in isoparametric coordinates, $\eta$ (Figure 5.2).

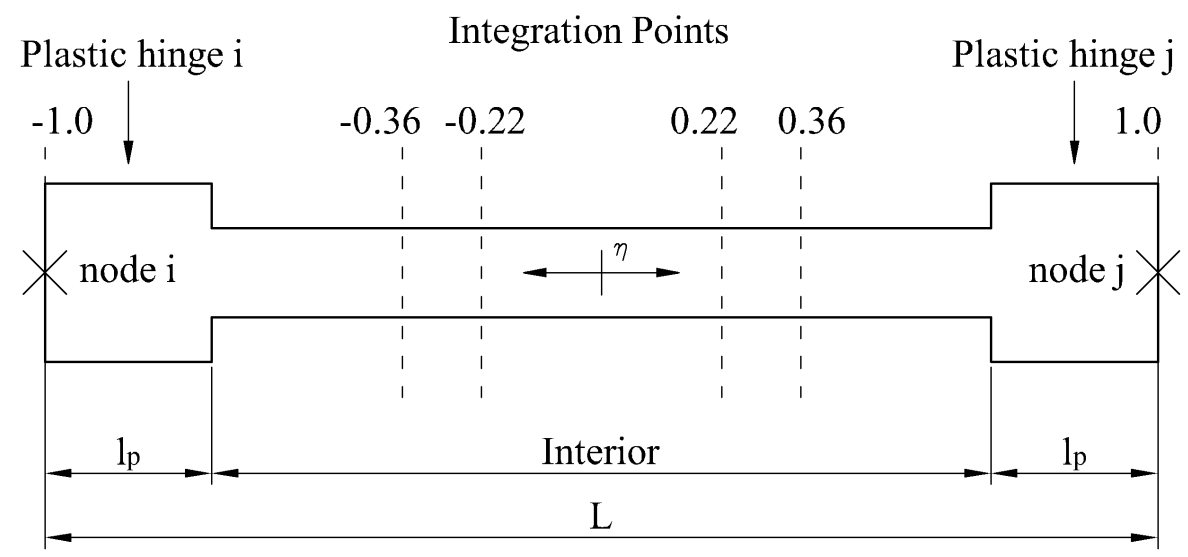

Figure 5. 2. Beam with hinges element

The frame element comprises three parts as shown Figure 5.2: the two end parts are lumped plastic hinges (concentrated plasticity), while the center part (interior) uses fiber sections (distributed plasticity). In the concentrate plasticity zone, sections can be defined with a fiber section or a moment-curvature relationship, then the software calculate the moment-rotation relationship multiplying by the plastic length $\left(l_{p}\right)$. To use one or another depends on the level of damage that the section undergoes. Fiber sections were assigned for low levels of damage, i.e. end sections of columns in the second story, since the upper columns were barely damaged during test, and 
moment-curvature relationships for high levels of damage, i.e., end sections of columns in the first story because they ended up highly damaged (Chapter 4).

Fiber sections were discretized by a grid of $2 \times 2 \mathrm{~mm}$ fibers of concrete and a single fibers for each additional longitudinal rebar following details shown in Figure 2.2. The hysteretic behavior of concrete was defined through the parametric material model Concrete02 (Mohd, 1995), adapted to the constitutive model proposed by Maekawa (2003) as Figure 5.3a shows. For the steel rebars, the Giuffré-Menegotto-Pinto model with isoparametric strain hardening (Filippou, Bertero, \& Popov, 1983) was used, which is defined in Opensees as Steel02 (Figure 5.3b). Table 5.1 lists the concrete and steel properties introduced in the model for fiber sections. As explained in Chapter 2 , only the maximum compression strength of concrete and the yield stress of steel were obtained from testing. The rest of parameters were either estimated applying the Spanish Concrete Code EHE-08 (Ministerio de Fomento 2008): strain at maximum strength, Young's modulus of concrete $\left(E_{c}=8500 \sqrt[3]{f_{c m}}\right.$, being $f_{c m}$ the maximum compression strength of concrete), concrete Poisson's ratio, concrete density, Young's modulus of steel, steel Poisson's ratio and steel density.
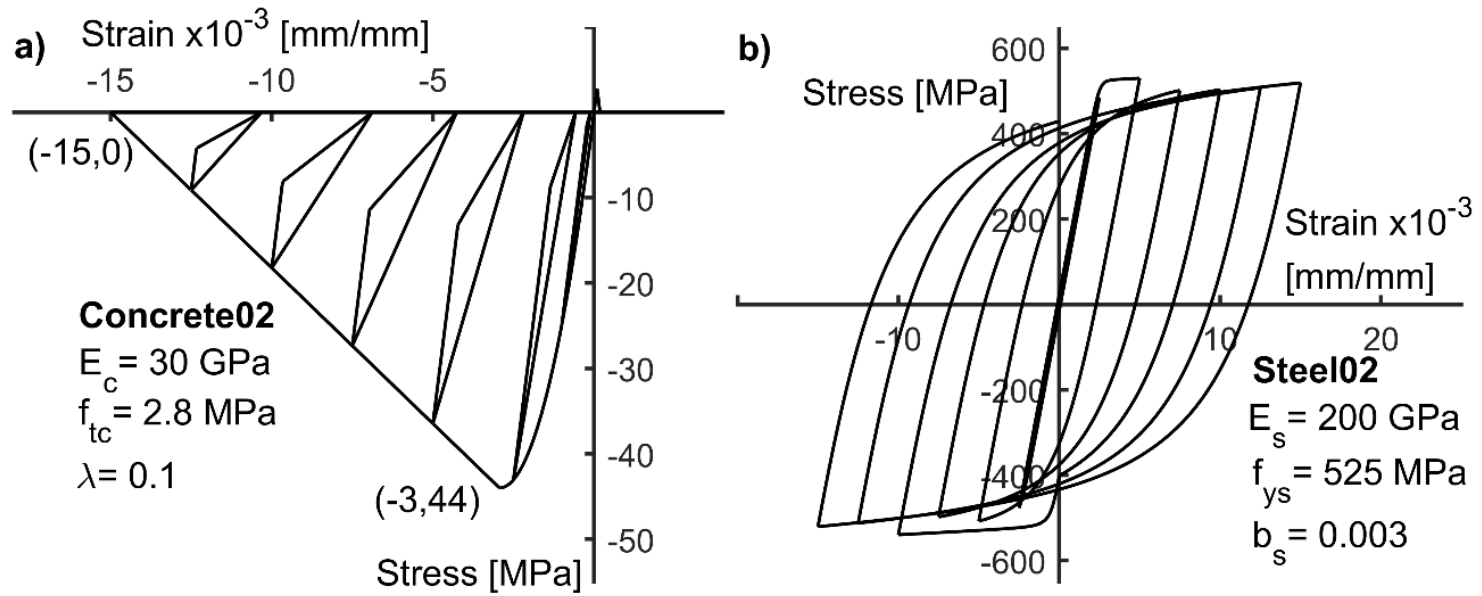

Figure 5. 3. Hysteretic curves of fiber materials: a) Concrete and b) Steel

Table 5. 1. Fiber materials properties

\begin{tabular}{lclc}
\hline Concrete & \multicolumn{1}{c}{ Steel } \\
\hline Compressive strength $\left(\boldsymbol{f}_{\boldsymbol{c}}\right)$ & $44 \mathrm{MPa}$ & Young modulus $\left(\boldsymbol{E}_{\boldsymbol{s}}\right)$ & $200 \mathrm{GPa}$ \\
Strain at max. strength $\left(\boldsymbol{\varepsilon}_{\boldsymbol{c}}\right)$ & $3.0 \times 10^{-3}$ & Max. strength $\left(\boldsymbol{f}_{\boldsymbol{y} \boldsymbol{s}}\right)$ & $525 \mathrm{MPa}$ \\
Crushing strength $\left(\boldsymbol{f}_{\boldsymbol{c u}}\right)$ & $0.0 \mathrm{MPa}$ & Strain-hardening ratio $\left(\boldsymbol{b}_{\boldsymbol{s}}\right)$ & 0.003 \\
Strain at crushing strength $\left(\boldsymbol{\varepsilon}_{\boldsymbol{c} \boldsymbol{u}}\right)$ & $15.0 \times 10^{-3}$ & $\boldsymbol{R}_{\mathbf{0}}$ & 18.5 \\
Tensile strength $\left(\boldsymbol{f}_{\boldsymbol{t} \boldsymbol{c}}\right)$ & $2.8 \mathrm{MPa}$ & $\boldsymbol{c} \boldsymbol{R}_{\mathbf{1}}$ & 0.925 \\
Tension softening stiffness $\left(\boldsymbol{E}_{\boldsymbol{t} \boldsymbol{s}}\right)$ & $3.0 \mathrm{GPa}$ & $\boldsymbol{c} \boldsymbol{R}_{\mathbf{2}}$ & 0.15 \\
$\boldsymbol{\lambda}$ & 0.1 & --- & -- \\
Poisson ratio $\left(\boldsymbol{v}_{\boldsymbol{c}}\right)$ & 0.2 & Poisson ratio $\left(\boldsymbol{v}_{\boldsymbol{s}}\right)$ & 0.3 \\
Density $\left(\boldsymbol{\rho}_{\boldsymbol{c}}\right)$ & $2.4 \mathrm{~T} / \mathrm{m}^{3}$ & Density $\left(\boldsymbol{\rho}_{\boldsymbol{s}}\right)$ & $7.85 \mathrm{~T} / \mathrm{m}^{3}$ \\
\hline \hline
\end{tabular}

The length of the lumped plastic hinges is determined by the plastic hinge length, $l_{p}$, which is taken here as the depth of the transverse section, i.e. $l_{p}=160 \mathrm{~mm}$ according to ACI $318 \mathrm{M}-14$ (2014). Other formulas are found on the literature, such as $l_{p}=0.08 l+0.022 d_{b} f_{y}=146 \mathrm{~mm}$ (Paulay \& Priestley, 1992), where the first term correspond with the plastic length based on the integration of the curvature distribution, and the second term, with the tensile strength penetration, which represents the continuity of the steel tensile strains some depth into the footing. In this formula, $l$ is the shear length $(1330 / 2 \mathrm{~mm}), d_{b}$ is the rebar diameter $(8 \mathrm{~mm})$ and $f_{y}$ is the steel 
yielding strength (525 MPa). Both formulas gave very similar results. Rodrigues et al. (2013) claimed that there is some experimental evidence that plastic hinges zone length tend to be stable at around the theoretical values and are not strongly affected by biaxial loading. In short, lumped plastic sections were created using the above value for the plastic hinge length and defining a force-deformation relationship for each DOF. Axial, torsion and shear behaviors were assumed linear while bending in both directions was considered nonlinear. Coupling between DOFs was not considered because the Beam with Hinges element does not allow it.

The $M-\varphi$ hysteretic law is characterized using Pinching4 material that is based on the yield moment, $M_{y}$, and the yield and ultimate curvatures, $\varphi_{y}$ and $\varphi_{u} . M_{y}$ was estimated using the empirical expression (3.26) proposed by Fardis (2009) with a reduction of $20 \%$ (interaction factor) to account for the bidirectional cyclic loading (Table 3.10). $\varphi_{y}$ and $\varphi_{u}$ were calculated as $\varphi_{y}=\theta_{y} / l_{p}$ and $\varphi_{u}=\theta_{u} / l_{p}$ (Table 5.2), where $\theta_{y}$ and $\theta_{u}$ are the yielding and ultimate rotation obtained from equations recommended by EN 1998-3 (CEN, 2005), based on the work by Fardis (2009) and others (Table 4.6). Next, these initial values were modified to fit the results of the shaking table tests. In this sense, the calibrated curve was defined by 4 points (Figure 5.4 and Table 5.3). The first point corresponds to the cracking moment defined as a quarter of $M_{y}$. Second and third points represent the maximum biaxial moment capacity of the hinge, the third point is a little higher than the second to have a positive stiffness in order to enhance the convergence and, finally, the fourth point represents the failure of the hinge.

Table 5. 2. Yield and ultimate curvatures of columns from Fardis's equations

\begin{tabular}{lcccccc}
\hline & S12 & S22 & S32 & S10/S11 & S20/S21 & S30/S31 \\
\hline$\varphi_{y}[\mathrm{rad} / \mathrm{m}]$ & 0.049 & 0.049 & 0.049 & 0.054 & 0.054 & 0.054 \\
$\varphi_{u}[\mathrm{rad} / \mathrm{m}]$ & 0.216 & 0.218 & 0.218 & 0.224 & 0.236 & 0.236 \\
\hline \hline
\end{tabular}

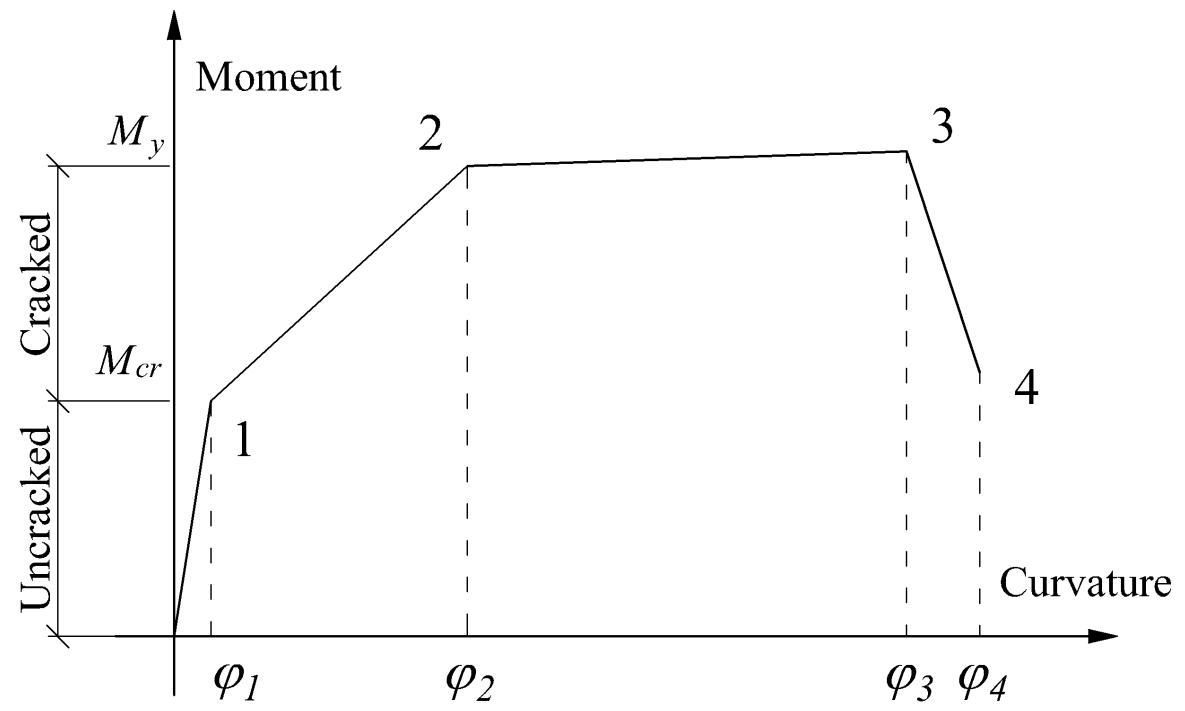

Figure 5. 4. Idealized backbone curve for bending moment

Table 5. 3. Values for the calibrated curve in both directions 


\begin{tabular}{ccccccccc}
\hline Section & $\begin{array}{c}\varphi_{1} \\
{[\mathbf{r a d} / \mathbf{m}]}\end{array}$ & $\begin{array}{c}M_{1} \\
{[\mathbf{k N m}]}\end{array}$ & $\begin{array}{c}\varphi_{2} \\
{[\mathbf{r a d} / \mathbf{m}]}\end{array}$ & $\begin{array}{c}M_{2} \\
{[\mathbf{k N m}]}\end{array}$ & $\begin{array}{c}\varphi_{3} \\
{[\mathbf{r a d} / \mathbf{m}]}\end{array}$ & $\begin{array}{c}M_{3} \\
{[\mathbf{k N m}]}\end{array}$ & $\begin{array}{c}\varphi_{4} \\
{[\mathbf{r a d} / \mathbf{m}]}\end{array}$ & $\begin{array}{c}M_{4} \\
{[\mathbf{k N m}]}\end{array}$ \\
\hline $\mathbf{S 1 0 X}$ & 0.012 & 4.4 & 0.095 & 16.7 & 0.239 & 17.6 & 0.263 & 10.6 \\
$\mathbf{S 1 0 Y}$ & 0.011 & 4.4 & 0.085 & 16.7 & 0.239 & 17.6 & 0.263 & 10.6 \\
$\mathbf{S 2 0 / S 3 0 X}$ & 0.012 & 3.5 & 0.092 & 13.3 & 0.239 & 14.0 & 0.263 & 8.4 \\
$\mathbf{S 2 0 / S 3 0 Y}$ & 0.010 & 3.5 & 0.082 & 13.3 & 0.239 & 14.0 & 0.263 & 8.4 \\
$\mathbf{S 1 1 X}$ & 0.011 & 5.2 & 0.086 & 19.8 & 0.239 & 20.8 & 0.263 & 12.5 \\
$\mathbf{S 1 1 Y}$ & 0.011 & 5.2 & 0.086 & 19.8 & 0.239 & 20.8 & 0.263 & 12.5 \\
$\mathbf{S 2 1 / S 3 1 X}$ & 0.011 & 3.7 & 0.084 & 14.2 & 0.239 & 15.0 & 0.263 & 9.0 \\
$\mathbf{S 2 1 / S 3 1 Y}$ & 0.011 & 3.7 & 0.084 & 14.2 & 0.239 & 15.0 & 0.263 & 9.0 \\
$\mathbf{S 1 2 X}$ & 0.011 & 4.6 & 0.086 & 17.5 & 0.239 & 18.4 & 0.263 & 11.0 \\
$\mathbf{S 1 2 Y}$ & 0.011 & 4.6 & 0.086 & 17.5 & 0.239 & 18.4 & 0.263 & 11.0 \\
\hline \hline
\end{tabular}

Hysteretic loops were controlled by: i) pinching shape, ii) cyclic degradation for unloading stiffness, iii) cyclic degradation for reloading stiffness, and iv) cyclic degradation for strength. Table 5.4 shows the calibration parameters. Pinching shape was calibrated in such a way that the hysteretic curve had a similar pinching shape than the same section defined with fibers; the stiffness degradation was calibrated following the study carried out by Rodrigues et al. (2015); the reloading degradation was not considered and the strength degradation was slightly allowed to match with test results. In addition, the cover concrete of central sections of columns in the first story was eliminated to take into account the loss of stiffness due to the cracking during the shaking table trainings. In the calibration, it turned out essential to match the numeric frequencies at the beginning of the simulations as much as possible to those measured in the test.

Table 5. 4. Parameter to define hysteretic loops

\begin{tabular}{cccccccc}
\hline \multicolumn{2}{c}{ Pinching shape } & \multicolumn{2}{c}{$\begin{array}{c}\text { Unloading } \\
\text { degradation }\end{array}$} & \multicolumn{2}{c}{$\begin{array}{c}\text { Reloading } \\
\text { degradation }\end{array}$} & \multicolumn{2}{c}{$\begin{array}{c}\text { Strength } \\
\text { degradation }\end{array}$} \\
\hline rDisp & 0.5 & gK1 & 1.0 & gD1 & 0.0 & gF1 & 0.25 \\
rForce & 0.8 & gK2 & 0.0 & gD2 & 0.0 & gF2 & 0.0 \\
uForce & 0.05 & gK3 & 0.2 & gD3 & 0.0 & gF3 & 1.0 \\
gE & 8.0 & gK4 & 0.0 & gD4 & 0.0 & gF4 & 0.0 \\
dmgType & energy & gKlim & 0.95 & gDLim & 0.0 & gFLim & 0.3 \\
\hline \hline
\end{tabular}

In sum up, the Beam with Hinges element was a very suitable element for the purpose of this investigation because it combines the advantages of distributed and concentrate plasticity formulations. While the distributed plasticity models reproduce variations of the stresses and strains through the cross section and along the element in more detail, it is not able to simulate complex phenomena such as strength degradation due to local buckling of steel reinforcement bars or the nonlinear interaction of flexural and shear (Deierlein, Reinhorn, \& Willford, 2010). The concentrate plasticity models can replicate hysteretic curves $M-\varphi$ at end nodes with precision but cannot provide information on the phenomena occurring in the cross section. Therefore, this configuration allows not only developing the plasticity at ends but also allows that plasticity spreads beyond the plastic hinge regions to the interior part of the element. Nonetheless, unfortunately the element does not work with biaxial interaction. Opensees has elements that allow biaxial interaction such as CoupledZeroLength element, but it generated convergence problems and was avoided in this study.

\subsubsection{Slab joists}

Slab joists were defined with 4 different sections as Figure 5.5 shows. These sections were assumed elastic with a $20 \%$ of stiffness reduction to take into account the concrete cracking 
occurred during the white noise displacement imposed in the shaking table training and the gravity loads. Euro Code 8 (CEN, 2005) allows a reduction of the stiffness up to one-half of its respective uncracked values. These elements were introduced in Opensees through the command elasticBeam Column.
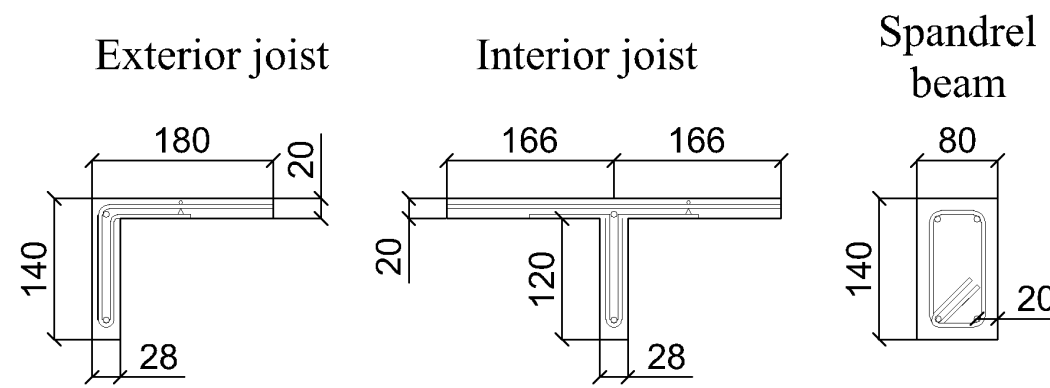

Edge beam

Figure 5. 5. Elastic sections

In addition, the spandrel beam of the exterior plate-column connection, which corresponds to S8Y and S9Y (Figure 2.6b), experienced severe damage due to torsion during the test (Figure 4.18 and Table 4.11). Because of that, the beam was updated with nonlinear torsional behavior. The implementation in Opensees was carried out by an elasticBeamColumn element with a torsional section aggregated, whose nonlinear behavior is estimated using Pinching4 material as follows. The torsional backbone curve was defined through 3 points: the cracking torsion $\left(\varphi_{1}, T_{\text {cr }}\right)$; the ultimate torsional capacity $\left(\varphi_{3}, \mathrm{~T}_{\mathrm{u}}\right)$; and the torsional failure $\left(\varphi_{u}, \mathrm{~T}_{\mathrm{u}}\right)$. This curve is a trilinear approach of the work conducted to Valipour et al. (2010), whose comparison is shown in Figure 5.6 .

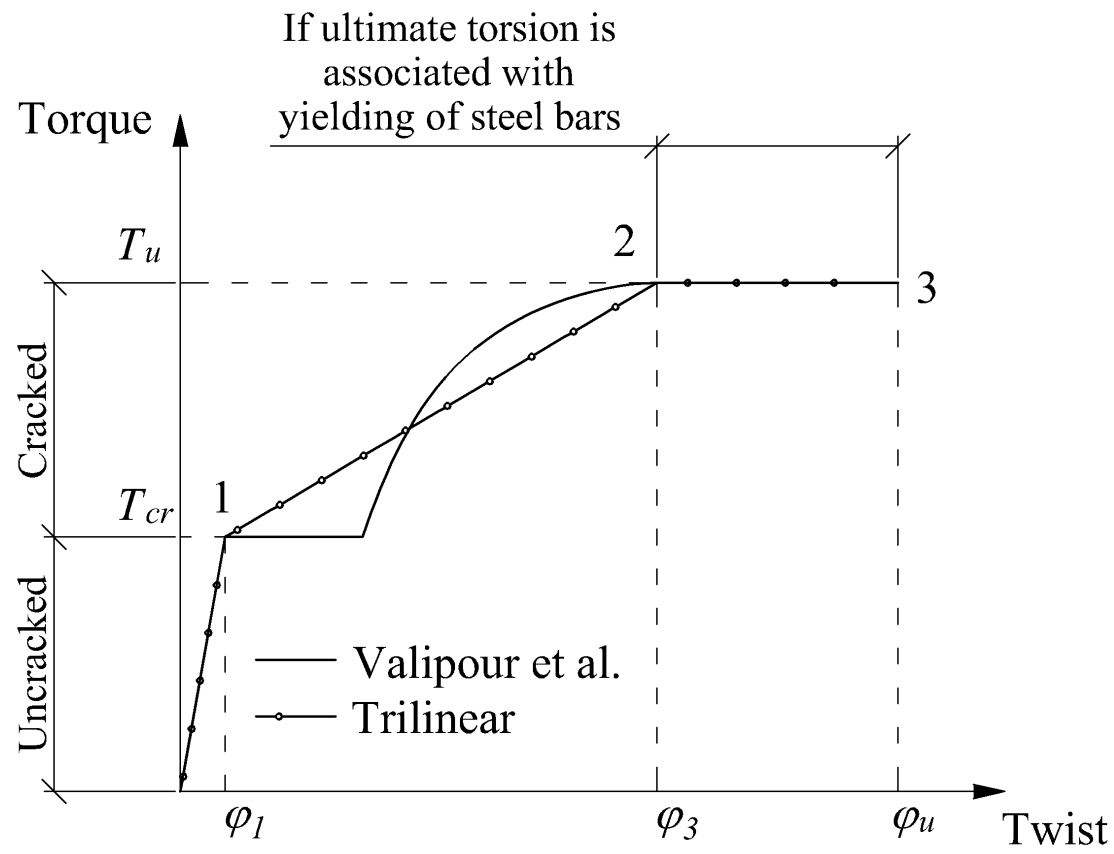

Figure 5. 6. Torsion model for the spandrel beam

For pre-cracking stage, the cracking torque was calculated through the elastic thin-walled tube theory, which can be obtained from:

$$
T_{c r}=[1+(n-1) \rho]\left(\frac{A_{c}^{2}}{u_{c}}\right) f_{t c}=0.86 \times 10^{6} \mathrm{Nmm}
$$


Where $A_{c}$ is the gross area of concrete, $u_{c}$ is the perimeter of the concrete cross-section, $f_{t c}$ is the direct tensile strength of the concrete. The parameter $n$ is equal to $E_{s} / E_{c}$ where $E_{s}$ and $E_{c}$ are the elastic modulus of steel and concrete, respectively, and $\rho$ is the total volumetric ratio of the reinforcement. Cracking twist was calculated by the Saint-Venant's theory of elastic torsion for a rectangular section as follows:

$$
\varphi_{1}=\frac{T_{c r}}{G_{c} J_{1}}=4.46 \times 10^{-6} \mathrm{~mm}^{-1}
$$

Where $G_{c}$ is the shear modulus of concrete $\left(G_{c}=E_{c} /(2(1+v))\right.$ being $v$ the Poisson's ratio $)$ and $J_{1}$ is the polar moment of inertia (Young, Budynas, \& Sadegh, 2002), which gives:

$$
J_{1} \cong w h^{3}\left[\frac{1}{3}-0.21 \frac{h}{w}\left(1-\frac{h^{4}}{12 w^{4}}\right)\right] \text { for }(h \leq w)=1.54 \times 10^{7} \mathrm{~mm}^{4}
$$

Where $h$ and $\mathrm{w}$ are the sides of the rectangular section.

For post-cracking stage, the torsional ultimate capacity $\left(T_{u}\right)$ was obtained according to the space truss analogy. After the section starts cracking, torsion is resisted by a truss action of compressive stresses in diagonal concrete struts and tensile stresses in longitudinal and transverse reinforcement (Hsu, 1984). Therefore, $T_{u}$ was calculated applying the thin-walled tube theory of torsion for an equivalent hollow section applying the method prescribed by the Spanish Concrete Code EHE-08 (Ministerio de Fomento, 2008), the value obtained was $1.75 \mathrm{kNm}$. The twist capacity $\left(\varphi_{3}\right)$ was defined through (5.4) according to the work of Valipour et al. (2010).

$$
\varphi_{3}=\frac{1.5 S \varepsilon_{c 0}}{h_{e} \sin (2 \theta)}=6.6 \times 10^{-5} \mathrm{~mm}^{-1}
$$

Where $\varepsilon_{c 0}$ is the strain corresponding with uniaxial compressive strength of concrete $\left(\varepsilon_{c 0}=\right.$ $0.2 \%$ ) and $S$ can be obtained from (6.5). In addition, $h_{e}$ is the effective wall thickness defined in EHE-08 (Ministerio de Fomento, 2008) which had a value of $40 \mathrm{~mm}$. Finally, $\theta$ is the inclination angle of the compressive struts with respect to element longitudinal axis, this value was assumed as $45^{\circ}$.

$$
0.4 \leq \frac{1}{0.8+170 \varepsilon_{c 0}} \leq 1.0, S=0.877
$$

The failure mode was associated with the yielding of the reinforced bars. Therefore, the ultimate twist capacity of the section was defined as $\varphi_{u}=1.5 \varphi_{3}$ adopting the concept of section ductility (Valipour \& Foster, 2010). Hysteretic loops were defined with the same parameters used for bending in columns (Table 5.3).

\subsubsection{Drop panels}

Drop panels were assumed as reinforced walls. Opensees can mainly simulate walls using elements such as MITC4 or ShellNLDKGQ. However, the former has a limited capacity for large deformations (geometric nonlinearity is not supported) and it thus cannot be used to simulate advanced stages of damage close to collapse. Consequently, ShellNLDKGQ was the element used, which is a quadrilateral element (shell element) with 4 nodes and 6 DOFs per node. The element has 4 Gauss Integration Points $(g p)$ whose isoparametric coordinates $(\xi-\eta)$ are the combination of $\pm 0.577 \pm 0.577$ (Figure 5.7). Originally, the element was born as a combination of a planar membrane element $G Q 12$ and a plate bending element $D K Q$ (Lu \& Guan, 2017). 


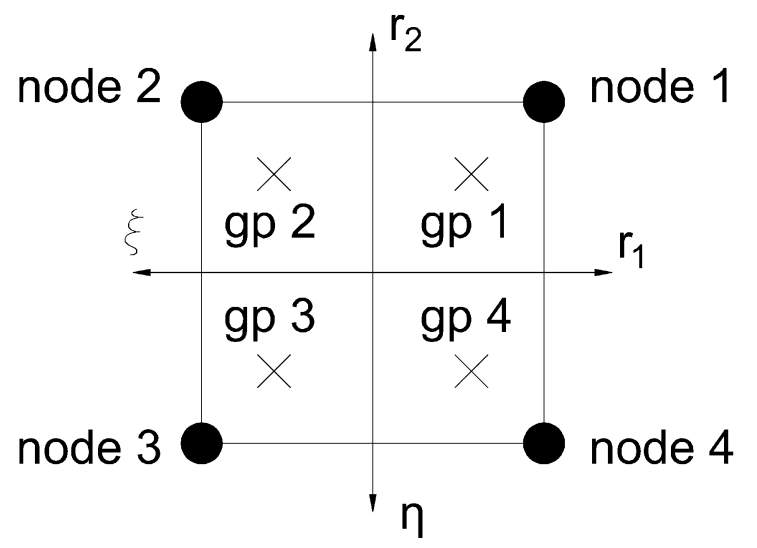

Figure 5. 7. Shell element

The external drop panel was designed with 360 ShellNLDKGQ and each internal drop panel with 576. The dimensions of each shell were around $42 \times 42 \mathrm{~mm}$. This large discretization gave the possibility of capturing the nonlinear behavior with high accuracy because it allowed placing the reinforcing bars on its exact position. Furthermore, not all shell elements were defined as nonlinear because it was observed that during the test parts in the drop panels never entered the nonlinear range. This simplification allowed enhancing greatly the convergence and reduced the computational burden. Figure 5.8 shows with hatched area the nonlinear elements and with blank area the linear ones.

\section{External drop panel}

(North)

Internal drop panel (West)

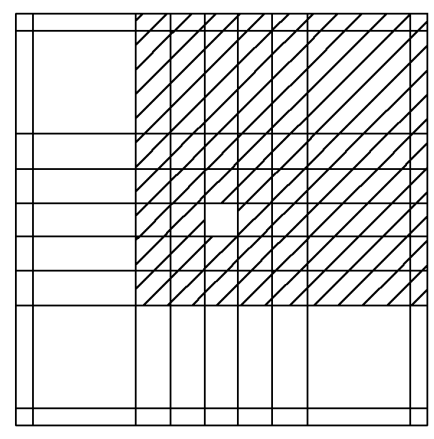

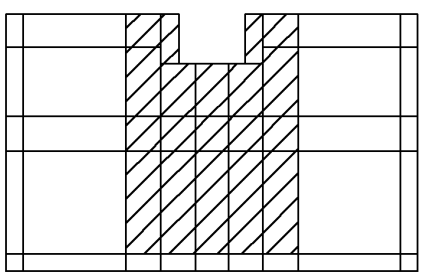

Hatched area: Nonlinear Blank area: Linear

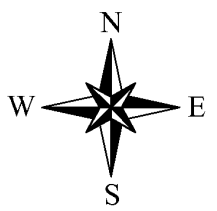

Internal drop panel (East)

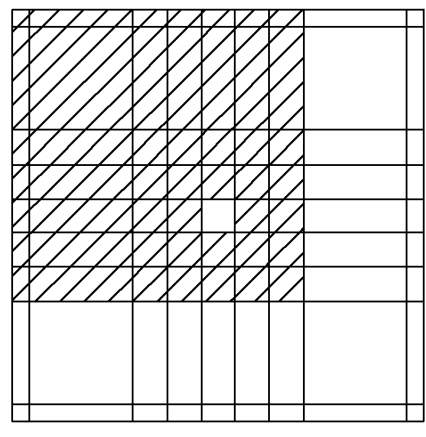

Figure 5. 8. Linear/Nonlinear zones in drop panels

The nonlinear behavior of shells were defined through multilayer shell sections with 9 layers in total. This is introduced in Opensees through command section LayeredShell, where the tag section, material and thickness of each layer were defined. The thickness of each layer depended on the material. Rebars at top and bottom of the plate cross section did not form a layer strictly speaking because they appeared as discrete points, so that, they were considered as smeared steel layers of equivalent thicknesses. On the other hand, the 7 remaining layers were defined as concrete with variable thickness until covering the whole cross section. Owning to the heterogeneous distribution of the reinforcement, different section were created. The internal drop 
panel was split in 15 different sections and external drop panels in 14. Figure 5.9 shows a quarter of the internal drop panels and a half of the external drop panel with the sections labelled.

INTERNAL DROP PANELS
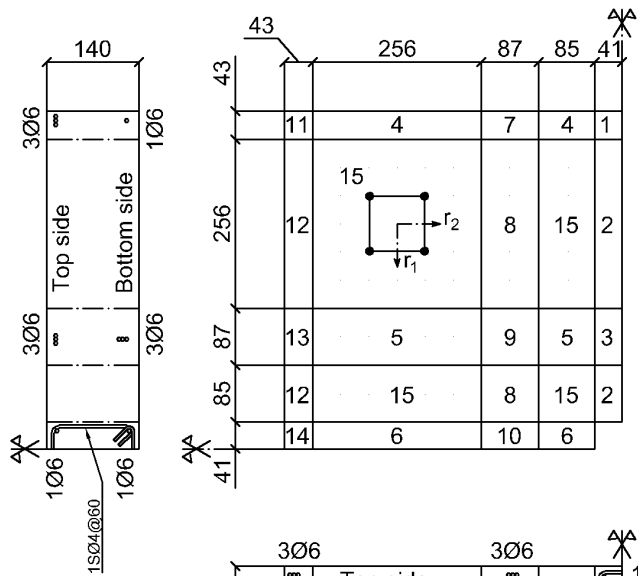

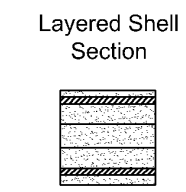
(Total 9 layers)
WIII Steel bars

(Layers X \& Y)

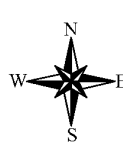

EXTERNAL DROP PANEL

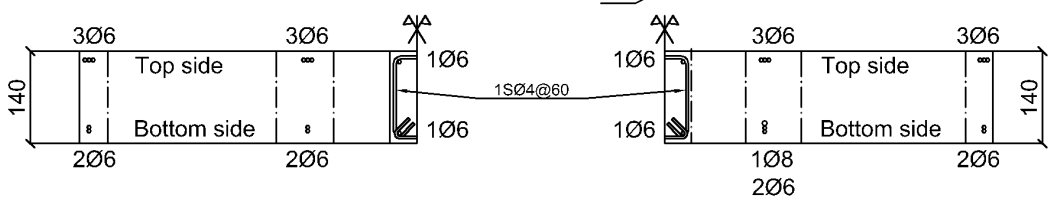

Figure 5. 9. Drop panels

Tables 5.5 and 5.6 show the distribution of materials in layers with its thickness for each section shown in Figure 5.9.

Table 5. 5. Thickness of layers in $\mathrm{mm}$ (form bottom to top) for internal panels

\begin{tabular}{cccccccccc}
\hline \multirow{2}{*}{ Section } & \multicolumn{10}{c}{ Layer } \\
\cline { 2 - 9 } & $\mathbf{1}$ & $\mathbf{2}$ & $\mathbf{3}$ & $\mathbf{4}$ & $\mathbf{5}$ & $\mathbf{6}$ & $\mathbf{7}$ & $\mathbf{8}$ & $\mathbf{9}$ \\
\hline $\mathbf{1}$ & 12.0 & $2.0\left(\mathrm{r}_{2}\right)$ & $0.7\left(\mathrm{r}_{1}\right)$ & 36.0 & 31.6 & 36.0 & $0.7\left(\mathrm{r}_{1}\right)$ & $0.7\left(\mathrm{r}_{2}\right)$ & 20.3 \\
$\mathbf{2}$ & 12.0 & 2.0 & $0.7\left(\mathrm{r}_{1}\right)$ & 36.0 & 31.6 & 36.0 & $0.7\left(\mathrm{r}_{1}\right)$ & 0.7 & 20.3 \\
$\mathbf{3}$ & 13.0 & $1.0\left(\mathrm{r}_{2}\right)$ & $0.7\left(\mathrm{r}_{1}\right)$ & 36.0 & 31.0 & 36.0 & $1.3\left(\mathrm{r}_{2}\right)$ & $0.7\left(\mathrm{r}_{1}\right)$ & 20.3 \\
$\mathbf{4}$ & 12.0 & $2.0\left(\mathrm{r}_{2}\right)$ & 1.0 & 36.0 & 31.0 & 36.0 & 1.0 & $0.7\left(\mathrm{r}_{2}\right)$ & 20.3 \\
$\mathbf{5}$ & 13.0 & $1.0\left(\mathrm{r}_{2}\right)$ & 1.0 & 36.0 & 30.7 & 36.0 & $1.3\left(\mathrm{r}_{2}\right)$ & 1.0 & 20.0 \\
$\mathbf{6}$ & 13.0 & 1.0 & $0.7\left(\mathrm{r}_{2}\right)$ & 36.0 & 31.6 & 36.0 & $0.7\left(\mathrm{r}_{2}\right)$ & 1.0 & 20.0 \\
$\mathbf{7}$ & 13.0 & $1.0\left(\mathrm{r}_{1}\right)$ & $2.0\left(\mathrm{r}_{2}\right)$ & 36.0 & 30.3 & 36.0 & $0.7\left(\mathrm{r}_{1}\right)$ & $0.7\left(\mathrm{r}_{2}\right)$ & 20.3 \\
$\mathbf{8}$ & 13.0 & $1.0\left(\mathrm{r}_{1}\right)$ & 2.0 & 36.0 & 30.3 & 36.0 & $0.7\left(\mathrm{r}_{1}\right)$ & 0.7 & 20.3 \\
$\mathbf{9}$ & 13.0 & $1.0\left(\mathrm{r}_{1}\right)$ & $1.0\left(\mathrm{r}_{2}\right)$ & 36.0 & 30.7 & 36.0 & $1.3\left(\mathrm{r}_{2}\right)$ & $0.7\left(\mathrm{r}_{1}\right)$ & 20.3 \\
$\mathbf{1 0}$ & 13.0 & $1.0\left(\mathrm{r}_{1}\right)$ & $0.7\left(\mathrm{r}_{2}\right)$ & 36.0 & 30.6 & 36.0 & $0.7\left(\mathrm{r}_{2}\right)$ & $0.7\left(\mathrm{r}_{1}\right)$ & 20.3 \\
$\mathbf{1 1}$ & 12.0 & $2.0\left(\mathrm{r}_{1}\right)$ & $2.0\left(\mathrm{r}_{2}\right)$ & 36.0 & 29.6 & 36.0 & $1.4\left(\mathrm{r}_{1}\right)$ & $0.7\left(\mathrm{r}_{2}\right)$ & 20.3 \\
$\mathbf{1 2}$ & 12.0 & $2.0\left(\mathrm{r}_{1}\right)$ & 2.0 & 36.0 & 29.6 & 36.0 & $1.4\left(\mathrm{r}_{1}\right)$ & 0.7 & 20.3 \\
$\mathbf{1 3}$ & 12.0 & $2.0\left(\mathrm{r}_{1}\right)$ & $1.0\left(\mathrm{r}_{2}\right)$ & 36.0 & 30.7 & 36.0 & $1.3\left(\mathrm{r}_{2}\right)$ & $1.4\left(\mathrm{r}_{1}\right)$ & 19.6 \\
$\mathbf{1 4}$ & 12.0 & $2.0\left(\mathrm{r}_{1}\right)$ & $0.7\left(\mathrm{r}_{2}\right)$ & 36.0 & 30.9 & 36.0 & $1.4\left(\mathrm{r}_{1}\right)$ & $0.7\left(\mathrm{r}_{2}\right)$ & 20.3 \\
$\mathbf{1 5}$ & 13.0 & 1.0 & 1.0 & 36.0 & 31.0 & 36.0 & 1.0 & 1.0 & 20.0 \\
\hline \hline
\end{tabular}

Note: $\left(\mathrm{r}_{1}\right),\left(\mathrm{r}_{2}\right)$ or blank represent reinforcement in direction $\mathrm{r}_{1}, \mathrm{r}_{2}$ or concrete, respectively (Figure 5.9). 
Table 5. 6. Thickness of layers in $\mathrm{mm}$ (form bottom to top) for external panel

\begin{tabular}{cccccccccc}
\hline \multirow{2}{*}{ Section } & \multicolumn{9}{c}{ Layer } \\
\cline { 2 - 10 } & $\mathbf{1}$ & $\mathbf{2}$ & $\mathbf{3}$ & $\mathbf{4}$ & $\mathbf{5}$ & $\mathbf{6}$ & $\mathbf{7}$ & $\mathbf{8}$ & $\mathbf{9}$ \\
\hline $\mathbf{1}$ & 13.0 & 1.0 & $0.7\left(\mathrm{r}_{1}\right)$ & 36.0 & 31.3 & 36.0 & 1.0 & $0.7\left(\mathrm{r}_{1}\right)$ & 20.3 \\
$\mathbf{2}$ & 13.0 & $1.0\left(\mathrm{r}_{2}\right)$ & $0.7\left(\mathrm{r}_{1}\right)$ & 36.0 & 31.3 & 36.0 & $1.0\left(\mathrm{r}_{2}\right)$ & $0.7\left(\mathrm{r}_{1}\right)$ & 20.3 \\
$\mathbf{3}$ & 12.0 & $2.0\left(\mathrm{r}_{2}\right)$ & $0.7\left(\mathrm{r}_{1}\right)$ & 36.0 & 30.9 & 36.0 & $1.4\left(\mathrm{r}_{2}\right)$ & $0.7\left(\mathrm{r}_{1}\right)$ & 20.3 \\
$\mathbf{4}$ & 12.0 & $2.0\left(\mathrm{r}_{1}\right)$ & 0.7 & 36.0 & 30.9 & 36.0 & $1.4\left(\mathrm{r}_{1}\right)$ & 0.7 & 20.3 \\
$\mathbf{5}$ & 13.0 & $1.0\left(\mathrm{r}_{1}\right)$ & 1.0 & 36.0 & 30.7 & 36.0 & $1.3\left(\mathrm{r}_{1}\right)$ & 1.0 & 20.0 \\
$\mathbf{6}$ & 13.0 & 1.0 & $1.0\left(\mathrm{r}_{2}\right)$ & 36.0 & 31.0 & 36.0 & 1.0 & $1.0\left(\mathrm{r}_{2}\right)$ & 20.0 \\
$\mathbf{7}$ & 13.0 & 1.0 & $1.0\left(\mathrm{r}_{2}\right)$ & 36.0 & 31.0 & 36.0 & 1.0 & $1.0\left(\mathrm{r}_{2}\right)$ & 20.0 \\
$\mathbf{8}$ & 13.0 & $1.0\left(\mathrm{r}_{1}\right)$ & $1.0\left(\mathrm{r}_{2}\right)$ & 36.0 & 30.7 & 36.0 & $1.3\left(\mathrm{r}_{1}\right)$ & $1.0\left(\mathrm{r}_{2}\right)$ & 20.0 \\
$\mathbf{9}$ & 12.0 & $2.0\left(\mathrm{r}_{1}\right)$ & $1.0\left(\mathrm{r}_{2}\right)$ & 36.0 & 30.6 & 36.0 & $1.4\left(\mathrm{r}_{1}\right)$ & $1.0\left(\mathrm{r}_{2}\right)$ & 20.0 \\
$\mathbf{1 0}$ & 13.0 & $1.0\left(\mathrm{r}_{1}\right)$ & $1.0\left(\mathrm{r}_{2}\right)$ & 36.0 & 30.7 & 36.0 & $1.3\left(\mathrm{r}_{1}\right)$ & $1.0\left(\mathrm{r}_{2}\right)$ & 20.0 \\
$\mathbf{1 1}$ & 12.0 & $2.0\left(\mathrm{r}_{1}\right)$ & $1.0\left(\mathrm{r}_{2}\right)$ & 36.0 & 31.0 & 36.0 & $1.0\left(\mathrm{r}_{2}\right)$ & $1.4\left(\mathrm{r}_{1}\right)$ & 19.6 \\
$\mathbf{1 2}$ & 13.0 & $1.0\left(\mathrm{r}_{1}\right)$ & $2.0\left(\mathrm{r}_{2}\right)$ & 36.0 & 29.7 & 36.0 & $1.3\left(\mathrm{r}_{1}\right)$ & $1.4\left(\mathrm{r}_{2}\right)$ & 19.6 \\
$\mathbf{1 3}$ & 12.0 & $2.0\left(\mathrm{r}_{1}\right)$ & $2.0\left(\mathrm{r}_{2}\right)$ & 36.0 & 29.6 & 36.0 & $1.4\left(\mathrm{r}_{2}\right)$ & $1.4\left(\mathrm{r}_{1}\right)$ & 19.6 \\
$\mathbf{1 4}$ & 13.0 & 1.0 & 1.0 & 36.0 & 31.0 & 36.0 & 1.0 & 1.0 & 20.0 \\
\hline \hline
\end{tabular}

Note: $\left(r_{1}\right),\left(r_{2}\right)$ or blank represent reinforcement in direction $r_{1}, r_{2}$ or concrete, respectively (Figure 5.9).

Concrete material simulates a plane stress material that, in overall terms, is based on the concept of damage mechanics and the smeared crack model. Cracks are assumed to form when the principal tensile stress exceeds the specified concrete tensile strength. After the cracking, concrete is then treated as an orthotropic material. The shear stiffness degradation is incorporated through the shear retention factor in (5.6), which takes into account the aggregate interlocking effects (Lu, Xie, Guan, Huang, \& Lu, 2015; Lu \& Guan, 2017).

$$
\tau=\beta \mathrm{G} \gamma
$$

Where $\tau$ is the shear stress, $G$ is the concrete shear modulus, $\beta$ is the shear retention factor with a value assumed in the model of 0.08 , and $\gamma$ is the shear deformation.

Lu et al. (2015) proposed how to define the concrete material for layered shell elements in Opensees through the commands nDMaterial Plane Stress User Material and nDMaterial Plate From Plane Stress. Parameters that fed the concrete model were the same previously listed in Table 5.1 plus the ultimate tensile strain, which was defined as $f_{t c} / E_{c}$.

Steel material for reinforcing steel is derived from the uniaxial materials for rebars Steel02 (Filippou et al., 1983) in conjunction with their corresponding angles (Lu \& Guan, 2017). In this sense, the steel layer is defined in Opensees through the command DMaterial PlateRebar where the angle of rebar is defined taking as zero degrees the vector $r_{1}$ in Figures 5.7 and 5.9.

\subsection{Damping model}

A sequence of seismic simulations with increasing intensity implies the development of plastic deformations and the ensuing variation of the stiffness matrix. Damping models proportional to the tangent stiffness matrix (classical damping matrix) are more appropriate in order to prevent spurious damping values in numerical models with lumped plastic hinges than using an initial tangent stiffness matrix (non classical damping matrix) (Charney, 2008; Chopra \& McKenna, 2016). However, this assumption slows down the numeric evaluations. In this study, to capture the increase of damping measured during the shaking table tests (Table 4.2) with a classical damping matrix, the simple mass-proportional damping model $\left(\mathbf{C}=a_{0} \mathbf{M}\right.$ where $\mathbf{C}$ and $\mathbf{M}$ are the 
damping and mass matrices, respectively) was used in the numerical model. The parameter $a_{0}$ is defined as $a_{0}=2 \xi_{i} \omega_{i}$, where $\xi_{i}$ and $\omega_{i}$ are the damping ratio and the angular frequency of the $i_{\text {th }}$ vibration mode. In the end, the damping model was defined as follows. Firstly, a modal analysis was run before applying the seismic loadings to obtain the $i$ modal frequencies, $f_{i}$. The three main vibration frequencies were $f_{1}=2.66 \mathrm{~Hz}$ and $f_{2}=f_{3}=3.17 \mathrm{~Hz}$, which are close to those obtained experimentally (Table 4.2). Next, a damping ratio $\xi=3 \%$ was established for the second vibration mode because with this value the displacement response of the model under free-vibration in test T10 matched pretty well with the test (Figures 5.15c and 5.16c). Therefore, $a_{0}$ was obtained using $\xi_{2}=3 \%$ and $\omega_{2}=2 \pi f_{2}=19.92 \mathrm{rad} / \mathrm{s}$, i.e. equal to 1.20 . The expected evolution of the damping is shown in Figure 5.10, monotonically increasing under decreasing frequencies and similar to experimental results.

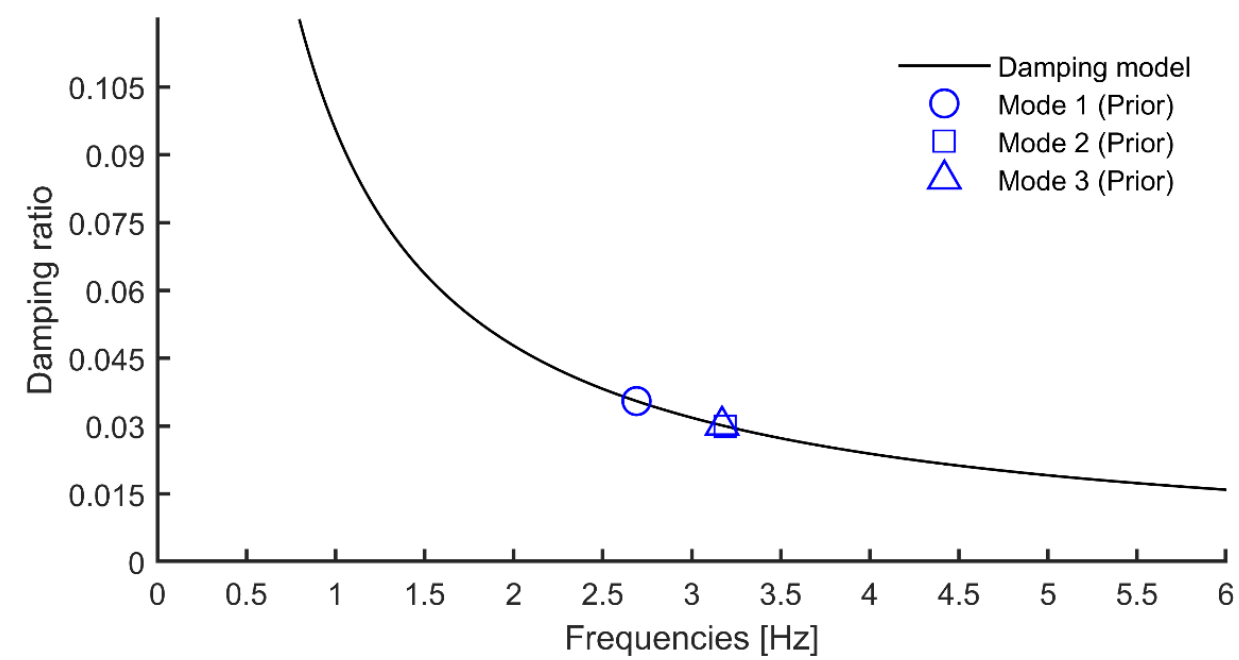

Figure 5. 10. Damping model

Therefore, by applying $f_{1}, f_{2}$ and $f_{3}$ to the damping model, the damping ratios obtained were $3.5 \%, 3 \%$ and $3 \%$, respectively. Once the seismic loading was applied up to a point of collapse, it is expected that $f_{1}$ decreases up to $1.3 \mathrm{~Hz}$ following experimental results, for which the damping model provides a ratio of $7.2 \%$. The damping ratio for the first vibration mode at failure (= $7.2 \%)$ is close to the measured at the end of the test, $9.2 \%$.

\subsection{Analysis}

Modal, pushover and response history analyses were run to analyze the response of the model. These analyses aim to obtain the dynamic properties, global strength under monotonic loading and displacement and strength when it is subjected to the same seismic simulations applied during the shaking table test.

In the Nonlinear Pushover analysis (NPA), gravity loads were simulated first, and a monotonic loading followed. The monotonic loading was applied to the nodes at the center of masses of each level (Figure 5.1). The load pattern applied in both directions $\mathrm{X}$ and $\mathrm{Y}$ had an inverted triangular shape and the analysis was done with displacement control. This means that the node at top underwent a displacement 1.44 times larger than nodes at slab level. The parameters to submit the analysis in Opensees are shown in Table 5.7. As a reference, the computation time was about $30 \mathrm{~min}$. 
Table 5. 7. Parameters for NPA in Opensees

\begin{tabular}{cccccc}
\hline Constrains & $\begin{array}{c}\text { Linear } \\
\text { solver }\end{array}$ & Convergence & Algorithm & Integration & GeomTransf \\
\hline Penalty & & Norm Displacement & & Displacement & Control \\
method & UmfPack & Increment Test & Krylov- & Point: Center & PDelta \\
$\alpha=10^{16}$ & SOE & $\begin{array}{c}\text { tol }=10^{-3} \mathrm{~mm} \\
\text { Nowton }\end{array}$ & of mass 1 & \\
& & $\Delta U=0.5 \mathrm{~mm}$ & & $U_{\max }: 64 \mathrm{~mm}$ & \\
\hline \hline
\end{tabular}

In the Nonlinear Response History Analysis (NRHA), gravity load were simulated first, and then the initial training signal T10 and seismic simulations (C35, C50, C100, C200i, C200, C300) followed. All motions from T10 to C300 were applied in series (in a unique input file) in order to reproduce the same sequence applied during the test. At the beginning and at the end of each input motion, an eigenvalue analysis was submitted to obtain the modal frequencies at that step. The parameters to submit the analysis in Opensees are shown in Table 5.8. As a reference, the computation time was about $21 \mathrm{~h}$.

Table 5. 8. Parameters for NRHA in Opensees

\begin{tabular}{cccccc}
\hline Constrains & $\begin{array}{c}\text { Linear } \\
\text { solver }\end{array}$ & Convergence & Algorithm & Integration & GeomTransf \\
\hline $\begin{array}{c}\text { Transformation } \\
\text { method }\end{array}$ & $\begin{array}{c}\text { UmfPack } \\
\text { SOE }\end{array}$ & $\begin{array}{c}\text { EnergyIncr Test } \\
\begin{array}{c}\text { tol }=10^{-2} \mathrm{~mm} \\
\Delta t=0.01 \mathrm{~s}\end{array}\end{array}$ & $\begin{array}{c}\text { Krylov- } \\
\text { Newton }\end{array}$ & $\begin{array}{c}\text { HHT } \\
\alpha=0.9\end{array}$ & PDelta \\
\hline \hline
\end{tabular}

\section{RESPONSE PREDICTED WITH NUMERICAL MODEL}

The response of the numerical model is compared with the results of the shaking table tests. The simulation and the test results are superposed to show the goodness of the fit in terms of periods, displacements, forces and energies.

\subsection{Dynamic characterization}

The dynamic characterization consisted on obtaining natural periods and damping ratios of the structure along the series of motions applied. Table 5.9 lists natural periods, frequencies and the damping ratio of the first three main modes of the structure for each test. It is worth noting that the model damping ratio of mode 1 at failure $(11.8 \%)$ was slightly higher than the measured in the test $(9.2 \%)$ but quite closed. The elastic mode shapes of the first three modes are shown in Figures 5.11 (first mode), 5.12 (second mode) and 5.13 (third mode). As these figures display, the first mode shows a vibration shape in Y-direction with a larger displacement in the exterior column $\left(C_{1}\right)$ than in the interior columns $\left(C_{2}\right.$ and $\left.C_{3}\right)$. The third model shows a similar vibration shape in Y-direction but in this case interior columns $\left(C_{2}\right.$ and $\left.C_{3}\right)$ exhibit a larger displacement than the exterior column $\left(C_{1}\right)$. Therefore, in both cases there are twist movements. The second mode shows a translational mode in X-direction. Second and third modes have practically the same free-vibration frequencies in linear range. These results are very similar to the two-mass lumped model used for the preliminary characterization of the tests specimen (Table 3.8). 


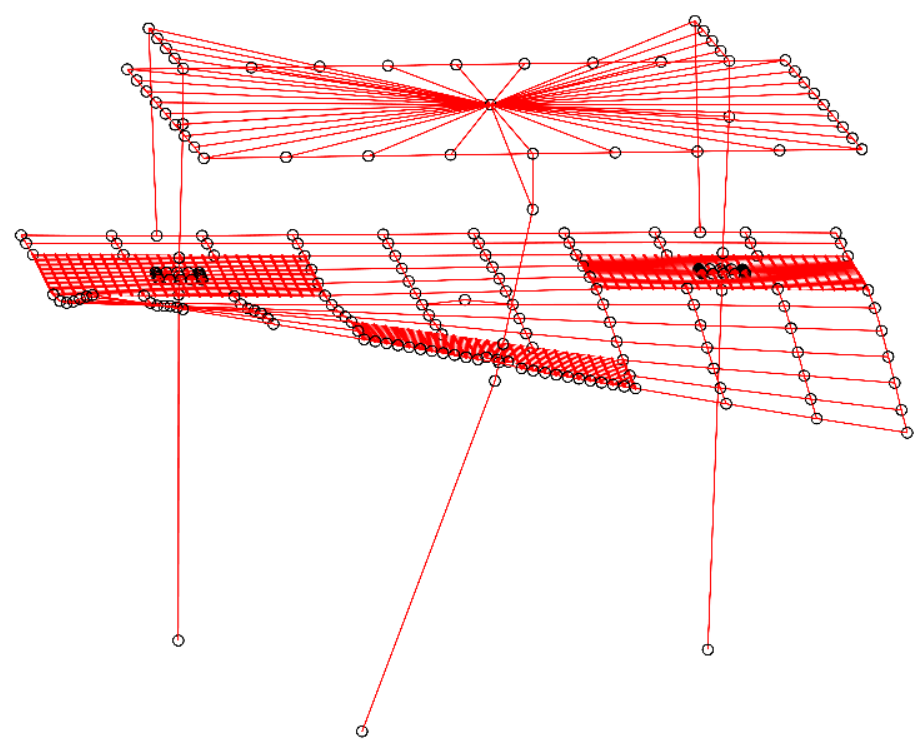

Figure 5. 11. First mode shape (Y-Twist)

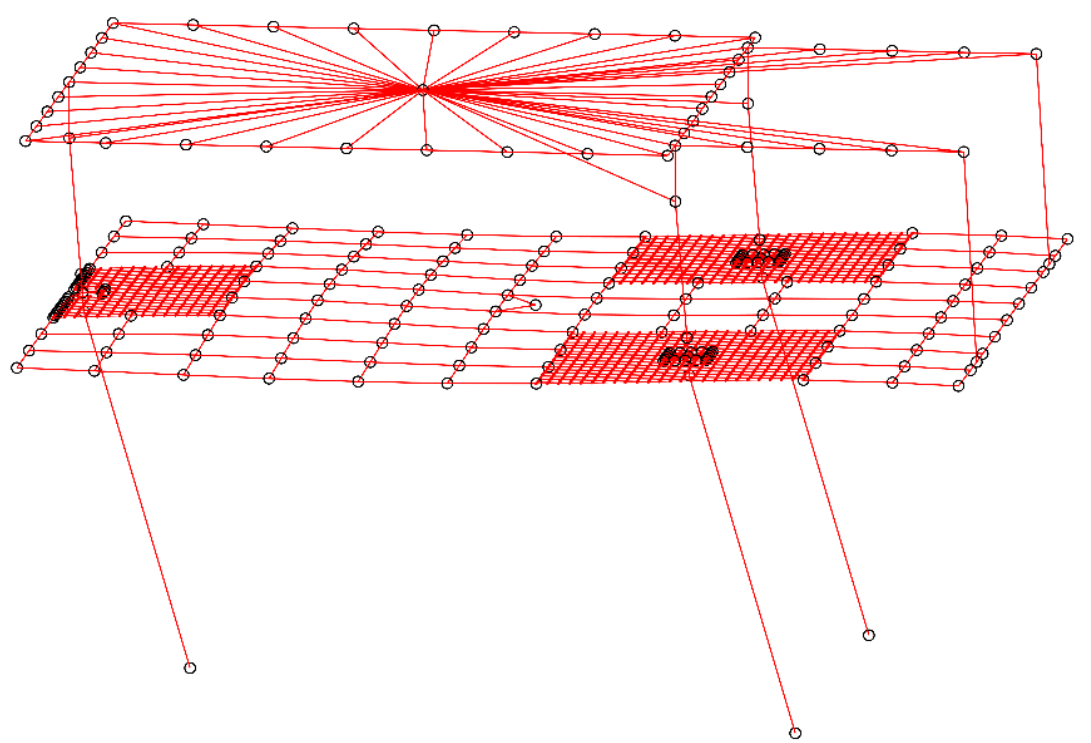

Figure 5. 12. Second mode shape (X) 


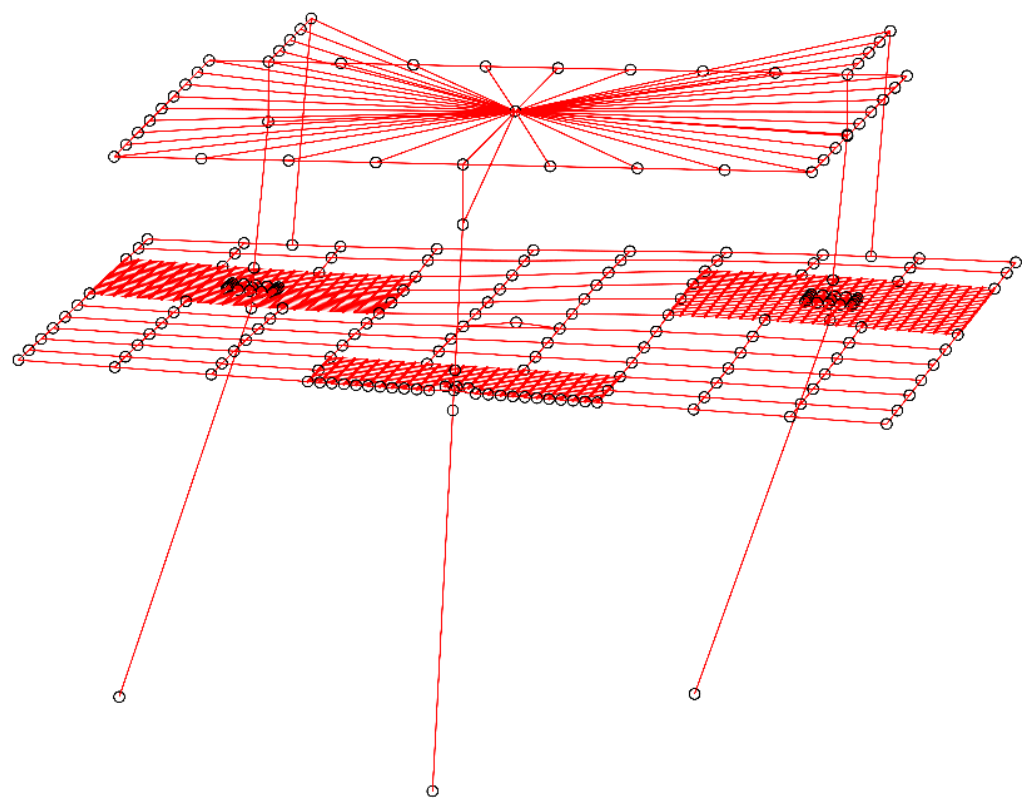

Figure 5. 13. Third mode shape (Y-Twist)

Table 5. 9. Evolution of natural periods and damping ratios

\begin{tabular}{lccccccccc}
\hline \multicolumn{1}{c}{ Test } & $\begin{array}{c}\mathbf{T}_{\mathbf{1}} \\
{[\mathbf{s}]}\end{array}$ & $\begin{array}{c}\mathbf{f}_{\mathbf{1}} \\
{[\mathbf{H z}]}\end{array}$ & $\begin{array}{c}\mathbf{T}_{\mathbf{2}} \\
{[\mathbf{s}]}\end{array}$ & $\begin{array}{c}\mathbf{f}_{\mathbf{2}} \\
{[\mathbf{H z}]}\end{array}$ & $\begin{array}{c}\mathbf{T}_{\mathbf{3}} \\
{[\mathbf{s}]}\end{array}$ & $\begin{array}{c}\mathbf{f}_{\mathbf{3}} \\
{[\mathbf{H z}]}\end{array}$ & $\begin{array}{c}\boldsymbol{\xi}_{\mathbf{1}} \\
{[\boldsymbol{\%}]}\end{array}$ & $\begin{array}{c}\boldsymbol{\xi}_{\mathbf{2}} \\
{[\mathbf{\%}]}\end{array}$ & $\begin{array}{c}\boldsymbol{\xi}_{\mathbf{3}} \\
{[\mathbf{\%}]}\end{array}$ \\
\hline Prior & 0.38 & 2.66 & 0.32 & 3.17 & 0.32 & 3.17 & 3.5 & 3.0 & 3.0 \\
T10 & 0.48 & 2.10 & 0.43 & 2.33 & 0.40 & 2.51 & 4.5 & 4.1 & 3.8 \\
C35 & 0.48 & 2.10 & 0.43 & 2.33 & 0.40 & 2.51 & 4.5 & 4.1 & 3.8 \\
C50 & 0.48 & 2.10 & 0.43 & 2.33 & 0.40 & 2.51 & 4.5 & 4.1 & 3.8 \\
C100 & 0.48 & 2.05 & 0.43 & 2.31 & 0.42 & 2.39 & 4.7 & 4.1 & 4.0 \\
C200i & 0.50 & 2.01 & 0.46 & 2.17 & 0.44 & 2.24 & 4.8 & 4.4 & 4.3 \\
C200 & 0.56 & 1.78 & 0.49 & 2.04 & 0.48 & 2.10 & 5.4 & 4.7 & 4.6 \\
C300* $^{2}$ & 1.24 & 0.81 & 0.70 & 1.42 & 0.68 & 1.47 & 11.8 & 6.7 & 6.7 \\
\hline
\end{tabular}

\subsection{Response in terms of displacements}

Figures 5.14 and 5.15 show, superposed, the displacements obtained with the numerical model and the displacements obtained from the shaking table tests in directions $\mathrm{X}$ and $\mathrm{Y}$ at the centers of mass Level 1 and 2 of the specimen (Figure 5.1). The response in $\mathrm{X}$ and $\mathrm{Y}$ directions of the successive motions, such as T10, C35, C50, C100, C200i, C200 and C300, are depicted at the center of the Figures 5.14 and 5.15. Further, some zooms of the response history, which correspond to specific simulations, are shown at the top and bottom of each figure. The seismic simulations C50 and C200i are depicted for the X direction at the top and the training T10, and seismic simulations C200i and C300 for the $\mathrm{Y}$ direction are shown at the bottom. A good agreement is observed between the response histories obtained numerically and experimentally for displacements, especially for moderate intensity levels, i.e. until the onset of C200. Nevertheless, for higher intensity levels (C200 and C300) the large strength degradation observed experimentally (Figures 4.14 and 4.15), especially at the ends of columns and at the exterior column-slab connection, could not be properly reproduced in the numerical model which led to the observed differences. 


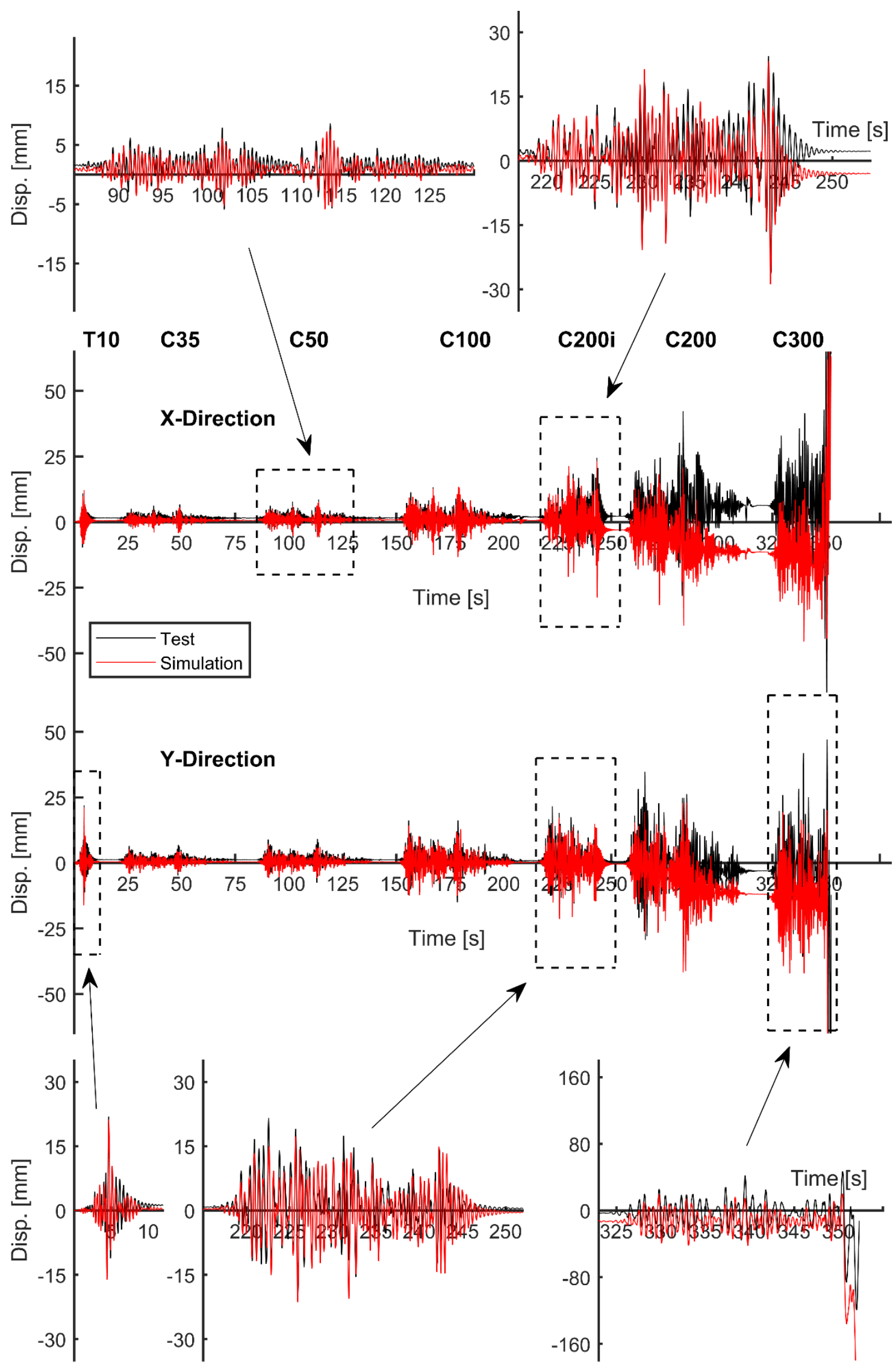

Figure 5. 14. History of slab-level (first level) displacements in directions X and Y with zooms at top and bottom 


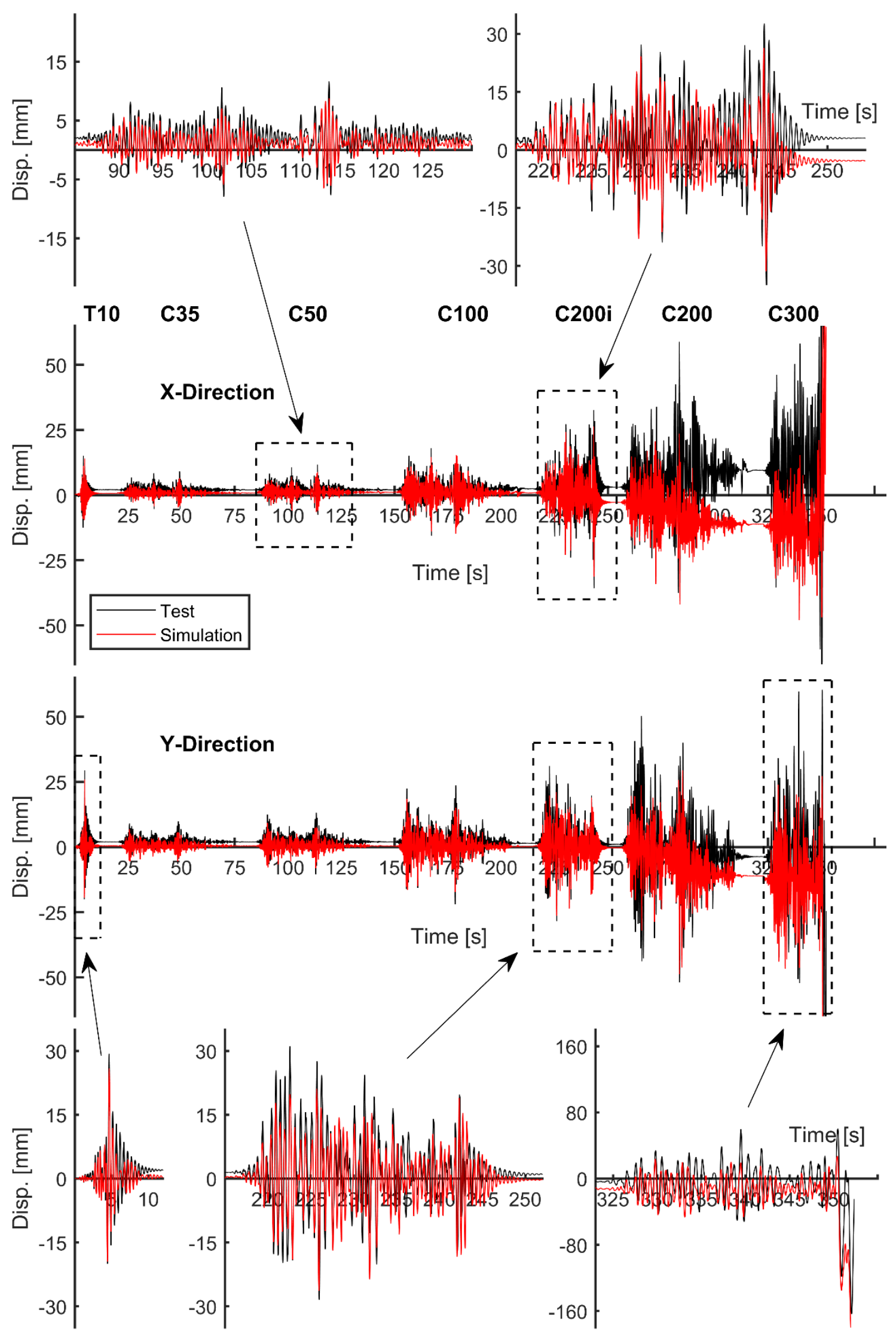

Figure 5. 15. History of top-level (second level) displacements in directions $\mathrm{X}$ and $\mathrm{Y}$ with zooms at top and bottom 


\subsection{Maximum displacements}

In order to summarize the displacement response for training $\mathrm{T} 10$ and for each seismic simulation, Figure 5.16 shows the absolute maximum displacement response of the model against the values obtained experimentally for each horizontal direction. In the plot, training T10 and seismic simulations from C35 to C200 matched perfectly with test results for both directions. Afterwards, simulation C200 in direction X started to depart slightly from the dash line in direction X while direction $\mathrm{Y}$ is successful. It is worth emphasizing the very good match between prediction and test results even when the specimen was very heavily damaged (simulation C200). At the beginning of the last simulation C300 the specimen collapsed, and the numerical model was not able to reproduce the very large displacements measured in the test after collapse.

a)

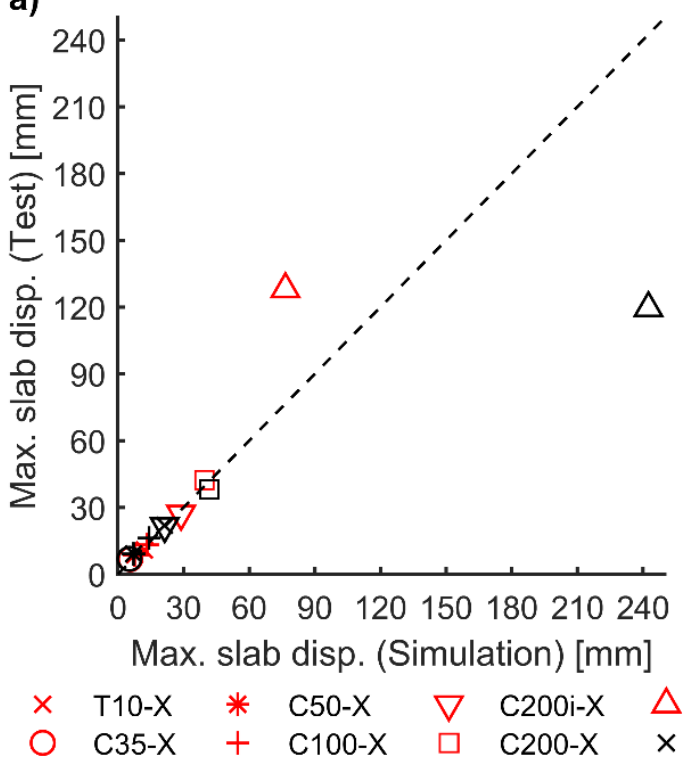

b)

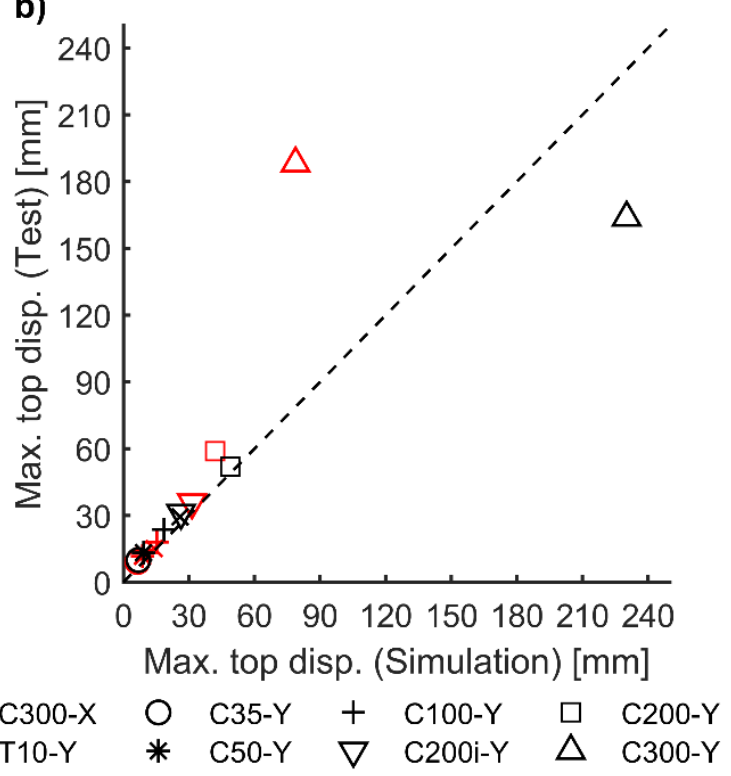

Figure 5. 16. Maximum of displacements: a) Slab-level and b) Top level

\subsection{History of base shears exerted by inertial forces}

Figure 5.17 exhibits the superposition of the base shears exerted by inertial forces predicted with the numerical model and the test in directions $\mathrm{X}$ and $\mathrm{Y}$. Provided that the inertial forces are the sum of the restoring forces plus the damping forces (4.1), restoring forces were obtained from Gauss points located at the bottom section of columns and the damping forces were estimated by the two-mass model in such a way that $\mathbf{F}_{\boldsymbol{\xi}}=\mathbf{C} \dot{\mathbf{u}}(t)$, where $\mathbf{C}$ is the damping matrix and $\dot{\mathbf{u}}(t)$ is the vector of velocity. The acceleration obtained from the model in the centers of mass had an enormous noise. The figure has the same subfigures presented in Figures 5.14 and 5.15 but in this case showing inertial forces versus time. A good match was found for the training T10 and simulations C35 to C200. After that, in simulation C300, the test developed larger base shear forces than the model, especially in negative domain. 

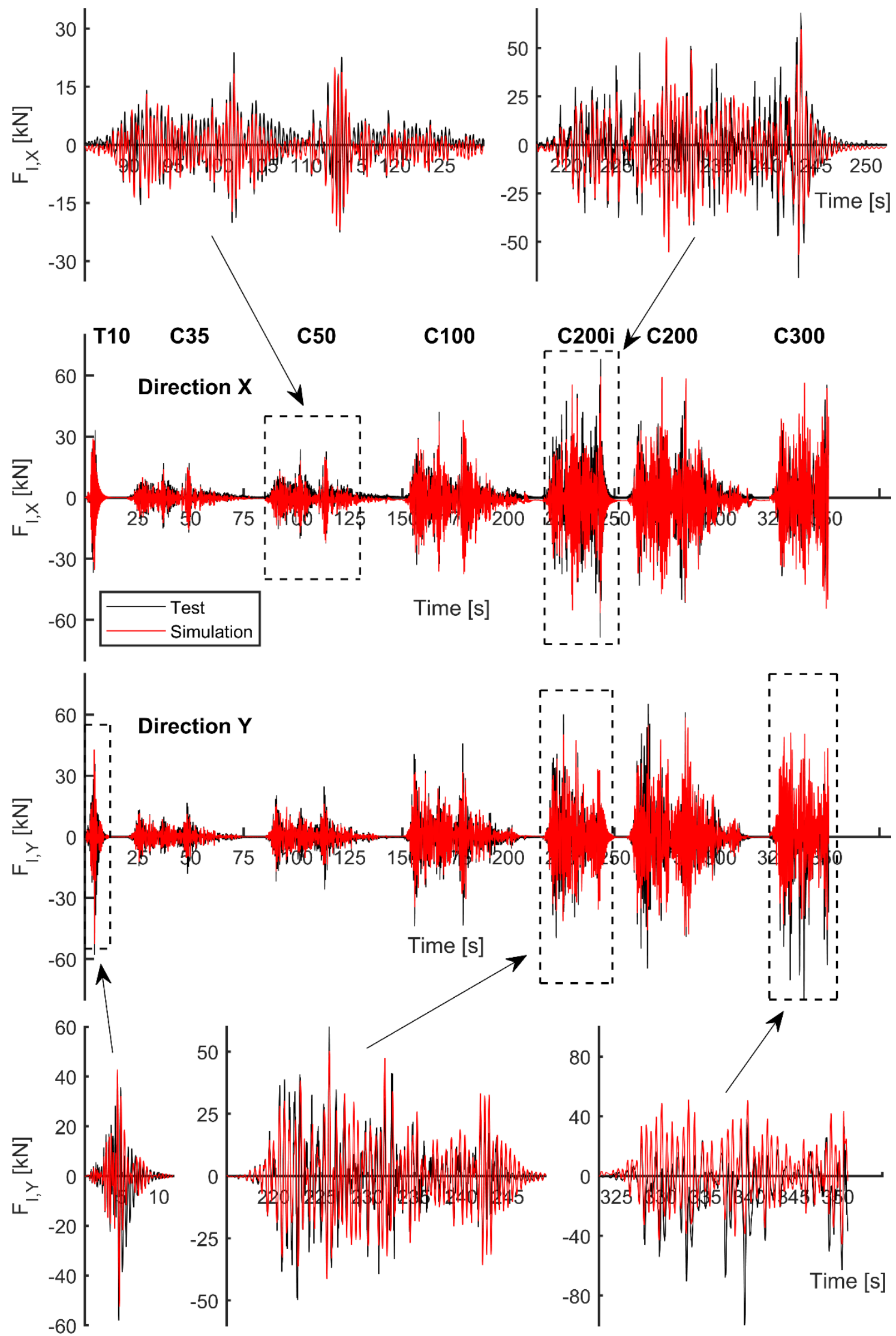

Figure 5. 17. History of base shears exerted by inertial forces in direction $\mathrm{X}$ and $\mathrm{Y}$ with zooms at top and bottom 


\subsection{Maximum base shears exerted by inertial forces}

Figure 5.18 compares the maximum absolute base shears exerted by inertial forces obtained from the shake table tests and the prediction with the numerical simulation. Results indicate that the model underestimates a little the base shears exerted by inertial forces up to C200 in both horizontal directions. In simulation $\mathrm{C} 300$, the maximum base shear force exerted by the inertial force in direction $\mathrm{X}$ matched pretty well, while in direction $\mathrm{Y}$ the base shear force measured during the test was much larger than that predicted with the numerical simulation.

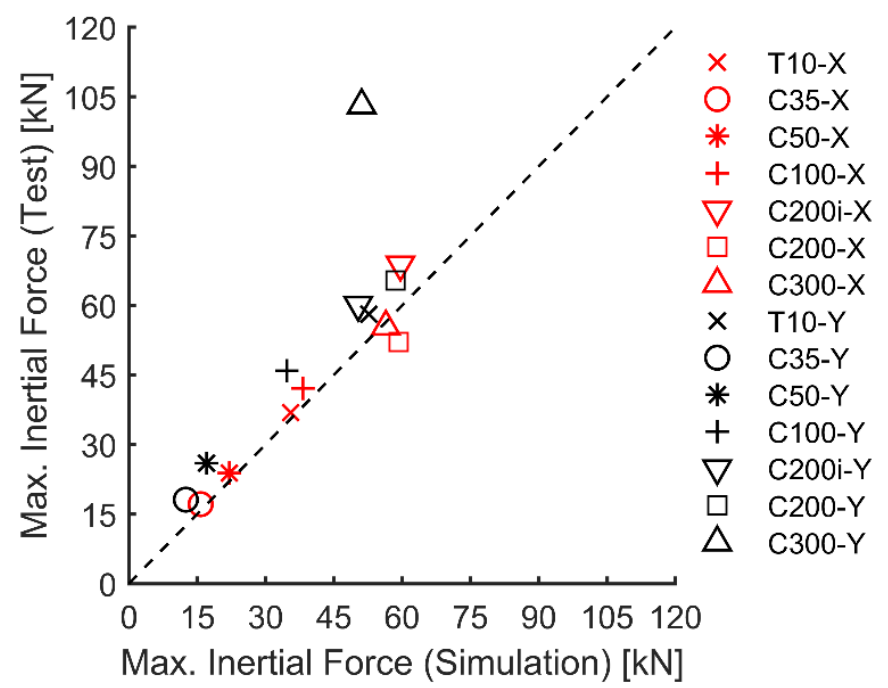

Figure 5. 18. Maximum Inertial Force

\subsection{Capacity curve}

The Capacity curve or also called Pushover curve relates a single point displacement of the structure (generally a point on the top) with the shear forces underwent at the base. In general, the curve represents the nonlinear behavior of the structure and is generated typically applying an inverted triangular distribution of lateral loads over the height of the structure. Figure 5.19 shows the capacity curves obtained with the numerical model and those obtained from the shake table test in directions $\mathrm{X}$ and Y. With the numerical model the curve was obtained through a NPA (that is, a non-linear static analysis), and the experimental curve was obtained connecting the points of the base inertial force versus top displacement where velocity cancels (as explained in Chapter 4). It is worth noting that, a good fitting was achieved between curves up to a displacement of 35 $\mathrm{mm}$ in $\mathrm{X}$ direction and up to $55 \mathrm{~mm}$ in $\mathrm{Y}$ direction. The drop of strength occurred in the numerical model for a displacement of $74 \mathrm{~mm}$ in $\pm X$ direction and of $55 \mathrm{~mm}$ in $\pm Y$ direction. In the direction $\mathrm{Y}$ this displacement is very close to the experimental one exhibited by the specimen in the tests, but in the $\mathrm{X}$ direction it is notable larger. In regards to the maximum strength, the prediction of the numerical model is close to the experimental results. 


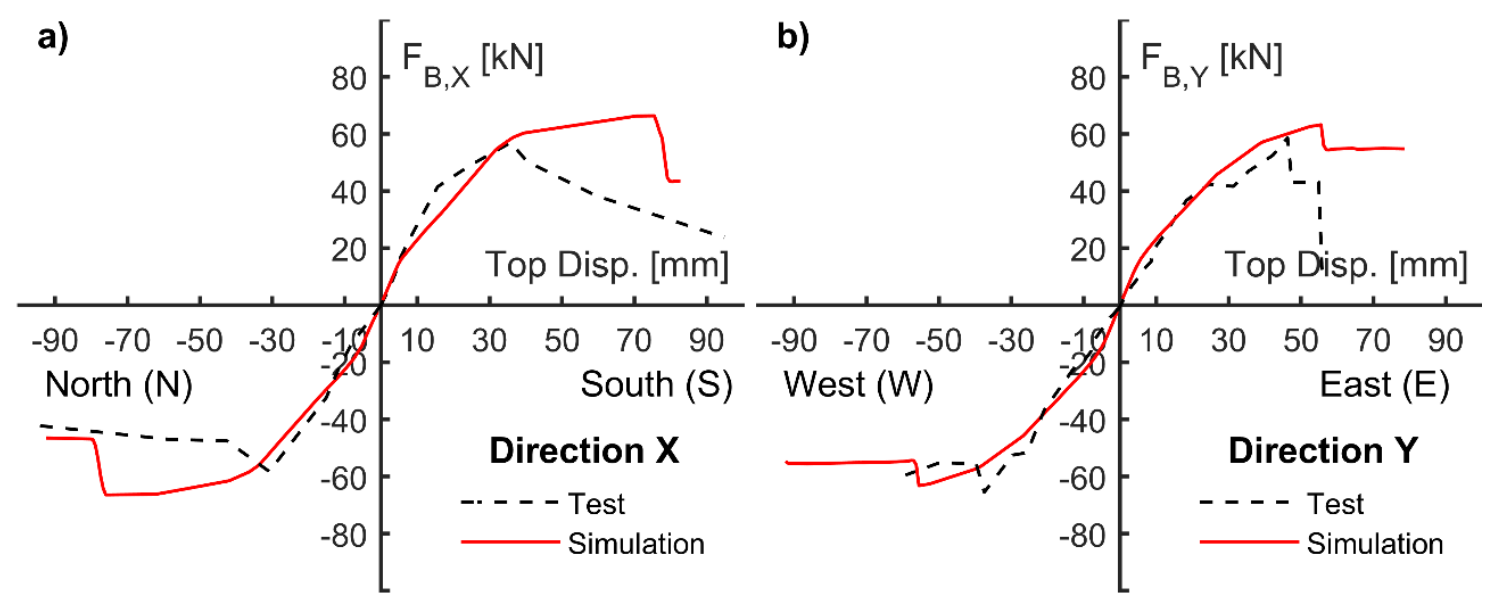

Figure 5. 19. Capacity curve: a) Direction X; b) Direction Y

\subsection{Plastic hinges at beams and columns}

The final state (collapse) of the test specimen was governed by the plastic hinges that formed at columns ends and by the torsional failure of the spandrel beams at the exterior column-slab connections (Figure 4.18). Figure 5.20 shows the torsional behavior of the spandrel beam at each side of the column $C_{1}$ obtained with the numerical model.

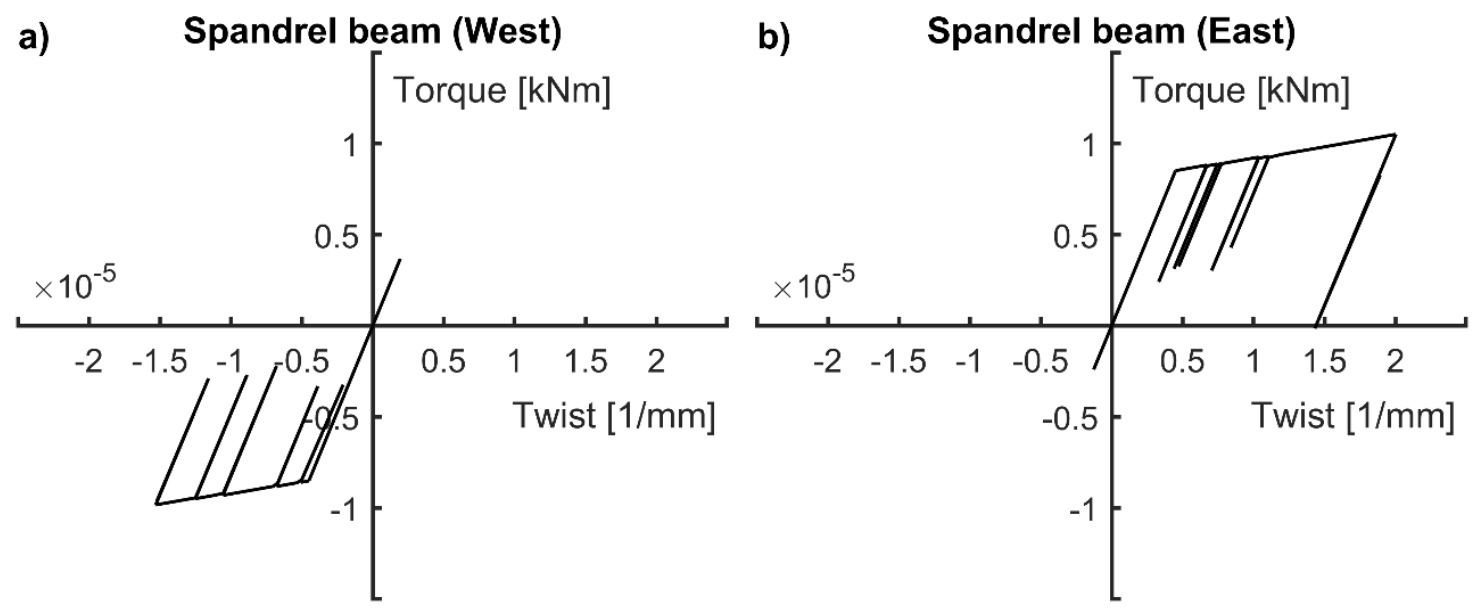

Figure 5. 20. Hysteretic behavior or the spandrel beam: a) West side and b) East side

Apparently, the model reflected that at both sides of column $C_{1}$, the spandrel beam underwent a strong nonlinear behavior as occurred in the test (Figure 4.18 and Table 4.11). Although the model was not successful in representing the ultimate exhaustion of the hinge because it did not reach the ultimate torsion capacity of the beam.

Figures 5.21, 5.22 and 5.23 show the bidirectional behavior in terms of moment-curvature $(M-$ $\varphi$ ) of column sections (Figure 2.2). Figures display in rows the three columns, i.e., $C_{1}, C_{2}$ and $C_{3}$; and in columns the two directions of loading, i.e., $X$ and $Y$. Moments and curvatures are shown in local coordinates, $\mathrm{Z}^{*}$ is the local coordinate aligned with $-\mathrm{X}$ in global coordinates and $\mathrm{Y}^{*}$ is the local coordinate aligned with $+\mathrm{Y}$ in global coordinates. 


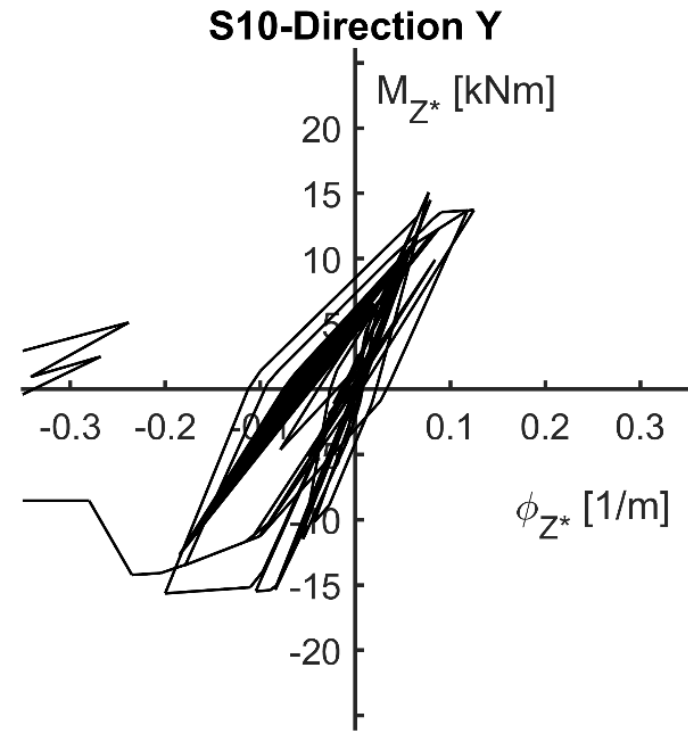

S20-Direction $Y$
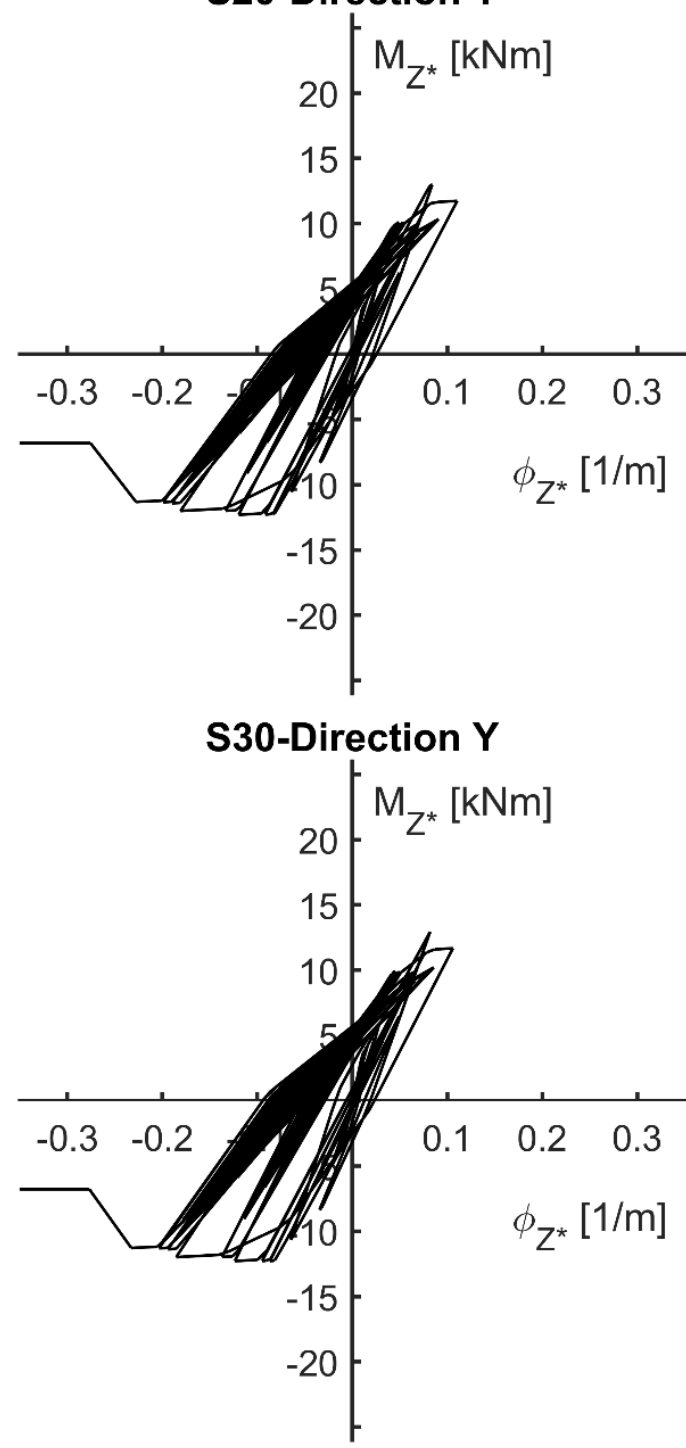

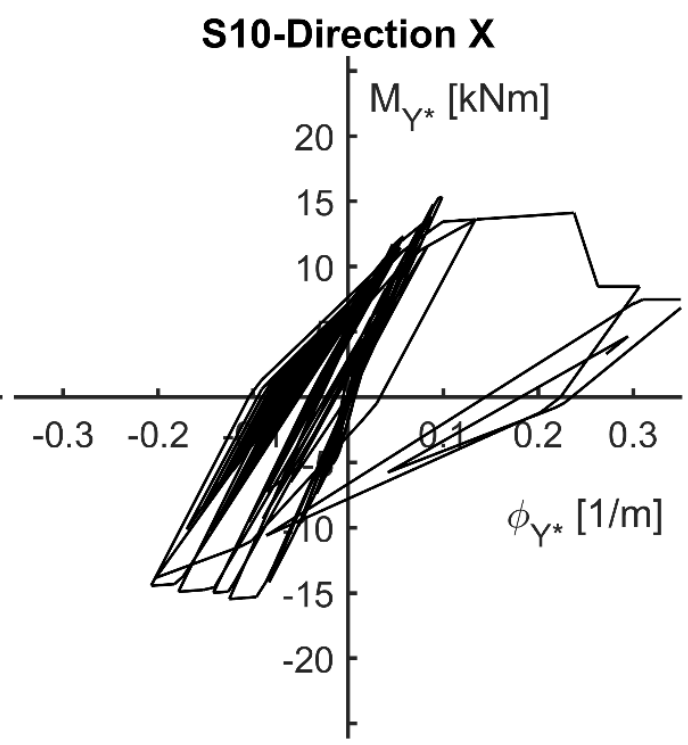

S20-Direction X

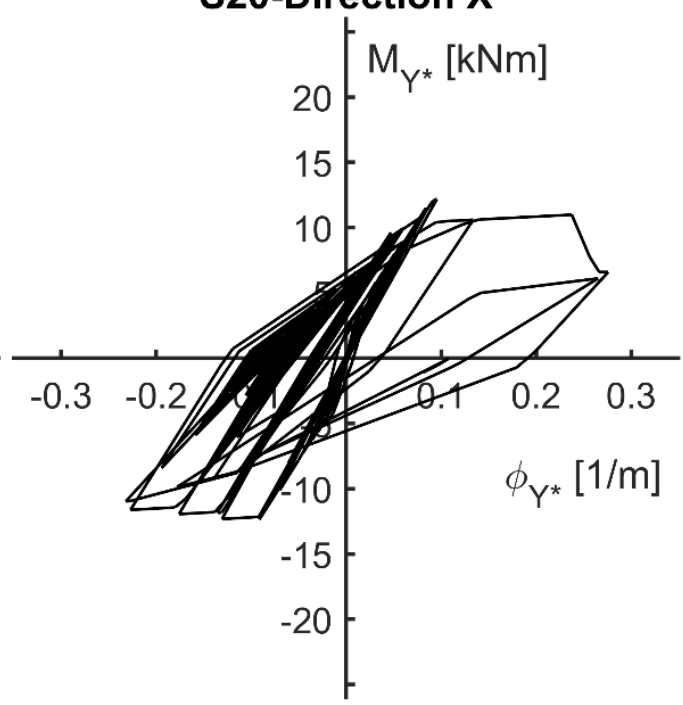

S30-Direction X

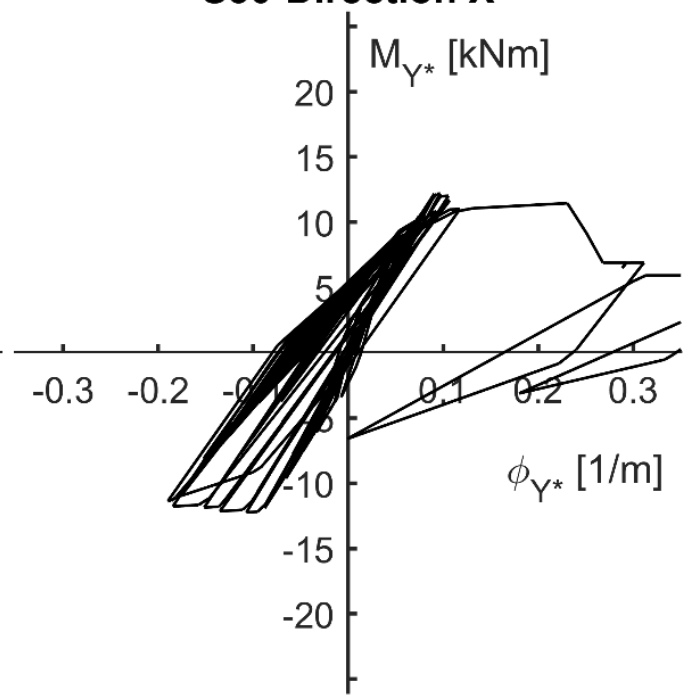

Figure 5. 21Bidirectional behavior of plastic hinges at columns base of first level 

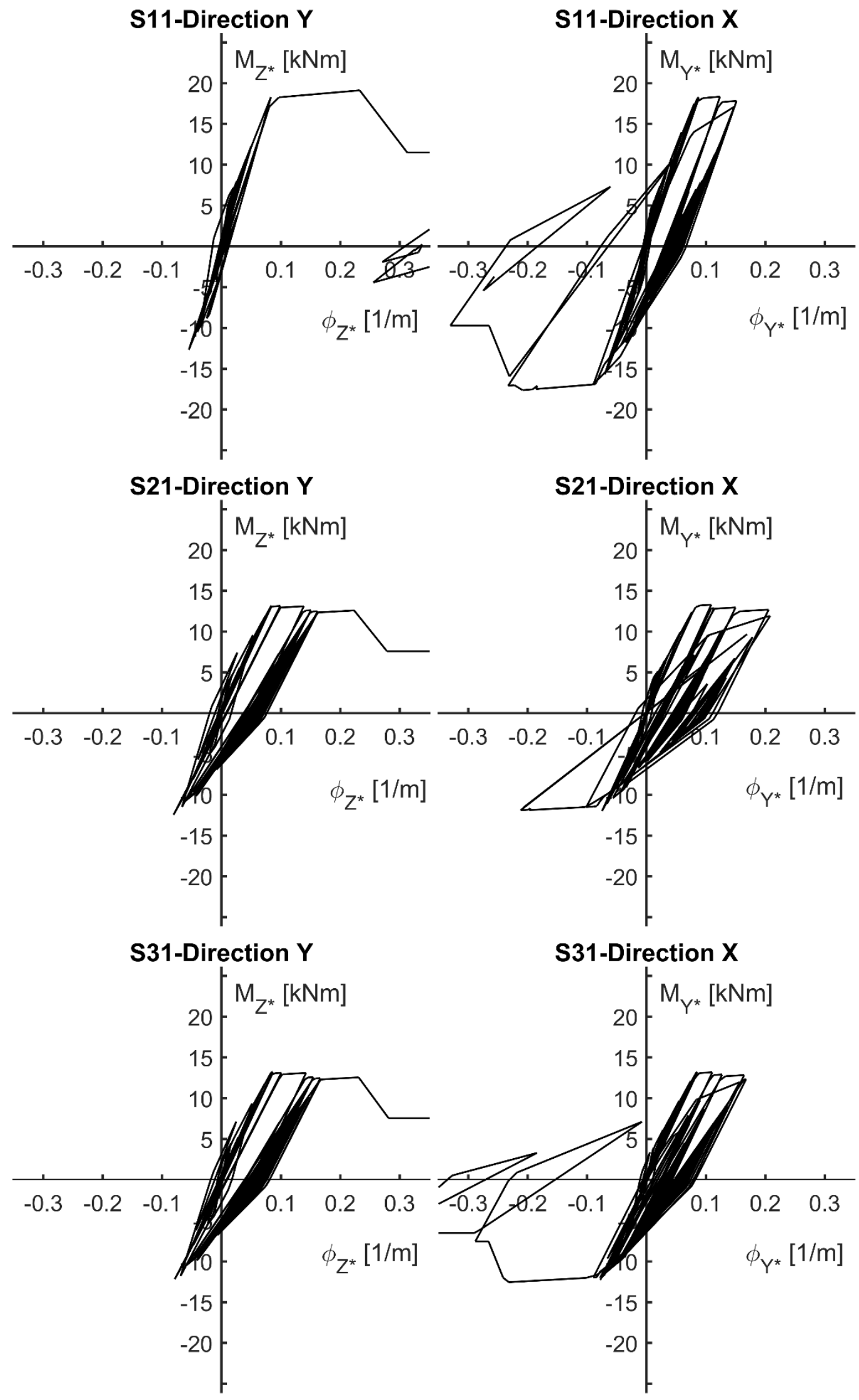

Figure 5. 22 Bidirectional behavior of plastic hinges at columns head of first level 

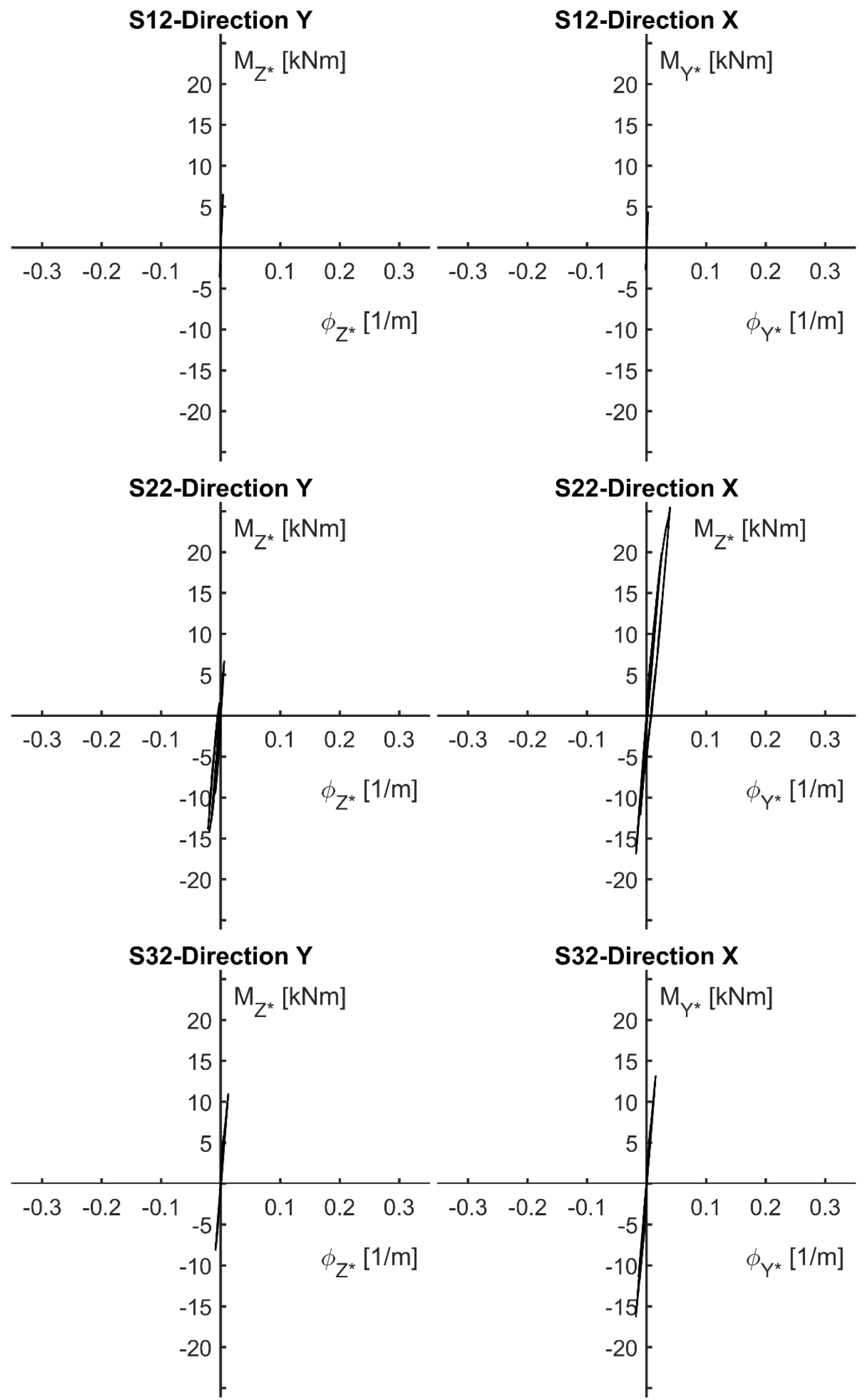

Figure 5. 23 Bidirectional behavior of plastic hinges at columns base of second level 
Columns at base and head of first story overcome widely the values of $\varphi_{u}$ listed in Table 5.2, what reflects its state of exhaustion. It is worth noting that the model deeply entered the plastic range in section S11, unlike the test specimen that remained in elastic range (Figure 4.18). This would explain why the model did not reach the torsion ultimate capacity of the spandrel beam.

Figure 5.23 shows the hinges performance in the second story. All of them remained in the elastic range, i.e., $\varphi<\varphi_{y}$. It is important to note that all sections with the exception of S22 also remained elastic in the test (Figure 4.18 and Table 4.11). Section S22 was the most solicited in both, test and model, but model was unable to reproduce the plastic behavior.

\subsection{History of input energy}

The total input energy absorbed by the model was calculated using (1.3a) considering only two components of the ground motion. Figure 5.24 shows the history of energy input in both, the test specimen and the numerical model. The total input energy and the input energy in the $\mathrm{X}$ and $\mathrm{Y}$ directions are plotted. It can be observed that the numerical model predicts correctly the input energy until the onset of the simulation C200i. From this point on, the numerical model slightly underestimates the input energy measured experimentally. It is important to note that the comparison of responses in terms of history of input energy provides the most accurate and reliable criterion to judge the goodness of fit between numerical model and experimental results, much better than comparing the response in terms of displacements or forces. Two of the reasons are that: (i) energy combines both, i.e. it is the product of force and displacement; (ii) energy is a scalar quantity that can synthesize the response in the $\mathrm{X}$ and $\mathrm{Y}$ directions, while displacements and forces are vectors. Displacements and forces can be obtained for specific parts of the structure but energy involves the entire structure, where complex 3D loading effects caused by earthquakes are represented through a scalar (Fardis, 2018). Moreover, the variations in the input energy history are better distinguished by using a logarithmic scale. As can be seen in Figure 5.24, the fit between prediction of the numerical model and experimental results noticeably good in terms of input energy.

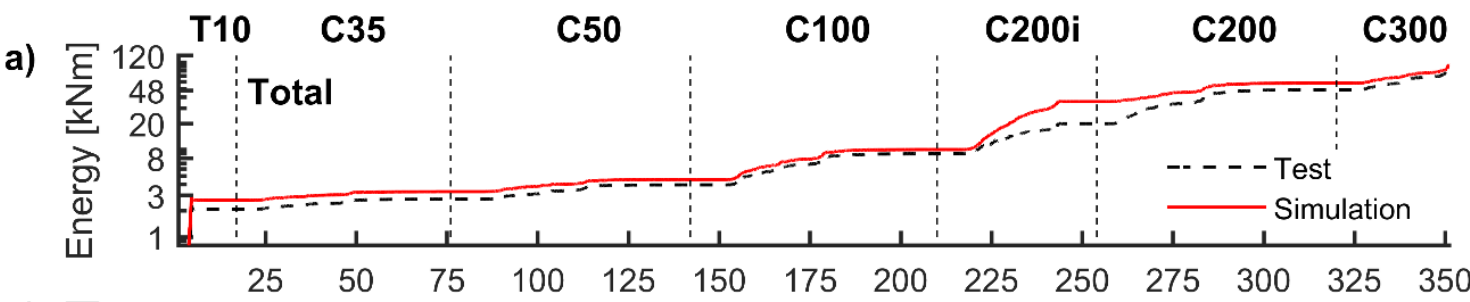

b)

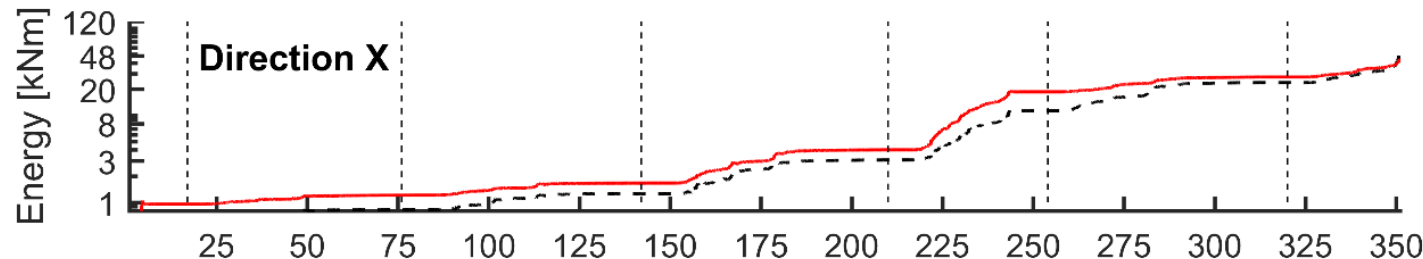

c)

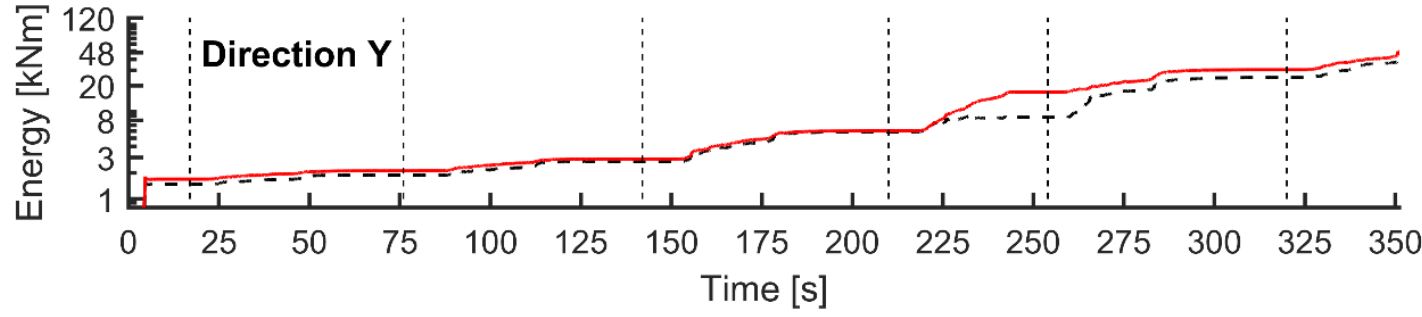

Figure 5. 24. Input Energy response: a) Total, b) direction $\mathrm{X}$ and c) direction $\mathrm{Y}$ 


\section{SEISMIC CAPACITY OF WFP STRUCTURES IN TERMS OF ENERGY}

A complete analysis is conducted here to obtain the seismic capacity of WFP structures under bidirectional loading in terms of energy. The benchmark numerical model validated experimentally in the previous section is used here to perform a large number of non-linear response history analyses (NRHAs) using five sets of seven ground motions records organized according to the intensity level between the horizontal components. Furthermore, two additional sets of records were formed with the components NS and EW of one record of each set in order to investigate the response under unidirectional loadings in $\mathrm{X}$ and $\mathrm{Y}$ directions. Results in terms of input energy and dissipated energy were obtained.

\subsection{Sets of ground motions}

The ground motion records were selected from the database (Lucchini, Franchin, \& Mollaioli, 2017) which was built up from the international database (Campbell \& Bozorgnia, 2008) by excluding all records with moment magnitude $\left(M_{w}\right)$ smaller than 5 and with recognizable pulse in the history of ground velocity (i.e. excluding pulse-like ground motion records). The criteria established to select the records were: i) a maximum scale factor $(S F)$ of 3 to achieve the total input energy of $V_{E}=70 \mathrm{~cm} / \mathrm{s}$ for which the specimen was on the brim of yielding in the lab test under unidirectional (Benavent-Climent, Donaire-Avila, \& Oliver-Saiz, 2016) and bidirectional loading (Chapter 4); and ii) a maximum value of $0.3 \mathrm{~g}$ for the component of the record with the highest scaled PGA, in order to prevent unrealistic values of PGA in successive scaled simulations until failure.

The records were classified in five sets, according to the ranges of the ratio $V_{E y} / V_{E x}$ between horizontal components of the input energy. Defining a pseudo-angle in the $V_{E x}-V_{E y}$ plane as $\theta=\operatorname{atan}\left(V_{E y} / V_{E x}\right)$, the ranges of the sets were as follows: i) $22.91^{\circ}-32.65^{\circ}$ for Set 1 ; ii) $32.65^{\circ}$ - $42.40^{\circ}$ for Set 2 ; iii) $42.40^{\circ}-52.14^{\circ}$ for Set 3 ; iv) $52.14^{\circ}-61.88^{\circ}$ for the Set 4 ; and v) $61.88^{\circ}$ $71.62^{\circ}$ for the Set 5 . Seven records were eventually selected for each set according to the lowest scale factor, and avoiding, where it was possible, different stations of the same earthquake. The main properties of the selected ground motions for each set are listed in Tables 5.10 to 5.14. It is worth noting that the way to identify these earthquakes hereafter is by its Earthquake Name plus the number of the Station Name, e.g., Friuli (1976) is referred to Friuli-125. In addition, acceleration and velocity signals and acceleration, velocity, displacement and input energy spectra of these earthquakes are shown in Appendix 3. 
Table 5. 10. Main properties of the ground motions for the Set 1

\begin{tabular}{|c|c|c|c|c|c|c|c|c|c|}
\hline $\begin{array}{c}\text { Earthquake } \\
\text { Name }\end{array}$ & Year & $\begin{array}{c}\text { Station } \\
\text { Name }\end{array}$ & $M_{w}$ & $S F$ & $\begin{array}{c}\text { PGAx } \\
{[\mathrm{g}]}\end{array}$ & $\begin{array}{c}\text { PGAy } \\
{[\mathrm{g}]}\end{array}$ & $\begin{array}{c}V_{E x} \\
{[\mathrm{~cm} / \mathrm{s}]}\end{array}$ & $\begin{array}{c}V_{E y} \\
{[\mathrm{~cm} / \mathrm{s}]}\end{array}$ & $\begin{array}{c}\theta \\
{\left[{ }^{0}\right]}\end{array}$ \\
\hline $\begin{array}{l}\text { Manjil } \\
\text { (Irán) }\end{array}$ & 1990 & $\begin{array}{l}\text { Qazvin } \\
(1636)\end{array}$ & 7.37 & 1.05 & 0.18 & 0.13 & 57.94 & 32.84 & 29.54 \\
\hline $\begin{array}{c}\text { Cape } \\
\text { Mendocino } \\
\text { (USA) }\end{array}$ & 1992 & $\begin{array}{c}\text { Euroka- } \\
\text { Myrtle\&West } \\
\text { (826) }\end{array}$ & 7.01 & 1.07 & 0.15 & 0.18 & 57.15 & 32.41 & 29.56 \\
\hline $\begin{array}{c}\text { San } \\
\text { Fernando } \\
\text { (USA) }\end{array}$ & 1971 & $\begin{array}{l}\text { Hollywood } \\
\text { Stor FF (68) }\end{array}$ & 6.61 & 1.12 & 0.21 & 0.17 & 52.63 & 33.57 & 32.53 \\
\hline Sierra & & LA-City & & & & & & & \\
\hline $\begin{array}{c}\text { Madre } \\
\text { (USA) }\end{array}$ & 1991 & $\begin{array}{l}\text { Terrace } \\
(1643)\end{array}$ & 5.61 & 1.70 & 0.11 & 0.09 & 35.24 & 21.37 & 31.23 \\
\hline $\begin{array}{l}\text { Chi-Chi } \\
\text { (Taiwan) }\end{array}$ & 1999 & $\begin{array}{l}\text { TAP051 } \\
(1435)\end{array}$ & 7.62 & 1.74 & 0.11 & 0.06 & 35.08 & 19.89 & 29.55 \\
\hline $\begin{array}{c}\text { Imperial } \\
\text { Valley } \\
\text { (USA) }\end{array}$ & 1979 & $\begin{array}{l}\text { Niland Fire } \\
\text { Sta. (186) }\end{array}$ & 6.53 & 1.77 & 0.11 & 0.07 & 33.29 & 21.19 & 32.48 \\
\hline $\begin{array}{l}\text { Landers } \\
\text { (USA) }\end{array}$ & 1992 & $\begin{array}{c}\text { Anaheim- } \\
\text { WB Rd (833) }\end{array}$ & 7.28 & 2.69 & 0.05 & 0.04 & 22.08 & 13.76 & 31.94 \\
\hline
\end{tabular}

Table 5. 11. Main properties of the ground motions for the Set 2

\begin{tabular}{|c|c|c|c|c|c|c|c|c|c|}
\hline $\begin{array}{c}\text { Earthquake } \\
\text { Name }\end{array}$ & Year & $\begin{array}{l}\text { Station } \\
\text { Name }\end{array}$ & $M_{w}$ & $S F$ & $\begin{array}{c}P G A x \\
{[g]}\end{array}$ & $\begin{array}{c}\text { PGAy } \\
{[\mathrm{g}]}\end{array}$ & $\left.\begin{array}{c}V_{E x} \\
{[\mathrm{~cm} / \mathrm{s}]}\end{array}\right]$ & $\begin{array}{c}V_{E y} \\
{[\mathrm{~cm} / \mathrm{s}]}\end{array}$ & $\begin{array}{c}\theta \\
{\left[{ }^{0}\right]}\end{array}$ \\
\hline $\begin{array}{l}\text { Chi-Chi } \\
\text { (Taiwan) }\end{array}$ & 1999 & $\begin{array}{c}\text { TCU050 } \\
(1490)\end{array}$ & 7.62 & 1.00 & 0.15 & 0.13 & 53.39 & 45.78 & 40.62 \\
\hline $\begin{array}{l}\text { Northridge } \\
\text { (USA) }\end{array}$ & 1994 & $\begin{array}{l}\text { Elizabeth } \\
\text { Lake } \\
(971)\end{array}$ & 6.69 & 0.98 & 0.15 & 0.11 & 57.76 & 41.97 & 36.00 \\
\hline $\begin{array}{l}\text { Hector Mine } \\
\text { (USA) }\end{array}$ & 1999 & $\begin{array}{l}\text { Amboy } \\
(1762)\end{array}$ & 7.13 & 0.95 & 0.18 & 0.15 & 59.38 & 43.37 & 36.15 \\
\hline $\begin{array}{c}\text { Duzce } \\
\text { (Turkey) }\end{array}$ & 1999 & $\begin{array}{l}\text { Mudumu } \\
\text { (1619) }\end{array}$ & 7.14 & 1.06 & 0.12 & 0.06 & 53.85 & 38.40 & 35.50 \\
\hline $\begin{array}{l}\text { Morgan Hill } \\
\text { (USA) }\end{array}$ & 1984 & $\begin{array}{c}\text { Gilroy } \\
\text { Array } 7 \\
(460)\end{array}$ & 6.19 & 0.89 & 0.19 & 0.11 & 60.11 & 50.94 & 40.28 \\
\hline $\begin{array}{c}\text { Imperial } \\
\text { Valley (USA) }\end{array}$ & 1979 & $\begin{array}{l}\text { EL Centro } \\
12(175)\end{array}$ & 6.53 & 1.18 & 0.14 & 0.12 & 46.25 & 37.23 & 38.83 \\
\hline $\begin{array}{c}\text { Loma Prieta } \\
\text { (USA) }\end{array}$ & 1989 & $\begin{array}{c}\text { Airport } \\
(799)\end{array}$ & 6.93 & 0.59 & 0.24 & 0.33 & 91.34 & 77.28 & 40.24 \\
\hline
\end{tabular}


Table 5. 12. Main properties of the ground motions for the Set 3

\begin{tabular}{|c|c|c|c|c|c|c|c|c|c|}
\hline $\begin{array}{c}\text { Earthquake } \\
\text { Name }\end{array}$ & Year & $\begin{array}{c}\text { Station } \\
\text { Name }\end{array}$ & $M_{w}$ & $S F$ & $\begin{array}{c}P G A x \\
{[\mathrm{~g}]}\end{array}$ & $\begin{array}{c}P G A y \\
{[\mathrm{~g}]}\end{array}$ & $\begin{array}{c}V_{E x} \\
{[\mathrm{~cm} / \mathrm{s}]}\end{array}$ & $\begin{array}{c}V_{E y} \\
{[\mathrm{~cm} / \mathrm{s}]}\end{array}$ & $\begin{array}{c}\theta \\
{\left[{ }^{\circ}\right]}\end{array}$ \\
\hline $\begin{array}{l}\text { Chi-Chi } \\
\text { (Taiwan) }\end{array}$ & 1999 & $\begin{array}{c}\text { TCU107 } \\
\text { (1534) }\end{array}$ & 7.62 & 1.01 & 0.12 & 0.16 & 45.00 & 53.05 & 49.69 \\
\hline $\begin{array}{l}\text { Kobe } \\
\text { (Japan) }\end{array}$ & 1995 & $\begin{array}{c}\text { Sakai } \\
(1115)\end{array}$ & 6.90 & 0.99 & 0.16 & 0.12 & 50.13 & 50.13 & 45.00 \\
\hline $\begin{array}{l}\text { Northridge } \\
\text { (USA) }\end{array}$ & 1994 & $\begin{array}{l}\text { Brentwood- } \\
\text { VAHosp. } \\
\text { (986) }\end{array}$ & 6.69 & 1.03 & 0.19 & 0.16 & 43.79 & 51.58 & 49.67 \\
\hline $\begin{array}{l}\text { Landers } \\
\text { (USA) }\end{array}$ & 1992 & $\begin{array}{c}\text { Desert Hot } \\
\text { Springs } \\
(850)\end{array}$ & 7.28 & 0.94 & 0.17 & 0.15 & 51.91 & 53.78 & 46.02 \\
\hline $\begin{array}{l}\text { Hector } \\
\text { Mine } \\
\text { (USA) }\end{array}$ & 1999 & $\begin{array}{l}\text { Baker Fire } \\
\text { Sta. (1766) }\end{array}$ & 7.13 & 1.25 & 0.13 & 0.09 & 36.32 & 42.60 & 49.55 \\
\hline $\begin{array}{c}\text { Coalinga } \\
\text { (USA) }\end{array}$ & 1983 & $\begin{array}{c}\text { Parkfield } \\
\text { VinC2W } \\
\text { (362) }\end{array}$ & 6.36 & 1.59 & 0.07 & 0.08 & 27.53 & 34.44 & 51.37 \\
\hline $\begin{array}{c}\text { Whittier } \\
\text { Narrows } \\
\text { (USA) }\end{array}$ & 1987 & $\begin{array}{c}\text { Panorama } \\
\text { City-Roscoe } \\
(673) \\
\end{array}$ & 5.99 & 1.65 & 0.10 & 0.11 & 29.51 & 30.61 & 46.04 \\
\hline
\end{tabular}

Table 5. 13. Main properties of the ground motions for the Set 4

\begin{tabular}{|c|c|c|c|c|c|c|c|c|c|}
\hline $\begin{array}{c}\text { Earthquake } \\
\text { Name }\end{array}$ & Year & $\begin{array}{c}\text { Station } \\
\text { Name }\end{array}$ & $M_{w}$ & $S F$ & $\begin{array}{c}\text { PGAx } \\
{[\mathrm{g}]}\end{array}$ & $\begin{array}{c}\text { PGAy } \\
{[\mathrm{g}]}\end{array}$ & $\begin{array}{c}V_{E x} \\
{[\mathrm{~cm} / \mathrm{s}]}\end{array}$ & $\begin{array}{c}V_{E y} \\
{[\mathrm{~cm} / \mathrm{s}]}\end{array}$ & $\begin{array}{c}\theta \\
{\left[{ }^{\circ}\right]}\end{array}$ \\
\hline Superstition & & Wild Life & & & & & & & \\
\hline $\begin{array}{l}\text { Hills } \\
\text { (USA) }\end{array}$ & 1987 & $\begin{array}{l}\text { Liq. Ar } \\
\text { (729) }\end{array}$ & 6.54 & 0.84 & 0.18 & 0.21 & 43.34 & 71.56 & 58.80 \\
\hline $\begin{array}{c}\text { Irpinia } \\
\text { (Italy) }\end{array}$ & 1980 & $\begin{array}{l}\text { Calitri } \\
(289)\end{array}$ & 6.90 & 0.82 & 0.13 & 0.18 & 44.95 & 72.46 & 58.18 \\
\hline $\begin{array}{l}\text { Kocaeli } \\
\text { (Turkey) }\end{array}$ & 1999 & $\begin{array}{l}\text { Goynuk } \\
\text { (1162) }\end{array}$ & 7.51 & 1.26 & 0.13 & 0.12 & 34.03 & 44.19 & 52.40 \\
\hline $\begin{array}{c}\text { Hector } \\
\text { Mine (USA) }\end{array}$ & 1999 & $\begin{array}{c}\text { San } \\
\text { Bernardino - } \\
\text { Mont.M } \\
(1829)\end{array}$ & 7.13 & 1.28 & 0.09 & 0.13 & 29.25 & 46.39 & 57.77 \\
\hline $\begin{array}{c}\text { Coalinga } \\
\text { (USA) }\end{array}$ & 1983 & $\begin{array}{l}\text { Parkfield - } \\
\text { Gold Hill } \\
\text { 3W (352) }\end{array}$ & 6.36 & 1.55 & 0.14 & 0.12 & 24.03 & 38.40 & 57.96 \\
\hline $\begin{array}{l}\text { Landers } \\
\text { (USA) }\end{array}$ & 1992 & $\begin{array}{c}\text { San } \\
\text { Bernardino - } \\
\text { E\&Hosp. } \\
(888)\end{array}$ & 7.28 & 1.48 & 0.08 & 0.09 & 27.36 & 38.49 & 54.59 \\
\hline $\begin{array}{l}\text { Friuli } \\
\text { (Italy) }\end{array}$ & 1976 & $\begin{array}{c}\text { Tolmezzo } \\
\text { (125) }\end{array}$ & 6.50 & 0.56 & 0.35 & 0.31 & 64.73 & 107.60 & 58.97 \\
\hline
\end{tabular}


Table 5. 14. Main properties of the ground motions for the Set 5

\begin{tabular}{|c|c|c|c|c|c|c|c|c|c|}
\hline $\begin{array}{c}\text { Earthquake } \\
\text { Name }\end{array}$ & Year & $\begin{array}{c}\text { Station } \\
\text { Name }\end{array}$ & $M_{w}$ & $S F$ & $\begin{array}{c}P G A x \\
{[g]}\end{array}$ & $\begin{array}{c}\text { PGAy } \\
{[\mathrm{g}]}\end{array}$ & $\begin{array}{c}V_{E x} \\
{[\mathrm{~cm} / \mathrm{s}]}\end{array}$ & $\begin{array}{c}V_{E y} \\
{[\mathrm{~cm} / \mathrm{s}]}\end{array}$ & $\begin{array}{c}\theta \\
{\left[{ }^{\circ}\right]}\end{array}$ \\
\hline Hector & & Joshua & & & & & & & \\
\hline $\begin{array}{l}\text { Mine } \\
\text { (USA) }\end{array}$ & 1999 & $\begin{array}{l}\text { Tree } \\
(1794)\end{array}$ & 7.13 & 0.79 & 0.15 & 0.19 & 36.78 & 80.52 & 65.45 \\
\hline $\begin{array}{l}\text { Chi-Chi } \\
\text { (Taiwan) }\end{array}$ & 1999 & $\begin{array}{l}\text { ILA066 } \\
\text { (1349) }\end{array}$ & 7.62 & 1.28 & 0.08 & 0.10 & 19.92 & 51.12 & 68.71 \\
\hline $\begin{array}{c}\text { Chalfant } \\
\text { Valley } \\
\text { (USA) }\end{array}$ & 1986 & $\begin{array}{l}\text { Bishop - } \\
\text { LADWP }\end{array}$ & 6.19 & 0.75 & 0.25 & 0.17 & 33.97 & 86.80 & 68.62 \\
\hline $\begin{array}{l}\text { Landers } \\
\text { (USA) }\end{array}$ & 1992 & $\begin{array}{c}\text { Featherly } \\
\text { Park - } \\
\text { Maint } \\
(854)\end{array}$ & 7.28 & 1.68 & 0.05 & 0.05 & 18.72 & 37.18 & 63.28 \\
\hline $\begin{array}{l}\text { Northridge } \\
\text { (USA) }\end{array}$ & 1994 & $\begin{array}{l}\text { Seal Beach } \\
\text { - Off Bldg. } \\
\text { (1079) }\end{array}$ & 6.69 & 1.84 & 0.06 & 0.08 & 17.16 & 33.99 & 63.21 \\
\hline $\begin{array}{l}\text { Chi-Chi } \\
\text { (Taiwan) }\end{array}$ & 1999 & $\begin{array}{l}\text { ILA036 } \\
\text { (1328) }\end{array}$ & 7.62 & 2.54 & 0.06 & 0.07 & 9.82 & 25.75 & 69.12 \\
\hline $\begin{array}{c}\text { Loma Prieta } \\
\text { (USA) }\end{array}$ & 1989 & $\begin{array}{l}\text { Gilroy } \\
\text { Array } 1 \\
(765)\end{array}$ & 6.93 & 0.36 & 0.41 & 0.47 & 79.93 & 179.16 & 65.96 \\
\hline
\end{tabular}

\subsection{Non-linear analyses in successive numerical simulations}

The numerical evaluations consisted in launching successively each ground motion record with the accelerations scaled in amplitude until the collapse of the numerical model, similarly to what occurred in the experimental test described in Chapter 4. In this case, the multipliers that scale the reference accelerogram were always integers $(1,2,3 \ldots)$, where the reference accelerograms were the original ones scaled by $S F$. In addition, the numerical model was subjected to unidirectional loading using one ground motion from each set. Each component was launched separately in such a way that $\mathrm{X}$ direction is aligned with NS component and $\mathrm{Y}$ direction is aligned with EW component. This aims to investigate the differences of the response under unidirectional and bidirectional loadings. So that, five records were selected whose components $\mathrm{X}$ and $\mathrm{Y}$ formed the corresponding Set X and Set Y, respectively. In this case, the interaction factor adopted in columns under bidirectional ground motions was not considered (i.e. the strength reduction of 20\%). Therefore, 45 NRHAs were submitted in parallel scheme (OpenseesMP.exe) using a Dell Precision Tower 5810 with 12 cores at $3.60 \mathrm{GHz}$ in order to minimize as much as possible the computational time. As a reference, the mean computational time required was 29 hours per core and record. Furthermore, the elastic limit and failure states were defined in terms of the maximum top displacement, obtained through the capacity curve of the tested specimen (Figures 4.10 and 4.11). Hence, the yield top displacement, $\delta_{y T}$, and the maximum displacement achieved at the capacity curve, $\delta_{u T}$, were used to define the maximum allowed displacement for both the elastic limit and failure states, respectively. In order to simplify the analyses, intermediate values were accounted for among those obtained in each direction and domain, i.e. $\delta_{y T}=25 \mathrm{~mm}$ and $\delta_{u T}=$ $55 \mathrm{~mm}$, a range of values for which the benchmark numerical model was validated experimentally. 


\subsection{Results}

\subsubsection{Input and dissipated energy}

The input energy $E_{I}$ on a structure subjected to bidirectional (horizontal) seismic loading can be expressed in terms of equivalent velocity $V_{E}$ by (1.5), and by components as $V_{E}=\sqrt{V_{E, X}{ }^{2}+V_{E, Y}^{2}}$ because $V_{E}$ can be interpreted as the modulus of a vector in the $V_{E, X}-V_{E, Y}$ plane. The same can be applied to the total energy that contributes to damage, $E_{D}=E_{I}-W_{\xi}$, which can be also expressed in terms of equivalent velocity $V_{D}$ by (1.6) and by components as $V_{D}=$ $\sqrt{V_{D, X}{ }^{2}+V_{D, Y}{ }^{2}}$. While the components of the input energy, $E_{I, X}$ and $E_{I, Y}$ are well stablished in (4.3), the components of the energy that contributes to damage are strongly dependent on the components of damping energy, $W_{\xi, X}$ and $W_{\xi, Y}$. There is no a standard definition of these components in the literature for bidirectional loadings. In this study $W_{\xi, X}$ and $W_{\xi, Y}$ were defined in (4.5), using the uncoupled relationship between the displacements in $X$ and the displacements in $\mathrm{Y}$ and twist in elastic range (Chapter 3). Further, $W_{p}$ can be estimated by $E_{D}$ for high levels of deformations (Chapter 4). Therefore, the energy that contributes to damage can be calculated independently in the $\mathrm{X}$ and $\mathrm{Y}$ directions, $E_{D, X}$ and $E_{D, Y}$, and is almost equal to the energy dissipated by hysteresis in the $\mathrm{X}$ and $\mathrm{Y}$ directions, $W_{p, X}$ and $W_{p, Y}$, i.e. $E_{D, X} \approx W_{p, X}$ and $E_{D, Y} \approx$ $W_{p, Y}$. Based on above considerations, the values of $V_{D}, V_{D, X}$ and $V_{D, Y}$ when the structure is on the brink of collapse can be interpreted as the ultimate energy dissipation capacity of the structure in the form of plastic deformations, expressed in terms of equivalent velocities.

In Figure 5.25, subfigures a) and c) show the input energy absorbed by the benchmark model in terms of $V_{E}$ defined by its components $V_{E X}$ and $V_{E Y}$, subjected to the five sets of bidirectional ground motion records (Set $1, \ldots$, Set 5 , identified each one by a specific color) and the unidirectional ones (Set $\mathrm{X}$ and Set $\mathrm{Y}$ ), whose records are identified in the legend with the letters $\mathrm{X}$ or $\mathrm{Y}$ added accordingly to the record name. Two states of input energy are represented in the figure for each record: firstly, the state on the brink to yield (subfigure a), denoted hereafter by $V_{E e}$, and secondly the state of collapse (subfigure b), denoted hereafter by $V_{E u}$. The mean and mean $\pm \sigma$ (standard deviation) obtained from all the numeric simulations are also depicted (red and blue dashed lines, respectively) for both $V_{E e}$ and $V_{E u}$. Those values define the range of values of the input energy for which the specimen undergoes plastic deformations, being on average $96 \mathrm{~cm} / \mathrm{s}$ for $V_{E e}$ and $226 \mathrm{~cm} / \mathrm{s}$ for $V_{E u}$ with standard deviations equal to $23 \mathrm{~cm} / \mathrm{s}$ and $63 \mathrm{~cm} /$ $s$, respectively. This entails a capacity of the structure to absorb energy when the damage is allowed of more than twice than the undamaged one in terms of equivalent velocity, i.e. more than fivefold in terms of energy. A more detailed analysis of the results is reported in Table 5.15, where the mean and the coefficient of variation, COV , are also shown for each set of records. Moderate differences appear among the different groups obtained for each variable. The highest values for the ratio $V_{E u} / V_{E e}$ are observed under unidirectional loadings (2.63 and 2.67 for $\mathrm{X}$ and $\mathrm{Y}$ directions, respectively) but no so far from the mean $2.38(\mathrm{COV}=0.22)$.

Furthermore, subfigure c) in Figure 5.25 shows the maximum dissipated energy in terms of equivalent velocity, $V_{D}$, achieved in the numerical model, i.e. at failure, under the aforementioned sets of ground motion records, following the same representation criteria established previously for $V_{E}$ in subfigures a) and b). On average, $V_{D}=142 \mathrm{~cm} / \mathrm{s}$ with a standard deviation of $43 \mathrm{~cm} / \mathrm{s}$. Table 5.15 reports that $C O V$ for both $V_{E u}$ and $V_{D}$ are 0.28 and 0.30 , respectively. 


$\begin{array}{llllllllll}+ & \text { MANJII-1636 } & \times & \text { DUZCE-1619 } & \triangle & \text { WHITTIER-673 } & * & \text { CHALFANT-549 } & \times & \text { SMADRE-1643Y } \\ \bigcirc & \text { CAPEMEND-826 } & \nabla & \text { MORGAN-460 } & + & \text { SUPERST-729 } & \times & \text { LANDERS-854 } & + & \text { CHICHI-1490Y } \\ * & \text { SFERN-68 } & \diamond & \text { IMPVALL-175 } & \bigcirc & \text { ITALY-289 } & \nabla & \text { NORTHR-1079 } & \bigcirc & \text { KOBE-1115Y } \\ \times & \text { SMADRE-1643 } & \triangle & \text { LOMAP-799 } & * & \text { KOCAELI-1162 } & \searrow & \text { CHICHI-1328 } & \diamond & \text { LANDERS-888Y } \\ \nabla & \text { CHICHI-1435 } & + & \text { CHICHI-1534 } & \times & \text { HECTOR-1829 } & \triangle & \text { LOMAP-765 } & * & \text { CHALFANT-549Y } \\ \diamond & \text { IMPVALL-186 } & \bigcirc & \text { KOBE-1115 } & \nabla & \text { COALINGA-352 } & \times & \text { SMADRE-1643X } & \star & \text { Test (Chapter 4) } \\ \triangle & \text { LANDERS-833 } & * & \text { NORTHR-986 } & \diamond & \text { LANDERS-888 } & + & \text { CHICHI-1490X } & ---\bar{x} \\ + & \text { CHICHI-1490 } & \times & \text { LANDERS-850 } & \triangle & \text { FRIULI-125 } & \bigcirc & \text { KOBE-1115X } & ---\bar{x} \pm \sigma \\ \bigcirc & \text { NORTHR-971 } & \nabla & \text { HECTOR-1766 } & + & \text { HECTOR-1794 } & \diamond & \text { LANDERS-888X } & & \\ * & \text { HECTOR-1762 } & \diamond & \text { COALINGA-362 } & \bigcirc & \text { CHICHI-1349 } & * & \text { CHALFANT-549X } & & \end{array}$
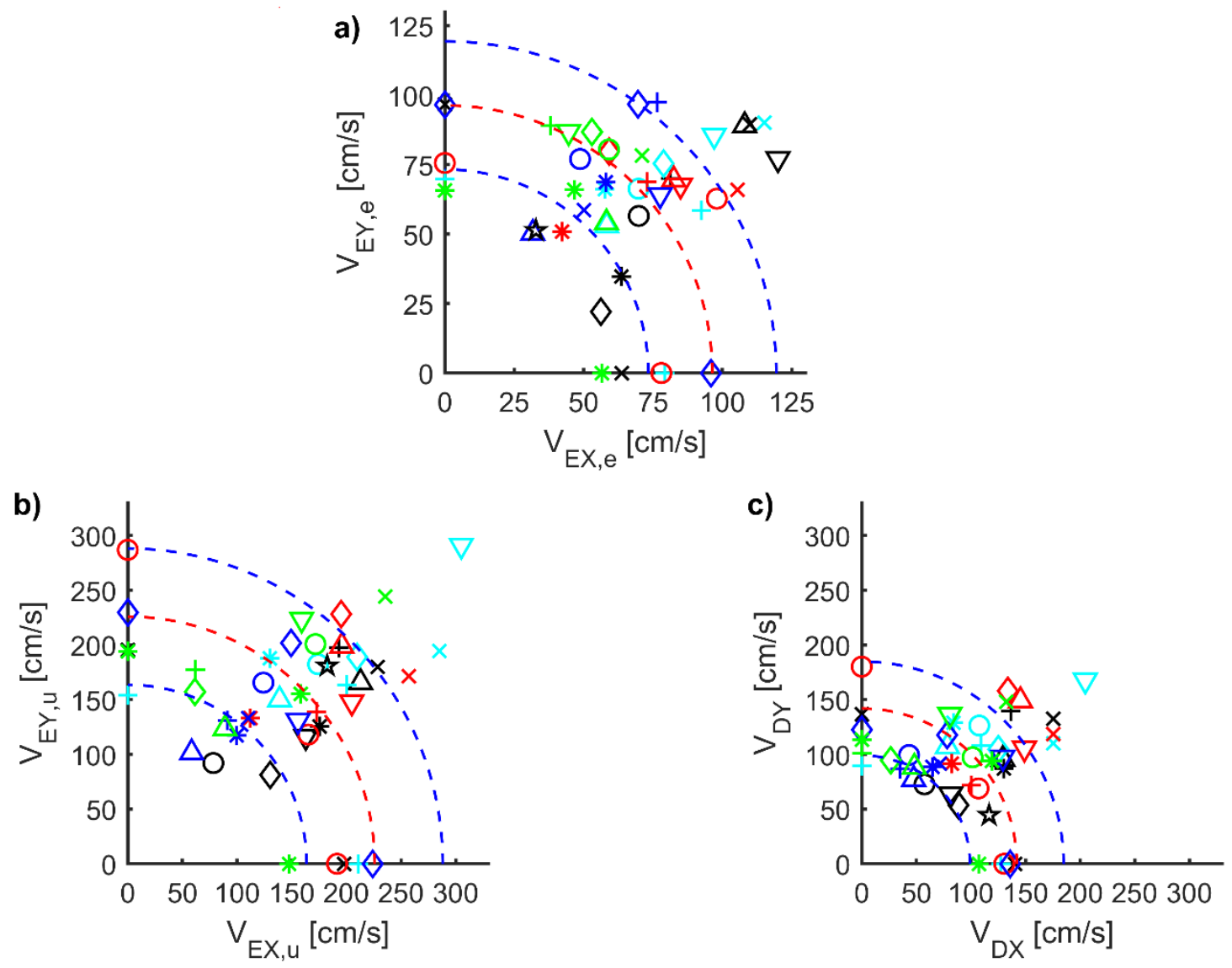

Figure 5. 25. Energy capacity of the structure with dampers: a) elastic input energy b) input energy at failure and c) hysteretic energy at failure

Table 5. 15. Analysis of the input energy and the energy that contributes to damage obtained from NRHAs

\begin{tabular}{|c|c|c|c|c|c|c|c|c|c|c|}
\hline Set & $\begin{array}{c}\text { mean } \\
V_{E e} \\
{[\mathrm{~cm} / \mathrm{s}]}\end{array}$ & $\begin{array}{c}\mathrm{COV} \\
V_{E e} \\
{[\mathrm{~cm} / \mathrm{s}]}\end{array}$ & $\begin{array}{c}\text { mean } \\
V_{E u} \\
{[\mathrm{~cm} / \mathrm{s}]}\end{array}$ & $\begin{array}{c}\mathrm{COV} \\
V_{E u} \\
{[\mathrm{~cm} / \mathrm{s}]}\end{array}$ & $\begin{array}{c}\text { mean } \\
\frac{V_{E u}}{V_{E e}}\end{array}$ & $\begin{array}{c}\text { COV } \\
\frac{V_{E u}}{V_{E e}}\end{array}$ & $\begin{array}{c}\text { mean } \\
V_{D} \\
{[\mathrm{~cm} / \mathrm{s}]}\end{array}$ & $\begin{array}{c}\mathrm{COV} \\
V_{D} \\
{[\mathrm{~cm} / \mathrm{s}]}\end{array}$ & $\begin{array}{c}\text { mean } \\
\frac{V_{D}}{V_{E u}}\end{array}$ & $\begin{array}{c}\text { COV } \\
\frac{V_{D}}{V_{E u}}\end{array}$ \\
\hline $\bar{X}$ & 74.72 & 0.18 & 194.35 & 0.13 & 2.63 & 0.10 & 128.22 & 0.09 & 0.67 & 0.08 \\
\hline 1 & 107.79 & 0.30 & 218.10 & 0.28 & 2.12 & 0.27 & 147.35 & 0.31 & 0.68 & 0.12 \\
\hline 2 & 108.12 & 0.20 & 284.60 & 0.24 & 2.63 & 0.11 & 177.23 & 0.23 & 0.63 & 0.05 \\
\hline 3 & 103.24 & 0.17 & 248.53 & 0.19 & 2.43 & 0.15 & 169.00 & 0.23 & 0.68 & 0.09 \\
\hline 4 & 94.50 & 0.22 & 180.69 & 0.22 & 1.94 & 0.16 & 117.39 & 0.20 & 0.66 & 0.15 \\
\hline 5 & 94.57 & 0.10 & 229.73 & 0.27 & 2.42 & 0.22 & 134.30 & 0.27 & 0.59 & 0.11 \\
\hline Y & 80.87 & 0.16 & 212.07 & 0.21 & 2.67 & 0.24 & 105.52 & 0.30 & 0.49 & 0.19 \\
\hline$\overline{\text { All }}$ & 96.35 & 0.24 & 225.86 & 0.28 & 2.38 & 0.22 & 141.90 & 0.30 & 0.63 & 0.15 \\
\hline
\end{tabular}


Figure 5.26 shows the mean and error bars of $\theta_{V E, e}=\operatorname{atan}\left(V_{E e, Y} / V_{E e, X}\right)$ and $\theta_{V E, u}=$ $\operatorname{atan}\left(V_{E u, Y} / V_{E u, X}\right)$ obtained in the elastic state and at failure, respectively. It can be observed that the $\theta_{V E, e}$ obtained with sets 1 and 2 (with values lower than $42^{\circ}$ ) undergoes a remarkable increase with the development of plastic deformations $\left(\theta_{V E, u}\right)$. This means a higher increase of $V_{E, Y}$ than the obtained in $V_{E, X}$ when the $\mathrm{X}$ component of the seismic actions is stronger than the counterpart $Y$. Nevertheless, this effect is not clearly shown in sets 3,4 and 5. The specimen along the $Y$ direction is eccentric for both mass and stiffness (mass-eccentric and stiffness-eccentric building following (Perus \& Fajfar, 2005)). The specimen has a rigid edge which includes the columns $C_{2}$ and $C_{3}$ and a flexible edge which includes the column $C_{1}$ (Figure 2.5). Along the $\mathrm{X}$ direction, the specimen shows both mass and strength symmetry. Moreover, the first three modal periods are $T_{1}=0.38 \mathrm{~s}, T_{2}=0.32 \mathrm{~s}$ and $T_{3}=0.32 \mathrm{~s}$, being the first a torsional vibration mode, the second a pure translational along the $\mathrm{X}$ axis and the third also torsional. Therefore, for the $\mathrm{X}$ and Y directions, respectively, $\Omega_{x}=T_{2} / T_{1}<1$ and $\Omega_{y}<1$ (there is not a pure translational vibration mode along Y direction), and according to this, the specimen is considered as a flexible torsional building in both directions. The asymmetry of the specimen along the $\mathrm{Y}$ direction can produce two effects (Marušić \& Fajfar, 2005): (i) under small to moderate plastic levels, high rotations are expected along with large displacements for both edges stiff and flexible respect to the center of mass in direction Y (as corresponds to flexible torsional buildings), which lead to the yield firstly of the elements at the flexible edge with the consequent decrease of the stiffness and the increase of the eccentricity; (ii) under high plastic levels, the influence of the torsional effects decreases in comparison with that exhibited for the lower levels. For sets 1 and 2, it is observed a progressive increase of $V_{E, Y}$ in higher proportion than for $V_{E, X}$ until failure, which suggests an important role of the torsional forces under moderate damage along the Y direction. Nevertheless, for the sets 3, 4 and 5 this effect was not observed. In this case, the strong component of the seismic actions tended be applied along the $\mathrm{Y}$ direction which led to high levels of plastic deformations, reducing the effects produced by the torsional forces.

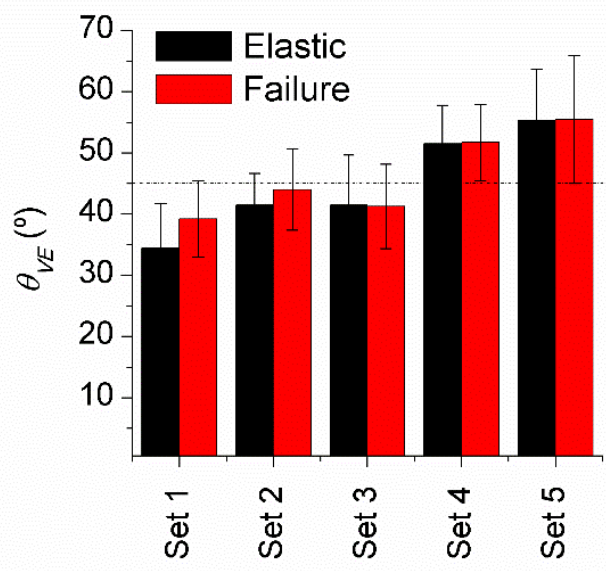

Figure 5. 26. Mean and error bars for $\theta_{V E}=\operatorname{atan}\left(V_{E Y} / V_{E X}\right)$ in the different sets of records

Furthermore, for the different sets of records reported in Table 5.15, it is shown that the specimen subjected to records within the range of $52^{\circ} \leq \theta<90^{\circ}$, i.e. sets 4 and 5 , has the lowest capacity in terms of $V_{D}$, with a mean of $126 \mathrm{~cm} / \mathrm{s}$, a $24 \%$ lower than the obtained for $0<\theta \leq 52^{\circ}$, i.e. sets 1,2 and 3, with a mean of $164 \mathrm{~cm} / \mathrm{s}$. Therefore, even the dispersion values around the mean shows that these differences are not significant, it is true that the direction $\mathrm{Y}$ seems weaker to dissipate energy by plastic deformations, maybe due to its asymmetry and the consequent torsional effects. 
Finally, Table 5.15 also reports the mean of the ratio $V_{D} / V_{E u}$ obtained in the simulations. A range between 0.63 and 0.68 were observed except for Set 5 and Set $\mathrm{Y}$ with 0.59 and 0.49 , respectively, for which low values for $V_{D}$ were also obtained, i.e. with low capacity to dissipate energy by plastic deformations. Taking into account all the analyses, the mean of $V_{D} / V_{E u}$ obtained was 0.63 and a COV of 0.15. Considering the expression proposed by Akiyama (1985) for estimating $V_{D} / V_{E u}$, Equation (1.7), and using the estimation of the inherent relative damping for the first vibrational mode in elastic range in the benchmark numerical model, i.e. $\xi=0.035$ (Table 5.9), the value predicted with Akiyama's expression for $V_{D} / V_{E u}$ is 0.75 which is a little larger than the mean obtained in the analyses, i.e. 0.63 . Therefore, the value predicted by Akiyama's expression is a little conservative for design purpose.

\subsubsection{Seismic capacity of the specimen subjected to unidirectional and bidirectional loadings}

Seismic capacity of structures obtained through independent unidirectional analysis along two orthogonal directions is still a matter of controversy (De Stefano \& Faella, 1996; Dutta \& Kunnath, 2013; Lee \& Hong, 2010; Rodrigues, Arêde, Varum, \& Costa, 2013; Rodrigues et al., 2015). To shed light to this issue, a comparison is conducted in this section between the capacity of the WFP system obtained from the analyses under unidirectional seismic loadings using the records included in sets $\mathrm{X}$ and $\mathrm{Y}$, and that obtained from the analyses under bidirectional seismic loading using both components of the records simultaneously. In Table 5.16, the results of the analyses under unidirectional loading for structures on the brink of yielding are represented by $V_{E X, e}^{u n i}$ and $V_{E Y, e}^{u n i}$ for direction $\mathrm{X}$ and $\mathrm{Y}$, respectively. In table 5.17, the same variables than Table 5.16 are incorporated but at the ultimate state as $V_{E X, u}^{u n i}$ and $V_{E Y, u}^{u n i}$. Moreover, these tables also include the total input energy estimated by means of the aforementioned uniaxial components as $V_{E b, e}^{u n i}=\sqrt{\left(V_{E X, e}^{u n i}\right)^{2}+\left(V_{E Y, e}^{u n i}\right)^{2}}$ and $V_{E b, u}^{u n i}=\sqrt{\left(V_{E X, u}^{u n i}\right)^{2}+\left(V_{E Y, u}^{u n i}\right)^{2}}$, in order to be compared with those obtained under bidirectional loadings, $V_{E e}$ and $V_{E u}$. It is observed a mean for the ratio $V_{E X, e}^{u n i} / V_{E e}$ and $V_{E Y, e}^{u n i} / V_{E e}$ of $67 \%$ and $72 \%$, respectively. Further, the mean for the ratio $V_{E b, e}^{u n i} / V_{E e}$ is very close to 1.0 indicating that the amount of energy, expressed in terms of pseudovelocity $V_{E}$, required to lead to structure to the brink of yielding can be successfully estimated by means of the results obtained through unidirectional analysis. The energy ratios to lead the structure to collapse, $V_{E X, u}^{u n i} / V_{E u}$ and $V_{E Y, u}^{u n i} / V_{E u}$ achieve on average values of $80 \%$ and $89 \%$, respectively, higher than those obtained to lead the structure to the brink of yielding. In this case, $V_{E b, u}^{u n i}=248.12 \mathrm{~cm} / \mathrm{s}$ is a $21 \%$ higher on average than the obtained under bidirectional loadings. This means that evaluating the ultimate energy dissipation capacity of the structure in terms of input energy from the values obtained independently in each $\mathrm{X}$ and $\mathrm{Y}$ direction, $V_{E X, u}^{u n i}$ and $V_{E Y, u}^{u n i}$, by $V_{E b, u}^{u n i}=\sqrt{\left(V_{E X, u}^{u n i}\right)^{2}+\left(V_{E Y, u}^{u n i}\right)^{2}}$ is unsafe and leads to an overestimation of the earthquake resistance of the structure. This overestimation in terms of energy is $\left(1.21^{2}=1.46\right)$ about $50 \%$. 
Table 5. 16. Uni and bidirectional input energy absorbed by the specimen for elastic deformations

\begin{tabular}{|c|c|c|c|c|c|c|}
\hline Records & $\begin{array}{c}V_{E X, e}^{u n i} \\
{[\mathrm{~cm} / \mathrm{s}]}\end{array}$ & $\begin{array}{c}V_{E Y, e}^{u n i} \\
{[\mathrm{~cm} / \mathrm{s}]}\end{array}$ & $\begin{array}{c}V_{E b, e}^{u n i} \\
{[\mathrm{~cm} / \mathrm{s}]}\end{array}$ & $\frac{V_{E X, e}^{u n i}}{V_{E e}}$ & $\frac{V_{E Y, e}^{u n i}}{V_{E e}}$ & $\frac{V_{E b, e}^{u n i}}{V_{E e}^{u}}$ \\
\hline S. Madre-1643 & 63.8 & 96.7 & 115.8 & 0.45 & 0.68 & 0.82 \\
\hline Chichi-1490 & 79.3 & 69.8 & 105.6 & 0.73 & 0.64 & 0.97 \\
\hline Kobe-1115 & 78.0 & 75.6 & 108.6 & 0.67 & 0.65 & 0.93 \\
\hline Landers-888 & 95.9 & 96.5 & 136.1 & 0.80 & 0.81 & 1.14 \\
\hline Chalfant-549 & 56.6 & 65.7 & 86.7 & 0.70 & 0.81 & 1.07 \\
\hline mean & 74.7 & 80.9 & 94.7 & 0.67 & 0.72 & 0.99 \\
\hline $\mathrm{COV}$ & 0.17 & 0.15 & 0.44 & 0.16 & 0.10 & 0.10 \\
\hline
\end{tabular}

Table 5. 17. Uni and bidirectional input energy absorbed by the specimen at failure

\begin{tabular}{|c|c|c|c|c|c|c|}
\hline Records & $\begin{array}{l}V_{E X, u}^{u n i} \\
{[\mathrm{~cm} / \mathrm{s}]}\end{array}$ & $\begin{array}{l}V_{E Y, u}^{u n i} \\
{[\mathrm{~cm} / \mathrm{s}]}\end{array}$ & $\begin{array}{c}V_{E b \boldsymbol{u}}^{u n i} \\
{[\mathrm{~cm} / \mathrm{s}]}\end{array}$ & $\frac{V_{E X, u}^{u n i}}{V_{E u}}$ & $\frac{V_{E Y, u}^{u n i}}{V_{E u}}$ & $\frac{V_{E b, u}^{u n i}}{V_{E u}}$ \\
\hline S. Madre-1643 & 198.0 & 195.4 & 278.2 & 0.68 & 0.67 & 0.96 \\
\hline Chichi-1490 & 210.8 & 154.1 & 261.1 & 0.82 & 0.60 & 1.01 \\
\hline Kobe-1115 & 191.5 & 286.9 & 344.9 & 0.94 & 1.41 & 1.70 \\
\hline Landers-888 & 223.9 & 229.8 & 320.8 & 0.89 & 0.91 & 1.28 \\
\hline Chalfant-549 & 147.6 & 194.2 & 243.9 & 0.67 & 0.88 & 1.10 \\
\hline mean & 194.4 & 212.1 & 248.1 & 0.80 & 0.89 & 1.21 \\
\hline $\mathrm{COV}$ & 0.12 & 0.19 & 0.43 & 0.13 & 0.29 & 0.20 \\
\hline
\end{tabular}

Table 5.18 reports the results obtained for $V_{D}$ under unidirectional loadings in $\mathrm{X}$ and $\mathrm{Y}$, i.e. $V_{D x}^{u n i}$ and $V_{D y}^{u n i}$, as well as $V_{D b}^{u n i}=\sqrt{\left(V_{D X}^{u n i}\right)^{2}+\left(V_{D Y}^{u n i}\right)^{2}}$ to be compared with the obtained under bidirectional loadings, $V_{D}$. It is shown that the directions $\mathrm{X}$ and $\mathrm{Y}$ show the same capacity to dissipate energy under unidirectional loadings, approximately $128 \mathrm{~cm} / \mathrm{s}$, lower than that observed under bidirectional loadings as indicated by the ratios $V_{D X}^{u n i} / V_{D}$ and $V_{D Y}^{u n i} / V_{D}$ which mean values are 0.83 and 0.74 , respectively. Therefore, the specimen under unidirectional seismic loading shows lower capacity to dissipate energy than subjected to bidirectional loading. Taking into account the layout of columns in the specimen, variable axial loads are expected under seismic loading. Rodrigues et al. (2015) reported that for columns under bidirectional loading and variable axial loads, the dissipated energy is higher than the observed under uniaxial ones depending on the load path applied on the columns. Finally, it is worth noting that $V_{D b}^{u n i}=$ $156.34 \mathrm{~cm} / \mathrm{s}$ is a $20 \%$ higher on average that the obtained under bidirectional loadings, nearly the same percentage obtained for the counterpart variables in input energy. Once again, this means that evaluating the ultimate energy dissipation capacity of the tests structure in terms of amount of energy dissipated through plastic deformations, from the values obtained independently in each $\mathrm{X}$ and $\mathrm{Y}$ direction, $V_{E X, u}^{u n i}$ and $V_{E Y, u}^{u n i}$, by $V_{E b, u}^{u n i}=\sqrt{\left(V_{E X, u}^{u n i}\right)^{2}+\left(V_{E Y, u}^{u n i}\right)^{2}}$ is unsafe and leads to an overestimation of the earthquake resistance of the structure. This overestimation in terms of energy is $\left(1.20^{2}=1.46\right)$ about $45 \%$. 
Table 5. 18. Uni and bidirectional energy dissipated by the specimen at failure

\begin{tabular}{|c|c|c|c|c|c|c|}
\hline Record & $\begin{array}{c}V_{D X}^{u n i} \\
{[\mathrm{~cm} / \mathrm{s}]}\end{array}$ & $\begin{array}{c}V_{D Y}^{u n i} \\
{[\mathrm{~cm} / \mathrm{s}]}\end{array}$ & $\begin{array}{c}V_{D b}^{u n i} \\
{[\mathrm{~cm} / \mathrm{s}]}\end{array}$ & $\frac{V_{D X}^{u n i}}{V_{D}}$ & $\frac{V_{D Y}^{u n i}}{V_{D}}$ & $\frac{V_{D b}^{u n i}}{V_{D}}$ \\
\hline S. Madre-1643 & 140.34 & 136.62 & 195.86 & 0.64 & 0.62 & 0.89 \\
\hline Chichi-1490 & 127.37 & 89.49 & 155.67 & 0.83 & 0.58 & 1.01 \\
\hline Kobe-1115 & 130.47 & 180.12 & 222.41 & 1.03 & 1.42 & 1.75 \\
\hline Landers-888 & 135.78 & 122.43 & 182.82 & 0.96 & 0.87 & 1.29 \\
\hline Chalfant-549 & 107.17 & 113.30 & 155.96 & 0.71 & 0.75 & 1.03 \\
\hline mean & 128.23 & 128.39 & 156.34 & 0.83 & 0.74 & 1.20 \\
\hline $\mathrm{COV}$ & 0.08 & 0.21 & 0.44 & 0.16 & 0.34 & 0.23 \\
\hline
\end{tabular}

\section{SUMMARY}

A refined tridimensional FE model was developed and calibrated to predict the nonlinear response of the specimen BS1 subjected a successive scaled ground accelerations recorded at Calitri station of the Lucano-Campano earthquake (Italy, 1980). The model was written using the framework Opensees and had 1802 nodes with 6 DOFs per node and 1810 elements. The elements used to simulate every part of the structure were: (i) Beam with Hinges elements for columns, (ii) Elastic elements for ribs/joists in the slab, and (iii) Layered shell elements for the drop panels. The definition of each element was addressed with the highest grade of detail. It is worth noting that in the case of simulating columns in a structure until collapse, it turned out more successful to use sections defined by moment-curvature relationships than fiber sections. The reason is that fiber sections are unable to reproduce complex phenomena such as strength degradation due to local buckling of reinforcement or nonlinear interaction between flexural and shear. Furthermore, a $20 \%$ of strength reduction was adopted to take into account the biaxial moment coupling. In regards to the concrete cracking generated during the training of the shake table, the inertia of elastic elements were reduced a $20 \%$ and the cover concrete was eliminated in the nonlinear elements. Furthermore, the response predicted numerically with this model was compared with test results and a satisfactory agreement was found in general. The comparisons were made in terms of history of displacements, base inertial forces and energy input as well as in terms of capacity curve. It is emphasized that the key representation to validate a numerical model is the comparison between input energies (model and test results) using a vertical logarithmic scale.

Using this refined 3D FE model, an extensive numerical study with a large number of ground motions records was conducted, in order to investigate the amount of energy required to lead to structure to the brink of yielding, and to cause its collapse (ultimate energy dissipation capacity). Five sets of seven ground motion records were selected according to different ranges for the ratio of the input energy introduced by their two horizontal components. After this, non-linear response history analyses were carried out using the numerical model, applying each record in scaled successive simulations until the onset of plastic deformations, and until the collapse. The amount of energy input to reach these two states, and the amount of energy dissipated by the structures up to collapse were quantified and expressed in terms of equivalent velocities $V_{E}$ and $V_{D}$. Finally, five records were selected from each set to launch non-linear evaluations under unidirectional loading using separately their components. The following results are worthy of interest in regards to these analyses:

1. The $C O V$ of the values obtained for $V_{E}$ and $V_{D}$ are relatively small (around 0.30 ), which suggests a certain stability on the capacity of the structures in terms of energy, independently of the amount of energy input by each component. Moreover, the amount of input energy required to lead the structure to collapse (ultimate energy dissipation capacity) was more that 
5 times larger than the amount of energy required to lead the structure to the brink of yielding.

2. The ratio of the input energy $V_{E Y} / V_{E X}$ showed a tendency to increase when the seismic action is stronger in the direction of the axis of symmetry of the structure (X direction) (Sets 1 and 2 ). When the stronger seismic component of the ground motion is applied along the direction of no symmetry of the structure (Y direction) (sets 3, 4 and 5), this tendency is not observed probably due to torsional interactions.

3. The ratio $V_{D} / V_{E}$ is an essential magnitude in energy-based design methods, which traditionally has been obtained through analyses under unidirectional loadings. The results obtained in this study with bidirectional loadings showed that the value of this ratio at the collapse state is 0.63 with $C O V=0.15$. This value is a little lower than the one predicted with Akiyama`s equation (0.75) for the damping ratio calculated for the structure in elastic range $(\xi=3.5 \%)$. Therefore, the value predicted by Akiyama's expression is a little conservative for design purpose.

4. In general, the specimen subjected to bidirectional seismic loading showed higher capacity to dissipate energy by plastic deformations than under unidirectional loading.

5. The input energy required under bidirectional loading to lead the structure to the brink of yielding, $V_{E e}$ coincided on average with the value estimated with $V_{E b, e}^{u n i}=$ $\sqrt{\left(V_{E X, e}^{u n i}\right)^{2}+\left(V_{E Y, e}^{u n i}\right)^{2}}$ using the energies $V_{E X, e}^{u n i}$ and $V_{E Y, e}^{u n i}$ obtained separately and independently under unidirectional loading. This means that the amount of energy, expressed in terms of pseudo-velocity, $V_{E}$, required to lead to structure to the brink of yielding can be successfully estimated combining the results obtained through unidirectional analysis with the square root of the sum of the squares.

6. The input energy and the energy dissipated through plastic deformations until failure estimated from the counterpart energies obtained independently under unidirectional seismic loading, i.e. $V_{E X, u}^{u n i}, V_{E Y, u}^{u n i}, V_{D X, u}^{u n i}$ and $V_{D Y, u}^{u n i}$, combined with $V_{E b, u}^{u n i}=\sqrt{\left(V_{E X, u}^{u n i}\right)^{2}+\left(V_{E Y, u}^{u n i}\right)^{2}}$ and $V_{D b, u}^{u n i}=\sqrt{\left(V_{D X, u}^{u n i}\right)^{2}+\left(V_{D Y, u}^{u n i}\right)^{2}}$, result in unsafe estimations of the actual energy capacities of the structure under bidirectional loading. The overestimations are about $50 \%$ in terms of energy. 


\section{Chapter 6}

\section{NUMERICAL INVESTIGATION: RESPONSE OF WFP STRUCTURES WITH ENERGY DISSIPATION DEVICES UNDER BIDIRECTIONAL SEISMIC LOADING}

The effectiveness of energy dissipation systems (EDDs) for controlling the buildings response is widely recognized despite their brief history (starting in the mid-1990s). EDDs are able to increase the robustness and resilience of buildings. EDDs must be conceived not only as supplementary elements that improve the response of the structure, but as the key part of the building to meet the demands that sever earthquakes impose in structures. The main function of EDDs is to dissipate most of the energy input by the earthquake, thus reducing or cancelling the inelastic energy dissipation demand on the framing system of a structure. Recent large earthquakes revealed that many conventional buildings designed conforming modern seismic codes did not collapse, but were no longer functional after the earthquake and were demolished. In the last decades, the need for a new philosophy for earthquake-resistant design has been underscored by many researchers (Takagi and Wada, 2019). This new philosophy should be focused on sustainable development 
goals. It is necessary to move the seismic performance objectives from live-saving to business continuity, to attain resilient buildings, cities and societies. The EDDs can play an important role to reach these objectives. The EDDs reduce drastically the damage in the frame system, enlarging the life of buildings (Symans et al., 2008). Devices such as metallic dampers, friction dampers, viscous fluid dampers and viscoelastic solid dampers are the most commonly used for seismic protection of structures. However, this type of devices have a strong nonlinear behavior that along with the inherent properties of the parent structure, the characteristics of the ground motion, and the limit state investigated can make the design of structures with EDDs cumbersome. To develop new and robust methods to design structures with EDDs, it is necessary understand well the behavior of this type of systems, and this calls for extensive nonlinear response-history analyses. In this sense, this Chapter aims to investigate the seismic performance of WFP structures with metallic dampers (a type of hysteretic damper). This source of the energy dissipation in this type of devices is the plastic deformation of metals (commonly steel). In general, they can endure minor, moderate or even large ground motions without being replaced. In this Chapter, a metallic damper is tested and characterized to calibrate a numerical model in order to implement it in the benchmark model developed in Chapter 5. Afterwards, the contribution of dampers is evaluated performing response history analyses employing the same inputs used in the shaking table test of the specimen BS1 (Chapter 4). Finally, an overall performance study of the updated structure subjected to a large number of far field ground motions until collapse is conducted in order to investigate the response in terms of energy.

\section{DESCRIPTION OF THE SLIT-PLATE HYSTERETIC DAMPER}

The slit-plate (SP) hysteretic damper is an assemblage of steel plates with slits and two tubes arranged in a telescopic way, that can be installed in a frame as a conventional diagonal bar, as Figure 6.1 shows.

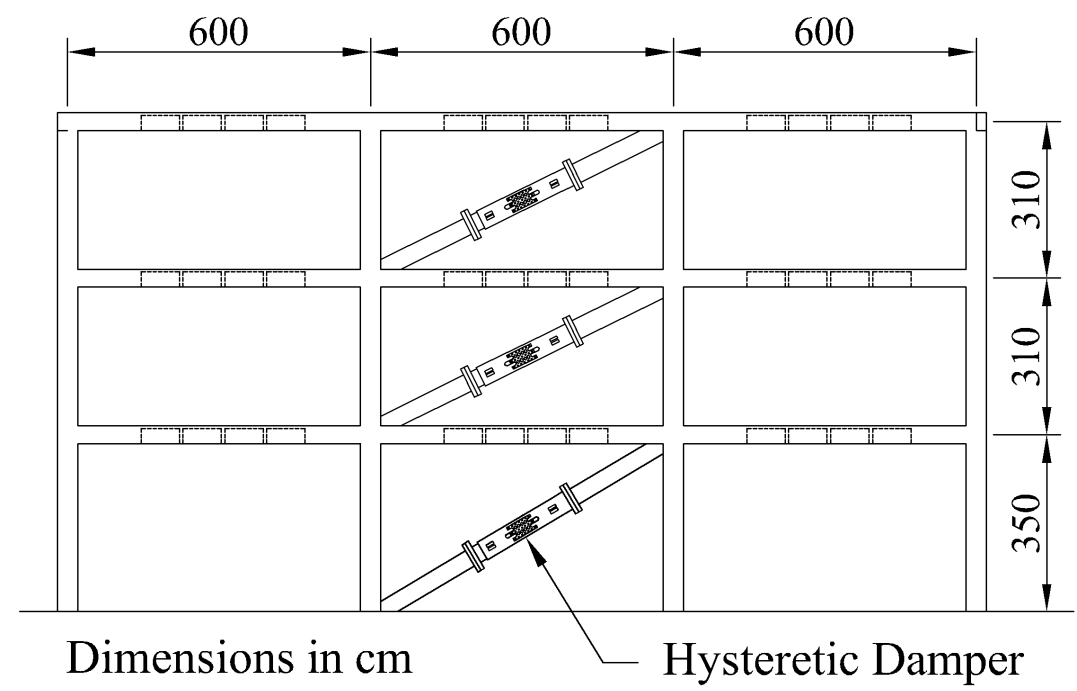

Figure 6. 1. General view of a damper installed in a building

It is constructed by assembling two standard hollow structural rectangular sections, one into the other, forming a tube-in-tube type bracing member as Figure $6.2 \mathrm{c}$ shows. The damper was inspirited in the seismic damper developed by Benavent-Climent (2010). Unlike the latter, in which some area of walls of the outer hollow sections took over the dissipation of energy, the 
new design uncouples the energy dissipation from the tubes and adds a new piece that plays this role and can be made with a material different from that of the tubes. This piece, dissipative component hereafter, is made of stainless-steel and has form of a plate with slits (Figure 6.2a). The two tubes and the dissipative components are joined by high strength bolts. Tubes are totally independent each other and the continuity of the system passes through two dissipative components, one per face. The outer tube connects with the exterior flanges of the dissipative components, and the interior flanges connect with the inner tube. This configuration allows, in case of replacement, the substitution of the damaged piece only, avoiding the replacement of the whole brace.
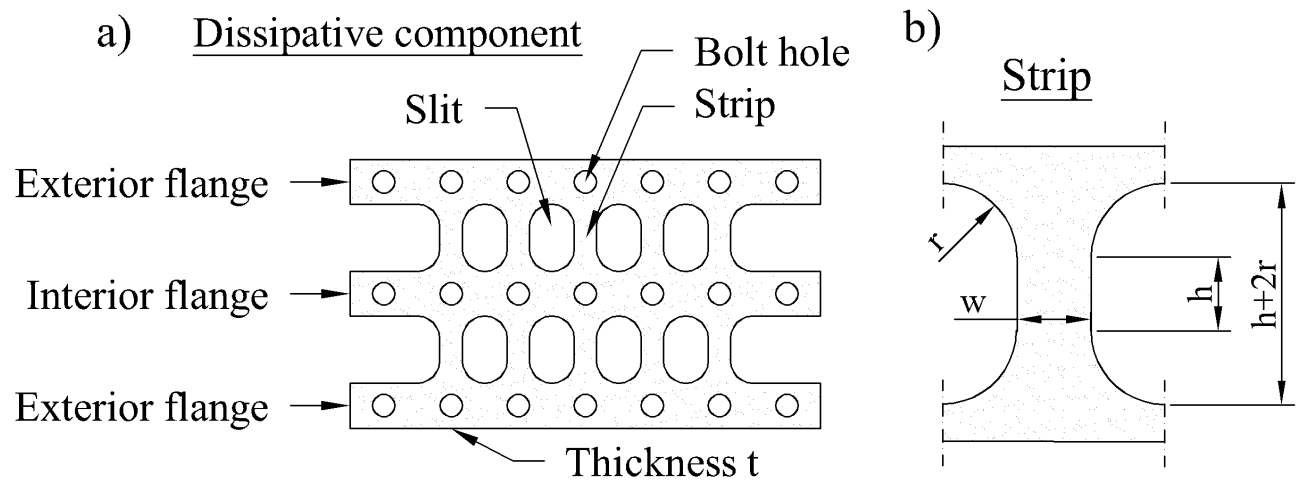

c) Hysteretic Damper

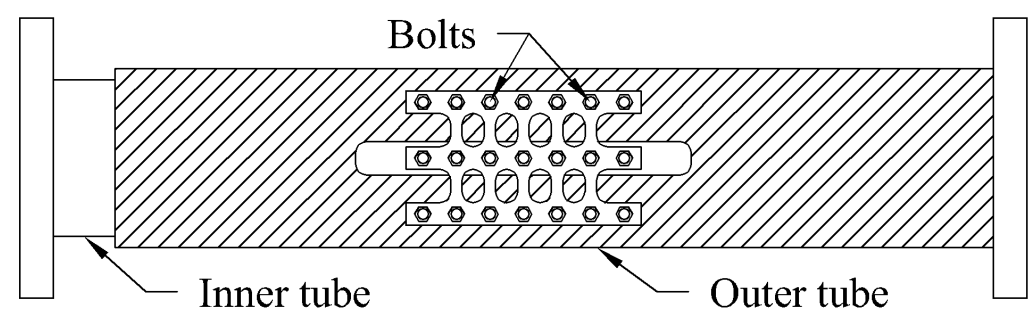

Figure 6. 2. Description of the hysteretic damper

Under seismic loading, the brace is subjected to axial forces induced by the relative displacement between tubes. This movement produces a relative displacement between interior and exterior flanges of the slit-plate in such a way that strips behave as a series of fixed-ended beams and deform in double curvature. Plastic deformations take place at both ends of the strip, where bending moment attains maximum values. The tube-in-tube configuration and the overlapping length of one tube into the other prevents buckling of the overall brace.

\section{STATIC CYCLIC TEST OF SLIT-PLATE DAMPERS}

To investigate the behavior of the SP hysteretic damper, five dissipative components similar to the one shown in Figure 6.2a were built. They are identified as TDC1, TDC2, TDC3, TDC4 and TDC5 herein. They were designed and manufactured in the University of Granada (Granada, Spain), and hereafter are called as Test Dissipative Component (TDC). They consisted of two external flanges, an internal flange and only two strips that join both external flange with the internal one (Figure 6.3). The slit plates specimens were made of hot-rolled stainless steel, grade 304-AISI, whose mechanical properties were as follows: yield stress $f_{y}=230 \mathrm{~N} / \mathrm{mm}^{2}$, maximum stress $f_{B}=620 \mathrm{~N} / \mathrm{mm}^{2}$, Young's modulus $E=2 \times 10^{5} \mathrm{~N} / \mathrm{mm}^{2}$, Poisson ratio 0.3 and shear modulus $G=7.7 \times 10^{4} \mathrm{~N} / \mathrm{mm}^{2}$. 
The supplementary equipment to test the specimens consists of two hollow structural section with rectangular shape, one inside the other, forming a tube-in-tube configuration. The dimensions of the outer tube were $160 \times 160 \times 8 \mathrm{~mm}$ and the dimensions of the inner tube $140 \times 140 \times 8 \mathrm{~mm}$. Flanges were drilled to fix them to tubes by high strength bolts. The interior flange of the slit plate was fixed to the inner tube through a longitudinal slit cut in the outer tube and the exterior flanges were fixed directly at the outer tube, connecting the two parts that undergo relative displacements. Thick end plates were welded to the tubes that in turn were clamped solidly by bolts to the head and the base of a servopulser machine SAXEWAY T1000, developed by MOOG Inc. (East Aurora, New York, USA). The outer tube was clamped to the head and the inner tube to the base of the hydraulic actuator. The test machine has a maximum load capacity of $1000 \mathrm{kN}$. Figure 6.4 shows a general view of the test apparatus ready to test.

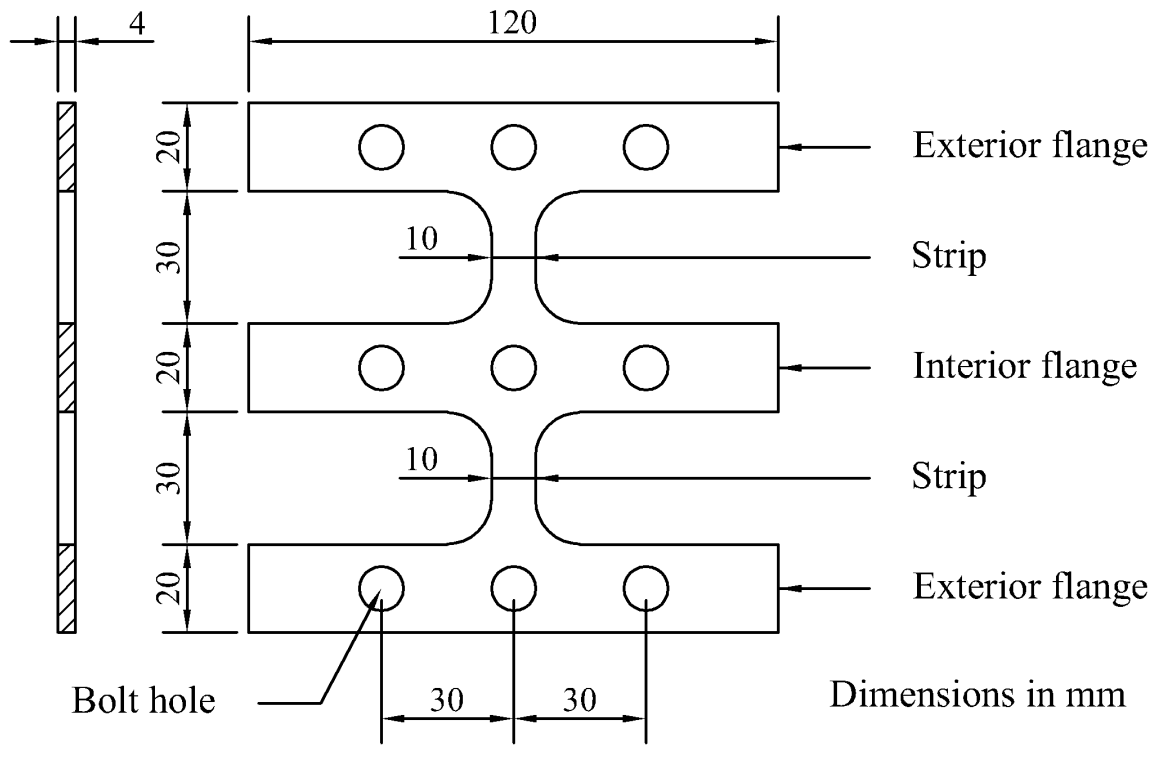

Figure 6. 3. Test Dissipative Component (TDC) of the hysteretic damper
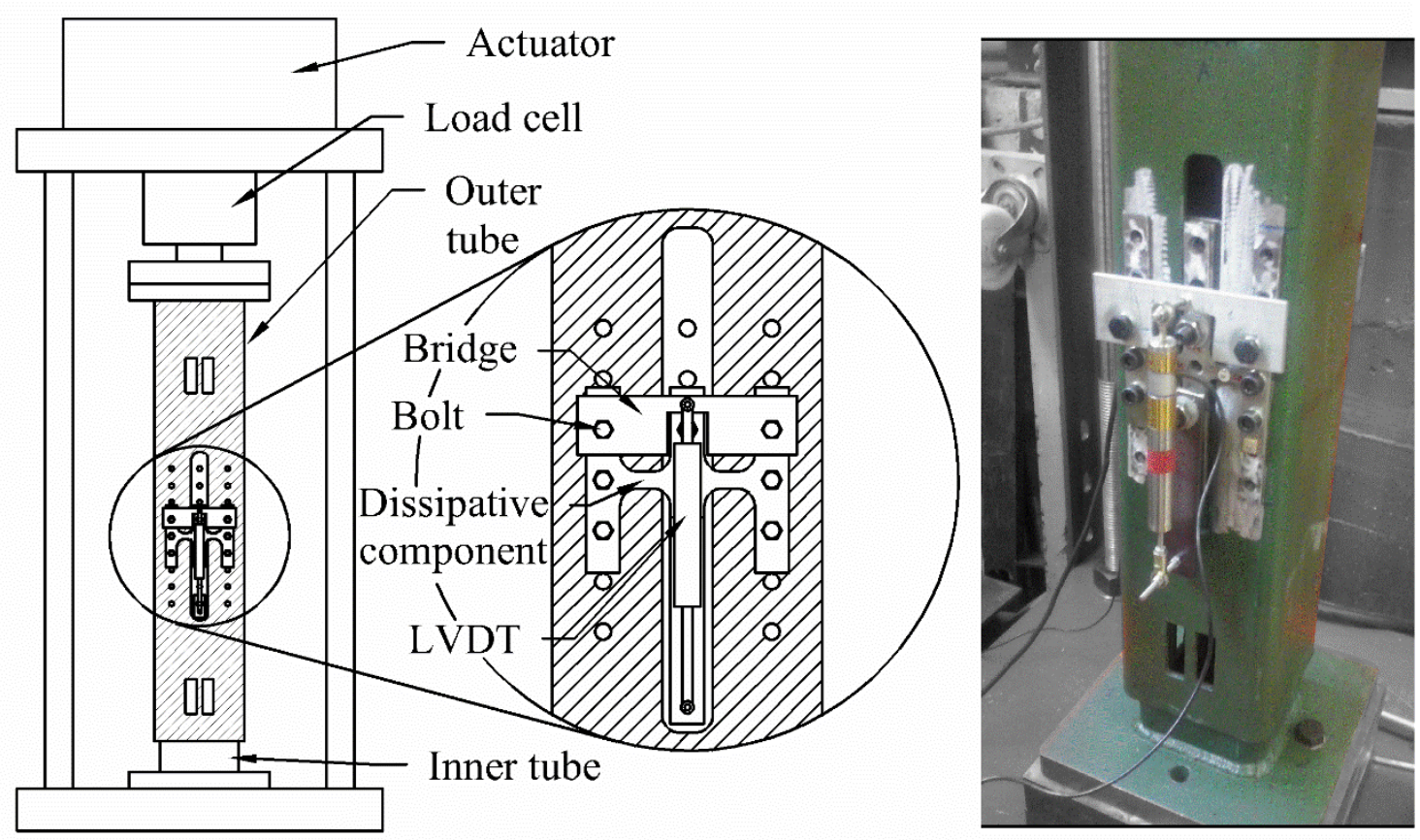

Figure 6. 4. Experimental setup used during the cyclic tests 
The servopulser actuator situated at the top of the test machine applied a quasi-static loading to force vertical displacements. A load cell installed also at the top measured the applied force and two displacements transducers (LVDT), one at each face, measured the relative displacement between external an internal flanges in the direction of the applied load. The test specimens were subjected to displacement-control cyclic test that caused relative displacements between exterior and interior flanges and induced different levels of damage in the strips. Figure 6.5 depicts the deformation pattern of the specimens as a consequence of the relative displacements. The hatched area indicates the approximated region where plastic deformation took place.

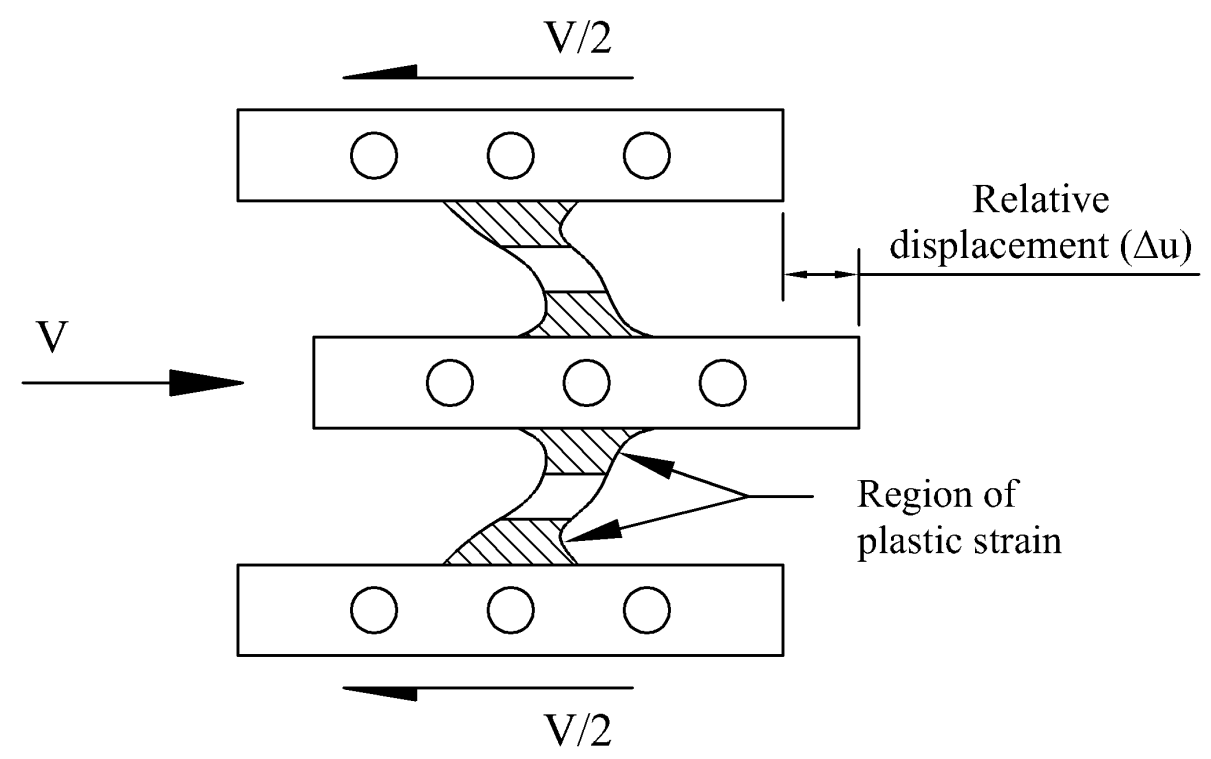

Figure 6. 5. Relative displacement between external and internal flanges

All test specimens were subjected to sine cycles of increasing amplitude of $0.4 \mathrm{~mm}$. The frequency of the cyclic test was $0.05 \mathrm{~Hz}$, which has a significant influence on the stainless steel. Concretely, the yield stress increases as long as the frequency increases, while the Young's modulus remains basically the same. The low cycle fatigue life increases as decreasing frequency. Each test specimen was subjected to a number of cycles larger than its predecessor, in order to induce a different levels of damage. Figure 6.6 shows the displacement imposed and summarizes, by means of a bar diagram, the number of cycles (in brackets) and the time required for each test.

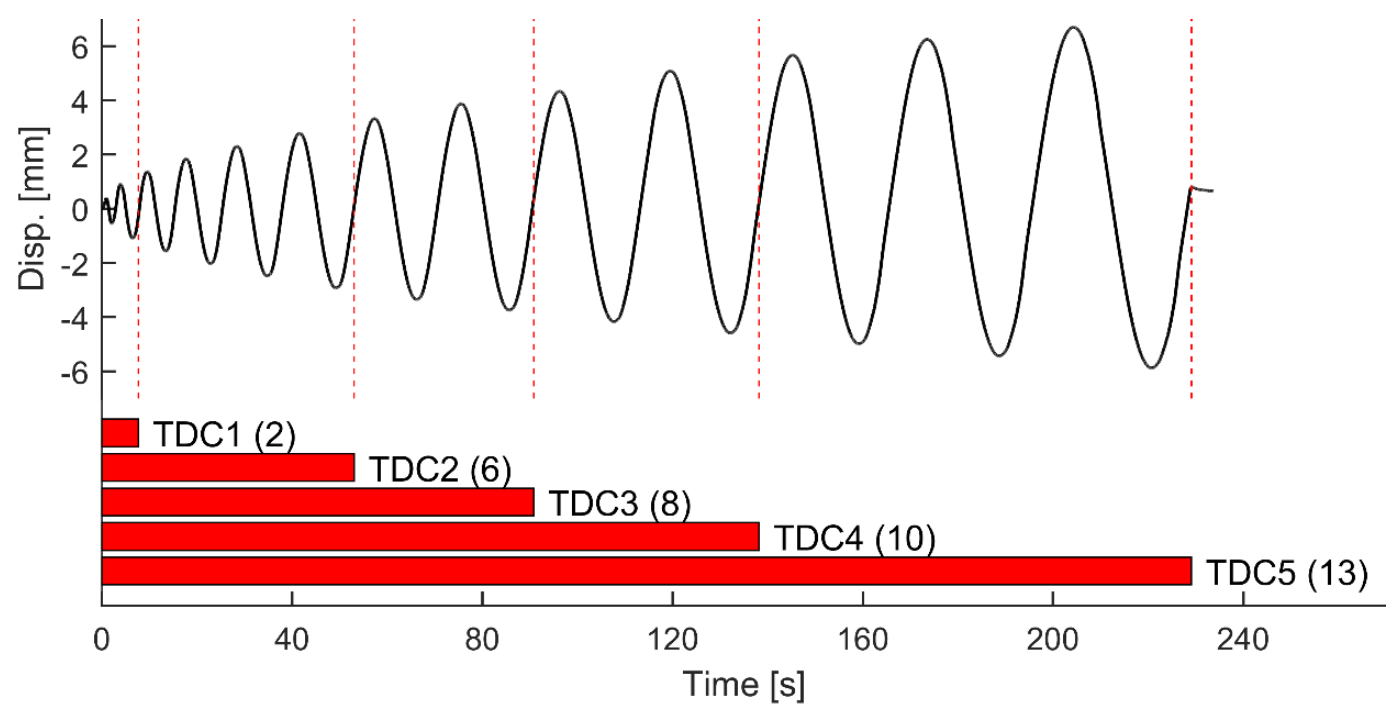

Figure 6. 6. Displacement-control applied to specimens TDC1 to TDC5 


\section{MECHANICAL INDEX OF DAMAGE}

The typical force-displacement curve ( $Q-\delta$ curve hereafter) obtained by testing of a metallic damper under cyclic loading until failure is depicted in Figure 6.7. The failure of the device is assumed to occur when a steadily decrease in the force response starts to be visible in the $Q-\delta$ curve whereas the control system continues increasing displacements. The integration of the curve gives the total amount of plastic strain energy, provided that the system is unloaded at the end of the test. This energy corresponds to the total energy dissipated, since the energy dissipated by damping in a quasi-static test is negligible. This energy can be decomposed in the energy consumed in the skeleton part and the energy consumed in the softened part of the curve by Bauschinger effect, Bauschinger part herein (Kato et al, 1973, Benavent-Climent, A., 2007). The skeleton part is formed by sequentially connecting the segments of the $Q-\delta$ curve that exceed the load level attained in preceding cycles in the same domain of loading. Using Figure 6.7, this means to connect sequentially the segments labeled as $0-1,5-6,11-12,17-18,23-24$ and 29-30 in the positive domain, and 2-3, 8-9, 14-15, 20-21 and 26-27 in the negative domain.

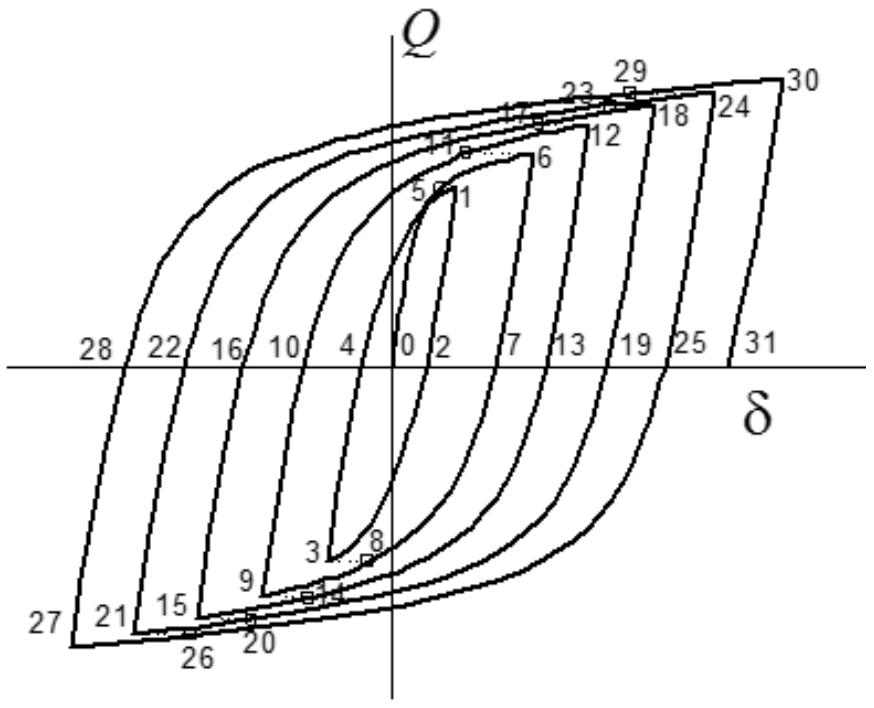

Figure 6. 7. Typical $Q-\delta$ curve

Taking these segments out from the $Q-\delta$ curve and putting them in series in a graph, this gives the curve shown in Figure 6. 8.

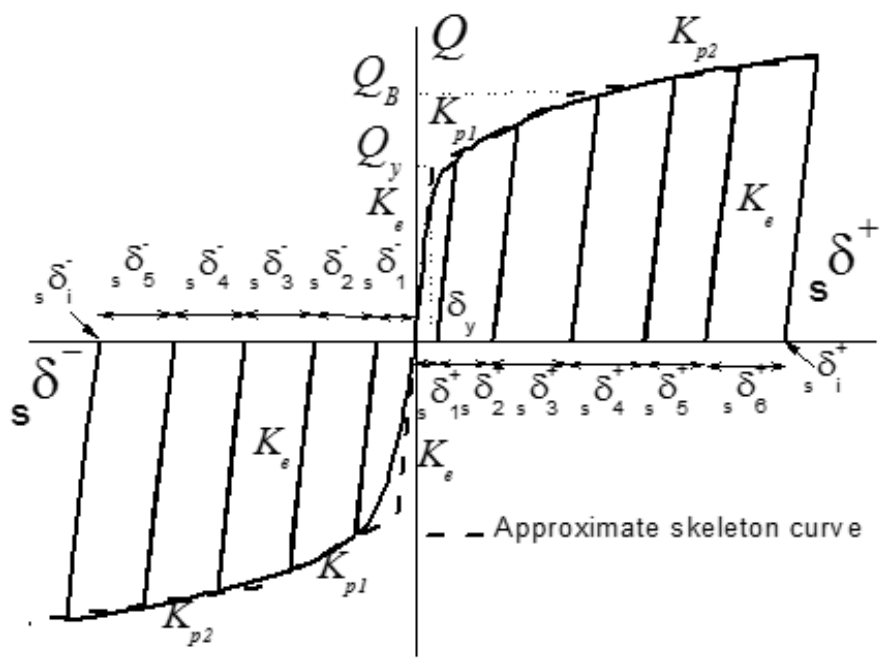

Figure 6. 8. Decomposition in skeleton part 
As shown in previous studies (Benavent-Climent, A., 2007), the positive and negative skeleton curves can be simplified as a trilinear curve (plot with dash line in Figure 6. 8), which is characterized by the yield force $Q_{y}$, the yield displacement $\delta_{y}$, the initial stiffness $K_{e}=Q_{y} / \delta_{y}$, the force corresponding to the onset of the second segment $Q_{B}$, the first plastic stiffness $K_{p 1}$ and the second plastic stiffness $K_{p 2}$. For slit-plate dampers, $\delta_{y}$ and $Q_{y}$ can be easily estimated from the geometry and the mechanical properties of the steel with the following equations based on the fundamental principles of the strength of materials:

$$
\begin{gathered}
Q_{y}=\min \left\{n \frac{f_{y} t w^{2}}{2 h^{\prime}}, n \frac{2 f_{y} t w}{3 \sqrt{3}}\right\} \\
Q_{B}=\min \left\{n \frac{f_{B} t w^{2}}{2 h^{\prime}}, n \frac{2 f_{B} t w}{3 \sqrt{3}}\right\} \\
\delta_{y}=\frac{Q_{y} h^{\prime 3}}{n E t w^{3}}\left(1+3 \ln \frac{h+2 r}{h^{\prime}}\right)+\frac{3 Q_{y} h^{\prime}}{2 n t w G}\left(1+\ln \frac{h+2 r}{h^{\prime}}\right)
\end{gathered}
$$

Where $w$ and $h$ are the width and the height of the strip, respectively, $r$ is the radius of the end part of the strip (Figure 6.2b), $t$ is the thickness of the plate, $n$ is the total number of the strips and $h^{\prime}$ is a modified height defined as $h^{\prime}=h+\left(2 r^{2} /(h+2 r)\right)$. The positive and negative maximum displacements in the skeleton part are denoted hereafter as ${ }_{S} \delta_{i}^{-}$and ${ }_{S} \delta_{i}^{+}$. Kato et al. (1973) decomposed the stress-strain curve of a steel specimen subjected to cyclic loading and found that the skeleton curve coincides approximately with the stress-strain curve obtained under monotonic loading. This applies also to the $Q-\delta$ curve since it is basically a geometric transformation of the stress-strain relationship of the material. For each domain of loading, the area under the skeleton curve up to a given point $\left(\delta_{i}, Q_{i}\right)$ is the energy consumed on the skeleton part, which are denoted as ${ }_{s} W_{i}^{-}$and ${ }_{s} W_{i}^{+}$for negative a positive domain, respectively. In Figure 6.7, segments 4-5, 10-11 and 16-17, 22-23 and 28-29 in the positive domain, and 7-8, 13-14,19-20,25-26 in the negative domain of loading are the segments that form the Bauschinger part of the curve (Figure 6.9).

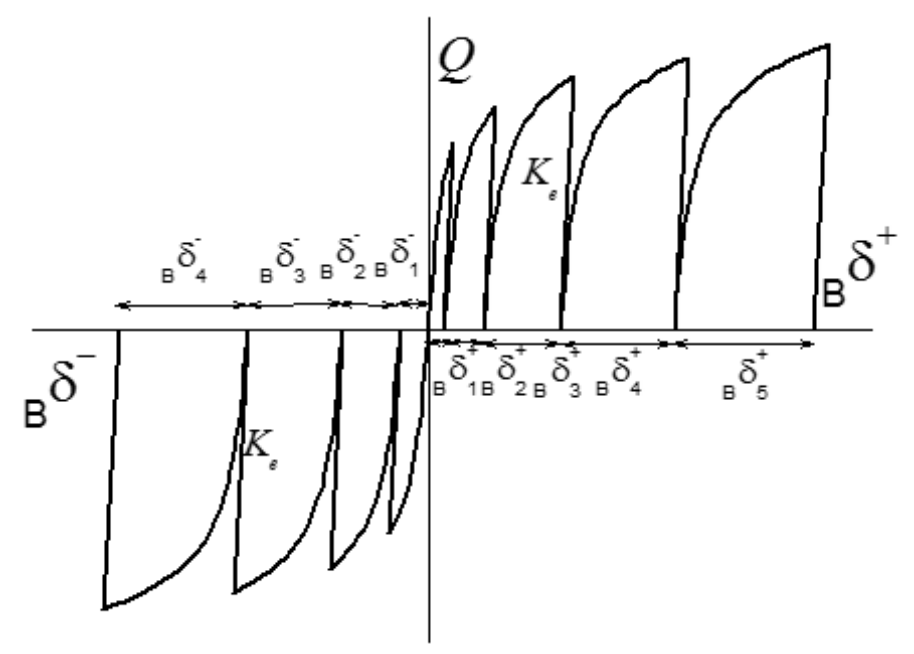

Figure 6. 9. Decomposition in Bauschinger part

These segments begin at zero load $(Q=0)$ and finish when the load overcomes the last maximum committed in preceding cycles in the same domain of loading. Additionally, an unloading segment 
with a slope equal to the initial stiffness $K_{e}$ is added at the end of each segment. For each domain of loading, the sum of the areas enclosed under the Bauschinger part curve up to a given point $\left(\delta_{i}, Q_{i}\right)$ refers to the energy consumed on the Bauschinger part and they are denoted as ${ }_{B} W_{i}^{-}$and ${ }_{B} W_{i}^{+}$for negative a positive domain, respectively. For convenience, these energies are expressed non-dimensionally as follows:

$$
\begin{aligned}
& { }_{s} \eta_{i}^{-}=\frac{{ }_{s} W_{i}^{-}}{Q_{y} \delta_{y}} ; \quad{ }_{s} \eta_{i}^{+}=\frac{{ }_{s} W_{i}^{+}}{Q_{y} \delta_{y}} ; \\
& { }_{B} \eta_{i}^{-}=\frac{{ }_{B} W_{i}^{-}}{Q_{y} \delta_{y}} ; \quad{ }_{B} \eta_{i}^{+}=\frac{{ }_{B} W_{i}^{+}}{Q_{y} \delta_{y}} ;
\end{aligned}
$$

The sum of ${ }_{S} W_{i}^{+}+{ }_{B} W_{i}^{+}$in the positive domain, and ${ }_{s} W_{i}^{-}+{ }_{B} W_{i}^{-}$in the negative domain, constitute the total plastic energy dissipated by the damper in each domain of loading.

$$
\eta_{i}^{-}=\frac{{ }_{s} W_{i}^{-}+{ }_{B} W_{i}^{-}}{Q_{y} \delta_{y}} ; \eta_{i}^{+}=\frac{{ }_{s} W_{i}^{+}+{ }_{B} W_{i}^{+}}{Q_{y} \delta_{y}}
$$

Moreover, the maximum displacements in the skeleton part, ${ }_{S} \delta_{i}^{-}$and ${ }_{S} \delta_{i}^{+}$, can be normalized as follows:

$$
{ }_{e p} \eta_{i}^{-}=\frac{{ }_{S} \delta_{i}^{-}}{\delta_{y}} ; \quad{ }_{e p} \eta_{i}^{+}=\frac{{ }_{S} \delta_{i}^{+}}{\delta_{y}}
$$

The failure of metallic dampers subjected to flexural/shear deformations without axial forces can be estimated in terms of energy for each domain of loading calculating the ultimate values of $\eta_{i}^{-}$ and $\eta_{i}^{+}$, which are denoted hereafter as $\eta_{u}^{-}$and $\eta_{u}^{+}$. They represent the (normalized) ultimate energy dissipation capacity of the damper in the positive and negative domain of loading. Benavent-Climent (2007) showed that they are path dependent parameters, i.e., $\eta_{u}^{-}$and $\eta_{u}^{+}$vary with ${ }_{S} \eta_{i}^{-},{ }_{s} \eta_{i}^{+},{ }_{B} \eta_{i}^{-}$and ${ }_{B} \eta_{i}^{+}$and proposed the following expression:

$$
\begin{aligned}
\eta_{u}=\frac{7.33 m}{m-1}\left\{\chi_{2}\right. & +\frac{1}{k_{p 2}}\left(\frac{7.33}{m-1}-\sqrt{\left(\frac{7.33}{m-1}\right)^{2}+\frac{7.33 k_{p 2} m \chi_{2}}{0.5(m-1)}--b k_{p 2}+\left(\tau_{B}-7.33\right)^{2} \frac{k_{p 1}-k_{p 2}}{k_{p 1}}}\right. \\
& \left.\left.+\frac{40.07 k_{p 2}}{k_{p 1}}-53.73\right)\right\}
\end{aligned}
$$

Where $\chi_{2}$ is defined in (6.9), $\tau_{B}=f_{B} / f_{y}, m=(1+p) /(0.39+1.09 p)$ where $p=N /\left(f_{y} A\right)$ (here $N$ is the axial force, $f_{y}$ is the yield stress of the steel and $A$ is the strip cross area). Further, the normalized slopes $k_{p 1}$ and $k_{p 2}$ are defined as $k_{p 1}=K_{p 1} / K_{e}$ and $k_{p 2}=K_{p 2} / K_{e}$.

$$
\chi_{2}=\frac{{ }_{s} \eta_{i}}{7.33}-\frac{\eta_{i}}{7.33 m}-\frac{\tau_{B}-1}{k_{p 1}}+\frac{\tau_{B}}{k_{p 2}}+\frac{b}{14.66}
$$

Where ${ }_{s} \eta_{i}$ and $\eta_{i}$ must be taken equal to ${ }_{s} \eta_{i}^{-}$and $\eta_{i}^{-}$to obtain $\eta_{u}^{-}$, and equal to ${ }_{s} \eta_{i}^{+}$and $\eta_{i}^{+}$to calculate $\eta_{u}^{+}$. Finally, $b$ is an empirical parameter which is determined by testing a damper under cyclic loading up to failure (Benavent-Climent, A., 2007), as follows: 


$$
b=\left({ }_{B} \eta_{u}^{+}+7.33_{e p} \eta_{u}^{+}\right)+\left({ }_{B} \eta_{u}^{-}+7.33_{e p} \eta_{u}^{-}\right)
$$

Where ${ }_{B} \eta_{u}^{+},{ }_{e p} \eta_{u}^{+},{ }_{B} \eta_{u}^{-}$and ${ }_{e p} \eta_{u}^{-}$are the values of ${ }_{B} \eta_{i}^{+},{ }_{e p} \eta_{i}^{+},{ }_{B} \eta_{i}^{-}$and ${ }_{e p} \eta_{i}^{-}$for a specimen tested until failure. The level of damage in a metallic damper subjected to arbitrary applied cyclic loading up to a point $\left(\delta_{i}, Q_{i}\right)$ can be computed using the following index of damage $I D_{i}$ proposed by Benavent-Climent (2007):

$$
I D_{i}=\max \left\{\frac{\eta_{i}^{-}}{\eta_{u}^{-}}, \frac{\eta_{i}^{+}}{\eta_{u}^{+}}\right\}
$$

The index damage $I D_{i}$ has been validated with extensive experimental results (Benavent-Climent, A., 2007). The value $I D_{i}=0$ means no damage, while $I D_{i} \geq 1$ means failure. After failure $\left(I D_{i} \geq 1\right)$, the damper is still able physically to absorb some energy but the strength goes down.

\section{EXPERIMENTAL RESULTS}

Figures 6.10 to 6.14 show the $Q-\delta$ curves, the values of the mechanical index of damage $I D_{i}$ and the paths followed in the plane ${ }_{s} \eta-\eta$ obtained from the cyclic tests. In regards to the $Q-\delta$ curves, due to the strain hardening of the material, the amplitude of the loops along the vertical axis increases in each consecutive cycle. The shape of the hysteretic loops informs that the slitplate damper exhibits stable energy dissipation characteristics. On the other hand, paths followed in the plane ${ }_{s} \eta-\eta$ are necessary to obtain the mechanical index of damage, $I D_{i}$. Firstly, the skeleton part and the Bauschinger part were obtained for each test, as illustrates Figure 6.15, which shows this decomposition for the specimen TDC5 (this is the only specimen that was tested until failure). Then, the values of ${ }_{s} \eta_{i}^{-},{ }_{B} \eta_{i}^{-},{ }_{e p} \eta_{i}^{-},{ }_{s} \eta_{i}^{+},{ }_{B} \eta_{i}^{+}$and ${ }_{e p} \eta_{i}^{+}$were obtained, whose last values of ${ }_{B} \eta_{i}^{-},{ }_{e p} \eta_{i}^{-},{ }_{B} \eta_{i}^{+}$and ${ }_{e p} \eta_{i}^{+}$were used to calculate $b$ through (6.10), which, for this hysteretic damper, took the value $b=7615$. After that, the ultimate capacity of the specimens was calculated by (6.8), in which $m=2.56, \chi_{2}=884.7, \tau_{B}=2.6957, k_{p 1}=0.0369$ and $k_{p 2}=$ 0.0068 , what resulted in the values of $\eta_{u}^{+}=2543$ and $\eta_{u}^{-}=2529$. Finally, the mechanical index of damage $I D_{i}$ was calculated through (6.11) for each specimen and results are shown in Figures 6.10 to 6.14 in the middle of plot $b$ ).
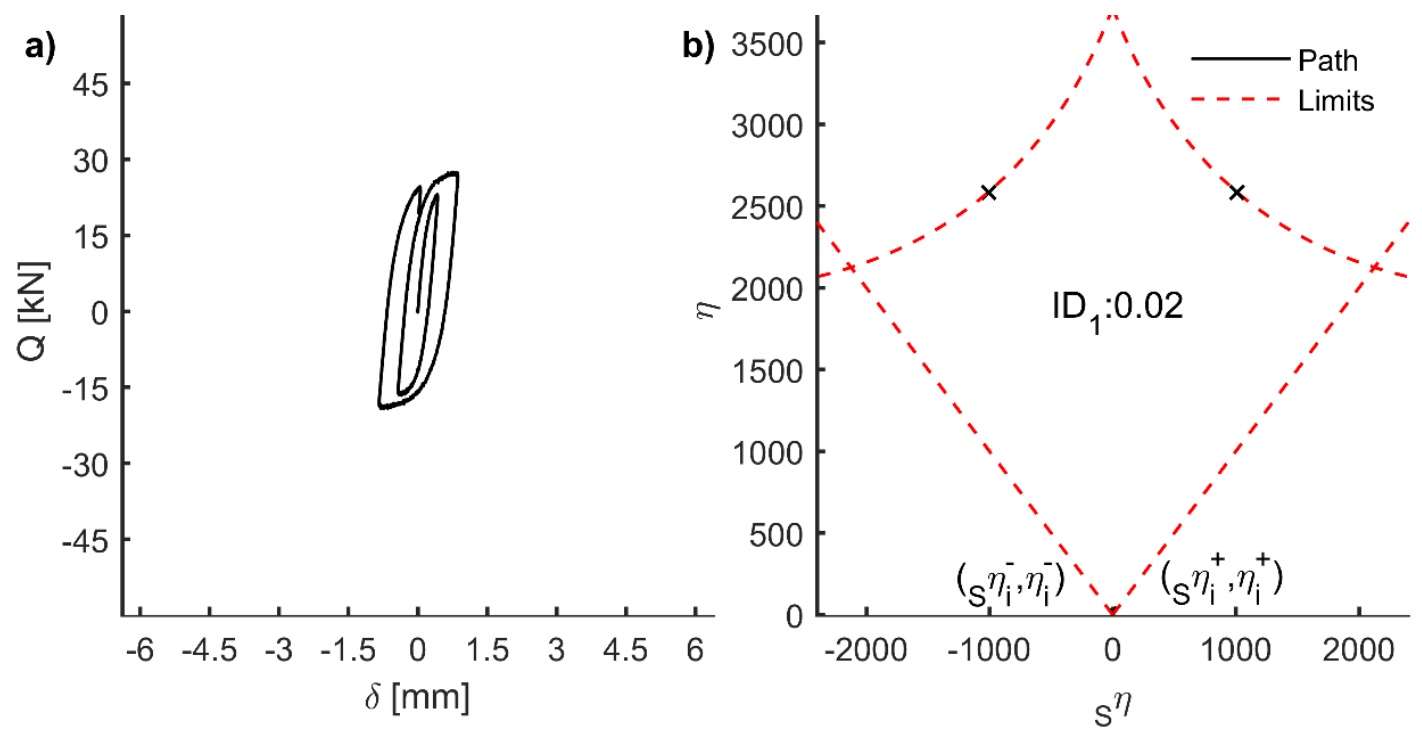

Figure 6. 10. TDC1: a) $Q-\delta$ curve and b) ID and the path followed in plane ${ }_{s} \eta-\eta$ 

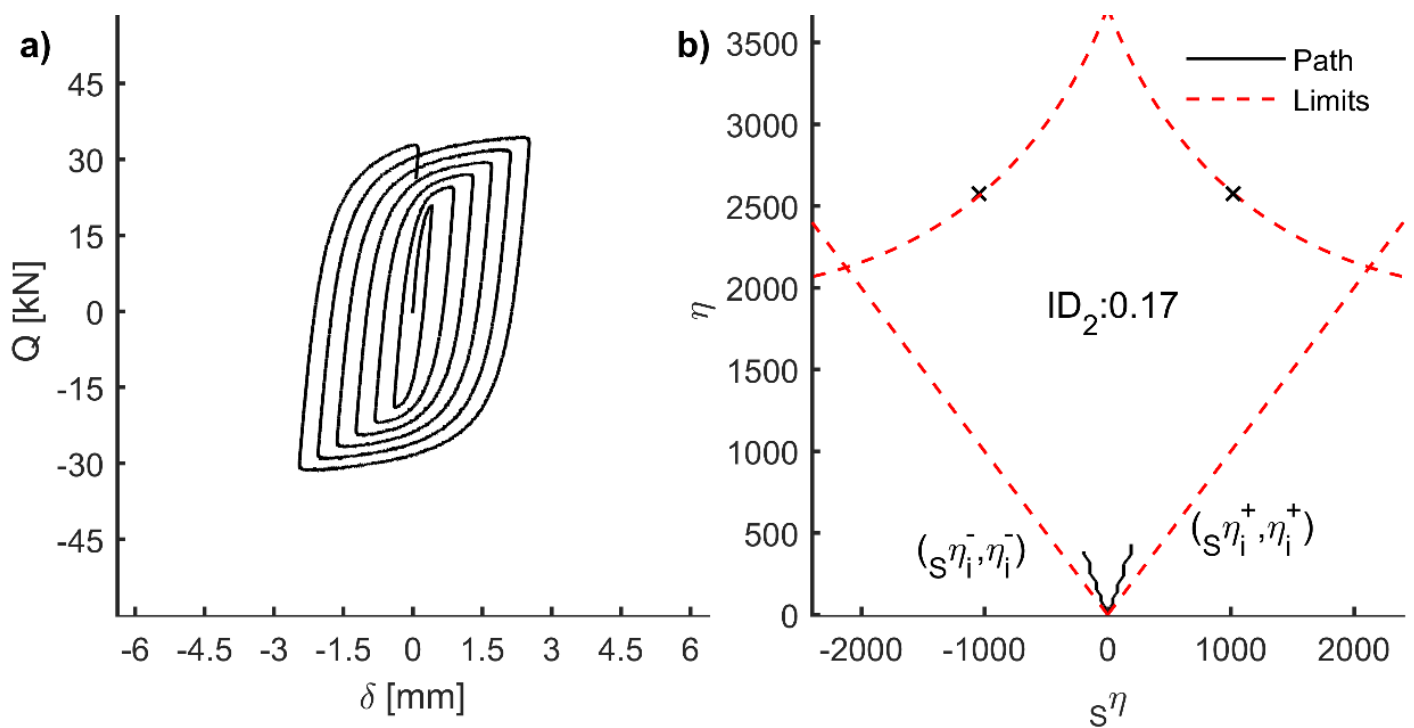

Figure 6. 11. TDC2: a) $Q-\delta$ curve and b) ID and the path followed in plane ${ }_{s} \eta-\eta$
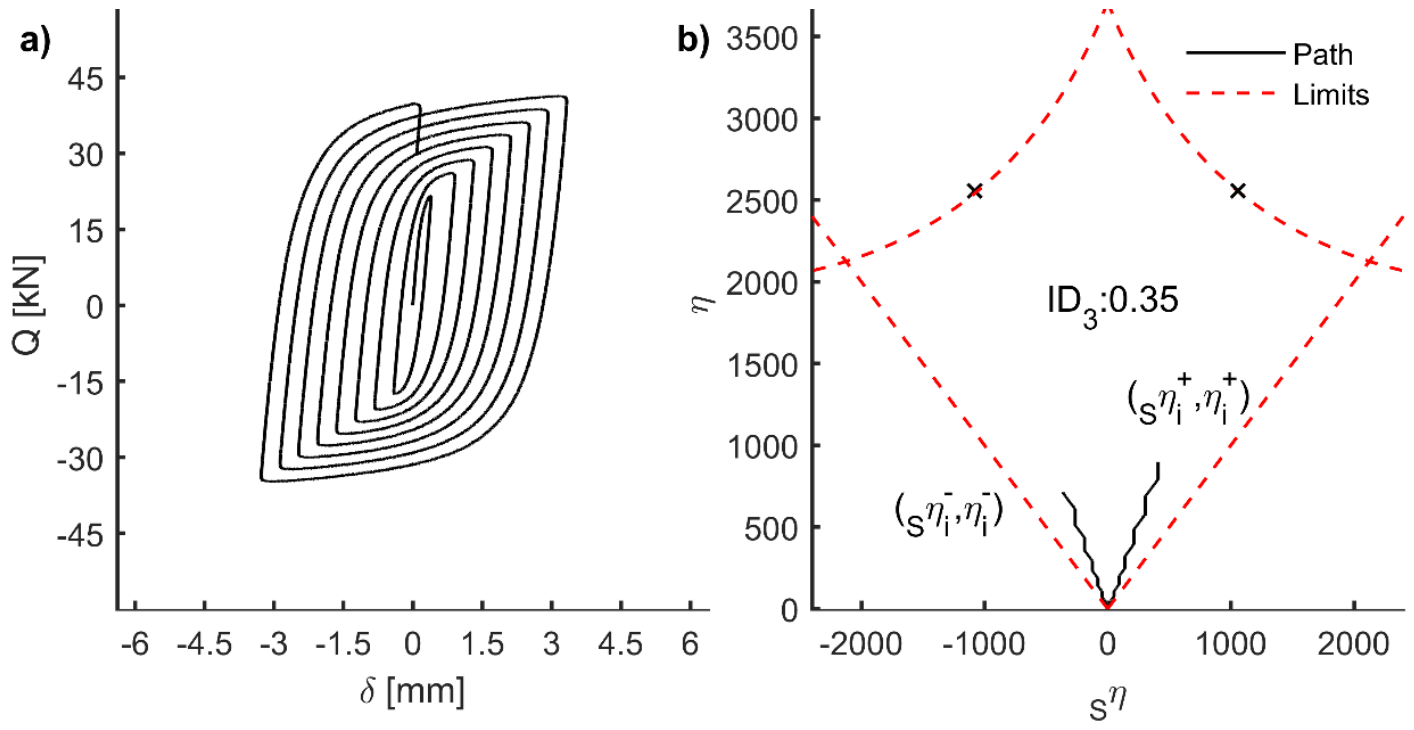

Figure 6. 12. TDC3: a) $Q-\delta$ curve and b) ID and the path followed in plane ${ }_{s} \eta-\eta$
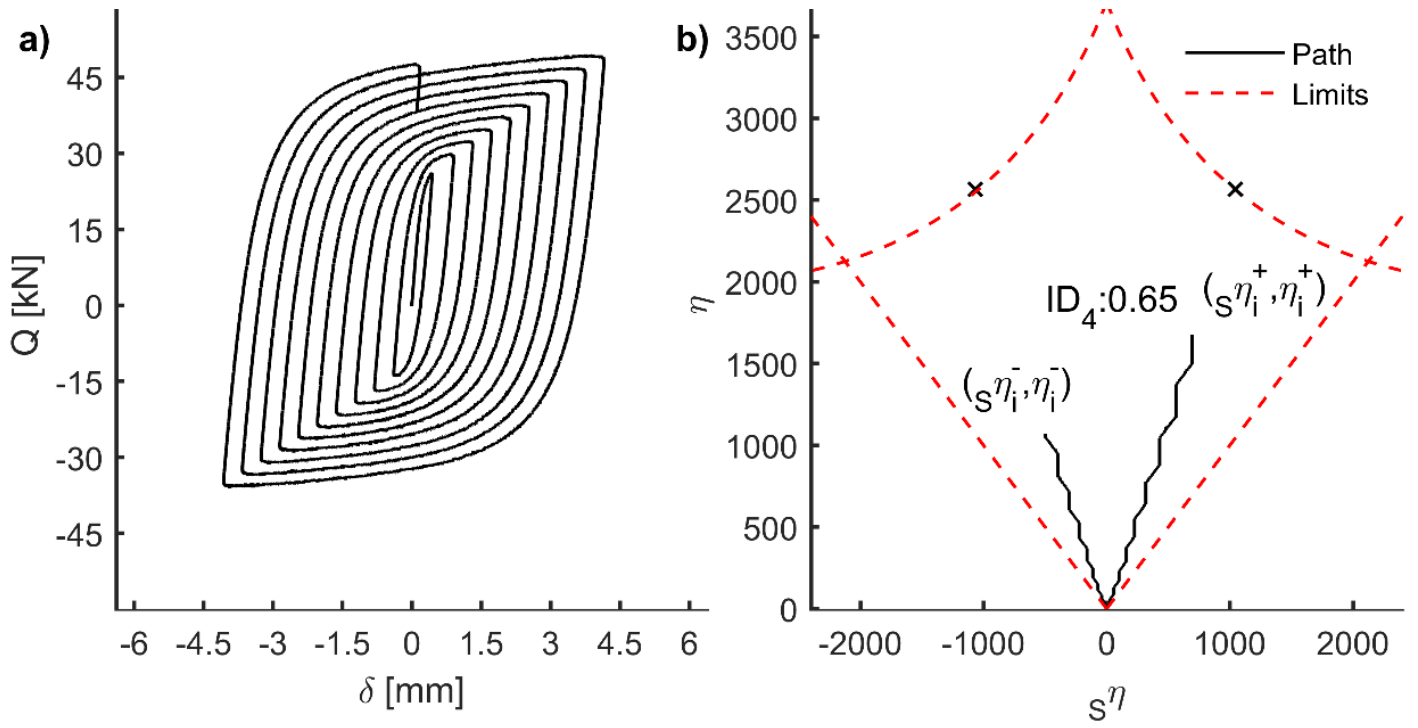

Figure 6. 13. TDC4: a) $Q-\delta$ curve and b) ID and the path followed in plane ${ }_{s} \eta-\eta$ 

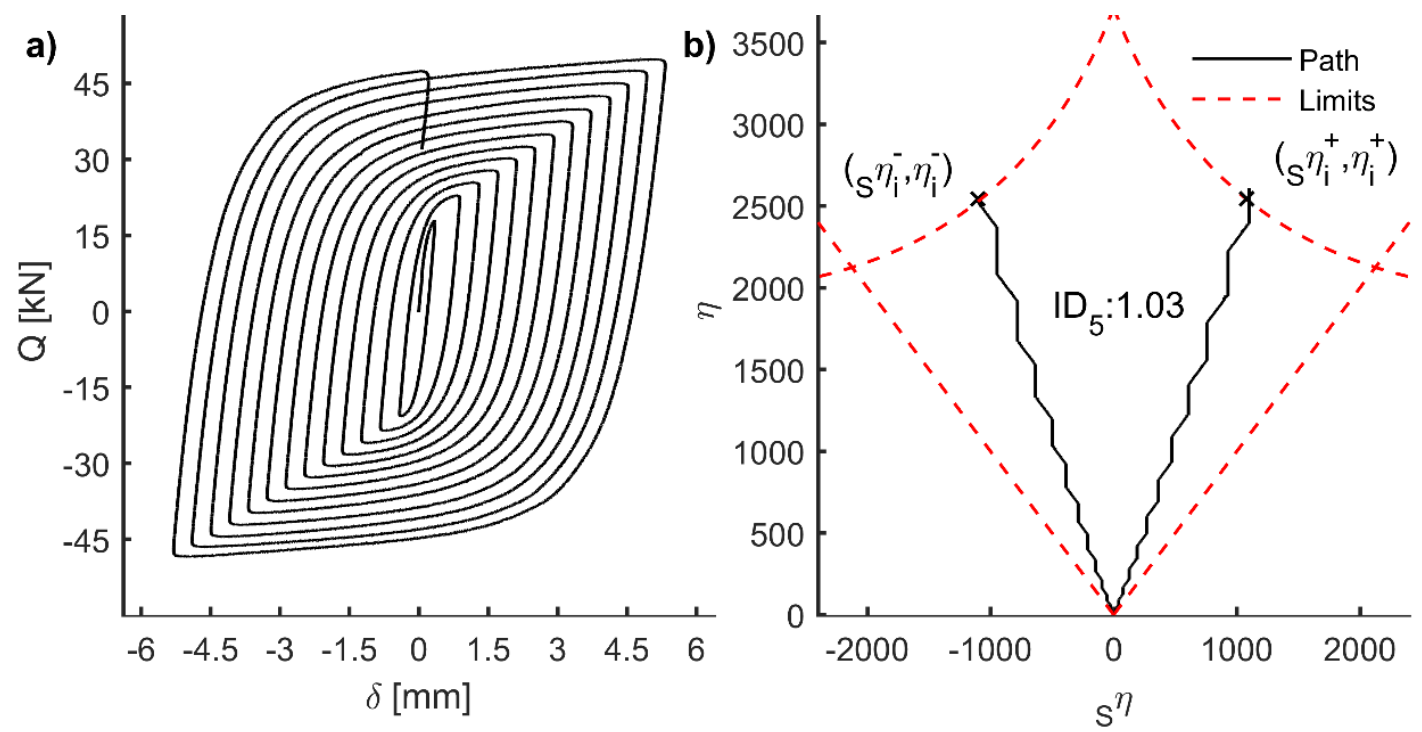

Figure 6. 14. TDC5: a) $Q-\delta$ curve and b) ID and the path followed in plane ${ }_{s} \eta-\eta$

a)

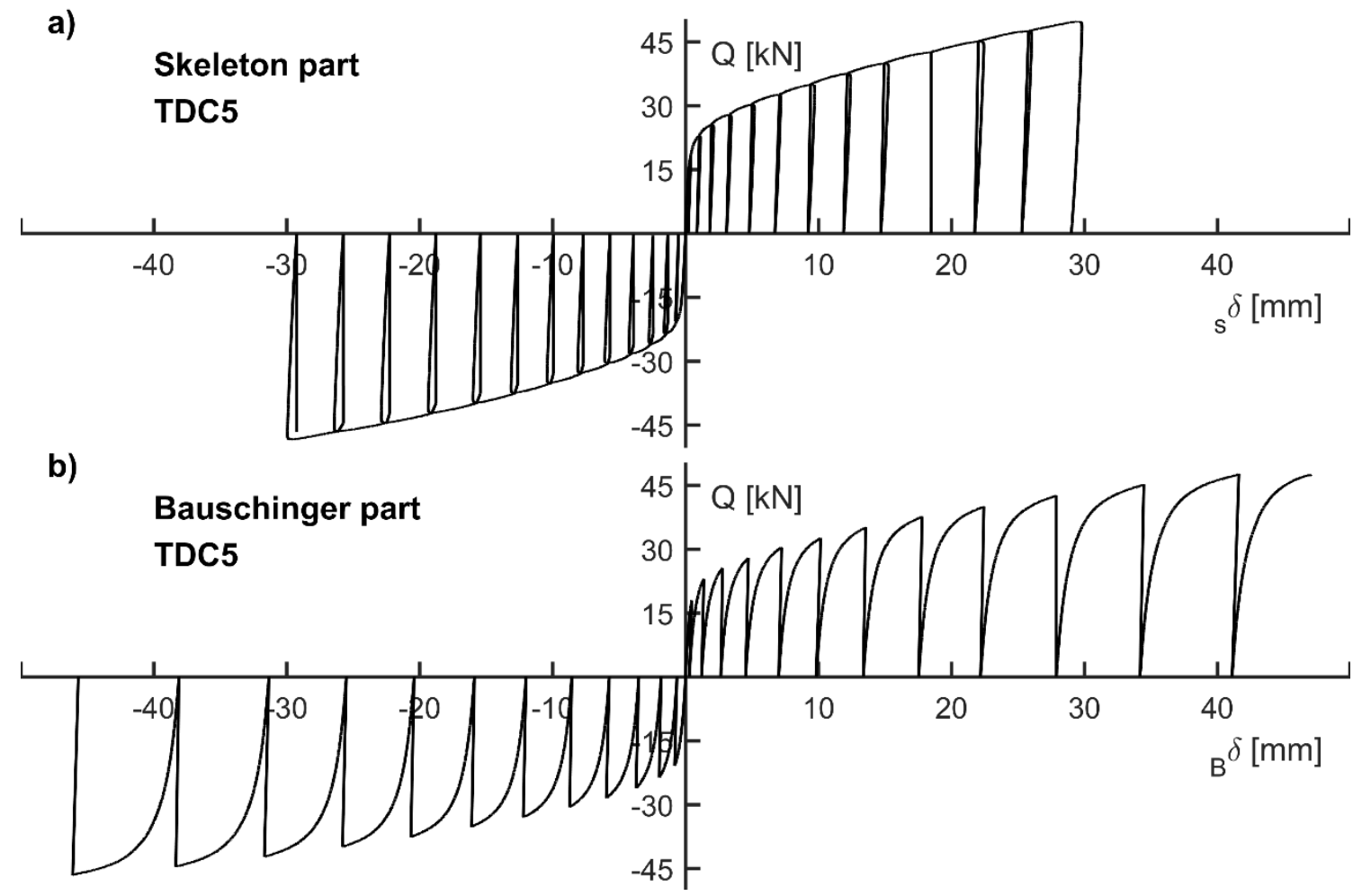

Figure 6. 15. Decomposition of the cyclic curve of specimen TDC5 into: a) Skeleton part and b) Bauschinger part

\section{NUMERICAL MODEL FOR SLIT-PLATE DAMPERS}

A numerical model of the slit-plate damper described in previous section was developed and calibrated with the results of the tests. This numerical model was implement in the benchmark model of the WFP structure described in Chapter 5 to conduct non-linear response history analyses. The numerical model of the damper consisted of a nonlinear spring whose hysteretic 
behavior followed the Giuffré-Menegotto-Pinto model with isoparametric strain hardening (Filippou, Bertero, \& Popov, 1983) implemented in Opensees as Uniaxial Material Steel02. This model was calibrated to reproduce the hysteretic curves (cyclic tests) from specimen TDC5. The material properties are listed in Table 6.1 following the parameters used in Opensees Manual (Mazzoni, McKenna, Scott, \& Fenves, 2006). Figure 6.16 depicts the superposition of the $Q-\delta$ curve for the specimen TDC5 and the numerical calibrated model.

Table 6. 1. Calibrated nonlinear spring to simulate the slit-plate damper tested

\begin{tabular}{cccccccccccc}
\hline $\begin{array}{l}\text { Uniaxial } \\
\text { Material }\end{array}$ & $\begin{array}{c}\mathrm{Fy} \\
{[\mathrm{kN}]}\end{array}$ & $\begin{array}{c}\mathrm{E} \\
{[\mathrm{GPa}]}\end{array}$ & $\mathrm{b}$ & $\mathrm{R} 0$ & $\mathrm{cR} 1$ & $\mathrm{cR} 2$ & $\mathrm{a} 1$ & $\mathrm{a} 2$ & $\mathrm{a} 3$ & $\mathrm{a} 4$ & sigInit \\
\hline Steel02 & 16 & 100 & 0.005 & 22.0 & 0.925 & 0.15 & 0.13 & 1.0 & 0.13 & 1.0 & 0.0 \\
\hline \hline
\end{tabular}

The ratios $Q_{y} / F_{y}$ and $K_{e} / E$ that correlate the Giuffré-Menegotto-Pinto model's yield stress $\left(F_{y}\right)$ with the predicted yield stress $Q_{y}(6.1)$ and the model's stiffness $(E)$ with the predicted stiffness $K_{e}$ using (6.1) and (6.3) are equal to 0.68 . The index of damage $I D_{i}$ estimated with the calibrated numerical model gives 1.03 , which is the same that the $I D_{5}$ calculated experimentally.

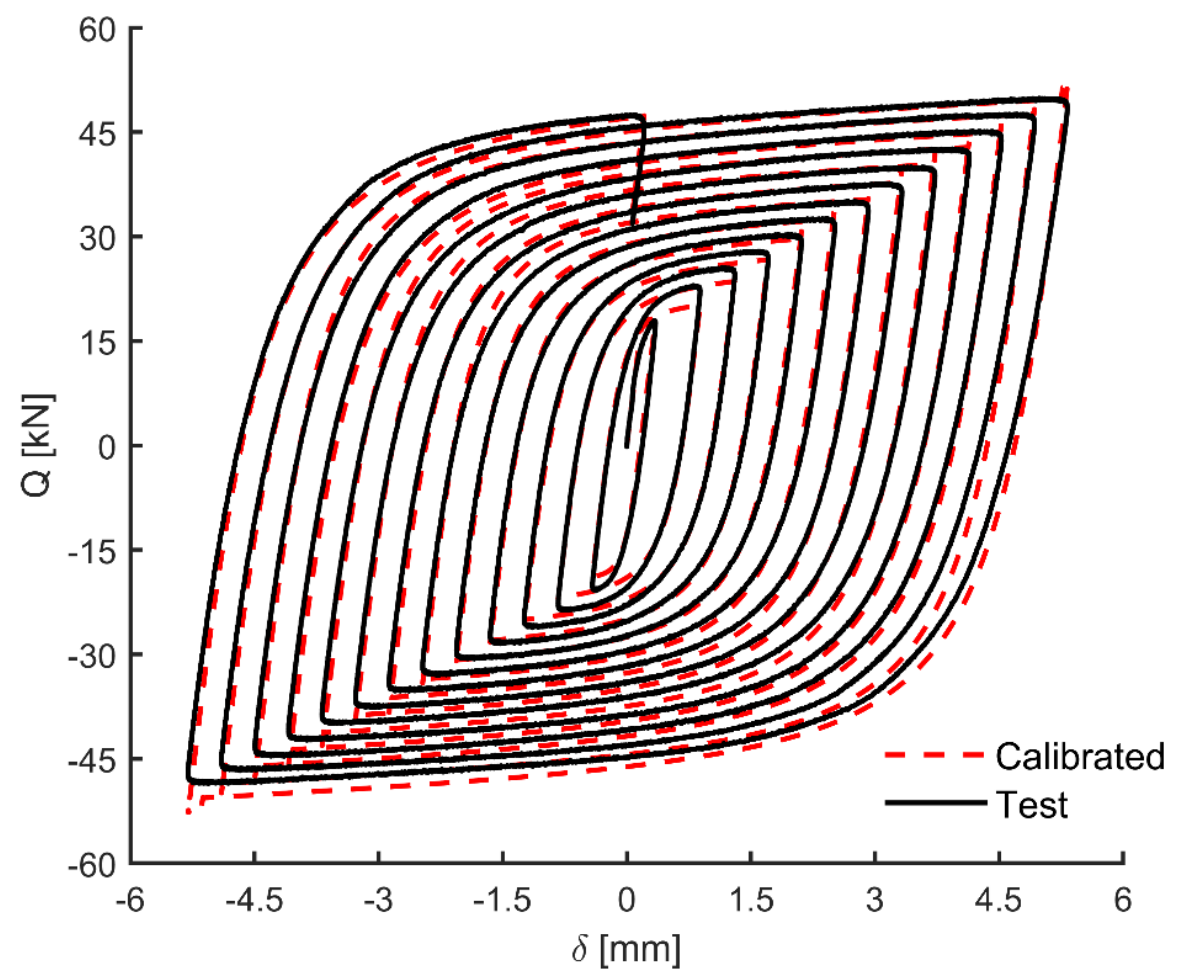

Figure 6. 16. Superposition of the $Q-\delta$ curve for the specimen TDC5 (Test and calibrated model)

\section{DESIGN AND IMPLEMENTATION OF SLIT-PLATE DAMPERS IN SPECIMEN BS1}

The dampers installed in specimen BS1 were designed based of the following considerations:

1. Only one type of damper per story, independently of its location.

2. The layout of the dampers must reduce the eccentricity between center of mass and center of stiffness. 
3. The lateral shear strength provided by the dampers installed in the $i$-th story, ${ }_{s} Q_{y, i}$, does not exceed the $50 \%$ of the lateral strength of the main structure (i.e. the WFP structure) as recommended the standard ASCE-SEI/41-13 (2014). In the first story, the lateral strength of the dampers is made equal to $50 \%$ of the lateral strength of the main structure. In the rest of stories, the yield-strength follows the optimum distribution implemented in the Building Standard Law of Japan (JBC, 2009).

4. The yield displacement of dampers, $\delta_{s}, i$, equals to the $40 \%$ of the yield displacement of the main structure $\left({ }_{s} \delta_{y, i}=0.4{ }_{f} \delta_{y, i}\right)$ as recommend (Benavent-Climent, Amadeo, Donaire-Avila, \& Oliver-Sáiz, 2018; Oviedo, Midorikawa, \& Asari, 2010).

Figure 6.17 shows a detail of the layout of the dampers at the first story in the WFP system, placed between column ends.

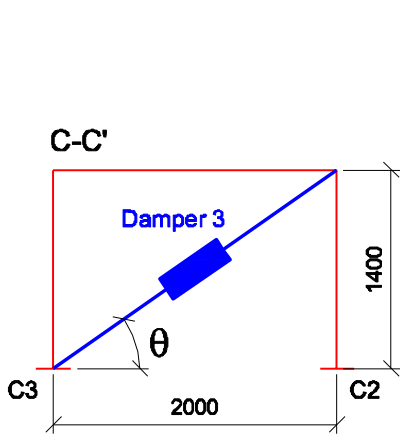

Dimensions in $\mathrm{mm}$

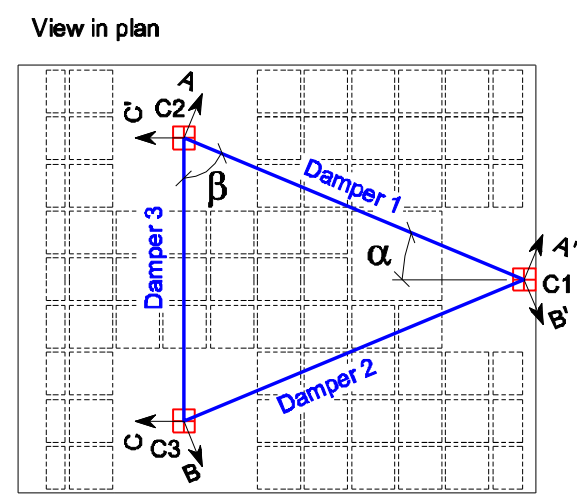

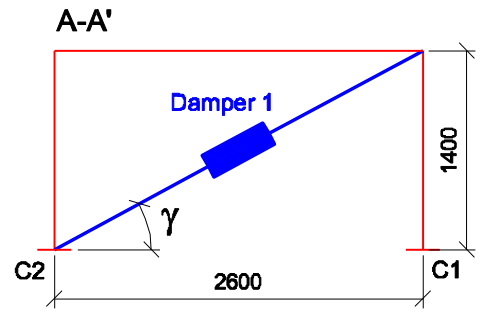

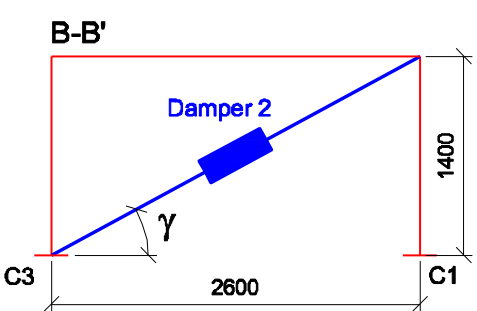

Figure 6. 17. Layout of dampers at the first story

The procedure to design dampers starts with the dampers located at the first story, whose yieldstrength was determined following the criteria proposed by the standard ASCE-SEI/41-13 (2014), which establishes a base shear for the dampers equal, at most, to the $50 \%$ of the main structure. The base shear strength of WFP specimen tested in laboratory in X and Y directions, ${ }_{f} Q_{y X, 1}$ and ${ }_{f} Q_{y Y, 1}$, were $57.5 \mathrm{kN}$ and $62.5 \mathrm{kN}$, respectively, obtained in each case as the mean of the positive and negative maximum values achieved on each deformation domain (Chapter 4). These results were corroborated by the pushover analysis carried out in the numerical model of the WFP specimen. Therefore, the base shear of the dampers in $\mathrm{X}$ and $\mathrm{Y}$ directions, ${ }_{s} Q_{y X, 1}$ and ${ }_{s} Q_{y Y, 1}$, was limited to $28.75 k N$ and $31.25 k N$, respectively. Then, the axial yield strength of the dampers at the first story, ${ }_{s} N_{y, 1}$, can be obtained for $\mathrm{X}$ and $\mathrm{Y}$ directions, ${ }_{s} N_{y X, 1}$ and ${ }_{s} N_{y Y, 1}$, respectively, as follows. For $\mathrm{X}$ direction, ${ }_{s} Q_{y X, 1}$ is equated to the sum of the $\mathrm{X}$-components of axial force for the dampers 1 and 2, through the expression ${ }_{s} Q_{y X, 1}=2{ }_{s} N_{y X, 1} \cos \alpha \cos \gamma$ giving ${ }_{s} N_{y X, 1}=17.72 k N$. For $\mathrm{Y}$ direction, by adding the Y-components of axial force for the three dampers and equating the result to ${ }_{s} Q_{y Y, 1}$ through the expression ${ }_{s} Q_{y Y, 1}={ }_{s} N_{y Y, 1}(\cos \theta+$ $2 \cos \beta \cos \gamma$ ), yielding ${ }_{s} N_{y Y, 1}=20.93 \mathrm{kN}$. Finally, the value adopted for ${ }_{s} N_{y, 1}$ is the minimum of both directions, i.e. ${ }_{s} N_{y, 1}=\min \left\{{ }_{s} N_{y X, 1},{ }_{s} N_{y Y, 1}\right\}=17.72 \mathrm{kN}$, which fulfills with the limitation of the base shear strength of the dampers stated before. Furthermore, the yield displacement for the dampers, $\delta_{y, 1}$, was limited to $0.4{ }_{f} \delta_{y, 1}$ (Benavent-Climent, A. et al., 2018; 
Oviedo et al., 2010), where $\delta_{y, 1}$ is the yield displacement of the WFP system at the first floor. Considering that $\delta_{y, 1} \approx 0.01 h_{1}=14 \mathrm{~mm}$ for both $\mathrm{X}$ and $\mathrm{Y}$ directions (a little lower than the values obtained in Chapter 4), where $h_{1}$ is the height of the first story (Figure 2.5), the value obtained for $\delta_{s} \delta_{y, 1}$ is equal to $5.6 \mathrm{~mm}$. Then, the axial yield displacement for the dampers, ${ }_{s} \Delta \mathrm{u}_{y, 1}$, is obtained from ${ }_{s} \delta_{y, 1}$ through the expression ${ }_{s} \Delta u_{y, 1}=\frac{{ }_{s} \delta_{y, 1} \cos \gamma}{\cos \alpha}=5.35 \mathrm{~mm}$. Therefore, the stiffness of dampers is ${ }_{s} k_{1}=\frac{{ }_{s} N_{y, 1}}{{ }_{s}^{\Delta u_{y, 1}}}=\frac{17.72}{5.35}=3.31 \mathrm{kN} / \mathrm{mm}$.

For the rest of stories, Akiyama (1985) proposed to use a yield-strength for the $i$ story, $Q_{y, i}$, that prevented the damage concentration in terms of energy. $Q_{y, i}$ can be expressed dimensionless by the yield-force coefficient, $\alpha_{i}$, defined in (1.10). Akiyama (1985) proposed that there is an optimum yield-shear strength coefficient distribution, $\bar{\alpha}_{i}$, defined as $\bar{\alpha}_{i}=\alpha_{i} / \alpha_{1}$, that leads to an even distribution of the damage in the structure. In this study, $\bar{\alpha}_{i}$ is approximated by (1.14), although Donaire-Avila (2018) showed that this approximation leads to an overstrength in higher stories of low rise buildings (3 stories).

The eigenvalue analysis carried out in the numerical model of the WFP system (Table 5.8) showed that the fundamental periods of $\mathrm{X}$ and $\mathrm{Y}$ directions are $T_{X, 1}=0.32 \mathrm{~s}$ and $T_{Y, 1}=0.38 \mathrm{~s}$. Therefore, by applying $T_{X, 1}$ in (1.14) for the X-direction, the value obtained for $\bar{\alpha}_{X, 2}$ is equal to 1.278. Afterwards, the total shear strength at the first story in X-direction, $Q_{y X, 1}$ is obtained as $Q_{y X, 1}={ }_{f} Q_{y X, 1}+{ }_{s} Q_{y X, 1}=57.5+28.75=86.25 \mathrm{kN} \quad, \quad$ this implies that $\alpha_{X, 1}=$ $86.25 /((6.45+5.78) g)=0.72$. Then, the optimum value for the shear strength coefficient at the second story in $\mathrm{X}$ direction, $\alpha_{X, 2}^{O p t}$, is obtained as $\alpha_{X, 2}^{O p t}=\bar{\alpha}_{X, 2} \alpha_{X, 1}=0.92$ and the required shear strength is $Q_{y X, 2}^{O p t}=\alpha_{X, 2}^{O p t} \sum_{j=2}^{2} m_{j} g=58.15 \mathrm{kN}$. Following a similar procedure for Ydirection, $Q_{y Y, 1}={ }_{f} Q_{y Y, 1}+{ }_{s} Q_{y Y, 1}=62.5+26.5=89 \mathrm{kN}, \alpha_{Y, 1}=0.74, \bar{\alpha}_{Y, 2}=1.302$ (for $\left.T_{Y, 1}=0.38 \mathrm{~s}\right), \alpha_{Y, 2}^{O p t}=\bar{\alpha}_{Y, 2} \alpha_{Y, 1}=0.97$ and finally $Q_{y X, 2}^{O p t}=\alpha_{Y, 2}^{O p t} \sum_{j=2}^{2} m_{j} g=61.3 \mathrm{kN}$. Furthermore, the yield-shear strength at the second story of the WFP specimen in X and Y direction was obtained through a pushover analysis, giving ${ }_{f} Q_{y X, 2} \approx{ }_{f} Q_{y Y, 2}=138 \mathrm{kN}$. Therefore, no dampers were considered at the second story because the strength of WFP system in $\mathrm{X}$ and $\mathrm{Y}$ directions exceeded the optimum value required for the story, i.e., ${ }_{f} Q_{y X, 2}>Q_{y X, 2}^{O p t}$ and ${ }_{f} Q_{y Y, 2}>Q_{y Y, 2}^{O p t}$. This set up, using dampers only in specific stories, have been applied successfully in the past (Kasai et al., 2009).

The numerical model of the WFP specimen with EDDs is shown in Figure 6.18. This model is formed by simply adding the non-linear springs that represent the dampers in the benchmark model of the WFP structure described in Chapter 5. The three dampers added were modeled using twoNodeLink elements implemented in OpenSees (Mckenna, 1999). Its constitutive model was the one described in section 5 but updated for a yield strength and a stiffness of ${ }_{s} N_{y, 1}=$ $17.72 \mathrm{kN}$ and ${ }_{s} k_{1}=3.31 \mathrm{kN} / \mathrm{mm}$, being the rest of properties those indicated in Table 6.1. 


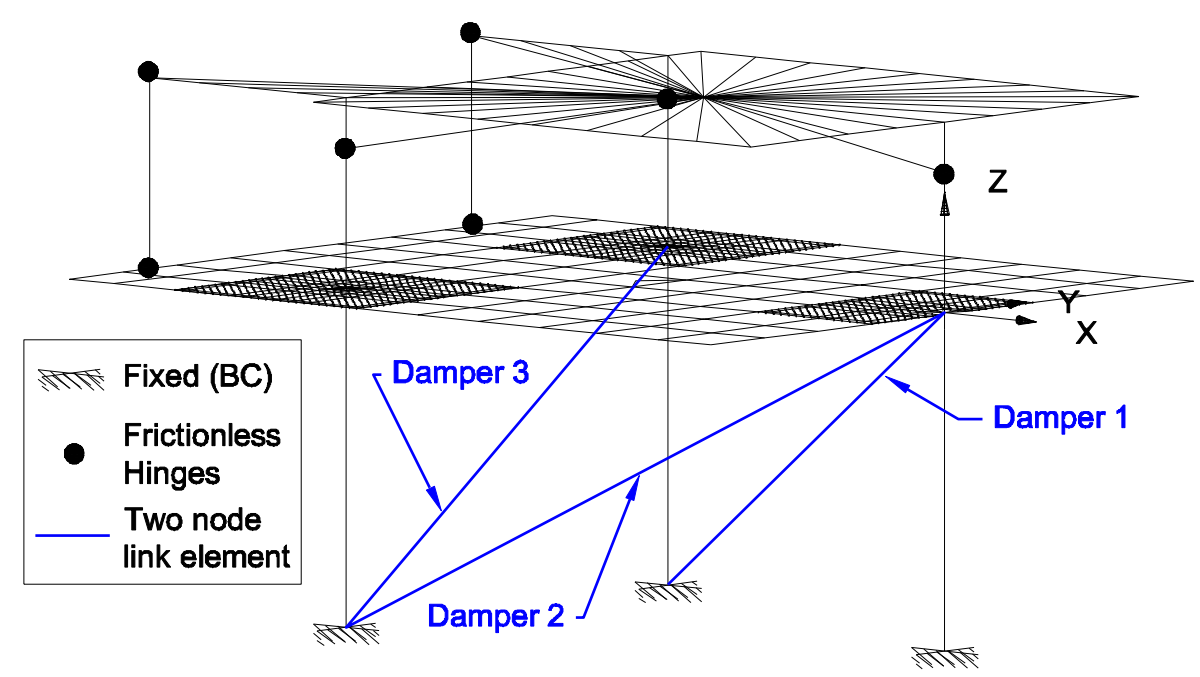

Figure 6. 18. Overview of the numerical model with dampers

Moreover, the mass-proportional damping model, $\boldsymbol{C}=a_{0} \boldsymbol{M}$, was redefined for the WFP system with hysteretic dampers in order to keep the relative damping values established for the WFP system without dampers (Chapter 5). The new elastic stiffness matrix led to new modal frequencies for the first and second vibration modes, being $f_{1}=3.08 \mathrm{~Hz}$ and $f_{2}=3.95 \mathrm{~Hz}$ (Table 6.2). According to the damping model considered for the WFP system without dampers, where $\xi_{2}=3 \%$ for $f_{2}$, the parameter $a_{0}$ was updated holding the same $\xi_{2}$, but adding a new value for $\omega_{2}=2 \pi f_{2}=2 \pi 3.95=24.82 \mathrm{rad} / \mathrm{s}$, being equal to $a_{0}=2 \xi_{2} \omega_{2}=1.49$.

\section{SEISMIC RESPONSE OF SPECIMEN BS1 WITH DAMPERS}

The specimen BS1 with the slit-plate dampers designed in section 6 is subjected here to the same series of seismic simulations applied to the specimen BS1 during the shaking table test. The training signal T10 has been also included for completeness although it does not represent an earthquake. The goal is to show how the seismic response changes due to the addition of the dampers.

\subsection{Dynamic characterization}

In order to investigate the dynamic response of the specimen with hysteretic dampers, an eigenvalue analysis was submitted at the end of each simulation, obtaining periods and frequencies along the series of seismic simulations. Once the information of periods and frequencies was obtained, the damping ratios were calculated applying the damping model explained in Section 6. Table 6.2 and Figure 6.19 shows periods, frequencies and damping ratios for each simulation. Figures 6.20 to 6.22 depict elastic mode shapes, where the main system is represented with red lines and dampers with blue lines. As these figures show, the first mode shows a vibration shape in Y-direction with a larger displacement in the exterior column $\left(C_{1}\right)$ than in the interior columns $\left(C_{2}\right.$ and $\left.C_{3}\right)$, therefore it has a twist component. The second model shows a vibration shape almost translational in Y-direction with a little twist component. Apparently, dampers were successful in improving the torsional behavior in this mode. The third mode shows a translational mode in $\mathrm{X}$-direction (axis of symmetry).

The main structure is the unique part of the structure whose stiffness can drop if it is damaged, because dampers do not experience any strength or stiffness degradation until failure. Any change of stiffness must be thus attributed to the occurrence of damage in the main structure. Table 6.2 
shows how periods barely change along the simulations. This means that the main structure remains basically undamaged, as discussed next. This contrast notably with the response of the WFP structure without dampers that underwent heavy damaged during the seismic simulation C200 and collapsed during C300.

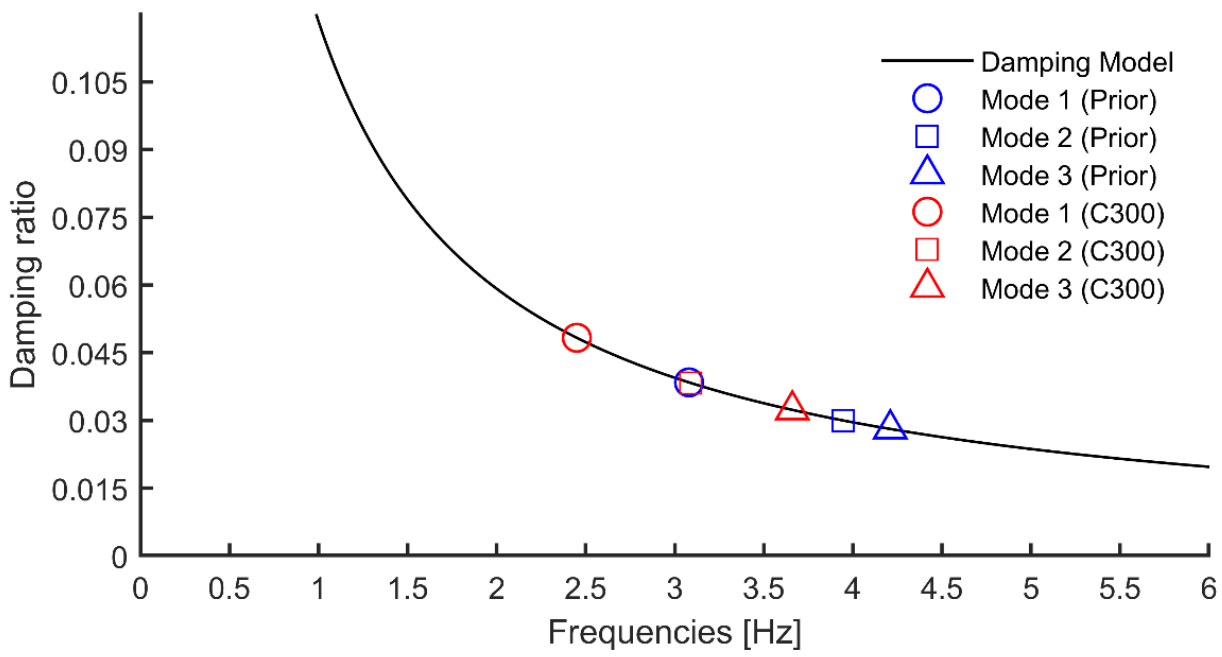

Figure 6. 19. Damping model and damping values at the beginning and at the end of simulations

Table 6. 2. Evolution of natural periods and damping ratios

\begin{tabular}{cccccccccc}
\hline Simulation & $\begin{array}{c}\mathbf{T}_{\mathbf{1}} \\
{[\mathbf{s}]}\end{array}$ & $\begin{array}{c}\mathbf{f}_{\mathbf{1}} \\
{[\mathbf{H z}]}\end{array}$ & $\begin{array}{c}\mathbf{T}_{\mathbf{2}} \\
{[\mathbf{s}]}\end{array}$ & $\begin{array}{c}\mathbf{f}_{\mathbf{2}} \\
{[\mathbf{H z}]}\end{array}$ & $\begin{array}{c}\mathbf{T}_{\mathbf{3}} \\
{[\mathbf{s}]}\end{array}$ & $\begin{array}{c}\mathbf{f}_{\mathbf{3}} \\
{[\mathbf{H z}]}\end{array}$ & $\begin{array}{c}\boldsymbol{\xi}_{\mathbf{1}} \\
{[\mathbf{\%}]}\end{array}$ & $\begin{array}{c}\boldsymbol{\xi}_{\mathbf{2}} \\
{[\boldsymbol{\%}]}\end{array}$ & $\begin{array}{c}\boldsymbol{\xi}_{\mathbf{3}} \\
{[\boldsymbol{\%}]}\end{array}$ \\
\hline Prior & 0.32 & 3.08 & 0.25 & 3.95 & 0.24 & 4.21 & 3.8 & 3.0 & 2.8 \\
$\mathbf{T 1 0}$ & 0.39 & 2.59 & 0.30 & 3.31 & 0.27 & 3.71 & 4.6 & 3.6 & 3.2 \\
$\mathbf{C 3 5}$ & 0.39 & 2.59 & 0.30 & 3.31 & 0.27 & 3.71 & 4.6 & 3.6 & 3.2 \\
$\mathbf{C 5 0}$ & 0.39 & 2.59 & 0.30 & 3.31 & 0.27 & 3.71 & 4.6 & 3.6 & 3.2 \\
$\mathbf{C 1 0 0}$ & 0.39 & 2.59 & 0.30 & 3.31 & 0.27 & 3.71 & 4.6 & 3.6 & 3.2 \\
$\mathbf{C 2 0 0 i}$ & 0.39 & 2.59 & 0.30 & 3.31 & 0.27 & 3.70 & 4.6 & 3.6 & 3.2 \\
$\mathbf{C 2 0 0}$ & 0.39 & 2.59 & 0.30 & 3.29 & 0.27 & 3.69 & 4.6 & 3.6 & 3.2 \\
$\mathbf{C 3 0 0}$ & 0.41 & 2.45 & 0.32 & 3.09 & 0.27 & 3.66 & 4.8 & 3.8 & 3.2 \\
\hline \hline
\end{tabular}

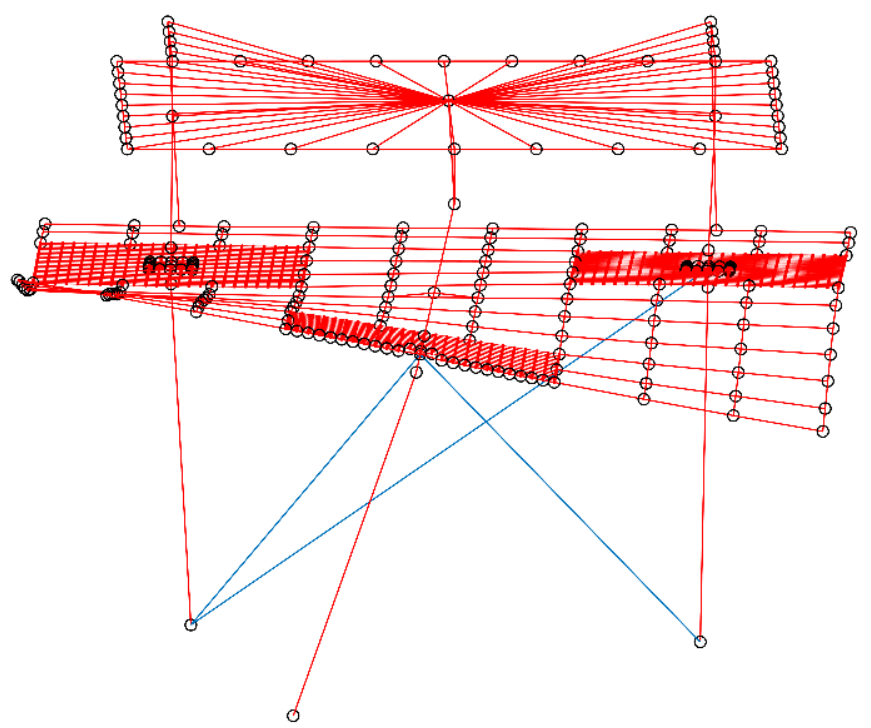

Figure 6. 20. First mode shape (Y-Torsion) 


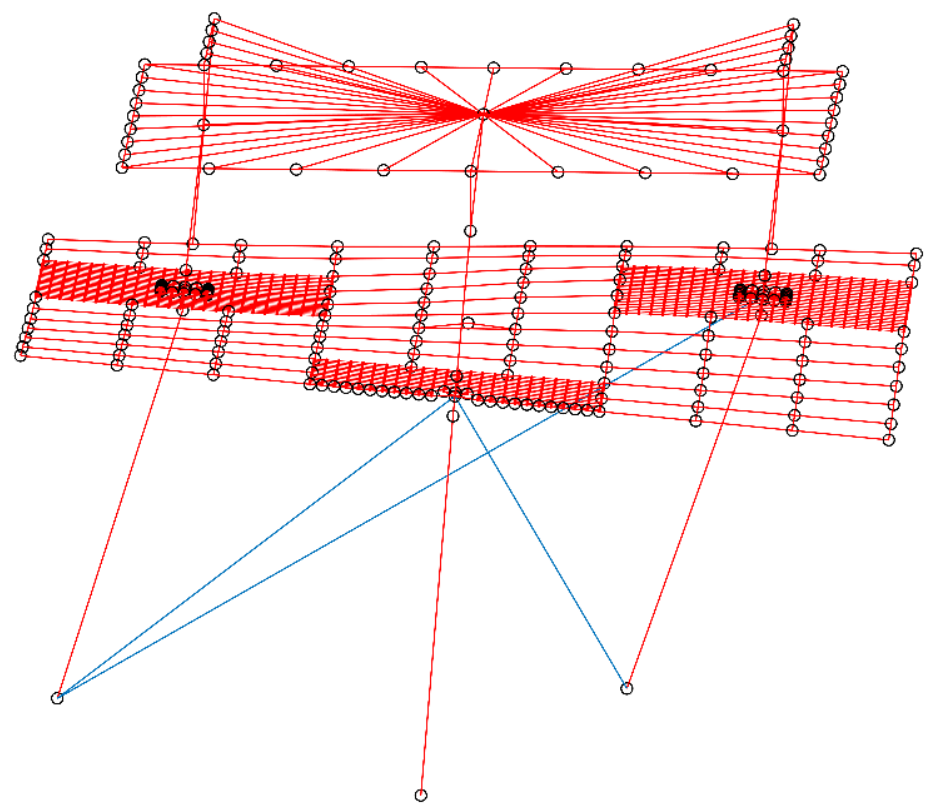

Figure 6. 21. Second mode shape (Y-Torison)

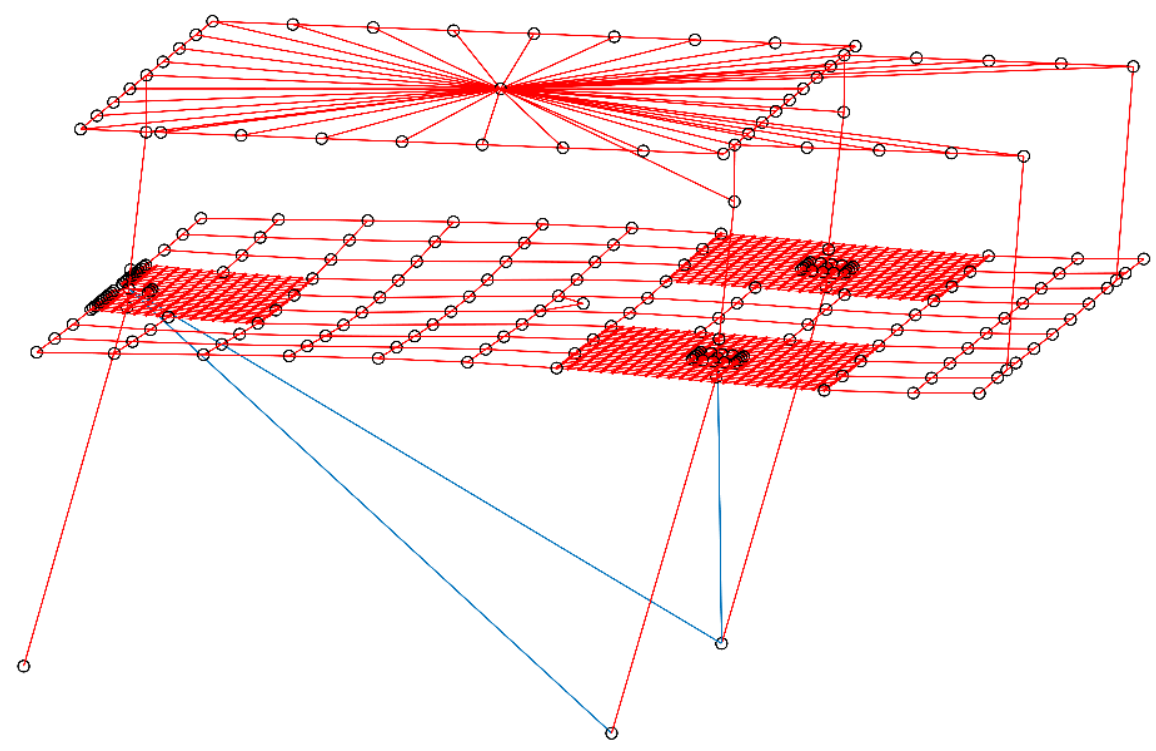

Figure 6. 22. Third mode shape (X)

\subsection{Response in terms of displacements}

\subsubsection{History of displacements}

Figure 6.23 shows the histories of displacement, relative to the ground, at the centers of mass of each level in concordance with the two-mass lumped model (Chapter 3). DOF 1 to 3 corresponds to displacements $\mathrm{X}, \mathrm{Y}$ and rotation about $\mathrm{Z}$ at the first level, and DOF 4 to 6 corresponds to the displacements $\mathrm{X}, \mathrm{Y}$ and rotation about $\mathrm{Z}$ at the second level. The training signal $\mathrm{T} 10$ has been included for completeness although it does not represent an earthquake. The specimen did not reach failure, although in the last simulation there were small permanent displacements in $\mathrm{Y}$ direction that indicates minor damage. 


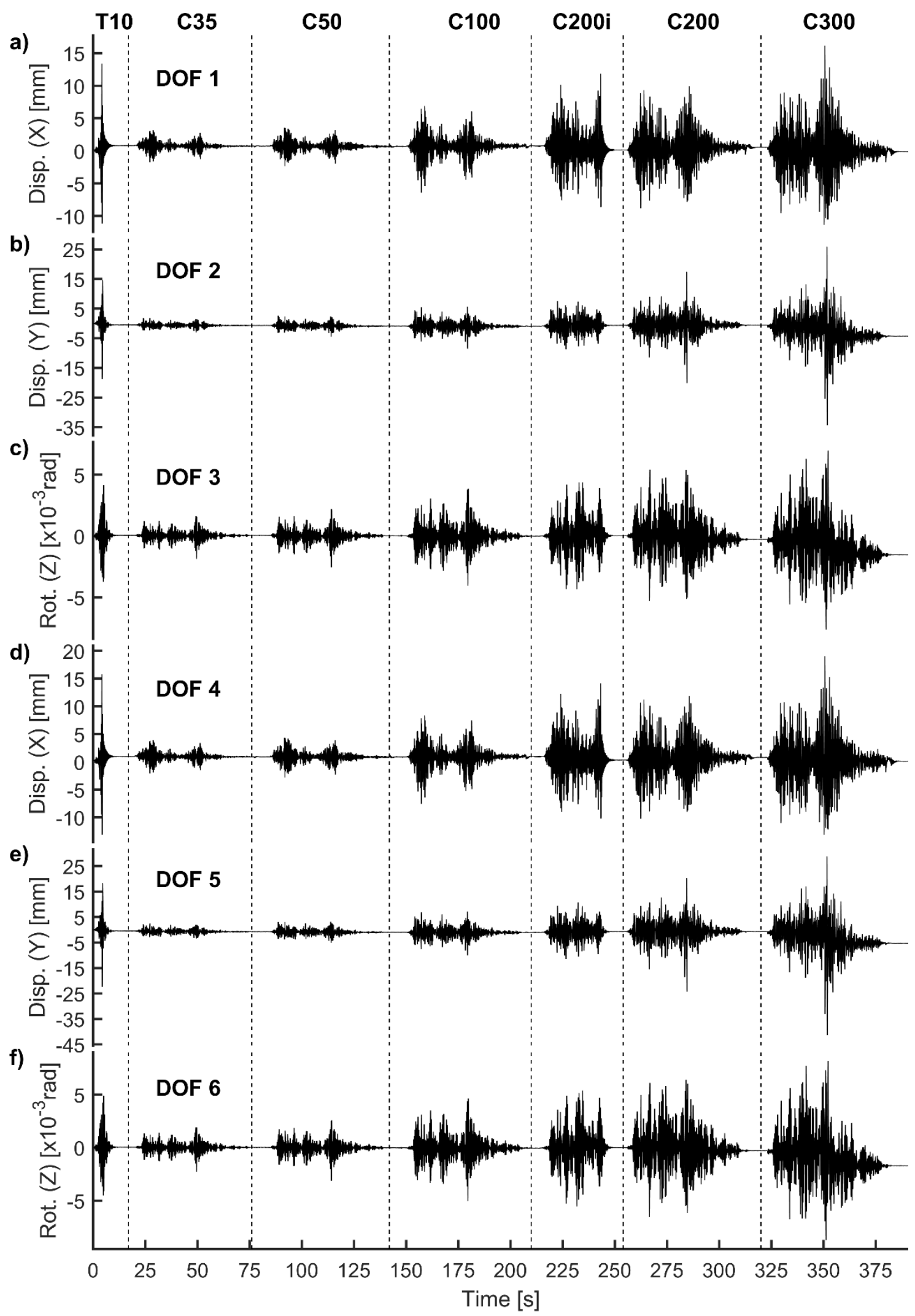

Figure 6. 23. Histories of displacement of the centers of mass for the specimen with dampers following the two-mass model schema: DOF 1, b) DOF 2, c) DOF 3, d) DOF 4, e) DOF 5 and f) DOF 6 


\subsubsection{Maximum inter-story drift index}

The maximum response in terms of Inter-story Drift Index (IDI) and residual or permanent Interstory Drift Index $\left(I D I_{r}\right)$ in directions $\mathrm{X}$ and $\mathrm{Y}$ are showed in Tables 6.3 and 6.4. These values were calculated normalizing the Inter-story Drift by the story height, $1400 \mathrm{~mm}$ (story 1) and $620 \mathrm{~mm}$ (story 2), and by the total height of the specimen, $2020 \mathrm{~mm}$, for the case of Top (Figure 2.5). In these tables, the response for each test is related with a SPL applying two different criteria. The first criterion is based on the drift limits proposed by the Structural Engineers Association of California (SEAOC, 1995) and the second criterion is based on the results of Chapter 4. Table 6.5 summarizes the maximum rotational response and the residual rotation about the center of mass per story and at the top.

Table 6. 3. Maximum translational response in direction $\mathrm{X}$

\begin{tabular}{|c|c|c|c|c|c|c|c|c|c|c|}
\hline \multirow[b]{2}{*}{ Simulation } & \multicolumn{3}{|c|}{ Story 1} & \multicolumn{3}{|c|}{ Story 2} & \multicolumn{2}{|c|}{ Top } & \multicolumn{2}{|c|}{ SPL } \\
\hline & $\begin{array}{c}\ddot{\boldsymbol{u}}_{\text {max }}^{t} \\
{[\boldsymbol{g}]}\end{array}$ & $\begin{array}{l}\text { IDI } \\
{[\%]}\end{array}$ & $\begin{array}{c}I D I_{r} \\
{[\%]}\end{array}$ & $\begin{array}{c}\ddot{\boldsymbol{u}}_{\text {max }}^{t} \\
{[\boldsymbol{g}]}\end{array}$ & $\begin{array}{l}I D I \\
{[\%]}\end{array}$ & $\begin{array}{c}\ddot{u}_{\max }^{t} \\
{[g]}\end{array}$ & $\begin{array}{l}I D I \\
{[\%]}\end{array}$ & $\begin{array}{l}I D I_{r} \\
{[\%]}\end{array}$ & $\begin{array}{c}\ddot{u}_{\max }^{t} \\
{[g]}\end{array}$ & Proposed \\
\hline C35 & 0.14 & 0.23 & 0.05 & 0.16 & 0.05 & 0.01 & 0.19 & 0.05 & $\mathrm{O}$ & $\mathrm{O}$ \\
\hline C50 & 0.19 & 0.25 & 0.05 & 0.22 & 0.06 & 0.01 & 0.21 & 0.04 & $\mathrm{O}$ & $\mathrm{O}$ \\
\hline C100 & 0.36 & 0.49 & 0.05 & 0.44 & 0.10 & 0.01 & 0.41 & 0.05 & $\mathrm{O}$ & $\mathrm{O}$ \\
\hline C200i & 1.07 & 0.85 & 0.01 & 1.34 & 0.16 & 0.01 & 0.70 & 0.02 & LS & $\mathrm{O}$ \\
\hline C200 & 0.54 & 0.71 & 0.04 & 0.67 & 0.14 & 0.02 & 0.59 & 0.04 & LS & $\mathrm{O}$ \\
\hline C300 & 0.65 & 1.15 & 0.01 & 0.78 & 0.21 & 0.01 & 0.94 & 0.00 & LS & O-LS \\
\hline
\end{tabular}

Table 6. 4. Maximum translational response in direction $\mathrm{Y}$

\begin{tabular}{|c|c|c|c|c|c|c|c|c|c|c|}
\hline \multirow[b]{2}{*}{ Simulation } & \multicolumn{3}{|c|}{ Story 1} & \multicolumn{3}{|c|}{ Story 2} & \multicolumn{2}{|c|}{ Top } & \multicolumn{2}{|c|}{ SPL } \\
\hline & $\begin{array}{c}\ddot{u}_{\text {max }}^{t} \\
{[\boldsymbol{g}]}\end{array}$ & $\begin{array}{l}I D I \\
{[\%]}\end{array}$ & $\begin{array}{l}I_{\boldsymbol{I}} \boldsymbol{I}_{\boldsymbol{r}} \\
{[\%]}\end{array}$ & $\begin{array}{c}\ddot{u}_{\text {max }}^{t} \\
{[g]}\end{array}$ & $\begin{array}{l}\text { IDI } \\
\text { [\%] }\end{array}$ & $\begin{array}{c}\ddot{u}_{\max }^{t} \\
{[g]}\end{array}$ & $\begin{array}{l}\text { IDI } \\
{[\%]}\end{array}$ & $\begin{array}{c}I D I_{r} \\
{[\%]}\end{array}$ & $\begin{array}{c}\ddot{u}_{\max }^{t} \\
{[g]}\end{array}$ & Proposed \\
\hline C35 & 0.11 & 0.22 & 0.05 & 0.12 & 0.08 & 0.00 & 0.17 & 0.03 & $\mathrm{O}$ & $\mathrm{O}$ \\
\hline C50 & 0.15 & 0.32 & 0.07 & 0.19 & 0.11 & 0.01 & 0.25 & 0.05 & $\mathrm{O}$ & $\mathrm{O}$ \\
\hline C100 & 0.26 & 0.61 & 0.07 & 0.30 & 0.21 & 0.01 & 0.49 & 0.05 & LS & $\mathrm{O}$ \\
\hline C200i & 0.65 & 0.63 & 0.04 & 0.87 & 0.28 & 0.00 & 0.57 & 0.03 & LS & $\mathrm{O}$ \\
\hline $\mathrm{C200}$ & 0.54 & 1.44 & 0.04 & 0.70 & 0.35 & 0.01 & 1.20 & 0.03 & LS & LS \\
\hline C300 & 0.88 & 2.46 & 0.31 & 1.04 & 0.56 & 0.07 & 2.05 & 0.26 & $\mathrm{NC}$ & LS \\
\hline
\end{tabular}

Table 6. 5. Maximum rotational response about the centers of mass

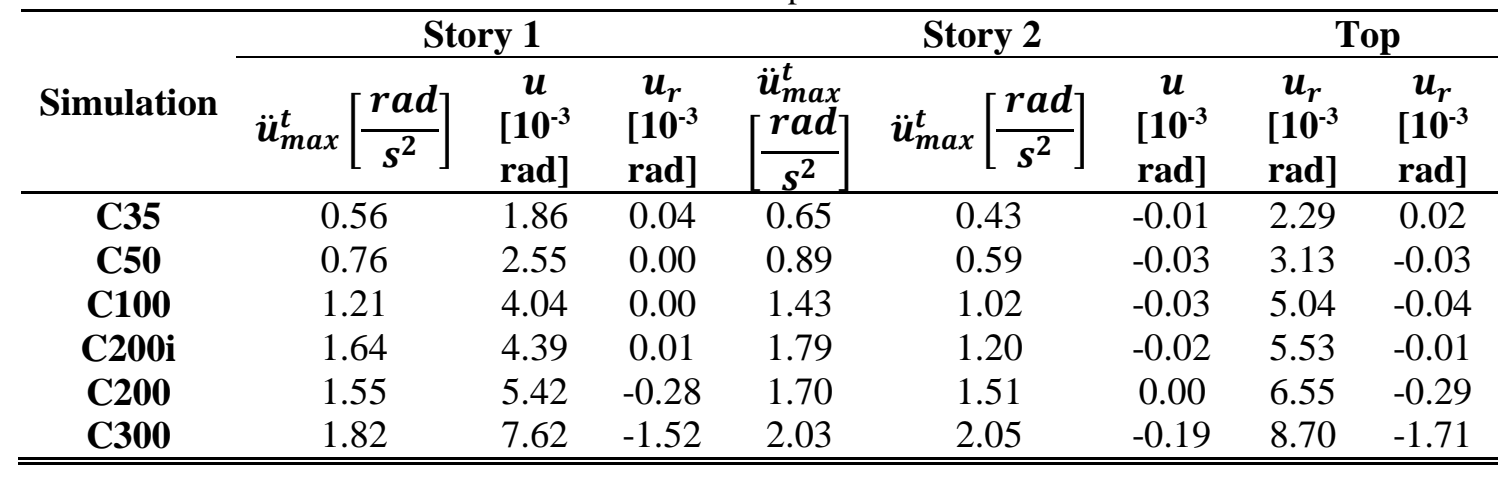




\subsubsection{Chord rotations}

The chord rotations demands in direction $\mathrm{X}$ and $\mathrm{Y}, \theta_{X}$ and $\theta_{Y}$, are shown in Figures 6.24 to 6.28 for each plastic hinges located at columns ends following section columns defined in Figure 2.2.
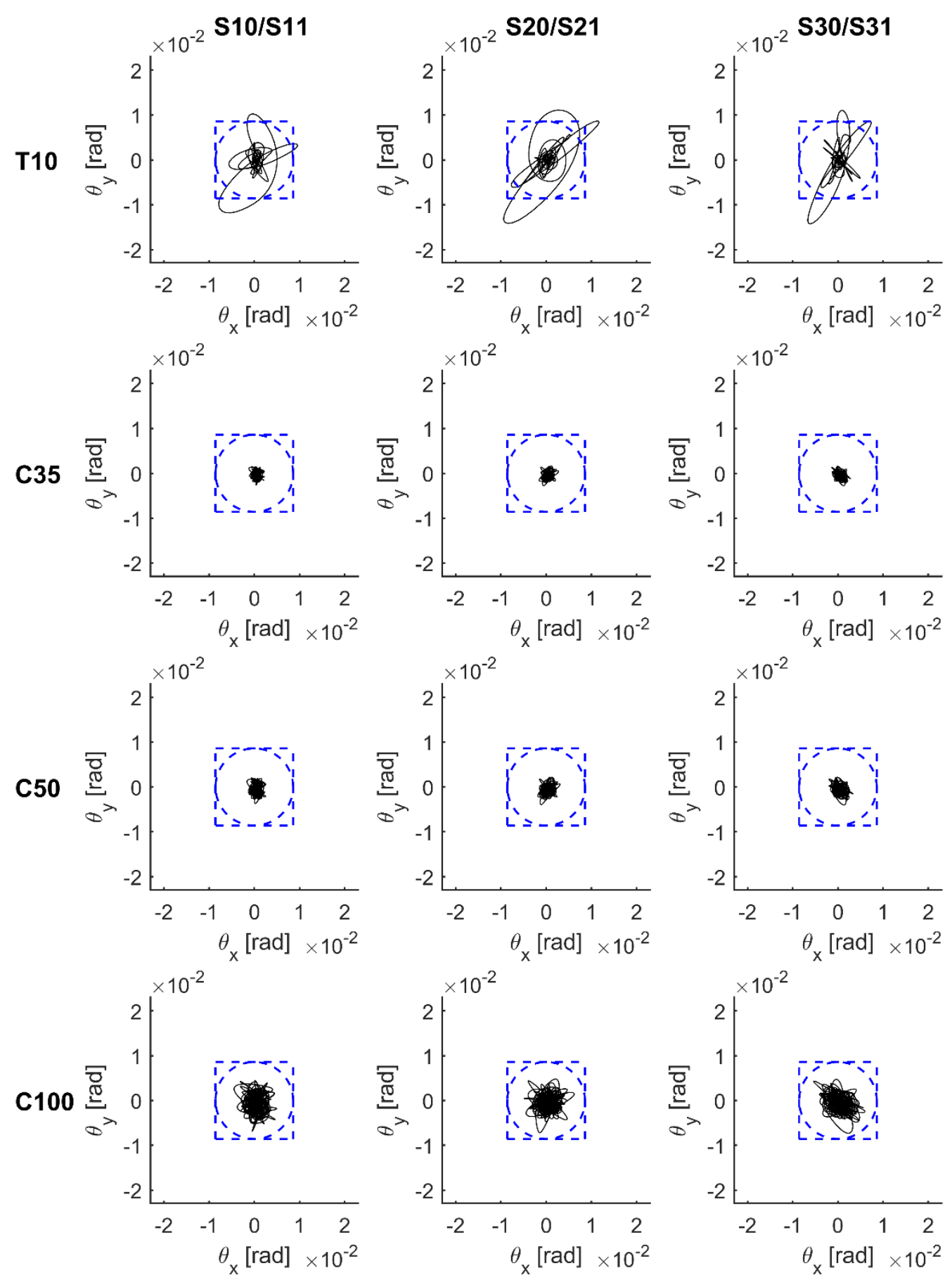

Chord rotation - - - - Yield rotation capacity

Figure 6. 24. Chord rotations of sections S10/S11, S20/S21 and S30/S31 at base and at top columns of first story for simulation T10, C35, C50 and C100 with dampers 

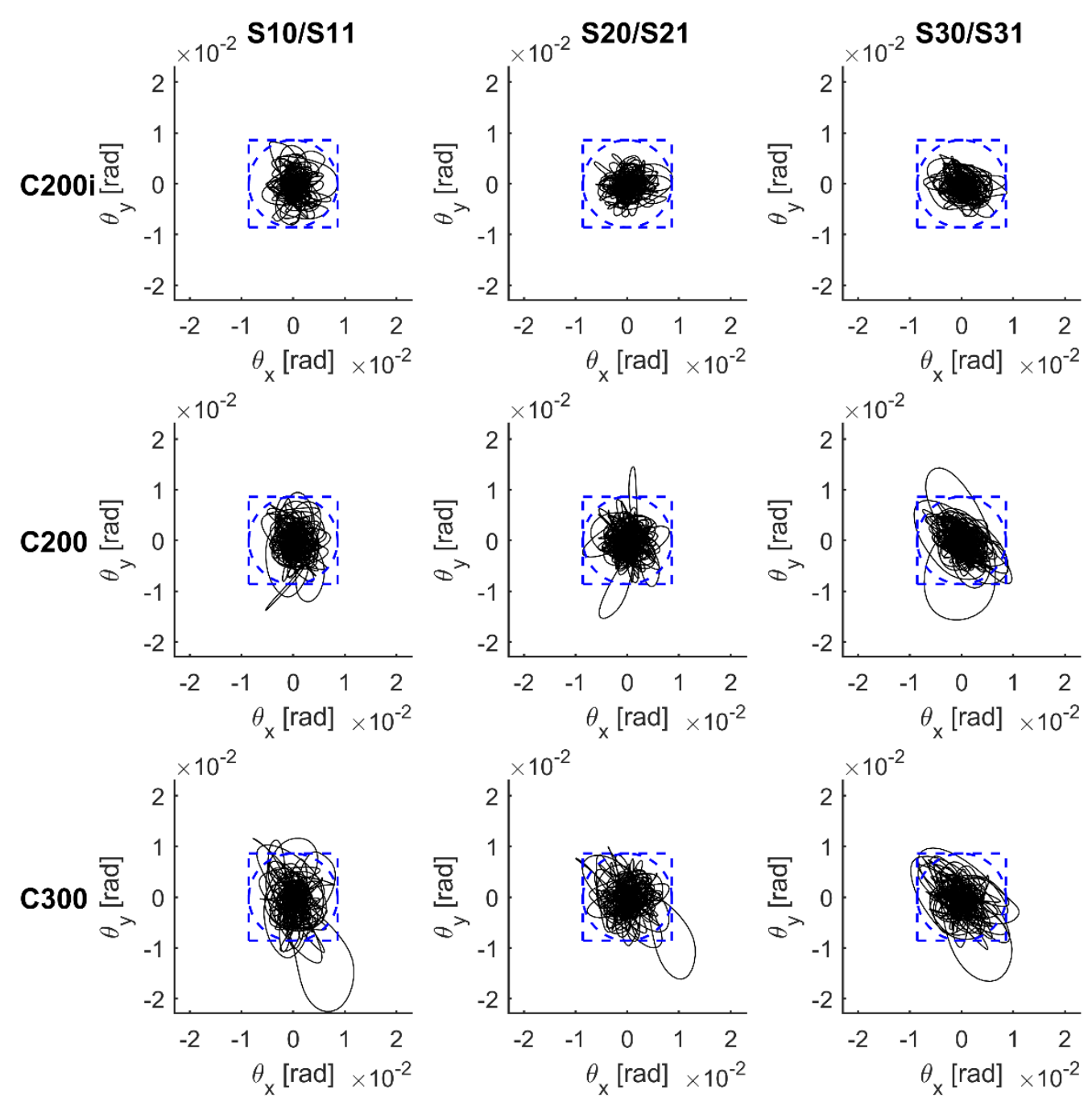

Chord rotation - - - - Yield rotation capacity

Figure 6. 25. Chord rotations of sections S10/S11, S20/S21 and S30/S31 at base and at top columns of first story for simulation C200i, C200 and C300 with dampers

Figures 6.24 to 6.28 are organized showing the training signal T10 and the seismic simulations C35 to C300 in rows and the different columns sections (S10 to S32) in columns as its counterpart Figure 4.4 and 4.7 for the specimen without dampers. Note that the training signal T10 has been included for completeness although it does not represent an earthquake. In the current case, plots maintain the scale and only show the yield rotation capacity because section were far from reaching the ultimate chord rotation. The yield rotation threshold was plotted considering two possible interaction curves in $\mathrm{X}$ and $\mathrm{Y}$ directions (circular and square). The chord rotations capacity were shown in Table 4.6. 

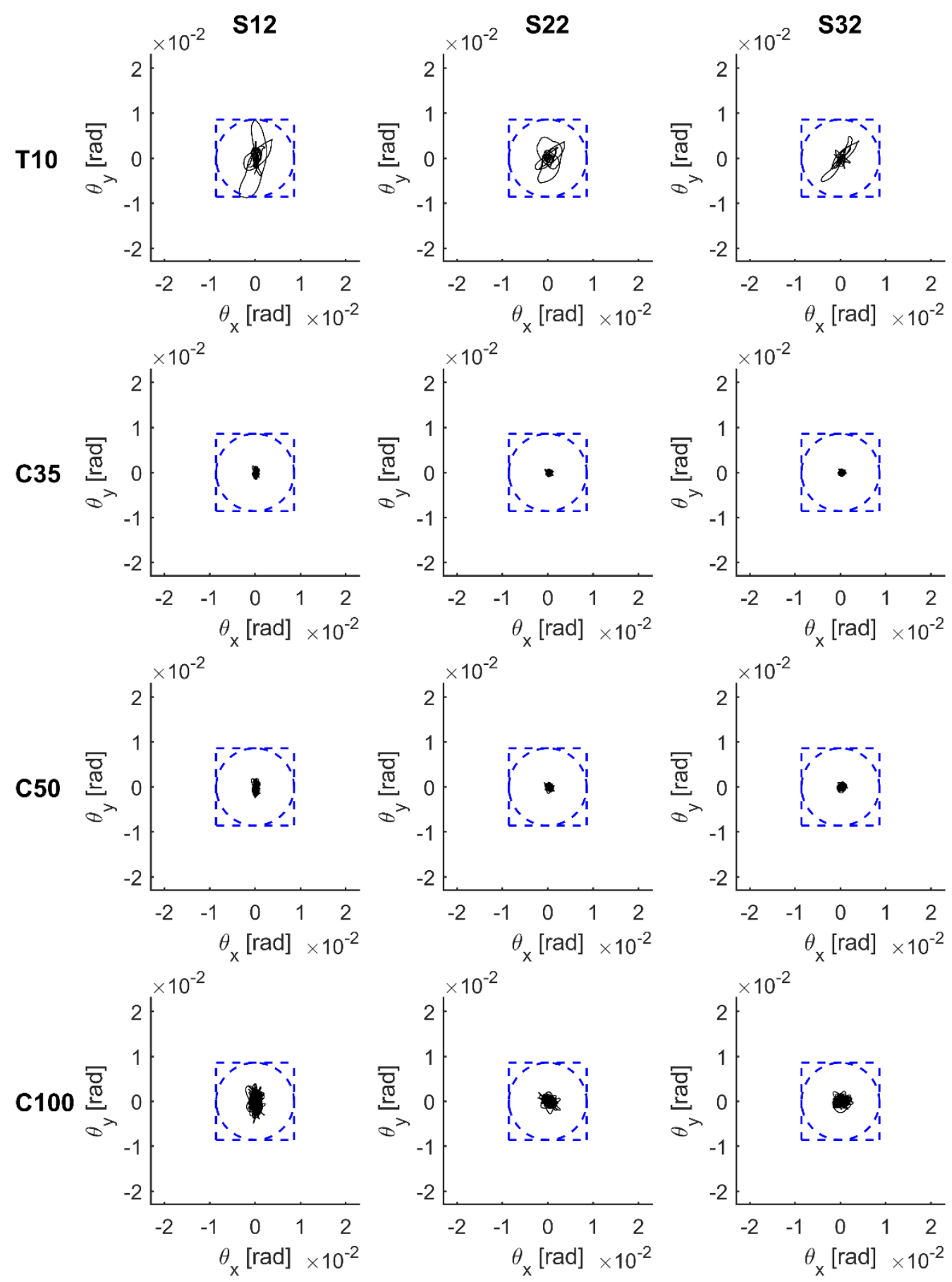

Chord rotation - - - - Yield rotation capacity

Figure 6. 26. Chord rotations of sections S10/S11, S20/S21 and S30/S31 at base and at top columns of first story for simulation T10, C35, C50 and C100 with dampers 

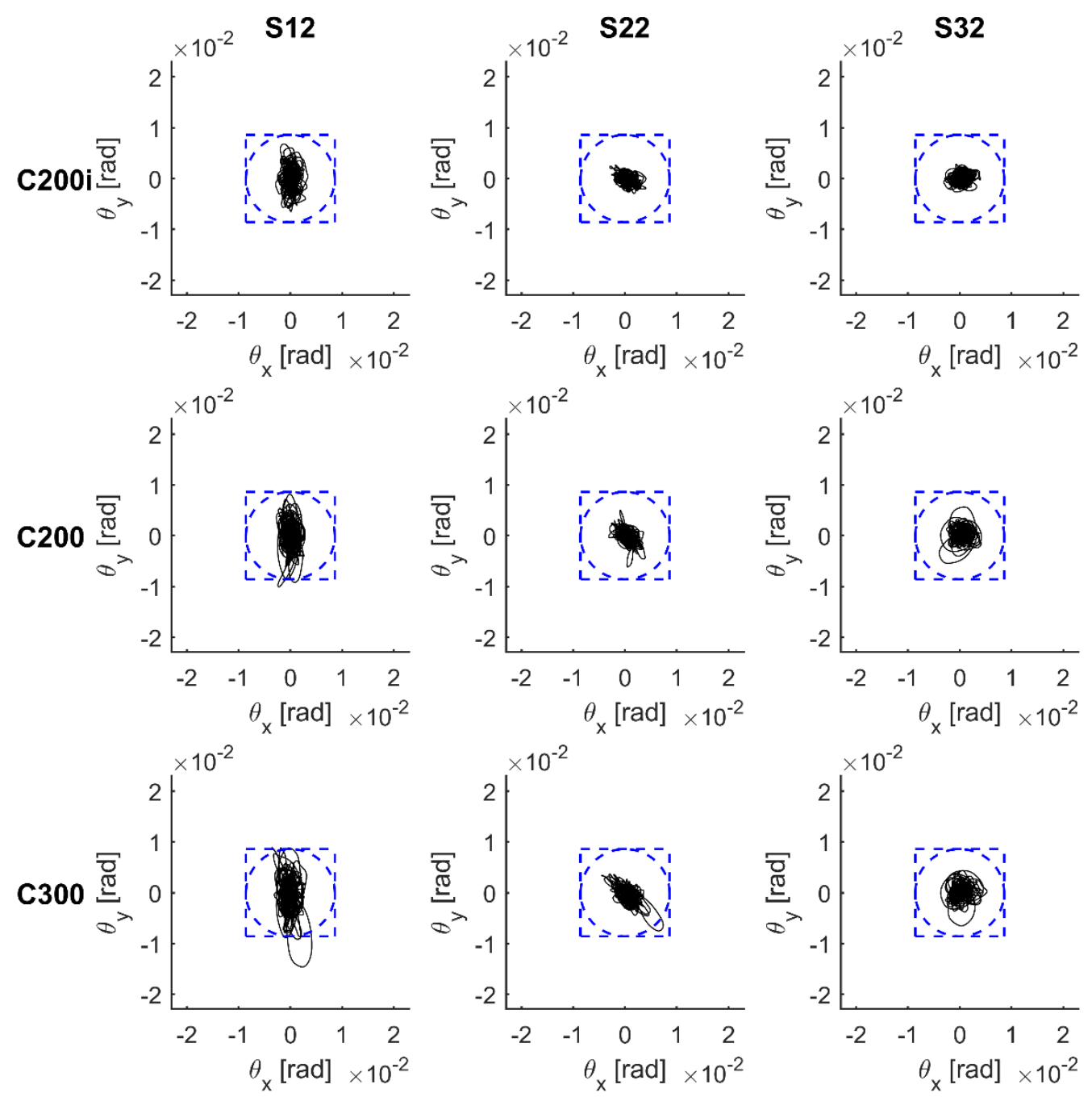

Chord rotation - - - - Yield rotation capacity

Figure 6. 27. Chord rotations of sections S12, S22 and S32 for simulation C200i, C200 and $\mathrm{C} 300$

Tables 6.6 and 6.7 summarizes the maximum chord rotations in the training signal T10 and for each seismic simulation calculated in two different ways: $\theta_{\text {sqrt }}=\max \left\{\sqrt{\theta_{X}^{2}+\theta_{Y}^{2}}\right\}$ (circular) and $\theta_{m X Y}=\max \left\{\theta_{X}, \theta_{Y}\right\}$ (square). Then, these values were normalized by the ultimate rotation capacity of each section $\theta_{u}$ as indicator of damage. Results indicate that sections entered in nonlinear range but, in general terms, only half of the total chord rotation capacity was reached at the end of the severest seismic simulation C300.

Table 6. 6. Relative maximum rotation at column ends $\left(\boldsymbol{\theta}_{\text {sqrt }} / \boldsymbol{\theta}_{\boldsymbol{u}}\right)$

\begin{tabular}{cccccccc}
\hline Sections & T10 & C35 & C50 & C100 & C200i & C200 & C300 \\
\hline S12 & 0.26 & 0.05 & 0.07 & 0.14 & 0.20 & 0.30 & 0.43 \\
$\mathbf{S 2 2}$ & 0.16 & 0.04 & 0.05 & 0.10 & 0.13 & 0.18 & 0.29 \\
$\mathbf{S 3 2}$ & 0.19 & 0.04 & 0.05 & 0.08 & 0.12 & 0.17 & 0.19 \\
$\mathbf{S 1 0 / S 1 1}$ & 0.38 & 0.08 & 0.1 & 0.19 & 0.26 & 0.41 & 0.66 \\
$\mathbf{S 2 0 / S 2 1}$ & 0.44 & 0.07 & 0.11 & 0.19 & 0.23 & 0.43 & 0.52 \\
$\mathbf{S 3 0 / S 3 1}$ & 0.41 & 0.08 & 0.11 & 0.2 & 0.24 & 0.42 & 0.47 \\
\hline \hline
\end{tabular}


Table 6. 7. Relative maximum rotation at column ends $\left(\boldsymbol{\theta}_{\boldsymbol{m} X \boldsymbol{Y}} / \boldsymbol{\theta}_{\boldsymbol{u}}\right)$

\begin{tabular}{cccccccc}
\hline Sections & T10 & C35 & C50 & C100 & C200i & C200 & C300 \\
\hline S12 & 0.26 & 0.05 & 0.07 & 0.14 & 0.20 & 0.29 & 0.42 \\
S22 & 0.16 & 0.04 & 0.04 & 0.08 & 0.12 & 0.18 & 0.22 \\
S32 & 0.15 & 0.04 & 0.05 & 0.08 & 0.12 & 0.16 & 0.19 \\
S10/S11 & 0.33 & 0.07 & 0.1 & 0.19 & 0.24 & 0.39 & 0.63 \\
S20/S21 & 0.38 & 0.07 & 0.11 & 0.19 & 0.23 & 0.41 & 0.43 \\
S30/S31 & 0.38 & 0.08 & 0.11 & 0.19 & 0.23 & 0.41 & 0.44 \\
\hline \hline
\end{tabular}

\subsection{Response in terms of forces}

The history of restoring forces of columns in direction $\mathrm{X}$ and $\mathrm{Y}$ of each level are shown in Figures 6.28 (level 1) and 6.29 (level 2). The training signal T10 has been included for completeness although it does not represent an earthquake. The restoring forces of each level were calculated as the sum of the shear forces developed at the base of the columns of each story, using the Gauss point closest to the column base.

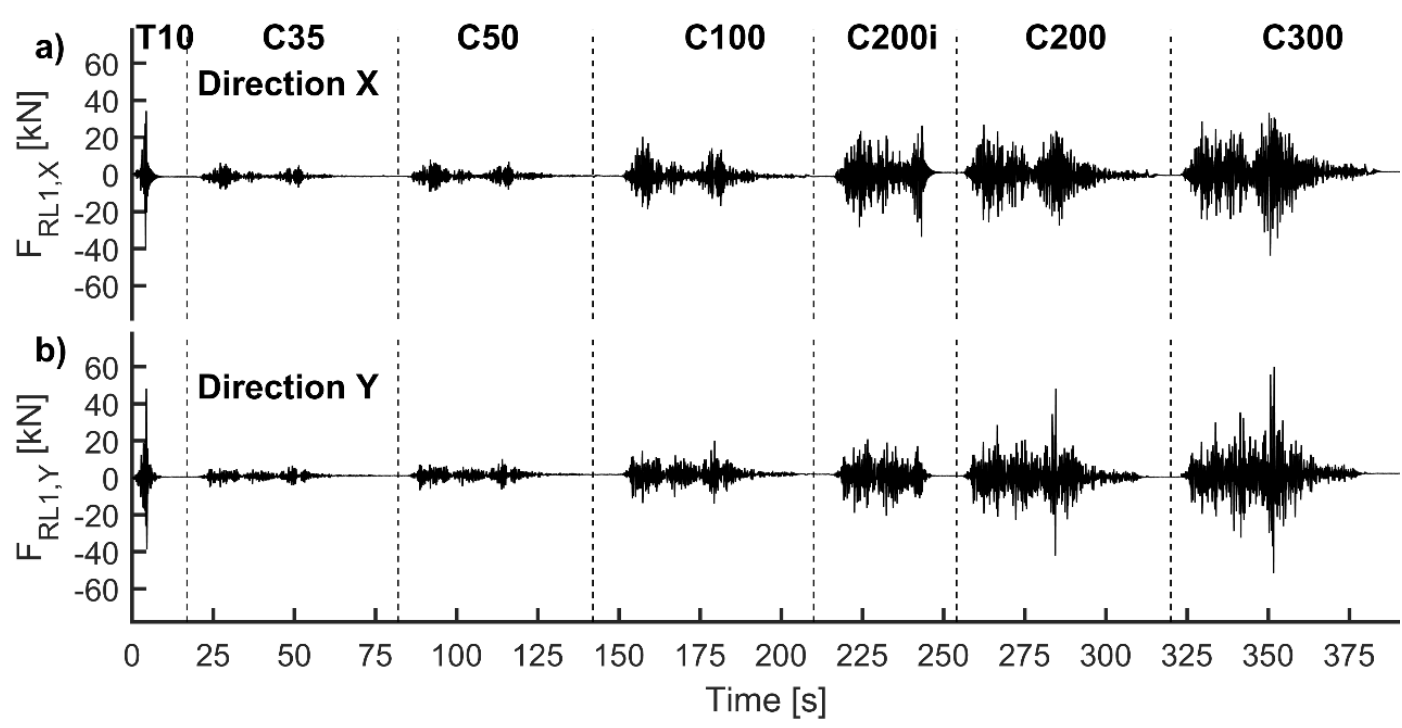

Figure 6. 28. History of restoring forces developed in the first level: a) $\mathrm{X}$ and b) $\mathrm{Y}$

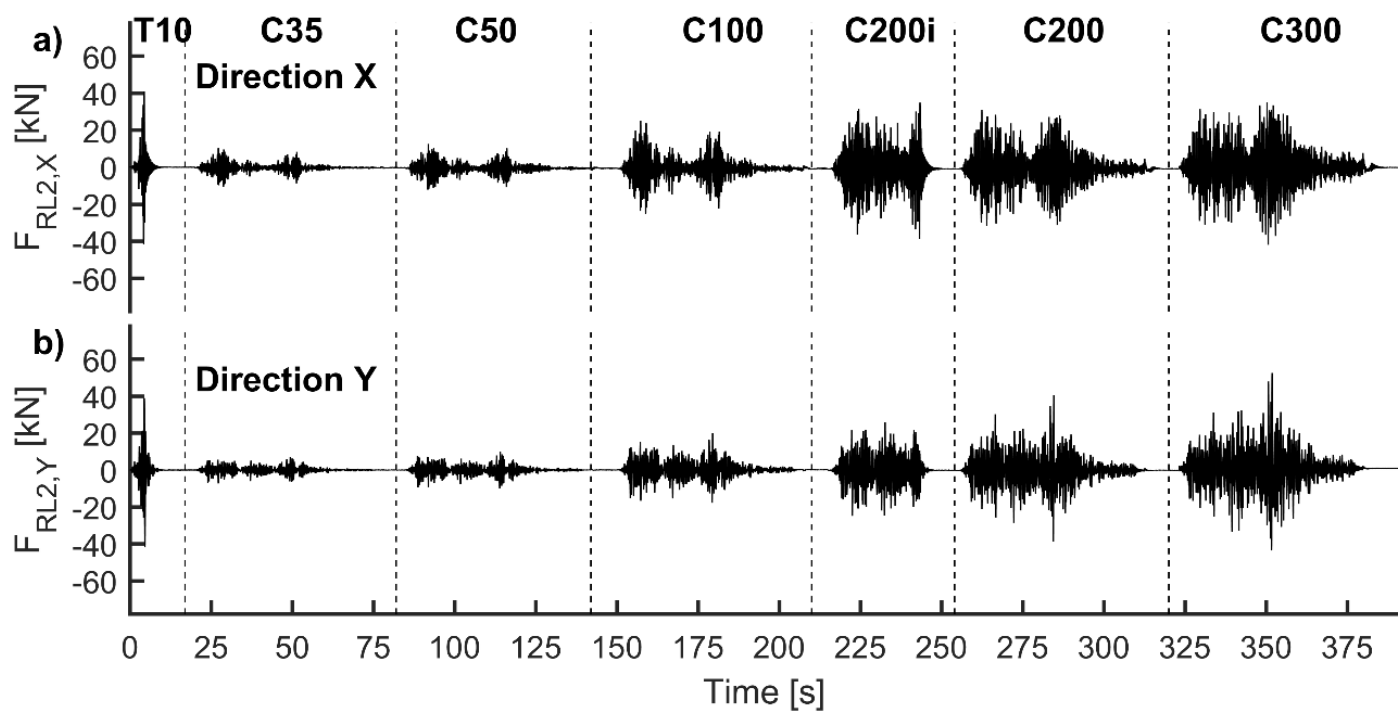

Figure 6. 29. History of restoring forces developed in the second level: a) X and b) Y 
Table 6.8 lists the maximum shear force per level, simulation and direction. For low intensity levels (C35 and C50), the maximums does not overcome $13 \mathrm{kN}$, and as long as the intensity grows, the response increases up to $60 \mathrm{kN}$ in simulation $\mathrm{C} 300$.

Table 6. 8. Restoring forces by levels, simulations and directions

\begin{tabular}{ccccc}
\hline \multirow{2}{*}{ Simulation } & \multicolumn{2}{c}{ Level 1 } & \multicolumn{2}{c}{ Level 2 } \\
\cline { 2 - 5 } & $\begin{array}{c}\text { Dir X } \\
{[\mathbf{k N}]}\end{array}$ & $\begin{array}{c}\text { Dir Y } \\
{[\mathbf{k N}]}\end{array}$ & $\begin{array}{c}\text { Dir X } \\
{[\mathbf{k N}]}\end{array}$ & $\begin{array}{c}\text { Dir Y } \\
{[\mathbf{k N}]}\end{array}$ \\
\hline T10 & 39.55 & 48.19 & 41.48 & 41.78 \\
$\mathbf{C 3 5}$ & 8.11 & 6.67 & 10.46 & 7.21 \\
$\mathbf{C 5 0}$ & 9.19 & 10.19 & 12.61 & 10.12 \\
$\mathbf{C 1 0 0}$ & 20.31 & 20.00 & 25.38 & 20.07 \\
$\mathbf{C 2 0 0 i}$ & 33.70 & 20.82 & 38.72 & 25.80 \\
$\mathbf{C 2 0 0}$ & 27.64 & 48.21 & 31.74 & 40.46 \\
$\mathbf{C 3 0 0}$ & 43.85 & 59.95 & 41.93 & 52.53 \\
\hline \hline
\end{tabular}

\subsection{Response in terms of energy}

The history of input energy $E_{I}$, energy dissipated by inherent viscous damping $W_{\xi}$ and energy dissipated by plastic strains $W_{p}$, which is decomposed into the energy dissipated by the flexible part of the structure ${ }_{f} W_{p}$ (main system) and the energy dissipated by the stiff part ${ }_{s} W_{p}$ (dampers), are shown in Figures 6.30 to 6.32 and the numeric values are listed in Tables 6.9 to 6.12. The methodology used to extract these results has been the same presented in Chapter 4 .

Figure 6.30 and Table 6.9 show the total input energy $E_{I}$ and the input energy by directions $E_{I, X}$ and $E_{I, Y}$. The training signal T10 has been included for completeness although it does not represent an earthquake. Results indicate that the maximum total input energy at the end of the sequence of simulations was $84.08 \mathrm{kNm}$ and, in average, the $44 \%$ was contributed by $E_{I, X}$ and the rest by $E_{I, Y}$. In all simulations, except C200i, $E_{I, Y}$ was larger than $E_{I, X}$. Table 6.9 also lists the contribution to the input energy of the training signal T10 and each seismic simulation $\Delta E_{I, X}$, $\Delta E_{I, Y}$ and $\Delta E_{I}$. Moreover, Figure 6.30 depicts the total absorbed energy $W_{\xi}+W_{p}$ that is approximately equal to the total input energy for high levels of energy dissipation (see Chapter 4).

Table 6. 9.Input energy

\begin{tabular}{ccccccccc}
\hline Test & $\begin{array}{c}\Delta \boldsymbol{E}_{\boldsymbol{I}, \boldsymbol{X}} \\
{[\mathbf{k N m}]}\end{array}$ & $\begin{array}{c}\boldsymbol{E}_{\boldsymbol{I}, \boldsymbol{X}} \\
{[\mathbf{k N m}]}\end{array}$ & $\begin{array}{c}\Delta \boldsymbol{E}_{\boldsymbol{I}, \boldsymbol{Y}} \\
{[\mathbf{k N m}]}\end{array}$ & $\begin{array}{c}\boldsymbol{E}_{\boldsymbol{I}, \boldsymbol{Y}} \\
{[\mathbf{k N m}]}\end{array}$ & $\begin{array}{c}\Delta \boldsymbol{E}_{\boldsymbol{I}} \\
{[\mathbf{k N m}]}\end{array}$ & $\begin{array}{c}\boldsymbol{E}_{\boldsymbol{I}} \\
{[\mathbf{k N m}]}\end{array}$ & $\frac{\boldsymbol{E}_{\boldsymbol{I}, \boldsymbol{X}}}{\boldsymbol{E}_{\boldsymbol{I}}}$ & $\frac{\boldsymbol{E}_{\boldsymbol{I}, \boldsymbol{Y}}}{\boldsymbol{E}_{\boldsymbol{I}}}$ \\
\hline T10 & 1.61 & 1.61 & 2.47 & 2.47 & 4.08 & 4.08 & 0.39 & 0.61 \\
$\mathbf{C 3 5}$ & 0.19 & 1.80 & 0.28 & 2.76 & 0.48 & 4.56 & 0.40 & 0.60 \\
$\mathbf{C 5 0}$ & 0.30 & 2.11 & 0.53 & 3.29 & 0.83 & 5.39 & 0.39 & 0.61 \\
C100 & 1.64 & 3.75 & 2.17 & 5.46 & 3.81 & 9.21 & 0.41 & 0.59 \\
$\mathbf{C 2 0 0 i}$ & 14.63 & 18.38 & 9.50 & 14.96 & 24.13 & 33.33 & 0.55 & 0.45 \\
$\mathbf{C 2 0 0}$ & 6.19 & 24.57 & 9.90 & 24.85 & 16.09 & 49.42 & 0.50 & 0.50 \\
C300 & 12.22 & 36.79 & 22.44 & 47.29 & 34.65 & 84.08 & 0.44 & 0.56 \\
Mean & --- & --- & --- & --- & --- & --- & 0.44 & 0.56 \\
\hline \hline
\end{tabular}




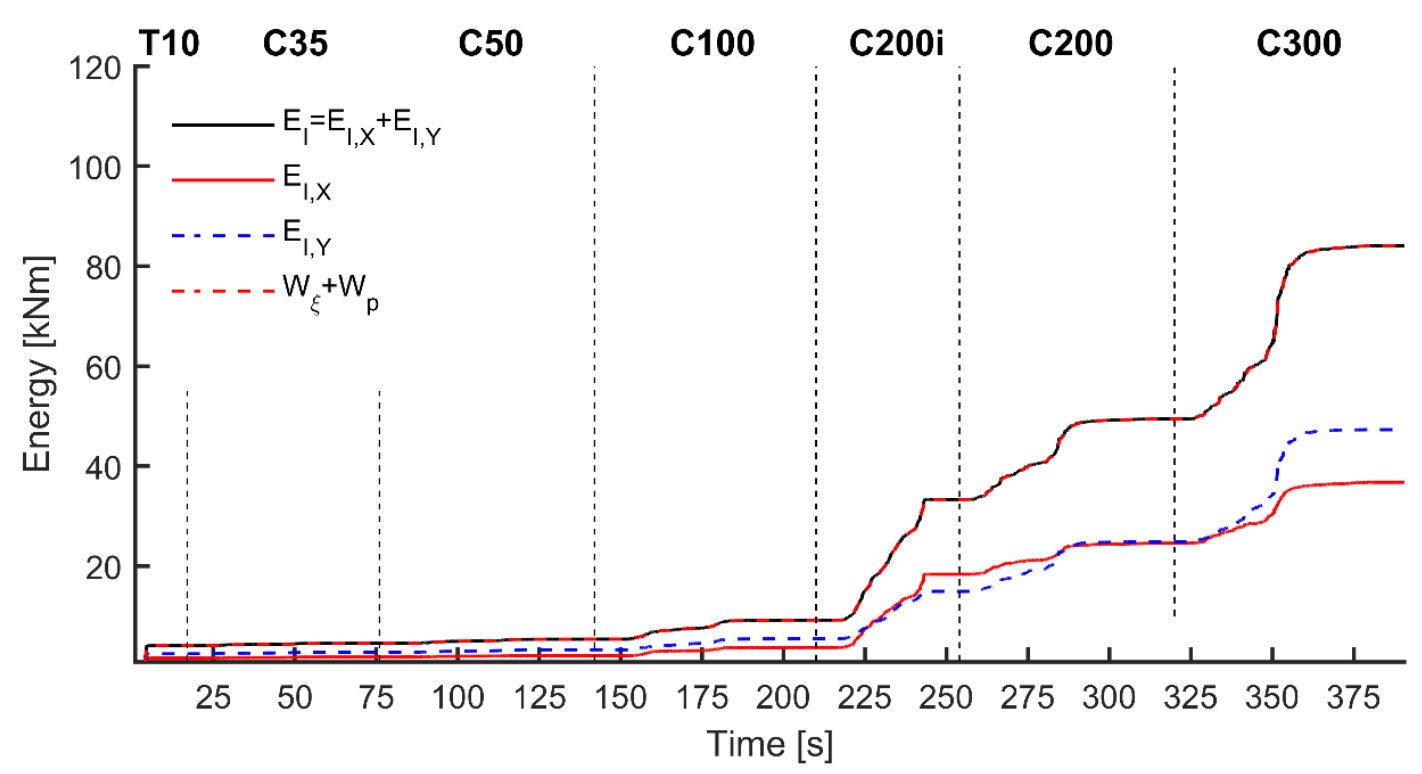

Figure 6. 30. History of input energy

Figure 6.31 exhibits the history of the energy that contributes to damage $E_{D}$, which is defined as $E_{D}=E_{I}-W_{\xi} \approx{ }_{s} W_{p}+{ }_{f} W_{p}$, where ${ }_{s} W_{p}$ is the energy dissipated through plastic deformations by dampers and ${ }_{f} W_{p}$ is the energy dissipated through plastic deformations by the main structure. Numeric values of these parameters are listed in Table 6.10.

Some features deserve mention in Figure 6.31:

7. The maximum $E_{D}$ at the end of simulations was $29.58 \mathrm{kNm}, 35 \%$ of the $E_{I}$ (Tables 6.10 and 6.11). The simulations that developed the highest values of $E_{D}$ were C200i and C300, which together represented about $80 \%$ of the total $E_{D}$.

8. During the training T10 and seismic simulations C35, C50 and C100, where the energy dissipated by plastic strains was relatively low (about $10 \%$ of the total $E_{D}$ ), dampers dissipated 2.2 times the energy dissipated by the main structure. However from the onset of simulation C200i on, the energy dissipated by dampers started to grow exponentially. At the end of the test, the proportion of energy dissipated by dampers was 5.7 times larger than the energy dissipated by the main structure. This means that dampers dissipated $85 \%$ and the main system $15 \%$ of $E_{D}$ (Table 6.10).

9. The ratio $E_{D} / E_{I}$ in terms of equivalent velocity $V_{D} / V_{E}$, ie. $\sqrt{E_{D} / E_{I}}$ was approximated following Akiyama (1985) with an equation that only depends on the inherent damping ratio $\xi$ in elastic range (1.7). This equation estimates $V_{D} / V_{E}=0.71$, whereas the value obtained in the simulation was 0.59 (Table 6.11). Akiyama`s equation is thus conservative.

10. The dissipated energy by damping $W_{\xi}$, plastic strains in the main structure ${ }_{f} W_{p}$ and plastic strains in dampers ${ }_{s} W_{p}$ represented $65 \%, 5 \%$ and $30 \%$ of the total input energy $E_{I}$ respectively (Table 6.11). 


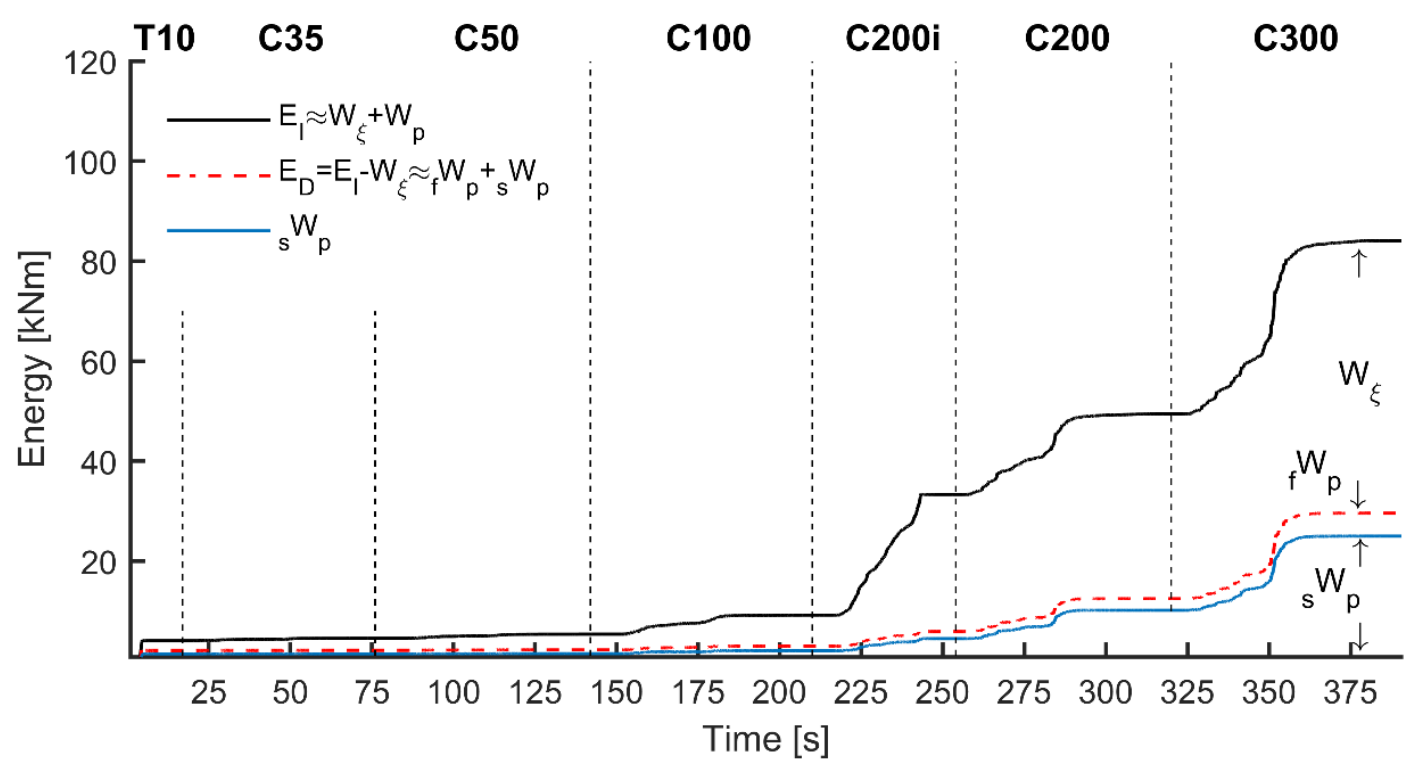

Figure 6. 31. History of energy dissipated by the structure

Table 6. 10. Energies that contribute to damage

\begin{tabular}{cccccccccc}
\hline Test & $\begin{array}{c}\boldsymbol{W}_{\xi} \\
{[\mathbf{k N m}]}\end{array}$ & $\begin{array}{c}\Delta \boldsymbol{E}_{\boldsymbol{D}} \\
{[\mathbf{k N m}]}\end{array}$ & $\begin{array}{c}\boldsymbol{E}_{\boldsymbol{D}} \\
{[\mathbf{k N m}]}\end{array}$ & $\begin{array}{c}{ }_{\boldsymbol{s}} \boldsymbol{\Delta} \boldsymbol{W}_{\boldsymbol{p}} \\
{[\mathbf{k N m}]}\end{array}$ & $\begin{array}{c}{ }_{\boldsymbol{s}} \boldsymbol{W}_{\boldsymbol{p}} \\
{[\mathbf{k N m}]}\end{array}$ & $\begin{array}{c}\boldsymbol{f}^{\Delta} \boldsymbol{\Delta} \boldsymbol{W}_{\boldsymbol{p}} \\
{[\mathbf{k N m}]}\end{array}$ & $\begin{array}{c}{ }_{\boldsymbol{f}} \boldsymbol{W}_{\boldsymbol{p}} \\
{[\mathbf{k N m}]}\end{array}$ & $\frac{{ }_{\boldsymbol{s}} \boldsymbol{W}_{\boldsymbol{p}}}{\boldsymbol{E}_{\boldsymbol{D}}}$ & $\frac{{ }_{\boldsymbol{f}} \boldsymbol{W}_{\boldsymbol{p}}}{\boldsymbol{E}_{\boldsymbol{D}}}$ \\
\hline $\mathbf{T 1 0}$ & 1.93 & 2.15 & 2.15 & 1.48 & 1.48 & 0.68 & 0.68 & 0.69 & 0.31 \\
$\mathbf{C 3 5}$ & 2.38 & 0.02 & 2.18 & 0.01 & 1.48 & 0.01 & 0.69 & 0.68 & 0.32 \\
$\mathbf{C 5 0}$ & 3.14 & 0.08 & 2.25 & 0.03 & 1.51 & 0.05 & 0.74 & 0.67 & 0.33 \\
$\mathbf{C 1 0 0}$ & 6.18 & 0.78 & 3.03 & 0.59 & 2.10 & 0.19 & 0.93 & 0.69 & 0.31 \\
$\mathbf{C 2 0 0 i}$ & 27.44 & 2.87 & 5.90 & 2.40 & 4.50 & 0.47 & 1.40 & 0.76 & 0.24 \\
$\mathbf{C 2 0 0}$ & 36.94 & 6.59 & 12.49 & 5.68 & 10.18 & 0.91 & 2.31 & 0.82 & 0.18 \\
$\mathbf{C 3 0 0}$ & 54.50 & 17.09 & 29.58 & 14.82 & 25.00 & 2.28 & 4.58 & 0.85 & 0.15 \\
\hline \hline
\end{tabular}

Table 6. 11. Energies in terms of equivalent velocities and relations with $E_{I}$

\begin{tabular}{|c|c|c|c|c|c|c|c|c|c|}
\hline Test & $\begin{array}{c}\Delta V_{E} \\
{[\mathrm{~cm} / \mathrm{s}]}\end{array}$ & $\begin{array}{c}V_{E} \\
{[\mathrm{~cm} / \mathrm{s}]}\end{array}$ & $\begin{array}{c}\Delta V_{D} \\
{[\mathrm{~cm} / \mathrm{s}]}\end{array}$ & $\begin{array}{c}V_{D} \\
{[\mathrm{~cm} / \mathrm{s}]}\end{array}$ & $\frac{W_{\xi}}{E_{I}}$ & $\frac{{ }_{s} W_{p}}{E_{I}}$ & $\frac{f^{W_{p}}}{E_{I}}$ & $\frac{E_{D}}{E_{I}}$ & $\frac{V_{D}}{V_{E}}$ \\
\hline T10 & 81.73 & 81.73 & $\begin{array}{l}9.35 \\
\end{array}$ & 59.35 & 0.47 & 0.36 & 0.17 & 0.53 & 0.73 \\
\hline C35 & 27.87 & 86.35 & 6.00 & 59.65 & 0.52 & 0.33 & 0.15 & 0.48 & 0.69 \\
\hline C50 & 36.95 & 93.93 & 11.08 & 60.67 & 0.58 & 0.28 & 0.14 & 0.42 & 0.65 \\
\hline C100 & 78.96 & 122.71 & 35.64 & 70.36 & 0.67 & 0.23 & 0.10 & 0.33 & 0.57 \\
\hline C200i & 198.63 & 233.48 & 68.52 & 98.22 & 0.82 & 0.13 & 0.04 & 0.18 & 0.42 \\
\hline C200 & 162.20 & 284.29 & 103.79 & 142.89 & 0.75 & 0.21 & 0.05 & 0.25 & 0.50 \\
\hline C300 & 238.05 & 370.80 & 167.19 & 219.93 & 0.65 & 0.30 & 0.05 & 0.35 & 0.59 \\
\hline
\end{tabular}

Table 6.12 lists the mechanical index of damage $I D_{i}$ of each damper installed in the specimen for each simulation. The maximum index falls short an $8 \%$, therefore more than $90 \%$ of the dampers capacity is still available at the end of simulations. In view of results, the most damaged damper is always the damper $\mathrm{N}^{\circ} 3$ and the least damaged up to simulation $\mathrm{C} 200$ is the damper $\mathrm{N}^{\circ} 1$. At the end of simulation $\mathrm{C} 300$, damper $\mathrm{N}^{\circ} 1$ consumed a $4.6 \%$, damper $\mathrm{N}^{\circ} 2$ a $4.3 \%$ and damper $\mathrm{N}^{\circ} 3$ a $7.7 \%$ of their ultimate capacity. This indicates that for low levels of intensity, the damage is distributed quite heterogeneously among dampers, however for high levels of intensity, the damage tends to approach in both horizontal directions. Figure 6.32 depicts the forcedisplacement curves of dampers up to the end of the last seismic simulation. 
Table 6. 12.Mechanical index of damage $I D_{i}$ of the slit-plate dampers (Figure 6.18)

\begin{tabular}{cccccccc}
\hline \multirow{2}{*}{ Damper } & $\begin{array}{c}\text { T10 } \\
{[\%]}\end{array}$ & $\begin{array}{c}\text { C35 } \\
{[\%]}\end{array}$ & $\begin{array}{c}\text { C50 } \\
{[\%]}\end{array}$ & $\begin{array}{c}\text { C100 } \\
{[\%]}\end{array}$ & $\begin{array}{c}\text { C200i } \\
{[\%]}\end{array}$ & $\begin{array}{c}\text { C200 } \\
{[\%]}\end{array}$ & $\begin{array}{c}\text { C300 } \\
{[\%]}\end{array}$ \\
\hline $\mathrm{N}^{\circ} 1$ & 0.1 & 0.1 & 0.1 & 0.2 & 0.8 & 1.8 & 4.6 \\
$\mathrm{~N}^{\circ} 2$ & 0.3 & 0.3 & 0.4 & 0.5 & 1.2 & 2.1 & 4.3 \\
$\mathrm{~N}^{\circ} 3$ & 0.5 & 0.5 & 0.5 & 0.7 & 1.2 & 3.1 & 7.7 \\
\hline \hline
\end{tabular}
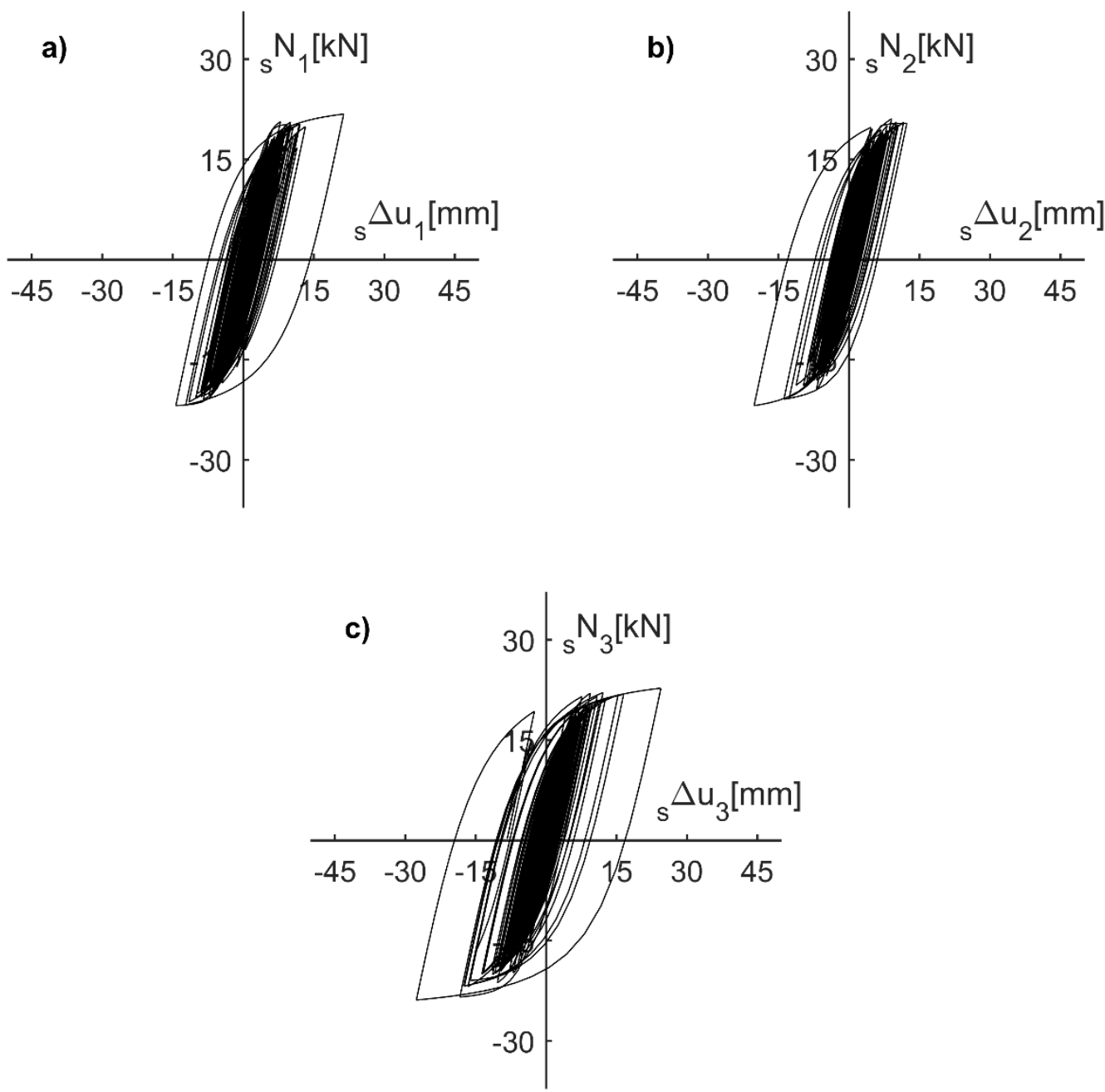

Figure 6. 32. Damper force-displacement curves up to simulation C300: a) Damper $\mathrm{N}^{\circ} 1$, b) Damper $\mathrm{N}^{\circ} 2$ and c) Damper $\mathrm{N}^{\circ} 3$

\section{COMPARISON OF THE REPSONSE OF SPECIMEN BS1 WITHOUT AND WITH DAMPERS}

The calibrated numerical model that represented the specimen BS1 was equipped with hysteretic dampers and subjected to the same initial training signal T10 and seismic simulations used in the shaking table tests. The responses of the structure with and without dampers are compared in terms of frequencies/periods, displacements, forces and energies in this section. The numerical model with dampers is referred to as BS1D herein.

The WFP structure without dampers (BS1) is more flexible than the one with dampers (BS1D). The fundamental period in the elastic range of BS1 was $0.38 s$, while BS1D had a fundamental 
period of $0.32 \mathrm{~s}$. Both structures have the same mass, but different damping matrix because although both used the same damping model i.e., $\mathbf{C}=a_{o} \mathbf{M}$, the value of $a_{o}$ was different. This parameter was obtained using the same value of $\xi$ at second mode, resulting that $a_{0, B S 1 D} / a_{0, B S 1}=1.24$. This means that the level of damping in the structure with dampers is $24 \%$ larger than in the structure without dampers. If this level of damping is expressed in terms of fraction of damping $\xi$, since the mass and the coefficient of damping are the same in BS1 and BS1D, the value of $\xi$ obviously increases as the frequency decreases when the structure enters the nonlinear range (Charney, 2008). Figure 6.33 shows the fraction of damping for both structural systems and highlights with symbols the damping ratios for the three main modes in elastic range (indicated with "Prior") and at the end of C300. BS1 reached a higher damping ratio than BS1D because BS1 resulted more damaged and therefore its free-vibration frequencies enlarged more than in BS1D. The damping ratios show in Figure 6.33 for BS1 come from applying the frequencies listed in Table 4.2 to the damping model, thus damping ratios here are not the values measured in the test, they are only approximations.

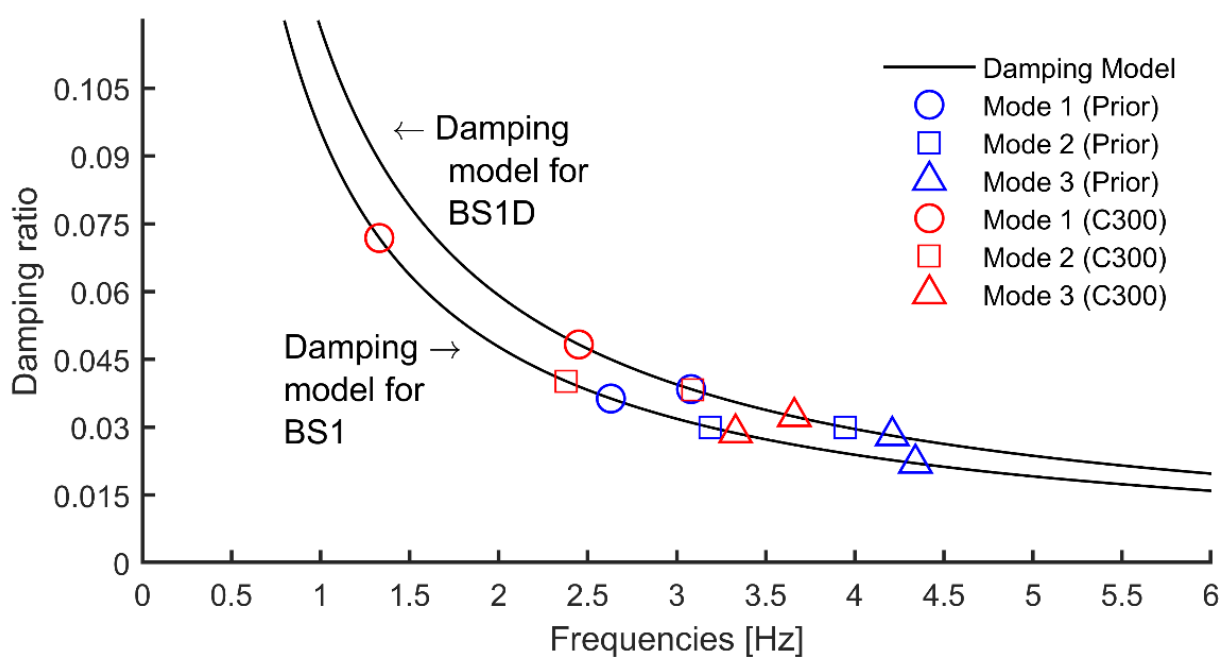

Figure 6. 33.Damping models for the specimens with and without dampers

One commonly used parameter to assess the damage in a building is the Inter-story Drift Index (IDI) (Tables 4.3 and 4.4 for BS1 and Tables 6.3 and 6.4 for BS1D). The two drift limits indicators used in this study (SEAOC and the proposed) pointed out that the structure without dampers reached the point of collapse while the structure with dampers barely reached the Life Safety (LS) threshold at the end of the tests. A very similar indicator to IDI but focusing on columns, it is the chord rotation demand. The maximum chord rotations normalized by the ultimate rotation capacity considering a circular $\left(\boldsymbol{\theta}_{\boldsymbol{s q r t}} / \boldsymbol{\theta}_{\boldsymbol{u}}\right)$ and rectangular $\left(\boldsymbol{\theta}_{\boldsymbol{m X Y}} / \boldsymbol{\theta}_{\boldsymbol{u}}\right)$ interaction are shown in Tables 4.7 and 4.8 for BS1 and Tables 6.6 and 6.7 for BS1D. The values of these ratios confirmed also that the specimen without dampers overcame the point of collapse (values greater than 1.0), whereas the specimen with dampers hardly scraped one-half of its capacity.

Table 6.13 shows the ratios of the maximum restoring forces of columns between both structural systems by levels, directions and tests. This ratio is defined as $F_{B S 1 D, \max } / F_{B S 1, \max }$, where $F_{B S 1 D, \text { max }}$ is the maximum restoring force in BS1D (Table 6.8) and $F_{B S 1, \max }$ (Table 4.10) is the maximum base shear exerted by inertial force in BS1. It is worth noting that the maximum base shear exerted by inertial forces are very close to the maximum restoring force because the former occurs near maximum displacements and therefore velocity is virtually zero. Results indicate that the addition of dampers in the first story produced an increase in the maximum restoring force response of columns in the first story (20\% in direction X and $29 \%$ in direction Y in average). 
Furthermore, in the second story, there was no influence in direction $\mathrm{X}$, and the maximum restoring force in the BS1D decreased a $25 \%$ in average in direction $\mathrm{Y}$.

Table 6. 13. Restoring forces ratios $\left(F_{B S 1 D, \max } / F_{B S 1, \max }\right)$

\begin{tabular}{ccccc}
\hline \multirow{3}{*}{ Test/Simulation } & \multicolumn{2}{c}{ Story 1 } & \multicolumn{2}{c}{ Story 2 } \\
\cline { 2 - 5 } & $\begin{array}{c}\text { Dir X } \\
{[\mathbf{k N}]}\end{array}$ & $\begin{array}{c}\text { Dir Y } \\
{[\mathbf{k N}]}\end{array}$ & $\begin{array}{c}\text { Dir X } \\
{[\mathbf{k N}]}\end{array}$ & $\begin{array}{c}\text { Dir Y } \\
{[\mathbf{k N}]}\end{array}$ \\
\hline T10 & 1.71 & 1.99 & 1.21 & 1.02 \\
$\mathbf{C 3 5}$ & 1.06 & 0.83 & 0.95 & 0.67 \\
$\mathbf{C 5 0}$ & 0.89 & 0.91 & 0.87 & 0.64 \\
C100 & 1.01 & 1.04 & 1.05 & 0.68 \\
C200i & 1.22 & 0.89 & 0.72 & 0.60 \\
C200 & 1.05 & 1.67 & 0.85 & 1.04 \\
C300 & 1.46 & 1.67 & 1.34 & 0.61 \\
\hline Mean & 1.20 & 1.29 & 1.00 & 0.75 \\
\hline \hline
\end{tabular}

Some differences were observed in terms of input energy between both structures, while in BS1 the input energy at the end of simulation C300 reached $109.31 \mathrm{kNm}$, the input energy in BS1D was $84.08 \mathrm{kNm}$, a $23 \%$ bellow. This difference is related with the difference of stiffness between both structures, since the input energy is a very stable quantity that is governed almost exclusively by the fundamental period and the mass of the structure. The values of input energy in terms of equivalent velocity $V_{E}$ were $423 \mathrm{~cm} / \mathrm{s}$ and $371 \mathrm{~cm} / \mathrm{s}$, respectively. Furthermore, the distribution of the input energy by directions was quite similar in average $\left(E_{I, X} / E_{I_{B S 1 D}}=\right.$ $0.44, E_{I, Y} / E_{I_{B S 1 D}}=0.56, E_{I, X} / E_{I_{B S 1}}=0.40$ and $\left.E_{I, Y} / E_{I_{B S 1}}=0.60\right)$.

On the other hand, in terms of the energy dissipated by inherent viscous damping $W_{\xi}$, the ratio $W_{\xi, B S 1 D} / W_{\xi, B S 1}$ gives 1.25 at the end of simulation C35 (both structures in elastic range) and then this ratio decreases up to 0.75 at the end of simulation C300 (Tables 4.13 and 6.10). Finally, in regard to the energy that contribute to damage $E_{D}$, an amount of $36.62 \mathrm{kNm}$ was dissipated in BS1, while $29.58 \mathrm{kNm}$ were dissipated in BS1D of which $25 \mathrm{kNm}$ were dissipated by dampers, and $4.58 \mathrm{kNm}$ by the main structure. In spite of the amount of $E_{D}$ dissipated for both systems was very similar, the main system in BS1D only dissipated the $15 \%$ of the total, which resulted in final states quite different, while BS1D remained with minor damage, BS1 collapsed.

\section{SEISMIC CAPACITY OF WFP STRUCTURES WITH HYSTERETIC DAMPERS IN TERMS OF ENERGY}

The seismic capacity in terms of energy of a WFP structure equipped with hysteretic dampers is analyzed under uni and bidirectional seismic loading. The benchmark numerical model calibrated with dynamic tests for the main structure and with pseudo-static tests for the SP dampers is used. The benchmark numerical model with dampers is subjected to the same seven sets of ground motions described in Chapter 5, five sets with seven bidirectional ground motions plus two sets with five unidirectional ground motions. The earthquakes were amplified with the same initial scaling factor $S F$, and after that scaled with integer multipliers (x1, x2, x3 ...) until the structure reached the seismic performance level (SPL) of Near Collapse (NC). Three limit states characterized by their corresponding SPLs were considered in this study. The first one corresponds to the SPL Fully Operational (FO), in which the structure and the dampers remain fully elastic and therefore without damage. The second is SPL Operational (OP), in which the WPF system remains elastic and only the dampers are damaged. The third SPL is NC, in which the main system is severely damaged and the dampers are also damaged but without failing. The 
Inter-story Drift Index of the $i$ story, $I D I_{i}$, defined as the ratio between the Inter-story Drift and the story height $\left(h_{i}\right)$, is used here as the engineering parameter to establish the upper limit of $I D I_{i}$ for the different SPLs defined above, denoted as $I D I_{i, F O}, I D I_{i, O P}$ and $I D I_{i, N C}$, respectively. Therefore, for FO, IDI $I_{1, F O}=0.4 \%\left({ }_{s} \delta_{y, 1}=0.4{ }_{f} \delta_{y, 1}\right.$ being $\left.{ }_{f} \delta_{y, 1}=0.01 h_{1}\right)$ and $I D I_{2, O P}=$ $1 \%$ for the second story (without dampers). For OP, the reference was the yield-displacement of the WFP system, thus $I D I_{i, O P}=1 \%$ for both stories. Finally, for SPL NC and according to the results obtained in Chapter 4, the limit was established at $I D I_{i, N C}=2.6 \%$ for both stories.

\subsection{Results}

\subsubsection{Input and dissipated energy}

Following the energy analysis developed in Chapter 5, the input energy $E_{I}$ on a structure under bidirectional seismic loading can be expressed in terms of equivalent velocity $V_{E}$ by (1.5), which can be decomposed in its components $V_{E, X}$ and $V_{E, Y}$. The same is applied to the total energy that contributes to damage, $E_{D}=E_{I}-W_{\xi}$, which can be also expressed in terms of equivalent velocity $V_{D}$ by (1.6) and divided in its components $V_{D, X}$ and $V_{D, Y}$. Moreover, $V_{D}$ and its components can be interpreted as the energy dissipation capacity through plastic deformations.

Figure 6.34 shows the energy capacity of the structure when it reached the SPLs of FO, OP and $\mathrm{NC}$, respectively. More precisely, in this figure, the subfigures a), b) and d) show $V_{E}$ (defined by its components $V_{E, X}$ and $V_{E, Y}$ ) obtained from nonlinear response history analyses (NRHAs) of the WFP structure model with hysteretic dampers and subjected to five sets of bidirectional ground motion records (sets 1 to 5) and two sets of unidirectional ground motions records (set $\mathrm{X}$ and $\mathrm{Y}$ ). The results of each set are identified in the figure with different colors. In regards to the unidirectional ground motion, they are identified in the legend with the letter X or Y added to the record name and hold the same symbol than its counterpart as bidirectional ground motion. The mean $\bar{x}$ (red dash line) and mean plus/minus one standard deviation $\sigma$ (blue dash line) are also depicted in the figure.

The average values shown in Figure 6.34, subfigure a), b) and d), are $\bar{V}_{E, F O}=36 \mathrm{~cm} / \mathrm{s}, \bar{V}_{E, O P}=$ $112 \mathrm{~cm} / \mathrm{s}$ and $\bar{V}_{E, N C}=301 \mathrm{~cm} / \mathrm{s}$, with standard deviations equal to $11 \mathrm{~cm} / \mathrm{s}, 34 \mathrm{~cm} / \mathrm{s}$ and $84 \mathrm{~cm} / \mathrm{s}$, respectively. In terms of equivalent velocity this entails that the energy capacity of the structure in terms of input energy for SPL NC is, on average, 2.70 times larger than that for SPL OP. In terms of energy, the increase is more than sevenfold, i.e. $7.29\left(=2.70^{2}\right)$.

For comparison purposes, the seismic performance of the structure without dampers (BS1) subjected to the same ground motions is discussed next. Figure 6.35 shows the energy capacity of the structure without dampers when it reached the SPL of OP and NC. It is worth noting that the energies presented in Chapter 5 for the structure without dampers are different from those shown in Figure 6.34. The former refer to the state when the structure is on the brink of yielding and at failure, while the later refer to the SPL of OP and NC determined form the IDIs as explained at the beginning of this section. The same representation criteria as in Figure 6.34 are used. The average values shown in Figure 6.35 , subfigure a), b) are, $\bar{V}_{E, O P}=64 \mathrm{~cm} / \mathrm{s}$ and $\bar{V}_{E, N C}=171 \mathrm{~cm} / \mathrm{s}$, with standard deviations equal to $14 \mathrm{~cm} / \mathrm{s}$ and $45 \mathrm{~cm} / \mathrm{s}$, respectively. According to Chapter 5 , the value of $\bar{V}_{E, N C}$ represents $76 \%$ of its ultimate capacity $\left(V_{E u}=\right.$ $226 \mathrm{~cm} / \mathrm{s}$ ). Note that the criterion for determining the SPL of NC and the state of failure are not the same; this is the reason why the values of $\bar{V}_{E, N C}$ and $V_{E u}$ are different. Further, the ratio $\bar{V}_{E, N C} / \bar{V}_{E, \text { OP }}$ is equal to 2.67 , practically equal to that obtained for the structure with dampers 
(2.70). In addition, the structure with dampers is able to endure 1.76 times more energy input in terms of $V_{E}$ than the structure without dampers until SPL NC. In terms of energy, this means three times more energy $\left(=1.76^{2}\right)$.

\begin{tabular}{|c|c|c|c|c|c|c|}
\hline MANJIL-1636 & DUZCE-1619 & WHITTIER-673 & 米 & CHALFANT-549 & $x$ & SMADRE-1643Y \\
\hline CAPEMEND-826 & MORGAN-460 & SUPERST-729 & $\times$ & LANDERS-854 & + & CHICHI-1490Y \\
\hline SFERN-68 & IMPVALL-175 & ITALY-289 & & NORTHR-1079 & $\mathrm{O}$ & KOBE-1115Y \\
\hline SMADRE-1643 & LOMAP-799 & KOCAELI- 1162 & & CHICHI-1328 & $\diamond$ & LANDERS-888Y \\
\hline CHICHI-1435 & CHICHI- 1534 & HECTOR-1829 & $\triangle$ & LOMAP-765 & 米 & CHALFANT-549Y \\
\hline IMPVALL-186 & KOBE-1115 & COALINGA-352 & $x$ & SMADRE-1643X & ---- & $\bar{x}$ \\
\hline LANDERS-833 & NORTHR-986 & LANDERS-888 & + & CHICHI-1490X & ---- & $\bar{x} \pm \sigma$ \\
\hline CHICHI-1490 & LANDERS-850 & FRIULI-125 & $\mathrm{O}$ & KOBE-1115X & & \\
\hline NORTHR-971 & HECTOR-1766 & HECTOR-1794 & \rangle & LANDERS-888X & & \\
\hline HECTOR-1762 & COALINGA-362 & CHICHI-1349 & 米 & CHALFANT-549X & & \\
\hline
\end{tabular}
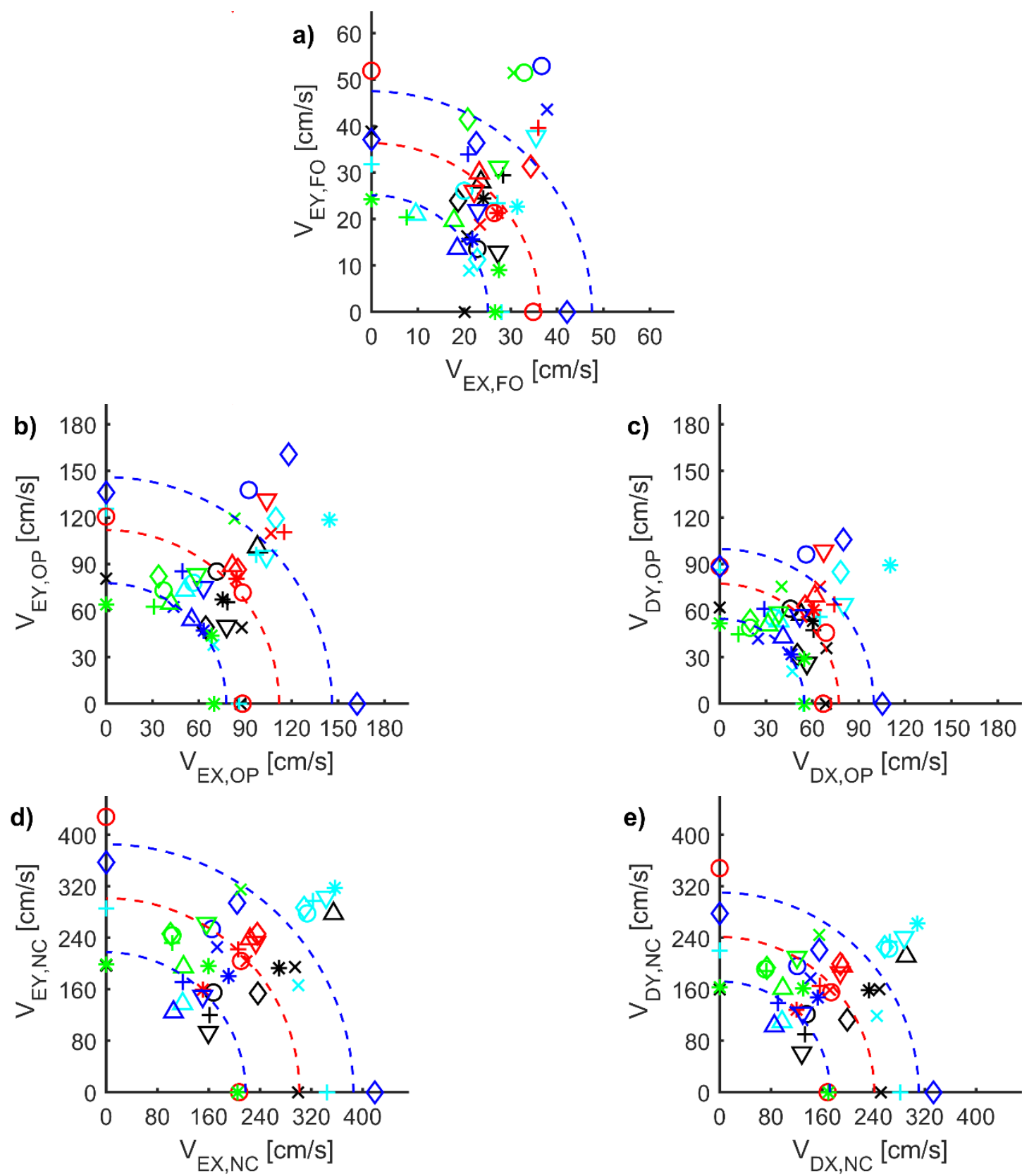

Figure 6. 34. Energy capacity of the structure with dampers: a) input energy for SPL FO, b) input energy for SPL OP, c) hysteretic energy for SPL OP, d) input energy for SPL NC and e) hysteretic energy for SPL NC 


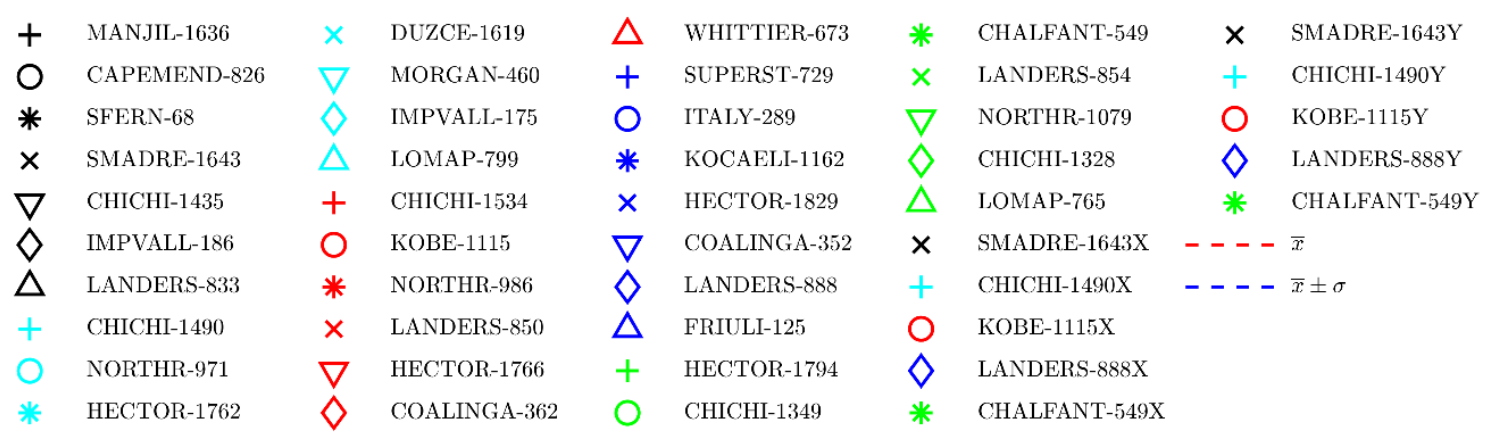

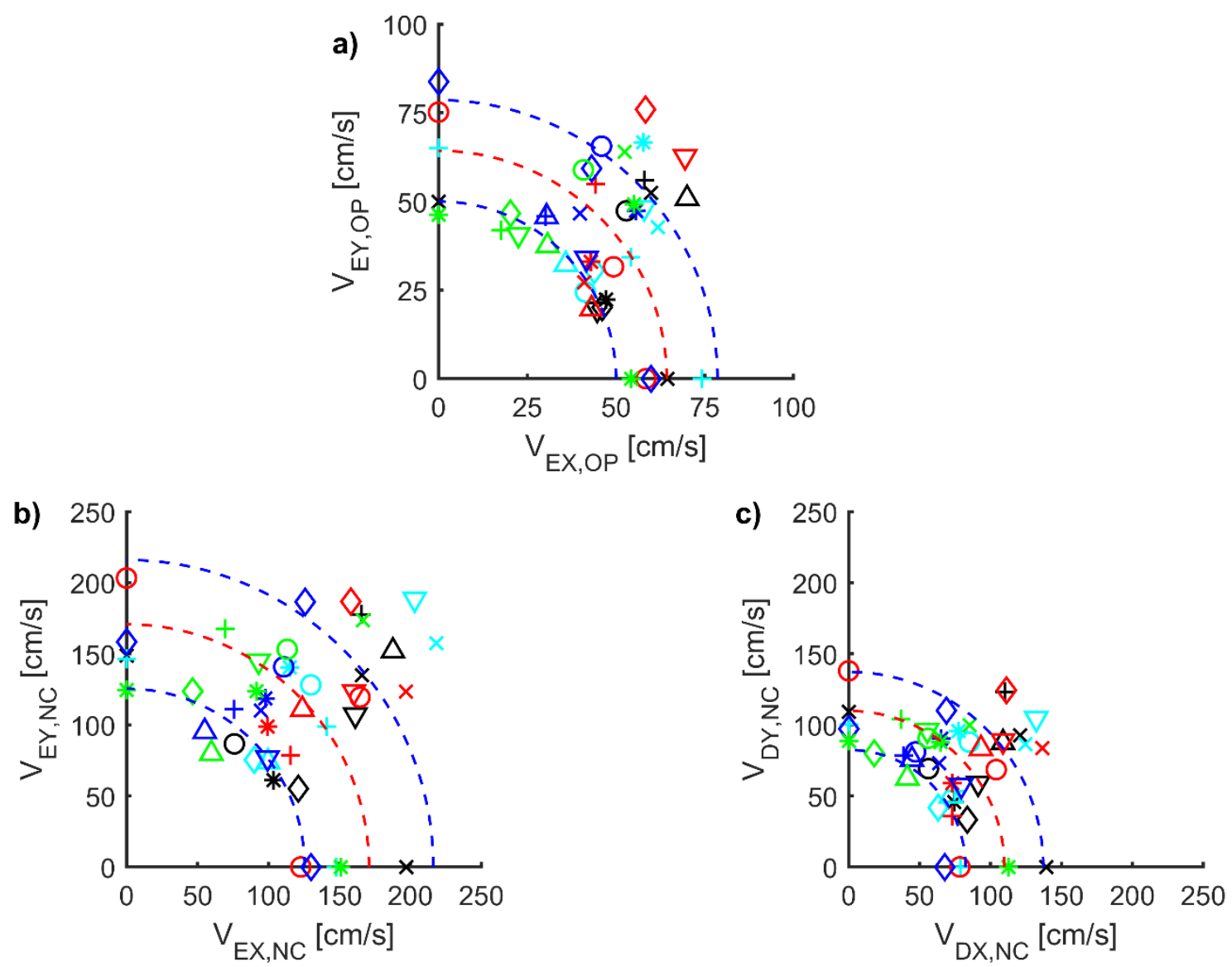

Figure 6. 35. Energy capacity of the structure without dampers: a) input energy for SPL $\mathrm{OP}, \mathrm{b})$ input energy for SPL NC and c) hysteretic energy for SPL NC

A more detailed analysis of the results obtained for the structure with dampers is reported in Table 6.14, where the mean and the coefficient of variation, COV , of the input energy of the three SPLs are shown for each set of records. Moderate differences are seen among the different groups for $V_{E, F O}$ which increased for $V_{E, O P}$ and especially for $V_{E, N C}$, with $C O V S$ around 0.30 . Furthermore, the differences between the input energy achieved for the different SPLs under each set of ground motions are analyzed by means of the ratios $V_{E, O P} / V_{E, F O}$ and $V_{E, N C} / V_{E, F O}$. Moderate differences are seen for $V_{E, O P} / V_{E, F O}$, with a mean of 3.22. For $V_{E, N C} / V_{E, F O}$ the mean increases to 8.82. The highest values for the latter are found under Set X, Set 1 and especially Set $2\left(V_{E, N C} / V_{E, F O}=\right.$ 12.23). Further, the structure under the sets 4,5 and $Y$ showed the highest values for the elastic input energy $V_{E, F O}$, but the trend was reversed for $V_{E, N C}$ (i.e. when the structure undergoes large plastic deformations), by obtaining the highest values under sets $X, 1$ and 2 . Therefore, it is observed a reduction of the seismic capacity of the structure in terms of energy dissipated through plastic deformations when the $\mathrm{Y}$ component of the seismic action is the strongest. It is worth 
remembering that the structure analyzed in this study presents eccentricities of the center of mass respect to the center of stiffness in the $\mathrm{Y}$ direction, while is symmetric in the $\mathrm{X}$ direction.

Table 6. 14. Analysis of the input energy obtained from NRHAs.

\begin{tabular}{|c|c|c|c|c|c|c|c|c|c|c|}
\hline Set & $\begin{array}{l}\text { mean } \\
V_{E, F O} \\
(\mathrm{~cm} / \mathrm{s})\end{array}$ & $\begin{array}{c}C O V \\
V_{E, F O}\end{array}$ & $\begin{array}{l}\text { mean } \\
V_{E, O P} \\
(\mathrm{~cm} / \mathrm{s})\end{array}$ & $\begin{array}{c}C O V \\
V_{E, O P}\end{array}$ & $\begin{array}{l}\text { mean } \\
V_{E, N C} \\
(\mathrm{~cm} / \mathbf{s})\end{array}$ & $\begin{array}{c}C O V \\
V_{E, N C}\end{array}$ & $\begin{array}{l}\text { mean } \\
V_{E, O P} \\
V_{E, F O}\end{array}$ & $\begin{array}{l}\text { COV } \\
V_{E, O P} \\
V_{E, F O}\end{array}$ & $\begin{array}{l}\text { mean } \\
\frac{V_{E, N C}}{V_{E, F O}}\end{array}$ & $\begin{array}{l}\text { COV } \\
V_{E, N C} \\
V_{E, F O}\end{array}$ \\
\hline $\mathbf{X}$ & 30.36 & 0.25 & 98.58 & 0.33 & 294.89 & 0.28 & 3.28 & 0.21 & 10.15 & 0.31 \\
\hline 1 & 32.15 & 0.15 & 104.14 & 0.17 & 289.98 & 0.30 & 3.29 & 0.18 & 9.19 & 0.31 \\
\hline 2 & 32.94 & 0.29 & 127.21 & 0.29 & 391.20 & 0.24 & 4.00 & 0.29 & 12.23 & 0.23 \\
\hline 3 & 38.64 & 0.20 & 136.04 & 0.16 & 301.72 & 0.12 & 3.64 & 0.24 & 8.04 & 0.19 \\
\hline 4 & 40.87 & 0.35 & 113.43 & 0.40 & 255.92 & 0.24 & 2.92 & 0.32 & 6.69 & 0.26 \\
\hline 5 & 40.85 & 0.36 & 92.30 & 0.26 & 278.61 & 0.16 & 2.44 & 0.24 & 7.55 & 0.30 \\
\hline $\mathbf{Y}$ & 36.77 & 0.25 & 105.36 & 0.27 & 293.24 & 0.31 & 2.93 & 0.25 & 8.02 & 0.19 \\
\hline All & 36.31 & 0.31 & 111.81 & 0.31 & 301.39 & 0.28 & 3.22 & 0.30 & 8.82 & 0.33 \\
\hline
\end{tabular}

Figure 6.36 shows the mean and error bars of $\theta_{V E}$ defined as $\theta_{V E}=\operatorname{atan}\left(V_{E, Y} / V_{E, X}\right)$, obtained for each SPL under the different sets of bidirectional ground motions (Set 1 to Set 5). It can be observed that as long as the intensity of the seismic action grows, the differences between components are also higher. For this reason, $\theta_{V E}$ decreases from SPL FO to SPL NC in Set 1 and the opposite occurs in sets 3,4 and 5. This effect can be attributed to the lack of redistribution of the damage due to torsional effects. The dampers installed in the WFP system successfully reduced the torsional response because of: i) the eccentricity reduction in design, ii) the lack of stiffness degradation and iii) the overstrength gained by strain hardening (Figure 6.16).

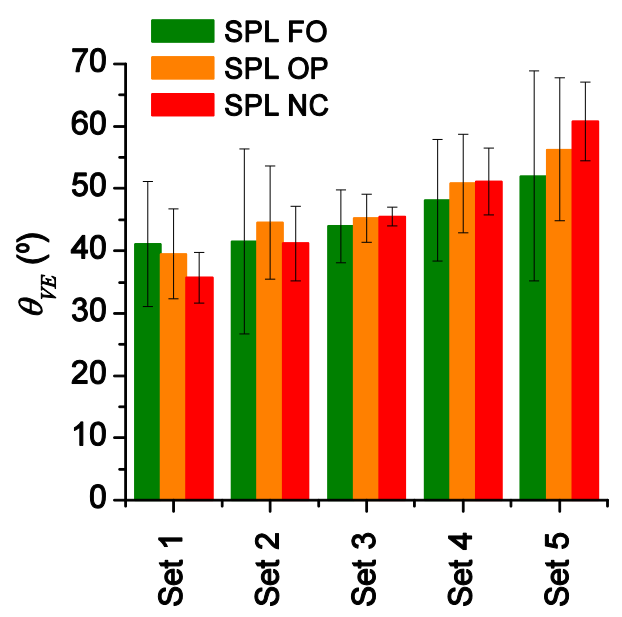

Figure 6. 36. Mean and error bars of $\theta_{V E}$ for the different SPLs

In Figure 6.34, the subfigures c) and e) show the maximum energy dissipated by the WFP structure with dampers (BS1D) through plastic deformations for SPLs OP and NC in terms of equivalent velocity, i.e. $V_{D, O P}$ and $V_{D, N C}$, respectively. The same representation criteria as in the subfigure a) are used. The average values shown in these subfigures with red dashed lines are $\bar{V}_{D, O P}=77 \mathrm{~cm} / \mathrm{s}$ and $\bar{V}_{D, N C}=241 \mathrm{~cm} / \mathrm{s}$, with standard deviations in dashed blue lines equal to $22 \mathrm{~cm} / \mathrm{s}$ and $70 \mathrm{~cm} / \mathrm{s}$, respectively. In Figure 6.35, subfigure c) reports the maximum energy dissipated through plastic deformations in the structure without dampers (BS1). The average value shown in these subfigure is $\bar{V}_{D, N C}=110 \mathrm{~cm} / \mathrm{s}$ with standard deviations equal to $27 \mathrm{~cm} / \mathrm{s}$. These results indicate that the structure with dampers is able to dissipate through plastic deformations, expressed in terms of equivalent velocity, much more energy (2.19 times) that the 
structure without dampers. In terms of energy, about five times more $\left(=2.19^{2}\right)$ when both reach the SPL NC.

A more detailed analysis of the results on the energy that contributed to damage for the structure with dampers is reported in Table 6.15. It is shown that under the sets of ground motions $X, 1$ and 2 the structure exhibits the highest capacity to dissipate energy by plastic deformations. The same trend was observed with the input energy. Moreover, this capacity is on average more than threefold, in terms of equivalent velocity, for SPL NC than the obtained for SPL OP. In terms of energy, it is more than ten times $\left(=3.24^{2}\right)$. The highest differences appear under unidirectional seismic loadings (Sets $\mathrm{X}$ and $\mathrm{Y}$ ) and the bidirectional seismic loadings formed by Sets 1, and 2 for which the $\mathrm{X}$ component is the strongest component of the seismic action.

Table 6. 15. Analysis of the energy that contributes to damage obtained from NRHAs.

\begin{tabular}{|c|c|c|c|c|c|c|c|c|c|c|}
\hline Set & $\begin{array}{l}\text { mean } \\
V_{D, O P} \\
{[\mathrm{~cm} / \mathrm{s}]}\end{array}$ & $\begin{array}{c}\text { COV } \\
V_{D, O P}\end{array}$ & $\begin{array}{l}\text { mean } \\
V_{D, O P} \\
V_{E, O P}\end{array}$ & $\begin{array}{l}\text { COV } \\
V_{D, O P} \\
V_{E, O P}\end{array}$ & $\begin{array}{c}\text { mean } \\
V_{D, N C} \\
{[\mathrm{~cm} / \mathrm{s}]}\end{array}$ & $\begin{array}{c}\text { COV } \\
V_{D, N C}\end{array}$ & $\begin{array}{l}\text { mean } \\
V_{D, N C} \\
V_{E, N C}\end{array}$ & $\begin{array}{c}\text { COV } \\
V_{D, N C} \\
V_{E, N C}\end{array}$ & $\begin{array}{l}\text { mean } \\
V_{D, N C} \\
V_{D, O P}\end{array}$ & $\begin{array}{l}\text { COV } \\
V_{D, N C} \\
V_{D, O P}\end{array}$ \\
\hline$X$ & 70.04 & 0.27 & 0.72 & 0.09 & 241.06 & 0.27 & 0.82 & 0.02 & 3.53 & 0.26 \\
\hline 1 & 73.08 & 0.11 & 0.71 & 0.11 & 235.98 & 0.31 & 0.81 & 0.03 & 3.22 & 0.28 \\
\hline 2 & 89.77 & 0.33 & 0.70 & 0.06 & 320.27 & 0.25 & 0.82 & 0.02 & 3.77 & 0.29 \\
\hline 3 & 94.53 & 0.13 & 0.70 & 0.07 & 240.51 & 0.13 & 0.80 & 0.03 & 2.57 & 0.16 \\
\hline 4 & 78.98 & 0.37 & 0.70 & 0.07 & 202.71 & 0.21 & 0.80 & 0.04 & 2.80 & 0.33 \\
\hline 5 & 61.92 & 0.19 & 0.68 & 0.09 & 220.27 & 0.15 & 0.79 & 0.03 & 3.60 & 0.10 \\
\hline $\mathrm{Y}$ & 67.36 & 0.18 & 0.66 & 0.11 & 223.43 & 0.31 & 0.76 & 0.04 & 3.27 & 0.18 \\
\hline All & 77.22 & 0.29 & 0.70 & 0.09 & 241.35 & 0.29 & 0.80 & 0.04 & 3.24 & 0.28 \\
\hline
\end{tabular}

Furthermore, Table 6.15 also reports the mean of the ratios $V_{D, O P} / V_{E, O P}$ and $V_{D, N C} / V_{E, N C}$, obtained for the different set of records for both SPL, OP and NC. The mean of $V_{D, O P} / V_{E, O P}$ under each set of records was in a range between 0.66 and 0.72 , being the absolute mean, taking into account all the records, equal to 0.70 . In regards to $V_{D, N C} / V_{E, N C}$, the values move in a range between 0.76 and 0.82 and the absolute mean is 0.80 . Two aspects related to these results deserve special attention. The first one is the low dispersion achieved for both cases, with $C O V$ equal at most to 0.11 and 0.04 for $V_{D, O P} / V_{E, O P}$ and $V_{D, N C} / V_{E, N C}$, respectively. The second one is that if and when the stronger component of the seismic action is the $\mathrm{X}$ direction (i.e. the direction of the axis of symmetry of the specimen), the aforementioned ratios are higher, and therefore, the capacity to dissipate energy by plastic deformations is also higher.

As indicated above, the mean of $V_{D, O P} / V_{E, O P}$ was $0.70(C O V=0.09)$ and the mean of $V_{D, N C} / V_{E, N C}$ was $0.80(\mathrm{COV}=0.04)$. Substituting the damping ratio (3.8\% established in Table $6.2)$ in the equation proposed by Akiyama (1.7) gives 0.71 , which is close to both values $(0.70$ and 0.80$)$.

\subsubsection{Differences on the capacity under unidirectional and bidirectional seismic loadings}

As pointed out in Chapter 5, there is still controversy in regards to the seismic capacity of structures obtained through independent unidirectional analysis along two orthogonal directions

(De Stefano \& Faella, 1996; Dutta \& Kunnath, 2013; Lee \& Hong, 2010; Rodrigues, Arêde, Varum, \& Costa, 2013; Rodrigues, Furtado, \& Arêde, 2015). To shed light to this issue, a comparison is carried out in this section between the capacity of the WFP system with hysteretic dampers (obtained from the analysis under unidirectional seismic loadings using the records 
included in Set $\mathrm{X}$ and Set $\mathrm{Y}$ ) and that obtained from the analyses under bidirectional seismic loadings using both components of the records considered in the previous ones. In this case, only SPLs OP and NC are considered. The input energy and dissipated energy obtained for each SPL in terms of equivalent velocity under unidirectional loading are represented by $V_{E X S P L}^{u n i}$ and $V_{D X, S P L}^{u n i}$ along $\mathrm{X}$ direction, and by $V_{E Y, S P L}^{u n i}$ and $V_{D Y, S P L}^{u n i}$ along the $\mathrm{Y}$ direction. Moreover, $V_{E X, S P L}^{u n i}$ and $V_{E Y, S P L}^{u n i}$ can be used to obtain an estimation of the capacity of the structure in terms of input energy, $V_{E, S P L}^{*}$, through the expression $V_{E, S P L}^{*}=\sqrt{\left(V_{E X, S P L}^{u n i}\right)^{2}+\left(V_{E Y, S P L}^{u n i}\right)^{2}}$. By applying a similar procedure, the estimation of the total dissipated energy, $V_{D, S P L}^{*}$, is obtained through the expression $V_{D, S P L}^{*}=\sqrt{\left(V_{D X, S P L}^{u n i}\right)^{2}+\left(V_{D Y, S P L}^{u n i}\right)^{2}}$.

Tables 6.16 and 6.17 report the results obtained to compare, for each SPL, the seismic capacity of the WFP system with hysteretic dampers under unidirectional or under bidirectional loadings, in terms of input energy and dissipated energy, respectively.

Table 6. 16. Seismic capacity comparison in terms of input energy: unidirectional vs bidirectional loadings

\begin{tabular}{|c|c|c|c|c|c|c|}
\hline Records & $\frac{V_{E X, O P}^{u n i}}{V_{E, O P}}$ & $\frac{V_{E Y, O P}^{u n i}}{V_{E, O P}}$ & $\frac{V_{E, O P}^{*}}{V_{E, O P}}$ & $\frac{V_{E X, N C}^{u n i}}{V_{E, N C}}$ & $\frac{V_{E Y, N C}^{u n i}}{V_{E, N C}}$ & $\frac{V_{E, N C}^{*}}{V_{E, N C}}$ \\
\hline S. Madre-1643 & 0.86 & 0.80 & 1.18 & 0.85 & 0.56 & 1.02 \\
\hline Chichi-1490 & 0.63 & 0.92 & 1.12 & 0.78 & 0.65 & 1.02 \\
\hline Kobe-1115 & 0.78 & 1.06 & 1.31 & 0.71 & 1.46 & 1.62 \\
\hline Landers-888 & 0.81 & 0.68 & 1.06 & 1.17 & 1.00 & 1.54 \\
\hline Chalfant-549 & 0.86 & 0.79 & 1.17 & 0.81 & 0.78 & 1.13 \\
\hline mean & 0.79 & 0.85 & 1.17 & 0.86 & 0.89 & 1.26 \\
\hline $\mathrm{COV}$ & 0.10 & 0.14 & 0.07 & 0.17 & 0.33 & 0.19 \\
\hline
\end{tabular}

Table 6. 17. Seismic capacity comparison in terms of dissipated energy: unidirectional vs bidirectional loadings

\begin{tabular}{|c|c|c|c|c|c|c|}
\hline Records & $\frac{V_{D X, O P}^{u n i}}{V_{D, O P}}$ & $\frac{V_{D Y, O P}^{u n i}}{V_{D, O P}}$ & $\frac{V_{D, O P}^{*}}{V_{D, O P}}$ & $\frac{V_{D X, N C}^{u n i}}{V_{D, N C}}$ & $\frac{V_{D Y, N C}^{u n i}}{V_{D, N C}}$ & $\frac{V_{D, N C}^{*}}{V_{D, N C}}$ \\
\hline S. Madre-1643 & 0.88 & 0.80 & 1.19 & 0.85 & 0.54 & 1.01 \\
\hline Chichi-1490 & 0.63 & 1.00 & 1.19 & 0.80 & 0.62 & 1.01 \\
\hline Kobe-1115 & 0.81 & 1.07 & 1.34 & 0.72 & 1.49 & 1.66 \\
\hline Landers-888 & 0.79 & 0.67 & 1.04 & 1.23 & 1.03 & 1.61 \\
\hline Chalfant-549 & 0.88 & 0.84 & 1.22 & 0.82 & 0.79 & 1.13 \\
\hline mean & 0.80 & 0.70 & 1.19 & 0.88 & 0.78 & 1.28 \\
\hline $\mathrm{COV}$ & 0.10 & 0.17 & 0.07 & 0.19 & 0.36 & 0.21 \\
\hline
\end{tabular}

For OP, the capacity showed for most records under unidirectional loadings is smaller than that obtained under bidirectional loadings, being on average $79 \%$ to $85 \%$ for $V_{E}$ and $70 \%$ to $80 \%$ for $V_{D}$. For SPL NC the same trend is observed, but with higher values $86 \%$ to $89 \%$ for $V_{E}$ and $78 \%$ to $88 \%$ for $V_{D}$. Similar results were obtained by Rodriguez H. et al. (2015) in columns subjected to biaxial cyclic loadings and variable axial loads. Nevertheless, there are some exceptions; one is the response under the $\mathrm{Y}$ component of Kobe-1115; the other is the $\mathrm{X}$ component of Landers-888 in SPL NC. Both cases show values of $V_{E}$ and $V_{D}$ that are higher than those under bidirectional seismic action (about 50\% for Kobe-1115 and about 20\% for Landers888). The limited number of records used for this study do not allow to make a general statement 
about the higher capacity of structures under bidirectional loading in comparison with unidirectional loading. It is worth noting that the columns of the WFP system are prone to undergo variable axial loads under both unidirectional and bidirectional cyclic loadings due to the scheme of the structure itself (three columns). This could explain the results.

Furthermore, Tables 6.16 and 6.17 also indicate the differences observed between the capacity in terms of input energy estimated from the uniaxial analyses under $\mathrm{X}$ and $\mathrm{Y}$ components of the selected seismic actions and the obtained in the bidirectional analyses under both components of the referred seismic actions. In all cases, $V_{E, S P L}^{*}$ and $V_{D, S P L}^{*}$ exceeded the counterpart $V_{E, S P L}$ and $V_{D, S P L}$. For SPL OP the differences, on average, are about $18 \%$ with $C O V=0.07$. For SPL NC the differences are higher, being about $27 \%$ with $C O V=0.20$. According to results of this Chapter and the previous one, while the structure remains in elastic range $V_{E, S P L}$ can be approximated by $V_{E, S P L}^{*}$. However, when some parts of the structure enter in plastic range $V_{E, S P L}^{*}$ and $V_{D, S P L}^{*}$ overestimate $V_{E, S P L}$ and $V_{D, S P L}$, respectively.

\subsubsection{Ductility level for SPL NC}

The ductility level attained in the analyses for SPL NC is studied here through the apparent plastic deformation of the $i$ story along the $\mathrm{X}$ and $\mathrm{Y}$ directions, calculated separately for the WPF system (flexible system or main structure), ${ }_{f} \mu_{X, i}$ and ${ }_{f} \mu_{Y, i}$, and for dampers (the stiff part), ${ }_{s} \mu_{X, i}$ and ${ }_{s} \mu_{Y, i}$, respectively. For the flexible part (main system), ${ }_{f} \mu_{X, i}$ is defined as ${ }_{f} \mu_{X, i}=\left(\delta_{\max X, i}-\right.$ $\left.{ }_{f} \delta_{y X, i}\right) /{ }_{f} \delta_{y X, i}$ where $\delta_{\max X, i}$ and ${ }_{f} \delta_{y X, i}$ are the maximum Inter-story Drift (measured at the center of stiffness of the story) and the yield Inter-story Drift of the main structure for the $i$ story, respectively, along the $\mathrm{X}$ direction, and $\mu_{f} \mu_{Y, i}$ is as ${ }_{f} \mu_{Y, i}=\left(\delta_{\max Y, i}-{ }_{f} \delta_{y Y, i}\right) /{ }_{f} \delta_{y Y, i}$, where $\delta_{\max , i}$ and ${ }_{f} \delta_{y Y, i}$ are the counterpart variables defined above but along the $\mathrm{Y}$ direction. For the stiff part (dampers), the same definition is used for ${ }_{s} \mu_{X, i}$ and ${ }_{s} \mu_{Y, i}$, changing the subindex ' $f$ ' by ' $s$ ', and using ${ }_{s} \delta_{y X, i}$ and ${ }_{s} \delta_{y Y, i}$ for the yield Inter-story Drift of the dampers along $\mathrm{X}$ and $\mathrm{Y}$ directions instead of ${ }_{f} \delta_{y X, i}$ and ${ }_{s} \delta_{y Y, i}$. The SPL NC was achieved in all cases at the first story $(i$ $=1$ ), for which the analyses stopped when $I D I_{1}$ exceeded $I D I_{\max }=2.6 \%$ in any direction. In contrast, for the second story, the low values achieved for $\delta_{\max X, 2}$ and $\delta_{\max Y, 2}$ led to values about zero for both ${ }_{f} \mu_{X, 2}$ and ${ }_{f} \mu_{Y, 2}$. Taking into account that ${ }_{f} \delta_{y X, 1}={ }_{f} \delta_{y Y, 1}=14 \mathrm{~mm}$, ${ }_{s} \delta_{y X, 1}={ }_{s} \delta_{y Y, 1}=5.6 \mathrm{~mm}$ and $I D I_{\max }=I D I_{\max , N C}=2.6 \%$, the maximum apparent plastic deformation for WFP system and for hysteretic dampers is $\mu_{\max , 1}=1.6$ and ${ }_{s} \mu_{\max , 1}=5.5$, respectively. This means that for the structure investigated in this study, the ductility level demand in dampers is about triple than the considered in the WFP system. This is consistent with the fact that, in design, the yield deformation of the dampers was made 0.4 times that of the main structure (i.e. $1 / 0.4=2.5$, that is a value close to 3 ). Figure 6.37 offers the mean of the maximum apparent plastic deformation achieved in the WFP system in subfigure a), and in hysteretic dampers in subfigure $b$ ) under the different set of ground motion records for each direction. It can be observed that under sets X, 1 and 2, SPL NC is achieved under the X direction for which the input energy of the $\mathrm{X}$ component of the seismic action is the highest, because the mean of ${ }_{f} \mu_{X, 1}$ and ${ }_{s} \mu_{X, 1}$ correspond to $\mu_{\max , 1}$ and $\mu_{s} \mu_{\max , 1}$, respectively. The opposite occurs under sets 4,5 and $\mathrm{Y}$. Nevertheless, under set 3 there is no a specific direction for which SPL NC is achieved. 
a)

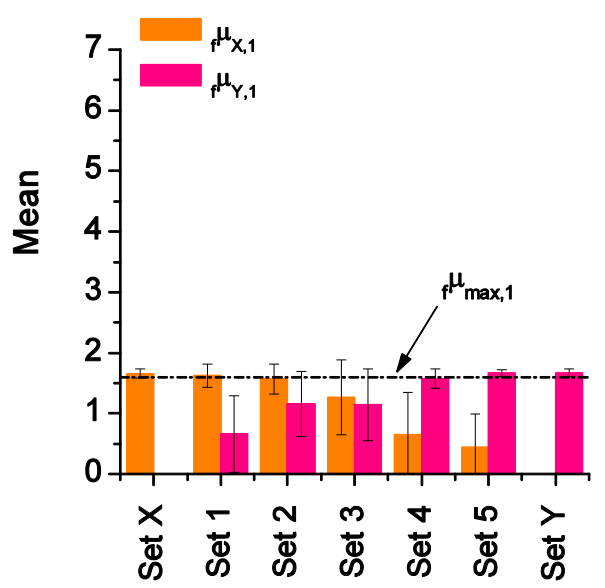

b)

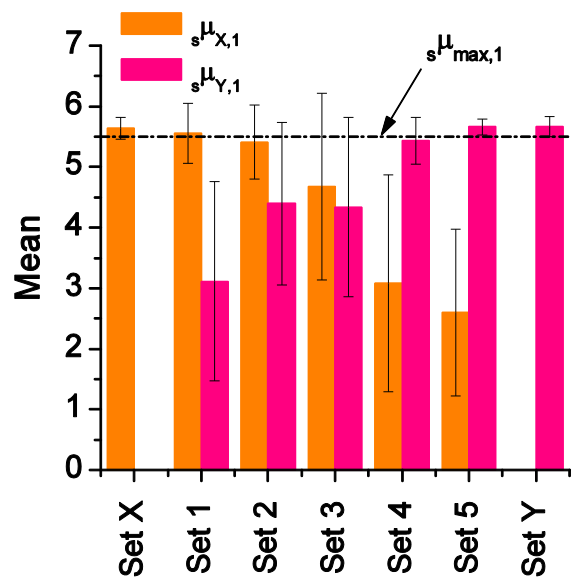

Figure 6. 37. Mean and error bars for $\mu$ along $\mathrm{X}$ and $\mathrm{Y}$ directions: a) main structure and b) hysteretic dampers

\subsubsection{Energy dissipated by plastic deformations for SPL NC}

The energy dissipated by plastic deformations, i.e. the damage, obtained in the analyses for SPL NC in both WFP system and hysteretic dampers are studied here. The damage at the $i$ story, $W_{p, i}$, is obtained by adding the damage in the flexible part (WFP system), ${ }_{f} W_{p, i}$, and that in the stiff part (hysteretic dampers), ${ }_{s} W_{p, i}$, i.e. $W_{p, i}={ }_{f} W_{p, i}+{ }_{s} W_{p, i}$. Further, $W_{p, i},{ }_{f} W_{p, i}$ and ${ }_{s} W_{p, i}$ can be expressed from their $\mathrm{X}$ and $\mathrm{Y}$ components as $W_{p, i}=W_{p X, i}+W_{p Y, i},{ }_{f} W_{p, i}={ }_{f} W_{p X, i}+$ ${ }_{f} W_{p Y, i}$ and ${ }_{s} W_{p, i}={ }_{s} W_{p X, i}+{ }_{s} W_{p Y, i}$. Then, the following relationships are deduced: $W_{p X, i}=$ ${ }_{f} W_{p X, i}+{ }_{s} W_{p X, i}$ and $W_{p Y, i}={ }_{f} W_{p Y, i}+{ }_{s} W_{p Y, i}$. The energy dissipated by the main structure at the $i$ story along $\mathrm{X}$ and $\mathrm{Y}$ directions under a given seismic record is obtained as follows: i) the contribution of the $j$ column to the dissipated energy along the $\mathrm{X}$ and $\mathrm{Y}$ directions is obtained through the expressions ${ }_{f} W_{p X, i j}=\int_{f} Q_{X, i j} d \delta_{X, i j}$ and ${ }_{f} W_{p Y, i j}=\int_{f} Q_{Y, i j} d \delta_{Y, i j}$, respectively, where ${ }_{f} Q_{X, i j}$ and ${ }_{f} Q_{Y, i j}$ are the shear force histories of the $j$ column along $\mathrm{X}$ and $\mathrm{Y}$ directions, and $\delta_{X, i j}$ and $\delta_{Y, i j}$ are the counterpart Inter-story Drift histories; ii) ${ }_{f} W_{p X, i}$ and ${ }_{f} W_{p Y, i}$ are obtained by adding the contribution of the dissipated energy of all the columns of the story along $\mathrm{X}$ and Y directions, i.e. ${ }_{f} W_{p X, i}=\sum_{j=1}^{N c}{ }_{f} W_{p X, i j}$ and ${ }_{f} W_{p Y, i}=\sum_{j=1}^{N c}{ }_{f} W_{p Y, i j}$, where $N c$ is the number of columns at the $i$ story. The dissipated energy of the dampers at the $i$ story is obtained by adding the contribution of all of them along the X and Y directions. The WFP system considered in this research has been upgraded with dampers located only at the first story arranged as showed in Figure 6.18. The energy dissipated by damper $k$ under a given seismic record, ${ }_{s} W_{p, i k}$, is obtained through the expression ${ }_{s} W_{p, i k}=\int{ }_{s} N_{k} d\left({ }_{s} \Delta u_{k}\right)$, where ${ }_{s} N_{k}$ and ${ }_{s} \Delta u_{k}$ are the axial force history and the relative axial displacement history of the damper, respectively. Damper 3 is aligned in Y direction and, therefore, its contribution to the dissipated energy for the first story is entirely considered in ${ }_{s} W_{p Y, 1}$. Nevertheless, dampers 1 and 2 contribute to dissipate energy in both $\mathrm{X}$ and $\mathrm{Y}$ directions (Figure 6.17). Then, the contribution of these dampers to ${ }_{s} W_{p X, 1}$ and ${ }_{s} W_{p Y, 1}$ is ${ }_{s} W_{p, 1 k}(\cos (\alpha))^{2}$ and ${ }_{s} W_{p, 1 k}(\sin (\alpha))^{2}$, respectively.

Figure 6.38 shows that the energy absorbed and dissipated by the dampers respect to the total at the first story ${ }_{s} W_{p, 1} / W_{p, 1}$ ranges, on average, from $80 \%$ to $90 \%$. The highest values are 
obtained under sets X, 2 and 3 where the higher input energy is in X-direction, and the lowest under set $Y$. This means that most of the energy is absorbed by the dampers. Further, it is also shown in the figure the same ratio but expressed from their $\mathrm{X}$ and $\mathrm{Y}$ components, ${ }_{s} W_{p X, 1} / W_{p X, 1}$ and ${ }_{s} W_{p Y, 1} / W_{p Y, 1}$, respectively. ${ }_{s} W_{p X, 1} / W_{p X, 1}$ ranges, on average, from $83 \%$ to $97 \%$ for bidirectional loadings (set 1 up to 5) and $100 \%$ under set $\mathrm{Y}$ (without seismic component in $\mathrm{X}$ direction). ${ }_{s} W_{p Y, 1} / W_{p Y, 1}$ ranges, on average, from $77 \%$ to $88 \%$ for bidirectional loadings and $100 \%$ under set $\mathrm{X}$ (without seismic component in $\mathrm{Y}$ direction) for which the torsional effects led to displacements and damage entirely absorbed by the dampers. Therefore, the symmetrical layout of dampers 1 and 2 (Figure 6.17) leads to higher efficiency to absorb and dissipate energy along $\mathrm{X}$ direction than along $\mathrm{Y}$ direction where the three dampers contribute to dissipate energy but not in the same proportion. Moreover, according to these results, WFP system absorbs and dissipates about $20 \%$, at most, of $W_{p, 1}$; that constitutes a moderate contribution and means that the dampers are effectively controlling (i.e. limiting) the damage on the main structure.

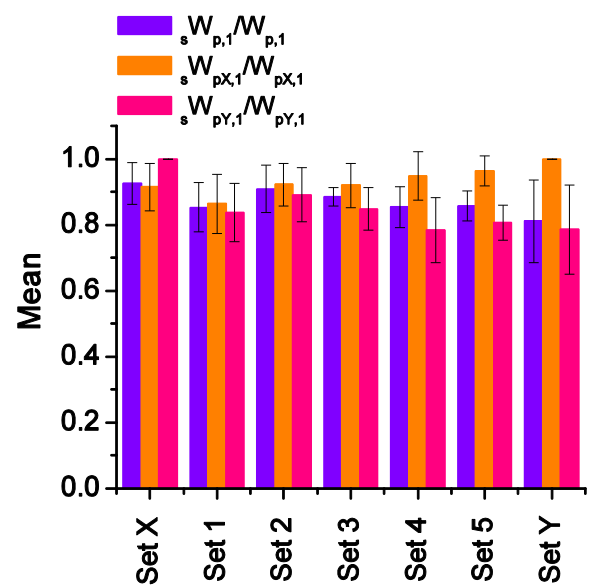

Figure 6. 38. Ratio of the dissipated energy in the hysteretic dampers respect to the total one at the first story, overall $\left({ }_{s} W_{p, 1} / W_{p, 1}\right)$ and by components $\left({ }_{s} W_{p X, 1} / W_{p X, 1}\right.$ and

$$
\left.{ }_{s} W_{p Y, 1} / W_{p Y, 1}\right)
$$

Furthermore, the damage along $\mathrm{X}$ and $\mathrm{Y}$ directions at the $i$ story for both the main part (WFP structure) and the stiff part (dampers) can be also expressed through the dimensionless variable $\eta_{i}$ defined in (1.13). Therefore, for the WFP system, the damage along $\mathrm{X}$ and $\mathrm{Y}$ directions is expressed as ${ }_{f} \eta_{X, i}={ }_{f} W_{p X, i} /\left({ }_{f} Q_{y X, 1} \delta_{y X, i}\right)$ and ${ }_{f} \eta_{Y, i}={ }_{f} W_{p Y, i} /\left({ }_{f} Q_{y Y, 1} \delta_{y Y, i}\right)$, respectively. For the hysteretic dampers, the counterpart expressions are ${ }_{s} \eta_{X, i}={ }_{s} W_{p X, i} /$ $\left({ }_{s} Q_{y X, 1}{ }_{s} \delta_{y X, i}\right)$ and ${ }_{s} \eta_{Y, i}={ }_{s} W_{p Y, i} /\left({ }_{s} Q_{y Y, 1}{ }_{s} \delta_{y Y, i}\right)$. Moreover, according to De Stefano and Faella (1996) the damage of the main part and the stiff part at the $i$ story can be expressed as ${ }_{f} \eta_{i}={ }_{f} \eta_{X, i}+{ }_{f} \eta_{Y, i}$ and ${ }_{s} \eta_{i}={ }_{s} \eta_{X, i}+{ }_{s} \eta_{Y, i}$, respectively. In Figure 6.39, subfigures a) and b) show ${ }_{f} \eta_{X, i},{ }_{f} \eta_{Y, i}$ and ${ }_{f} \eta_{i}$ for first $(i=1)$ and second story $(i=2)$, respectively. It can be observed higher values for ${ }_{f} \eta_{1}$ than those obtained for ${ }_{f} \eta_{2}$. This result is a consequence of the higher strength of the WFP system in the second story with respect to the value provided by the optimum distribution. 
a)

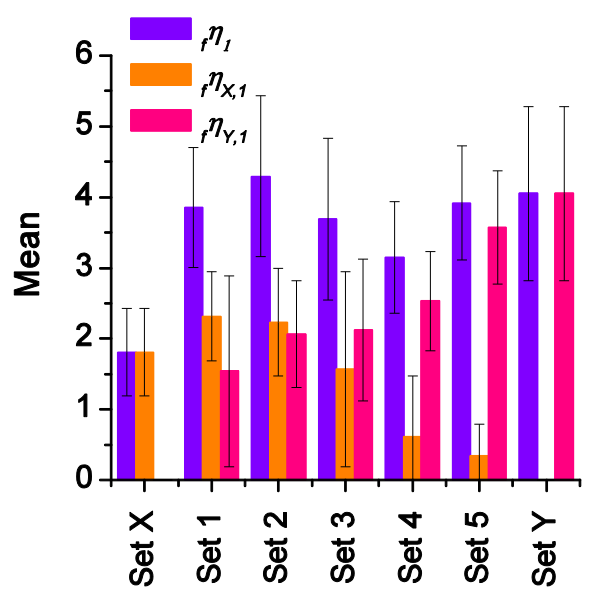

c)

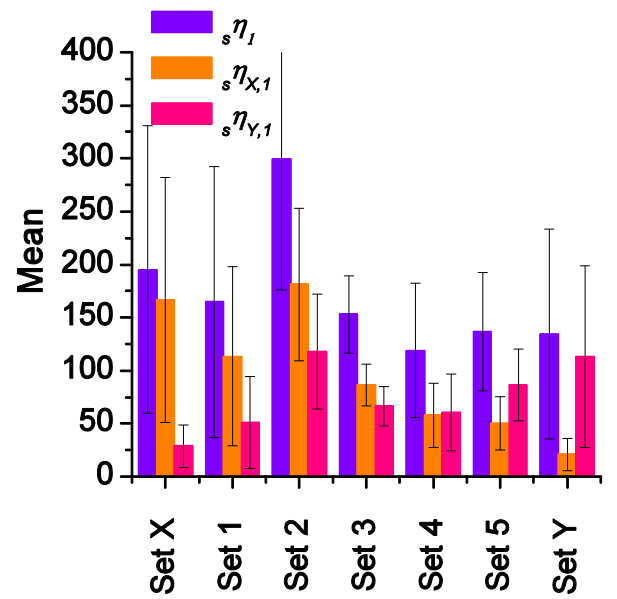

b)

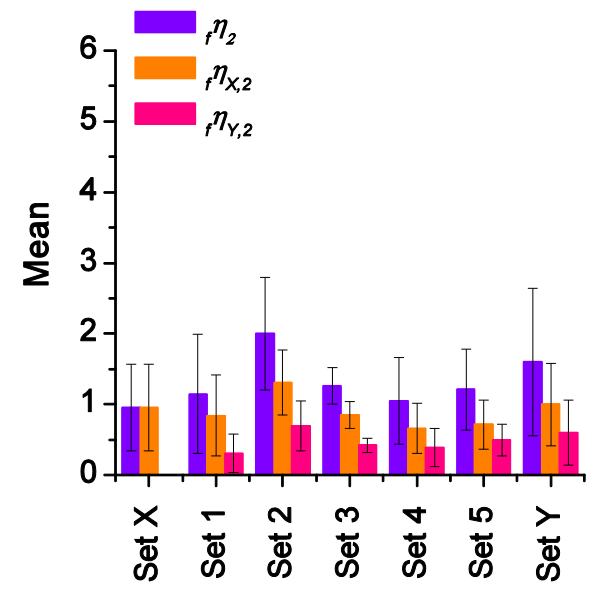

d)

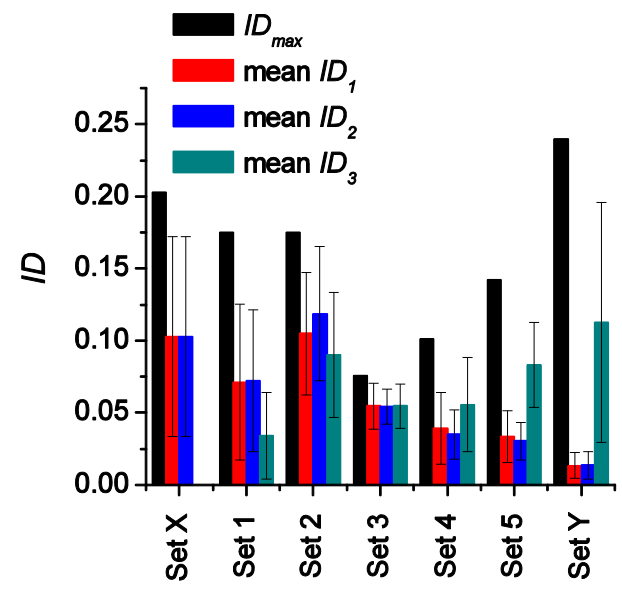

Figure 6. 39. Dimensionless representation of the damage: a) for WFP system at the first story and b) at second story; for hysteretic dampers, c) damage level and d) damage index

In Figure 6.39, subfigure a) also shows that the higher is the intensity of the $\mathrm{X}$ or $\mathrm{Y}$ component of the seismic action the higher is the damage ${ }_{f} \eta_{X, 1}$ or ${ }_{f} \eta_{Y, 1}$, respectively. The same response can be also observed for the hysteretic dampers in subfigure c). However, the efficiency showed by dampers in $\mathrm{X}$ direction under ground motion records with large intensity for $\mathrm{X}$ component is higher than those in $\mathrm{Y}$ direction under seismic actions with large intensity for $\mathrm{Y}$ component, according to the higher values observed for ${ }_{s} \eta_{X, 1}$ under sets $\mathrm{X}, 1$ and 2 than those for ${ }_{s} \eta_{Y, 1}$ under sets 4,5 and $\mathrm{Y}$.

Moreover, it is interesting to note the significant differences observed for the damage in the WFP system and dampers showed in Figure 6.39, subfigures a) and c), respectively, which is related to the energy dissipated in them (Figure 6.38). Nevertheless, despite the high energy dissipation demand in the dampers none of them failed, which was verified by the energy-based index of damage. This damage index is defined in the reference (Benavent-Climent, A., 2007) for steel elements and verified also by non-destructive evaluation tests (Abarkane et al., 2017; Abarkane et al., 2019; Abarkane et al., 2019). The index of damage varies from 0 to 1 , where 0 indicates no damage and 1 means failure. Figure $6.39 \mathrm{~d}$ shows the damage indices for the three dampers, $I D_{k}$ ( $k$ refers to dampers and varies from 1 to 3 ), achieved under each set of records, as well as the maximum damage index achieved for them under each set of records, $I D_{\max }$. It can be observed 
that $I D_{\max }$ ranges from 0.07 (Set 3) up to 0.25 (Set Y) which indicates that SPL NC is achieved by the collapse of the WFP system but not by the dampers. The mean values $I D_{k}$ obtained for the different dampers are the consequence of its distribution in the first story: i) along $X$ direction, dampers 1 and 2 are in symmetric layout, from the base of columns 2 and 3 to the outer columnplate connection; ii) along Y direction, non-symmetric layout is used for which damper 3 located between columns 2 and 3 is aligned within this direction. Therefore, $I D_{1}$ and $I D_{2}$ show, on average, similar values under the different set of records but $I D_{3}$ shows higher values under sets with large intensity in the Y component. Therefore, it is shown that the arrangement of dampers in the story is a key issue in order to prevent an uneven distribution of damage among them.

\subsubsection{Equivalent number of cycles for SPL NC}

The previous two sections addressed two important aspects of the seismic response of structures; one is the ductility level at each $i$ story expressed through the variable $\mu_{i}$ and the other is the hysteretic energy dissipated through cumulative cyclic reversals of each story $i$ expressed through the dimensionless variable $\eta_{i}$. The ratio $\eta_{i} / \mu_{i}$ is also a key aspect of the seismic response of the structure, that characterizes the efficiency of the structure in dissipating energy (Akiyama, 1985). The ratio $\eta_{i} / \mu_{i}$ is called in the literature equivalent number of cycles $n_{e q, i}\left(=\eta_{i} / \mu_{i}\right)$ and is influenced by the characteristics of the ground motion and the type of structure (Manfredi, Polese, \& Cosenza, 2003). In flexible-stiff mixed structures, this ratio can be defined for the main structure, ${ }_{f} n_{e q, i}={ }_{f} \eta_{i} /{ }_{f} \mu_{i}$, and for the stiff part, ${ }_{s} n_{e q, i}={ }_{s} \eta_{i} /{ }_{s} \mu_{i}$.

Figure 6.40 offers the mean of ${ }_{f} n_{e q, 1}$ and ${ }_{s} n_{e q, 1}$ obtained in the analyses for SPL NC at the first story along the $\mathrm{X}$ and $\mathrm{Y}$ directions, i.e. ${ }_{f} n_{e q X, i}={ }_{f} \eta_{X, i} /{ }_{f} \mu_{X, i}$ and ${ }_{f} n_{e q Y, i}={ }_{f} \eta_{Y, i} /{ }_{f} \mu_{Y, i}$ for the WFP system (Figure 6.40a) and ${ }_{s} n_{e q X, i}={ }_{s} \eta_{X, i} /{ }_{s} \mu_{X, i}$ and ${ }_{s} n_{e q Y, i}={ }_{s} \eta_{Y, i} /{ }_{s} \mu_{Y, i}$ for the hysteretic dampers (Figure 6.40b). It is important to note that the components $\mathrm{X}$ and $\mathrm{Y}$ used to calculate ${ }_{f} n_{e q, 1}$ and ${ }_{s} n_{e q, 1}$ were those for which the maximum ductility level, ${ }_{f} \mu_{\max , 1}$ and ${ }_{s} \mu_{\max , 1}$, were achieved under each seismic record. Figure 6.40 also shows ${ }_{f} n_{e q, \min 1}$ and ${ }_{s} n_{e q, \min 1}$ which are respectively the minimum values achieved for ${ }_{f} n_{e q, 1}$ and ${ }_{s} n_{e q, 1}$ in the analysis under each set of records.

In Figure 6.40, subfigure a) shows that ${ }_{f} n_{e q X, 1}$ ranges on average between 1.0 and 1.5, with a mean of 1.39 and $\operatorname{COV}=0.24$. ${ }_{f} n_{e q Y, 1}$ ranges between 1.5 and 2.5, with a mean of 2.0 and $\operatorname{COV}=0.28$. Further, it can be also observed that ${ }_{f} n_{\text {eqmin, } 1}$ ranges between 0.53 (Set $\mathrm{X}$ ) and 1.66 (Set Y) with a mean of 1.20 and $\operatorname{COV}=0.29$. These values obtained for ${ }_{f} n_{e q, 1}$ are similar to that proposed by Akiyama (1985) ${ }_{f} n_{e q}=2.0$ for flexible-sitff mixed systems which flexible part exhibits pinching (such is the case of WFP systems).

On the other hand, in Figure 6.40, subfigure b) shows that ${ }_{s} n_{e q X, 1}$ ranges on average between 7.0 and 35, with a mean about 24 and $C O V=0.60 .{ }_{s} n_{e q Y, 1}$ ranges between 10 and 20, with a mean about 15 and $\operatorname{COV}=0.59$. The higher values for both ${ }_{s} n_{e q X, 1}$ and ${ }_{s} n_{e q Y, 1}$ are concentrated under the sets of records for which the correspondent seismic component (X or Y) is large, i.e. sets $\mathrm{X}, 1$ and 2 for the former and sets 5 and $\mathrm{Y}$ for the latter. In addition, it can be also observed that ${ }_{s} n_{\text {eqmin,1 }}$ ranges between 3.1 (Set 4) and 10.7 (Set X) with a mean of 6.4 and COV $=0.39$. For flexible-stiff systems which stiff parts exhibits an elastic-perfectly plastic 
behavior Akiyama (1985) proposed ${ }_{s} n_{e q}=8$. This value is slightly higher than ${ }_{s} n_{e q m i n, 1}$ but close to the lower limit of the range of both ${ }_{s} n_{e q X, 1}$ and ${ }_{s} n_{e q Y, 1}$, indicated above.

It is important to note that the results obtained in the analyses for ${ }_{f} n_{e q, 1}$ and ${ }_{s} n_{e q, 1}$ come from the successive scaled seismic simulations until achieving SPL NC. Therefore, they can be used to obtain the cumulative damage in WFP structures with hysteretic dampers subjected to shocks and aftershocks.

a)

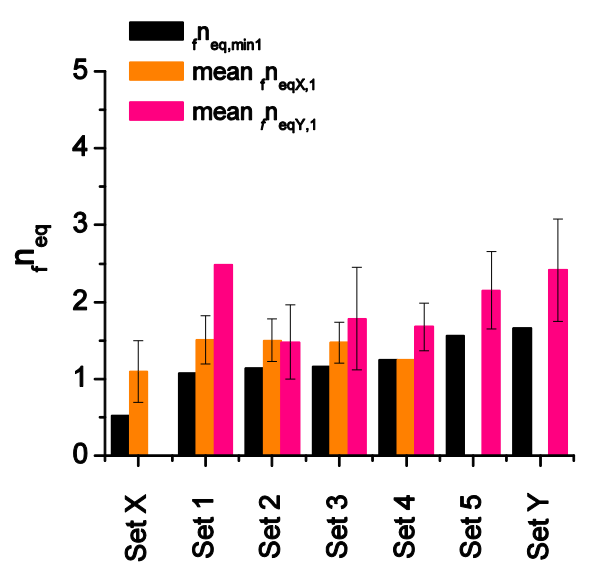

b)

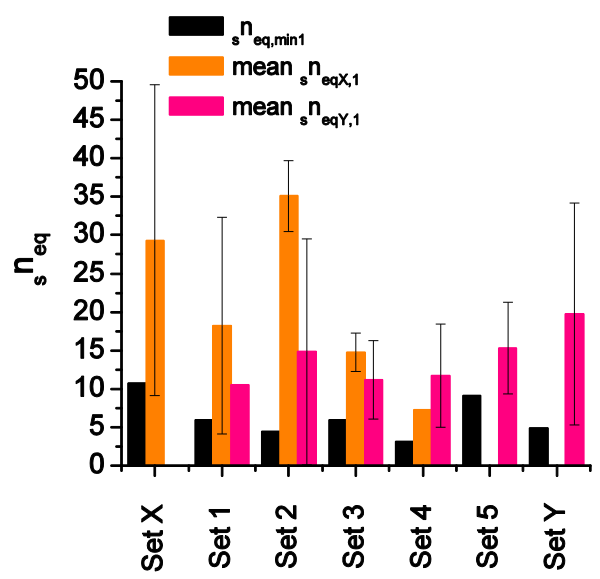

Figure 6. 40. Equivalent number of cycles obtained in the analyses at the first story: a) for WFP system and b) for hysteretic dampers

\section{SUMMARY}

This Chapter investigated the seismic behavior of reinforced concrete (RC) waffle-flat-plate (WFP) structures with hysteretic dampers subjected to uni and bidirectional seismic loading. To that end, slit-plate hysteretic dampers were installed in the WFP model calibrated in Chapter 5. To investigate the nonlinear behavior of the slit-type damper, five specimens were designed, manufactured and tested. Each specimen was subjected to a different level of damage under cycles of increasing amplitude. A numerical model based on the Giuffré-Menegotto-Pinto model was developed and calibrated with the test results to characterize the damper. The level of damage on the damper was also evaluated with an index of damage proposed in the literature that is able to predict the point of failure. The criteria to design the dampers were as follows:

9. Only one type of damper per story.

10. Layout of dampers aimed at enhancing the torsional resistance.

11. The yield shear strength of dampers was limited to $50 \%$ of yield shear strength of the main structure.

12. The yield displacement of dampers was made equal to 0.4 times the yield displacement of the main structure.

Afterwards, the numerical model of the WFP structure with the slit-type dampers was subjected to the same inputs applied in the experimental investigation presented in Chapter 4. The main finding can be summarized as follows:

1. The structure with dampers behaved, in general, much better than the structure without dampers. At the end of the sequence of ground motions, the WPF structure with dampers 
did not collapse (and the damage on the WPF system was relatively small) while the structure without dampers collapsed.

2. The free-vibration frequencies of the structure with dampers barely changed along the simulations (about 20\% at most), while the fundamental frequency of BS1 felt down up to one-half of its initial value. This confirms that the WFP structure with dampers was scarcely damaged in comparison with the specimen without dampers.

3. The Inter-story Drift Index limits for WFP structures proposed in Chapter 4 indicate that the structure with dampers was in the SPL "Life Safety" at the end of simulation C300 (a very rare earthquake associated with a return period of about 2500 years), while the structure without dampers exceeded the SPL "Collapse".

4. In the structure with dampers, the maximum chord rotations at columns ends normalized by the ultimate chord rotation estimated following (Fardis, 2009) gave values that hardly scrapes one-half of its capacity, indicating a limited damage on the columns at the end of the seismic simulations. In contrast, the maximum chord rotations in the specimen without dampers surpassed the capacity by far.

5. The restoring forces at first story increased about $20-30 \%$ when dampers were added to the story. The addition of dampers in the first story barely affected to the restoring force response in the second story.

6. The energy input in the structure with dampers was a $23 \%$ lower than the structure without dampers due to the differences in stiffness. The input energy distribution by directions was quite similar in both structures.

7. The ratio $W_{\xi, B S 1 D} / W_{\xi, B S 1}$ of energies dissipated by inherent viscous damping (accumulated) between both structures was decreasing along the simulations from 1.25 up to 0.75 , although the level of damping in the structure with dampers (in terms of coefficient $a_{0}$ ) was about $20 \%$ larger than the other.

8. The energy dissipated by the main system in terms of $E_{D}$ in BS1 was 8 times larger than the energy dissipated in BS1D, which reflects the remaining capacity of absorbing energy of BS1D. In addition, dampers consumed less than $10 \%$ of its ultimate capacity.

Finally, the model was subjected to the same five sets of seven bidirectional ground motion records and two set of five unidirectional ground motions than in Chapter 5 in order to achieve in this case three SPLs: full operational (FO, elastic behavior), operational (OP, damage only in dampers) and near collapse (NC, heavy damage in WFP and dampers). Each record was applied in a sequence of scaled seismic simulations until achieving SPL NC. The following conclusions were reached:

1. The total input energy or the total hysteretic energy (expressed in form of equivalent velocities $V_{E}$ or $V_{D}$ ) required to achieve SPLs FO, OP and NC remain basically the same, irrespective of the ground motion considered when the two horizontal components of the ground motion are simultaneously applied.

2. The input energy in terms of $V_{E}$ that the structure can endure until SPL NC was, on average, about three and eight times the values obtained for SPLs OP and FO, respectively. On the other hand, the energy dissipated through plastic deformations, 
expressed in terms of $V_{D}$, when the structure reaches SPL NC was, on average, about three times that obtained for SPL OP.

3. The input energy, expressed in terms of $V_{E}$, that structure endures until the SPL NC is incremented, on average, a $76 \%$ by adding dampers. On the other hand, a mean increment of $119 \%$ is observed in the structure with dampers when both structures are compared in terms of $V_{D}$ when they reach SPL NC.

4. Past studies on conventional structures pointed out that torsion effects tend to redistribute the damage in the structure. In terms of energy this means balancing the energy input by the $\mathrm{X}$ and $\mathrm{Y}$ components of the ground motion. This was not found in the structure with dampers under study, most probably due to the fact the dampers controlled the torsional movements.

5. The capacity of the structure under bidirectional loadings is, in most cases, slightly higher than under unidirectional loadings. Nevertheless, for some ground motions the response was opposite.

6. The values of $V_{E}$ and $V_{D}$ estimated from the energies obtained independently for the $\mathrm{X}$ and $\mathrm{Y}$ components of the ground motion (unidirectional analysis) are always larger than the actual value that is obtained applying the two components simultaneously (bidirectional analysis). The values are $18 \%$ larger for SPL OP and a $27 \%$ for SPL NC.

7. Values of $V_{D} / V_{E}$ predicted with Akiyama's equation resulted similar to the values obtained in the analysis for both SPL OP and SPL NC.

8. The maximum ductility level, estimated through the maximum apparent plastic deformation, was 1.6 in WFP system and 5.5 in SP Dampers.

9. Most of the energy (80\%) input and dissipated by the structure was absorbed by the dampers.

10. Despite of the large amount of energy dissipated by the dampers, the maximum damage index achieved in the analyses was $I D_{\max }=0.27$, far from the limit of failure $(=1)$.

11. The equivalent number of cycles obtained for the flexible and stiff parts rely on the characteristic of the main structure and the layout of dampers in $\mathrm{X}$ and $\mathrm{Y}$ directions. The average and minimum values obtained are ${ }_{f} n_{e q, 1}=2.0$ and ${ }_{f} n_{\text {eqmin, } 1}=1.2$, respectively, for flexible part, and ${ }_{s} n_{e q, 1}$ ranged between 15 and 24, with a minimum value of ${ }_{s} n_{\text {eqmin,1 }}=6.4$. The values found are in accordance with those proposed by Akiyama (1985). 


\section{Chapter 7}

\section{SUMMARY, CONCLUSIONS AND FUTURE RESEARCH DIRECTIONS}

This dissertation investigated the seismic performance of reinforced concrete (RC) waffle-flat plate (WFP) systems subjected to bidirectional seismic loadings and the improvements achieved in the dynamic response when passive energy dissipation devices (EDDs), also called dampers, of hysteretic type are added. WFP systems are effective to support gravitational loads but present important drawbacks under lateral loading such as low lateral stiffness, low ductility, low capacity to dissipate energy and proneness to brittle punching failure. However, when WFP systems are combined with EDDs forming what is known in the literature as "flexible-stiff mixed systems", the inherent lateral flexibility of the WFP structure becomes a positive feature that can be exploited to reach mixed systems with outstanding seismic performance. In the mixed system, dampers dissipate most of the energy introduced by the ground motion while the WFP structure support the gravity loads with minor damage (owing to their flexibility). The efficiency of the mixed system turns out in a significant reduction of maximum lateral displacements (controlling brittle failures by punching) and of the permanent plastic deformations in the parent structure once the ground motion stops.

The structural design must be aimed at maximizing the energy dissipation capacity of the structure. The energy approach is the most suitable method to achieve this target. Characterizing 
the loading effect of earthquakes in terms of energy instead of forces provides a more rational base for seismic design and constitutes the basis of the so-called energy-based design method.

The best and most reliable way to assess the seismic response of a structure under bidirectional ground motions is to perform a shaking table test. However, testing a whole building is something that only few laboratories worldwide can deal. In this dissertation, due to the limitations of the earthquake simulator (dimensions, payload and overturning), a portion of a scaled WFP prototype structure was used as test specimen and subjected to dynamic shaking table tests. The prototype consisted of three-story RC WFP system supported on isolated columns and intentionally symmetric only along one axis. This was firstly designed following the Spanish construction codes, then, escalated 2/5 and finally, a portion (test specimen) was taken cutting at points where the bending moments are nominally zero under lateral loading. The test specimen, named BS1, had the height of one-story and a half and the width of one-bay and a half. After casting, extra masses were added at top of the columns and at the slab to conform a weight of 12,23 $T$ in total. The specimen installed on the shaking table was strongly instrumented with LVDTs, lasers, accelerometers, strain gauges and load cells. Data from displacement and acceleration sensors was dealt to obtain results at the centers of masses. The shaking table test was controlled in accelerations and the input ground accelerations came from a European far-field earthquake recorded at Calitri during the Campano Lucano Earthquake (1980). Before being reproduced in the earthquake simulator, this record was escalated in time by a factor of 0.632 to fulfill similitude requirements.

Before testing, a two-mass lumped model with 6 DOFs that represented the test specimen was developed to characterize its dynamic properties and estimate the expected lateral strength. The DOFs were numbered as 1 (translation $X$ at first floor), 2 (translation $Y$ at first floor), 3 (rotation about $\mathrm{Z}$ at first floor), 4 (translation $\mathrm{X}$ at second floor), 5 (translation $\mathrm{Y}$ at second floor) and 6 (rotation about $\mathrm{Z}$ at second floor). Mass matrix was calculated concentrating the mass of each story in its center of masses. Centers of masses are not located in the same vertical, there is a distance between them of $370 \mathrm{~mm}$. Stiffness matrix was obtained applied some simplifications as well as the center of stiffness. Eccentricities between the centers of masses and centers of stiffness were of $77 \mathrm{~mm}$ at first floor and $312 \mathrm{~mm}$ at second floor. The stiffness in X direction resulted 3,89 $\mathrm{kN} / \mathrm{mm}$ and in $\mathrm{Y}$ direction $3,15 \mathrm{kN} / \mathrm{mm}$, considering a stiffness reduction of a $50 \%$ due to concrete cracking (CEN, 2004). Adopting this stiffness loss for the stiffness matrix, the first 3 periods calculated by modal analysis were $0,37,0,31$ and $0,27 \mathrm{~s}$. These values are very close to those obtained in the test. Moreover, the flexural capacity of the main elements were calculated to obtain the most likely ductile global collapse mechanisms for both directions, resulting the maximum capacity of the specimen in term of base shear force around $70 \mathrm{kN}$ in $\mathrm{X}$ direction and $75 \mathrm{kN}$ in $\mathrm{Y}$ direction. Therefore, considering the dimensions of the specimen, its total mass and its maximum strength, the shaking table payload was exceeded a little and the maximum overturning moment was far from its capacity, ensuring the safety of the facility.

The experimental campaign consisted in subjecting the test specimen (BS1) to bidirectional horizontal seismic loading on the shake table of the Laboratory of Structures of the University of Granada. This University participated in the research project funded by the Spanish Ministry of Economy that funded the test. The specimen was subjected sequentially to five seismic simulations that represented very frequent (C35 and C50), frequent (C100), design (C200) and very rare (C300) earthquakes at the assumed building site (Granada, Spain). During the training of the shake table with white noise (training T10), a spurious short-duration peak of acceleration was applied to the test specimen. Despite the large peak acceleration applied to the table, the damage caused on the test specimen was negligible (the energy input was less than $3 \%$ of its capacity). Although T10 is a signal that does not represent a ground motion, it has been included 
in the discussion of the thesis for completeness. Moreover, before the successful seismic simulation $\mathrm{C200}$, a failed attempt referred to as $\mathrm{C} 200 \mathrm{i}$ was interrupted due to a problem with the control system of the shake table. The following conclusions can be made:

1. The structure behaved within the elastic range under very frequent (C35 and C50) and frequent $(\mathrm{C} 100)$ earthquakes and underwent severe plastic deformations under the design (C200) and very rare (C300) earthquakes.

2. The design earthquake (C200) caused an appreciable loss of the lateral strength on the test structure; in terms of Inter-story Drift Index the specimen ended up on the limit of the SPL between LS and NC, according to SEAOC (1995).

3. Interior plate-column connections developed a weak column-mechanism in both directions, while the exterior connection developed a strong column-weak plate in both directions. The exhaustion of the spandrel beam of the exterior plate-column connection triggered the collapse of the structure.

4. The total amount of energy input in the test specimen under bidirectional ground motions when it collapsed was very similar to that obtained in previous studies on a similar specimen subjected to only one component of the same ground motion.

5. As the damage progressed, the dissipated energy by plastic strains acquired more prominence than the energy dissipated by damping.

6. Torsional effects tended to compensate the energy dissipated by columns

7. Based on the results of the test in terms of Inter-story Drift Indexes, it is proposed for WFP systems to increase the transient drift limits for "Operational", "Life Safety" and "Collapse" SPL prescribed by SEAOC to the following new values: $1.0 \%, 2.5 \%$ and $4 \%$, respectively, with a tolerance of $\pm 0.1 \%$.

A 3D nonlinear FE model of the tested specimen was built in Opensees and calibrated with the results of the shaking table tests. The model had 1802 nodes with 6 DOFs per node and 1810 elements. Different types of elements were used. Beam with Hinges elements with a $20 \%$ strength reduction to take into account biaxial interaction were used for columns. Moreover, the cover concrete (i.e. the concrete outside the perimeter of the hoops) was not considered to account for the concrete cracking. Elastic elements were used for ribs/joists in the waffle-flat plate; also a $20 \%$ reduction of stiffness due to the concrete cracking was considered. Layered shell elements were used for the drop panels and the concrete cover (i.e. the concrete outside the perimeter of the stirrups) was not considered. The simulation of the behavior of the columns until failure, it turned out more successful to define the properties of the section directly in terms of momentcurvature relationships than using fiber models. Furthermore, the response predicted numerically with this model was compared with test results and a satisfactory agreement was found in general. The comparisons were made in terms of history of displacements, inertial forces, capacity curve and energy input. The best parameter to validate a numerical model is the history of energy input. A particularly very good agreement was reached between test specimen and numerical model in terms of history of input energy.

To further investigate the seismic capacity of the WFP structures under bidirectional seismic loadings, five sets of seven far-field ground motion records were selected according to different ranges for the ratio of the input energy introduced by their horizontal components. A large number 
of nonlinear response history analyses were carried out with the numerical model that represented the specimen tested on the shake table, under each pair of the selected records. The records were scaled in successive simulations from the state on the brink of plastic behavior until collapse. Finally, five records were selected from each set to launch nonlinear evaluations under unidirectional loading using separately their components. The following conclusions were reached:

1. Under bidirectional ground motions, a stabilization of the capacity in terms of energy was observed independently of the input energy introduced by each component. Moreover, the amount of input energy required to lead the WFP structure to collapse, expressed in terms of equivalent velocity, was more than twice the energy required to lead the structure to the brink of yielding. In terms of energy, it was more than four times.

2. Torsional effects appeared when the evolution of the ratio $V_{E Y} / V_{E X}$ was analyzed.

3. The equation (1.7) proposed by Akiyama (1985) predicts reasonably well the ratio of energy that contributes to damage to the total input energy, both expressed in terms of equivalent velocities, $V_{D} / V_{E}$, when to horizontal components of the ground motion are applied simultaneously.

4. The specimen simulated under bidirectional seismic loading showed higher capacity to dissipate energy by plastic deformations than under unidirectional loading.

5. The amount of input energy, in terms of equivalent velocity $V_{E}$, required to lead the structure to the brink of yielding under bidirectional seismic loadings is approximately equal to the value obtained using the rule of the square root of the sum of the squares to the input energy required to lead the structure to the brink of yielding under unidirectional seismic loading in two orthogonal directions. However, applying the same procedure for estimating the energies $V_{E}$ and $V_{D}$, input and dissipated energies respectively, that the structure can endure until collapse results in a significant overestimation.

The 3D model of the WFP structure calibrated with the results of the shaking table tests was equipped with slit-type hysteretic dampers (SP dampers) to form a flexible-stiff mixed structure (structure BS1D). SP dampers consist of stainless steel plates with slits (dissipative part) mounted on two steel tubes arranged telescopically (auxiliary elements). The nonlinear behavior of the SP damper was investigated testing five specimens to cycles of increasing amplitude. A numerical model was developed to represent the SP damper, based on the Giuffré-Menegotto-Pinto model. Moreover, an index of damage already proposed in the literature was used and calibrated to quantify the level of damage and the failure of the SP damper. Several SP dampers were implemented in the WFP numerical model that represented the WFP structure. The criteria for designing the dampers were:

1. Only one type of damper per story.

2. Layout of the dampers aimed at enhancing the torsional behavior.

3. The maximum shear strength of dampers limited to the $50 \%$ of shear strength of the main structure per story.

4. The yield displacement of dampers less than $40 \%$ of the yield displacement of the main structure per story. 
Afterwards, the numerical model of the WFP structure with the SP dampers was subjected to the same ground accelerations used in the shaking table test of the WFP structure without dampers. While BS1 collapsed, BS1D survived with limited damage on the RC elements of the WFP systems. Further, the following results were reached:

1. The periods of the WFP structure with dampers barely changed with the seismic simulations (the fundamental period moved from 0.32 to 0.41 ); this indicates low damage in the RC structure.

2. At the end of the seismic simulations, the WFP structure with dampers remained in the border between SPL "Life Safety" and "Near Collapse".

3. The maximum chord rotations on the columns of the WFP structure with dampers hardly scraped one-half of their capacity.

4. The restoring forces at the base of the columns of the first story increased about $20-$ $30 \%$ with respect to the WFP structure without dampers. The additions of dampers barely affected the restoring force response in the second story.

5. The energy input was a $23 \%$ lower in the WFP structure with dampers than in the structure without dampers, due to the differences in stiffness.

6. Considering the RC structure capacity, the energy that contribute to damage absorbed by BS1, BS1D only consumed the $13 \%(1 / 8)$ of its capacity.

7. Dampers consumed less than $10 \%$ of their ultimate energy dissipation capacity.

Finally, the numerical model of the WFP structure with dampers was subjected to the same five sets of seven bidirectional ground motion records and the two sets of five unidirectional ground motions used to investigate the response of the WFP structure without dampers (BS1). In this case, the focus was put in three SPLs: full operational (FO, elastic behavior), operational (OP, damage only in dampers) and near collapse (NC, heavy damage in WFP and dampers). Each record was applied in a sequence of scaled seismic simulations until achieving SPL NC. The following conclusions were reached:

1. Similarly to the structure without dampers (BS1), the total input energy and the total hysteretic energy, in terms of equivalent velocities $V_{E}$ and $V_{D}$, required by the WFP structure with dampers (BS1D) to achieve SPLs FO, OP and NC remains basically constant irrespective of the bidirectional ground motion considered.

2. $V_{E}$ at SPL of NC was, on average, 3 and 8 times the values obtained for SPLs OP and FO, respectively.

3. $V_{E}$ at $\mathrm{SPL}$ of $\mathrm{NC}$ was 1.76 times larger in BS1D than in BS1.

4. $V_{D}$ at SPL of NC was, on average, 3 times the values obtained for SPL OP.

5. $V_{D}$ at SPL of NC was 2.19 times larger in BS1D than in the model of BS1. 
6. Damage distribution due to torsion was not found in BS1D, most probably due to the fact that dampers controlled the torsional response.

7. The energy capacity was slightly higher under bidirectional loading than under unidirectional loading in most of cases.

8. $V_{E}$ and $V_{D}$ calculated under bidirectional seismic loading was in all cases lower than the values of these parameters obtained combining with the rule of the square root of the sum of the squares, the values obtained under unidirectional seismic loading in each direction separately. Apparently, while the structure remains in the elastic range $V_{E}$ can be approximated by the square root of the sum of the squares of the unidirectional values. However, when some parts of the structure enter the plastic range, the approximation by the square root of the sum of the squares of the unidirectional values overestimate $V_{E}$ and $V_{D}$.

9. Values of $V_{D} / V_{E}$ predicted with Akiyama's equation resulted similar to those obtained in the analyses.

10. The maximum ductility level, estimated through the maximum apparent plastic deformation, was 1.6 in the WFP system and 5.5 in SP dampers.

11. The dampers absorbed most (more than $80 \%$ ) of the input and energy dissipation demand imposed by the earthquake.

12. The dampers consumed up to $30 \%$ of their ultimate capacity.

13. The values found for ${ }_{f} n_{e q}$ and ${ }_{s} n_{e q}$ were very close to those proposed by Akiyama (1985) for flexible-stiff mixed structures.

This research achieved the main objectives of analyzing the seismic performance of WFP structures, with and without hysteretic dampers, subjected to two horizontal components of farfield earthquakes. Throughout the research process, future research directions have been identified:

1. To further investigate the response of WFP structures under bidirectional seismic loadings, with or without dampers, more experimental tests and numerical analyses are required. Additional tests and analyses should investigate the response under near-field ground motions.

2. One of the main pillars in the energy-based approach is to characterize the ultimate energy dissipation capacity of structural elements. In Chapter 4, the energy dissipated by the waffle-flat plate and columns were estimated roughly. New procedures that avoid simplifications would improve the process to obtain the energy dissipated by plastic strains in the structure.

3. Another important pillar in energy-based approach is to know with enough precision the energy dissipated by damping. In this dissertation, a huge effort has been done to characterize the damping energy under bidirectional loadings but a deeper understanding is still needed. 
4. In asymmetric structures, the influence of torsion is crucial. More experimental and numerical studies are needed to quantify the influence of torsion in this kind of structures, especially for different levels of damage.

5. The equivalent number of cycles is a key parameter in the energy-based methodology. However, there is still a gap in the knowledge about the use of this parameter to design structures subjected to bidirectional loading, a little step was done in this dissertation. 


\section{Bibliography}

Abarkane, C., Galé-Lamuela, D., Benavent-Climent, A., Rescalvo, F. J., \& Gallego, A. (2019).

Diagnosis of hysteretic dampers used for seismic protection of structures by means ultrasonic measurements. Measurement, 137, 344-354.

Abarkane, C., Galé-Lamuela, D., Benavent-Climent, A., Suárez, E., \& Gallego, A. (2017).

Ultrasonic pulse-echo signal analysis for damage evaluation of metallic slit-plate hysteretic dampers. Metals, 7(12), 526.

Abarkane, C., Rescalvo, F. J., Donaire-Ávila, J., Galé-Lamuela, D., Benavent-Climent, A., \& Gallego Molina, A. (2019). Temporal acoustic emission index for damage monitoring of RC structures subjected to bidirectional seismic loadings. Materials, 12(17), 2804.

Abarkane, C., Ríos-García, G., Gale-Lamuela, D., Rescalvo, F., Gallego, A., \& BenaventCliment, A. (2019). Metallic slit-plate dampers: Damage evaluation with metal magnetic memory technique and application to structures with rocking columns. Metals, 9(9), 953.

Abdul-Wahab, H. M., \& Khalil, M. H. (2000). Rigidity and strength of orthotropic reinforced concrete waffle slabs. Journal of Structural Engineering, 126(2), 219-227.

Committee 318 Building Code Requirements for Structural Concrete (ACI 318M-14) and Commentary (ACI 318RM-14); American Concrete Institute: Farmington Hills, MI (USA) ISBN 978-0-87031-964-8. (2014).

ACI Committee. (2005). Building code requirements for structural concrete (ACI 318-05) and commentary (ACI 318R-05). Paper presented at the

Aiken, I. D., Nims, D. K., Whittaker, A. S., \& Kelly, J. M. (1993). Testing of passive energy dissipation systems. Earthquake Spectra, 9(3), 335-370. 
Akiyama, H. (1985). Earthquake-resistant limit-state design for buildings University of Tokyo Press.

Akiyama, H. (2002). Metodología de proyecto sismorresistente de edificios Reverté.

Seismic Evaluation and Retrofit of Existing Buildings; American Society of Civil Engineers; Reston, VA (USA); ISBN 9780784412855. (2014).

Avramidis, I., Athanatopoulou, A., Morfidis, K., Sextos, A., \& Giaralis, A. (2015). Eurocodecompliant seismic analysis and design of $R / C$ buildings Springer.

Bajaj, A. S., \& Mendis, P. (2005). New method to evaluate the biaxial interaction exponent for RC columns. Journal of Structural Engineering, 131(12), 1926-1930.

Bayhan, B. (2013). Numerical simulation of shaking table tests on 3D reinforced concrete structures. Structural Engineering and Mechanics, 48(2), 151-171.

Benavent-Climent, A. (2007). An energy-based damage model for seismic response of steel structures. Earthquake Engineering \& Structural Dynamics, 36(8), 1049-1064.

Benavent-Climent, A., Donaire-Avila, J., \& Oliver- Sáiz, E. (2016). Shaking table tests of a reinforced concrete waffle-flat plate structure designed following modern codes: Seismic performance and damage evaluation. Earthquake Engineering \& Structural Dynamics, 45(2), 315-336.

Benavent-Climent, A., Donaire-Avila, J., \& Oliver-Sáiz, E. (2018). Seismic performance and damage evaluation of a waffle-flat plate structure with hysteretic dampers through shaketable tests. Earthquake Engineering \& Structural Dynamics, 47(5), 1250-1269.

Benavent-Climent, A., López-Almansa, F., \& Bravo-González, D. A. (2010). Design energy input spectra for moderate-to-high seismicity regions based on Colombian earthquakes. Soil Dynamics and Earthquake Engineering, 30(11), 1129-1148. 
Benavent-Climent, A., Morillas, L., \& Escolano-Margarit, D. (2014). Inelastic torsional seismic response of nominally symmetric reinforced concrete frame structures: Shaking table tests. Engineering Structures, 80, 109-117.

Benavent-Climent, A. (2010). A brace-type seismic damper based on yielding the walls of hollow structural sections. Engineering Structures, 32(4), 1113-1122.

Benavent-Climent, A. (2011). An energy-based method for seismic retrofit of existing frames using hysteretic dampers. Soil Dynamics and Earthquake Engineering, 31(10), 1385-1396.

Benavent-Climent, A., Cahis, X., \& Catalan, A. (2009). Reinforced concrete exterior waffle flat plate-column connections subjected to lateral earthquake loading. Journal of Earthquake Engineering, 13(3), 275-292.

Benavent-Climent, A., Cahís, X., \& Catalán, A. (2008). Seismic behavior of interior connections in existing waffle-flat-plate structures. Engineering Structures, 30(9), 25102516.

Benavent-Climent, A., Escolan0-Margarit, D., \& Morillas, L. (2014). Shake-table tests of a reinforced concrete frame designed following modern codes: Seismic performance and damage evaluation. Earthquake Engineering \& Structural Dynamics, 43(6), 791-810.

Benavent-Climent, A., Gallego, A., Romo-Melo, L., \& Morillas, L. (2014). Health monitoring of web plastifying dampers subjected to cyclic loading through vibration tests. Structural Health Monitoring, 13(1), 33-49.

Benavent-Climent, A., Morillas, L., \& Escolano-Margarit, D. (2014). Seismic performance and damage evaluation of a reinforced concrete frame with hysteretic dampers through shaketable tests. Earthquake Engineering \& Structural Dynamics, 43(15), 2399-2417.

Benavent-Climent, A., Morillas, L., \& Vico, J. M. (2011). A study on using wide-flange section web under out-of-plane flexure for passive energy dissipation. Earthquake Engineering \& Structural Dynamics, 40(5), 473-490. 
Borcherdt, R. D. (2002). Empirical evidence for site coefficients in building code provisions. Earthquake Spectra, 18(2), 189-217.

Bousias, S. N., Panagiotakos, T. B., \& Fardis, M. N. (2002). Modelling of RC members under cyclic biaxial flexure and axial force. Journal of Earthquake Engineering, 6(02), 213-238.

BSL (2009). The Building Standard Law of Japan. The Building Center of Japan [English Version]. Tokyo, Japan

Campbell, K. W., \& Bozorgnia, Y. (2008). NGA ground motion model for the geometric mean horizontal component of PGA, PGV, PGD and 5\% damped linear elastic response spectra for periods ranging from 0.01 to 10 s. Earthquake Spectra, 24(1), 139-171.

CEN. (2004). Eurocode 8: Design of Structures for Earthquake Resistance-Part 1: General Rules, Seismic Actions and Rules for Buildings, European Standard EN 1998-1:2004 U.S.C.

CEN (2005) Eurocode 8: Design of Structures for Earthquake Resistance-Part 3: Assessment and Retrofitting of Buildings, European Standard EN 1998-3:2005 U.S.C.

Chang, G. A., \& Mander, J. B. (1994). Seismic energy based fatigue damage analysis of bridge columns: Part 1-evaluation of seismic capacity.

Charney, F. A. (2008). Unintended consequences of modeling damping in structures. Journal of Structural Engineering, 134(4), 581-592.

Choi, Y., \& Stewart, J. P. (2005). Nonlinear site amplification as function of $30 \mathrm{~m}$ shear wave velocity. Earthquake Spectra, 21(1), 1-30.

Chopra, A. K., \& McKenna, F. (2016). Modeling viscous damping in nonlinear response history analysis of buildings for earthquake excitation. Earthquake Engineering \& Structural Dynamics, 45(2), 193-211. 
Chow, H., \& Selna, L. G. (1995). Seismic response of nonductile flat-plate buildings. Journal of Structural Engineering, 121(1), 115-123.

Christopoulos, C., \& Filiatrault, A. (2006). Principles of passive supplemental damping and seismic isolation Iuss press.

Clough, R. W. (1980). The finite element method after twenty-five years: A personal view. Computers \& Structures, 12(4), 361-370.

Clough, R. W., \& Penzien, J. (1992). Dynamics of structures. Berkeley, California: CSI Computers \& Structures, Inc.

Connor, J. J. (2003). Structural motion control Pearson Education, Inc.

Constantinou, M. C., Soong, T. T., \& Dargush, G. F. (1998). Passive energy dissipation systems for structural design and retrofit.

Cosenza, E., \& Manfredi, G. (1997). The improvement of the seismic-resistant design for existing and new structures using damage concept. Proceedings of the International Workshop on Seismic Design Methodologies for the Generation of Code, pp. 119-130.

De Stefano, M., \& Faella, G. (1996). An evaluation of the inelastic response of systems under biaxial seismic excitations. Engineering Structures, 18(9), 724-731.

Decanini, L. D., \& Mollaioli, F. (2001). An energy-based methodology for the assessment of seismic demand. Soil Dynamics and Earthquake Engineering, 21(2), 113-137.

Deierlein, G. G., Reinhorn, A. M., \& Willford, M. R. (2010). Nonlinear structural analysis for seismic design. NEHRP Seismic Design Technical Brief, 4, 1-36.

Del Pezzo, E., Iannaccone, G., Martini, M., \& Scarpa, R. (1983). The 23 november 1980 southern Italy earthquake. Bulletin of the Seismological Society of America, 73(1), 187200. 
Donaire Ávila, J. (2014). Proyecto sismorresistente de estructuras con forjado reticular y disipadores histeréticos basados en el balance de la energía. Universidad de Granada.

Donaire-Ávila, J., \& Benavent-Climent, A. (2020). Optimum strength distribution for structures with metallic dampers subjected to seismic loading. Metals, 10(1), 127.

Donaire-Avila, J., Lucchini, A., Benavent-Climent, A., \& Mollaioli, F. (2018). New approach for the optimal yield-force coefficient distribution in the seismic design of buildings. 16th European Conference on Earthquake Engineering, Thessaloniki (Greece),

Dovich, L. M., \& Wight, J. K. (2005). Effective slab width model for seismic analysis of flat slab frames. ACI Structural Journal, 102(6), 868.

Durrani, A. J., Du, Y., \& Luo, Y. H. (1995). Seismic resistance of nonductile slab-column connections in existing flat-slab buildings. Structural Journal, 92(4), 479-487.

Dutta, S. C., \& Kunnath, S. K. (2013). Effect of bidirectional interaction on seismic demand of structures. Soil Dynamics and Earthquake Engineering, 52, 27-39.

Einstein, A. (1983). Geometry and experience, (1921). Albert Einstein, Sidelights on Relativity, $25-56$.

Fajfar, P. (2018). Analysis in seismic provisions for buildings: Past, present and future. Paper presented at the European Conference on Earthquake Engineering Thessaloniki, Greece, pp. 1-49.

Fajfar, P., \& Vidic, T. (1994). Consistent inelastic design spectra: Hysteretic and input energy. Earthquake Engineering \& Structural Dynamics, 23(5), 523-537.

Fardis, M. N. (2009). Seismic design, assessment and retrofitting of concrete buildings: Based on EN-eurocode 8 Springer Science \& Business Media.

Fardis, M. N. (2018). From force-to displacement-based seismic design of concrete structures and beyond. Paper presented at the Recent Advances in Earthquake Engineering in 
Europe: 16th European Conference on Earthquake Engineering-Thessaloniki 2018, pp. $101-122$

Filippou, F. C., Bertero, V. V., \& Popov, E. P. (1983). Effects of bond deterioration on hysteretic behavior of reinforced concrete joints.

Gallego, A., Benavent-Climent, A., \& Romo-Melo, L. (2015). Piezoelectric sensing and nonparametric statistical signal processing for health monitoring of hysteretic dampers used in seismic-resistant structures. Mechanical Systems and Signal Processing, 60, 90-105.

Goel, R. K. (1997). Seismic response of asymmetric systems: Energy-based approach. Journal of Structural Engineering, 123(11), 1444-1453.

González-Sanz, G., Escolano-Margarit, D., \& Benavent-Climent, A. (2020). A new stainlesssteel tube-in-tube damper for seismic protection of structures. Applied Sciences, 10(4), 1410.

Hong, H. P., Pozos-Estrada, A., \& Gomez, R. (2009). Orientation effect on ground motion measurement for mexican subduction earthquakes. Earthquake Engineering and Engineering Vibration, 8(1), 1-16.

Housner, G. W. (1956). Limit design of structures to resist earthquakes. Paper presented at the Proc. of 1st WCEE, pp. 5.1-5.13.

Hsu, T. T. C. (1984). Torsion of reinforced concrete

Hudson, D. E. (1956). Response spectrum techniques in engineering seismology. Paper presented at the Proceedings of the World Conference on Earthquake Engineering, 4. pp. 1.

Hudson, D. E. (1962). Some problems in the application of spectrum techniques to strongmotion earthquake analysis. Bulletin of the Seismological Society of America, 52(2), 417430. 
Hueste, M. B. D., \& Wight, J. K. (1999). Nonlinear punching shear failure model for interior slab-column connections. Journal of Structural Engineering, 125(9), 997-1008.

Hwang, S., \& Moehle, J. P. (2000). Models for laterally loaded slab-column frames. Structural Journal, 97(2), 345-352.

Kasai, K., Pu, W., \& Wada, A. (2012). Response of passively-controlled tall buildings in tokyo during 2011 great east japan earthquake. Paper presented at the Proceedings of the 15th World Conference on Earthquake Engineering, Lisbon, Portugal,

Kasai, K., Nakai, M., Nakamura, Y., Asai, H., Suzuki, Y., \& Ishii, M. (2009). Building passive control in japan. Journal of Disaster Research, 4(3), 261-269.

Kassimali, A. (2012). Matrix analysis of structures SI version Cengage Learning.

Kato, B., Akiyama, H., \& Yamanouchi, H. (1973). Predictable properties of material under incremental cyclic loading. Paper presented at the IABSE Symposium,

Kuang, Y., Jiang, X., \& Jiang, N. (2018). Inelastic parametric analysis of seismic responses of multistorey bidirectional eccentric structure. Shock and Vibration, 2018

Kuwamura, H., \& Galambos, T. V. (1989). Earthquake load for structural reliability. Journal of Structural Engineering, 115(6), 1446-1462.

Lawson, R. S., \& Krawinkler, H. (1995). Cumulative damage potential of seismic ground motion. Paper presented at the 10th European Conference on Earthquake Engineering, pp. 1079-1086.

Lee, C. S., \& Hong, H. P. (2010). Statistics of inelastic responses of hysteretic systems under bidirectional seismic excitations. Engineering Structures, 32(8), 2074-2086.

López-Almansa, F., Yazgan, A. U., \& Benavent-Climent, A. (2013). Design energy input spectra for high seismicity regions based on turkish registers. Bulletin of Earthquake Engineering, 11(4), 885-912. 
Lu, X., \& Guan, H. (2017). Earthquake disaster simulation of civil infrastructures Springer.

Lu, X., Xie, L., Guan, H., Huang, Y., \& Lu, X. (2015). A shear wall element for nonlinear seismic analysis of super-tall buildings using OpenSees. Finite Elements in Analysis and Design, 98, 14-25.

Lucchini, A., Franchin, P., \& Mollaioli, F. (2017). Uniform hazard floor acceleration spectra for linear structures. Earthquake Engineering \& Structural Dynamics, 46(7), 1121-1140.

Maekawa, K., Okamura, H., \& Pimanmas, A. (2014). Non-linear mechanics of reinforced concrete CRC Press.

Magliulo, G., \& Ramasco, R. (2007). Seismic response of three-dimensional r/c multi-storey frame building under uni-and bi-directional input ground motion. Earthquake Engineering \& Structural Dynamics, 36(12), 1641-1657.

Manfredi, G. (2001). Evaluation of seismic energy demand. Earthquake Engineering \& Structural Dynamics, 30(4), 485-499.

Manfredi, G., Polese, M., \& Cosenza, E. (2003). Cumulative demand of the earthquake ground motions in the near source. Earthquake Engineering \& Structural Dynamics, 32(12), 18531865.

Martínez Solares, J. M., Cabañas, L., Benito, B., Ricas, A., Gaspar, J. M., Ruíz, S., et al. (2013). Actualización de mapas de peligrosidad sísmica de España 2012. Centro Nacional De Información Geográfica, Madrid,

Marušić, D., \& Fajfar, P. (2005). On the inelastic seismic response of asymmetric buildings under bi-axial excitation. Earthquake Engineering \& Structural Dynamics, 34(8), 943-963.

Mayergoyz, I. D. (1991). Mathematical models of hysteresis Springer-Verlag, New York.

Mazzoni, S., McKenna, F., Scott, M. H., \& Fenves, G. L. (2006). Opensees command language manual. Pacific Earthquake Engineering Research (PEER) Center, 264 
Mckenna, F. T. (1999). Object-oriented finite element programming: Frameworks for analysis, algorithms and parallel computing. Dissertation

McKenna, F., Scott, M. H., \& Fenves, G. L. (2009). Nonlinear finite-element analysis software architecture using object composition. Journal of Computing in Civil Engineering, 24(1), 95-107.

Meli, R., \& Avila, J. A. (1989). The Mexico earthquake of september 19, 1985 -analysis of building response-. Earthquake Spectra, 5(1), 1-17.

Meli, R., \& Rodriguez, M. (1988). Seismic behavior of waffle plate buildings. Concrete International, 10(7), 33-41.

Ministerio de Fomento (2003). Norma De Construcción Sismorresistente: Parte General y Edificación.

Ministerio de Fomento (2008). Instrucción De Hormigón Estructural EHE-08

Mohd, Y. M. (1995). Nonlinear analysis of prestressed concrete structures under monotonic and cyclic loads.

Mosalam, K. M., \& Naito, C. J. (2002). Seismic evaluation of gravity-load-designed columngrid system. Journal of Structural Engineering, 128(2), 160-168.

Nakata, N. (2010). Acceleration trajectory tracking control for earthquake simulators. Engineering Structures, 32(8), 2229-2236.

Newmark, N. M., \& Hall, W. J. (1982). Engineering monographs on earthquake criteria, structural design, and strong motion records. Earthquake Spectra and Design, 3

Nielsen, L. O., Mualla, I. H., \& Iwai, Y. (2004). Seismic isolation with a new frictionviscoelastic damping system. Paper presented at the 13th World Conference on Earthquake Engineering, Vancouver, Canada, 
Oviedo, A., Midorikawa, M., \& Asari, T. (2010). Earthquake response of ten-story story-driftcontrolled reinforced concrete frames with hysteretic dampers. Engineering Structures, 32(6), 1735-1746.

Oviedo, J. A. (2012). Influence of the story stiffness of reinforced concrete frame with proportional hysteretic dampers on the seismic response. Revista EIA, (17), 121-137.

Park, H., \& Eom, T. (2006). A simplified method for estimating the amount of energy dissipated by flexure-dominated reinforced concrete members for moderate cyclic deformations. Earthquake Spectra, 22(2), 459-490.

Paulay, T., \& Priestley, M. N. (1992). Seismic design of reinforced concrete and masonry buildings.

Perus, I., \& Fajfar, P. (2005). On the inelastic torsional response of single-storey structures under bi-axial excitation. Earthquake Engineering \& Structural Dynamics, 34(8), 931-941.

Rizwan, M., Ahmad, N., Khan, A. N., Qazi, S., Akbar, J., \& Fahad, M. (2020). Shake table investigations on code non-compliant reinforced concrete frames. Alexandria Engineering Journal,

Robertson, I. N., Kawai, T., Lee, J., \& Enomoto, B. (2002). Cyclic testing of slab-column connections with shear reinforcement. Structural Journal, 99(5), 605-613.

Robertson, I., \& Johnson, G. (2006). Cyclic lateral loading of nonductile slab-column connections. ACI Materials Journal, 103(3), 356.

Rodrigues, H., Arêde, A., Varum, H., \& Costa, A. (2013). Damage evolution in reinforced concrete columns subjected to biaxial loading. Bulletin of Earthquake Engineering, 11(5), $1517-1540$.

Rodrigues, H., Furtado, A., \& Arêde, A. (2015). Behavior of rectangular reinforced-concrete columns under biaxial cyclic loading and variable axial loads. Journal of Structural Engineering, 142(1), 04015085. 
Rodrigues, H., Varum, H., Arêde, A., \& Costa, A. (2012). A comparative analysis of energy dissipation and equivalent viscous damping of RC columns subjected to uniaxial and biaxial loading. Engineering Structures, 35, 149-164.

Rodrigues, H., Varum, H., Arêde, A., \& Costa, A. G. (2013). Behaviour of reinforced concrete column under biaxial cyclic loading — state of the art. International Journal of Advanced Structural Engineering, 5(1), 4.

Rodriguez, M. E., Santiago, S., \& Meli, R. (1995). Seismic load tests on two-story Waffle-Flatplate structure. Journal of Structural Engineering, 121(9), 1287-1293.

Romo, L., Benavent-Climent, A., Morillas, L., Escolano, D., \& Gallego, A. (2015). Health monitoring of a new hysteretic damper subjected to earthquakes on a shaking table. Earthquakes and Structures, 8(3), 485-509.

Rubinstein, M. F. (1966). Matrix computer analysis of structures. Englewood Cliffs, N.J., Prentice-Hall, Inc., $1966.402 P$,

Scott, M. H., \& Fenves, G. L. (2006). Plastic hinge integration methods for force-based beamcolumn elements. Journal of Structural Engineering, 132(2), 244-252.

SEAOC. (1995). Vision 2000: Performance-based seismic engineering of buildings.

Sebastiani, P. E., Liberatore, L., Lucchini, A., \& Mollaioli, F. (2018). A new method to predict the critical incidence angle for buildings under near-fault motions. Structural Engineering and Mechanics, 68(5), 575-589.

Sordo, E., Teran, A., Guerrero, J. J., Juarez, H., \& Iglesias, J. (1989). The Mexico earthquake of september 19, 1985 -ductility and resistance requirements imposed on a concrete building. Earthquake Spectra, 5(1), 41-50.

Symans, M. D., Charney, F. A., Whittaker, A. S., Constantinou, M. C., Kircher, C. A., Johnson, M. W., et al. (2008). Energy dissipation systems for seismic applications: Current practice and recent developments. Journal of Structural Engineering, 134(1), 3-21. 
Takagi, J., \& Wada, A. (2019). Recent earthquakes and the need for a new philosophy for earthquake-resistant design. Soil Dynamics and Earthquake Engineering, 119, 499-507.

Taranath, B. S. (2004). Wind and earthquake resistant buildings: Structural analysis and design $\mathrm{CRC}$ press.

Thomas, H. K., \& Wallace, J. W. (2004). Shake table tests of reinforced concrete flat plate frames and post-tensioned flat plate frames. 13th World Conference on Earthquake Engineering Vancouver, BC, Canada, pp. 11-19.

Uang, C., \& Bertero, V. V. (1988). Use of energy as a design criterion in earthquake-resistant design Earthquake Engineering Research Center, University of California Berkeley ....

Valipour, H. R., \& Foster, S. J. (2010). Nonlinear reinforced concrete frame element with torsion. Engineering Structures, 32(4), 988-1002.

Vargas, Y. F., Pujades, L. G., Barbat, A. H., \& Hurtado, J. E. (2013). Capacity, fragility and damage in reinforced concrete buildings: A probabilistic approach. Bulletin of Earthquake Engineering, 11(6), 2007-2032.

Veletsos, A. S., \& Newmark, N. M. (1960). Effect of inelastic behavior on the response of simple systems to earthquake motions. Paper presented at the

Wight, J. K., Cagley, J. R., Criswell, M. E., Durrani, A. J., Ehsani, M. R., Garcia, L. E., et al. (1988). Recommendations for design of slab-column connections in monolithic reinforced concrete structures. ACI Struct.J., 85(6), 675-696.

Young, W. C., Budynas, R. G., \& Sadegh, A. M. (2002). Roark's formulas for stress and strain McGraw-Hill New York.

Zeris, C. A., \& Mahin, S. A. (1991). Behavior of reinforced concrete structures subjected to biaxial excitation. Journal of Structural Engineering, 117(9), 2657-2673. 
Zhou, Y., Gong, S. M., \& Lu, X. L. (2013). Study on similarity of hysteretic loops and characteristic parameters of viscoelastic dampers with test verifications. Paper presented at the Applied Mechanics and Materials, 353. pp. 1970-1975. 
Appendix 1

SHAKING TABLE RESPONSE 

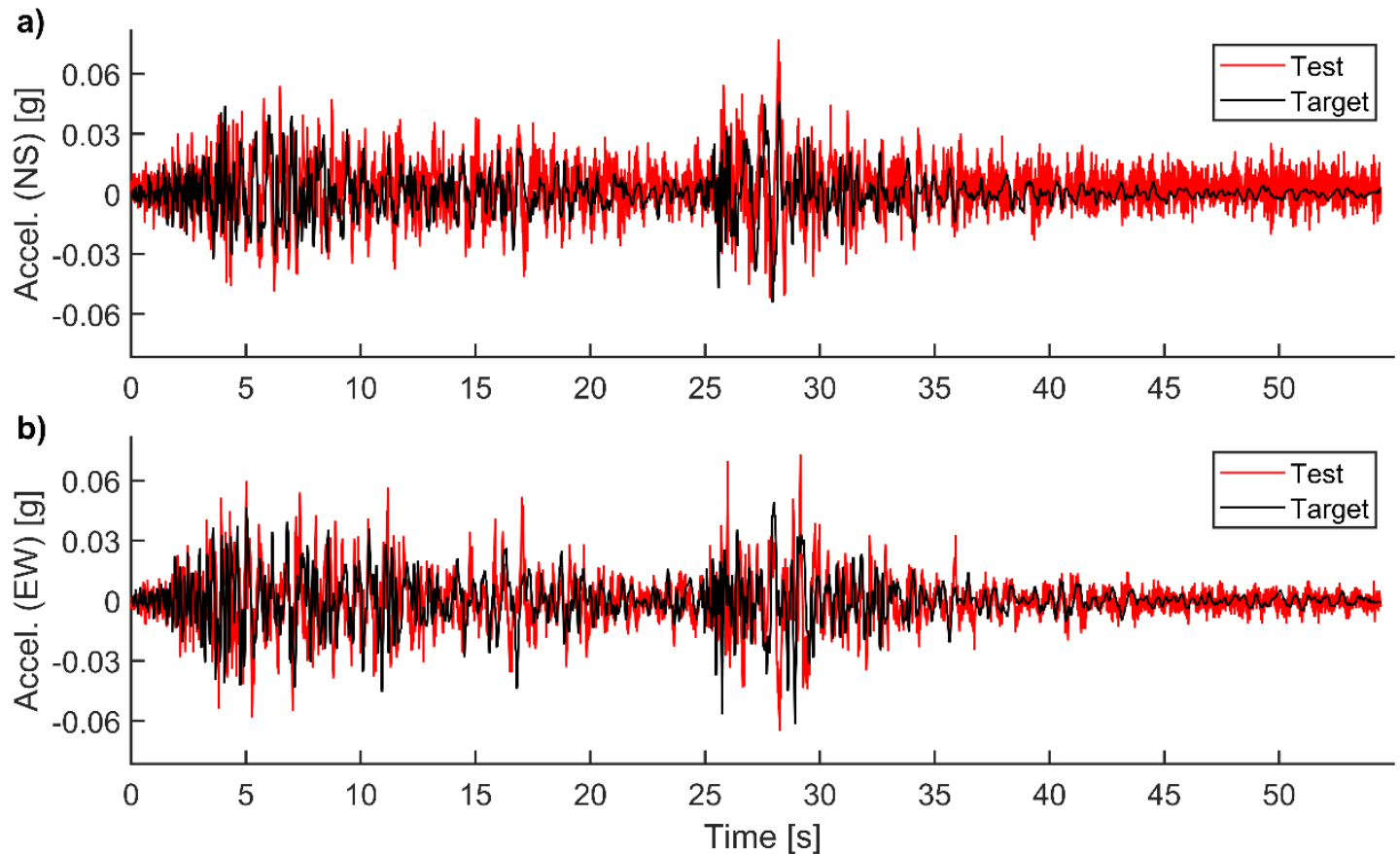

Figure A1. 1. History of accelerations superposed (Target and Test) for simulation C35: a) Component NS (direction X) and b) Component EW (direction Y)

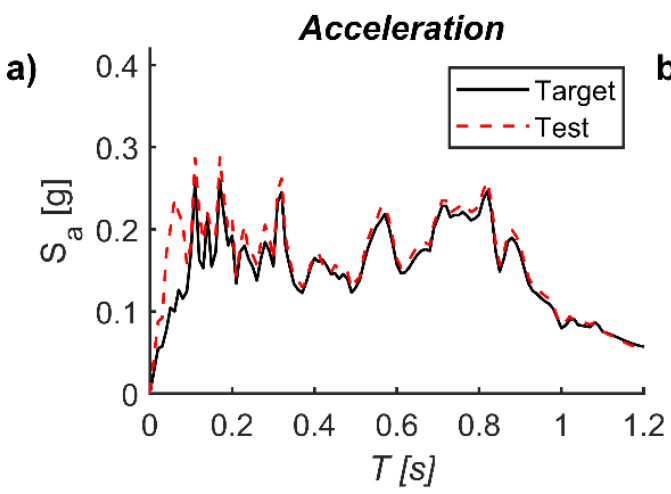

c)

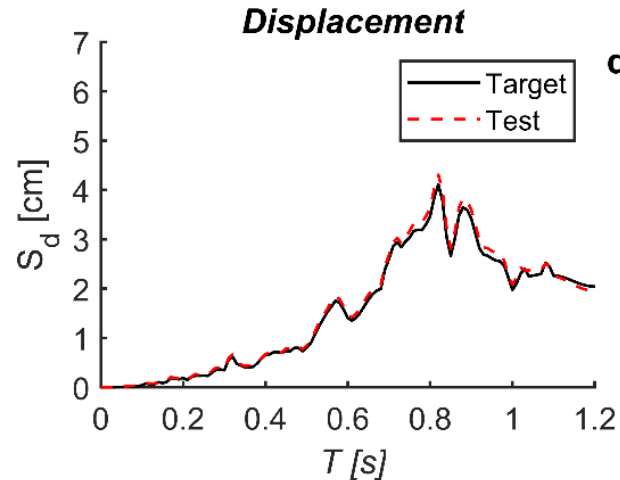

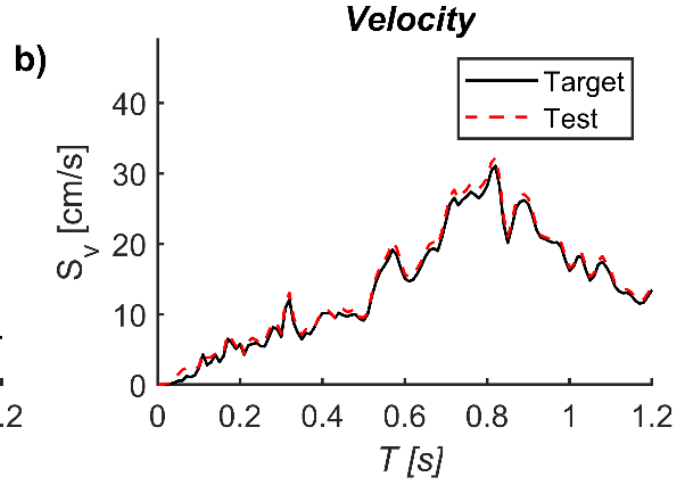

Energy

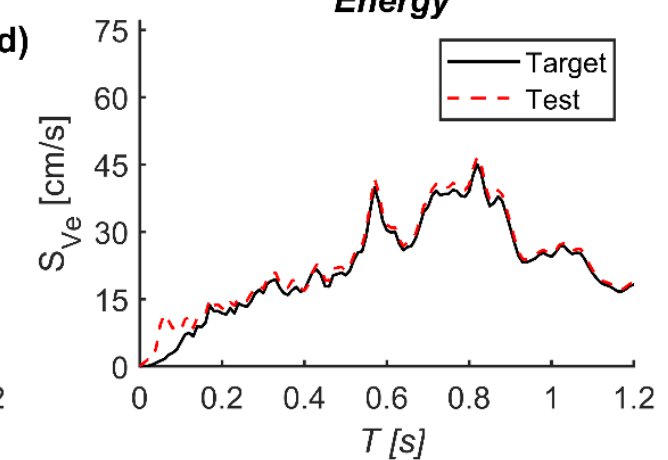

Figure A1. 2. Spectrums superposed (Target and Test) for Component NS (direction X) simulation C35: a) Acceleration, b) Velocity, c) Displacement and d) Energy 

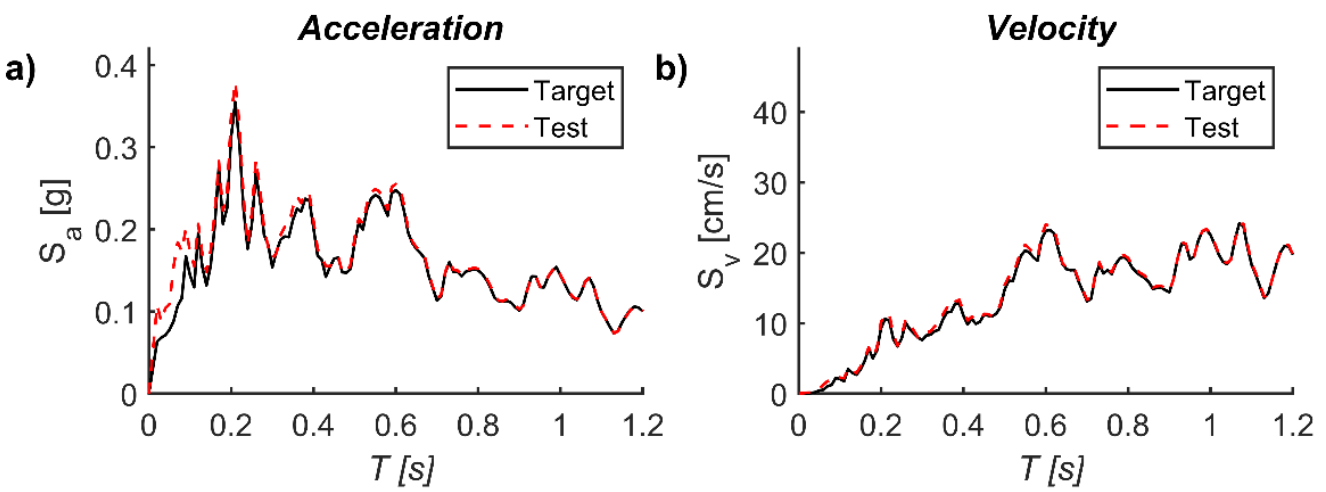

c)
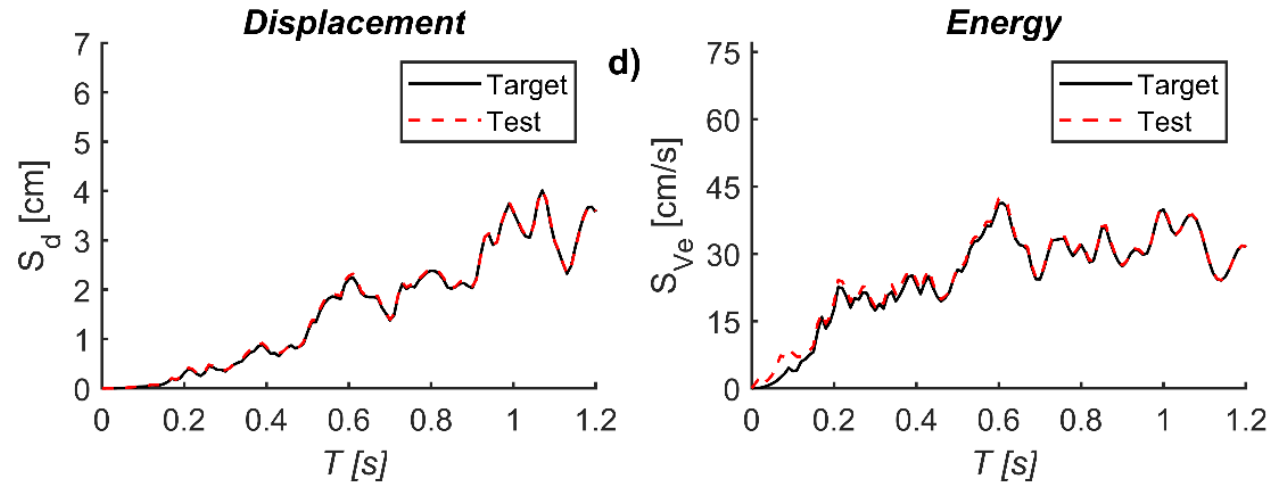

Figure A1. 3. Spectrums superposed (Target and Test) for Component EW (direction Y) simulation C35: a) Acceleration, b) Velocity, c) Displacement and d) Energy
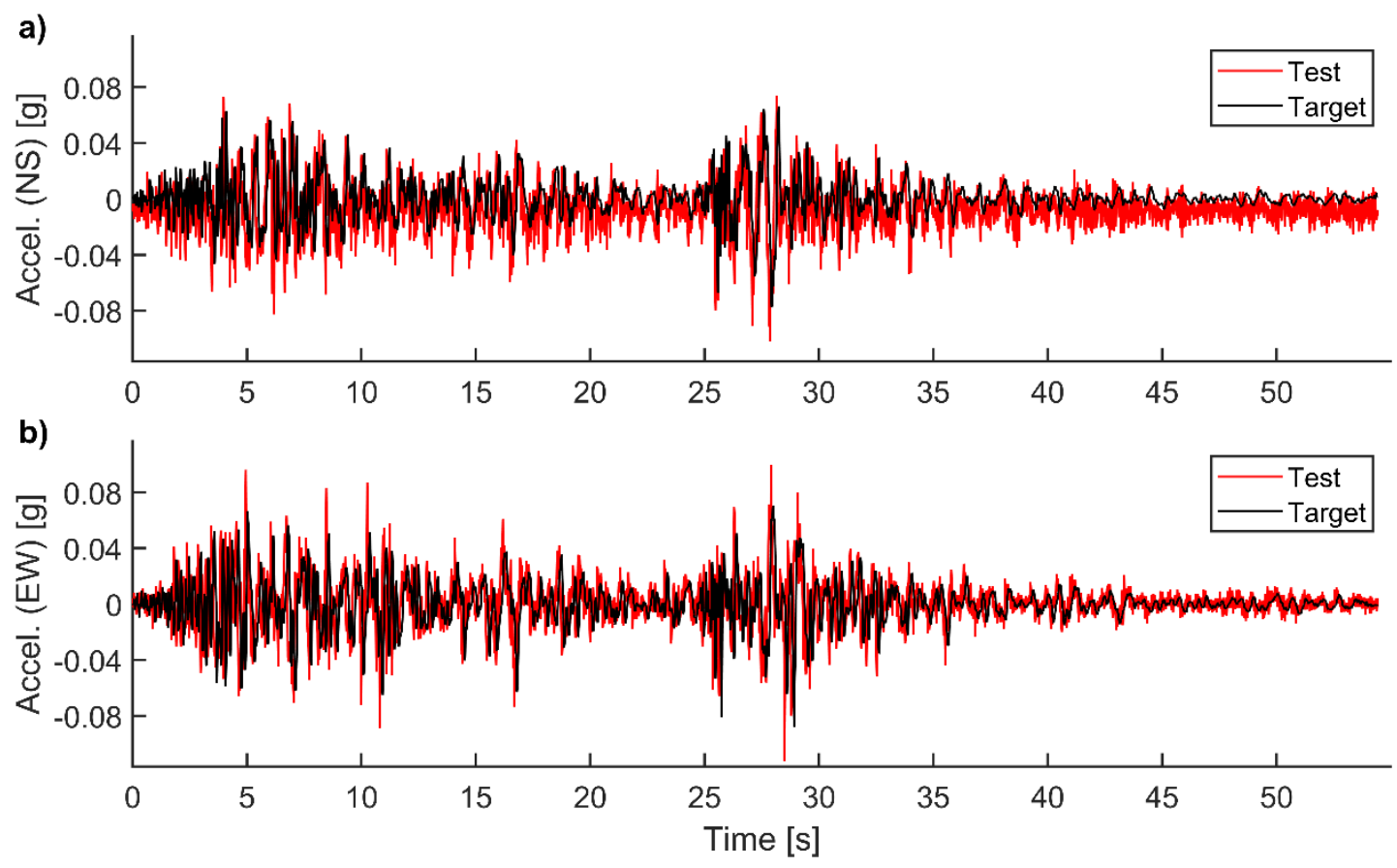

Figure A1. 4. History of accelerations superposed (Target and Test) for simulation C50: a) Component NS (direction X) and b) Component EW (direction Y) 
a)

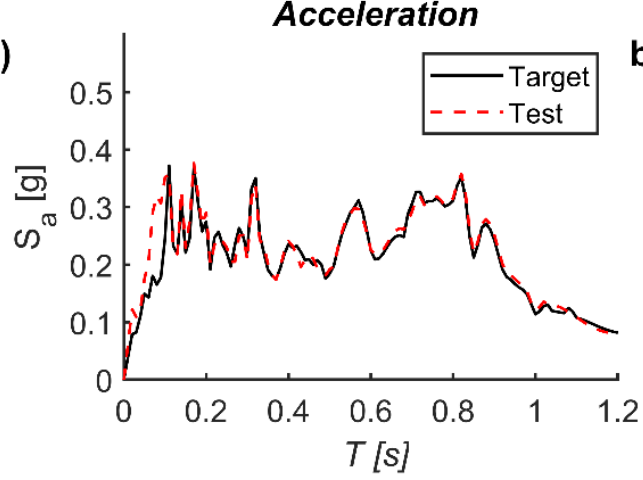

c)

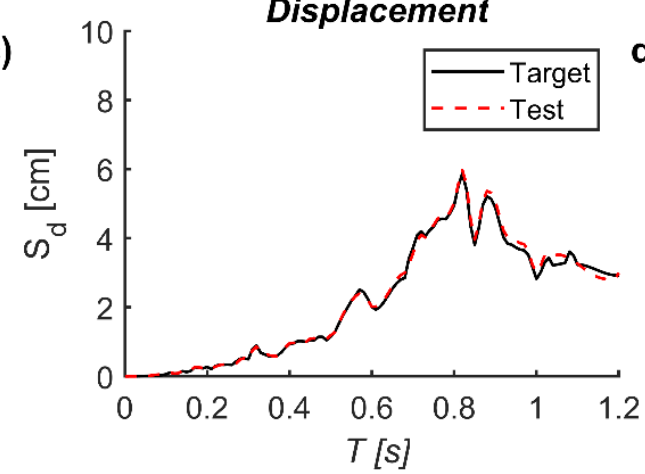

b)

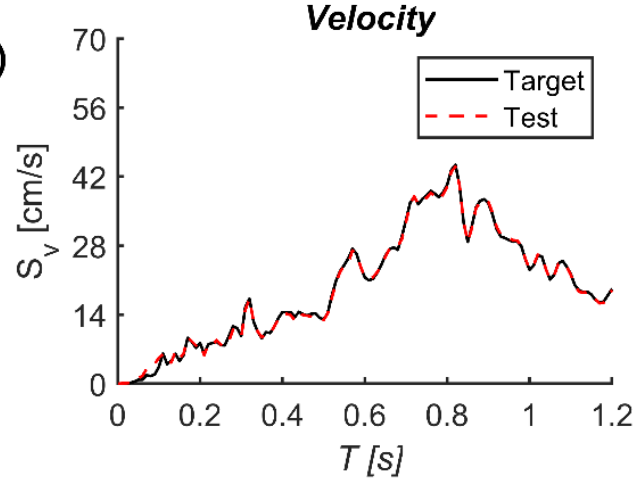

Energy

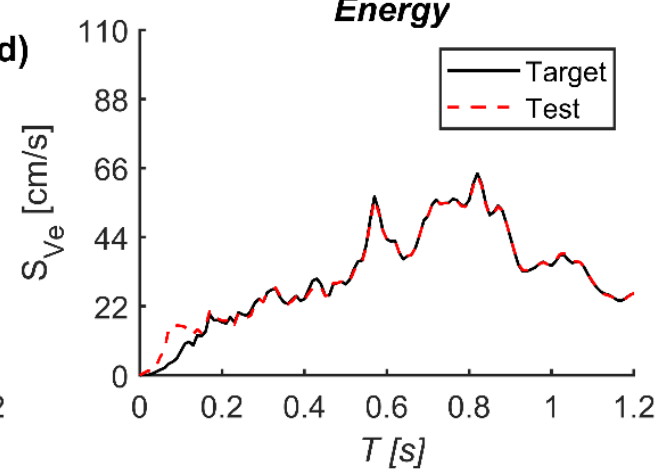

Figure A1. 5. Spectrums superposed (Target and Test) for Component NS (direction X) simulation C50: a) Acceleration, b) Velocity, c) Displacement and d) Energy
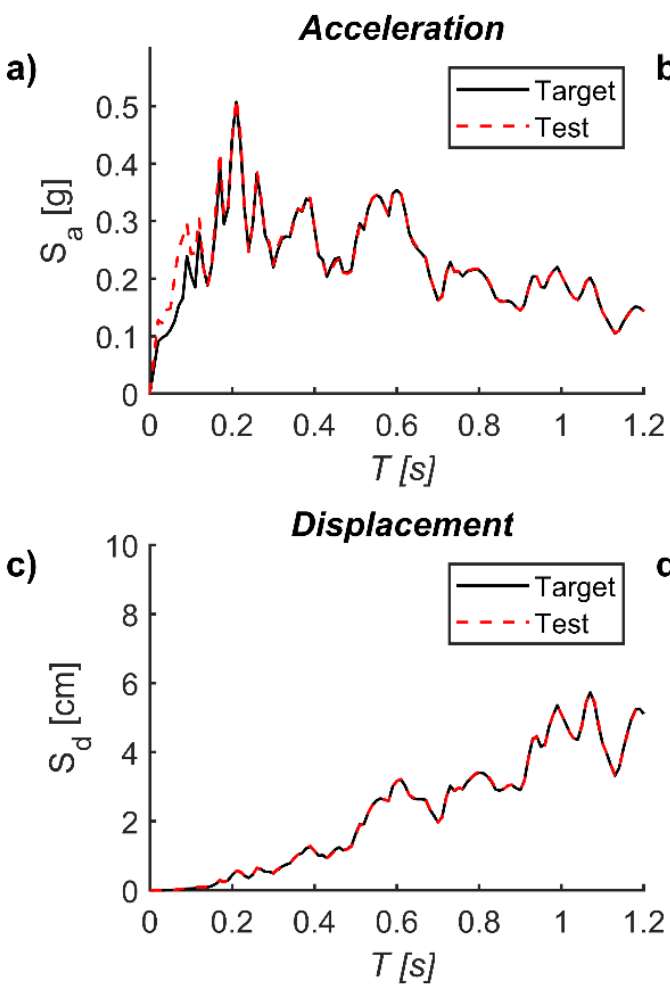

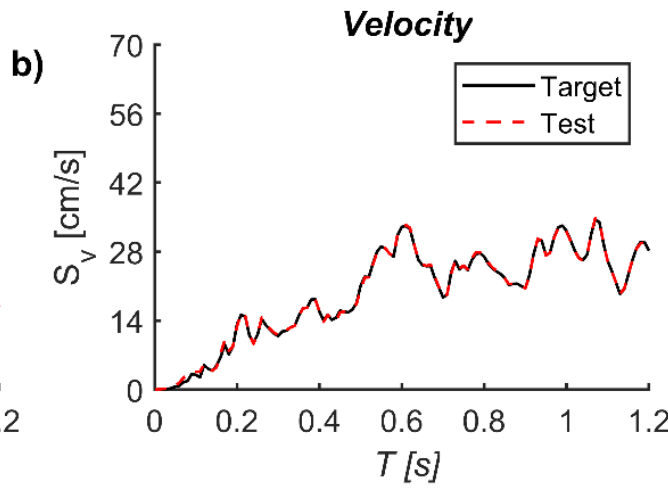

Energy

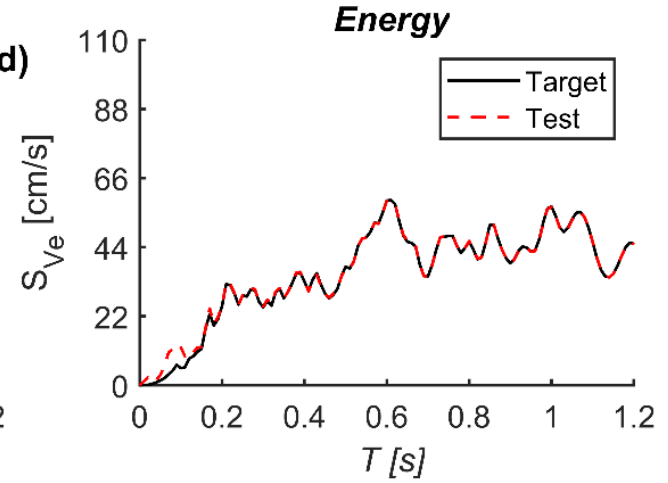

Figure A1. 6. Spectrums superposed (Target and Test) for Component EW (direction Y) simulation C50: a) Acceleration, b) Velocity, c) Displacement and d) Energy 

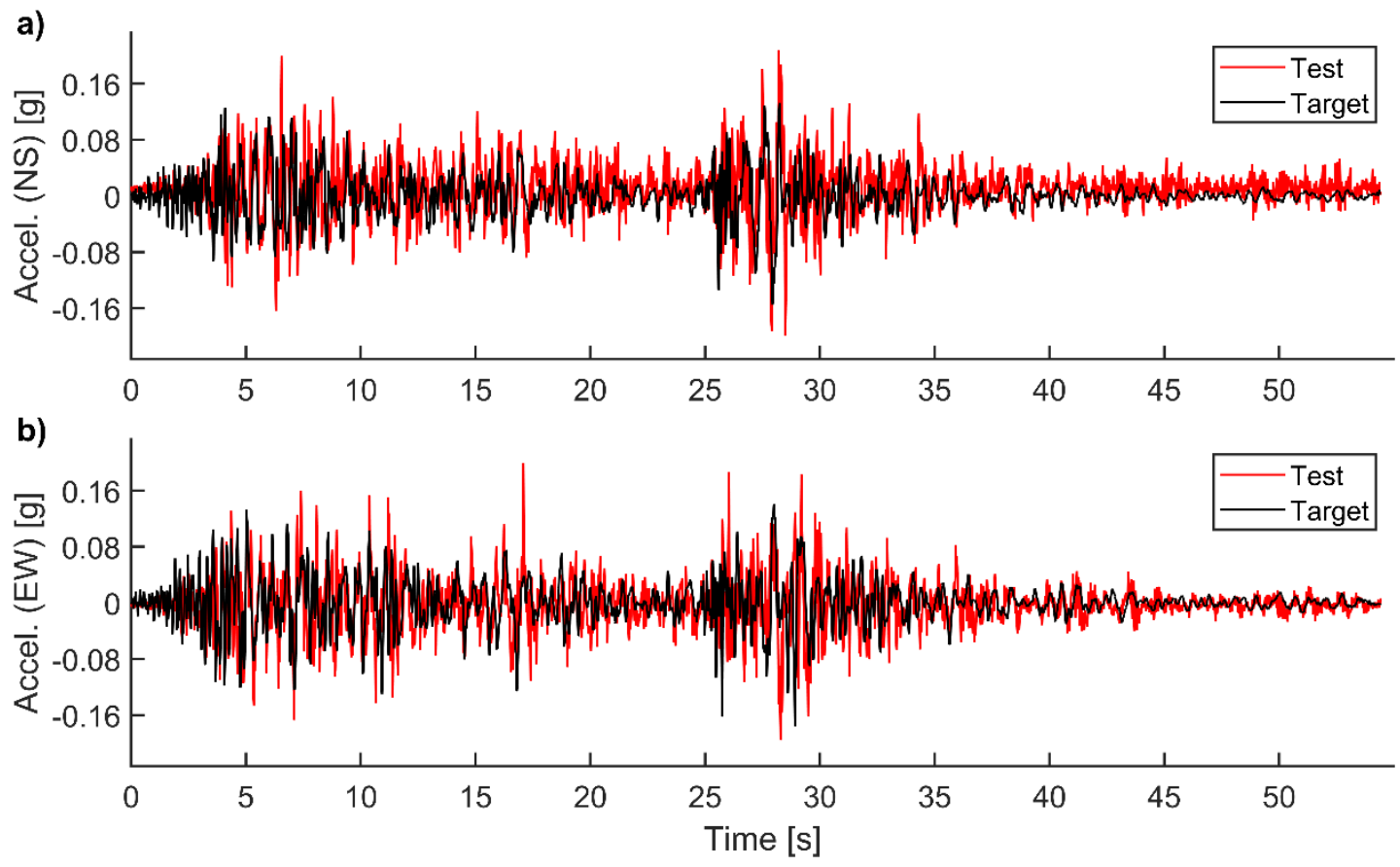

Figure A1. 7. History of accelerations superposed (Target and Test) for simulation C100: a) Component NS (direction X) and b) Component EW (direction Y)
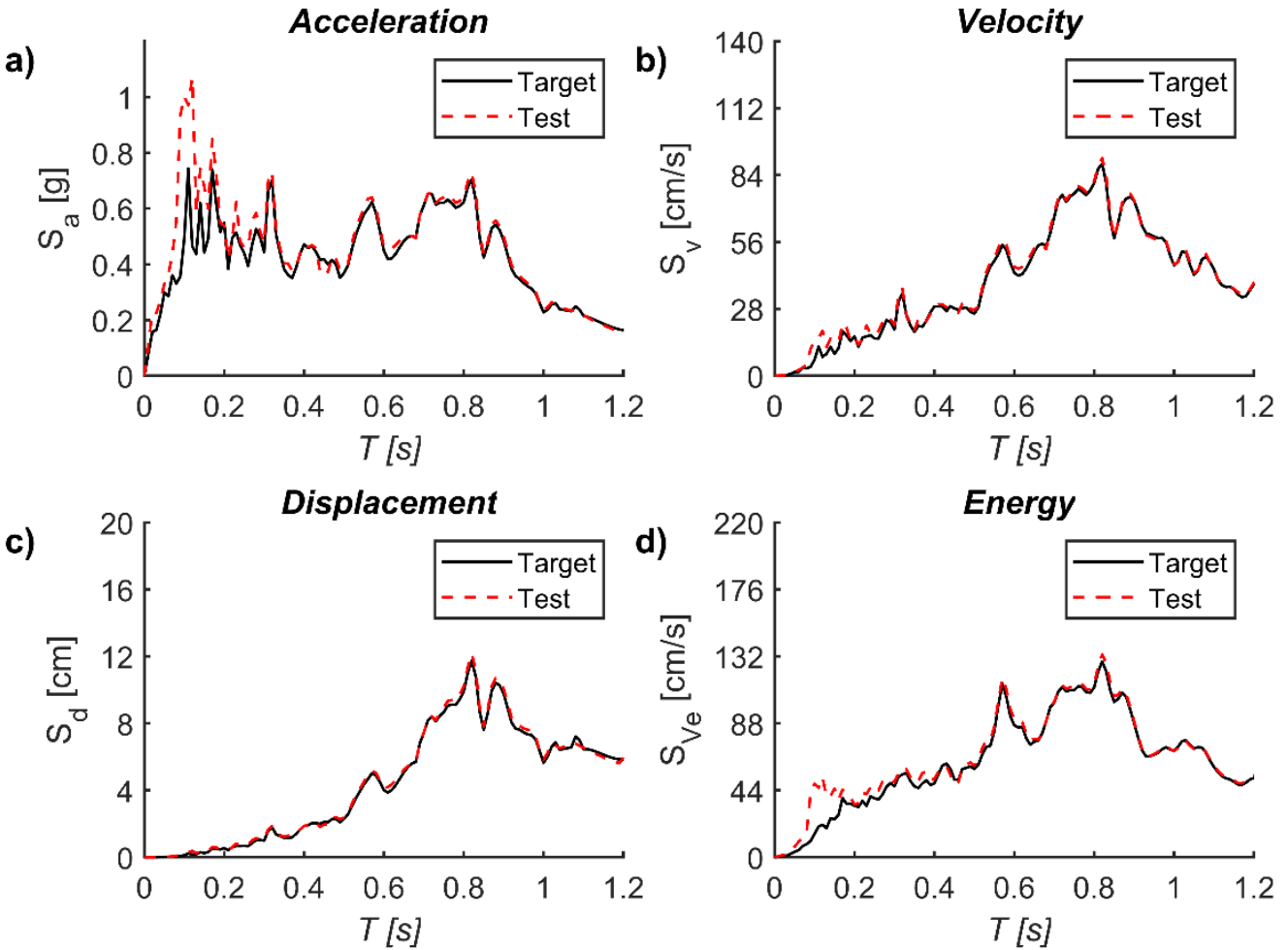

Figure A1. 8. Spectrums superposed (Target and Test) for Component NS (direction X) simulation C100: a) Acceleration, b) Velocity, c) Displacement and d) Energy 
a)

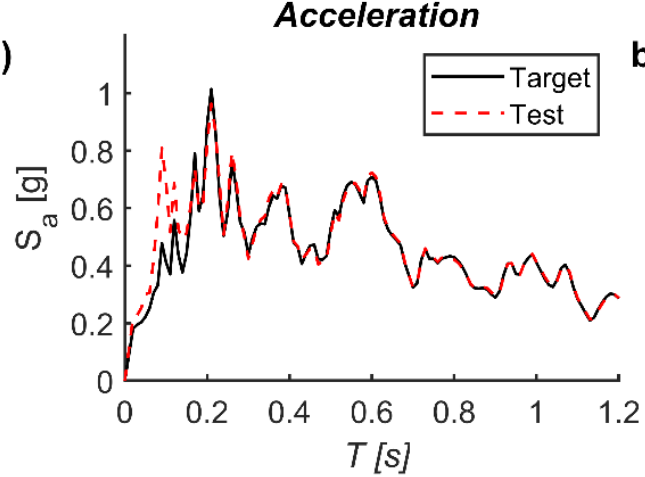

c)

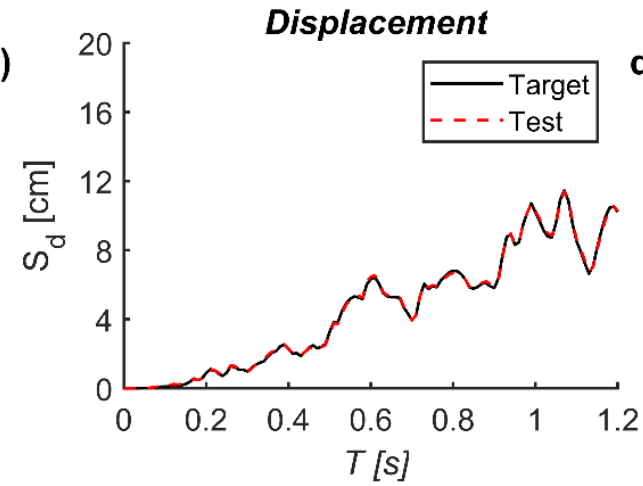

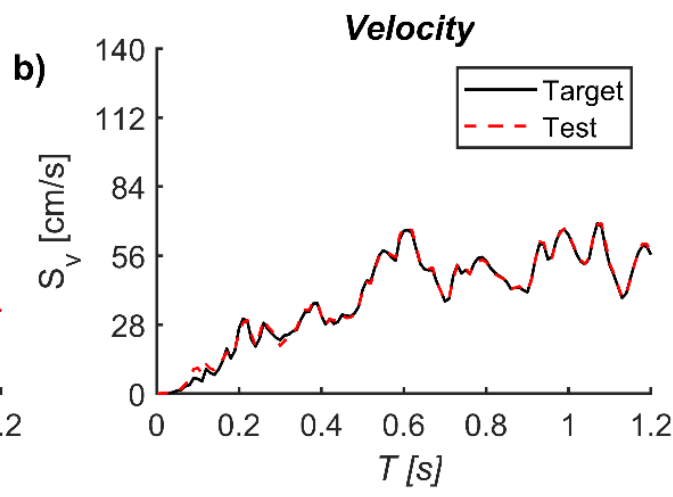

Energy

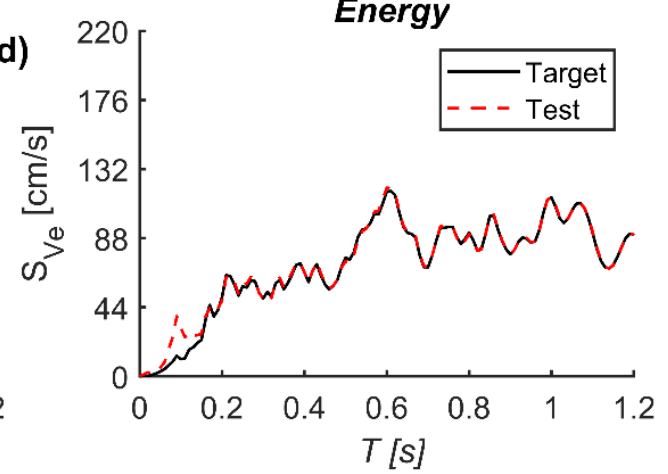

Figure A1. 9. Spectrums superposed (Target and Test) for Component EW (direction Y) simulation C100: a) Acceleration, b) Velocity, c) Displacement and d) Energy
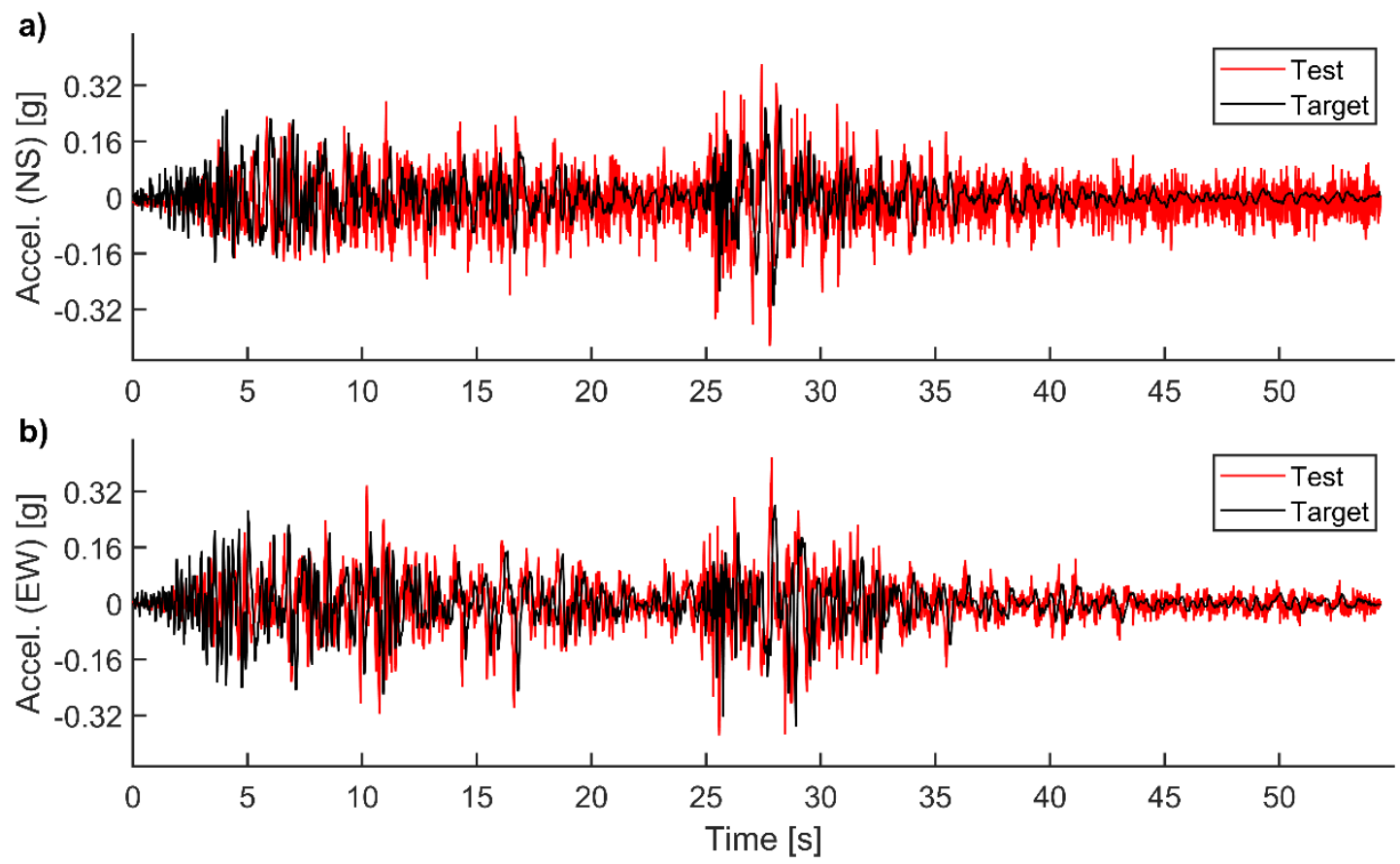

Figure A1. 10. History of accelerations superposed (Target and Test) for simulation C200: a) Component NS (direction X) and b) Component EW (direction Y) 
a)

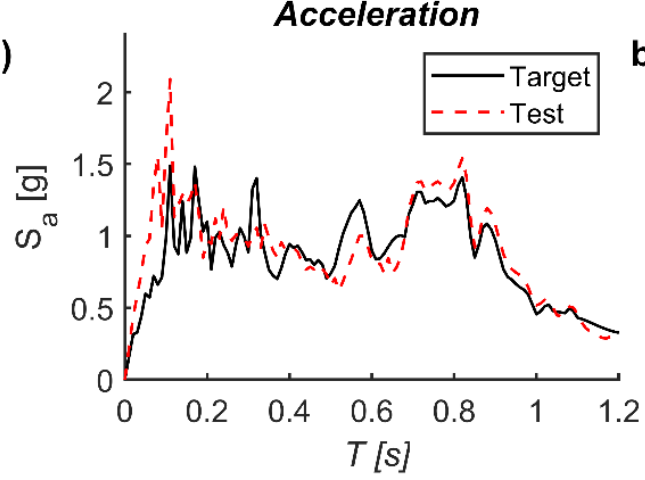

c)

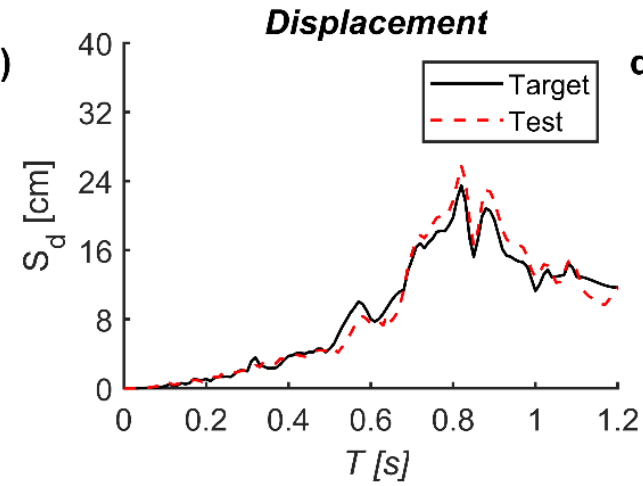

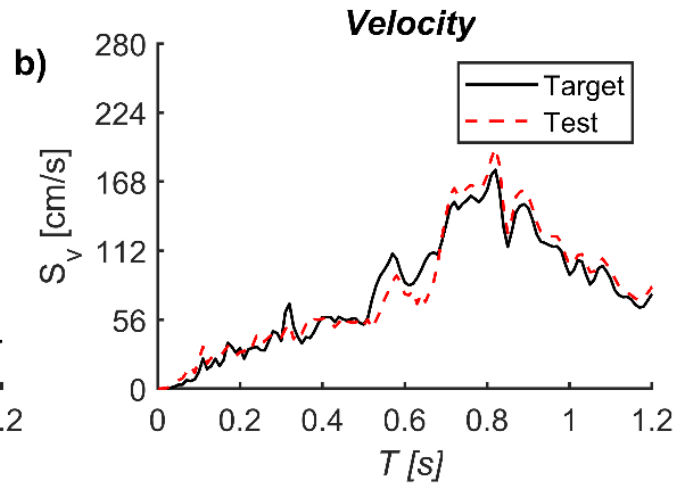

Energy

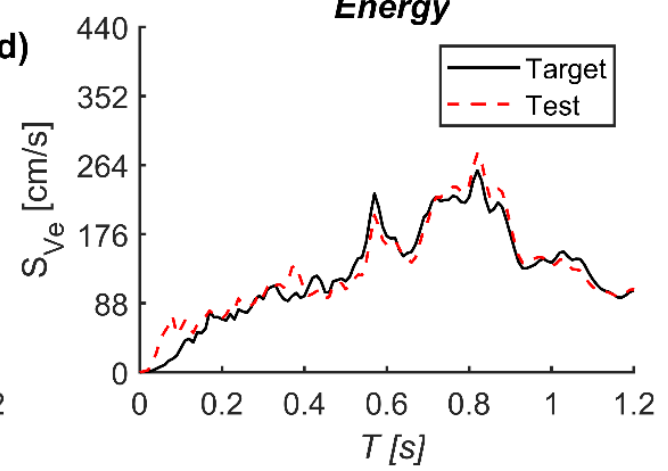

Figure A1. 11. Spectrums superposed (Target and Test) for Component NS (direction X) simulation C200: a) Acceleration, b) Velocity, c) Displacement and d) Energy
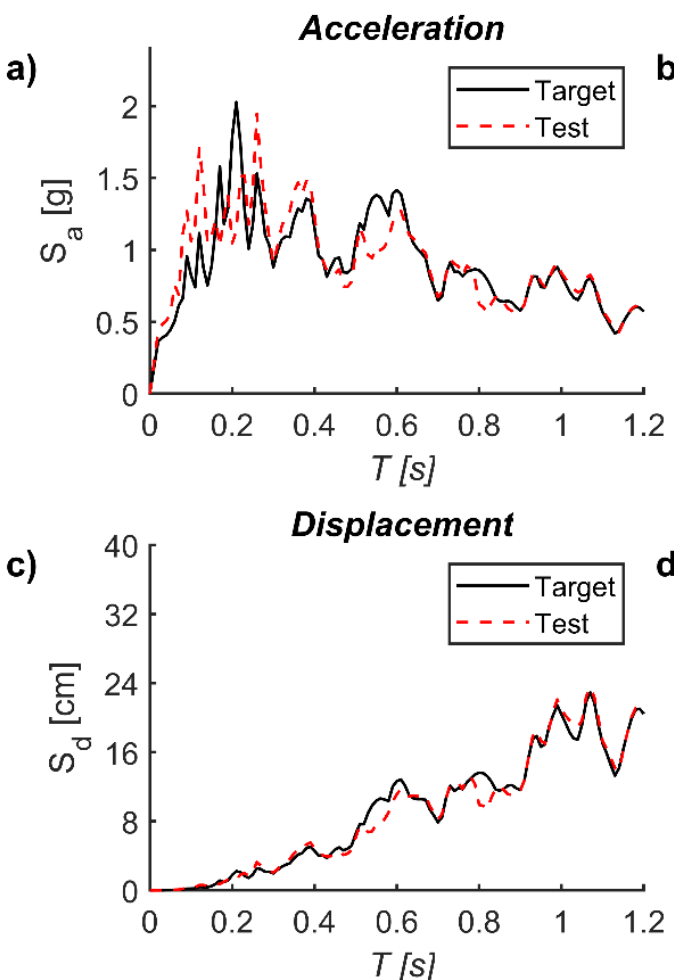

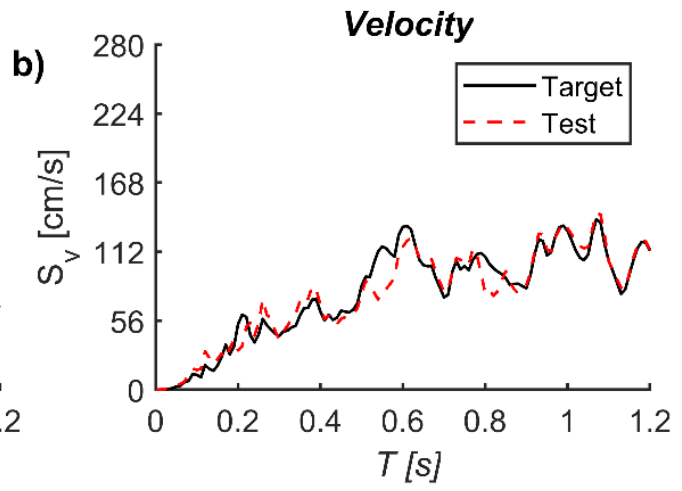

Energy

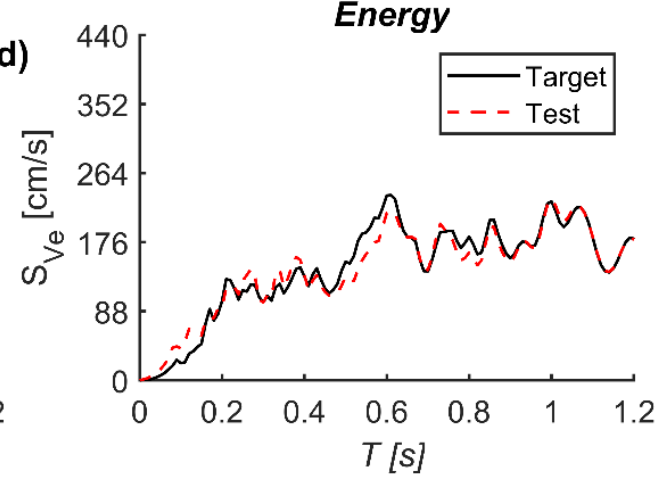

Figure A1. 12. Spectrums superposed (Target and Test) for Component EW (direction Y) simulation C200: a) Acceleration, b) Velocity, c) Displacement and d) Energy 

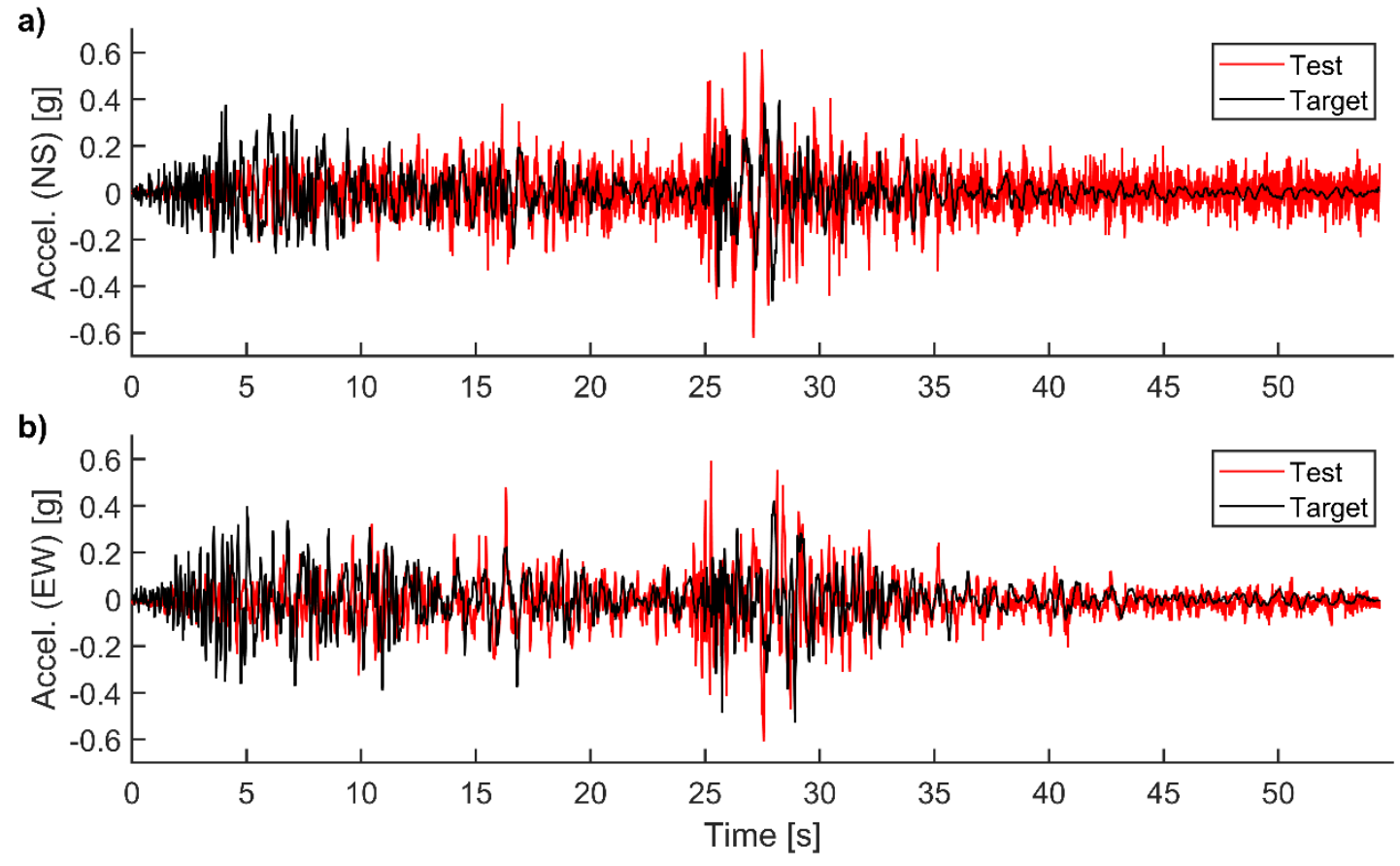

Figure A1. 13. History of accelerations superposed (Target and Test) for simulation C300: a) Component NS (direction X) and b) Component EW (direction Y)
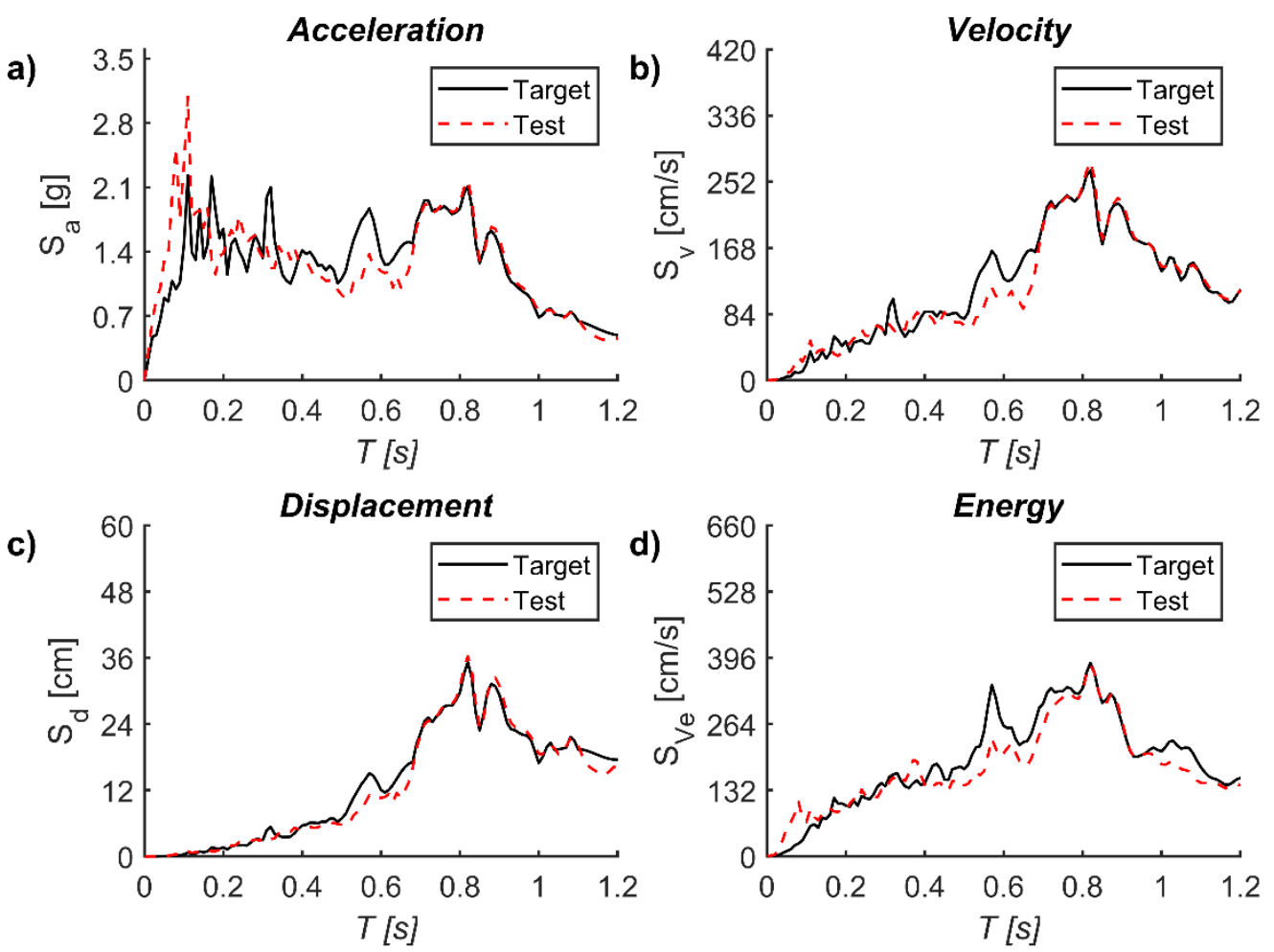

Figure A1. 14. Spectrums superposed (Target and Test) for Component NS (direction X) simulation C300: a) Acceleration, b) Velocity, c) Displacement and d) Energy 

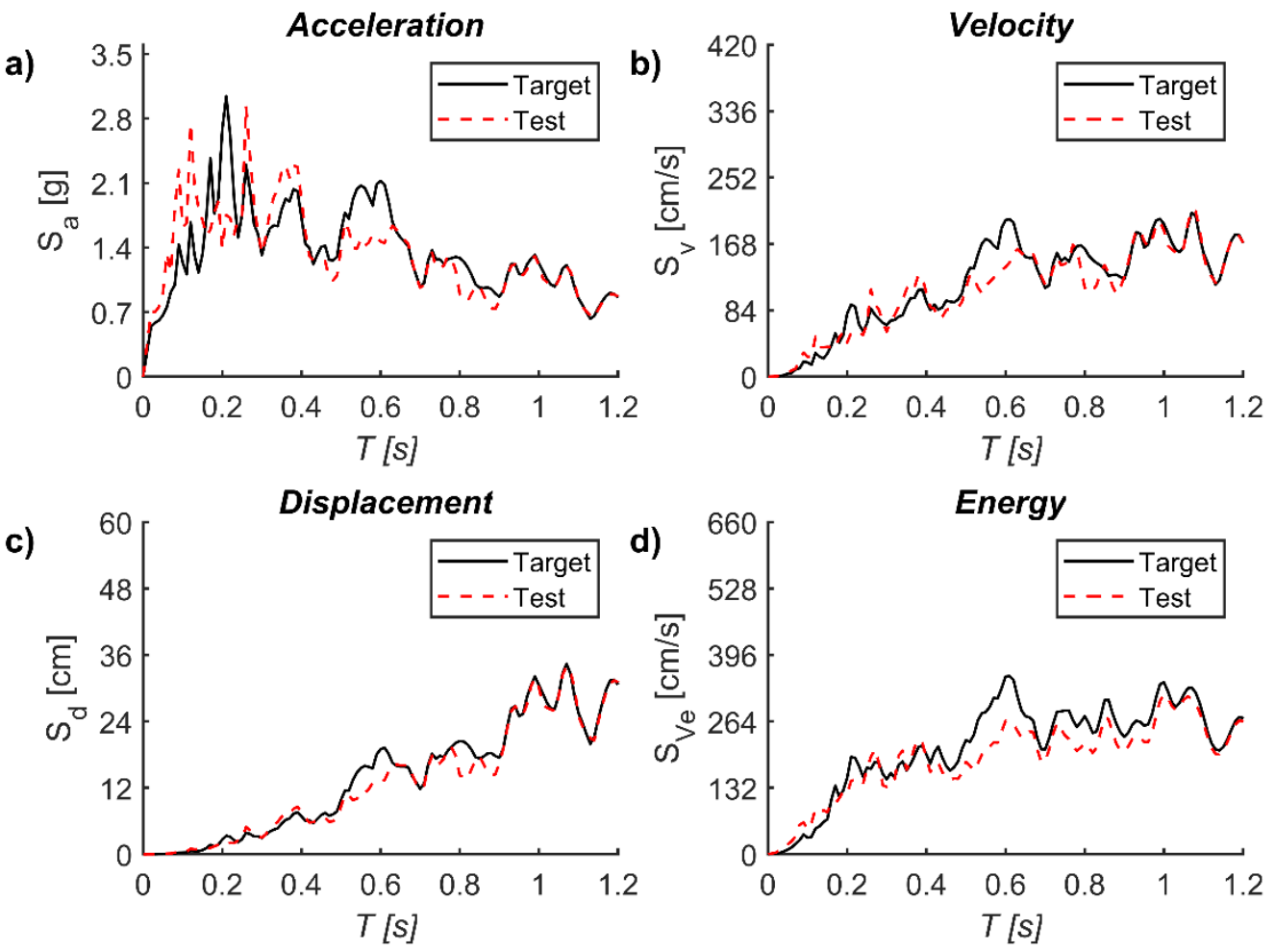

Figure A1. 15. Spectrums superposed (Target and Test) for Component EW (direction Y) simulation C300: a) Acceleration, b) Velocity, c) Displacement and d) Energy 
Appendix 2

STRAIN GAUGES RESULTS 

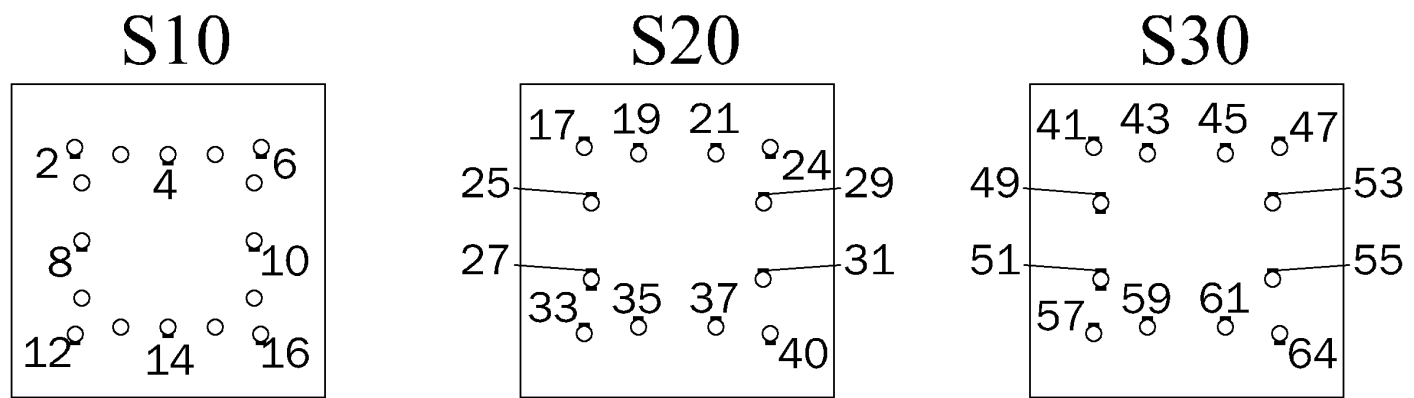

Figure A2. 1. Gauges locations at base column sections in first story

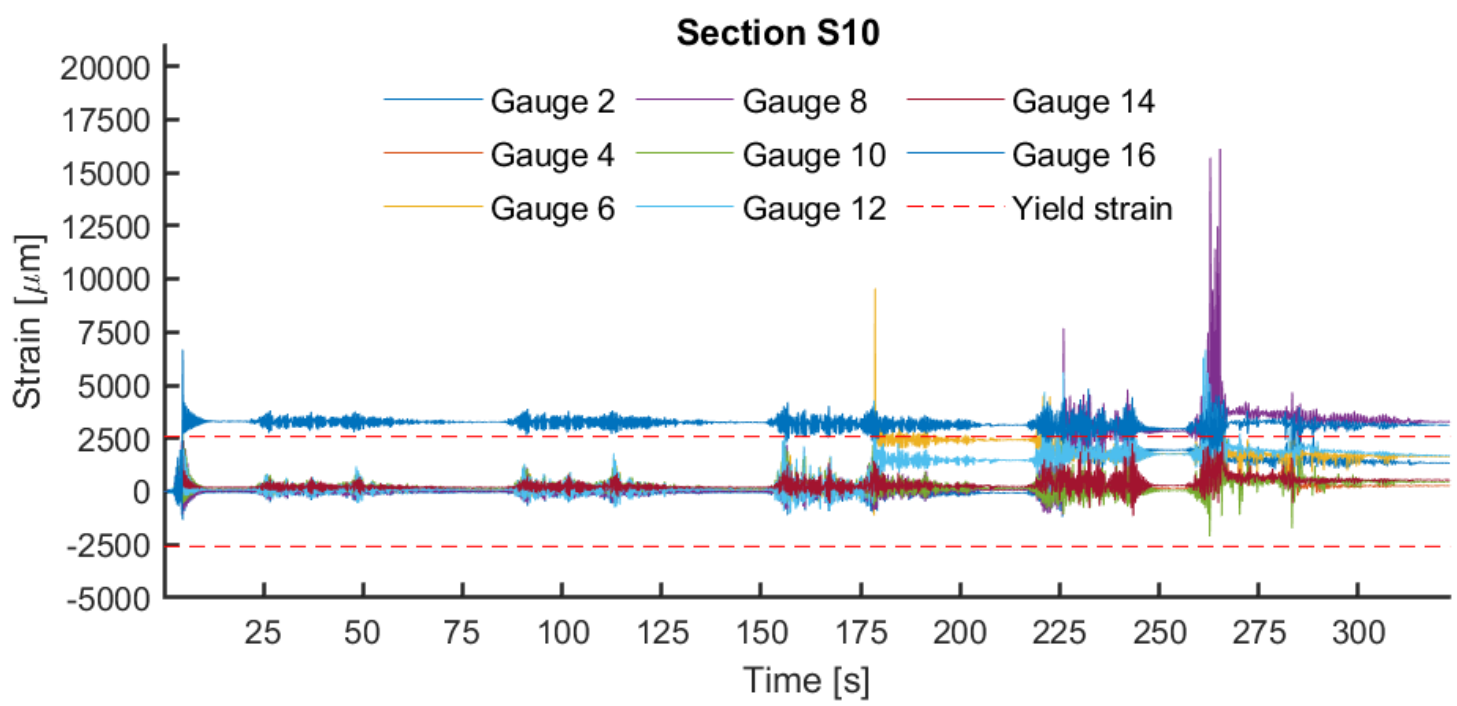

Figure A2. 2. Gauges results in section S10

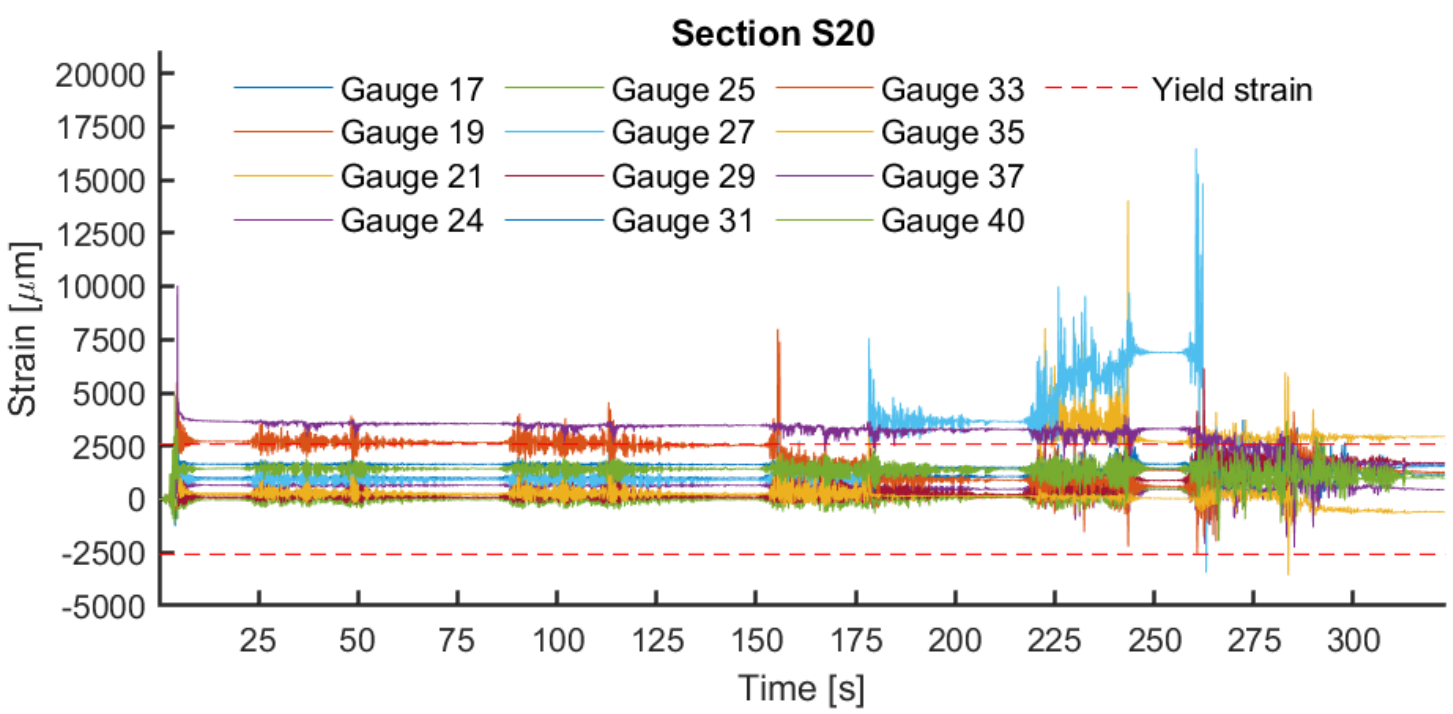

Figure A2. 3. Gauges results in section S20 


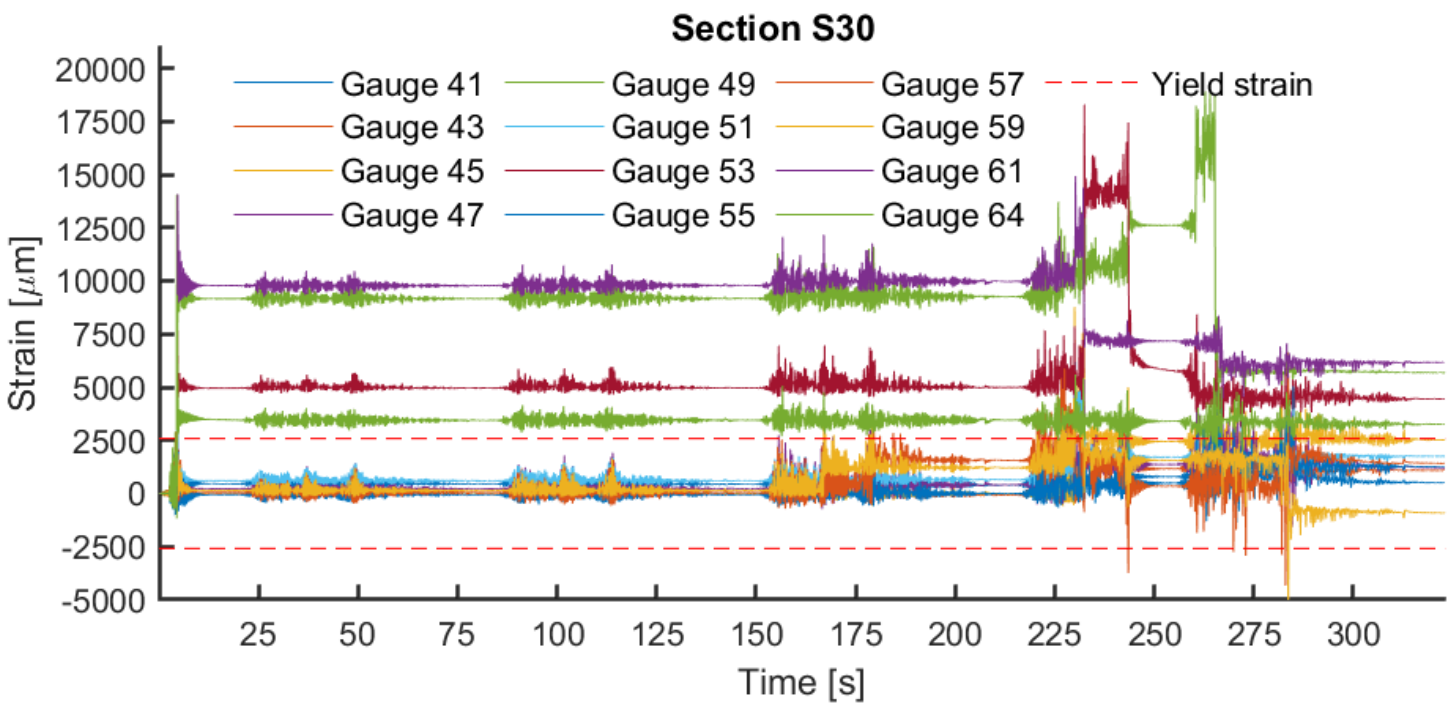

Figure A2. 4. Gauges results in section S30

S11

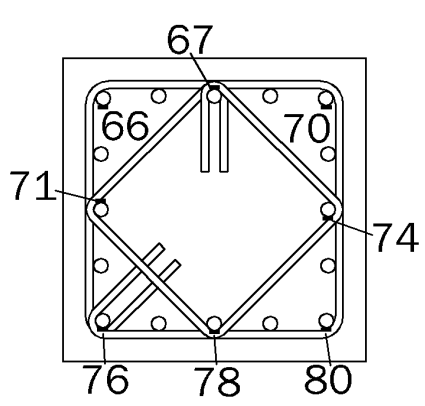

$\mathrm{S} 21$

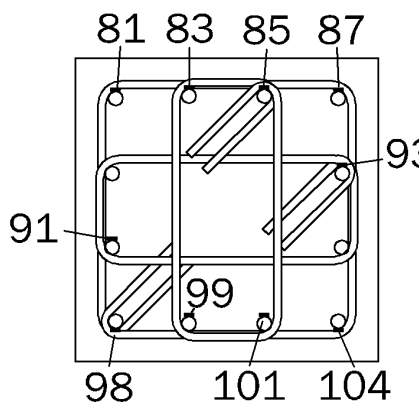

S31

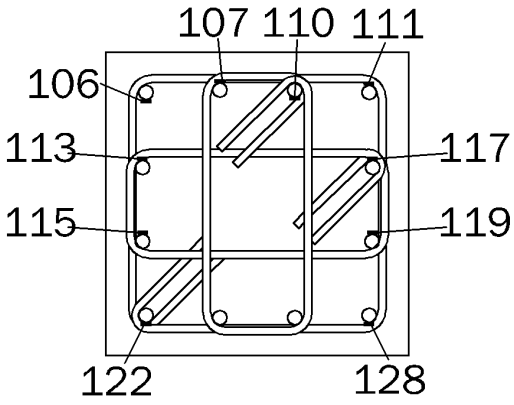

Figure A2. 5. Gauges locations at head column sections in first story

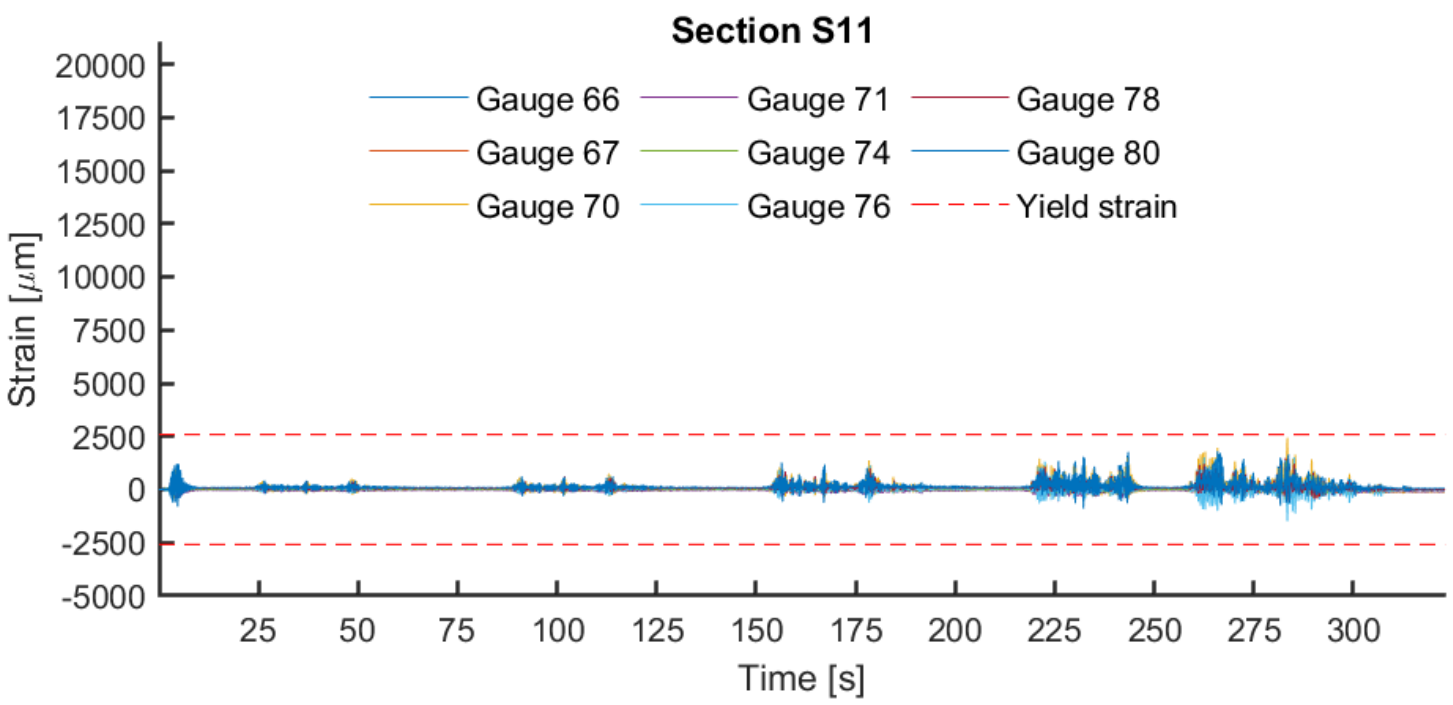

Figure A2. 6. Gauges results in section S11 


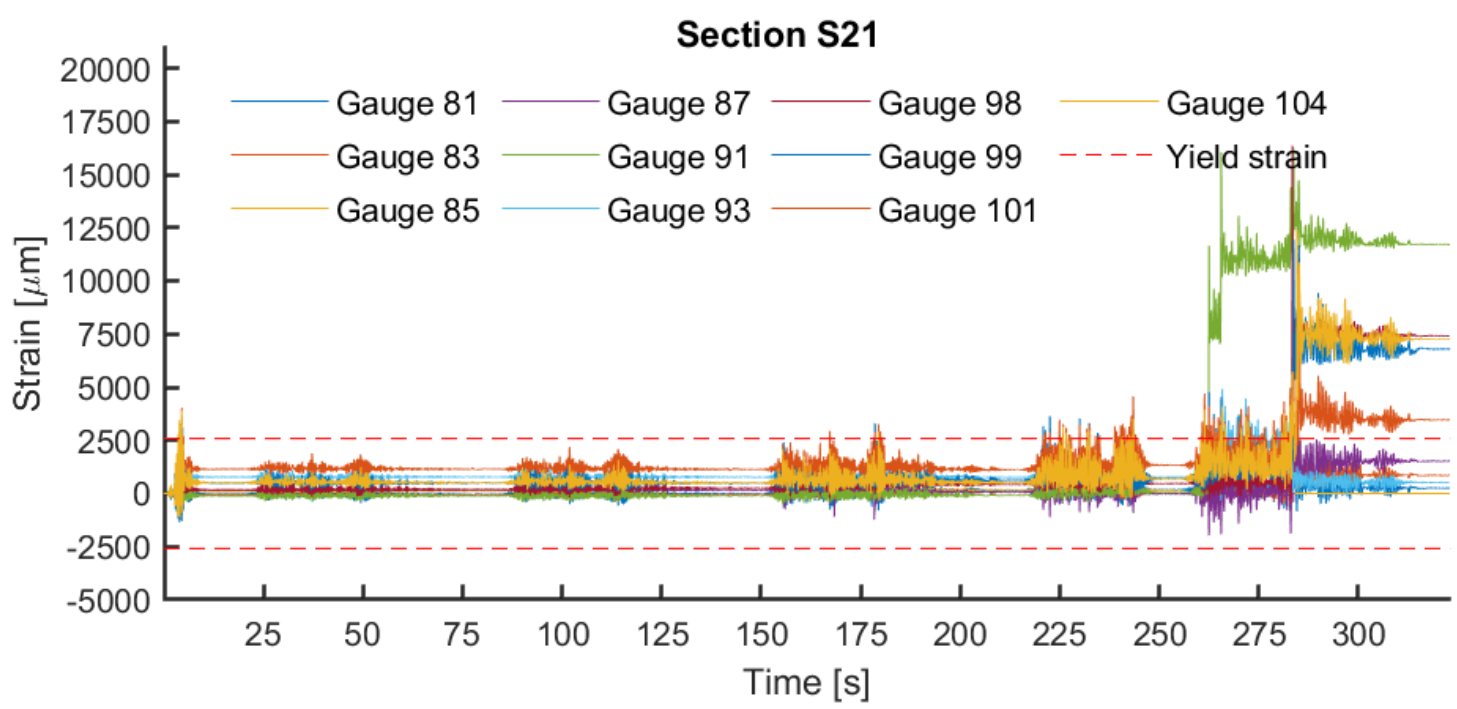

Figure A2. 7. Gauges results in section $\mathrm{S} 21$

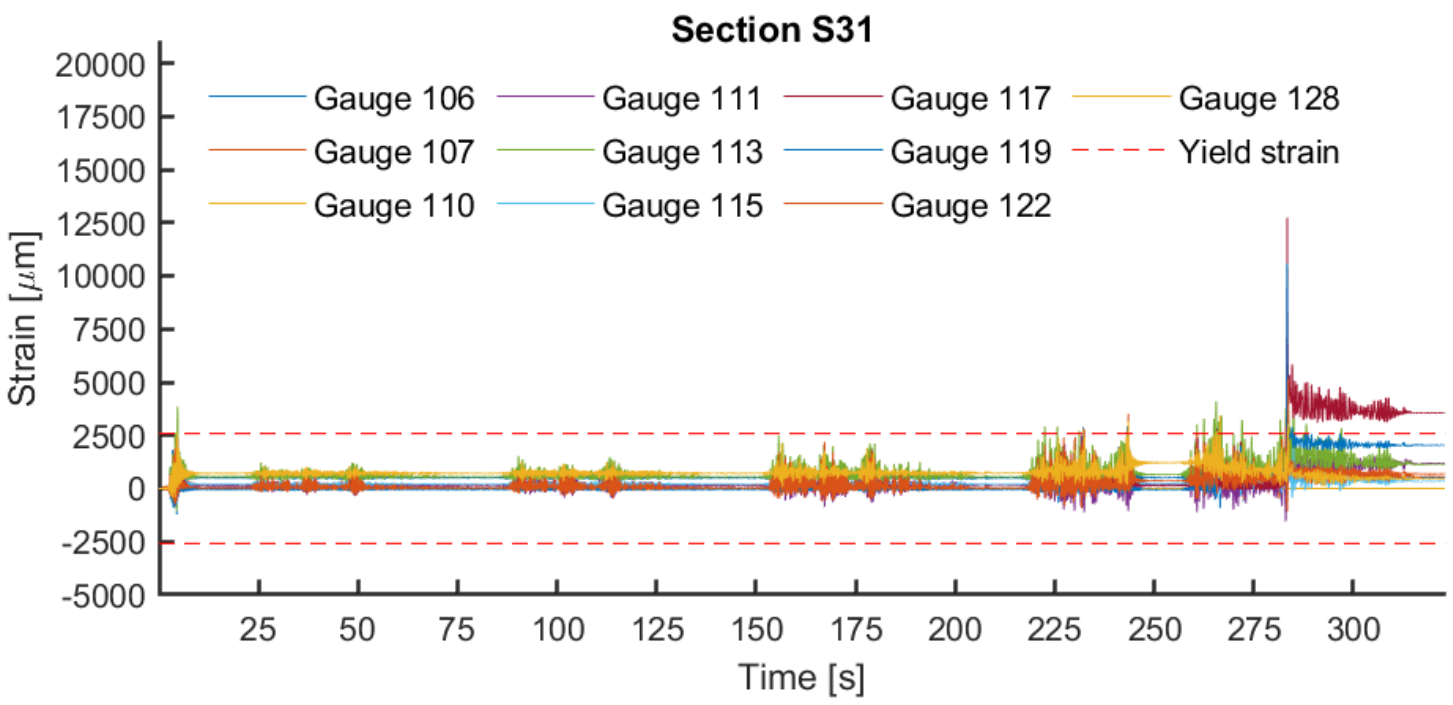

Figure A2. 8. Gauges results in section $\mathrm{S} 31$

$\mathrm{S} 12$

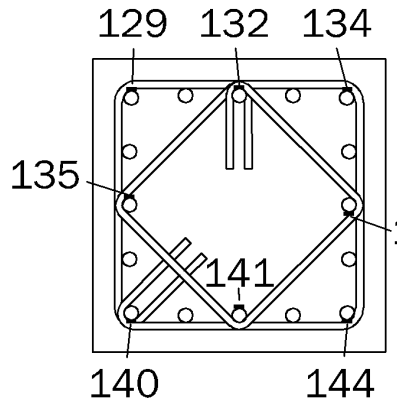

S22

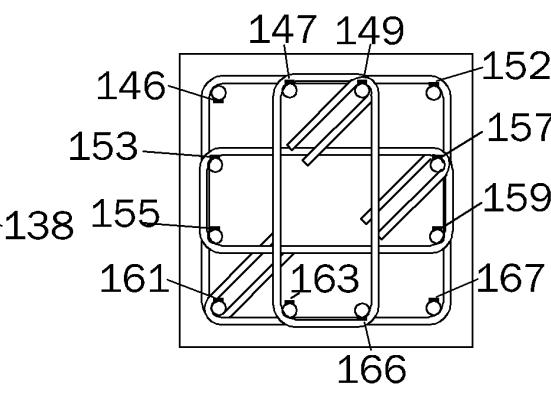

S32

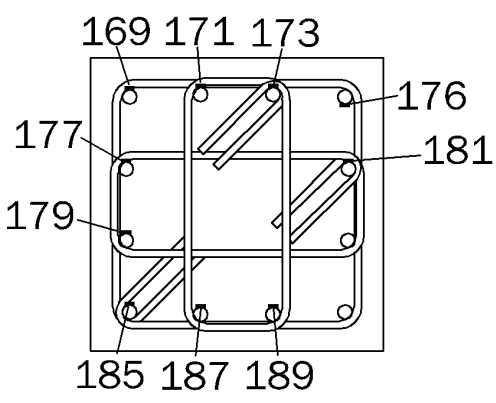

Figure A2. 9. Gauges locations at base column sections in second story 


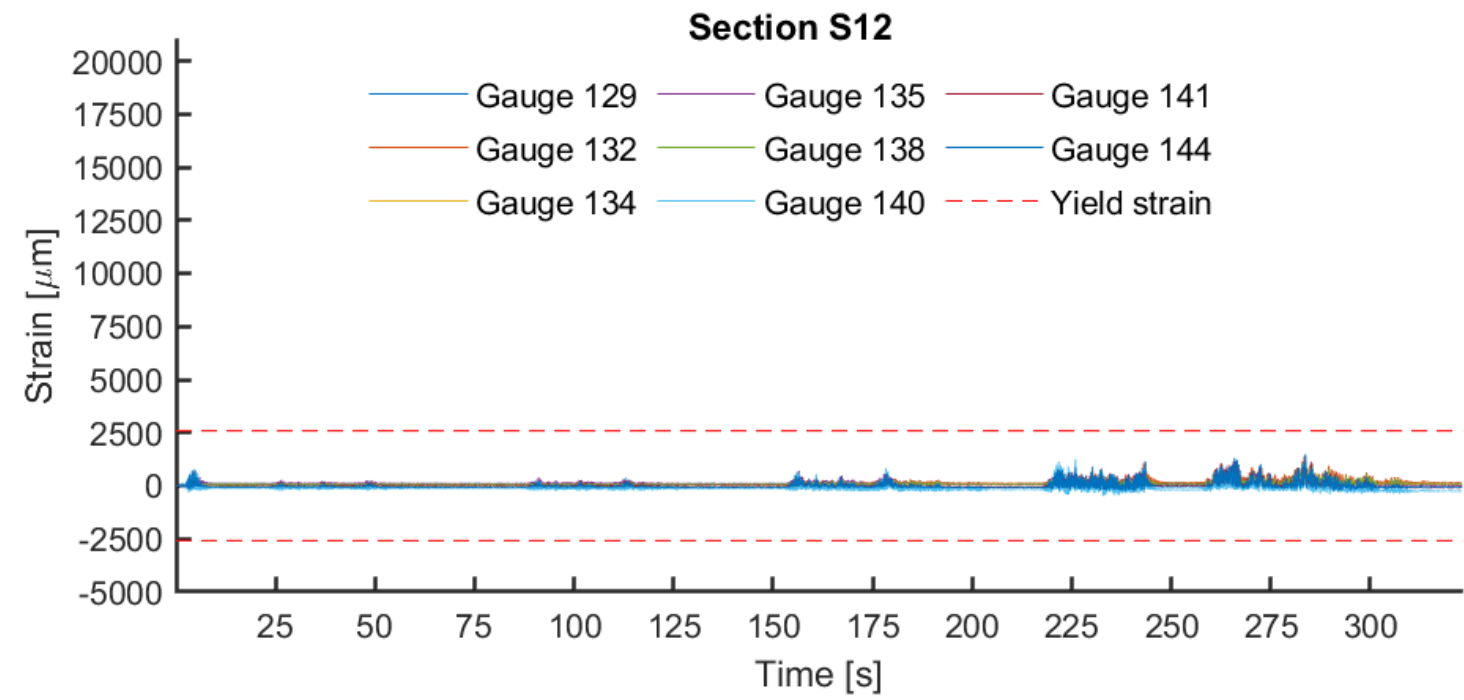

Figure A2. 10. Gauges results in section S12

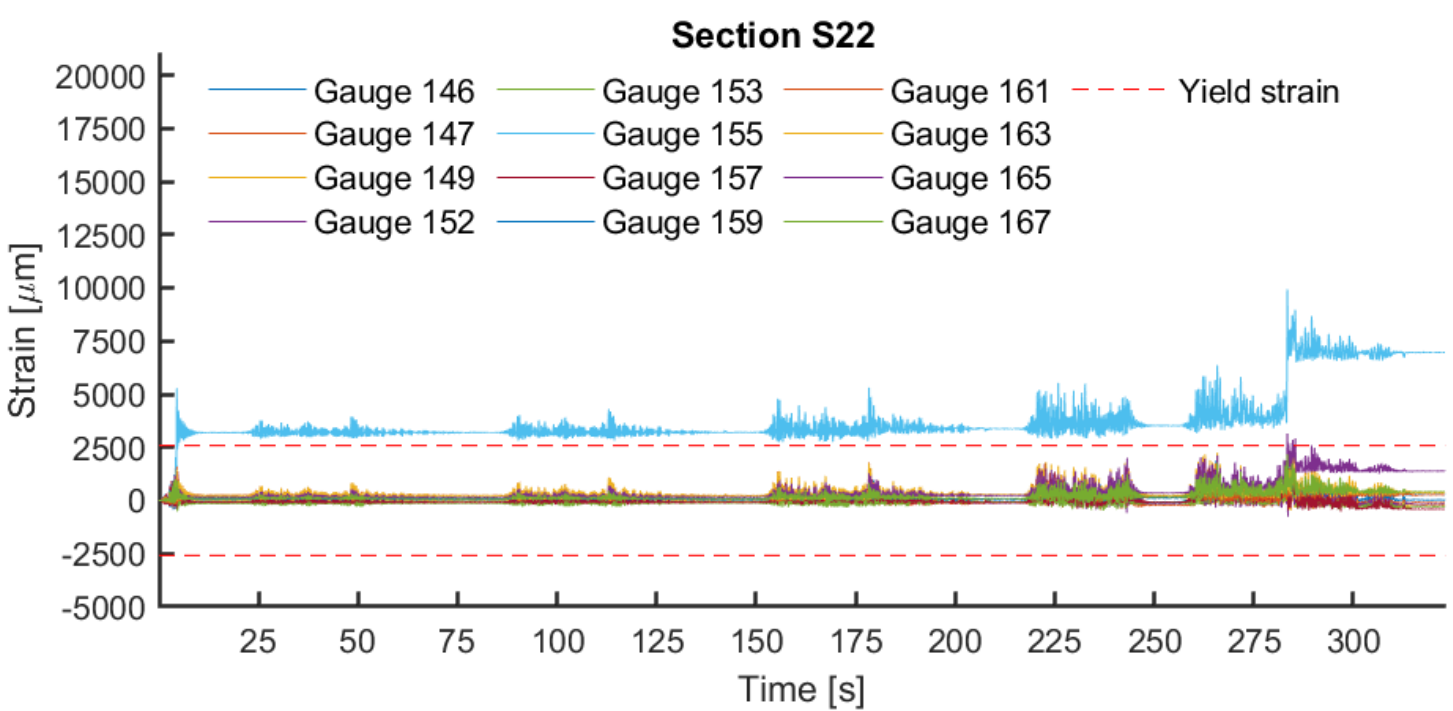

Figure A2. 11. Gauges results in section S22

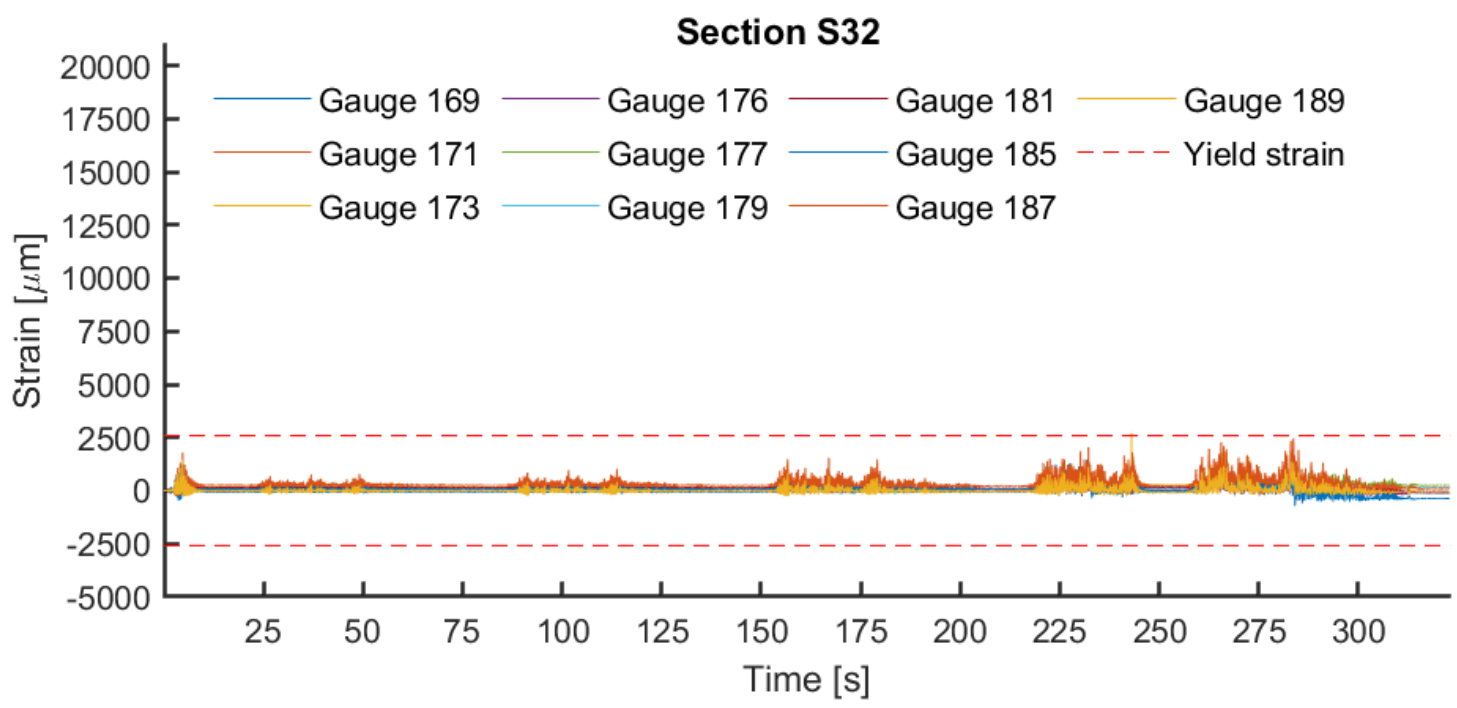

Figure A2. 12. Gauges results in section S32 


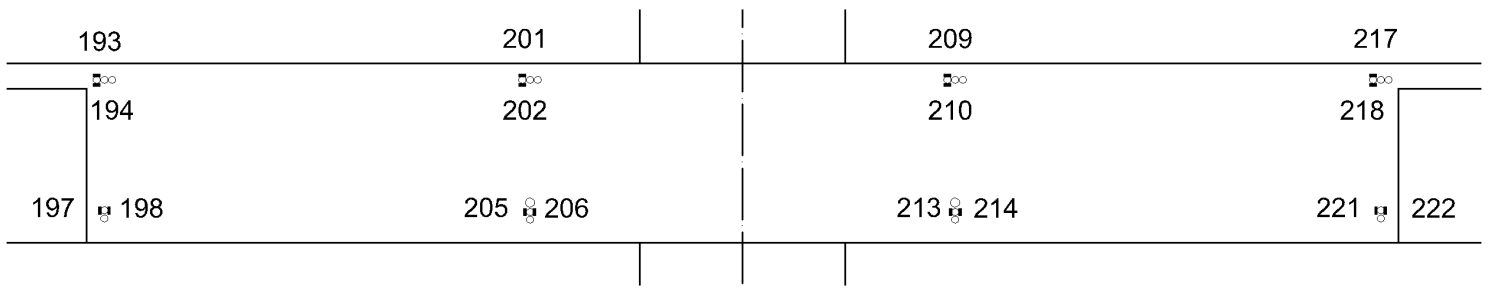

Figure A2. 13. Gauges locations at section S1X

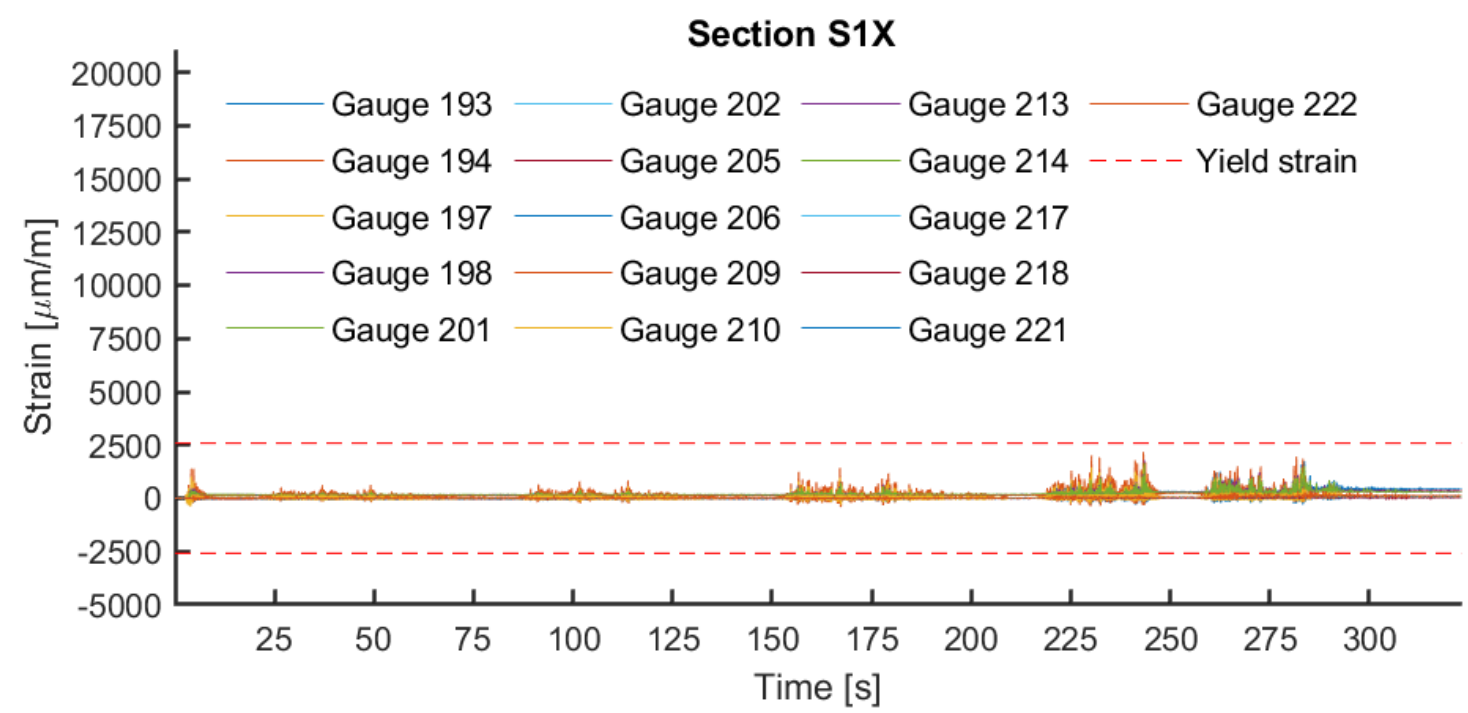

Figure A2. 14. Gauges results in section S1X

\begin{tabular}{|c|c|c|c|c|c|c|c|}
\hline & 25 & 233 & 417 & 419 & 241 & \multicolumn{2}{|c|}{249} \\
\hline & $\begin{array}{l}30 \\
226\end{array}$ & $\begin{aligned} &=0 \\
& 234\end{aligned}$ & 418 & $4 \stackrel{0}{420}$ & $\begin{array}{r}5=0 \\
242\end{array}$ & $\begin{array}{r}=50 \\
250\end{array}$ & \\
\hline 229 & g 230 & 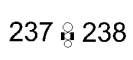 & $\begin{array}{c}421 \\
\Omega\end{array}$ & 423 & 245 \& 246 & 253 g & 254 \\
\hline
\end{tabular}

Figure A2. 15. Gauges locations at section S2X

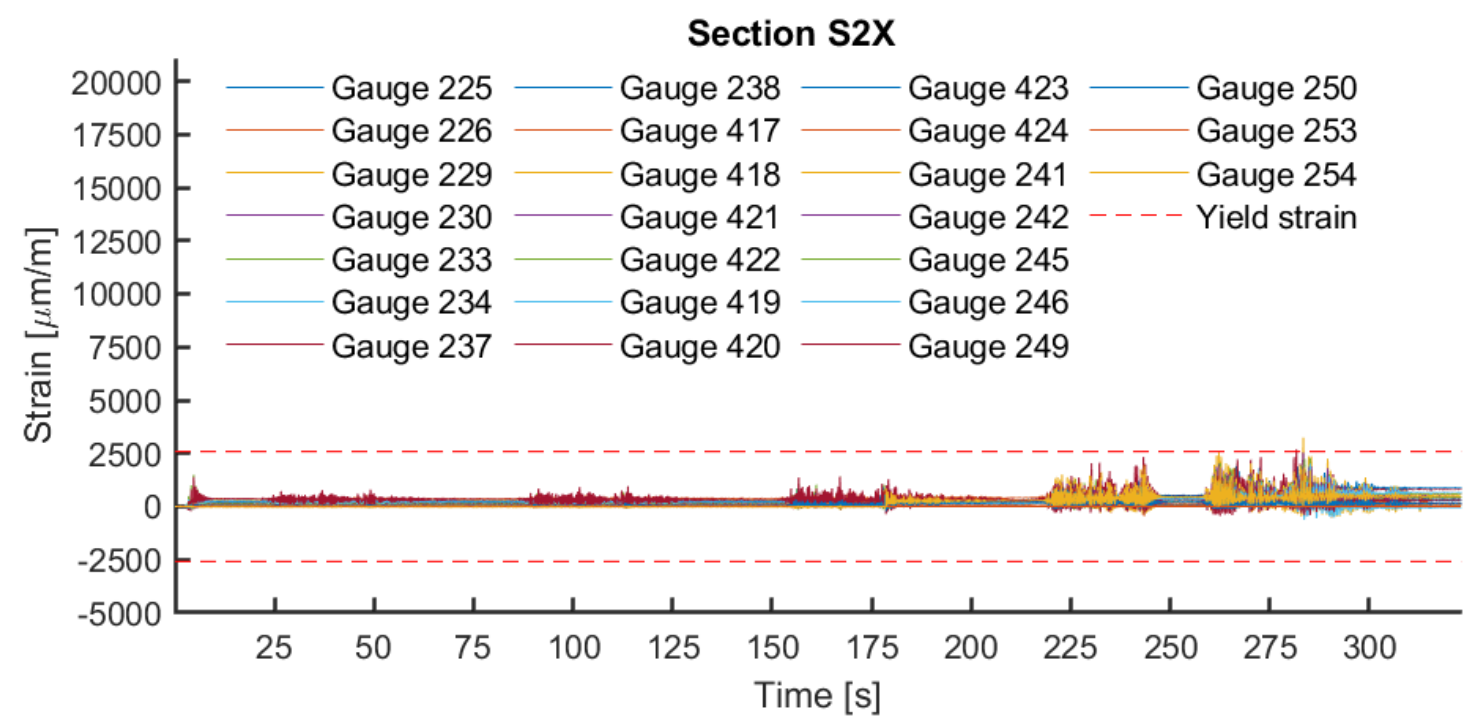

Figure A2. 16. Gauges results in section S2X 


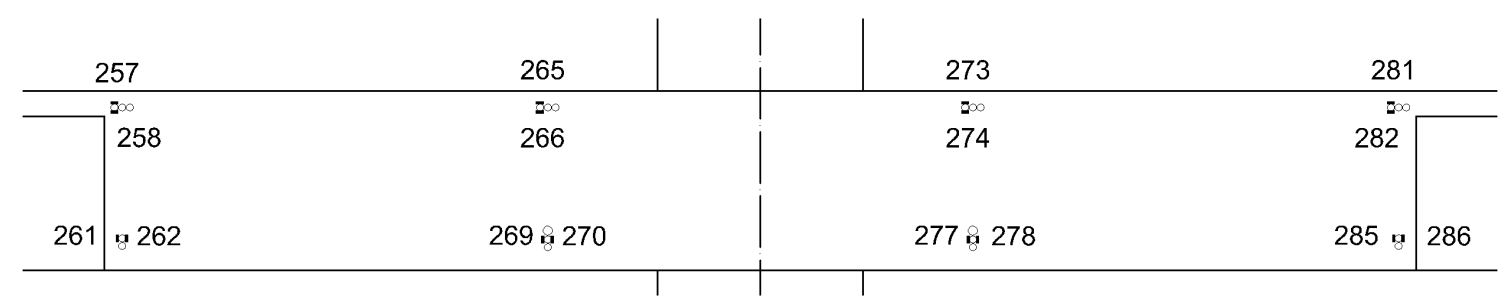

Figure A2. 17. Gauges locations at section S3X

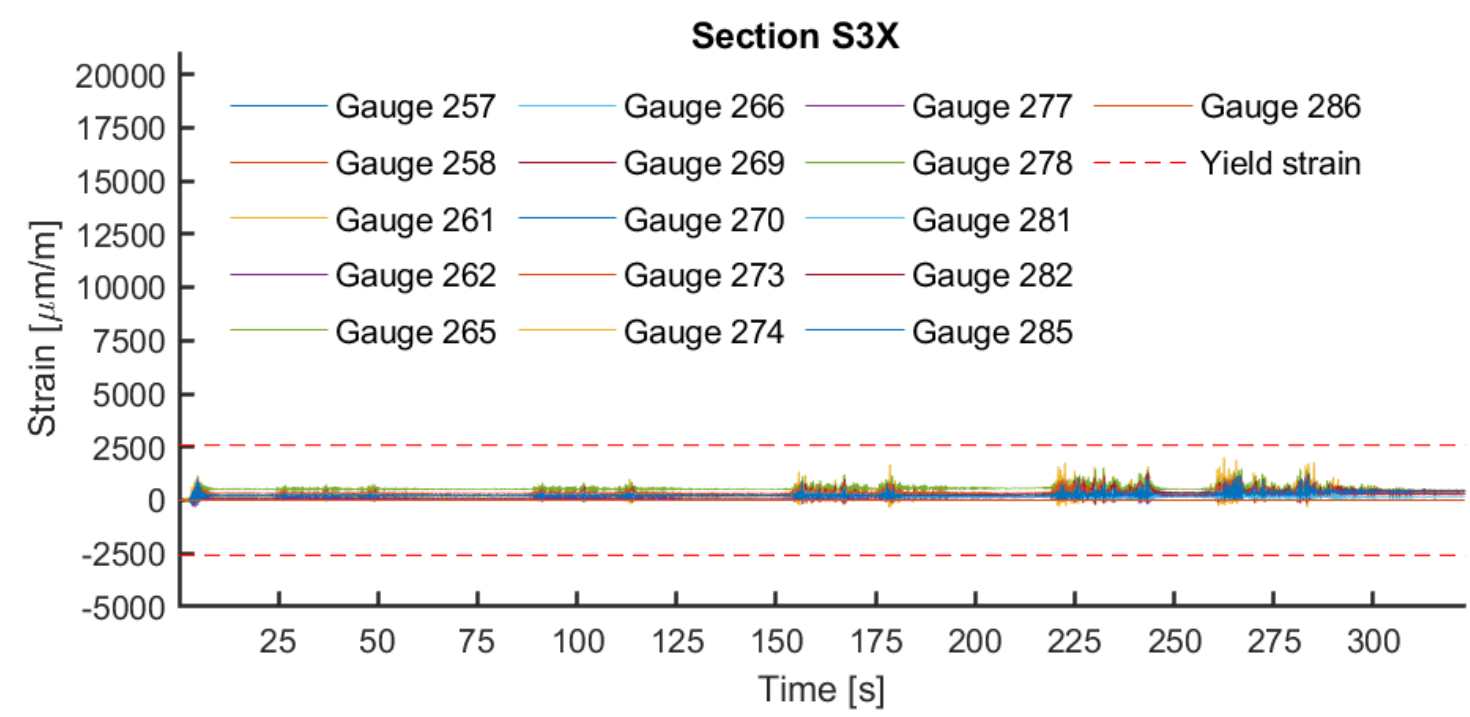

Figure A2. 18. Gauges results in section S3X

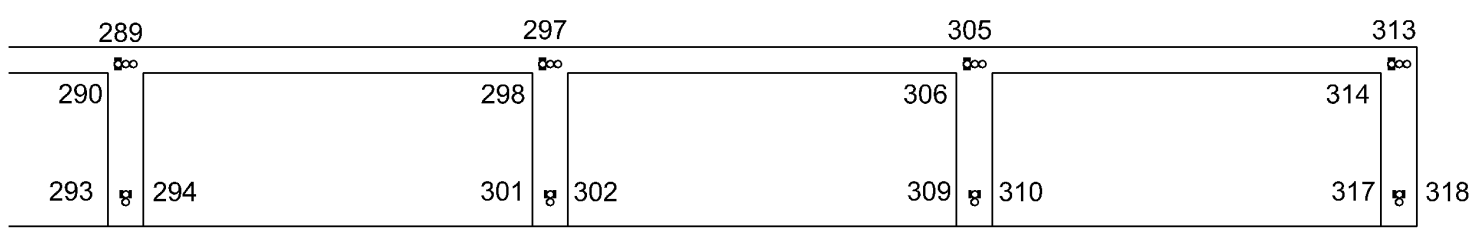

Figure A2. 19. Gauges locations at section S4X

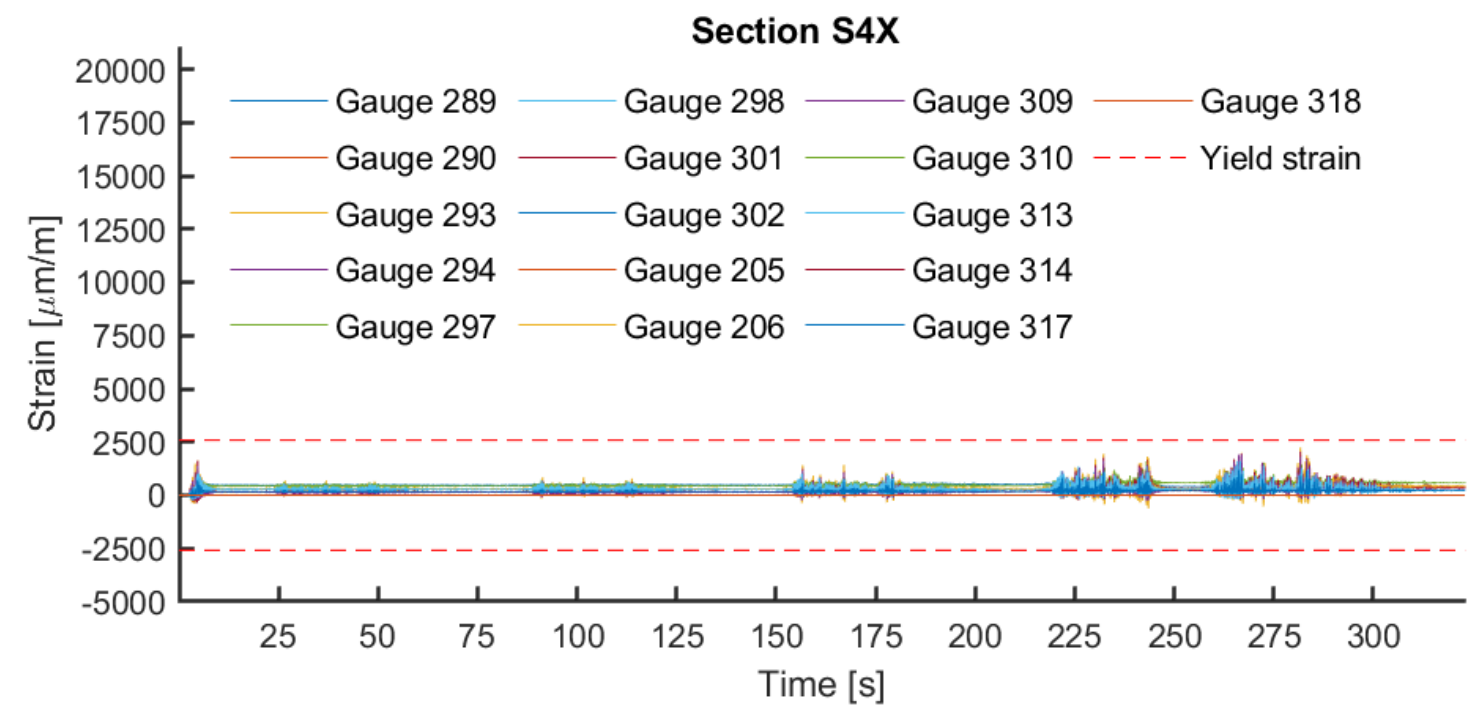

Figure A2. 20. Gauges results in section S4X 


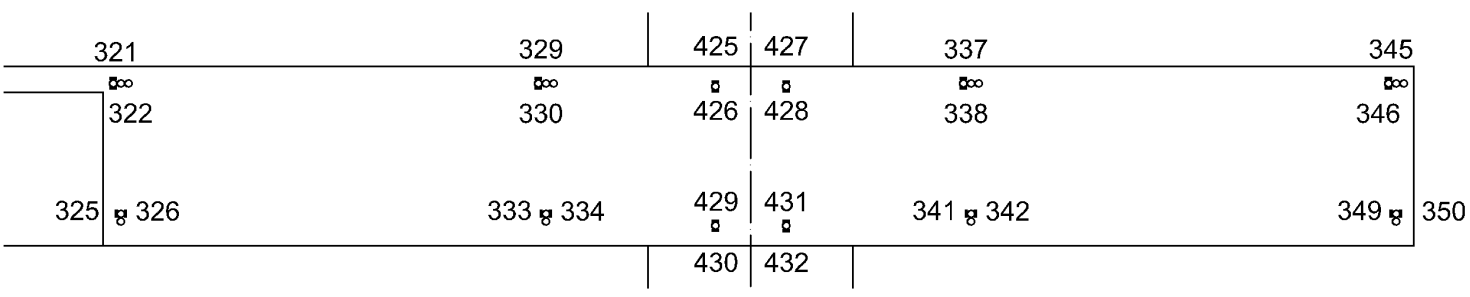

Figure A2. 21. Gauges locations at section S5X

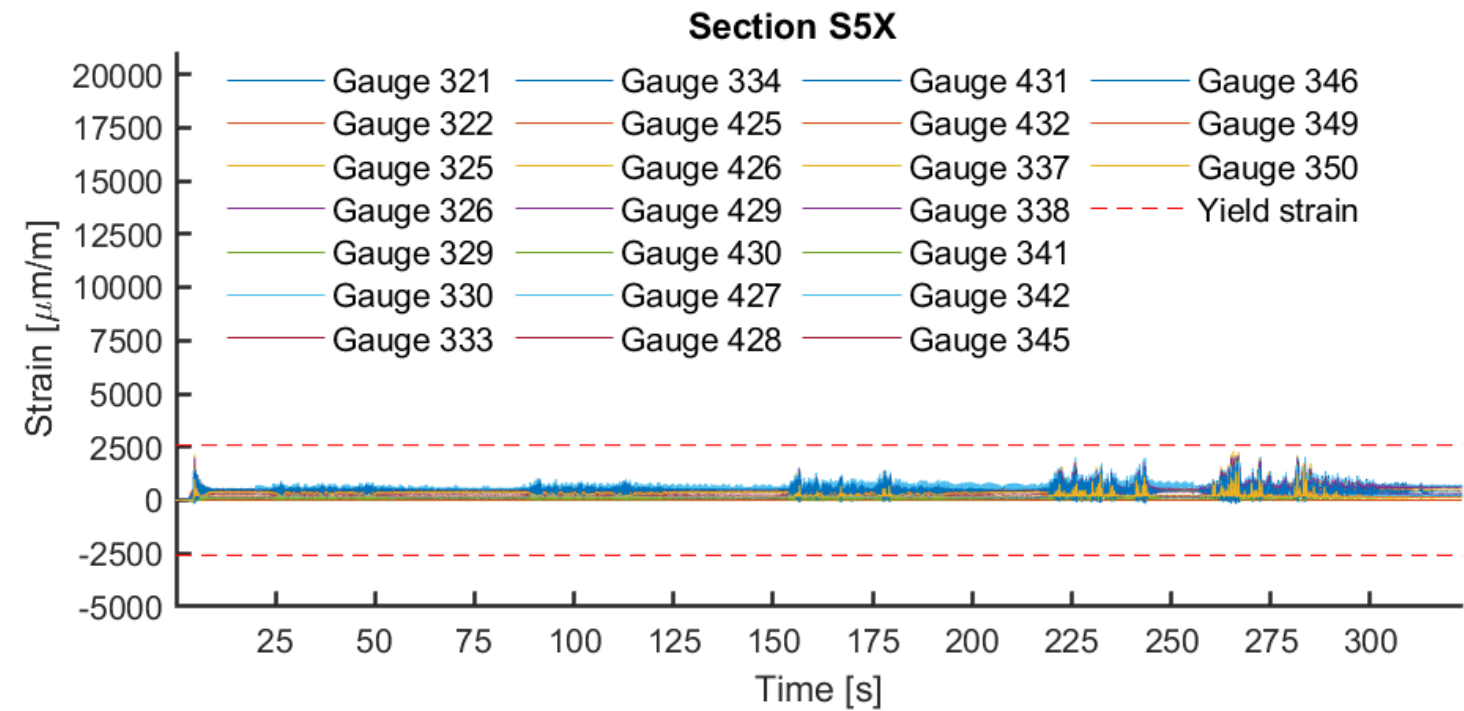

Figure A2. 22. Gauges results in section S5X

\begin{tabular}{|c|c|c|c|c|c|c|}
\hline & 353 & 361 & 433 & 435 & 369 & 377 \\
\hline & 500 & $5 \infty$ & $\therefore$ & 8 & $\infty \infty$ & $\infty \infty$ \\
\hline & 354 & 362 & 434 & 436 & 370 & 378 \\
\hline & 8358 & 365 \& 366 & 437 & 439 & 373 g 374 & $381 \mathrm{~g}$ \\
\hline
\end{tabular}

Figure A2. 23. Gauges locations at section S6X

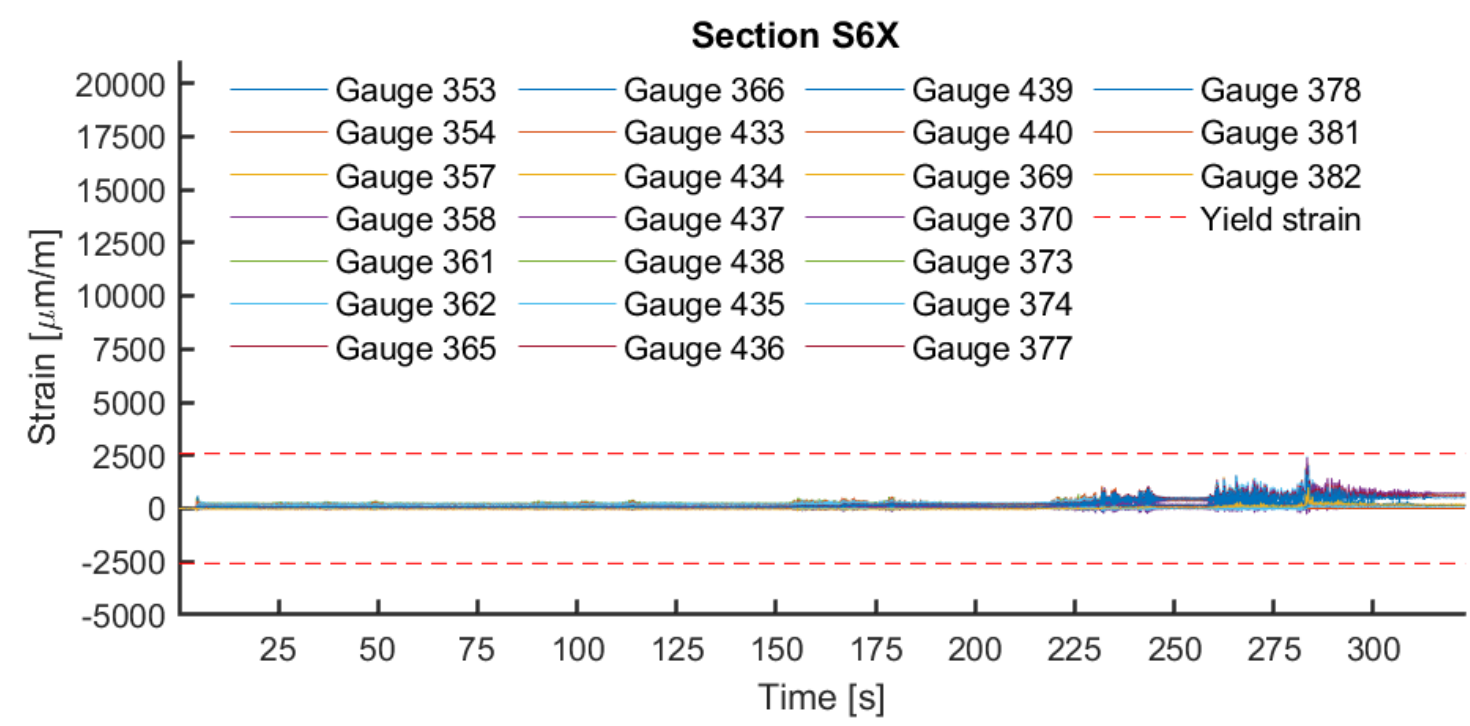

Figure A2. 24. Gauges results in section S6X 


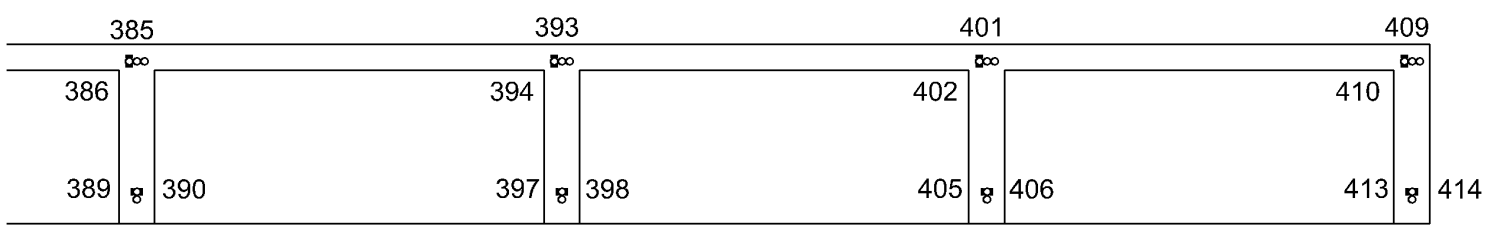

Figure A2. 25. Gauges locations at section S7X

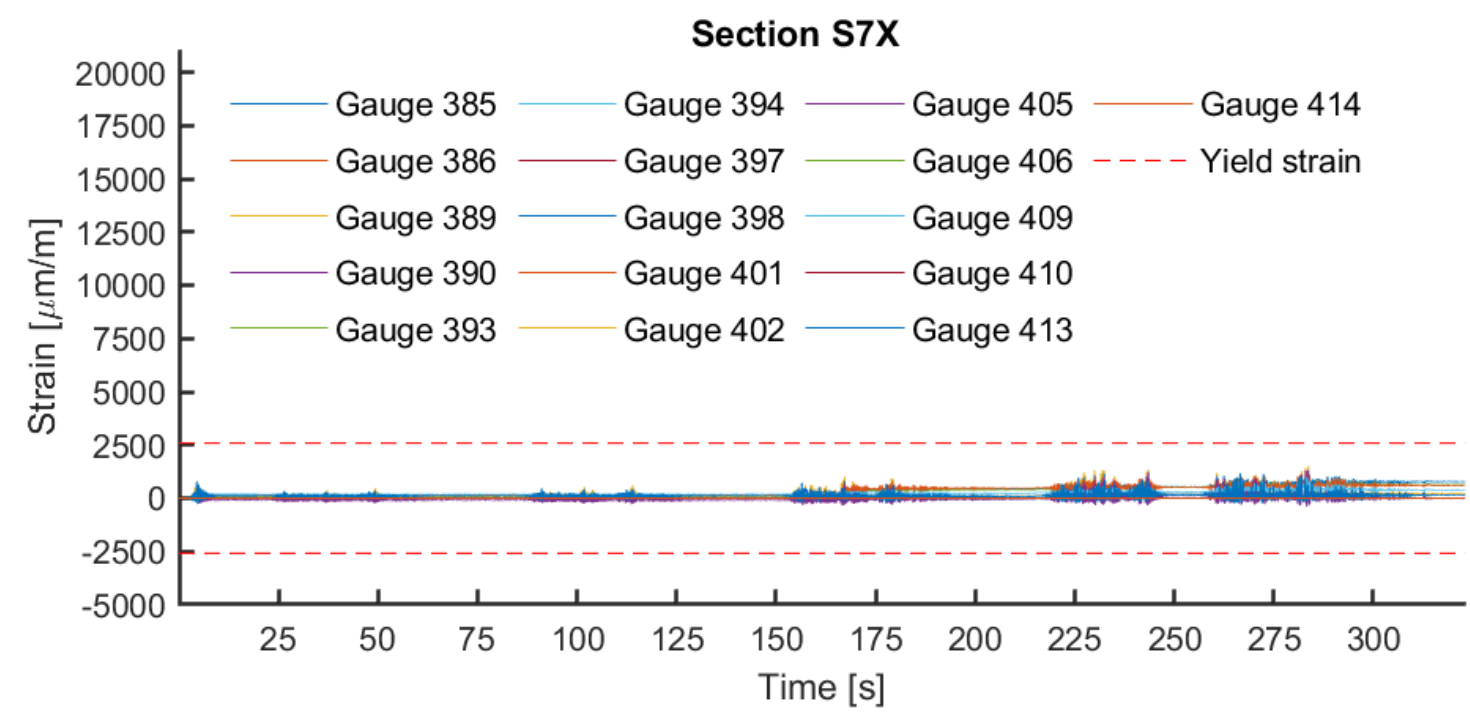

Figure A2. 26. Gauges results in section S7X

a)

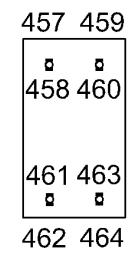

b)

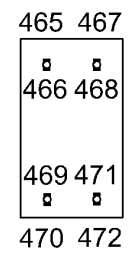

Figure A2. 27. Gauges locations at section: a) S8Y and b) S9Y

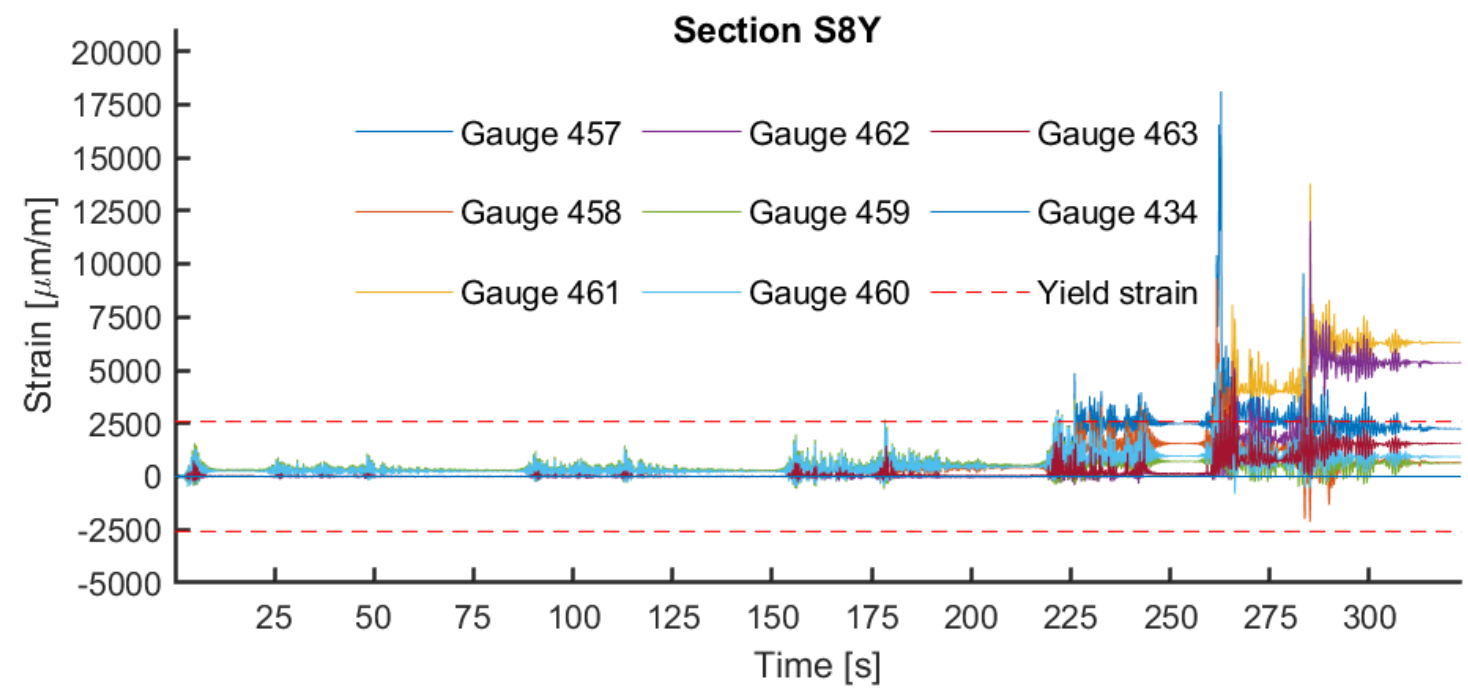

Figure A2. 28. Gauges results in section S8Y 


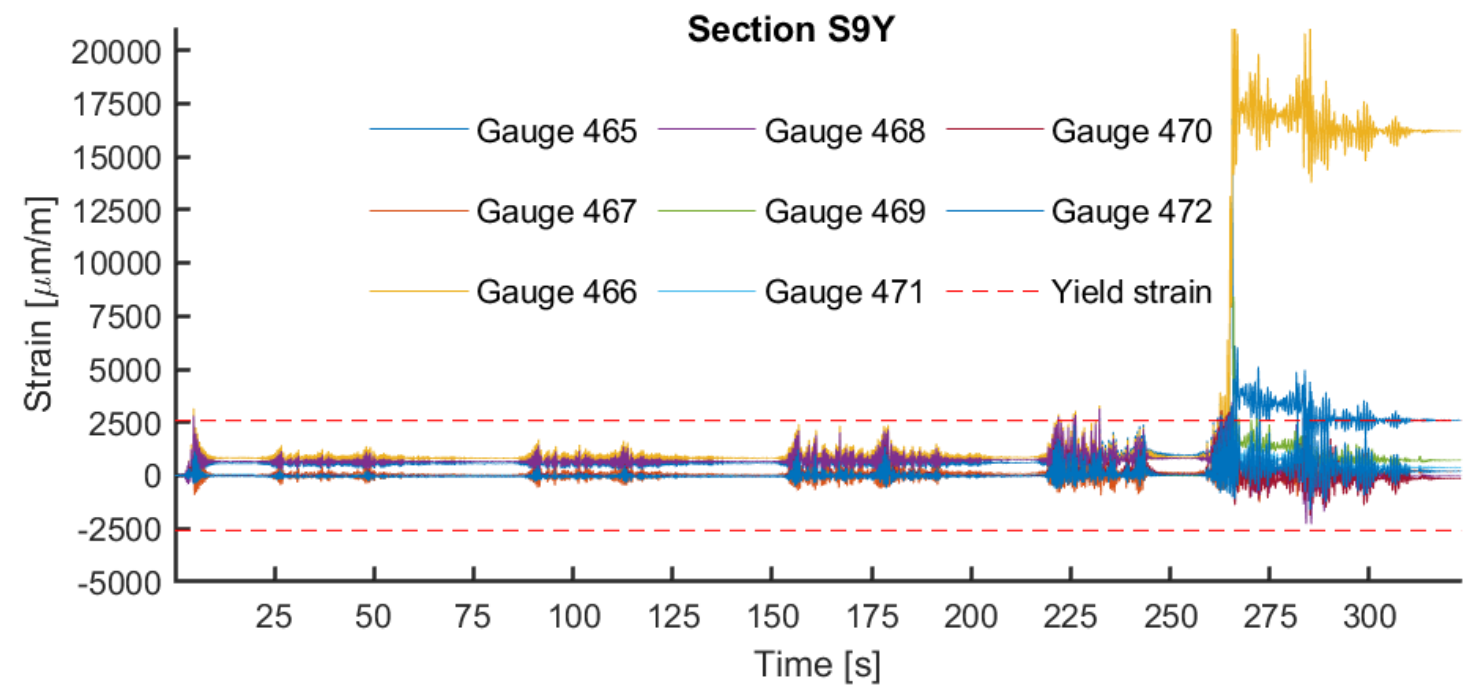

Figure A2. 29. Gauges results in section S9Y

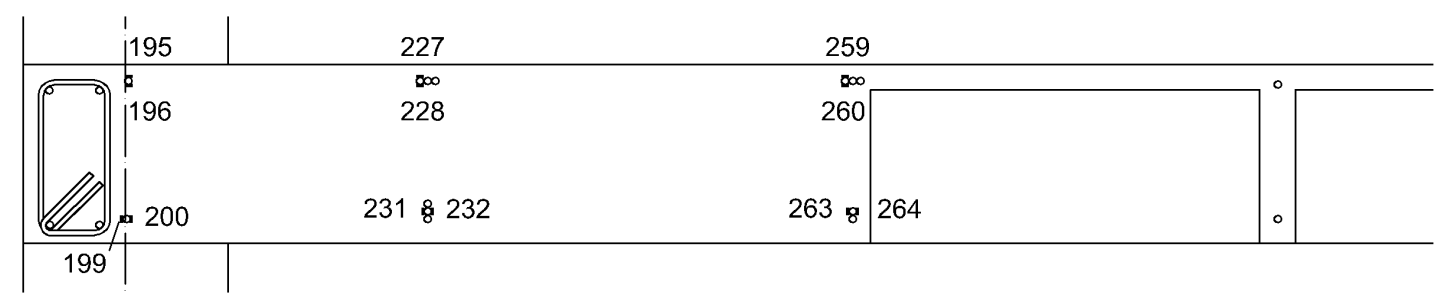

Figure A2. 30. Gauges locations at section S10Y

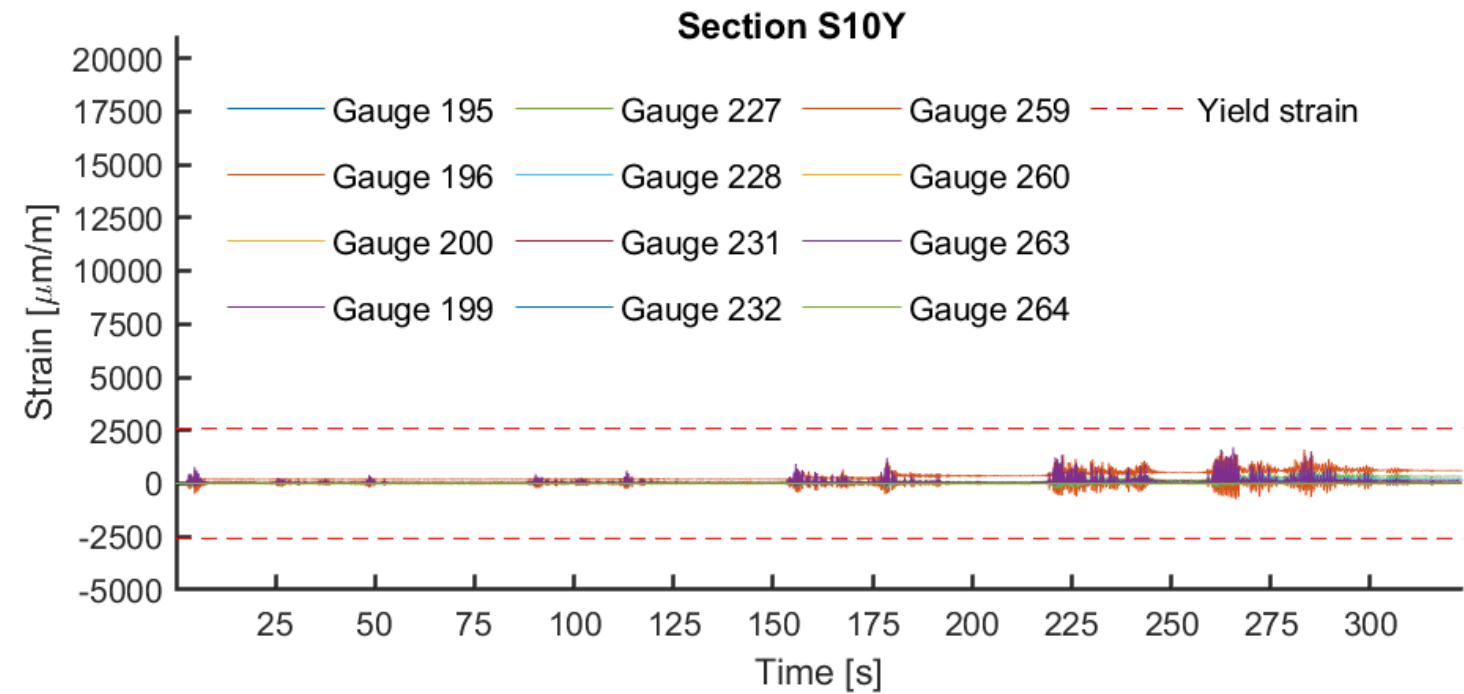

Figure A2. 31. Gauges results in section S10Y

\begin{tabular}{|c|c|c|c|c|c|}
\hline & 203 & 235 & 267 & & \\
\hline 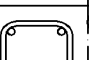 & 804 & 50 & $\begin{array}{l}500 \\
260\end{array}$ & & \\
\hline$(11$ & 208 & $239 \& 240$ & 271 g & 272 & . \\
\hline
\end{tabular}

Figure A2. 32. Gauges locations at section S11Y 


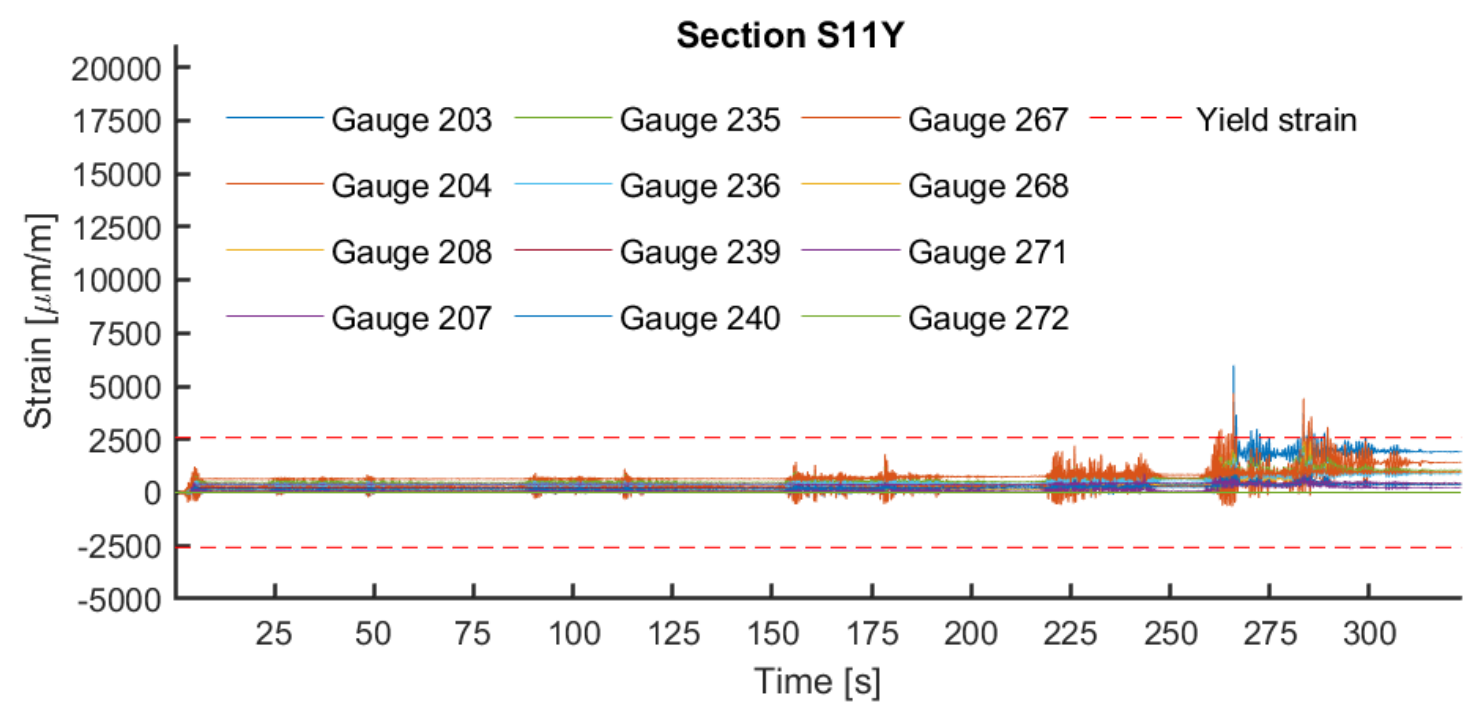

Figure A2. 33. Gauges results in section S11Y

\begin{tabular}{|c|c|c|c|c|}
\hline 211 & 243 & 275 & & \\
\hline & $5 \infty$ & 500 & & \\
\hline 212 & 244 & 276 & & \\
\hline (U216) & $247 \& 248$ & $279 \mathrm{~g}$ & 280 & $\circ$ \\
\hline
\end{tabular}

Figure A2. 34. Gauges locations at section S12Y

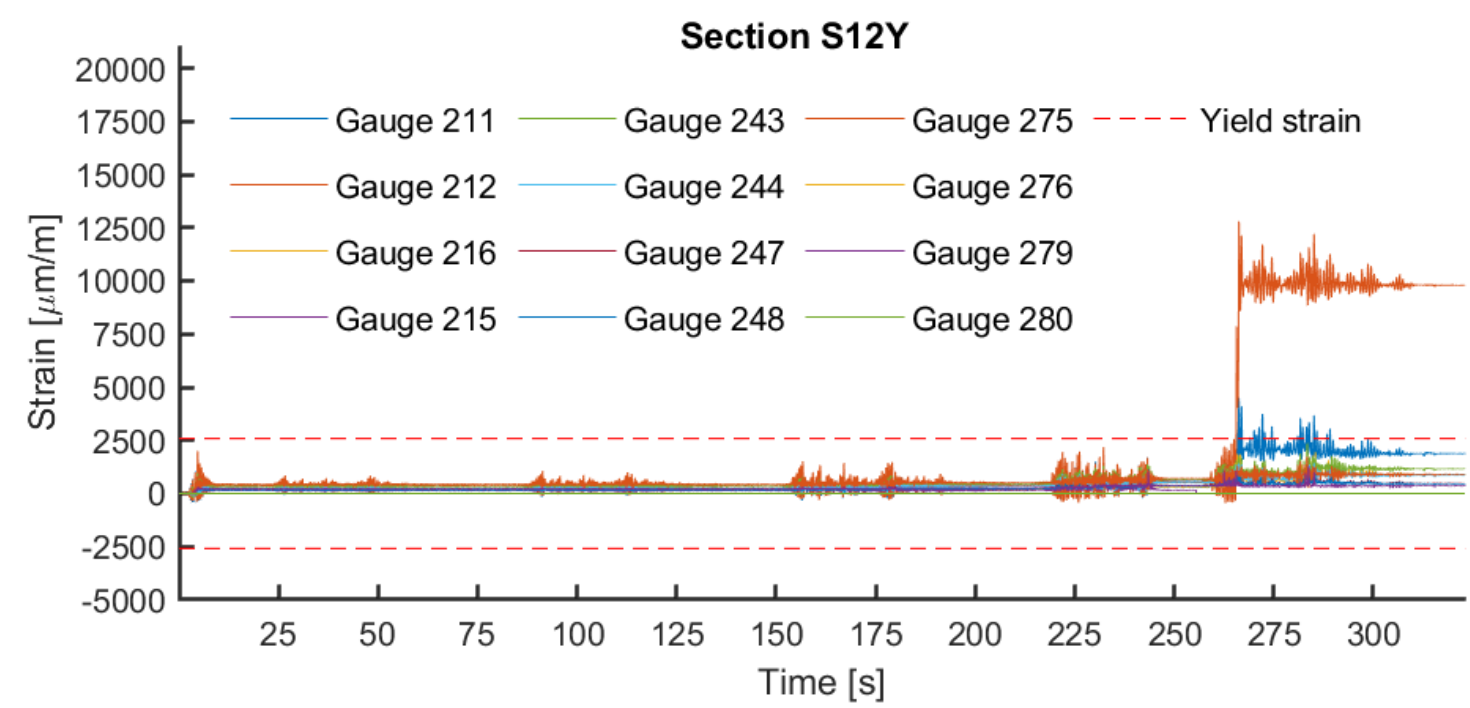

Figure A2. 35. Gauges results in section S12Y

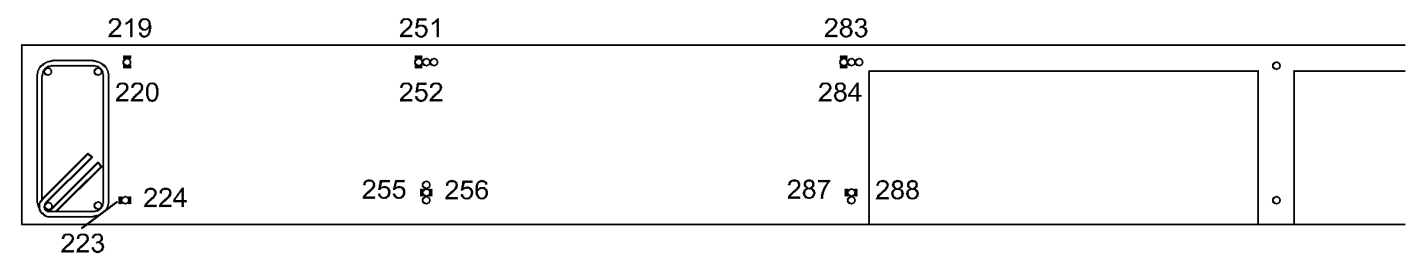

Figure A2. 36. Gauges locations at section S13Y (North) 


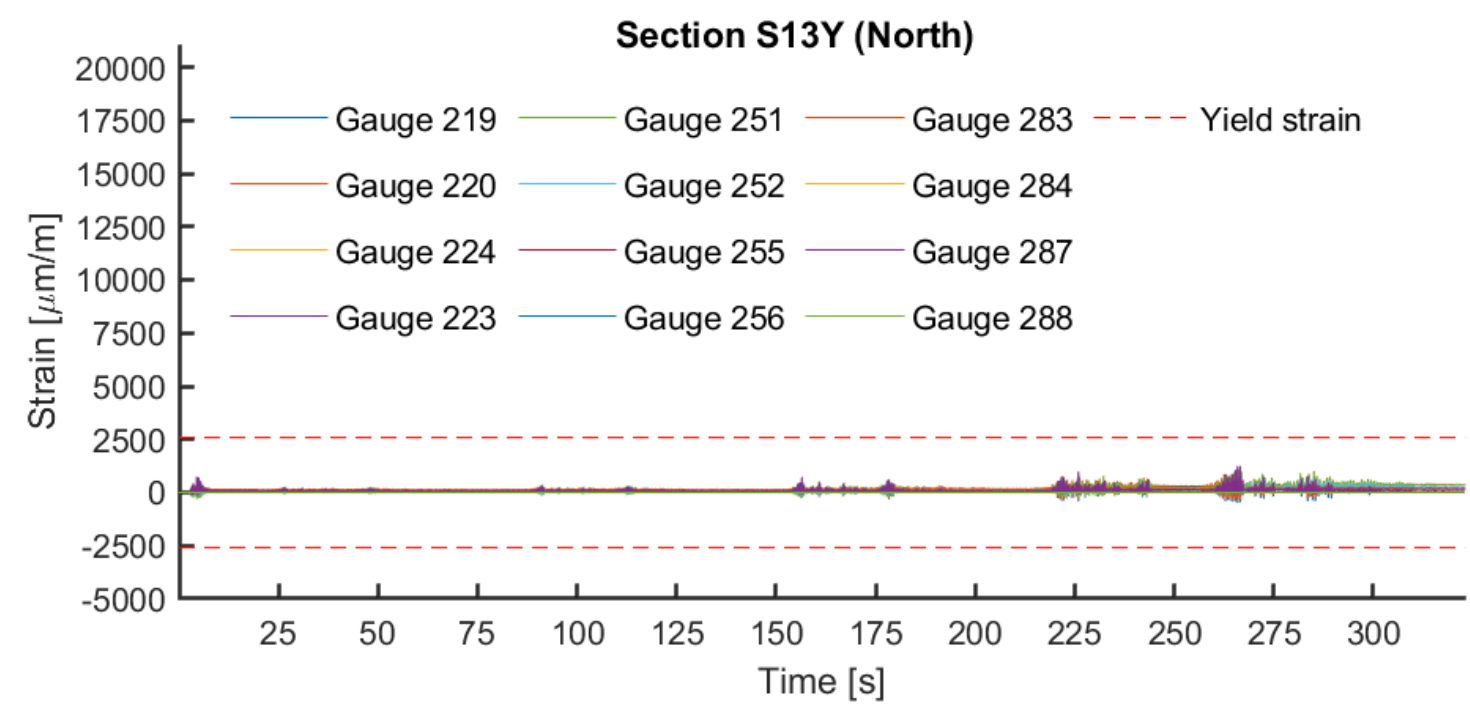

Figure A2. 37. Gauges results in section S13Y (North)

\begin{tabular}{|c|c|c|c|c|}
\hline & 291 & 323 & 355 & 387 \\
\hline & $8 \infty$ & $5 \infty$ & $5 \infty$ & $5 \infty$ \\
\hline & 292 & 324 & 356 & 388 \\
\hline & - 296 & $327 \& 328$ & $359 \& 360$ & 391 a 392 \\
\hline
\end{tabular}

Figure A2. 38. Gauges locations at section S13Y (South)

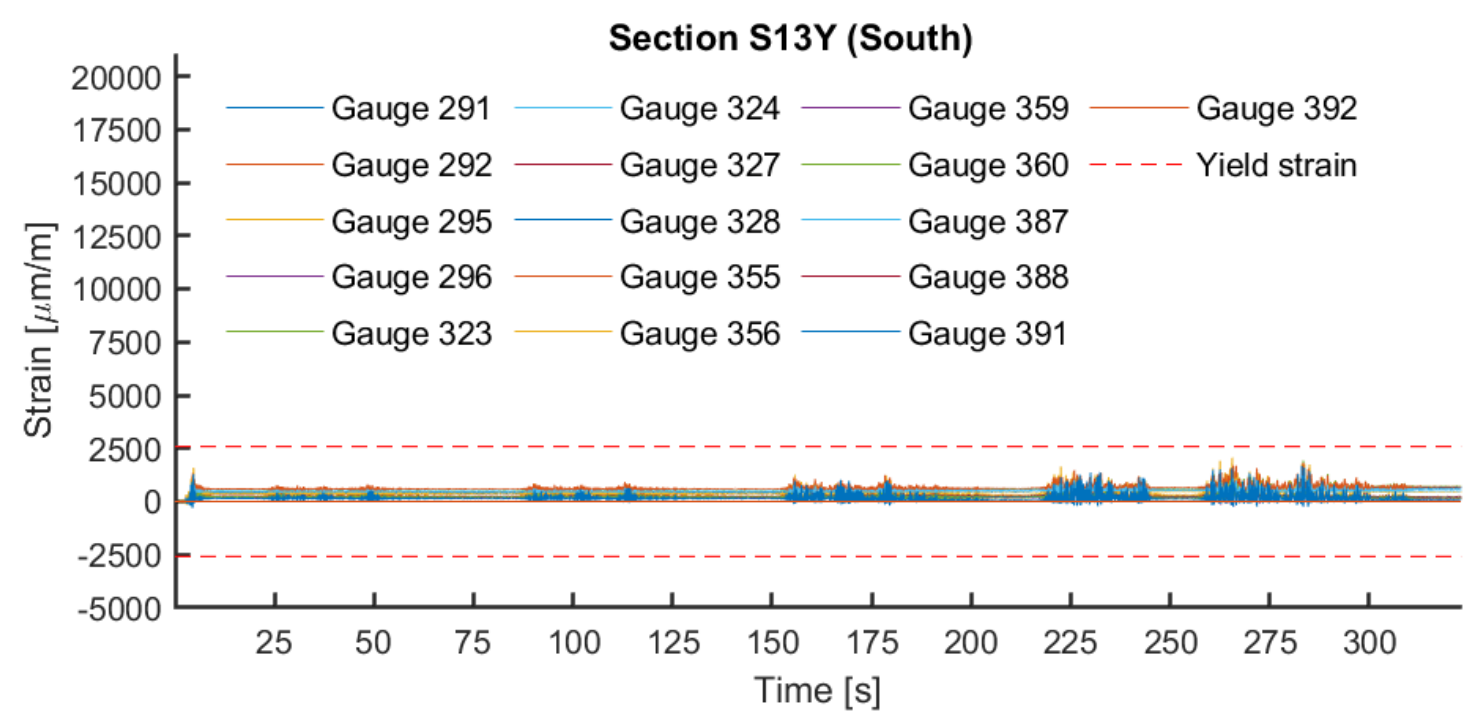

Figure A2. 39. Gauges results in section S13Y (South)

\begin{tabular}{|c|c|c|c|c|c|c|c|}
\hline & 99 & 331 & 441 & 443 & 363 & 395 & \\
\hline & $\begin{array}{l}500 \\
300\end{array}$ & $\begin{array}{r}-\infty \\
332 \\
332\end{array}$ & $\stackrel{\circ}{4}$ & $\stackrel{\circ}{444}$ & $\begin{array}{r}500 \\
364\end{array}$ & $\begin{array}{r}50 x \\
396\end{array}$ & \\
\hline 303 & - 304 & $335 \& 336$ & 445 & 447 & 367 \& 368 & 399 a & 400 \\
\hline
\end{tabular}

Figure A2. 40. Gauges locations at section S14Y 


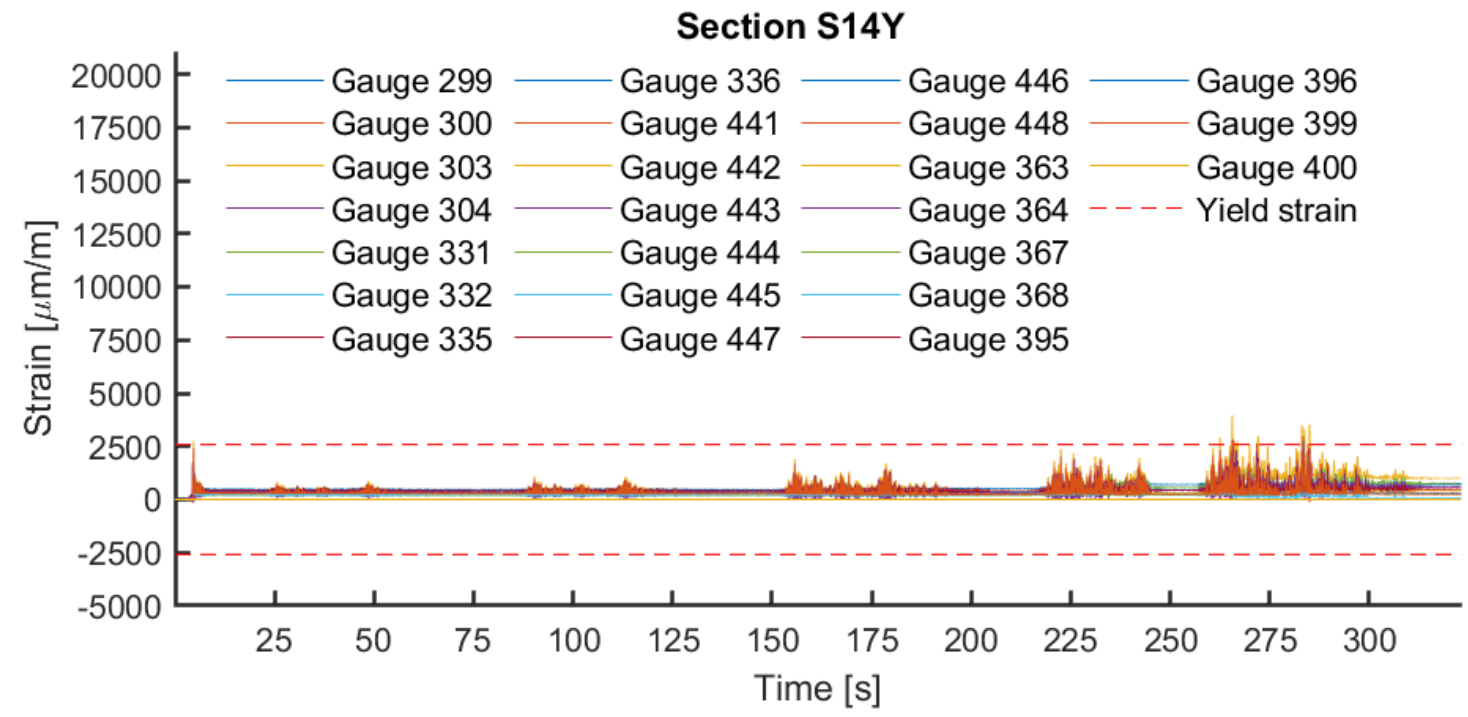

Figure A2. 41. Gauges results in section S14Y

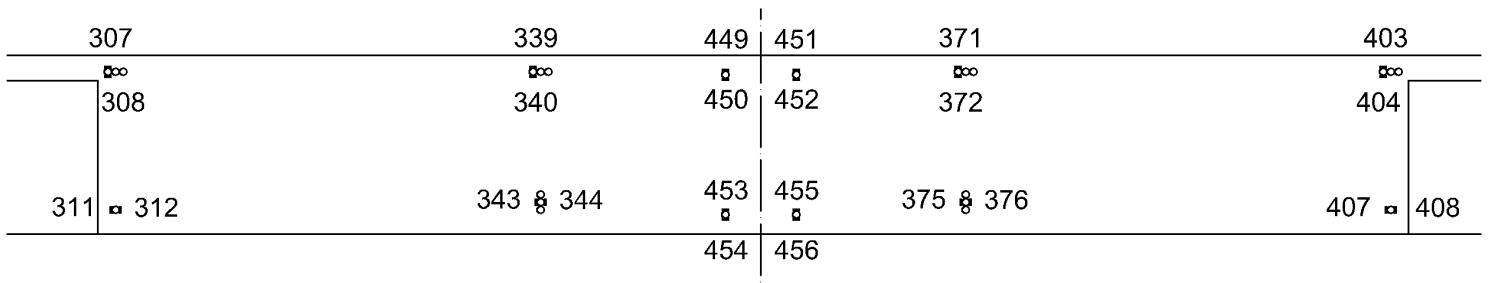

Figure A2. 42. Gauges locations at section S15Y

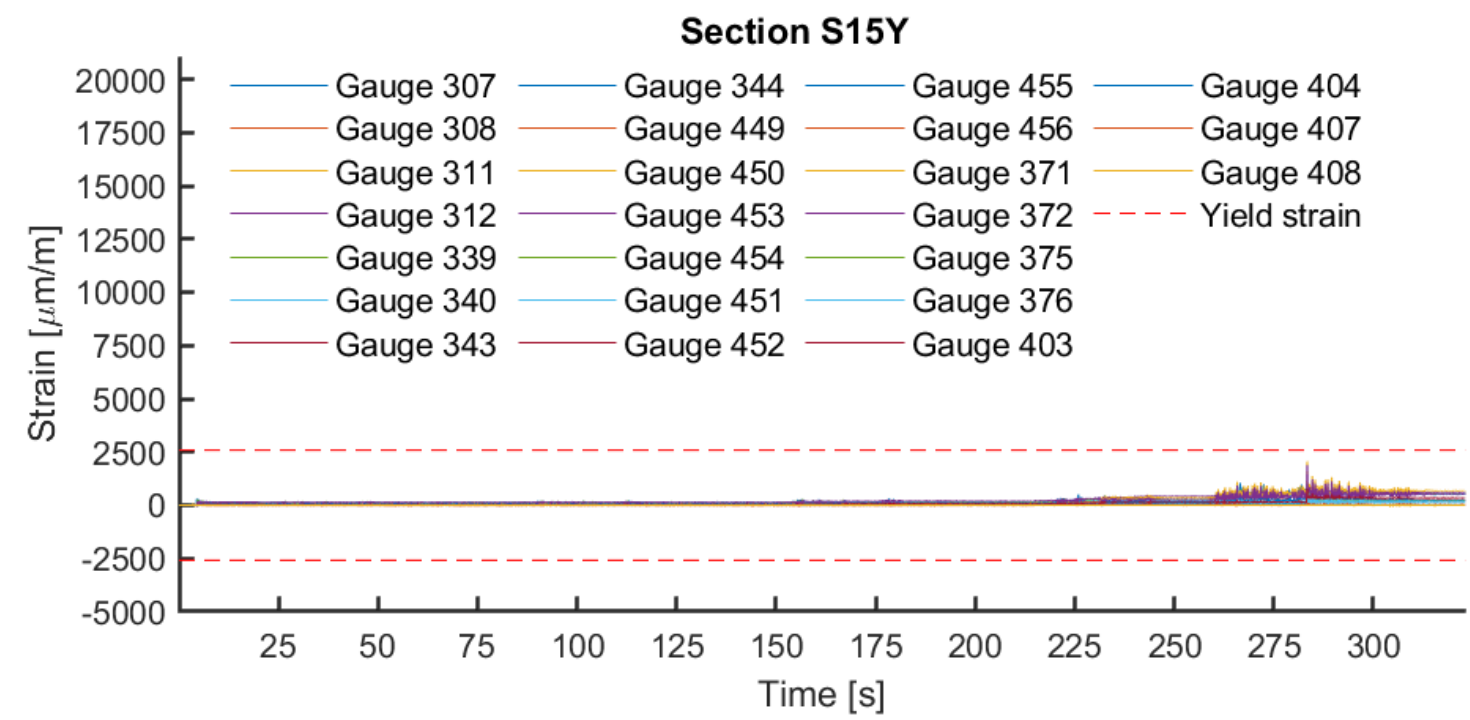

Figure A2. 43. Gauges results in section S15Y

\begin{tabular}{|c|c|c|c|c|}
\hline 315 & 347 & 379 & 411 & \\
\hline$\square^{\infty \infty}$ & $5 \infty$ & 500 & 500 & \\
\hline 319 a 320 & $351 \& 352$ & $383 \& 384$ & $415 \mathrm{a}$ & 416 \\
\hline
\end{tabular}

Figure A2. 44. Gauges locations at section S16Y 


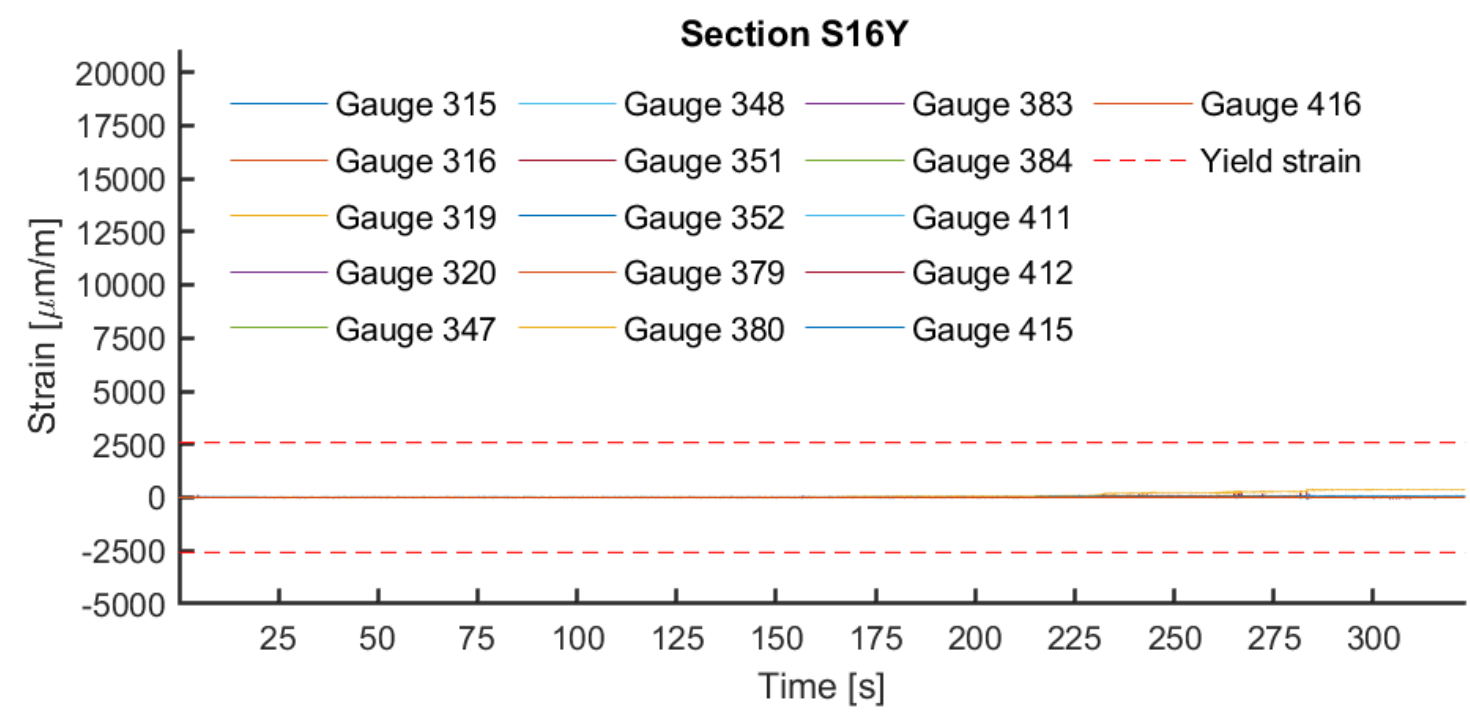

Figure A2. 45. Gauges results in section S16Y 
Appendix 3

FAR-FIELD GROUND MOTIONS 

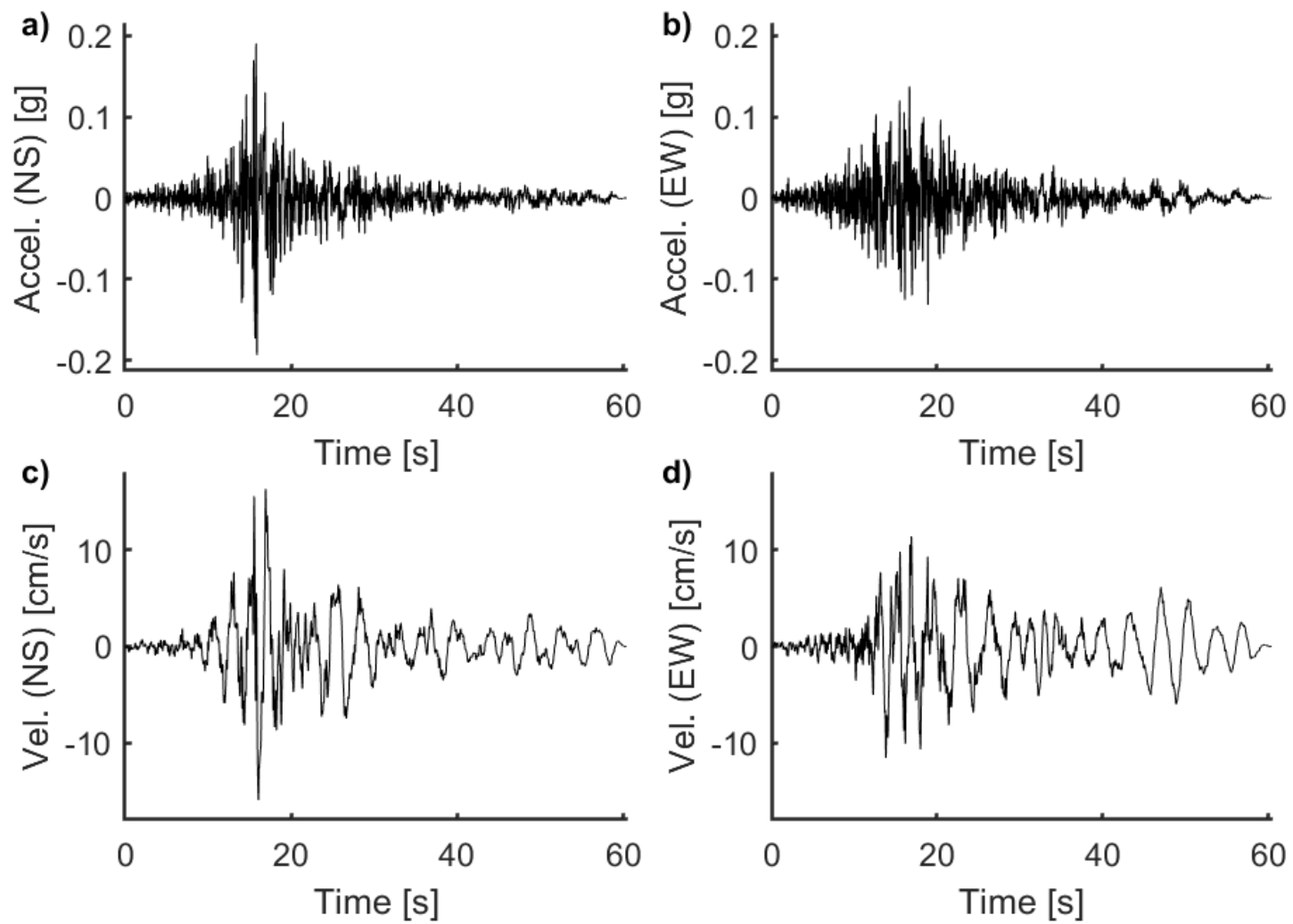

Figure A3. 1. Acceleration and velocity signals for Manjil-1636: a) Acceleration (NS), b) Acceleration (EW), c) Velocity (NS) and d) Velocity (EW)
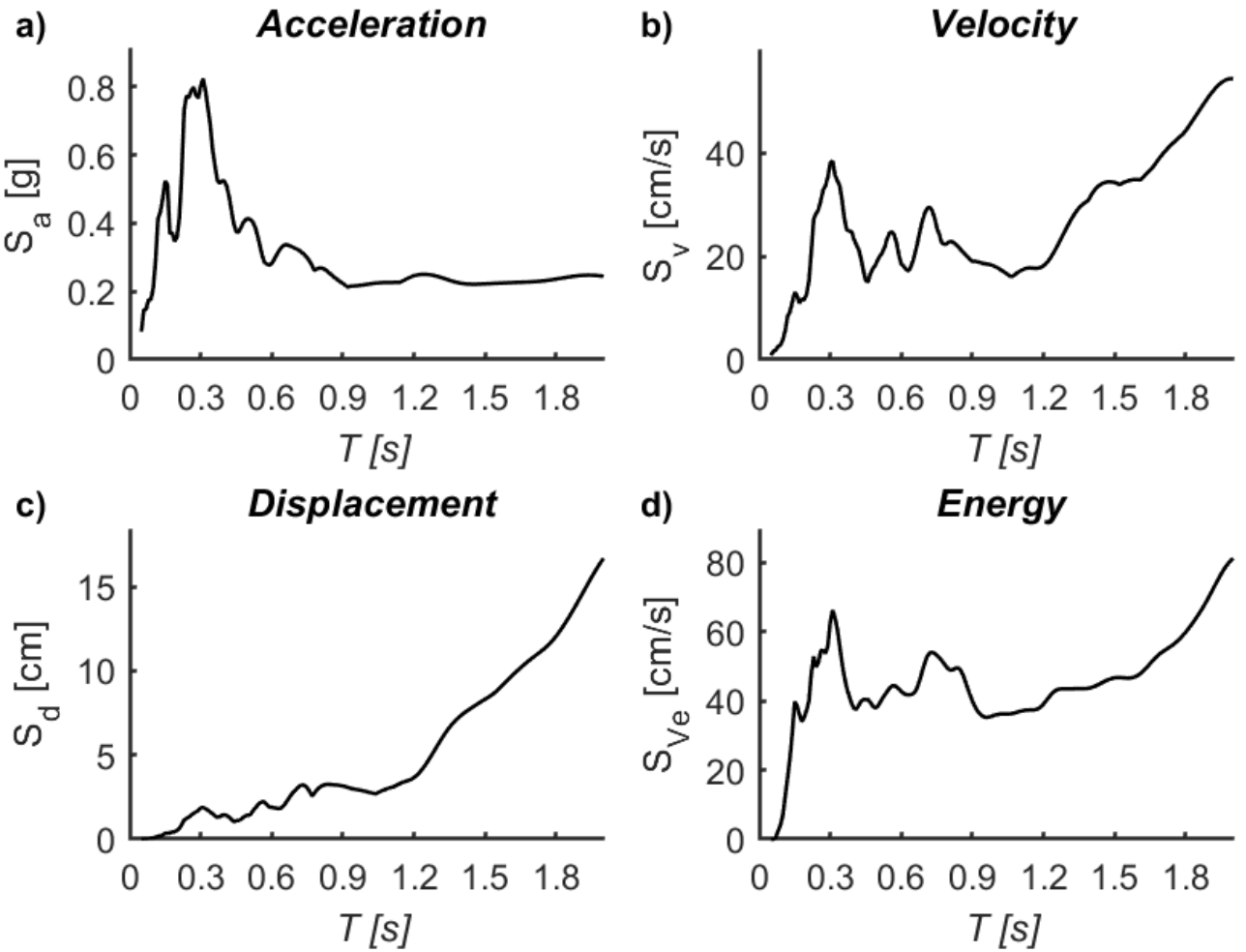

Figure A3. 2. Spectra of Manjil-1636 (NS): a) Acceleration, b) Velocity, c) Displacement and d) Input energy 

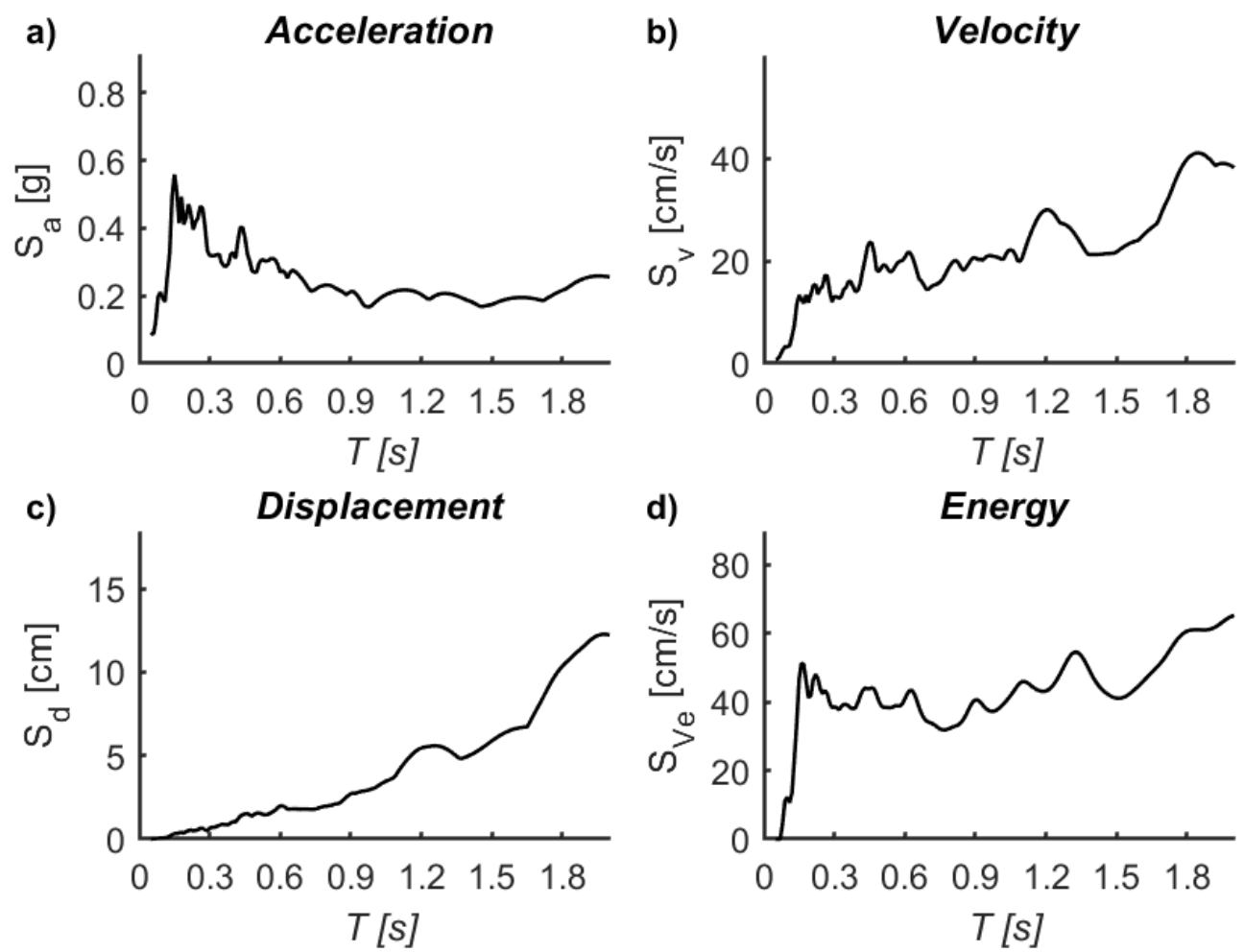

Figure A3. 3. Spectra of Manjil-1636 (EW): a) Acceleration, b) Velocity, c) Displacement and d) Input energy
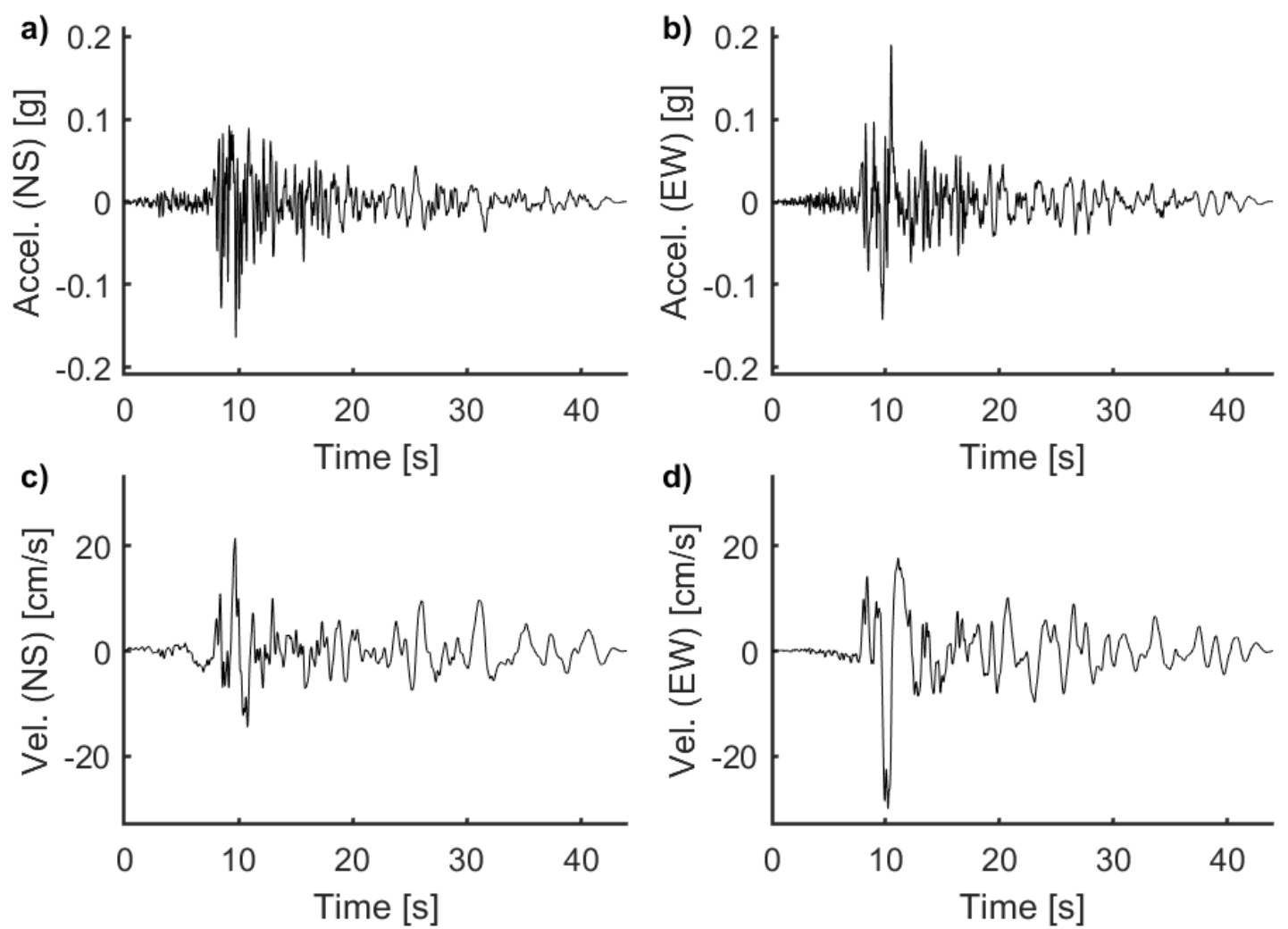

Figure A3. 4. Acceleration and velocity signals for Capemend-826: a) Acceleration (NS), b) Acceleration (EW), c) Velocity (NS) and d) Velocity (EW) 

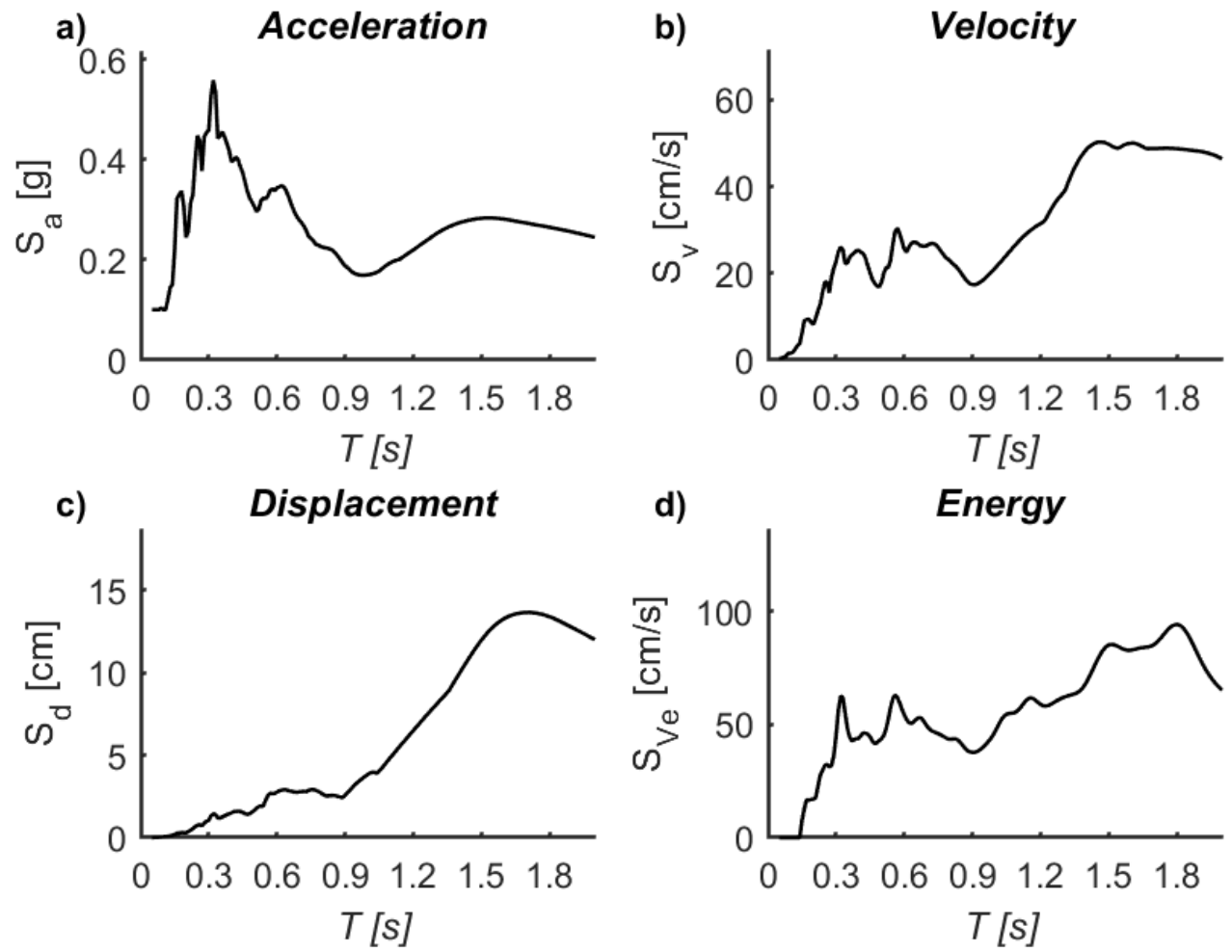

Figure A3. 5. Spectra of Capemend-826 (NS): a) Acceleration, b) Velocity, c) Displacement and d) Input energy
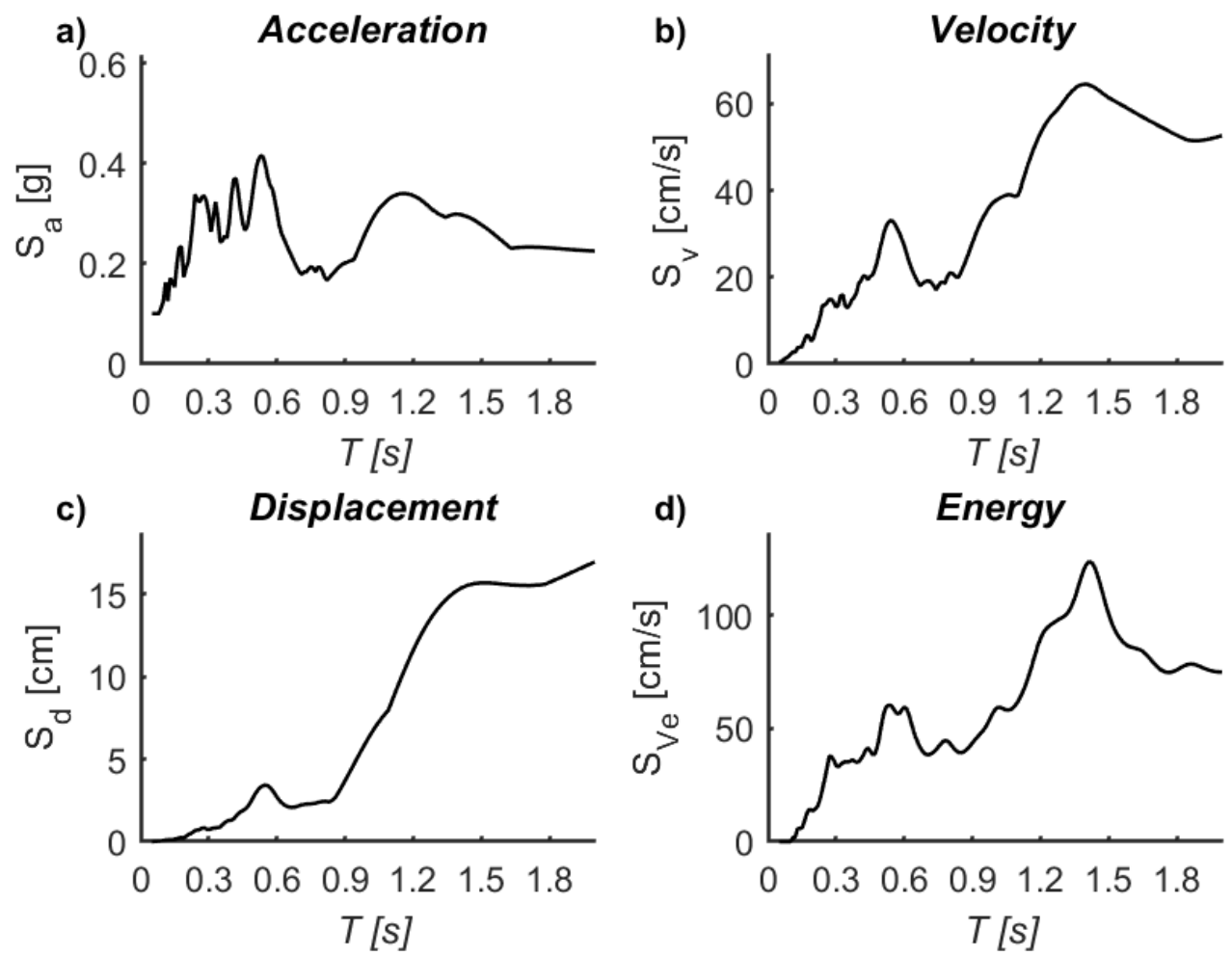

Figure A3. 6. Spectra of Capemend-826 (EW): a) Acceleration, b) Velocity, c) Displacement and d) Input energy 

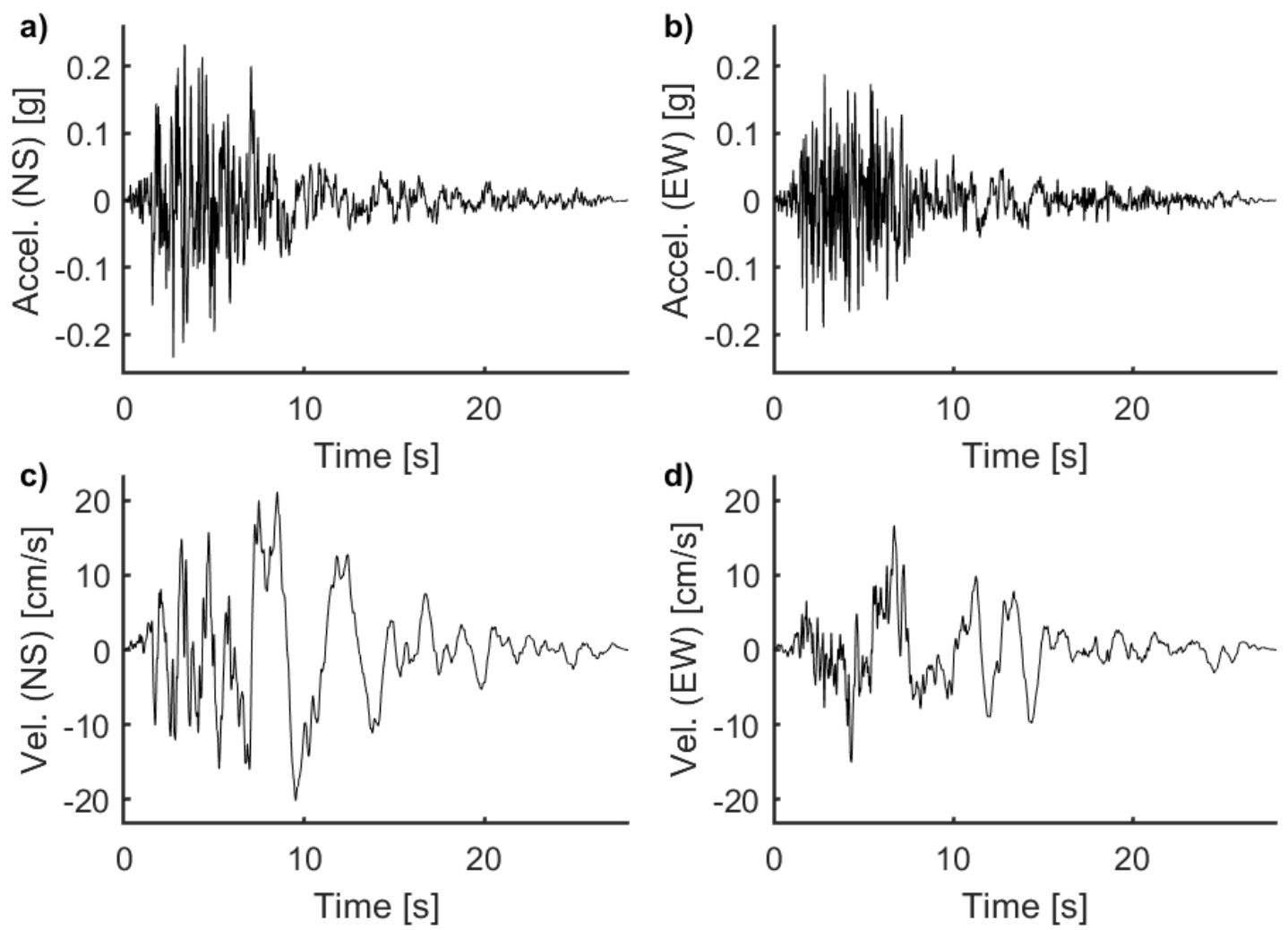

Figure A3. 7. Acceleration and velocity signals for Sfern-68: a) Acceleration (NS), b) Acceleration (EW), c) Velocity (NS) and d) Velocity (EW)
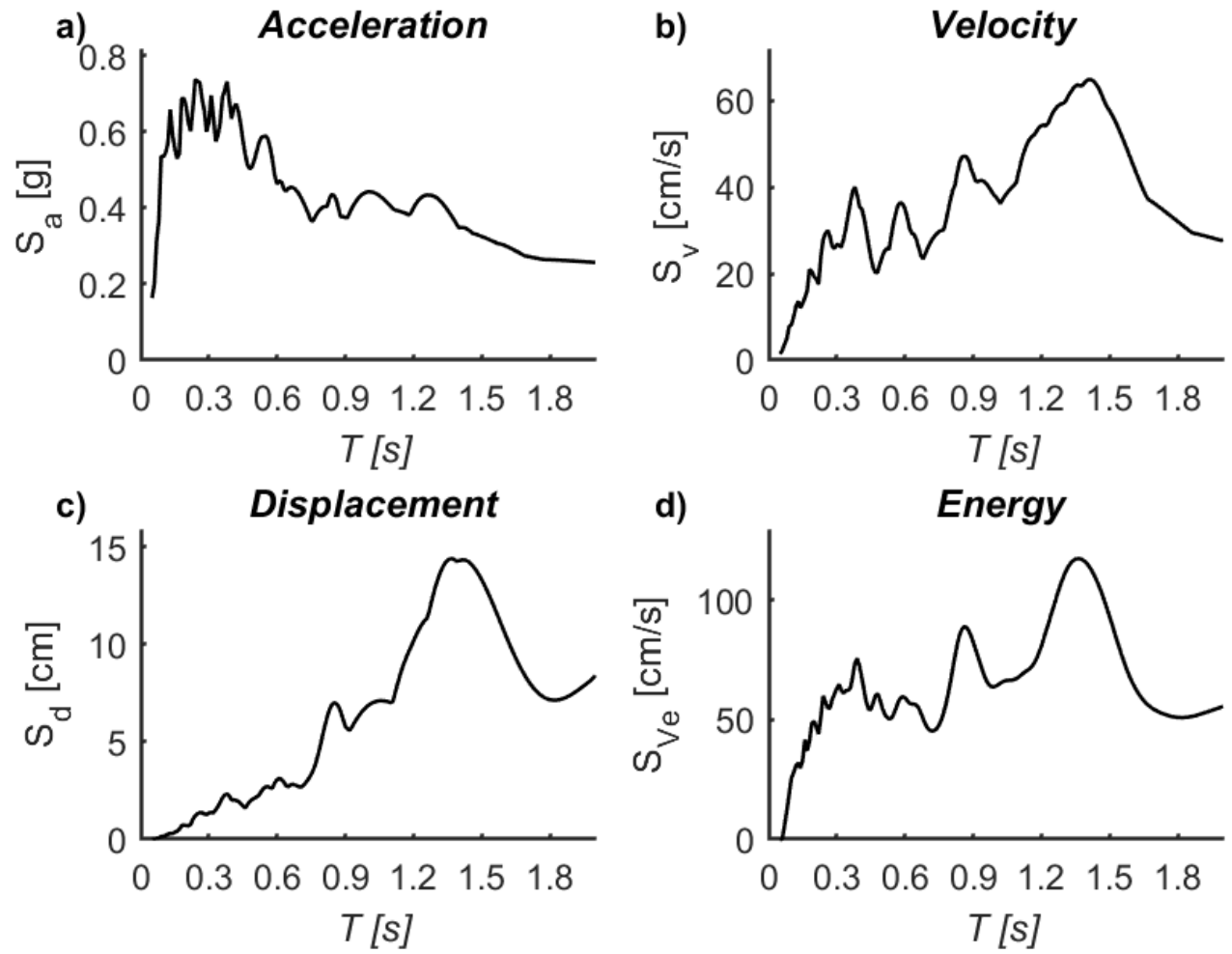

Figure A3. 8. Spectra of Sfern-68 (NS): a) Acceleration, b) Velocity, c) Displacement and d) Input energy 

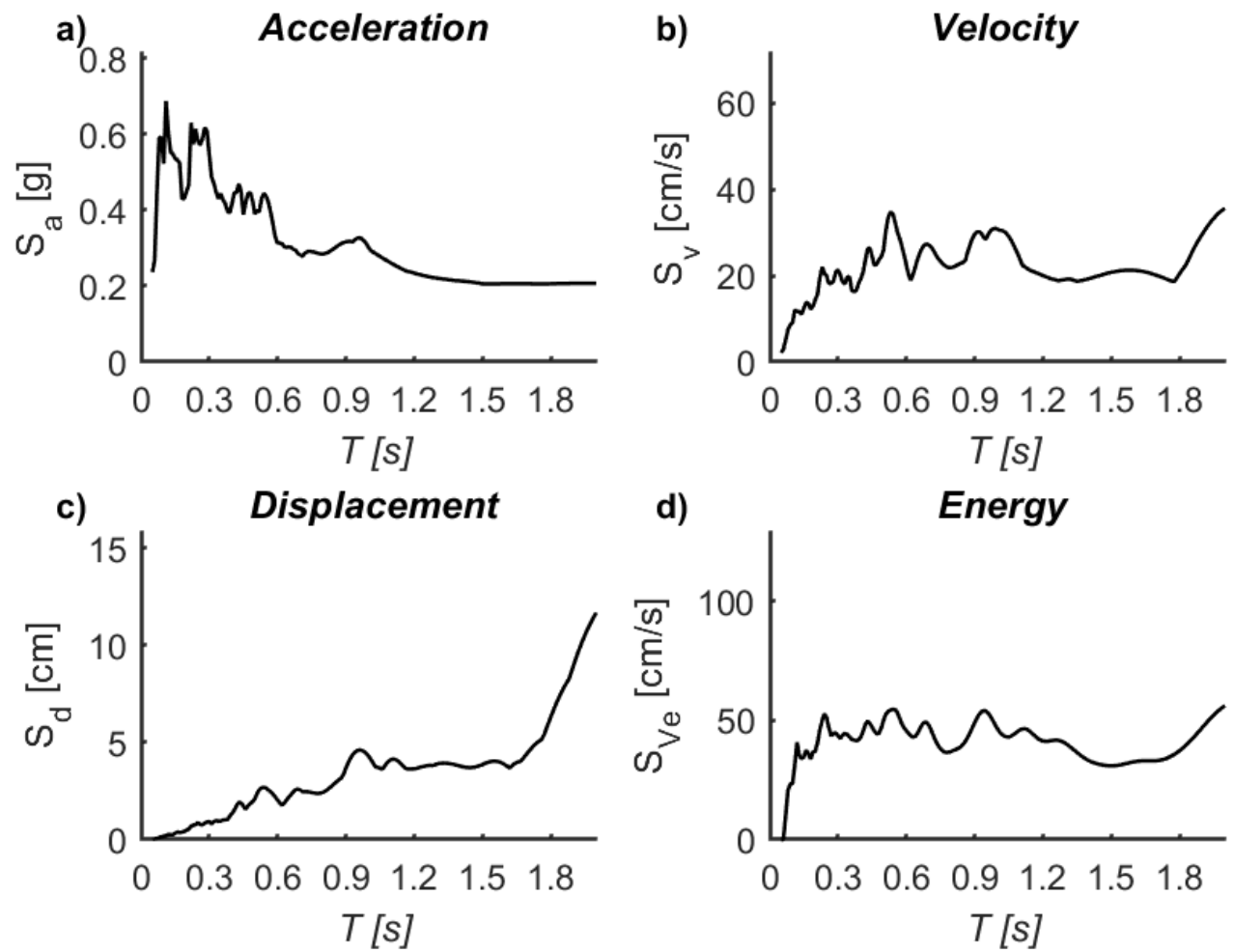

Figure A3. 9. Spectra of Sfern-68 (EW): a) Acceleration, b) Velocity, c) Displacement and d) Input energy
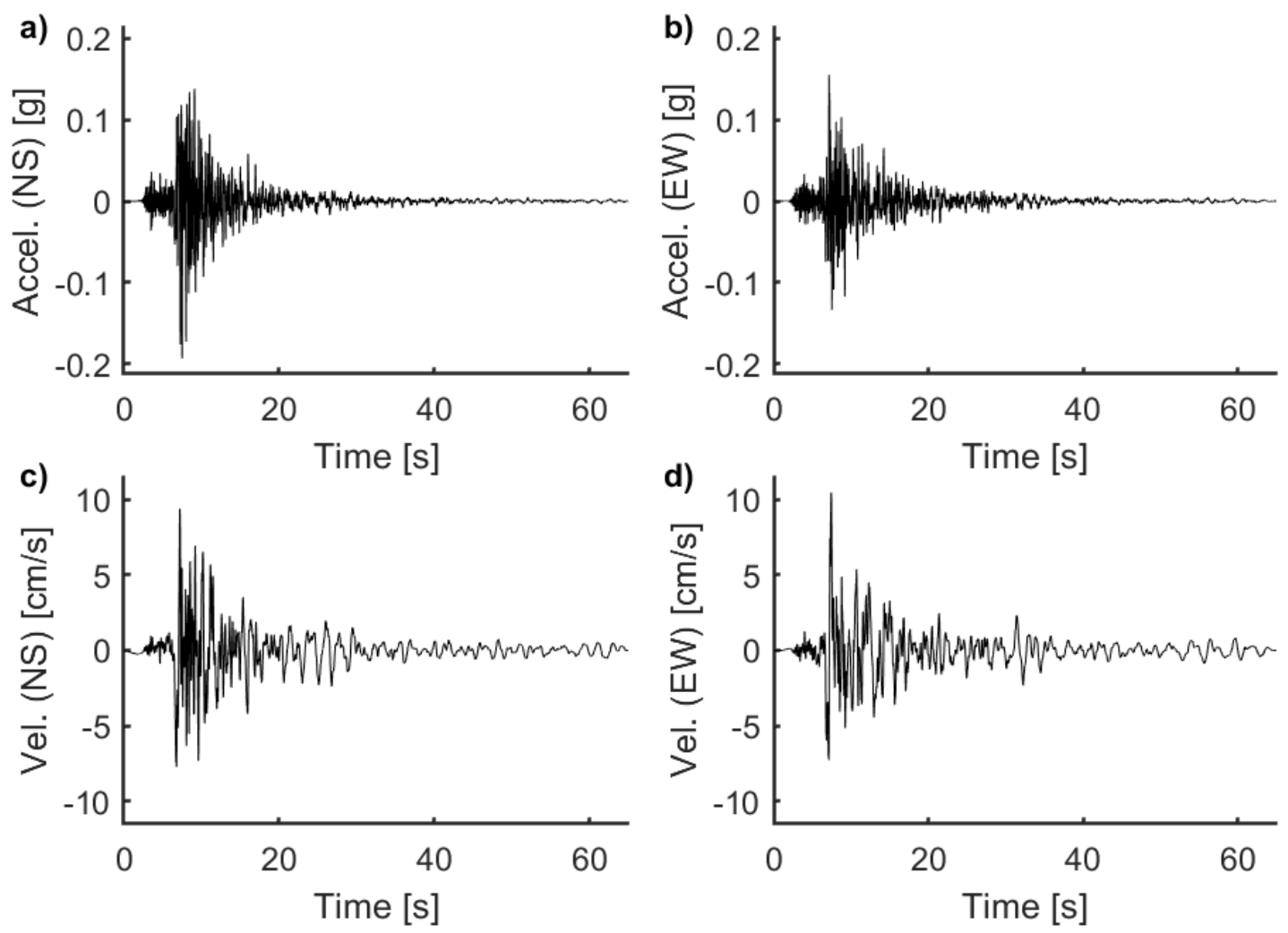

Figure A3. 10. Acceleration and velocity signals for Smadre-1643: a) Acceleration (NS), b) Acceleration (EW), c) Velocity (NS) and d) Velocity (EW) 

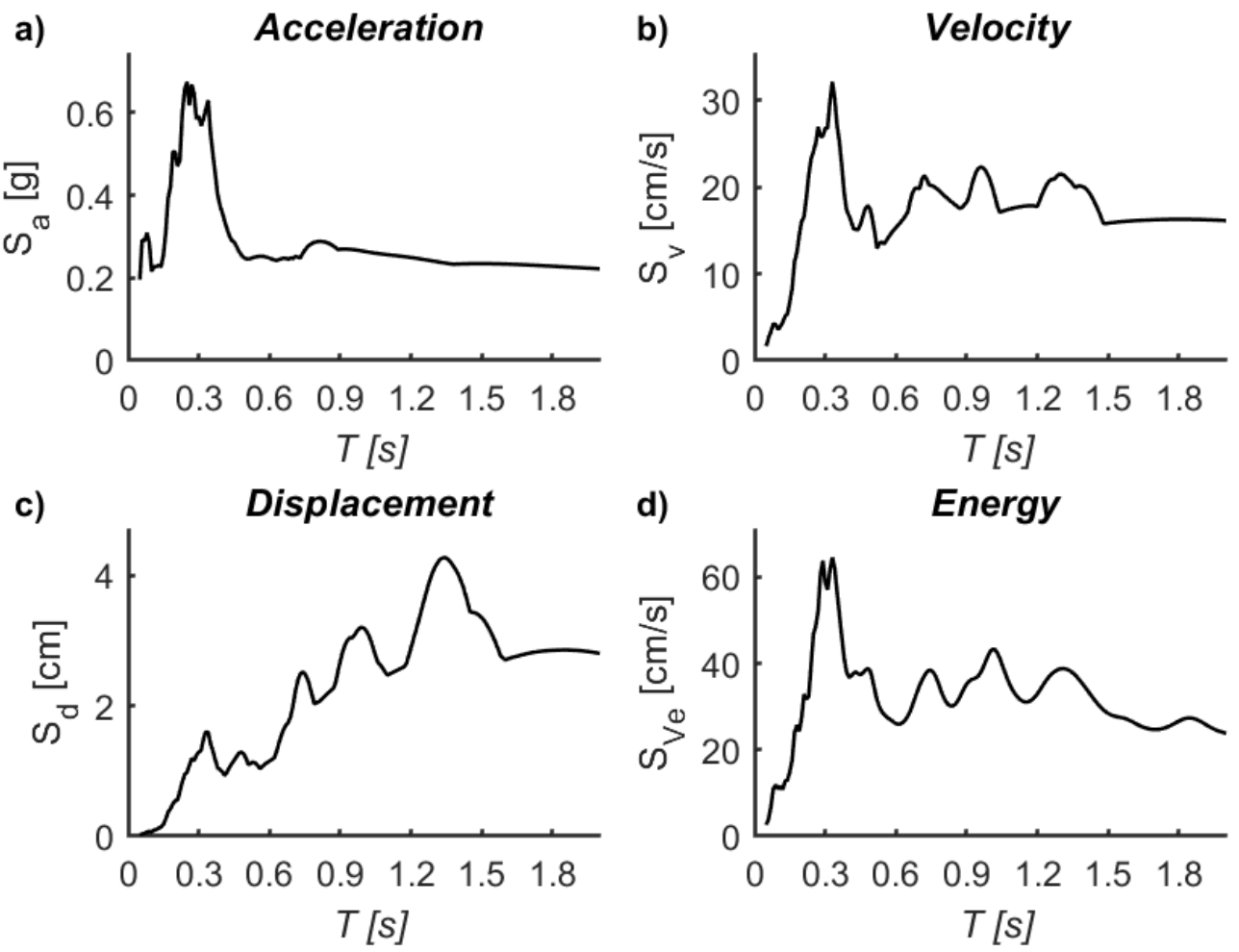

Figure A3. 11. Spectra of Smadre-1643 (NS): a) Acceleration, b) Velocity, c) Displacement and d) Input energy

a)

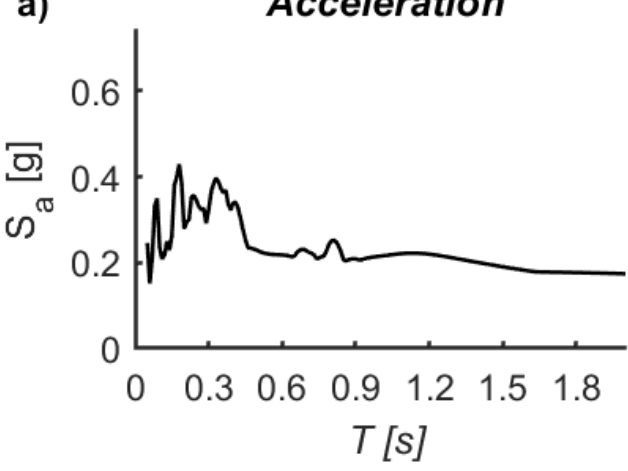

c)

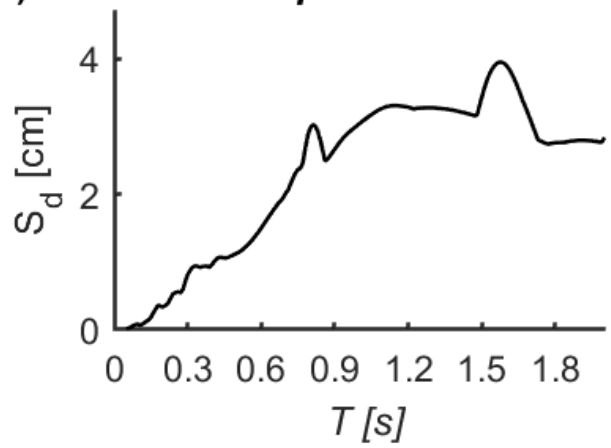

b)

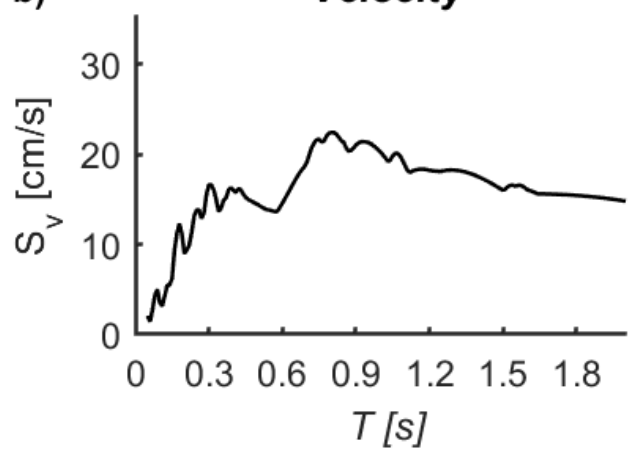

d)

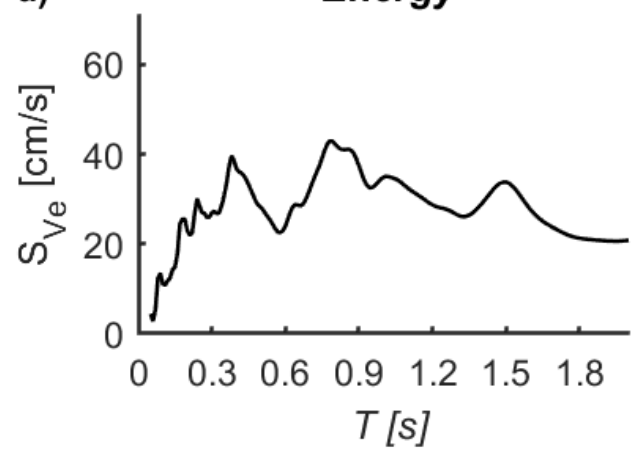

Figure A3. 12. Spectra of Smadre-1643(EW): a) Acceleration, b) Velocity, c) Displacement and d) Input energy 

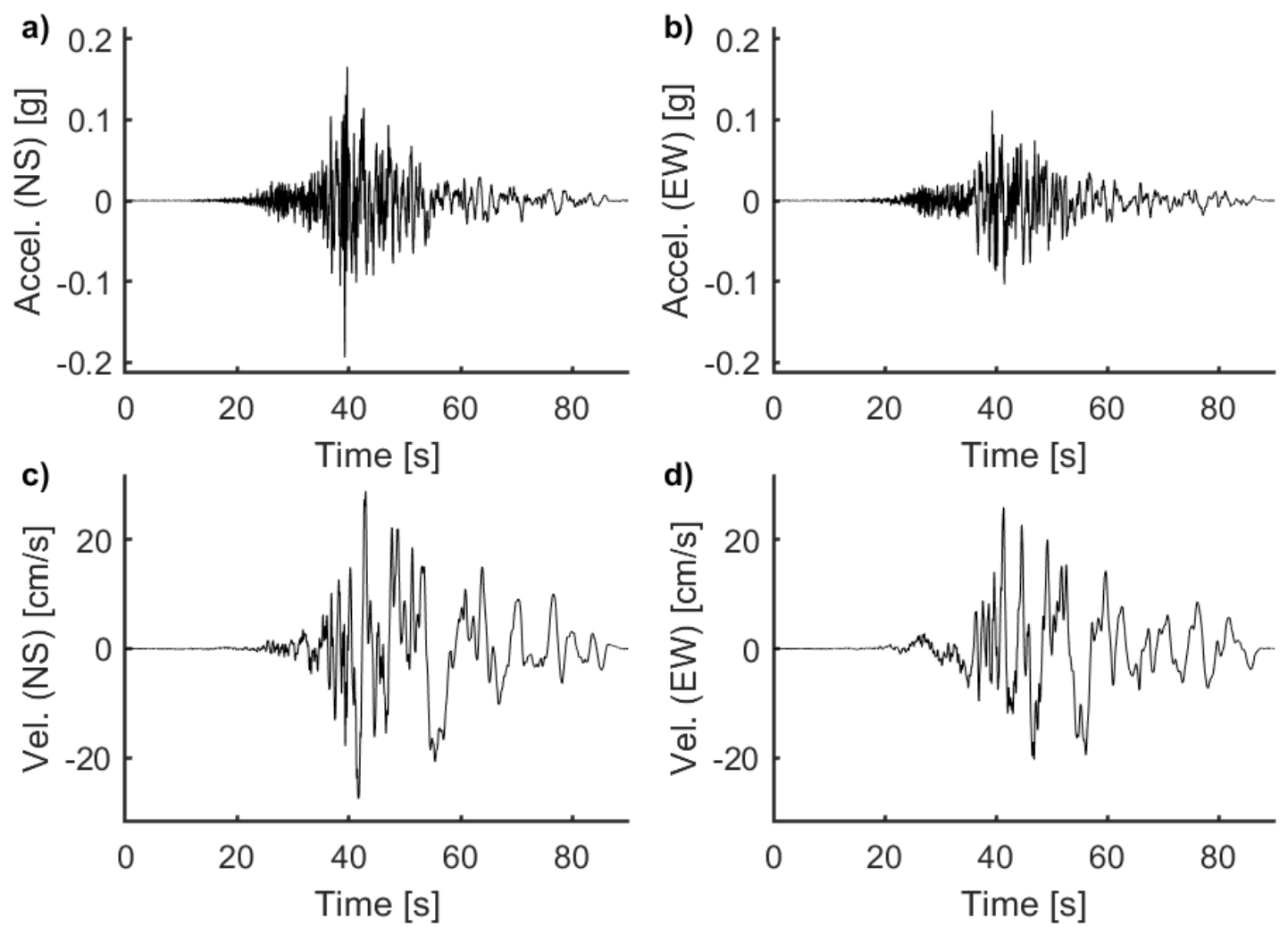

Figure A3. 13. Acceleration and velocity signals for Chichi-1435: a) Acceleration (NS), b) Acceleration (EW), c) Velocity (NS) and d) Velocity (EW)
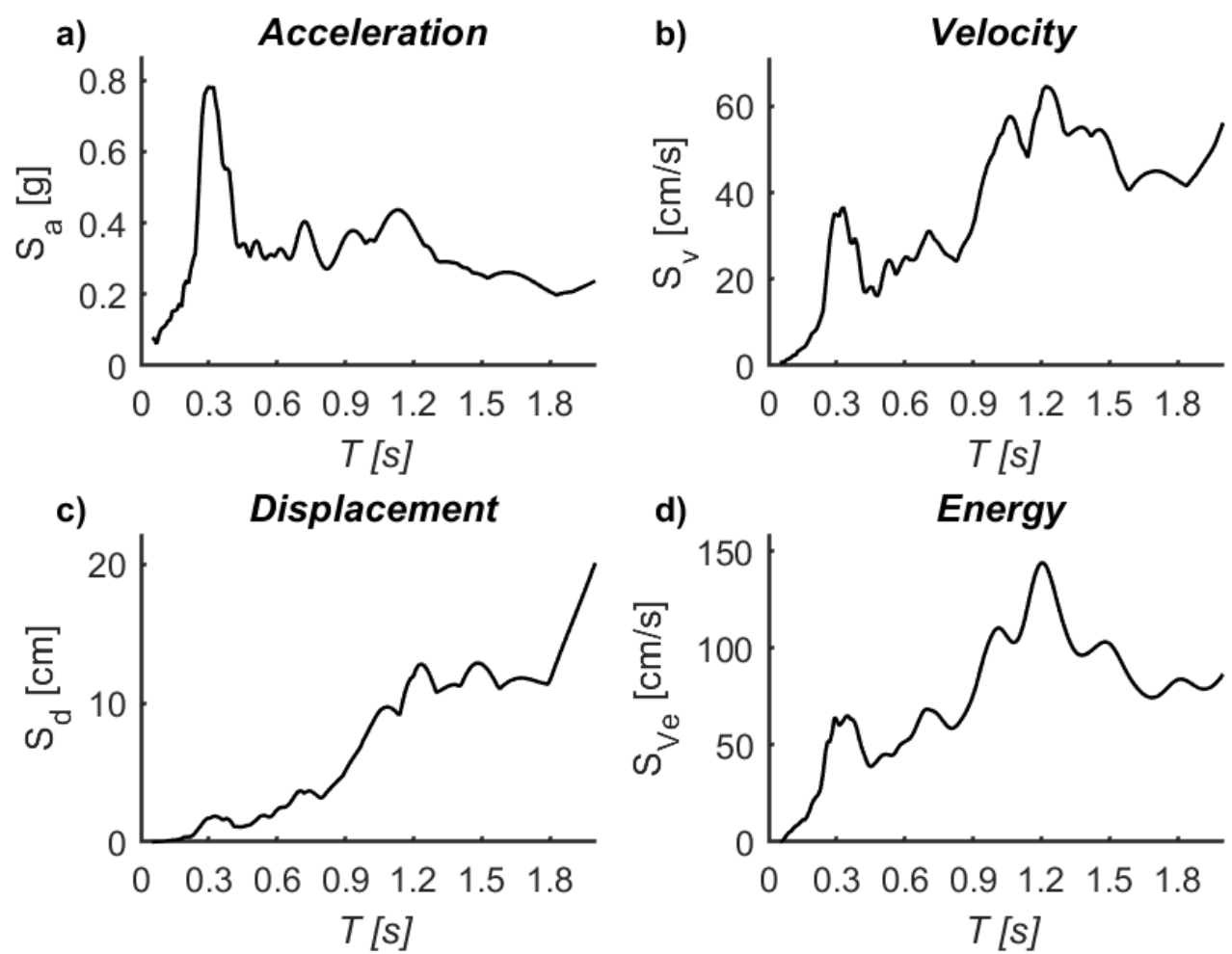

Figure A3. 14. Spectra of Chichi-1435 (NS): a) Acceleration, b) Velocity, c) Displacement and d) Input energy 

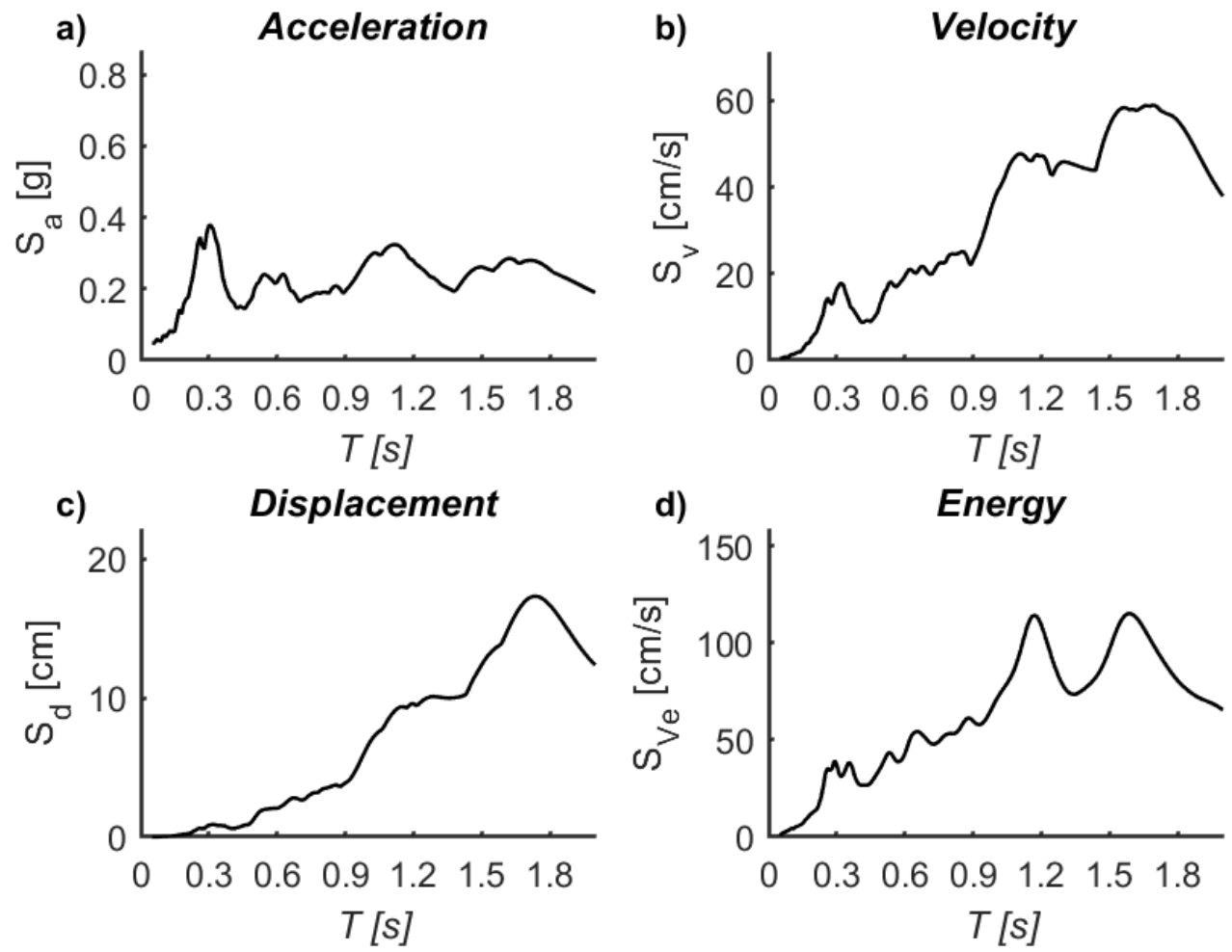

Figure A3. 15. Spectra of Chichi-1435 (EW): a) Acceleration, b) Velocity, c) Displacement and d) Input energy
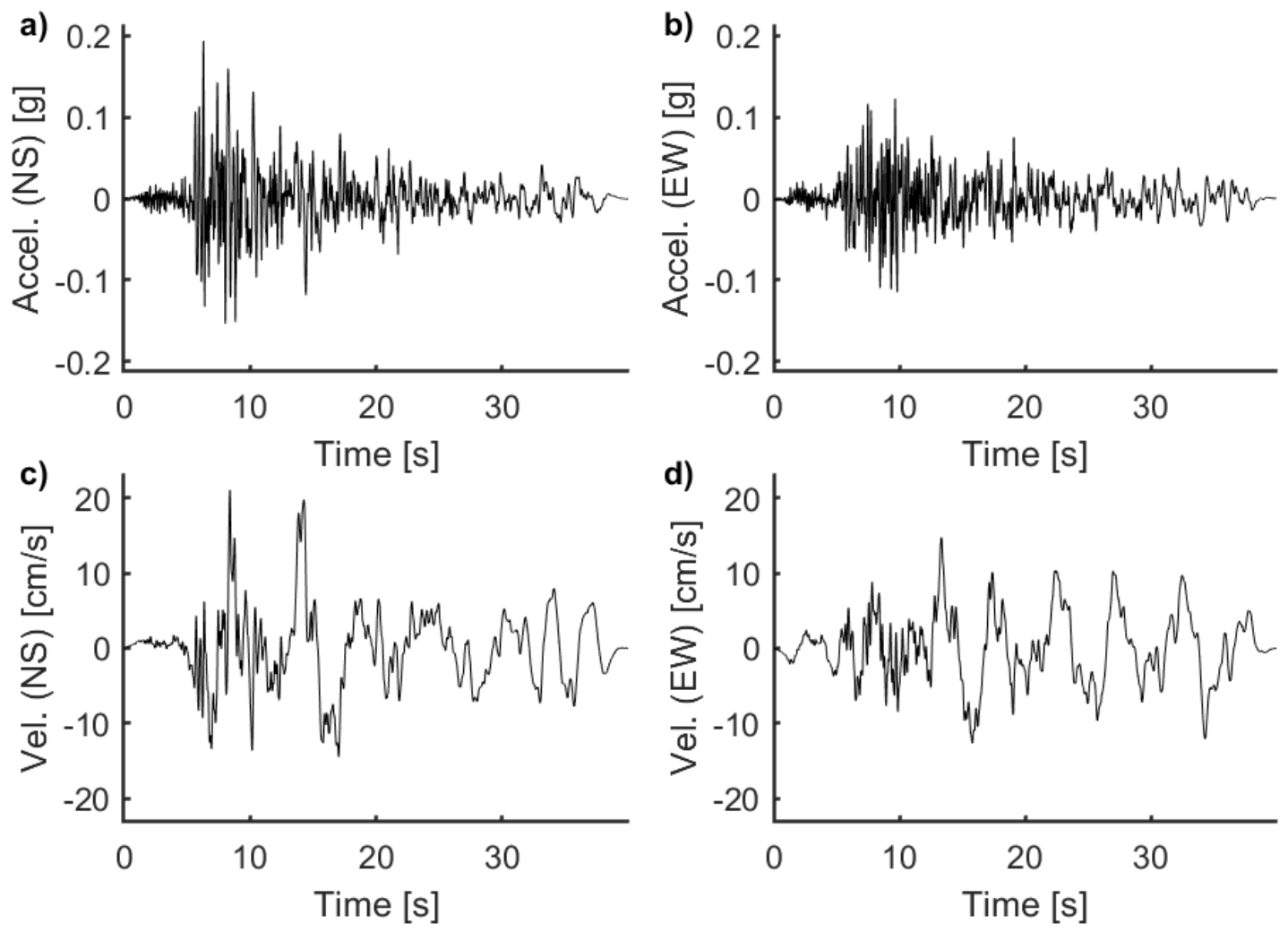

Figure A3. 16. Acceleration and velocity signals for Impvall-186: a) Acceleration (NS), b) Acceleration (EW), c) Velocity (NS) and d) Velocity (EW) 

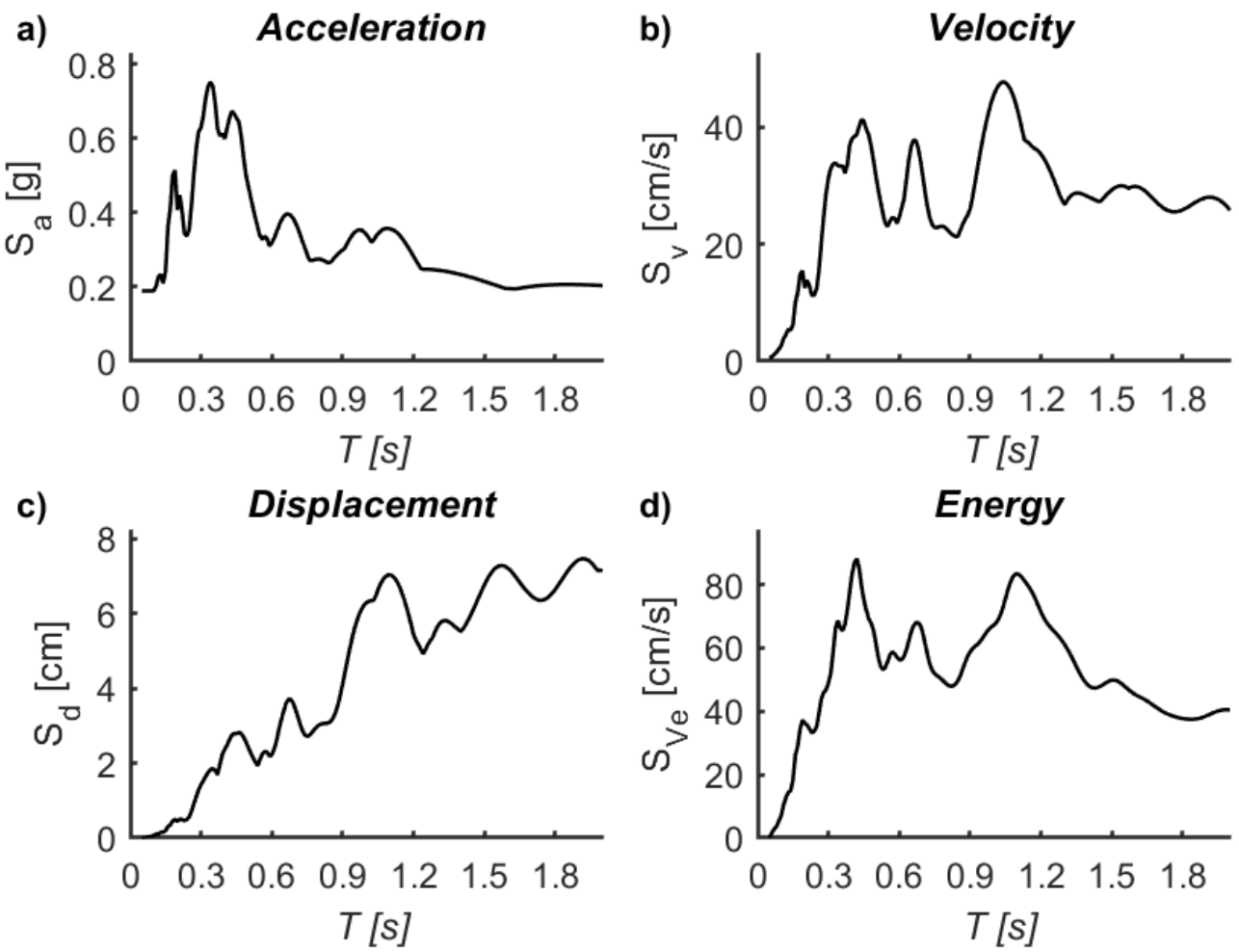

Figure A3. 17. Spectra of Impvall-186 (NS): a) Acceleration, b) Velocity, c) Displacement and d) Input energy
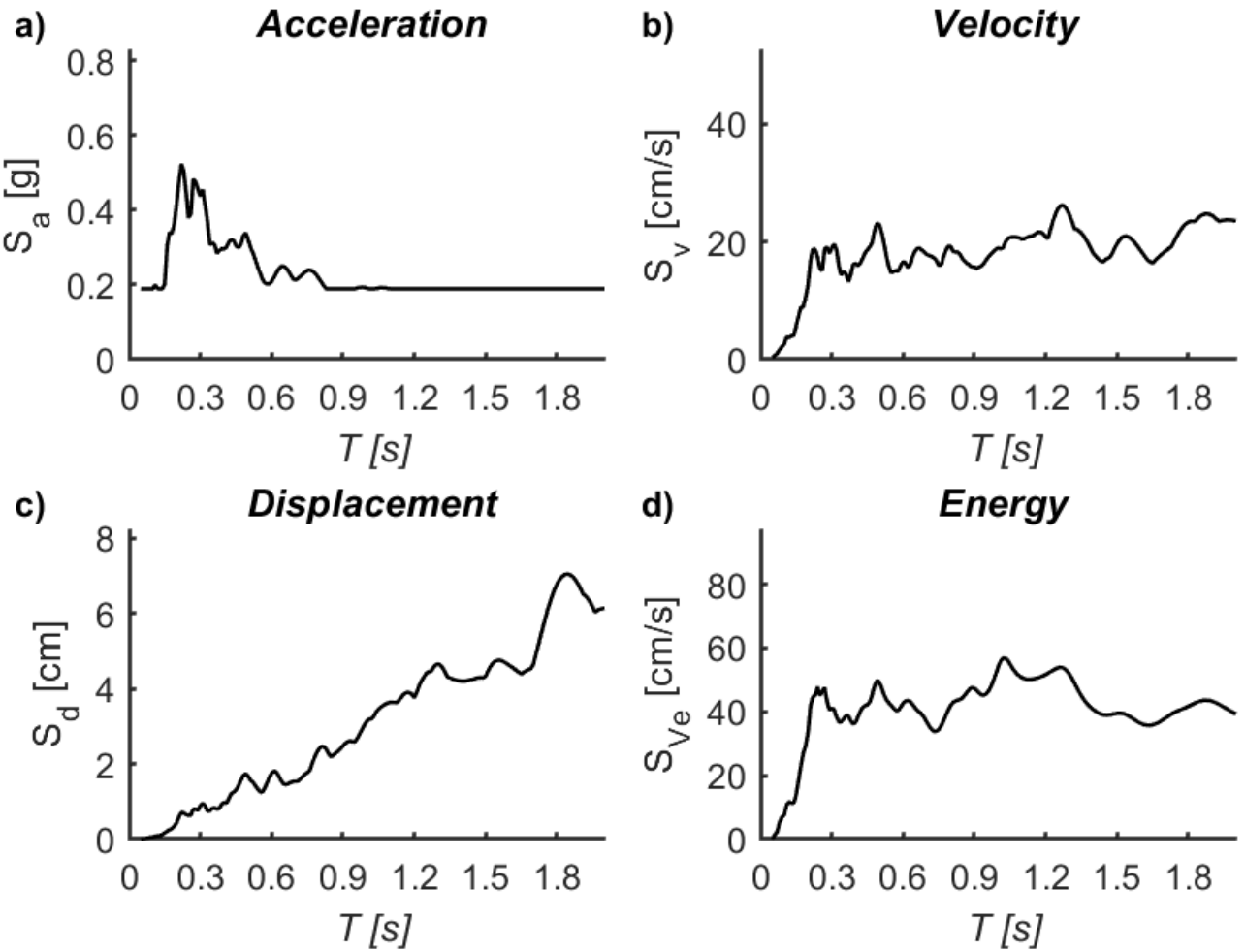

Figure A3. 18. Spectra of Impvall-186 (EW): a) Acceleration, b) Velocity, c) Displacement and d) Input energy 

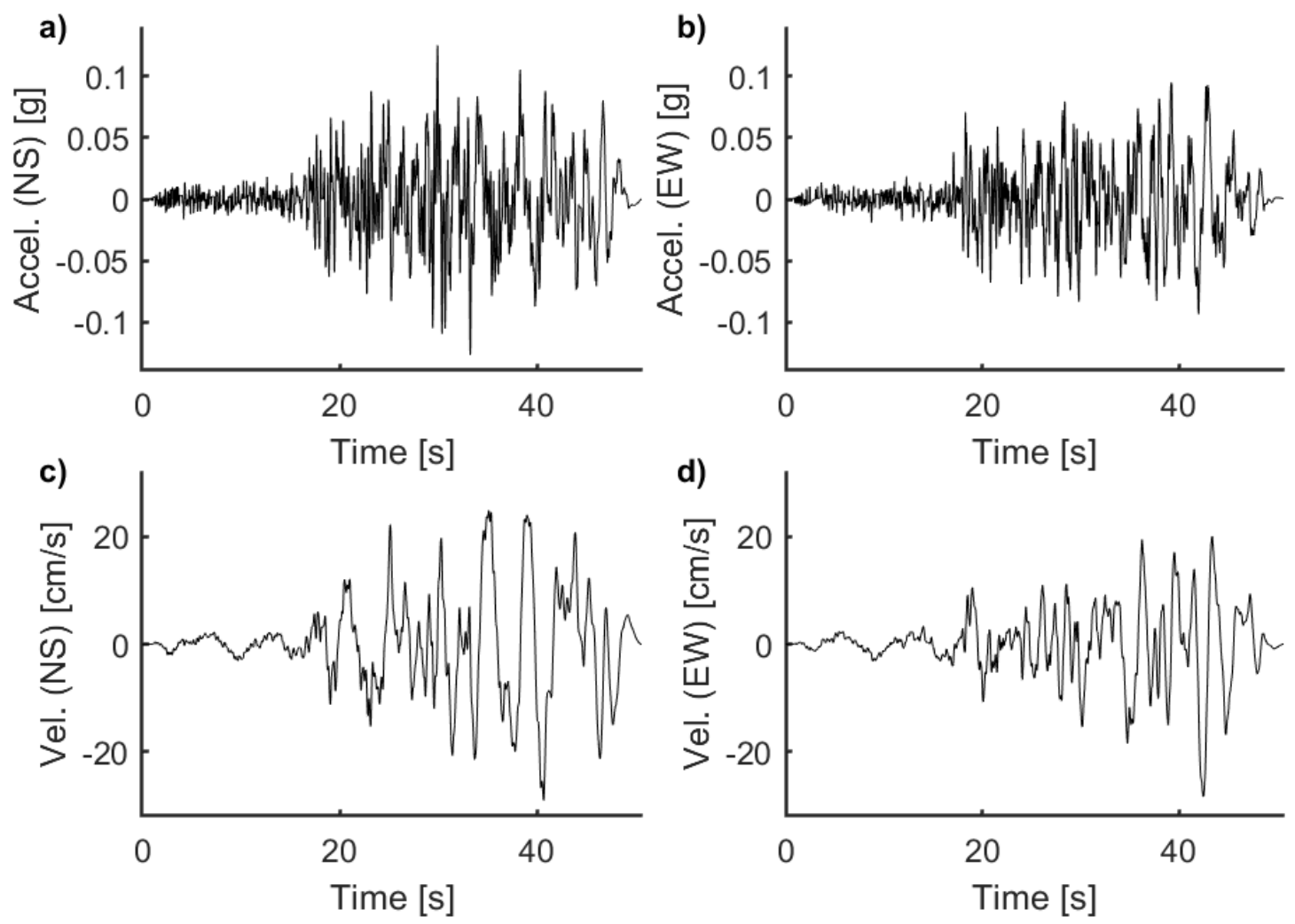

Figure A3. 19. Acceleration and velocity signals for Landers-833: a) Acceleration (NS), b) Acceleration (EW), c) Velocity (NS) and d) Velocity (EW)
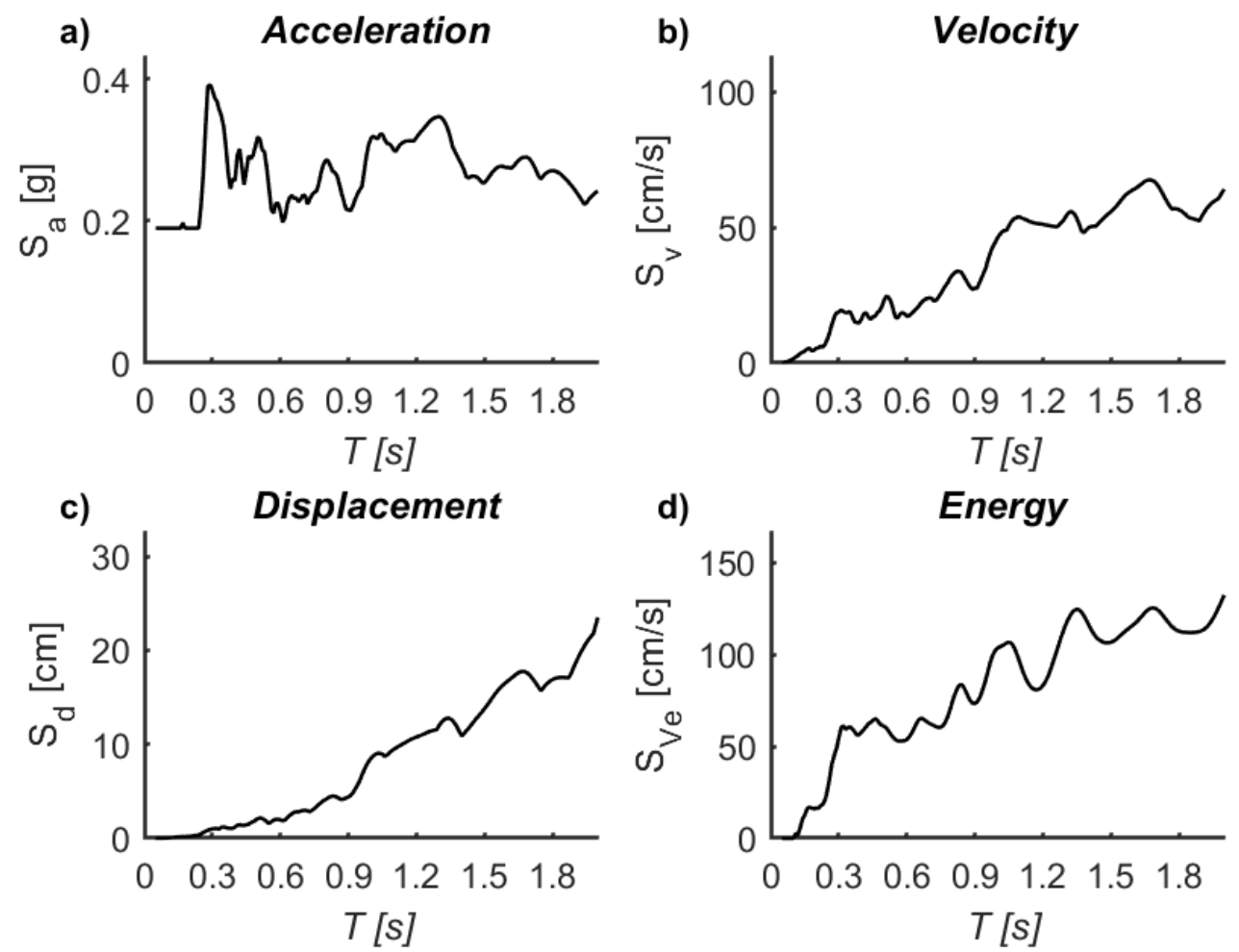

Figure A3. 20. Spectra of Landers-833 (NS): a) Acceleration, b) Velocity, c) Displacement and d) Input energy 

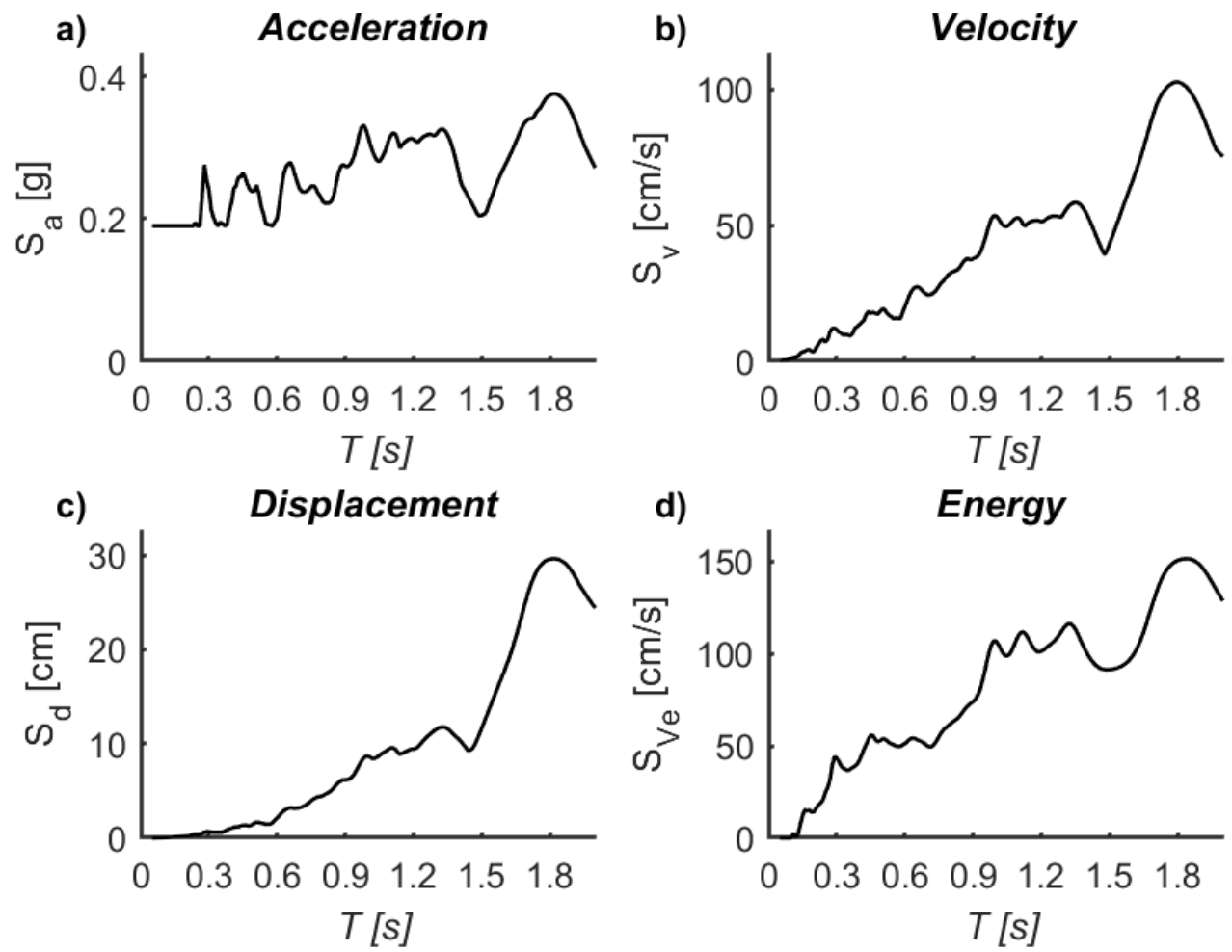

Figure A3. 21. Spectra of Landers-833 (EW): a) Acceleration, b) Velocity, c) Displacement and d) Input energy

a)
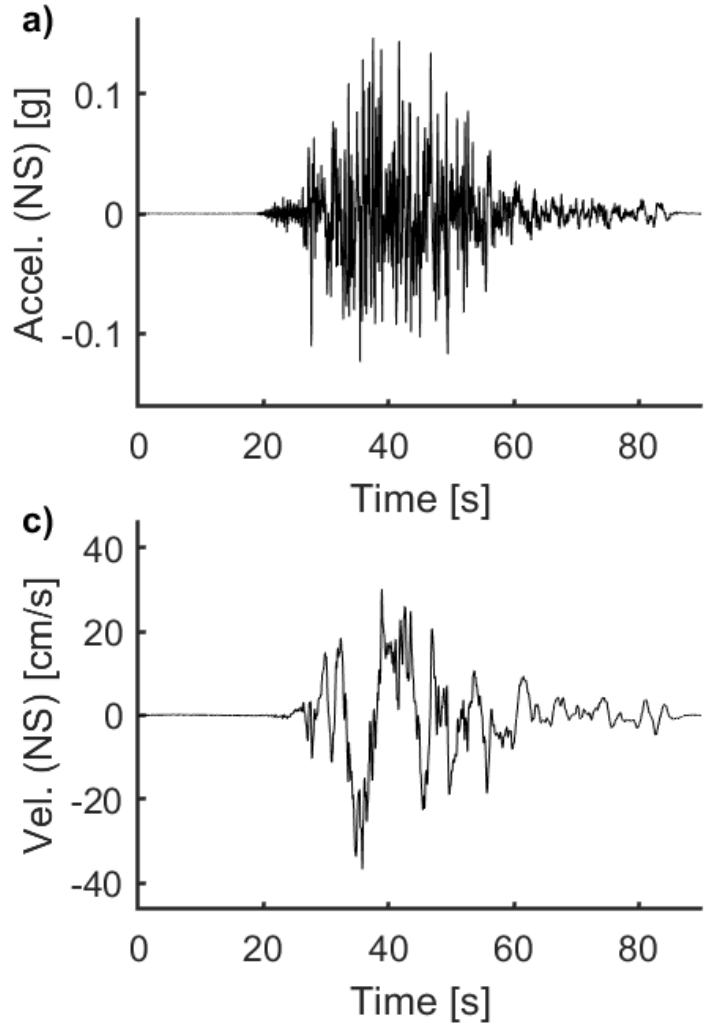

b)
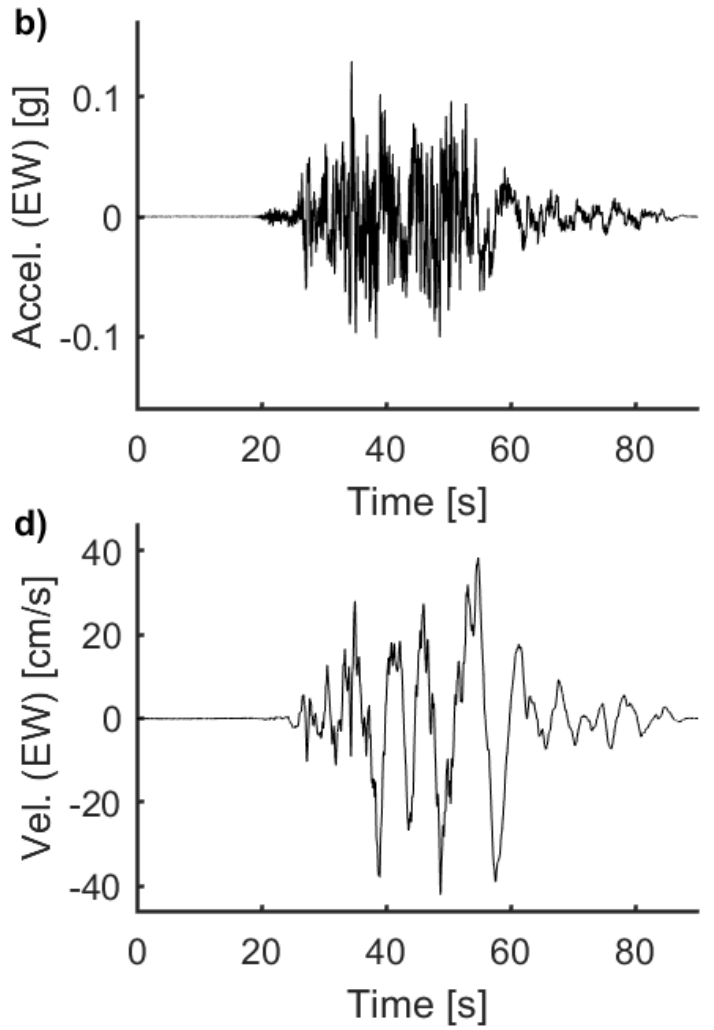

Figure A3. 22. Acceleration and velocity signals for Chichi-1490: a) Acceleration (NS), b) Acceleration (EW), c) Velocity (NS) and d) Velocity (EW) 

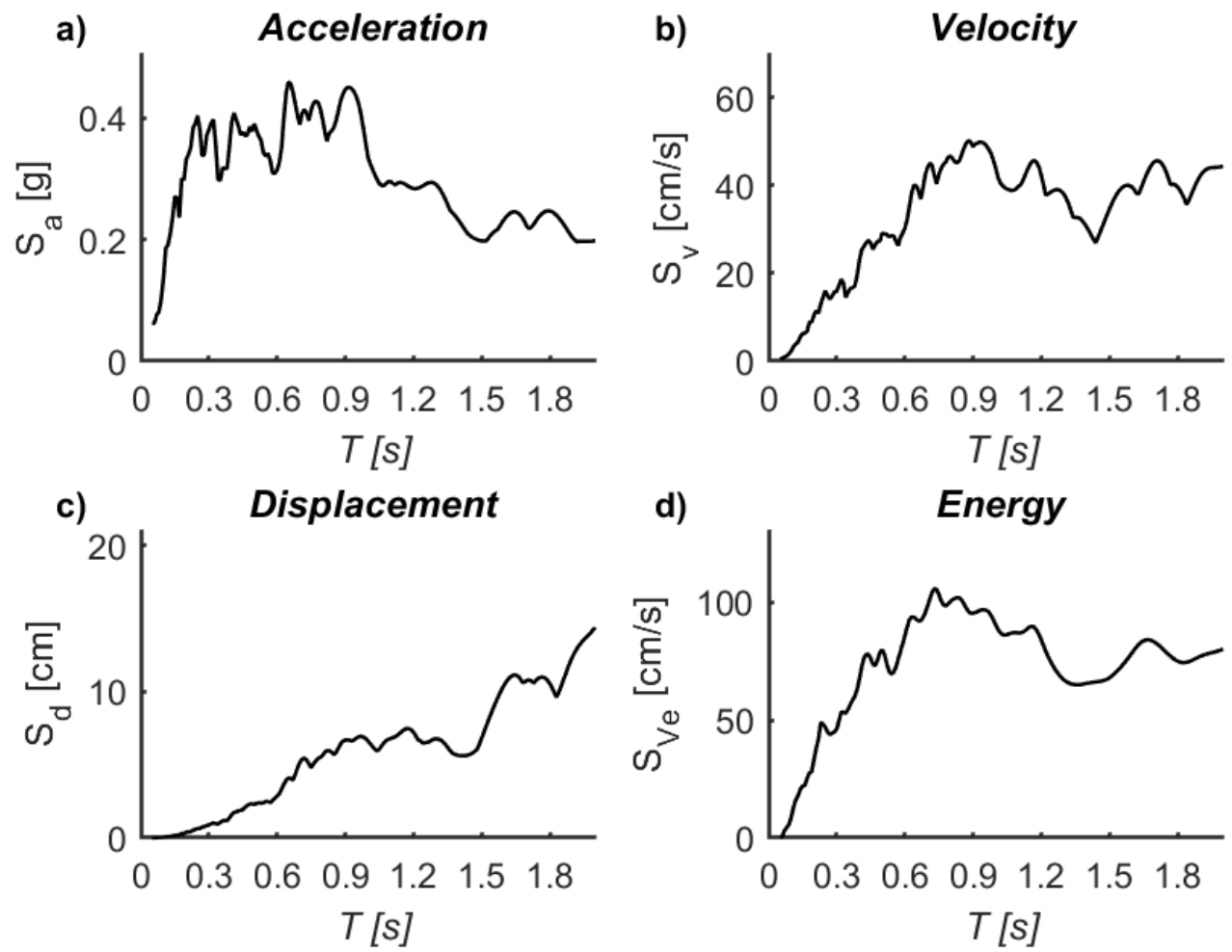

Figure A3. 23. Spectra of Chichi-1490 (NS): a) Acceleration, b) Velocity, c) Displacement and d) Input energy
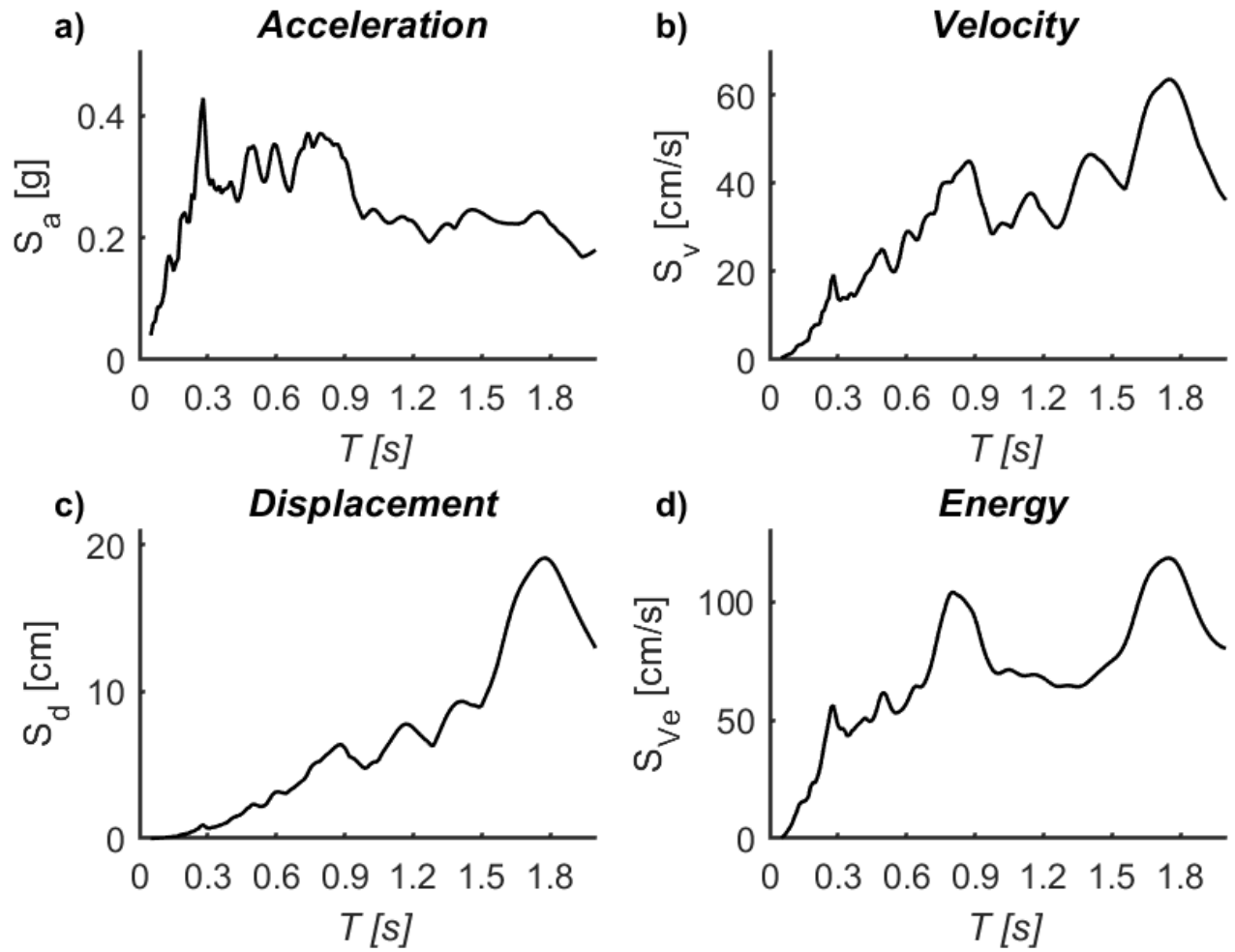

Figure A3. 24. Spectra of Chichi-1490 (EW): a) Acceleration, b) Velocity, c) Displacement and d) Input energy 
a)

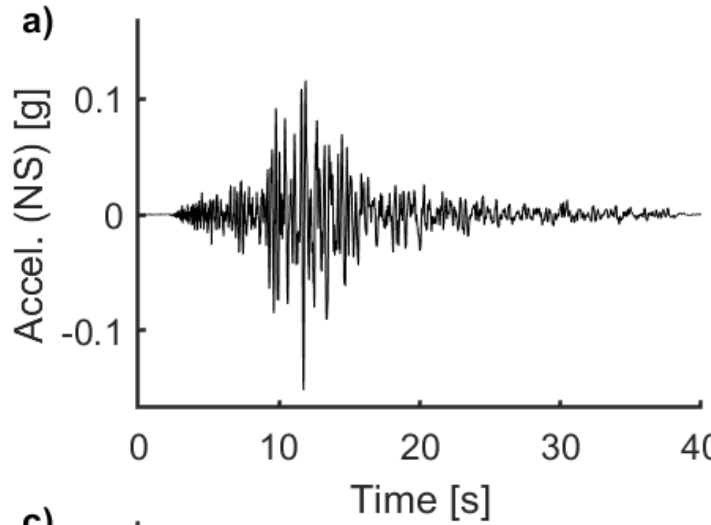

c)

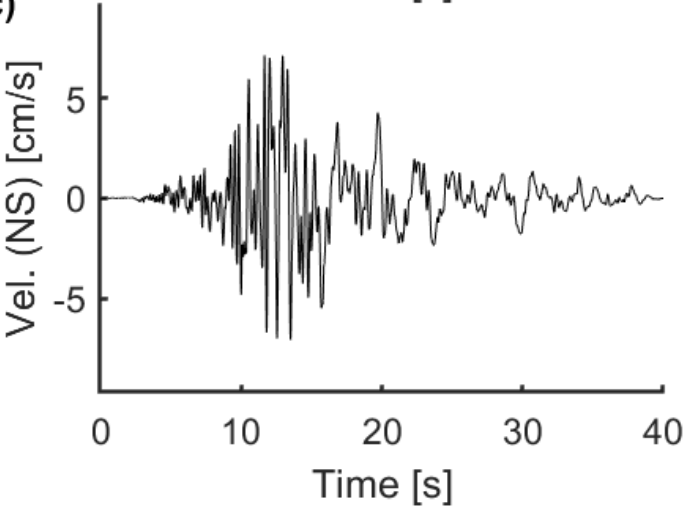

b)

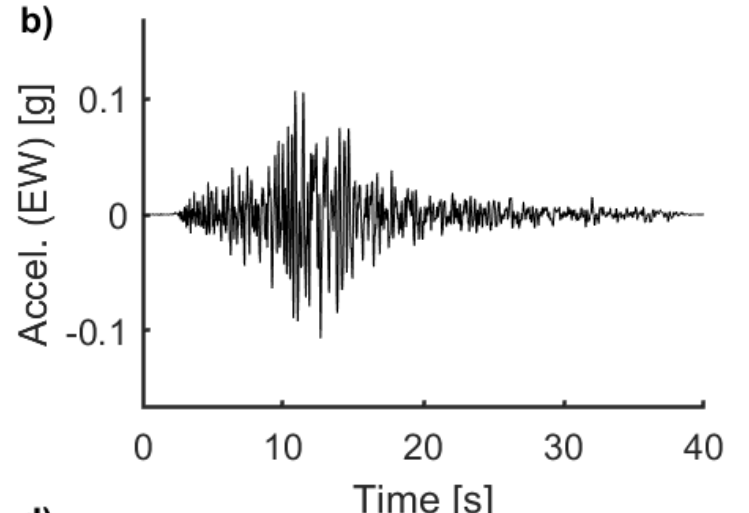

d)

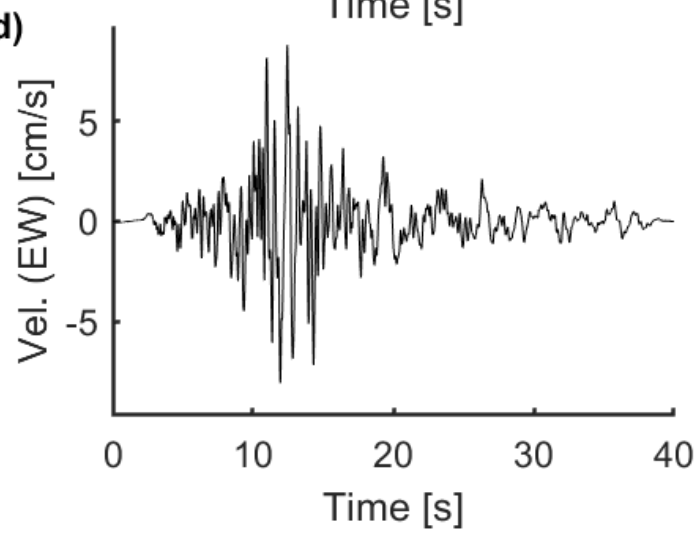

Figure A3. 25. Acceleration and velocity signals for Northr-971: a) Acceleration (NS), b) Acceleration (EW), c) Velocity (NS) and d) Velocity (EW)

a)

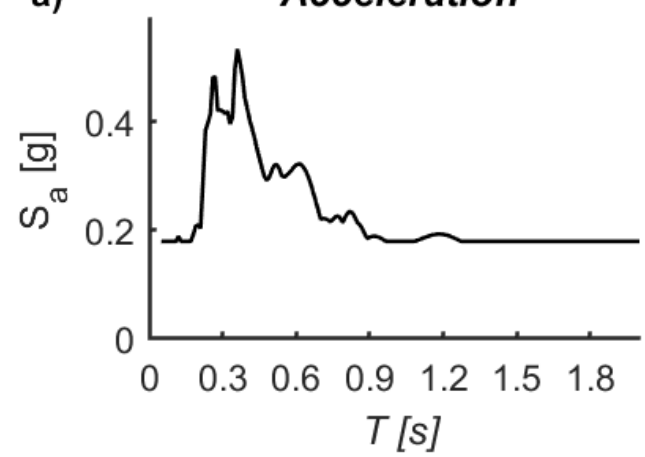

c)

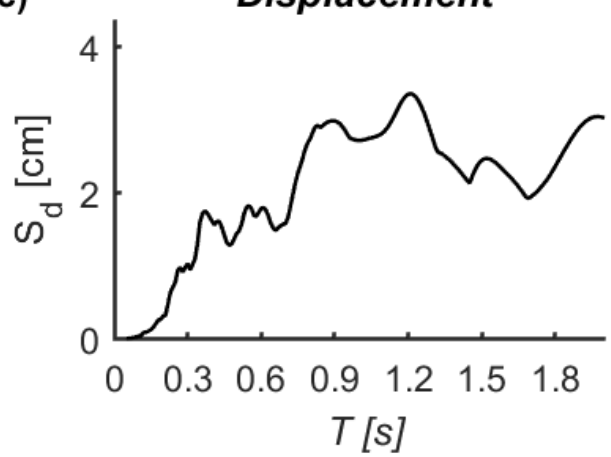

b)

Velocity

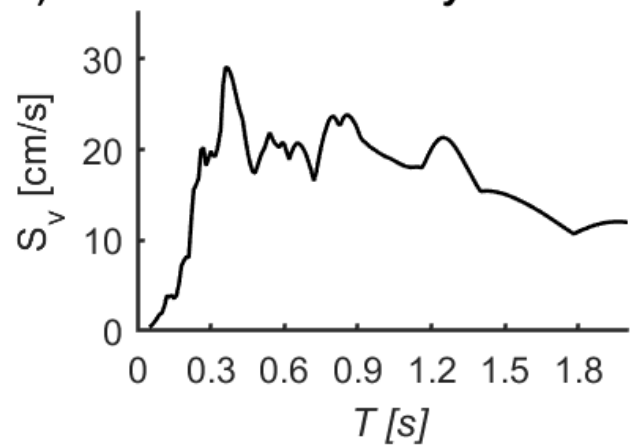

d)

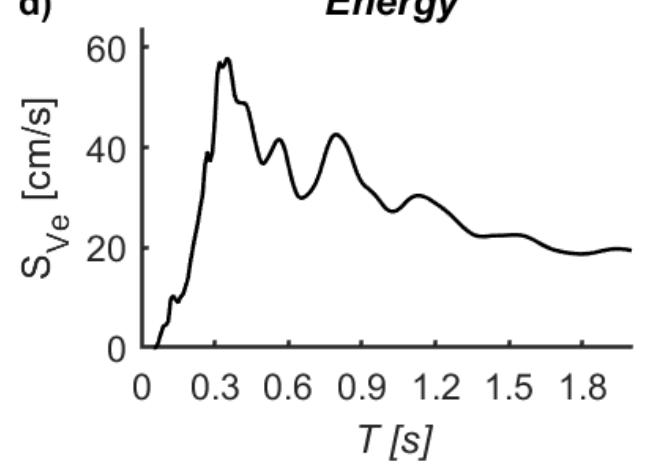

Figure A3. 26. Spectra of Northr-971 (NS): a) Acceleration, b) Velocity, c) Displacement and d) Input energy 

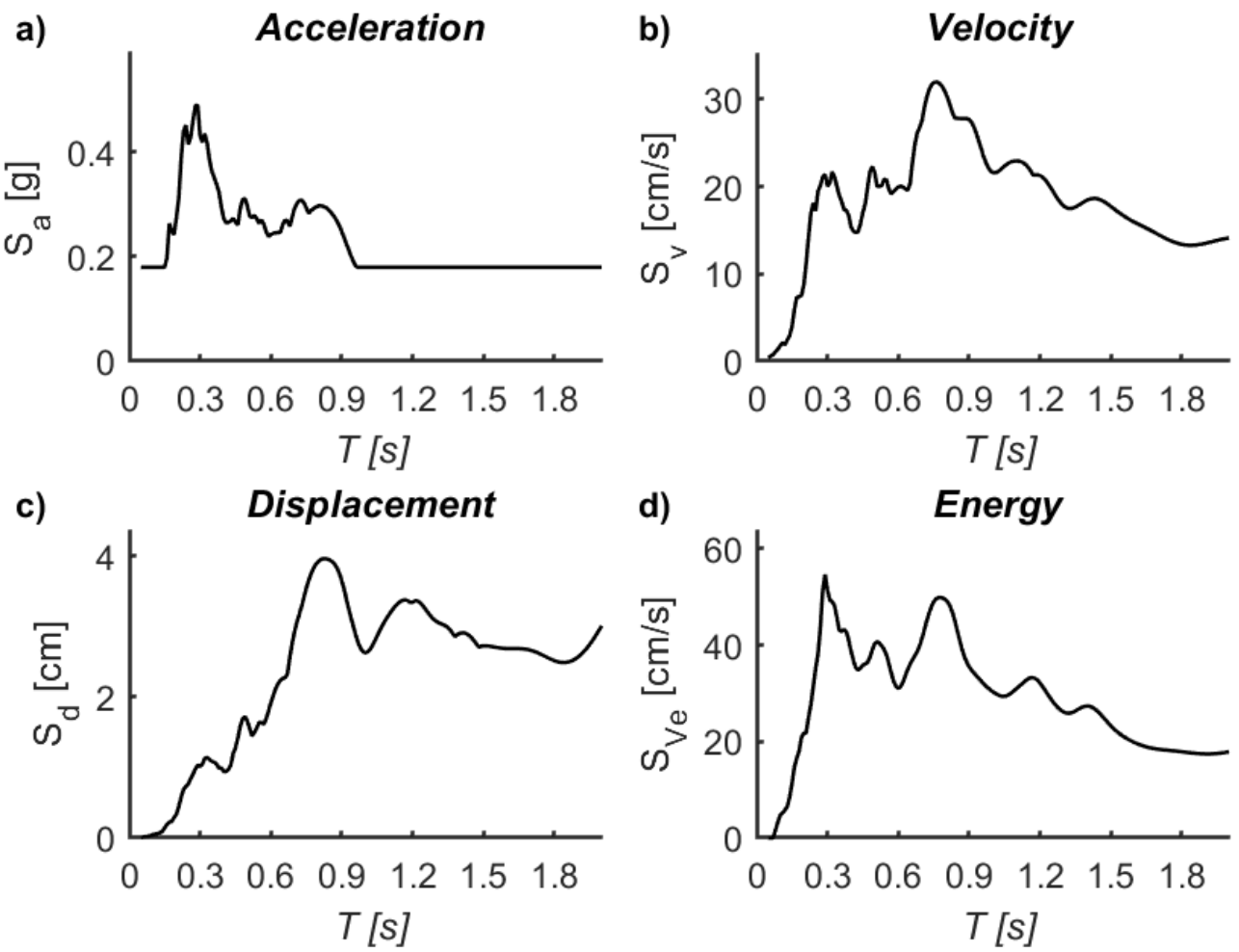

Figure A3. 27. Spectra of Northr-971 (EW): a) Acceleration, b) Velocity, c) Displacement and d) Input energy
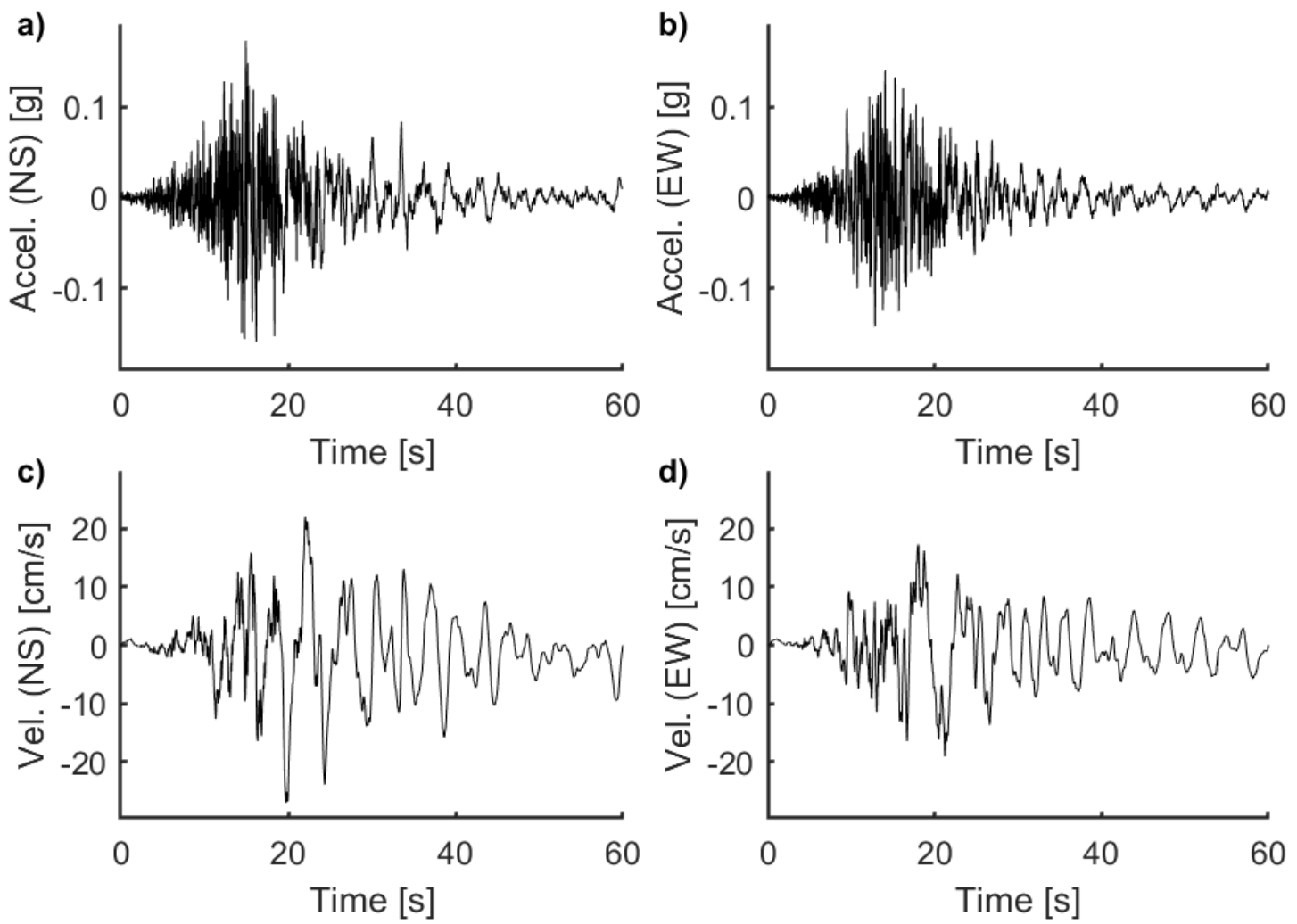

Figure A3. 28. Acceleration and velocity signals for Hector-1762: a) Acceleration (NS), b) Acceleration (EW), c) Velocity (NS) and d) Velocity (EW) 

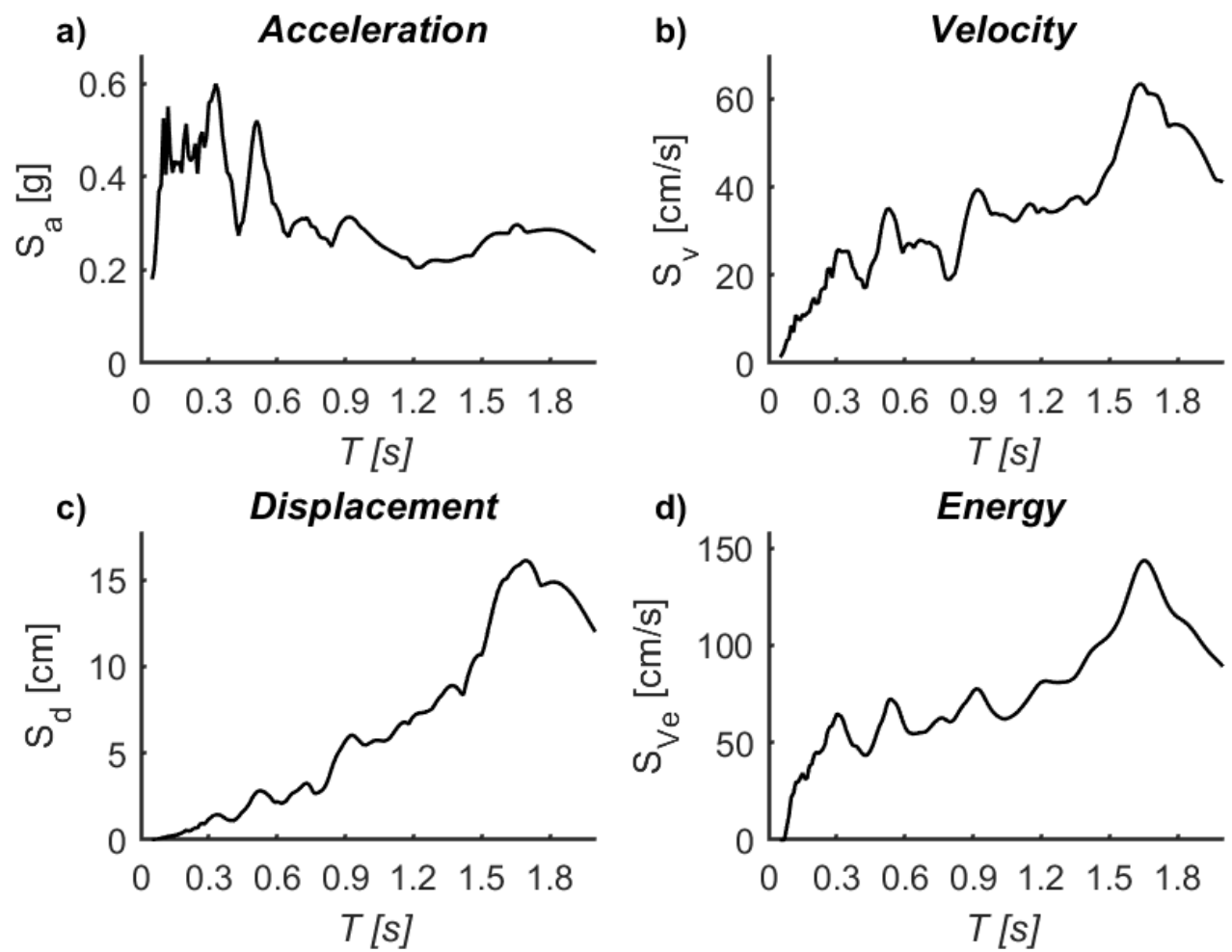

Figure A3. 29. Spectra of Hector-1762 (NS): a) Acceleration, b) Velocity, c) Displacement and d) Input energy
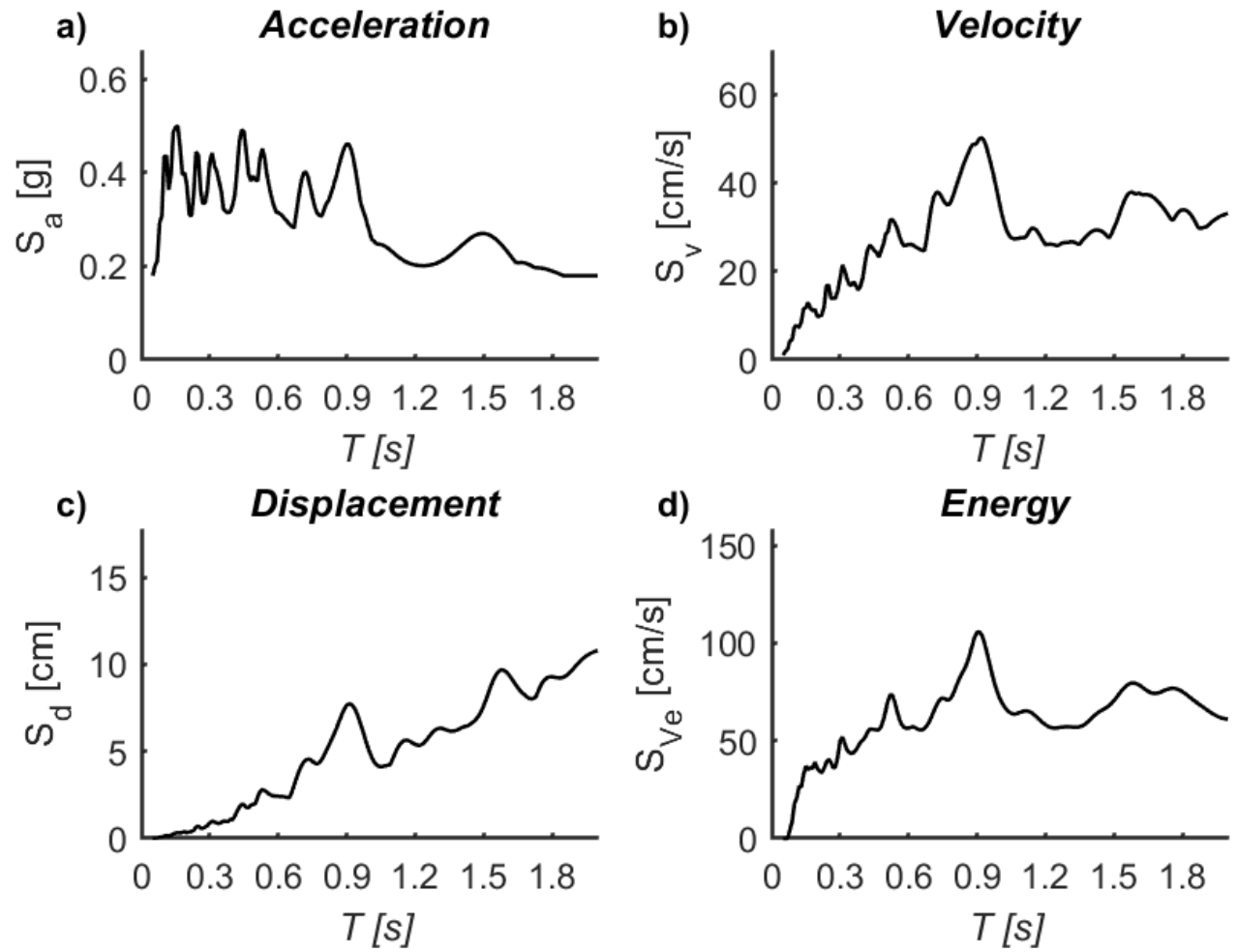

Figure A3. 30. Spectra of Hector-1762 (EW): a) Acceleration, b) Velocity, c) Displacement and d) Input energy 

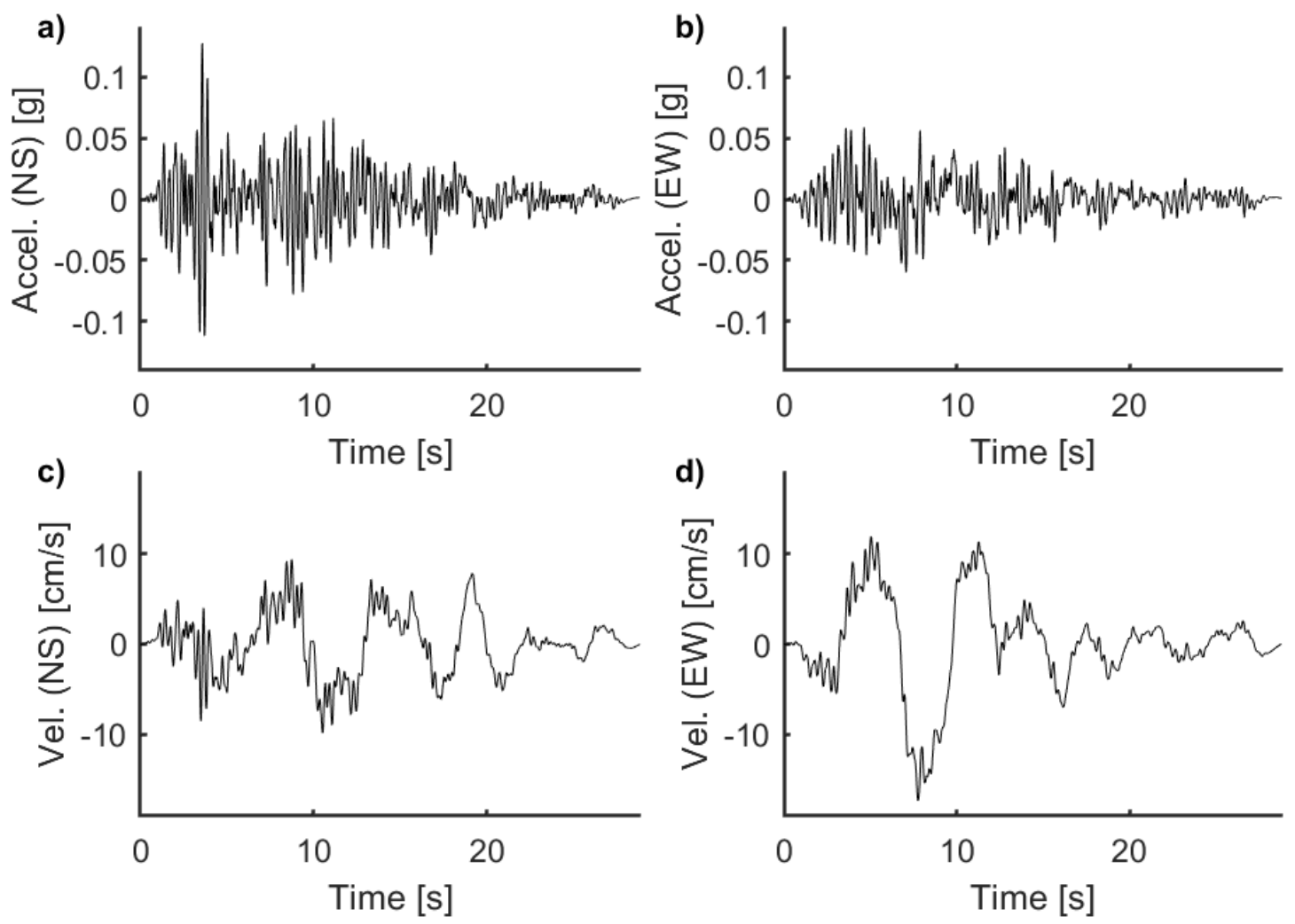

Figure A3. 31. Acceleration and velocity signals for Duzce-1619: a) Acceleration (NS), b) Acceleration (EW), c) Velocity (NS) and d) Velocity (EW)
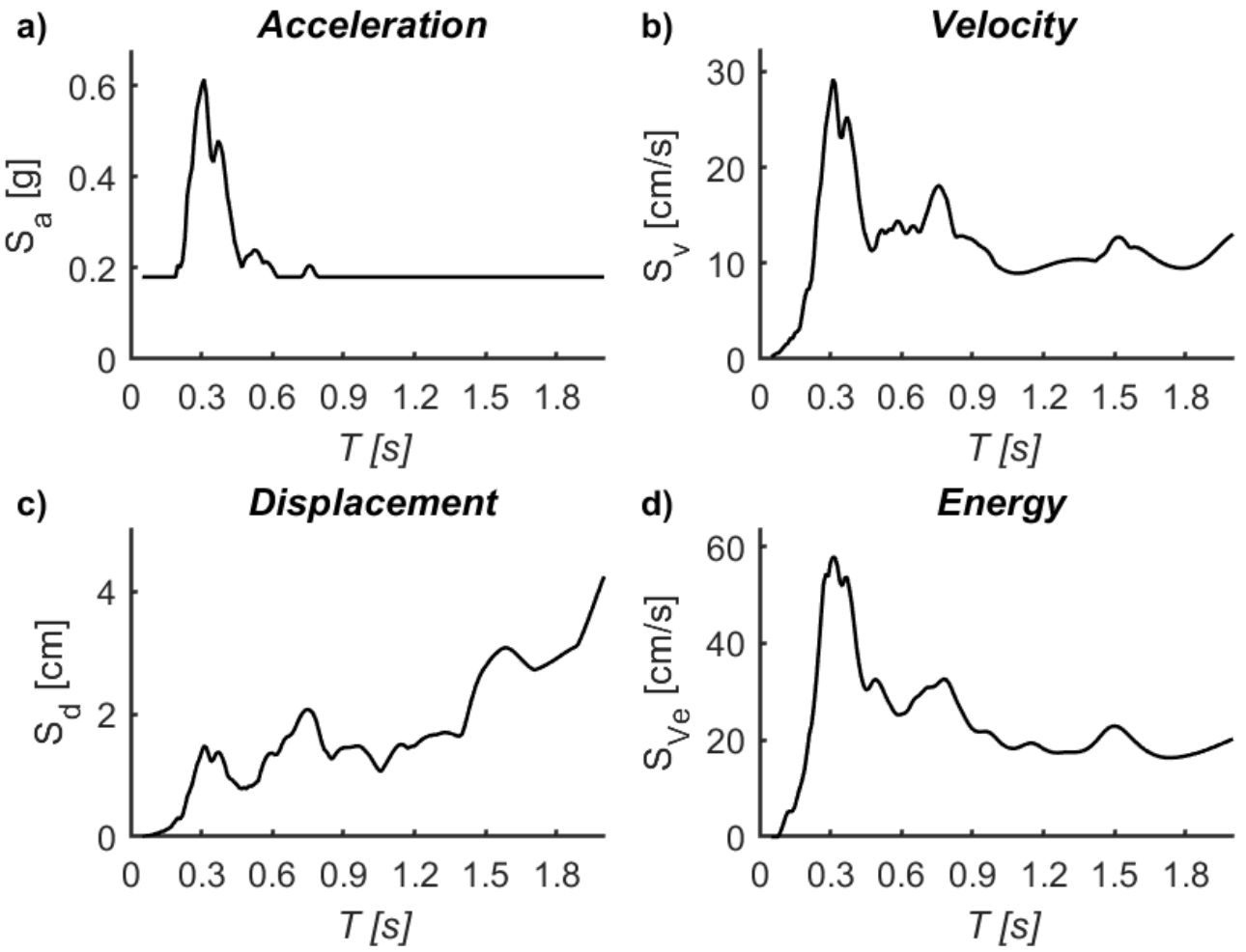

Figure A3. 32. Spectra of Duzce-1619 (NS): a) Acceleration, b) Velocity, c) Displacement and d) Input energy 

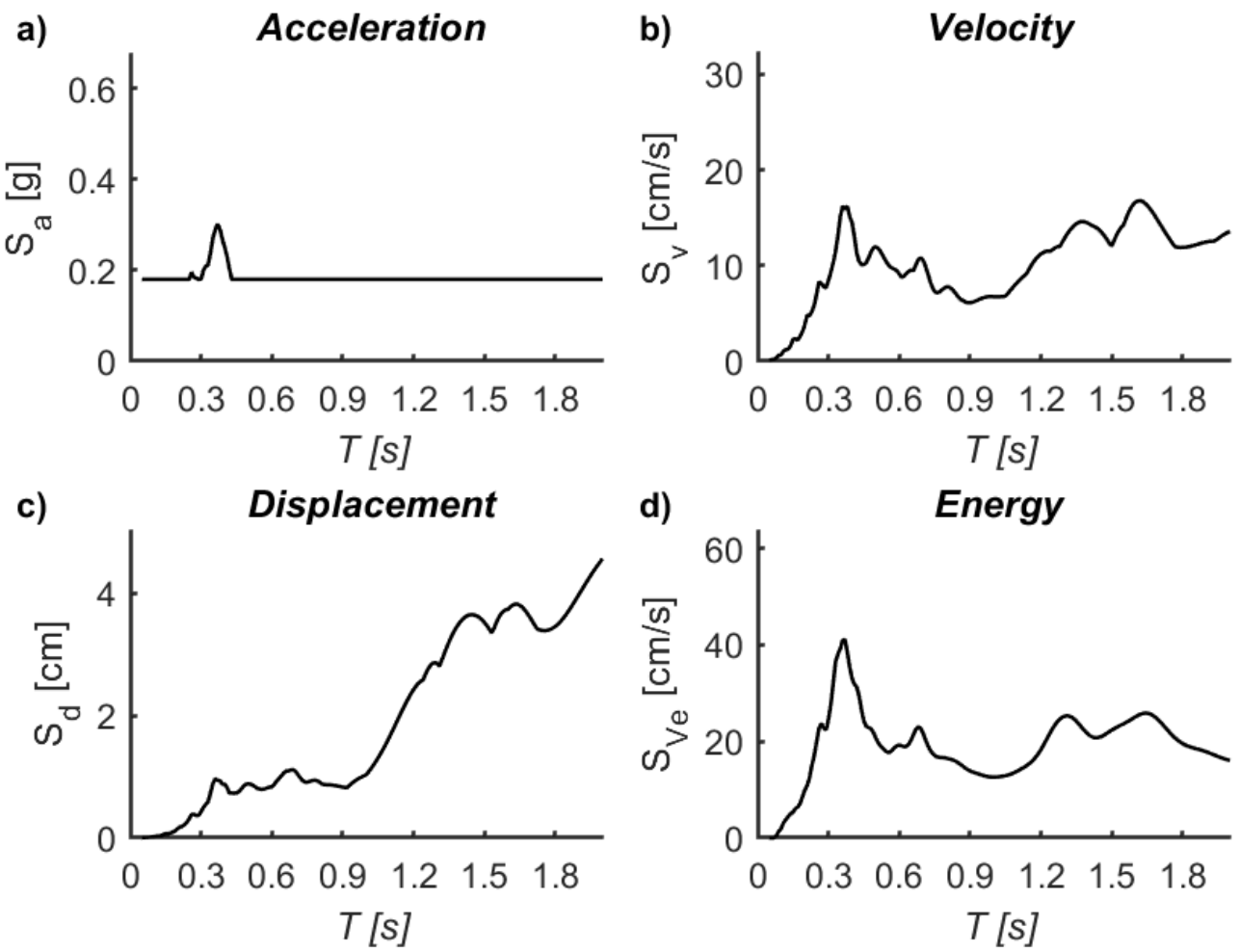

Figure A3. 33. Spectra of Duzce-1619 (EW): a) Acceleration, b) Velocity, c) Displacement and d) Input energy

a)

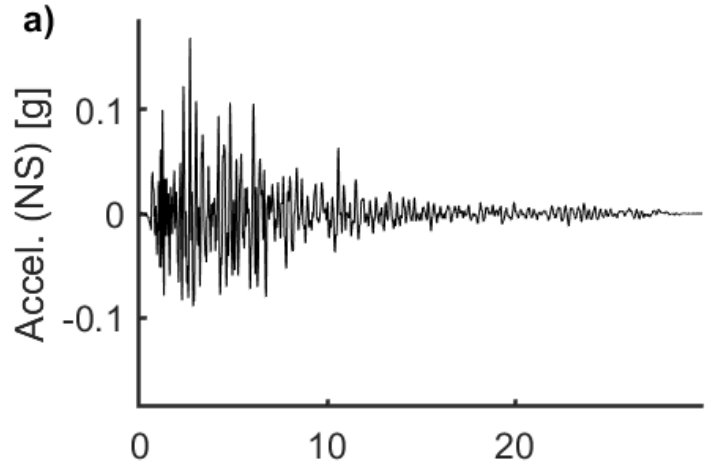

c)

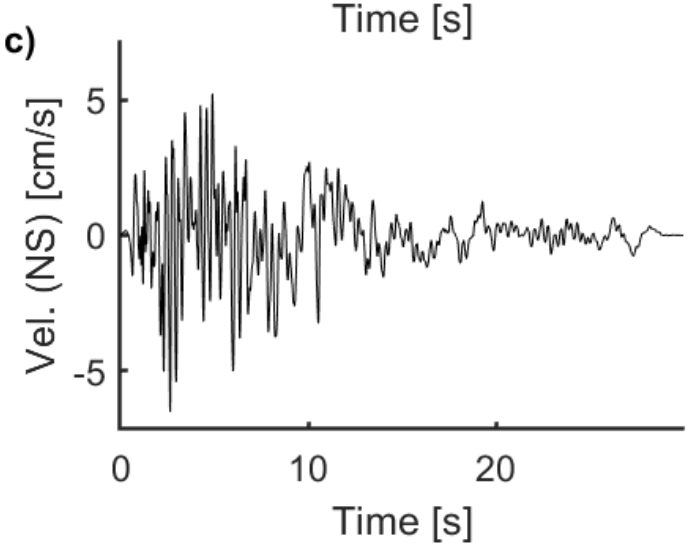

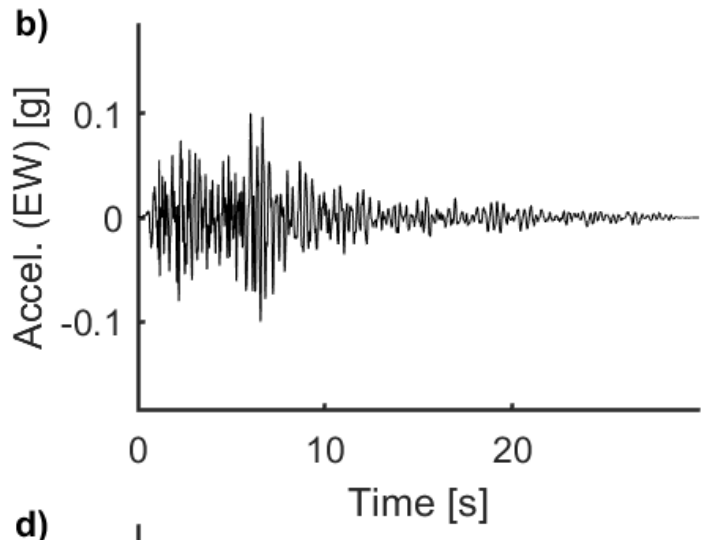

d)

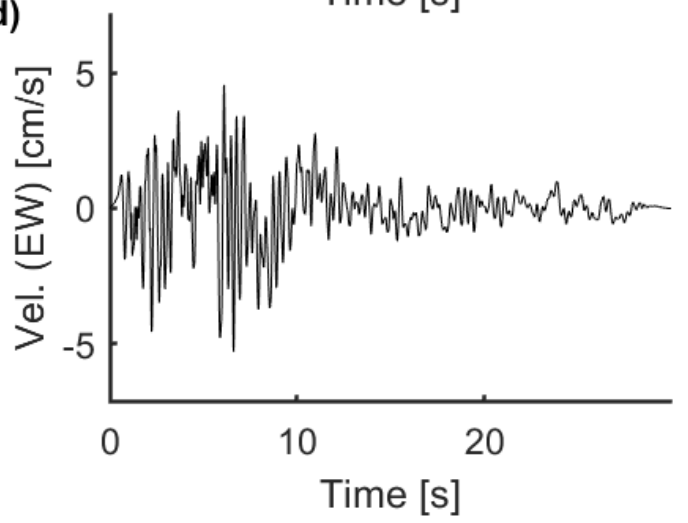

Figure A3. 34. Acceleration and velocity signals for Morgan-460: a) Acceleration (NS), b) Acceleration (EW), c) Velocity (NS) and d) Velocity (EW) 

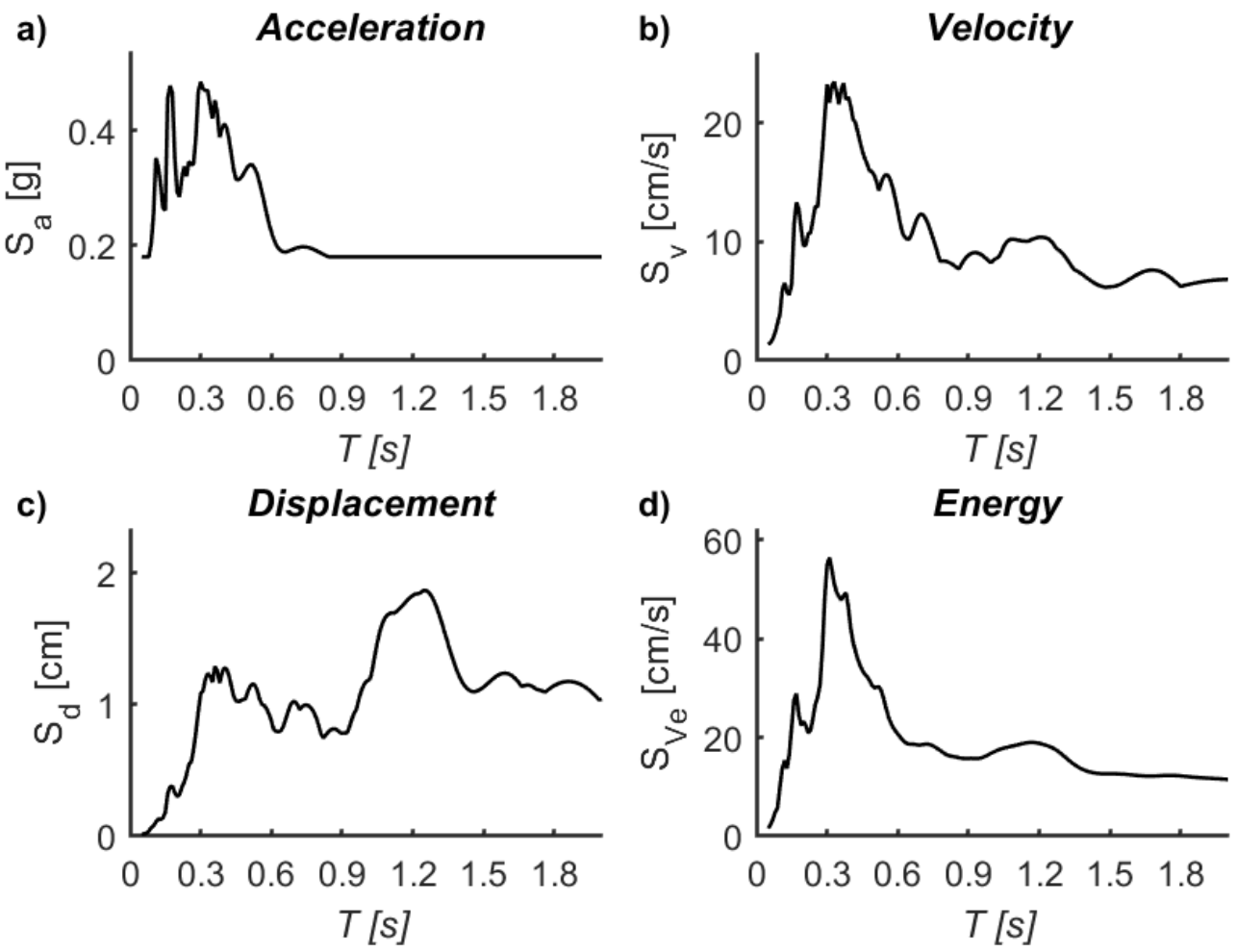

Figure A3. 35. Spectra of Morgan-460 (NS): a) Acceleration, b) Velocity, c) Displacement and d) Input energy
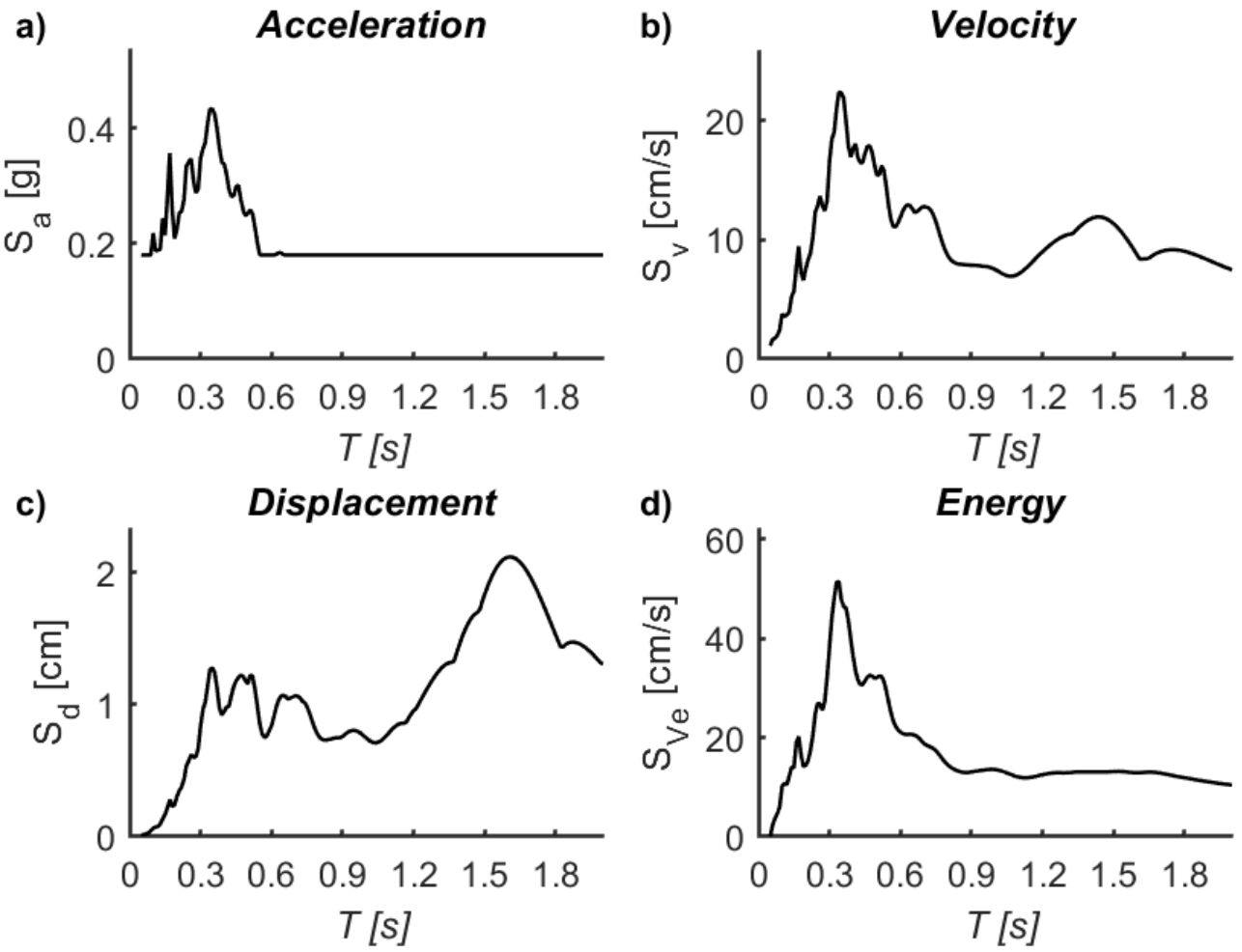

Figure A3. 36. Spectra of Morgan-460 (EW): a) Acceleration, b) Velocity, c) Displacement and d) Input energy 
a)
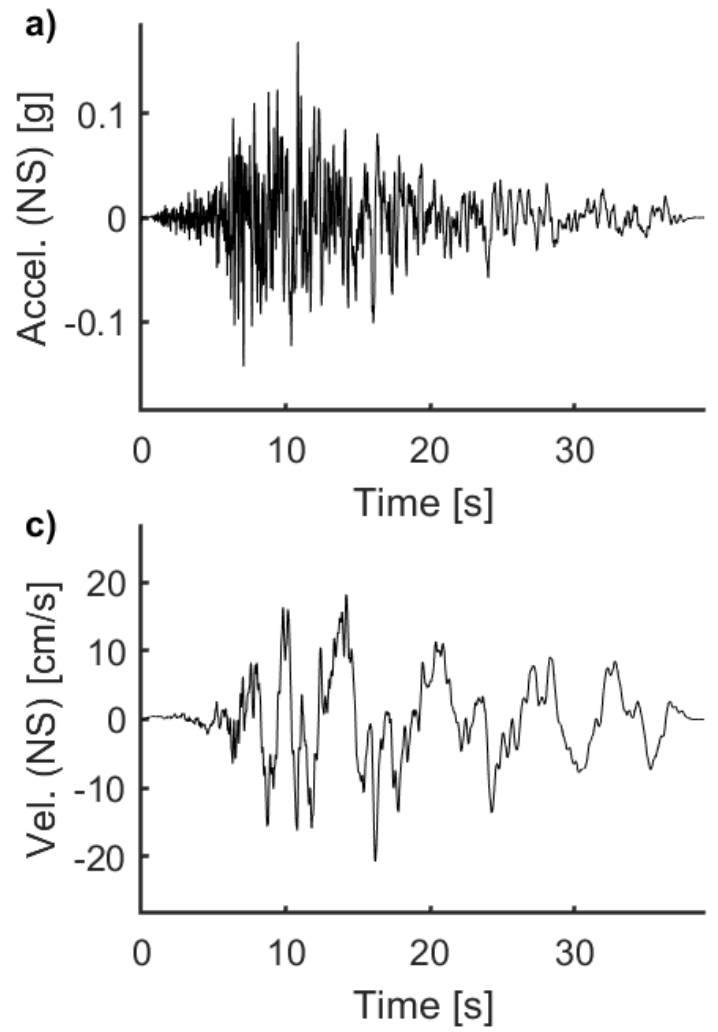

b)
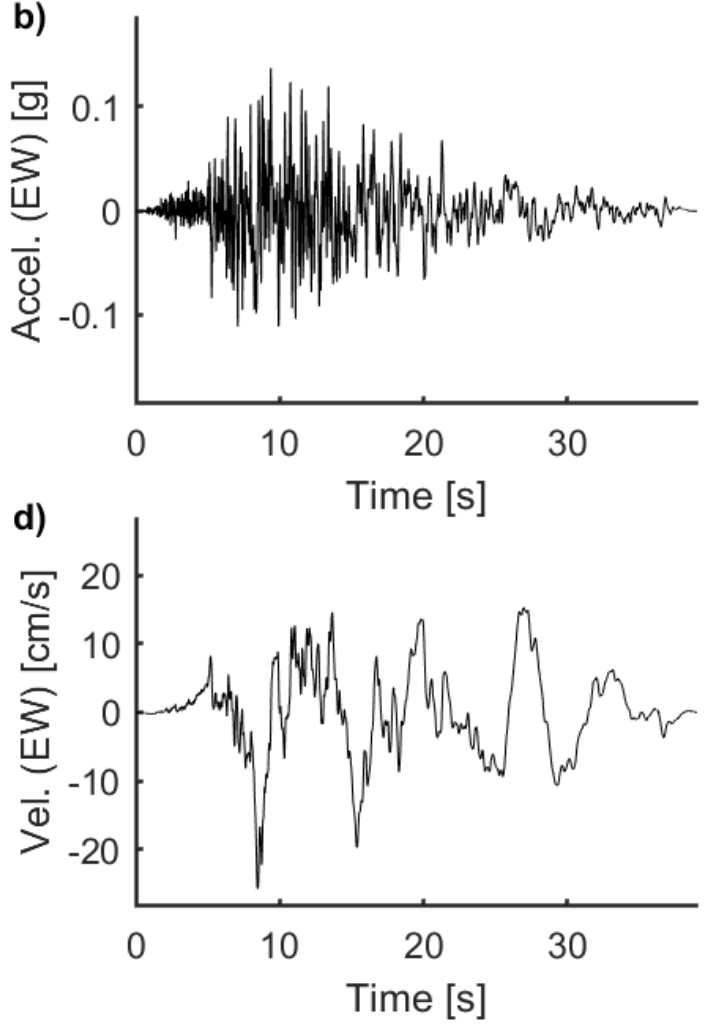

Figure A3. 37. Acceleration and velocity signals for Impvall-175: a) Acceleration (NS), b) Acceleration (EW), c) Velocity (NS) and d) Velocity (EW)

a)

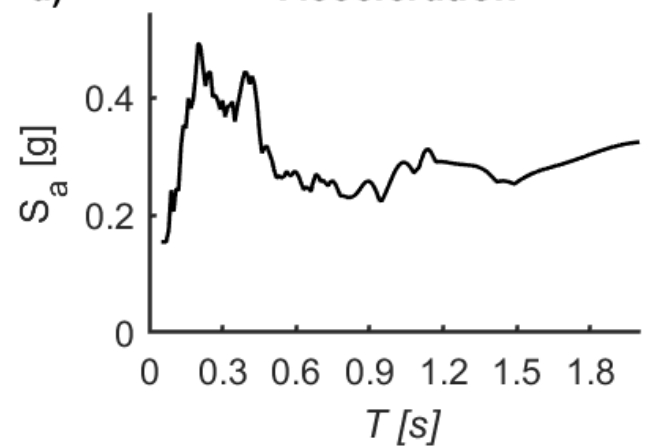

c)

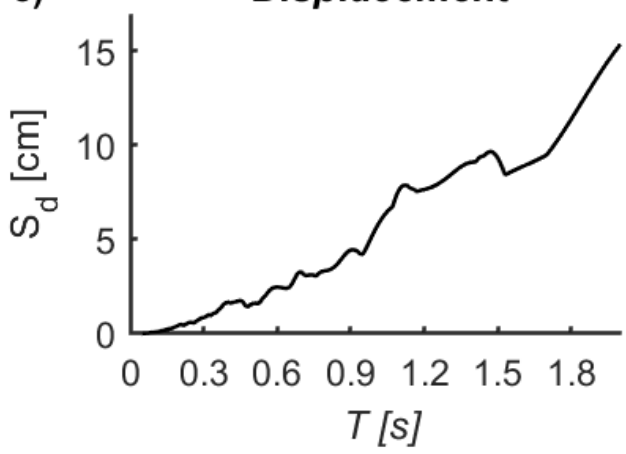

b) Velocity

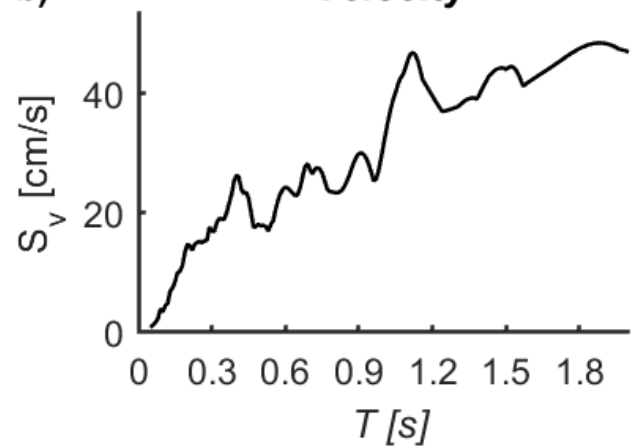

d)

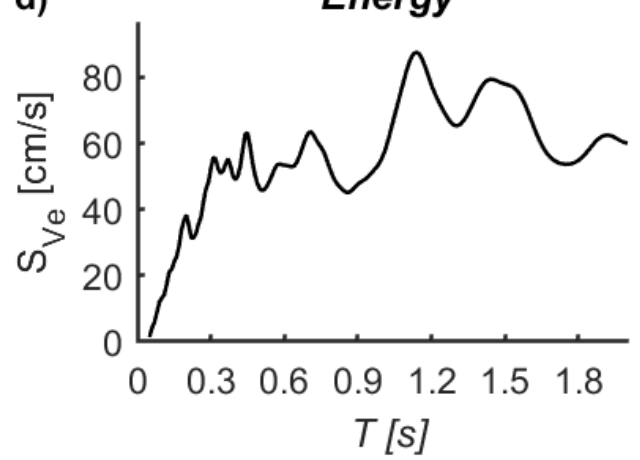

Figure A3. 38. Spectra of Impvall-175 (NS): a) Acceleration, b) Velocity, c) Displacement and d) Input energy 

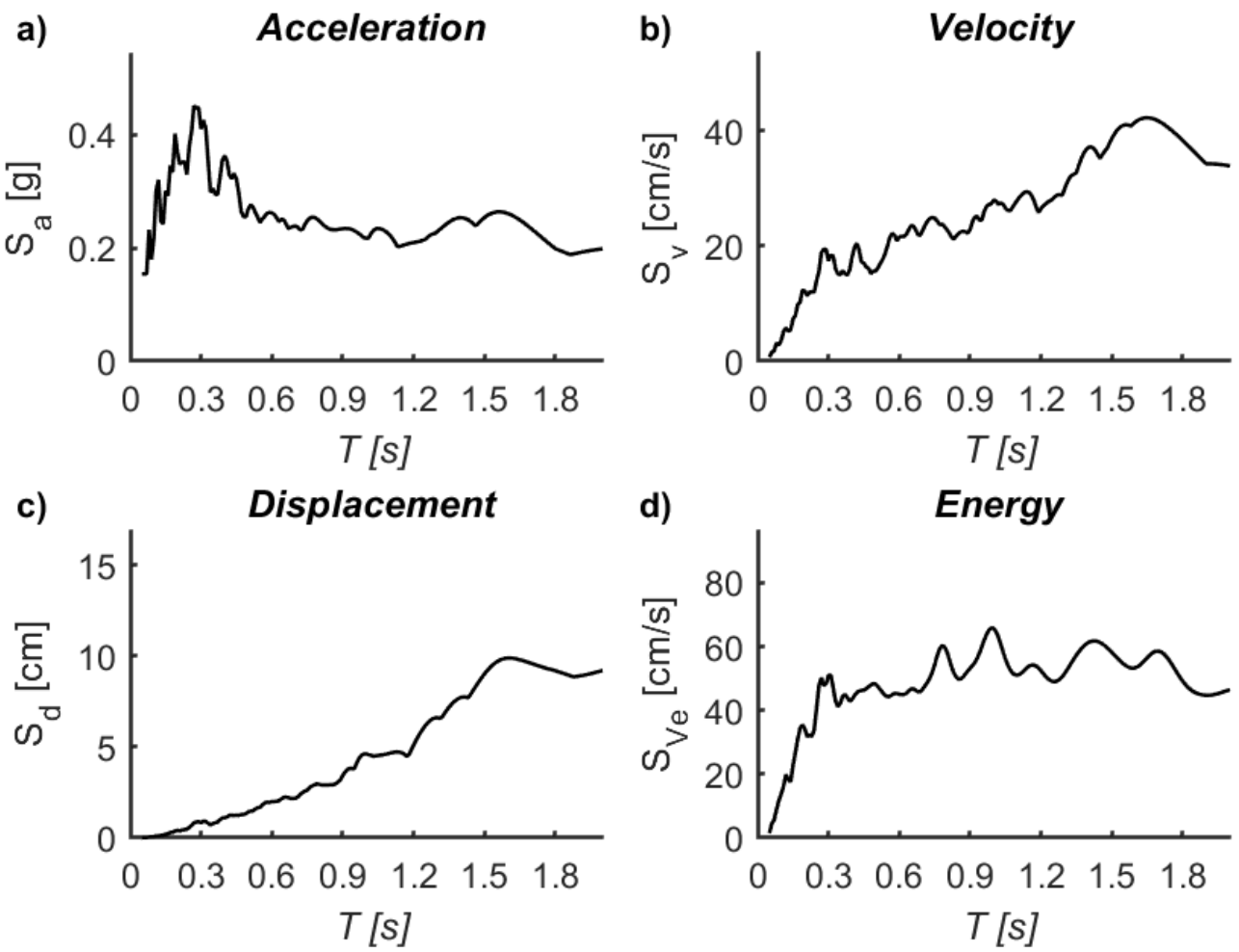

Figure A3. 39. Spectra of Impvall-175 (EW): a) Acceleration, b) Velocity, c) Displacement and d) Input energy
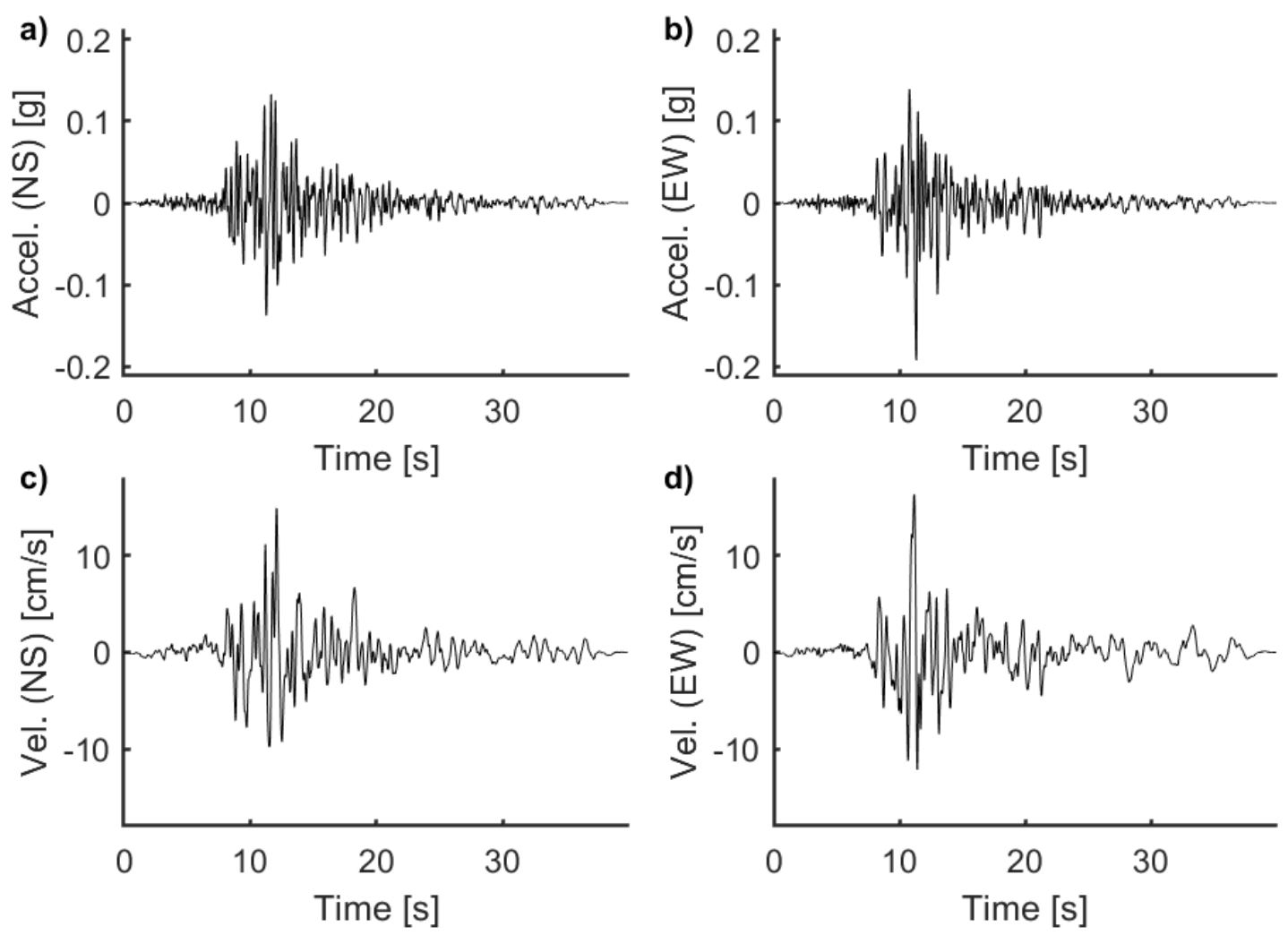

Figure A3. 40. Acceleration and velocity signals for Lomap-799: a) Acceleration (NS), b) Acceleration (EW), c) Velocity (NS) and d) Velocity (EW) 

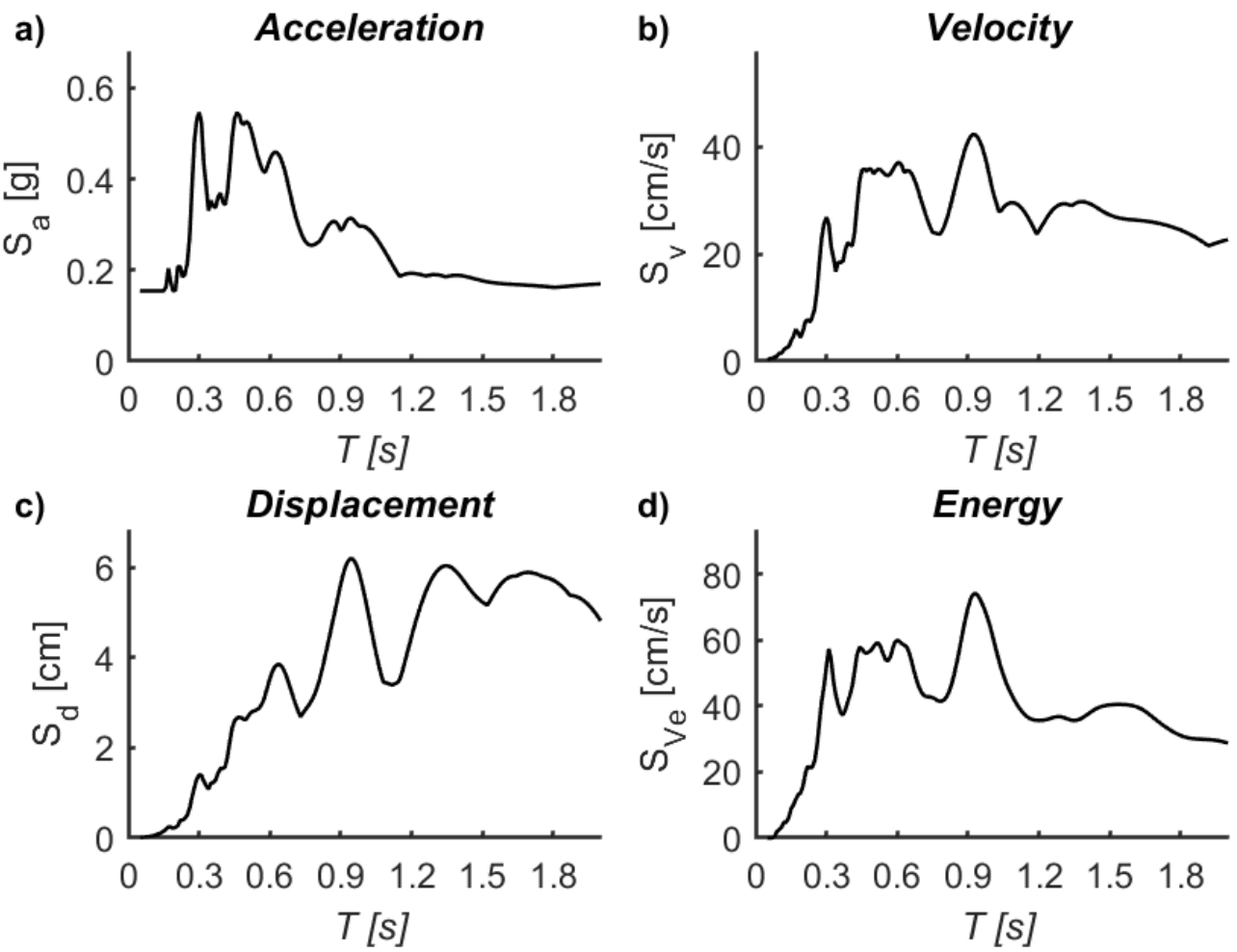

Figure A3. 41. Spectra of Lomap-799 (NS): a) Acceleration, b) Velocity, c) Displacement and d) Input energy
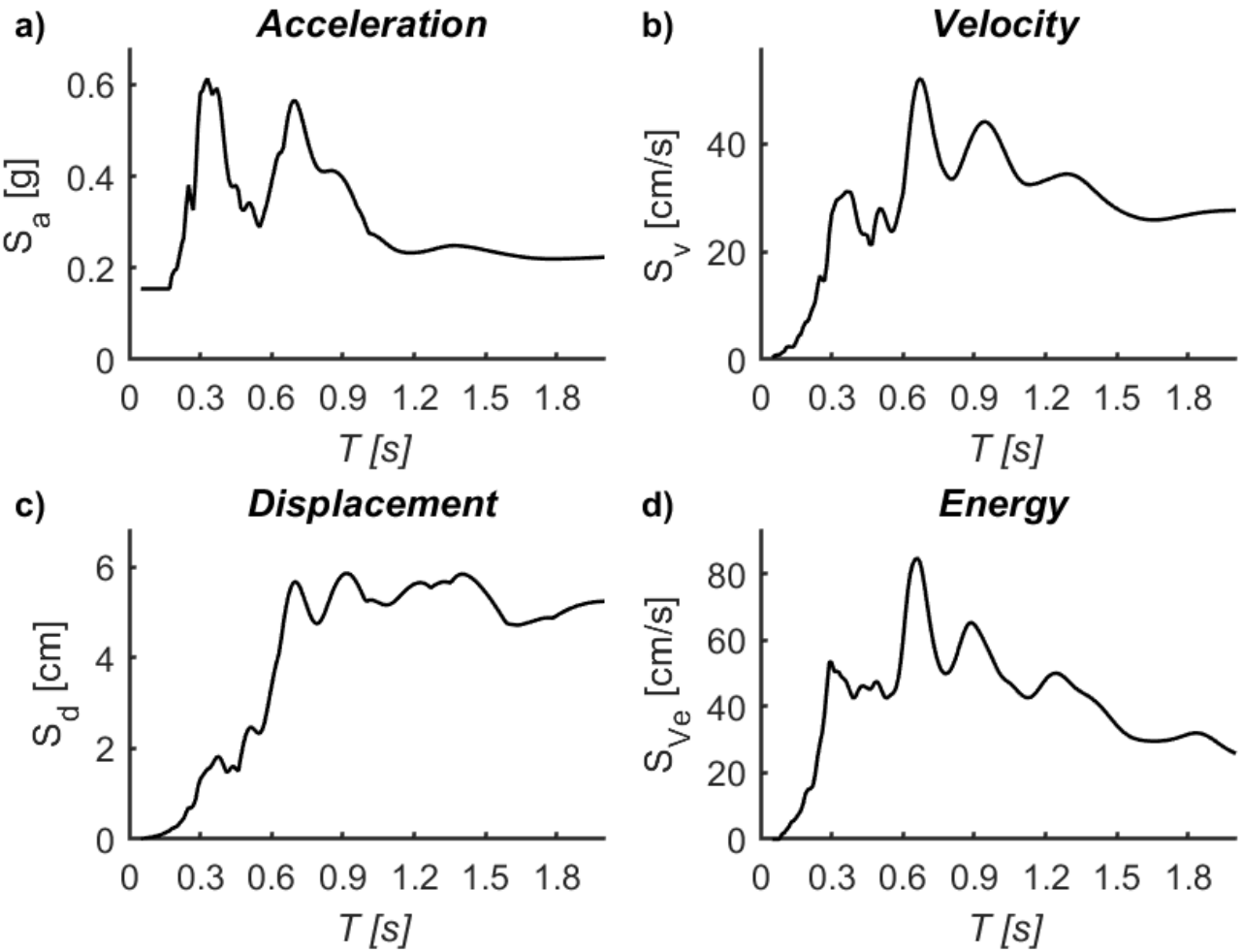

Figure A3. 42. Spectra of Lomap-799 (EW): a) Acceleration, b) Velocity, c) Displacement and d) Input energy 
a)
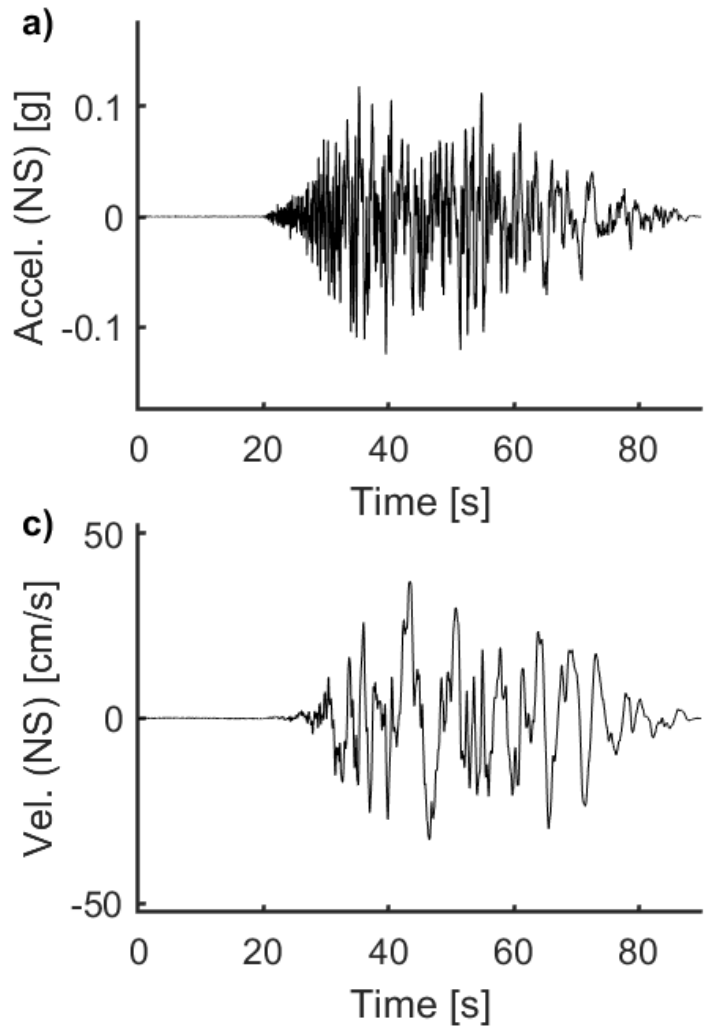

b)
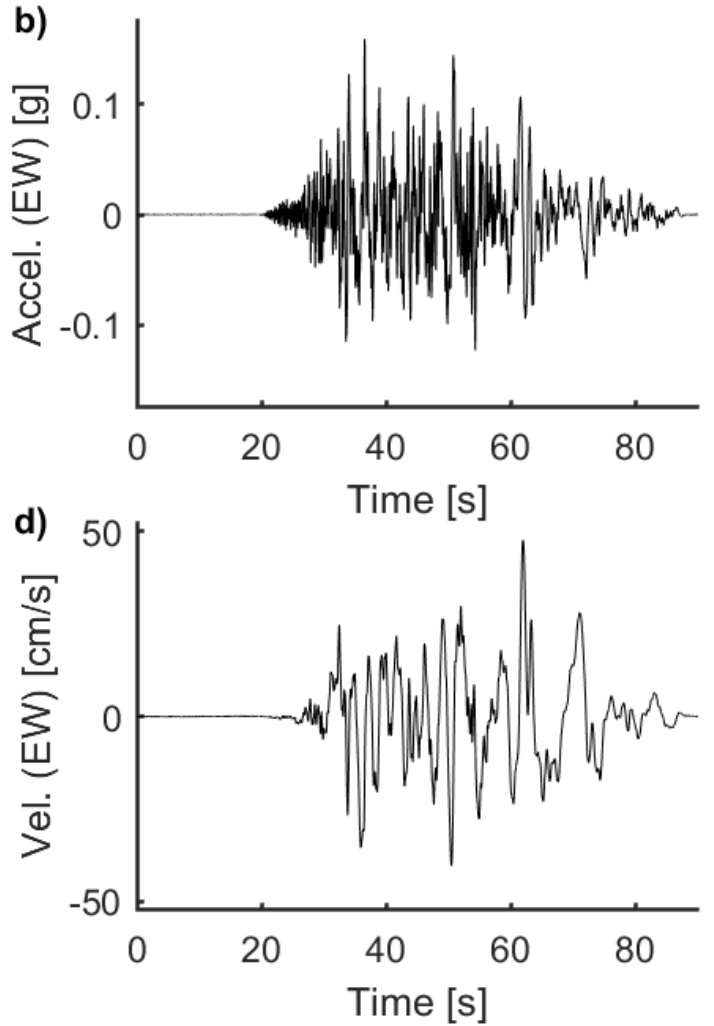

Figure A3. 43. Acceleration and velocity signals for Chichi-1534: a) Acceleration (NS), b) Acceleration (EW), c) Velocity (NS) and d) Velocity (EW)
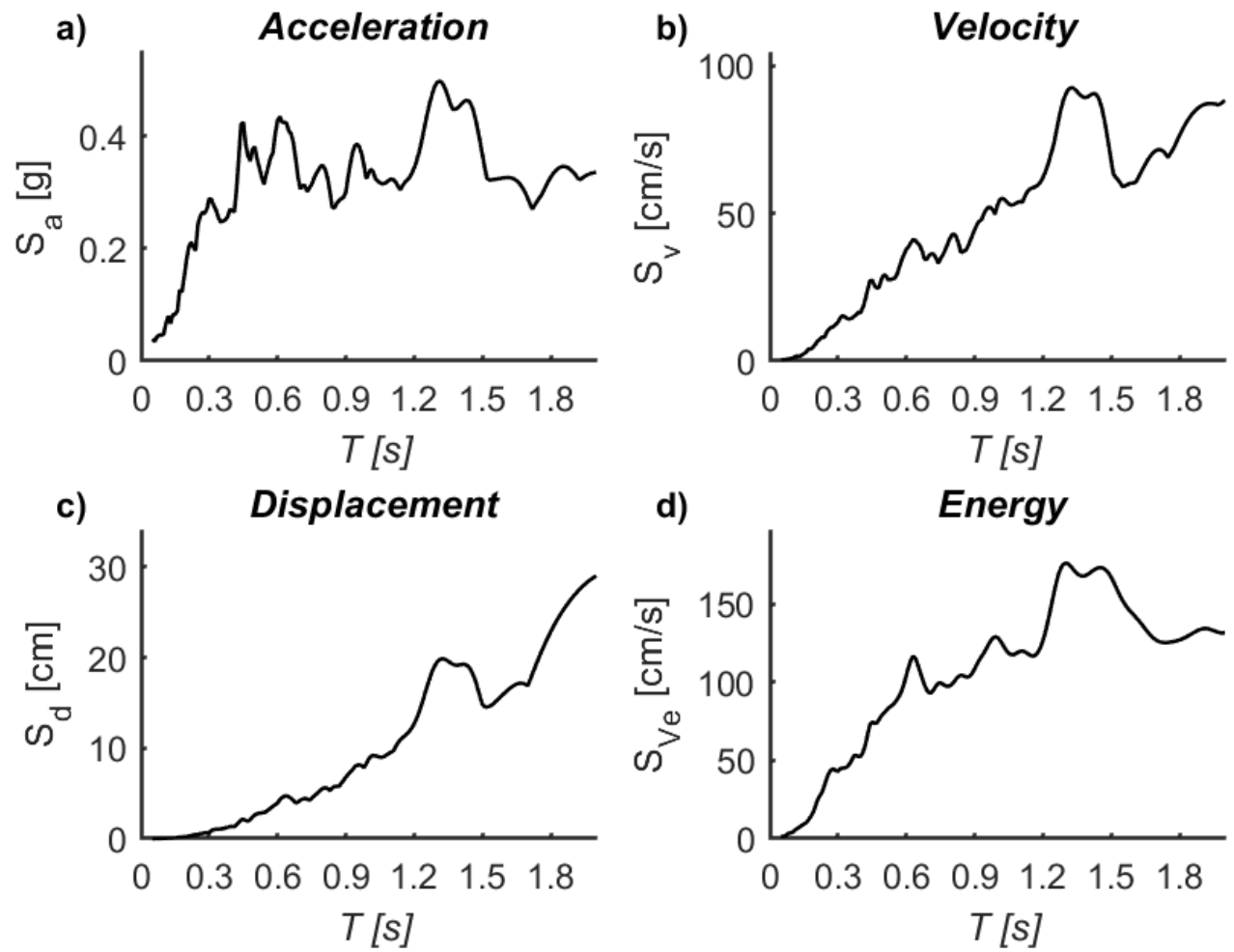

Figure A3. 44. Spectra of Chichi-1534 (NS): a) Acceleration, b) Velocity, c) Displacement and d) Input energy 

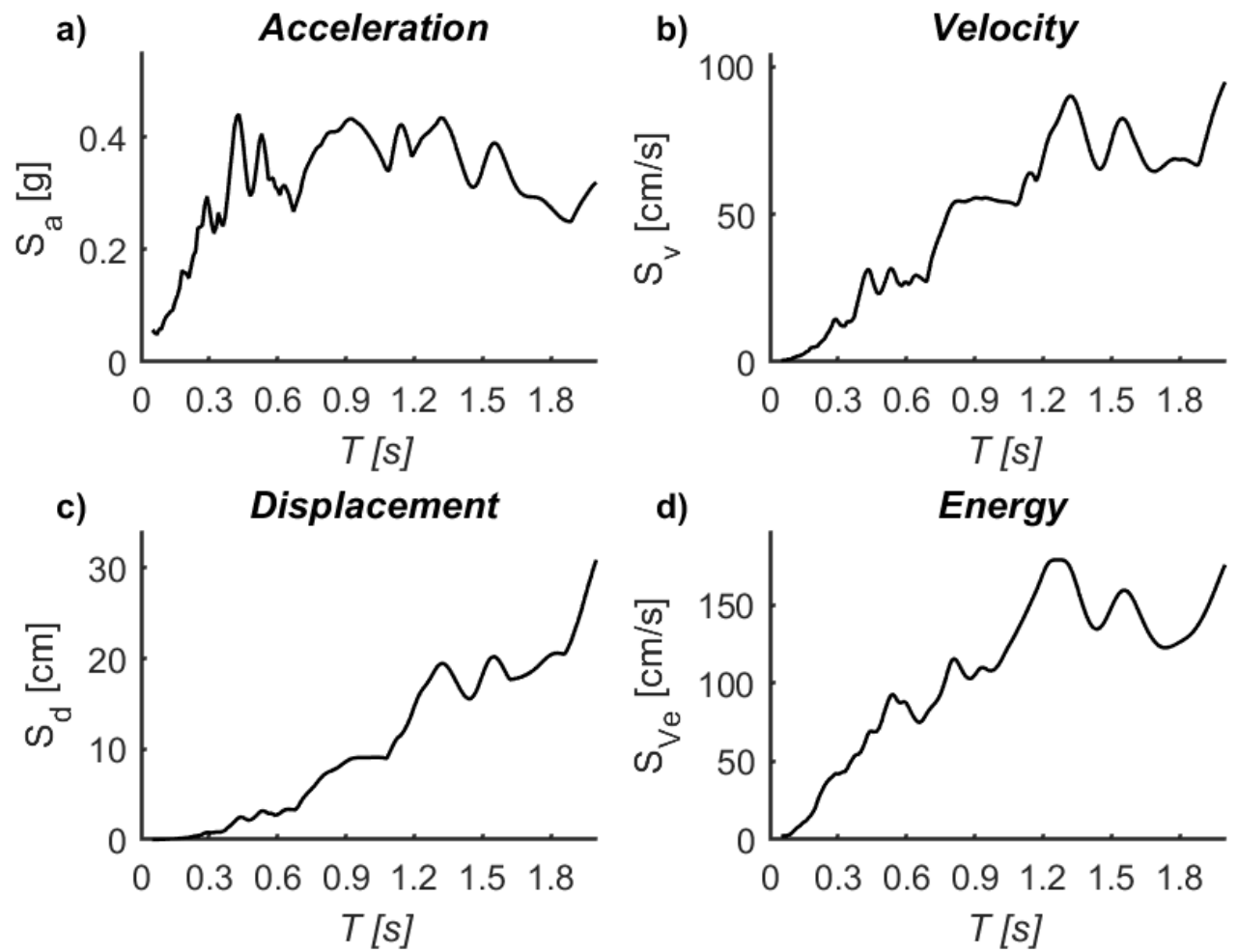

Figure A3. 45. Spectra of Chichi-1534 (EW): a) Acceleration, b) Velocity, c) Displacement and d) Input energy

a)
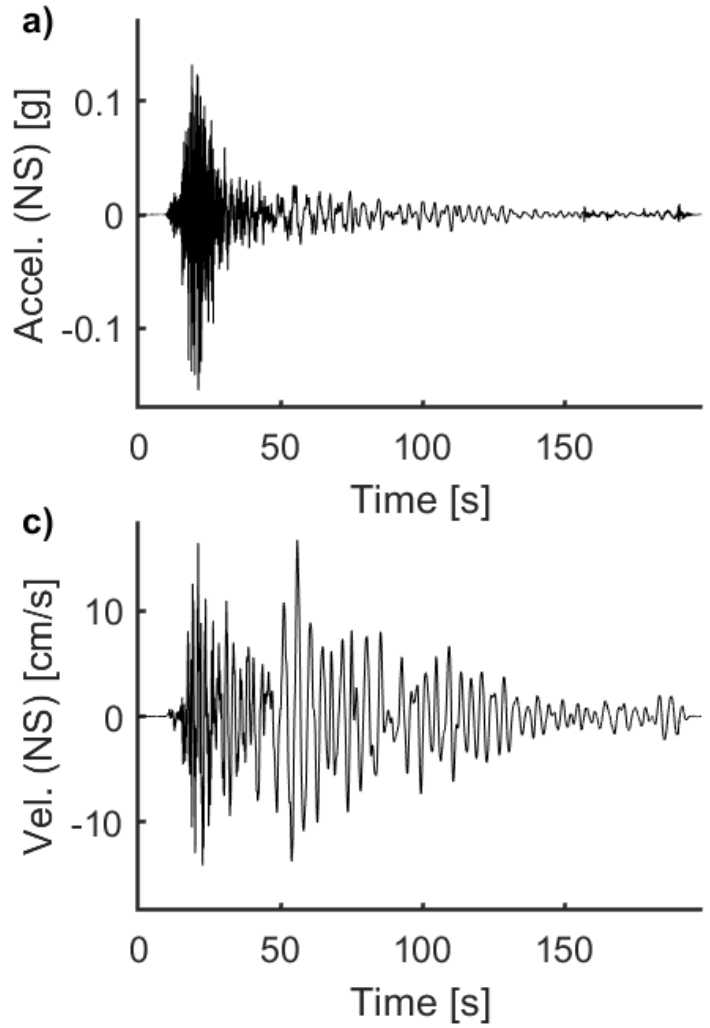

b)

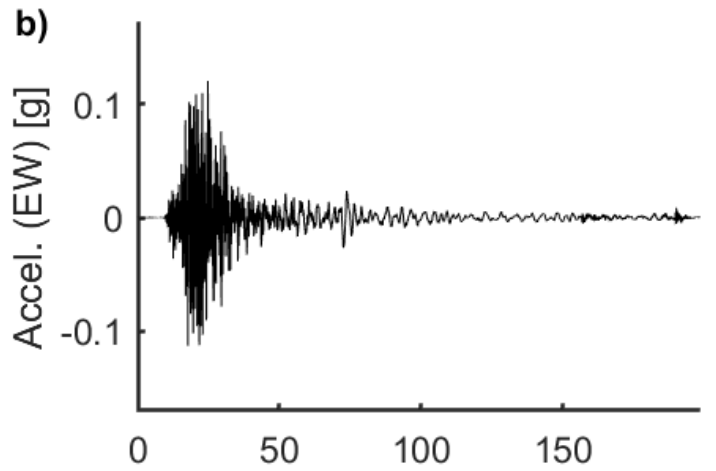

d)

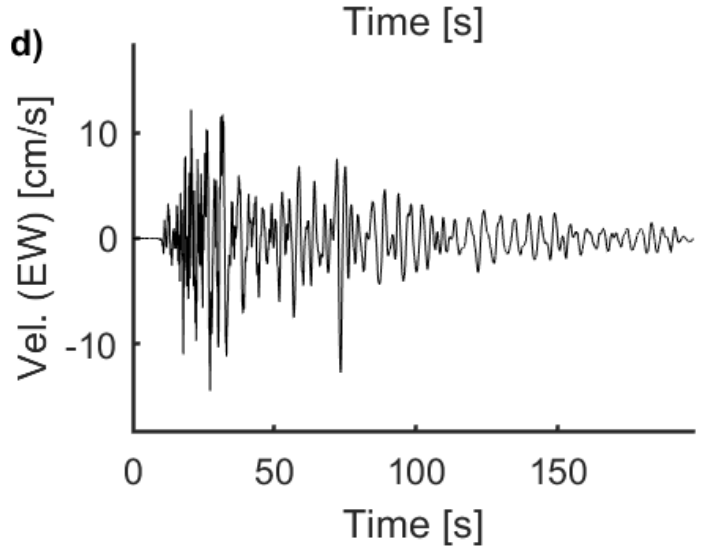

Figure A3. 46. Acceleration and velocity signals for Kobe-1115: a) Acceleration (NS), b) Acceleration (EW), c) Velocity (NS) and d) Velocity (EW) 

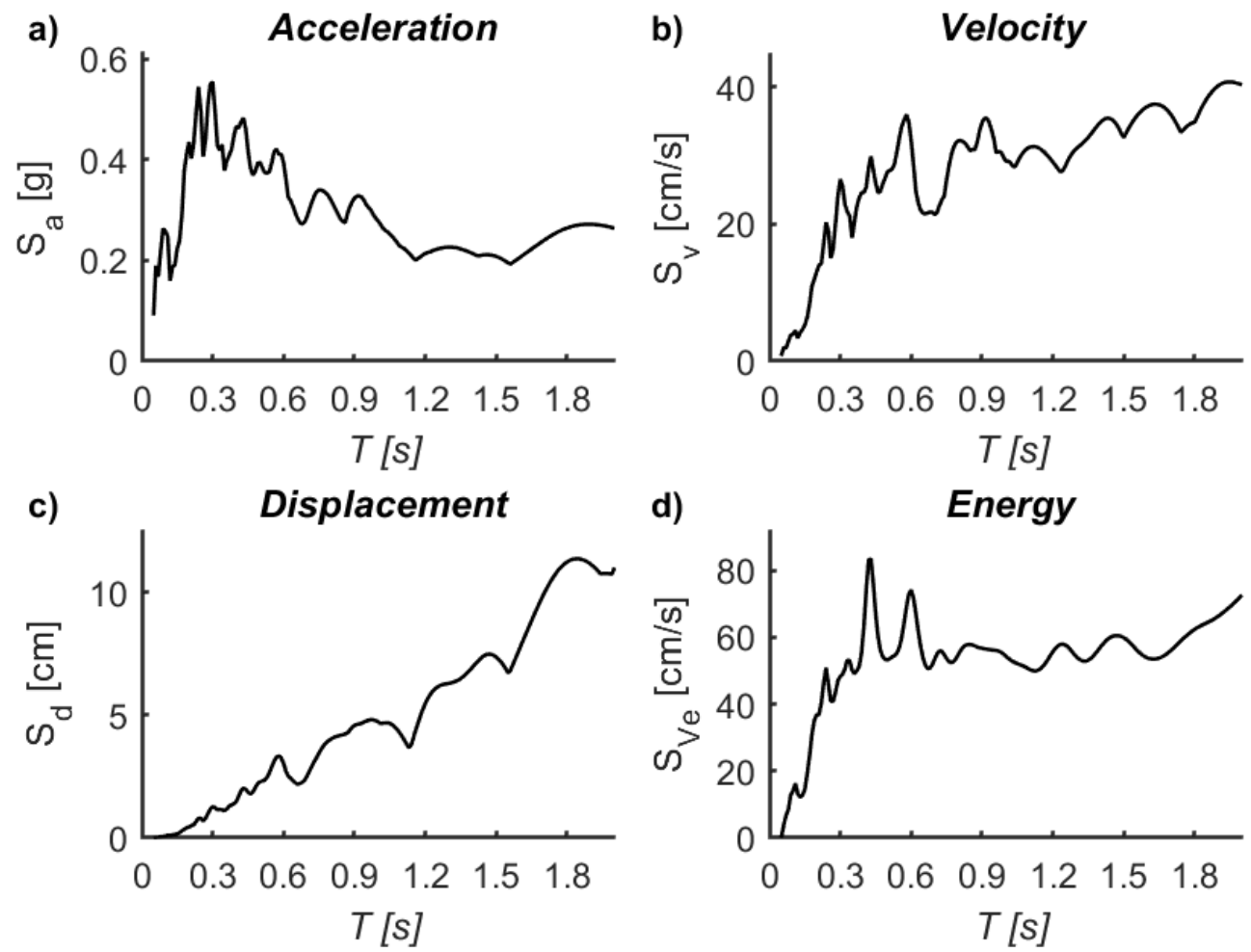

Figure A3. 47. Spectra of Kobe-1115 (NS): a) Acceleration, b) Velocity, c) Displacement and d) Input energy
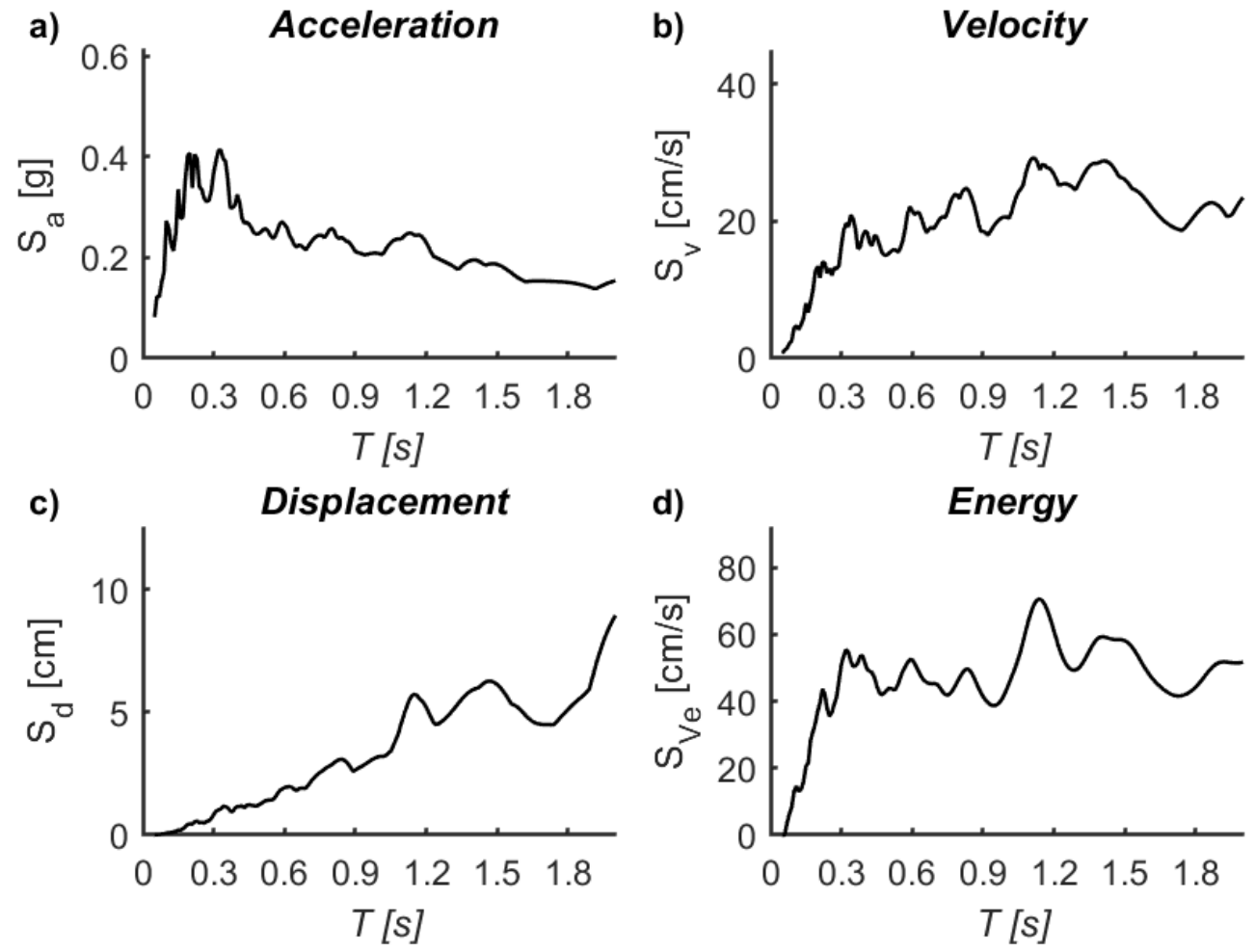

Figure A3. 48. Spectra of Kobe-1115 (EW): a) Acceleration, b) Velocity, c) Displacement and d) Input energy 

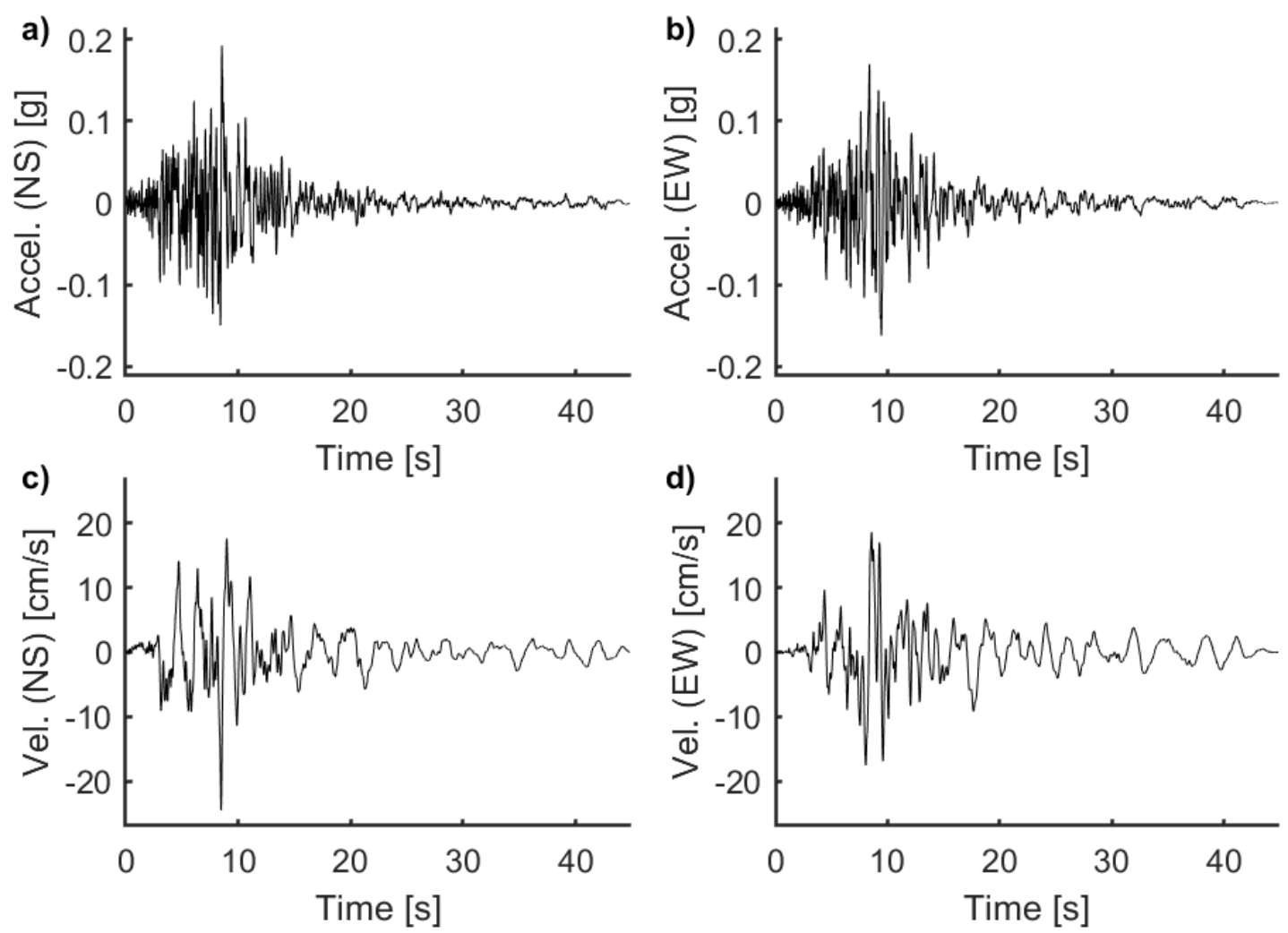

Figure A3. 49. Acceleration and velocity signals for Northr-986: a) Acceleration (NS), b) Acceleration (EW), c) Velocity (NS) and d) Velocity (EW)

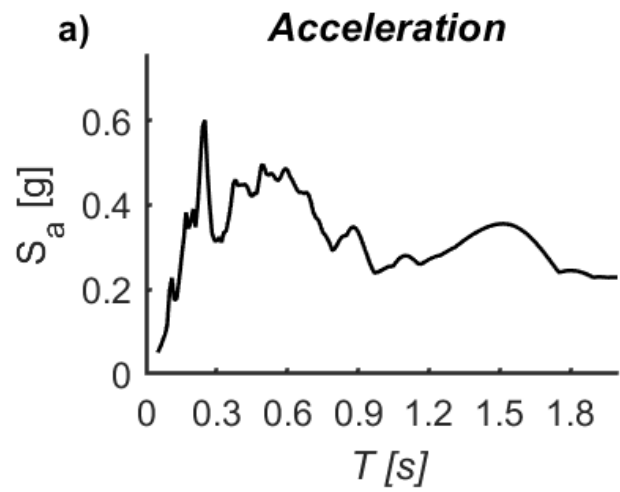

b) Velocity
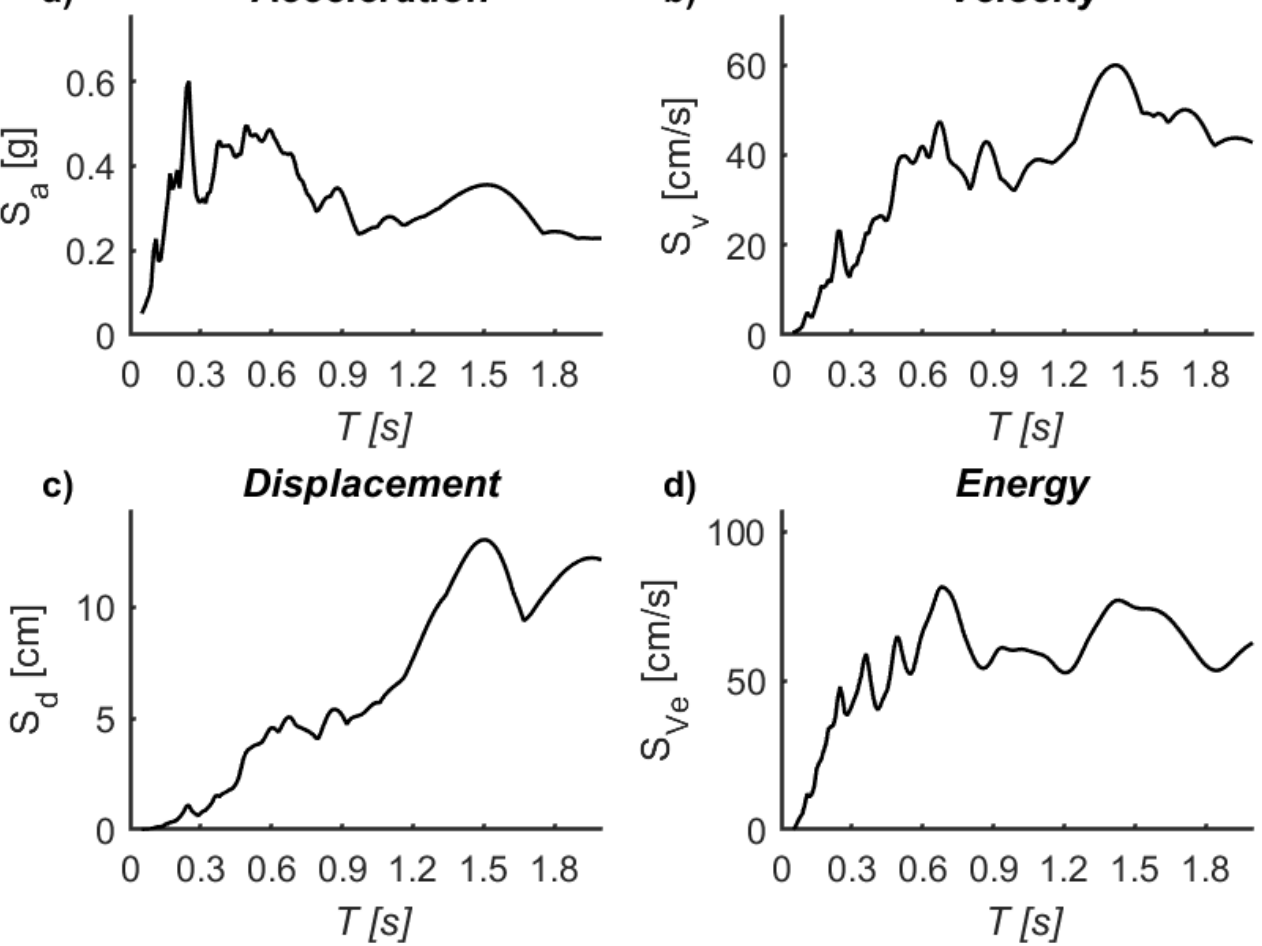

Figure A3. 50. Spectra of Northr-986 (NS): a) Acceleration, b) Velocity, c) Displacement and d) Input energy 

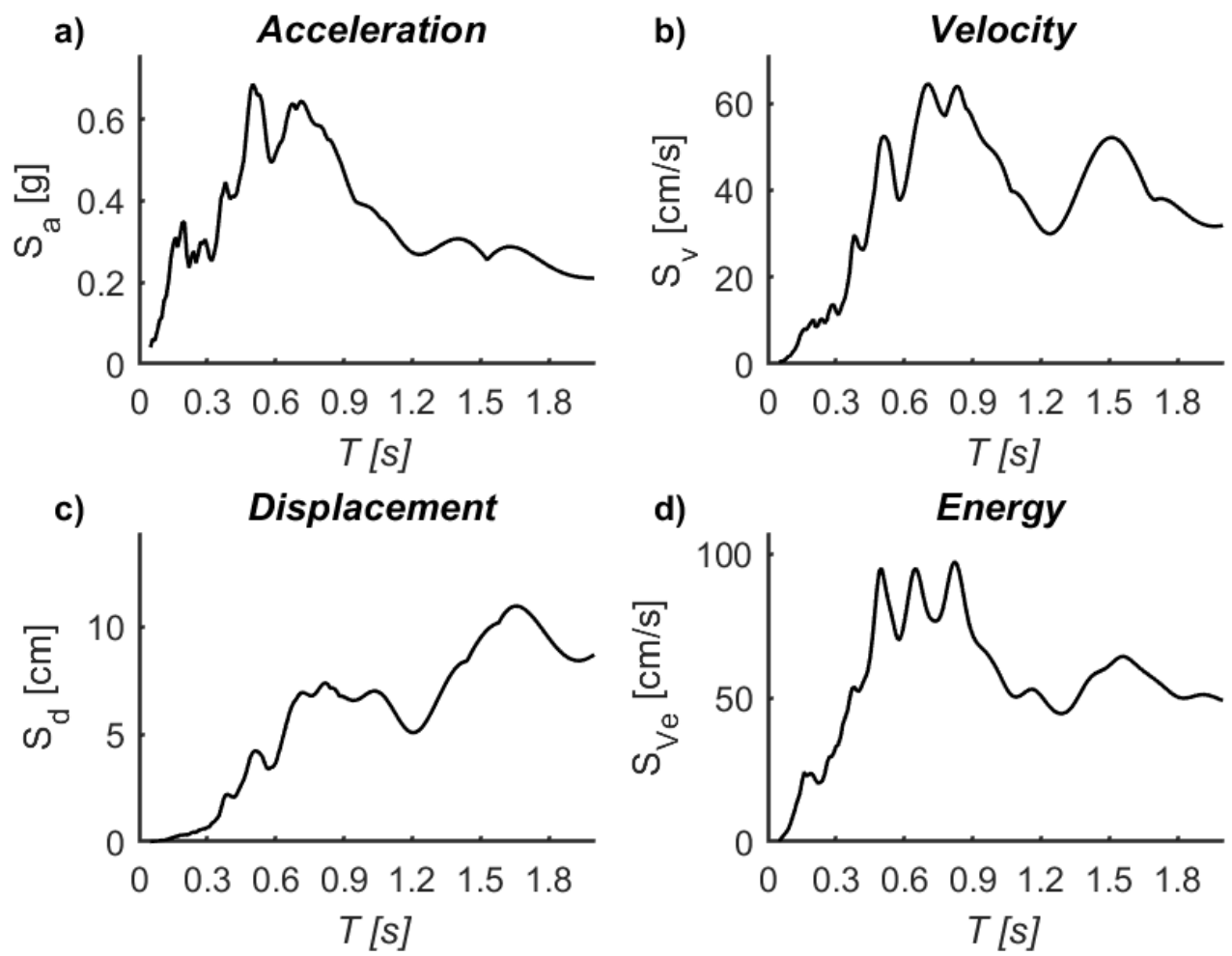

Figure A3. 51. Spectra of Northr-986 (EW): a) Acceleration, b) Velocity, c) Displacement and d) Input energy

a)
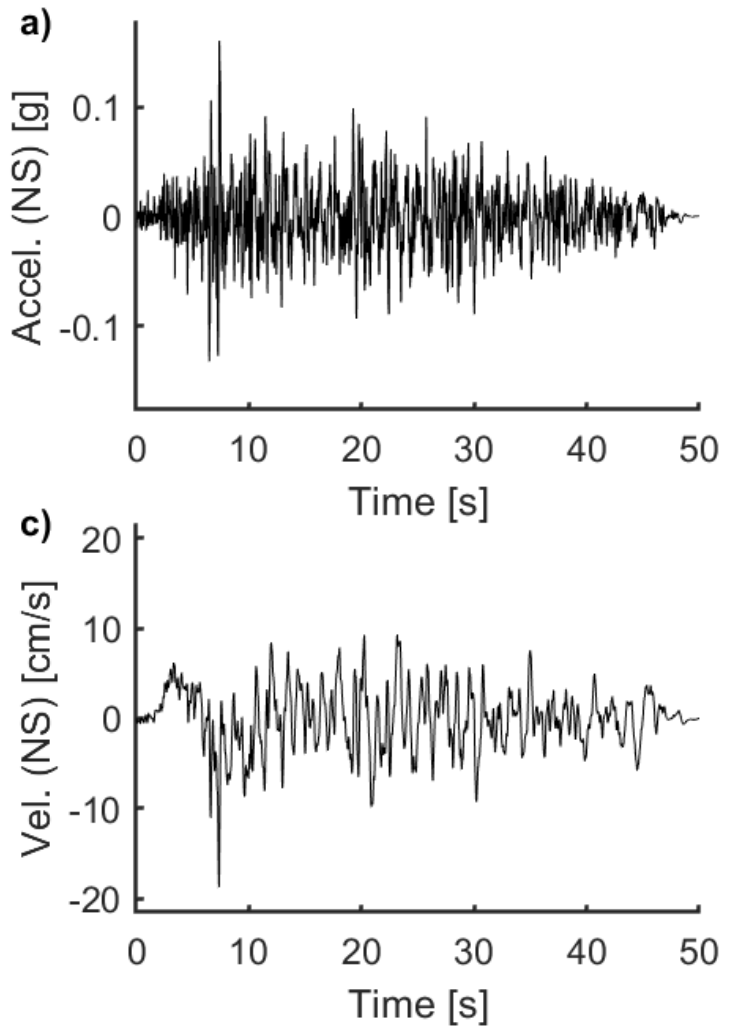

b)
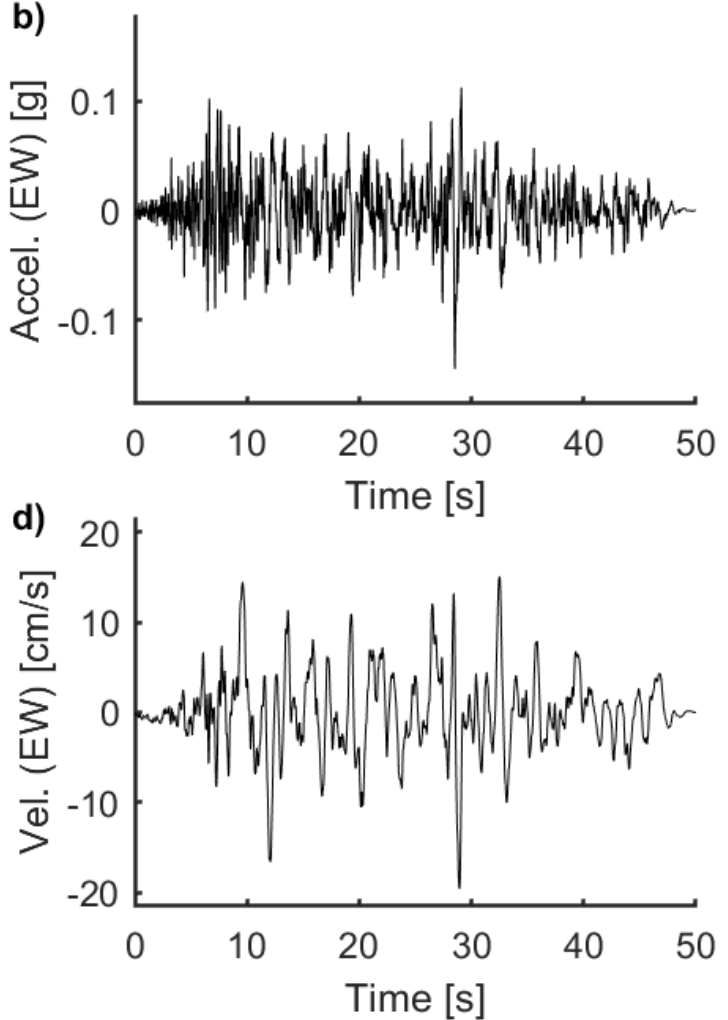

Figure A3. 52. Acceleration and velocity signals for Landers-850: a) Acceleration (NS), b) Acceleration (EW), c) Velocity (NS) and d) Velocity (EW) 

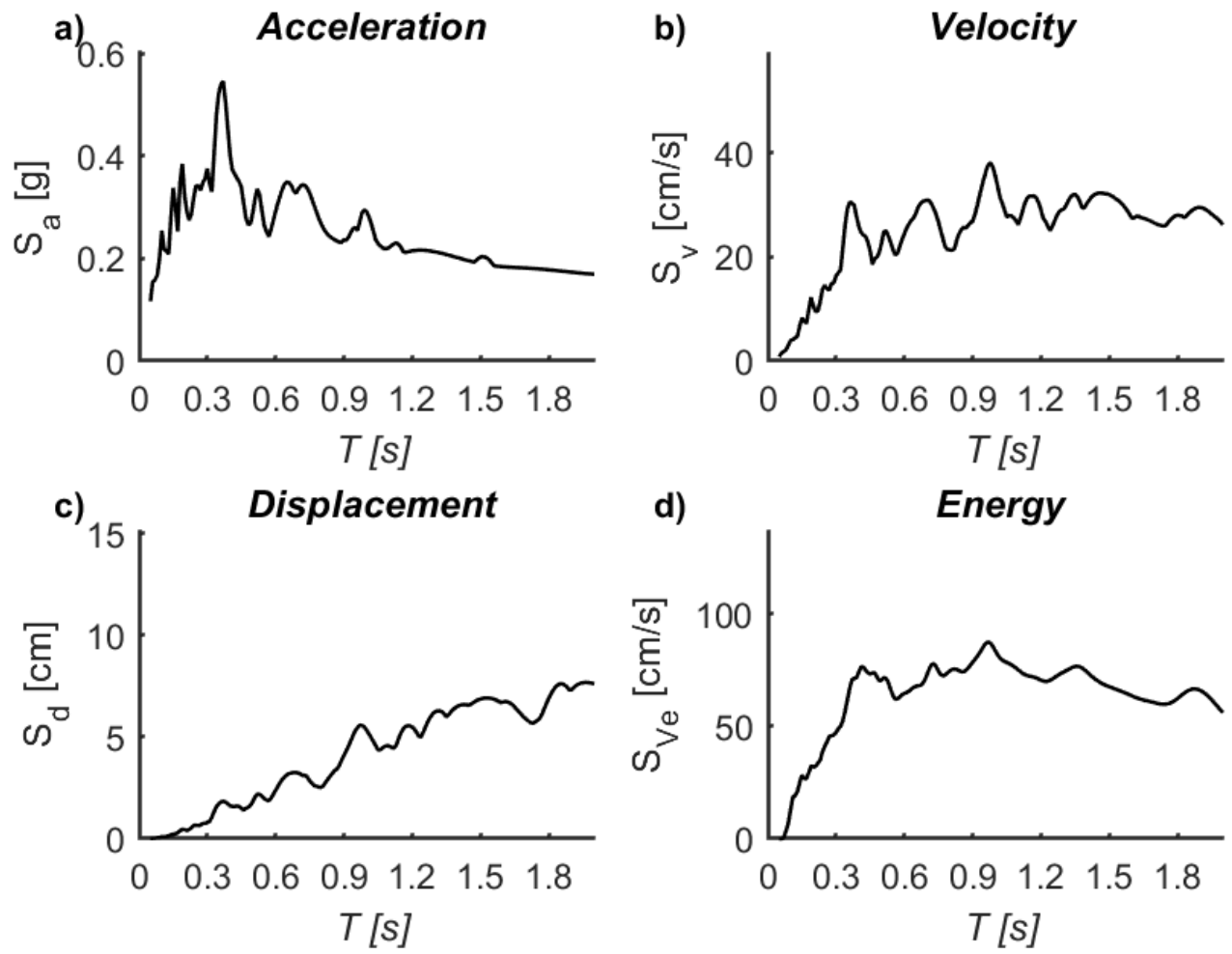

Figure A3. 53. Spectra of Landers-850 (NS): a) Acceleration, b) Velocity, c) Displacement and d) Input energy
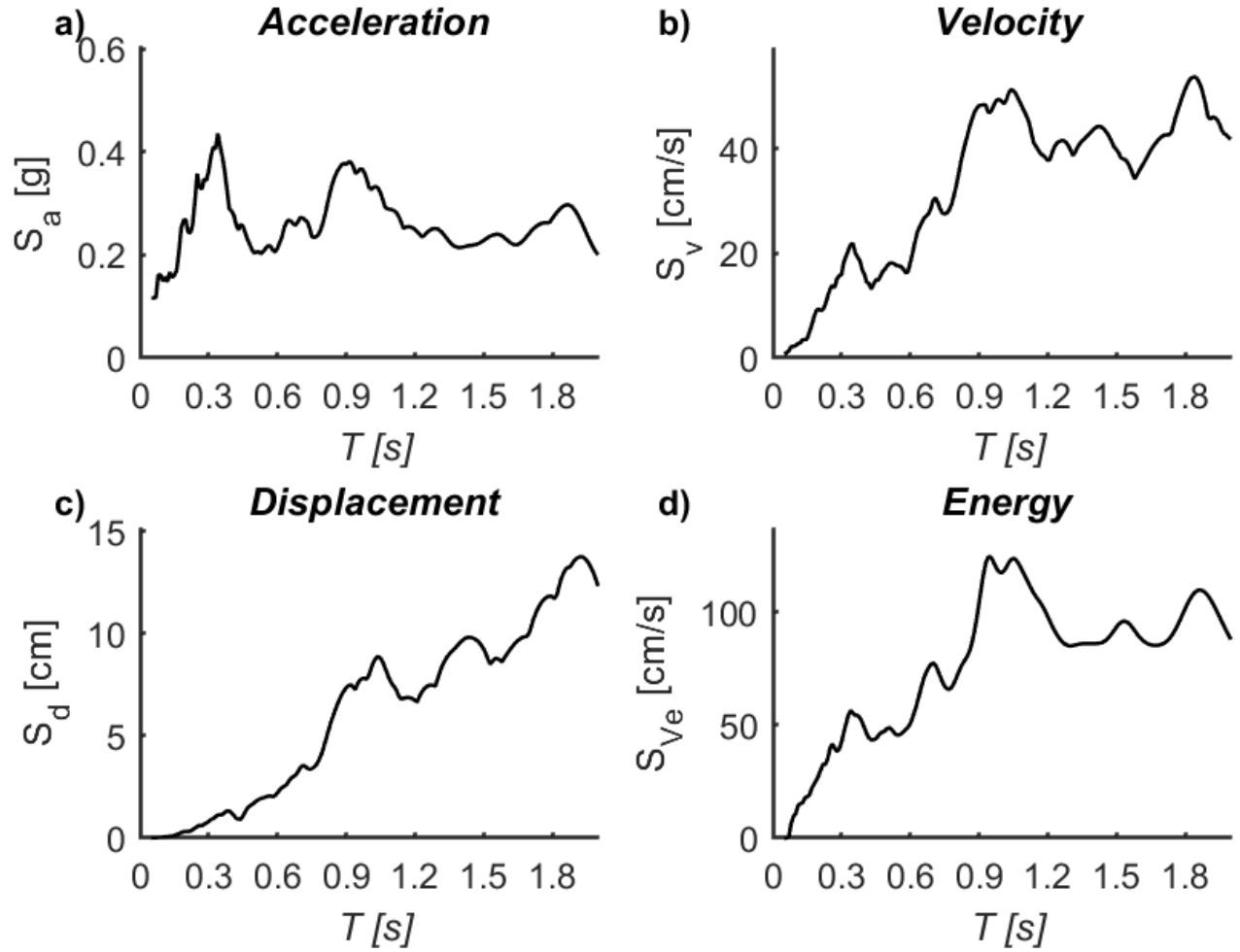

Figure A3. 54. Spectra of Landers-850 (EW): a) Acceleration, b) Velocity, c) Displacement and d) Input energy 
a)
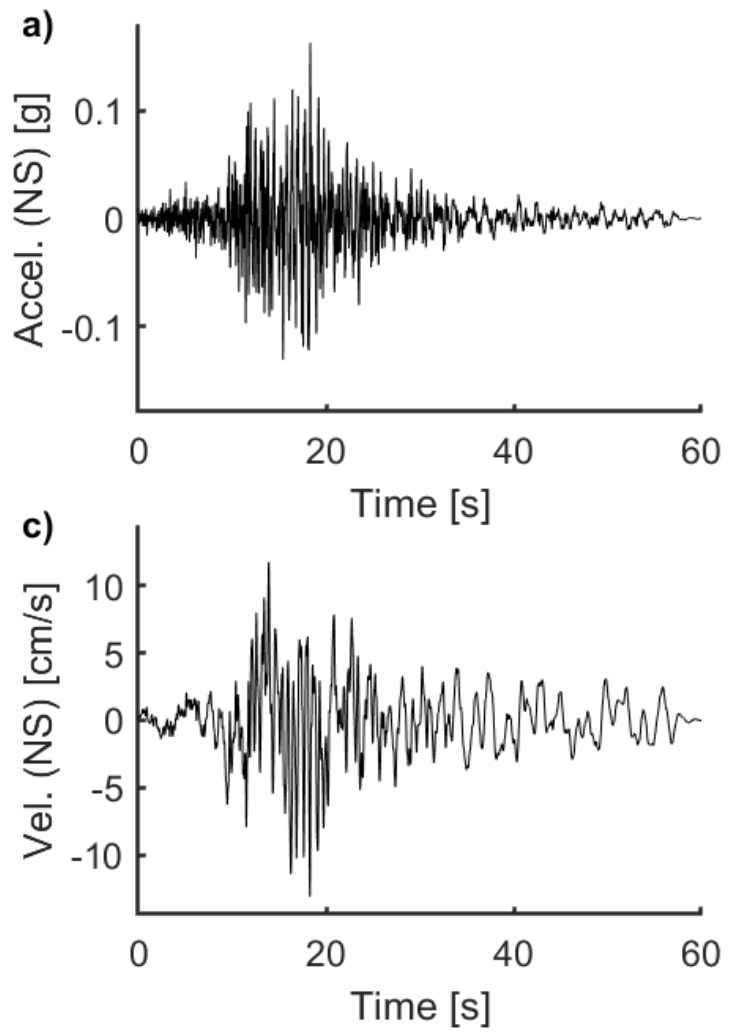

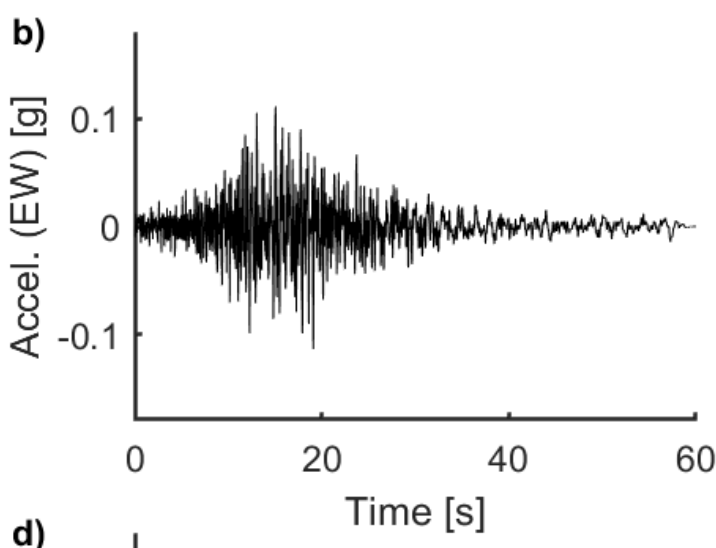

d)

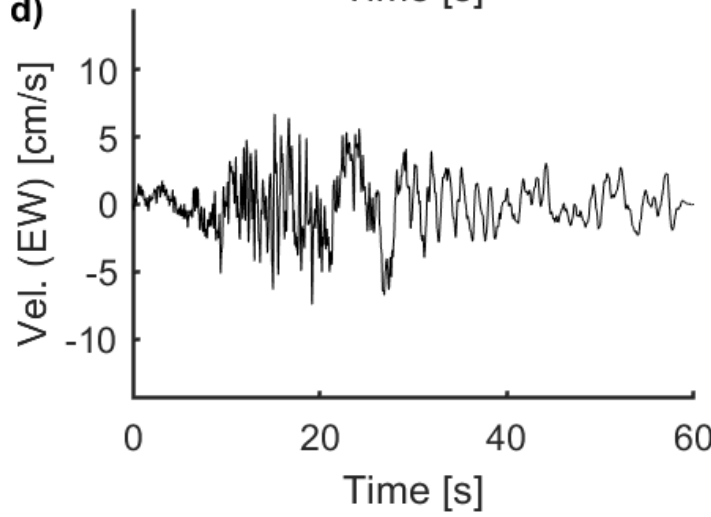

Figure A3. 55. Acceleration and velocity signals for Hector-1766: a) Acceleration (NS), b) Acceleration (EW), c) Velocity (NS) and d) Velocity (EW)
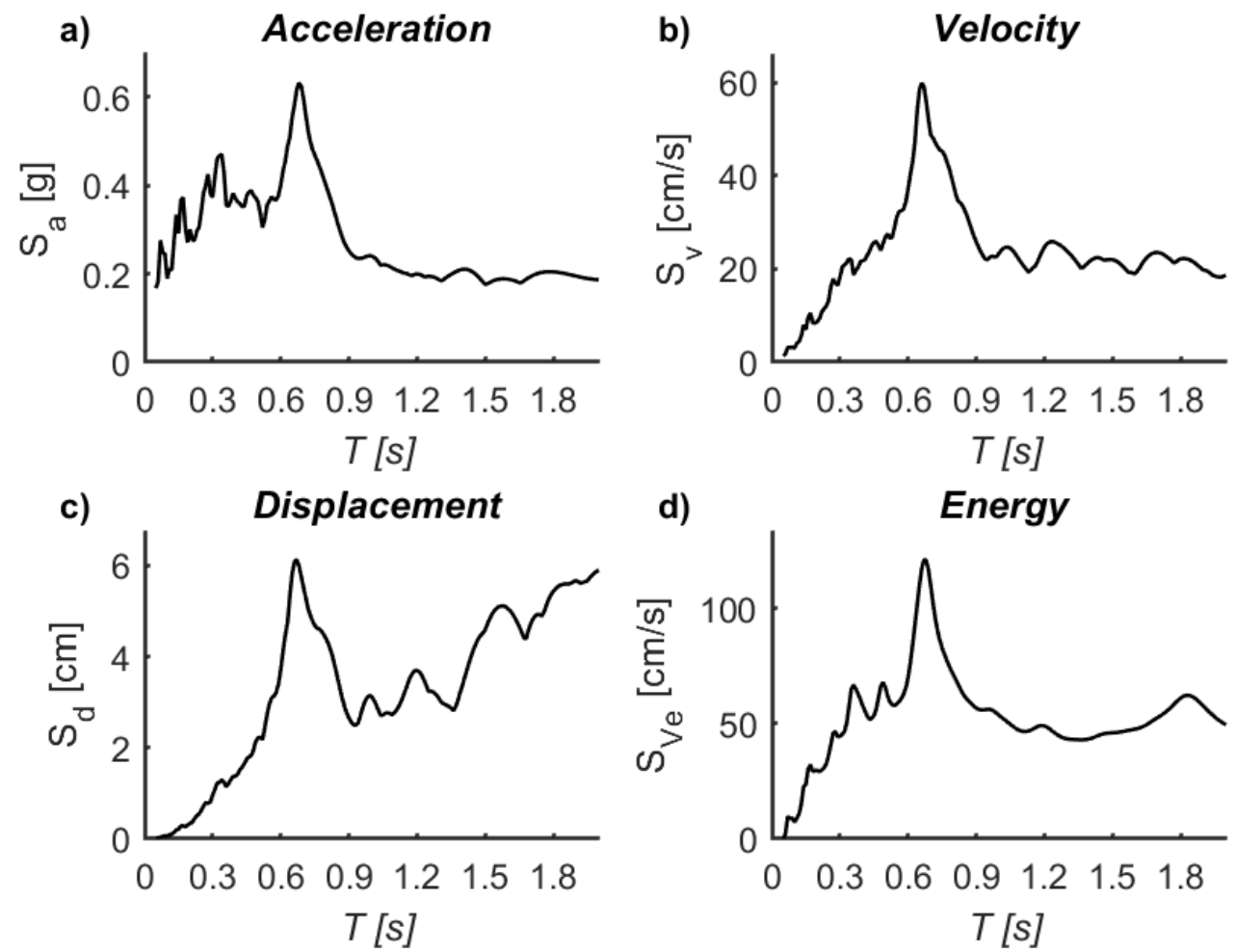

Figure A3. 56. Spectra of Hector-1766 (NS): a) Acceleration, b) Velocity, c) Displacement and d) Input energy 

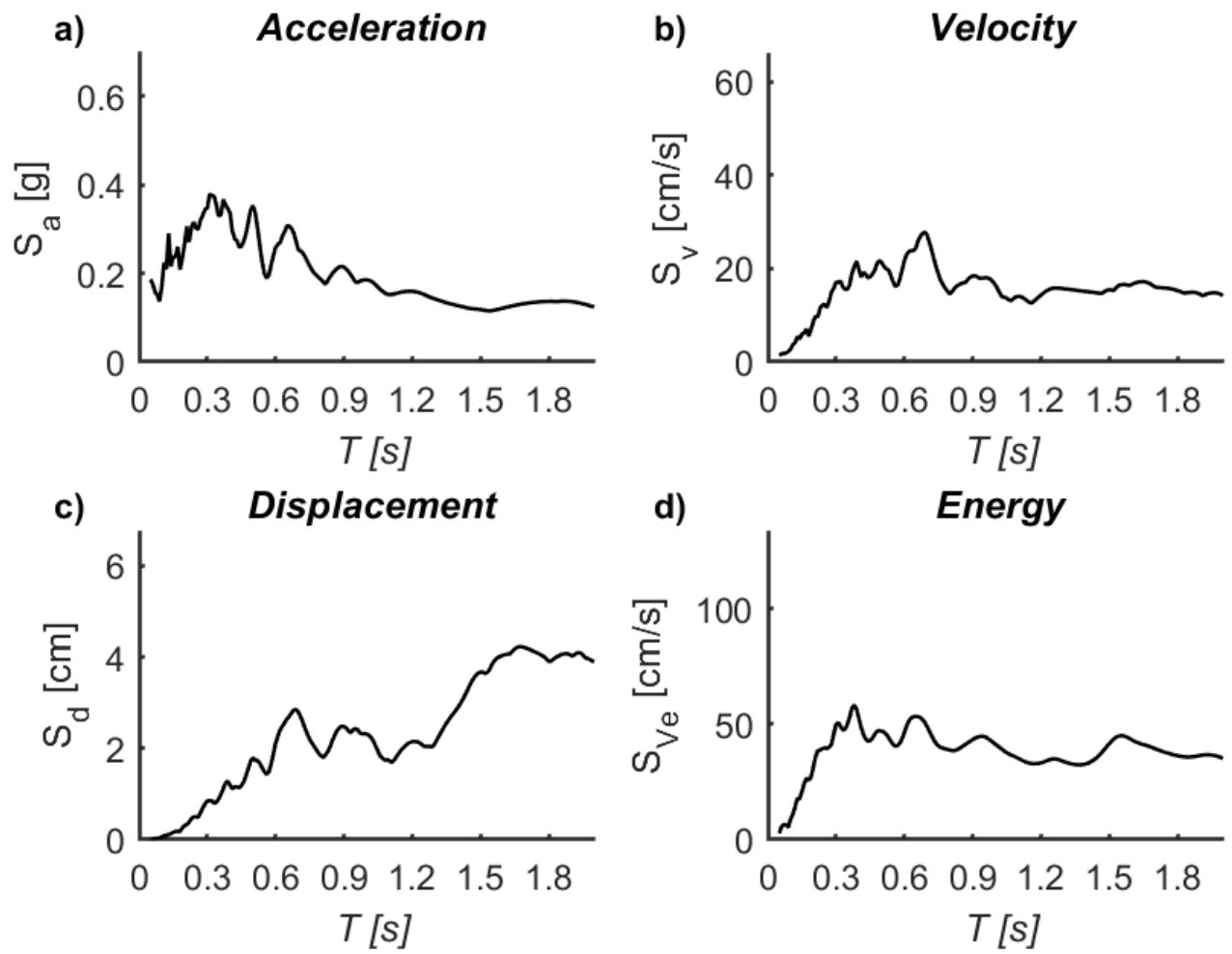

Figure A3. 57. Spectra of Hector-1766 (EW): a) Acceleration, b) Velocity, c) Displacement and d) Input energy
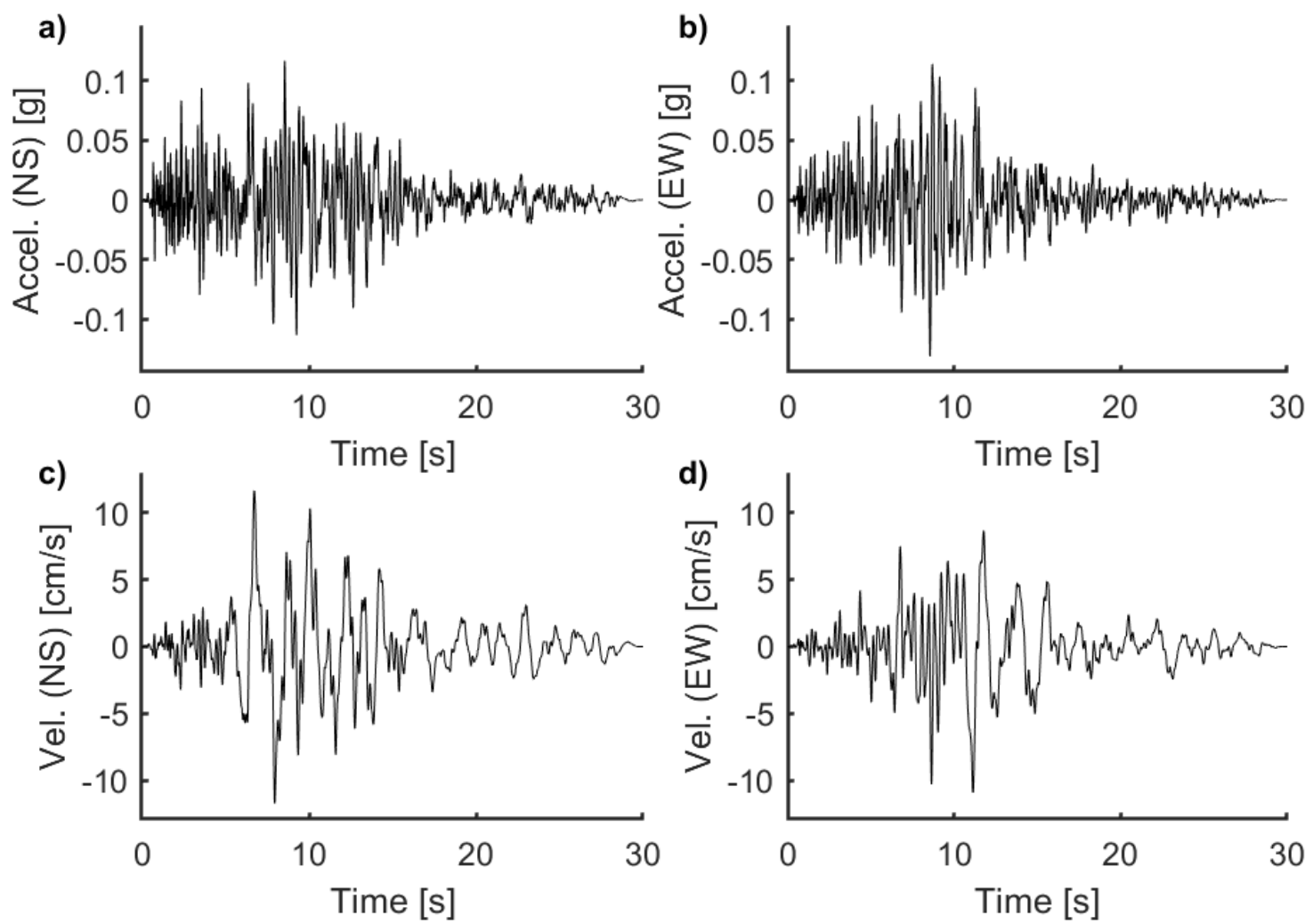

Figure A3. 58. Acceleration and velocity signals for Coalinga-362: a) Acceleration (NS), b) Acceleration (EW), c) Velocity (NS) and d) Velocity (EW) 

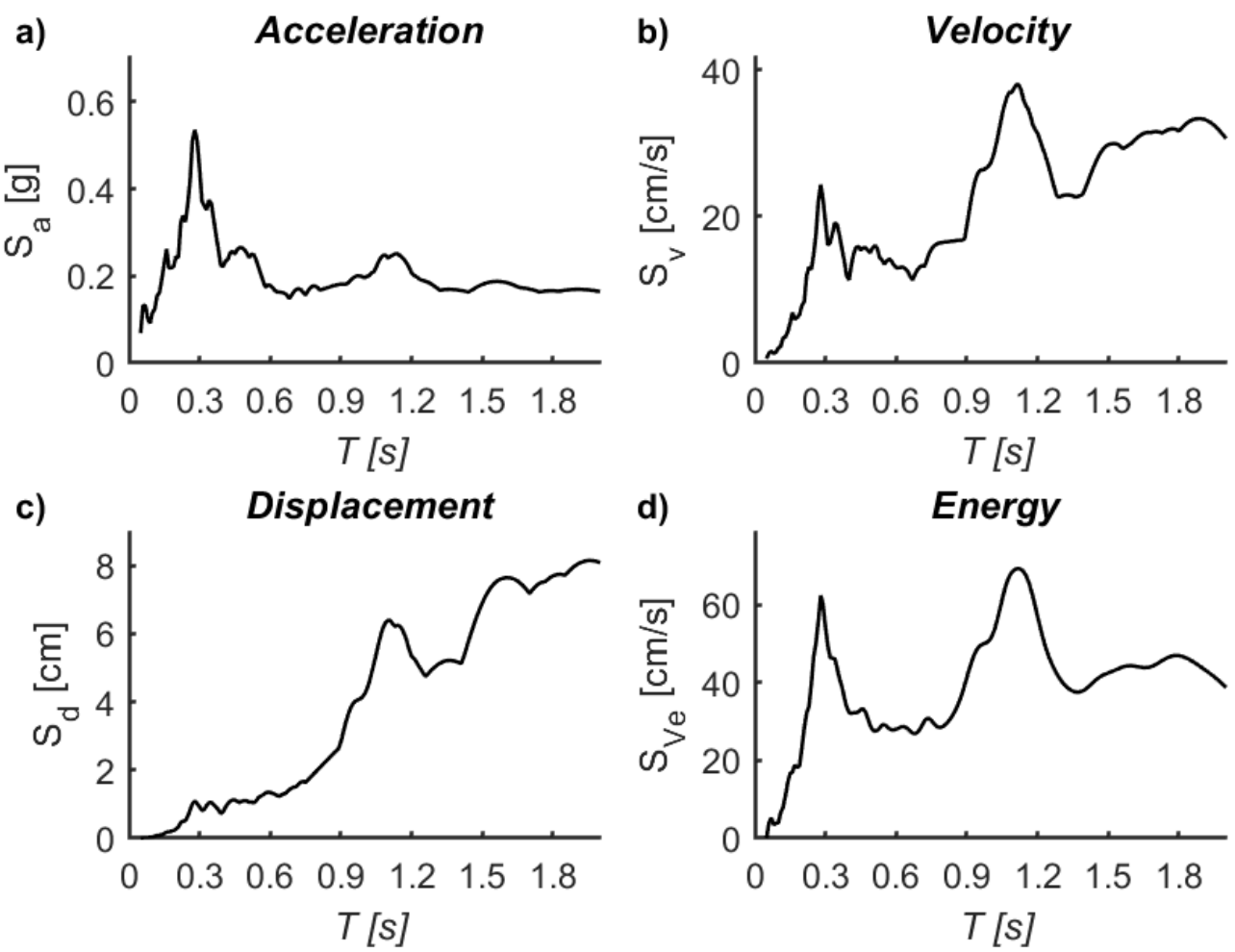

Figure A3. 59. Spectra of Coalinga-362 (NS): a) Acceleration, b) Velocity, c) Displacement and d) Input energy
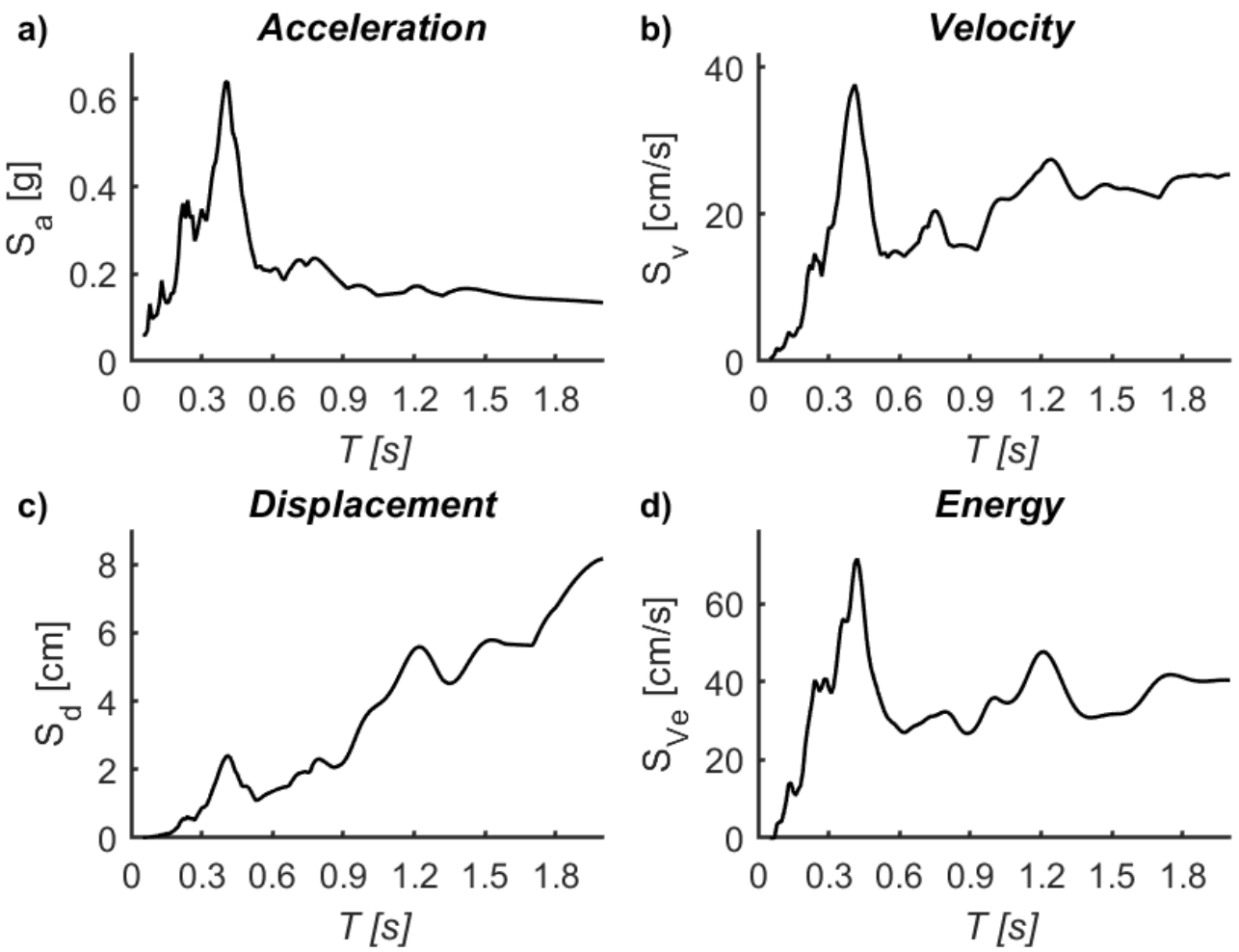

Figure A3. 60. Spectra of Coalinga-362 (EW): a) Acceleration, b) Velocity, c) Displacement and d) Input energy 
a)
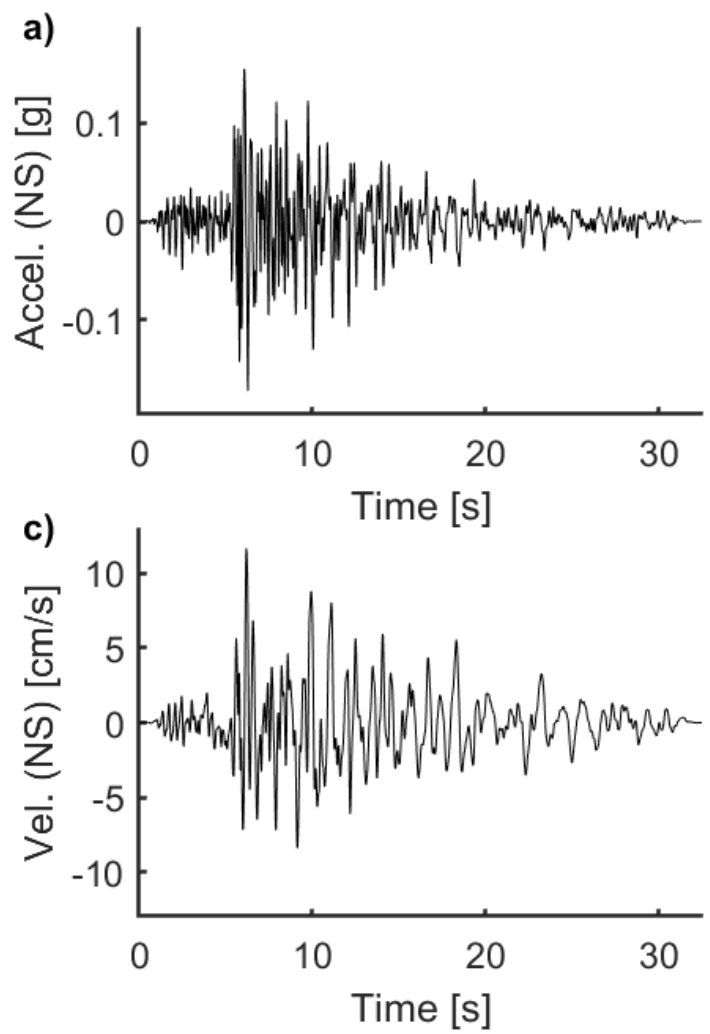

b)

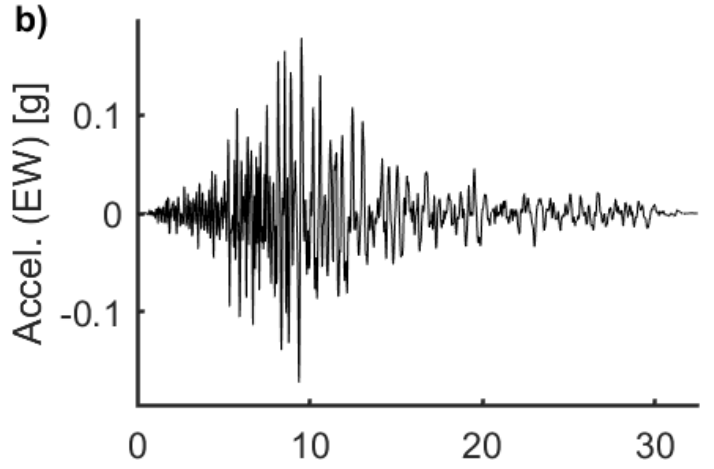

d) Time [s]

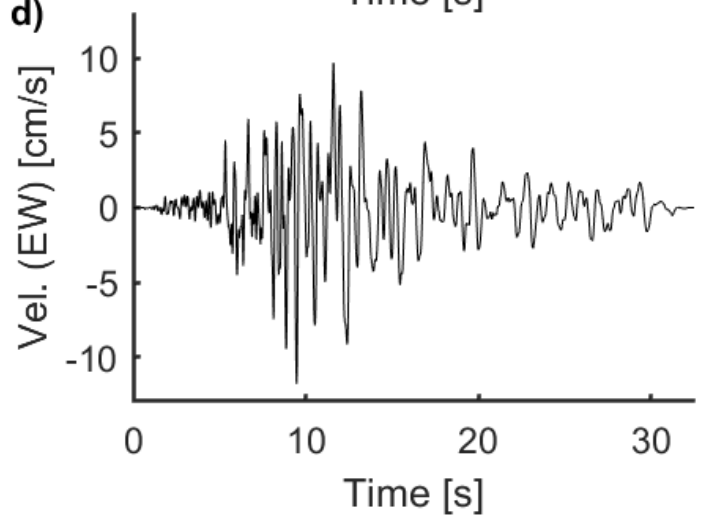

Figure A3. 61. Acceleration and velocity signals for Whittier-673: a) Acceleration (NS), b) Acceleration (EW), c) Velocity (NS) and d) Velocity (EW)
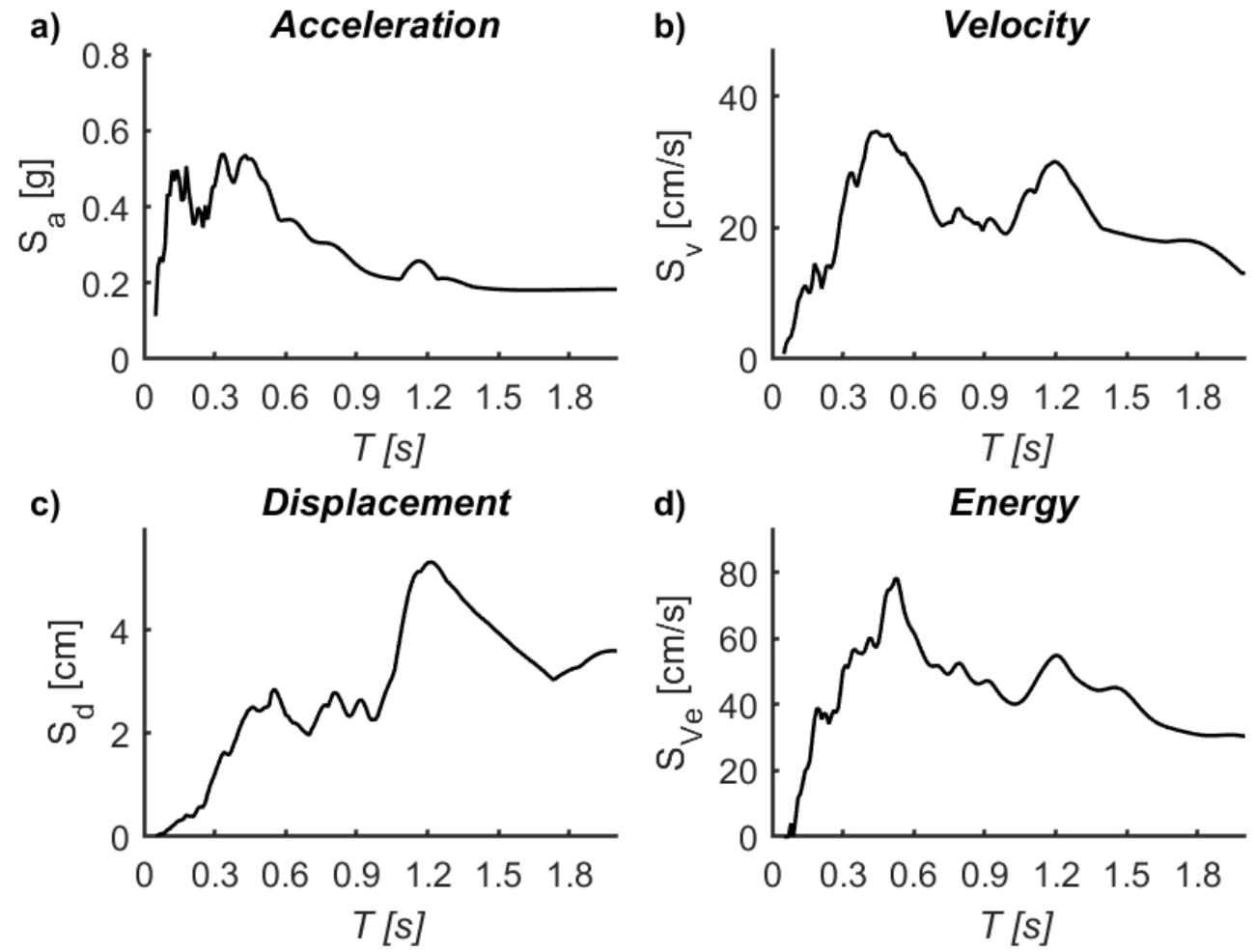

Figure A3. 62. Spectra of Whittier-673 (NS): a) Acceleration, b) Velocity, c) Displacement and d) Input energy 

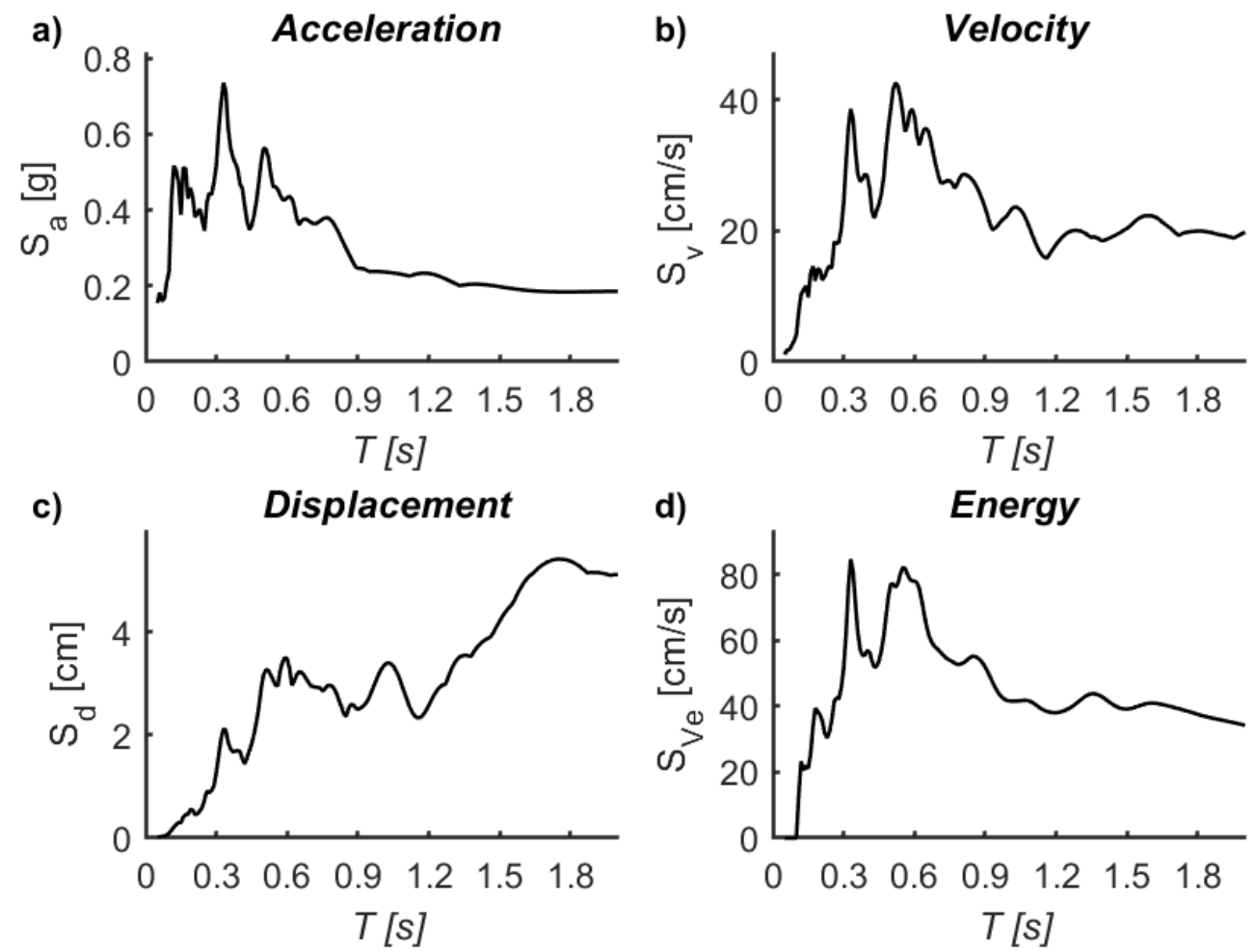

Figure A3. 63. Spectra of Whittier-673 (EW): a) Acceleration, b) Velocity, c) Displacement and d) Input energy

a)
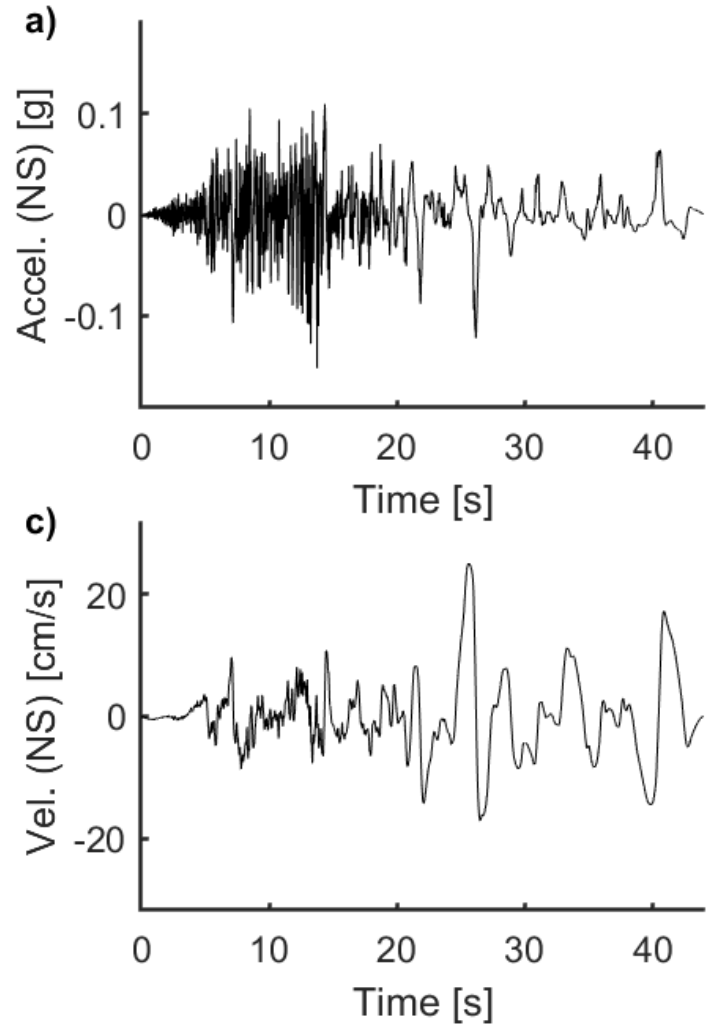

b)

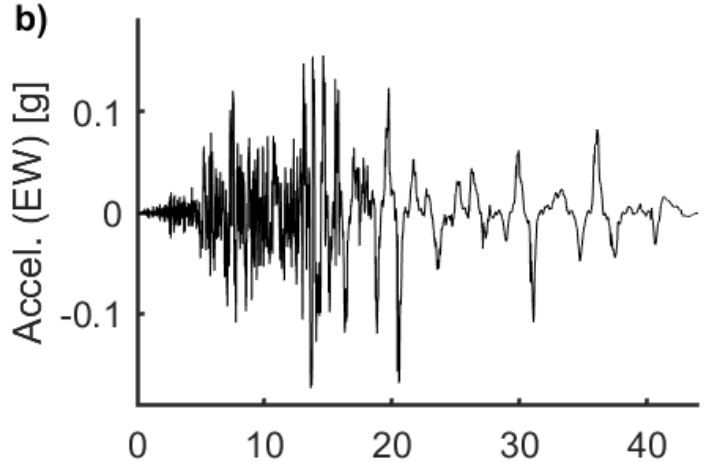

d)

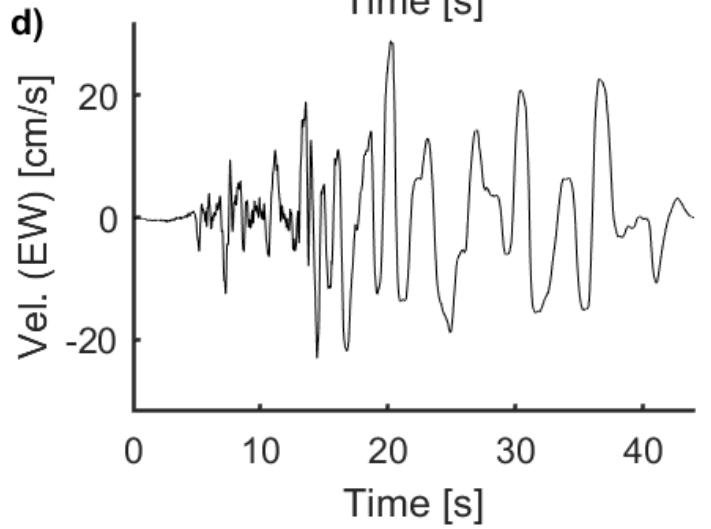

Figure A3. 64. Acceleration and velocity signals for Superst-729: a) Acceleration (NS), b) Acceleration (EW), c) Velocity (NS) and d) Velocity (EW) 

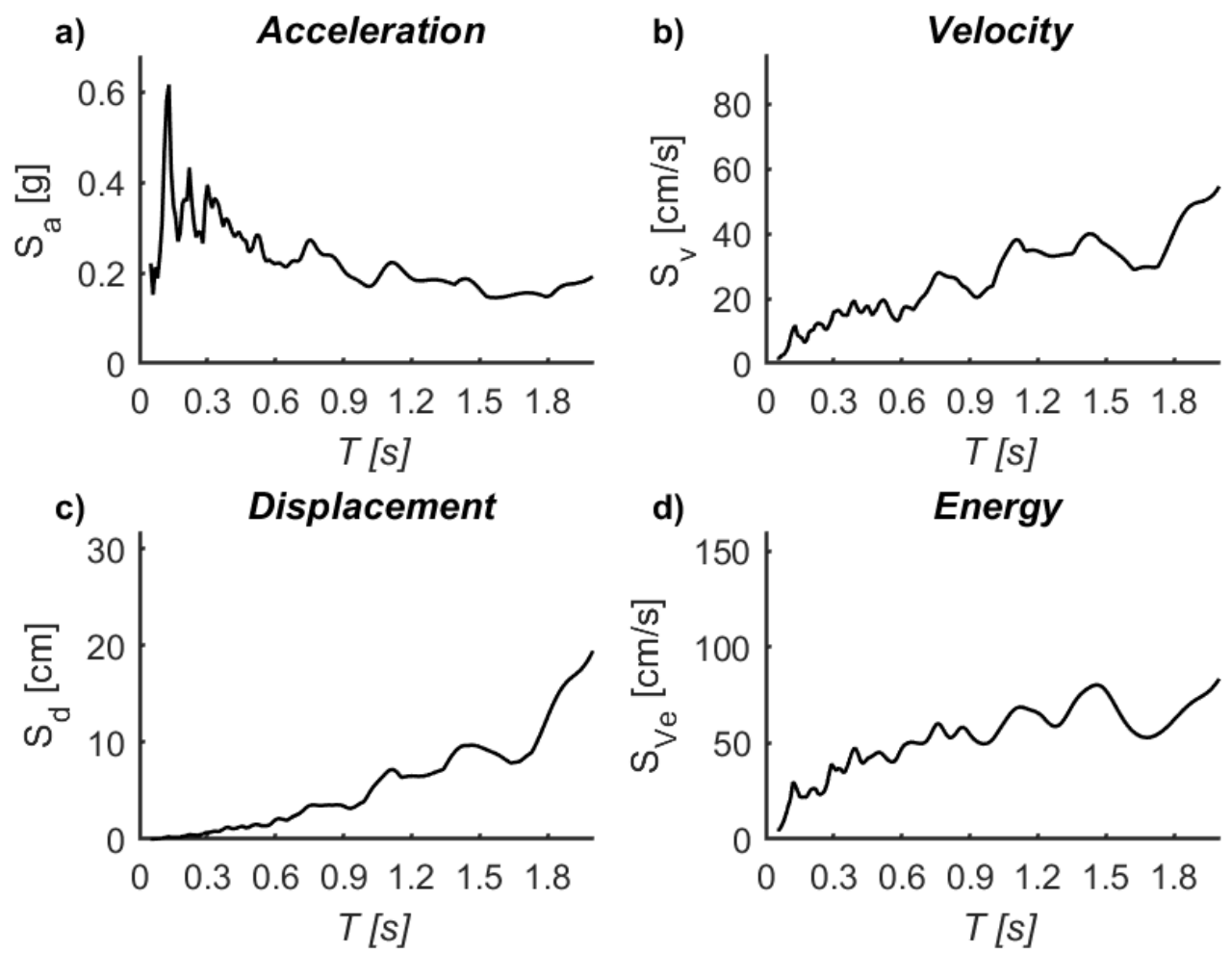

Figure A3. 65. Spectra of Superst-729 (NS): a) Acceleration, b) Velocity, c) Displacement and d) Input energy
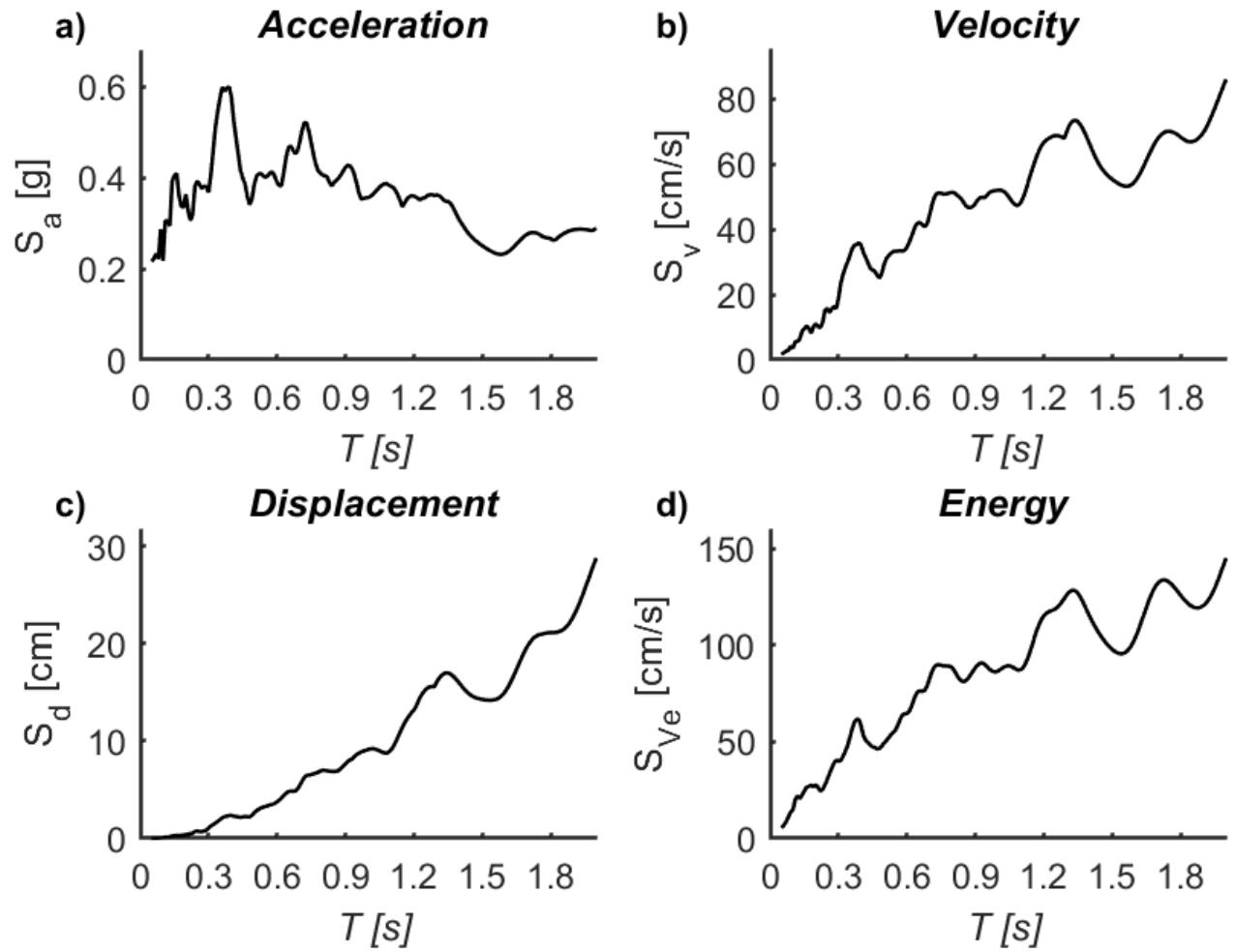

Figure A3. 66. Spectra of Superst-729 (EW): a) Acceleration, b) Velocity, c) Displacement and d) Input energy 
a)
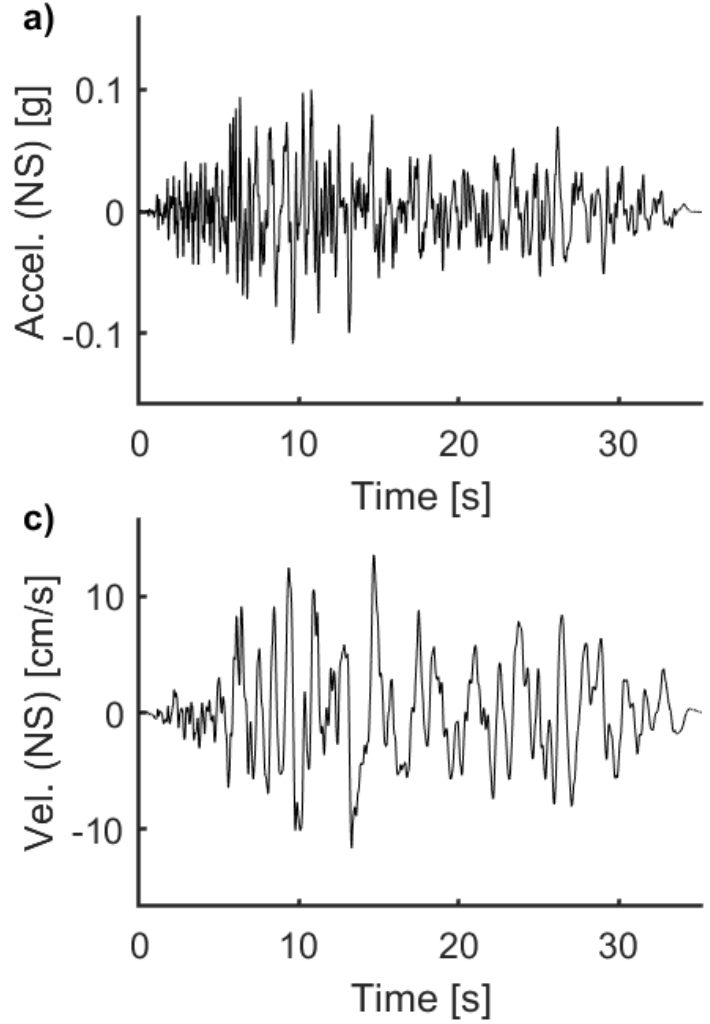

b)

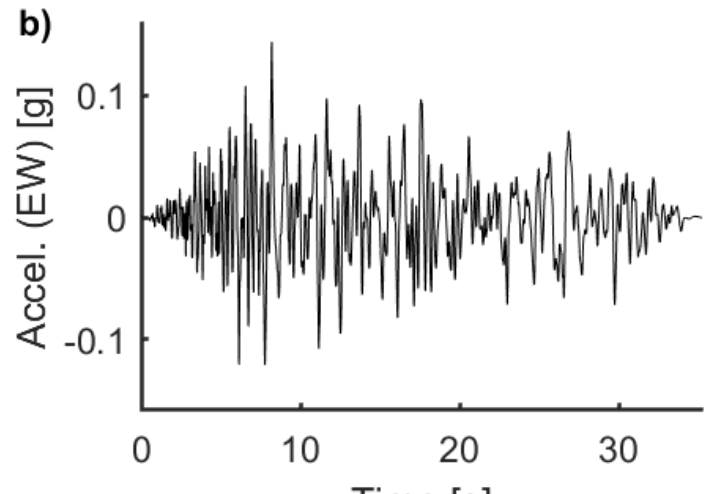

d)

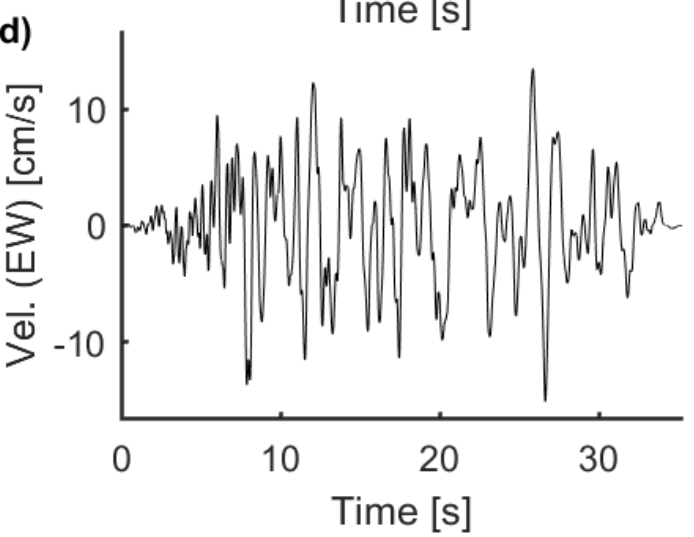

Figure A3. 67. Acceleration and velocity signals for Italy-289: a) Acceleration (NS), b) Acceleration (EW), c) Velocity (NS) and d) Velocity (EW)
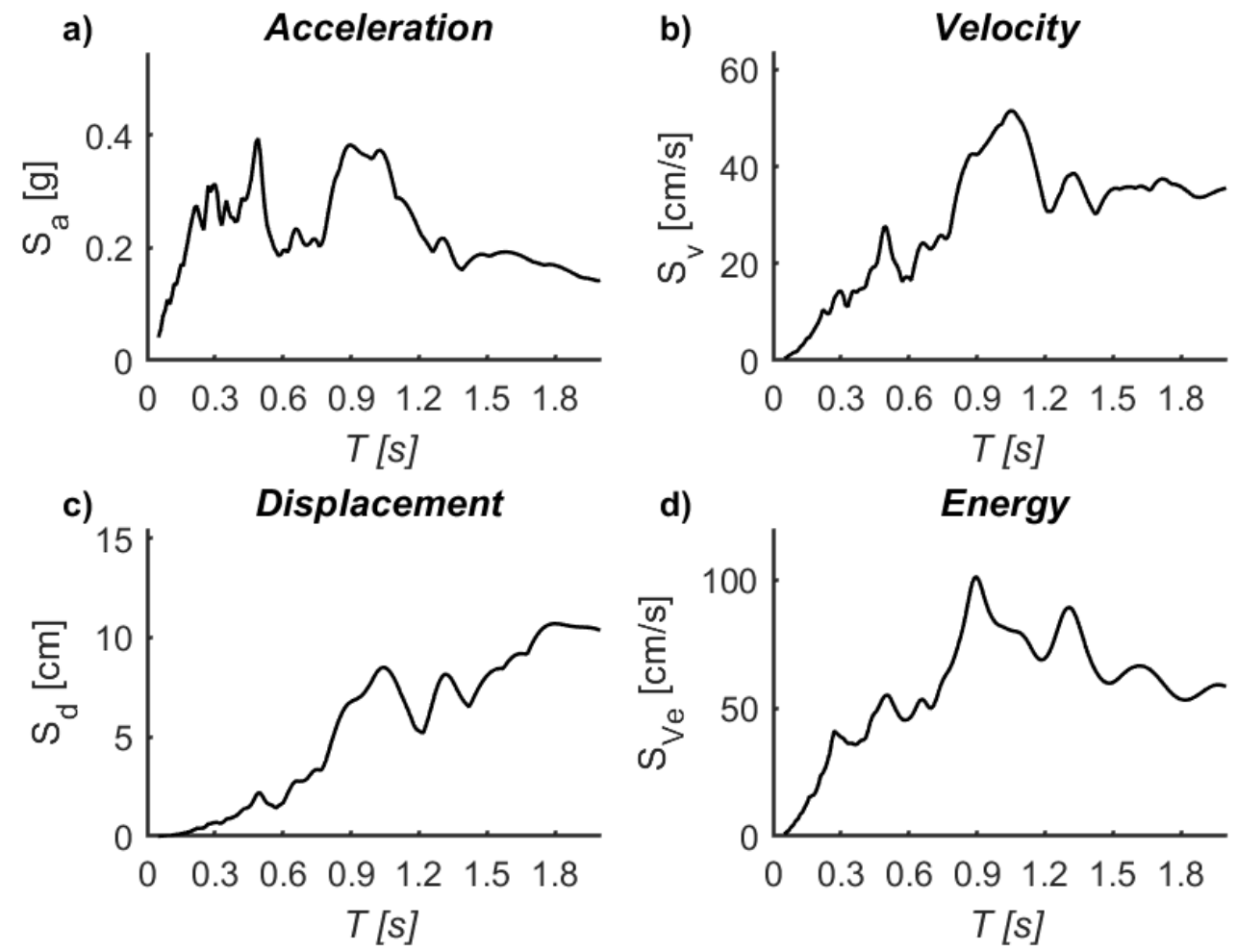

Figure A3. 68. Spectra of Italy-289 (NS): a) Acceleration, b) Velocity, c) Displacement and d) Input energy 

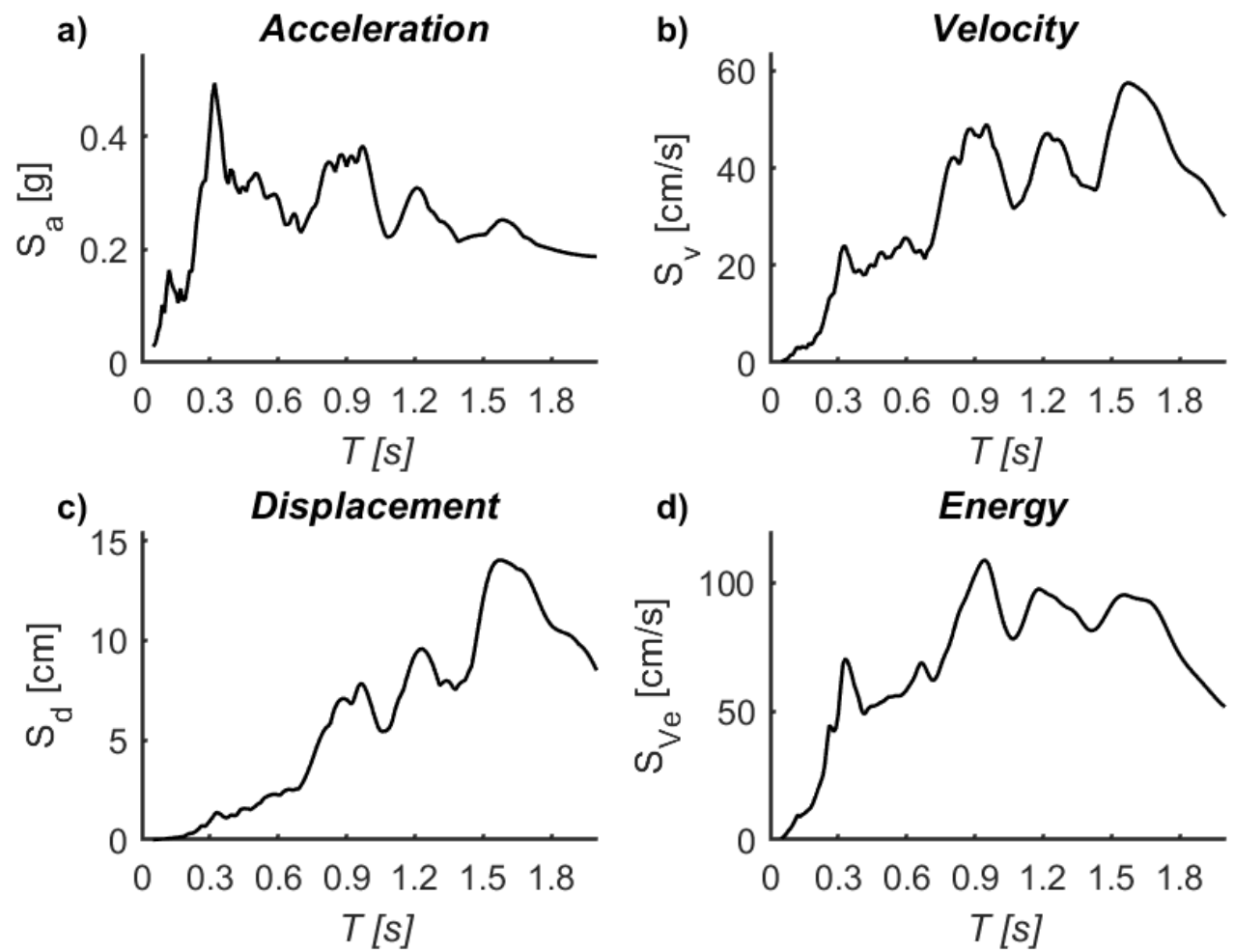

Figure A3. 69. Spectra of Italy-289 (EW): a) Acceleration, b) Velocity, c) Displacement and d) Input energy

a)
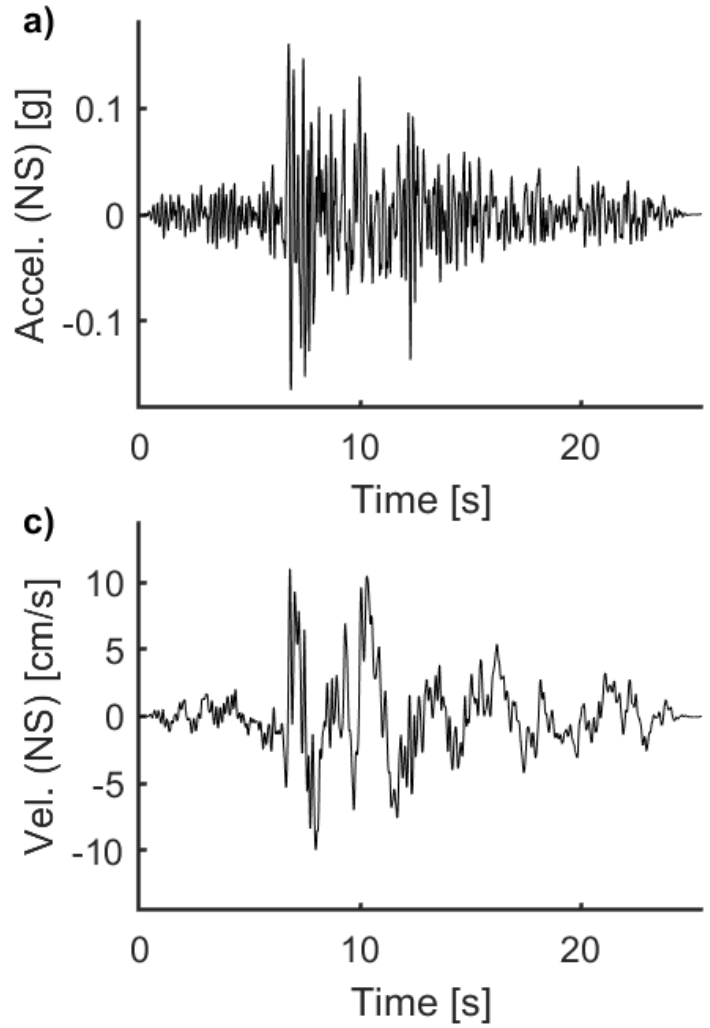

b)
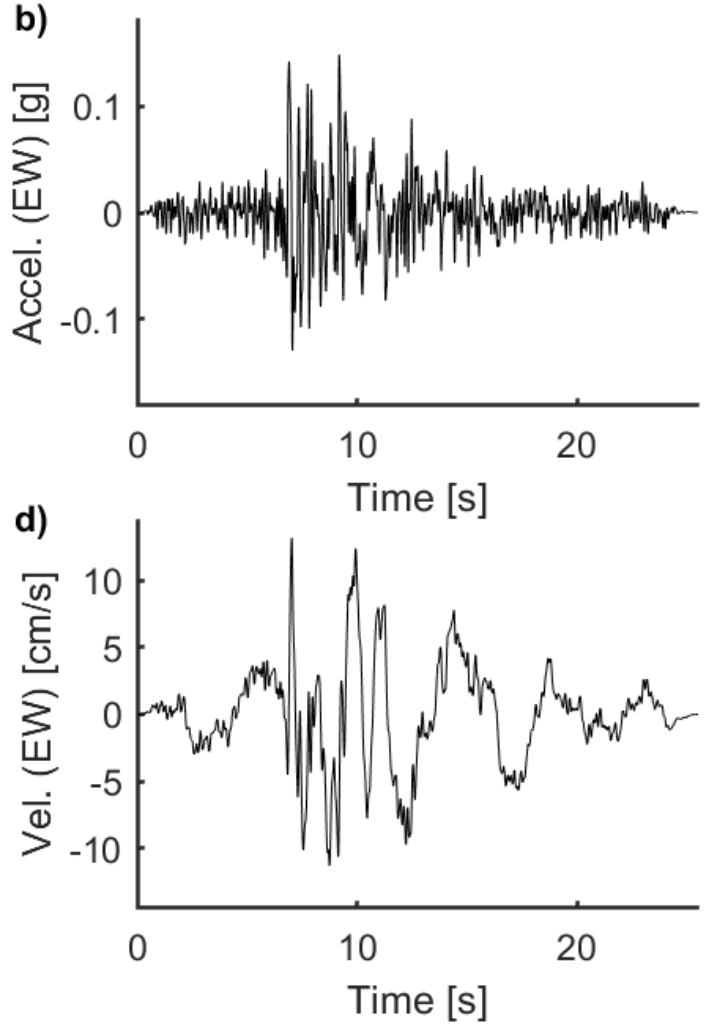

Figure A3. 70. Acceleration and velocity signals for Kocaeli-1162: a) Acceleration (NS), b) Acceleration (EW), c) Velocity (NS) and d) Velocity (EW) 
a)
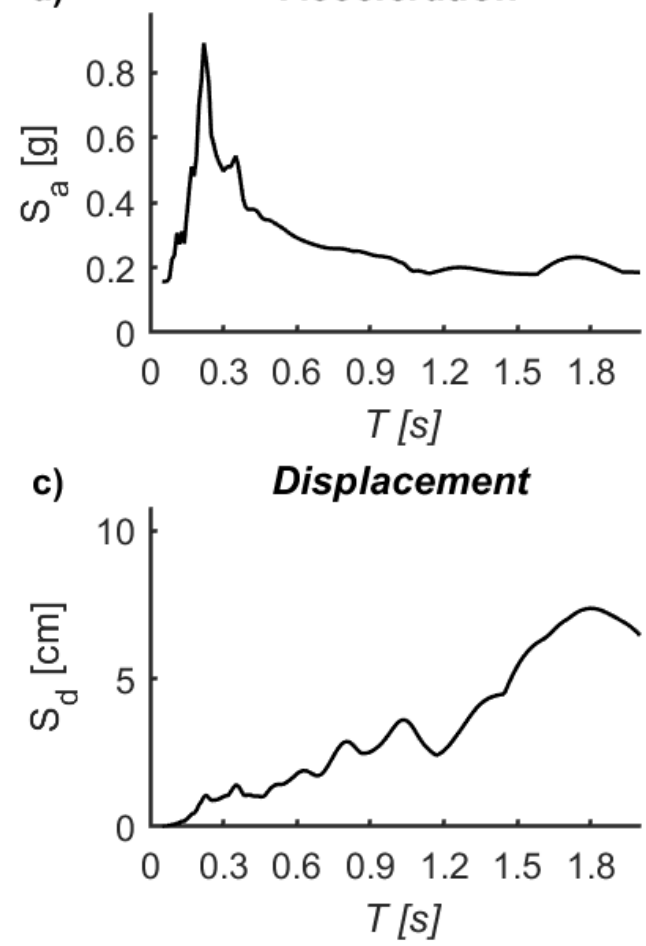

b) Velocity

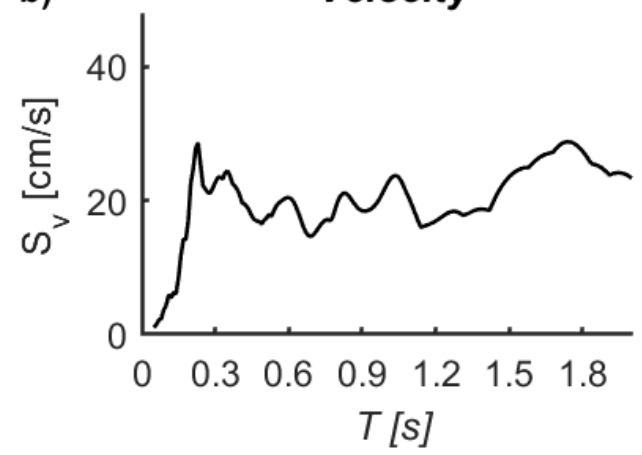

d)

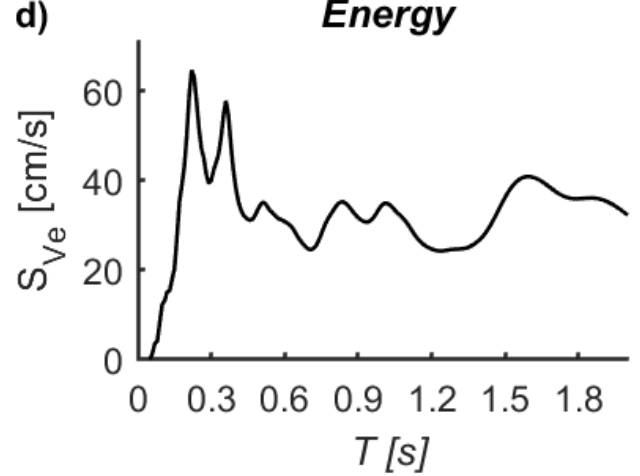

Figure A3. 71. Spectra of Kocaeli-1162 (NS): a) Acceleration, b) Velocity, c) Displacement and d) Input energy

a)

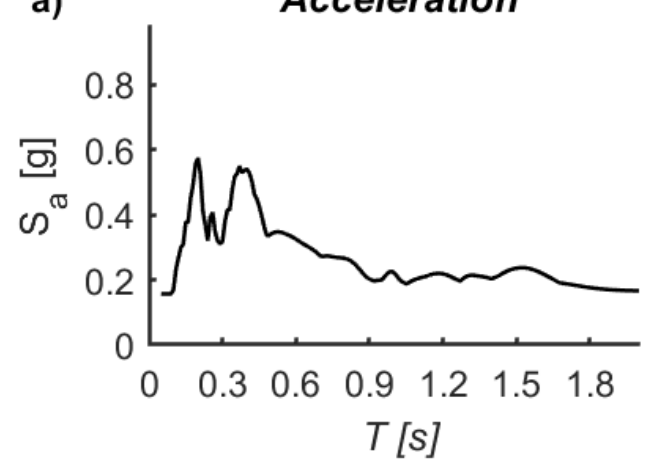

c)

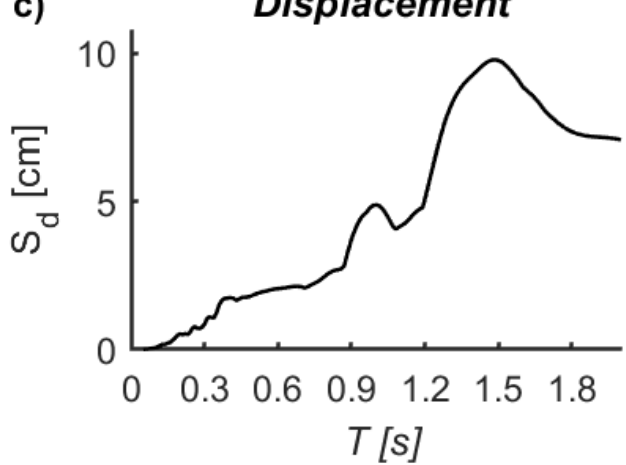

b) Velocity

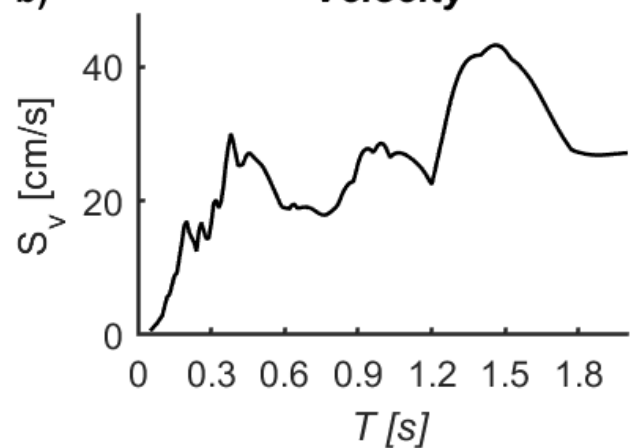

d)

Energy

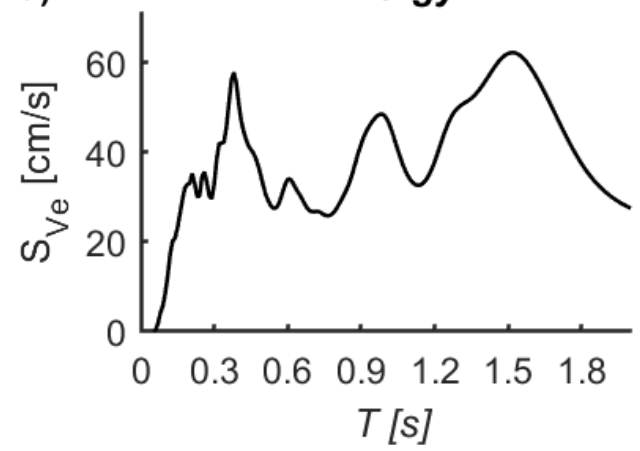

Figure A3. 72. Spectra of Kocaeli-1162 (EW): a) Acceleration, b) Velocity, c) Displacement and d) Input energy 
a)
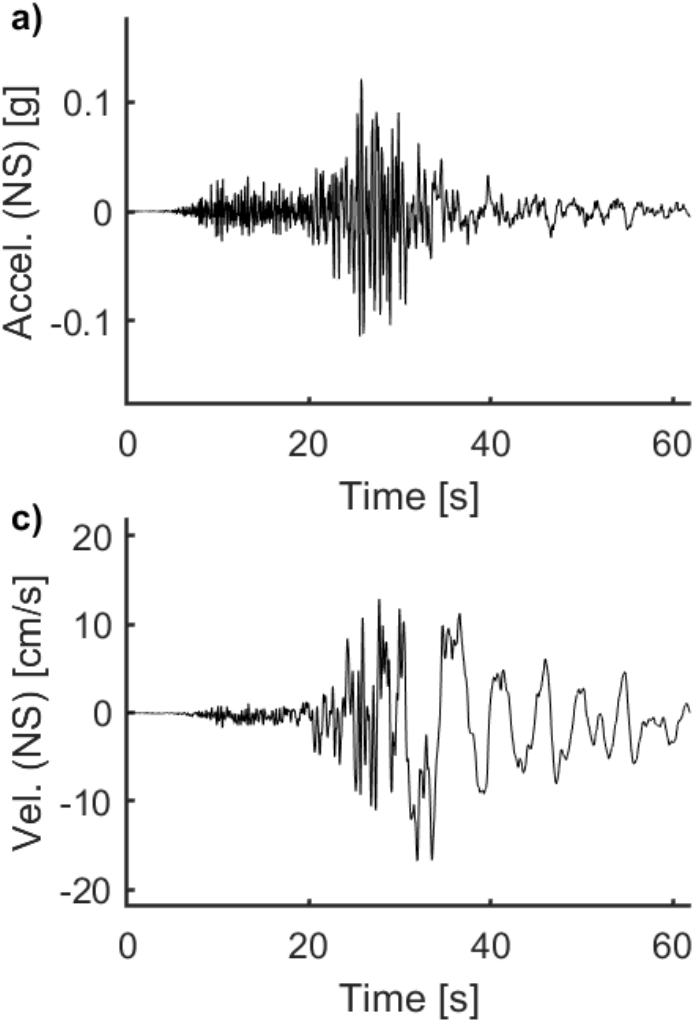

b)

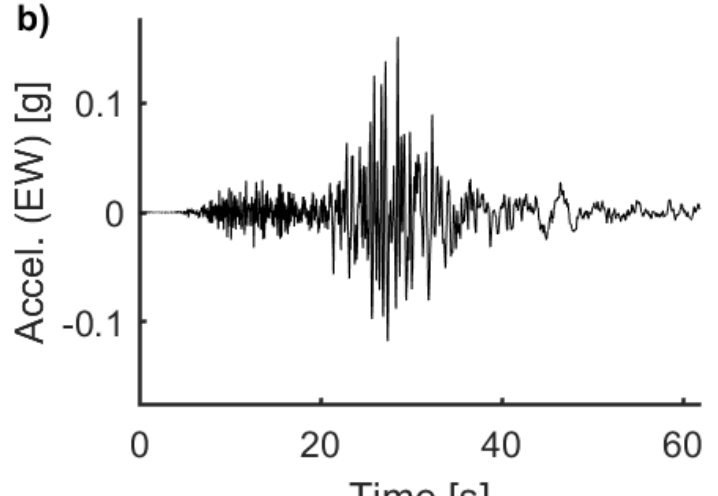

d) Time [s]

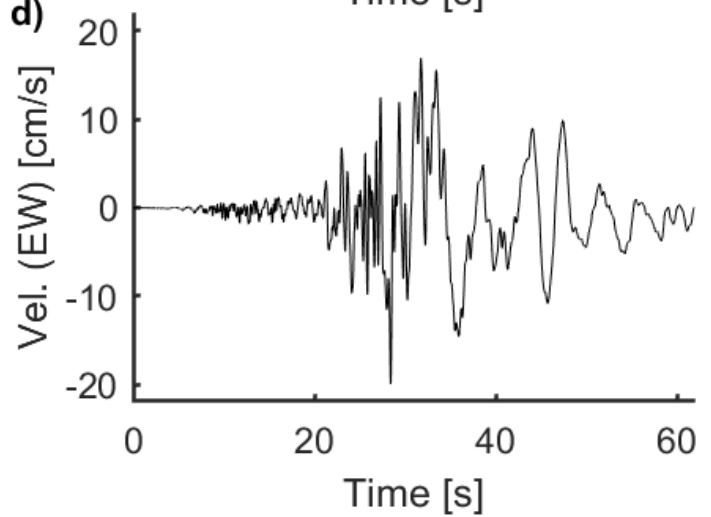

Figure A3. 73. Acceleration and velocity signals for Hector-1829: a) Acceleration (NS), b) Acceleration (EW), c) Velocity (NS) and d) Velocity (EW)
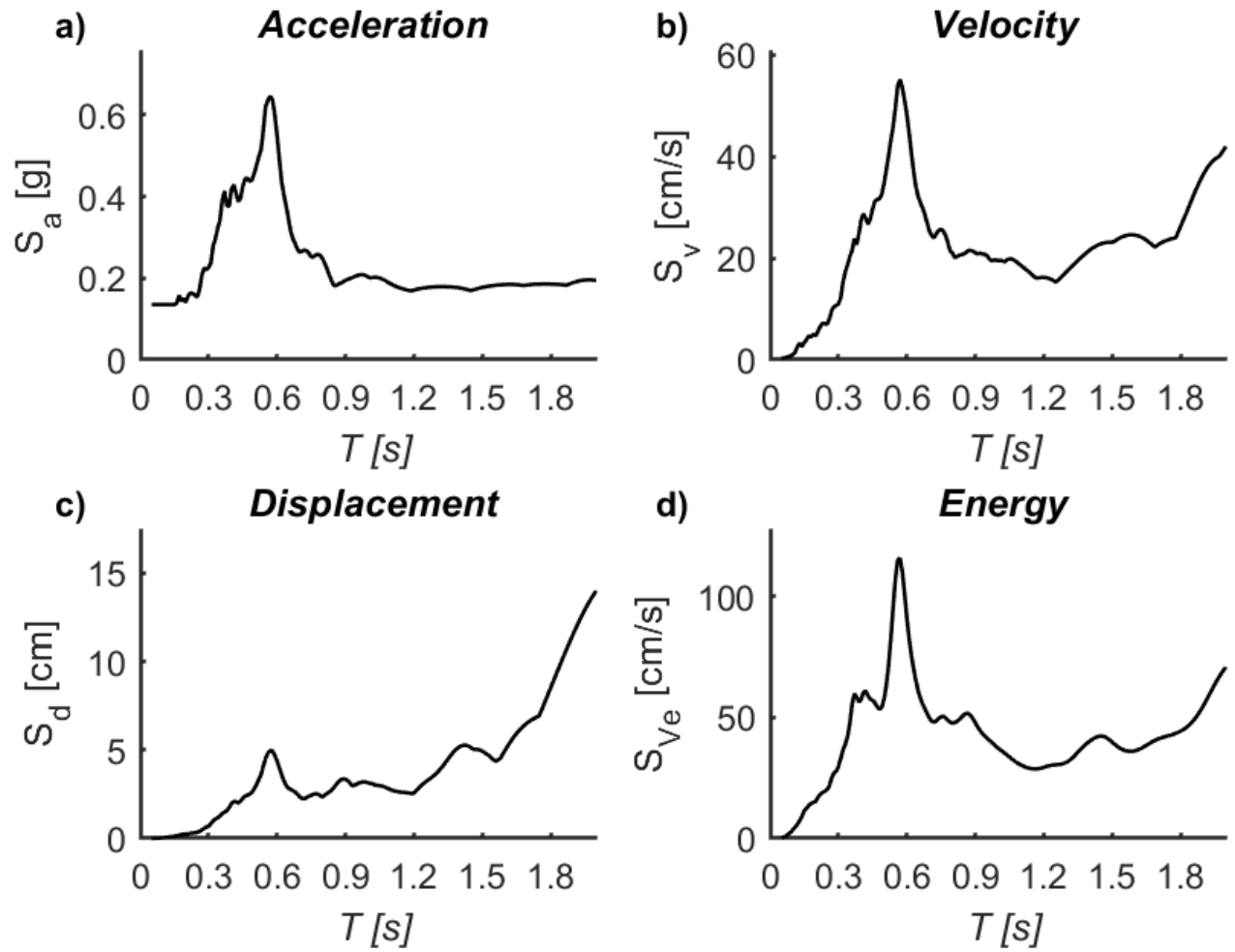

Figure A3. 74. Spectra of Hector-1829 (NS): a) Acceleration, b) Velocity, c) Displacement and d) Input energy 

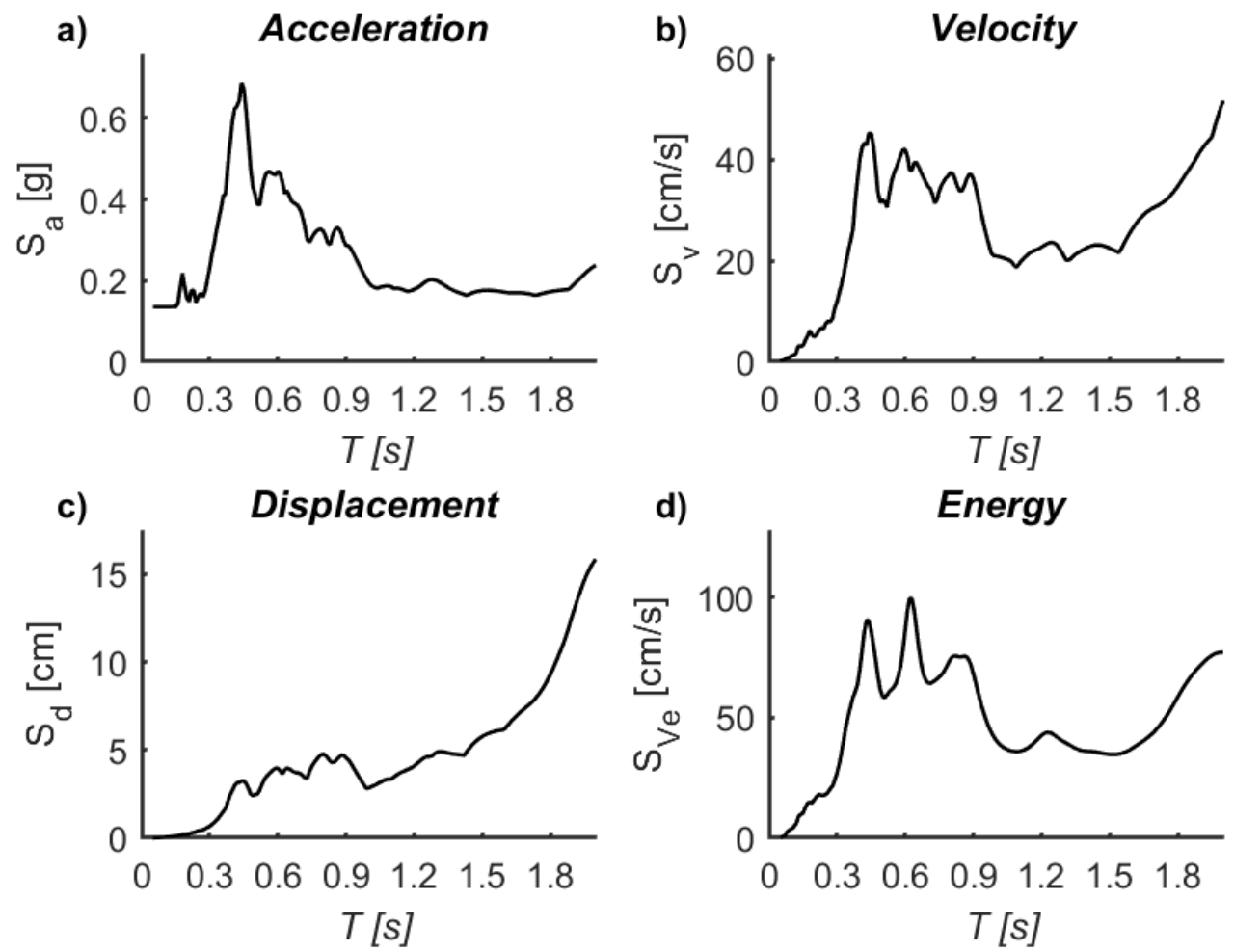

Figure A3. 75. Spectra of Hector-1829 (EW): a) Acceleration, b) Velocity, c) Displacement and d) Input energy
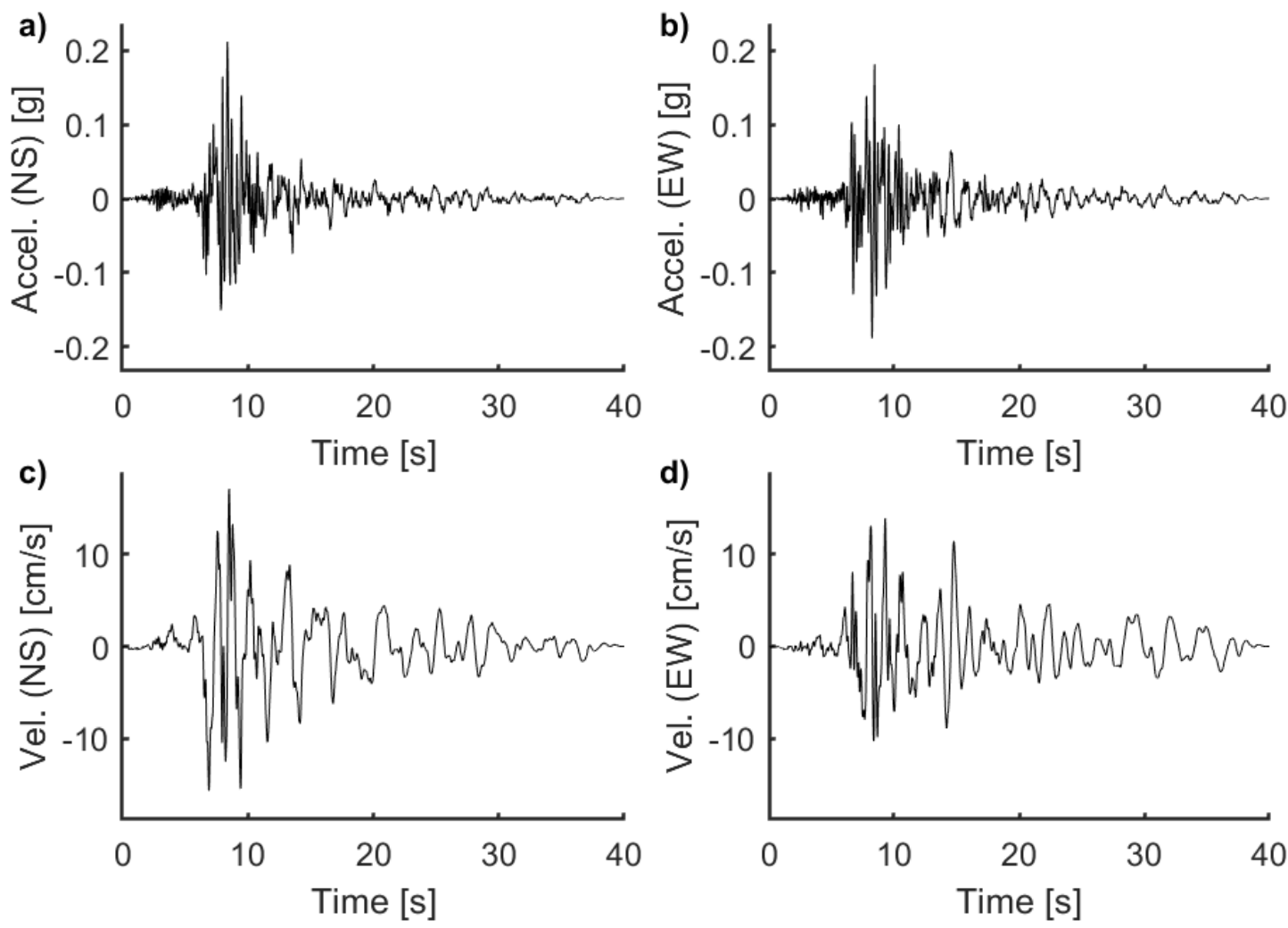

Figure A3. 76. Acceleration and velocity signals for Coalinga-352: a) Acceleration (NS), b) Acceleration (EW), c) Velocity (NS) and d) Velocity (EW) 

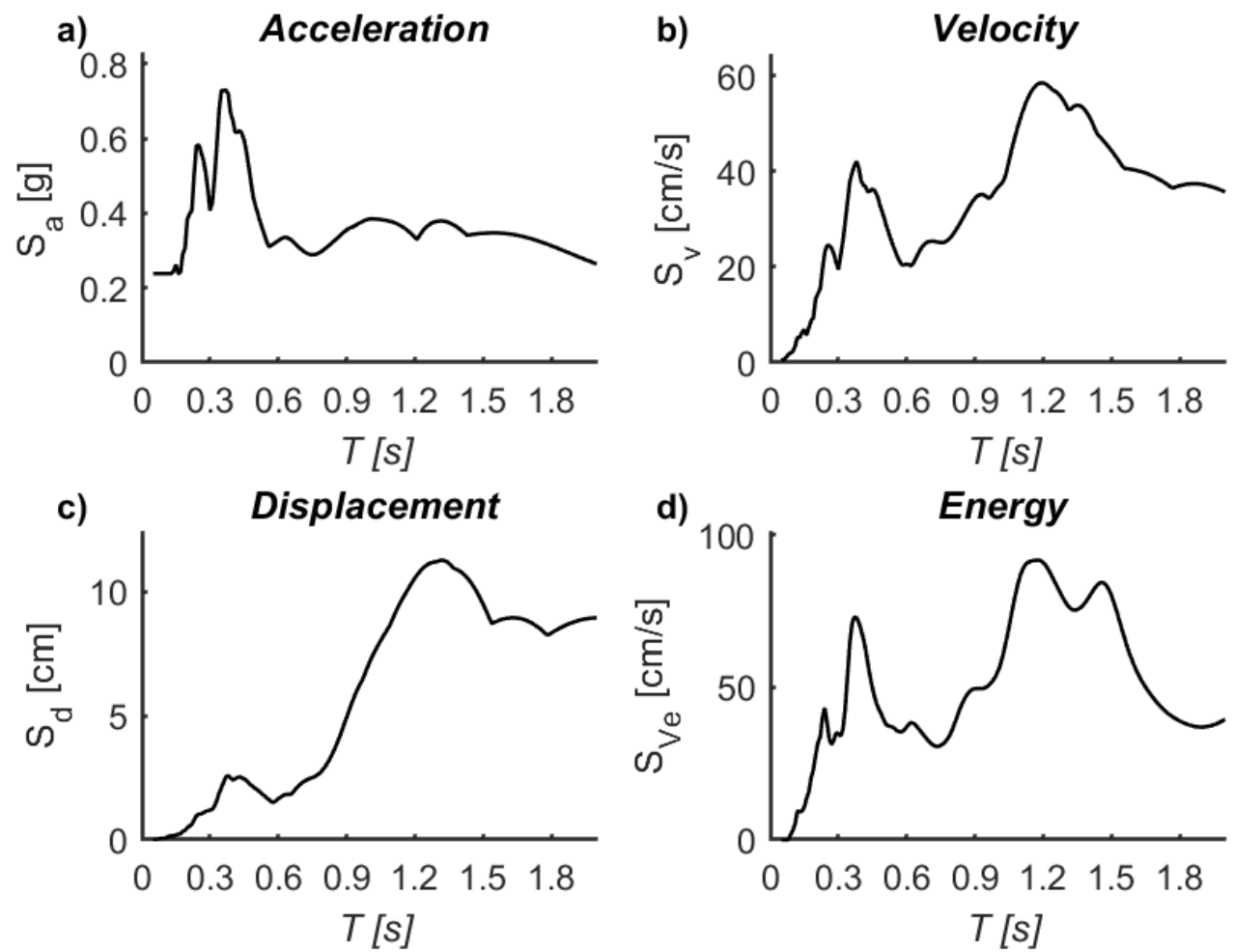

Figure A3. 77. Spectra of Coalinga-352 (NS): a) Acceleration, b) Velocity, c) Displacement and d) Input energy
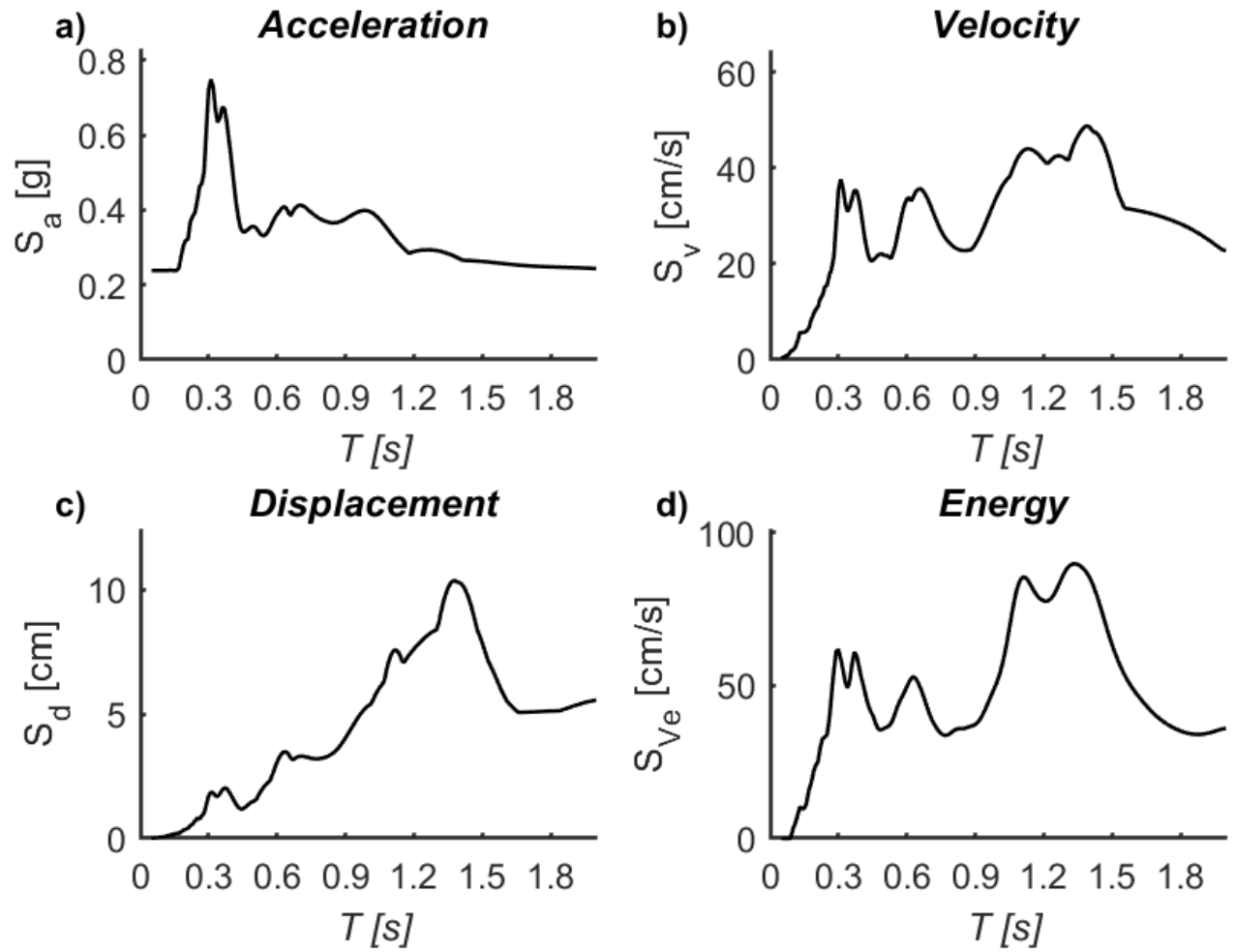

Figure A3. 78. Spectra of Coalinga-352 (EW): a) Acceleration, b) Velocity, c) Displacement and d) Input energy 

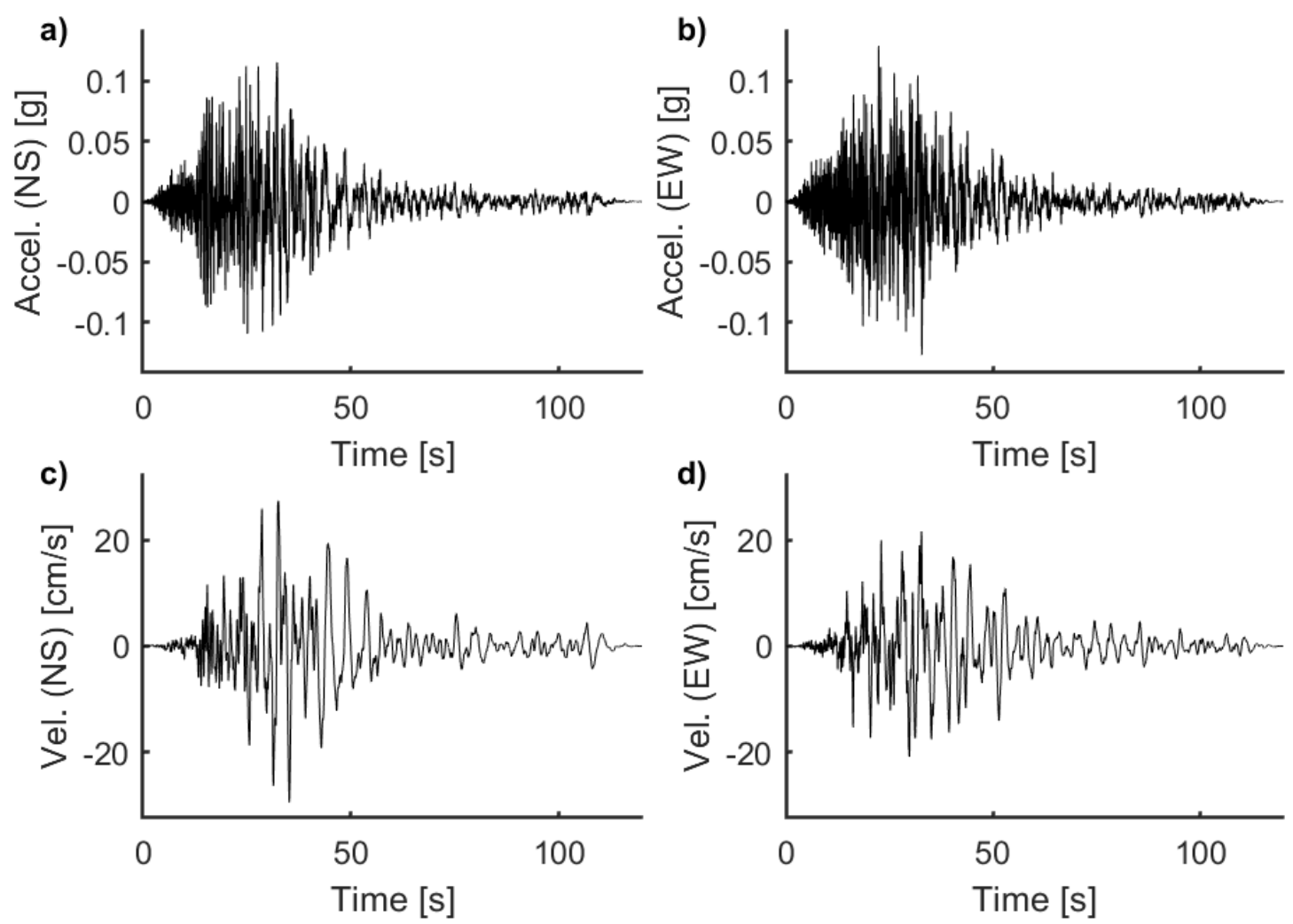

Figure A3. 79. Acceleration and velocity signals for Landers-888: a) Acceleration (NS), b) Acceleration (EW), c) Velocity (NS) and d) Velocity (EW)
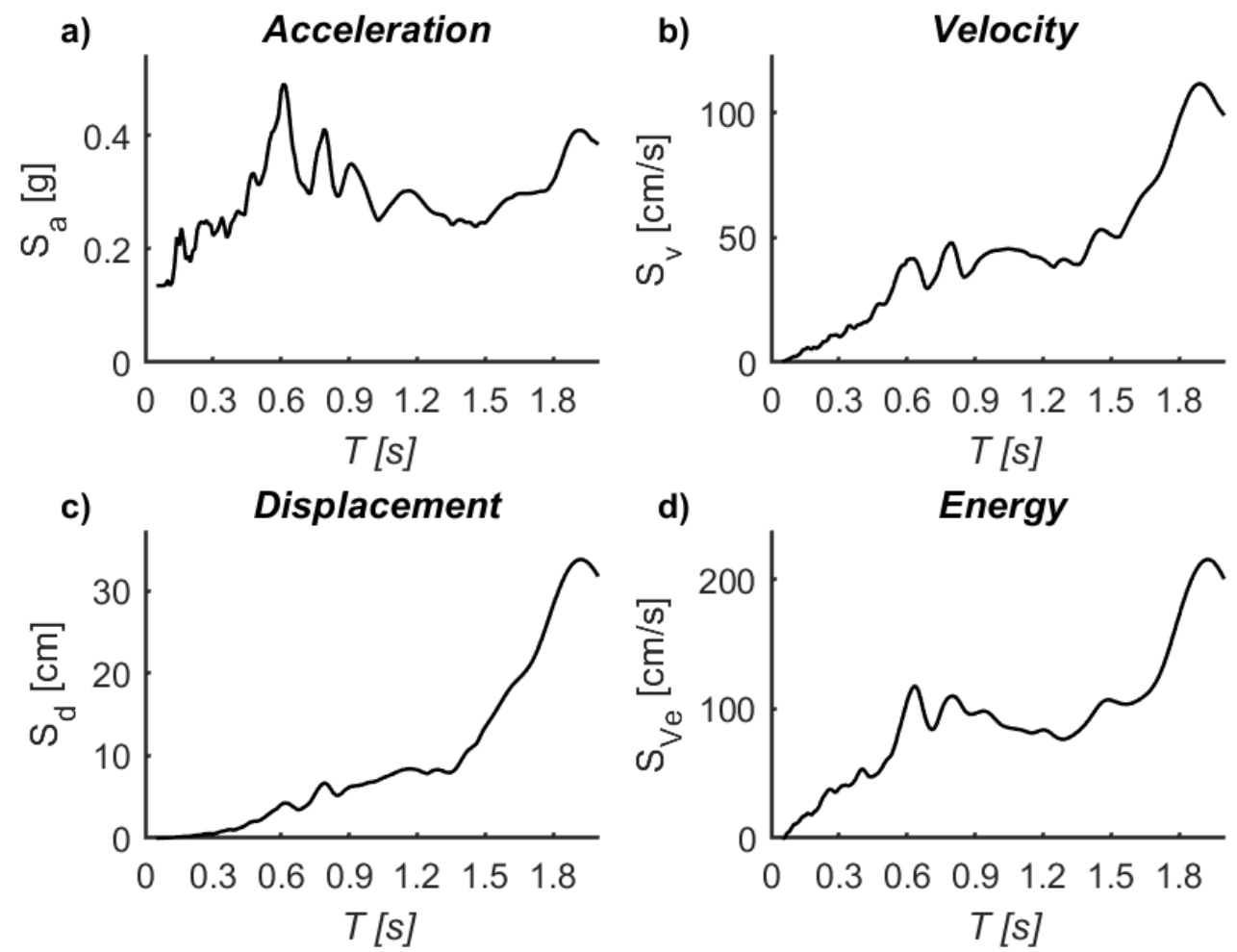

Figure A3. 80. Spectra of Landers-888 (NS): a) Acceleration, b) Velocity, c) Displacement and d) Input energy 

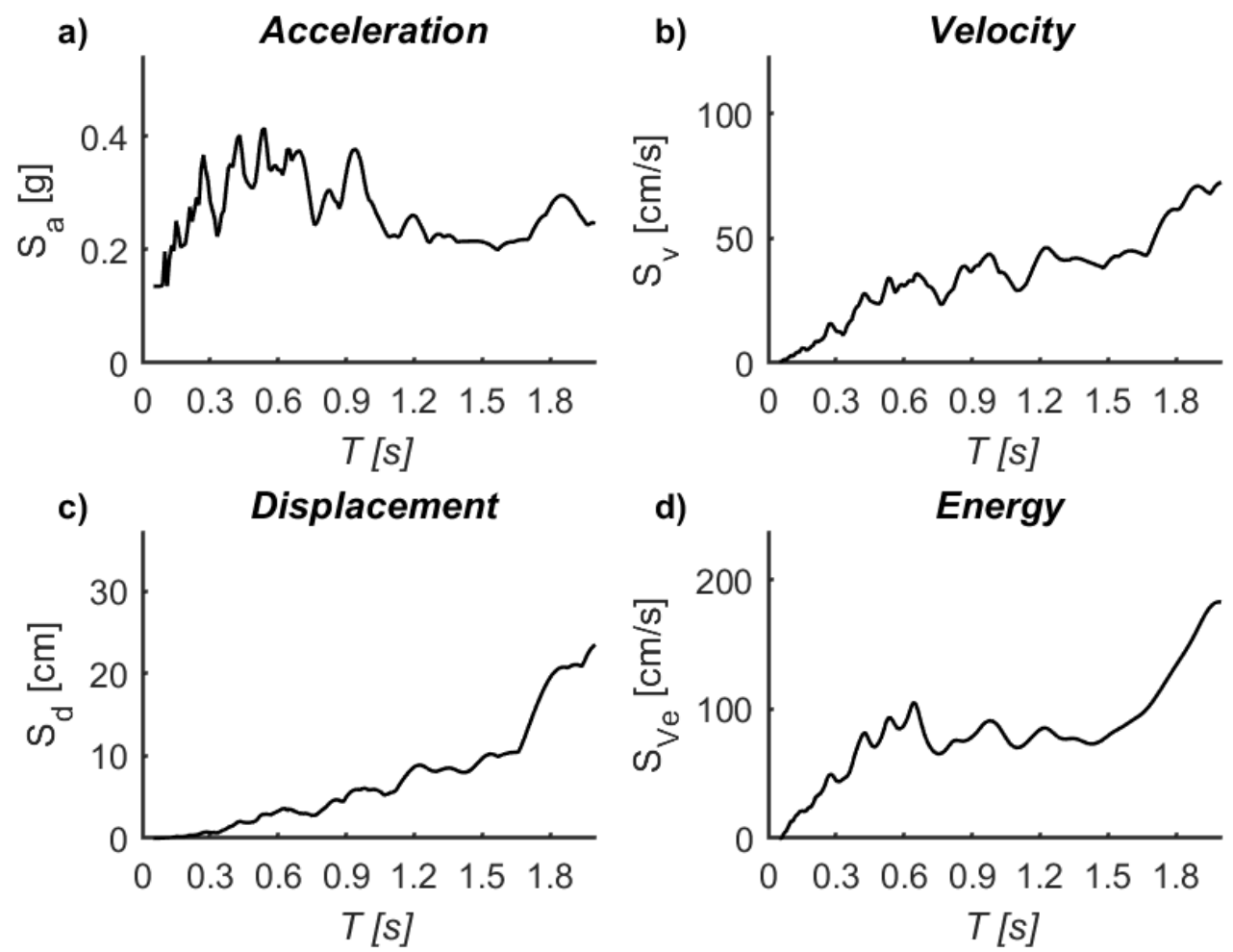

Figure A3. 81. Spectra of Landers-888 (EW): a) Acceleration, b) Velocity, c) Displacement and d) Input energy
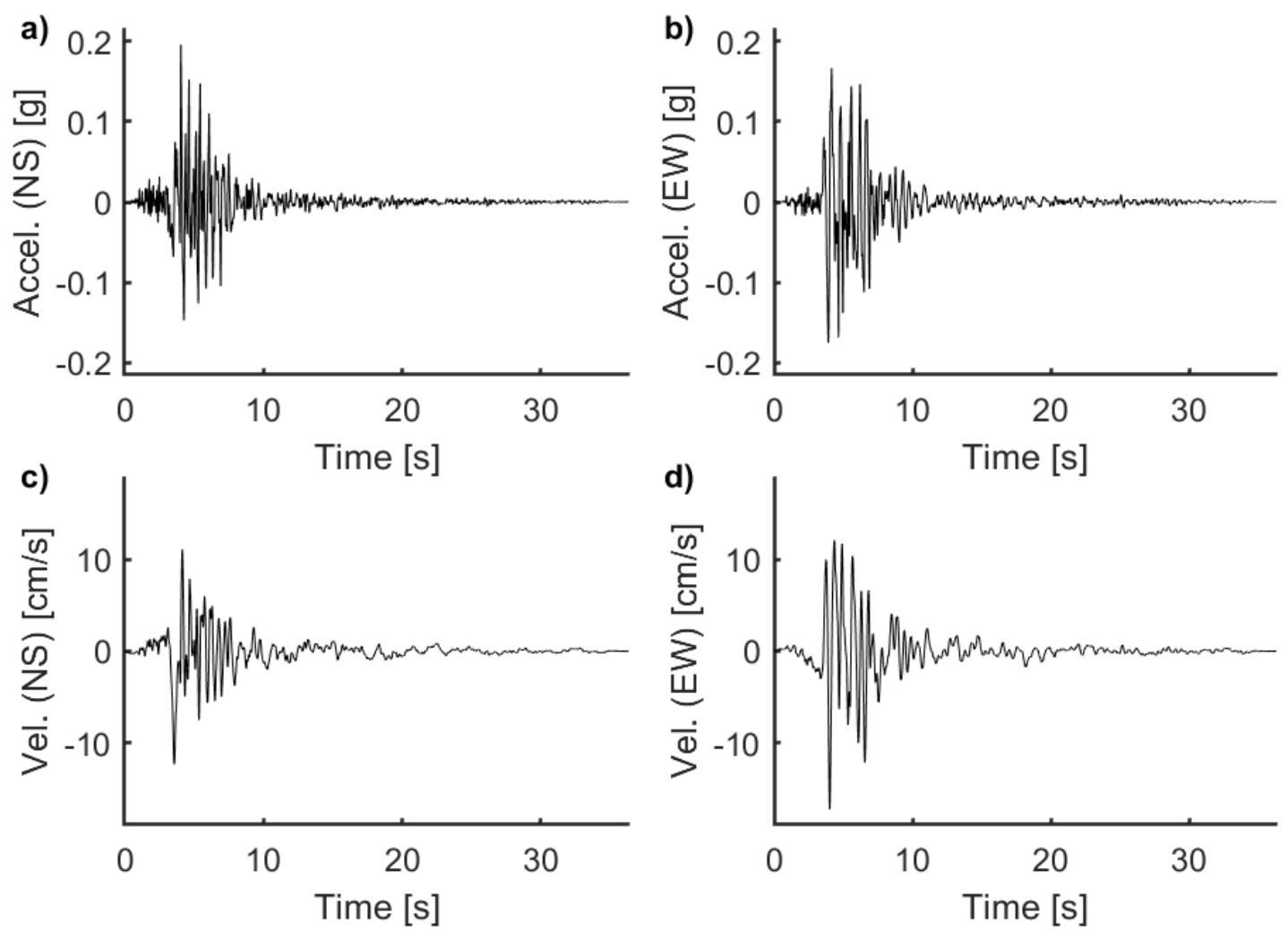

Figure A3. 82. Acceleration and velocity signals for Friuli-125: a) Acceleration (NS), b) Acceleration (EW), c) Velocity (NS) and d) Velocity (EW) 

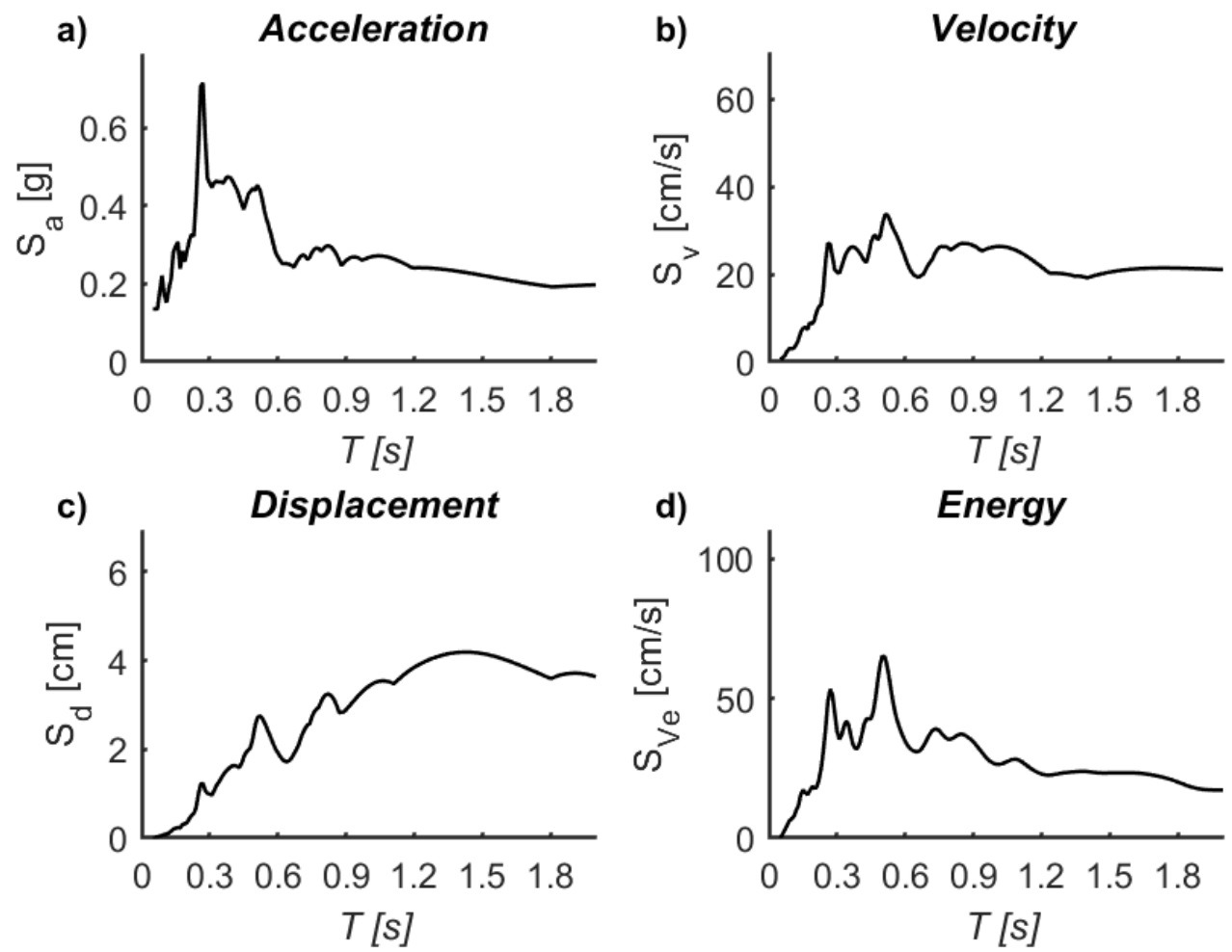

Figure A3. 83. Spectra of Friuli-125 (NS): a) Acceleration, b) Velocity, c) Displacement and d) Input energy
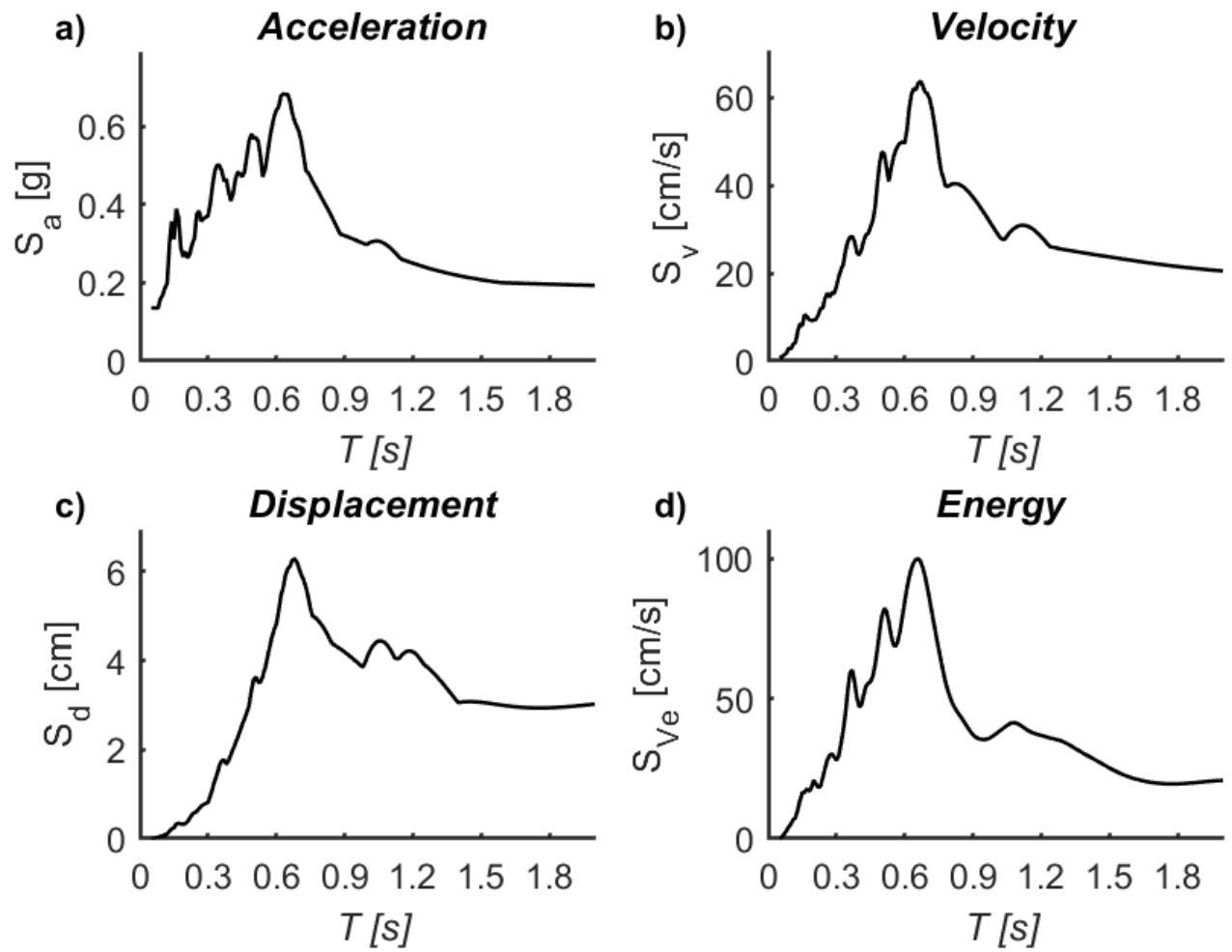

Figure A3. 84. Spectra of Friuli-125 (EW): a) Acceleration, b) Velocity, c) Displacement and d) Input energy 
a)
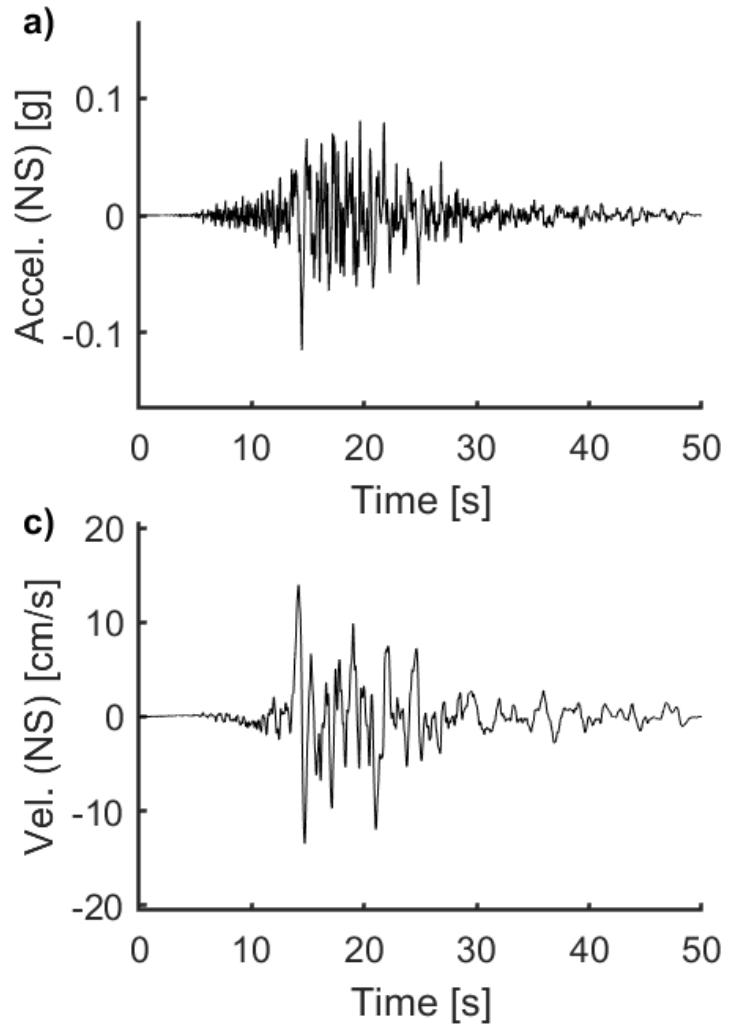

b)

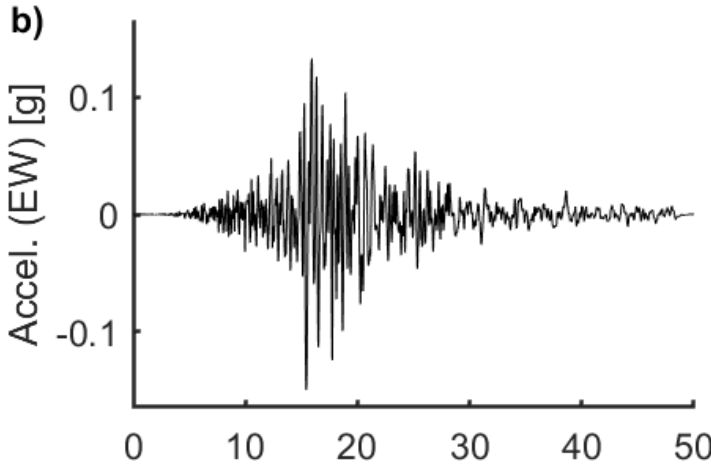

d) 20 Time [s]

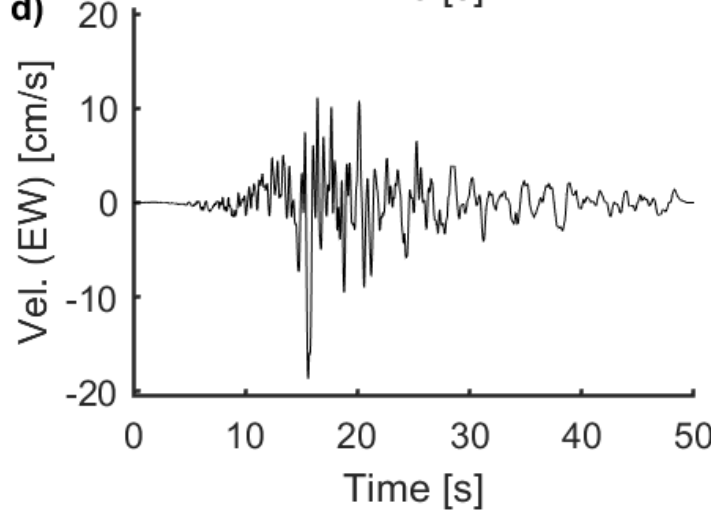

Figure A3. 85. Acceleration and velocity signals for Hector-1794: a) Acceleration (NS), b) Acceleration (EW), c) Velocity (NS) and d) Velocity (EW)
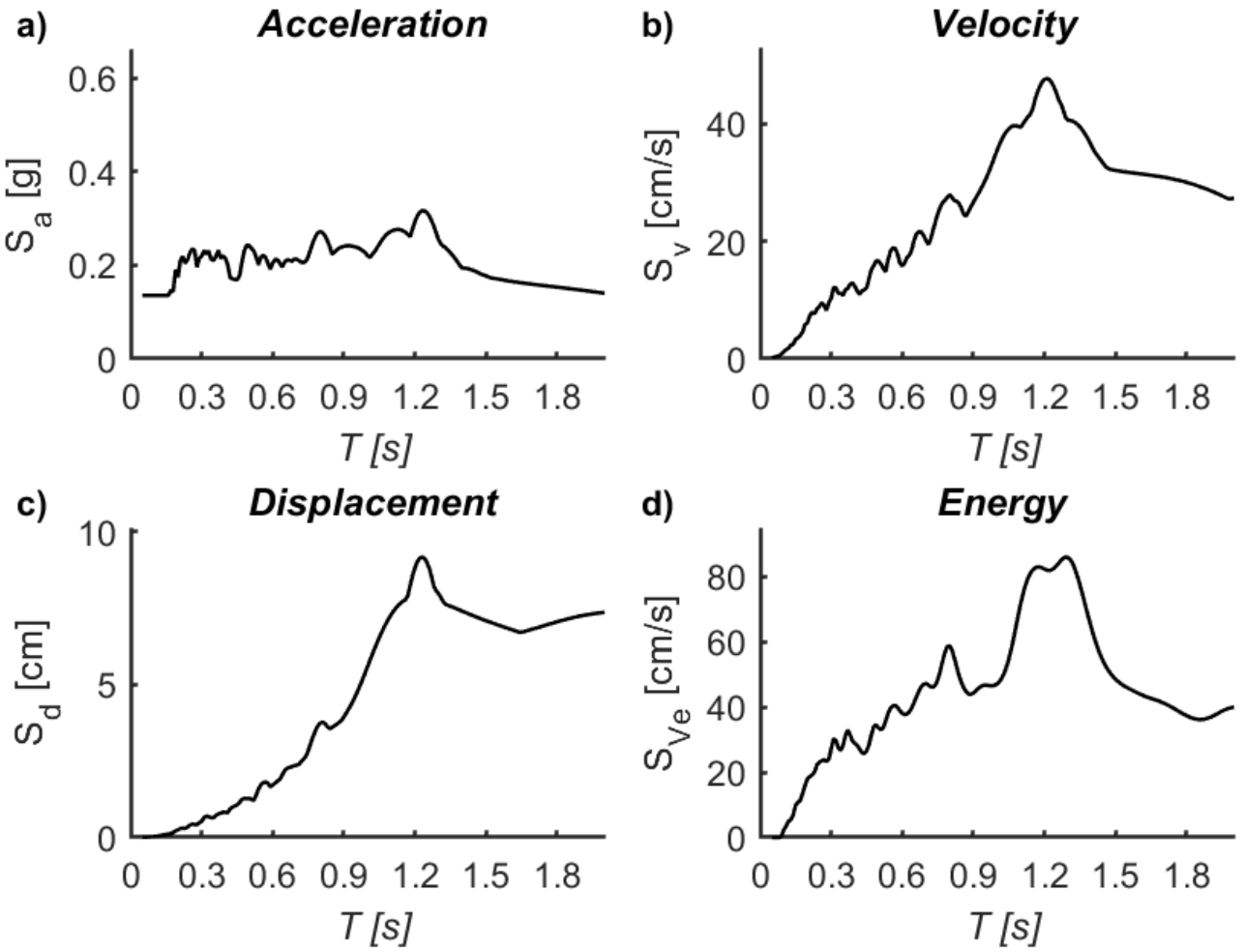

Figure A3. 86. Spectra of Hector-1794 (NS): a) Acceleration, b) Velocity, c) Displacement and d) Input energy 

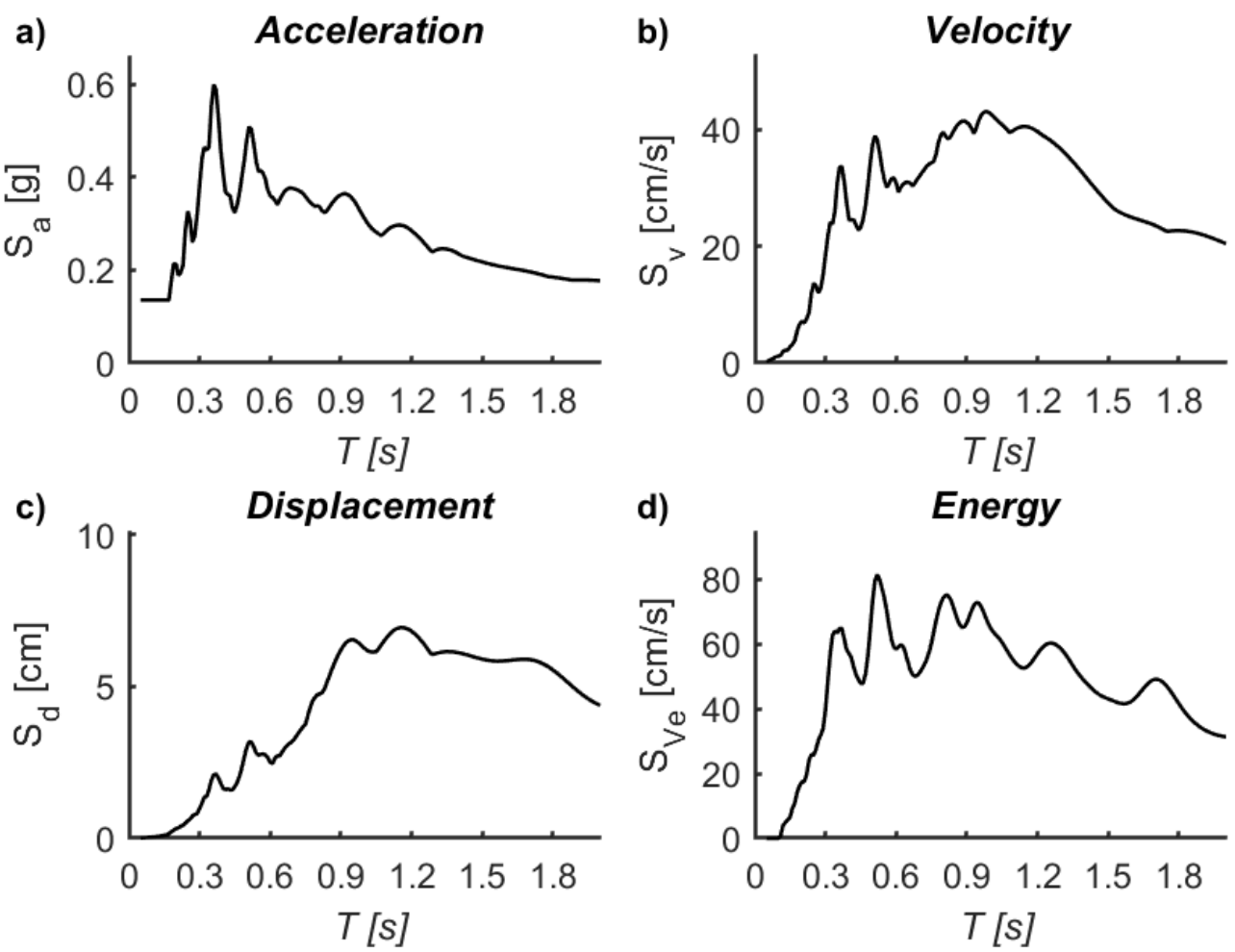

Figure A3. 87. Spectra of Hector-1794 (EW): a) Acceleration, b) Velocity, c) Displacement and d) Input energy
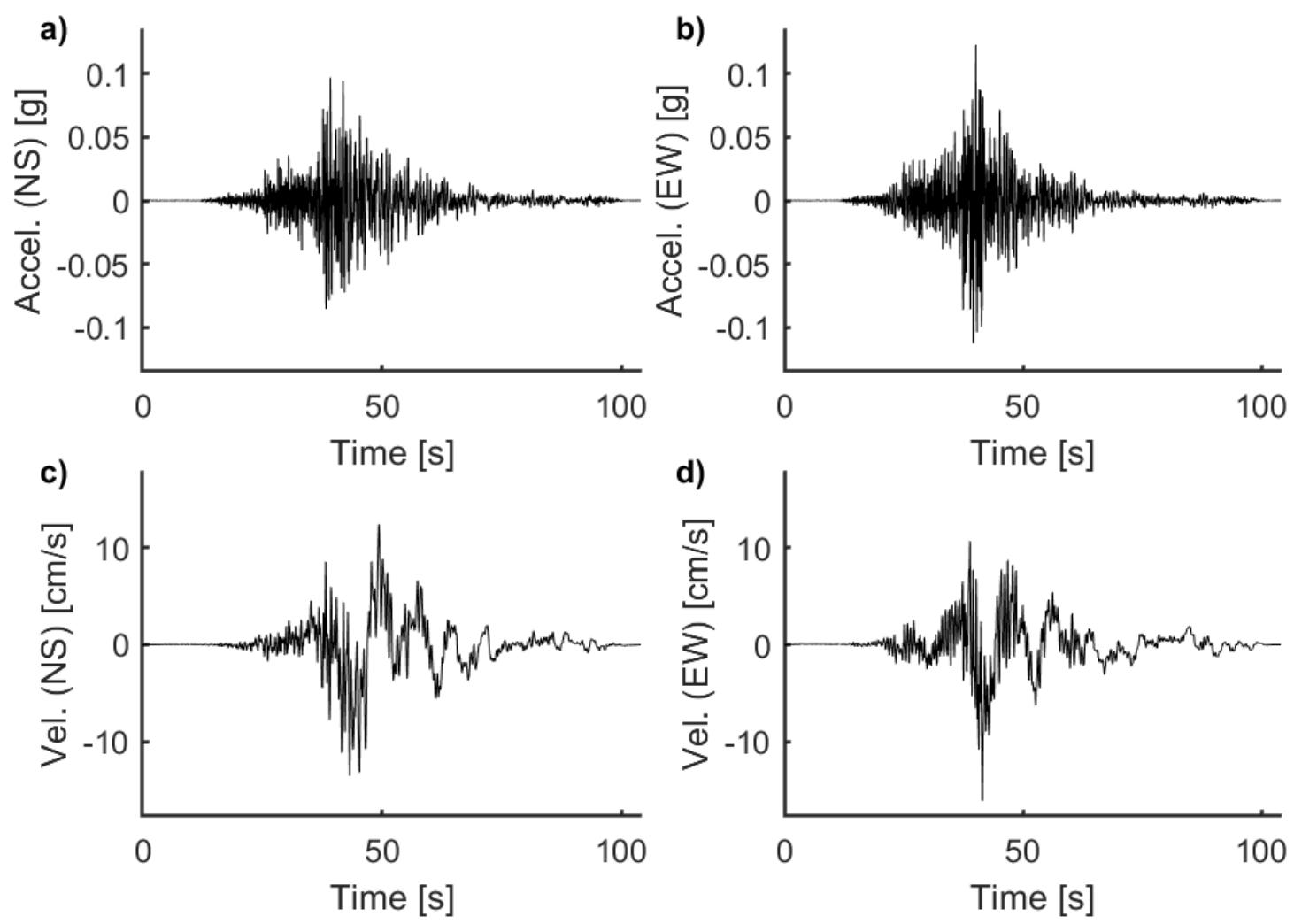

Figure A3. 88. Acceleration and velocity signals for Chichi-1349: a) Acceleration (NS), b) Acceleration (EW), c) Velocity (NS) and d) Velocity (EW) 

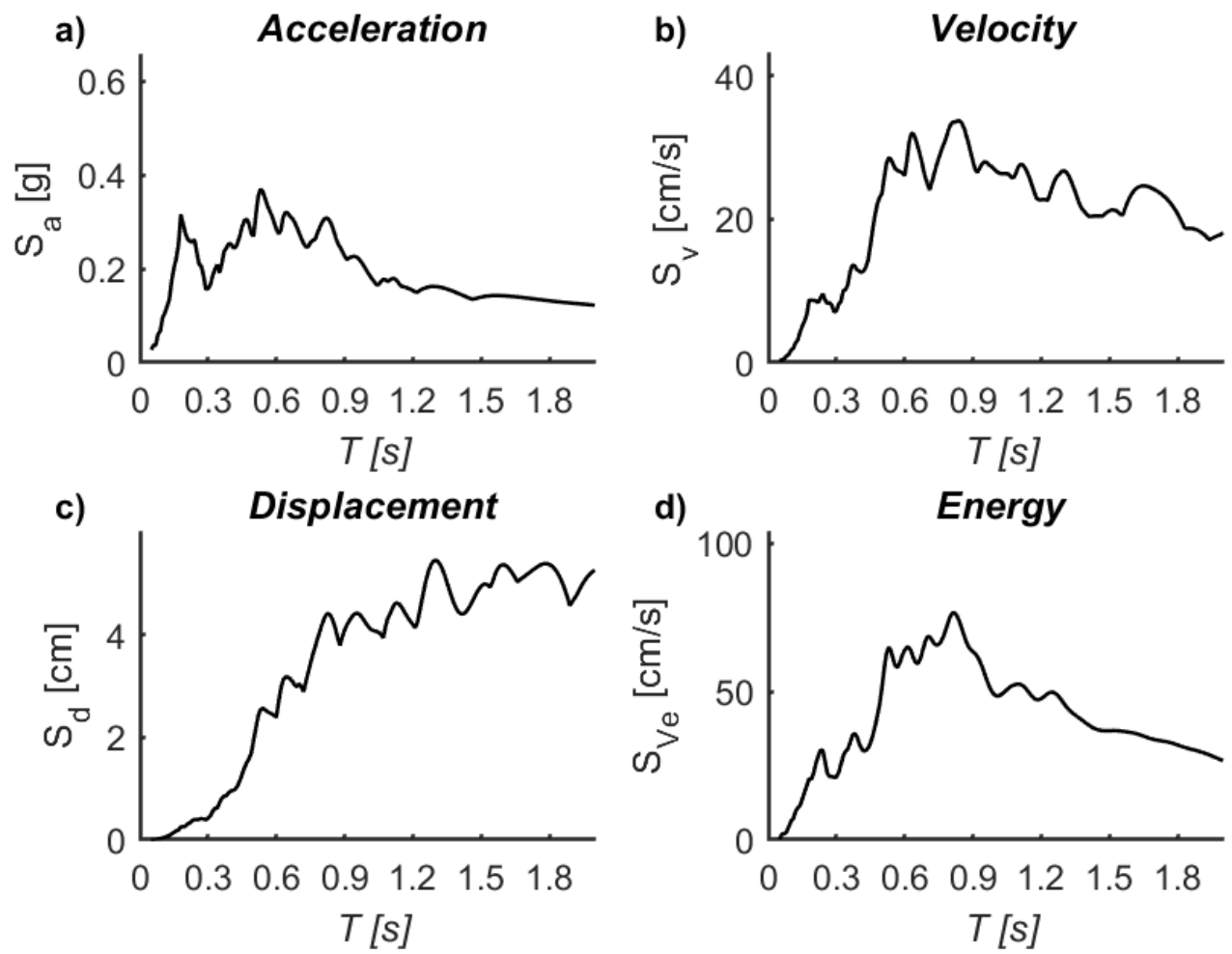

Figure A3. 89. Spectra of Chichi-1349 (NS): a) Acceleration, b) Velocity, c) Displacement and d) Input energy
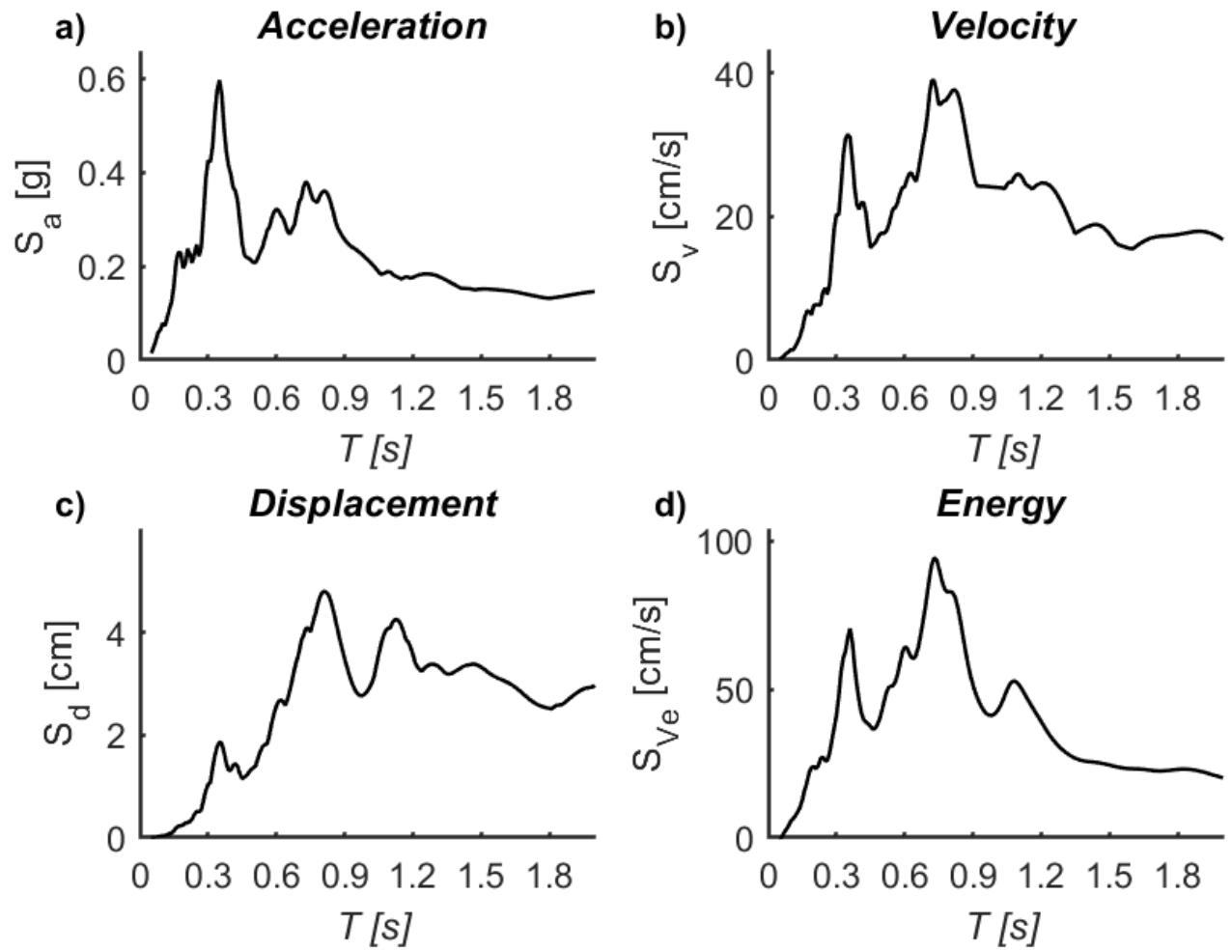

Figure A3. 90. Spectra of Chichi-1349 (EW): a) Acceleration, b) Velocity, c) Displacement and d) Input energy 

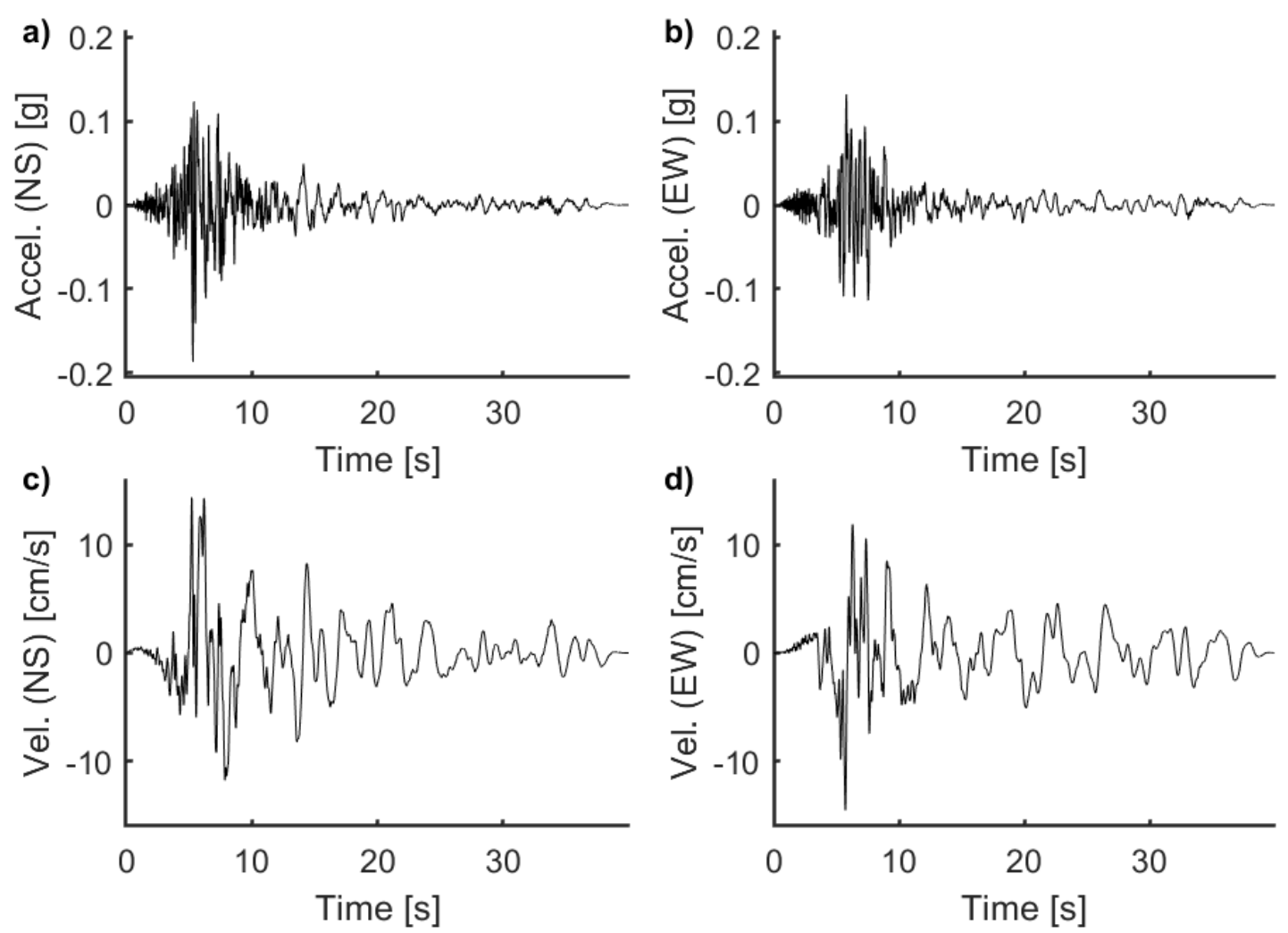

Figure A3. 91. Acceleration and velocity signals for Chalfant-549: a) Acceleration (NS), b) Acceleration (EW), c) Velocity (NS) and d) Velocity (EW)

a)

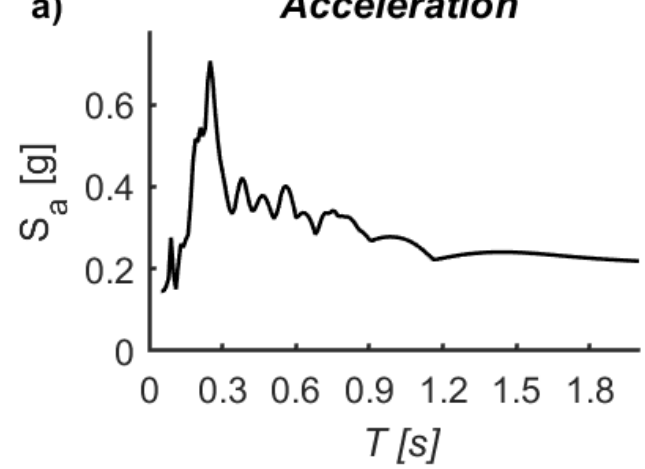

c)

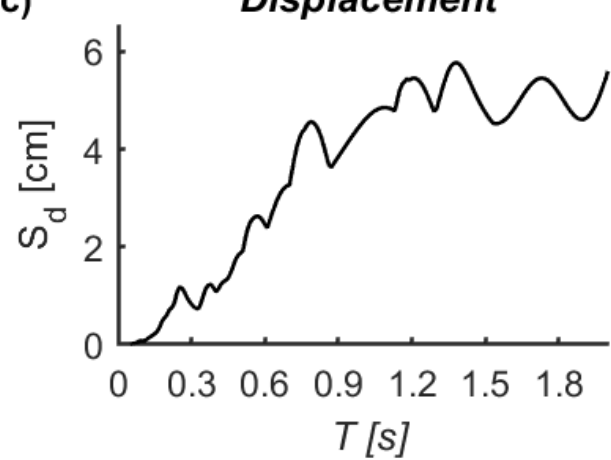

b) Velocity

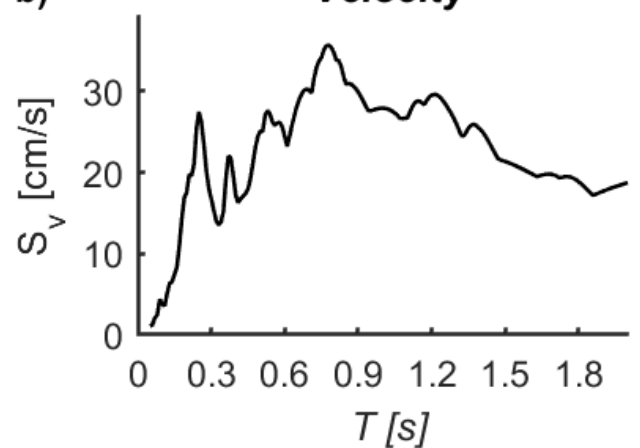

d)

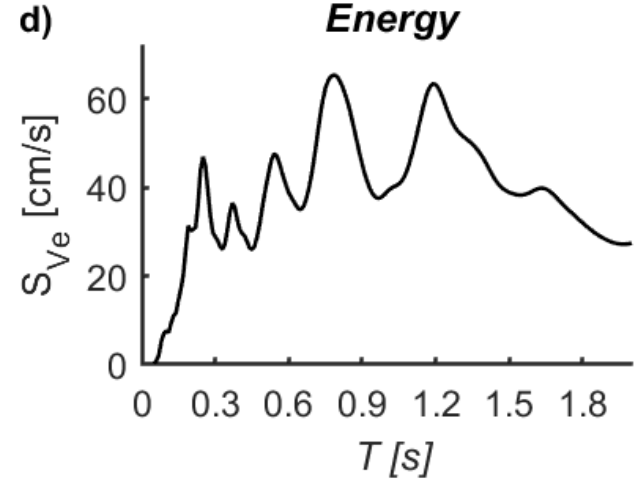

Figure A3. 92. Spectra of Chalfant-549 (NS): a) Acceleration, b) Velocity, c) Displacement and d) Input energy 
a)
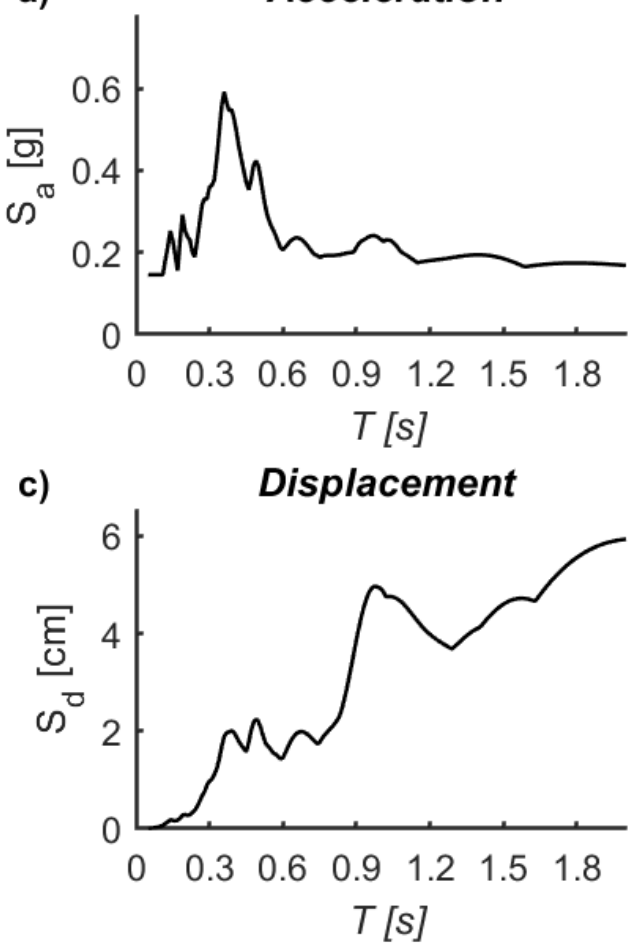

b) Velocity

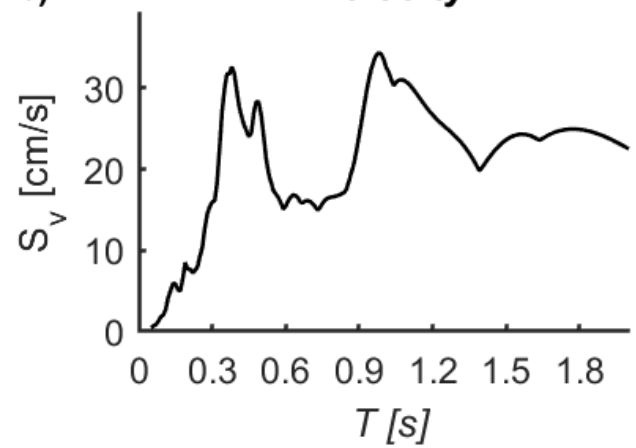

d)

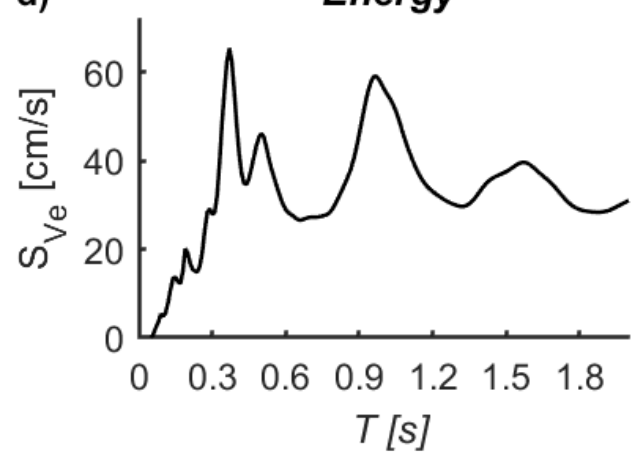

Figure A3. 93. Spectra of Chalfant-549 (EW): a) Acceleration, b) Velocity, c) Displacement and d) Input energy
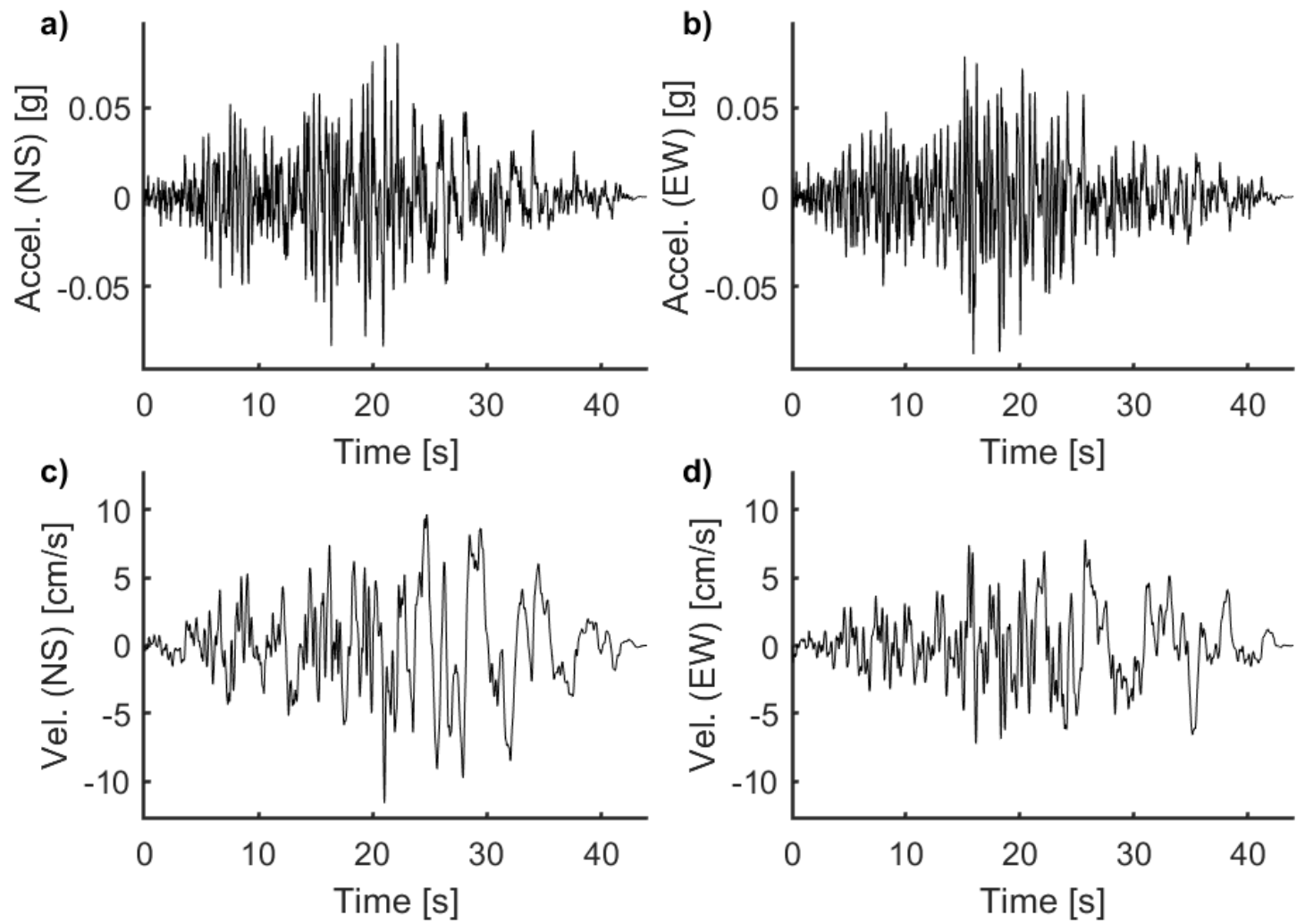

Figure A3. 94. Acceleration and velocity signals for Landers-854: a) Acceleration (NS), b) Acceleration (EW), c) Velocity (NS) and d) Velocity (EW) 

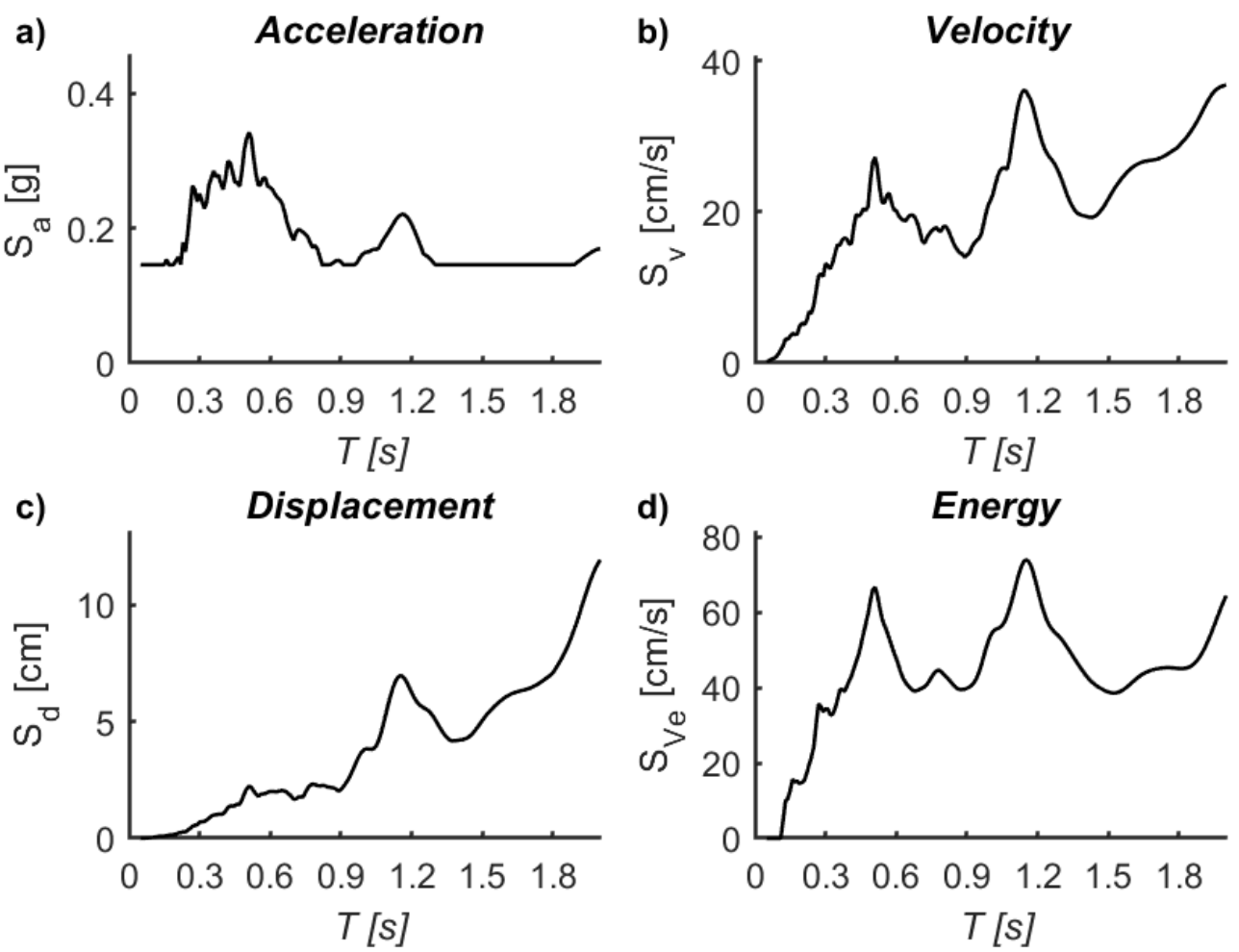

Figure A3. 95. Spectra of Landers-854 (NS): a) Acceleration, b) Velocity, c) Displacement and d) Input energy
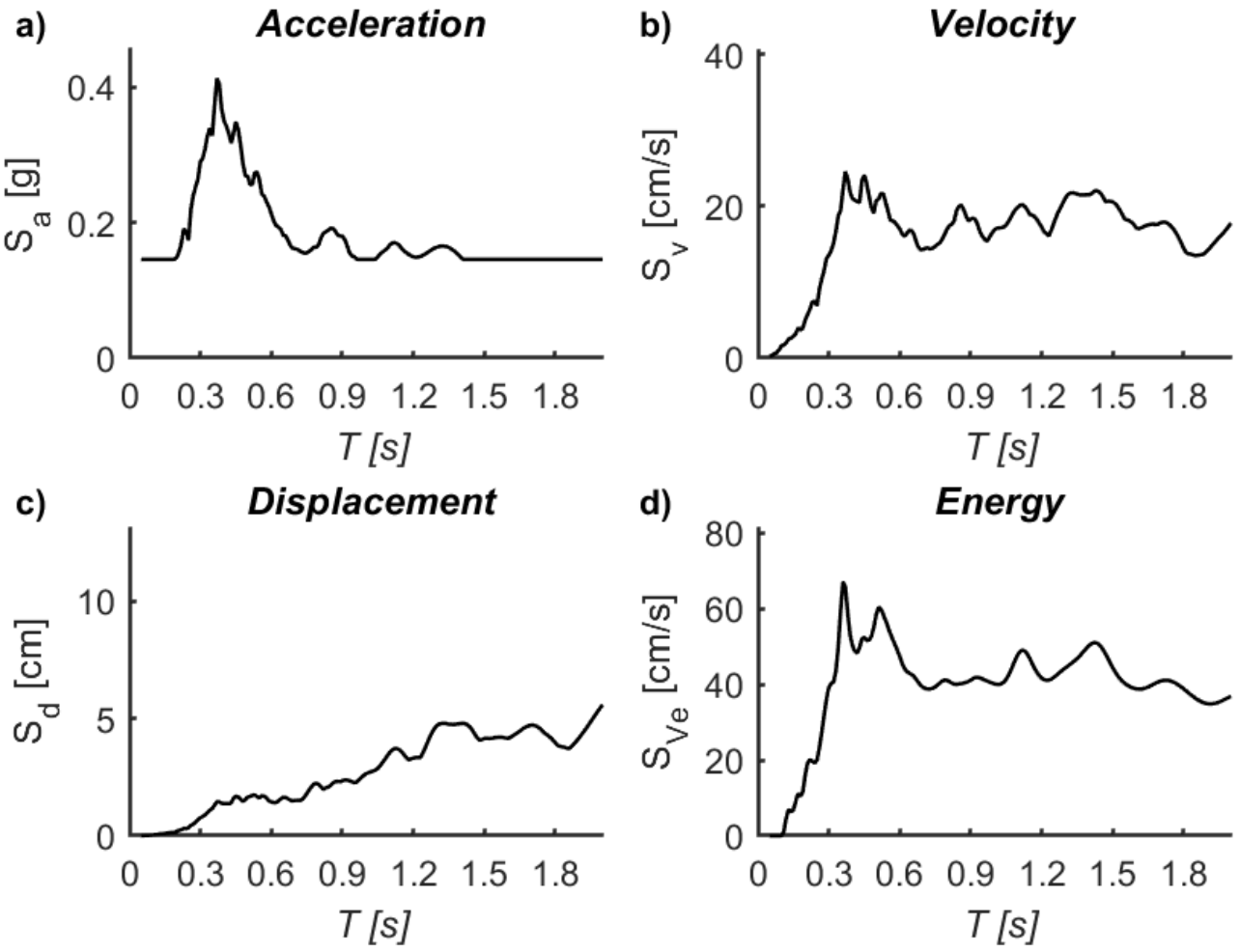

Figure A3. 96. Spectra of Landers-854 (EW): a) Acceleration, b) Velocity, c) Displacement and d) Input energy 
a)

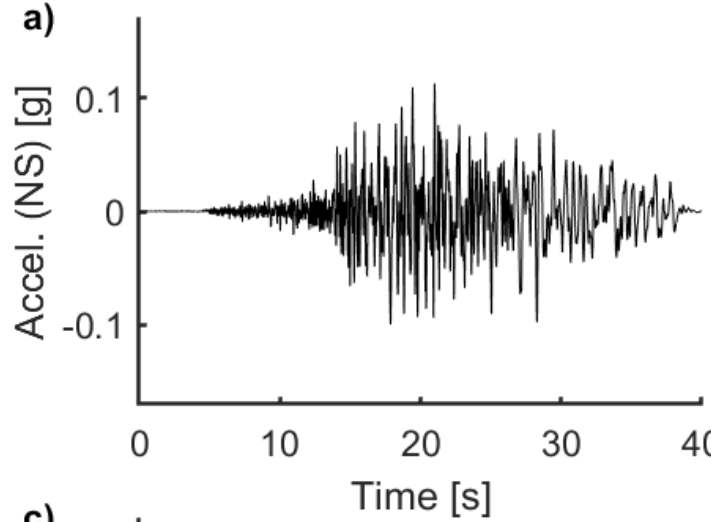

c)

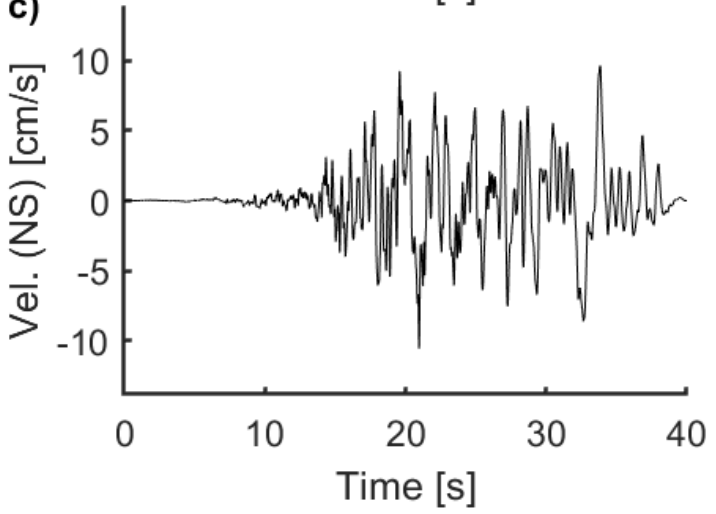

b)

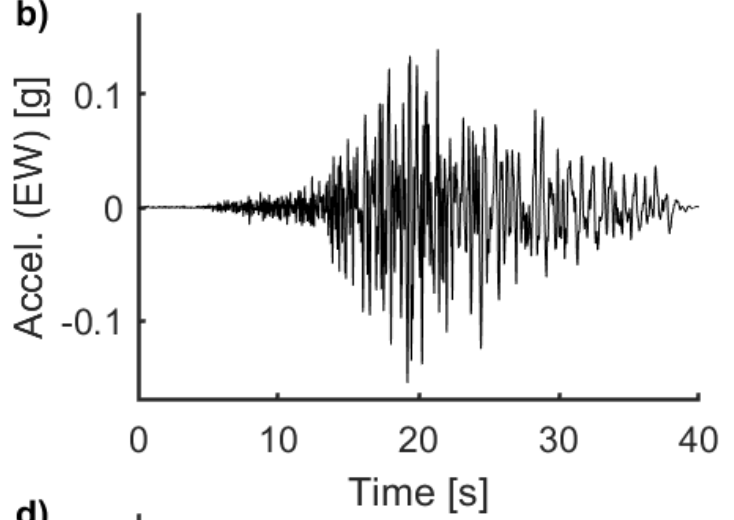

d)

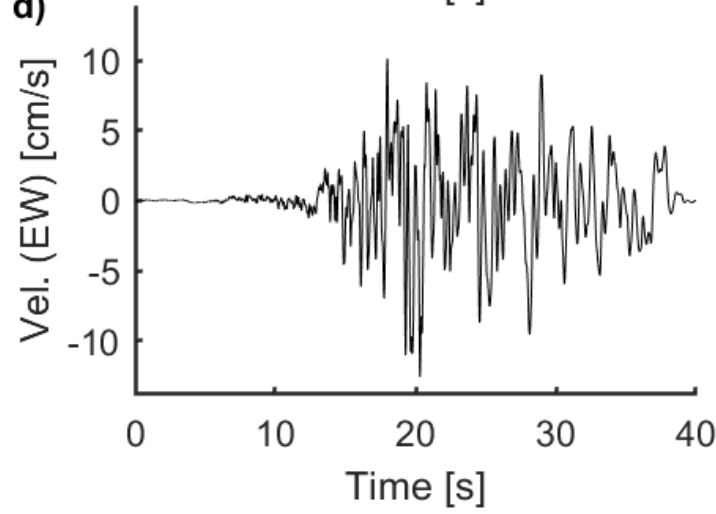

Figure A3. 97. Acceleration and velocity signals for Northr-1079: a) Acceleration (NS), b) Acceleration (EW), c) Velocity (NS) and d) Velocity (EW)
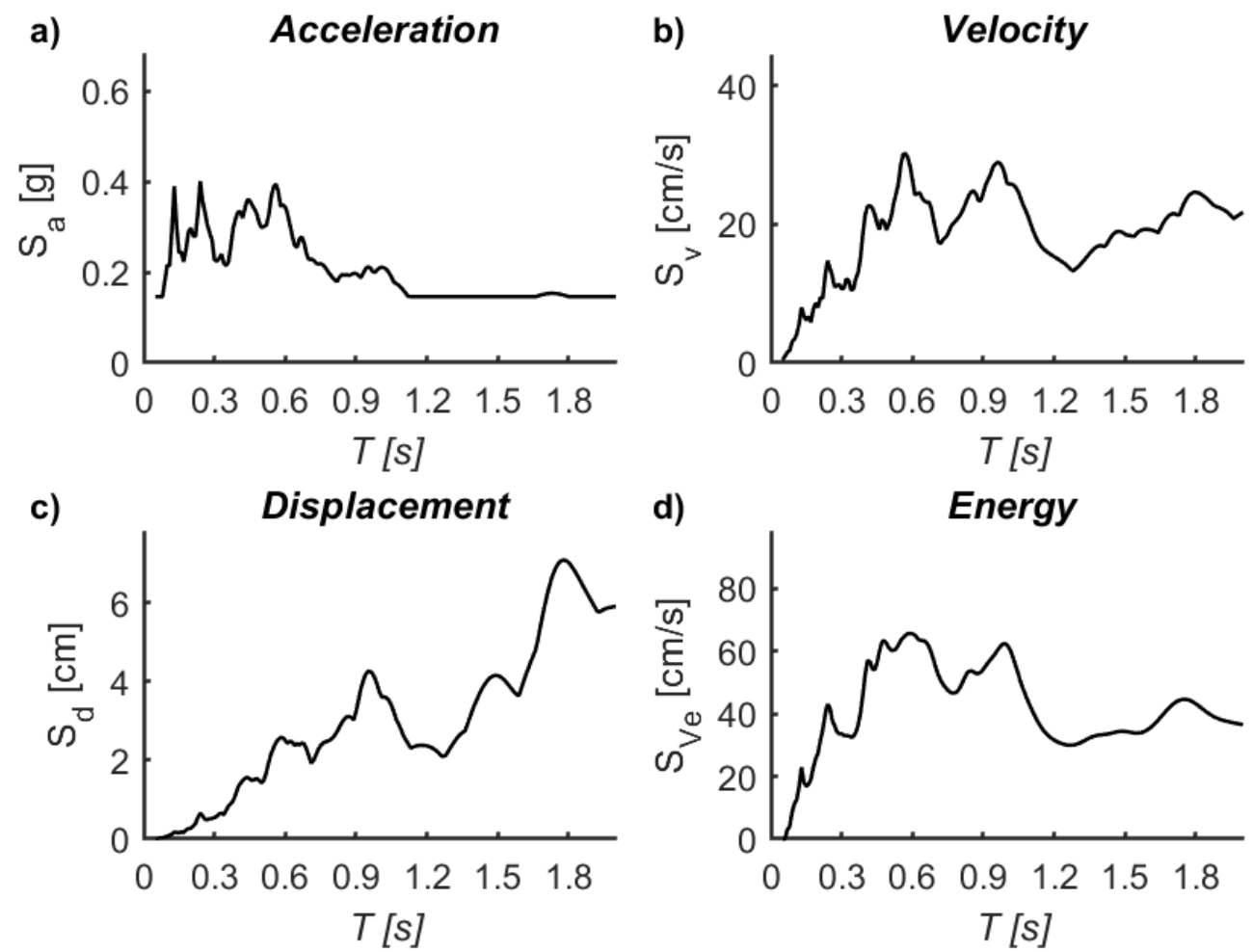

Figure A3. 98. Spectra of Northr-1079 (NS): a) Acceleration, b) Velocity, c) Displacement and d) Input energy 

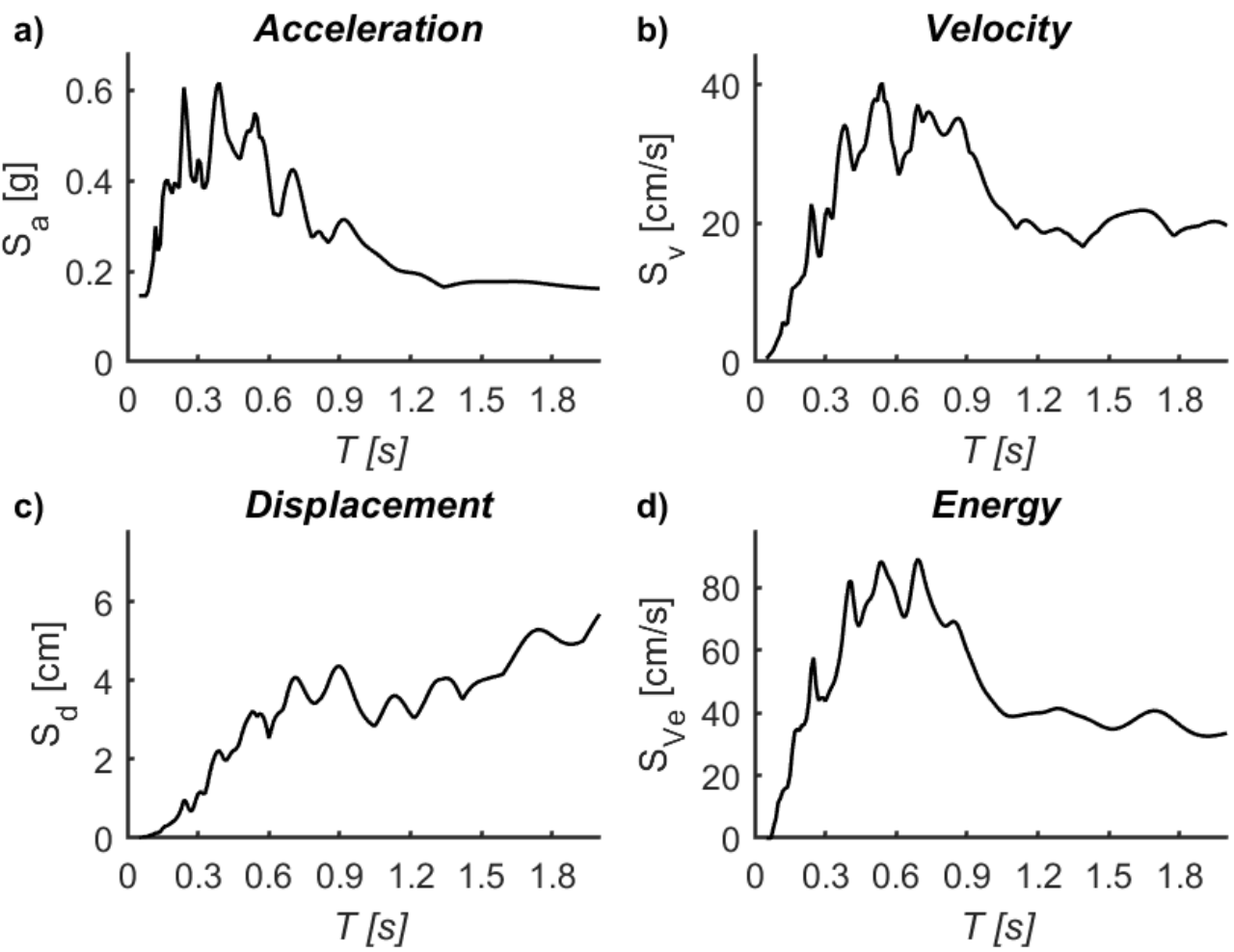

Figure A3. 99. Spectra of Northr-1079 (EW): a) Acceleration, b) Velocity, c) Displacement and d) Input energy

a)
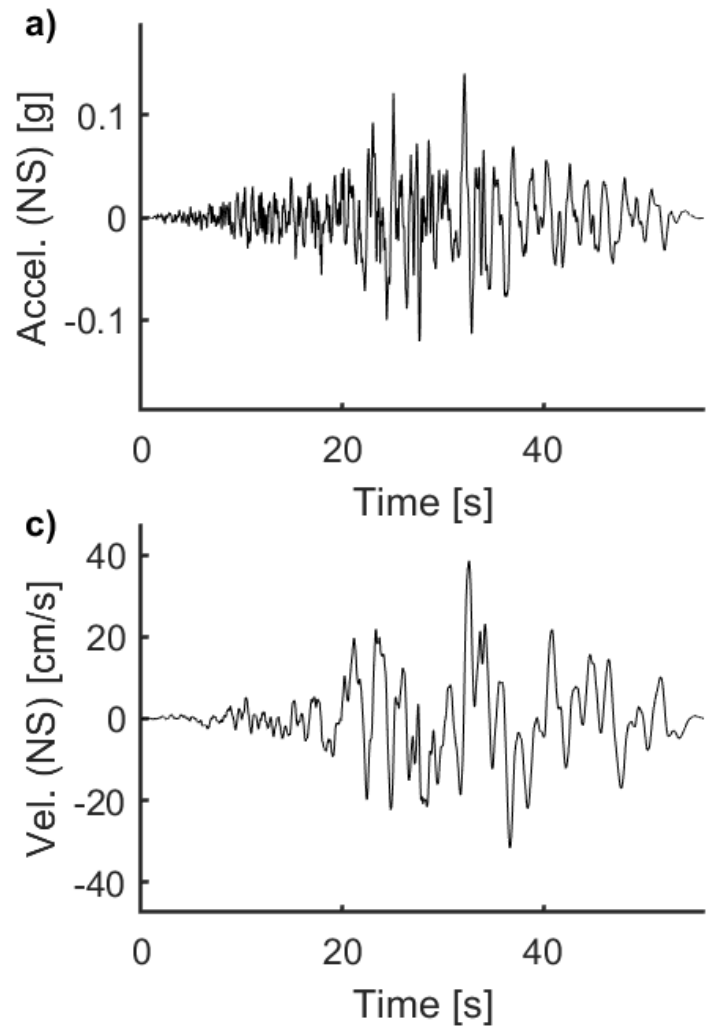

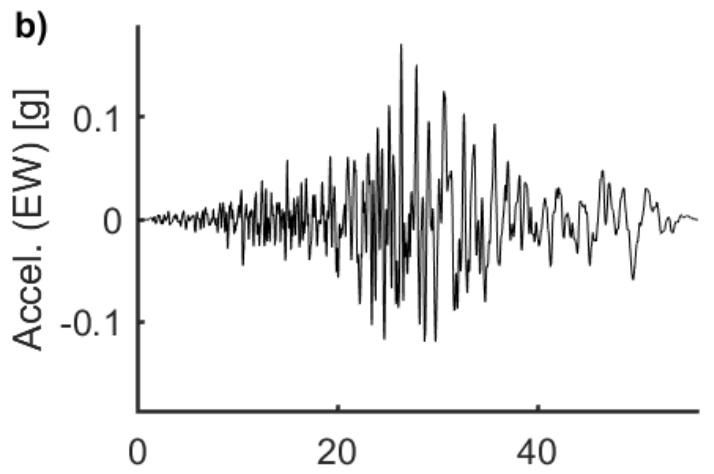

Time $[\mathrm{s}]$

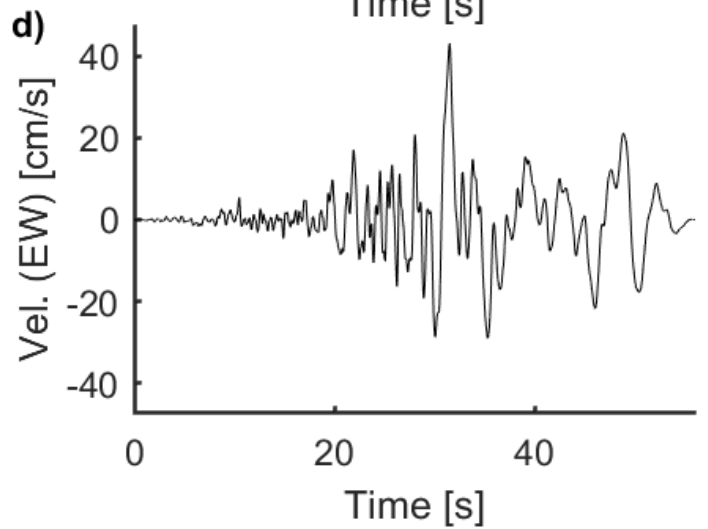

Figure A3. 100. Acceleration and velocity signals for Chichi-1328: a) Acceleration (NS), b) Acceleration (EW), c) Velocity (NS) and d) Velocity (EW) 

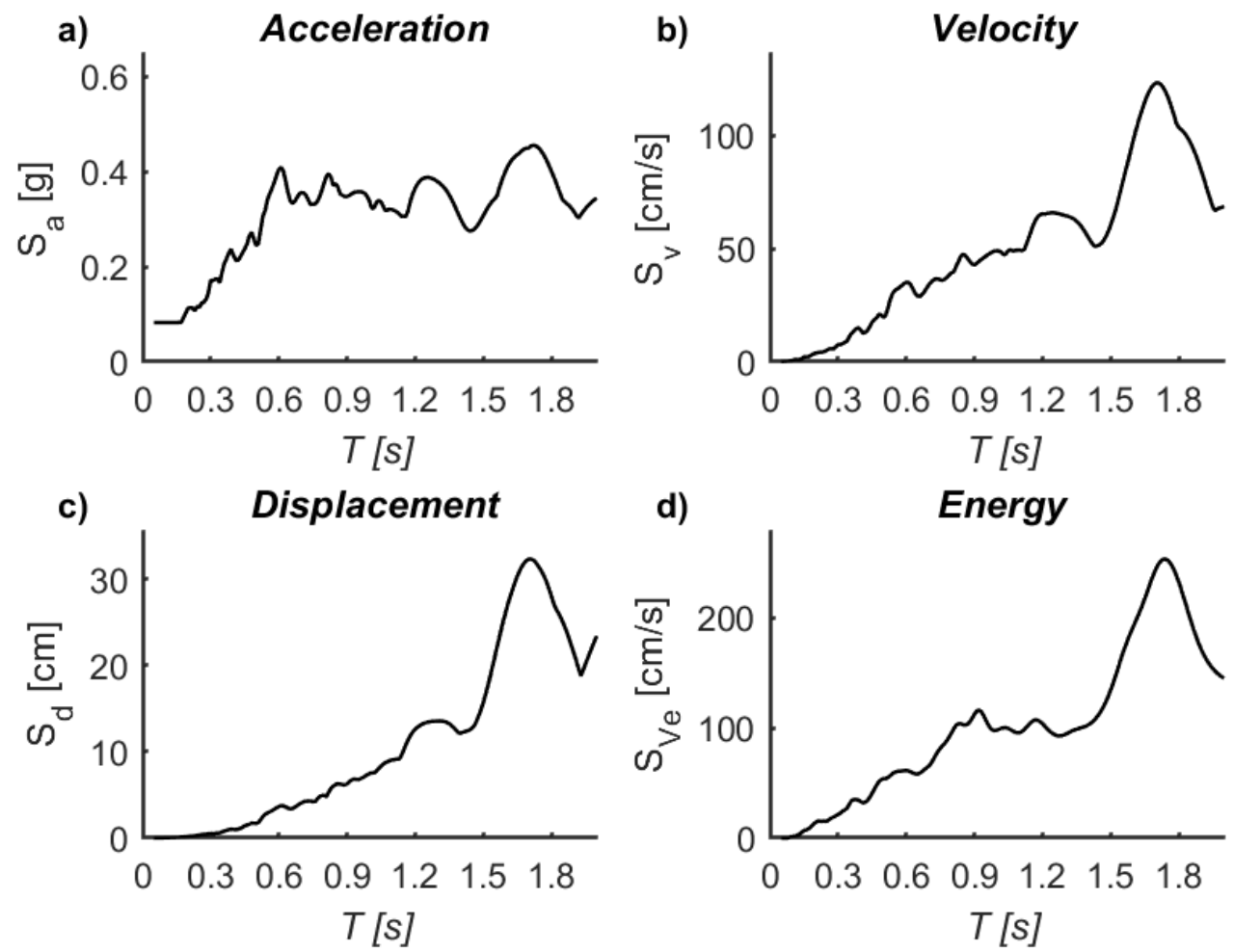

Figure A3. 101. Spectra of Chichi-1328 (NS): a) Acceleration, b) Velocity, c) Displacement and d) Input energy
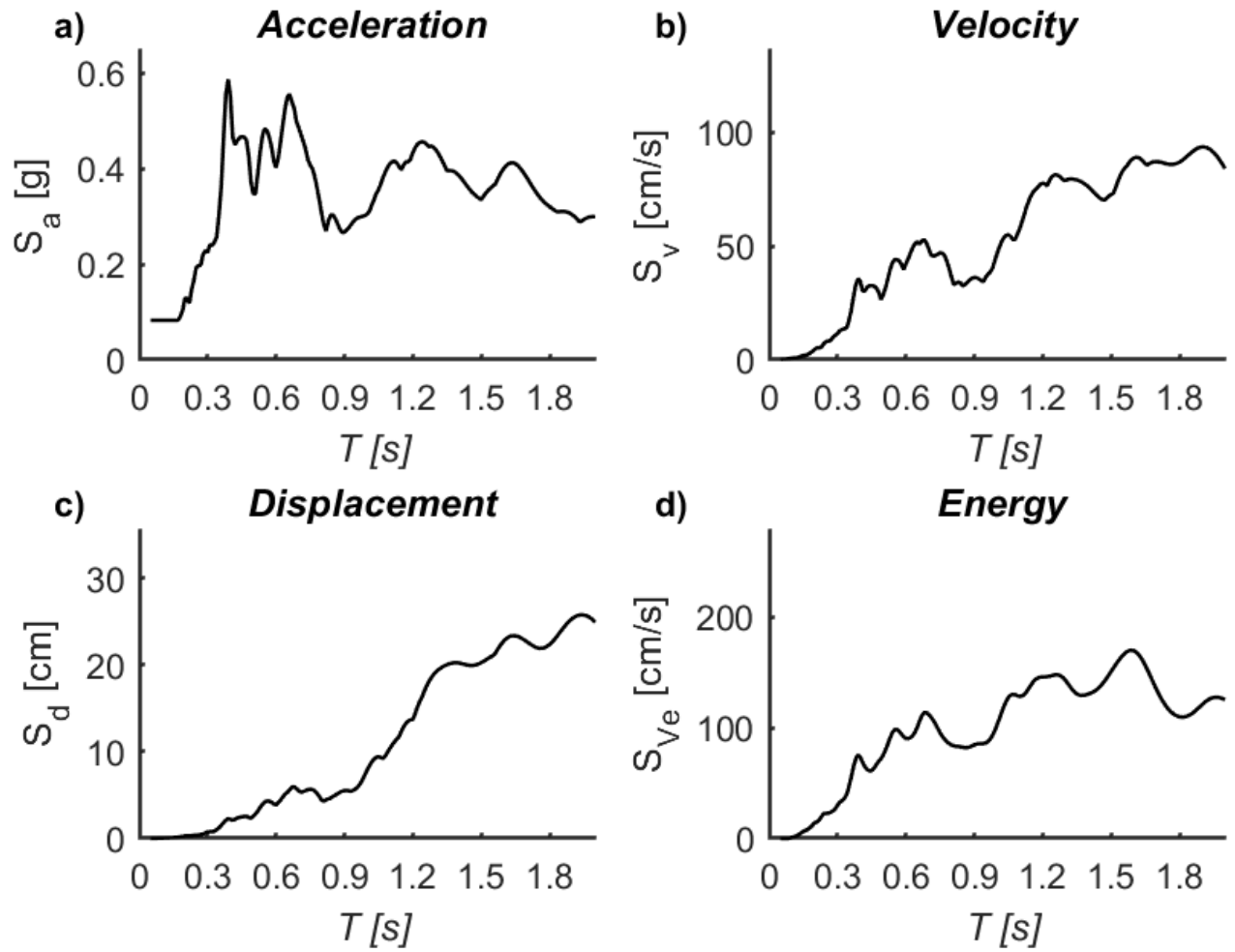

Figure A3. 102. Spectra of Chichi-1328 (EW): a) Acceleration, b) Velocity, c) Displacement and d) Input energy 
a)
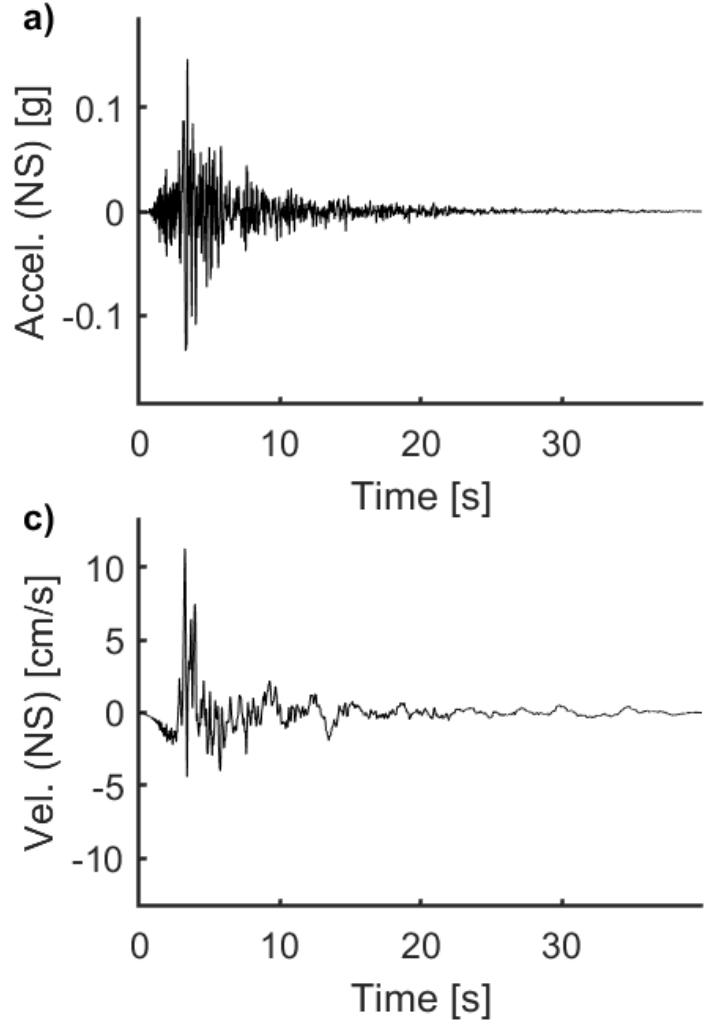

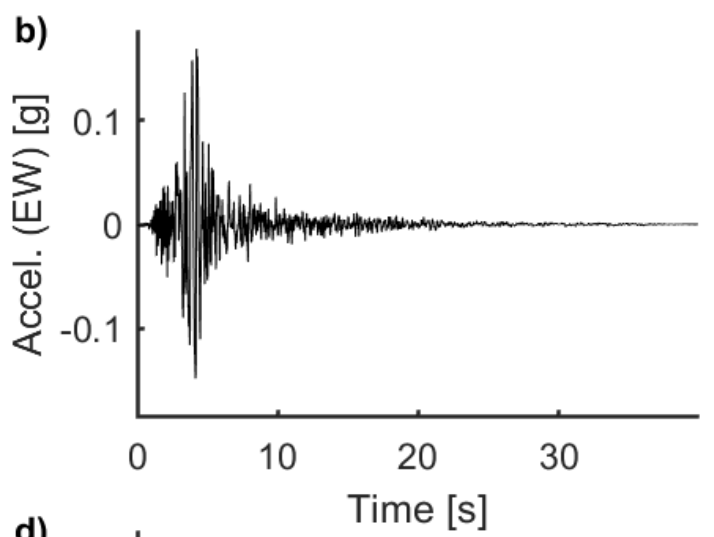

d)

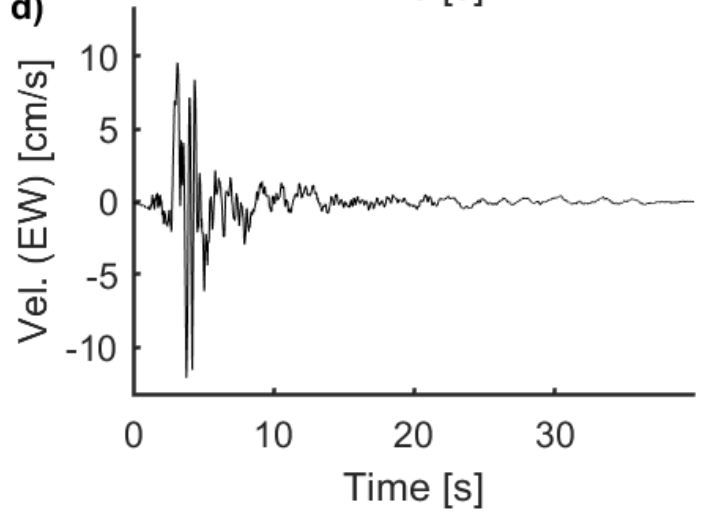

Figure A3. 103. Acceleration and velocity signals for Lomap-765: a) Acceleration (NS), b) Acceleration (EW), c) Velocity (NS) and d) Velocity (EW)
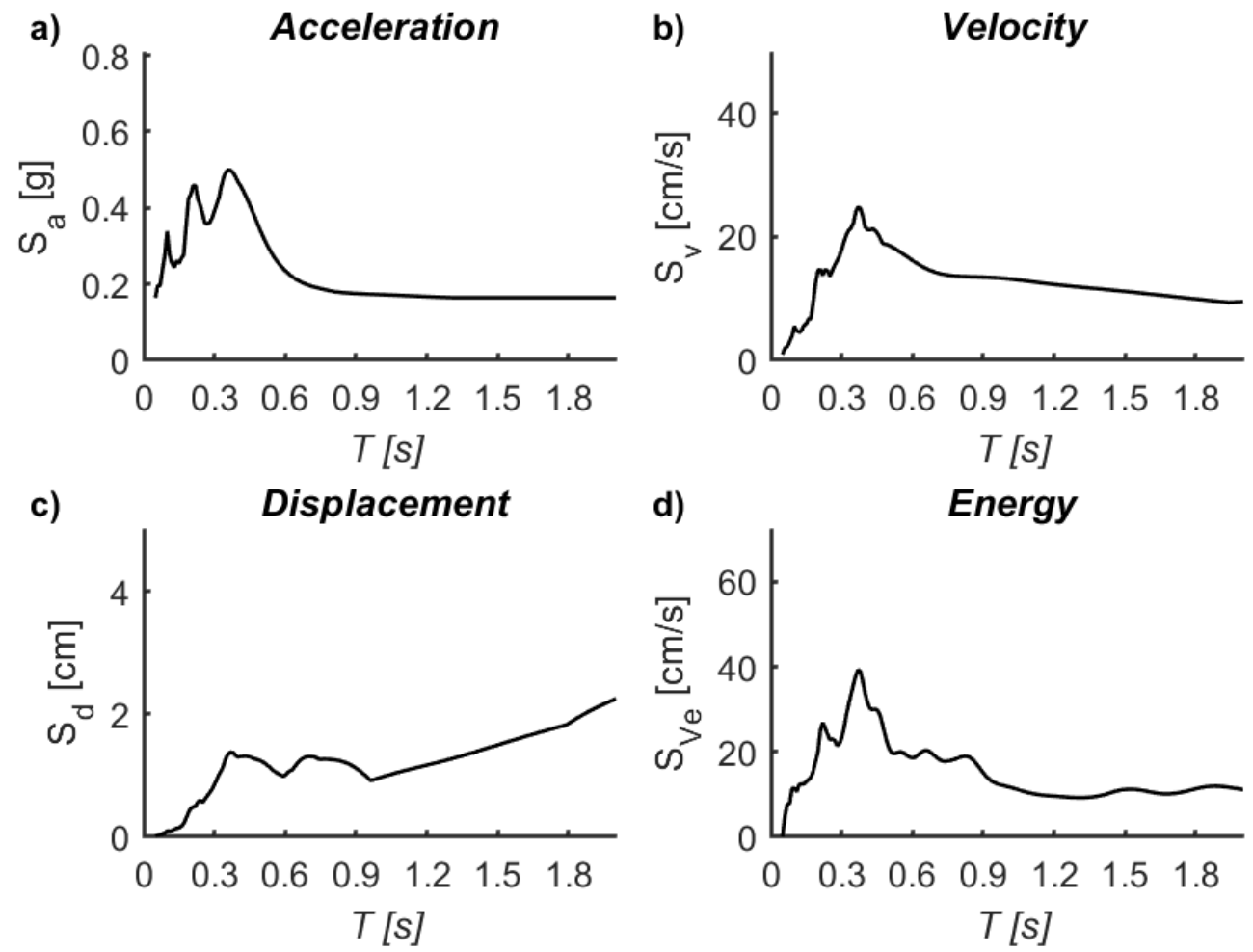

Figure A3. 104. Spectra of Lomap-765 (NS): a) Acceleration, b) Velocity, c) Displacement and d) Input energy 

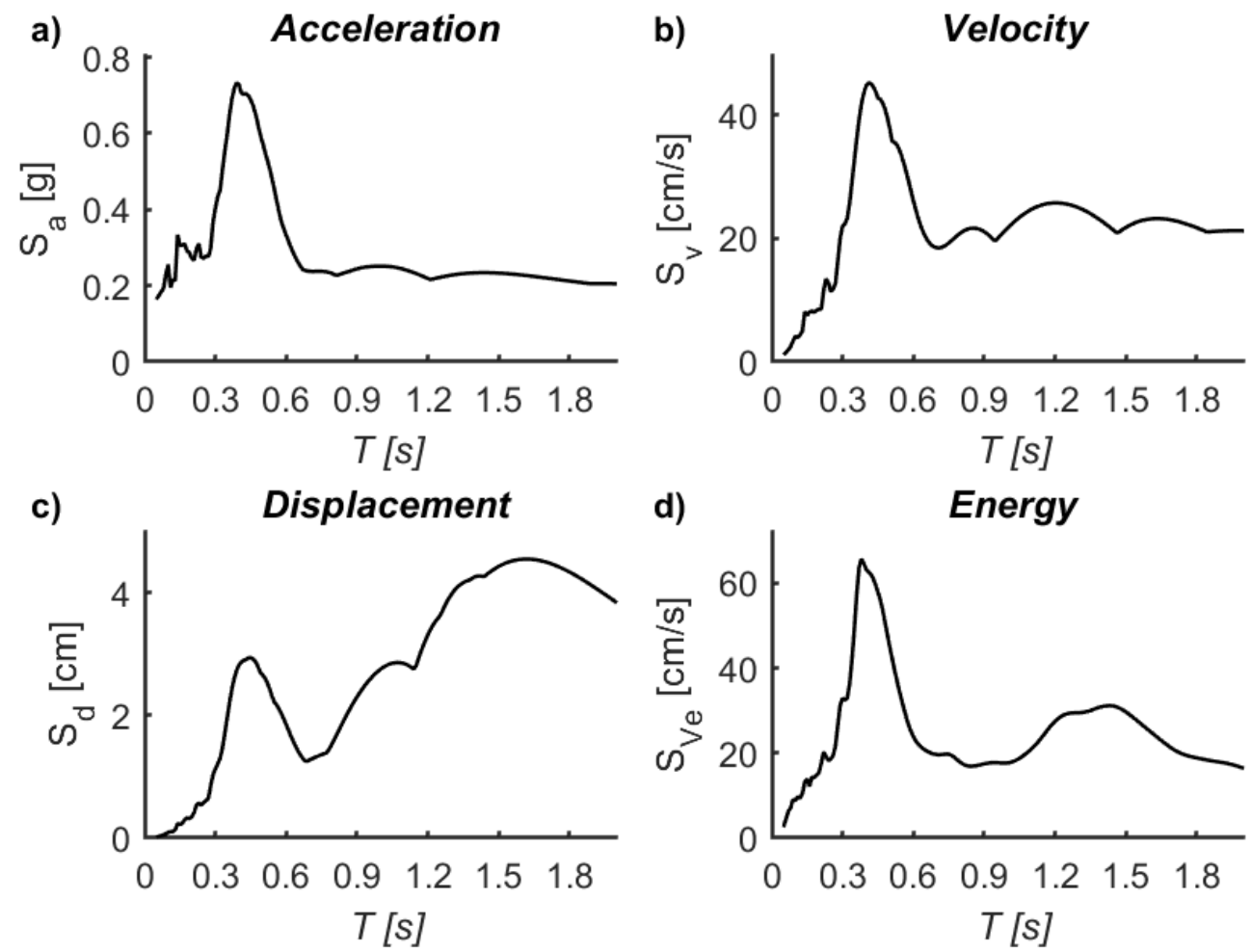

Figure A3. 105. Spectra of Lomap-765 (EW): a) Acceleration, b) Velocity, c) Displacement and d) Input energy 



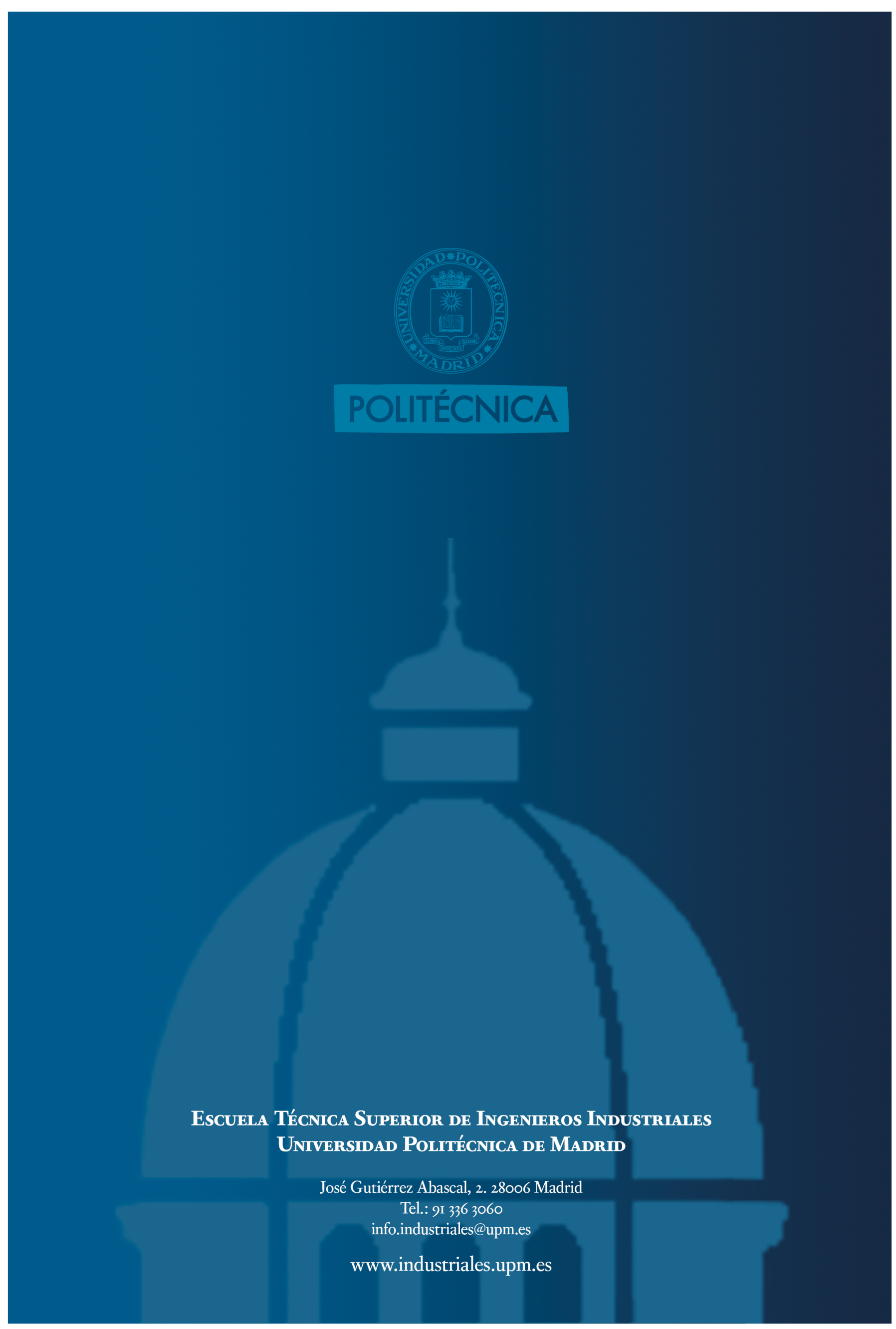

